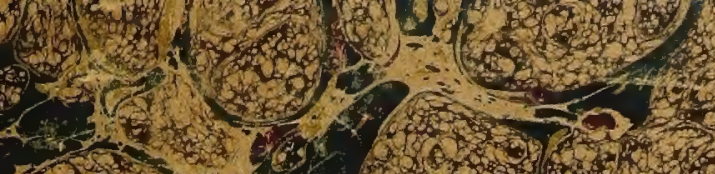




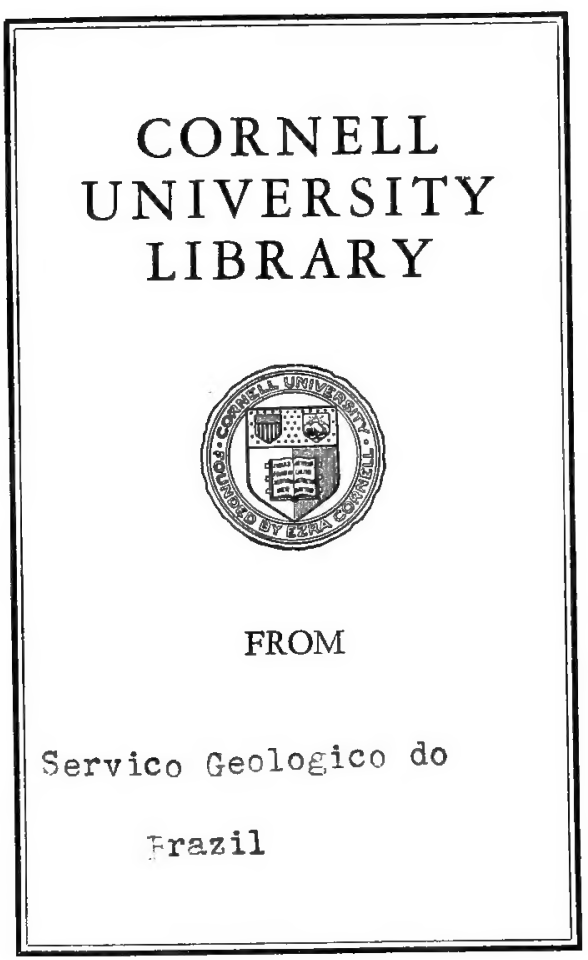


QE 235.A31

Final report presented to $H$. Ex. Dr. Lau

Final report presented to H. Ex. DH. Lau

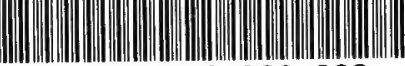

31924003968223 


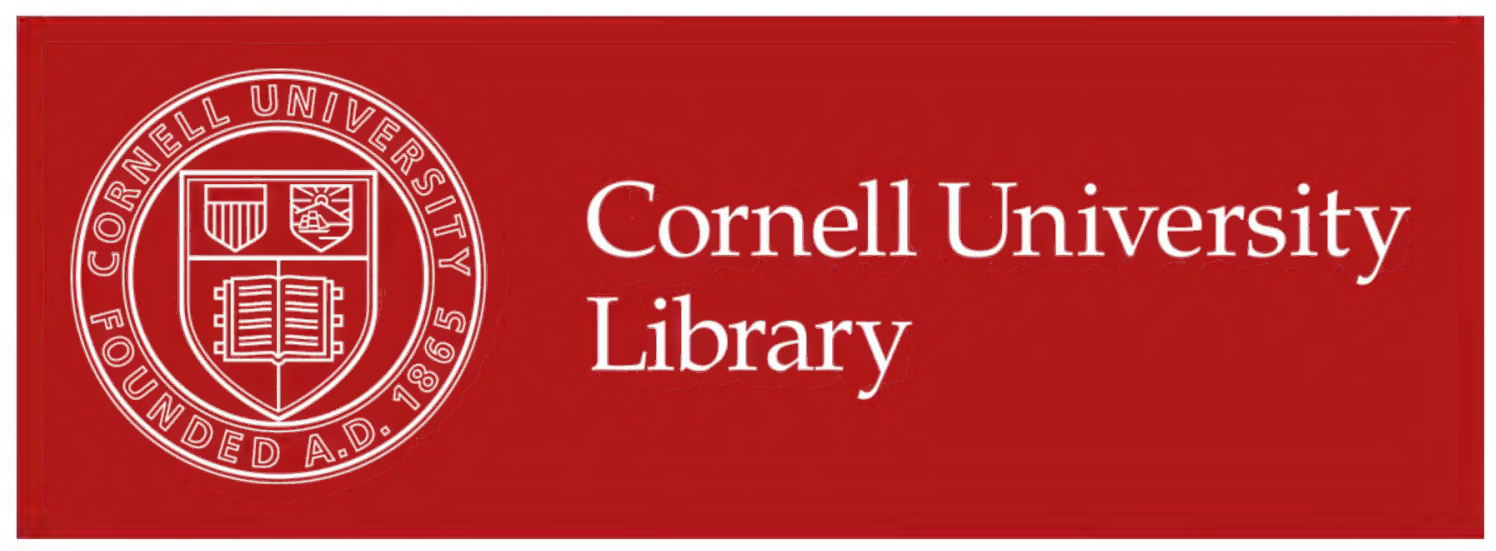

The original of this book is in the Cornell University Library.

There are no known copyright restrictions in the United States on the use of the text.

http://www.archive.org/details/cu31924003968223 



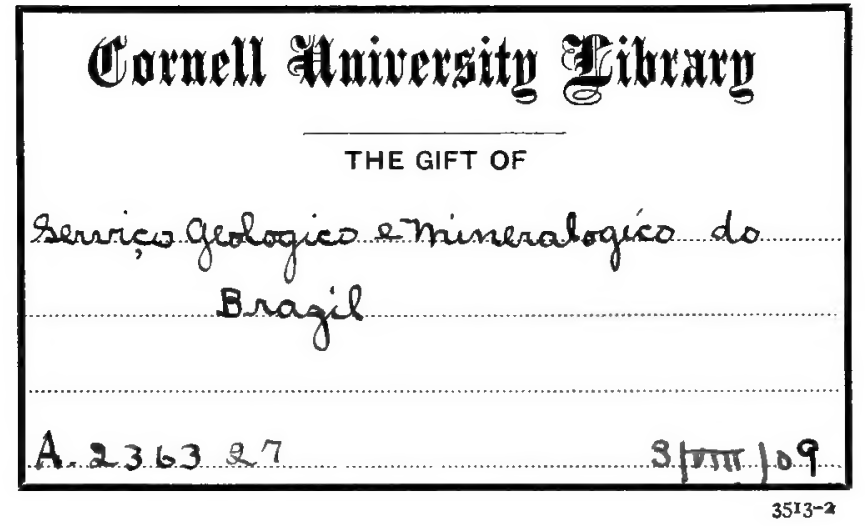




\section{RELATORIO FINAL}

Do

DR. I. C- W FIITE

Ohofo da Oommissão

1 de Julho de 1904 a 31 de Maio de 1906

I PARTE - Geologia, pelo Dr. I. C. White.

II PARTE - Menosaurus braziliensin, pelo Dr. J. H. Mc. Gregor.

III PARTE - Plantas fosseis, pelo Dr. David White.

\section{FINAL REPORT}

OF

DR - I. O. WIITE

Obiof of the Brazilian Ooal Commission

FROM

Jaly 1st, 1904 to May 31st, 1906

PART I - Geology, by Dr. I. C. White.

PART II - Mesosaurue brasliensis, by Dr. J. H. Mc Gregor.

PART III - Fossil Plants, by Dr. David White. 


\title{
RELATORIO FINAL
}

\author{
APRESENTADO A \\ S. Ėx. o Sr. Dr. Làuro Severiàno Mülle
}

MINISTRO DA INDUSTRIA, VIAÇÃO E OBRAS PUBLICAS

POR

I. C. WThite

CHEFE DA COMMISSĀO

TRADUCÇĀO

DE

Carlos Moreira

EX-SECRETARIO DÁ COMMISSÃO

RIO DE JANEIRO

IMPRENSA INACIONAI

I 908

D 


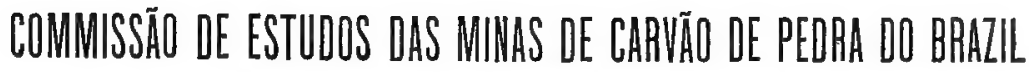

\section{FINAL REPORT}

PRESENTED TO

\section{PE. Exx. Dr. Làuro Severiàno Müller}

MINISTER OF INDUSTRY, HIGHWAYS AND PUBLIC WORKS

BY

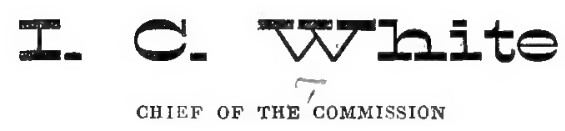

CHIEF OF THE COMMISSION

RIO DE JANEIRO

IMPREINSA INACIOINAI

1908

D 


\section{INDICE}

Carta de hemessa do relatorio. . . . . . . . . . . . . . . . X X

Prefacio do Autor . . . . . . . . . . . . . . . . . . . . . . XII

Corrigenda. . . . . . . . . . . . . . . . . . . . . . XXV

Parte I. Relatorio sobre as «Coul Measuresn e rochas associadas, do sul do Brazil, pelo Dr. I. C. White.

Capitulo I.-Topographia e geographia physica do sul do Brazil:

Evídencia de abaixamento. . . . . . . . . . 2

Ausencia de periodo glacial recente no sul do Brazil . . . . . 10

Periodo glacial antigo. . . . . . . . . . . 10

Feição geral topographica e hydrographica. . . . . . . 14

Capitulo II.-Rochas pre-carboniferas do sul do Brazil:

Camadas Devonianas. . . . . . . . . . . . . 20

Relatorio do Dr. John M. Clarke. . . . . . . . . 22

Capitulo III.-As rochas carboniferas e Triassicas. . . . . . . . . . . 28

Classificação de Santa Catharina . . . . . . . . 32

Secẹões e sondagens. . . . . . . . . . . . 34

Capitulo IV.-Série do rio Tubarāo. . . . . . . . . . . . . . . 48

Conglomerato de Orleans . . . . . . . . . . . . 50

Camadas do rio Bonito (Coal Measures) . . . . . . . 52

Secçōes . . . . . . . . . . . . . . . . . 54

Capitulo V.-Descripção detalhada dos leitos de carvão e outros horizontes das camadas do rio Bonito . . . . . . . . . . . 64

Camada de plantas Joaquim Branco . . . . . . . . . 64

Camada de carvāo Bonito. . . . . . . . . . . . . . o ó6

Secçöes. . . . . . . . . . . . . . . 63

0 grés Bonito superior e inferior. . . . . : . . . . . 80

Carvão Ponte Alta. . . . . . . . . . . . . . 80

Schistos fossiliferos, com plantas fosseis. . . . . . . . 82

Carvāo Irapuá . . . . . . . . . .

Schisto Irapuá, com plantas fosseis . . . . . . . . . 84

Grés Barro Branco, inferior. . . . . . . . . . 86

Schisto com plantas fosseis . . . . . . . . . . 86

Carvāo Barro Branco . . . . . . . . . . . . . . . 83

Secçōes e sondagens. . . . . . . . . . . . . . 90

Carvão Treviso . . . . . . . . . . . . . 132

Qualidade e valor do carvāo braziloiro como combustivel. . . 136

Analyses . . . . . . . . . . . . . . . . . . 140

Relatorio das Humboldt Engineering Works . . . . . . 146

Briquettes. . . . . . . . . . . . . 162

Relatorio do Laboratorio de ensaio de carvāo, dos Estados Unidos. 166

Os schistos de Palermo . . . . . . . . . . . . 178

Capitulo VI.- A sèrie do Passa Dois . . . . . . . . . . . . . . 180

0 schisto preto de Iraty. . . . . . . . . . . . 180

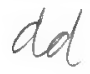




\section{TABLE OF CONTENTS}

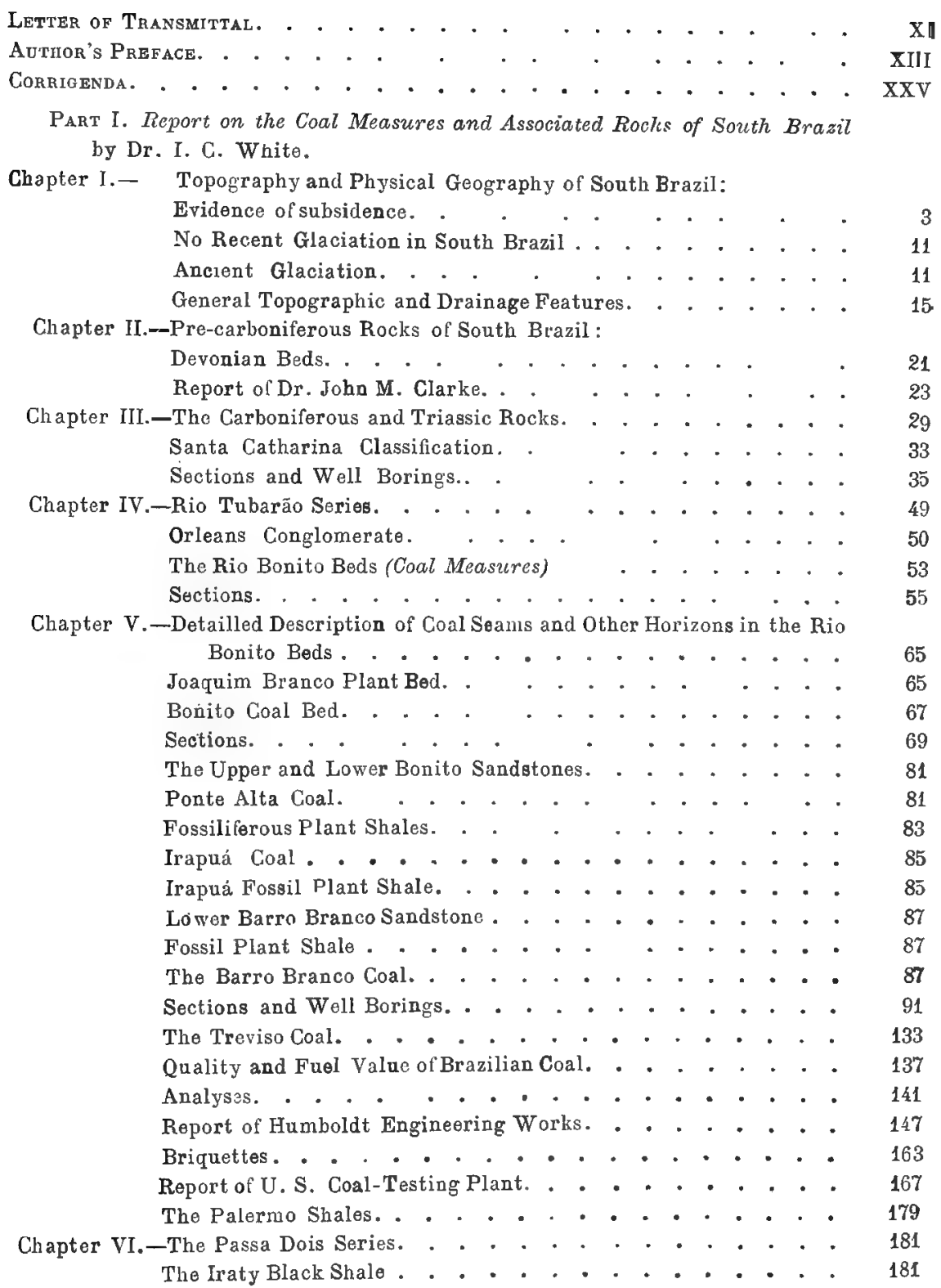


As camadas da Estrada Nova. . . . . . . . . . 190

o calcareo da Rocinha. . . . . . . . . . . . 192

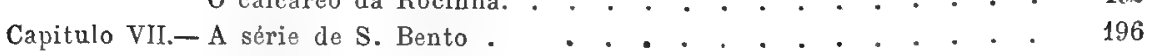

As camadas vermelhas do rio do Rasto . . . . . . . 198

Reptil fossil (Scaphonix fischeri) pelo Dr. A. Smith Woodward, com gravuras. . . . . . . . . . . . . . .

Analyse do asphalto do Bofete e relatorio, pelo Dr. Clifford Richardson. . . . . . . . . . . . . . .

O grés de S. Bento . . . . . . . . . . . . . 211

As rochas eruptivas da Serra Geral. . . . . . . . 216

Notas sobre rochas igneas brazileiras pelo Dr. Geo P. Merrill . . 220

Correlaçōes. . . . . . . . . . . . . 226

Origens dos sodimentos Carboniferos e Triassicos. . . . . . 230

Capitulo VIIt.- As formações geologicas mais recentes. . . . . . . . 234

Analysa do calcareo de Paineiras. . . . . . . . 234

Os schistos bituminosos de Taubaté . . . . . . . 236

A turfa, ou depositos de bogheal de Marahú. . . . . . . 240

A possibilidade de depositos de petroleo no Braztl. . . . . . 242

Appendice 1.- Carvão nacional, pelo Dr. Osorio de Almeida . . . . . . . 248

Ap̣pendice II.-- Especificações para uma usina de purificação e briquettagem de carvão, pelas Humboldt Engineering Works (MaschinenbauAnstalt Hunboldt). . . . . . . . . . . .

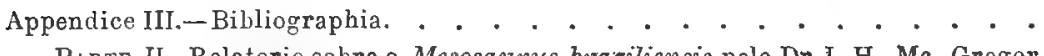

PARTe III. Relatorio sobre a Flora fossil das camadas carboniferas do Brazil, p३lo Dr. David White . . . . . . . . . .

Revista historica. . . . . . . . . . . . . 338

Procedencia e relaçōes estratigraphicas das colleccóes tratadas neste relatorio. . . . . . . . . . . . . . . 3丂̆

Estado de Santa Catharina . . . . . . . . . . 356

Estado do Rio Grande do Sul. . . . . . . . . . . $35 \mathrm{~S}$

Distribuição local das especies. . . . . . . . . . 360

Lista das plantas fosseis encontradas. . . . . . . . 362

Distribuição exotica das especies. . . . . . . . . . 372

Correlaçōes. . . . . . . . . . . . . . . . 376

Tabella comparativa . . . . . . . . . . 380

Idade da Flora. . . . . . . . . . . . . . . . 382

Descrip̧ão das especies. . . . . . . . . . . . 402

$\mathrm{G} \bumpeq \mathrm{n}$. Reinschia. . . . . . . . . . . . . . . . . . 406

Rosellinites . . . . . . . . . . . . . . . . . 412

Hysterites, . . . . . . . . . . . . . . . . . . . . 41f́

Equisetites . . . . . . . . . . . . . . . . . 418

Phyllotheca.. . .. . . . . . . . . . . . . . . . . 420

Schizoneura. . . . . . . . . . . . . . . . 432

Lycopodiopsis . . . . . . . . . . . . . . . . . . 436

Lepidodendron . . . . . . . . . . . . . . . . . . 442

Lepidophloios. . . . . . . . . . . . . . . . . . 450

Sigillaria. . . . . . : . . . . . . . . . . . . . . 454

Sphenopteris. . . . . . . . . . . . . . . . . 474

Psaronius. . . . . . . . . . . . . . . . . 478 
The Estrada Nova Beds. . . . . . . . . . . 191

The Rocinha Limestone. . . . . . . . . . . . . 193

Chapter VlI.-The São Bento Scries . . . . . . . . . . . . . . . 197

The Rio do Rasto Red Beds. . . . . . . . . . . . . 199

Fossil Heptile (Scaphonyx fischeri) by Dr. A. Smlth Woodward, with cuts. . . . . . . . . . . . . . .

Analysis of Asphalt from Bofete, and Report by Dr. Clifford Richardson . . . . . . . . . . . . . . 207

The Sảo Bento Sandstone. . . . . . . . . . . 211

The Serra Geral Eruptives. . . . . . . . . . . . 217

Notes on Brazilian Igneous Rocks by Dr. Geo. P. Merrill. . . 221

Correlations . . . . . . . . . . . . . . 227

Origin of the Carboniferous and Triassic Sedimenls. . . . . 231

Chapter VIII.- The Younger Geologic Formation: . . . . . . . . . . 235

Analyses of the Paineiras Limestone. . . . . . . . 235

The Bituminous Shales of Taubaté. . . . . . . . . 237

Tho Turf or Boghead Deposits of Marahu. . . . . . . . 241

The Possibility of Petroleum Deposits in Brasil. . . . . . 243

Appendix I.- National Coal, by Dr. Ozorio Almeida . . . . . . . . 249

Appendix II. - Specifications lor a Coal Purification and Briquetting Plant, by Humboldt Engineering Works (Maschinenbar-Anstalt Humboldt). . . . . . . . . . . . . . . 259

Appendice III. - Bibliography: . . . . . . . . . . . . . . . . . 287

PART II. Report on Mesosaurus brasiliensis, by Dr. J. H. Mc. Gregor . . 302

PART III. Report on the Fossil Flora of the Coal Measures of Brazil by Dr. David White. . . . . . . . . . . . . 337

Historical Review . . . . . . . . . . . . 339

Sources and Stratigraphic Rolations of the collections treated in this Report . . . . . . . . . . . . . , 355

State of Santa Catharina. . . . . . . . . . . . 357

State of Rio Grande do Sul. . . . . . . . . . . . 359

Local Distribution of the Species. . . . . . . . . 361

List of the Fossil Plant found . . . . . . . . . . 368

Foreign Distribution of the Species, . . . . . . . . 373

Correlations . . . . . . . . . . . . . . 377

Coroparative table . . . . . . . . . . . 381

Age of the Flora. . . . . . . . . . . . . . 383

Descripiion of the species . . . . . . . . . . 403

Gen. Reinschia. . . . . . . . . . . . . . . . 407

Rosallinites . . . . . . . . . . . . . . . 413

${ }^{\circ}$ Hysterites. . . . . . . . . . . . . . . . . . . . 415

Equisetites . . . . . . . . . . . . . . . . . . . 419

* Phyllotheca. . . . . . . . . . . . . . . . . 421

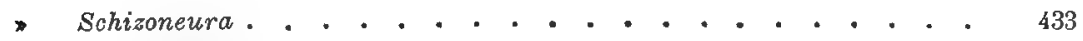

- Lycopodiopsis. . . . . . . . . . . . . . . . . . . . 437

, Lepidodendron. . . . . . . . . . . . . . . . . 443

* Lepidophloios. . . . . . . . . . . . . . . . . . . . 451

$\gg$ Sigillaria. . . . . . . . . . . . . . . . . . . 455

Sphenopteris. . . . . . . . . . . . . . . . . . 475

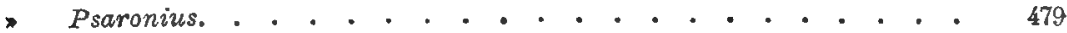


Gen. Neuropteridium. . . . . . . . . . . . . . 484

Glossopteris . . . . . . . . . . . . . . . . 490

Vertebraria. . . . . . . . . . . . . . . 518

"Gangamopteris . . . . . . . . . . . . . . . 520

Ottokaria. . . . . . . . . . . . . . . . 532

$\gg$ Arberia . . . . . . . . . . . . . . . . . . 536

" Derbyyella . . . . . . . . . . . . . . . . . 542

- Noeggerathiopssis . . . . . . . . . . . . . . 546

Cardiocapon. . . . . . . . . . . . . . . 556

${ }$ Valtzia. . . . . . . . . . . . . . . . . . 568

Dadoxylon . . . . . . . . . . . . . . . . . 572

Carpolithus . . . . . . . . . . . . . . . . 588

- Haztimima . . . . . . . . . . . . . . . . 588

Explicação das cstampas. . . . . . . . . . 606 
Gon. Teuroptevidizm . . . . . . . . . . . . . . . 485

$\$$ frlossopteris... . . . . . . . . . . . . 491

$\gg$ Vertebraria. . . . . . . . . . . . . . . 510

${ }^{\infty}$ Gangannopteris. . . . . . . . . . . . . . . 521

" Jltokaria. . . . . . . . . . . . . . . . . 533

${ }^{1}$ 1-jeria . . . . . . . . . . . . . . . 537

${ }^{n}$ Derbyella. . . . . . . . . . . . . . . . 5i;

* Vocggerathiopsis. . . . . . . . . . . . . . 547

" Tavdiararnon. . . . . . . . . . . . . . . . 5 5

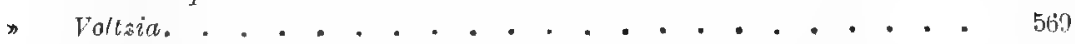

Dadoxylon... . . . . . . . . . . . . . . 513

- Carpolithus . . . . . . . . . . . . . . . 589

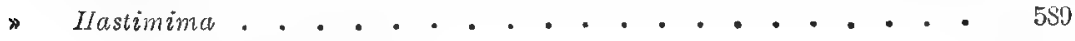

Explunation of plates. . . . . . . . . . 607 


\section{CABTIA DR REMESSA DO RELATOBIO}

Exm. SNR: Dr. Lauro Müller

MINISTRO DA INDUSTRIA, VIAÇÃO E OBRAS PUBLICAS

Tonho a honra de remetter-vos, junto, meu Relatorio Final sobre o trabalho da Commissão do Carvão durante os annos de 1904 e 190อ̆-b’, correspondente ao periodo no qual o autor foi chefe da Commissão.

A este respeito desejo testemunhar a cortesia uniforme, o interesse activo e proveitoso auxilio sempre manifestado pelo Ministro da Industria, para o avançamento dos trabalhos da Commissão.

Sou com grande respeito, vosso criado obediente,

I. C. Whirte.

MORGANTOWN, W. VA.,

1 de Setembro de 1906. 


\section{LERTRR OP TRAISMITAL}

Dr. Lauro MülLer

MINISTER OF INDUSTRY, HIGHWAYS AND PUBLIC WORKS

DEAR SIR:-

I have the honor to transmit you herewith my Final Report on the work of the Coal Commission during the years 1904 and 1905-6, covering the period in which the writer was Chief of the Commission.

In this connection I desire to testify to the uniform courtesy, active interest, and helpful assistance always manifested by the Minister of Industry, in advancing the labors of the Commission.

I remain with great respect,

Your obedient servant,

I. C. Whrte .

MORGANTOWN, W. VA.,

September 1, 1906. 


\section{PREFACIO DO AUTOR}

A Commissáo do Carvĩo foi creada por acto do Governo Brazilciro, de 23 de julho de igo4.

O Dr. Francisco de Paula Oliveira, do Museu Nacional que de longa data se occupou com successo, do estudo da gcologia brazileira tendo publicado varios trabalhos valiosos sobre esta, foi nomeado primeiro engenheiro da Commissão, por aviso de 23 de junho de Igo4.

O Dr. Oliveira em excursão ao Pará fez algumas investigaçóes nas camadas que conteem graphite naquella regiăo, no anno igo3 e depois explorou os affloramentos de carväo perto do Cedro no Estado do $\mathrm{Pa}$ raná, perfurando uma galeria na montanha e cavando dois póços com quịze metros, ou mais de profundidade, demonstrando que o carvăo não attinge espessura commercial na superficie, nesta parte do Estado.

Em 1904 a Secretaria de Estado dos Estados Unidos, a pedido do Dr. Lauro Müller, Ministro da Industria do Brazil, por intermedio do Embaixador dos Estados Unidos no Rio de Janeiro, o Exm. Sr. Darid R. Thompson, de Nebraska, recommendou para ser nomeado chefe da Commissão, o Dr. I. C. White geologo do Estado de West Virginia. A nomeaçăo foi subsequentemente feita pelo Dr. Lauro Müiller, datada de I de julho de I9of e o nomeado partio para o Brazil a 5 de julho de 1904, para dar principio ao cumprimento de seus dereres. A Commissão era entretanto reorganizada e augmentada com a nomeação de outros membros, de modo que, quando o Dr. White chegou ao Brazil seu pessoal era o seguinte :

Dr. I. C. White de Morgantown W. V. chefe.

Carlos Moreira, secretario.

Dr. Francisco de Paula Oliveira, $I^{\circ}$ engenheiro.

Dr. Esdras do Prado Seixas, engenheiro de Ia classe.

Dr. Benedicto José dos Santos, conductor.

Dr. Cicero Campos, conductor.

O pessoal da commissão conservou-se praticamente o mesmo até janeiro de Igo6, excepto quanto a Dr. Seixas que retirou-se da com- 


\section{AUTHOR'S PREFACE}

The Coal Commission was authorized by an act of the Brazilian Go* vernment dated July 23d, 1904 .

Dr. Francisco de Paula Oliveira, of the Museu Nacional, who had long been a successful student of Brazilian Greology, publishing many valuable papers thereon, was appointed as First Engineer of the Commission on the $23^{31}$ of July of rgo.4.

Dr. Oliveira visited Pará and made some investigations of the beds holding graphite in that region during the year 1903 and later he explored the outcrops of coal near Cedro, in the state of Paraná, extending a drift mine into the hill, and sinking two shafts, fifteen meters or more in depth, demonstrating the fact that the coal does not attain commercial thickness at the surface in that portion of the state.

In 1904, the State Department of the United States, at the solicitation of Dr. Lauro Muller, the Minister of Industry for Brazil, through the United States Embassador at Rio de Janeiro, the Hon. David R. Thompson, of Nebraska, recommended for appointment as Chicf of the Commission, Dr. I. C. White, State Geologist of West Virginia. This appointment was subsequently made by Dr. Müller, dating from July lst, Igot, and the appointed sailed for Brazil July 5th, I904 to enter upon his duties. In the meantime, the Commission was reorganized and enlarged by the addittion of other members, so that when Dr. White arrived in Brazil, its personnel was as follows:

Dr. I. C. White, Morgantown, W. Va., Chief ;

Mr. Carlos Moreira, Secretary.

Dr. Francisco de Paula Oliveira, First Engineer;

Dr. Esdras do Prado Seixas, Second Engineer;

Dr. Benedicto dos Santos, Assistant Engineer ;

Dr. Cicero Campos, Assistant Engineer ;

The membership of the Commission cemained practically the same until January, IgoG, except that Dr. Seixas retired from the Commis- 
missão a 31 de março de 1905 , pela razão de falta de saude. A I de janeiro de 1906 a Commissão teve seu pessoal augmentado com mais dois membros devido aos trabalhos de sondagem que iam ser iniciados, de fórma que actualmente está organizada deste modo :

Dr. I. C. White, chefe.

Carlos Moreira, secretario.

Dr. Francisco de Paula Oliveira, $I^{*}$ engenheiro.

Dr. Benedicto dos Santos, engenheiro ajudante.

Dr. Cicero Campos, engenheiro ajudante.

Sr. Charles Mc. Carthy, engenheiro mecanico.

Sr. Frederico Dahne, conductor.

O chefe completou os trabalhos de reconhecimento no campo, que segundo o contracto deviam estar concluidos em fevereiro de 1906 e seguiu para os Estados Unidos a 3 do mesmo mez, deixando o logar de chefe no fim de seu contracto, a 3 I de maio de 1 go6; depois desta data tem o Dr. Oliveira sido chefe da Commissão.

O Sr. Ministro Dr. Lauro Müller confiou ao Dr. Oliveira a acquisição de instrumentos, os fornecimentos, etc., e encarregou-o da parte financeira da Commissảo, ficando Carlos Moreira encarregado do archivo, das contas e livros da Commissão bem como de servir como interprete e auxiliar em geral, do chefe.

O Dr. Seixas tomou a si o encargo do levantamento de um mappa exacto das explorações de carvão nos arredores de Lauro Müller (estação das Minas) em Santa Catharina, onde foram iniciados os primeiros trabalhos de campo e com o auxilio dos Drs. Campos e Santos completou o levantamento do excellente mappa daquella regiảo, publicado separadamente, como parte deste relatorio. O desenho deste mappa foi executado pelo Dr. Seixas segundo as notas de campo dos Drs. Campos e Santos, concorrendo muito, tambem para augmentar a collecção de plantas fosseis, da Commissão, emquanto esteve estacionario em Minas.

O Dr. Seixas ficou encarregado da sondagem de ensaio iniciada em Minas pelo Dr. Oliveira, depois que este seguiu com a Commissão a 4 de setembro de 1905 , até que tendo adoecido partio para o Rio de Janeiro a 15 de outubro de rgo5, O Dr. Santos tomou então, conta dos trabalhos de sondagem em Santa Catharina e completou felizmente a sondagem até o granito, depois do que removeu a sonda para o Cedro no Estado do Paraná por indicação do Dr. Oliveira e fez alli um furo de 100 metros de profundidade, demonstrando a ausencia de camadas de carvâo, abaixo do pequeno leito que afflora á superficie. 
sion the 3lst of March, I905, by reason of failing health. On January lst, rgo6, the Commission had two additional members added to its numbers on account of the drilling operations to be undertaken, so that on that date the organization was as follows:

Dr. I. C. White, Chief ;

Mr. Carlos Moreira, Secretary;

Dr. Francisco de Paula Oliveira, First Engineer;

Dr. Benedicto dos Santos, Assistant Engineer;

Dr. Cicero Campos, Assistant Engineer ;

Mr. Charles Mc. Carthy, Mechanical Engineer.

Mr. Frederico Dahne, Assistant ;

The Chief completed the reconnaisance studies in the field which as per contract were to end with February, I906, and sailed for the United States on the $3^{d}$ of the same morth, retiring as Chief at the end of his engagement, May 3ist, Igo6. Since this latter date, Dr. Oliveira has been the chief executive officer of the Commission.

To Dr. Oliveira was assigned by Minister Müller the duty of making all purchases of instruments, supplies, etc., and of attending to the financial affairs of the Commission, while to Mr. Moreira was given the task of keeping the records, accounts, and books of the Commission, as well as acting as interpreter and general aid to the Chief.

Dr. Seixas took charge of the surveys for an acurate map of the coal explorations around Minas, Santa Catharina, where the first field work was undertaken, and with the aid of Drs. Campos and Santos completed the surveys for the excellent map of that region published separately as a part of this report. The drafting for this map was executed by Dr. Seixas from the field notes af Drs. Campos and Santos. He also added largely to the Commission's collection of fossil plants while stationed at Minas.

Dr. Seixas had general charge of the test boring located at Minas by Dr. Oliveira after the latter left there with the Commission on September $4^{\text {th }}$, I go5, until the former's health failed and he sailed for Rio de Janeiro, October I 5 th, L905. Dr. Santos then took charge of the drilling operations in Santa Catharina and successfully completed the boring to the granite, after which he moved the machinery to Cedro in the state of Paraná by direction of Dr. Oliveira and sunk a bore hole there to a depth of more than roo meters, demonstrating the absence of any beds of coal below the small seam cropping at the surfacc. 
Tendo terminado cedo em igo6 o trabalho no Cedro, o Dr. Santos mudou a sonda para o Barro Branco Velho em Santa Catharina, fazenda uma sondagem para verificar a presença da camada Bonito, achando-a em boas condiçóes a profundidade de 65 metros abaixo da camada Barra Branco. Mais tarde mudou a machina para perto de Treviso fazendo alli uma sondagem de ensaio.

O Dr. Cicero Campos depois de terminar os trabalhos de campo para a confecçăo do mappa da regiåo de Minas, juntou-se a Commissío em sua volta do Rio Grande do Sul em outubro de 1904 e acompanhou-a nas subsequentes excursóes pelo Paraná, S. Paulo, Minas Geraes e Bahia; mais tarde acompanhou Carlos Moreira a Minas em Santa Catharina e a S. Jeronymo no Rio Grande do Sul, para superintender a extracçăo de amostras de carvão que deviam ser remettidas para a Allemanha para ensaios. Em igo5 o Dr. Campos acompanhou a Commissảo em suas viagens e estudos no Rio Grande do Sul, Santa Catharina, $\mathrm{Pa}$ raná e S. Paulo, tendo feito uma excursão pelo rio Tibagy para estudar e apresentar relatorio sobre os affloramentos de carvão e outras rochas daquella regiáo.

Posteriormente o Dr. Campos fez uma excursão ao valle do rio Paranapanema, ao sul de Avaré, em S. Paulo, perto da villa de Santo Antonio da Boa Vista, a instancias do capitão Manoel Marcellino de Souza Franco, afim de verificar a possibilidade da existencia de carvão naquella regiåo, voltando com a noticia que o schisto preto de Iraty, tendo camadas bituminosas e silicosas, representa as suppostas camadas de carvăo, pelo qual tem sido tomado, por engano, tăo a meudo.

Em março de 1906 o Dr. Campos voltou a Santa Maria, no Rio Grande do Sul, por ordem do chefe, afim de colleccionar e estudar especimens do reptil fossil (Scaphonyx fischeri), alli descoberto pelo Dr. Jango Fischer; foi muito feliz, conseguindo uma boa collecçáo de ossos, que foram enviados ao Dr. Woodward, do Museu Britannico, para estudos ulteriores.

De volta do Rio Grande do Sul escolheu um ponto para sondagem perto de Araranguá, em Santa Catharina, afim de determinar a presença, ou ausencia, alli, das camadas de carvío.

Carlos Moreira, além de seus deveres de secretario da Commissão, sempre acompanhou o chefe em suas viagens, servindo como auxiliar no campo e como interprete e traductor. Em abril de 1905 veio para os Estados Unidos e acompanhou o autor á Allemanha, onde passaram o mez de junho superintendendo os ensaios do carvão brazileiro em Kalk que para alli tinha sido previamente remettido sob a fiscalização do secretario, 
Having finished the work at Cedro early in 1905 , Dr. Santos removed the drilling machinery to Barro Branco Velho, in Santa Catharina, and drilled a well to test the presence of the Bonito coal bed, finding the same in good condition at a depth of 65 meters below the Barro Branco bed. Later he removed the machinery to the vicinity of Treviso, and sunk a test bore there.

Dr. Cicero Campos, after the completion of the field work for the preparation of the map of the Minas region, rejoined the Commission on its return from Rio Grande do Sul in October, Igo4, and accompanied the same in the subsequent excursions through Paraná, S. Paulo, Minas Geraes, and Bahia. Later, in January of 1905 , he accompanied Mr. Moreira to Minas, Santa Catharina, and S. Jeronymo, Rio Grande do Sul, to supervise the collection of samples of coal to be shipped to Germany for testing purposes. During the season of 1905 , Dr. Campos accompanied the Commission on its travels and studies in Rio Grande do Sul, Santa Catharina, Paraná, and S. Paulo, makiing a separate excursion down the Rio Tibagy to study and report upon the coal exposures and other rocks of that region.

Later, Dr. Campos made an excursion to the valley of Rio Paranapanema, south from Avaré in S. Paulo, near the villa of Santo Antonio da Boa Vista, at the instance of Capt. Manoel Marcellino de Souza Franco, in order to examine into the possibility of coal existing in that, region, returning with the report that the Iraty black shale, having flinty and bituminous layers, represents the supposed coal beds for which it has so often been mistaken.

In March 1906, Dr. Campos by direction of the Chief returned to Santa Maria, in Rio Grande do Sul, in order to study and collect specimens of the fossil reptile (Scaphony.x fischeri) discovered there by Dr. Jango Fischer. In this he was quite successful, securing a fair collection of bones which have been forwarded to Dr. Woodward of the British Museum for further study.

On his return from Rio Grande do Sul, he selected a site for a coal boring test to be sunk near Araranguả in Santa Catharina in ordcr to determine the presence or absence of the coal Measures there.

Mr. Moreira, in addition to his general duties as Secretary of the Commission, always accompanied the chief in his travels, acting as aid in the field as well as interpreter and translator. In April, 1905, he came to the United States, and accompanied the writer to Germany where the month of June was spent in supervising the test of Brazilian coal at Kalk, which had proviously been shipped there under the supervision 5560 
Carlos Moreira, das minas do Rio Grande do Sul e Santa Catharina. Linguista consummado, fallando e escrevendo inglez, francez, allemão e portuguez com igual fluencia, os serviços de Carlos Moreira foram de grande valor para a Commissão em geral e para o chefe em particular.

O chefe muito deve, tambem, ao Dr. Oliveira, que tão cuidadosamente providenciou para o conforto material da Commissảo, tanto no campo como nos acampamentos e cuja longa experiencia no estudo da geologia do Brazil foi de grande valor para a Commissão. De facto, o autor não póde enaltecer bastante a cooperaçáo e auxilio dados ao chefe por cada membro da Commissão; devendo tambem, mencionar os serviços praticos e valiosos prestados pelo Sr. José Pio da Silva, um dos empregados da Commissão.

E' tăo grande o numero de brazileiros a quem a Commissão deve amavel cooperação e interesse pelos seus trabalhos, que nem posso tentar mencionar o nome de todos. Comtudo, a Commissão tanto deve aos seguintes cavalheiros, que delles deve ser feita esta publica menção :

Dr. Ramiro Barcellos, distincto senador pelo Rio Grande do Sul, que tanto fez para facilitar o trabalho da Commissão, guiandoma no .campo ;

O Exm. Sr. Dr. Borges de Medeiros, presidente do Estado do Rio Grande do Sul, que tão generosamente poz á disposiçăo da Commissão os recursos de seu grande Estado;

O Exm. Sr. coronel Vidal Ramos, governador do Estado de Santa Catharina e seu habil successor coronel Pereira de Oliveira, ambos tomaram grande interesse pelos trabalhos da Commissão, auxiliando-a de muitos modos;

O Exm. Sr. Dr. Vicente Machado, presidente do Estado do Paraná, que prestou á Commissăo valiosos serviços ;

O Exm. Sr. Dr. Jorge Tibiriçá, presidente do Estado de S. Paulo que com seu habil secretario da Agricultura, Dr. Carlos Botelho e Dr. Arthur de Oliveira Borges, inspector de Estradas de Ferro, prestaram muito valiosos serviços á Commissão;

O Exm. Sr. Dr. José Marcellino de Souza, governador do Estado da Bahia e seu distincto secretario da Agricultura Dr. Miguel Calmon du Pin e Almeida, que tanto fizeram para tornar a excursĩo da Commissão a Ma. rahú expedita e agradavel;

Ao Dr. Orville A. Derby, distincto ex-chefe da Commissão Geogra- 
of the Secretary, Mr. Moreira from the mines of Rio Grande do Sul, and Santa Catharina. An accomplished linguist, speaking and writing English, French, German, and Portuguese with equal fluency, Mr. Moreira's services proved of great value to the Commission in general, and to the chief in particular.

Also to Dr. Oliveira, who looked so carefully after the material comforts of the Commission in both field and camp, and whose long experience in the study of Brazilian geology proved of great value to the Commission, the chief is greatly indebted. In fact, the writer cannot too highly commend the aid and assistance given the chief by every member of the Commission. In this connection, the practical and valuabie services of Sr. José Pio da Silva, one of the employees of the Commission, must be acknowledged.

The number of Brazilian people to whom the Commission is in. debited for kindly assistance and interest in its work is so large that no attempt can be made to name them all. However, the Commisson is so greatly indebted to the following persons that this public acknowledgment must be made; namely.

Dr. Ramiro Barcellos, the distinguished Senator of Rio Grande do Sul, who did so much to expedite the work of the Commission by his active leadership in the field.

His Excellency, Dr. Borges Medeiros, the President of the State of Rio Grande do Sul, who so generously placed the resources of his great Commonivealth at the disposal of the Commission.

His Excellency, Colonel Vidal Ramos, the Governor of the State of Santa Catharina, and his able successor, Colonel Pereira de Oliveira, both of whom took great interest in the work of the Commission, and aided it in many ways.

His Excellency, Dr. Vicente Machado, the President of the State of Paraná, who rendered the Commission valuable services.

His Excellency, Dr. Jorge Tibiricá, the President of the State of São Paulo, who in connection with his able Secretary of Agriculture, Dr. Carlos Botelho, and Dr. Arthur A. de Oliveira Borges, Inspector of Railwars, rendered the Commission very raluable services.

His Excellency, Dr. José Marcellino de Souza, the Governor of the State of Bahia, and his distinguished Secretary of Agriculture, Dr. Miguel Calmon du Pin e Almeida, who did so much to render the visit of the Commission to Marahú both pleasant and expeditious.

To Dr. Orville 1. Derby, the distinguished ex-chief of the Greogra- 
phica e Geologica do Estado de S. Paulo, que ha tanto tempo estuda com vantagem a geologia de S. Paulo, bem como de outros Estados do Brazil, o autor é especialmente devedor pelo proveitoso auxilio e interesse pelos trabalhos da Commissão.

A Commissão deve, tambem, muitos favores e apoio officíal ao Dr. João P. Cardoso, actual director da Commissão Geographica e Geologica de S. Paulo.

Os directores de todas as estradas de ferro do sul do Brazil foram excessivamente amaveis para a Commissäo, auxiliando-a $\mathrm{cm}$ seu trabalho com trens especiaes, sempre que eram requisitados.

A Commissão deve obrigacúes e especiaes favores aos seguintes cavalheiros do Rio Grande do Sul: Srs. Otto Spalding, surperintendente geral da Companhia Estrada de Ferro e Minas de S. Jeronymo, Dr. Eugenio Dahne, distincto engenheiro e geologo; Dr. G. Vauthier, Dr. F. Nonnenberg e Dr. Jorge Benedicto Ottoni.

Aos seguintes caralheiros do Paraná: coronel Joaquim Macedo, Romario Martins, Dr. Carlos Gutierres, Dr. Roberto Helling, Dr. J. Westermann.

Aos seguintes cavalheiros do Rio de Janciro deve o autor, bem como a Commissão, muitas obrigaçóes por numerosos favores recebidos :

Dr. Castro Barbosa, do Conselho Municipal ;

Drs. Miguel Arrojado Lisboa e Teixeira Soares, os eminentes engenheiros de Petropolis, Dr. C. Miranda Jordăo;

Hon. David R. Thompson, ex-ministro dos Estados-Unidos no Brasil, actualmente embaixador no Mexico;

Hon. Eugene Seeger, consul geral dos Estados-Unidos;

Dr. Falke, consul geral da Allemanha;

Sr. Lilbourn Cave Irvine, ex-vice-consul dos Estados Unidos da America; Sr. George A. Chamberlain, ex-rice-consul dos Estados-Unidos.

Aos seguintes cavalheiros deve a Commissão muitas obrigaçóes por muitos favores recebidos:

Sur. E. Ferreira de Camargo, de S. Paulo e Dr. Nicoláo Pederneiras, Dr. Fausto de Souza, Snrs. Alfredo Pessi, Angelo Bianchin e Pedro Marcellino de Carvalho, de Santa Catharina.

A' Commissão Geologica dos Estados-Unido; e seu habil director, Dr. Chas D. Walcost, deve a Commissão os ensaios feitos com o carvăo brazileiro sob a inspecção do Dr. J. A. Holmes em seu grande Labotorio de Ensaio de Carváo em St Louis, Missouri. 
phical and Geological Commission of the State of S. Paulo, who has so long and successfully studied the geology of S. Paulo, as well as many other states of Brazil, the writer is especially indebted for very helpful aid and interest in the work of the Commission.

Also to Dr. João P. Cardoso, the present Director of the S. Paulo G. and Geol. Commission, and his official force, the Commission is indebted for many favors.

The Directors of all the railways of South Brazil were exceedingly kind to the Commission in aiding its work with special service whenever requested.

The Commission is under obligations for especial favors to the following gentlemen of Rio Grande do Sul : Mr. Otto Spalding, General Superintendent of the Companhia Estrada de Ferro e Minas de S. Jeronymo, Xarqueadas, Dr. Eugenio Dahne, the distinguished engineer and geologist, Dr. G. Vauthier and Dr. F. Nonnenberg, Dr. Jorge Benedicto Ottoni.

To the following gentlemen of Paraná : Colonel Joaquim Macedo, Mr. Romario Martins, Dr. João Carlos Gutierres, Dr. Roberto Helling, Dr. J. Westermann.

To the following gentlemen of Rio de Janeiro, the writer, as well as the Commission, is under many obligations for numerous favors received :

Dr. Castro Barbosa, of the Municipal Council;

Drs. Miguel Arrojado Lisboa, and Teixeira Soares, the eminent engineers of Petropolis, Dr. C. Miranda Jordão;

Hon. David R. Thompson, Ex U.S. Minister to Brazil now Ambassador to Mexico;

Hon. Eugene Seeger, Consul General of the U.S. A.;

Dr. Falke, Consul General of Germany ;

Mr. Lilbourn Cave Irvine, Ex Vice-Consul, U. S. A.; Mr. George A. Chamberlain, Ex Vice-Consul, U. S. A.

To the following gentlemen the Commission is under many obligations for many favors received :

Snr. E. Ferreira de Camargo of S. Paulo, and Dr. Nicoláo Pederneiras, Dr. Fausto de Souza, Snrs. Alfredo Pessi, Angelo Bianchin e Pedro Marcellino de Carvalho of Santa Catharina.

To the United States Geological Survey, and its able Director, Dr. Chas. D. Walcott, the Commission is especially indebted for the courtesy of its great Coal Testing Plant at St. Louis, Missouri, on account of the tests therein made of Brazilian coal under the supervision of Dr. J. A. Holmes. 
Aos Drs. J. H. Mc. Gregor e H. F. Osborn, do Museu Americano de Historia Natural, de New-York deve a Commissão muitas obrigaçúes pela valiosa memoria publicada na segunda parte deste volume, sobre o interessante reptil fossil (Mesosaurus braziliensis).

Ao Dr. J. M. Clarke, geologo do Estado de New-York, e ao Dr. Geo. P. Merril, curador chefe, de geologia do Museu Nacional de Washington D. C., a Commissão é especialmente devedora pelos seus muito interessantes relatorios sobre fosseis Devonianos e rochas igneas, publicados neste relatorio ; tambem aos Drs. Girty e Stanton, da Commissão Geologica dos Estados Unidos, pela determinaçáo de restos animaes fosseis.

Finalmente, ao Dr. David White o distincto palrobotanico do Museu Nacional e da Commissão Geologiç de Washington D. C., a Commissão muito deve pelo seu arduo "trabalho por amor ", da organização da III parte sobre a collecçáo de plantas fosseis.

Ninguem, melhor que o autor, reconhece a natureza provisoria e preliminar de grande parte do trabalho geologico deste relatorio, especialmente a que se refere ás rochas superpostas ás camadas Rio Bonito, ou de carváo, en cujo estudo só foi possivel empregar tão pouco tempo.

$\mathrm{O}$ autor reconhece estas imperfeiçōes e espera que, observadores futuros, com melhores opportunidades, descobrirāo muitos erros no trabalho e conclusóes aqui relatados, mas isso é inevitavcl em todo o trabalho de explorador e năo póde ser evitado a, năo ser que o geologo deixe de publicar quacsquer conclusóes concernentes ao que quer que seja, sobre que paire alguma duvida.

E' de esperar que as genuinas contribuiçues para a sciencia, geologia e paleontologia, tratadas nas excellentes memorias de J. H. Mr. Gregur e David White, nas partes II e III deste relatorio, compensarăo de algum modo as imperfeiçōes e crros que se encontrem na parte I deste volume.

No appendice III, no fim deste volume, vae a lista de autores de trabalhos sobre a geologia do sul do Brazil, de alguns dos quaes o autor recebeu muito auxilio. 
To Drs.J. H. Mc. Gregor and H.F.Osborn, of the American Museum of Natural History, New York, the Commission is under many obligations for the valuable memoir published as Part II of this volume, on the interesting reptilian fossil, Mesosaurus brasiliensis.

To Dr. John M. Clarke, State Geologist of New York and to Dr. Geo. P. Merrill, Head Curator of Geology of the National Museum, Washington, D. C., the Commission is especially indebted for their very interesting reports on Devonian fossils and igneous rocks, respectively, published in this report. Also to Drs. Girty and Stanton of the U. S. Geological Survey for determinations of fossil animal remains.

Finally, to Dr. David White, the distinguished palrobotanist of the National Museum, and the U. S. Geological Survey, Washington, D. C., the Commission is greatly indebted for his arduous alabor of loves in the preparation of Part III, on the fossil plant collections.

No one realizes better than the writer the preliminary and provisional nature of much of the geological work in this report, especially that concerning the rocks lying above the Rio Bonito or Coal Measures beds, upon which so little time could be expended.

The writer is aware of these imperlections, and fully expects that future observers with better opportunities, will detect many errors in the work and conclusions herein recorded, but this is inevitable in all pioneer work, and cannot be avoided unless the geologist should fail to publish any conclusions whatever concerning which there can be any doubt.

It is hoped that the genuine contributions to the science of geology and paleontology recorded in the excellent memoirs of J. H. Mc. Gregor and David White in Part II and Part III of this Report will in some measure atone for the imperfections and errors discovered in Part I of this volume.

A list of authors upon the geology of South Brazil, from some of whose works the writer has received much aid, is given in Apendix III at the end of this volume. 



\section{CORRIGENDA}

Pag. 6 - linha 16, em rez de 0.404 , leia-se 0.440.

- 10 - linha 14, em vez de uroladom, leia-8e «arredondado».

"22 - linha 11, em vez «micacea», leia-se «argillo-micacea».

" 33 - Ieft side last key instead of 180 , read 280

* 34 - linha 11, em ve» de «e aguas claras», leia-se azues claros.

" 41 - linha 27, em vez de 51.74, leia-se 15.74.

» 64 - linha 2 e em outras paginas, em vez de «horisonte», leia-se «horizonte».

" 88 - linha 16, em vez de «adquirindo», leia-se «adquirio».

»90 - linhas 9 e 10, em vez de «chistoso», leia-se «schistoso",

》90 - linha 32 , em vez de 0,15 , leia-se 0,05 .

»92 - linha 5, de baixo para cima, em vez de «baucders», lia-se «boulders».

»92 - linha 2 , de baixo para cima, em vez de 0,1 , leia-se $0,1^{2}$.

" 96 - linha 10, de baixo para cima, em vez do «uma outra», leia-se «um outro».

" 112 - linha 12, de baixo para cima, em vez «coriespon le», leia-so «correspondem».

" 126 - linha 3, de baixo para cima, leia-se a 3 kilometros a sudoeste da estação.

" 126 - linha 10 , em vez de 30,5 , leia-se 3,05 .

* 126 - linha 26 , em vez de 0,35 , leia-se 1,22 ,

- 127 - linha 3, de baixo para cima, leia-se em vez de 547.57 kilometers, three kilometers.

》 141 - linha 11 da tabella, em vez de 1,21, leia-se 1,24.

» 162 - linha 4 da tabella, em vez de 38,42 , leia-se 33,42 .

\164 - linha 4 da tabella, em vez de 13,63, leia-se 13,68.

》 $\left\{\begin{array}{l}184 \\ 185\end{array}\right.$ - linhas 8 e 7 , em vez de Dr. Chifford, leia-se Dr. Clifford.

" 214 - linha 6, de baixo para cima, em vez de «gneisses», leia-se «gneiss».

»222 - linha 6, de baixo para cima, em vez de "nicoes», leia-se unicols".

» 223 - 5 line instead of «Dar-gray», read «Dark-gray».

"228 - linha 5, em vez de 100, leia-se 150.

"229 - linha 1 , em vez de 2 , leia-se 3.

》230 - linha 11, em vez de 1905, leia-se 1906.

»234 - linha 6, em vez de «mais antigos", leia-se "mai recentes».

" 258 - linha 16, em vez de «lavrar», leia-se «lavar».

》262 - linha 1, em vez de 350 , leia-se 320.

* 262 - linha 12, de baixo para cima, em vez de Tinman, leia-se Wissmann.

" 268 - linha 6, de baixo para cima, em vez de $1500 \mathrm{~mm}$, leia-se $15.000 \mathrm{~mm}$.

» 310 - linha 34, em vez de “Eram provavelmente», leia-se «Não eram provavelmente».

» 318 - linha 12, em vez de «a do», Ieia-se «as do».

" 335 - linha 8, em vez «of the first», 1:ia-se «of the skull on the tirst».

»346 - linha 2, de baixo para cima, em vez de «Lepidophyte», leia-se «Lepidophyte».

" 353 - linha 4, em vez de «Godwana», leia-se «Gondwana». 
Pag. 356 - linha 20, eln vez de 2.56, leia-se 225.

" 356 - linha 31 , em vez de 125 , leia-s 135.

" 357 - linha 2, de baixo para cima, em vez de «Neoggerathiopsis», leia-se «Noeggerathiopsism.

》 358 - linha 10, de baixo para cima, em vez de 20 , leia-se 120.

" 360 - linha 9, em vez de 3917, leia-se 3920.

» 360 - linha 14, em vez de 391 , leia-se 3919.

" 364 - linha 20, em vez de «equesitites», leia-se «Equisetites».

" 365 - linha 20, em vez de «Rosellinites, Derbyella». leia-se «Rosellinites, Equisetites, Derbyella».

»367 - linha 5, em vez ile attempat, leia-se xattempt».

" 367 - linha 6, em vez de nuture, leia-se «nature».

* 367 - linha 8, em vez de interglacia, leia-se «interglacial»

- 367 - linha 17, em vez de Snoth Africa, leia-se "South Africa».

" 370 - linha 7, em vez de" uumularium, leia-se «nummularium»

\372 - linha 6, em vez de do Lepidophytos, leia-se «dos Lepidophytos»

* 372 - linha 10, em vez de que no, leia-se «ao».

- 372 - linha 11, em vez de carbonifero, Jela-se «carbon ssa».

- 374 - linha 5, de bixo para cima, em vez de Africa Oriental, leia-se « da Africa Oriental».

"378 - linha 3, em vez de Sigillaria, murallis, Dadoxyllon, leia-se Sigillaria? muralis, Dadoxyllon!

- 382 - linha 13, eu vez de Colonyi, leia-se "Colonia do Cabo».

- 385 - linha 7, em vez de remnats, leia-se uremnants.

» 386 - linha 13, da nota em vez de 18S6, leia-se «1896m.

- 387 - linha 2, em vez de Gondwna, leia-se «Gondwana».

- 389 - linha 14, em vez de as the result of the athmosphere, leia-se «ss the result of impoverishment of the athm isphe ${ }^{\prime \prime}$.

" 390 - Ultima linha da nota, em $\nabla \theta z$ de prołucção, leia-se «reproduç̧āan.

* 392 - linha 8, de baixu para cima, em vez de Psygnophyllium, leia-se «Psygmophyllium* e pag. 392, linha 6 , de baixo para cima, em vez de citada, leia-se «citadas».

" 394 - linha 12 , em vez de stricta, leia-se «strictan.

* 398 - linha 9, em vez de conhecimento, leia-se ureconhecimenton.

- 400 - linha 1, da nota (1) em vez de Cladopthlebis, leia-se *Cladophlebis».

- 401 - linha 14, em vez de clmate, leia-se «climate.

- 402 - linha 3, de baixo para eima em vez de Etriage, leia-se «Ełhridgen.

* 406 - linha 20, em vez de sublobados, ou cerebriformes, leia-se "sublobado, crene. lado on cerebriforme».

" 410 - linha 18. em vez de Volvocaceas. Devem, loia-se "Volvocaceas, derem".

* 415 - linha 8, em vez de showon, leia-se «shown».

- 426 - linha 1, em vez de Phyllotheca Muelleriana, leia-se Phyllotheca Muelleriana $n . s p$.

" 427 - linha 2, de baixo para cima em vez de dilation, leia-se «dilatation".

" 428 - linha 4, em vez de mostam, leia-se «mostram".

" 428 - linha 15, em vez de autorida ta, leia-se «autoridaden.

* 432 - nota, em vez de 355, leia-se «325*.

» 436 - linha 11, em vez de $p l . n$., leia-se "pl. V».

- 436 - nota, em vez le 1881, leia-se 1884.

- 437 - linha 11, e n vez de Derby, leia-se Derbyi.

- 442 - linha 5, de baixo para cima, em vez de cinta, leia-se crista.

- 443 - linha 7, em vez de genns, leia-se genus. 
Pag. 446 - linha 1, de baixo para cima, em vez de ao, leia-se ou.

- 447 - linha 8, em vez de pl. fig. 2, leia-se pl. I, fig. 2.

- 448 - linhas 20 e 21 , em vez de obvatum e dichtomum, leia-se obovatum e dicho tomum.

- 448 - nota (3), em vez de Zeit. chr. d, Geol., leia-se Zeitschr, d. Deutsch. geol.

- 450 - Iinha 14, em vez de gennro, leia-se genero.

" 452 - linha 5, em vez de laricinus, leia-se laricinum.

- 453 - linha 14, em vez de 87 , leia-se 1871.

- 454 - nota (2), leia-se Costella: rib, cóte = saliencia, etc.

- 455 - linba 19, em vez de Sigilliaria, leia-se Sigillaria.

- 461 - linha 16, em vez de fig., leia-se fig. 1.

" $46 j$ - linha 11, em vez de aculina, leia-se oculina.

- 468 - linha 19, em vez de da, leia-se de.

* 474 - linha 20, em vez de XI, leia-se VI.

" 475 - linha 1, de baixo para cima, em vez de Mulubima, loia-se Mulubrina.

\478 - linha 2 , em vez de Dic, leia-se Die.

" 484 - linha 2 , de baixo para cima, em vez de Felices, leia-se Filices.

* 486 - linha 15, em vez de Plantianun, leia-se Plantianum.

- 487 -- linhas 18 e 19, em vez de ot leia-se of e em vez de Gordwana, leia-so Gondwana.

" 488 - linha 10 , om vez de $O^{\text {m }}, 6$, leia-se $0^{m}, 0$ j.

" 524 - linha 21, em vez de XIII, leia-se XXIIr.

n 529 - linha 4, de baixo para cima, em vez ther, leia-se other.

* 532 - 3 linha da nota, em vez de outros generos, leia-se outro genero.

* 540 - linha 10, en vez de litaes, leia-se distaes.

" 551 - linha 9, , " $f g 3$ " fig,

" 562 - linha 9, de baixo para cima, em vez de Moreirarum, leia-se Moreiranum.

"562 - linha 7, " " " " $"$ " chalaz, leia-se uma chalaza.

"563 - linha 4, " " " " 76, leia-se 0.75.

" 564 - linha 6, ein vez de Oliveirarum, leia-se Oliveiranum,

"564 - linha 10, " " Moreirarum, " Moreiranum.

" 567 - linha 22, " " greaterthn, leia-ge greater than.

- 569 - linha 25, " " 1829 , leia-se 1828.

" 576 - linha 7, de baixo para cima, em vez de Arancanianos, leia-se Auraucarianos.

\580 - linha 14, oin vez de auracariana, leia araucariana.

" 580 - linha 2, de baixo para cima, em vez de merydionale, leia-se meridionalo.

* 593 - linha 4, em vez de como os, leia-se como as.

" 597 - linha 16, " " lamince " laminr.

" 598 - linha $5, "$ " hg. 4, leia-se, fig. 3.

"600 - linha 25, " " estreitas do salientes, leia-se estreitas e salientes.

» 603 - linha 7, de baixo para cima, em vez de Hastimiua, leia-se Hastimima.

" 615 - linha 24, em vez de wells, leta-se walls. 


\section{Corrigenda do Mappa Geologico}

Linha 3 da Nota Explicativa, em vez de occorram, leia-se occorriam. "5" " $" ~ "$ oude se, leia-se onde se.

Onde s: lê gres de Botucatú (Botucatú sandstone), leia-se gres de Sāo Bento (São Bento sandstone),

Além desta «corrigenda * ha outros lapsos que o leitor intelligente saberá corrigir pelo sentido da phrase, ou pelo confronto dos textos inglez e portuguez. - N, do T. 
PARTE I

Relatorio sobre as «Coal Measures》 e rochas associadas

Do

Euxl do IBIaE11

POR

I. C. White

$P A R T I$

Heport on the Coal Measures and Associated Rocks

OF

South Jeraril

BY

I. C. White 


\title{
CAPITULO I
}

\author{
Topographia e geographia physica do Sul do Brasil
}

\section{EVIIENCIA LE ABAIXAMENTO}

A região comprehendida pelos estudos e viagens do autor abrange em parte os tres listados mais meridionaes do Brasil, a sajuer, Rio Glande do Sul, Santa Catharina e Paraná; fizeram-se tambem algumas excursões em S. Paulo e na parte éste de Minas Geraes, assim como a Marahủ na costa do Estado da Bahia ; não foi possivel, porém, um estudo serio nos tres Estadus mencionados por ultimo, por falta de tempo sufficiente.

Toda a linha da costa, ao menos ao sul do Rio de Janeiro, parece apresentar evidencia de submersão, de modo que os rios, bahias e ilhas apresentam o aspecto de submersão tal como se vê nos rios e bahias da Nova Escossia, Cape Breton e Terra Nora.

Este abaixamento ć indicado tanto pela profundidade a que está a rocha solida na embocadura dos rios. como pela ausencia de antigos depositos littoraes em elevaçũes sensireis acima das presentes linhas da costa. E' certo cque encontramos depositos de arêa e velhas dunas amontoadas a 20 , ou mesmo 30 metros acima do nivel do mar e se estendendo muito pelo interior, mas isto nada mais é que o que remos se dar ao longo das praias actuaes, de modo que a prescnça destas planicies haixas arenosas, especialmonte ao sul de Florianopolis, para o do Rio cirande do Sul, não é prora de clevação moderna da clunta.

A depressão da costa parece augmentar para o sul a julgar pelos unicos dados á mão; a saber, as sondagens para as oblas do portu do Rio de Janeiro, onde a rocha solidil apparece perto da praia a cerca de 15 a 20 metros alıaixo das marćs, ao passo que em Pelotas o gl'anito subjacente está além de cem (102) metros de profundidade.

Felizmente foi ronservado o registro de uma sondagem feita alli cm 1856-1862 de cue me foi amavelmente cedida uma copia pelo Ex. mo Sl. Dr. F. de P Gonçalves Moreira, Intendente de Pelotas. 


\section{CHAPTER I}

\section{Topography and Physical Geography of South Brazil}

\section{EVIDENCE OF SUBSIDENCF}

The region comprised by the writer's studies and travels covers in part the three most southern states of Brazil ; viz, Rin Grande do Sul, Santa Catharina, and Paraná. Some excursions were also made into S. Paulo, and through eastern Minas Geraes, as well as to Marahú on the coast of Bahia, but no serious study was possible in the three last mentioned states for want of sufficient time.

The whole coast line, at least from Rio de Janeiro southward, appears to present evidence of sulumergence, so that the rivers, bais, and islands exinibit the aspect, of drowning similar to that shown by the rivers and bays of Nova Scotia, Cape Breton, and New foundland.

This drowning is indicated alilie by the depth to solid bed-rock at the mouths of rivers as well as the absence of any old Jeach deposits at elevations sensibly above the present shore lines. True, we often find sand deposits and old dunes piled up to 20, or even 30 , meters above sea level, and extending far inland, but this is nothing more than we see taling place along the present beaches, so that the presence of these low sandy plains, especially from Florianopolis southward to the extreme point of Rio Grande do Sul, is no evidence of modern crustal elevation.

The amount of constal depression appears to increase southwards judging by the only data at hand; viz, the borings for the harbor works at Rio de Janeiro, where solid rock occurs near shore at about 15-20 meter's below tide, while at Pelotas, the deptls to the underlying granite is over one hundred (102) meter's.

The record of a boring made there in 1856-1862 has fortunately been preserved, and a copy of the same kindly given me by his honor, Dr. F. de P. Goncalves Moreira, the mayor of Pelotas. The 
0 registro desta interessante sondagem, cue foi feita pelo $\mathrm{Sr}^{\text {. An - }}$ gelo Cassapis, menciona o seguinte:

Altura da bocca do poço acima da maré média, 2 metros.

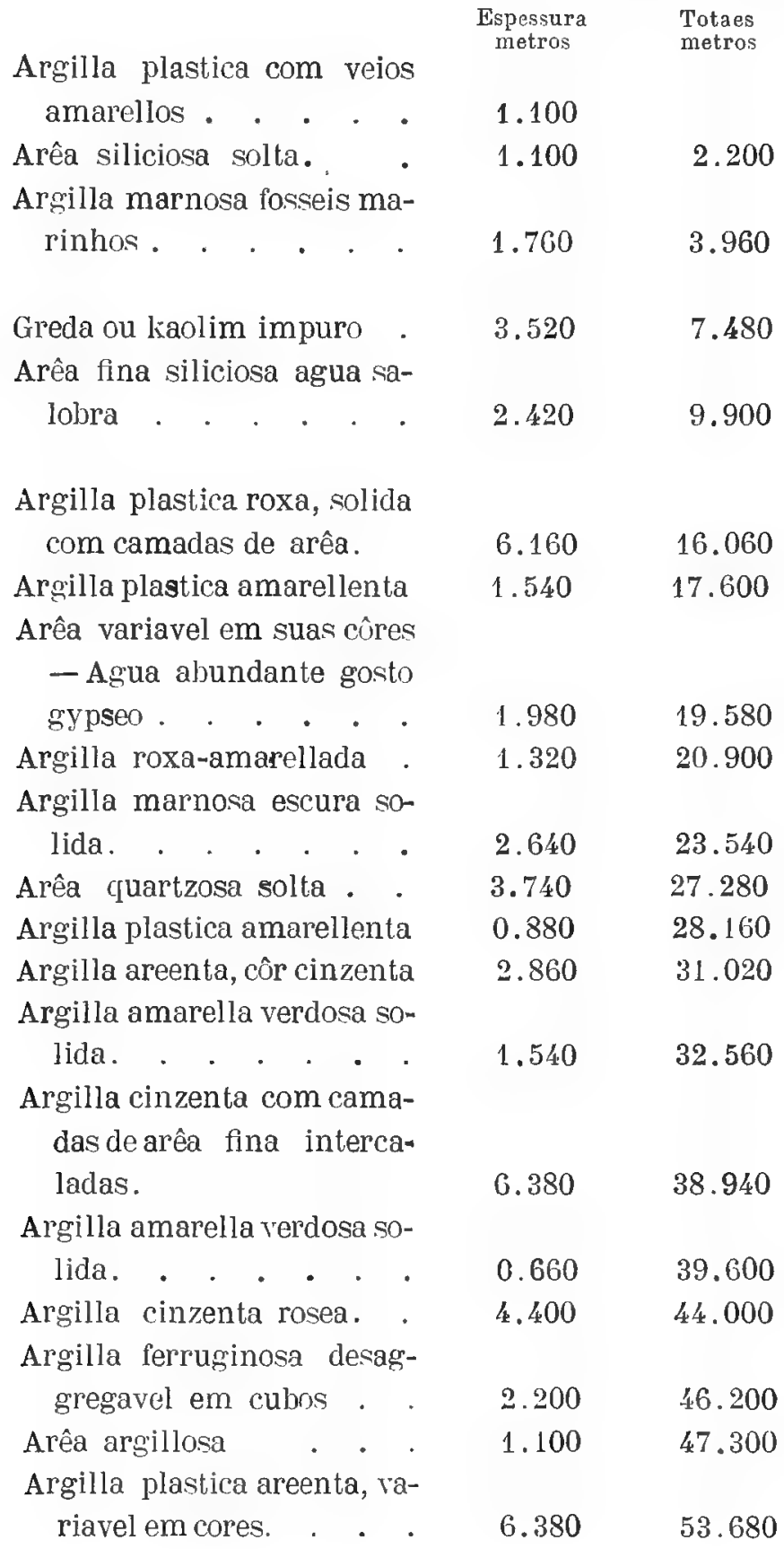


record of this interesting drilling, which was made by Sr. Angelo Cassapis, reads as follows :

Altitude of well mouth above mean tide level, 2 meters.

\begin{tabular}{|c|c|c|}
\hline lastic, with yellory & $\begin{array}{l}\text { Thicknessas, } \\
\text { meters. }\end{array}$ & $\begin{array}{l}\text { Totals } \\
\text { meters. }\end{array}$ \\
\hline reins . . . . . . & 1.100 & \\
\hline Sand, sharp, loose . . . & 1.100 & 2.000 \\
\hline $\begin{array}{l}\text { Clay, marly, with marine } \\
\text { fossils . . . . . . }\end{array}$ & 1.760 & 3.960 \\
\hline $\begin{array}{l}\text { Potters clay, or Kaolin, im- } \\
\text { pure } . . \\
\text {. . . . }\end{array}$ & 3.520 & 7.480 \\
\hline $\begin{array}{l}\text { Sand, fine, sharp, brackish } \\
\text { water } . . \\
\end{array}$ & 2.420 & 9.900 \\
\hline $\begin{array}{l}\text { Clay, plastic, compact, red, } \\
\text { interstratified with lay. }\end{array}$ & & \\
\hline ers of sand . . . . & 6.160 & 16.060 \\
\hline Clay, plastic, pale yellow . & 1.540 & 17.600 \\
\hline $\begin{array}{l}\text { Sand, variegated, abundant } \\
\text { water with gypseous }\end{array}$ & & \\
\hline taste $\cdot . \cdot \cdot \cdot \cdot$ & 1.980 & 19.580 \\
\hline Clay, variegated (red-yeliow) & 1.320 & 20.900 \\
\hline Clay, dark, marly, compact & 2.640 & 23.540 \\
\hline Sand, loose, quartzose . . & 3.740 & 27.280 \\
\hline Clay, plastic, pale yellow . & 0.880 & 28.160 \\
\hline Clay, sandy ashy hue. & 2.860 & 31.020 \\
\hline Clay, yellow-greenish, com- & & \\
\hline pact . . . . . & 1.510 & 32.560 \\
\hline $\begin{array}{l}\text { Clay, ashy, interstratified } \\
\text { with layers of fine sand . }\end{array}$ & 6.380 & 38.940 \\
\hline Clay, yellowish-green, com- & & \\
\hline pact. . . . . . & 0.660 & 39.600 \\
\hline Clay, ashy-led . . . . & 4.400 & 4'. 000 \\
\hline $\begin{array}{c}\text { Clay, ferruginous, separa- } \\
\text { ting in cubes. . . }\end{array}$ & 2.200 & 46.200 \\
\hline Sand, argillaceous . . . & 1.100 & 47.300 \\
\hline $\begin{array}{l}\text { Clay, plastic, sandy, varie- } \\
\text { gated . . . . . . }\end{array}$ & 6.380 & 53.680 \\
\hline
\end{tabular}


Arêa fina, pouco argillosa em via de consolidação .

Arêa solta . . . . .

Arêa fina, solida em partes, solta em outras.

$11.620 \quad 71.240$

Gres silicioso solido . .

$3.080 \quad 74.320$

Gres argilloso solido amarello. . . . .

$1.100 \quad 75.420$

Gres silicioso ]yranco muito solido . . . . .

$0.220 \quad 75.640$

Gres silicioso roseo solido .

$2.860 \quad 78.500$

Arêa solta amarellenta. $\quad \begin{array}{lll} & 0.880 & 79.580\end{array}$

Gres variavel em solidez . $\quad 3.080 \quad 82.460$

Arêa calcarea solida e solta. $\quad 5.060 \quad \$ 7.520$

Gres branco amarellento, cascalho e fosseis . . . $0.404 \quad 87.960$

Arêa siliciosa verdosa escura em via de consolidação . $2.860 \quad 90.820$ Árgilla areenta escura com fosseis . . . .

$0.880 \quad 91.700$

Poudingue passando a $b r^{2} e-$ chas (marmore) glutinoso com argilla

$1.760 \quad 93.460$

Fragmentos de varias grossuras, arêa grossa e fina, calháos rolados, mica, fosseis, tudo solto. . $\quad$. $\quad 5.390 \quad 98.850$

Gres argilloso amarello-verdoso solido. . . . . $\quad 1.180 \quad 103.030$

Granito decomposto. . $\quad \begin{array}{lll}1.100 \quad 104.130\end{array}$ 
Sand fine, slightly argillaceous, partially consolidated . . . . .

Quicksand . . . .

Sand, fine, partly compact and partly quicksand .

$3.520 \quad 57.200$

$2.420 \quad 59.620$

$11.620 \quad 71.240$

$3.080 \quad 74.320$

Rock (sandstone) argillaceous, compact, yellow .

Rock (sandstone), silicious, white, very compact.

Rock (sandstone), silicious, reddish, compact.

Sand, unconsolidated, pale yellow . . . .

Rock (sandstone) variable in hardness . . . .

Sand, calcareous, partly compact, and partlyquicksand . . . . . .

Rock (sandstone), white, pale yellow, pebbles and fossils . . . .

Sand, dark-green, sharp, partially consolidated .

Clay, dark, sandy, fossiliferous. • • •

Puddingstones passing into breccias ( marble) imbedded in clay . . .

Fragments of various size, sand, coarse and fine, water-worn flintstones, mica, fossils, all unconsolidated • • • •

Rock (sandstone), argillaceous, yellowish-green, compact - • . .

Granite, decomposed to bottom.
$0.220 \quad 75.640$

$2.860 \quad 78.500$

$0.880 \quad 79.380$

$3.080 \quad 82.460$

$5.060 \quad 87.520$

0.4 售0 87.960

$2.860 \quad 90.820$

$0.880 \quad 91.700$

$1.760 \quad 93.460$

$5.390 \quad 98.850$

$4.180 \quad 103.030$

$1.100 \quad 104.130$ 
Parece que nenhum fossil obtido na sondagem, foi conservado, porém a quantidade de arêa esverdecada encontrada indicaria que a metade inferior das camadas provavelmente pertencem a sedimentos cretacens, especialmente a porção abaixo de 71 metros de profundidade, portanto o principio do abaixamento que deprimiu a costa sul do Brasil e levu as ár'cas altas de gneiss e granito que se elevam tăo agudas ao longo da costa entre Rio de Janeiro e Florianopolis, a um nivel inferiı", data provavelmente da ipora pre-cretarea e deve estar em relaçãı com os grandes movimentos urogenicos que amontoaram os immensos derram's de rochas eruptivas, diques e laccolites na regriăo da Serra Geral, une tiveram logar posteriormente ao fim do periodo Triassico.

Esta depressão é provavelmente a uue submergiu o wontinente Gondwana» dos geologos inglezes, dectruindo assim a antiga terra clue ligava a Africa á America do Sul que permittiu a passagem livre de plantas e animaes de uma região para outra, como se vê pela identidade de restos fosseis das rochas do Sul do Brasil, Africa do Sul " India.

Os grandes derrames de rocha basaltica que precederam o fim do periodo Triassico, como era natural, modificaram profundamente a geographia physica do Brasil, mudando provavelmente o curso de muitos de seus rios pre-Triassicos e produzindo o admiravel systema de rapidos, cascatas e saltos que interrompem todos os rios do sul do Brasil, tornando difficil a navegação no interior e frequentemente impossivel a qualquer distancia consideravel da costa, por isto, praticamente, todos os rios e pequenas correntes dentro da área mencionada, se precipitam em cascatas e rapidos a poucas milhas do mar onde não existem diques de rocha eruptiva que interrompam seu curso, como entre Blumenau e Itajahy, ou talvez onde estes tenham sido deprimidos e obliterados pelo abaixamento apparente, ou mergulho da linha da costa a que me referi acima.

As grandes cataractas, como a "Sete Quédas" no Paraná e as numerosas cachoeiras e rapidos do Uruguaj e de outros rios dentro da zona da formação carbunifera e Triassica, são praticamente todas causadas por estes diques e derrames de roclıa eruptiva.

De modo que, emquanto estes e outros agentes igneos deram origem a condições que impedem grande commercio interno pelos rios do Sul do Brasil, proporcionaram ao mesmo tempo tăo grandes recursos para a producção barata de energia electrica, de modo a 
No fossils appear to have been preserved from the boring, but the amount of gronish sand found would indicate that the lower half of the beds probably belong to Cretareous sediments, especially the portion below 71 meters in depth, hence the beginning of the subsidence which has depressed the southern coast of Brazil, and carried the elevated gneiss and granite areas which rise so sharply along the coast between Rio de Janeiro and Florianopolis, to a lower level, problably dates from pre-Cretaceous times and may be connected with those great orogenic movements that piled up the immense flows of eruptives, dikes, and laccolites over the region of the Serra Geral which took place subsequent to the close of the T'riassic period. This depression is probably the one which sunk the "Gondwana Land " of the British geologists, thus destroying the former land connection of Africa with South Amcrica which permitted the passage of the plants and animals freely from one region to the other, as shown by the identity of the fossil remains in the rocks of South Brazil, South Africa and India.

The great outflows of basaltic rocks which heralded the clise of Triassic time have, of course, profoundly modified the physical geograpliy of Brazil, probably changilly the course of many of its pre-Triassic rivers, and causing that woniluful system of rapids, cascades, and vertical falls which interrupt all the rivers of South Brazil, rendering interior navigation difficult, and frequently impossible for any considerable distance away from the sea coast. Ilence, practically all of the rivers and smaller stream rising within the area mentioned, simply tumble down in cascades and rapids to within a lew miles of the sea whre no dikes of eruptive rocks are present to interupt their courses, as botween Blumenau and Itajahy, or perchance where the same may have been carried down and oblitered by the alparent sub-idence or drowning of the coast line referred to alsove.

The great cataracts, lilie the "Siren l'ulls" (Sete Quedar) of the Parana, and the numerous falls and rapids of the Uruguay and other rivers within the zone of the Carboniferous and Triassic formations, are practically all caused In thesc dilies and sills of eruptive rocks. Thus, while these and other igneous agencio- hava given rise to conditions which forbid a large inland commerce on the river's of South Brazil, they have at the same time provided such great resources for the cheap seneration of elcctric power, as to com- 
compensar largamente possivel deficiencia de rios navegaveis e depusitos de cirrũo em centros populosos, dispondo o Brasil de bastante ener'ria hydraulica fura mover todas as suas estradas de ferro e fubricas actuaes por meio de corrente electrica, deixando um enorme excesso para qualquer desenvolvimento futuro.

A recente utilisacàn das quédas do rio Tieté para luz e força da ciulule de S. Paulo e tambem das dı ribeirão das Lages para frirnecer luz o forra á srande cidarle do Rio de Janeiro é apenas o inicio do lew nnvolvimento dis elrormes recursos electricos proporcionados pelas griundes cuchoeiras e rapidos dos rios do sul do Brasil.

Ausencia de periodo glacial recente no sul do Brasil

Tenhuma evidencia, qualquer que fosse, de acção glacial durante a época Plcistocena poude se achar em cqualyuer das regiões do Brasil visitadas pelo autcr. Os grandes boulders rolados de granito, gneiss e outras rochas crystallinas que apparecem commumente á superficie e que para Agassiz e Hartt pareciam ser boa prova de condições glaciaes antigas s̃o em muitos casos simples "boulders de desintegração.» Do mesmo modo a capa de sólo vermelho que cobre tão grande superficie é devida aós mesmos agentes de desintegração, que estão sempre em actividade nos paizes tropicaes com grandes chuvas. Nenhuma superficie estriada ou calháo arranhado foi achado em nenhuma das áreas ao redor do Rio, consideradas typicas de condições glaciaes por Agassiz, pai, e Ilartt.

\section{Periodo glacial antigo}

Ao passo que nenlıuma evidencia satistactoria de glaciação recente poude ser encontrada no sul do Brasil, parece existirem factos que não podem ser interpretados, senão pela hỵpothose de condições glaciaes em principio do period, Permiano, em grande área do sul do Brasil, pois que em muitos pontos occorrem immensos boulders de granito, gneiss, ([uartzito e outras rochas sotopostas as camadas carboniferas e frequentemente incluidos em uma pasta fina, cinzenta, argillacea sem estratificar, ĩu apparente.

To Estado de Santa Catharina, na estrada entre Joinville e Rio Negro, a superficie do sólo é frequentemente coberta por grande quantidade destes boulder's, transportados, alguns dos quaes de $3 \times 3 \times \geq$ metros de volume e claramente embutidos nas rochas argillosas ha ponco 
pensate largely for possible deficiencies in navigable rivers, and coal deposits, in populous communities, since Brazil has enough water power to operate all her present railways and factories with the electric current, and leave an enormous surplus for any future developments. Thr recent utilization of water-falls on the Rio Ticte for light and power in the city of S. Paulo, and also of the falls of Ribeirão das Lages to furnish light and power for the large city of Rio de Jansiro, is only the leginning of the development of the enolmous electric possibilities afforded in the great cascades and rapids of South Brasilian rivers.

\section{No Recent Glaciation in South Brazil}

No evidence whatever of glacial action during the Pleistocene epoch could be found in any of the regions of Brazil visited by the writer. The great rounded boulders of granite, frneiss and olher crystalline rocks which often appear on the surface, and which to Agassiz, and IIartt, seemed to be rood evidence of former glacial conditions, are in most cases simply "Joulders of disintegration ". Likewise, the mantle of red soil that covers so much of the surface is due to the same agencies of disintegration which are ever active in tropical countries with large rainfall. Not a single striated surface or scratched houlder was found in any of the areas around Rio regarded as typical of glaciated conditions by the elder Agassiz and IJartt.

\section{Ancient Glaciation}

While no satisfactory cridence of recent slaciation could be found in South Brazil, there appears to be a body of facts that cannot be accounted for except upon the hypothesis of glacial "mulitions at the dawn of Permian time orer a ver'y large area in South Brazil, since at many points thare wrur immense boulders of granite, gneiss, quartzite, and other rocks underlying the cril Mrasures, and often imbedded in a fine gray argillaceous paste apparently without stratification.

In the State of Sinta Catharina on the road between Joinville and Rio Negro, the surfare uf the spound is frofuently covered with immense numbers of these transported boulders, some of which are $3 \times 3 \times 2$ meters in size, and clearly imbedded in the rlay rocks 
mencionadas, distantes muitos kilometros de qualquer affloramento də rochas graniticas.

Um destes depositos, em que foram contados 5 boulders de 3 metros de diametro, foi encontrado perto do kilometro 135 de Joinville.

Um grande deposito de boulclers é enrontrado tambem logo abaixo das camadas carboniferas cm muitos pontos no Rio Grande do Sul, principalmente perto das minas des. Jeronymo, perto de Butiá, bem como perto de $\mathrm{s}$. Sepé e em numerosas outras localidades.

No Estado do Paraná ha uma enorme massa de seixos, grandes boulders, madeira petrificada, etc., superposta em discordancia a schistos com fosseis Devonianos, na vizinhança de Ponta Grossa e outros logares entre esta e Serrinha, especialmente entre os postes kilometricos 115 e 125 de Curitýla. L' provavelmente a mesma formação que deu origem í "Rock city", chamada Villa Velha, nos altos, a alguns kilometros ao sul de Ponta Grossa.

O Dr. Derby refere a presença de grandes boulders de sranito e outras rochas crystallinas cm uma pasta, tambem não estratificada, de pedra de lama em muitas localidades no Estado de S. Paulo, de modo que, apezar de não terem sido observadas estrias de gelo, ou boulders arranhados em connexão com estas morcines fosseis, como na Africa do Sul e India, parece não haver razão para duvidar que estes depositos tenham tido a mesma origem que o conglomerato "Glacial » ou "Dvylia » da regičo africana. O autır não esteve na localidade em Minas Geraes, (Tralle do liı Borlachudo, affluente da margem occidental do rio sĩo Frinci-co)onde se encontram seixos facetados attribuidos á acção glacial, pelo Dr. Lisboa, (*) eminente engenheiro e geologo de Petrop.lis, que colleccionou muitor destes em uma localidade ao norte de meu proprio campo de trajalho.

Estes seixos, facetados de 1 a 3 pullegadas de diametro, o Dr. Lisjoa considera como perfeitos fac-similes dos do conglomerato de Dwyka da Africa do Sul ; e portant» c possivel que a hypothese de Corstorphine concernentc it distribuicãn geographica dos verdadeiros movimentos glikiaer sobre as terras septentrionacs e montcs de gelo

(*) In the Occurpence of Faceller Pelobles on the Cintral l'latuau of Brasil by Miguel Arrojala R. Linboa: Ameriran Jommal of Serenee. Taneiro 10ur. O Dr. While, baseado em r.miniscencias de uma conversa rapiela yue tere com o auctor antes de ser userpto este artigu, elabora pun erro, attribuindo-lhe a opinião definitiva a tavor da origem slacial do phenomeno em questä.

(Nota do editor) 
just mentionel at many kilometers from any outcrop of granite rocks.

One of these deposits, in which were counted 5 boulders 3 meters in diameter, was encountered near the 135th kilometer from Joinville.

A great boulder deposit may also be seen just under the Coal Measures at many points in Rio Grande do SuI, notably near the mines of S. Jeronymo, near Butiá, as well as near S. Sepé, and at. numerous other localities.

In the State of Paraná, there is an enormous mass of gravel, large boulders, petrified wood, etc., resting unconformably upon shales holding Devonian fossils, in the vicinity of Ponta Grossa, and other places between there and Serrinha, especially between lilometer posts 115 and 125 from Curityja. It is also probably the same formation that makes the "Rock City) known as Villa Velha, on the summits several kilometers south from Ponta Grossa.

Dr. Derby reports the presence of great boulders of granite and other crystalline rocks in a similar unstratified paste or mud stone at many localities in the State of S. Paulo, so that, although no ice strinc or scratched boulders have been observed in connection with this fossil moraine as in South Africa and India, ret there seems no reason to doubt that these deposits have had the same origin as the "Glacial" or "Dwyka" conglomerate of the African region. The writer has not visited the locality in Minas Geraes (Valley of Rio Borrachudo, a western affluent of the São Francisco) of the facetted pebbles ascribed to glacial action by Dr. Lisboa, (") the eminent engineer and geologist of Petropolis, who has collected many of these from a locality north from my proper field of work.

These facetted pebbles from 1 to $3 \mathrm{i}$ nches in diameter, Dr. Lisboa regards as perfect fac-similes of those figured from the Dwyka conglomerate of S. Africa; hence, it is barely possible that Corstorphine's hypothesis concerning the geographical distribution of true glacial movements on the land at the north, and floating ice-

( $\left.{ }^{\star}\right)$ Tbe Occurrence of Facetted Pebbles on the Central Plateau of Brazil by Miguel Arrojado R. Lisboa: American Journal of Siene. Jan. 1907. Dr. White from his recollection of a rapid conversation with the author, before this article was written, is in error in attributing to him a deflnite opinion in faror of the glacial origin of phenomenon in question,

(Editor's note). 
fluctuantes, deixando cahir grandes blúcos de granito nos sedimentos lodosos muito ao sul no continente africano, podia ter tido seu paral lelo no sul do Brasil, de Minas Geraes ao Rio Grande do Sul.

Foi provado que houve verdadeira acção glacial na Africa do Sul em principio do periodo Permo-Carbonifero, e como a mesma successão de rochas occor'e praticamente na mesma latitude (25-35 Sul) no Sul do Brasil tıda a presumpção é em farror da hypothese glacial para explicar os depositos do Rio Nerro, bem como os seixos facetados colligidos pelo Dr. Lisboa, em Minas Geraes.

Considerando deste modo a questão, Agassiz e Hartt tinham razão em affirmar ter havido uma época glacial no Brasil, porém assim foi, em fim do periodo carbonifero, em vez de ser durante o Pleistoceno. A occurrencia de phenomenos glaciaes durante o periodo Permiano, na Europa, sobre que alguns geologos teem insistido, pode ter sido contemporanea das mesmas condicões ao sul do equador.

O autor dispoz de pouco tempo para dedicar a estes interessantes problemas e sómente os menciona aqui, para estimular a investigação e pesquiza de outros investigadores.

\section{Feição geral topographica e hydrographica}

A topographia geral do sul do Brasil póde ser resumidamente esboçada nas curtas palavras que se seguem: A Serra do Mar, alta cadeia de montanhas, compostas na maior parte de granito e rochas gneissoides, frequentemente cortadas por diques de rochas eruptiras antigas e muitas vezes envolvendo velhas camadas sedimentares da idade cambriana, ou pre-cambriana, ergue-se abruptamente do mar", na região do Rio de Janeiro, estendendo-se para o sul parallela á linha littoral do Atlantico apenas poucas milhas distante desta, formando a borda externa da grande região do planalto.

Este massiço de montanhas, cuja ailtitude geral é de cerca àe 1000 metros, estendendorse para o sul por S. Paulo, Paraná, Santa Catharina, morrendo rapidamente ao sul de Florianopolis e praticamente desapparecendo sob o mar antes de alcançar o Rio Grande dः Sul, de facto a orientaçĩo da massa granitica parece leval-a na direção do mar, ondr desapparece gradualmente, on pelo abaixamento geral para sudoeste, ou por fallas, emruanto que o mar quasi completou a remoção dos picos, exceptuando os mais altos como 
Jergs dropping large granite boulders from the same in to the muddy sediments farther south, on the African continent, may have liad its parallel in South Brazil from Minas Geraes to Rio Grande do sul.

Certainly true glacial action has been proven to have taken place in South Africa at the beginning of Permo-Carboniferous time, and as the ame sucression of rockis occur: at practically the same latitude $\left(25^{\circ}-35^{\circ}\right.$ South) in South Brazil, the presumption is all in favor of the slacial hypothesis to accinnt fio the Rio Negro deposits, as well as for the lacetted pebbl's collected hy Dr. Lishoa in Minas Geraes.

Wvith this view of the matter, Agassi'z and Ilartt were right in asserting that there had been a Glacial epoch 'in Brazil, but it was during the closing period of Carboniferous time instead of during the Pleistocen'. The occurence of Glacial phenomena during Permian time in Europe upon which sime geologists have insisted, may have been contemporaneous with the same conditions south from the equator.

The writer had little time to devote to these interesting problems, and only mentions them here in order to stimulate inquiry and research by other investigators.

\section{General Topographic and Drainage Features}

The general topography of South Brazil may be briefly sketched in a few words as follows: The Serra do Mar, a high range of mountains composed mostly of granite and gneissoid rocks, freyuently cut with dilies of old eruptives, and often en wrappins ancient sedimentary beds of Cambrian or pre-Cambrian age, rises abruptly frum the sea in the region of Rio de Janeiro and trending southward parallel with.the Atlantic shore line, only a tew miles distant therefrom, makes the outer rim of the great plateau region.

This mountain mass, the general elevation of which is ajout 1000 meters, extends southrvard through S. Paulo, Paraná, and Santa Catharina dying down rapidly southward lrom Florianopolis, and practically disappearing from view beneath the sea before reaching the border of Rio Grande do Sul ; in fact the trend of the granitic mass appears to carry it out seaward where it disappears gradually either by the general south-west subsidence, or by faulting, while the sea has nearly completed the removal of all but the hisher peaks like Cochilha 
Cochilha das Lombas, etc. , que ficaram como postos avançados de uma antiga linha de costa.

Alguns remanentes desta cadeia reapparecem perto de PortoAlegre e é provavelmente o mesmo systema que se curva para oéste com o nome de serra do Herval, etc., e vai até o ponto extremo sul do Brasil.

A oèste desta cadeia de granito e gneiss contendo algumas faixas de velhos sedimentos metamorphicos temos um largo planalto ao norte, que se estende para oéste para a base da Serra Geral, cujos picos se elevam a uma altura de 1500 metros ou mais; a escarpa anterior da Serra Geral é formada pelo affloramento dos conglomeratos massiços côr de creme e grés vermelho do Trias, cobertos por grandes derrames de rochas eruptivas antigas, principalmente diabase, muita da cual de caracter amygdaloide. A Serra Geral é a divisora das aguas que correm para oéste para o Uruguay e Paraná, das que vertem para éste para o Atlantico.

Nos altos da Serra Geral ha vastas planicies conhecidas por Campos, que se estendem para oéste, para a fronteira occidental da Republica, cortadas naturalmente por numerosos rios e seus tributarios.

Largas faixas desta planicie são cobertas pela serie de S. Bento, ou Triassica especialmente visiveis nos cumes das mais altas montanhas do Rio Grande do Sul, Santa Catharina, Paraná e S. Paulo.

o rio Iguassú, tributario do Parana ao norte do rio Uruguay, cavou seu leito atravez da parte septentrional da Serra Geral do Estado de Santa Catharina para o do Paraná e nasce na fralda occidental da Serra do Mar, não obstante os altos cimos das montanhas de ambas as margens do Iguassú em Porto União coroados por penedias de grés Triassico e grandes derrames de diabase, marcam a verdadeira linha da Serra Geral,que continúa para o norte atravez do Paraná com o nome de Serra da Esperança, para ser cortada de novo pelo rio Ivahy nas grandes cachoeiras abaixo de Therezina e tambem pelo rio Tibagy e pelas aguas do rio Paranapanema, além do qual estas altas escarpas passam para o Estado de S. Paulo em direcção a Botucatú. Ainda mais além para noldéste a escar pa Triassica é de novo cortada pelos rios Tieté, Mogyguassu e Pardo, cujas nascentes, como as do Paranapanema, estão em velho complexo granitico e crystallino a éste, distante das rochas carboniferas e, cortando estas, se dirigem para oéste para aguas do Paraná.

O cur'so não commurn do rio Parahyba, cujas nascentes estão em 
das Lombas, etc., which remain as outposts of a former coast line.

Some remnants of this range reappear near Porto Alegre and it is probably the same system which curves westward from there under the name of Selra do Herval, etc., and passes on to the extreme southern point of Brazil.

Westward from this range of granite and gneiss holding some Jelts of old metamorphic sediments, we have a broad plateau at the north which extends westward to the base of the Serra Geral, the peaks of which rise to a height of 1500 meters or more. The front escarpment of the Serra Geral is made by the outcrop of the massive cream colored conglomerates and red sandstones of the Trias capped. above by great flows of old eruptives, principally diabase much of it amygdaloidal in character. The Serra Geral is the summit of the divide separating the waters which flow westward into the Uruguay and Parana from those which pass eastward into the Atlantic.

From the summit of the Serra Geral, there spreads out a wide plain known as the Campos, and it extends westward to the western boundary of the Republic, trenched of course by numerous rivers and their tributaries:

Broad belts of this plain are covered with the São Bento or Triassic sandstone series, especially conspicuous in the higher mountain summits of Rio Grande do Sul, Santa Catharina, Paraná, and São Paulo.

Rio Iguassú, a tributary of the Paraná, north from Rio Uruguay, has cut back through the northward cxtension of the Serra Geral from Santa Catharina into the state of Paraná, and heads on the western slopes of the Serra do Mar, although the lofty summits of the mountains on either side of the Iguassú at Porto União, crowned with cliffs of Triassic sandstone and great flows of diabase, mark the true line of the Serra Geral which continues northward across Paraná as the Serra da Esperança, to be trenched again by Rio Ivahy at the great cascades below Therezina, and also by Rio Tiljagy, and the waters of Rio Paranapanema, beyond. which these lofty escarpments pass into the state of S. Paulo toward Botucatú. Still farther to the north-east, the Triassic escarpment is again trenched by Rio Tieté, Rio Mogyguassú and Rio Pardo, whose fountain streams, like those of the Paranapanema, rise on the old granite and crystalline complex far east of the Carboniferous rocks and cutting tlirough the latter, pass westward into the waters of the Paraná.

The very unusual course of Rio Parahyba, whose liead waters 5569 
face do Atlantico a 150 kilometros a sudoéste do Rio de Janeiro, e depois de colrer para sudoéste approximadamente para o Tieté,curva-se bruscamente para traz em um arco de $180^{\circ}$ e passando parallelamente ao seu curso anterior, distante apenas alguns kilometros, se dirige para nordéste e desagua no Atlantico a 200 kilometros a nordéste do Rio de Janeiro, é um dos muito interessantes problemas da geographia physica do Brasil, cuja solução ainda não foi claramente dada.

os depositos de agua doce Terciarios (ou mais antigos) do valle do Parahyba, perto de Taubaté, que conteem peixes fosseis, etc., em seus schistos bituminosos, podem ser um guia para sua solução, quando forem cuidadosamente estudados e cartographados.

E' possivel que o curioso curso do rio, bem como a origem dos depositos em questão, sejam devidos a grandes erupçũes de trap e material basaltico, que cobriu tão grande região do Brasil, posteriormente ao periodo Triassico, obstruindo e formando lagos ao longo de muitos rios pre-Triassicos, desviando outros para novos canaes e modificando muito a antiga lopographia e os systemas de rios preexistentes. 
rise in sight of the Atlantic 150 kilometers south-west from Rio de Janeiro, and after flowing south-westward nearly to the Tieté, turn abruptly backward through an arc of $180^{\circ}$, and passing parallel to the former course, only a few kilometers distant, keep on to the northeast and enter the Atlantic, 200 kilometers north-east from Rio de Janeiro, is one of the very interesting problems in Brazilian physical geograpliy whiose solution has not yet been clearly demonstrated.

The Tertiary (ol' older) fresh water deposits along the valley of the Parahyba near Taubaté, which hold fossil fishes, etc., in its bituminous shales, may furnish the clue to its solution when carefully studied and mapped.

It is possible that the curious course of the river as well as the origin of the deposits in question may be due to the great outflows of trap and basaltic material which covered such a large region of Brazil subsequent to the Triassic period, obstructing and forming lakes along many of the pre-Triassic rivers, diverting others into new channels and greatly modifying the older topography and preexisting river systems. 


\section{CAPITULO II}

\section{Rochas pre-Carboniferas do Sul do Brasil}

Em muitos pontos do Rio Grande do Sul, Santa Catharina, Paraná e S. Paulo encontram-se faixas de marmore, ou calcareo semi-crystallino e outras rochas antigas, metamorphicas, ao longo da região da Serra do Mar, superpostas ao granito, ou encaixadas em suas dobras. Não foi possivel estudar estas camadas, mas foram notadas incidentemente, de passagem por ellas pertode Caçapava, onde ha uma faixa de calcareo semicrystallino com meio a um kilometro de largura e 10 a 12 de comprimento, cuja base em seu contacto com o granito está convertida em marmore. Nenhum fossil foi observado. Ha tambem marmore em Santa Catharina, a nordeste de Itajahy, segundo o Sr . coronel Eugenio Müller, que o viu; ha tambem no Paraná, S. Paulo e Minas Geraes. Provavelmente todo elle apparece no mesmo horizonte geologico e sem duvida pertence ao cambriano ou a mais antigo systema de rochas.

\section{Camadas Devonianas}

Immediatamente abaixo das camadas carboniferas no Estado do Paraná, e discordante com estas,encontrámos uma serie de rochas com fosseis Devonianos bem caracterisados. Estas camadas affloram perto de Ponta Grossa, no Paraná, bem como em muitas outras localidades ao longo dascabeceiras do Tibagy. Estão tambem claramente expostas em um corrte da estrada a tres kilometro ao sul de Jaguariahyva, onde são muito fossili feras .

As camadas superiores são de schistos, escuros no tope, azues e areentos em baixo, passando a um conglomerato massiço mais em baixo onde nenhum fossil foi olsservado.

A lista destes fosseis colligidos perto de Jaguariahyra e tambem perto de Tibagy é a seguinte, tendo as especies sido determinadas pelo Dr. John M. Clarkegeologo do estado de Nerv York que amavelmente apresentou as seguintes observações sobre estas: 


\section{CHAPTER II}

\section{Pre-Carboniferous Rocks of South Brazil}

Resting upon the granite at many points in Rio Grande do Sul, Santa Catharina, Paraná, and S. Paulo, or enclosed in its folds, we find belts of marble or semi-crystalline limestone, and other old metamorphic rocks along the region of the Serra do Mar. These beds could not be studied, but were incidentally noted in passing across them near Caçapava where there is a belt of semi-crystalline limestone $\frac{1}{2}$ to 1 kilometer wide and 10-12 kilometers long, the base of which in contact with the granite is converted into marble. No fossils were observed. There is also marble in Santa Catharina north-east from Itajahy, according to Colonel Eugenio Müller, who has observed it, as also in Paraná, S. Paulo and Minas Geraes. It probably all comes at the same geologic horizon, and doubtless belongs to the Cambrian or an older system of rocks.

\section{Devonian Beds}

Immediately bolow the Carboniferous beds in the state of Paraná, and unconformable therewith, we find a series of rocks with well marked Devonian fossils. These beds crop near Ponta Grossa in Paraná, as well as at many other localities along the head waters of Tibagy. They are also well exposed in a road cutting, 3 kilometers south from Jaguariahyva where they are quite fossiliferous.

The higher beds are shales, dark at top, but blue and sand $y^{\circ}$ below passing into massive conglomerates lower down in which no fossils were observed.

The list of these fossils collected near Jaguariahyra and also near Tibagy is as follows as identified by Dr. John M. Clarke, State Geologist of New York, who kindly submits the following remarks thereon: 
"Gabinete do Director, State Hall, Albany, N. Y. 11 de Junho de 1906.

Dr. I. C. White, Geologo do Estado.

Morgantown, W. Va.

Meu caro Sr.

Os fosseis devonianos que submettestes ao meu exame estavam rotulados como procedentes de tres (ou quatro) localidades. Tenho as seguintes observações a fazer respeito delles:

\section{Fistado do Paraná}

a (1) Tibagy. Impressões internas em rocha amarella micacea molle. Duas especies estão representadas:

Spirifer borbai v. Ihering.

Modiomorpha sp.

O Spirifer, grande e bella especie, foi comparado com S. vespertilio Sowerby, uma especie Permiana, e tambem com S. macropleurus, Hall do Helderbergiano (Devoniano inferior ).

Kayser, tratando dos fosseis desta localidade, (Revista do Museu Paulista, v. 4, 1900, p. 301-311) cita tambem olamellibranchio Pholadella radiata Hall que em New York occorre nas estratificações do Devoniano medio.

(2) Perto de Jaguariahyva.

Rocha semelhante em caracter geral, porém com menos ferro. Contém:

Spirifer ihering, Kayser (cf. S. murchisoni D’Orbigny);

Leptocoelia flabellites Conrad;

Leptostrophia cf. perplana Conrad;

Orthothetes cf. becraftensis Clarke;

Chonetes cf. hudsonicus clarlie;

Que esta serie é do Devoniano inferior é fóra de duvida, visto que todas as especies são de typo Devoniano muito antigo. Pequenas Leptostrophias do typo da $L$. perplana são communs nestas faunas. Or- 
"Director's Offlce, State Hall, Albany, N. Y. (July 11, 1906).

Dr. I. G. White, State Geologist.

Morgantown, W. Va.

My dear Sir :

The Devonic fossils from Brazil which you have submitted to my examination are labeled as from three (or four) localities. I have the following comments to make upon them:

\section{State of Paraná}

(I) Tibagy. Internal casts in soft yellow argillo-micaceous rock. Two species are here represented :

Spirifer borbai v. Ihering

Modiomorpha $s p$;

The spirifer, a fine large species, has been compared with $S$. vespertilio Sowerby a Permian species and also with S. macropleurus Hall of the Helderbergian, (Lowrer Devonic).

Kayser, in discussing the fossils of this locality, (Revista do Museu Paulista, v. 4, 1900, p. 301-311) cites also the lamellibranch Pholadella ridiata Ilall which in New York occurs in Middle Devonic. strata.

(2) Near Jaguariahyva.

A similar rock in general character but with less iron contents. It contains :

Spirifer ihering, Kayser, (cf. S. murchisoni D'Orbigny);

Leptocoelia flabellites Conrad;

Leptostrophia cf. perplana Conrad;

Orthothetes cf. becraftensis Clarke;

Chonetes cf. hudsonicus Clarke.

The Lower Devonic age of this combination is beyond reasonable doubt as all the species are of strongly early Devonic habit. Small Leptostrophias of the type of $L$. perplana are common in these faunas, 
thotheles becraftensis e Chonetes hudsonicus são especies do calcareo Oriskany e largamente espalhadas neste hori zonte.

(3) Ponta Grossa.

Rocha argillo-micacea cinzenta molle com:

Orbiculoidea, especies grandes e pequenas;

Homalonotus ;

Bactrites?

Leptocoelia flabellites;

Lingula especie grande não identificada.

Na collecção submeltida a meu exame ha apenas um unico specimen desta localidade, uma Orbiculoidea ; completei, porém, minha lista com material que é em parte aquelle a que o Dr. Derlsy se referiu in Neues Jahrbuch für Mineralogie, 1888, v. 2, p. 173.

Elle cita tambem Spirifer, Rhynchonella, Vitulina e Streptorhynchus. Um schisto mais preto da mesma localidade contem fragmentos de um Ophiurideo.

Esta rocha promette uma fauna consideravel e bem conservada e pelos nossos conhecimentos presentes das especies, deve ser organisada como a do periodo Devoniano inferior.

NotA - Aos specimens da lista acima de perto de Jaguariahyva, devo juntar a especie descripta por mim como Dalmanites gonzaganus, daquella localidade.

Entre os specimens remettidos ao Dr. Clarke para serem determinados havia um pequeno lote do Devoniano do Pará do Norte do Brasil, colligido pelo Dr. Francisco de Paula Oliveira , da Commissão do Carvão, que se verificou ser de grande interesse scientifico como se vê pelas seguintes notas do $\mathrm{Dr}$. Clarke:

\section{Estado do Pará}

(4) Schisto preto, Ereré.

Esta rocha contém em abundancia:

Nuculites, uma especie pequena.

Schizobolus truncatus Hall.

A ultima tem mais que interesse ordinario. 
Orthothetes becraftensis and Chonetes hudsonicus are species of the Oriskany limestone and are widespread at this horizon.

(3) Ponta Grossa.

A soft gray argillo-micaceous rock with :

Orbiculoidea, large and small species;

Homalonotus ;

Bactrites?

Leptocoelia flabellites;

Lingula, large unidentified species.

The collection submitted has but a single specimen from this locality, an Orbiculoiclea, but I have completed my list from material which is in part, that to which Dr. Derby has referred in Neues Jahrbuch fur Mineralogie, 1888, v. 2, p. 173.

He cites also, Spirifer, Rhynchonella, Vitulina and Streptorhynchus. A blacker shale from the same locality contains fragments of an Ophiuran.

This rock promises a considerable and well preserved fauna and from our present knowledge of the species, it must be construed as of lower Devonic age.

Note. To the specimens listed above as from near Jaguariahyva, I may add thereto from the latter locality the species described by me as Dalmanites gonzaganus.

Among the specimens sent Dr. Clarke for identification was a small lot from the Devonian of Pará in North Brazil, collected by Dr. Francisco de Paula Oliveira, of the Coal Commission, the specimens of which have proven of great scientific interest as shown hy the following remarks of $\mathrm{Dr}^{2}$, Clarke:

\section{State of Paná}

(1) Black shale, Lrepê, State of l'ar'i.

This rock contains abundantly:

Nuculites, a small species;

Schizobolus truncatus, Hall.

The latter is of more than ordinary interest. 
A especie (Discina truncata Hall) é o unico representante do genero Schizobolus e antes foi achado sumente nas camadas de schisto preto do Devoniano superior (Genesee e Cashaqua de New-York e o schisto preto de Kentucky). Os specimens do schisto do Pará são abundantes e bem conservados.

Para mim não existe duvida de sua identidade especifica e sua indicação, não sómente de um horizonte geologico no Estado do Pará, que não tinha sido anteriormente mencionado, como tambem de condições physicas naquelle tempo na America do Sul de que não tinhamos tido conhecimento.

Muito respeitosamente vosso

John M. Clarke, Geologo do Estado." 
The species, (Discina truncata, Hall is the only representative of the genus Schizobolus and has been found before only in the black shale beds of the Upper Devonic, (Genesee and Cashaqua of New York and the black shale of Kentucky). The specimens in the Pará shales are abundant and well preserved.

No doubt exists in my mind of their specific identity and of their indications not only of a geological horizon in the State of Pará not before recorded, but of phrsical conditions at this time in South America of which we have thus far had no intimation.

Very respectfully yours,

John M. Clarke, State Geologist.) 


\section{CAPITULO III}

\section{As rochas Carboniferas e Triassicas}

Geralmente encontramos um conglomerato muita grosseiro, ou muitas vezes simplesmente uma grande camada de grandes boulders, alguns dos quaes podem ter de dous a tres metros de diametro, superposto discordantemente aos schistos Devonianos, ou a camadas mais antigas, quando não ha Devoniano e algumas vezes mesmo ao granito. Esta camada de boulders parece determinar o principio do periodo carbonifero, no sul do Brasil. Destas camadas mais antigas e inferiores ao carbonifero, parece existir uma successão regular de rochas não alteradas por qualquer grande discordancia, nas camadas carboniferas, até o tope do grés e conglomerato Triassico, vermelho e cinzento que formam as penedias massiças e altas escarpas da parte oriental da Serra Geral.

Superposta a estes grés altos e muitas vezes introduzidas entre as estratificações massiças, vem uma série de antigas rochas eruptivas de caracter basaltico, ou diabasico que forma a superficie geral dos Campos e os picos mais altos da Serra Geral. Estas rochas vulcanicas estão bem expostas em Santa Catharina na Estrada do Rio do Rasto (Estrada Nova), estrada real na montanha, construida com grande custo na face quasi perpendicular destas velhas rochas eruptivas onde se superpõem aos mais altos grés do Trias, em grandes Iençóes de diabase e basalto, muito do qual amygdaloide e se estendem para cima com uma espessura de 600 metros até aos picos culminantes da montanha a uma altura de 1400 metros sobre o mar.

A seguinte secção das rochas expostas ao longo da Estrada Nova em Santa Catharina é baseada em medidas feitas sob a superintendencia do Dr. Esdras do Prado Seixas, engenheiro da Commissão do Carvão duranteo anno de 1904 e parte de 1905 , que procedeu ao nivelamento da Estrada Nova das Minas até o contacto da diabase com o grés do tope do Trias exposto perto do Morro Pallado a 19 1/2 kilometros a oeste de Minas e sob cuja direcção tambem foi feito o mappa da região de Minas publicado com este relatorio. 


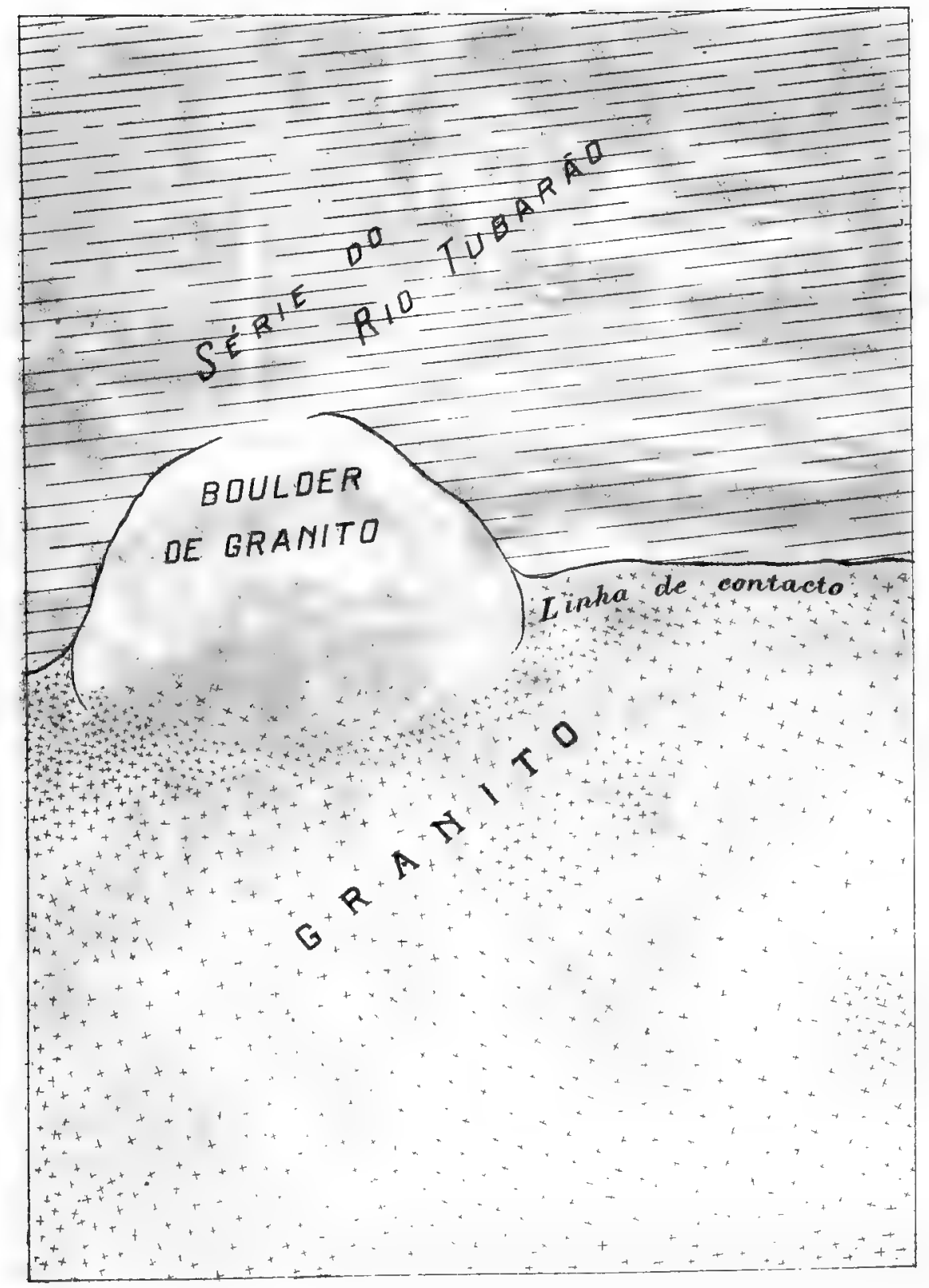





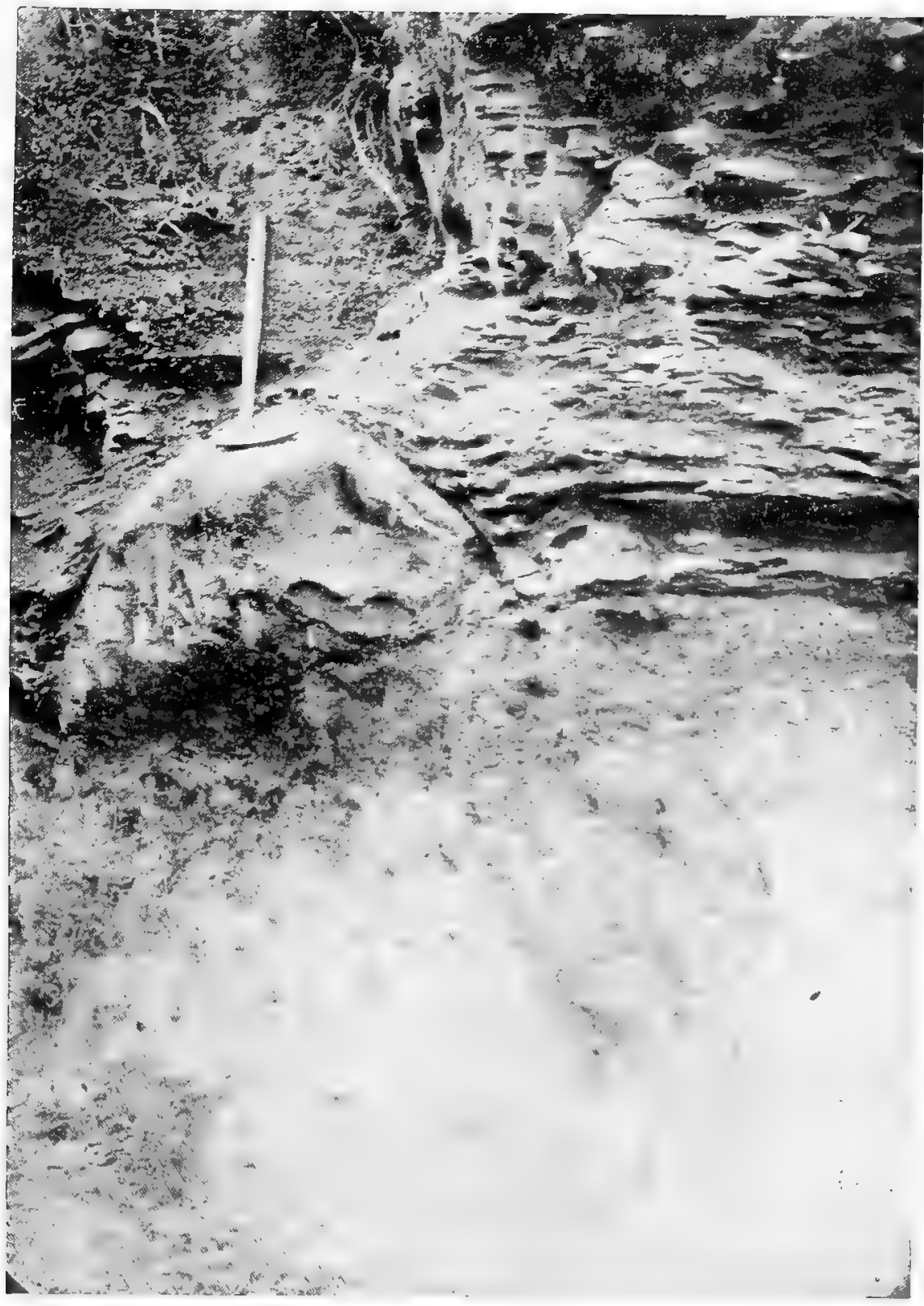

ESTADO DE SANTA CATHARINA

Contacto da serie sedimentaria com o granito a 2 kilometros da estaçāo Lauro Müller da E. F. D. Thereza Christina 



\section{CHAPTER III.}

\section{The Carboniferous and Triassic Rocks.}

Resting unconformably upon the Devonian shales, of older beds when the Devonian is absent, and sometimes upon the granite itself, we generally find a very coarse conglomerate, or often simply a great bed of large boulders some of which may be 2 to 3 meters in diameter, and this boulder bed appears to mark the beginning of Carboniferous time in South Brazil. From these oldest and lowest beds of the Carboniferous there appears to be a regular succession of rocks, unbroken by any great unconformity, up through the coal bearing series to the top of the red and gray Triassic sandstones and conglomerates which form massive cliffs and lofty escarpments high up the eastern face of the Serra Geral.

Resting upon these highest sandstones, and often thrust between the massive strata, there comes a series of old eruptives of basaltic, or diabasic character which form the general surface of the [Campos and the higher peaks of the Serra Geral. These volcanic rocks are well exposed in Santa Catharina along the Estrada do Rio do Rasto (Estrada Nova), a mountain highway constructed at great cost up the almost perpendicular face of these old eruptives where they overlie the highest sandstones of the Trias, in great sheets of diabase and basalt, much of it amygdaloidal, and extend upward with a thickness of 600 meters to the summit peaks of the mountain at an elevation of more than 1400 meters above the sea.

The following section of the rocks exposed along the Estrada Nova in Santa Catharina is based upon measurements made under the supervision of Dr. Esdras do Prado Seixas, Engineer for the Coal Commission, during the year 1904, and a portion of 1905, who ran a line of levels along the Estrada Nova from. Minas to the contact of the diabase with the topmost sandstone of the Trias exposed, near Morro Pellado 19 1/2 kilometers westward from Minas, and under whose supervision also was made the map of the Minas region published with this report. 
O mergulho geral destas camadas ao longo desta estrada é para oeste, mas de modo irregular, devidoá presença de diques de basalto que muitas vezes tendem a inverter o mergulho geral em curtas distancias, por isto foi dada margem nas medições, para o mergulho, que augmenta a espessura dada pelos nivelamentos. Isto, porém dá-se principalmente na porção Triassica superior da secção em que o mergulho para oeste é mais pronunciado.

Descendo do alto da Serra Geral, de perto da casa de Julio Dhern, na Estrada Nova, para Minas, ou estação Lauro Müller, ponto terminal da estrada de ferro D. Thereza Christina, no Estado de Santa Catharina, foi organisada a seguinte secção:

METROS

1. Rochas eruptivas, na maior parte diabase amygdeloide e outras

2. Uma serie de gres vermelho e cinzento e conglomeratos massiços, com diques e lençóes de diabase intercalados.

3. Schistos a grès massiços, giès vermelho massiço na base superposto com ligeira discordancia ao calcareo, approximadamente. . . . . . . . . . .

4. Calcareo (Rocinha), cinzento, duro escassamente fossilifero, formas minusculas apparentemente de agua doce, ou salobra . . . . . . . . . . . . 3

5. Schistos variegados com nodulos de silex . . . . 150

6. Schistos á miudo pretos (Iraty), alterados, cinzentos azulados, contendo muitos nodulos siliciosos perto do tope . . . . . . . , . . . . .

7. Schistos cinzentos e camadas areentas, uma serie de schistos areentos cinzentos, ou variegados e sedimentos de lodo, fazendo sempre máos caminhos . , .

8. Uma serie de grès cinzentos esbranquiçados e amarellos e conglomeratos, interestratificados com schistos cinzentos azulados $\theta$ cinzentos com varias camadas do carvão, os schistos contendo a flora de Glossopteris typica da Africa do Sul, India etc., e tendo um conglo. merato grosseiro na bise, espessura . . . 163

9. Schistos e grìs até o granito, em sondagem . . . 27

Espessura totil das camadas sedimentarias . . $\overline{803}$

A que si se addicionam as camadas eruptivas $\quad 600$

Obtemos o total de.. . . . . . $\overline{1403}$

1403 metros de espessura de rocha, do tope das camadas eruptivas sobre a serra Geral perto da casa de Julio Dhern, até o granito da base das camadas sedimentarias. 
The general dip of the beds is westward along this highway, but in an irregular manner, owing to the presence of dikes of basalt which often tend to reverse the general dip for short distances, hence in the measurements given an allowance for dip has been made which adds to the thickness given by the levels, but this is principally in the upper or Triassic portion of the section where the westward dip is most pronounced.

In descending from the summits of the Serra Geral, near Julio Dhern's along the Estrada Nova to Minas, or Laulo Muller, station, the terminus of the D. Thereza Christina railway in the state of Santa Catharina, the following section was constructed:

METERS.

1. Eruptive rocks, mostly diabase, amygdaloidal and otherwise. . . . . . . . . 600

2 A series of massive, gray anil rod sandstones and conglomerates with intruded sheets and dikes of diabase . . . . . . . . . . . . . 200

3. Red sandstones and shales, a massive red sandstone at the base resting with slight unconformity upon the underlying limestone, approximately.

4. Limestone (Rocinha), gray, hard, sparingly fossiliferous, minute forms, apparently fresh or brackish water.

5. Variegated shales with flinty nodules . . . . . 150

6. Shales, often black (Iraty), and weathering bluish gray, holding many silicious nuggets near top. . . .

7. Gray shales and sandy beds, a series of gray, or variegated sandy shales, and muddy sediments, always making bad roads.

8. A series of grayish white, and yellowish sandstones, and conglomerates interstratified with drab and bluish-gray shales with sevoral coal beds, the shales holding the typical Glossopteris flora of South Africa, India, etc., and liaving a coarse (Orleans) conglomer. ate at base, thickness. . . . . . . 163

9. Shales and sandstones to granite in bore hole. . . . Total thickness of sedimentary beds . . $\overline{803}$ To which if we add the eruptive beds. . $\frac{600}{1403}$

- meters of rock thickness from the top of the eruptive beds on the Serra Geral near Julio Dhern's down to the granite floor of the sedimentaries. 
Esta secção seria representada em tabella do modo seguinte :

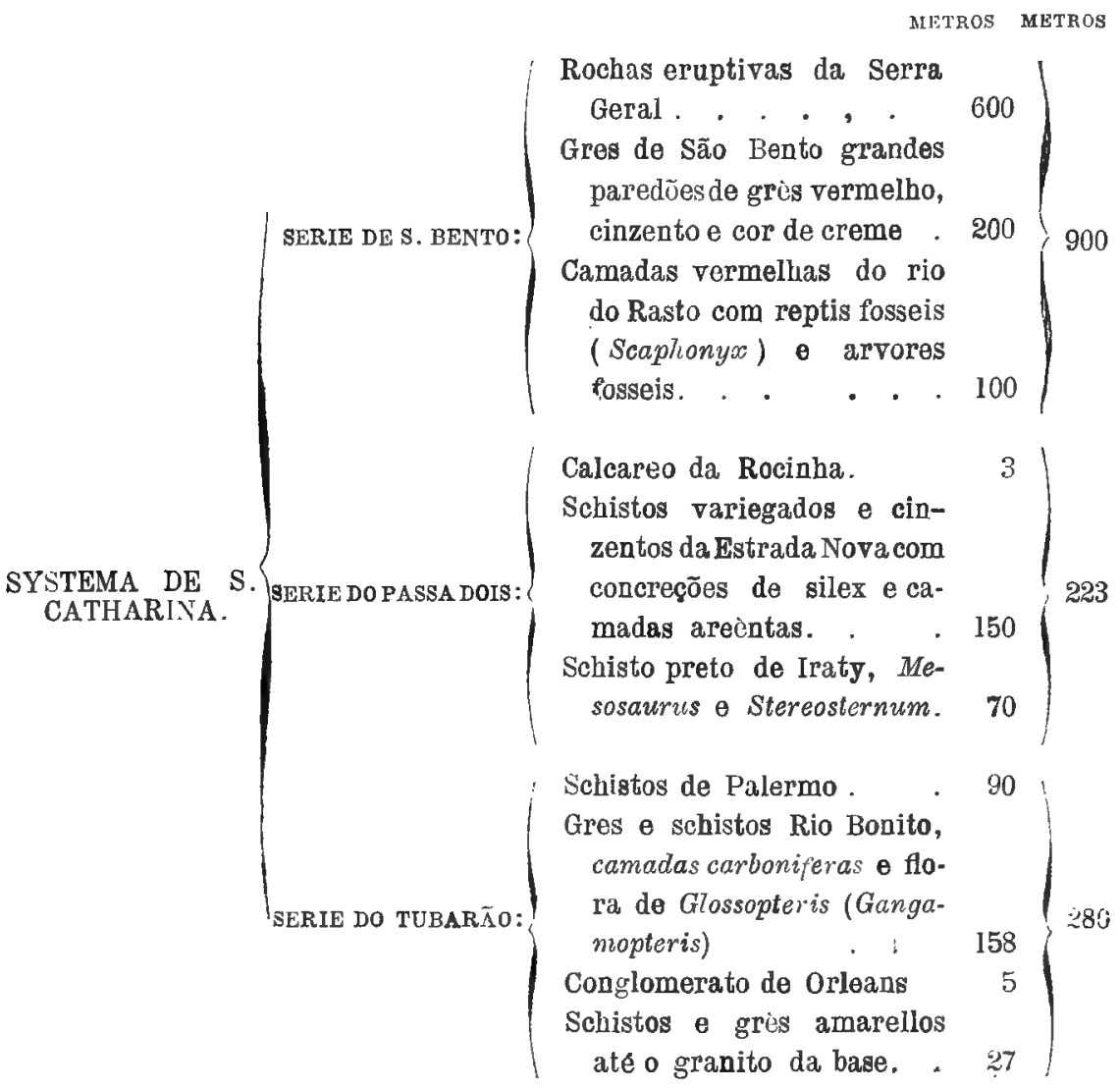

Para comparação com esta estructura geral do systema de Santa Catharina, serão dadas agora algumas secções de estados visinhos.

Em 1901-2 foi feita uma sondagem para petroleo sob a superintendencia do Sr. Arthur B. Reardon perto de Bofete no Estado de S. Paulo. O Sr. Reardon guardou amostras das rochas encontradas que estão actualmente em poder da Commissão Geographica e Geologica na cidade de S. Paulo.

Devido á amabilidade do Dr. O. A. Derby u antigo e liabil Dir'ectol' daquella commissão, foi-me permittido ver essas amostras e com ellas $\mathrm{flz}$ a seguinte secção das rochas atravessadas. A sondagem principia a cerca de 15 metros abaixo da base da serie (São Bento) de grès massiço cinzento e vermelho, de que uma camada, cheia de materlal asphaltico afflora nas collinas, 15 metros acima do soalho do velho derrick. Estes grès massiços cinzentos e vermelhos vão nas collinas 
This section might be tabulated as follows:

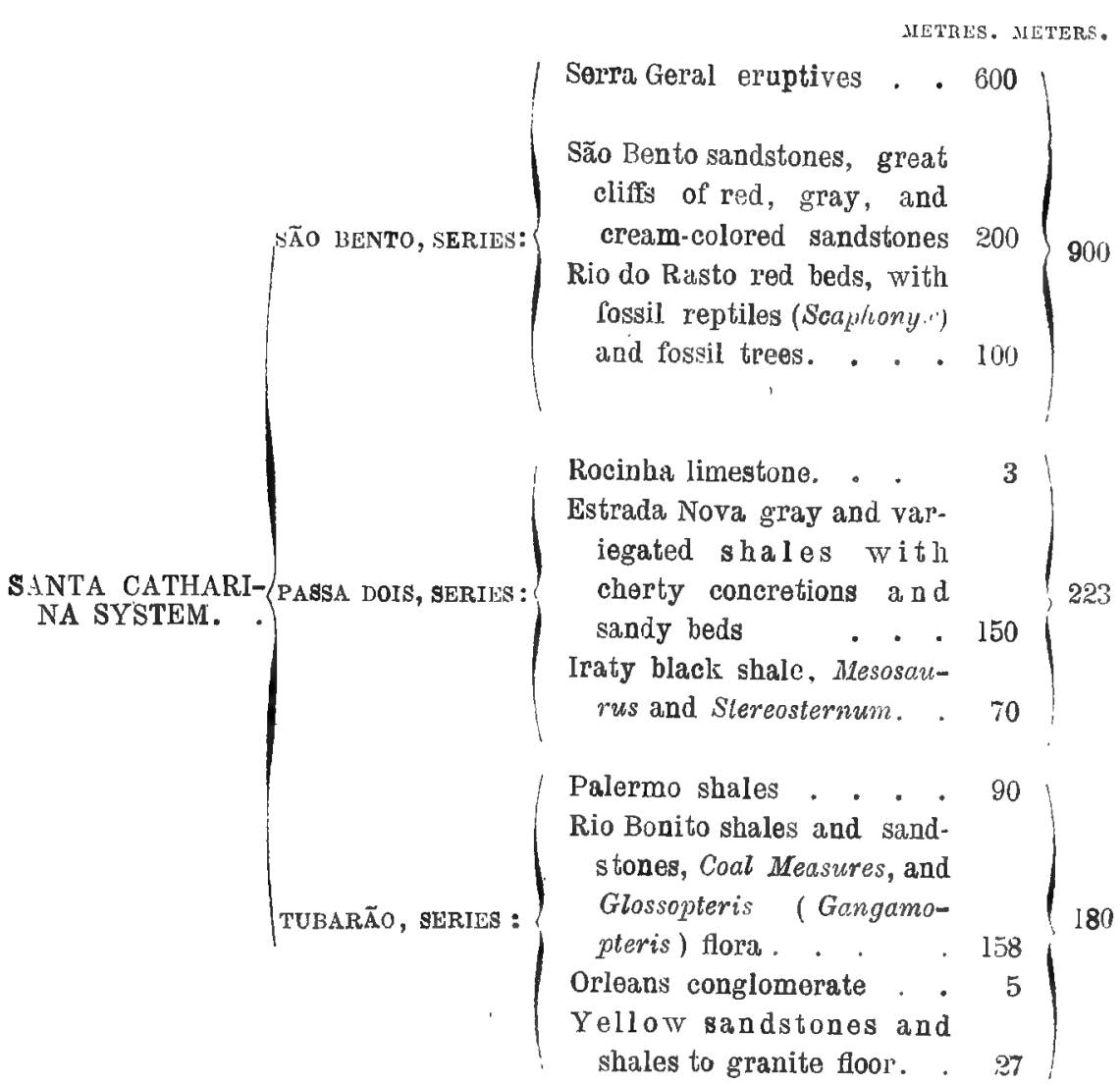

For comparison with this general structure of the Santa Catharina System, a few sections will now be given from adjoining states.

In 1901-2 a boring was made for petroleum, under the supervision of Mr. Arthur B. Reardon near Bofete in the State of São Paulo. $\mathrm{Mr}$. Reardon preserved samples of the rocks encountered and thesc are now in the possession of the Commissão Geographica e Genlogica in the city of São Paulo.

Through the lindness of Dr. O. A. Derby, the former ajole Director of that Commission, I wais permitted to view these samples, and from them made the following section of the rocks penetrated. The boring begins about 15 meters below the base of the massive gray and red sandstone series (São Bento), one stratum of which filled with asphaltic material crops in the hills 15 meters above the old derrick floor. These massive red and gray sandstones ex5569 
até a altura de 250 metros, ou mais e são coroados por um lençol de diabase que cobre os cumes perto de Bofete a 975 metros acima do mar.

A secção alli é a seguinte :

METROS

1. Gres massiço cinzento e vermelho, algum saturado de ma-

terial asphaltico, serie de S. Bento.

2. Encoberto e schistos com camadas siliciosas contendo troncos de arvores silicificados, mal expostos até a bocca do poço.

3. Camadas vermelhas amarellas e variegadas.

4. Schistos cinzentos e aguas claras.

5. Schistos escuros e ardosias pretas, pequeno desprendimento de gaz carbonico encontrado nestas camadas (schistos pretos de Iraty).

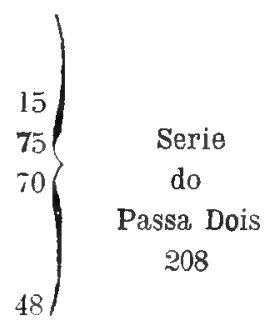

6. Schistos areentos cinzentos, algım calcareo com schistos escuros occasionaes.

7. Schistos escuros e camadas areentas.

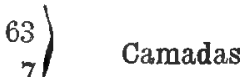

8. Camadas areentas avermelhadas. . . . .

9. Gres vermelho. . . . . . . . . . . .

10. Schistos escuros.

11. Gres branco, topo das camadas do Rio Bonito

12. Gres interestratificado com ardosia preta.

13. Gres branco.

14. Gres cinzento.

15. Gres branco.

16. Gres e ardosia escura.

17. Gres branco com algum oleo escuro pesado a 324-5 metros.

18. Gres com ardosias pretas interestratificadas até o fundo do poso a 448.50 metros.

o tope das camadas do Rio Bonito foi alcançado no n. 11 á profundidade de 278 metros, mas provavelmente a sonda não as tinha penetrado bastante, quando foi abandonada a sondagem. Nenhum carvão foi retirado do poço, mas acharam muita ardosia bituminosa no intervallo do n. 11 até o fundo.

Perto do tope do n. 2 acharam um exemplar de madeira silicificada, à superficie, que David White determinou como Lycopodiopsis Derbyi, Renault.

Em Iraty, no Estado do Paraná, encontra-se a seguinte série, que comeca a cerca de 10-25 metros abaixo do horizonte do schisto preto de 
tend up the hills to 'a height of 250 meters or more, and are crowned above by a great sheet of diabase which caps the summits near Bofete at 975 meters above the sea.

The section there is as follows:

METTERS.

1. Massive red anl gray sandstones, some of which are saturated with asphaltic material, S. Bento Series. . 250

2. Concealed and shales with flinty layers holding silicified stems of trees, not well exposed to mouth of well . . . . . . . . . .

3. Red, yellow, and variegated beds . . . . .

4. Light, gray and bluish shales . . . . . .

5. Dark shales and black slates, small flow of carbonic acid gas encountered in these beds (Iraty Black shales). . . . . . . . . , . . . .

6. Gray sandy shales, some limey with occasional dark shales . . . . . . . . . . .

7. Dark shales and sandy beds. . . . . . .

8. Reddish sandy beds. . . . . . . . . .

9. Red sandstone. . . . . . . . . . . .

10. Dark shales. . • • . • . . . . .

11. White sandstone, top of Rio Bonito beds. . .

12. Sandstone, interstratified with black slate. .

13. White sandstone . . . . . . . . .

14. Gray sandstone. . . . . . . . . . .

15. White sandstone . . . . . . . . .

16. Sandstone and dark slate . . . . . . . .

17. White sandstone with some dark heavy oil at 324-5 meters. . . . . . . . . .

18. Sandstone, with interstratilied black slates to bottom of well at 448.50 meters. . . . .
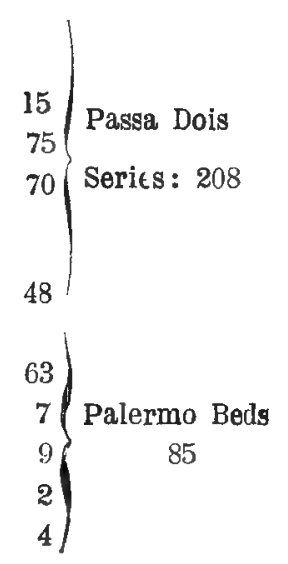

\begin{tabular}{r|r}
6.5 \\
3.5 \\
4 \\
7 \\
5 \\
1 \\
48 \\
95.5
\end{tabular}

The top of the Rio Bonito beds was apparently struck in No. 11, at a depth of 278 meters, but the drill probably had not fully penetrated them when the boring was abandoned. No coal was reported from the well, but much bituminous slate was found in the interval from No. 11 down to the bottom.

Near the top of No. 2 a specimen of silicified rood was found on the surface which David White identifies as Lycopodiopsis Derbyi, Renault.

At Iraty in the state of Paraná, the following succession occurs, leginning about 20-25 meter below the horizon of the Iraty black shale 
Iraty, determinada pela sondagem feita naquella localidade, sob a direcção da Commissão:

Terra regetal . . . . . . . . . . . . 1.50

Schisto escuro com impressões de plantas . . . . . . . . . 13.50

Schisto azulado com nodulos de pyrite . . . . . . . . . 13.42

Schisto amarellado com impressões de plantas. . . . . . . . . 3.60

Schisto escuro . . . . . . . . . . . . . . . . . 5.50

Schisto escuro com impressões de plantas . . . . . . . . . . 3.29

Schisto escuro com pyrites . . . . . . . . . . . . . . 7.01

Schisto areento. cintas pretas e cinzentas . . . . . . . . . 18.85

Calcareo escuro carbonoso . . . . . . . . . . . . . 0.16

Gres cinzento calcareo . . . . . . . . . . . . . . 2.48

Calcareo areento esbranquiçado. . . . . . . . . . . 1.52

Calcareo cinzento manchado, pederneirra. . . . . . . . . 3.58

Pederneira . . . . . . . . . . . . . . . . . . 0.40

Calcareo cinzento manchado, poderneira. . . . . . . . . 0.26

Calcareo esbranquiçado . . . . . . . . . . . . . . 0.45

Gres argilloso levemente calcareo esbranquiçado . . . . . . . 1.68

Schisto cinzento levemente calcareo . . . . . . . . . . 2.37

Gres cinzento argilloso e leviemente calcareo . . . . . . . . . 2.17

Schisto cinzento areento e levemente calcareo . . . . . . . . 0.76

Gres cinzento e levemente calcareo . . . . . . . . . 0.36

Schisto cinzento levemente calcareo . . . . . . . . . . 1.54

Gres cinzento levemente calcareo com veios de pyrite . . . . . $\quad 5.87$

Gres azulado calcareo. . . . . . . . . . . . . . . 2.29

Schisto verdoso calcareo . . . . . . . . . . . . . . . 1.20

Calcareo argilloso cinzento . . . . . . . . . . . . . 0.56

Schisto cinzento. . . . . . . . . . . . . . . 0.28

Calcareo argilloso cinzento . . . . . . . . . . . 0.87

Schisto cinzento. . . . . . . . . . . . . . . 1.63

Calcareo argilloso cinzento . . . . . . . . . . . . 1.30

Schisto cinzento. . . . . . . . . . . . . . . 1.35

Schisto cinzento, areento e calcareo. . . . . . . . . . . 4.69

Gres de gräo fino cinzento . . . . . . . . . . . . . 0.73

Schisto cinzento, areento e calcareo. . . . . . . . . . 3.52

Calcareo argilloso cinzento . . . . . . . . . . . . 0.51

Schisto cinzento, areento e calcareo . . . . . . . . . . . . 3.00

Calcareo argilloso cinzento . . . . . . . . . . . . . 0.15

Gres com faixas claras e escuras. . . . . . . . . . . . 1.00

Calcareo argilloso cinzento . . . . . . . . . . . . . . . 0.10

Gres com faixas claras e escuras. . . . . . . . . . . . . . 9.67

Gres escuro cinzento . . . . . . . . . . . . . . . . . 3.65

Gres cinzento claro. . . . . . . . . . . . . . . . . 1.40

Gres cinzento escuro . . . . . . . . . . . . . . 6.08

Schisto areento com faixas claras e escuras . . . . . . . . . . 2.99 
as determined by a boring put down under the direction of the Commission at the locality:

Meters

Soil cap . . . . . . . . . . . . . . . . . . . . 1.50

Shale, dark, plant impressions . . . . . . . . . . . 13.50

Shale, bluish nodules of pyrite. . . . . . . . . . . . 13.42

Shale, yellowish, plant impressions . . . . . . . . . . . 3.60

Shale, dark . . . . . . . . . . . . . . . . . 5.50

Shale, dark, plant impressions . . . . . . . . . . . . . . 3.29

Shale dark pyrites . . . . . . . . . . . . . . . . . . 7.01

Shale sandy, banded black and gray . . . . . . . . . . . 18.85

Limestone dark carbonaceous . . . . . . . . . . . . 0.16

Sandstone gray calcareous . . . . . . . . . . . . . . 2.48

Limestone sandy whitish . . . . . . . . . . . . . . . 1.52

Limestone gray mottled, cherty . . . . . . . . . . . 3.58

Chert . . . . . . . . . . . . . . . . . . . 0.40

Limestone, gray mottled, cherty . . . . . . . . . . . . 0.26

Limestone, whitish . . . . . . . . . . . . . 0.45

Sandstone, argillaceous, slightly, calcareous whitish . . . . . . 1.68

Shale drab; slightly calcareous . . . . . . . . . . . . . 2.37

Sandstone gray argillaceous and slightily calcareous . . . . . . . 2.17

Shale gray sandy and slightly caIcareous . . . . . . . . . 0.76

Sandstone, gray argillaceous and slightly calcareous . . . . . 0.36

Shale drab slightly calcareous . , . . . . . . . . . . . . 1.54

Sandstone, gray argillaceous and calcareous with veins of pyrite . - . 5.87

Sandstone bluish calcareous . . . . . . . . . . . . . . 2.29

Shale greenish calcareous. . . . . . . . . . . . . . . 1.20

Limestone argillaceous drab . • . . . . . . . . . . . 0.56

Shale $\mathrm{drab}$. . . . . . . . . . . . . . . . . . 0.28

Limestone, argillaceous drab. • . . . . . . . . . . 0.87

Shale, drab . . . . . . . . . . . . . . . . . . . 1.63

Limestone argillaceous drab . . . . . . . . . . . . . 1.30

Shale, drab . . . . . . . . . . . . . . . . . . 1.35

Shale, drab, sandy and calcareous . . . . . . . . . . . 4.69

Sandstone, fine grained, drab . . . . . . . . . . . . 0.73

Shale, drab, sandy and calcareous . . . . . . . . . . . 3.52

Limestone, argillaceous, drab . . . . . . . . . . . . . 0.51

Shale drab, sandy and calcareous . . . . . . . . . . . 3.00

Limestone, argillaceous, drab . . . . . . . . . . . . 0.15

Sandstone, banded light and dark . . . . . . . . . . 1.00

Limestone, argillaceous, drab . . . . . . . . . . . 0.10

Sandstone, banded light and dark . . . . . . . . . . . . 9.67

Sandstone, dark, drab. . . . . . . . . . . . . . . 3.65

Saudstone, ligth, gray. . . . . . . . . . . . . . . . . 1.40

Sandstone, dark, gray. . . . . . . . . . . . . . . . 6.08

Shale, sandy banded light and dark . . . . . . . . . . . 2.99 
Gres calcareo cinzento.

Gres calcareo escuro . . . . . . . . . . . . . . . . 1.33

Calcareo preto . . . . . . . . . . . . . . . . 1.00

Calcareo branco. . . . . . . . . . . . . . . 0.10

Calcareo areento com faixas claras e escuras. . . . . . . . . 1.10

Calcareo com manchas eseuras . . . . . . . . . . . . . 2.91

Calcareo e schisto com Jaixas claras e escuras . . . . . . . . . 1.18

Schisto calcareo escuro . . . . . . . . . . . . . . 0.70

Calcareo e schisto com faixas . . . . . . . . . . . . 1.3L

Calcareo escuro com pederneira . . . . . . . . . . . 0.12

Schisto calcareo escuro. . . . . . . . . . . . . . . . 0.65

Calcareo escuro com pederneira. . . . . . . . . . . . 0.10

Schisto calcareo escuro. . . . . . . . . . . . . . . . . 0.83

Calcareo e schisto com Paixas . . . . . . . . . . . . 0.15

Schisto areento com faixas . . . . . . . . . . . . 3.57

Schisto areento com faixas calcareas . . . . . . . . . . 8.33

Gres escuro . . . . . . . . . . . . . . . . . . . 0.32

Schisto areento com faixas calcareas . . . . . . . . . . . . 2.40

Schisto areento com faixas . . . . . . . . . . . . . . . 1.91

Gres cinzento escuro micaceo. . . . . . . . . . . . . . . 2.00

Ares grosseiro, cinzento com nodulos carbonosos . . . . . . . . 1.11

Gres com cintas carbonosas, restos vegetaes. . . . . . . . . . 1.97

Schisio areento com faixas claras e escuras . . . . . . . . . . 1.00

Schisto areento com faixas claras e escuras e placas de carvão . . . . 2.28

Schisto areento escuro compacto. . . . . . . . . . . . . . 1.05

Gres esbranquiçado. . . . . . . . . . . . . . . . . 0.20

Schisto escuro, compacto, algum tanto calcareo. . . . . . . . . 0.69

Schisto verdoso, compacto, algum tanto calcareo . . . . . . . . 1.52

Gres calcareo de grão fino, esbranquiçado. . . . . . . . . . . 2.00

Schisto escuro, compacto, algum tanto calcareo . . . . . . . . . 1.20

Gres calcareo de grão fino, esbranquiçado. . . . . . . . . . . 1.42

Schisto areento, compacto, escuro . . . . . . . . . . . 0.85

Gres, argilloso, cinzento verdoso . . . . . . . . . . . 1.18

Schisto areento, cumpacto escuro . . . . . . . . . . . . 1.21

Gres de grão fino, cinzento . . . . . . . . . . . . . . . 1.00

Gres grosseiro, cinzento, friavel. . . . . . . . . . . . 4 4.23

Gres de grão fino, cinzento . . . . . . . . . . . . . . 4.98

Gres de grão fino, com faixas. . . . . . . . . . . . . . 0.60

Gres grosseiro, verdoso. . . . . . . . . . . . . . . . 2.46

Gres grosseiro, esbranquiçado. . . . . . . . . . . . . . . 1.35

Gres grosseiro, manchado, calcareo. . . . . . . . . . . . 0.30

Gres duro, grosseiro, esbranquiçado. . . . . . . . . . . . 3.14

Gres de grāo fino, cinzento, com cintas de schisto escuro . . . . . . 6.60

Gres de grão fino, com faixas cinzentas . . . . . . . . . . . 3.30

Gres grosseiro, esbranquiçado . • . . . . . . . . . . 3.18

Schisto escuro . . . . . . . . . . . . . . . . 0.25 
Metres

Sandstone, calcareous gray • • • • • • • • • • • • • 2.66

Sandstone, calcareous dark . . . . . . . . . . . . . 1.33

Limestone, black . . . . . . . . . . . . . . . . 1.00

Limestone, white . . . . . . . . . . . . . . . . 0.10

Limestone, sandy, banded light and dark . . . . . . . . . . . . . 10

Limestone, dark mottled . . . . . . . . . . . . . . . 2.91

Limestone and shale banded light and dark , . . . . . . . . 1.18

Shale, calcareous dark . . . . . . . . . . . . . . . 0.70

Limestone and shale banded . . . . . . . . . . . . . . 1.31

Limestone cherty, dark . . . . . . . . . . . . . . 0.12

Shale, calcareous, dark . . . . . . . . . . . . . . . . 0.65

Limestone, cherty, dark . . . . . . . . . . . . . . 0.10

Shale, calcareous, dark . . . . . . . . . . . . . . . 0.83

Limestone and shale, banded. . . . . . . . . . . . . . 0.15

Shale, saudy banded . . . . . . . . . . . . . . . . . 3.57

Shale, sandy, banded calcareous. . . . . . . . . . . . . 8.33

Sandstone, dark. . . . . . . . . . . . . . . . . . 0.32

Shale, sandy, banded calcareous. . . . . . . . . . . . . 2.40

Shale, sandy, banded . . . . . . . . . . . . . . . . . 1.91

Sandstone, dark gray micaceous. . • . . . . . . . . . . 2.00

Sandstone coarse, gray with coaly nodules. . . . . . . . . . . 1.11

Sandstone, banded with coaly streaks, plant remains . . . . . . . 1.97

Shale sandy light and dark . . . . . . . . . . . . . . . 1.00

Shale, sandy, banded light and dark, with coaly patches . . . . . . 2.28

Shale, sandy, dark compact . . . . . . . . . . . . . 1.05

Sandstone whitish :. . . . . . . . . . . . . . . . . 0.20

Shale dark compact somewhat calcareous. . . . . . . . . . 0.69

Shale, groenish, csmpact somowhat calcareous. . . . . . . . . 1.52

Sandstone calcareous fine grained whitish. . . . . . . . . . . 2.00

Shale dark compact somewhat calcareous. . . . . . . . . . . 1.20

Sandstone calcareous fine grained whitish . . . . . . . . . . 1.42

Shale, sandy, compact dark . . . . . . . . . . . . . . 0.85

Sandstone argillaceous, greenish gray. . . . . . . . . . . . 1.18

Shale, sandy, compact dark . . . . . . . . . . . . . . 1.21

Sandstone, flne grained, gray . . . . . . . . . . . . . 1.00

Sandstone coarser gray friable . . . . . . . . . . . . . 4.23

Sandstone, fine grained, gray. . . . . . . . . . . . . . . 4.98

Sandstone, fine grained, banded. . . . . . . . . . . . 0.60

Sandstone, coarser greenish . . . . . . . . . . . . . . 2.46

Sandstone, coarser, whitish . . . . . . . . . . . . . . 1.35

Sandstone, coarser, mottled, calcareous . . . . . . . . . 1.30

Sandstone, hard, coarser, whitish . . . . . . . . . . . . 3.14

Sandstone, fine grained gray, banded with dark shale . . . • . 6.60

Sandstone, fine grained, gray banded . . . . . . . , . . . 3.30

Sandstone, coarser, whitish . . . . . . . . . . . . . 3.18

Shale, dark . . . . . . . . . . . . . . . . 0.25 
Metros

grão fino, manchado, esverdeado e escuro . . . . . . 0.60

Schisto preto, manchado, com placas levemente calcareas. . . . . 1.09

Gres de grão fino, esbranquiçado . . . . . . . . . . . . 4.50

Gres de grão fino, com faixas pretas . . . . . . . . . . 8.37

Schisto areento com faixas pretas e brancas . . . . . . . . . 4.52

Gres esbranquiçado, com faixas de schisto preto. . . . . . . . 1.32

(ires grosseiro, com faixas de schisto preto e restos vegetaes . . . . 1.07

Gres esbranquiçdo. . . . . . . . . . . . . . . . 1.43

Schisto oscuro, compacto. . . . . . . . . . . . . . 0.70

Schisto areento, com faixas brancas o pretas . . . . . . . . 0.60

Gres de grão fino, cinzento, algum tanto calcareo . . . . . . . 2.58

Gres de grão fino, cinzento, fortemente calcareo. . . . . . . . . 1.30

Gres de gräo fino, cinzento, com cintas pretas . . . . . . . . . 2.90

Gres de grão fino, cinzento azulado . . . . . . . . . . . . . 0.58

Gres grosseiro, cinzento, calcareo . . . . . . . . . . . 0.15

Diabase . . . . . . . . . . . . . . . . . . . 1.45

Foi feita uma sondagem profunda em Xarqueadas, no Rio Grande do Sul, perto da margem direita do rio Jacuhy, pelo Sr. Otto Spalding, superintendente geral da Estrada de Ferro e Minas de S. Jeronymo. Esta sondagem principia nos schistos cinzentos e variegados que estão entre o horizonte do schisto preto de Iraty e os espessos grès que formam alcantis, 100 a 200 metros mais altos na serie. o seguinte registro desta sondagem foi posto amavelmente á disposição da Commissão pelo Sr. Spalding.

METROS

1. Argilla vermelha. . . . . . . . . . 11.26

2. Conglomerato. . . . . . . . . . 2.30

3. Gres. . . . . . . . . . . 19.33

4. Schistos areètos. . . . . . . . 15.74

5. Schistos vermelhos e cinzentos. . . . . 8.55

6. Gres petrolifero. . . . . . . 1.15

7. Schisto vermelho e cinzento. . . . . . 16.26.

8. Schisto variegado. . . . . . . . . 13.95

9. Schisto vermelho. . . . . . . . . 3.97

10. Schisto azulado e vermelho. . . . . . . 4.86

11. Schisto vermelho, preto e azulado. . . . 13.05

12. Schisto variegado, preto e vermelho. . . . . 5.89

13. Schisto, preto (Iraty) com pyrites. . . . . . 33.01

14. Schisto, com camadas de calcareo. . . . 16.51

15. Schisto claro e escuro, . . . . . . . 4.99

16. Schisto escuro. . . . . . . . . . . 16.90

17. Schisto azulado. . . . . . . . . 13.05$\}$

18. Schisto acinzentado. . . . . . . 2.30 Palermo

19. Arêa movediça. . . . . . . . . . . . 1.28 112.95

do

Passa Dois

165.83

Camadas

de 
Metros

Sandstone fine grained mottled, greenish and drab . . . . . . . 0.60

Shale black mottled with spots sligtly calcareous . . . . . . . . 1.09

Sandstone, fine grained whitish . . . . . . . . . . . . . 4.50

Sandstone fine with black bands. . . . . . . . . . . . . 8.37

Shale, sandy, banded white and black . . . . . . . . . . . 4.52

Sandstone whitish with bands of black shale. . . . . . . . . . 1.32

Sandstone, coaser with bands of black shale with plant remains. . . 1.07

Sandstone, whitish. . . . . . . . . . . . . . . 1.43

Shale, dark, compact . . . . . . . . . . . . . . . . 0.70

Shale, sandy, banded black and white . . . . . . . . . . 0.60

Sandstone, fine grained, gray somewhat calcareous . . . . . . . 2.58

Sandstone, fine grained, gray, strongly calcareous . . . . . . . . 1.30

Sandstone, fine grained, gray with black streaks . " . . . . . . 2.90

Sandstone, fine grained, bluish gray . . . . . . . . . . . 0.58

Sandstone coarser gray calcareous . . . . . . . . . . . . 0.15

Diabase . . . . . . . . . . . . . . . . . . 1.45

At Xarqueadas, in Rio Grande do Sul, a deep boring has been sunk near the right bank of Rio Jacuhy loy Mr. Otto Spalding, the General Manager of the S. Jeronymo Railroad and Mines. This boring begins in the red variegated shales which lie between the Iraty black shale horizon and the great cliff sandstones 100 to 200 . meters higher. The following record of this boring was kindly placed at the disposal of the Commission by Mr. Spalding:

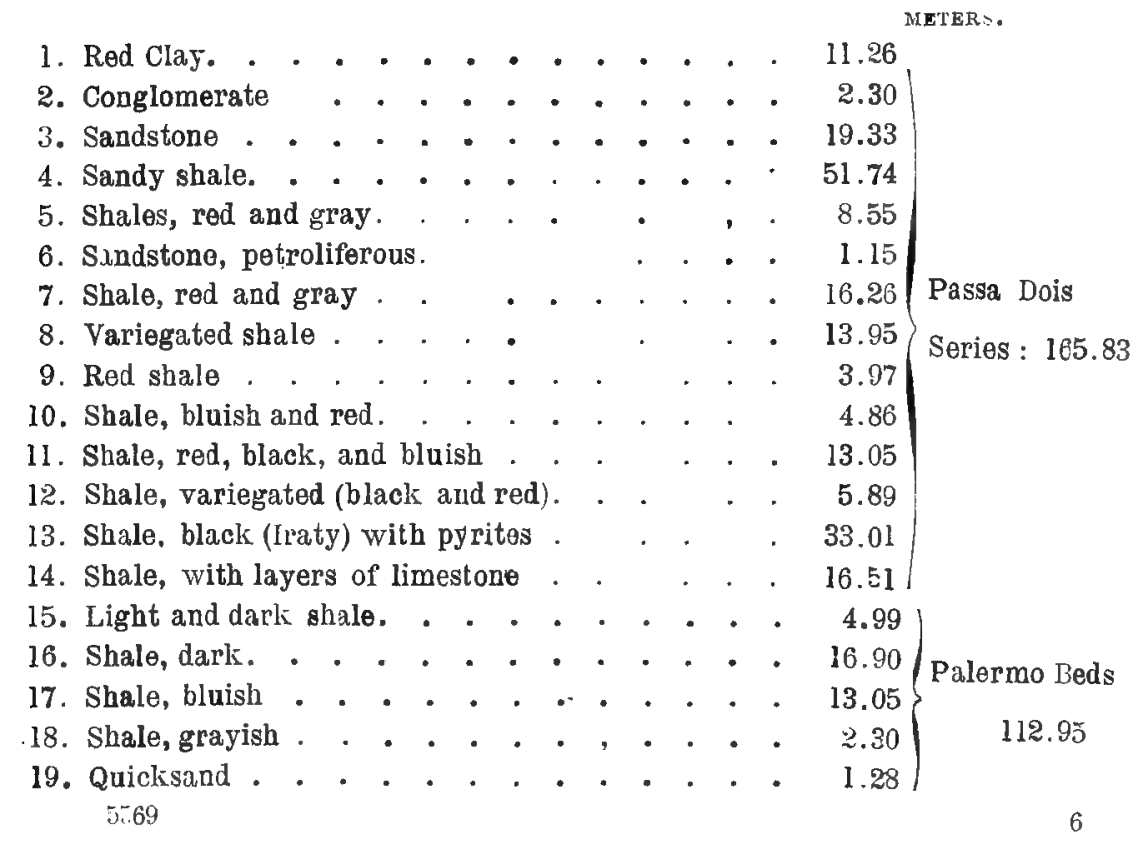


20. Schisto escuro e conglomerato grosseiro. . . 7.30

21. Schis Ło esverdeaclo. . . . . . . . 3.84

22. Schisto escuro. . . . . . . . . 11.03

23. Schisto esverdeado. . . . . . . . . 1.92

24. Schisto escuro. . . . . . . . . . 6.0\%

25. Schisto variegado. . . . . . . . . . 3.97

26. Schisto escuro. . . . . . . . . . 8.96

27. Schisto variegado, . . . . . . . . 14.88

28. Schisto preto. . . . . . . . . 1.02

29. Carvãa. . . . . . . . . . 0.10

30. Schisto escuro. . . . . . . . . . 2.90

31. Carvēo, tracos.

32. Schisto escuro.

33. Carvão, S. Jeronymo $\left\{\begin{array}{ll}\text { Carvão . . . } & 0.60 \\ \text { Schisto escuro. } & 1.50 \\ \text { Corvão. . . } & 1.30\end{array}\right\}$

34. Schisto escuro . . . . . . . . . . 11.60

35. Grès de cor clara. . . . . . . . . . 0.60

36. Schisto escuro, . . . . . . . . . 3.40

37. Carvão, Iropud. . . . . . . . . . . 0.60

38. Schisto claro e escuro. . . . . . . . 3.30

39. Schisto verde escuro. . . . . . . . . 6.00

40. Conglomerato. . . . . . . . . 0.70

41. Schisto verde escuro. . . . . . . . 2.70

42. Schisto claro e escuro. . . . . . . . . 0.60

43. Schisto escuro. . . . . . . . . 5.00

44. Gres claro . . . . . . . . . 0.60

45. Carvão. . . . . . . . . . . 0.15

46. Schisto escuro. . . . . . . . . . . . 1.40

47. Carvăo . . . . . . . . . . . 0.80

48. Schisto escuro. . . . . . . . . . 5.00

49. Conglomerato. . . . . . . . . . 0.90

50. Schisto escuro. . . . . . . . . . 1.30

51. Carvão. . . . . . . . . . . . 0.30

52. Conglonerato de Orleans. . . . . . . . 1.80

53. Granito ate o fundo. . . . . . . . . 6.10

Total. . . . . . . . . . . . $32 \overline{3.54}$
Camadas

de

Palermo

112.95

Camadas

do Rio Bonito

55.37

Nos testemunhos tirados do horizonte do schisto preto de Iraty, vi fragmentos de escamas, provavelmente de reptil e um dente semelhante aos do Mesosaurus brasiliensis.

O local desta sondagem está na margem occidental da bacia carlionifera e as camadas do Rio Bonito tornaram-se evidentemente mais finas de encontro áilha de granito que surge no Rio Jacuhy na villa de S. Jeronymo, alguns kilometros, rio acima. 
20. Dark shale and coarso conglomerate. . . . . 7.30

21. Shale, greenish. . . . . . , . . 3.84

22. Shale, dark. . . . . . 11.03

23. Shale, greonish . . . . . . . . . 1.92

24. Shale, dark. . . . . . . . . . . . . 6.02

25. Shale, variegated . . . . . . . . . . 3.97

26. Shale, dark. . . . . 8.96

27. Shale, variegated . . . . . . . 1.48

Palermo Beds

28. Shale, black

29. Cool . . . . . . . . . 0.10

30. Shale, dark. . . . . . . . . . . . 2.90

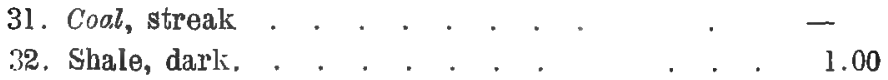

33. Coal, S. Jeronymo $\left\{\begin{array}{lll}\text { Coal. . . } & \cdot 0.60 \\ \text { Shale, dark. } & \cdot & 1.50 \\ \text { Coal. . . } & . & 1.30\end{array}\right\} \cdot 3.40$

34. Shale, dark. . . . . . . . . . . . 11.60

35. Sandstone, light colored. . . . . . . . . 0.60

36. Shale, dark. . . . . . . . . . . 3.40

37. Coal, Irapuá. . . . . . . . . . . . . 0.60

38. Shale, light and dark. . . . . . . . . 3.30

39. Shale, dark-green. . . . . . . . . . 6.00

40. Conglomerate . . . . . . . . . . . . 0.70

41. Shale, dark-green. . . . . . . . . . 2.70

42. Shale, light and dark. . . . . . . . . . 0.60

Rio Bonito Beds

43. Shale, dark. . . . . . . . . . . . 5.00

53.37

44. Sandstone, light . . . . . . . . . 0.60

45. Coal . . . . . . . . . . . . 0.15

46. Shale, dark. . . . . . . . . . . . 1.40

47. Coal . . . . . . . . . . . 0.80

48. Shale, dark. . . . . . . . . . . . . 5,00

49. Conglomerate . . . . . . . . . . 0.90

50. Shale, dark. . . . . . . . . . . . . 1.30

51. Cout . . . . . . . . . . . . 0.30

52. Conglomerate, Orleans. . . . . . . . . 1.80

53. Granite to bottom. . . . . . . . . 6.10

Total . . . . . . . . . $\overline{323.54}$

In the cores brought of from the Irnty black shale horizon, I saw fragments of sicules, probably reptilian, and a tooth resembling that of Mesosaurus brasiliensis.

The locality of this boring is on the western side of the coal basin and the Rio Bonito Beds have cridently thinned avay very materially against the island of granite which comes up along Rio Jacuhy at the town of S. Jeronymo a few kilometers above. 
Este adelgaçamento para oeste se vê no registro da sondagem n. II alguns cem metros $\mathrm{S} 15^{\circ} \mathrm{W}$ do Poço Fé e localizado a $18 \mathrm{kj}$. lometros ao sul de Xarqueadas. O registro é o seguinte, como foi dado pelo sl'. Spalding :

1. Argilla amarella. . . . . . . 5.25

2. Schisto azulado. . . . . . . . . 16.51

3. Conglomerato claro. . . . . . . . 0.64

4. Schisto azulado e vermelho. . . . . . 3.20

5. Conglomerato izul. . . . . . . . . 0.77

6. Schisto azul, seixos de quartzo. . . . . . 10.37

7. Pederneira. . . . . . . . . . 1.02

8. Schisto azul. . . . . . . . . . . 7.04

9. Schisto verde. . . . . . . . . . . 0.51

10. Schisto azul e vermelho. . . . . . . . 9.47

11. Schisto verde escruro. . . . . . . . . 0.90

12. Schisto escuro. . . . . . . . . . . 3.20

13. Schisto preto.. . . . . . . . . 3.4h

14. Schisto preto, finas camad's de carvăo. 2.69

15. Schisto preto.. . . . . . . . . . 0.51

16. Carvão. . . . . . . . . . . . 0.20

17. Schisto escuro. . . . . . . . . 5.86

18 Carvão, S Jeronymo (Barro Branco). . . . 4.00

19. Sehisto escuro. . . . . . . . . . $0.5 \mathrm{I}$

20. Carvĩo. . . . . . . . . . . . . 0.26

21. Schisto escuro. . . . . . . . . . 4.10

22. Carvão. • . . . . . . . . . . . . 0.20

23. Schisto escuro. • . . . . . . . . . 2.56

24. Carväo. . . . . . . . . . . . . 0.20

25. Schisto escuro. . . . . . . . . , 1.02

26. Carvão. . . . . . . . . . . . 0.10

27. Schisto escuro, . . . . . . . . . . 2.56

28. Carvão . . . • . . . . . . • . . 0.20

Camadas de

Palermo

55.68

29. Schisto escuro. • . . . . . . . . 3.07

30. Conglomerato. . . . . . . . . . 0.51

31. Gres calcareo. . . . . . . . . . 3.84

32. Brechá . . . . . . . . . . . . 0.51

33. Schisto escuro. . . . . . . . . . . 3.33

34. Carvăo. . . . . . . . . . . . . 0.15

35. Schisto escuro. . . . . . . . . . . 1.02

36. Carvão. . . . . . . . . . . . 0.20

37. Schisto escuro. . . . . . . . . . . 3.84

38. Schisto esverdeado. . . . . . . . . . 1.79

39. Schisto escuro. . . . . . . . . . . 4.86

40. Carvão. . . . . . . . . . . . 0.06

41. Schisto escuro. . . . . . . . . . . . 1.25

Camadas

do

Rio Bonito

145.58 
This westward thinning is shown by the record of boring No. II a few hundred meters S. $15^{\circ} \mathrm{W}$. of Poço Fé, and located 18 kilometers southward from Xarqueadas, This record is as follows, as given by Mr. Spalding :

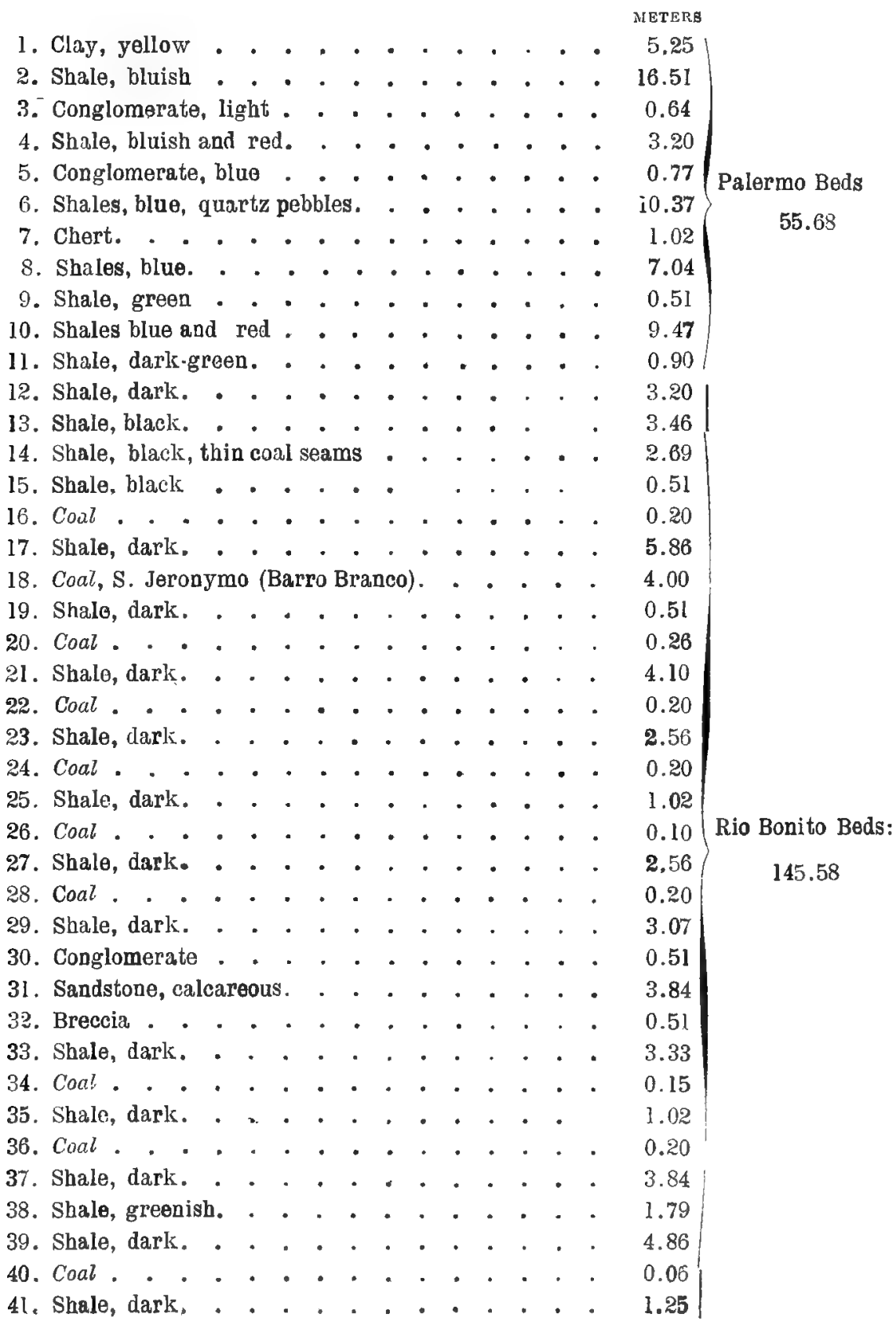


42. Carvão. . . . . . . . . . . . . . 0.12

43. Schisto escuro. . . . . . . . . . 1.25

44. Carvão. . . . . . . . . . . . . 0.15

45. Schisto escuro. $\quad$. . . . . . 1.25

46. Carväo. . . . . . . . . . 0.08

47. Schisto calcareo. . . . . . . . . . 2.94

48. Carvão. . . . . . . . . . 0.05

49. Schisto. . . . . . . . . 2.05

50. Carvão. . . . . . . . . . . . 0.15

5l. Gres e schistos calcareos com mica e pyrite. - 49.66

52. Schistos bituminosos com mica e pyrite. . . 30.72

53. Ardosia preta com traços de carvão. . . . . 1.10

54. Conglomerato de Orleans com grandes blocos de granito. . . . . . . . . . . 16.13

55. Granito vermelho ate o fundo da sondagem. , 2.00

Total. . . . . . . . . . . $21 \overrightarrow{9} .39$

Camadas

do

Rio Bonito

145.58

Aqui ha sómente uma camada de carvão de espessura commercial, n. 18 e como ella está perto do tope das camadas do Rio Bonito, parece ser identicá á camadá Barro Branco de Santa Catharina. Occorrem finas camadas de carvão na serie até $123^{\mathrm{m}}$ mais abaixo, ou 16.13 metros acima do granito solido que se encontrou a 138 metros ảaixo da base da camada principal de carvão de São Jeronymo.

o Sr. Spalding faz menção de grandes boulders de granito no n. 54 da secção. Este horizonte corresponderia ao conglomerato de Orleans.

As camadas do Rio Bonito teem aqui a espessura de 146 metros em contraste com a de $53^{\mathrm{m}}$ na secção a 18 kilometros distante de Xarqueadas e a de $158 \mathrm{em}$ Minas em Santa Catharina. Si se addicionar a espessura do conglomerato de Orleans ás camadas do Rio Bonito em cada uma das localidades respectivas de Minas e da sondagem n. II em S. Jeronymo, resulta uma espessura de 163 e 162 metros respectivamente para as meșmas camadas em cada localidade, concordancia que deve ser meramente accidental. 


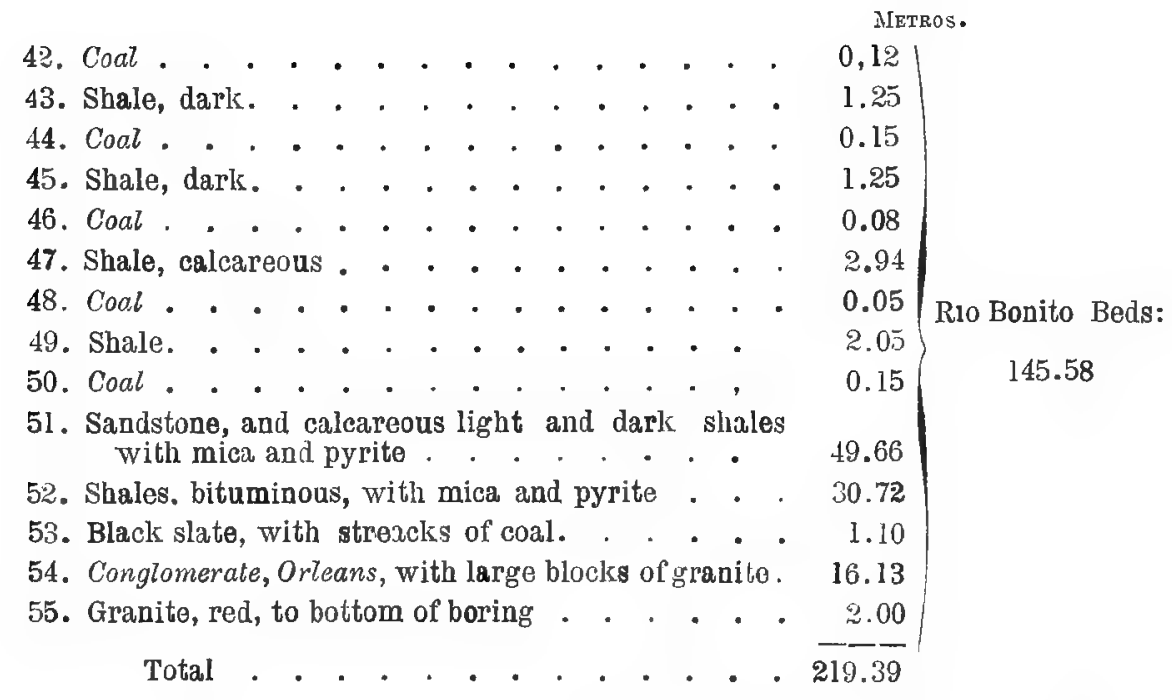

Here there is only one coal seam of merchantable thichness, No. 18, and as it comes near the top of the Rio Bonito Beds, it appears to be identical with the Barro Branco seam of Santa Catharina. Thin streaks of coal occur through the series to 123 meters lower, or 16.13 meters above the solid granite which was found at 138 meters below the base of the main S. Jerony mo coal.

Mr. Spalding reports large boulders of granite in No. 54 of the section, and this horizon would correspond to the Orleans conglomerate.

The Rio Bonito Beds have a thickness of 146 meters here, as against 53 in the section 18 kilometers distant at Xarqueadas, and 158 at Minas, Santa Catharina. If the thickness of the Orleans conglomerate be added to the Rio Bonito Beds, at each of the respective Iocalities of Minas and in bore hole No. II at S. Jeronymo, there results a thickness of 163 and 162 meters respectively for the same beds at each locality, a correspondence which must be largely accidental. 


\section{CAPITULO IV}

\section{Serie do Rio Tubarão}

Estas camadas designadas com o nome do rio que drena a principal região carbonifera do Estado de Santa Catharina são constituidas por varios membros differenter, apoiando-se o mais baixo no granito e não se parecendo lithologicamente com as camadas superiores. Estes gres e schistos inferiores teem perto de Minas, em Santa Catharina, um aspecto de alteração atmospherica, tendo os gres uma cor amarella ferrugenta, ao jlasso que os schistos superiores são azuei escuros. o contacto destas rochas inferiores com o granito subjacente é visivel em um córte da Estrada de Ferro D. Thereza Christina, 3 kilometros abaixo de Minas, e se estendem ao longo desta estrada de ferro e o leito do rio Tubarão, daquelle ponto até perto de Minas, onde mergulham para baixo do nivel das aguas.

A parte inferior é um grès duro, amarello, e em cima ha schistos escuros ferrugentos e azulados, sobre que ha gres amarellados, contendo fragmentos indeterminaveis de plantas; estes estendem-se até o conglomerato de Orleans, tendo o todo 27 metros de espessura, como foi determinado pela sondagem feita atravéz deste àté o granito, perto de Ninas.

Na estrada de Florianopolis a Lages, gres duros e schistös azues escuros occupam este intervallo entre o conglomerato de Orleans e o granito, tendo o todo uma espessura de 150 a 160 metros, em que nenhum fossil foi observado, excepto uma impressão semelhante ao rasto de um crustaceo. Este horisonte é um dos que estão raramente, claramente expostos, excepto em cortes artificiaes em estradas de rodagem, em todos os pontos, porém, em que estas camadas são visiveis na estrada de Florianopolis a Lages e entre Lages e Blumenau apparece uma pedra de amolar branca, acinzentada, muito dura, e de grão fino em camadas de 8 a 20 centimetros de espessura. Estas camadas deram o nome Navalhas á villa na estrada de Lages, perto da qual eram ellas exploradas em pedreira para pedras de amolar. Perto de Suspiro, no Rio Grande do Sul, camadas desta natureza com alguns metros de espessura estão em contacto com o granito, onde a 


\section{CHAPTER IV}

\section{Rio Tubarão Series}

These beds, designated from the river of that name which drains the principal coal region of the state of Santa Catharina, consist of several different members, the lowest one resting upon the granite, and looking very unlike the higher beds lithologically. These lower sandstones and shales near Minas, Santa Catharina, present a weathered aspect, the sandstones liaving a rusty yellow cast while the shales above are dark bluish. The contact of these lowest rocks with the underlying granite is visible in a cut along the Dona Thereza Christina railway, 3 lilometers below Minas, and they extend along the railway and the bed of Rio Tubarão from there to near Minas where they dip under water level.

The lower portion is a hard, yellowish sandstone, and above it come dark rusty and bluish shales, upon which rest yellowish sandstones holding indeterminable plant fragments, and these extend up to the Orleans conglomerate, the whole having a thickness of only 27 meters as determined by the boring made through them near Minas to the granite.

On the road to Lages from Florianopolis, some hard sandstone, and bluish-black shales occupy this interval between the Orleans conglomerate and the granite, the whole having a thickness of 150-160 meters, in which no fossils were observed except what is possibly the trail of a crustacean. This horizon is one which is seldom clearly exposed except in artificial cuttings along highways, but wherever these beds are visible along the road from Florianopolis to Lages, and between Lages and Blumenau, there appears a very hard fine-grained grayish white whetstone grit in layers 8 to 20 centimeters thick. These layers gave the name, Naval ha, to the village on the Lages road near which they were once quarried for whetstones. Strata of the same character a few meters in thickness, rest on the granite, near suspiro in Rio Grande do Sul, where the erosion, which accompanied the deposition of the Orleans conglomerate, has spared these older rocks. 5560 
erosão que acompanhou o deposito do conglomerato de Orleans poupou estas rochas mais antigas, tambem se veem camadas com este mesmo caracter ao longo do rio Trombudo, na estrada de Lages para Blumenau .

Não se sabe se estes gres e os schistos escuros que os acompanham na estrada de Lages são da mesma idade que os gres e schistos infériores que estão em contacto com o granito, perto de Minas.

\section{Conglomerato de Orleans}

Encontrámos bem exposto em orleans, em Santa Catharina, um conglomerato grosseiro que foi designado com o nome da localidade, superposto aos gres e schistos inferiores ás vezes em apparente discordancia, contendo boulders' (blocos arredondados) de granito, quartzito e de algumas outras rochas duras, tendo alguns destes de 20 a 25 centimetros de diametro. A mesma formação é visivel frequentemente ao longo do rio Tubarão, entre Minas e dous kilometros abaixo. A sondagem feita perto da estação das Minas foi iniciada perto do tope desta rocha e atravessou a mesma a uma profundidade de 5,35 metros. No Rio Grande do Sul encontram-se frequentemente neste horizonte grandes blocos de granito, bem como em muitos pontos no Paraná e nas regiões adjacentes de Santa Catharina, onde em varias localidades perto de Rio Negro, 40 kilometros distante de qualquel. affloramento de granito, se veem os boulders de granito em grande numero, tendo até 3 metros de diametro, todos imbutidos em um sedimento lodoso cinzento, fino e apparentemente não estratificado. Vê-se tambem em Ponta Grossa e outros localidades naquella região, um deposito grosseiro com grandes boulders arredondados de granito, quartzito, gres e madeira silicificada, etc., superposto discordantemente aos schistos Devonianos. Este deposito parece corresponder estreitamente ao conglomerato de Dwyka, da Africa do Sul e muito provavelmente é, como este, de origem glacial, embora não se tivesse observado arranhões nos boulder's em questão.

As formas fantasticas que constituem a "rock city " de Villa Velha, nas eminencias ao sul de Ponta Grossa, pertencem muito proravelmente a este mesmo horizonte, assim como a grande massa de conglomerado que está superposta discordantemente aos schistos Devonianos subjacentes, a 3 kilometros ao sul de Jaguariahyva, no Estado do Paraná: 
Beds of the same character are also visible along Rio Trombudo on the road between Lages and Blumenau.

Whether these whetstone grits and their accompanying dark shales along the Lages road are of same age as the lowver sandstone and shales which rest upon the granite near Minas is not known.

\section{Orleans Conglomerate}

Resting upon these lower sandstones and shales often in apparent unconformity, we find a coarse conglomerate which is well exposed in the town of Orleans, Santa Catharina, from which locality it has beon named. It contains boulders of granite, quartzite, and other hard rocks, some of which are 20 to 25 centimeters in diameter. The same formation is frequently visible along Rio Tubarão between Minas and 2 kilometers below. The bore hole put down near Minas station began near the top of this rock and passed through the same at a depth of 5.35 meters. In Rio Grande do Sul, large granite blocks are frequently found at this horizon, as well as at many points in Paraná and the adjoining region of Santa Catharina, where several localities, near Rio Negro, 10 kilometers from any outcrop of granite, exhibit granite boulders in vast numbers up to 3 meters in diameter, all imbedded in a fine and apparently unstratified gray muddy sediment. A very coarse deposit with large rounded boulders of granite, quartzite, sandstone, silicified wood, etc., may also be seen resting unconformably upon Devonian shales at Ponta Grossa, and other localities in that region. This deposit appears to correspond closely to the Dwyka conglomerate of South Africa, and most probably, like it, is of glacial origin although no scratches were observed upon the boulders in question.

The weird shapes constituting the "rock city» of Villa Velha on the sumits south from Ponta Grossa, most probably belong at this same horizon, as well as the great conglomerate mass which rests unconformably upon the underlying Devonian shales 3 kilometers south from Jaguariahyva, state of Paraná. 
Entre Rio Negro e Lapa veem-se frequentemente, nos cortes da estrada de ferro, numerosos grandes boulders de granito e outras rochas em um schisto cinzento escuro, que pertence provavelmente a este mesmo horizonte, bem como os de entre Serrinha e Palmeiras, na estrada de ferro entre Ponta Grossa e Curityba.

O Dr. Orville A. Derby, distincto geologo de S. Paulo, menciona a presença de um grande deposito de blocos (boulders) em muitas localidades no Estado de S. Paulo, neste mesmo horizonte geologico; e o Dr. Lisboa, eminente engenheiro de Petropolis, encontrou muitos seixos facetados em Minas Geraes que elle attribue á acção glacial. * Parece, portanto, haver grande evidencia da existencia de uma época glacial no sul do Brasil, approximadamente ao mesmo tempo que na Africa do Sul e India, ou durante a época dos conglomeratos de "Dwyka " "Trap ", " Glacial » e "Talchir ", daquellas regiões, e que precedel a época carbonifera no sul do Brasil.

\section{As camadas Rio Bonito (Coal Measures)}

Acima do conglomerato de Orleans vem uma serie de gres feldspathicos, amarellos e brancos acinzentados entremeiados, com schistos cinzentos azulados, em que occorrem varias camadas de carvão, uma das quaes perto do tope do grupo parece ser persistente em vasta região.

Estas camadas estão todas bellamente expostas ao longo do rio Bonito entre sua embocadura em Minas, na base de serie, e Palermo, 8 kilometros acima desta, justamente abaixo do qual os membros do tope das Coal Measures (") mergulham para baixo do nivel d'agua, pelo que estas rochas foram designadas Camadas Rio Bonito. Os gres das Camadas Rio Bonito, ou Coal Meosures, do Brasil, estão muitas vezes só parcialmente consolidados, ou emfim tão fracamente consolidados que se desaggregam promptamente quando expostos ao tempo, constituindo assim um material de construcção de má qualidade. Os schistos tambem se desaggregam promptamente formando argillas, de facto os schistos frequentemente apresentam o aspecto de argillas estratificadas.

\footnotetext{
* Vêde nota na p. 12

$\left(^{*}\right.$ Coal Mcasures - Formaçāo carbonifera.
} 
Between Rio Negro and Lapa, along the Railway cuts, numerous large boulders of granite and other rocks are frequently visible in a dark gray shale which probably belong at this same horizon, as well as those between Serrinha and Palmeiras on the railway between Ponta Grossa and Curityba.

Dr. Orville A. Derby, the distinguished geologist of S. Paulo, reports the presence of a great boulder deposit at many localities in the state of São Paulo at this same geological horizon, and Dr. Lisboa, the eminent engineer of Petropolis, has found many facetted pebbles in Minas Geraes wich he ascribes to glacial action, " hence there would appear to be abundant evidence that there was a Glacial epoch in South Brazil at approximately the same time as in South Africa and India or during the epoch of the "Dwyka", "Trap", "Glacial», and "Talchir" conglomerates of those countries, and that it preceded the coal making epoch in South Brazil.

\section{The Rio Bonito Beds (Coal Measures)}

Above the Orleans conglomerate there comes a series of yellow and grayish-white feldspathic sandstones, interbedded with bluish gray shales, in which several coal beds occur, one of which, near the top of the group, appears to be persistent over a wide region.

These beds are all finely exposed along Rio Bonito between its mouth at Minas in the base of the series, and the village of Palermo, 8 kilometers above, just below which the top members of the Coal, Measures pass below water level, and hence these rocks have been designated the Rio Bonito Beds. The sansdstones of the Rio Bonito Beds or Coal Measures of Brazil are often only partially consolidated, or at least so poorly consolidated that they readily disintegrate on exposure, and hence they make a very poor quality of building stone. The shales also disintegrate quite readily into clays, in fact the shales frequently present the aspect of stratified clays.

\footnotetext{
* See note on p. 13.
} 
A estructura detalhada das Camadas Rio Bonito, segundo as medidas tomadas an longo da Estrada Nova (estrada do rio do Rasto) perto de, Minas, em Santa Catharina, è a seguinte em ordem descendente :

1. Gres cinzento e camadas areentas. . . . . . . . $\quad \begin{array}{cc}\text { Metros } & 6.096\end{array}$

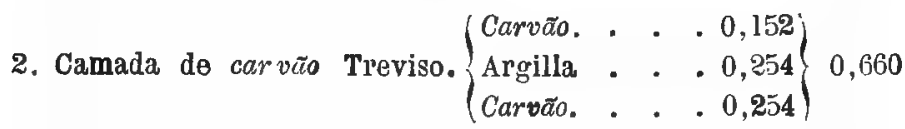

3. Encoberto e gres, Barro Branco superior . . . . 6,62

4. Carvão Barro Branco. . $\left\{\begin{array}{l}\text { Carvão e ardosia } 0,25 \\ \text { Argilla branca. } 0,555 \\ \text { Carvāo e ardosia } 0,305\end{array}\right\} 1,11$

5. Schistos com plantas fosseis, Glossopteris, Gangamo. pleris Noeggerathiopsis, Cardiocarpon . . . 0,15

6. Gres, branco massiço, Barro Branco inferior. . . . 9,14

7. Carvão e ardosia (Irapuá) com fragmentos de plantas fosseis . . . . . . . . . . . 0.15

8. Schistos pardos creme molles, com finos leitos de gres 9,14

9. Gres branco cinzesito. . . . . . . . 6,10

10. Schistos . . . . . . . . . . . 3,05

11. Gres. . . . . . . . . . . . . 3,05

12. Schistos pardos, muito fossiliferos na porção inferior, Glossopteris, Sphenopteris, Noeggerathiopsis, Sigillaria, Equisetites, Cardiacarpon, etc. . . 6,10

13. Gres cinzento . . . . . . . . . . . 3,05

14. Carvão Ponte Alta ?. . . . . . . . . . . 0,15

15. Schistos . . . . . . . . . . . . . . , 2,13

16. Gres massiço, Bonito superior. . . . . . 12,20

17. Carvăa, Bonito Rider. . . . . . . . . . . 0,455

18. Argilla e schisto carbonoso. . . . . . . . . 0,555

19. Camada de carvão Bonito (carvão e ardosia) . . $\quad 2.13$

20. Argilla refractaria e schistos de cor clara . . . 4,57

21. Gres massiços com seixos, Bonito inferior . . . 10,67

22. Schistos muitas vezes avermelhados quando alterados e encobertos . . . . . . . . . . . . 22,86

23. Gres massiço com seixos. . . . . . . . . 15,24

24. Schistos avermelhados quando alterados a amarellos em cima, porém cinzentos claros na base. - . 7,62

25. Schistos arenaceos micaceos, cinzentos claros, muito cheios de restos de plantas fosseis, Glossopteris, Gangamopteris, Noeggerathiopsis, Phyllotheca Derbyella, Hastimina, Rosellinites, Bysterites, Arberia, Cardiocarpon, etc., junto com muitas outras de que ha uma lista completa em outra parte deste relatorio . . . . . . . . . 0,305 
The detailed structure of the Rio Bonito Beds as measured along the Estrada Nova near Minas, Santa Catharina, is as follows in descending order:

1. Gray sandstone and sandy beds.

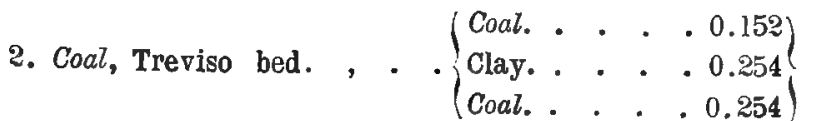

6.096

0.660

3. Concealed and sandstone, Upper Barro Branco. . . 6.62

4. Coal, Barro Branco .. $\left\{\begin{array}{l}\text { Coal, slaty. } \cdot 0.25 \\ \text { Clay, white } \cdot 0.555\end{array}\right\} \quad 1.11$

5. Shales with fossil plants, Glossopteris, Ganganopteris, Noeggerathiopsis, Cardiosarpon .. . . . . . . 0.15

6. Sandstone, massive, white, Lower Barro Branco . . 9.14

7. Slaty coal (Irapuá), fossil plant fragments. . . . 0.15

8. Soft creamy brown shales with thin layers of sandstone . . . . . . . . . . . . . . 9.14

9. Sandstone, grayish white. . . . . . . . 6.10

10. Shales. . . . . . . . . . . . 3.05

11. Sandstone. . . . . . . . . . . . . 3.05

12. Brown shales, quite fossiliferous in lower portion, Glos. sopleris, Sphenopteris, Noeggerathiopsis, Sigillaria, Equisetiles, Cardiucarpon, etc. . . . . . . . . . 6.10

13. Sandstone, gray. . . . . . . . . . . . 3.05

14. Coal, Ponte Alta. . . . . . . . . . . 0.15

15. Shales. • . . . . . . . . . . . 2.13

16. Sandstone, massive, Upper Bonito. . . . . 12.20

17. Coal, Bonito Rider . . . . . . . . . . . 0.455

18. Clay and coaly shale . . . . . . . . . 0.555

19. Bonito coal bed (coal and slate). . . . . . 2.13

20. Fire clay and light-colored shales. . . . ' . 4.57

21. Sandstone, massive, pebbly, Lower Bonito . . . 10.67

22. Shales, often weathering reddish, and concealed. . . 22.86

23. Sandstone, massive, pebbly . . . . . . . . 15.24

24. Shales weathering reddish and yellow above, but light gray at base. . . . . . . . . . . . . 7.62

25. Light gray sandy micaceous shale, very full of Glossopleris, Gangamopteris, Noeggerathropsis, Phyllotheca, Derbyella, Hastimima, Rosellinites, Hysterites, Arberia, Cardiocarpon, etc., together with many others, a full list of which is given in another part of this report. 
Metros

26. Schisto arenaceo cinzento . . . . . . . . 3,05

27. Gres . . . . . . . . . . . . , 6,10

28. Schistos azues escuros na base. . . . . . 3,0j

29. Grès e encoberto até a bocea da, sondagem a 197,2

metros acima do nivel do mar . . . . . 12,20

30. Conglomerato de Orleans, na sondagem . . . . . 5,35

31. Schistos e gres alternando até o granito . . . 27,00

Total. . . . . . . . 190,051

Uma outra secção leem detalhada, do tope das camadas Rio Bonito até o granito, foi medida na nova estrada em construcção entre Florianopolis e Lages. Esta secção principia nos altos, perto da fazenda do Sr. Leonel Luz, na região do 93 kilometro, a contar de Florianopolis e desce até o leito do Quebra-Dentes, do seguinte modo:

1. Encoberto desde os altos

Metros

2. Gres massiço, branco, Barro Branco superior. . 1524 30.38

3. Carvão, Barro Branco . . . . . . . . . 0.30

4. Schistos e gres escuros fossiliferos (plantas). . $\quad 9.14$

5. Schistos escuros e encoborto. . . . . . . 3.05

6. Grès muito massiço, Barro Branco inferior . . 18.29

7. Schistos, gres e encoberto . . . . . . 57.91

8. Schistos pretos . . . . . . . . . 0.61

9. Schistos e gres . . . . . . . . . . 15.24

10. Schisto escuro . . . . . . . . . . 0.30

11. Schisto cinzento. . . . . . . . . 3.05

12. Gres formando paredões . . . . . . . 36.58

13. Schistos e camadas aroentas. . . . . . 70.10

14. Schistos areentos cor de ferrugem, com grandes concreções com ferro, tendo de $0^{\mathrm{m}} .50$ a $2^{\mathrm{m}} .00 \mathrm{de}$ diametro

15. Schistos e camadas areentas. . . . . .

159.71

16. Gres conglomeratico, massiço, formando grandes paredões e superposto ás camadas interiores, em discordancia apparente . . . . . . . .

17. Schistos cinzentos o preto azulados, com seixos do granito visiveis a $67^{\mathrm{m}} .06$. . . . . . .

18. Gres massiço de grão fino. . . . . . . .

19. Schistos escuros a cinzentos até o granito no leito do Quebra-Dentes.

Ha alguma incerteza sobre o ponto em que terminam nesta secção, as camadas Rio Bonito, mas colloquei este provisoriamente na 


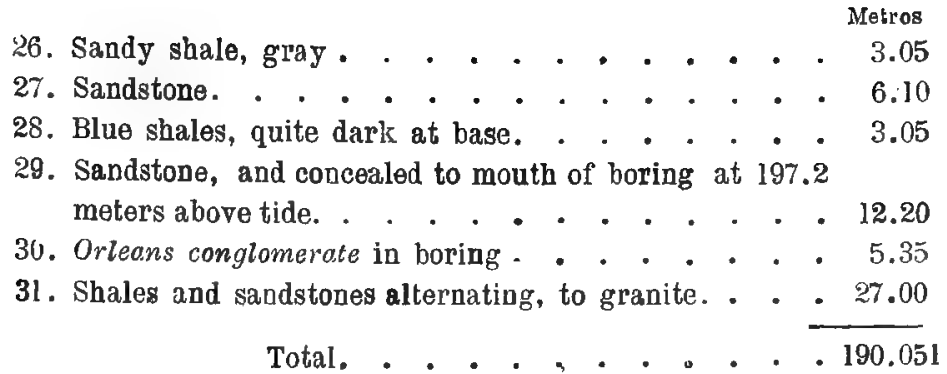

Another fairly detailed section from the top of the Rio Bonito Beds down to the granite was measured along the new road in construction between Florianopolis and Lages. This section begins on the summits near the fazenda of $\mathrm{Mr}$. Leonel da Luz in the region of the 93rd kilometer from Florianopolis, and descends to the hed of Quebra Dentes. It reads as follows:

1. Concealed from summit . . . . . . . . . . 30.38

2. Sandstone, Upper Barro Branco, massive, white . 15.24

3. Coal, Barro Branco . . . . . . . . . 0.30

4. Dark fossiliferous (plant) shales and sandstones. . 9.14

5. Dark shales, and concealed . . . . . . . 3.05

6. Sandstone, very massive, Lower Barro Bpanco. . 18.29

7. Shales, sandstone and concealed . . . . . 57.91

Rio Bonito Beds

8. Shales black. . . . . . . . . . . 0.61

159.71

9. Shales and sandstone . . . . . . . . 15.24

10. Shale, dark . . . . . . . . . . . 0.30

11. Shales, gray. . . . . . . . . . . . 3.05

12. Sandstone, makes cliffs . . . . . . . 36.58'

13. Shales and sandy beds. . . . . . . . . 70.10

14. Shales, sandy, rusty colored, with large ironbearing concretions 0.50 to 2.00 meters in diameter.

15. Shales and sandy beds. . . . . . . ...

16. Sandstone, conglomeratic, massive, makes great cliffs, and rests in apparent unconformity upon the underlying beds . . . . . . . . . . .

17. Shales, drab, and blue-black with granite pebbles seen at 67.06 meters.

18. Sandstone, massive, fine-grained. . . . . . .

19. Shales, dark and gray to granite in bed of Quebra

Dentes

There is some uncertainty as to were the Rio Bonito beds end in this section, but I have provisionaly placed it at the base of the 5539 
base do gres espesso, n. 12, o que dá uma espessura de $159.71 \mathrm{~m}$. a estas camadas nesta localidade para $157,27 \mathrm{~m}$. em Minas.

os 120.40 de camadas que estão abaixo do n. 12 e terminam na base com um conglomerato massiço devem representar as camadas cor de ferrugem que estâo abaixo do Conglomerato de Orleans e superpostas ao granito ao longo do rio Tubarão, emquanto que os $152,40 \mathrm{~m}$. de schisto escuro, etc., que estão abaixo destas e vão até o granito devem ser mais antigos que o Carbonifero.

Todas as espessas camadas de grès da secção acima são visiveis em longa serie de paredũes verticaes nos arredores do morro da Boa Vista, a mais elevada, de n. 2, fórma o tope deste, emquanto que a mais baixa, de $n$. 16, afflora nas mais salientes pene dias.

E' esta camada cque os viandantes da velha cstrada de Florianopolis a Lages encontram tanta difficuldade em transpor, pois que forma umas tão nuas penedias em redor das montanhas, dando passagem em um unico ponto e alli mesmo com um angulo approximadamente de $30^{\circ}$.

Todo o trafego do interior, e para descer este ingreme caminho. Presentemente, porém, a nova estrada inaugurada pelo actual governador de Santa Catharina, foi construida com uma rampa suave de $3^{\circ}$, cortando um grande paredão de conglomerato.

o Conglomerato de Orleans näo foi identificado, com certeza nesta secção e é bem possivel que não exista.

Os schistos pretos inferiores ao conglomerato n. 16, são de idade incerta, não tendo sido visto fosseis nelles. Apparecem seixos de granito perto do centro destas camadas escuras; um destes tinha 15 centimetros de diametro.

No Estado do Rio Grande do Sul, a 18 kilometros a éste de Xarqueadas, ha muito tempo que é explorada uma mina de carvão nas camadas Rio Bonito, pela Companhia Estrada de Ferro e Minas de S. Jeronymo, em aguas do Arroio dos Ratos. Foram feitas alli varias sondagens pela Companhia e uma destas, a n. II, que dá a successão detalhada e espessura das camadas Rio Bonito naquella localidade, já foi dada na pagina 4 4.

Para mostrar a continuidade destas camadas para o sul de S. Jeronymo, daremos mais duas secções, a primeira da fazenda do Dr. Ramiro Barcellos, na margem do rio Irapuá, a 55 kilometros a sudoéste de Cachóeira e a cerca de 200 de S. Jeronymo. 
great sandstone, $\mathrm{n} .12$, which grives a thickness of 159.71 meter's for these beds at this locality as against 157.27 meters at Minas.

The 120.40 meters of measures, which extend on below n. 12, and end at base with a very massive conglomerate, may possibly represent the rusty beds which underlie the Orleans conglomerate, and rest upon the granite along Rio Tubarão, while the 152.40 meters of dark shales; etc., which underlie them and extend dorvn to the granite may be older than the Carboniferous.

All of the thick sandstones in the above section stretch in long lines of vertical cliffs around the sides of Boa Vista mountain, the highest one n. 2, making its crest, while the lowest one n. 16 crops out in the most conspicuous cliffs.

It is this particular stratum which the travelers on the old road from Florianopolis to Lages found so much difficulty in surmounting, since it forms such a bold cliff around the mountains, being broken at only one point, and then at an angle of nearly $30^{\circ}$.

Up and down this steep descent all traffic to or from the interior of this region was compelled to pass, but now the new road inau gurated by the recent Governor of Sta. Catharina has been cut to a gentle $\left(3^{\circ}\right)$ grade through this great conglomerate cliff.

The Orleans conglomerate was not certainly identified in this section, and it is quite possible that it is not present.

The dark shales underlying the $n .16$ conglomerate are of uncertain age, no fossile having been seen in them. Granite pebbles, one of which had a diameter of 15 centimeters, occur near the center of these dark beds.

In the State of Rio Grande do Sul, 18 kilometers east from Xarqueadas, a coal mine has long been operated in the Rio Bonito Beds by the $\mathbf{S}$. Jeronymo Railroad and Mines Company on the waters of Arroio dos Ratos. Several borings have been put down through the series there by the company and one of these, $n$. II, which gives the detailed succession and thichness of the Rio Bonito Beds at that locality, has already been given on a previous page 45.

To show the continuity of these measures southward from $\mathrm{S}$. Jeronymo, we shall give two more sections, the first from the l'azenda of Dr. Ramiro Barcellos on the banlis of Rio Irapua, 55 kilometers south-rest from Cachoeira and about 200 from S. Jeronymo. 
A secção é a seguinte, descendo a ingreme encosta que margeia o rio, onde o Dr. Ramiro Barcéllos explorou as camadas:

1. Gres massico, grosseiro, cellular Metros

2. Gres conglomeratico . . . . . . . . . . . . . 7.62

3. Encoberto . . . . . . . . . . . . . . . 10.67

4. Schistos carbonosos (Treviso?) . . . . . . . . . . . 1.52

5. Gres massiço . . . . . . . . . . . . . . . . . 4.57

6. Schistos cinzentos. . . . . . . . . . . . . . . 0.51

7. Ardosia preta, laminas de carvão. . . . . . . . . . . . 1.22

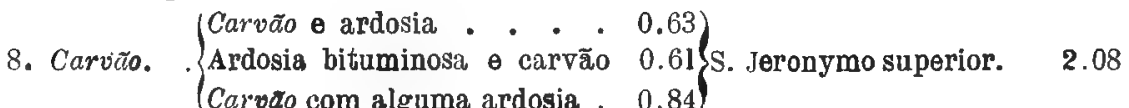

9. Argilla cinzenta clara e branca . . . . . . . . . . . 3.05

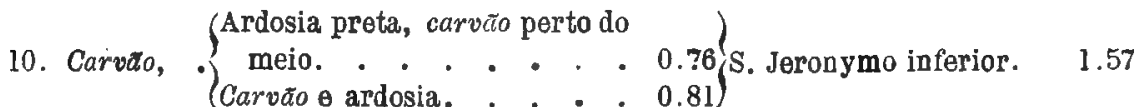

11. Argilla cinzenta escura . . . . . . . . . . . . . 1.07

12. Gres massico cinzento . . . . . . . . . . . . . 6.10

13. Schisto areento,plantas fosseis . . . . . . . . . . . 0.76

14. Ardosia preta e carvăo, Irapud. . . . . . . . . . . . . 0.91

15. Argilla branca, visivel . . . . . . . . . . . : . 0.61

16. Encoberto até o rio Irapuá. . . . . . . . . . . . . . 30.48

E' muito provavel que os ns. 8, 9 e 10 representem a camada de carvão S. Jeronymo, com a argilla que alli ha muito avolumada em espessurae tambem correspondem sem duvida á camada Barro Branco, de Santa Catharina. No n. 13 colligiram-se algumas plantas fosseis, entre as quaes o Dr. David White relacionou as seguintes especies occorrendo no horizonte do carvão Irapui, designação do n. 14 : Glossopteris Indica, Glossopteris Browniana, Cardiocarpon Barcellosum, Ottokaria ovalis, etc.

Uma outra secção parcial das camadas Rio Bonito a cerca de 400 kilometros a sudoeste de Irapuá, perto de Candiota, no Rio Grande do Sul, mostra a persistencia do carvão S. Jeronymo. Esta secção foi medida em Serro Partido, na fazenda do Sr. Coronel Manoel Lucas de Lima, que fica na regiăo que está entre o rio Candiota e o Tigre. Em ordem descendente a serie é a seguinte:

1. Gres cinzento duro conglomeratico . . . . . . . . . 6.10

2. Encoborto e schistos. . . . . . . . . . . . 6.10

3. Gres, bem massiço . . . . . . . . . . . . . . 6.10

4. Schistos cinzentos areentos. . . . . . . . . . . . . . 0.91

5. Schisto carbonoso escuro. . . . . . . . . . . . 0.91 
It reads as follows in descending the steep bluff bordering the river where Dr. Ramiro Barcellos has explored the measures :

Meters

1. Sandstone, massive, rough, cellular . . . . . . . . . 6.10

2. Sandstone, conglomeratic . . . . . . . . . . . . . 7.62

3. Concealed . . . . . . . . . . . . . . . . 10.67

4. Coaly shales (Treviso?) . . . . . . . . . . . . . . 1.52

5. Sandstone, massive . . . . . . . . . . . . . . 4.57

6. Shales, gray. . . . . . . . . . . . . . . . . 0.51

7. Slate, black, films of coal - . . . . . . . . . . . 1.22

8. Coal. $\quad\left\{\begin{array}{lll}\text { Coal and slate. } \cdot \dot{*} \cdot- & 0.63 \\ \text { Bituminous slate and coal } \cdot & - & 0.61 \\ \text { Coal, some slate } & 0.84\end{array}\right\}$ Upper S. Jeronymo. 2.08

9. Clay, light gray and white. . . . . . . . . . . . . 3.05

10. Coal. $\left\{\begin{array}{lll}\text { Black slate, coal near middle } . & 0.76 \\ \text { Coal and slate. . . . } .0 .81\end{array}\right\}$ Lower S. Jeronymo. 1.57

11. Clay, dark gray. . . . . . . . . . . . . . 1.07

12. Saudstone, massive, gray . . . . . . . . . . . . 6.10

13. Sandy shale, fossil plants. . . . . . . . . . . . . 0.76

14. Black slate and coal, Irapud́ . . . . . . . . . . . . . 0.91

15. White clay, visible . . . . . . . . . . . . . 0.61

16. Concealed to Rio Irapuá . . . . . . . . . . . . . . . 30.48

It is quite probable that ns. 8,9 and 10 represent the $\mathrm{S}$. Jeronymo coal bed, with the parting clay greatly increased in thickness and they are also doubtless identical with the Barro Branco bed of Santa Catharina. From n. 13 were collected some fossil plants among which Dr. David White has listed the following species as coming at the horizon of the Irapua coal, the designation of n. 14: Glossopteris Indica, Glossopteris Browniana, Cardiocarpon Barcellosum Ottokaria ovaris, etc.

Another partial section of Rio Bonito heds about 400 kilometers southwest from Irapuá, near Candiota in Rio Grande do Sul, will show the persistency of the $\mathrm{S}$. Jeronymo coa!. This section was measured at Serro Partido, on the fazenda of Cor. Manoel Lucas de Lima which occupies the region between Rio Candiota and Rio Tigre. It reads as follows in descending order :

1. Sandstone, gray, hard, conglomeratic . . . . . . . . 6.10

2. Concealed and shales . . . . . . . . . . . 6.10

Ł. Sandstone, quite massive . . . . . . . . . . . . 6.10

4. Shales, gray, sandy . . . . . . . . . . . . . . 0.91

5. Coaly shale, dark. . . . . . . . . . . . . . . . 0.91 
6. Schistos azues eseuros fossiliferos com Noeggerathiopsis a outras

formas . . . . . . . . . . . . . . . . .

7. Camada de ardozia carbonosa. . . . . . . . . . 0.305

8. Argilla do cor clara. . . . . . . . . . . . . . 1.52

9. Schistos escuros . . . . . . . . . . . . . . . . 0.61

10. Schisto amarello, plantas fossseis. . . . . . . . . 0.025

11. Schisto, escuro . . . . . . . . . . . . . . 0.305

12. Schisto amarello plantas fosseis. . . . . . . . . . 0.100

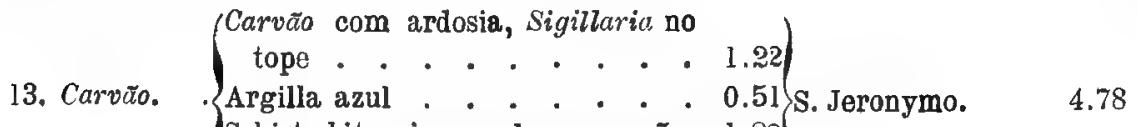

Schisto bituminoso, algum carvão. 1.22

Carvão impuro . . . . . 1.83 )

14. Argilla azul . . . . . . . . . . . . . . . . 0.13

15. Schistos escuros . . . . . . . . . . . . . . . . 0.43

16. Argilla branca cinzenta . . . . . . . . . . . . . 1.68

17. Argilla, cor de azeitona escura, atê a agua no velho poşo . . $\quad 3.35$

18. Intervallo referido, no po६̧ . . . . . . . . . . . . 12.19

19. Carvđ̆o referido (Irapuá?) . . . . . . . . . . . $0.20-0.36$

Total . . . . . . . . . . . $\overline{48.035}$

E' possivel que o intervallo n. 18 não tenha 12.19 , visto como nada de definitivo foi possivel saber a este respeito, excepto que foi achada uma pequena camada de bom carvão no fundo do poço.

Este carvão é muito provavelmente identico á camada de Irapuà, pois que ha pouca duvida que o n. 13 represente o tope e a parte inferior da camada S. Jeronymo, da secção Irapuá, porque foi encontrada a mesma Sigillaria no tope dos ns. 10 e 12 que estão cheios de restos fragmentarios de uma planta que é apparentemente identica á que foi achada junto á camada de carvão Barro Branco, perto de Minas, em Santa Catharina. 
6. Shales, dark blue, fossiliferous, Noeggeralhiopsis and other forms. $\quad 2.29$

7. Coaly, slaty layer . . . . . . . . . . . . 0.305

8. Clay, ljght colored . . . . . . . . . . 1.52

9. Shales, dark . . . . . . . . . . . . . . . 0.61

10. Shale, yellow, fossil plants . . . . . . . . . . . . 0.025

11. Shale, dark. . . . . . . . . . . . . . . . 0.305

12. Shale, yellow, fossil plants. . . . . . . . . . . . 0.100

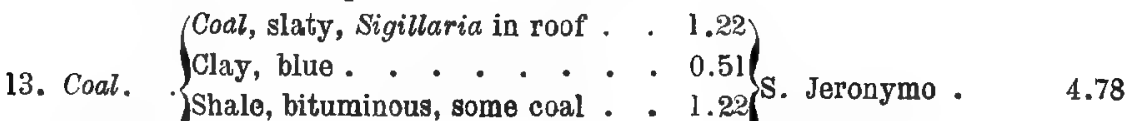

14. Clay, blue. . . . . . . . . . . . . . 1.13

15. Shales dark . . . . . . . . . . . . . . . . . 0.43

19. Clay, grayish white. . . . . . . . . . . . 1.68

17. Clay, dark-olive in color to water in old shaft . . . . . . 3.35

18. Interval l’eported in shaft . . . . . . . . . . . 12.19

19. Coal, reported (Irapuá). . . . . . . . . . . . 0.20-0.36

Total . . . . . . . . . . . . 48.035

The interval, $\mathrm{n} .18$, is possibly not so much as 12.19 meters, since nothing definite could be learned about it, except that a small seam of good coal had been found at the bottom of the shaft.

This coal is most probably identical with the Irapua bed, since there can be little doubt that $\mathrm{n} .13$ represents the Upper and Lower S. Jeronymo seams of the Irapuá section, because the same Sigillaria is found in the roof of each. Ns. 10 and 12 are both crowded with fragmentary remains of a plant which is apparently identical with one found in connection, with the Barro Branco coal bed near Minas, in Santa Catharina. 


\section{CAPITUI,O V}

Descripção detalhada dos leitos de carvão e outros horisontes das camadas Rio Bonito

Ao que parece nenhum leito de carvão de sensivel importancia, se apresenta na metade inferior das camadas "Rio Bonito", bem que alguns leitos de schistos escuros carbonosos e corn restos de vegetaes occorram no espaço de 5 a 6 metros acima do granito. Um destes schistos fossiliferos se apresenta no córte da estrada de ferro, entre os postes kilometricos 492 e 493 , alguns kilometros a sudoeste de Suspiro, no Rio Grande do Sul, porém, o schisto bituminoso não contem carvão verdadeiro. Logo acima do estrato escuro vem um schisto cinzento de Ganyamopteris obovata.

Este horizonte, que se acha a 6 metros apenas acima do granito, jaz provavelmente a mais de 100 metros abaixo do horizonte do carvão deS. Jeronymo, visto que este ultimo só se apresenta a 3 e 4 kilometros mais a oeste.

Na secção em Minas, Santa Catharina, não ha vestigio de carvão visivel nos 80 e mais metros de sedimentos entre a camada de carvão "Bonito" e o Conglomerato de Orleans, consistindo a formação em estratos alternados de gres e schistos com um horisonte muito rico em restos de plantas, a 65 metros abaixo do tope da camada de carvão "Bonito ".

\section{Camada de plantas Joaquim Branco}

Ao longo da Estrada Nova, meio kilometro ao norte da estação de Minas e logo abaixo da casa de Joaquim Branco, descobri um estrato delgado de schisto argilloso amarellado, muito rico em plantas fosseis. o estrato tem apenas 20 a 30 centimetros de espessura, mas forneceu uma collecção abundante que foi remettida ao Dr. David White, a eminente palaeobotanico da Commissão Geologica dos Estados Unidos, em Washington, que estudou e descreveu estas plantas para este volume. O Dr. White achou tres generos novos e diversas especies 


\section{CHAPTER V}

\section{Detailed description of Coal Seams and Other Horizons in the Rio Bonito Beds}

No coal beds of any importance appear to occur in the lower half of the Rio. Bonito beds, although some dark, plant-bearing sliales and carbonaceous beds occur within $5 \mathrm{ol}^{\circ} 6$ meters. of the granite. one of these fossil-bearing shales occur's in a railway cut, between, the $492 \mathrm{nd}$ and 493rd kilometer post several kilometers south-west from Suspiro in Rio Grande do Sul, but the bituminous shale contains no genuine coal. Just above the dark stratum is a gray shale filled with Gangamopteris obovata.

This horizon, only 6 meters above the granite, is probably more than 100 meters below the horizon of the $\mathrm{S}$. Jeronymo coal, since the latter does not come in for 3 to 4 kilometer's farther west.

In the section at Minas, Santa Catharina, there is not a trace of coal visible in the 80 odd meters of sediments between the Bonito coal bed and the Orleans, conglomerate but the measures consist of alternate strata of sandstone and shales with a very rich plant-bearing horizon 65 meters below the top of the Bonito coal bed.

\section{Joaquim Branco Plant Bed}

Along the Estrada Nova, one-half kilometer north from'the Pailway' station at Minas, and just below the cottage of Joaquim Branco, the writer discovered a thin stratum of jellowish sandy shale, very rich in fossil plants. The layel is unly 20 to 30 centimeter's in thickness, but from it a large collection was made, and sent to Mr. David White. the eminent Palaeobotanist of the U. S. Geological Survey, at Washington, D. C., who has studied and described these plants for this volume. "Dr. White finds 3 nerv genera, and several new especies at 5569 


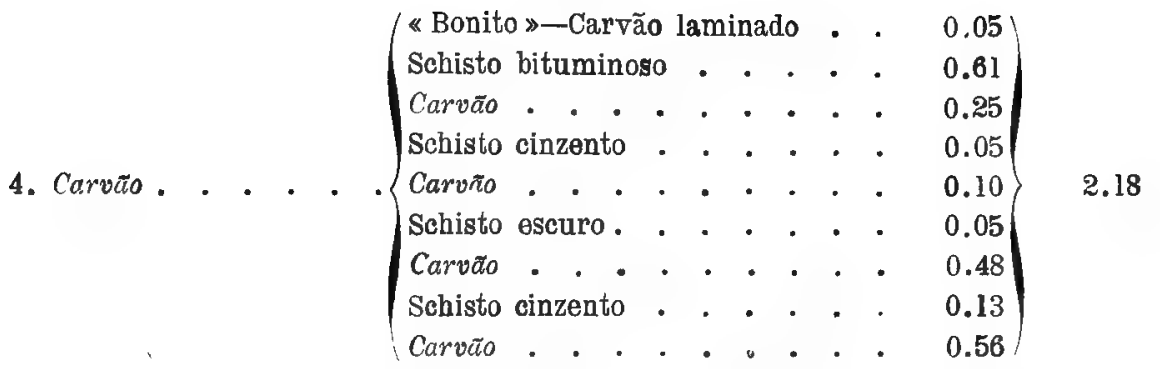

O leito pequeno de carvão, n . 2 que vem immediatamente abaixo do gres e se apresenta em todas as excavações em redor de Minas, contem muito enxofre e outras impurezas.

Os 61 centimetros de schisto bituminoso do tope do leito Bonito contem diversas camadas delgadas de carvão, mas estas se acham de tal modo interestratificadas com material argilloso que o carvão não é aproveitavel. A mina tem sido explorada em pequena escala para o consumo local e a galeria passa provavelmente a 40 ou 50 metros por baixo do morro. o carvão se apresenta em leito composto de lamellas bituminosas, brilhantes e lustrosas, de meio até cinco centimetros de espessura, separadas por schisto escuro bituminoso, de egual espessura, de modo que o carvão explorado contem muita cinza e apresenta um aspecto estratificado especial. Foram tiradas amostras para analyse e em outro capitulo deste relatorio serão dados os resultados. A elevação do fundo do leilo de carvão em Bonito n. I é de 241,5 metros acima do nivel do mar. Um dique vertical de diabase e da espessura de alguns metros corta o carvão a oeste de Bonito n. I.

Capoeira, acha-se situada a cerca de um kilometro ao sul da estar,ão terminal da estrada de ferro, das Minas e a $3 / 4$ de kilometro a sudoeste da cxploração de carvão "Bonito n. I". Nesta localidade foi aberta uma galeria de poucos metros, no leito Bonito e ahi foi medida a seguinte secção :

1. Gres massiço, Bonito Superior . . . . . . . . . . . . . 2.44

3. Argillas claras e escuras . . . . . . . . . . . . . . $0.9 \mathrm{l}$

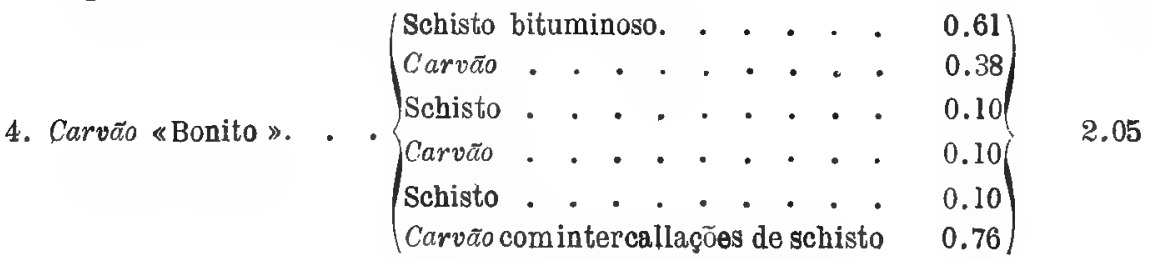




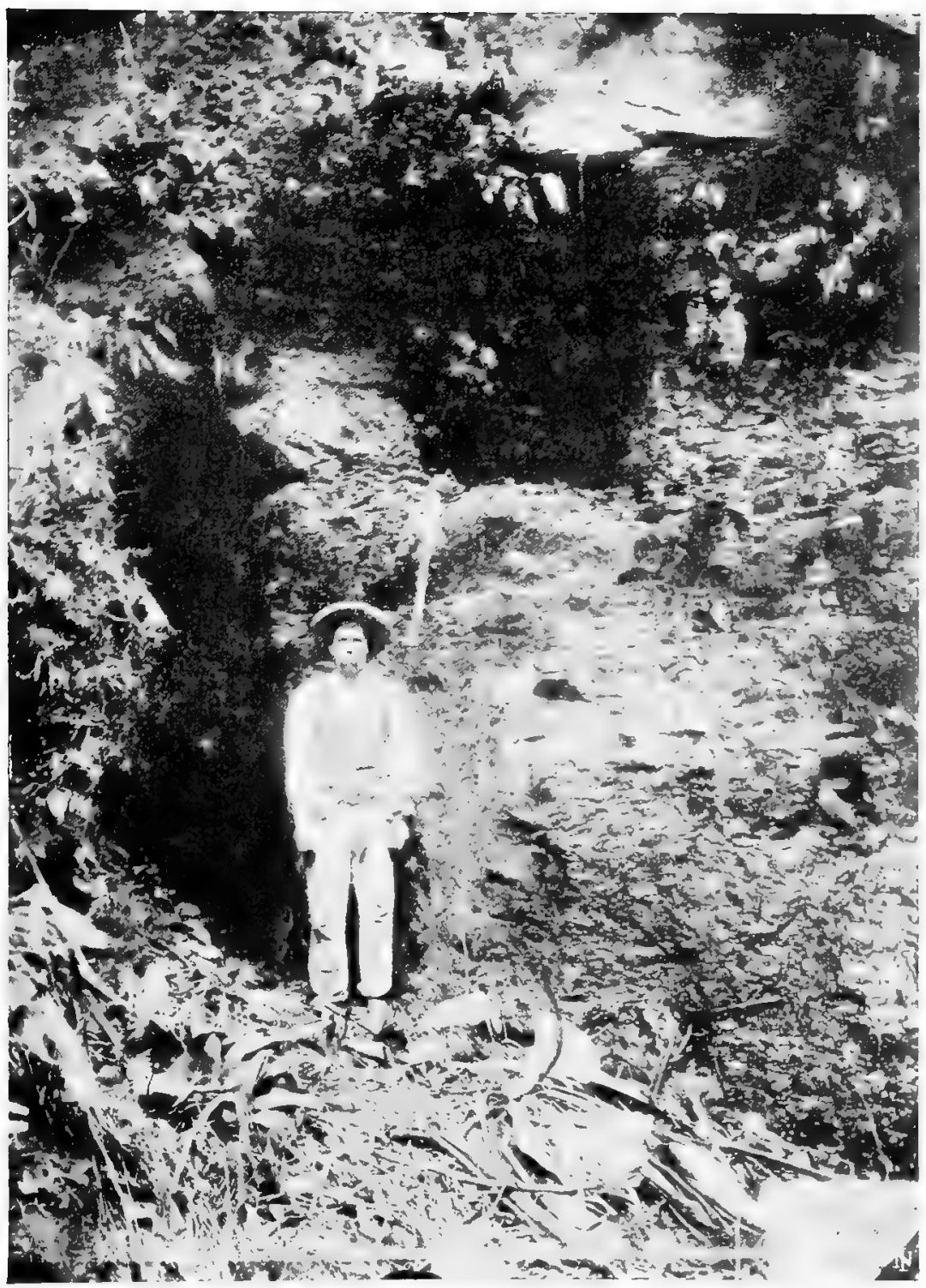

ESTADO DE SANTA CATHARINA

Affloramento "Capoeira" da camada de carvão "Bonito" 



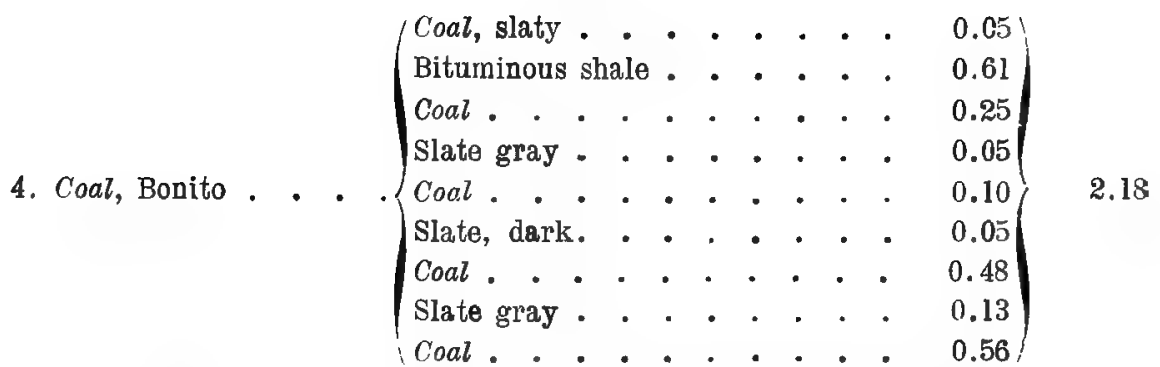

The little coal, n. 2, comes immediately below the sandstone, and is present at all the openings around Minas. It contains much sulphur and other impurities.

The 61 centimeters of bituminous shale at the top of the Bonito seam contains several thin layers of coal, but they are so interstratified wth slaty material that the coal in it is not available. The mine has been operated to a small extent for local use and the drift passes probably 40 to 50 meters under the hill. The coal occurs in layers of bright shining ordinary bituminous laminae $1 / 2$ to 5 centimeters in thickness, separated by dark bituminous slates of equal thickness, so that the fuel as mined is high in ash, and has a peculiar stratified appearance. Samples were taken for analysis, and the results will be given in another chapter of this report. Te elevation of the bottom of the coal at Bonito I is 241.5 meters above sea level. A nearly vertical dike of diabase several meters in width cuts through the coal just west from Bonito I.

Capoeira is about one kilometer due south from the railway terminus at Minas, and 3/4 kilometer south-east from the exploration at Bonito I. An entry has been driven into the Bonito bed at this locality for a few meters and the following section was measured there :

1. Sandstone, massive, Upper Bonito. . . . . . . . . . . 2.44

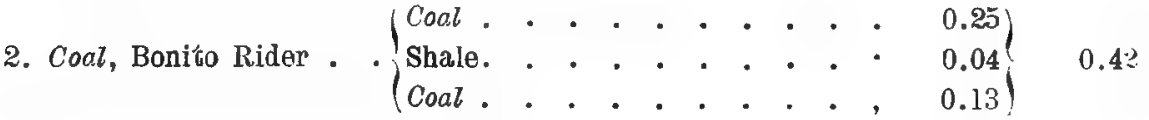

3. Clays, light and dark. . . . . . . . . . . . . 0.91

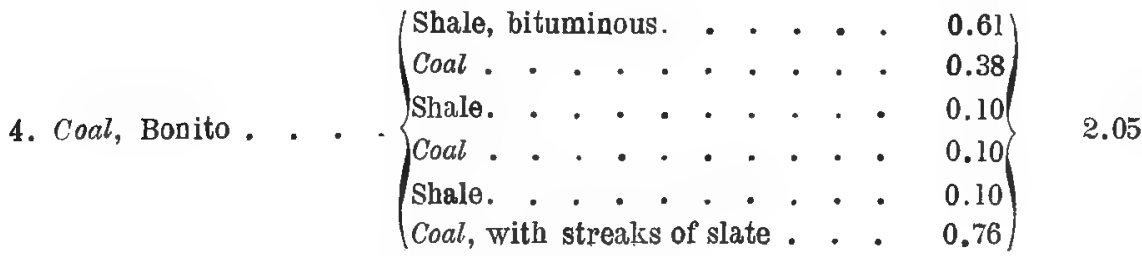


5. Argilla e schisto . . . . . . . . . . . . . . . 1.01

6. Carvão schistoso . . . . . . . . . . . . . . . . . 0.30

7. Argilla cinzenta, dura. • . . . . . . . . . • . . . . 1.52

A altitude a que está a base do carvão Bonito em Capoeira é de 276,4 metros.

Os 61 centimetros da parte superior do leito Bonito conteem provavelmente algum carvão, mas no affloramento está tão decomposto que apresenta o aspecto de schisto somente. A parte principal do carvão Bonito na abertura da Capoeira tem sempre gozado de bôa fama local, sendo reputado mais livre de impurezas que nas outras localidades da região.

O carvão delgado, n. 6, é provavelmente uma derivação (split) do leito Bonito principal.

A abertura Borell, no leito Bonito, acha-se situada a cerca de $1 / 3$ de kilometro distante de Capoeira, em rumo urn tanto a sudoeste. A secção ahi é a seguinte :

1. Gres - Bonito superior . . . . . . . . . . $\begin{array}{r}\text { Metros } \\ 3.05\end{array}$

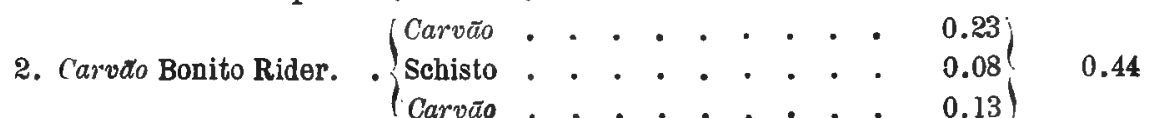

3. Argilla com carrão delgado junto da base . . . . . . . . . 0.96

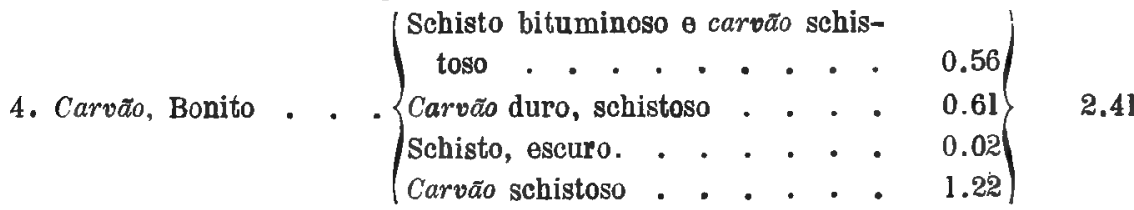

Altitude a que está a base do carvão, 254 metros.

Escada, é o nome da localidade quasi directamente ao sul de Borcll, distante 1/4 de kilometro somente, onde foi aberta uma galeria no carvão Bonito, na extensão de seis metros, revelando a seguinte successão :

1. Gres massiço, Bonito Superior . . . . . . . . . . . 3.05

2. Schisto arenoso, escuro . . . . . . . . . . . . . . . 0.15

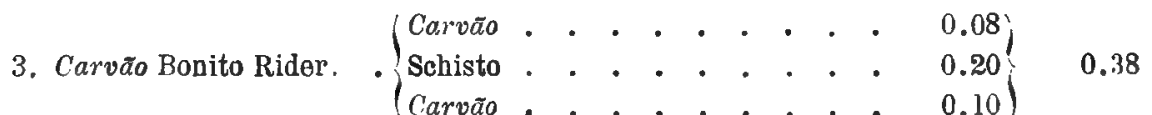

4. Schistos azues escuros. . . . . . . . . . . . . . . 1.14

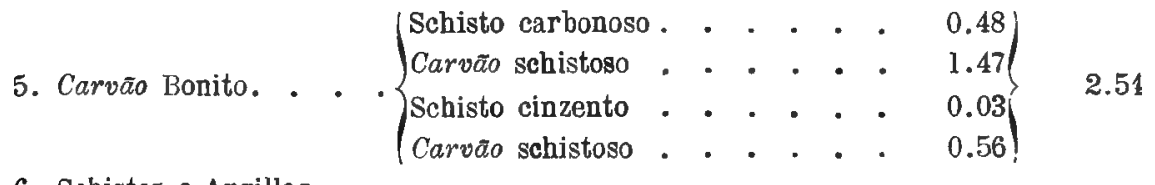

6. Schistos o Argillas. . . . . . . . . . . . . . . . -

Altitude a que está o carvão, 253,8 metros. 


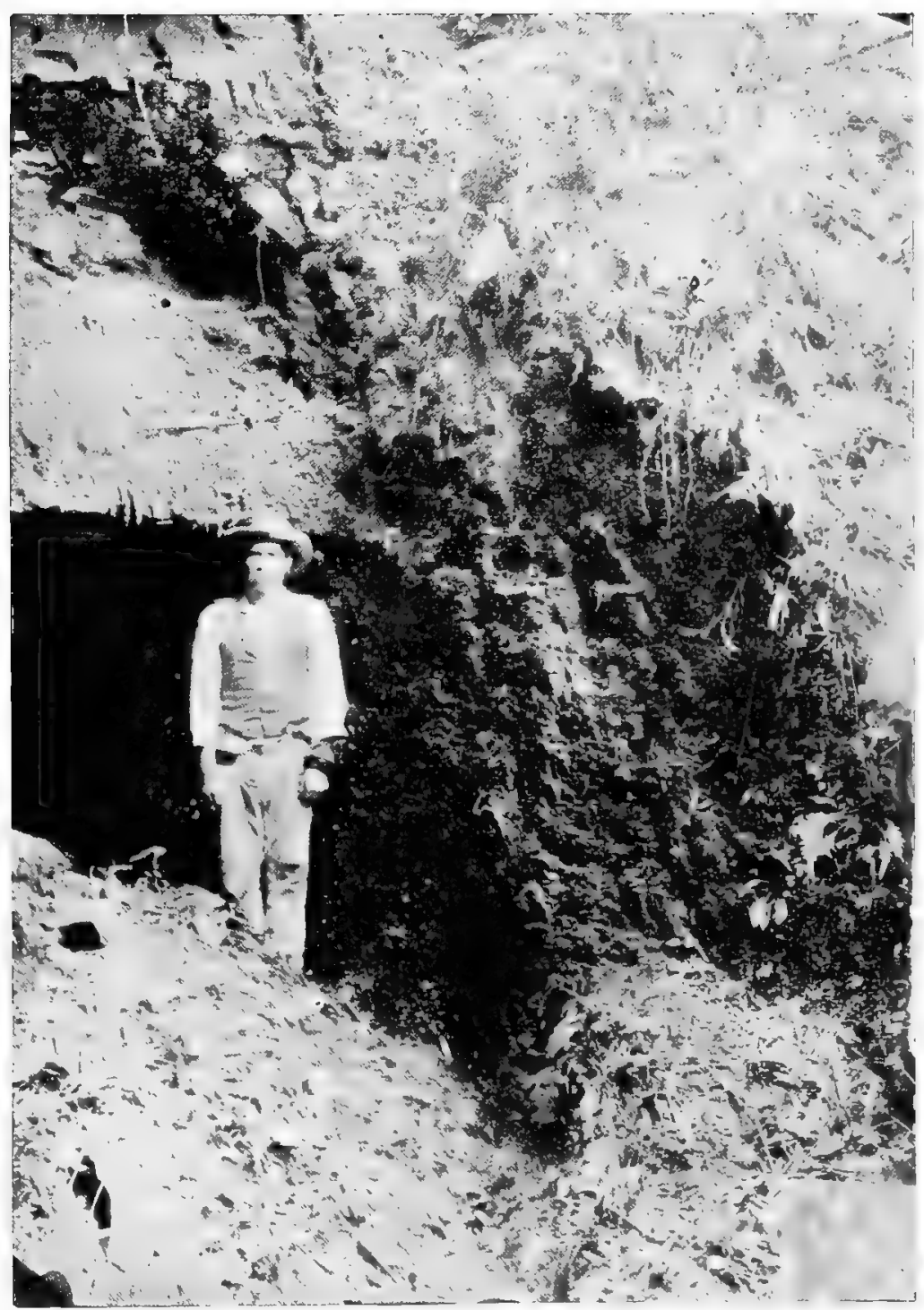

ESTADO DE SANTA CATHARINA

Affloramento "Borell" da camada de carvão "Bonito " 

5. Clay and shale. . . . . . . . . . . . . . . 1.01

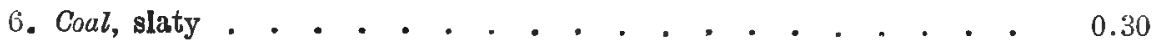

7. Clay, light gray . . . . . . . . . . . . . . . . 1.52

The elevation of the bottom of the Bonito coal at Capoeira is 276.4 meters.

'The upper 61 centimeters of the Bonito bed probably contains some coal, but the outcrop is so badly decomposed that it looks like shale only. The main portion of the Bonito coal at the Capocir $\alpha$ opening has always had a fairly good local rsputation, and is supposed to contain less of impurities there than elsewhere in the region.

The thin coal, n. 6, is probably a "split" from the main Bonito seam.

The Borell opening in the Bonito bed is alsouth $1 / 3$ kilometer distant from Capoeir $a$, in a direction slightly west of south from the same. The section there is as follows:

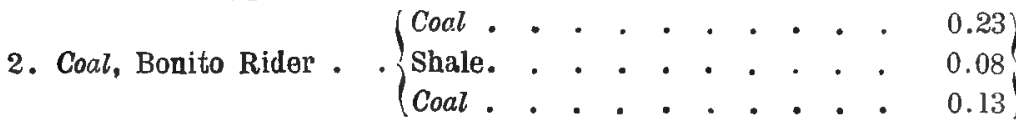

3. Clay, with thin coal near base. . . . . . . . . . . 0.96

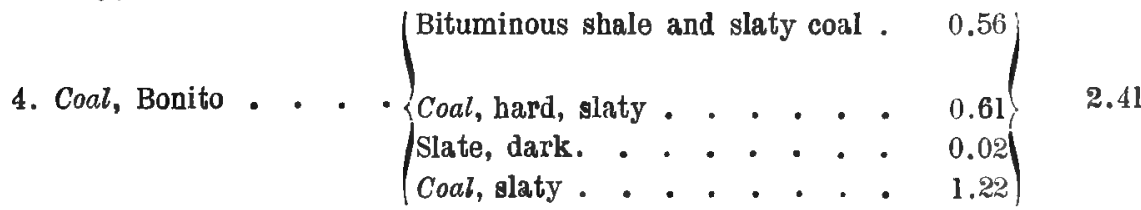

Elevation of bottom of coal, 254 meters.

Escada is the name of the locality nearly due soutl from Borell only $1 / 4$ kilometer, where a gallery has been driven into the Bonito coal about 6 meters, and reveals the following succession:

2. Shale, Sandy, dark . . . . . . . . . . . . . 0.15

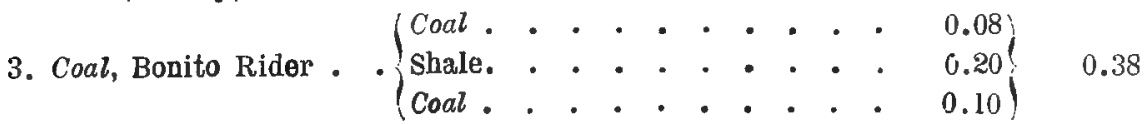

4. Shales, blue and dark. . . . . . . . . . . . . . . 1.14

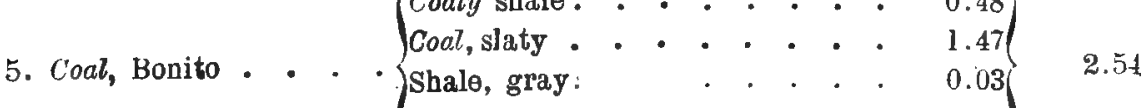

6. Shale and clay. . . . . . . . . . . . . . . . - -

Elevation of coal, 253.8 meter's. 
Cerca de 1/2 kilometro distante de Escada, em rumo quasi a sudoeste, acha-se a exploração Caraugueijo na camada Bonito, onde se notou a seguinte successão:

Motros

I. Gres massiço, Bonito Superior . . . . . . . . . . . 15.24

2. Carvão delgado, Bonito Rider . . . . . . . . . . . 0.08

3. Schistos arenosos, azulados . . . . . . . . . . . . 1.22

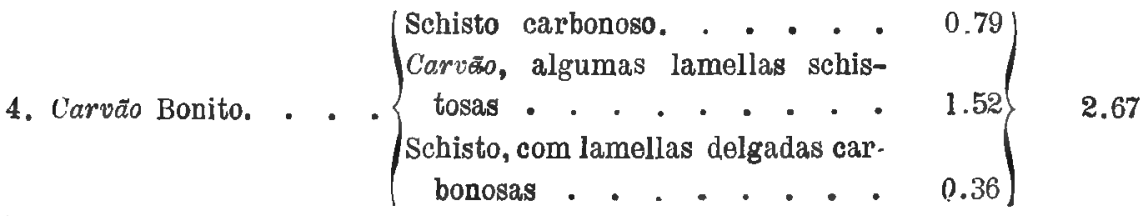

5. Argilla á vista. . . . . . . . . . . . . . . . . 0.15

Altitude da base do carvão Bonito, 266.4 metros.

Aqui o carvão levanta-se ligeiramente para sudoeste em virtude, ao que parece, do grande dique que atravessa a excavação perto de Bonito n. I.

Bonito II que se acha situado a cerca de $3 / 4$ de lilometro a sudoeste da localidade do Bonito I, apresenta a successão seguinte :

1. Gres massico, cinzento, Bonito Superior

2. Gres schistoso . . . . . . . . . . . . . . . 0.30

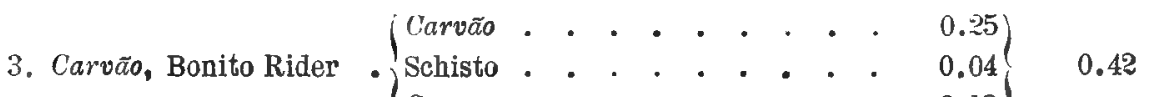

4. Argilla . . . . . . . . . . . . . . . . . . . 0.61

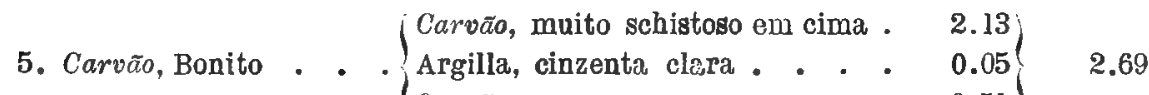

6. Schistos escuros. . . . . . . . . . . . . . . . . 0.69

7. Carvão schistoso . . . . . . . . . . . . . . . 0.25

Altitude a que está a base do carvão, 237,3 metros.

Cerca de 100 metros a nordeste da localidade do Bonito $\mathrm{n}$. II e a altitude de 251,6 metros, ou 14,3 metros mais alto que o n. II, existe um outro afforamento de carvão que se presumia antes representar uma camada em horisonte superior ao leito do Bonito, ao descobril' completamente esta camada, porém, se verificou que apresenta a mesma estructura que a Bonito e por isto a sua localidade foi denominada Bonito $N . V$ no mappa junto. Sua secrão e a seguinte:

2. Corvão, Bonito Rider. . . . . . . . . . . . . 0.10

3. Argilla . . . . . . . . . . . . . . . . 0.56 
About 1/2 kilometer distant from Escada and nearly south-west from same, is the Carangueijo exploration on the Bonito seam, where the following succession is exposed:

Meturs

1. Sandstune, massive, Upper Bonito. . . . . . . . . . . 15.24

2. Coal, thin, Bonito Rider. . . . . . . . . . . . 0.08

3. Shales, sandy, bluish . . . . . . . . . . . . 1.22

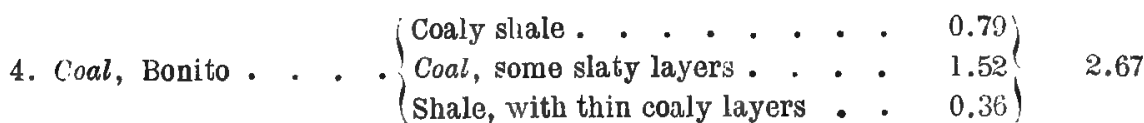

5. Clay visiblo. . . . . . . . . . . . . . . 0.15

Elevation hase ol Bonito coal, 266.4 meters.

Here the coal has a slight south-westward-rise due apparently to the great dike which crosses the measures near Bonito I.

Bonito II, which is about $3 / 4$ kilometer south-west from the locality of Bonito I, yields the following succession:

1. Sandstone, massive, gray, Upper Bonito. . . . . . . , $\begin{array}{r}\text { Meter's } \\ 3.05\end{array}$

2. Sandstone, shaly . . . . . . . . . . . . . . 0.30

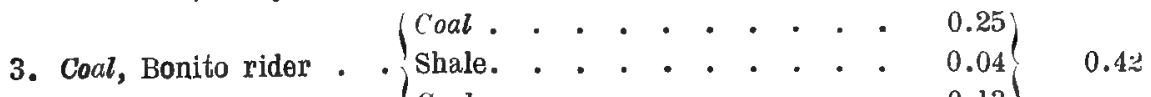

4. Clay . . . . . . . . . . . . . . . . . . . 0.61

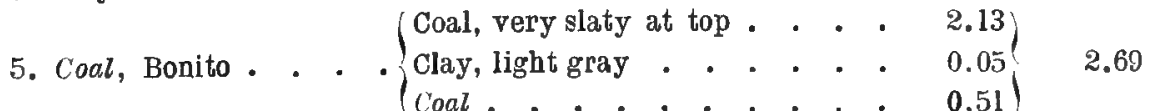

6. Shales, dark . . . . . . . . . . . . . . 0.6 !

7. Coal, slaty . . . . . . . . . . . . . . 0.25

Elevation, base of coal, 237.3 meters.

About 100 meters north-east from the locality of Bonito II and at an elevation of 261.6 meters, or 14.3 meters higher than No. II is another outcrop of coal which was formerly supposed to represent a bed lying above the Bonito seam. On opening up the same fully however, it proved to have the structure of the Bonito Jsed, and its locality has been termed Bonito No. $^{\text {to }}$ on the accompanying map. Its section is as follows:

Meter's

1, Sandstone, massive, Upper Bonito. . . . . . . . . . . 6.10

2. Coal, Bonito Rider. . . . . . . . . . . . . 0.10

3. Clay . . . . . . . . . . . . . . 0.56

5569 


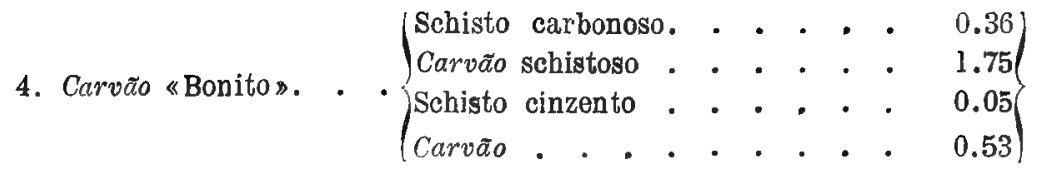

5. Argilla azul á vista. . . . . . . . . . . . . . . . 0.15

E' para notar que a camada principal tem essencialmente a mesma espessura nesta secção que na do Bonito $n$. II, e portanto, o leito deve ser o mesmo, devendo a differença de 14,3 metros em altitude ser attribuida á proximidade de um dique de diabase, cujo effeito é geralmente de produzir uma deslocação ou inclinações bruscas na sua visinhança immediata.

O rio Bonito fica a cerca de um kilometro a oeste da localidade da exploração do Bonito n. II, e ahi, na margem sul do rio, o Bonito n. III apresenta a seguinte successão:

1. Gres massiço, Bonito Superior........... Metros

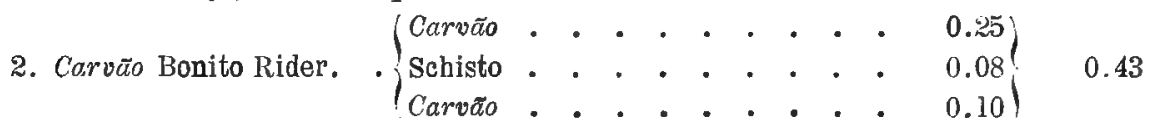

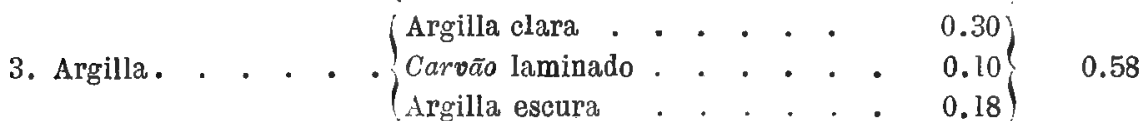

4. Carvão, Bonito, schistoso. . . . . . . . . . . . . 2.13

5. Argilla, escura e encoberta . . . . . . . . . . . 3.65

6. Gres massiço, Bonito inferior, visivel no leito do rio Benito . . . -

A altitudo a que está o carvão é de 226,2 metros, portanto, com um mergulho de 11,1 por kilometro a oeste do Bonito n. II.

O gres Bonito superior fórma um grande paredão ao longo das margens do rio neste ponto, ao passo que a gres Bonito inferior fór ma o leito do rio. o carvão está muito deteriorado pelo tempo e apresenta um aspecto laminado no seu affloramento, passando para baixo do nivel das aguas a cerca de 100 metros acima deste ponto.

O carvão do Bonito se eleva rapidamente para nordeste desde a localidade n. III e a 200 metros N. $15^{\circ}$. E. alcança 18 metros acima do rio Bonito, estando 212 metros mais alto que no $\mathrm{n}$. III, ou 238,2 acima do nivel do mar. Alli, na localidade de Bonito $n$. IV, se acha exposta a seguinte serie:

1. Gres massico, Bonito Superior. .......... Metros

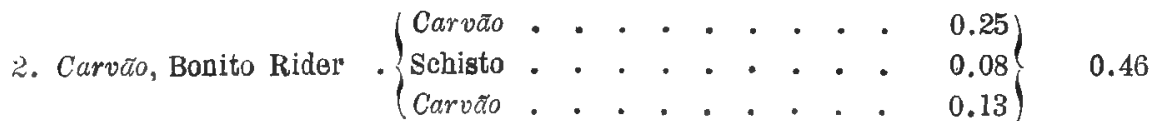




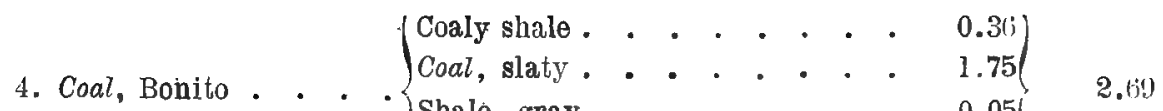

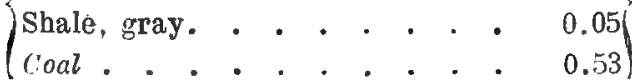

5 Clay, blue, visible.

It will be olsserved that the main lued has practically the same thickness and structure in this section as that shown at Bonito No. II, and hence they must be one and the same seam, the difference of 14.3 meters in elevation being due to proximity of a dike of diabase, the effect of which is generally to cause either a dislocation, or rapid dips in its immediate vicinity.

Rio Bonito is about one kilometer due west from the locality of the exploration at Bonito II and there on the soutl bank of the stream occurs the following succession at Bonito III :

Meters

1. Sandstone, massive, Upper Bonito. . . . . . . . . . . 15.24

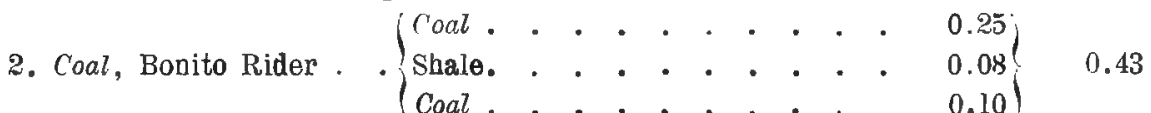

3. Clay. . . . . $\begin{array}{lllll}\text { Clay, light colored . . . . . } & 0.39 \\ \text { Coal, slaty . . . . . . } & 0.10 & 0.58\end{array}$

Clay, dark . . . . . . . . . 0.18$\}$

4. Coal, Bonito, slaty . . . . . . . . . . . 2.13

5. Clay, dark, aud concealed . . . . . . . . . . . . . 3.65

6. Sandstone, massive, Lotver Boniio, visible in bed of Rio Bonito. . -

Elevation of coal, 226.2 meters, thus giving a dip of 11.1 meters in the kilometer west from Bonito No. II.

The Upper Bonito sandstone makes a great cliff along the banks of the stream at this point, while the Lower Bonito floors the bed of the river. The coal is much weathered, and slaty looking at its outcrop and passes helow water level about 100 meters above this point.

The Bonito coal rises rapidly to the north-east from the locality of No. III, and 200 meters N. $15^{\circ}$ E. gels 18 meters alove Rio Bonito, and is 12 meters higher than at no. III, or 238.2 meters above tide. Here, at the locality of Bonito $\mathrm{lY}$, the following succession is exposed :

Meters

1. Sandstone, massive, Upper Bonito. . . . . . . . . . 16.70

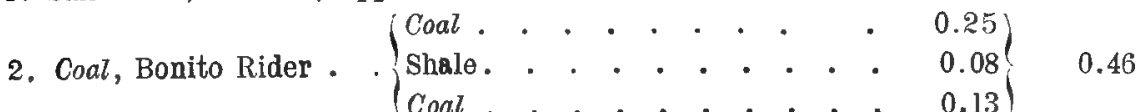


3. Argilla de côr clara . . . . . . . . . . . . . . . 0.48

4. Leito carbonoso. . . . . . . . . . . . . . . . 0.05

5. Schisto escuro . . . . . . . . . . . . . . . . 0.30

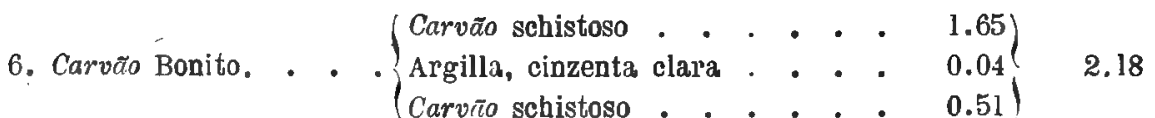

7. Encoberto até o Río Bonito. . . . . . . . . . . . 18.28

Tres Saltos, localidade assim denominada pelo Dr. Ramiro Barcellos, acha-se situada a cerca de um kilometro e $1 / 3$ ao norte do Bonito n. IV. Alli um corrego tributario do rio Passa Dois, desce em tres bellas cascatas sobre affioramentos dos gres Bonito, tanto superior como inferior, dando uma excellente exposição natural da camada de carvão Bonito com a seguinte secção :

1. Gres massico, Bonito superior, visivel $\quad 9.14$

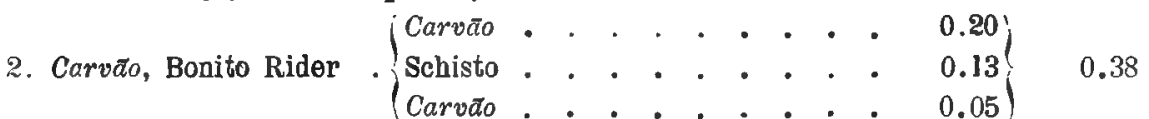

3. Argilla e schisto . . . . . . . . . . . . . . . 0.66

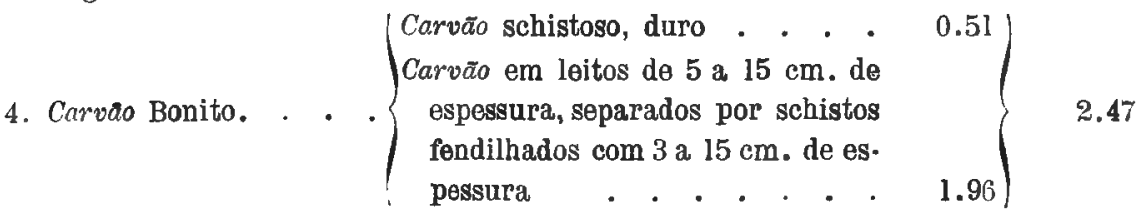

5. Argilla e schistos arenosos . . . . . . . . . . . . . 3.65

6. Gres Bonito inferior, cinzento, massiço atê o leito do corrego. . . 7.62

Altitude a que está o carvão Bonito, 252,5 metros.

A cerca de um kilometro e $1 / 3$ quasi ao norte de Tres Saltos ha um affloramento de carvão Bonito na Estrada Nova, distante dois kilometros e 1/4 da estação de Minas, com a seguinte secção abaixo da estrada.

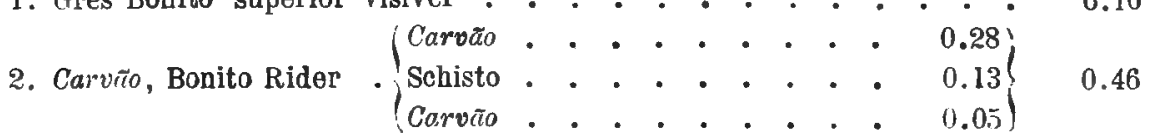

2. Argilla e schistos, cinzentos claros. . . . . . . . . . . 0.66

4. Carvão Bonito. . $\left\{\begin{aligned} \text { Carvão schistoso com divisões de } & \\ \text { schisto cinzento. . . . . } & 0.56 \\ \text { Carvão schistoso com algumas divi- } & \\ \text { sōes de schisto cinzento perto da } & \\ \text { base . . . . . . . . . } & 2.13\end{aligned}\right\} 2.69$

5. Argilla e schistos arenosos molles. . . . . . . . . . . . 3.65

6. Gres massiço cinzento com seixos massiços, Bonito inferior visivel . $\quad 9.14$ 


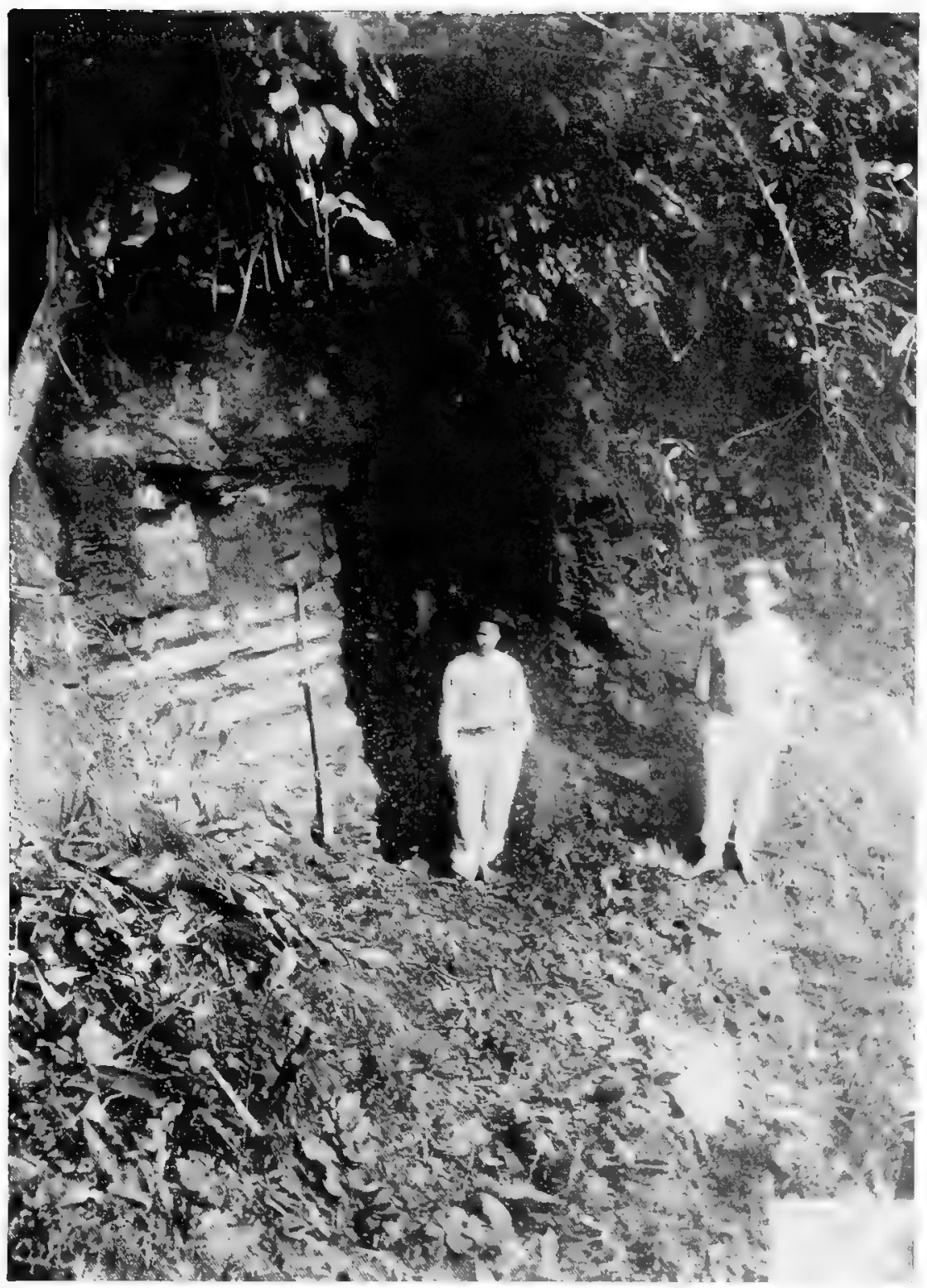

ESTADO DE SANTA (ATHARINA

Aftloramento "Tress Sultos" da camada de carraìn "Bonito" 

3. Clay, light colored. . . . . . . . . . . . . . . 0.48

4. Coaly layer . . . . . . . . . . . . . . . . 0.05

5. Shale, dark . . . . . . . . . . . . . . . . 0.30

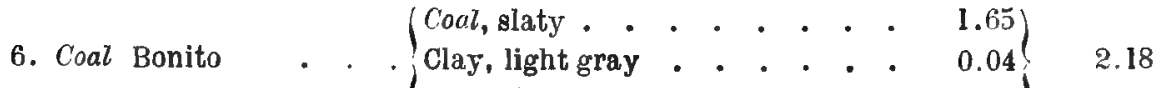

7. Concealsd to Rio Bonito. . . . . . . . . . . 18.28

Tres Saltos, a locality named hy Dr. Ramiro Barcellos, is about one kilometer and a third due north from Bonito IV. There a small stream tributary to Rio Passa Dois makes three beautiful cascades in passing over the outcrops of both the Upper and Lower Bonito sandstones, affording a fine natural exposure of the Bonito coal bed in the following section:

1. Sandstone, massive, Upper Bonito, visible

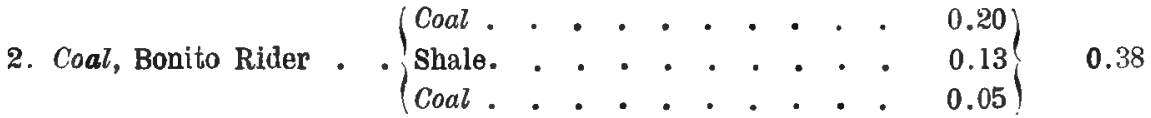

3. Clay and shale . . . . . . . . . . . . . . 0.66

4. Coal, Bonito . - $\left\{\begin{array}{l}\text { Coal, slaty, hard } \cdot . \cdot \cdot \cdot 0.51 \\ \text { Coal, in layers } 5 \text { to } 15 \mathrm{c} . \mathrm{m} \text {. thick } \\ \text { separated by block slates } 3 \text { to } 15 \\ \text { com thick }\end{array}\right\} 2.47$

5. Clay, and sandy shales . . . . . . . . . . . . . . 3.65

fi. Sandstone, Lower Bonito gray, massive to bed of stream. . . . . 7.62

Elevation of Bonito coal, 252.5 meters.

About one kilometer and a third nearly due north from Tres Saltos is the outcrop of the Bonito coal hed on the Estrada Nova two kilometers and a caurter from Minas station where it exhilits the following structure as it passes under the highway:

1. Sandstone, Upper Bonito, visible

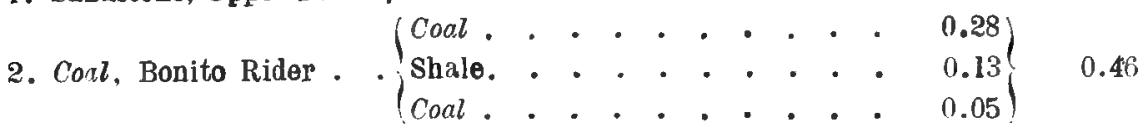

3. Clay and shales, light gray. . . . . . . . . . . . 0.66

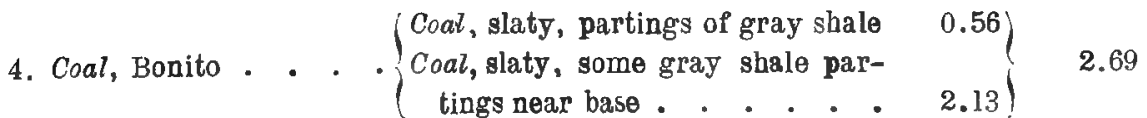

5. Clay and sandy shales, soft. . . . . . . . . . . . . 3.65

6. Sandstone, gray, pebbly, massive, visible, Lower Bonito . . . . . 9.14 
Altitude a que está o carvão Bonito n. VI, denominação dada a esta localidade no mappa, 280,7 metros.

A cerca de dois kilometros $\mathrm{S} .75^{\circ} \mathrm{W}$. desta ultima localidade ha um affloramento de carvão visivel no rio Tirịica, onde cahe sobre o gres do Bonito superior antes de se juntar ao rio Passa Dois. A camada Bonito não está toda exposta como se póde ver na seguinte secção :

1. Gres massiço, visivel, Bonito superior. . . . . . . . 10.66

2. Schistos carbonosos, pyritosos . . . . . . . . . . 0.15

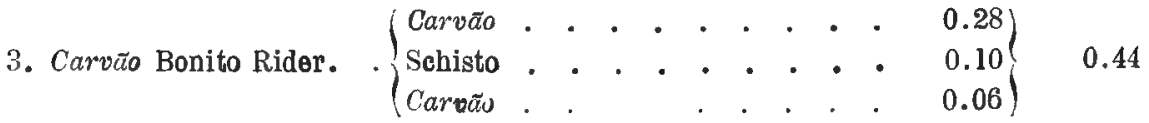

4. Argilla do côr clara . . . . . . . . . . . . . . 0.30

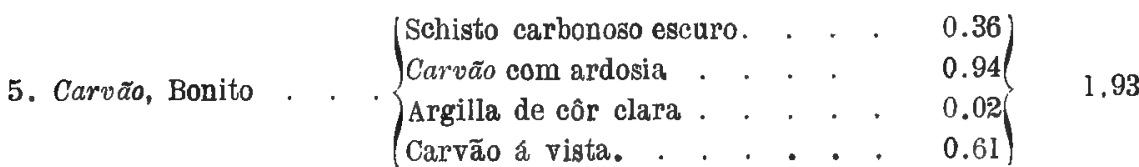

Altitude a que está o carvão, 239.7 metros.

No Barro Branco Velho foi feito um furo com sonda de diamante pela commissão do carvão, sob a superintendencia do Dr. Santos, tendo sido começado na base do leito do carvão Barro Branco. o carvão Bonito Rider foi alcançado á profundidade de 65 metros e a secção da camada Bonito, dada pelo Dr. Oliveira, que serve como chefe da Commissão de carvão, é a seguinte :

Metros

1. Carvão Barro Branco. . . . . . . . . . . . . . . . . -

2. Gres, schistos, etc. . . . . . . . . . . . . . . . . 65.00

3. Carvão, Bonito Rider. . . . . . . . . . . . . . . 0.32

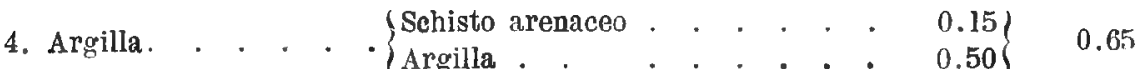

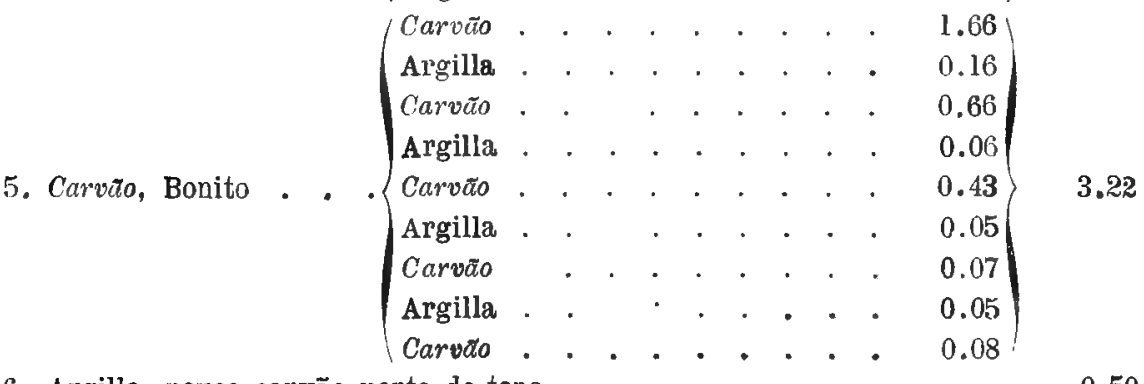

6. Argilla, pouco carvão perto do tope . . . . . . . . . . 0.50

7. Carvão . . . . . . . . . . . . . . . . . . . . 0.44

8. Schistos e gres até o fim da sondagem . . . . . . . . 3000 
Elevation of Bonito coal at Bonito $\mathrm{VI}_{\text {, }}$ as this locality is named on the map, 280.7 meters.

About 2 kilometers S. $75^{\circ} \mathrm{W}$. from the last locality, there is an outcrop of coal visible on Rio Tiririca where it falls over the Upper Bonito sandstone Jjefore joining Rio Passa Dois. Not all of the Bonito bed is exposed, as may be observed from the following section :

1. Sandstone, massive, visiblo, Upper Bonito . . . . . . . 10,60

2. Coaly shales, pyritous . . . . . . . . . . . . . 0.15

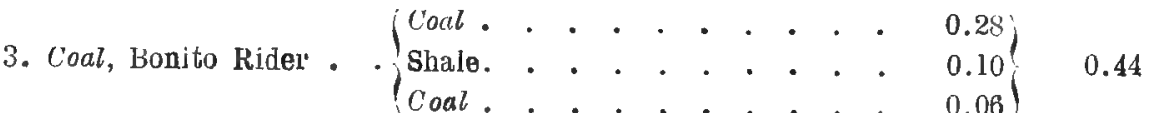

4. Clay, light colored. . . . . . . . . . . . . . . 0.30

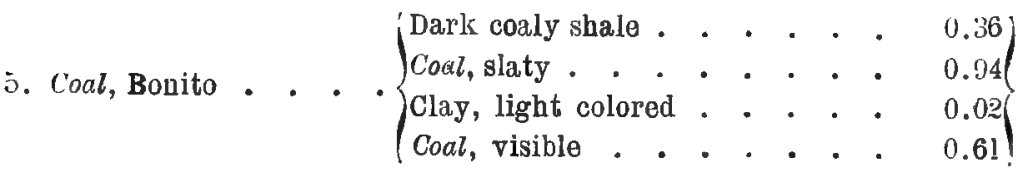

Elevation of coal, 239.7 meters.

At Barro Branco Velho, a diamond drill hole was sunk by the Coal Commission under the supervision of Dr. Santos, beginning at the J ase of the Barro Branco coal bed. The Bonito rider coal was struck at a depth of 65 meters and the section through the Bonito hed as given Jy Dr. Oliveira, acting Chief of the Coal Commission, is as follows:

1. Barro Branco Coal.

Melers

2. Sandstone, shale, etc.

65.00

3. Coal, Bonito Rider. . . . . . . . . . . . . 0.32

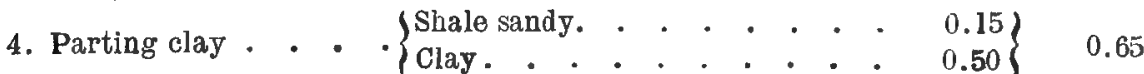

$\left(\begin{array}{lllllllllll}\text { Coal } . & \cdot & \cdot & \cdot & \cdot & \cdot & \cdot & \cdot & \cdot & \cdot & 1.66 \\ \text { Clay } \cdot & \cdot & \cdot & \cdot & \cdot & \cdot & \cdot & \cdot & \cdot & \cdot & 0.16 \\ \text { Coal } \cdot & \cdot & \cdot & \cdot & \cdot & \cdot & \cdot & \cdot & \cdot & \cdot & 0.66 \\ \text { Clay } \cdot & \cdot & \cdot & \cdot & \cdot & \cdot & \cdot & \cdot & \cdot & \cdot & 0.06\end{array}\right)$

5. Coal, Bonito.... Coal........ . . 0.43$\}$

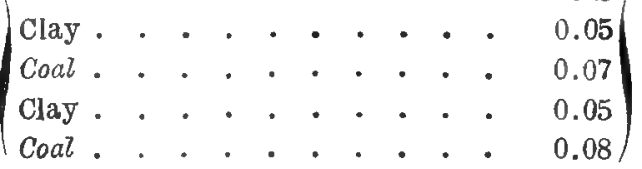

6. Clay, streak of coal near top. . . . . . . . . . . . 0.50

7. Coal . . . . . . . . . . . . . . . . . . . . 0.44

8. Shales and sandstone to bottom of boring . . . . . . . 30.00 
A camada de carvão, como se vê, tem muito da estructura que se nota em Capoeira e em dois ou tres outros pontos, o pequeno leito rider está presente como de costume sobre a camada principal de carvão, bem como a pequena camada que ás vezes se apresenta a cerca da mesma distancia abaixo do leito principal. O Dr. Oliveira diz que cerca de tres metros de carvãu é relativamente puro.

As unicas plantas fosseis observadas em relação com o carvão do Bonito são alguns fragmentos de hastes e megasporos que o Dr. David White pensa que devem ser de Sigillarias.

\section{Os gres Bonito, superior e inferior}

Estes são nomes locaes dados aos dois grandes affloramentos de gles que se apresentam na região de Minas, a curta distancia acima $e$ abaixo do carvão do Bonito. O gres Bonito inferior contem frequentemente seixos brancos cinzentos, algum tanto feldspathicos, sempie massiço, produzindo geralmente rapidos e cachoeiras nas correntas.

o gres Bonito superior è tambem muito massiço, grosseiro e tambem feldspathico, tendo muitas vezes uma côr cinzenta amarellada e como o inferior fórma escarpas verticaes em torno das montanhas e cachoeiras nas correntes. Nenhuma destas camadas foi identificada além da região de Minas.

\section{Carvão Ponte Alta}

Nos affloramentos ao longo da Estrada Nova, acima do local du Bonito $\mathrm{n}$. IV, e 18 metros mais alto $(298.5 \mathrm{~m}$.), afflora, em alguns metros, uma camada fina de carvão com 20.25 centimetros de espessura. A distancia vertical do Bonito a esta é de menos de 18 metros, visto que as camadas se elevam rapidamente entre o affloramento desta e do carvão do Bonito. Seu horisonte está a cerca de dois metros acima do gres Bonito Superior.

Acerca de tres kilometros ao sul da estação de Minas foi explorada em pequena escala uma camada de carvão em um corrego tributario do rio Ponte Alta que se suppõe pertencer ao mesmo horisonte que a pequena camada de carvão da Estrada Nova, e por isto a camada foi designada carvão Ponte Alta. Tem a seguinte estructura na seç̧ão em sua localidade typica, perto do rio Ponte Alta:

2. Schisto . . . . . . . . . . . . . . . . . . 0.05 
The coal Jued, as may be observed has very much the structure shown at Capoeir a and two or three other points, the little "rider" bed being present as usual above the main coal, as well as the small seam which sometimes occurs at about the same distance below the main bed. Dr. Oliveira reports that about 3 meters of the coal is comparatively pure.

The only fossil plants observed in connection with the Bonito coal are some fragments of stems, and megaspores which Dr. David White thinks may be of sigillarian origin.

\section{The Upper and Lower Bonito sandstone}

These are local names given to the two great sandstone ledges which in the region of Minas occur at short intervals above and below the Bonito coal. The Lower Bonito Sandstone is frequently pebbly, grayish-white in color somewhat feldspathic, always massive, and generally makes rapids and cascades in the streams.

The Upper Bonito Sandstone is also quite massive, rather coarse, and also feldspathic, often having a yellowish-gray color, and like the lower one makes vercical cliffs around the hills and cascades in the streams. Neither of these beds has been identified bejond the region of Minas.

\section{Ponte Alta Coal}

In the exposures along the Estrada Nova, on above the locality of Bonito No. VI, and 18 meters higher $(298.5 \mathrm{~m}$.), a thin coal, 20-25 centimeters in thicliness, crops for several meters. Its vertical interval above the Bonito coal is less than 18 meters, however, since the strata rise rapidly betwean its crop and that of the Bonito coal. Its horizon is about 2 meters above the Upper Bonito Sandstone.

Alout 3 kilometers nearly due south from Minas station, a coal bed has heen exploited to a small extent on a little stream triluatar: to Rio Ponte Alta which is supposed to belong at the same horizon as the little coal on Estrada Yova, and hence the bed has Jemn designated the Ponte Alta coal. It has the following structure in the section at its type locality near Rio Ponte Alta:

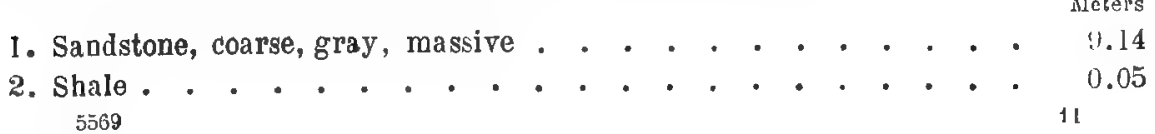




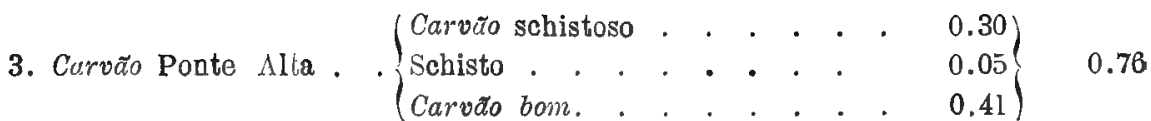

4. Argilla e schistos .. . . . . . . . . . . . . . 1.22

5. Gres massiço visivel . . . . . . . . . . . . . 7.62

Altitude a que está o carvão, 20 's metros.

A analyse do carvão desta localidade é dada em outra pagina deste relatorio.

O Dr, Luiz Philippe Gonzaga de Campos refere que foi feita uma sondagem perto de Ponte Alta que atravessou a seguinte serie, segundo informação verbal que teve:

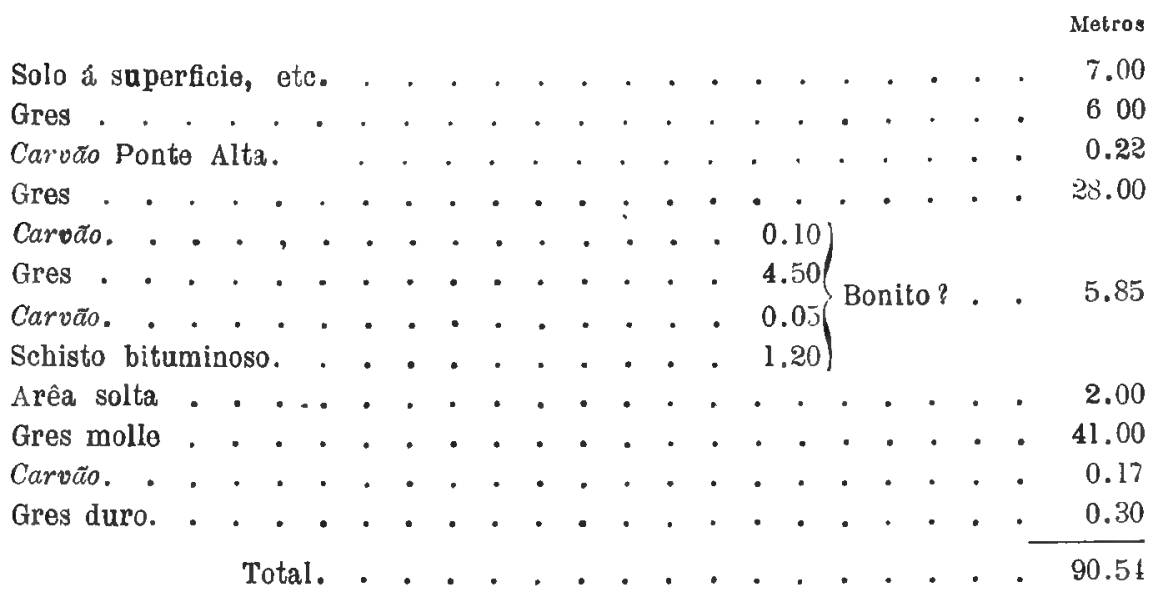

o carvão a 13 metros é provavelmente a camada Ponte Alta, ao passo que o de 41,22 a 47.07 deve representar a camada Bonito.

E' possivel que seja esta mesma camada que afflora na margem sul do rio Oratorio, dois kilometros abaixo da embocadura do rio do Rasto e a 15 kilometros a nordeste de Minas. Seu affloramento se mostra alli parcialmente exposto e parece ter 60 centimetros de espessura, tendo uma fina camada de schisto cinzento perto do centro. Foi explol'ada apenas em pequena extensão.

\section{Schistos fossiliferos com plantas}

Ia plantas fosseis nos schistos escuros que estão superpostos á camada de carvão Ponte Alta em alguns metros, ao longo da Estrada Nova, perto de Minas á altitude de 300.36 metros acima do nivel do mar, como foi determinado pelo Dr. Seixas. 


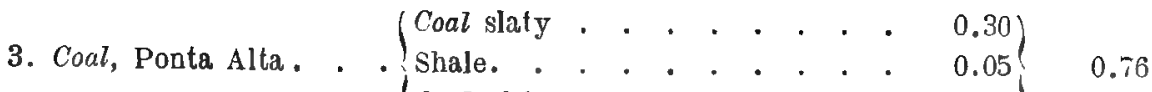

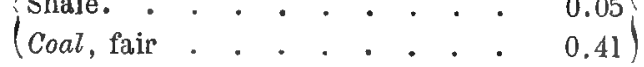

4. Clay and shales. . . . . . . . . . . . . . . . . . 1.22

5. Sandstone, massive visible . . . . . . . . . . . . 7.62

Elevation of coal, 204 meters.

The analysis of the coal from this locality is given on another page of this report.

Dr. Luiz Felippe Gonzaga de Campos reports that a boring was once made near Ponte Alta, which encountered the following succession, according to a verbal statement made to him:

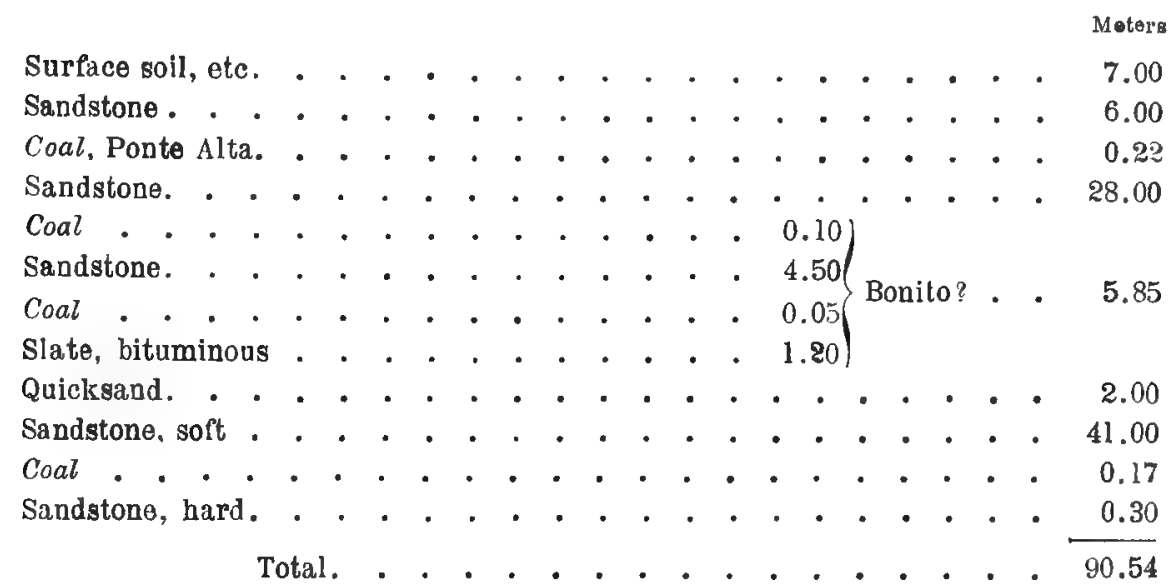

The coal at 13 meters is most probably the Ponte Alta seam, while that at 41.22 to 47.07 may be the representative of the Bonito bed.

It is possibly this same bed which crops on the south bluff of Rio Oratorio, 2 kilometers below the mouth of Rio do Rasto and 15 kilometers north-east from Minas. Its crop is there partially exposed, and appears to be about 60 centimeters thick with a thin gray shale near the center. It has been exploited to only a small extent.

\section{Fossiliferous plant shale}

Fossil plants occurin the dark shales which overlie the Ponte Alta coal bed by a few meters along the Estrada Nova, near Minas, at an altitude of 300.36 meters above sea level, as determined by Dr. Seixas. 
Foi feita uma pequena collecção de especimens, nesta Iocalidade, entre as quaes o Dr. David White determinou as segintes especies:

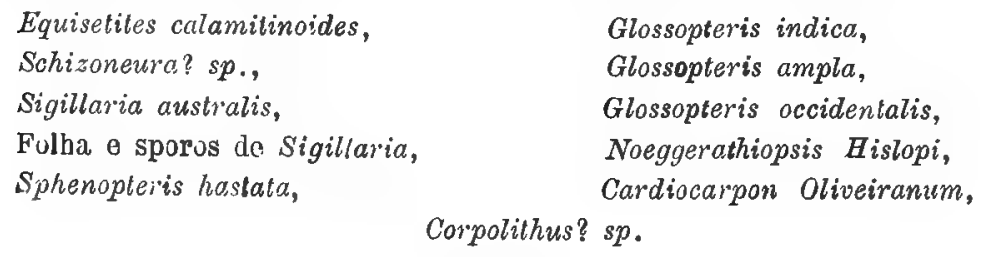

\section{Caṛão Irapuà}

Nos barrancos ingremes do rio Irapuá, perto da fazenda do Dr. Ramiro Barcellos, no Rio Grande do Sul, foi excavada uma pequena camada de carrão schistoso com 40 a 50 centimetros de espessura, a cerca de oito metros abaixo do que se suppõe representar a divisão inferior do carvão $\mathrm{S}$. Jeronymo, ou horizonte Barro Branco da região das Minas.

o carvão não parece ser de importancia economica em nenhuma localidade dentro de todo o districto carbonifero, visto que não alcança espessura commercial. As duas camadas de carvão encontradas nas sondagens I, II e III perto do poço Fé da Companhia S. Jeronymo, á profundidade de 15 a 20 metros abaixo do tope da camada de carvão $\mathrm{S}$. Jeronymo, representam provavelmente este horizonte, ao passo que na sondagem profunda em Xarqueadas seria representado pelo carvão encontrado a 284 metros, com 60 centimetros de espessura, a 15.60 abaixo da base do carvão S. Jeronımo.

\section{Schisto Irapuá com plantas fosseis}

No tope do carvão Irapuá, da localidade tỵpica do Rio Grande do Sul, acima descripta, encontram-se numerosos restos de plantas fosseis em um schisto areento, ou gres schistoso.

São principalmente da mesma especie que occorrem nas camadas Rio Bonito de Santa Catharina, não sendo entretanto, a variedade tão grande. As seguintes especies de Irapuá foram determinadas pelo Dr. David White :

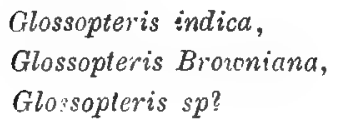

\author{
Noeggerathiopsis Hislopi, \\ Ottokaria ovalis, \\ Cardiocarpon Barcellosum.
}


A small collection of specimens was made at this locality among which Dr. David White has identified the following species :

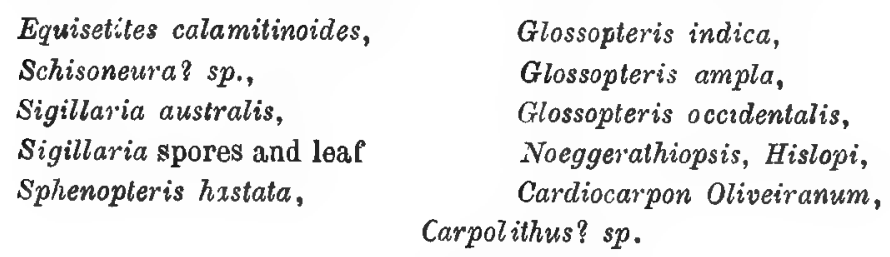

\section{Irapuá cjal}

On the steep Jluffs of Rio Irapuá near the fazenda of Dr. Ramiro Barcellos in Rio Grande do Sul, a small slaty coal, 40 to 50 centimeters in thickness, has been opened about 8 meters below what is supposed to represent the lower division of the S. Jeronymo coal or Barro Branco horizon of the Minas region.

The coal does not appear to be of economic importance at any locality within the entire coal field, since it does not attain to commercial size. The thin streaks of coal encountered in the borings I, II and III near Poço Fé, of the S. Jeronymo Company at a depth of 15 to 20 meters below the top of the S. Jerony mo coal bed, prohally represent this horizon, while in the deep Joring at Xarqueada, it would be represented by the coal struck at 284 meters, and 60 centimeters in thickness 15.60 meters below the base of the S. Jeronymo coal.

\section{Irapuá fossil plant shale}

In the roof of the Irapua coal, at the type locality as ahove described in Rio Grande do Sul, there occur numerous remains of fossil plants, in a sandy shale, or shaly sandstone.

They are principally of the same species occurring in the Rio Bonito Beds of Santa Catharina, although the variety is not so large. The following species have been identified by Dr. David White from the Irapuá locality :

$\begin{array}{ll}\text { Glossopteris indica, } & \text { Noeggerathiopsis Hislopi, } \\ \text { Glossopteris Brovniana, } & \text { Oltokaria ovalis, } \\ \text { Glossopteris sp?, } & \text { Cordiocarpon Barcellosum, }\end{array}$


Na secção ao longo da Estrada Nova, perto de Minas, em Santa Catharina, ha uma delgada camada de carvão (10 centimetros) com fragmentos de plantas fosseis no tope, 329.2 metros acima do nivel do mar, immediatamente abaixo de um gres massiço branco cinzento, e 10 metros abaixo do carvão Barro Branco. Este deve representar o horizonte do carvão do Irapuá do Rio Grande do Sul, mas as plantas fosseis estão demasiadamente fragmentadas para serem determinadas.

\section{Gres Barro Branco Inferior}

Ha entre a pequena camada de carvão que vem de ser mencionada e o carvão (Barro Branco), logo acima, em toda a região de Minas, um gres molle, ás vezes quasi branco, excepto onde é manchado pelo ferro. Contem menos material feldspathico que qualquer outro membro da serie e occasionalmente é bastante puro para constituir uma arêa de boa qualidade para vidros de vidraça e garrafas communs, especialmente lavada. Forma um affloramento conspicuo ao Iongo da Estrada Nova (estrada do rio do Rasto) logo abaixo do cume da montanha a 2.2 kilometros a noroeste de Minas .

\section{Schist, com plantas fosseis}

No tope do gres Barro Branco inferior e sotoposto ao carvão ha um schisto escuro que contem plantas fosseis, no ponto em que está exposto em uma volta do caminho na Estrada Nova a $31 / 4$ kilometros de Minas e á altitude de 338 metros acima do nivel do mar.

Foram colligidas neste horizonte as seguintes especies, segundo as determinações do Dr. David White:

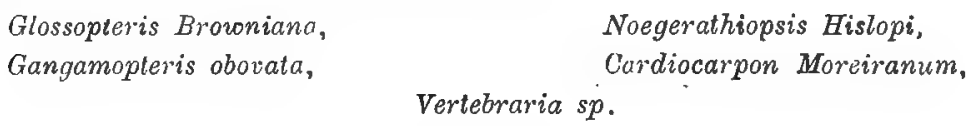

\section{Carvão Barro Branco}

A pequena distancia abaixo do tope das camadas Rio Bonito e interposta a dois estratos de gres, Barro Branco superior e inferior, se apresenta a camada de carvăo de mais valor e mais largamente persistente da serie, que pelo facto de ser geralmente dividida em duas partespor argilla branca, foi denominada camada Barro Branco. 
In the section along the Estrada Nova near Minas, Santa Catharina, a thin (10 centimeters) coal with fragments of fossil plants in its roof, occurs at 329.2 meters above sea level, immediately under a massive grayish-white sandstone, 10 meters jelow, the Barro Branco coal. This would represent the Irapuá coal horizon of Rio Grande do Sul, but the fossil plants are too fragmentary for identification.

\section{Lower Barro Branco sandstone}

Lying between the little coal bed just mentioned, and the coal (Barro Branco) next above, there occurs throughout the Minas region a rather soft sandstone, sometimes almost white ịn color, except where stained with iron. It contains less feldspathic material than any other member of the series, and occasionally is pure enough to make a fair quality of sand for window glass and ordinary bottles, especially if washed. It makes a conspicuous outcrop along the Estrada Nova, just below the crest of the hill, 2.2 kilometers north-west from Minas.

\section{Fossil plant shale}

Immediately on top of the Lower Barro Branco sandstone and underlying the coal next above, there is a dark shale which holds fossil plants where exposed at the turn of the road on the Estrada Nova $31 / 4$ kilometers from Minas, and at an elevation of 338 meters above sea level. From this horizon the following species were collected, as identified by Dr David White :

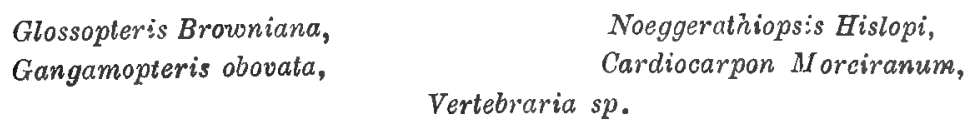

The Barro Branco coal

At a short interval below the top of the Rio Bonito Beds, and intercalated between two strata of sandstone, the Upper and Lower Barro Branco sandstones, there comes the most valuable, and widely persistent coal seam of the series which, from the fact that it is generally separated into two divisions by white clay, has been termed the Barro Branco bed. 
Este estrato parece ser o horizonte em que foi pela primeira vez descoberto carvão em Santa Catharina.

o Visconde de Barbacena primeiro concessionario deste districto mineiro forneceu-me o seguinte historico da primeira descoberta de carvão em Santa Catharina, por alguns caçadores, na primeira metade do secula passado.

Os caçadores que tinham acampado perto do presente local da mina Barro Branco Vello, collocaram algumas pedras de aspecto negro (como julgavam) como apoio de uma panella em que estavam cozinhando carne. Com grande espanto destes as pedras pegaram fogo e arderam.

0 visconde de Barbacena, ao ser-lhe narrado o facto por um dos caçadores, reconheceu immediatamente, familiarizado como era com o combustivel pela sua longa residencia na Inglaterra, que se tratava de pedaços de carvão e não de simples pedras pretas communs, não perdeu tempo em visitar a região, para confirmar sua supposição e adquirindo uma concessão de cerca de 14 kilometros quadrados.

Com essa concessão, elle formou um syndicato de capitalistas inglezes para explorar o carvão e leval-o ao mercado em uma via ferrea (D. Thereza Christina) construida por outro sindicato inglez, de Laguna e de Imbituva a Minas. Como aquella primeira tentativa de exploração do districto carbonifero de Tubarão falhou devido a extravagancia e desaso dos chefes de serviço, é uma velha historia na região de Minas.

Foi na camada Barro Branco que o syndicato iniciou os trabalhos de exploração no local denominado Barro Branco Novo, no mappa detalhado da região, a 3 kilometros do ponto terminal da estrada de ferro, e separado deste por alta montanha cujo cimo é conhecido por Boa Vista.

o carvão era transportado por aquella montanha acima, por uma estrada de ferro de cabo, de rampa suave e arriado pela fralda éste da montanha, por meio de um outro cabo por uma encosta mais ingreme, atẻ a estação da estrada de ferro de Minas.

o carvão foi mal minado sem que se fizesse a minima tentativa para purifical-o, ou libertal-o dos schistos e refugo. Com tão grandes despezas para levar o carvão até os vagões e até bordo dos vapores em Imbituba a palavra fallencia estava francamente escripta nos portaes ta mina desde o começo, pois que, diz-se que o primeiro carregamento de carvão embarcado para Buenos Ayres que custara 25\$ a tonelada apenas deu $6 \$$ no mercado. 
This stratum appears to have been the horizon at which coal was first discovered in Santa Catharina.

Visconde de Barbacena, the original concessioner of this mining district, gave me the following account of the first discovery of coal in Santa Catharina by a party of hunters, in the first half of the past century.

The hunters, who were camping near the present site of Barro Branco Velho mine, had placed some black-looking stones (as they supposed) for supports under a kettle in which some meat was being cooked.

To their great surprise the ston'es took fire and burned. Viscount Barbacena, to whom the story was related by one of the party, and who had become familiar with coal from his long residence in England, at once recognized the description as lumps of coal instead of ordinary black. stones, and lost no time in visiting the locality, confir.. ming his suspicions, and acquiring a concession of land about 14 kilo. meters square.

Upon this concession, he formed a syndicate of English capitalists to exploit the coal, and market the sameover a railroad (Dona Theresa Christina) built by another English syndicate from Laguna, and Imbituba to Minas. How that first mining entẹprise in the Tubarão coal field failed through the extravagance, and mismanagement of the chief officers, is an old story in the Minas region.

Barro Branco bed is the one upon which mining operations were begun by the English syndicate, at the locality shown as Barro Branco Novo on the accompanying detailled map of the region, 3 lilometers distant from the terminus of the railroad, and separated from it by a high ridge, the summit of which is known as Boa Vista.

The coal was transported up this ridge by wire cable over a long gently inclined railway and lowered on the eastern side of the ridge by another cable over a much steeper slope to the Railvay Station at Minas.

The coal was badly mined, with no attempt to purify, or free it from slate, and refuse. With so much expense incurred to place the coal upon tho cars, and on board steamers at Imbituba the word "failure" was written large over the portals of the mine from the beginning, since it is reported that the first cargo of coal shippt ed to Buenos Ayres, which had cost 25 milreis per ton, broughonly 6 in the coal market. 
A seguinte secção foi medida na bocca da mina abandonada em Barro Branco Novo:

1. Gres, Barro Branco Superior . . . . . . . . . . .

2. Schisto . . . . . . . . . . . . . . 0.15

3. Schisto carbonoso . . . . . . . . . . . . . . . . . 0.08

4. Schisto cinzento . . . . . . . . . . . . . . . . . 0.15

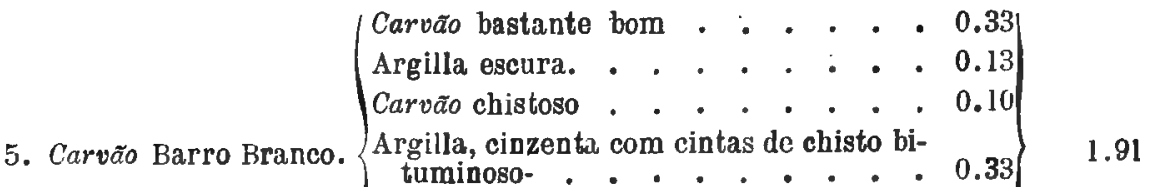
Argilla de cor clara. $\cdot$ - : $\cdot$ -
Carva com $0^{2 n}, 10$ de argilla perto do centro, á vista. . . . . . 0.61

Altitude a que está o carvão 266 metros.

Esta secção mostra francamente um metro de carvão aproveitavel e me disseram, que se torna um pouco mais espesso na mina que estava cheia dagua e onde não se podia entrar quando alli estive. Comtudo o melhor carvão n. 2 do tope disseram que não foi explorado. Esta mina está perto de um pequeno corrego que desagua no rio Ponte Alta. As analyses do carvão Barro Branco desta e de outras localidades serão dadas em um outro capitulo deste relatorio.

A cerca de um kilometro a sudoeste do Barro Branco Novo está o Barro Branco Velho onde foi pela primeira vez explorado o carvão. Este está tambem, perto de um tributario do rio Ponte Alta e a bocca da mina está mesmo acima do nivel d'agua. Foi extrahida grande quantidade de carvão deste para uso local e para ser embarcado como amostra do combustivel.

A secrão á loocca da mina apresenta a seguinte successão:

1. Gres branco acinzentado, Barro Branco superior . . . . . .

Motros

2. Schistos pretos bituminosos . . . . . . . . . . . .

3. Camada carbonifora . . . . . . . . . . . . . . . .

4. Argilla de cor clara . . . . . . . . . . . . . . . .

(Carvão . . . . . . . . . . . . . 0.33

0.15

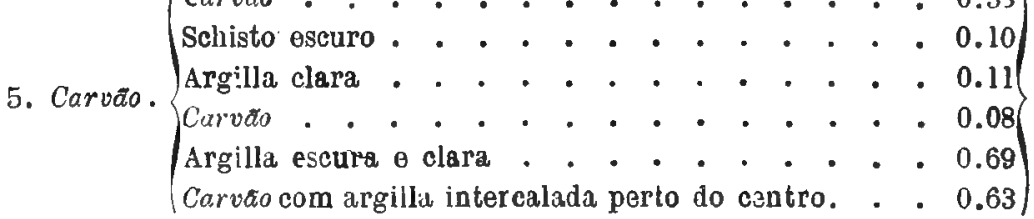


The following section was measured at the mouth of the abandoned mine at Barro Branco Novo:

1. Sandstone, Uppør Barro Branco.

Meters

2. Shale . . . . . . . . . . . . . . . . . . 0.15

3. Coaly shale . . . . . . . . . . . . . . . 0.08

4. Shale, gray. . . . . . . . . . . . . . . 0.15

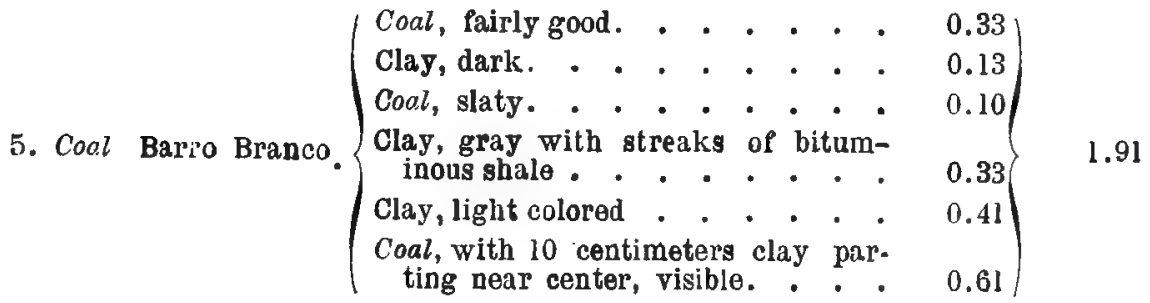

Elevation of coal, 266 meters.

This section shows practically one meter of available coal, and it is reported to have thickned up some in the mine which was filled with water, and could not be entered at the time of our visit. The best coal, however, n. 2 at the top, it is said, was not taken down at all. This mine is near the head of a small brook which empties into Rio Ponte Alta. Analyses of the Barro Branco coal at this, and other localities will be given in another portion of this report.

About one kilometer south-ivest from Barro Branco Novo, is Barro Branco Velho where the coal was first exploited. This is also on a tributary of Rio Ponte Alta, and the mouth of the mine is just above water level. A considerable quantity of coal has been mined there for local use, and for shipment as samples of the fuel.

The section at the mouth of the mine reveals the following succession :

Meters

1. Sandstone, grayish-white, Upper Barro Branco . . . . . . . . 9.14

2. Shalce, dark, bituminous. . . . . . . . . . . . . 0.18

3. Coaly layer . . . . . . . . . . . . . . . . 0.05

4. Clsy, light colored . . . . . . . . . . . . . . . 0.15

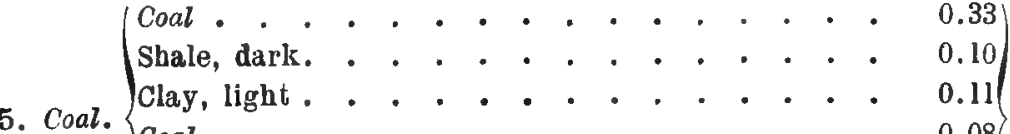

Coal . . . . . . . . . . . 0.08$\}$

Clay, dark and light . . . . . . . . . . 0.69

Coal, with clay parting near center . . . . 0.63 ) 
Outra secção tomada na face do carvão no fundo da galeria principal cerca de 75 metros distante da bocca da mina dá praticamente o mesmo resultado que se viu acima.

A altitude a que está a lapa do carvão em Barro Branco Velho é de 239.1 metros acima do nivel do mar segundo o Dr. Seixas.

A cerca de 200 metros a sudeste do Barro Branco Vèlho e 11.1 metros maịs baixo $(228 \mathrm{~m}$.) foi explorado um carvão sob um paredão de gres (Barro Branco superior) que parece ser identico ao carvão Barro Branco. A. secção nesta localidade denominada no mappa Barro Branco II, é a seguinte :

1. Gures branco massiço . . . . . . . . . . . . . . 9.14

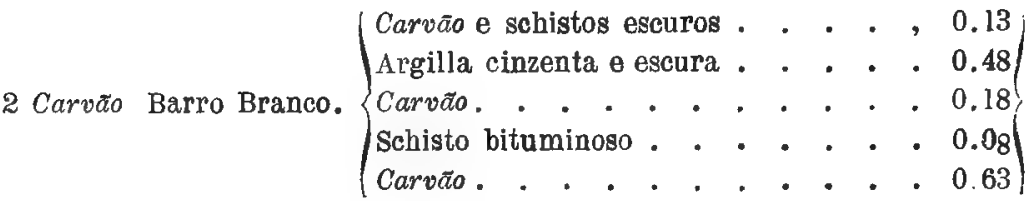

3. Argilla á vista. . . . . , . . • . . . . . . • . . 0.15

o carvão da base tem boa apparencia nesta localidade, ao passo que o do tope torna-se muito delgado.

A cerca de um kilometro ao sul do Barro Branco Velho está Carahá a $228 \mathrm{~m}$. acima do nivel do mar, onde foram feitas, ha alguns annos explorações em busca de carvão. Actualmente apenas se veem 30 centimetros de carvão e a porção superior deste é muito pyritosa.

O Dr. Gonzaga de Campos diz que o carvão tem 50 centimetros de espessura, com uma porcão central de schisto, sendo a parte central daquelle mais pura e os ferreiros delle gostam. Abaixo do carvão veem 70 centimetros de argilla escura e depois gkes duro. Os depositos da superficie encobrem o tope do carvão.

Outrora foi cavado um poço nesta localidade e dizem que foi encontrada á profundidade de 28 metros uma camada de carvão com $3.80 \mathrm{~m}$. de espessura.

Tijuco Preto é uma localidade a 200 metros a sudoeste do Barro Branco Novo onde foi ha tempo cavado um poço pouco profundo em busca da camada de carvão Barro Branco. Foram tomadas as seguintes medidas no velho poço:

Metros

1. Arêa da superficio e baueders . . . . . . . . . . . . 3.31

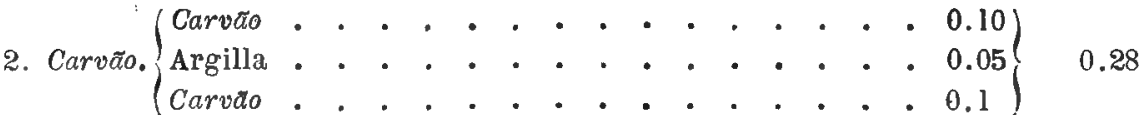

3. Argilla cinzenta até o fundo do poço. . . . . . . . . . 0.41 
Another section taken from the face of the coal at the head of the main entry about 75 meters distant from the mouth of the mine, gives practically the same result as that shown above.

The elevation of the bottom of the coal at Barro Branco Velho is 239.1 meters above sea level according to Dr. Seixas.

About 200 meters south-east from Barro Branco Velho, and 11.1 meters lower (228 m.), a coal has been explored under a cliff of sandstone (Upper Barro Branco) which appears to be identical with the Barro Branco coal. The section at this locality termed Barro Branco II on the map is as follows:

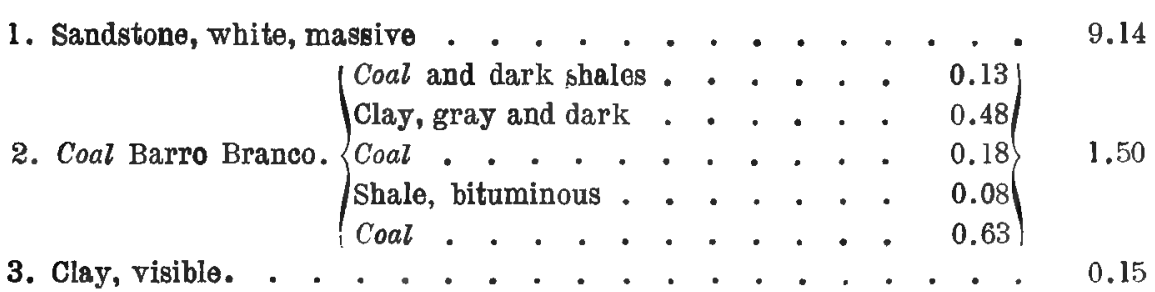

The bottom coal has a fair appearance at this locality while the top member has thinned away very much.

About one kilometer nearly due south from Barro Branco Velho is Caraha, 228 meters above sea level, where explorations were made for coal, several years ago. At the present time only 30 centimeters of coal can be seen, and the upper portion of that is very pyritous.

Dr. Gonzaga de Campos states that the coal is 50 centimeters in thickness, with a middle parting of slate, the upper half being purer, and prized by the smiths. Belorv the coal comes dark clay 70 centimeters thick and then hard sandstones, surtace deposits conceal the top of the coal.

A shaft was once sunk here and it is reported that at a coal 3.80 meters in thickness was found at a depth of 28 meters.

Tijuco Preto is a locality 200 meters south-east from Barro Branco Novo where a shallow shaft was once sunk for the Barro Branco coal. The following measurements were made in the old pit:

1. Surface sand and boulders . . . . . . . . . . . 3.84

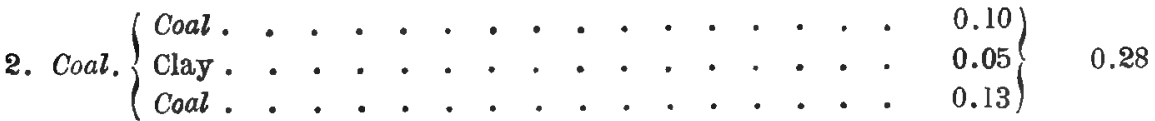

3. Clay, gray to bottom of shaft . . . . . . . . . 0.41 
Altitude a que está o carvão nesta localidade 249.1 metros, on $16.9 \mathrm{~m}$. mais baixo que o carvão no Barro Branco Novo (266). Visto que o mergulho é bastante rapido para sudeste em Barro Branco Novo, não pode haver duvida que o carvão encontrado em Tijuco Preto é a porção superior da camada Barro Branco.

Esta camada de carvão está exposta em um córte da Estrada Nova no cimo da montanha 3 kilometros distante de Minas e 338.2 metros acima do nivel do mar, sendo porem, alli fino como se vê na secção geral dada em pagina anterior. A excavação das cabeceiras do Rio Pequeno foi feita provavelmente neste mesmo carvão, a $71 / 2$ kilometros de Minas perto da Estrada Nova e a 334 metros acima do nivel do mar.

No rio Passa Dois, meio kilometro a oeste da embocadura do rio Carvão, este carvão mergulha até perto do nivel d'agua a $268.9 \mathrm{~m}$. acima do nivel do mar.

Nesta localidade um derrame de diabase penetrou horisontalmente entre dois estratos dos que estão superpostos ao carvão e no barranco a prumo da margem esquerda da corrente está patente a seguinte serie :

Metios

1. Gres massiço, tornado vermelho pelo calor da rocha eruptiva sotoposta . . . . . . . . . . . . . . . . . 4.57

2. Schistos escuros e carbonosos, Pragmentarios . . . . . . . 0.66

3. Diabase . . . . . . . . . . . . . . . . . 1.57

4. Conglomerato massa de schisto, argilla e diabass decomposta . . . 0.23

5. Schisto escuro, plantas fosseis. tornadas anthraciticas pelo calor . . 0.13

6. Argilla azul escura . . . . . . . . . . . . . 0.20

7. Carvão inpuro . . . . . . . . . . . . . . . 0.15

8. Schisto escuro . . . . . . . . . . . . . . . 0.20

9. Schistos azues . . . . . . . . . . . . . . . 0.15

10. Argilla azul clara, . . . . . . . . . . . . . 0.28

11. Carvăo bom. . . . . . . . . . . . . . . . . 0.18

12. Argilla escura . . . . . . . . . . . . . . . . 0.08

13. Carvẵo bom. . . . . . . . . . . . . . . . . . . 0.28

14. Carvão schistoso . . . . . . . . . . . . . . . . . 0.15

15. Gres massiço . . . . . . . . . . . . . .

A intrusăo da cliabase produziu apparentemente aqui a ruptura e discontinuidade do banco superior de carvão, visto que os ns. 11 a 14 representam a estructura typica do banco inferior.

o carvão Barro Branco parece se elevar do Passa Dois para oeste quasi tão rapidamente como o leito do rio, visto como o mesmo carvão apparece 2 kilometros a oeste, a uma altitude de 305 acima do nivei do mar, tendo alli $1.68 \mathrm{~m}$. de espessura incluindo os schistos. 
Elevation of coal here, 249.1 meters. or 16.9 meters lower than the coal at Barro Branco Novo (266). Since the dip is quite rapid to the south-east at Barro Branco Novo, there can be no doubt that the coal found at Tijuco Preto is the upper division of the Barro Branco bed.

This coal bed is exposed in a road cutting along the Estrada Nova at the crest of the hill 3 kilometers from Minas and 338.2 meters above sea level, but is there thin as shown in the general section given on a previous page. It is possibly the same coal that has Jeen dur into at the head of Rio Pequeno, 7 1/2 kilometers from Minas near the Estrada Nova and 334 meters above sea level.

On Rio Passa. Dois, one-half kilometer west from the mouth of Rio Carvão, this coal comes down to near water level at 268.9 meters above tide.

At this locality a sheet of diabase has penetrated horisontally between the strata which overlie the coal, and in the steep left bank of the stream there is visible the following succession :

1. Massive sandstone. reddened by heat from the eruptive rock below .

Meters

2. Shales, dark and coaly, fragmental . . . . . . . . . 0.66

3. Diabase . . . . . . . . . . . . . . . . . 1.57

4. Conglomerate mass of shale, clay and decomposed diabase. - . 0.23

5. Shalo, dark, fossil plants, anthracitized from heat . . . . . . 0.13

6. Clay, dark blue . . . . . . . . . . . . . 0.20

7. Coal impure. . . . . . . . . . . . . . . . 0.15

8. Shale, dark. . . . . . . . . . . . . . . . . 0.20

9. Shales, blue. . . . . . . . . . . . . . . . . 0.15

10. Clay, light blue . . . . . . . . . . . . . . 0.28

11. Coal, fair . . . . . . . . . . . . . . . 0.18

12. Clay, dark . . . . . . . . . . • • . • . . 0.08

13. Coal, fair . . . . . . . . . . . . . . 0.28

14. Coal slaty . . . . . . . . . . . . . . . 0.15

15. Sandstone, massive . . . . . . . . • . . . .

The intrusion of the diabase has here apparently disrupted and broken up the upper bench of the coal, since Nos. 11 to 14 represent the typical structure of the lower bench.

The Barro Branco coal appears to rise westward from Passa Dois about as fast as the bed of the stream since the same coal occurs 2 kilometers west at an elevation of 305 meters above sea level where it is 1.68 meters thick, with included slates. 
Esta camada afflora nos barrancos do rio Bonito. a cerca de um kilometro a éste de Palermo no caminho de Treviso e 7 kilometros e $1 / 3$ de Minas. O carvão está á altitude de $273.7 \mathrm{~m}$. sobre o nivel do mar mostrando assim uma elevação para oeste de $34.6 \mathrm{~m}$. nos $3 \mathrm{kilo}$ metros do local Barro Branco Velho, concordando neste ponto com o levantamento para oeste que as camadas mostram ao longo do Passa Dois.

o carvão foi cuidadosamente medido abaixo de Palermo pelo Dr. Seixas que deu a seguinte estructura do affloramento :

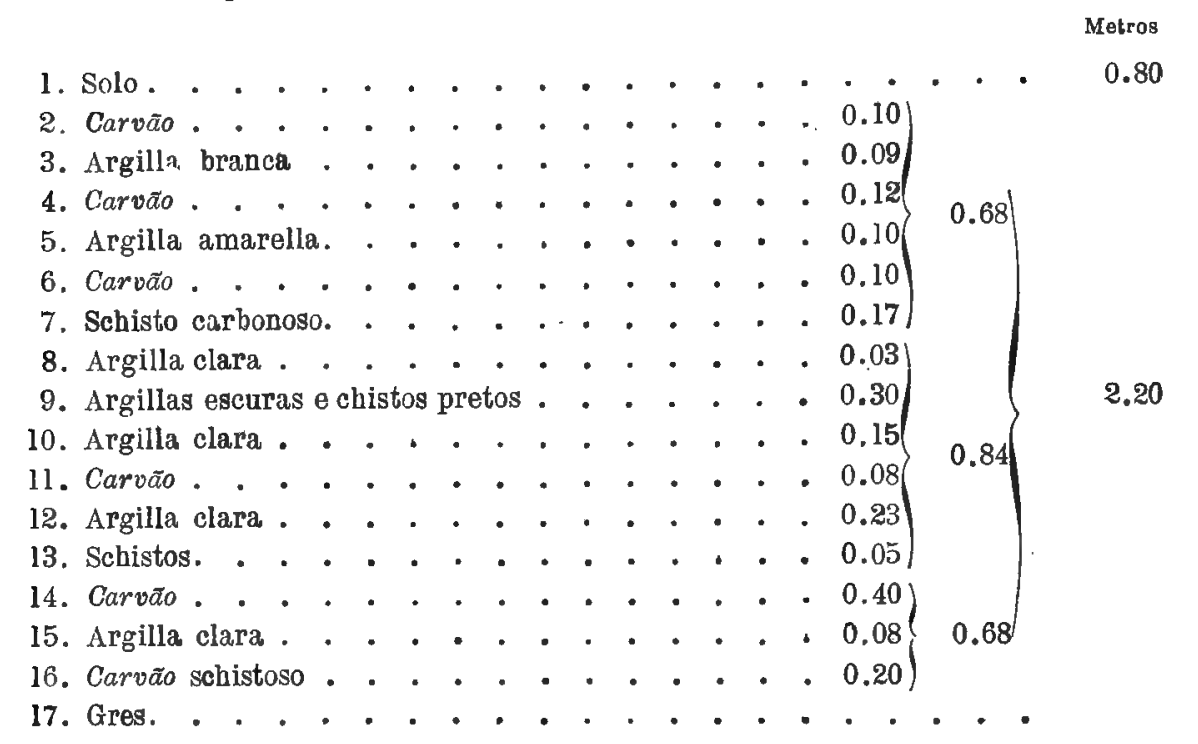

Esta secção mostra a separação bem definida da camada em 3 divisões pelas argillas de cor clara intercaladas. Como esta está em affloramento superficial o carvão será encontrado mais espesso sem duvida quando fôr examinado nas montanhas. Seu horizonte está a cerca de 9.14 metros acima do rio Bonito nesta localidade e um paredão massiço de gres cinzento (Barro Branco inferior) afflora abaixo della ao longo d'aquelle rio, ao passo que uma outra (Barro Branco superior) forma paredõas nas montanhas immediatamente acima.

A cerca de um kilometro e meio a sudoeste de Treviso, emerge do rio Pio, tributario do rio Mãe Luzia, uma camada de carvão em rapido mergulho para noroéste que parece representar a camada Barro Branco.

A secção alli é a seguinte:

Metro

1. Gres (Barro Branco superior) massiço, oinzento, grosseiro, forma paredões. . . . . . . . . . . . . . . . . 9.14

2. Schisto escuro . . . . . . . . . . . . . . . $0.3^{3}$

3. Argilla de cốr clara . . . . . . . . . . . . . . 0.61 
This bed crops on the banks of Rio Bonito about one kilometer east of the village of Palermo along the Treviso road and $71 / 3 \mathrm{kilo-}$ meters from Minas. The coal has an elevation of 273.7 meters above sea level thus showing a westward rise of 34.6 meters in the $3 \mathrm{ki}$ lometers from the locality of Barro Branco Velho, and in this agrceing with the westward rise of the beds revealed along Passa Dois.

The coal was carefully measured below Palermo by Dr. Seixas who reports its structure at the outcrop as follows:

1. Soil.

Meters

2. Coab

0.80

3. Clay, whit

4. ('oal.

5. Clay, yellow

6. Coal.

7. Coaly slate

8. clay, light.

9. Dark clays and black shales

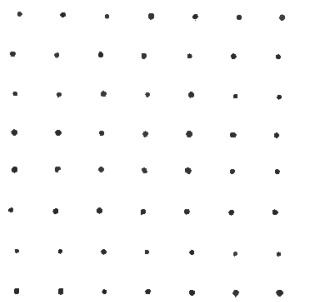

$$
\left.\begin{array}{l}
0.10 \\
0.09 \\
0.12 \\
0.10 \\
0.10 \\
0.17 \\
0.03 \\
0.30 \\
0.15
\end{array}\right\}
$$

10. Clay, light.

Coal. . . . . . . . . . . 0.08

12. Clay, light. . . . . . . . . . . 0.23

13. Shales . . . . . . . . . . . 0.05

14. Coal. . . . . . . . . . . . 0.40

15. Clay, light. . . . . . . . . . 0.08

16. Coal, slaty. . . . . . . . . . 0.20

17. Sandstone .

This section shows the rell defined separation of the Jed into 3 divisions by the intervening light colored clays. As this is at the surface crop, the coal would doubtless thiclien considerably when followed into the hills. Its horizon is about 9.1 moters above Rio Bonito, at this locality, and a massive cliff of gray sandstone (Lower Barro Branco) crops under it along that stream, while another (Upper Barro Branco) makes cliffs in the hills immediatelly above.

About one kilometer and a half south-wesl from Treviso, a bed of coal comes out of Rio Pio, a triluutary of Rio Nãe Luzia on a sharp dip to the north-west, and it appears to be the representative of the Barro Branco bed. The section there is as follows:

Beters

1. Sandstone (Upper Barro Branco), milssive, gray, coaríe, makes cliffs . 9.14

2. Shale, dark . . . . . . . . . . . . . 0.33

3. Clay, light colored . . . . . . . . . . . . 0.61 5669 
4. Carvão bon . . . . . . . . . . . . . . . . . . 0.25

5. Argilla cinzenta escura . . . . . . . . . . . . . . 0.15

6. Carvão schistoso . . . . • . • . • • . . . . . . 0.53

7. Schisto escuro . . . . . . . . . . . . . . . . . 0.15

8. Gres (Barro Branco inferior') massiço, no leito do rio Pio . . . . .

o carvão foi explorado em pæquena extensão por excavações superficiaes.

A éste de Treviso ergue-se alta montanha (300 metros) de rocha eruptiva (diabase) conhecida por Belvedere que separa as aguas do rio Mãe Luzia (que desagua no Atlantico pelo rio Araranguá) das do Urussanga que desagua no mar entre Laģuna e a emboccadura do Araranguá. No alto desta montanha, ao norte da igreja, dizem que ha carvão, mas a unica substancia parecida com este que se pôde encontrar, foi um deposito de schisto bituminoso preto muito decomposto, no leito de um pequeno corrego. E' possivel que a erupção da grande massa de diajase tenha carregulo alguns blocos de estrato contendo carvão, do valle para o alto da montanha.

O rio Carvão, tributalio do Urussanga, nasce na fralda oriental de Belvedere e córta seu leito atravez do horizonte do carvão Barro Branco, 8 a 10 kilometros acima de Urussanga.

A seguinte secção se encontra exposta em uma cachoeira sobre o gres massiço acima do carvão logo abaixo da estrada de Belvedere a Urussanga .

1. Gres, Barro Branco superior . . . . . . . . . . . . . . . . 10.66

2. Schistos . . . . . . . . . . . . . . . . . . 1.52

3. Cavvão . . . . . . . . . . . . . . . . . . . . . . . . . . .

4. Schistos areentos e argilla . . . . . . . . . . 1.02$\} 1.75$

5. Carvão schistoso. . . . . . . . . . . . . . 0.43

6. Sclistos areentos . . . . . . . . . . . . . . . . 1.22

7. Gres, Barro Branco in ferior, massiço visivel . . . . . . . . . 0.61

O mergulho é aqui bastante rapido para sudéste e a um e meio kilometros o carvão está abaixo do nivel d'agua no rio Carvão onde foi explorado superficialmente, tendo a seguinte secção :

Metros

1. Gres, Barro Branco superior. . . . . . . . . . . . 10.66

2. Schistos cinzentos e escuros . . . . . . . . . . . . . 1.52

3. Calvão bom . . . . . . . . . . . . . . . 0.30

4. Schistos escuros. . . . . . . . . . . . . . . 0.23

5. Carvato . . . . . . . . . . . . 0.04$\} 1.13$

6. Schistos carbonosos até o leito do rio . . . . . . . . 0.51 
4. Coul, good . . . . . . . . . . . . . . . 0.25

5. Clay, dark gray. . . . . . . . . . . . . . . . 0.15

6. Coal, slaty . . . . . . . . . . . . . . . . 0.53

7. Shale, dark. . . . . . . . . . . . . . . . . . . 0.15

8. Sundstone (Lower Barro Branco), massive, in bed of Rio Pio. . . .

The coal has been exploited to a small extent by surface stripping .

Eastward from Treviso, there rises a high (300 meters) mountain of eruptive rock (diabase) known as Belvedere, and it separates the drainage of Rio Mãe Luzia (which reaches the Atlantic through Rio Ararangua) from tha waters of Rio Urussanga which empties into the sea between Laguna and the mouth of Rio Araranguá. In the summit of this mountain north from the church, conl is reported as present, but the only substance resembling coal that could be found is a darli bituminous shaly deposit greatly decomposed, along the bad of a small stream. It is possible that the eruption of the great mass of diabase may have lifted some blocks of the coal-bearing strata from the valley below to the summit of the mountain.

Rio Carvão, a tributary of Rio Urussanga, rises on the eastern slope of Belvedere, and cuts down through the Barro Branco coal liorizon, 8 to 10 kilometers ajoove the village of Urussanga.

The following section is exposed at a water-fall over the massive sandstone above the coal just below the road leading from Belvedere to Urussanga :

Xieters

1. Sandstone, Upper Barro Branco . . . . . . . . . 10.66

2. Shales . . . . . . . . . . . . . . 1.52

3. Coal . . . . . . . . . . . . . . . 0.30 j

4. Sandy ehales and clay . . . . . . . . . . 1.021 1. .

5. Coal, slaty . . . . . . . . . . . . . . 0.43 !

6. Shales, sanily . . . . . . . . . . . . . . . 1.22

7. Sandstone, Lower Barro Bratico, massive, visible. . . . . . . 0.61

The dip is here quite rapid to the south-east, and a kilometer and a half below, the coal is down to water level on Rio Carvão where it has lieen explored by stripping and reveals the frillotving section:

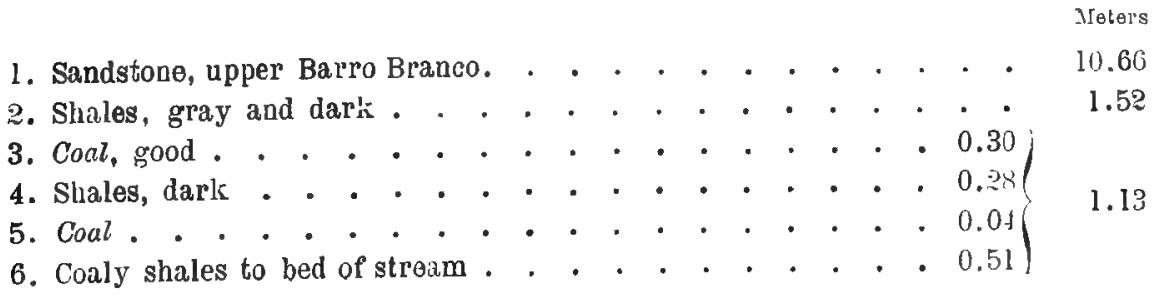


O carvão do tope é bastante bom, tendo assim o caracter da camada Barro Branco em toda a parte.

Na estrada de Treviso a B.lluno, säo vistos frequententente affloramentos de uma camada de carvão, especialmente ao atravessar o rio Fiorita e outros.

Mruito provavelmente é o mesmo carvão que afflora nas cachoeiras do rio Kuntzer, em Belluno, onde a seguinte secção está exposta :

Metros

1. Gres, branco cinzento, Barro Branco superior . . . . . . . 3.65

2. Schistos argillosos . . . . . . . . . . . . . . . 0.66

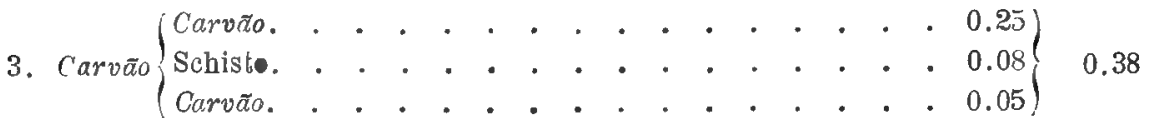

4. Argilla e sçhisto claro e escuro . . . . . . . . . . . 1.07

5. Carväo visivel no leito do rio . . . . . . . . . . . . .

Esta é a estructura typica da camada Barro Branco e os ns. 3 a 5 representam sem duvida aquella camada.

A espessura do n. כ̃ não pôde ser medida devido a estar coberta por um metro d'agua no leito do rio.

Este carvão foi cavado em varias localidades no rio Fiorita e tambem perto das cachoeiras deste, em terras do Sr. Lorenzo Burigo.

Na região de Nova Veneza não são visiveis affloramentos de carvão, porque um grande derrame do rochas eruptivas cobre a superficie e occulta a totalidade dos sedimentos. Passando de Nova Veneza a Cresciuma, apparecem gres cinzentos no leito do rio Maina, cerca de 4 a 5 lilometros distante da primeira localidade, que mergulham para o sul, na razão de $10^{\circ}$ ou mais .

A uns 4 kilometros de Cresciuma, em um pequeno affiuente do Mãe Luzia, occorre um affloramento de carvão, em terras do $\mathrm{Sr}$. Pirola Luige, apresentando a seguinte estructura:

Metros

1. Carvăo . . . . . . . . . . . . . . . . .

Schisto argilla . . . . . . . . . . . . 0.30

2. $\{$ Argilla misturada com cintas de carvão . . . . . 0.36 .

$\{$ Carväo. . . . . . . . . . . . . . 0. 0 4$\}$

Argilla branca . . . . . . . . . . 0.25 )

3. Carvão schistoso . . . . . . . . . . . . . . . 0.91

Esta é a estructura da camada Barro Branco. O banco superior, n. 1 , é de carvão bastante bom, mas o inferior, n. 3, contém muitas intercalações de schisto e argilla. 
The top portion of the coal is fairly good, and thus corresponds with the character of the Barro Branco seam elsewhere.

Along the road from Treviso to Belluno, the outcrop of a coal bed is frequently visible, especially at the crossing of Rio Fiorita and other streams.

It is most probably the same coal which outcrops at the falls of Rio Kuntzer in the village of Belluno where the following succession is exposed :

1. Sandstone, grayish-white, Upper Barro Branco . . . . . . 3.65

2. Shales, argillaceous . . . . . . . . . . . . 0.66

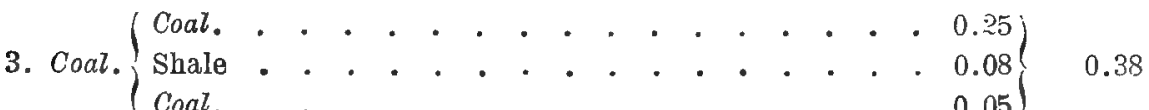

4. Clay and shale, light and dark. . . . . . . . . . 1.07

5. Coal, visible in bed of river. . . . . . . . . . . . . .

This is the typical structure of the Barro Branco seam, and Nos 3 to 5 doubtless represent that bed.

The thickness of No. 5 could not be measured as it is covered by a meter of water in the bed of the strearn.

This coal has been dug into several localities along Rio Fiorita, and also near the head of the same on the land of $\mathrm{M}$ Lorenzo Burigo.

In the region of Nova Veneza no outcrops of coal are visible, since a great flow of eruptive rock covers the surface and conceals all of the clastic sediments. In passing from Nova Veneza to Cresciuma, we see gray sandstone in the bed of Rio Maina $k$ to 5 kilometers from the former village, and they dip southward at the rate of $10^{\circ}$ or more.

About 4 kilometers from Cresciuma, and on a small tri]sutary of Rio Mãe Luzia, the outcrop of a coal bed occur's on the land of Sr. Pircla Luige where it exhibits the following structure:

Meters

l. Coal . . . . . . . . . . . . . . 0.331

(Shales and clay . . . . . . . . , 0.30

2.

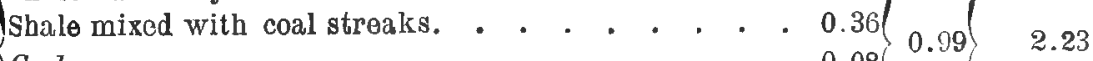

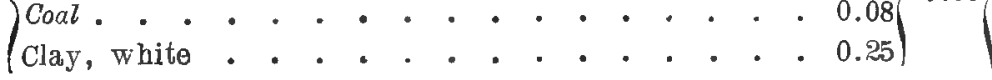

3. Coal. slaty . . . . . . . . . . . . 0.91

This is the structure of the Barro Branco bed. The upper bench, n. 1, is fairly good coal, but the lower, n. 3 , has sereral streaks of slate and clay. 
E' provavelmente o carvão Barro Branco que occorre nas proxi* midades do leito do rio Cresciuma, na localidade do mesmo nome, onde foi encontrado em um piç̧o ahertı pelo Sr. Joăo Targhetta, 3 metros apenas abaixo da superficie.

E tambem o que tem sido explorado a dois kilometros de Gresciuma e empregado em forjas e para outros fins naquella povoação. Alli a exposição é apenas parcial ao longo do leito de um corrego, onde mostra o seguinte:

Motros

I. Carvão, indicios. . . . . . . . . . . . . . . . .

2. Argilla, interestraficada com diversas cintas de carvão de 3 a 10 centimetros . . . . . . . . . . . . . . 0.97

3. Carvão visivel até o nivel d'agua . . . . . . . . . . . . 0.41

A parte superior da camada Barro Branco está alli encoberta, bem que se encontrem os seus indicios.

Cerca de 15 centimetros da parte superior do n. 3, leito inferior, são de carvão regularmente bom que tem sido empregado nas forjas no logar.

Ao passar de Cresciuma, a sudoeste para Araranguá, a serie Tubarão se inclina para baixo do nivel das aguas e o schisto preto de Iraty apresenta-se afflorando ao longo da estrada, na distancia de 10 a 12 kilometros de Cresciuma, tendo sido tomado por carvão em muitos pontos da região.

$E^{\prime}$ possivel que tenha sido esta camada de schisto preto que foi dada como sendo de carvão, perto da villa de Araranguá, visto que as rochas expostas nos morros da visinhança pertencem á serie Passa-Dois, acima das camadas Rio Tubarão.

A nordeste da região de Tubarão, nenhuma excavação foi feita em qualquer das camıdas de carvão da serie, atéchegar á visinhança de Quebra-Dentes, na estrada entre Florianopolis e Lages, a cerca de 60 kilometros de Minas. Ahi, a cerca de 4 kilometros do posto kilometrico 93, foi feita uma exploração de carvão na fazenda dos Srs. Leonel IIeliodoro da Luz e Fernando Gil Born, onde se acha exposta a seguinte successão:

Metros

1. Schistos escuros bituminosos. . . . . . . . . . . . 0.91

2. Carväo regularmente bom . . . . . . . . . . . . . . 0.28

3. Schisto escuro, plantas fosseis . . . . . . . . . . . . . 1.52

4. Schistos o encobertos até o gros massiço cinzento . . . . . . . 7.62 
It is probably the Barro Branco coal which occurs near the bed of Rio Cresciuma in the village of the same name where it was struck in the well of Sr. João Targhetta, only 3 meters below the surface.

It is also the one that has been exploited, 3 kilometers distant from Cresciuma, and used for smithing and other purposes in that village. It is there only partially exposed along the bed of a small stream where.it shows as follows:

Meters

1. Coal, blossom . . . . . . . . . . . . . . .

2. Clay, interstratified with several streaks of coul 3 to 10 centimeters thick. . . . . . . . . . . . . . . . . . . . . 0.97 3. Coul, visible to water level. . . . . . . . . . . 0.41

The upper portion of the Barro Branco bed is there concealed although its Jjlossom is visible.

About 15 centimeters of the top of $n .3$, the lower bench of the coal is fairly good, and has been used for smithing purposes.

In passing from Cresciuma south-westward to Araranguá, the 'Tubarão series dips below water level, and the Iraty black shale comes down, cropping along the road 10 to 12 kilometers distant from Cresciuma, and having been reported as coal at many points in the region.

It is possibly this bed of black shale that has been reported as coal near the town of Araranguá, since the roclis exposed in the hills ther'e belong to the Passa Dois series above the Rio Tubarão beds.

Nurtli-eastward from the Tubarão region, no developments have been made on any of the coal of the series until in the vicinity of Quebra Dentes on the road batween Florianopolis and Lages, about 60 kilometers from Minas. There, about 4 kilometer's from the 93rd kilometer post, a coal has bəen exploited on the fazenda of Messrs. Leonel Heliodoro da Luz and Fernando Gil Born, where at one of the strippings, the following succession is exposed:

Meters

1. Shales, dark, bituminuus. . . . . . . . . . . . . . . 0.91

2. Coal, fairly good . . . . . . . . . . . . . . 0.28

3. Shale, dark, fossil plants . . . . . . . . . . . . . . . 1.52

4. Shales and concealed to massive gray sandstone. . . . . . . 7.62 
Numa outra excavação neste carvão, distante $1 / 2$ kilometro em r'umo de $\mathrm{N}, 60^{\circ} 0$. encontramos a seguinte secção :

1.

2. Schisto bituminoso 0.66

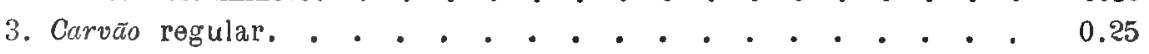

4. Schisto preto, plantas fosseis. . . . . . . . . . . . . .

Este carvão parece representar o leito Barro Branco de Minas, visto que uma sú camada massiça de gres se apresenta acima delle, vindo em seguida os schistos molles das camadas da Estrada Nova O banco inferior do carvão, sempre presente na região de Tubarão, parece ter se transformado em schisto preto, sendo representado pelo n. \& da secção. Nelle apparecem exemplares de Glossopteris, Gangamopteris, Noeggerathiopsis e Sigillaria ou Lepidophloios.

o carvão contém bastante enxofre e outras impurezas e o leito é demasiado delgado para ter valor commercial, salvo para o consumo local.

A seguinte analyse do carvão foi feita pelo Prof. B. H. Hite :

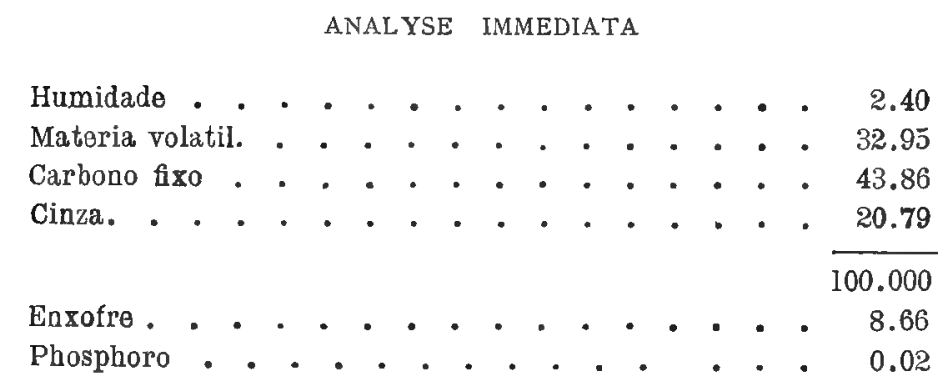

ANALYSE ELEMENTAR

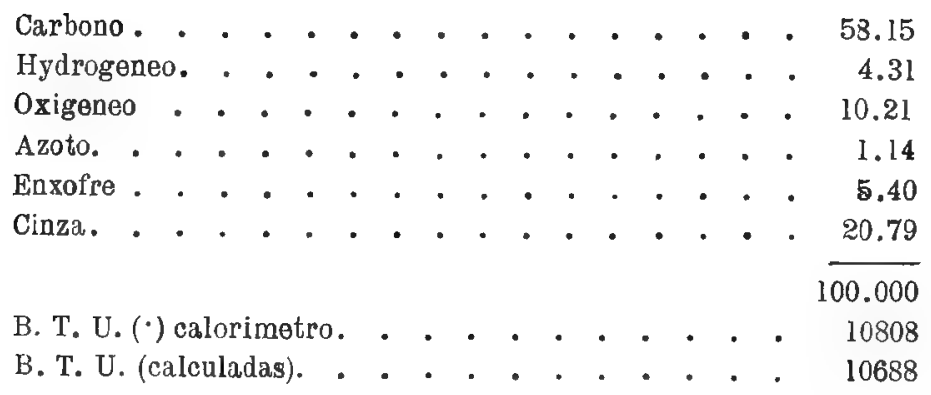

(•) B. T. U. - Unidades thermicas inglezas. 
At another opening in this coal $1 / 2$ kilometer distant, $\mathrm{N} .60^{\circ}, \mathrm{W}$, we get the following:

Melers

1. Sandstone, white, visible. . . . . . . . . . . . . 3.05

2. Shale, bituminous . . . . . . . . . . . . . . . 0,66

3. Coal, fair. . . . . . . . . . . . . . 0.25

4. Slate, black, fussil plints . . . . . . . . . . . .

This coal appears to represent the Barro Branco seam of Minas, since above it is only one massive ledge of sandstone, and then come the soft shales of the Estrada Nova beds. The lower bench of the coal; always present in the Tubarão region, appears to have passed into blacls slate here and is represented by $\mathrm{n}$. 4 of the section. In it occur' sfocimens of Glossopteris, Gangamopteris, Noeggerathiopsis, and Sigillaria, or Lepidophloios.

The coal contains consideral)le sulphur and other impurities, and is too thin to be of any commercial value, except for local purposes.

The following analysis of a sample of the coal is reported by Prof, B. H. Hite :

PROXIMATE ANALYSIS

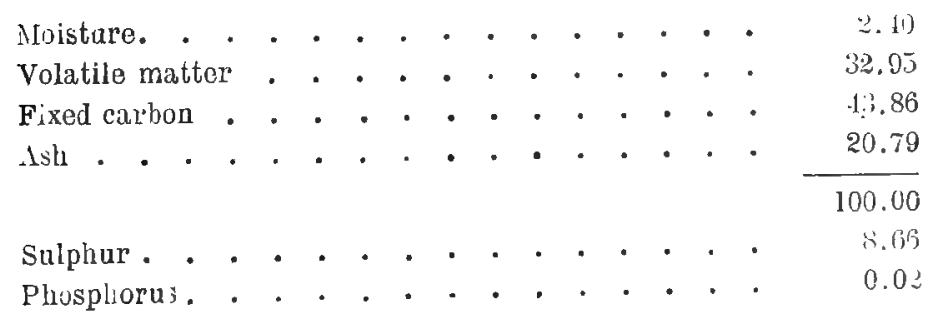

ULTINATE ANALYSIS

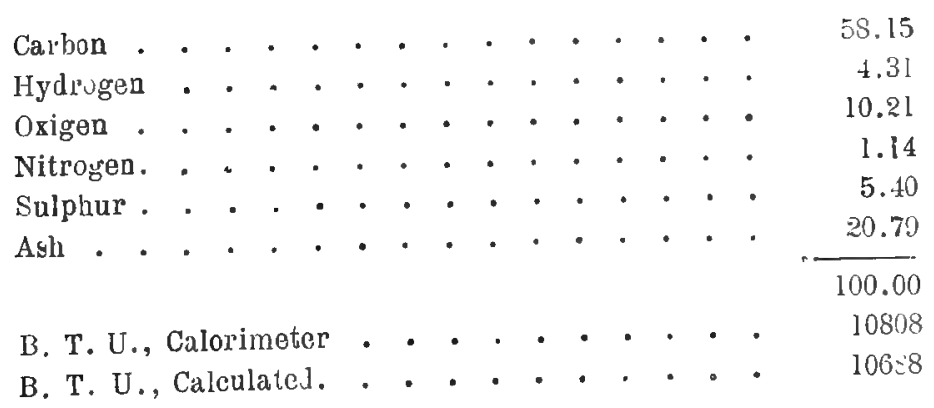


Tanto quanto pude saber nenhuma exploração de carvão foi feita a nordeste de "Quebra-Dentes», porem, ao sulsir a estrada nova que se afasta do rio Itajahy do Sul,no kilometro 11 z e sobe a montanha, a seris Tubarão se apresenta entre os kilometros 120 e 122, a contar de Floria-

olis. Nestas rochas os indicios de carvão, são visiveis perto do púste kilometrico 122. A serie consiste em schistos cinzentos e gres massiços, cinzentos esbranquiçados, dos quaes alguns são conglomeraticos.

Ha tambem noticia de affloramentos de carvão num dos affluentes meridionaes do rio Iguassú, entre Porto da União e a cidade do Rio Negro.

Na região de Teixeira Soares, Estado do Paraná, o coronel Macedo, de Curityba e outros, fizeram algumas exploraçũes de carvão. Uma destas localidades acha-se situada a 3 kilometros a oesle da estação de Teixeira Soares e a uns 45 metros mais abaixo, cstando alli exposta a seguinte secção :

Metros

I. Gres molle, visivel . . . . . . . . . . . . . . . 0.91

2. Argilla escura . . . . . . . . . . . . . . . . . 0.91

3. Schisto carbonoso com pyrite. . . . . . . . . . . 0.20

4. Argilla clara. . . . . . . . . . . . . . . . . . . 0.76

5. Gres visivel . . . . . . . . . . . . . . 0.30

o carvão se apresenta em leitos delgados no schisto preto, sendo acompanhado de muita pyrite.

A cerca de 3 kilometros ao $\mathrm{N}, 30^{\circ} \mathrm{O}$., da ultima localidade, encontrou-se um affloramento delgado de carvãu numa grota chamada Jacusinho, onde se vê a seguinte successão :

Metros

1. Gres . . . . . . . . . . . . . . . .

2. Argilla, branca. . . . . . . . . . . . . . . .

3. Schisto bituminoso com cintas delgadas, de car rão pyritoso . . . $\quad 0.30$

4. Schistos escuros argillosos . . . . . . . . . . . . 1.83

5. Gres, massiço, amarello, visivel. . . . . . . . . . 0.91

Este horizonte de carvão é o mesmo que o da primeira localidade e tambem contem grande quantidade de pyrite. Está a 15 metros mais baixo que a outra localidade.

A cerca de 1 kilometro a S. $10^{\circ}$ O. de Teixeira Soares e 90 metros mais baixo ha uma camada delgada, ( 6 centimetros) de schisto carbonoso cm terras do Sr. Antonio Fogaça. A exposição é olscula e a posição da camada carbonosa só pôde ser determinada approximadamente devido a um desmoronamento de terra, perto do 
North-eastrward from Quebia Dentes, no explorations have been made for coal, so far as could ]) learned, but in ascending the new road which leaves Rio Itajahy do Sul at the $115 \mathrm{th}$ kilometel and passes up on to the mountain, the Tubrão series comes down between the 120th and 122nd kilometer from Florianopolis. In these rocks the blossom of a coal is visible near the $122 \mathrm{nd}$ kitometer post. The series consists of gray shales and massive, grayishwhite sandstones, some of which are conglomeritic.

Coal has also been reported as cropping on one of the streams which put into Rio Iguassú from the south between Porto da União and the town of Rio Negro.

In the region of Teixeira Soares,state of Paraná, some exploitations have been made for coal by Col. Macedo, of Curityba, and others. One of these localities is 3 kilometers west from the railway station of Teixeira Soares and about 45 meters lower where the following section is exposed :

Meters

1. Sandstone, soft, visille . . . . . . . . . . . 0.91

2. Clay, dark . . . . . . . . . . . . . . 0.91

3. Coaly slate with pyrite . . . . . . . . . . . 0.20

4. Clay, light . . . . . . . . . . . . . . . 0.76

5. Sandstone, visible. . . . . . . . . . . . 0.30

The coal comes in thin layers in the black slate and much pyrites accompanies the same.

About 3 kilometers $\mathrm{N} .30^{\circ} \mathrm{W}$. from the last locality, a thin cropping of cual is visible in a ravine known as Jacusinho, where the following succession is exposed :

Meters

1. Sandstone. . . . . . . . . . . . . . . .

2. Clay, white. . . . . . . . . . . . . . . . . . .

3. Shale, bituminous, with thin streaks of pyritous coal. • • $. \quad . \quad 0.30$

4. Shales, dark clayey. . . . . . . . . . . . . 1.83

5. Sandstone, massive, yellow, visible. . . . . . . . . 0.91

This is the same coal horizon as that at the first locality, and it also contains a large quantity of pyrites. It is 15 meters lower than the other locality.

At about one kilometer S. $10^{\circ} \mathrm{VV}$. from Teixeira Soares and 90 meters lower, a thin ( 6 centimeters) coaly slate crops on the land of sr. Antonio Frgaça. The exposure is poor, and the position of the coal layer could only be determined approximately owing to a small landslide near the horizon of the outcrop. Its position, however, is so far 
horizonte do affloramento. A sua posição, porém, é abaixo do horizonte do outro carvão pyritoso, que no caso deste representar a camada Barro Branco, aquelle deve estar approximadamente no horizonte da camada Bonito.

Ainda mais ao Nnrte, no Cedro, em terras do Coronel Macedo, perto de Imbituva, houve uma consideravel exploração de carvão, occupando o horizonte da camada Barro Branco, feita pelo Dr. Oliveira, $1^{\circ}$ engenheiro da Commissão do Carvão; numa destas localidades foi olservada a seguinte secção :

I. Gres cinzento claro. . . . . . . . . . . . 3.05

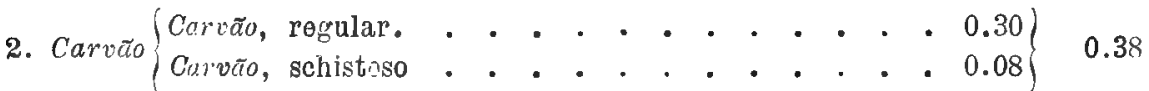

3. Argilla de cor clara . . . . . . . . . . . . . . . 1.22

Abaixo desta secção foram feitos um poço e uma sondagem até a profundidade de mais de 100 metros sem encontrar mais carvão, ao passo que a 25 metros acima apresenta-se um conglomerato grosseiro e depois os schistos e camadas molles do grupo Palermo. Assim é hem possivel, ainda que não seja certo, que o carvão no Cedro represente o leito Barro Branco.

A composição do carvão no Cedro, conforme analyse feita no labnratorio do Prof. Ilite, é a seguinte:

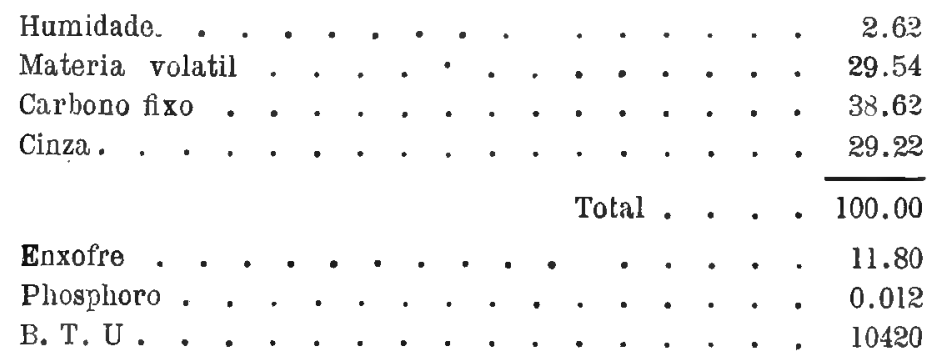

A quantidade de enxofre é muito grande na amostra tirada, mas provavelmente o termo medio no uso geral não será tão elevado.

E' provavel que esta scja a mesma camada de carvão que foi explorada em um corrego, um kilometro e meio a sudoeste da villa de Imbituva, onde o carvão bom só tem 8 a 10 centimetros, ou mais de schisto preto com delgadas intercalações de carvão.

Muitas leguas a nordeste de Imbituva ha diversos affloramentos de carvão, ao longo do curso do rio Tibagy, cerca de 60 kilometros ao Norte da cidade do mesmo nome. o primeiro se acha na locali- 
below that of the other pyritous coal, that if the former slould represent the Barro Branco bed, this one would proljlaljy come near the horizon of the Bonito seam.

Still farther north at Cedro on the land of Col. Macedo, near Imbituva, a coal occupying the horizon of the Barro Branco bed has been explored to a considerable extent by Dr. Oliveira, First Engineer of the Coal Commission. At one of these localities the following section was observed :

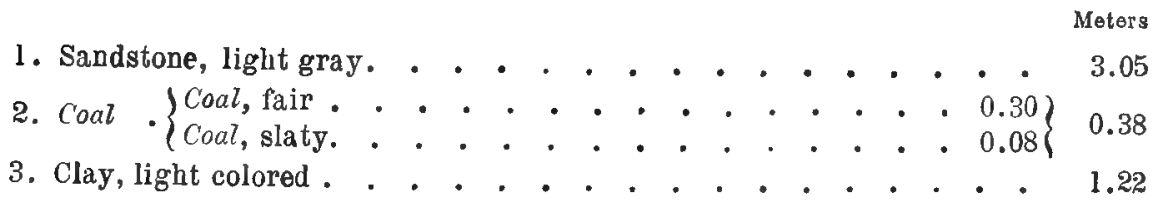

Under this a shaft and boring were made to a depth of more than 100 meters, but no more coal was found, while alove it, at 25 meters, comes a coarse conglomerate, and then the shales, and soft measures of the Palermo Beds. Hence, while it is not certain, it is quite possible that the coal at Cedro represents the Barro Branco seam.

The composition of the coal at Cedro is shown by the following analysis made in Prof. Histe's laboratory :

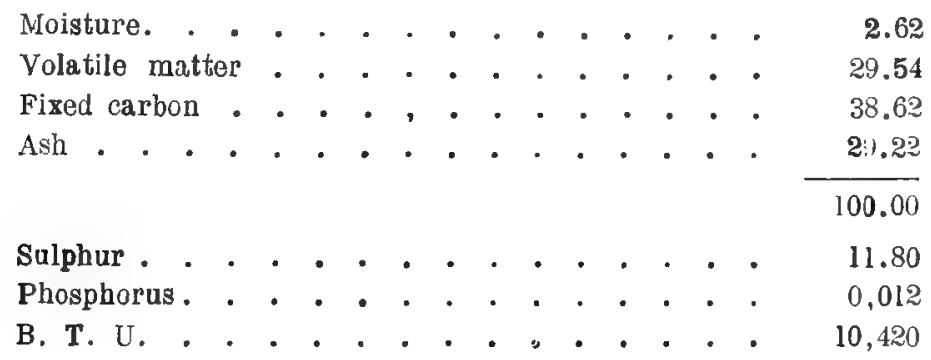

The quantity of sulpliur is very large in the specimen taken, but would probably not average so much in general use.

This is probably the same bed of coal that has been explored along a small stream, one kilometer and a half south-west from the village of Imbituva, where the good coal is only 8 to 10 centimeters thick with 60 centimeters or more of black slate below, in which are thin streaks of coal.

Many leagues nort-eastward from Imbituva, there are several outcrops of coal along the waters of Rio Tibagy about 60 kilometers north from the town of the same name. The first outcrop makes its 
dade Imbausinho e ahi o Dr. Cicero Campos, engenheiro ajudante da Commissão, refere que apresenta a espessura de 45 centimetros, scndo o carvão de qualidade legular. o Dr. Campos encontrou um outro aflluramento da mesma camada a 12 kilometros mais ao Norte, no Salto Apparado, com a espessura de 49 centimetros.

As analyses de amostras dos carvões de Imbausinho e Salto Apparado, colleccionadas pelo Dr. Campos, deram os seguintes resultados referidos pelo Prof. B. H. Hite:

\section{ANALYSE IMMEDIATA}

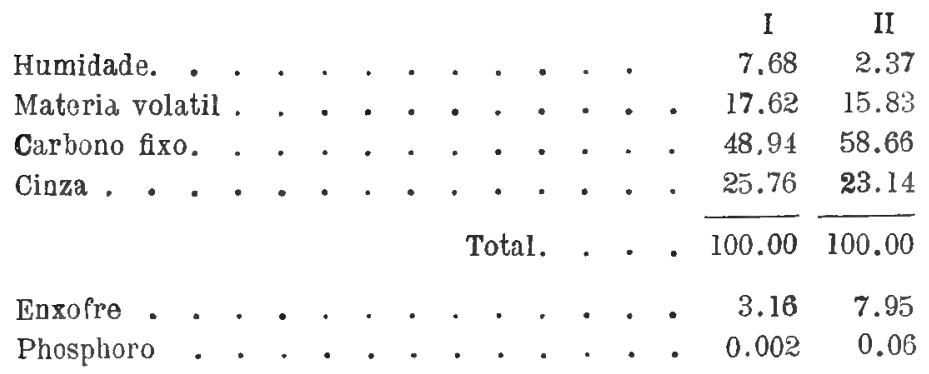

ANALYSE ELEMENTAR

\begin{tabular}{|c|c|c|c|c|c|c|c|c|c|c|c|c|c|c|}
\hline Carbono. & & . & . & 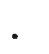 & - & . & & & & & & & $50.6 n$ & 00.00 \\
\hline Hydrogened & & • & . & . & . & - & - & - & . & . & - & & 3.11 & 3.78 \\
\hline Oxigeneo. & & & . & . & . & . & . & . & . & . & . & & 17.73 & 7.18 \\
\hline Azuto. . & . & & . & & . & . & . & . & - & & & & 0.80 & 0.95 \\
\hline Enxofre. & . & . & . & . & & . & . & . & . & & & & 2.00 & 4 \\
\hline Cinza & . & & . & . & . & . & - & . & & 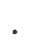 & & & 25.76 & 23.14 \\
\hline & & & & & & & & & & & & & 100.00 & \\
\hline & alc & & & & & & & & & & & & $\begin{array}{l}8003 \\
8037\end{array}$ & \\
\hline
\end{tabular}

I - Amostra de carvão de Imbausinho, colleccionada pelo Dr. Cicero Campos.

II - Amostra de carvão de Salto Apparado, colleccionada pelo Dr. Cicero Campos.

No Listado de S. Paulo, entre o rio Feio e o Tatuhy, em um affloramente do rio da Onça, foi explorada uma camada de carvão da espessura de 50 centimetros apenas, que se apresenta em baixo de um gres massiço cinzento. E' muito provavel que pertença ao mesmo horizonte que os carrões do Cedro e Tibagy, no Estado do Paraná. 
appearence at a locality known as Imluausinho, and there Dr. Cicero Campos, assistant engineer of the Commission, reports it as 4 .j centimeters in thickness, and fairly good coal. He identifies it with the coal at Cedro, as also another outcrop of the same bad 12 liilometers farther north at Salto Apparado where it is 43 centimaters in thickness.

The analyses of the coal at Imbausinho and Salto Apparado from samples collected by Dr. Campos give the lollowing results as reported by prof. B. II. Hite :

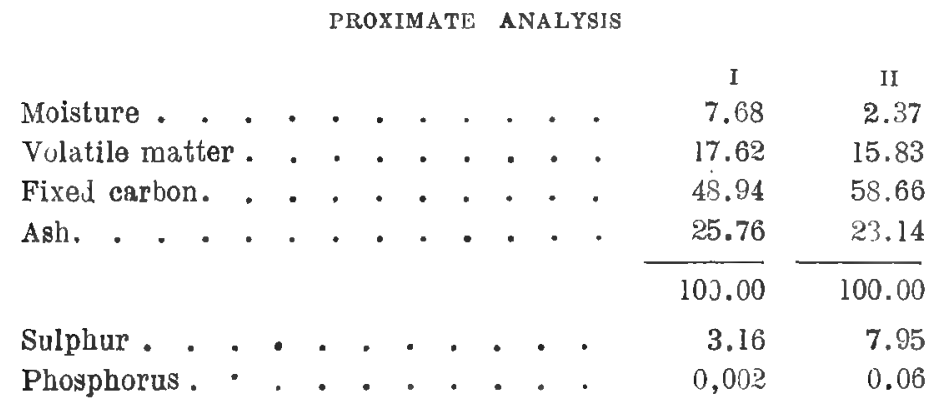

ULTIMA $\perp T E$ NALYSIS

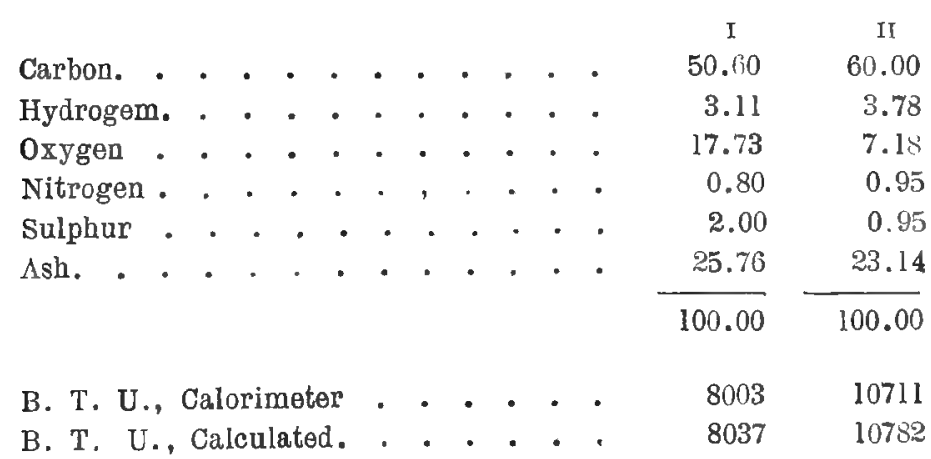

1. Sample of coal from Imbausinbo, collected by $\mathrm{Dr}$. Cicero Campos.

2. Sample of coal from Salto Apparado, collected by $\mathrm{Dr}^{2}$. Cicero Campos.

In the state of S. Paulo, hetween Rio Feio and Tatuhy, on a branch of Rio d'Onça, a bed of coal only 30 centimeters thick has been exploited under a massive, gray sandstone. It most probadly comes at the same horizon as the Cedro and Tijagg! coals of Paraná. It appears to be the same thin cual bed which crops in a ravine near Cerquilho 
Ao que parece é a mesma camada delgada de carvão que afflora em uma grota perto da estação de Cerquil ho, na estrada de forro Sorocabana e que foil tambem atravessada num poço para agua, perto da estação, na profundidade de 10 a 12 metros.

Como já foi dito, a sudoeste de Clesciuma, em Santa Catharina, o mergulho da formação carbonifera naquelle rumo, leva as camadas de carvão para baixo do nivel das aguas, ao longo da região costeira e as camadas superiores das series Passa Dois e S. Bento descem a constituir os affloramentos superficiaes, desde a região de Araranguá pelo Estado do Rio Grande do Sul, de modo que não ha mais carvão visivel ao Sul de Cresciuma para alem de Porto-Alegre, até chegar á região de $\mathrm{S}$. Jeronymo.

Si as camadas Rio Bonito, com seus carvũes, schistos e gres cinzento, passam por baixo desta capa de rochas superiores, só póde ser determínado pela sonda. E' possivel que a serie S. Bento tenha transgredido para léste, além dos limites das camadas Rio Bonito, visto que nenhum affloramento de carvão foi apontado entre a serie.São Bento e o granito, onde este surge de novo, ao Norte de Porto-Alegre, depois de ter desapparecido debaixo da mesma, ao Nordeste de Araranguá.

Seja como for, as camadas carboniferas se apresentam de novo a cerca de 50 kilometros a Sudoeste de Porto-Alegre, na região de S. Jeronymo e ha muito tempo que uma camada tem sido explorada no Arroio dos Ratos, tributario do rio Jacuhy, cujas secções, baseadas em sondagens, já foram dacias.

A posição estratigraphica deste carvão de S. Jeronymo, assim como a sua estructura individual, corresponde tão bem á da camada Barro Branco de Santa Catharina, que é muito provavel que seja a mesma, bem que a sua identidade não ten ha sido provada pela verificação de aftloramentos seguidos na região intermediaria, entre as duas localidades.

To Poço Fé, com 90 metros do profundidade, nas minas do Arroio dos Ratos, pərto de S. Jeronymo, o carvão mostra a seguinte estructura :

Metros

1. Schisto preto e carvão impuro com plantas fosseis . . . . . . .

2. Carväo regular. . . . . . . . . . . . . 0.86

3. Argilla, cinzenta clara. . . . . . . . . . . . 0.10

4. Schisto e carrvão em camadas delgadas, altelıa las de 3 a-s centi- $\quad 2.68$ metros. . . . . . . . . . . . . 0.81

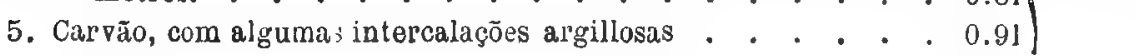




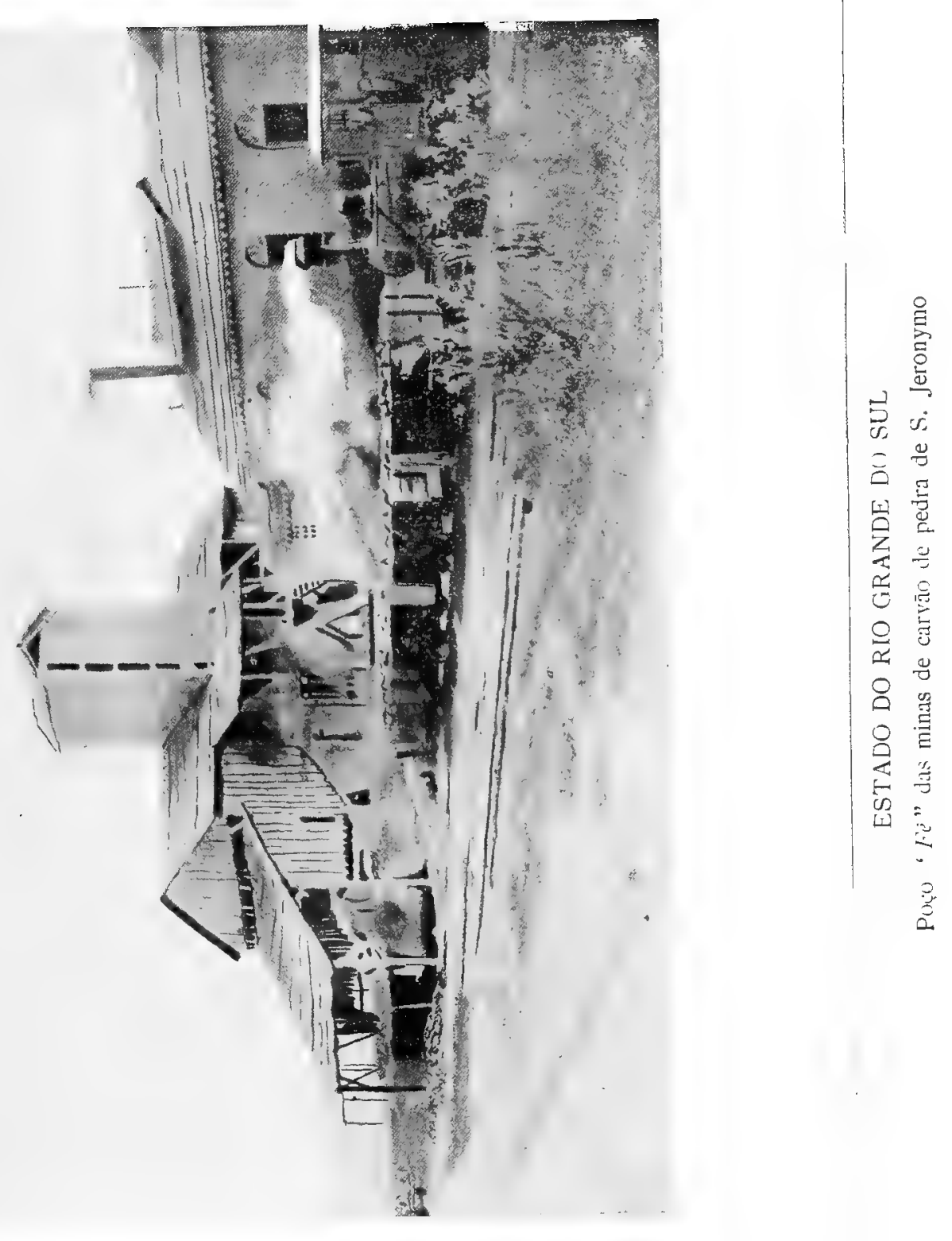



station on the Sorocabana Railway and was also dug through there in the shaft for water at a depth of 10 to 12 meters.

South-westward from Cresciuma in Santa Catharina, as already stated, the general dip of the measures in that direction, carries the coal beds below water level along the coastal region, and the higher rocks of the Passa Dois and $\mathrm{S}$. Bento series come down and make the surface outcrops from the region of Ararangua on in to the state of Rio Grande do Sul, so that no more coal beds are visible southward of Cresciuma until Porto Alegre is passed, and the region of S. Jeronymo is reached.

Whether or not the Rio Bonito beds with thcir couls shales, and gray sandstones, pass under this overlying mantle of higher rocks, nothing but the drill can determine. It is possible that the Săo Bento series has transgressed eastward beyond the range of the Rio Bonito beds since where the granite again comes out of the sea, north from Porto-Alegre, after disappearing below the same nortl-east from Araranguá, no outcrops of coal have been reported between it and the São Bento series.

But however this may be, the coal beds again make their appearance ajout 50 kilometers south-west from Porto-Alegre, in the region of S. Jeronymo, and one bed lias long been mined on Arroio dos Ratos, a tributary of Rio Jacuhy where sections from borings have already leen given.

The stratigraphical position of this $\mathrm{S}$. Jeronymo coal, as vell as its individual structure corresponds so closely to that of the Barro Branco bed of Santa Catharina, that although its identity therewith cannot be proven from continuous tracing, yet it is most probalsly the same bed.

In Poço Fé shaft, 90 meters in depth, at the mines operated on Alroio dos Kalos, neal S. Jeronymo, the coal shows the following structure :

Meters.

1. Black slate and bony coal with fossil plants . . . . . . .

2. Coal, fairly good . . . . . . . . . . . . . 0.86

3. Clay, light gray. . . . . . . . . . . . . . . 0.10

4. Slate and coal in alternate thin Iayers 3 to 8 centimeters $\} 2.0 \varepsilon$ each . . . . . . . . . . . . . . . 0.81

5. Coal, some slaty layers . . . . . . . . . 0.91 5569 
O schisto preto e carvão impuro do tecto da mina contém numerosos restos de Sigillaria, Lepidophloios e folhas de Lepidodendron.

A porção superior do carvão n. 2 é geralmente melhor que a inferior, $\mathrm{n}$. 5: bem que contenha mais enxofre, tem menos materia argillosa. O caracter deste carvão, bem como o do de Santa Catharina e alhures, 6 discutido em outro capitulo deste relatorio.

A intercallação de argilla cinzenta, n. 3, varia muito em espessura nas differentes partes da mina, ás vezes augrmentando 60 centimetros ou mais, ás vezes se adelgaçando até um centimetro. O n. 4 contém muito carvão bom, mas este se acha tão interestratificado com schisto preto que não se póde separal-o sem britação e lavagem .

O n. 5 tambem contém intercalações de schisto e de carvão impuro, mas algumas destas podem sel eliminadas por trajıalho cuidadoso na mineração, entretanto o carvão ficará sempre com alta percentagem de cinzas.

Outras medições em diversas partes da mina deram os seguintes resultados :

1. Carvão impuro, plantas fosseis . . . . . . . . . . .

2. Carvão regulav . . . . . . . . . . . . . . . . . 1.04

3. Argilla branca . . . . . . . . . . . . . . . . . 00.5

4. Schisto escuro, interestraticicado com carvão . . . . . . . 0.61

5. Carvão schistoso . . . . . . . . . . . . . . . 0.76

Uma outra deu o seguinte :

1. Carvão impuro, plantas fosseis . . . . . . . . . . . .

2. Carvão regular. . . . . . . . . . . . . . 0.86

3. Argilla . . . . . . . . . . . . . . . 0.10

4. Sohisto preto, interestratificado com carvão. . . . . 0.81 2.91

5. Carvão argilloso . . . . . . . . . . . . . 1.14

Metros

O carvão é ás vezes reduzido por ondulaçõos a menos de $1^{\mathrm{m}}, 50$. Outras partes da mina deram as seguintes medições para os differentes membros desta camada de carvão:

\begin{tabular}{|c|c|c|c|c|c|c|c|c|c|c|}
\hline & & & & & & & $\frac{I}{M \in t r o s}$ & ${ }_{\text {Metros }}^{\text {II }}$ & $\frac{\text { III }}{\text { Metros }}$ & $\begin{array}{c}\text { IV } \\
\text { Metros }\end{array}$ \\
\hline 1 Carvão impuro & . . & . & . . & . & . & . . & - & - & - & - \\
\hline 2 Carvão do banco superior . & . . & . & . $\cdot$ & . & - & - . & 0.76 & 0.71 & 0.83 & 0.86 \\
\hline 3 Schisto o calvão. . . . & . . & - & . . & . & . & . $\cdot$ & 0.71 & 0.86 & 0.56 & 0.83 \\
\hline A Carvâo da porenão inferiol. & - . & - & . . & . & - & $\cdot \cdot$ & 0.86 & 0.86 & 1.12 & 0.97 \\
\hline . . . . . & . & , & . & . & - & . . . & 2.33 & 2.43 & 2.51 & 2.69 \\
\hline
\end{tabular}


The black slate and bony coal in the roof of the mine is filled with remains of Sigillaria, Lepidophloios and leaves of Lepidodendron.

The upper division of the coal, $n .2$, is generally Jetter than the lower n. 5, since, although it appears to hold more sulphur, yet it has less slaty material than $n$. 5 . The caracter of this coal as well as that in Santa Catharina and elsorvhere is discussed in another chapter of this report.

The light colered clay parting, n. 3, varies much in thickness in different portion of the mine, sometimes running up to 60 centimeters or more, and again thinning down to 1 . N. 4 contains much good coal, but it is so interstratified with black slate that it cannot be separated without crushing and washing.

N. 5 alsu contains slaty and bony layers, but some of them can be eliminated in careful mining, though the coal will remain high in ash.

Other measurements in different portions of the mine give the following results :

1. Bone coal, fossil plants . . . . . . . . . . . . . .

2. Coal, fair. . . . . . . . . . . . . 1.04

3. Clay, white . . . . . . . . . . . . 0.05

4. Shale, dark, interstratified with coal ....... 0.01$\} 2.46$

5. Coul, slaty . . . . . . . . . . . 0.76

Another gives the following:

Meters.

1. Bone coal, fossil plants . . . . . . . . . . . . . .

2. Coal, fair. . . . . . . . . . . . . . 0.86

3. Clay . . . . . . . . . . . . . . . . . 0.10

4. Shale, black, interstratified with coal. . . . . . . . 0.81 ,

5. Coal, slaty . . . . . . . . . . . . . . . . 1.14

Rolls sornetimes cut the coal dorvn to less than 1.50 meters in all. other portions of the mine give the following measurements for the different members of this coal :

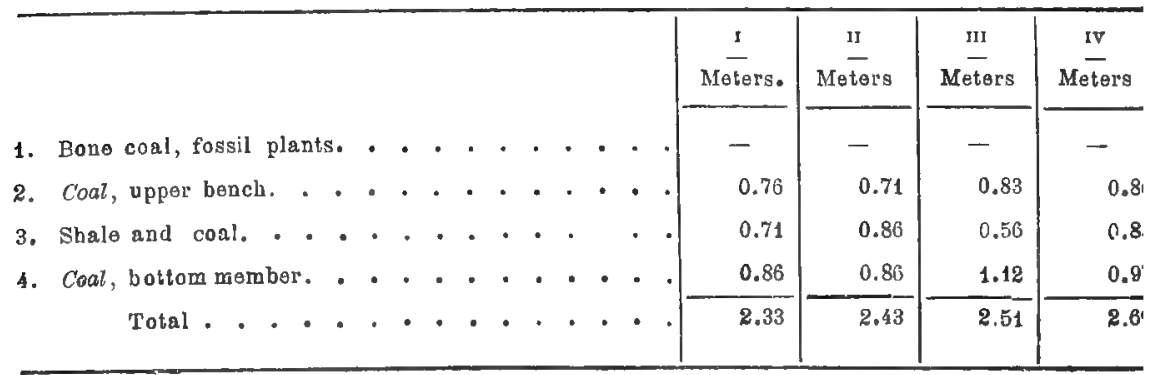


Immediatamente abaixo do carvăo, no fundo do poço, existe um conglomerato preto cheio de seixos de quartzo e outras rochas.

Um dique de rocha eruptiva corta o carvão verticalmente a cerca de 50 metros a oéste do fundo do Poço Fé. Tem cerca de 3 metros de lar. gura e corre quasi exactamente de Norte para Sul. Este foi seguido na mina na distancia de 400 metros e na extensão de 3 a 4 metros ao longo da linha de contacto, o carvão foi muito deslocado e parcialmente convertido em coke.

Para a parte Sul da mina o dique se divide, primeiramente em duas partes e depois em tres. O Dr. Grol'ge P. Merrill, do Museu Nacional de Washington, D. C., a quem foram remettidas amostras da rocha do dique, julga a sua composição mineral mais andesitica que basaltica . (Vide suas observações em outra pagina.)

Além da sondagem a diamante, cuja nota já foi dada, foram praticadas duas outras na vizinhança do Poço F'é, na bacia do Arroio dos Ratos, de que foram, graciosamente, fornecidas notas á Commissão pelo Sr. Spalding. Uma destas sondagens no poço antigo chamado Poço Isabel e 900 metros distante da sondagem n. II, já dada, e começando 25 metros mais alto, tem o seguinte registro:

Argilla variegada. . . . . . . . . . . . . . . 10.20

Schietos de varias côres. . . . . . . . . . . . . 29.70

Cinta fina de carvão. . . . . . . . . . . . . .

Schisto. . . . . . . . . 3.50

Carvão (Treviso ?) . . . . . 0.10

Schisto escuro . . . . . . 12.80

Carvão S. Jeronymo . . 1.20

Argilla e schisto. . . . 5.30

Carvão, S. Jeronymo, banco

inferior. •. . . . 0.50

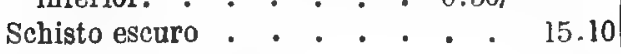

Schisto branco . . . . . 1.00$\rangle$ Camada Rio Bonito 85.88

Scbisto verde escuro . . . . . 1.10

Gres verdo escuro e amarello. . $\quad 3.40$

Schisto verde escuro . . . . 5.40

Schisto areento e calcareo . . 7.90

Carvão . . . . . . . . 0.06

Schisto areento. . . . . . 4.50

Carvão. . . . . . . . . 0.12

Gres argilloso e calcareo . . . . 23.90 


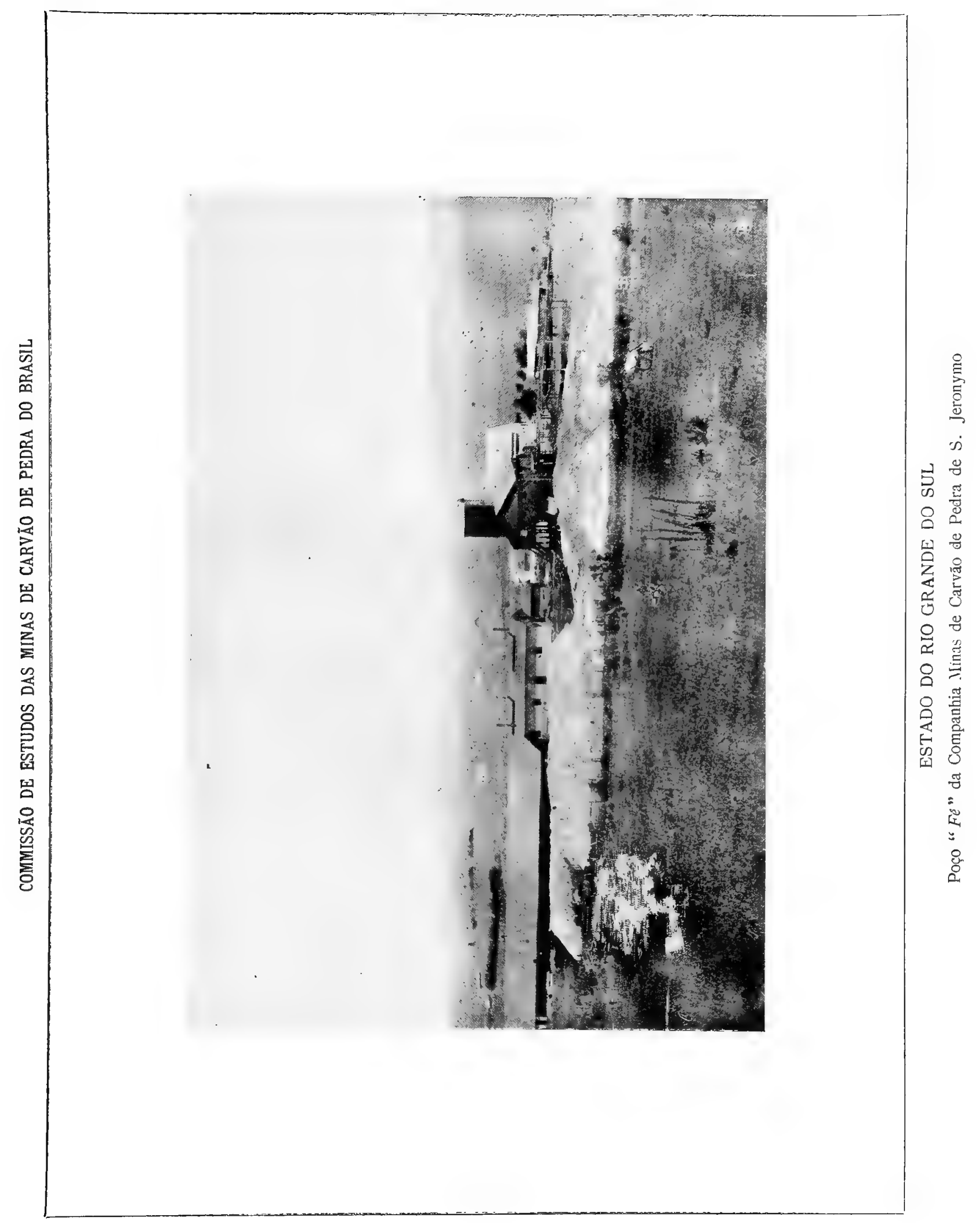



Irnmediately beneath the coal at the bottom of the shaft is a blakc conglomerate filled with quartz and other pebbles.

A dike of eruptive rock cuts through the coal nearly vertically, about 50 meters west from the Jottom of the shaft, known as Poço Fé. It is ajout 3 meters wide and runs nearly north and south. It has been traced in the mine for 400 meters, and the coal has been partially colied and much disturbed for 3 to 4 meters along the line of contact. Toward the southern portion of the mine, the dike separates first into two divisions and then into three. Dr. Geo P. P. Merrill, of the National Nuseum, Washington, D. C., to whom specimens of the dike rock were sul)mitted for examination, thinks the dike is more andesitic in its mineral nature than basaltic. (See his remarks concerning it on another page.)

Two other horings with the diamond drill in addition to the one whose record has already been given were made in the vicinity of Poço Fé, on the waters of Arroio dos Ratos, the records of which were kindly placed at the disposal of the Commission by Sr. Otto Spalding. One of these borings at the old shaft known as Poço Izabel, 900 meters distant from boring $\mathrm{n} .2$ already given, and beginning 25 meters higher, has the following record :

Moters,

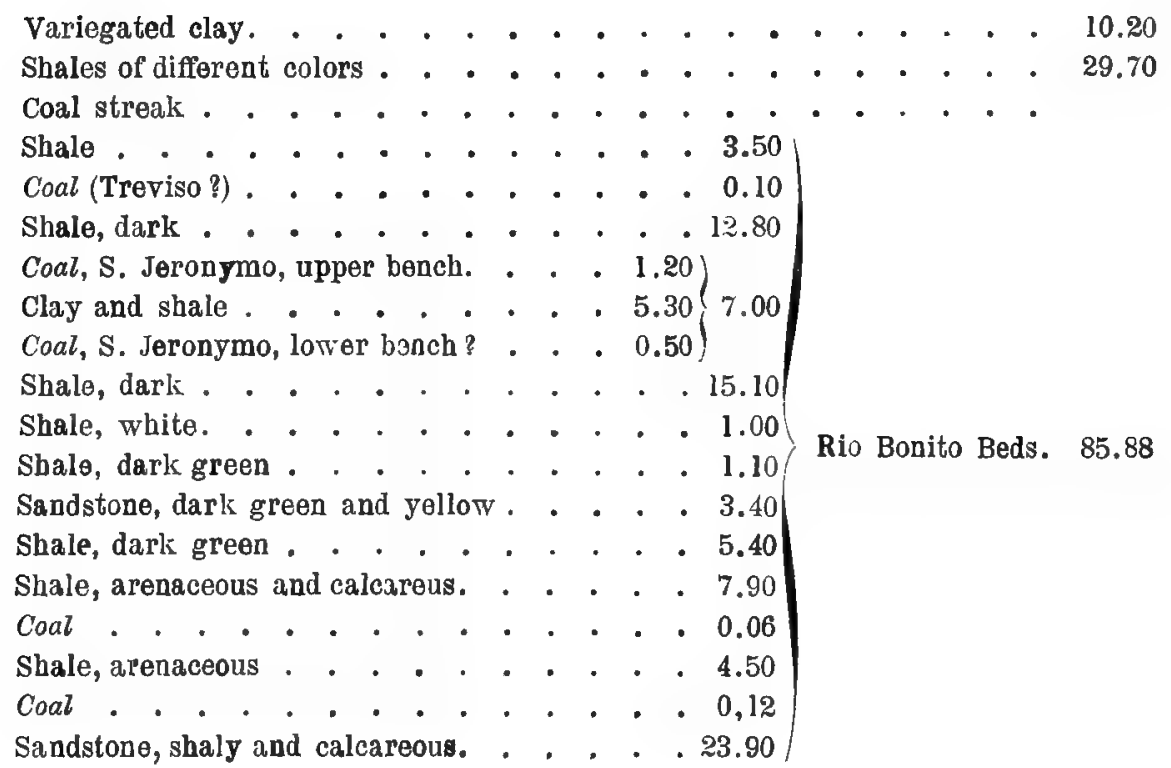




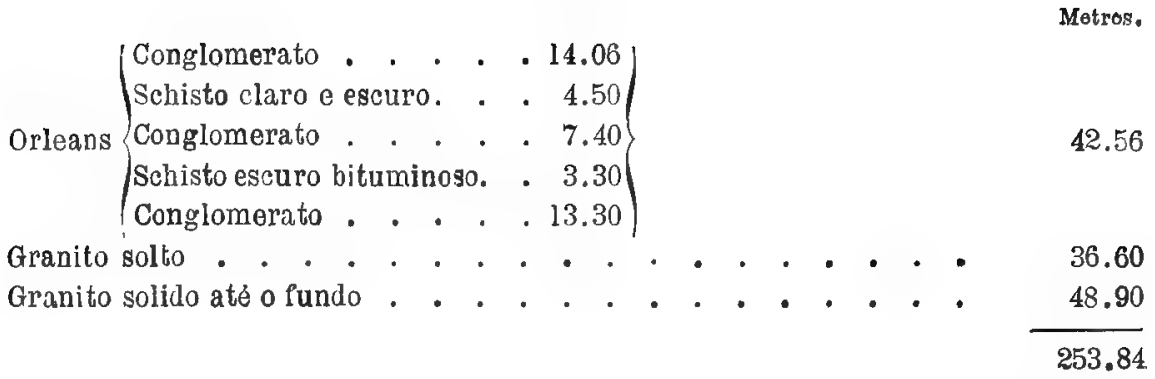

Aqui o conglomerato da base ou de Orleans que, conforme o Sr. Spalding, é composto principalmente de boulders de granito, acha-se sepapado em tres divisões por intercalaçües de schisto, sendo ìastante bituminosa a ultima destas. O intervallo, nesta sondagem desde o tope das camadas Rio Bonito até o granito solto, é de 128,44 metros e até o granito solido 165,04 metros.

A sondagem n. III está a 1750 metros ao sul do Poço Fé e começa a cerca de 30 metros ajsaixo do nivel do Poço Isabel, cujo registro é o seguinte :

Metros

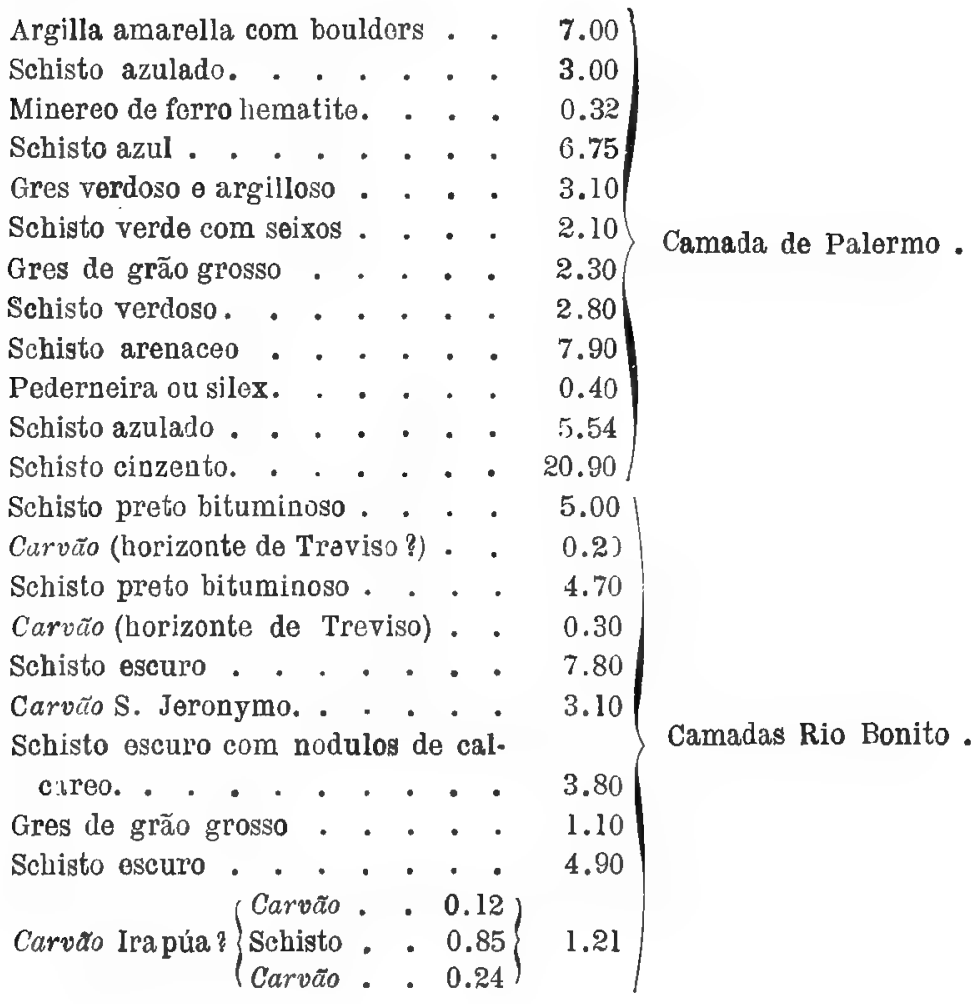




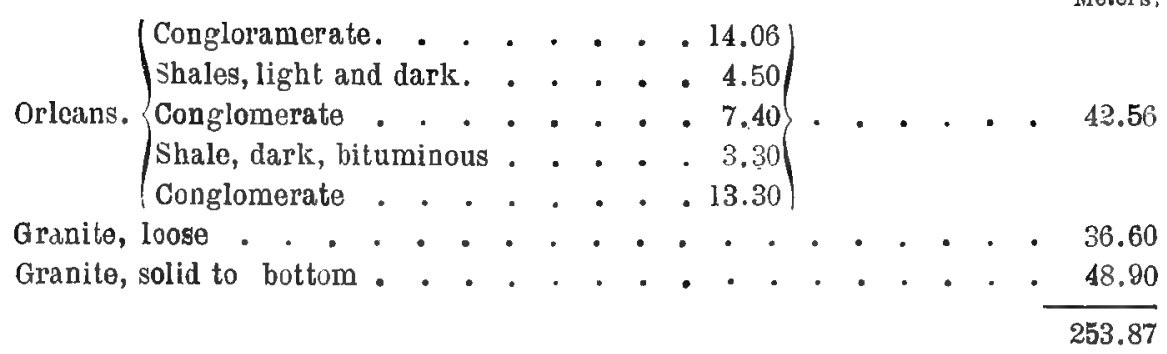

ITere the Juasal, or Orleans conglomerate, composed largely of granite houlders, according to $\mathrm{Mr}$. Spalding, is separated into 3 divisions by shales, the lower stratum of shale being quite bituminous.

The interval in this boring from the top of the Rio Bonito beds to the loose granite is 128.44 meters, and to the solid granite is 165.04 meters.

Boring n. 3 is 1750 meters south from Poço Fé, and begins about 30 meters below the level of Poço Izabel. The record there is as follows :

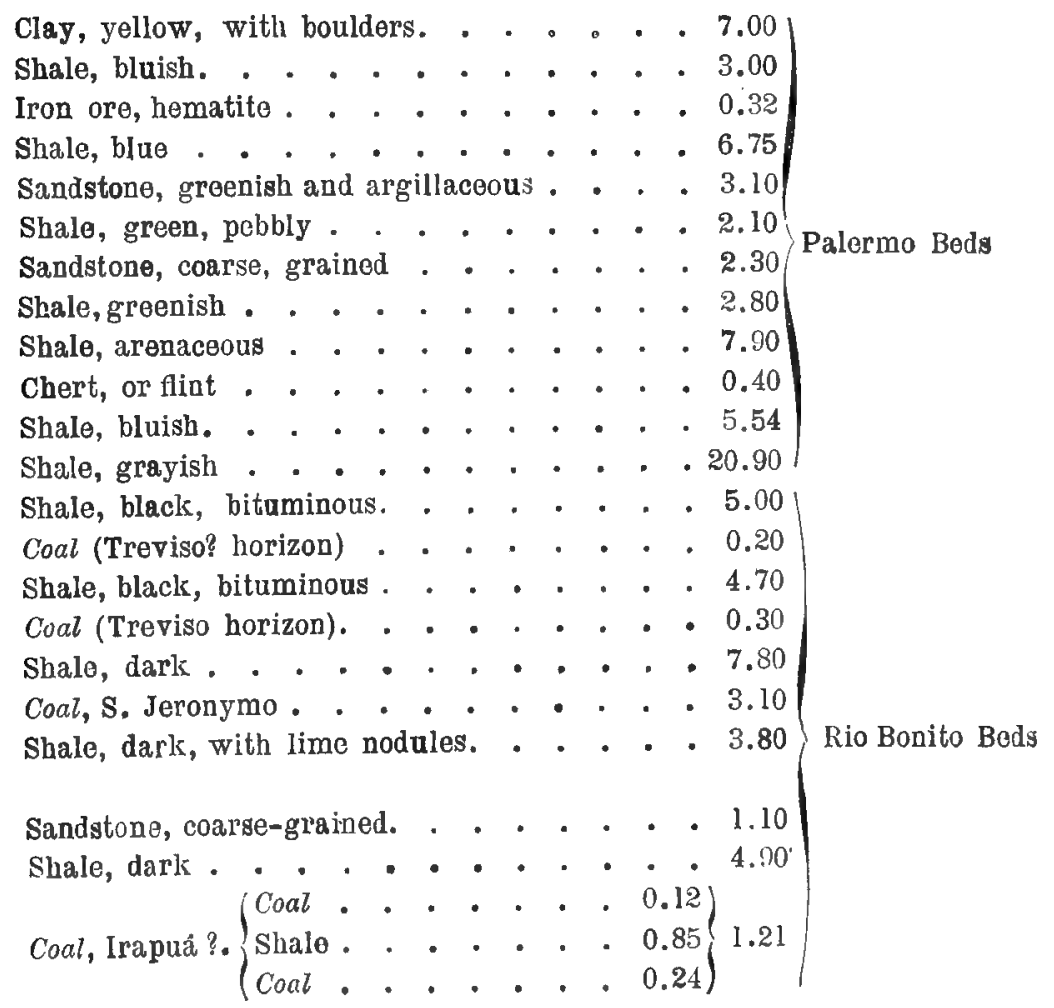

Meters. 


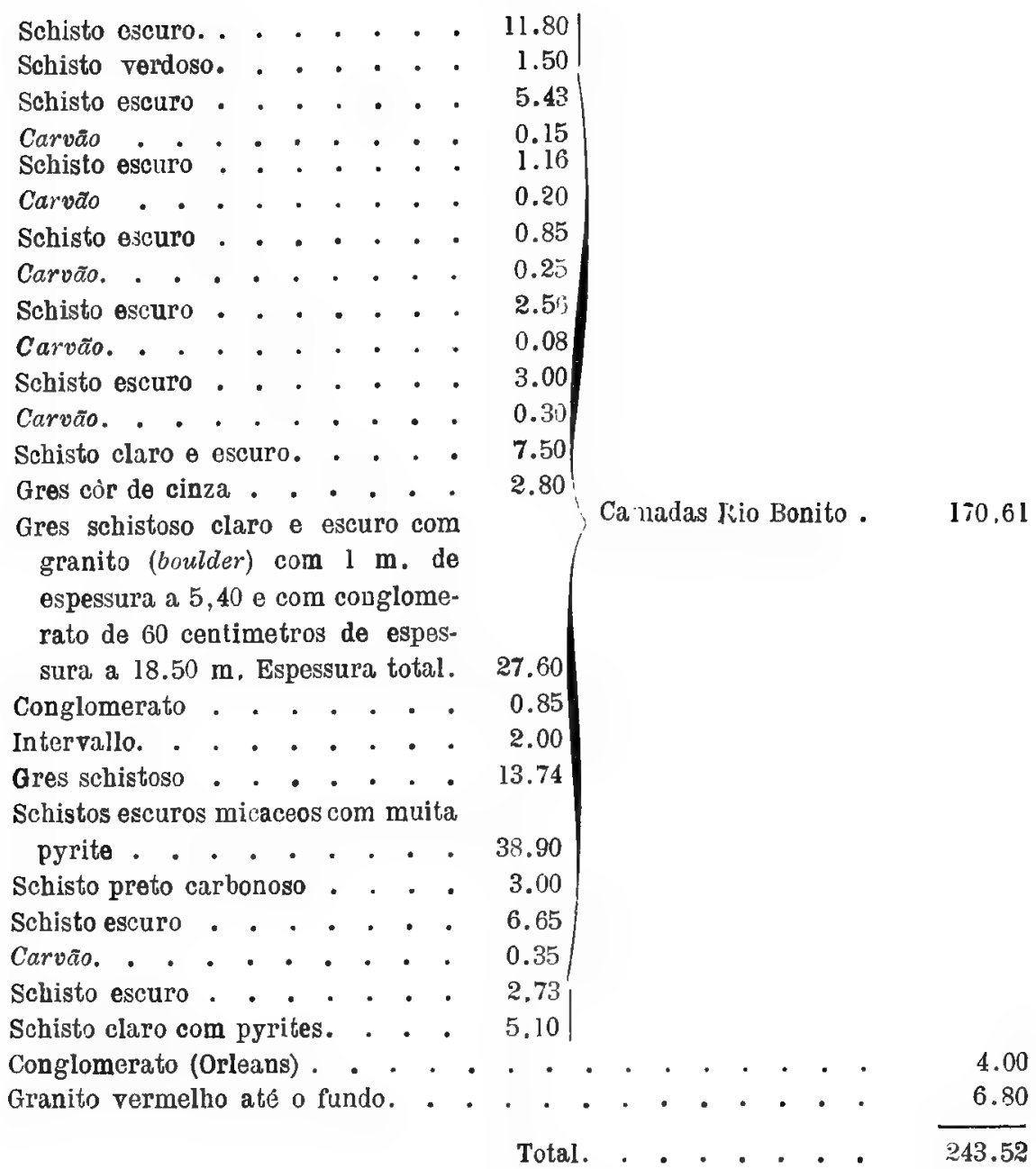

Esta sondagem dá a medida de 170.61 metros para espessura das camadas Rio Bonito e um intervallo de 174.61 do tope destas ao granito. Na regiăo de Minas, em Santa Catharina, este é de cerca de 190 melros.

Como se póde ver nestes registros de sondagem, varias pequenas camadas de carvão foram encontradas abaixo da S. Jeronymo, embora nenhuma seja bastante espessa para ter valor commercial. Encontra-se quasi sempre uma pequena camada de carvão com 20 a 30 centimetros de espessura, de 8 a 10 metros abaixo da camada S. Jeronymo, esta camada delgada corresponderia ao carvão de Treviso de Santa Catharina. 


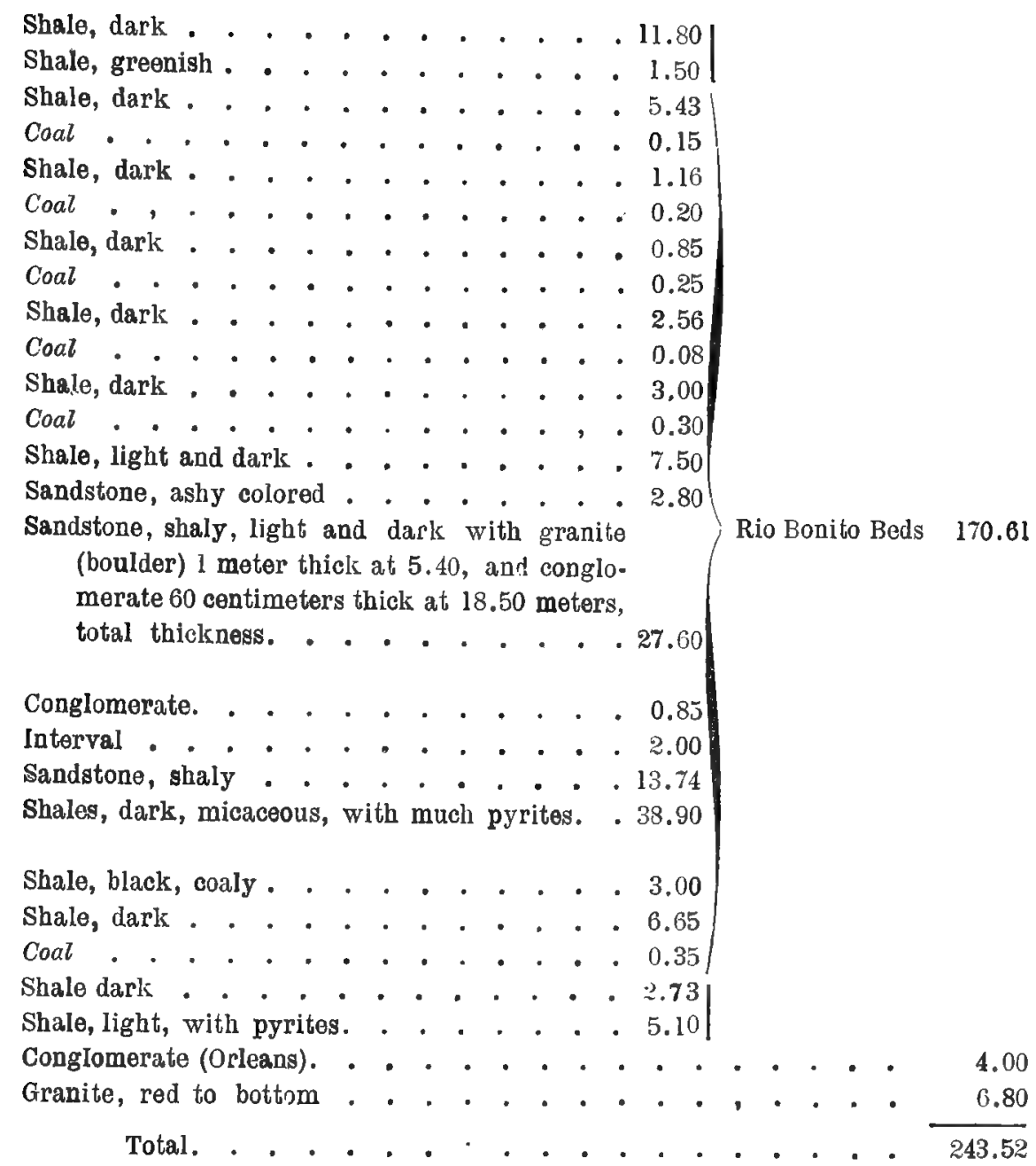

This boring gives a measurement of 170.61 meters for the thicliness of the latter to the solid granite In the Minas region of Santa Catharina this interval is about 190 meters.

As may be seen from these records, several small coal seamwere struck below the S. Jeronymo hed, jet none of them was thick enough to prove of economic importance. A small coal, 20 to 30 centimeters in thickness, is nearly always found at 8 to 12 meter's above the $\mathrm{S}$. Jeronymo ljed and this thin seam would correspond with the Tresviso coal of Santa Catharina. 
Secçōes intermediarias em Butiá, S. Sepé, Suspiro e outros pontos do Rio Grande do Sul, confirmam as que vimos de dar; isto é, que as series de rochas carboniferas, exceptuando sómente as da região de Minas, em Santa Catharina, conteem apenas uma camada importante de carvão, que está perto do tópe das camadas Rio Bonito. As mesmas condições parece existirem em localidades do Paraná e S. Paulo, onde ha carvão.

Butiá está a cerca de 30 kilometros a sudoéste da villa de S. Jeronymo e alli, em aguas da Sanga da Mina, foi explorado em pequena extensão o mesmo carvão em exploração no Arroio dos Ratos, que apresenta a seguinte secção em um barranco perto do qual foi aberto um poro atravez do carvão sob a direcção do Dr. Eugenio Dahne:

1. Schistos variegados visiveis . . . . . . . . . . . 3.05

2. Carvão bom . . . . . . . . . . . . . . . . 0.76

3. Schisto azul. . . . . . . . . . . . . . . 0.15

4. Conglomerato, seixos de quartzo . . . . . . . . . 0.30 . 2.02

5. Schistos aztes escuros. . . . . . . . . . . . . 0.56

6. Carvão . . . . . . . . . . . . . . , 0.25

7. Conglomerato escuro . . . . . . . . . . . . . 3.05

8. Gres branco com seixos . . . . . . . . . . . . . . . 3.05

Lsta localidade está na fazenda do Sr. coronel Antonio Soares de Carvalho.

Este carvão foi explorado em varios pontos entre Butiá e o rio Irapuá e parece ter uma estructura triplice em todos.

Perto da casa do Sr. Dr. Barcellos, no rio Irapuá, uma outra secção a oéste desta, deu as seguintes medidas:

1. Encoberto desde a casa . . . . . . . . . . . . 6.10

2. Gres aspero cellular . . . . . . . . . . . . . . . . 9.14

3. Conglomerato . . . . . . . . . . . . . . . . 6.10

4. Schistos cinzentos e claros . . . . . . . . . . . . . . 3.05

5. Schistos carbonosos (horizonte de Treviso). . . . . . . . . . 2.44

6. Gres . . . . . . . . . . . . . . . . . 7.62

7. Schistos . . . . . . . . . . . . . . . . 1.52

8. Carvão, com schistos pretos no tope, S. Jeronymo, superior. . . 3.05

9. Encoberto e argilla branca . . . . . . . . . . . . 3.05

10. Carvão schistoso S. Jeronymo, inferior . . . . . , . . 1.52

11. Argilla . . . . . . . . . . . . . . . . . 1.07

12. Gres. . . . . . . . . . . . . . . . . . 6.10

13. Sclistos areentos, plantas fosseis. . . . . . . . . 0.15 
Intermediate sections at Butiá, S. Sepé, Suspiro, and other poinls in Rio Grande do Sul; confirm the evidence of these sections just given namely, that the coal-bearing series of rocks, with the single exception of the Minas region in Santa Catharina, hold but one important coal seam, and that is near the top of the Rio Bonito beds. The same state of affairs appears to exist also at all localities in Paraná, and S. Paulo where coal occurs.

Butiá is about 30 kilometers south-west from the town of S. Jeronymo, and there the same coal mined on Arroio dos Ratos has been explored to a small extent on the waters of Sanga da Mina. IIere it exhibits the following section in a ravine, ncar where an old shaft was sunk through the coal under the supervision of Mr. Eugenio Dalne :

Meters.

1. Shales, variegated, visible . . . . . . . . . . . . .

2. Coal, fair. . . . . . . . . . . . . . 0.76

3. Shale, blue . . . . . . . . . . . . . . . . 0.15

4. Conglomerate quartz pebbles. . . . . . . . . 0.30$\} 2.02$

5. Shales, dark blue . . . . . . . . . . . . . . . 0.56

6. Coal. . . . . . . . . . . . . . . 0.25!

7. Conglomerate, dark . . . . . . . . . . . . 3.05

8. Sandstone, white, pebbly. . . . . . . . . . . 3.05

This locality is on the fazenda of Col. Antonio Soares de Carvalho.

This coal has been exploited at several points between Butiá and Rio Irapuá and it appears to have a triple structure in all.

Near the home of Dr. Barcellos, on Rio Irapuá, another section w'est from the house gave the following measurements:

Meters.

1. Concealed from house . . . . . . . . . . . . 6.10

2. Saudstone, rough, cellular . . . . . . . . . . . . 9.14

3. Conglomerate . . . . . . . . . . . . . . . 6.10

4. Shales, gray and light . . . . . . . . . . . . . 3.05

5. Coaly shales. (Treviso horizon). . . . . . . . . . . . . 2.44

6. Sandstone . . . . . . . . . : . . . . . . 7.62

7. Stiales . . . . . . . . . . . . . . . . . . 1.52

8. Coal, with black shales at top, Upper S. Jeronymo . • • • . 3.05

9. Concealed and white clay . . . . . . . . . . . . . 3.05

10. Caal, slaty, Lower S. Jeronymo . . . . . . . . . . 1.52

11. Clay . . . . . . . . . . . . . . . . . 1.07

12. Sandstone . . . . . . . . . . . . . . . 6.10

13. Sandy shale, fossil plants. . . . . . . . . . . . . 0.15 
14. Conglomerato . . . . . . . . . . . . . . . 0.30

15. Schisto areento, plantas fosseis . . . . . . . . . . . . 0.30

16. Carza, Irapua e schisto preto. . . . . . . . . . . . 0.76

O local desta secção é differente do da que foi dada em outra pagina e mostram, portanto, leves variações.

Foram cavados, tambem, dois poços para examinar as camadas de carvão a nordéste da residencia do Dr. Barcellos. O mais baixo destes, começa 100 pés a])aixo do tope de um grés massiço, ou 130 pés abaixo do nivel da rasa do Dr. Ramiro Barcellos e atravessou o seguinte:

1. Sólo, ote. .

2. Grés. • . . . . . . . . . . . . . . . . 1.52

3. Camadas areentas schistosas . . . . . . . . . . 3.35

4. Curvão e schisto escuro (Irapuá). . . . . . . . . . . . 1.60

5. Schisto até o fundo do poço . . . . . . . . . . . 0.10

Total. . . . . . . . . . . . . .

O carvão do fundo do poço foi iuentificado ao horizonte Irapuá, visto estar a 15.24 metros aljaixo do tope em que se encontrou uma camada de carvão, tendo praticamente a mesma espessura, a 5.33 metros ou 9.91 metros mais altoe 3.35 metros abaixo da base do que parece ser a porção superior da camada de carvão S. Jeronymo, A porção superior afflora na bocca do poço e ajuaixo desta, e os 3.35 metros de material que os separa são inteiramente de argilla. Estes carvões estão muito alte. rados em ambos os porsos, de modo que sua verdadeira qualidade nãose póde apreciar, mas ambos conteem uma grande quantidade de material schistoso.

Descendo o rio Irapuá, da fazenda do Dr. Barcellos, todas as camadas de car'vão logo mergulham para l saixo do nivel das aguas, sendo o mergulho rapido naquella direcção (noroéste). O affloramento das camadas da formação carbonifera dirigem-se do rio Irapuá para oéste, e, embora muito pouco ten ham sido exploradas, encontram-se occasionalmente em exposiçc̃es naturaes e assim se sabe que o carvão existe.

Uma destas exposições produzida por um desbarrancamento existe na fazenda da sesmaria do tenente Ricardo a cerca de 15 kilometros a oéste do rio Irapuá, onde se vê a seguin te successão de camadas :

Metros

1. Schisto molle gypsiforo (Palermo) . . . . . . . . . . .

2. Gres e conglomerato . . . . . . . . . . . . . . 24.38

3. Carvăo e schisto carbonoso (Treviso ?). • , . . . . . . . 0.91

4. Grés com pouco schisto . . . . . . . • • . • • . . . 9.14

5. Carvão e schistos protos carbonosos, porção superior de S. Jeronymo, visivel . . • . • . . • . . • . • . . • 1.83 
14. Conglomerate . . . . . . . . . . . . . . . 0.30

15. Sandy shale, fossil plants . . . . . . . . . . . 0.30

16. Coal, Irapuá, and black slate . . . . . . . . . . . . 0.76

The place of this section is al a different localion from that given on a previous page, and of course exhibits slight variations therefrom.

Two shafts were also sunk to test the coal heds north-east from the residence of Dr. Barcellos. The lower one of these Jegins at 100 feet below the top of a massive sandstone, or 130 feet below the level of Dr. Barcellos's house, and passed through the following:

1. Surface, soil, etc. . . . . . . . . . . . 1.83

2. Sandstone. . . . . . . . . . . . . . . . 1.52

3. Shaly, sandy beds . . . . . . . . . . . . . . 3.35

4. Coal and slate, dark ([rapuã). . . . . . . . . . . . . 1.60

5. Shale, to bottom of shaft . . . . . . . . . . . . 0.10

Total . . . . . . . . . . . . . . . $\overline{8.40}$

The coal at the bottom of the shaft has been identified with the Irapuá horizon, since it lies 15.24 meters below the top of the upper shaft in which a coal bed of practically the same thickness was struck at 5.33 meters, or 9.91 meters higher, and 3.35 meters under the Jase of what appears to be the upper division of the $\mathrm{S}$. Jeronymo coal bed. The upper division crops at and Jjelcw the mouth of the shaft, and the 3.35 meters of separating material is entirely of clay. These coals are very much weathered at both shafts, so that their true nature is not revealed, jut both contain a large proportion of slaty material.

In passing down Rio Irapua from the fazenda of Dr. Barcellos, all of the coal beds soon sink below water level, since the rate of dip is rapid in that direction (north-west). The outcrop of the coal measures swings westward, from Rio Irapuá, and while very little cxuloration has Jeen made, natural exposures are occasionally found, and thus the coal is linown to tye persistent.

One of these natural exposures, made ly a land-ilide, is on the fazenda da sesmaria do tenente Ricardo, about 15 kilometers west from Rio Irapuá, where the following succession is visible :

Meters.

1. Shale, soft, gypsiferous (Palelmo) . . . . . . . . . . . .

2. Sandstone, and conglomerate. . . . . . . . . . . . . 24.3

3. Coal and coaly slate (Treviso?) . . . . . . . . . . . . . 0.91

4. Sandstone, with Ilttle shale . . . . . . . . . . . . . . 9.14

5. Coal, and coaly black shales, upper division of S. Jeronymo, visible. $\quad$ - 1.83 
No $\mathrm{n} .2$ foi encontrado um specimen que o Dr. David White identificou, em duvida, ao Lepidophloios laricinus.

Na fazenda do Cantinho a 6 kilometros, S. $30^{\circ}$ Éste de S. Sepé, o carvão S. Jeronymo foi explorado nas calseceiras de uma grota justamente ao sul das casas da fazenda, onde ha exposta a seguinte successão de camadas:

Metros

1. Gres conglomeratico massiço . . . . . . . . . 15.24

2. Encoberto e grís. . . . . . . . . . . . . . . 6.10

3. Conglomerato escuro . . . . . . . . . . . . 6.10

4. Grés branco. . . . . . . . . . . . . . . . . . 30.5

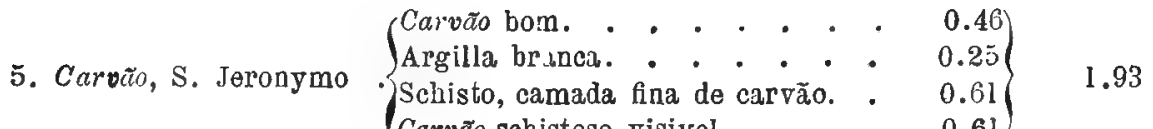

A cerca de um kilometro a sudoéste da exploração de carvão de Cantinho ha uma outra na fazenda de S. Raphael, onde foram feitas as seguintes medições em uma grota :

Metros

1. Grés massiço, schistoso, visivel. . . . . . . . . . . . 3.05

2. Encolerto, com conglomerato escuro . . . . . . . . . . . 9.14

3. Grés branco cinzento. . . . . . . . . . . . . 3.05

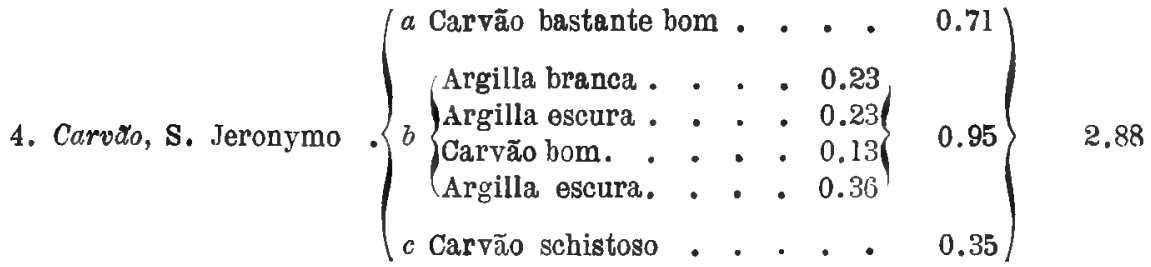

5. Argilla branca. . . . . . . . . . . . . . . 0.61

6. Grés massiço, cinzento, visivel . . . . . . . . . . 6.10

Um specimen de Sigillaria, ou Lepidophloios foi visto na parte superior da camada de carvão.

A cerca de 12 kilometros a Sudoéste de S. Sepé este mesmo carvão foi explorado e empregado em pequena escala em fornalhas de caldeiras da mineração de ouro em Serrito do Ouro, segundo dizem, com bom resultado.

A sudoéste de S. Sepé não se fizeram mais explorações para carvão até perto de Suspiro, a 547.57 kilometros de Porto Alegre. Alli, a 3 kilometros da estação da estrada de ferro foi explorado na fazenda do Sr.Antonio Vazo que parece ser a camada S. Jeronymo. 
In n. 2 was found a specimen of what Dr. David White doubtfully identifies as Lepidophloios laricinus.

On Fazenda do Cantinho, 6 kilometers S. $30^{\circ}$ East from S. Sepé, the S. Jeronymocoal has been exploited at the head of a ravine just south from the farm buildings where there is exposed the following succession :

Meters.

1. Sandstone, conglomeratic, massive . . . . . . . . . 15.24

2. Concealed and sandstone . . . . . . . . . . . 6.10

3. Conglomerate, dark . . , . . . . . . . . . 6.10

4. Sandstone, white. . . . . . . . . . . . . . . . 3.05

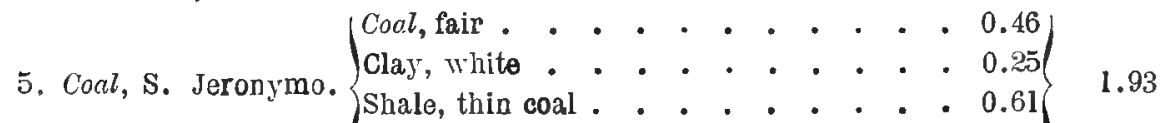

About one liilometer south-west from the Cantinho exploration for coal, there is another on the São Rafael fazenda where at the head of a ravine, the following measurement was made :

1. Sandstone, massive, flinty, visible . . . . . . . . . . 3.05

$\approx$ Concealed with dark conglomerate. . . . . . . . . . . 9.14

3. Sandstone. grayish white. . . . . . . . . . . . . 3.05

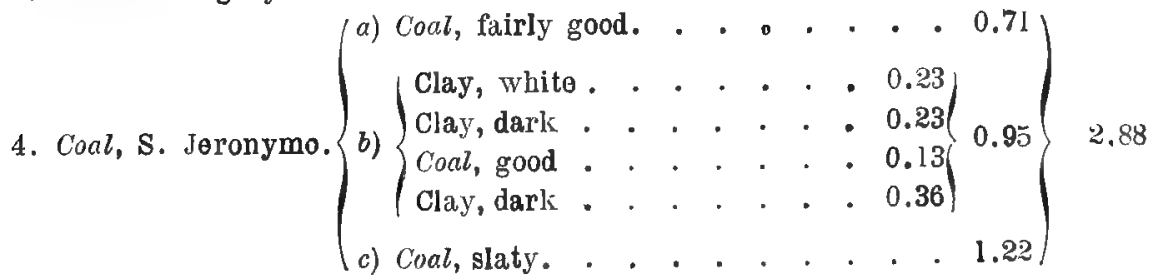

5. Clay, white. . . . . . . . . . . . . . . 0.61

6. Sandstone, massive, gray, visible . . . . . . . . . . 6.10

A specimen of Sigillaria or Lepidophloios was seen in the top portion of the coal.

About 12 kilometers south-west from the town of S. Sepé, this same coal was once mined in a small way to furnish steam power for gold mining in Serrito do Ouro, with reported fair results.

South-westward from S. Sepé, no more explorations have been made for coal until in the vicinity of Suspiro, 547.57 kilometers southwest from the railway station, what appear's to the the S. Jeronyma coal has been exploited on the fazenda of Sr. Antonio Vaz. 
Foi cavado um poço através das camadas, encontrando-se a seguinte successão destas :

Metros

1. Argillas o schistos superficiaes. . . . . . . . . . . . 4.60

2. Carväo . . . . . . . . . . . . . . . . 0.40

3. Argillas cinzentas e brancas. . . . . . . . . . . . . . 4.00

4. Carväo. . . . . . . . . . . . . . . . . . . . 1.70

5. Camadas areentas e pyritosas até o fundo. . . . . . . . . 0.30

Na face excavada no barranco observou-se a seguinte successão de leitos:

Metros

1. Argilla branca o cinzenta . . . . . . . . . . . . 2.44

2. Schisto escuro . . . . . . . . . . . . . . . . . . 0.15

3. Carvão . . . $\left\{\begin{array}{llll}\text { Carvão e schisto bituminoso. } & \cdot & \cdot & 0.81 \\ \text { Argilla branca. } . . \cdot & \cdot & . & 0.01 \\ \text { Carvão o schisto bituminoso. } & \cdot & 0.81\end{array}\right\} \quad 1.63$

4. Schisto azul pyritoso . . . . . . . . . . . . 0.15

5. Grés massiço cinzento. . . . . . . . . . . . . . . 1.52

o n. 3 corresponde a toda, ou a uma parte da camada de carvão S. Jeronymo.

Foi exploradoalli e remettido para S. Gabriel afim de ser experimentado na usina electrica.

A cerca de 3 kilometros ao sul da estação de Rio Negro, da estrada de ferro, a camada de carvão S. Jeronymo foi explorada em alguma extensão na margem oéste do Rio Negro e enviado a Bagé para ser queimado nas xarqueadas, etc.

Duas excavações foram feitas na fazenda do Sr. Carlos Brett, em uma das quaes a seguinte successão de camadas foi medida:

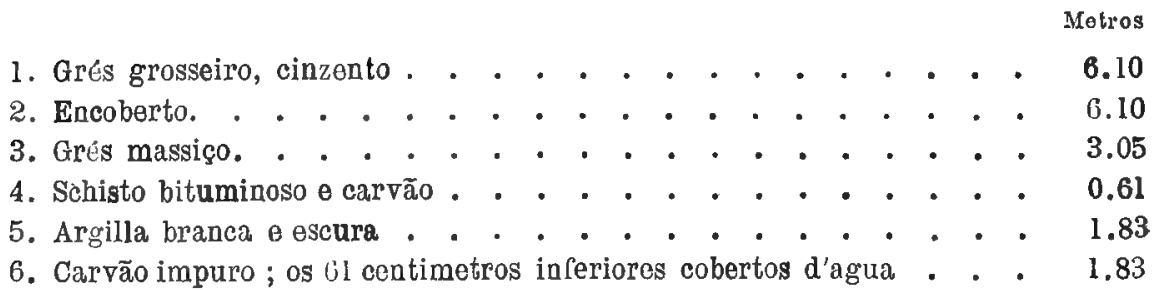

Na parte inferior do $n .5$ ha uma fina camada de argilla côr de chocolate com fragmentos de plantas fosseis.

Em uma outra excavação no carvão, poucos metros rio abaixo, se vê praticamente a mesma successão de camadas. 
A shaft has been sunk through the measures with the following reported succession :

Meters

1. Surface clays and s'lales . . . . . . . . . . . . . 4.60

2. Coal . . . . . . . . . . . . . . . 0.40

3. Clays, gray and white. . . . . . . . . . . . . . . 4.00

4. Coul . . . . . . . . . . . . . . . 1.70

5. Sandy, pyritous bods to bottom . . . . . . . . . . 0.33

At the face of the stripping in the lavine, the following succession was olsserved :

Meters

1. Clay, white and gray . . . . . , . . . . . . 2.44

2. Shale, dark . . . . . . . . . . . . . . 0.15

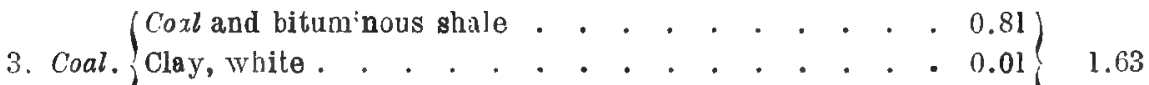

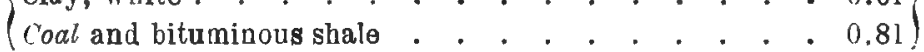

t. Shale, blue, pyritous . . . . . . . . . . . . . . . 0.15

5. Sandstone, massive, gray. . . . . . . . . . . . 1.52

N. 3 is very probably the replesentative of all or a portion of the S. Jerony mocoal.

It has been exploited here and shipped to S. Galsriel for testing in the electric light works.

About 3 kilometers south from the railway station of Rio Negro, the S. Jeronymo coal bed has been mined to some extent on the west bank of Rio Negro, and shipped to Bagé for use in the xarqueadas etc.

Two openings have there leeen made on the fazenda of Mr. Carles Brett, at one of which the following succession was measured :

Metor' 1

1. Sandstone, coarse, gruy . . . . . . . . . . . . . 6.10

2. Concealed. . . . . . . . . . . . . . . . . 6.10

3. Sandstone, massive. . . . . . . . . . . . . . 3.05

4. Bituminous slate and coal. . . . . . . . . . . . . 0.61

5. Clay, white, and dark. . . . . . . . . . . . . . 1.83

6. Coal, impure, the lower 61 centimeters being covered with water. . 1.83

In the lower portion of $n .5$ is a thin layer of chocolate colcred clay with fragments of fossil plants.

Another opening in the coal a few meters farther down stream exhibits practically the same succession. 
Na margem opposta, ou éste do Rio Negro " mesmo carvão foi minado em gl'ande extensão a céo ałerto, na fazenda do Sr. Freitas, (inde se mediu a seguinte secção:

Metros

1. Gres, massiço, visivel . . . . . . . . . . . . . 3.05

2. Argilla e schisto de cor clara. . . . . . . . . . . . . 0.30

3. Schisto escuro carbono . . . . . . . . . . . 0.30

4. Argilla branca . . . . . . . . . . . . . . : . . 1.52

5. Schisto escuro com faixas cor de cilocolate contendo plantas fussejs. - 0.30

6. Carvão schistogo . . . . . . . . . . . . . . . . 1.68

7. Argilla de $\mathrm{cer}^{\circ}$ clara até o fundo . . . . . . . . . . 0.30

O n. 6 é plovavelmente a por'ão superior da camada de carvão deS. Jeronymo, a não ser que o n. 3, represente a parte superior daquella camada.

Foi mandado para Bagé para comlıntivel, mas contém muilu schisto enxofre.

A' cerca de 20 kilometros mais além, para sudoeste e a 2 kilometros ao norte da estrada de ferro, este mesmo carvão foi explorado na fazonda do Sr. Francisco Borges Lucase alli em uma profunda grota foi medida a seguinte successão de camadas:

1. Gres massiço . . . . . . . . . . . . . . . 6.10

2. Schistos bituminosos carbonosos (Treviso?) . . . . . . . . . . 0.91

3. Argilla branca . . . . . . . . . . . . . . . . 1.52

4. Schisto bituminoso. . . . . . . . . . . . . . . 0.61

5. Argilla cor de chocolate plantas fosseis . . . . . . . . . . $0,0 \mathrm{l}$

6. Schistos escuros, carbonosos. . . . . . . . . . . . . 0.25

7. Schisto, cor de chocolate claro, plantas fosseis. . . . . . . . 0.10

8. Cåvão S. Jeronymo $\cdot\left\{\begin{array}{lll}\text { Carvão chistoso. } \cdot . \cdot \cdot \cdot & 1.83 \\ \text { Argilla branca e encoberto } \cdot \cdot \cdot & 1.52 \\ \text { Carvão schistoso incompletamente } & \\ \text { exposto. } \cdot \cdot \cdot \cdot \cdot \cdot & 1.52\end{array}\right\} 4.87$

9. Argilla branca visivel até o fundo da grota. . . . . . . . 0.30

O ir. 8 parece representar a camada de carvão S. Jeronymo ao passo que o n. 2 deve representar a camada superior de carvão, ou Treviso.

A secção aqui é muito semelhante á que se ve em pagina anterior, de Serro Partido, na fazenda do coronel Manoel Lucas de Lima, 10 kilometros a oeste e ha pouca duvida que represente a mesma camada de carvão, isto é, de S. Jeronymo.

E' provavel que o carvão que ha no rio Jaguarão tambem pertença a este horisonte, embora a falta de tempo me impedisse de fazer pessoalmente uma visita an logar. 
On the opposite or easl Jank of Rio Negro, the same coal has been extensively mined $M$ stripping on the fazenda of Sr, Freitas, where the following section was measured :

Meters

l. Sandstone, massive. . . . . . . . . . . . . 3.05

2. Clay and shale, light colored. . . . . . . . . . . . 0.30

3. Shale, dark, coaly . . . . . . . . . . . . . . . . 0.30

4. Clay, white . . . . . . . . . . . . . . . 1.52

5. Shale, dark, with chocolate hanls containing fossil plants. . . . 0.30

6. Coall, slaty . . . . . . . . . . . . . . . 1.68

7. Clay, light colored to boltom of exposure. . . . . . . . . 0.30

N. 6 is prolnaly the upper portion of the S. Jeronymo coal unless n. 3 could represent the upper part of that bed.

It has heen slipped to Bagé for fuel but contains much slate and sulphur.

About 20 kilometer's farther to the south-west, and 2 kilometers north of the railway, this same coal has jeen exploited on the fazenda of Mr. Francisco Borges Lucas, and there in a deep ravine, the following succession was measured:

1. Sandstone, massive. . . . . . . . . . . . 6.10

2. Shales, bituminous, coaly (Treviso ?) . . . . . . . . 0.91

3. Cl:ty, white. . . . , . . . . . . . . . 2.52

4. Shale, bicuminous . . . . . . . . . . . . . 0.61

5. Clay, chocolato colored, fossil plantis . . . . . . . . . . $\quad 0.01$

6. Shales dark, coaly . . . . . . . . . . . . . . . . 0.25

7. Shale, light choculate, fossil plants. . . . . . . . . . . . 0.10

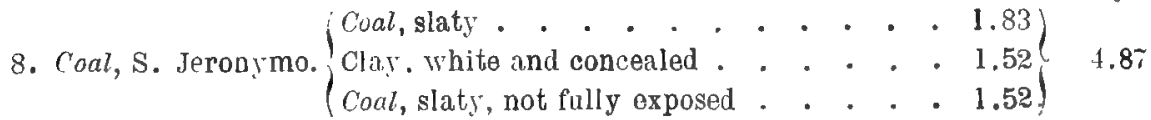

9. Clay, white, visible to bottom of the ravine. : . . . . . 0.30

N. 8 appears to represent the S. Jeronymo coal bed while n. 2 may represent the overlying or Treviso coal.

The section here is very much the same as that shown on a pre. vious page from serro Partido on the fazenda of $\mathrm{Col}^{\circ}$. Nannel Lucas de Lima, 10 kihmeters wert, and there can be little doubt that it represents the same coal hed; namely, thes. Jeronymo.

It is rery prolialnle that the coal along Rio Jaguarão also belongs at this horizon, although lack of time prevented a personal visit to the place. 
o coronel Lucas deu-me a seguinte composição de dois specimens de carvão do Serro Partido, determinada no laboratorio do Lyceu Riograndense de Pelotas:

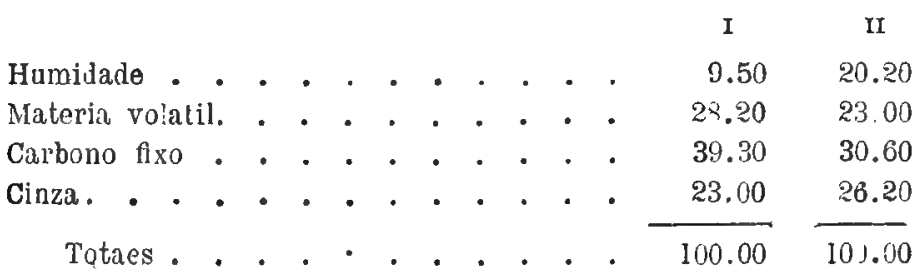

\section{Carvão Treviso}

Nos altos das montanlias, ao longo da estrada nova, \& 1/2 kilometros a noroeste de Minas em Santa Catharina e a 342.4 metros acima do nivel do mar ha um affloramento de uma pequena camada de carvão que parece estar acima do horisonte da camada Barro Branco que que afflora em uma volta da estrada um kilometro a éste, apresentando a seguinte estructura segundo as medidas do Dr. Seixas :

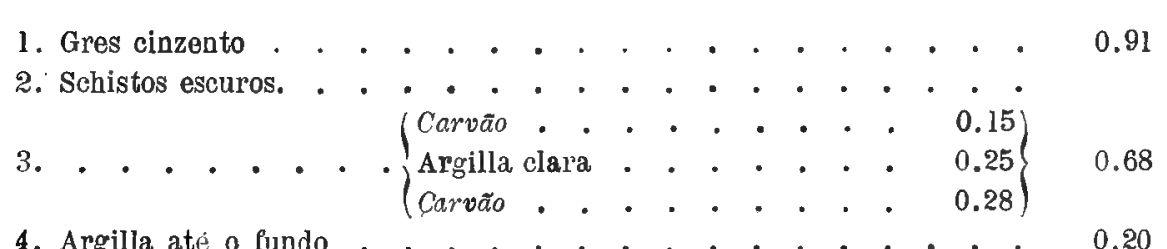

E' possivel que esta seja a camada Barro Branco, mas ao passo que a altitude desta (338.2) uma millıa a éste é de 4.2 menos que a supposta camada Treviso, o Dr. Seixas sol) cuja direcção as altitudes foram determinadas, considera as camadas de carvã distinctas, embora suas estructuras se assemelhem muito.

Em 'Treviso, 30 kilometros a sudoeste de Minas, ha uma camada de carvão schistoso que afflora no barranco da margern e no leito do rio Mãe Luzia e onde foi cavado um poco perto dos fundamentos do moinho do Sr. Bianchin. O carvão tem alguns pés de espessura, mas contém muito material schistoso. Este é o carvão Treviso e é o mais alto leito de carvão das camadas Rio Bonito.

O rio Ferreiro correndo do sul desagua no Mãe Luzia em Treviso e á cerca de uma milha r’io acima a camada de car'vão Treviso apparece á 
Cor. Lucas gave me the following for the composition of two specimens of coal from Serro Partido as determined in the laboratory of the Lyceu Riograndense at Pelotas:

\begin{tabular}{|c|c|c|c|c|c|c|c|c|c|}
\hline & & & & & & & & I & II \\
\hline Moisture & . & & & - & - & . & . & 9,50 & 20.20 \\
\hline Volatile matter & • & & . & • & . & - & - & 28.90 & 23.00 \\
\hline Fixed carbun . & - & & & . & . & . & - & 39.80 & 30.60 \\
\hline Asli, . . & - & & . & . & . & . & - & 23.00 & 26.20 \\
\hline Totals . & . & & & . & . & . & . & 100.030 & 100.000 \\
\hline
\end{tabular}

\section{The Treviso coal}

In the summit of the hills along the Estrada Nova, is 1/2 kilometers north-west from Minas, Santa Catharina, and at 342.4 meters a]ove sea level, there occurs the outcrop of a small coal hed. It appears to be above the horizon of the Barro Branco seam which crops at the turn of the road a lilometer eastward. It exhilsits the following structure as measúred by Dr. Seixas :

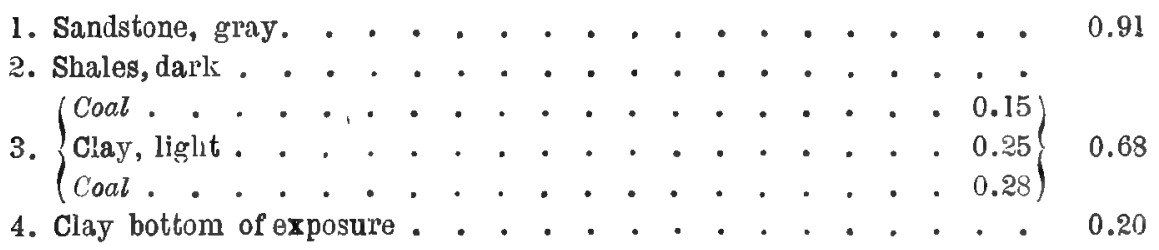

This may possiljly the the Barro Branco coal, Jut since the later's elevation (338.2) a mile eastward is 4.2 meters less than the supposed Treviso bed, Dr. Seixas, under whnse supervision the elevations were taken, considers the coals distinct, althougl their structure is much the same.

At Treviso, 30 kilometers south-ivest from Minas, there is a Jed of slaty coal which crops in the bank and bed of Rio Mäe Luzia, and has been dug into in a shaft sunk from the Jasement of Mr Bianchin's mill near by. The coal is soveral feet in thickness, but contains much slaty material. This is the Trevls, coal, and is the highest coal seam of the Rio Bonito beds.

Rio Ferreiro puts into Rio Mãe Luzia at Treviso from the south,and about one mile up this stream, the Treviso coal comes out to daylight 
superficie, na elevação sudeste dos estratos onde foi medida a seguinte successão de camadas :

Metros

1. Schistos pretos . . . . . . . . . . . . . . 0.61

2. Carväo, cinta . . . . . . . . . . . . . 0.05

3. Schistos carbonosos. . . . . . . . . . . . . 0.91

4. Carvão schistoso . . . . . . . . . . . 0.38$\} 1.95$

5. Schisto preto com fidas camadas de carvão . . . . . . 0.61

6. Schistos escuros. . . . . . . . . . . . . . . . •

7. Gres massiço no leito do rio . . . . . . . . . . 0.15

A porção superior do n. \& é bastante pura em 10 a 15 centimetros e foi um pnuco explorada em um corte aberto, para uso local, onde tem apparencia anthracitica, por terem sido as camadas cortadas por um dique de diabase a poucos pés de distancia.

A seguinte analyse feita sol as vistas do prof B. H. Hite mostra a composição cliimica do carvão Treviso desta localidade :

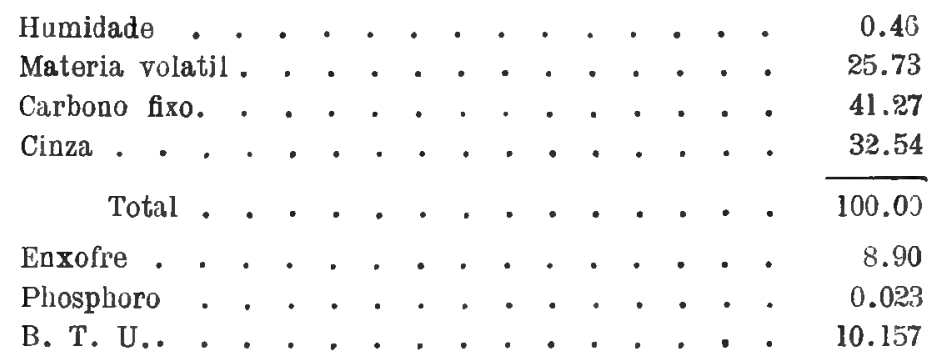

Esta analyse mostra ser este um combustivel com bastantes impurezas, tanto cinza como enzofie sendo, portanto, de pouco valor commercial.

Nas secçĩes dadas, de S. Jeronýmo, Irapuá e de qualquer outra parte do Rio Grande do Sul, vê-se um carvão schistoso a 8, ou 10 metros acima da camada principal da regiăo, representando provavelmente o carvão Treviso, visto sar'sempre de má qualidade e sem importancia cummercial, sendo ainda, a mais elevada camada da serie.

Provavelmente foi este mesmo carvão o explorado em Capellinha, ou mina das Flor'es, 15 kilometros a nordeste da fazenda do Dr. Barcellos nnde foi medida a seguinte secrĩo em uma das velhas galerias: 
on the south-east rise of the strata, where the following succession was measured :

1. Black shales.

3. Coaly slates

4. Coal, slaty . . . . . . . . . . . . . . 0.381 .95

5. Slate, black, with thin coaly layers. . . . . . . . . . . 0.61

6. Shales, dark. . . . . . . . . . . . . . . 0.15

7. Sandstone, massive in bod of river . . . . . . . . . . . .

The upper portion of $n$. \& is a fairly pure for from 10 to 15 centimeters, and has bren explored some in an open cutting for local use, where it has an anthracitic appearance, since the measures are cut by a dike of diabase only a fer feet distant.

Fhe following analysis made under the supervision of Prof. B. II. Iite shows the chemical constitution of the Treviso coal at this locality :

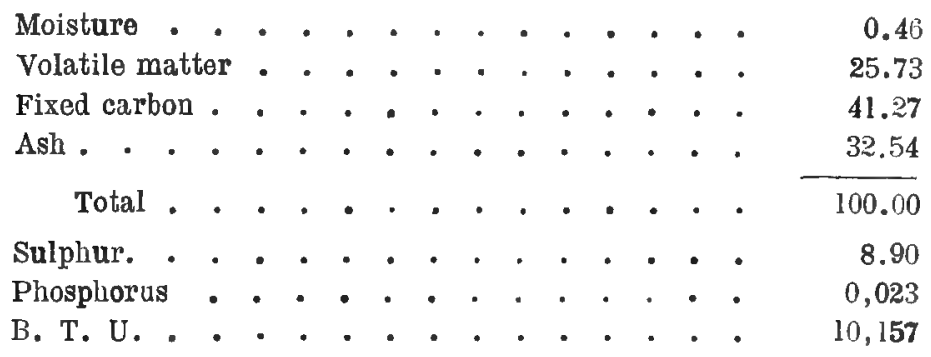

This shows a fuel quite high in impurities of Joth ash and sulphur and hence the coal is of little economic importance.

In the sections shown from S. Jeronymo; Irapua, and elsewhere in Rio Grande do Sul, a slaty coal is visible 8 to 12 meters above the main bed of the region, and this is possibly a representative of the Treviso coal since it is always of poor quality, and of no economic importance, and is, in addition, the highest coal bed of the series.

It is probajoly this same coal that has been explored at Capellinha, or mina das Flores, 15 kilometers nort-east from the fazenda of Dr. Barcellos, where the following section was measured at one of the old galleries :

Meters

1. Maroon colored shales . . . . . . . . . . . . .

2. Conglomerate and sandstone. . . . . . . . . . . . 9.14 


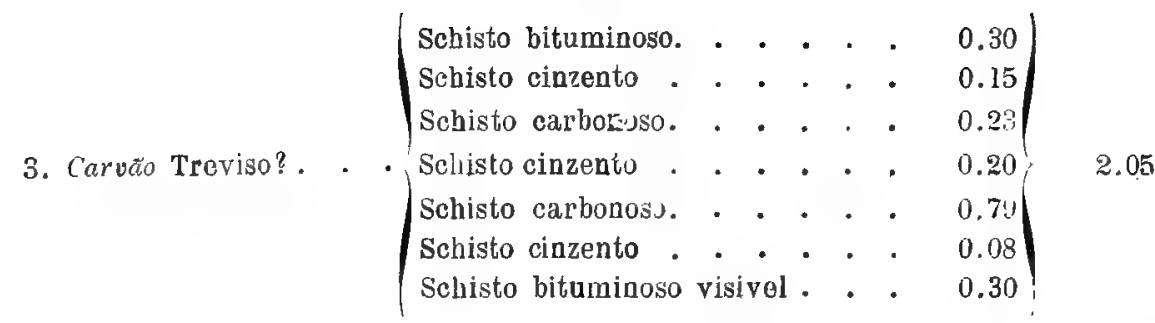

No schistn hituminuso ha camadas de meio a um centimetro de cal'vão de apparencia J)rilhante e l'ica. Varias galerias loram alli abertas nas montanhas para explorar o carvão, mas nada de ralı foi descoberto.

Na fazenda do sr. Joaquim Colrea de Oliveira, 6 kilometros distante de Capellinha, foi feita outr'ora uma oulra exploração para carvão, neste mesmo horizonte.

0 affloramento lá é tamluem de um schisto preto em que ha finas camadas de carvão sob uma camada massiça de gres conglomeratico com 15 a 20 metros de espussura.

Ha muito schisto bituminoso sobre o solo, que foi retirado das galerias cavadas nas montanhas para explorar o carvão, mas este foi encontrado somente em finas camadas, interstratificado com o schisto.

\section{Qualidade $\theta$ valor do carvão brazileiro, como combustivel}

Muitas analyses e relatorios sobre o carvão Jjrazileiro têm sido publicados.

Em muitos destes relatorios parece que as amostras foram esco1hidas das mais puras porções dos leitos de carvão em questão, em vez de sel-o de amostras medias que representassem o leito inteiro. Com este methodo de tirar amostras obtinham-se resultados muito contradictorios quando os mesmos carvões eram submettidos a ensaios com fins commerciaes.

As analyses publicadas levaram muita gente a esperar que um car'vão mais puro seria eventualmente encontrado em quantidade e que em estado natural deslocaria o carvão Cardiff, da industria brazileira.

o resultado do trabalho da Commissão de Estudo das Minas de Carvão de Pedra em 1904 (que foi completamente confirmado pelos estudos posteriores em 1905-06) foi de se abandonar a esperança de encontrar camadas de carvão puro e com espessura exploravel no Brazil, pois que era muito evidente que o carvão em cada aftloramento e exploração 


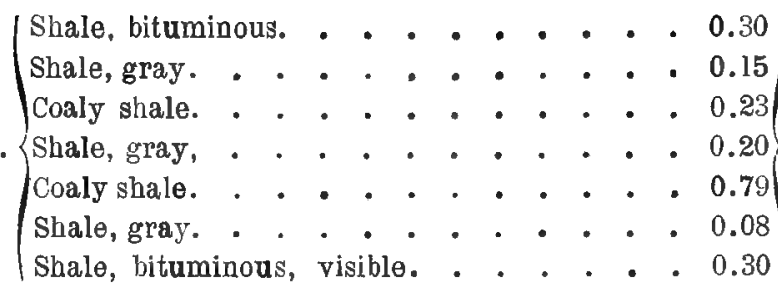

Bright rich looking layers of coal $1 / 2$ to 1 centimeter thick occur in the bituminous shale. Several galleries were driven into the hills here to explore the coal, but nothing valuable was discovered.

On the fazenda of Mr. Joaquim Corrêa de Oliveira, 6 kilometer's distant from Capellinha, another exploration was once made for coal at this same horizon.

The outcrop there is also a black shale in which are thin seams of coal under a massive ledge of conglomeritic sandstone 15 to 20 meters thick.

Much bituminous shale lies about the surface which was taken from the galleries driven in to the hills for coal, but the latter was found in only thin layers interstratified vith the shale.

\section{Quality and fuel value of Brazilian coal}

Many analyses and reports on Brazilian coal have lyeen published in the past.

In most of these reports, the samples appear to have been selected from the purest portions of the coal beds in question instead of from average samples which would include the entire bed. By this method of sampling, very contradictory results vere olstained when the same coals were subinitted to test of actual commercial use.

The analyses published led many people to hope that a purer coal would eventually be found in good quantity, something that would in its natural state displace Cardiff coal in Brazilian industry.

The result of the work of the CoalCommission during the year 1904 (which was fully confirmed by the further studies in 1905-6) was to abandon hope of finding beds of pure coal of explorable thickness in Brazil, since it was only too apparent at every outcrop and exploitation visited that the coal was everywhere of practically the same quality; 
examinados era em qualquer ponto praticamente da mesma qualidade, que havendo car'vão bastante puro em cada camada estava tão interestratificado e entremeiado com schisto bituminoso, ou ardosia de modo a tolnar a separação impossivel pelos methodos ordinarios de mineração.

Colligiram-se amostras de todos as pontos visitadios onde houve exploraçùes, nos listadus de Santa Catharina, Rio Grande do Sul e Paraná.

Estas amostras foram tiradas de toda a face da camada, de alto a baixo e foram analysadas soly as vistas do prof. B. H. Hite, chimico da estação de agricultura experimental de Mest Virginia e chimico chefe da Commissão Geologica de TVest Virginia. O professor Hite foi auxiliado neste lrabalho pelos Srs. Frank F. Grout, Leirester Pathon e C. S. Forlium, chimicos assistentes da Commissão Geologica e da Estação Experimental.

Todas as amostras, cum excepção das das minas da Companhia S. Jeronymo no Rio Grande do Sul, foram tiradas perto do affloramento do carvão e portanto estavam mais ou menos alteradas, apresentando por esta razão mais alta porcentagem de cinza e impurezas.

As seguintes tabellas dão o resultado das analyses de amostras de carvão brazileiro, colligidas no campo sob) a fiscalisação directa do chefe da Commissão. 
that while some fairly pure coal existed in every bed, it was so interstratified and ingrained with bituminous shale or slate as to render the separation lyy ordinary mining methods impossible.

Samples of coal from all the points risited in Santa Catharina, Rio Grande do Śl, and Paraná, where exploilations had been made, were collected.

These samples were taken entirely across the face of each seam, and were analyzed under the supervision of Prof. B. II. Hite, Chemist of the West Virginia Geological Survey. Prof. Hite was aided in this work by Messrs. Frank F. Grout, Leicester Patton, and C. S. Forkum, the assistant chemists of the Geological Survey and Experiment Station.

All of the samples except those from the mines of the S. Jeronymo Co. in Rio Grande do Sul, were taken from near the crop of the coal and hence were in a more or less weathered condition, thus increasing the percentage of ash impurities.

The fallowing tables give the results of the analyses of Brazilian coal from samples collected in the field under the direct supervision of the Chief of the commission : 
TABELLA N. 1

ANALYSES IMMEDIATAS

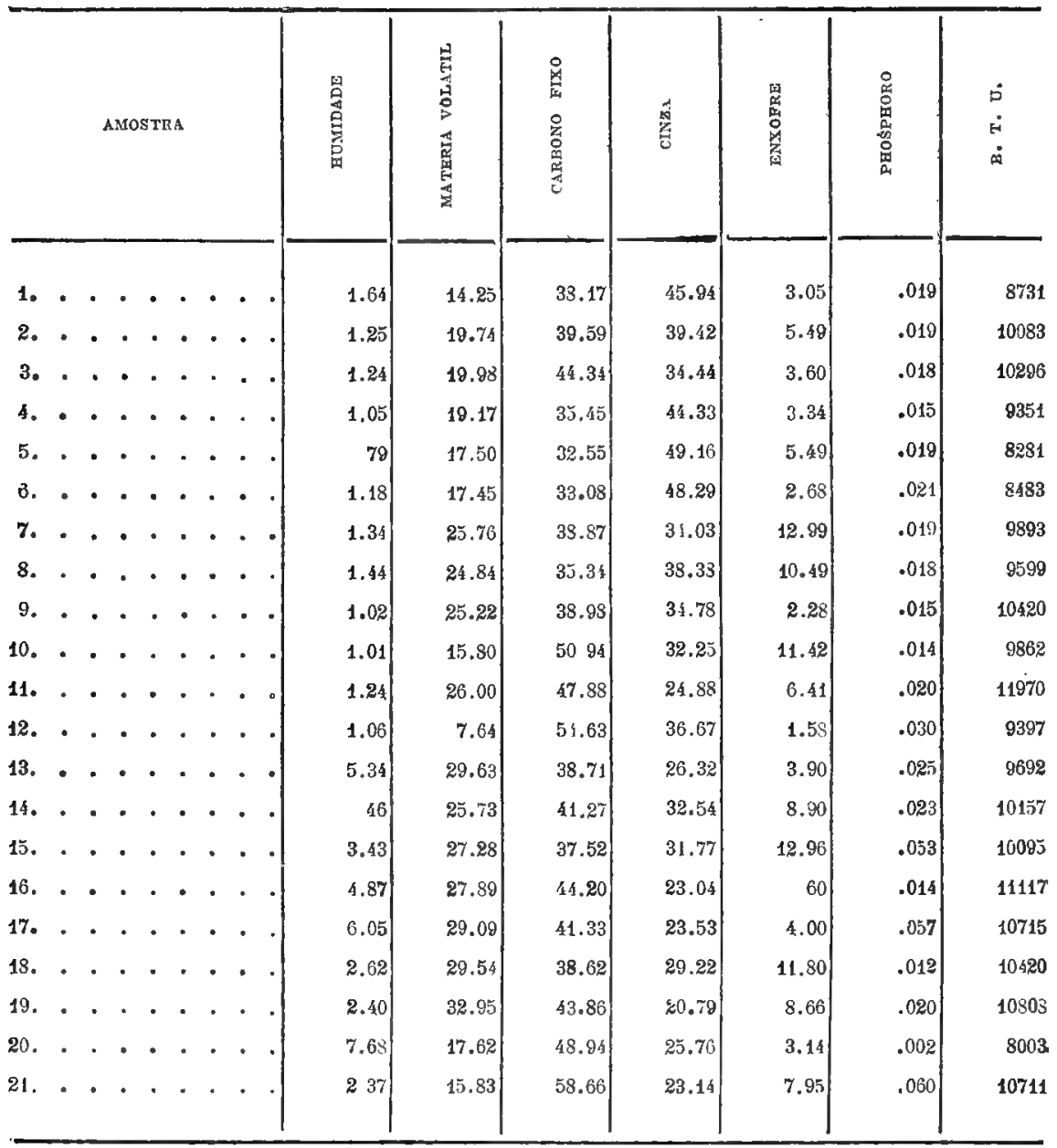

Nomes das minas, etc.

Amostras ns.

1 Bancos medio o superior, Bonito n. 1, Santa Catharina.

2 Banco inferior, Bonito n. 1 , idem.

3 Do monte de carvão sob telheiro, Bonito n. 1 , idem.

4 Bonito $\mathrm{n}$. 2, idem.

5 Bonito n. 3, idem.

6 Camada Bonito, Tres Saltos, idem.

7 Bonito Rider, carvão na estrada nova, idem. 
TABLE N. 1

PROXIMATE ANALYSES

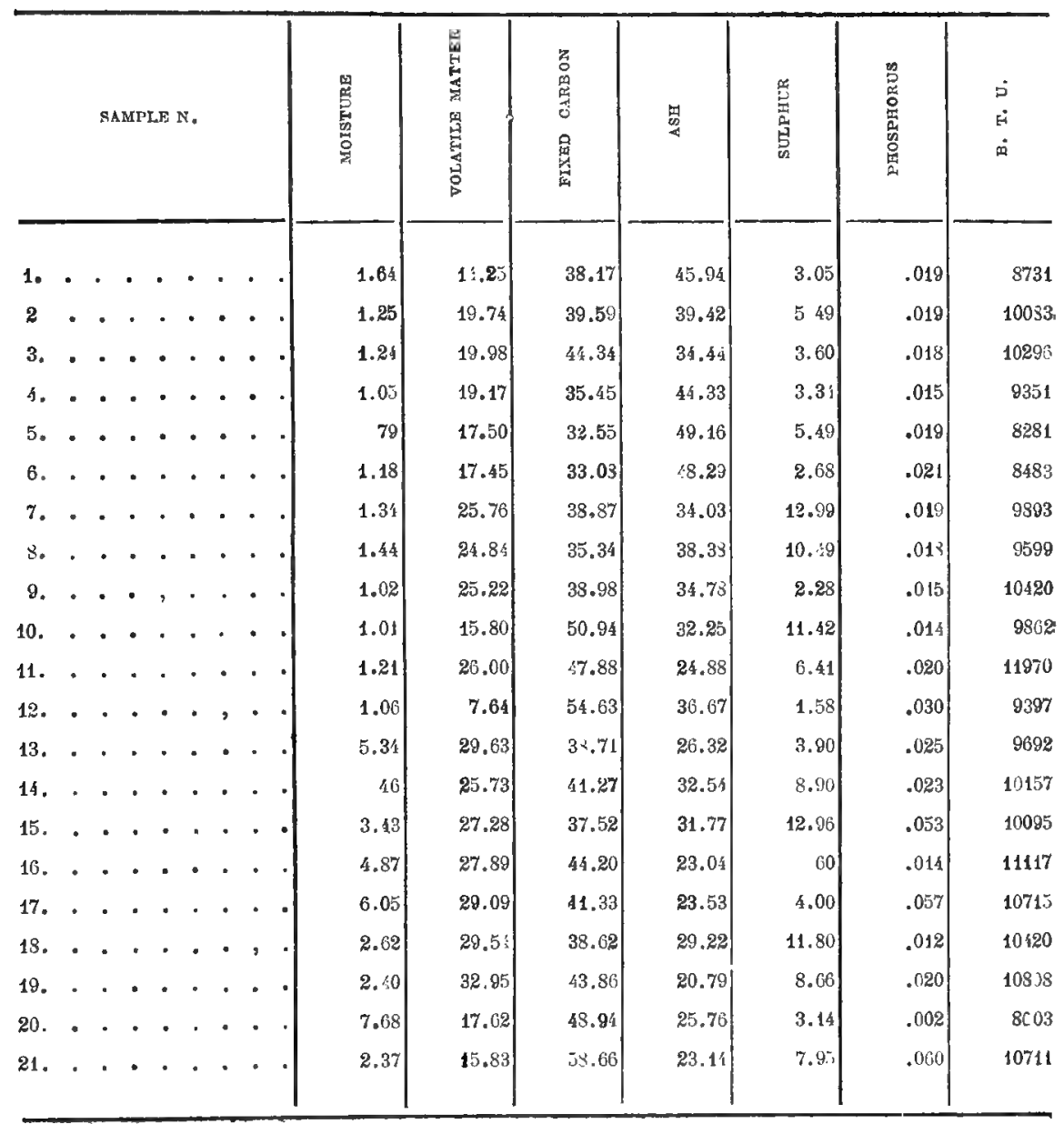

Names of mines

Sample Ns.

1 Middle and upper benches, Bonito n. I, Santa Catharina .

2 Lowel bench, Bonito n. 1, Santa Catharina.

3 From pile of coal in shed, Bonito n. 1, Santa Catharina.

4 Bonito n. 2, Santa Catharina.

5 Bonito n. 3, Santa Catharina.

6 Bonito bed, Tres Saltos, Santa Catharina.

7 Bonito rider, coal on Estrada Nova, Santa Catbariua. 
Amost ias ns.

8 Porção superior e inferior (75 motros) na mina Barpo Branco Velho, Sauta Catharina.

9 Do monte no deposito do carvão, mina Burro Branco Velho, idem.

10 Barro Branco no rio Passa Dois, sob basalto, idem.

11 Camada Barro Branco na Rocinha, idem.

12 Camada Barro Branco no río Carvão, perto de Urussanga, idem.

13 Ponte Alta, ilem.

14 Carvão Treviso, perto de Treviso, jlem.

15 Banco superior, S. Jerunymo, Rio Grande do Sul.

16 Banco inferior, idem, idem.

17 Bancos superior $\theta$ inferior, idem idem.

18 Carvăo da propriedade do Sr. coronel Macedo, no Cedro, Paraná.

19 Carrão da fazenda do Sr. Leonel Heliodoro da Luz e Fornandes Gil Born, perto de Quebra Dentes, Santa Catharina.

20 Carvão de Imbausinho, colligido pelo Dr. Cicero Campos.

21 Cárvão de Salto Apparado, colligido pelo Cicero Campos.

TABELLA N. 2

\section{ANALYSES ELEMENTARES}

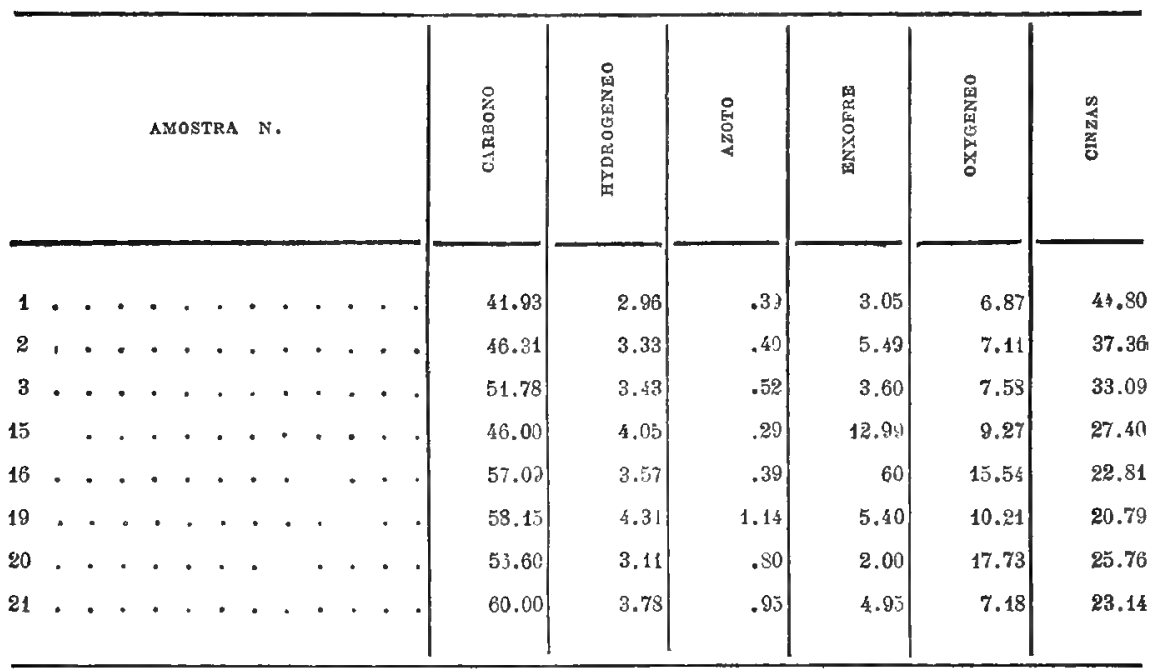

Os resultados destas diversas analyses mostrando que o carvão em toda a parte contém muita cinza e enxofre pareceram provar concludentemente que o carvão deve ser submettido a processos de purificação sem o que não se poderia esperar introduzil-o no consumo geral como combustivel, excepto na região onde é explorado e em suas immediações. Quando estas circumstancias foram communicadas ao Dl. Lauro Müller, Ministro da Industria, elle autorisou a tirar amostras de valor com- 
Samplo Ns.

8 Top and bottom (75 moters), Barro Branco Velho mine, Sant a Catharina

9 From pile in coal house, Burro Branco Velho mine, Santa Catharina.

10 Barro Branco at Passa Dois under basalt, Santa Catharina.

11 Barro Branco seam at Rocinha, Santa Catharina.

12 Barro Branco seam at Rio Carvão, noar Crussangr, Santa Catharina.

13 Ponte Alta, Santa Catharina.

11 Treviso coal, near Treviso, Santa Catharina.

15 Upper bench, S. Jaronymo, Rio Grande do Sul.

16 Lower bench, $\mathrm{S}$. Jeronymo, Rio Grande do Sul.

17 Upper and lowor benches, S. Jeronymo, Rio Grande do Sul.

18 Coal at Col. Macedo's (Cedro), Paraná.

19 Coal from the fazenda of Messrs. Leonel Heliodoro da Luz and Fernanto Gil Born, near Quebra Dentes.

20 Coal from Imbausinho, collected by Dr. Cicero Campos.

2l Coal from Salto Apparado, collected by Dr. Cicero Campos.

TABLE N. 2

ULTIMATE ANAI,YSES

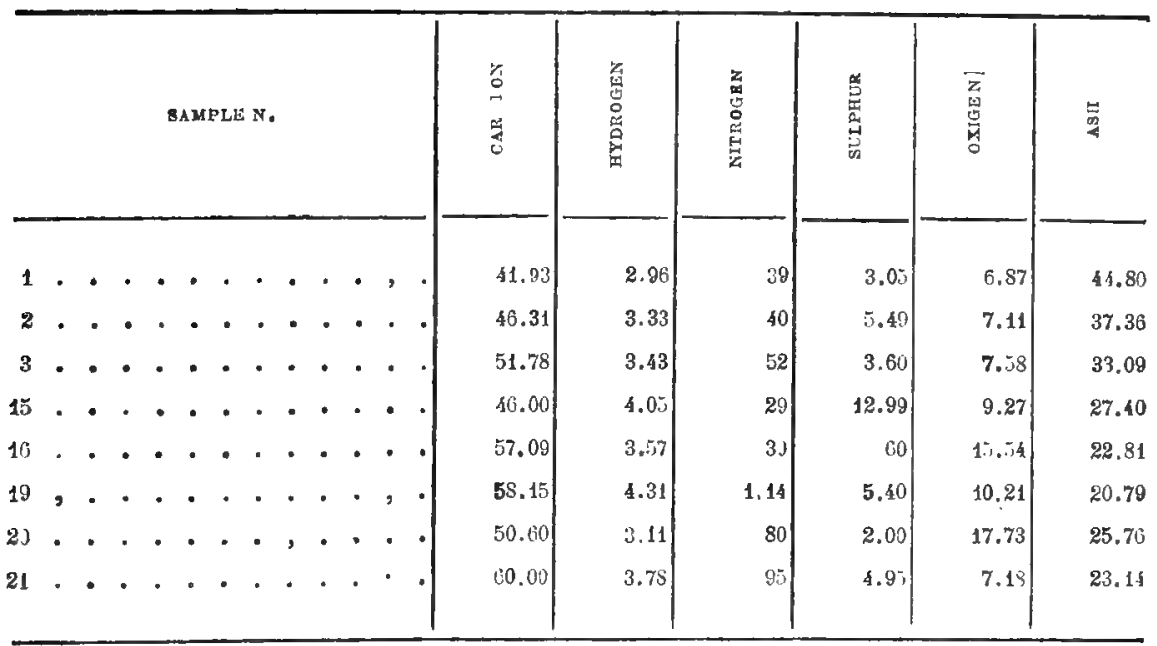

The results of these several analyses, showing the coal everywhere to bevery high in both ash and sulphur, appeared to prove conclusively that the coal must be submitted to purification processes before there could be any hope for it to enter into general consumption for fuel except in the immediate region where it is produced. When the facts in the case were communicated to Dr. Lauro Müller, the Minister of Industry, he authorized that samples of the coal of com- 
mercial tanto do Rio Grande do Sul como de Santa Catharina e remetter para os paizes em que já houvesse laboratorios installados para a purificação do carvão.

O Si . Carlos Moreira, secretario da Commissão, acompanhado pelo engenheiro Cicero Campos, voltaram para as minas em Santa Catharina e conseguiram algumas toneladas de carvão tanto da camada Bonito como da Barro Branco, indo para o Rio Grande do Sul para fiscalisar a tirada deamostras da mina explorada no Arroio dos Ratos pela Companhia Listrada de Ferro e Minas de S. Jeronymo, de que conseguiram algumas toneladas.

Estas amostras, tiradas sob a fiscalisação directa dos membros da cornmissão foram embarcadas para Allemanha para as Humbe ldt Engineering Worlis em Kalk do outro lado do Rheno em face de Cologne, onde soube por correspondencia previamente trocada, que existia um dos mellıores laboratorios do velho mundo para o ensaio de carvōes, bem como para processos e installaçóes de machinas para purificar o mesmo.

Devido a cortezia do Dr. Walcott foi remettida uma nutra amostra de carvão das minas de S. Jeronymo, de cerca de 20 e tantas toneladas, para St. Louis para ser enviada ao grande Laboratorio de ensaio de combustiveis da Commissão Geologica dos Estados Unidos, esta ultima amostra foi escolhida pelo Sr. Otto Spalding, superintendente da Companhia S. Jeronyma que recebeu instrucções para remetter uma amostra media geral de seu carvão commercial que elle remette para Porto Alegre, Pelotas, margem do Taquary e para outros pontos para fins industriaes.

O Sr. Carlos Moreira veio para os Estados Unidos em maío de 1905 e mais tarde partimos para a Allemanha empregando o mez de junho alli, superintendendo os ensaios de purificação feitos em Kalk pelo Dr. Esser, perito em combustiveis, das Humboldt Engineering W'orks que a 5 de julho de 1905 remetteu o seguinte relatorio sobre o carvão em questão: 
mercial size from both Rio Grancle do sul and Santa Catharina should be collected and shipped to otlier countries where laboratories for coal purification tests were already installed.

Mr. Carlos Moreir'a, the Secretar'y of the Commission, accompanied Jy the ensineer Cicero Campos, returned to Minas, Santa Catharina, and secured several tons of coal from loth the Bonilo and Barro Branco coal Jeds, and then went to Rio Grande do Sul, and superintended the sampling of the mine oparated on Arroio dos Ratos Jy the Companhia Estrada de Ferro e Minas de Săo Jeronrmo, from which sıveral tons were secured.

These samples, thus taken under the direct supervision of members of the Coal Commission, wore shipped to the llumboldt lingineeling Works at kialk, Germany, just across the Rhein from Cologne, where it was learned from previous correspondence was located one of the Jest lajoratories of the old world for the testing of coals, as also for the installation of coal purifying machinery, and processes.

Throtigh the courtesy of Dr Walcolt of the U. S. Geological Survey, another sample of the coal from the S. Jeronymo mines, amounting to 20 odd tons was shipped to st. Louls for testing in the great fuel testing plant ol the U. s. Geological survey. This lattel' sample was selected J, Mr. otto spalding, superintendenl of the S.Jer'unimo Company, who was instutucted to send a general average sample of his commercial coal which he ships to Porto Alegtre, Pelotas, Margem do Tacuary and elsewhere for industrial purposes.

Mr. Carlos Moreira came to the United States in May, 1905, and later we sailed forGermany spending the month of June there in super. vising the purification tests made at Kalk by Lieut. Esser, the fuel expert of the IJum]soldt Engrineering Works, who under date of July 5th 1905 transmitted the folluwing report upon the coal in question: 


\section{RELATORIO}

\section{SOBRE ENSAIOS DE LAVAGEM DO CARVÃO BRAZILEIRO}

FHITUS PARA O

Dr. I. C. White, chefe da Commissĩo de Estudo das Minas de Carvão de Pedra

Enscio n. 1 - Pala este ensaio foram lomadas quantidades eguaes das duas variedades S. J. B. (") e S. J. T. (" ")

Amostras medias destas continham $3 \stackrel{4}{4}, 9 \%$ de cinza.

o fim do ensaio era determinar o methodo pelo qual se obteria um carvão com 10-15\% de cinza .

Como o carvão estava entremeiado com consideravel quantidade de schisto bituminosu, pareceu a principio impossivel olster um carvão com a percentagem de cinza exigida, sem J,ritamento preliminar.

Pequenos ensaios preliminares mostraram que era necessaria quelıar o carrãoem pedarcis de nurnos que $6 \mathrm{~mm}$,

Todo o material foi portanto quej,rado em um moinho conico, em pedaços menores que $6 \mathrm{~mm}$. edepois lavado em um lavador fino tendo fundo de feldspatho.

Os productos resultantes foram.

Carvão n. 1, carvão n. 2 e schi isto com pỵ rites.

Os lodos foram recolhidos em dois lanques de decantarão e tiremos deste modo:

Lodo n. 1 e lodo n. 2.

Os resultados olstidos neste ensaio estão reunidos na tajella junta.

Todos os pesos são calculados por cem do total tratado de material secco.

(·) Porção inlerior da camada de carvão s. Jeronymo.

(*) Porção superior da cauala de carvāo b. Jeronymo. 


\section{REPORT}

ON WASHING TESTS WITH BRAZILIAN COAL

$F \cap R$

Dr. I. C. White. Chief of the Brazilian Coal Commission

Test n. 1-For this test equal quantities of the two varjelies of S. J. B. $\left({ }^{*}\right)$ \& S. J. T. $\left({ }^{* *}\right)$ were taken.

Average samples of these contained $34.9 \%$ of ash.

The object of the tests was to determine the method by which to obtain a coal containing 10-15 o/ of ash.

As the coal was streaked with a considerable amount o bituminous shale, it appeared at first impossible to obtain a coal with the required percentage of ash without preliminary crushing.

Small preliminary tests showed that crushing to below $6 \mathrm{~mm}$ was necessary.

The whole of the material was therefore crushed on a bell mill dotwn to under $6 \mathrm{~mm}$. and then washed on a Fine-IVasher having a felspar Jottom.

The resulting products were:

Coal n. 1. Coal n. 2, and shale with pyrites.

The slimes were collected in two neighboring settling tanks, and we thus liave:

Slimen. 1 and Slime n. 2.

The results obtained in this test are collected in the accompanying table. All weights are the weights of the dry material per cent. of stuff worked up.

(*) Bottom menther s. Jeronymo coal.

(•) Top member s. Jeronymo coal. 


\section{TABELLA N. I}

4.270 kig. de carvãos. J. B. c S. J. T. $-100 \%$ em peso.

A amostra media n. 0 contem 34.9 por cento de cinza.

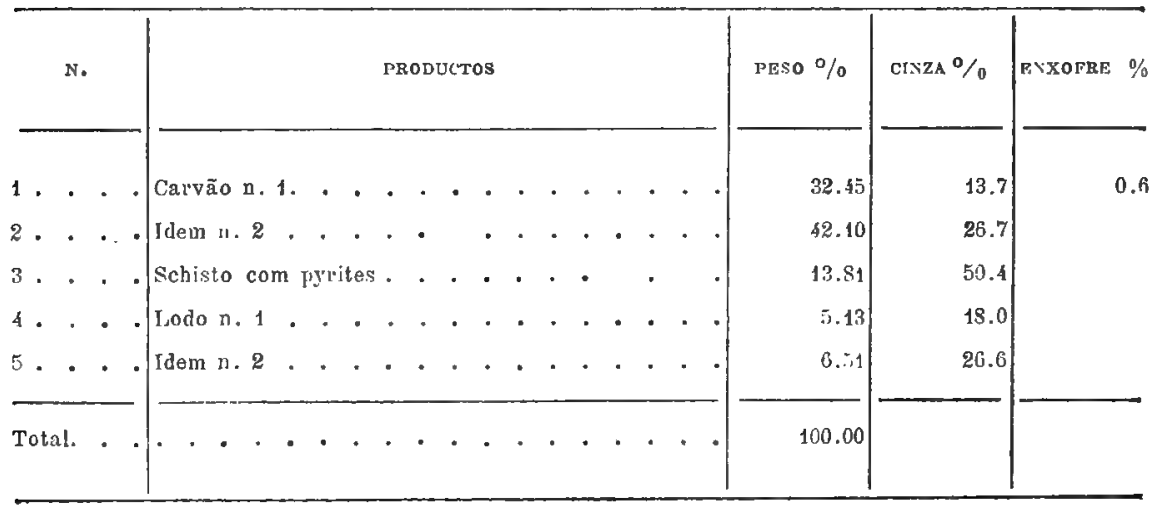

Como se rê, por esta talella esto ensaio produziu:

$32.45 \%$ de carvãon. 1 contendo $13.7 \%$ de cinza e $0.6 \%$ de en. xofre.

Além disto foram separados $42.10 \%$ de carvão n. 2 com $26.7 \%$ de cinza bem como $13.81 \%$ de schisto com pyrites contendo $50.4 \%$ de cinza.

o lodo n. 1 de que $5.13 \%$ contendo $18 \%$ de cinza poderia ser addicionado ao carvão n. 2 . O lodo n. 2 contendo $26.6 \%$ de cinza tambom poderia ser addicionado ao carvão n. 2.

o schisto com pyrites foi destinado a ser sulmmettido a um ensaio a parte para se conseguir pyrites puras.

Chamando 100 a quantidade de schisto e pyrite é possivel obter-se desta $78.22 \%$ de schisto e $21.78 \%$ d pyrites, nos pulsores.

Um quinto desce produrto pode portanto ser nutidn como pyrites puras.

Ensaio de briquettagem com o carvio n. 1 do ensaio n. 1

Todo a carvão n. 1 mencionado na tahella n. 1 empregamos em. fazcr um ensaio na mina Altstaden afim de olster tanto quanto possivel, resultados similares aos que se culteriam na pratica.

O carvão foi briqueltado depois de juntar-lhe $5.5 \%$ de breu. 


\section{TABLE N, I}

Weighed out $4279 \mathrm{~kg}$. of Coal S. J. B. and S. J. T. - $100 \%$ by weight.

Average sample n. 0 contains 34.9 per cent. of asll.

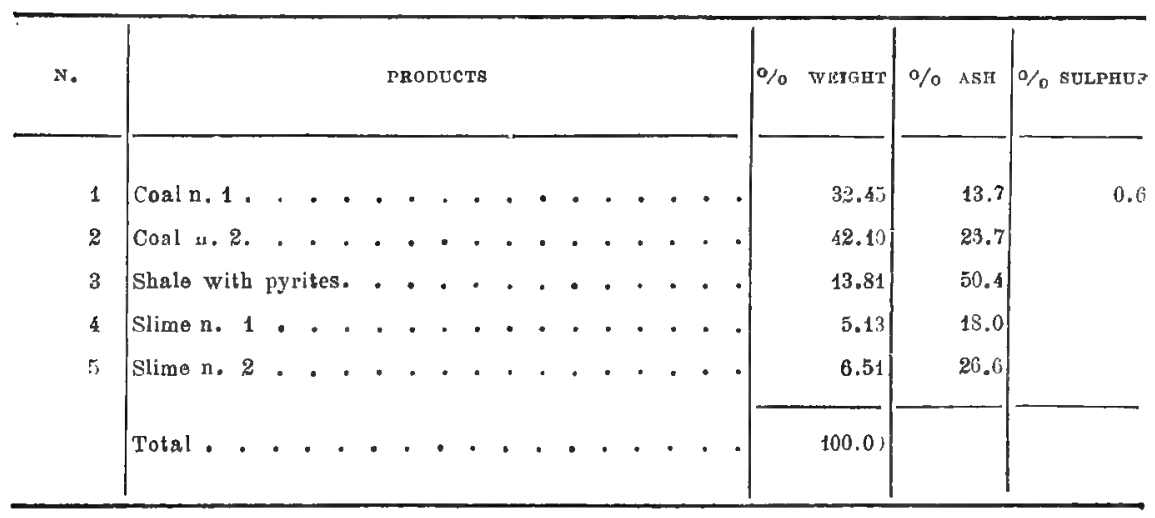

As will he seen from this taljle this test yielded:

$32.45 \%$ of coal n. 1 containing $13.7 \%$ of ash and $0.6 \%$ of sulphur.

Further $42.10 \%$ of coal n. 2 with $267 \%$ of ash were ultimately jigged, as well as $13.81 \%$ of shale with pyrites containing $50.4 \%$ of ash.

Slime $\mathrm{n} .1$ of which there was $5.13 \%$, contained $18.0 \%$ of ash and could be added to coal n. 2 .

Slime n. 2 contained $26.6 \%$ of ash, and could be added to coal n. 2 as well.

The shale with pyrites was made to undergo a separate test in order to olntain pure pyrites.

Calling the quantity of shale and pyrites 100, it is possilyle to olstain therefrom $78.22 \%$ of shale and $21.78 \%$ of prites ly jigging.

One-fifth of this product can therefore be oljtained as pure pyrites.

\section{Briquetting-test with coal $n, 1$, from test $n, 1$}

The whole of the Coal $n .1$ mentioned in talle $n .1$ was used for making a test at the Altstaden Mine, in order, as far as possible, to obtain results similar to those that would be obtained in practice.

The coal was briquelted after adding $5.5 \%$ of pitch. 
As Jriquettes tcem boa apparencia e queimam satisfactoriamente. Emquanto ardem não se reduzem a pó, mas quelıram-se em pedaços de bom tamanho.

Parece que não é tão vantajoso reduzir o carvão a pedacinhos de 0 a $6 \mathrm{~mm}$. para briquettal-o como a pedacinhos de 0 a $4 \mathrm{~mm}$.

Por esta razão é aconselhavel na pratica quehrar o carvãoa $4 \mathrm{~mm}$. em um desintegrador, antes de ]riquettal-o sendo assim muito possivel que seja sufficiente menor quantidade de breu para produzir boas briquetts, que a que foi previamente estajselecida.

\section{Ensaio n. 2 do carvão marcado B. B. $(\cdot)$}

A apparencia deste carvão é muito melhor que a do ensaio n. 1 pois que o carvão puro se apresenta em grande quantidade em pedaços.

Era portanto evidente que não seria necessario quelırar o carvão tão fino como o do ensaio n. 1 mas era de suppor que poderia ser tratado em loruto.

Depois de ter primeiramente lavadotoda a argilla que poderia ser entretanto separada na pratica, o material foi passado em uma peneira de dez millimetros. Tanto o carvão maior, como o menor de $10 \mathrm{mil}$ limetros foi lavado em um lavador de dois compartimentos.

Do carvão maior de dez millimetros foram obtidos $52.31 \%$ de carvão e $22.96 \%$ de schisto.

Do carvão menor de dez millimetros: $15.15 \%$ de carvão e $9.5 \% \%$ de schisto.

Total $67.50 \%$ de carvão e $32.50 \%$ de schisto.

Ao ser determinada a percentagem de cinza, no carvão maior de $10 \mathrm{~mm}$. (18.7\%) achoul-se que tinha muita cinza para ser immediatamente utilisado.

Ensaios posteriores mostraram que não se póde obter carvão puro em pedaços grandes, o que só so póde conseguir quebrando-o primeiramente menor que $20 \mathrm{~mm}$. Em consecjuencia do que o ensaị foi recomecado e todo o carvão foi passado na peneira de $20 \mathrm{~mm}$. c o carvão grosso maior que $20 \mathrm{~mm}$. quebrado menor que $20 \mathrm{~mm}$.

Todo o carvão quełrado foi então pascado na peneira de $10 \mathrm{~mm}$. e os tamanhos de 20 a $10 \mathrm{~mm}$. e abaixo de $10 \mathrm{~mm}$. cada um tratado separadamente nos lavadores.

(*) Camada Barro Branco. 
The briquettes look well and burn satisfactorilly. While burning they do not fall to dust, but ]reak up into fair-sized pieces.

It appears that a fineness of 0 to $6 \mathrm{~mm}$. is not so advantageous for briquetling as one of 0 to i $\mathrm{mm}$.

For this reason, it would be advisable in practice to crush the coal down to $4 \mathrm{~mm}$. in a desintegrator befure briquetting, wherehy it is quite possible that a smaller quantity of pitch than that previously stated would ba sufficient to turn out good loriquettes.

$$
\text { Test. n.2. -- on coal marked B. B. (') }
$$

The appearance of this coal is far hetter than that in test n. 1 as, the pure coal appears to the greater extent in lumps.

It was therefore evident that the coal did not require such fine crushing as that in test No. 1 , but one could assume that itrould be trealed straight away in a coarse condition.

After washing away first of all the clay, which, however, could in practice be kept away from the coal, the material was passed through a ten millimeters screen. Both the coal above, and that below, ten millimeter size was then washed in a two-compartment washer.

From the coal above ten millimeter size were obtained: $52.31 \%$ of coal and $22.96 \%$ of sliale.

I'rom the coal under $10 \mathrm{~mm} .: 15.15 \%$ of coal and $9.5 \% \%$ shale.

Total $67.50 \%$ of coal and $32.50 \%$ of shale.

On determining the percentage of ash in the coal above $10 \mathrm{~mm}$. $(18.7 \%)$ it was found that it was too high to enable the coal to be. immediatelly utilized.

Later tests showed that a sufficiently pure coal can not be obtained when crushed firstly to below $20 \mathrm{~mm}$., in consequence of which the test was therefore started afresh, and the whole of the coal screened off with $20 \mathrm{~mm}$. and the coarse coal above $20 \mathrm{~mm}$. crushed down to below $20 \mathrm{~mm}$.

All crushed coal was then screened off with $10 \mathrm{~mm}$. and the sizes 20 to $10 \mathrm{~mm}$. and below $10 \mathrm{~mm}$. each treated separately on washers.

(•) Bario branco bed. 
De 20 a $10 \mathrm{~mm}$. foi obitido :

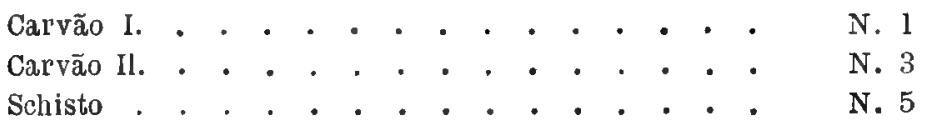

De cal'vão menor de $10 \mathrm{~mm}$. temos:

Carvão I. • . . . . • . . . . • . . . N. 2

Carvāo Il. • . . . . . . . . . . . . . N. 4

Residuo . . . . . . . . . . . N. 6

Os resultados são dados na tabella seguinte em que a lama dos lavadores é indicada pelo $n .7$.

Todos os pesos são thmados a secco e correspondem ao peso por cem da quautidade de material bruto tratado.

TABELLA N. II

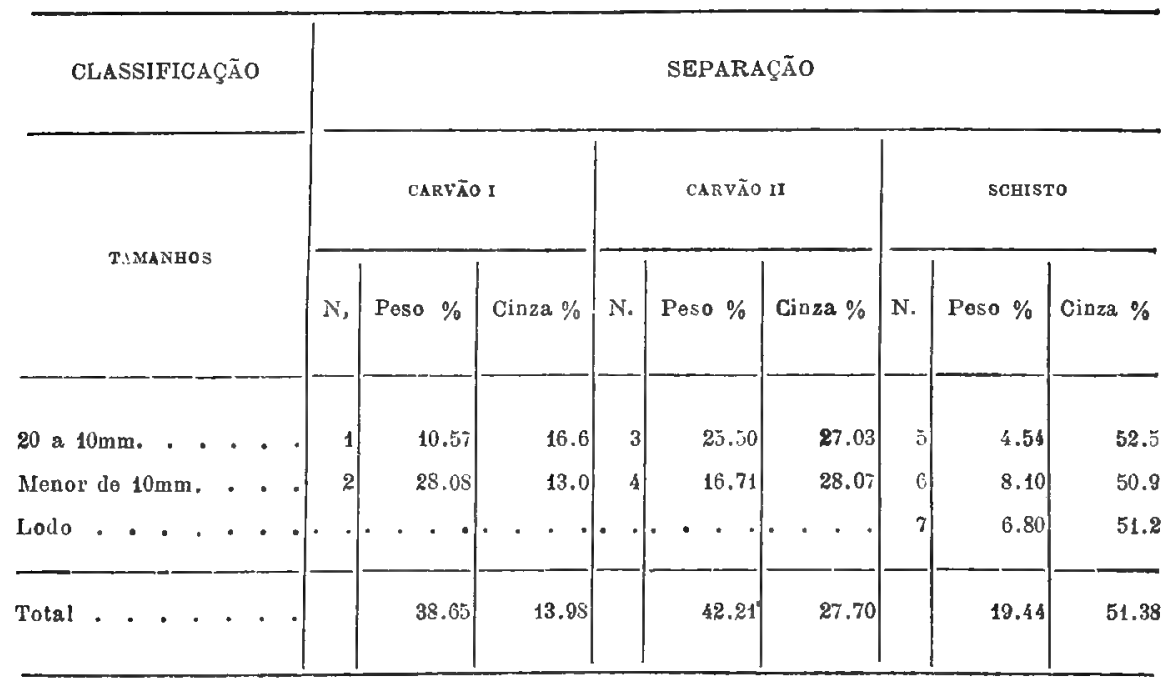

Temos portanto do ensaio n. $2: 38.65 \%$ de carvão n. I com uma média de $13.98 \%$ de cinza, mais $42.21 \%$ de carvão $n$. II com uma media de $27.70 \%$ de cinza e $19.44 \%$ de schisto e lodo com uma média de $51.38 \%$ de cinza. As pyrites estăo principalmente contidas no schisto.

\section{Ensaio n. 3 do carvăo marcado B (')}

Este era um outro caso de carvão muito sclitoso que apparentemente requeria ser quebrado para que se podesse ubter carvão. Todo o

(·) Cimmada Bunilo. 
In size 20 to $10 \mathrm{~mm}$. Was obtained:
Coal I.
Coal II.
N. 1
Shale.
N. :3
of the coal below $10 \mathrm{~mm}$. we have :

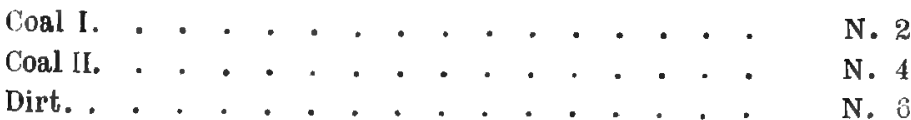

The results are given in the following table in which the sludge from the washers is marked $n .7$.

All weights are dry weights, and given in weight \% of the quanlity of the raw mater'ial treated.

TABLE N. II

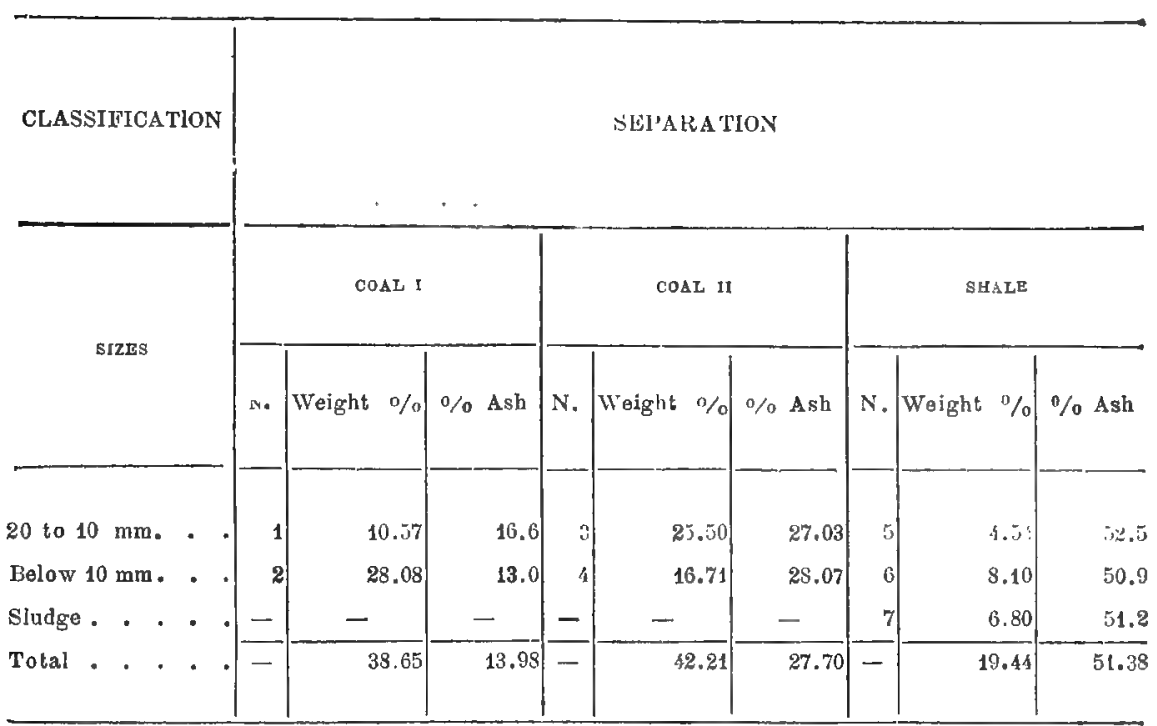

From test $n .2$ we therefore have: $38.65 \%$ of coal n. I averaging $13.98 \%$ of ash. Further, $42.21 \%$ of coal n. II, averaging $27.70 \%$ of ash, and $19.44 \%$ of shale and sludge averaging $51.38 \%$ of ash. The pyrites is chiefly contained in the shale.

\section{Test $n .3$ coal marked $B(\cdot)$}

This was again a case of a considerably streaked coal which apparently would nequire to be crushed in order to be able to obtain coal at

(*) Bunito bed. 
cal'vão foi portanto quebrad", menol" que $6 \mathrm{~mm}$. e tíatado em um lavador" de carvão, fino.

Os resultados deste ensaio estão reunidos na tabella seguinte.

Todos as pesos forlam lomados a secco e são dados em pes) por cem da quantidade do material bruto tratado.

\section{TABELLA N. III}

Carvão B egual a $100 \%$ do peso - Percentagem da cinza $49.4 \%$

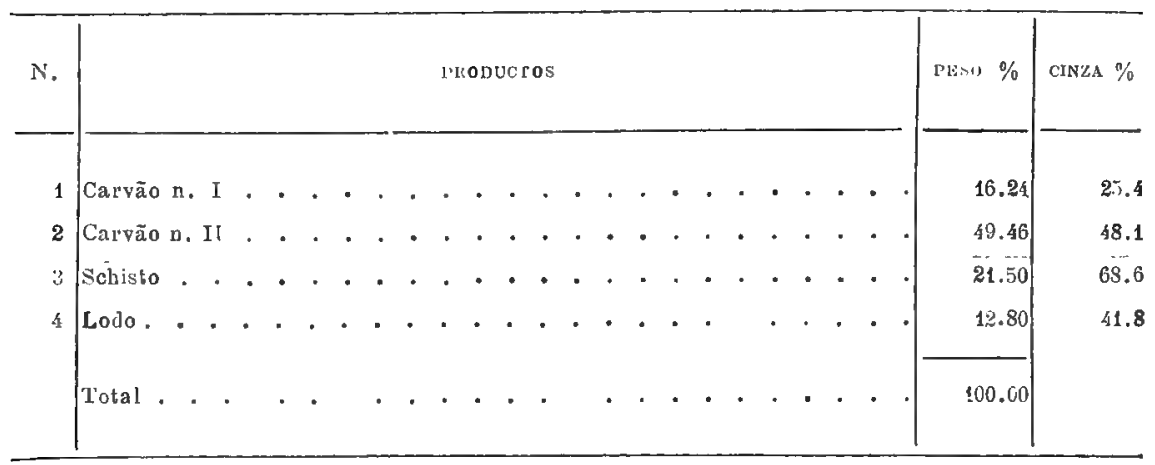

Os resultados mostram que, mesmo britado menor que $6 \mathrm{~mm}$. só se pode obter $16.24 \%$ de carvão contendo $25.4 \%$ de cinza, não valendo a pena o tratamento deste carvão.

\section{MASCHINENBAU-ANSTALT HUMBOLDT}

\section{(Assignado):}

IV. F. BARTEL.

Lieut. Esser.

Afim de velificar as determinações do Dr. Esser foram colleccionadas amostras das differentes qualidades de carvăo schisto, lodos, etc., sejarados em Kalk do carvão de Santa Catharina e Rio Grande do Sul e cnviados ao prof. B. II. Ilite de Morgantown, West Virginia, U.S. A rm cujo laboratorio eslas amostras foram analysadas com os seguintes resullados. 
all. The whole of the coal was therefore crushed to under $6 \mathrm{~mm}$. and treated in a fine coal washer.

The results of this test are collected in the following table. All weights are dry weights, and are given in weight \% of the quantity of the raw material treated.

TABLE N. III

Coal $\mathrm{B}$ equals $100 \%$ by weight, percentage ash, $49,4 \%$

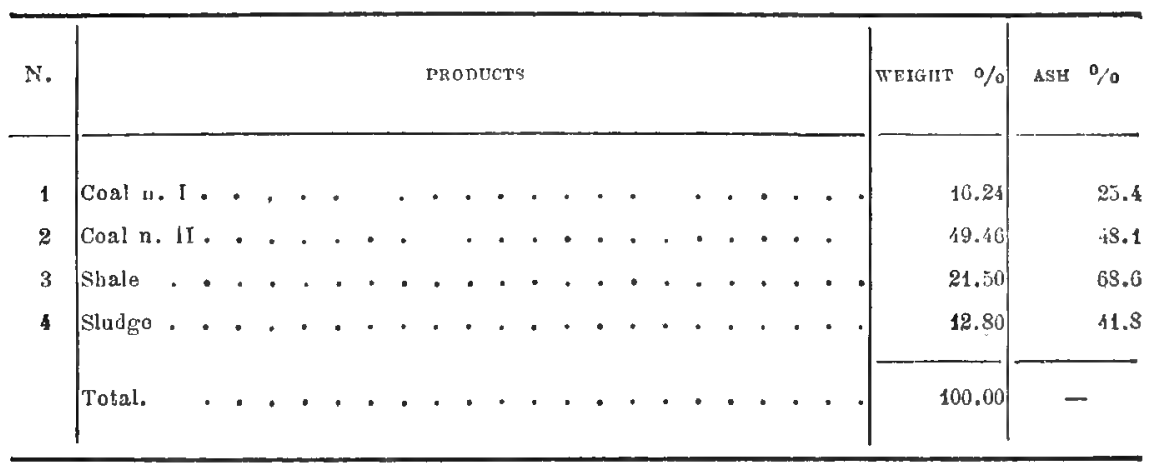

The results show that even when crushing down to under $6 \mathrm{~mm}$. only 16.2 k $\%$ of coal, containing $25.4 \%$ of ash, are ollainalsle; therefore treating this coal would not pay.

MASCHINE'NBAU-ANSTALT HUMBOLDT,

(Signed)

W. F. BARTEL,

Lieut. Eser.

In order to check the determinations of Lieut. Esser, samples of the different grades of coal, slate, slimes, etc., into which the coal from Santa Catharina, and Rio Grande do Sul, had Jeen separated at Kalk, were collected and transmitted to Prof. B. II. Hite at Morgantown, West Virginia, U. S. A., in whose labnratory these samples were analyzed with the following results: 
TABELLA N, I

\section{Analyse dos productos separados em Kalk, do carvão de}

\section{S. Jeronymo}

\begin{tabular}{|c|c|c|c|c|c|c|c|}
\hline ANALYSE & INIME & DIAT & & & S. J. T \& B. & S. J. T. \& B. & S. J. T. \& B. \\
\hline Humidarle. . & . & . & & . & 6.42 & 6.37 & 4.71 \\
\hline Materia volatil & - & - & . & . & 26.72 & 32.70 & 25.52 \\
\hline Carbono fixo. & $\cdot$. & . & . & . & 39.47 & 47.15 & 39.77 \\
\hline Cinza. . . & . . & . . & - & - & 27.39 & 13.78 & 30.00 \\
\hline Total. . & . . & . & . & - & 100.00 & 100.00 & 100.00 \\
\hline Enxofre. . & . . & $\therefore$ & $\cdot$ & . & 3.35 & 0.54 & 0.64 \\
\hline Phosphoro. . & . $\cdot$ & - $\cdot$ & . & - & 0.03 & 0.04 & 0.025 \\
\hline$\triangle N A L Y S E$ & ELEM & FNT & & & & & \\
\hline Carbono. & . & . & . & . & 47.0 .3 & 61.23 & 50.49 \\
\hline Hytl roggeneo. . & . . & - & - & . & 4.0 .3 & 5.17 & 3.54 \\
\hline Oxygenes. & . & . & . & - & 20.313 & 19.23 & 15.54 \\
\hline Azoto. . . & - $\cdot$ & , & . & - & 0.35 & 0.45 & 0.27 \\
\hline Enxorre. . & . $\cdot$ & - & • & - & 3.35 & 0.54 & 0.61 \\
\hline Cinza (corrigido & para 0 & $\theta n x$ & ofre & & 24.88 & 13.38 & 29.52 \\
\hline Total . & . . & . & . & & 100.00 & 100.00 & 100.00 \\
\hline
\end{tabular}

(*) S. J. T. \& B. - Carvão bruto de S. Jeronymo não lavado, partes superior e inferior misturallas.

(•) S. .T. T. \& B. - Primeira qualidado de carvāo lavado de S. Jaronymo, partes superior e inferior misturadas; 32 por cento.

(‥) S. J. T. \& B. - Segunda qualidade de carvão lavado de S. Jeronymo, partes superior o inferior; 42 por cento. 
TABLE N. I

Analyses of separation products made at Kalk from S. Jeronymo coal

\begin{tabular}{|c|c|c|c|c|c|c|c|c|c|c|c|c|c|c|}
\hline & PRO & XIM & ATE & 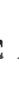 & & $\mathrm{AL}$ & $\mathrm{SE}$ & & & & & 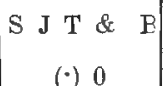 & $\mid \begin{array}{c}\mathrm{S} J \mathrm{~T} \& \mathrm{~B} \\
(*) 1\end{array}$ & $\begin{array}{c}\mathrm{S} J \mathrm{~T} \& \mathrm{~B} \\
(\cdots) 2\end{array}$ \\
\hline Moisture & - & & - & - & & . & . & . & - & - & & 6.42 & 6.37 & 4.71 \\
\hline Volatile Matte & ter. & - & - & - & . & • & - & - & - & . & & 26.72 & 32.70 & 25.52 \\
\hline Fixerl carbon & . & - . & . & • & . & • & . & - & . & • & & 39.47 & 47.15 & 39.77 \\
\hline Ash . . • & - & $\cdot$ & . & . & . & - & . & - & • & • & & 27.39 & 1.7 .78 & 30.00 \\
\hline Total & . & $\cdot$ & . & • & • & - & - & - & • & , & & 100.00 & 100.00 & 100.00 \\
\hline Sulphur. . & . & - . & - & . & . & • & - & - & • & • & & 3.35 & 0.54 & 0.64 \\
\hline Phosphorus. & - . & - & . & • & & • & - & - & . & • & • & 0.03 & 0.04 & 0.025 \\
\hline & ULT & IMA & $\mathrm{TE}$ & & & $L Y$ & SES & & & & & & & \\
\hline Carbon . & • & • & $\cdot$ & . & & . & - & 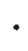 & • & . & & 47.03 & 01.23 & 50.49 \\
\hline Hydrogen . & • & $\cdot$ & . & • & & $\cdot$ & . & - & $\cdot$ & • & & 4.03 & 5.17 & 3.54 \\
\hline Oxygen . & - . & & & & & - & - & ${ }^{\circ}$ & • & . & & 20.36 & 19.23 & 15.54 \\
\hline Nitrogen . & - . & . & - & & & • & - & - & • & • & & 0.35 & 0.45 & 0.27 \\
\hline Sulphur. . & - & • & - & $\cdot$ & & • & - & • & . & . & & 3.35 & 0.54 & $0.14^{\prime}$ \\
\hline Ash (correcter & d for & S.) & . & . & & • & · & - & - & . & & $24 . \mathrm{ES}$ & 13.38 & 29.52 \\
\hline Total. & - $\cdot$ & . & . & & & • & - & $\cdot$ & • & 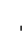 & & 100.00 & 100.00 & 100.00 \\
\hline
\end{tabular}
mixed.

(') S J T \& B - S. Jeronymo raw unwashed coal, top and bottom portions

(..) S J T \& B - 1 st quality of washed S. Jeronymo coal, top and bottom portions mixed; 32 per cent.

(‥) S J T \& B - 2 nd quality of washed S. Jeronymo coal, top and bottom portions mixed; 42 per cent. 
A analyse do carvão da camada Bonito, de Santa Catharina, tratado em Kalk, deu o seguinte resultado depois de Jeneficiado:

Analyse do carvão Bonito, perto de Minas, Santa Catharina, Brazil

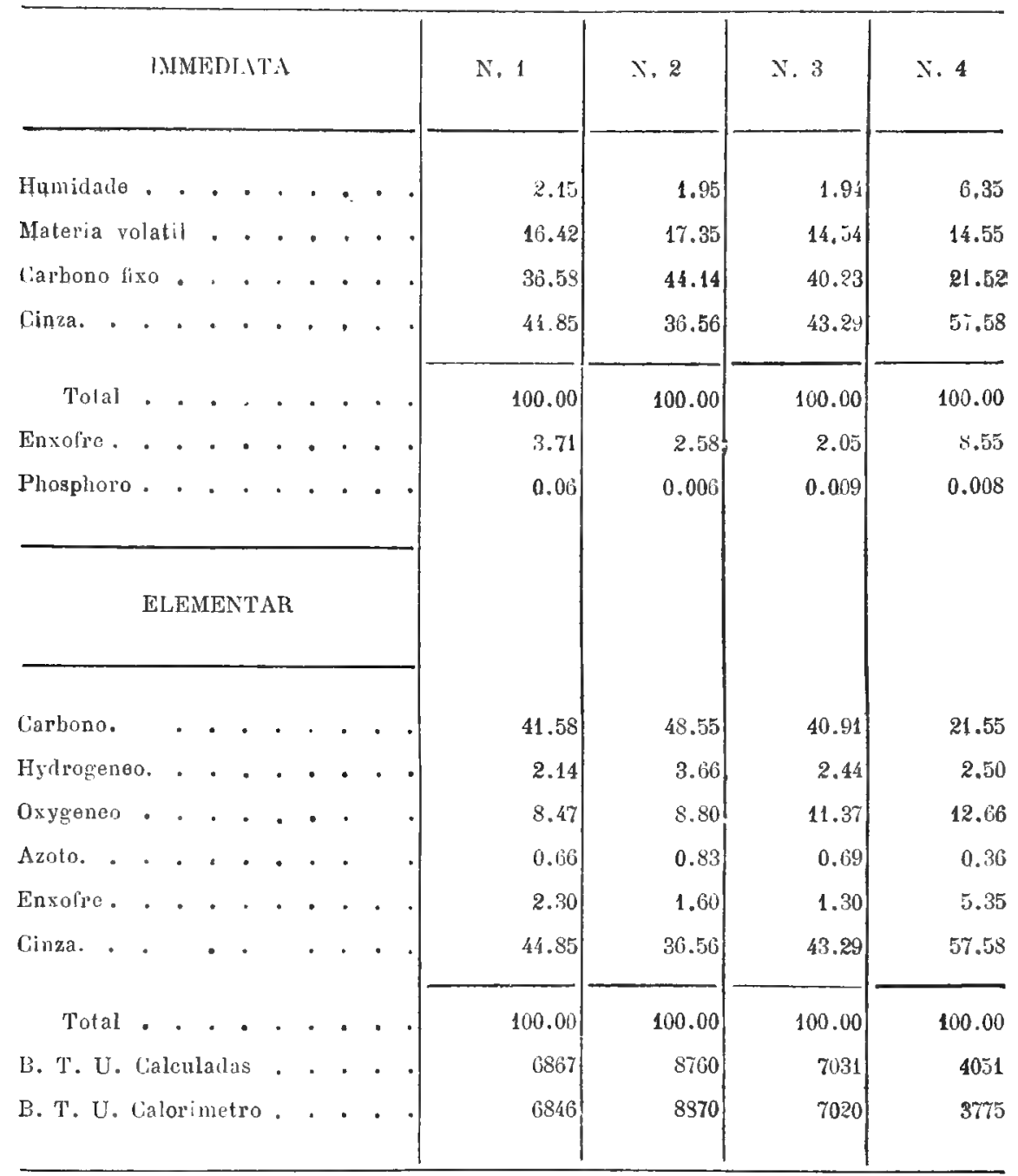

X. 1 - Cir, $\bar{a} o$ nã. l.trado dil camada Bonito. total.

X. $2-$ Qualidade 11.1 re carvāo lavado da camarla Bonito $16.24^{\circ}$ por cento do total.

N. 3 - Qualidarle n. 2 de carvāo lavarlo da camada Bonito 49.46 por cento do

N. 4 - Refugo ou residuos do carvão da camada Bonito 34.3 por cento do total. 
The coal from the Bonito bed of Santa Catharina treated at Kalk gave the following results on analysis after treatment:

Arialyses of Bonito coal, near Minas, Santa Catharina, Brazil

\begin{tabular}{|c|c|c|c|c|c|c|c|c|c|c|c|c|c|}
\hline & & ROX & III. & & & & & & & $x .1$ & $x .2$ & x. 3 & N. 4 \\
\hline Moisture . . & - & . . & . & . & & - & . & . . & . & 2.15 & 1.95 & 1.94 & 6.35 \\
\hline Volatile matter. & . & . . & . & . & • & . & - & . . & - & 16.42 & 17.35 & 14.54 & 14.55 \\
\hline Fixod carbon. . & . & . . & . & - & . & . & . & • & . & 36.58 & -14.14 & 40.23 & 21.52 \\
\hline$\Lambda$ sh . . . . . & - & . . & . & . & . & - & - & . . & $\cdot$ & $4 i .85$ & 36.56 & 43.20 & 57.58 \\
\hline Total. . & - & . . & . & & & & . & . . & . & 100.00 & 100.00 & 100.00 & 109.00 \\
\hline Sulphur. . . & - & · · & • & • & . & . & . & . . & . & 3.71 & 2.58 & 2.05 & 8.55 \\
\hline Phosphorus . & . & . . & . & . & . & . & - & . . & . & 0.06 & 0.006 & 0.003 & 0.008 \\
\hline & & ULTI & $M \Lambda$ & & & & & & & & & & \\
\hline Carbon . . . & . & . . & 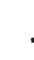 & & & & . & . . & . & 41.58 & 48.55 & 40.91 & 21.55 \\
\hline Hydrogen . . & - & . . & . & . & - & & . & . . & • & 2.14 & 3.66 & 2.44 & 2.50 \\
\hline Oxygen . . & . & . . & . & . & . & & - & . . & . & $\therefore .47$ & 8.80 & 11.37 & $\$ 2.66$ \\
\hline Nitrogen . . & . & . & & . & - & $\theta^{\circ}$ & • & - . & . & 0.66 & 0.88 & 0.69 & $0.3 \mathrm{i}$ \\
\hline Sulphur. . . & . & . & & & $\cdot$ & & . & . . & . & 2.30 & 1.60 & 1.30 & 5.35 \\
\hline Ash . . . . & . & - . & , & & 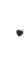 & & • & - . & . & 44.85 & 36.56 & 43.20 & 57.58 \\
\hline Total & . & - . & . & & & & • & - . & . & 100.00 & 100.00 & 100.00 & 100.00 \\
\hline Calculatel B. T. & $\mathrm{U}$ & . & & & & & • & & . & 6867 & 8760 & 7031 & 4051 \\
\hline Calorimeter B. I & & & & & & & • & - & - & 6846 & $88 \%$ & 7020 & 3775 \\
\hline
\end{tabular}

N. 1. Unrashed coal from Bonito bed.

N. 2. N. 1 quality of washed Bonito coal 16.2 f per cent. of whole.

X. 3. $x 2$ quality of washell Bunito coal 49.46 per cent. of whole.

x. A. Refuso or wasle from Bonito cual 34.3 per cent. of ithote. 
Analyse dos productos de separaçđo do carvão Barro Branco de Santa Catharina, feita em Kalk

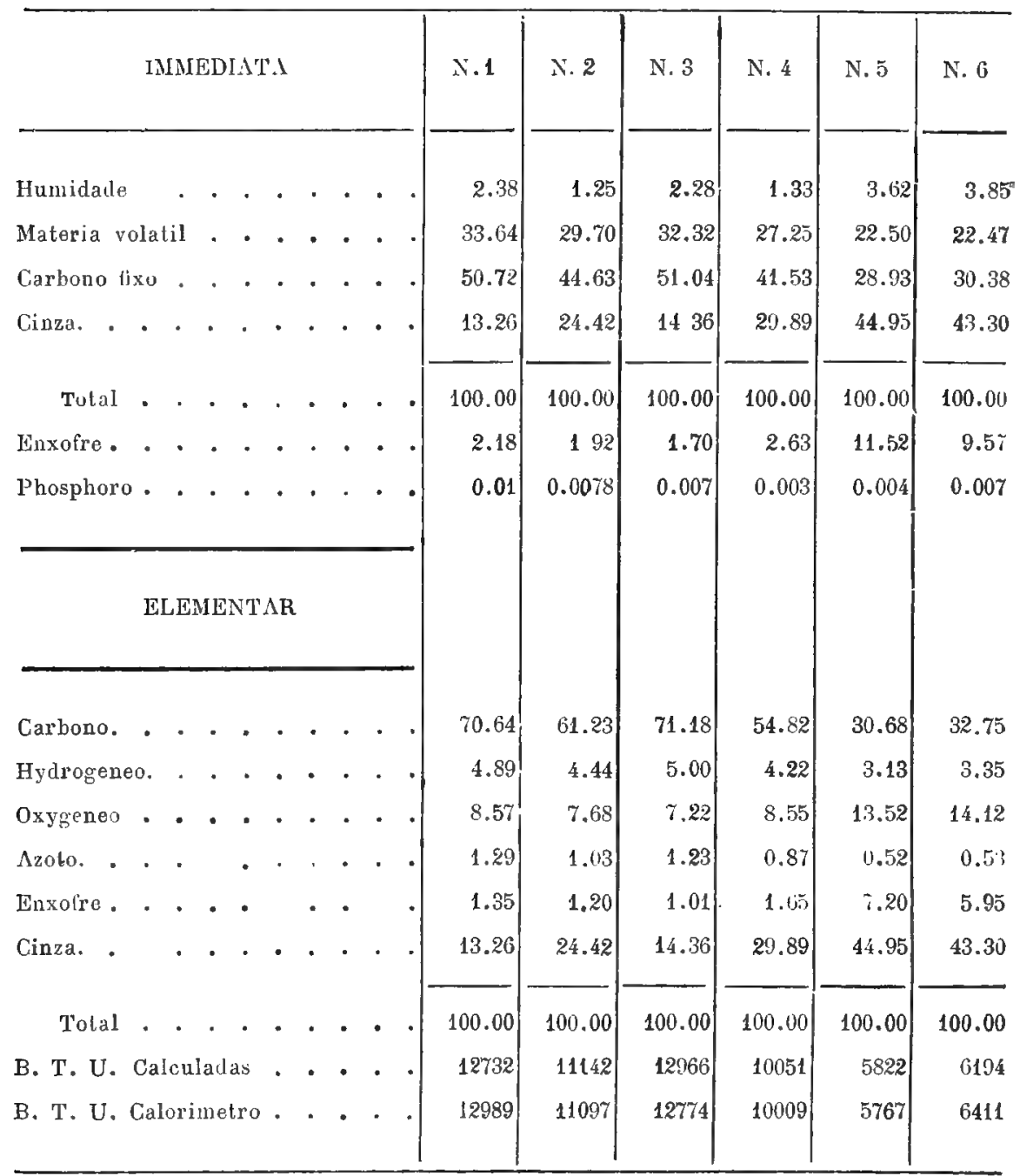

N. 1 - Carvāo nut (') lavado de $1^{\text {a }}$ qualidade, tamanho $10.20 \mathrm{~mm}$. da camada Barro Branco 10.57 por cento do total.

N. 2- Carvão nut, lavado de.2a qualidade, tamanho $10.20 \mathrm{~mm}$. da camada Barro Branco, 25,50 por cento do total.

N. 3 - Carvão lavado de primeira qualidade da camacla Barro Branco, menor de $10 \mathrm{~mm} .28 .08$ por cento do total.

N. 4 - Carvão lavallo da segunda qualidade da camada Barro Branco, menor de $10 \mathrm{~mm} .16 .71$ por cento do total.

N. 5 - Refugo, schisto de $10.20 \mathrm{~mm}$. carvăo Barro Branco 4.54 por cento. cento.

N. 6 - Impurezas e lodo da lavagem do carvão da camada Barro Branco 14.90 por

(•) Carvão nut - Carvão do tamanho de uma noz. 
Analyses of separation products made at Kalk from Barro Branco coal, Santa Catharina

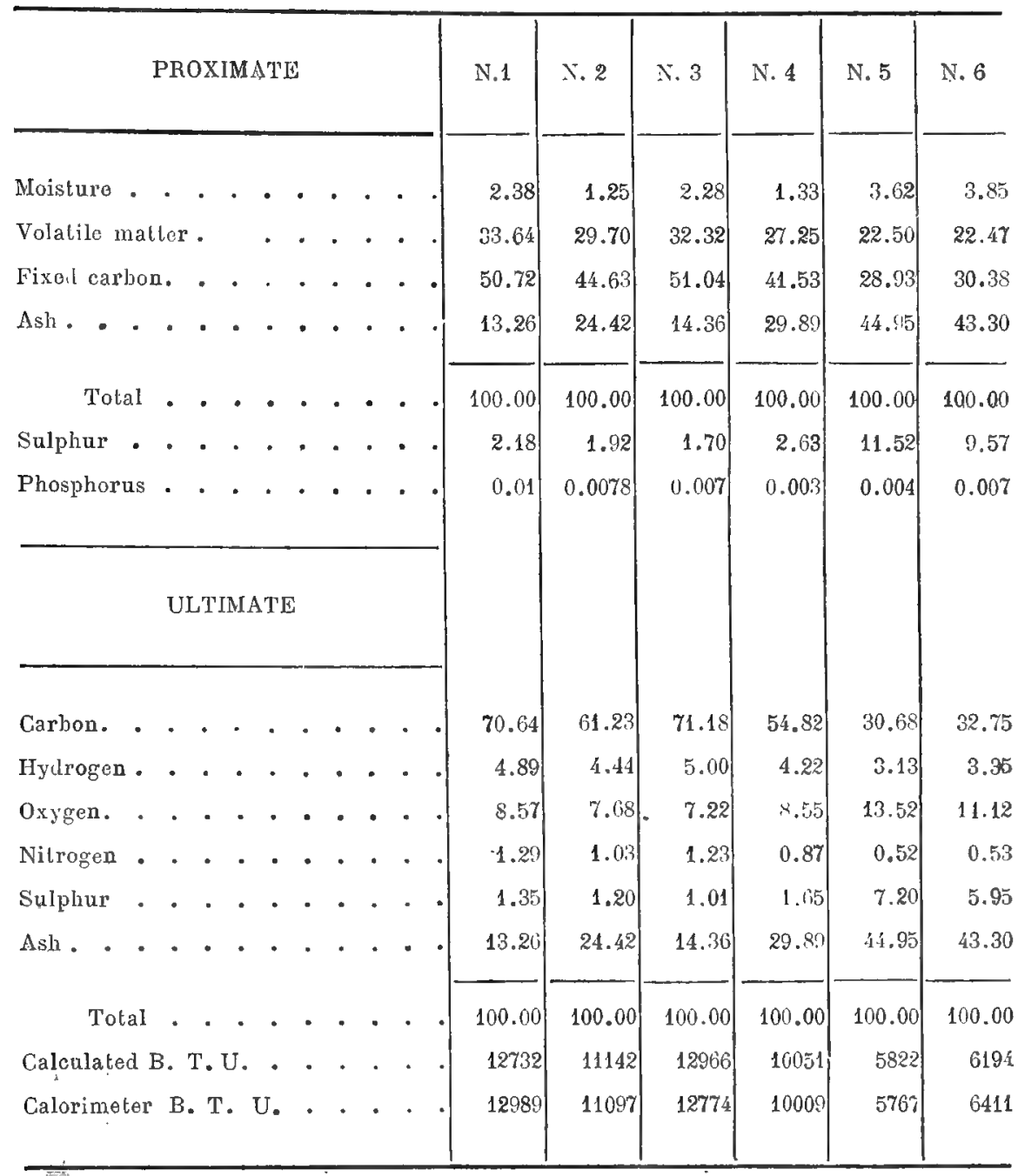

N. 1, First quality washed nut coal, $10.20 \mathrm{~mm}$. size, of Barro Branco bed, 10.57 per cent. of whole.

N. 2, Second quality of washed nut coal, 10.20mm. size, of Barro Branco bed, 25.50 per cent. of whole.

N. 3. First quality of washed Barro Branco coal, under 10mm. size, 2x.0 per cent. of whole.

N. 4, Second quality of washed Burro Branco coal, unler $10 \mathrm{~mm}$. size, 16.71 per cent, ef whole.

N. 5, Refuse shale, sizes $10.20 \mathrm{~mm}$. Barro Branco coal, 4.54 per cent.

N. 6, Dirt anll sludge washings from Barro Branco be.1, 14.90 per cent. 


\section{Briquettes}

As briquettes feitas em Kalk com o carvão brasileiro, foram tambem analysadas sob as vistas do prof. Hite, bem como duas qualidades de briquettes de Cardiff tiradas, para comparação, dos depositos, no Brasil.

Fizeram-se, tambem analyses de duas velhas briquettes, fabricadas em S. Jeronymo, havia muitos annos.

Todas estas analyses de bricuettes, feitas em Morgantown, assim como duas feitas em St. Louis pelo laboratorio de ensaio de combustiveis da Commissão Geologica dos Estados Unidos, vão reunidas na tabella seguinte:

Anàlyses immediatas

\begin{tabular}{|c|c|c|c|c|c|c|c|c|c|c|}
\hline & Amosira & N." & & 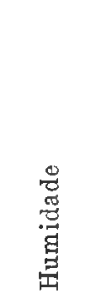 & 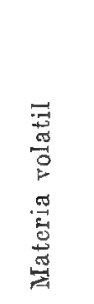 & 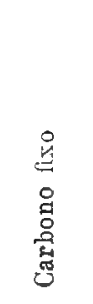 & 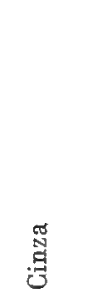 & $\begin{array}{l}\text {. } \\
\text { 芯 } \\
\text { 㡙 }\end{array}$ & 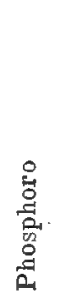 & 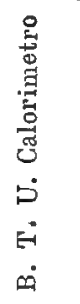 \\
\hline 1. & . & . & . & 1.43 & 29.75 & 59.83 & 8.99 & 1.56 & 003 & 13427 \\
\hline 2. & . . & . & . . & 1.48 & 32.70 & 50.75 & 9.05 & 1.16 & 003 & 13669 \\
\hline 3. & . . , & . & . . & 1.76 & 32.52 & 53.61 & 12.11 & 1.31 & - & 13090 \\
\hline 4. & . . . & . & . . & 5.03 & 38.42 & $50 . .7$ & 10.78 & 0.61 & 033 & 12496 \\
\hline 5. & . . & . & . . & 9.49 & 28.48 & 42.02 & 20.01 & 0.62 & - & 9479 \\
\hline 6. & . . . & . & . & 1.18 & 13.18 & 78.39 & 7.25 & 0.66 & 040 & 14306 \\
\hline 7. & , & . & . . & 1.28 & 15.38 & 73.87 & 9.47 & 0.78 & 040 & 13931 \\
\hline 8. & . . & . & . . & 0.70 & 14.42 & 70.21 & 14.67 & 0.74 & 050 & 13080 \\
\hline 9. & . . . & . & . & 9.00 & 25.43 & 45.25 & 20.32 & 0.55 & 003 & 9302 \\
\hline 10. & . . . & . & . & 7.38 & 26.72 & 45.52 & 20.38 & 0.76 & 006 & 9707 \\
\hline
\end{tabular}




\section{Briquettes}

The briquettes made at Kalk from Brasilian coal were also analyzed under the supervision of prof. Hite, as also two grades of Cardiff bri quettes taken from stock supplies, in Brasil for comparison.

Analyses were also made of two old briquettes manufactured at S. Jeronymo many years ago.

All these briquettes analyses made at Morgantown, as well as two made at S. Louis by the U. S. Geological survey Fuel Testing Laboratory, are collected in the following table:

\section{Proximate analyses}

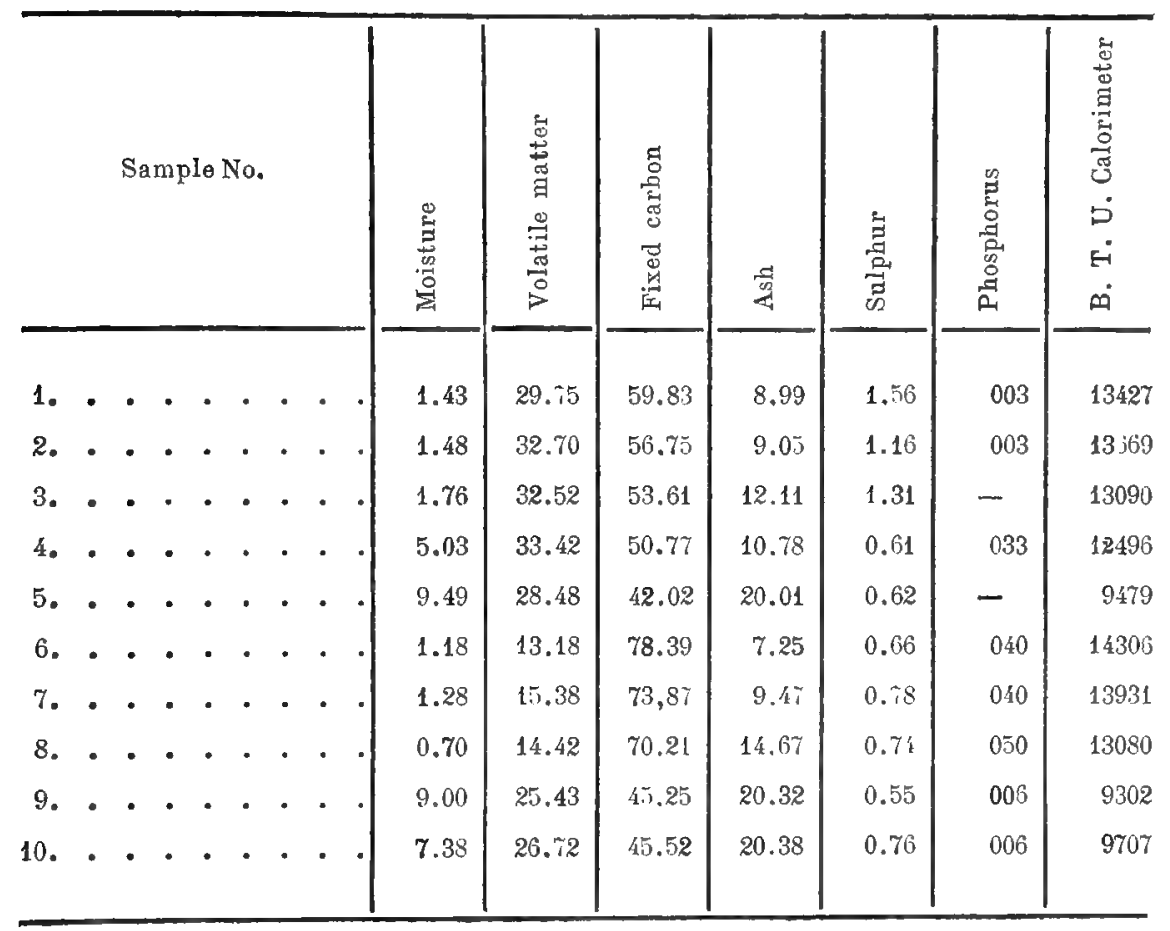




\section{Analyses elementares}

\begin{tabular}{|c|c|c|c|c|c|c|c|c|c|c|c|c|c|}
\hline & & Amost & & N.o & & & 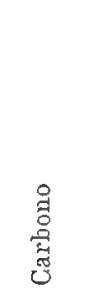 & 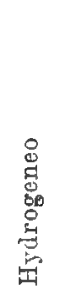 & 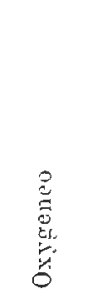 & 总 & 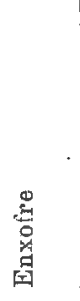 & 莡 & 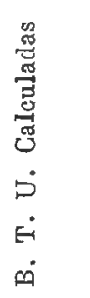 \\
\hline 1. & . & . . & . & . & . & & 77.45 & 3.89 & 7.49 & 1.20 & 0.98 & 8.99 & 13156 \\
\hline 2. & . & . . & . & . . & . & . . & 78.27 & 4.99 & 5.68 & 1.28 & 0.73 & 9.05 & 13903 \\
\hline 3. & . & . . & . & . . & . & • & 73.35 & 4.68 & 7.18 & 1.27 & 1.31 & 12.11 & 13065 \\
\hline 4. & . & . . & . & . & . & • & 70.16 & $5.16 j$ & 13.63 & 11.5 .1 & 0.61 & 9.84 & - \\
\hline 5. & • & . & . & . & . & & 55.38 & 4.24 & 18.93 & 0.82 & 0.62 & 20.01 & 9239 \\
\hline 6. & . & . . & . & . & . & & 84.55 & 4.00 & 2.80 & 0.99 & 0.41 & 7.25 & 1 1 \\
\hline 7. & . & . & . & . & . & . & 81.13 & $\because 3 \times 0$ & 3.96 & 1.07 & 0.48 & 9.47 & 14934 \\
\hline 8. & . & . & • & $\bullet$ & & & 75.27 & 3.56 & 1.12 & 4.98 & 0.40 & 14.67 & 12302 \\
\hline 9. & . & . . & - & . & . & . & 56.45 & 3.94 & 18.24 & 0.70 & 0.35 & 20.32 & 9076 \\
\hline 10. & . & . . & . & . . & . & . . & 57.27 & 4.11 & 16.89 & 0.87 & 0.48 & 20.38 & 9599 \\
\hline
\end{tabular}

N. 1-Briquette de carvão Barro Branco, Minas, Santa Catharina.

N. 2-Briquette de carvão Barro Branco, Minas, Santa:Catharina.

N. 3-Briquette de carvão Barro Branco de primeira qualidacle Iavalo, analyse feita no Laboratorio de ensaio de carvăo da Commissão Geologica dos Estarlos Unilos, das minas de Santa Catharina.

N. 4-Briquette de carvāoS. Jeronymo, feita em Kalk, Allemanlia.

N. 5-Briquet te feita om Kalk de carvão de S. Jeronymo, l̀avado, de segunda qualidade, analyse feita no Laboratorio de onsaió rle carvão da Commissāo Geologica dos Estados Unielos.

N. 6-Briquette "corôa» de carvāo Cardil?, Nova Galles. .

N. 7-Briquette "corôa» de carvão Cardiff, Nova Galles.

N. 8-Briquette «ancora» dle Carvão Caruliır, Nova Galles.

T. 9-Vella briquette, S. Jeronymo.

N. 10-Velha briquette, S. Jeronymo.

Estas analyses de hlic puettes feitas com carvão brasileiro purificado, mostram que quanto a seu valor como combustivel são levemente inferiores ás de Cardiff de melhor qualidade "corôa» e eguaes, ou mesmo superiores ás de marca "ancora» de que se consome grande quantidade no Brasil. 


\section{Ultimate analyses}

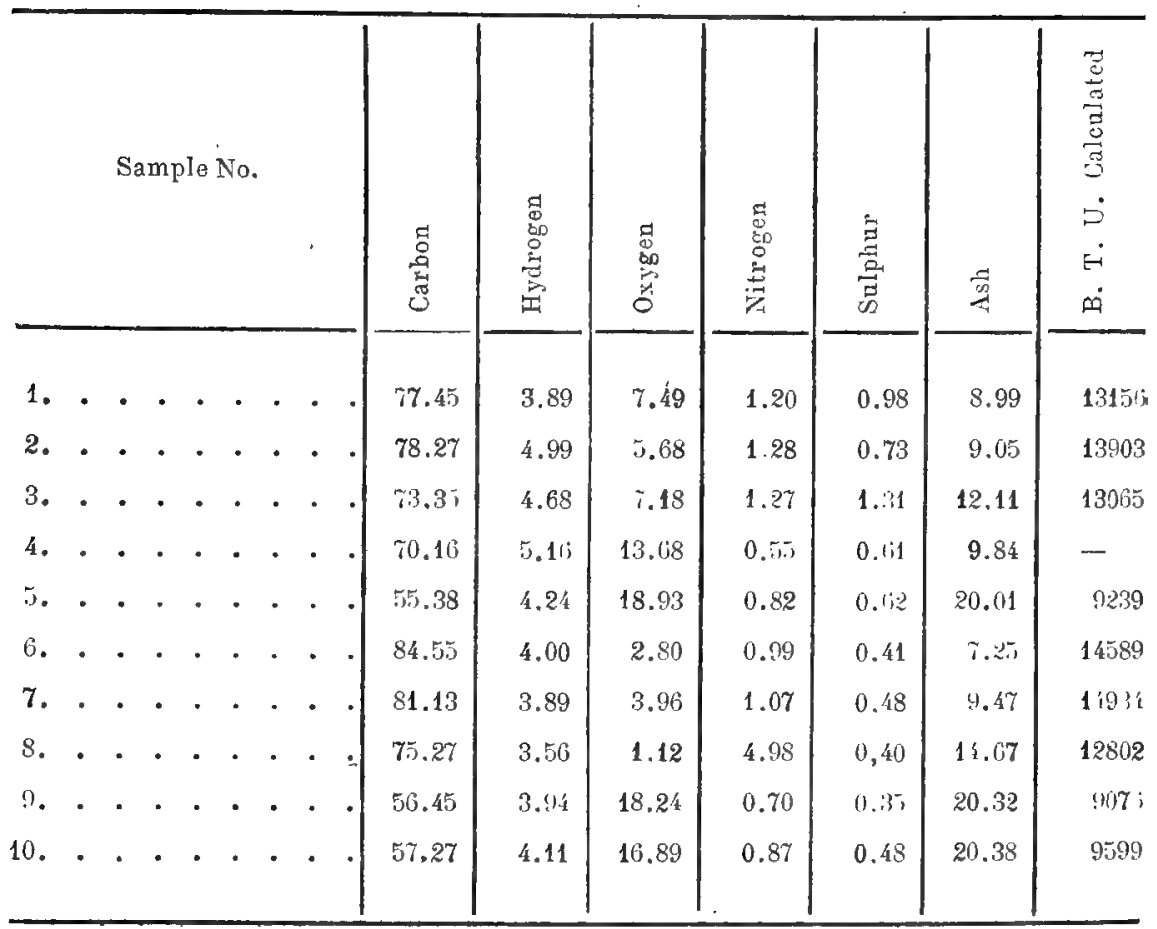

No. 1-Briquette, Barro Branco coal, Minas, Santa Catharina.

No. 2-Briquette, Barro Branco coal, Minas, Santa Catharina.

No. 3-Briquette, Barro Branco coal, first grade washed, analysis made lỵ U. S. Geological Survey Coal-Testing Plant, from Santa Catharina mines.

No. 4-Briquette from S. Jeronymo coal, made at Kalk, Gormany.

No. 5-Briquette, made at Kalk lrom S. Jeronymo washed coal, second grade. analysis Jy U. S. Geulogical Survey Coal-Truting Plant.

No. 6-Crow n Briquette, Garelilf coal, Tralox.

No. 7-Grown Briquette, Cardill coal, Wales.

No. 8-Anchor Briquette, Carilill coal, Wale;.

No. 9-Old Briquette, S. Jeronymo.

No. 10-Old Briquatte, S. Jeronymo.

These analyses of briquettes made from the purifled Brazilian coal show that while their fuel values are slightily inferior to the best. grad "crown" of Cardiff briquette, yet they are equal to or even superior to the "anchor" brand, large quantities of which are used in Brasil. 
A pouca quantidade de enxofre encontrada nas velhas Briquettes de S. Jeronymo é devido ao facto de ter sido este eliminado durante varios annos de exposição ao tempo.

Estas analyses foram dadas para mostrar a grande porcentagem de cinza deixada no carvão pelos velhos methodos de briquettagem.

A analyse feita pela Commissão Geologica da carga de carvão mandada de S. Jeronymo para St. Louis é a seguinte:

Laboratorio de ensaio de carvão da Commissão Geologica dos Estados Unidos

RELATORIO DO LABORATORIO CHIMICO

Analyse do carvão brasileiro

Immediata . . . . . . . . ..$\left\{\begin{array}{l}\text { Humidade . . . } 11.52 \\ \text { Combustivel volatil . . } 26.75 \\ \text { Carbono fixo . . . } 40.00 \\ \text { Cinza . . . . } 21.93\end{array}\right.$

Valor calorifico determinado . . . . . $\quad \begin{cases}\text { Calorias. . . . . . . } & \mathbf{5 1 3 5} \\ \text { Unidades thermicas inglezas } & 9243\end{cases}$

Valor calorifico calculado pelas analyses elementares. $\left\{\begin{array}{c}\text { Calorias. } \\ \text { Unidades thermicas inglezas }\end{array}\right.$

St. Louis, 23/7/905.-(Assignado) E. E. Somermeier, chimico.

As tabellas seguintes representam os resultados obtidos pela Commissão Geologica dos Estados Unidos em St. Louis, do ensaio do valor como combustivel de uma carga de carvão das minas da Companhia S. Jeronymo: 
The low results in sulphur found in the old S. Jeronymo briquette are due to the fact that the sulphur liad been leached out during several years of exposure to the elements.

These analyses are given to show the high per cent. of ash left in the coal by the old methods of briquetting.

The analysis made by the U. S. Geological Survey of the car load of eoal sent from $\mathrm{S}$. Jeronymo to St. Louis is reported as follows:

\title{
U. S. Geological Survey Coal-Testing Plant
}

\author{
CHEMICAL LABORATORY REPORT
}

Analysis of brasilian coal

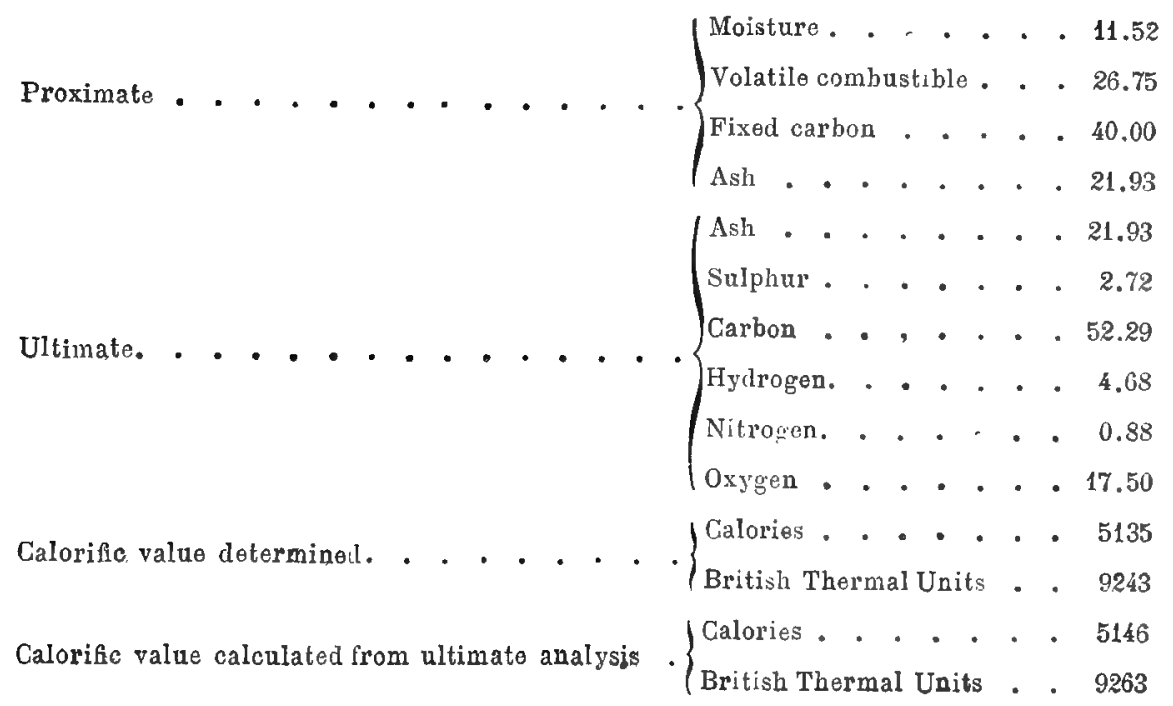

St. Louis, 7/28/05.-(Signed) E. E. Somermeier, chemist.

The following tables represent the results obtained by the U. S. Geological Survey at St. Louis in testing the fuel value of the car load of the S. Jeronymo Company: 
ENSAIO DE CALDEIRA, N. 172

Brasil n. 1

DURAÇÃO DO ENSAIO-3h,35 QUALIDADE DO CARVÃO-COMMUM DE MINA

Tamanho do carvão-Diametro medio em pollegadas-1.42

QUALIDADE DAS GRELHAS-SIMPLES

B. T. U. por? libra de carvão secco

Porcentagem d: cavallo-vapor ava-

lialla pela calcleira. . . . 73.38

1002 Equivalente de agua evapurala:

Ellic:encia. . . . . . . 58.83

Por libra de carvão como loi quei-

Agua eraporada por libra de carvāo

queimalo.. . . . . .

mado. . . . . . . . 5.16

Por libra de carväo secco . . 5.80

Por libra de combustivel . . . 8.43

Temperatura da fornalha em gráos Fahr. . . . . . 1900

Equivalente em libras do carvão queimado no motor, por Secco . . . . . . 4.88 cavallo-vapor hora indicado. . . . . . . . Como loi queimado . 5.48

Equívalente om libras de carvăo queimado por cavallo-jSecco . . . . . 6.02 vapor electrico hora, desenvolvido no quadro de dis-

tribuição . . . . . . . . . . Como foi queimado . 6.77

\section{Analyses}

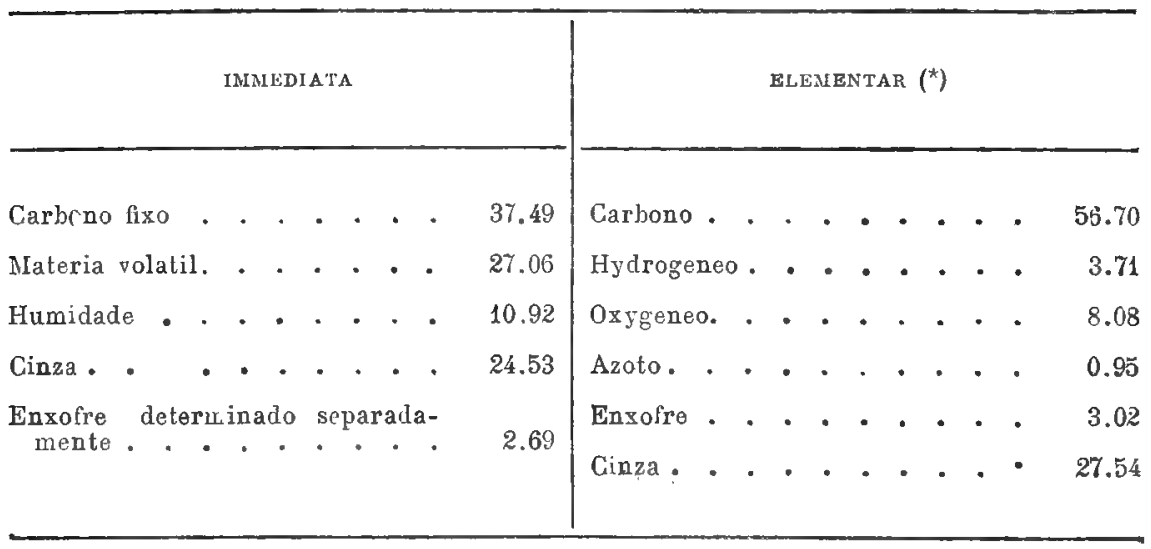

(") De uma amostra de vagāo. 
BOILER TEST, N. 1Y2

Brasil n. 1

DURATION OF TEST-3.35 HOURS KIND OF COAL-MINE RUN

Size of coal-average diameter in inches -1.42

KIND OF GRATE-PLAIN

B. T. U. perlb. dry ceal. - . 10028 Equivalent water evapora:ed:

Per cent of rated h. p, of Boiler. - 73.38 Per lb. of coal as fired. . . . 5.16

Elliciency . . . . . . . 58.83 Per lb. dry coal. . . . . 5.80

Water ovaporated per lb. coal as $\quad$ Per lb. combustille. . . . . 8.43

fired . . . . . . . . 4.18

Furnace temperature, degrees Fahr . . . . . . 1900

Equivalent los. of coal used per I. H. P.(") hour at steam pry . . . . . . 4.88

engine . . . . . . . . . . . . As fired. . . . 5.48

Equivalent lbs. of coal used E.H.P. hour $\left(^{\star \star}\right)$ leveloped pry . . . . . 0.02

at switchboard. . . . . . . . . . . . fired . . . 6.77

\section{Analyses}

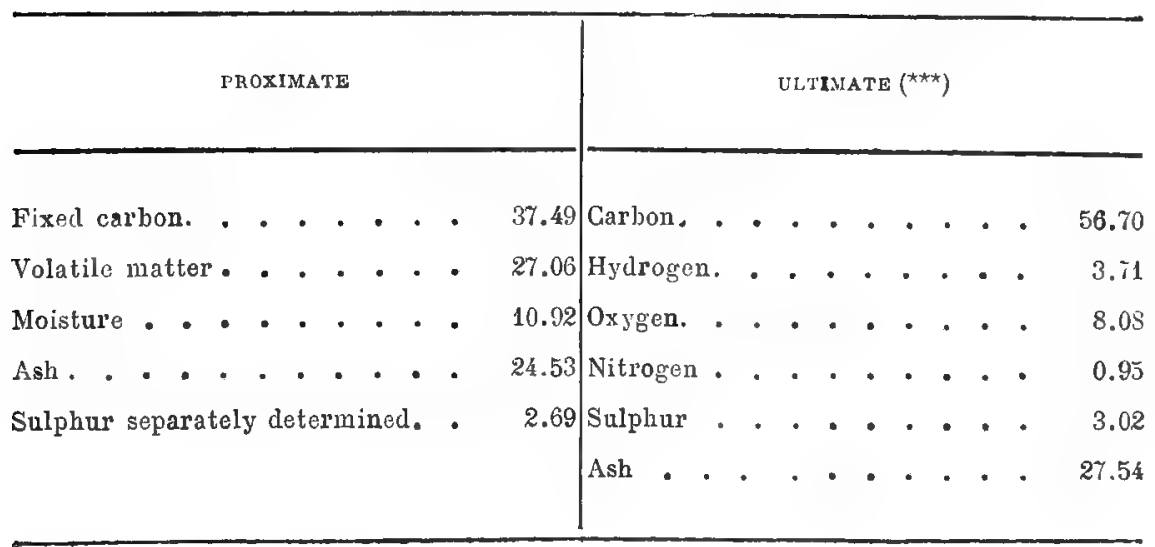

(") Indicated Horso Power.

("*) Electric Horse Power.

(***) Figured from car samplo. 
ENSAIO DE CALDEIRA, N. 173

\section{Bràsil n. 1}

DURAĞÃO DO ENSAIO-5h,6 QUALIDADE DO CARท̆̃O-COMMUM DE' MINA

Tamanho do carvão-Diametro medio em pollegadas-1.26

QUALIDADE DAS GRELINS-SIMPLES

B. T. U. por libra de carvão seccu. Forcentagem de vallo-vapor ava-

liada pela caldeira. . . . 85.00

Élliciencia. . . . . . . . 13.38

Agua evaporada por libra de carvàu

como foi qucimado. . . . . 4.67

9830 Equivalente de agua evaporada:

Por lilira de carvão como foi

queimulo.... . . . . 5.43

Por libra de carvão secco • . 6.09

Pur libra de combustivel. . . . 8.94

Temperatula da fornalha em gráos Fahr. . . . . 1858

Liquiralente em lìbras do carvão queimado no motor por Secco . . . . . $\quad 4.64$

cavallo-vapor-hora indicado. . . . . . . . Como foi queimado . 5.21

Equivalente em libras de carvāo queimado por cavallo- Secco . . . . . 5.73

vapor electrico hora, desenvolvido no quadro de dis-?

tribuição. . . . . . . . . Como fui queimarlo . 6.4's

\section{Analyses}

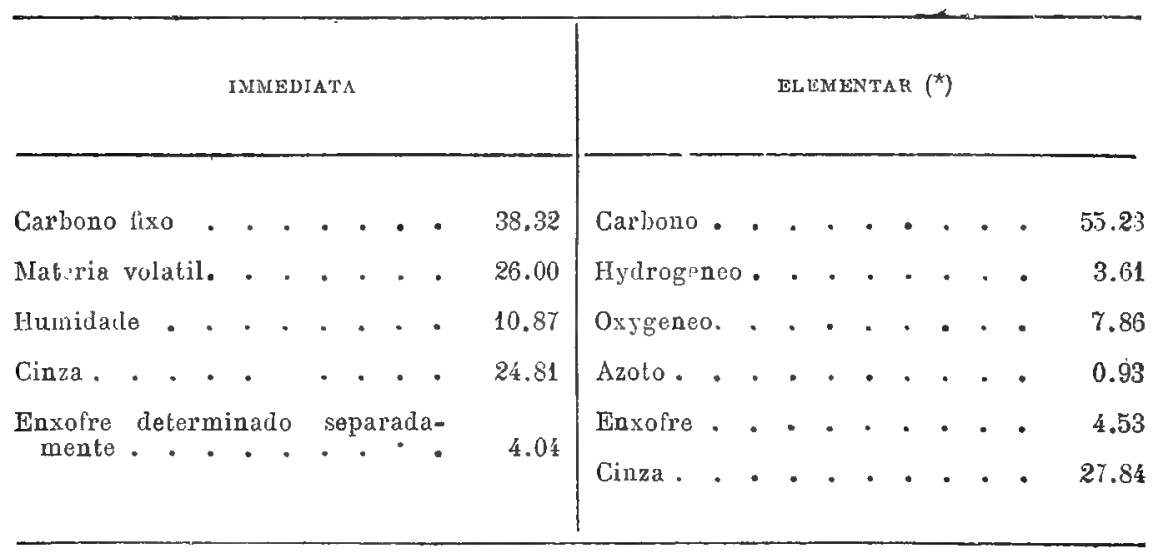

(*) De uma amostra de vagão. 
BOILER TEST, N. 173

Brasil n. 1

LURATION OF TEST-5.6 HOURS, KIND OF COAL-MINE RUN

Size of coal-average diameter in inches-1.26

KIND OF GRATE-PLAIN

B.T.U. per lb. lry coat. . - 9830 Equivalent watcr evaporaterl :

Por cent of rated h. p. of Boiler. . 85.00 Per lb. of coal as fired. . . . 5.43

Elliciency . • . . . . . 63.38 Per lb. dry coal . . . . . 6.09

Water evaporaterl per Ib. coal as
fired . . . . . . . . . . . 4.67

Furnace temperature, degrees Fahr . . . . . . 1858

Equivalent Ibs. of coal used por J.II. P. hour at steam Dry . . . . . 4.64 engine. . . . . . . . . . . . As liren... . 5.21

Equivalont lhs. of coal userl per E. II. P. houl deve Dry . • . • . 5.73

loped at swilchboard . . . . . . . . Is fired. . . . 0.43

\section{Analyses}

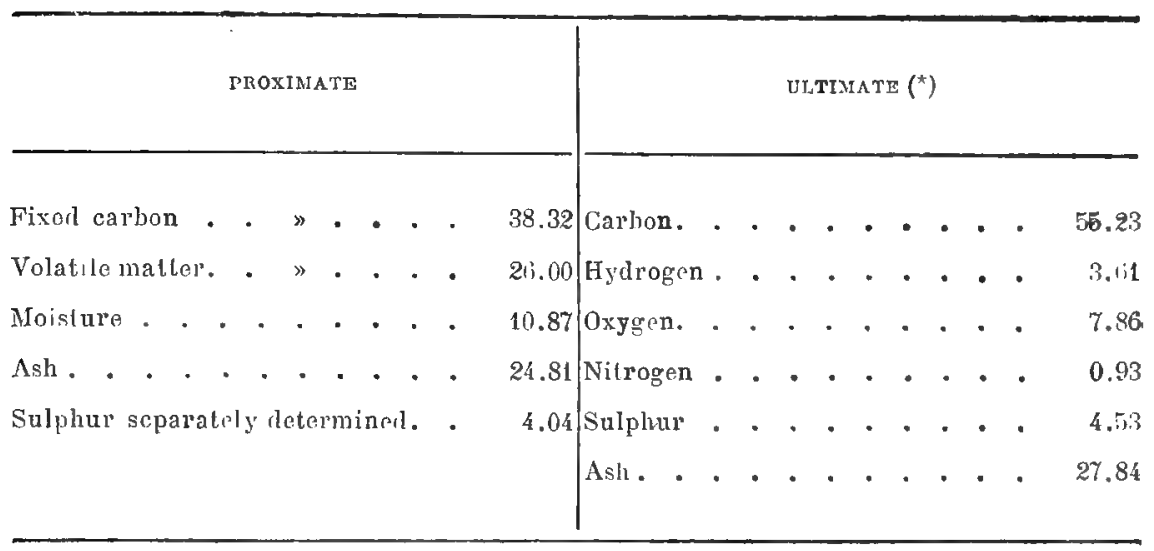

(*) Figured from car sample. 


\title{
ENSAIO DO GAZOGENEO, N , 44
}

\author{
Brasil n. 1
}

Duração do ensaio: 24 horas — Qualidade do carvāo: Commum de mina

Libras consumidas no gazogeneo por cavallo-vapor electrico aproveitavel para fins externos . . . . . . . .

Libras consumidas no gazogeneo por cavallo-vapor electrico desenvolvido no quadro de distribuiçāo . . . . . .

I,ibras consumidas no gazogeneo por cavallo-vapor brake aproveitavel para fins externos.

Libras consumidlas no gazogeneo por cavallo-vapor brake desenvolvido no motor . . . . . . . .

Equivalente en libras, consumido na fabrica do gaz por cavallovapor electrico aproveitavel para fins externos. . . . .

Equivalonte em libras consumido na fabrica de gaz por cavallovapor electrico desenvolvido no quadro de distribuição . .

Equivalente em libras consumido na fabrica degaz por cavallovapor brake aproveitavel para fins externos. . . . . .

Equivalente em libras, consumido na fabrica de gaz por cavallo-

vapor brake desenvolvido no motor. . . . . . . .

Média dle cavallos-vapor electricos . • . • • • • • • • • • • • 141.8

Média de unidades thermicas inglezas do gaz por pé cubico . . . . . . . 130.9

Total do carvăo queimalo. . . . . . . . . . . . . . . 8100

(*) Carvão como foi queímado.

(**) Carvão secco.

$\left({ }^{\star \star *}\right)$ Combustivel.
CARYÃO

POR GAVALLO-VAPOR-HORA

\begin{tabular}{|c|c|c|}
\hline$\left({ }^{\star}\right)$ & $(\star \star)$ & $\left({ }^{\star \star \star}\right)$ \\
\hline 2.63 & 2.35 & 1.73 \\
\hline 2.38 & 2.12 & 1.56 \\
\hline 2.24 & 1.99 & 1.47 \\
\hline 2.02 & 1.80 & 1.33 \\
\hline 2.88 & 2.56 & 1.89 \\
\hline 2.60 & 2.32 & 1.71 \\
\hline 2.45 & 2.18 & 1.61 \\
\hline 2.21 & 1.97 & 1.45 \\
\hline - $\cdot$ & · $\cdot$ & 141.8 \\
\hline$\cdot \cdot$ & $\cdot \cdot \cdot$ & 130.9 \\
\hline . . & . . . & 8100 \\
\hline
\end{tabular}




\section{GAS PRODUOER TEST, NO. 44}

Brasil no. 1

Duration of Test : 24 hours — Kind of coal : Mine run

\begin{tabular}{|c|c|c|c|}
\hline & \multicolumn{3}{|c|}{$\begin{array}{c}\text { COAL PER } \\
\text { HORSEPOWER PER HOUR }\end{array}$} \\
\hline & $\left({ }^{*}\right)$ & $\left({ }^{* *}\right)$ & $\left({ }^{\star \star \star}\right)$ \\
\hline $\begin{array}{l}\text { Lbs. consumed in producer per E. H. P. arailable for outsie } \\
\text { purposes }\end{array}$ & 2.63 & 2.35 & 1.73 \\
\hline $\begin{array}{l}\text { Lbs. consumed in prorlucer per E. H. P. developed at switch- } \\
\text { board. }\end{array}$ & 2.38 & 2.12 & 1.56 \\
\hline $\begin{array}{l}\text { Lbs, consumed in producer per B. II. P. avaiablo for outside } \\
\text { purposes } \\
\end{array}$ & 2.24 & 1.99 & $1.4 i$ \\
\hline 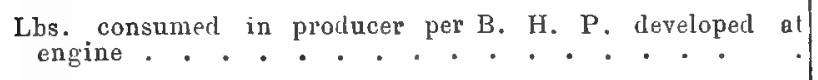 & 2.02 & 1.80 & 1.33 \\
\hline $\begin{array}{l}\text { Equivalent lbs. used by producer plant per E. H. P. available } \\
\text { for outside purposes. }\end{array}$ & 2.88 & 2.56 & 1.89 \\
\hline $\begin{array}{l}\text { Equivalent lbs. used by producer plant por E.H.P. developed } \\
\text { at switchboard } . .\end{array}$ & 2.60 & 2.32 & 1.71 \\
\hline $\begin{array}{l}\text { Equivalent lbs. used by producer plant per B. H. P. (I) } \\
\text { avaiable for outside purposes. }\end{array}$ & 2.45 & 2.18 & $1.6 \mathrm{l}$ \\
\hline $\begin{array}{l}\text { Equivalent lbs. used by producer plant per B. H. P. developed } \\
\text { at ongine. } . .\end{array}$ & 2.21 & $1.9 i$ & 1.45 \\
\hline Average Electrical Horse Power. . . . . . . . . . & - & • & 141.8 \\
\hline Average B. T. U. gas per cubic foot $\quad \cdot$. . . . . . & - & . & 130.9 \\
\hline Total coal fred. . . . . . . . . . . . . . . . & $\cdot \cdot \cdot$ & - & 8100 \\
\hline
\end{tabular}

(*) Coal as fired.

$\left.{ }^{(\star}\right)$ Dry coal.

(**) Combustible.

(1) Brake horse powcr. 
ANALYSES

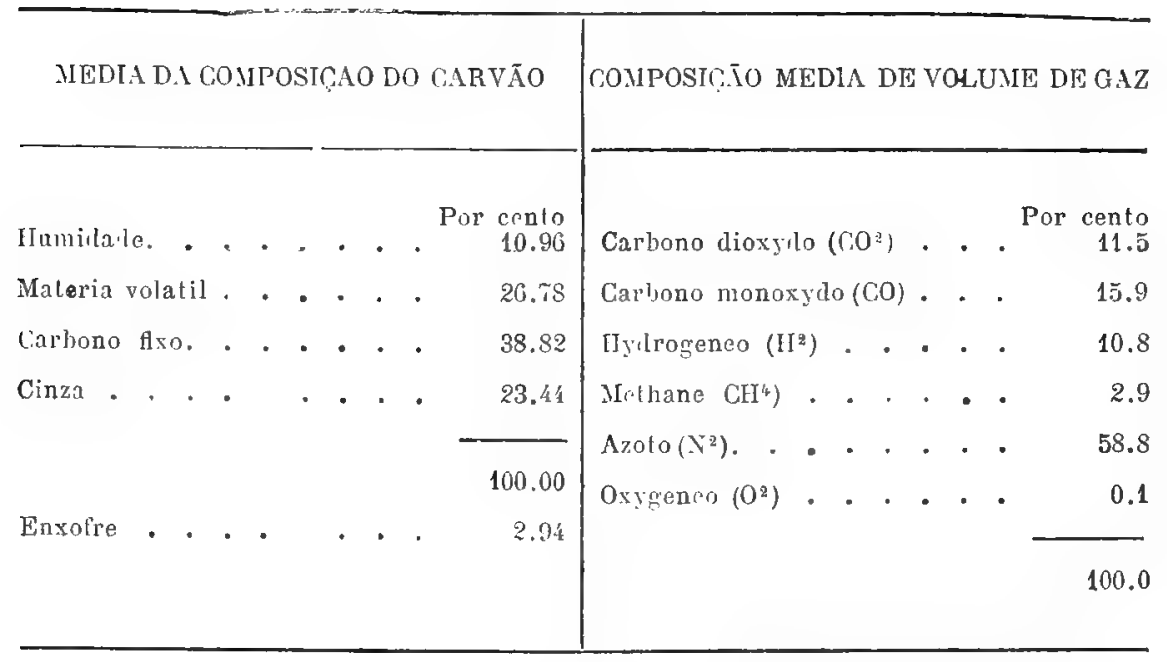

OS resultados liquidos dos ensaios de purificação feitos em Kalk e das analyses feitas alli e em outras partes podem ser summariados do seguinte modo :

Primeiro - Todo carvão brasileiro explorado commercialmente apresentará alta porcentagem de cinza e enxofre, contendo um total de $20 \%$ a $35 \%$ destas impurezas de que $2 \%$ a $8 \%$ são de enxofre.

Segundo - o enxofre se apresenta principalmente em massas de pyrite de ferro que podem ser quasi completamente eliminadas do carvão, pelos methodos modernos de britamento e lavagem e as pyrites obtidas empregadas no fabrico de acido sulfurico.

Terceiro - Do carvão de S. Jeronymo, no Rio Grande do sul, pódese obter duas qualidades de combustivel purificado: qualidade n. 1 $32 \%$ do total tratado, tendo menos de $14 \%$ de cinza e muito pouco $(0.6 \%)$ de enxolre e qualidade $n .2$ que se eleva a $42 \%$ do total tendo um pouco menos de 27 por cento de cinza e muito pouco enxofre.

Quarto - Do carvão Barro Branco de Santa Catharina póde-se tambem obter duas quaiidades: a primeira, $38 \%$ do total, tendo $14 \%$ de cinza e a segunda $4 \div \%$ do total com $28 \%$ de cinza, ambas as qualidades contendo sómente um ponco mais que $1 \%$ de enxofre. Tambem se póde conseguir uma boa qualidade de carvão "nut » do da camada Barro Branco que póde ser empregado sem briquettar. 


\section{ANALYSES}

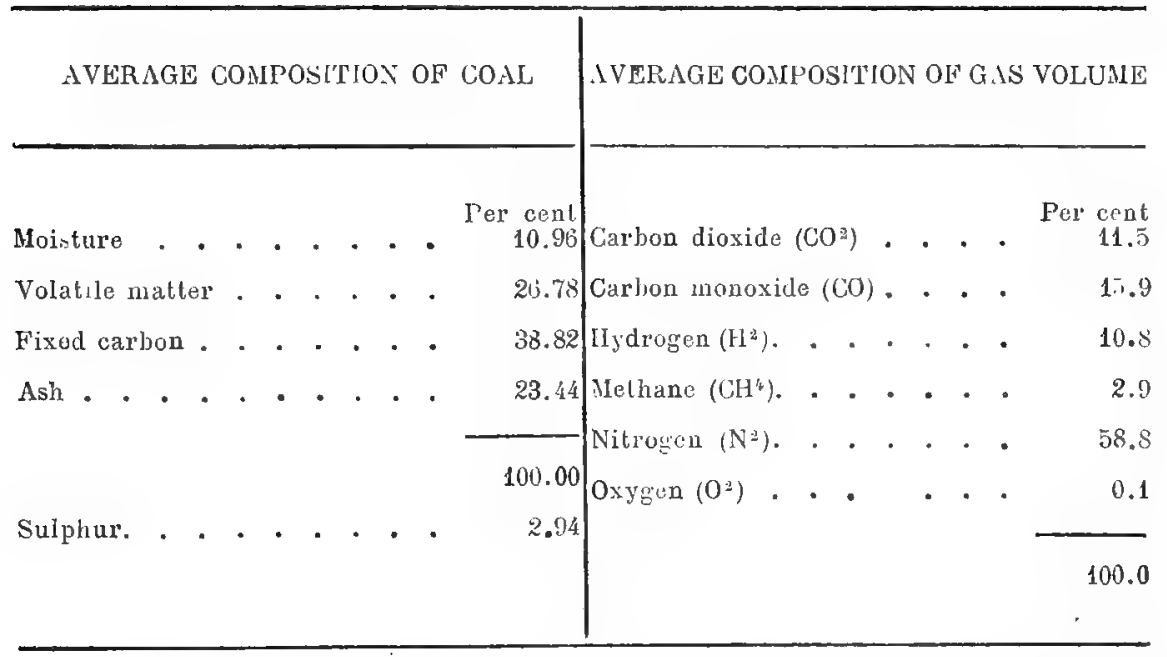

The net results of the purification tests at Kalk, and the analyses made there and elsewhere may besummarized as follows:

First-All Brasilian coal mined in a commercial way will be high in both ash and sulphur, containing a total of 20 to 35 per cent. of impurities, of which 2 to 8 per cent is sulphur.

Second-The sulphur occurs mostly in nuggets of iron pyrites, which can nearly all be removed from the coal by modern processes of crushing and washing, and the recovered pyrites utilized in the manufacture of sulphuric acid.

Third-From the coal of S. Jeronymo, in Rio Grande do Sul, two grades of purified fuel can be obtained; grade No. 1, 32 per cent. of the amount treated, having less than 1 \& per cent. of ash, and very low (0.6) in sulphur, while grade No. 2 , amounting to 42 per cent. of the whole, will have a little less than 27 per cent. of ash and very little sulphur.

Fourth-From the Barro Branco coal of Santa Catharina, two grades of coal can also be obtained, the first grade, 38 per cent. of the whole, having 14 per cent. of ash while the second grade, 42 per cen. of the whole will have 28 per cent. of ash, both grades containing only a little over 1 per cent. of sulphur. It is also possible to secure a fair grade of "nut" coal from the Barro Brancolyed that can be used without briquetting. 
Quinto - Com o carvão de primeira qualidade, tanto de Santa Catharina como de Rio Grande do sul póde-se fabricar briquettes comparaveis com vantagem ás que são importadas de Cardiff, Galles, sendo ligeiramente inferiores em valor calorifico ás de marca "corôa " e eguaes, ou superiores ás briquettes de Cardiff marca "ancora"; podendo o carvão de segunda qualidade ser empregado com hom resultado tanto como combustivel geral para obter força, como o carvão fino, ou moinha das minas, ou póde ser utilisado para a producção de gaz para motores.

Sexto - As amostras de carvão da camada Bonito de Santa Catharina que foram remettidas para Kalk foram naturalmente tiradas do carvão do affloramento, muito alterado e as conclusões do tenente Esser são que elle contém tanto refugo de cinzas que seu tratamento em uma usina de beneficiamento seria improficuo, poderia entretanto ser utilisado em gazogeneos para a producção de gaz para motores e é provavel que em ponto mais profundo da bacia o carvão contenha muito menos cinza que nas amostras da superficie, visto ter o Dr. Oliveira, primeiro engenheiro da commissão, referido que a camada foi encontrada com cinco metros de espessura na sondagem recentemente feita no Barro Branco Velho, de que tres metros, diz elle, são de carvão bastante puro, á profundidade de 65 metros apenas abaixo da superficie.

Setimo - Uma das descobertas capitaes feitas pelo grande Laboratorio de Ensaio de Carvão da Commissão Geologica dos Estados Unidos em Saint Louis foi que carvões impuros contendo muita cinza e enxofre podem ser utilizados no fabrico de gaz para motores (o enxofre não tem influencia alguma deleteria) e assim empregados os carvões de qualidade muito inferior offerecem mais vantagens como geradores de energia que as melhores qualidades de carvão Cardiff, ou Pocahontas quando utilisados em motores a vapor ; mesmo o refugo e residuos das minas dão grande resultado transformados em força, quando utilisados no fabrico do gaz.

Os ensaios feitos em Saint Louis com o cárvão brasileiro para a producção de gaz, mostram que elle póde ser vantajosamente utilisado para este fim.

Estas conclusões tornam muito provavel que o carvão de Santa Catharina e Rio Grande do Sul possa ser collocado no mercado competindo com vantagem com o carvão estrangeiro, sendo convenientemente preparado pelos methodos modernos de purificação, á vista do alto preço do carvão importado em qualquer ponto do Brasil. 
Fifth-From the coal of first grade both in Santa Catharina and Rio Grande do Sul, briquettes can be manufactured which compare favorably with those imported from Cardifl, IVales, being but little inferior in lieating value to the "rown» brand, and equal to or superior to the "anchor" brand of Cardiff Juriquettes, while the second grad of coal can be used successfully either as a general fuel for power purposes, like the fine or slack coal from mines, or it can be utilized in the manufacture of ploducer gas for sras engines.

Sixth-The coal samples sent to Kalk from the Lonito bed of Santa Catharina were necessarily taken from the very much weathered crop coal, and Lieut. Esser's conclusions are that it contains so much ashy refuse that ils breatment would prove umprofitalsle in a coal purification plant. It could be utilized, however, in the manufacture of producer gas for gas engines, and it is probable that deeper down in the Jasin the coal rould hold much less ash than the surface samples, since Dr. Oliveira, the first engineer of the coal commission, reports the bed as 5 meters thick in the boring recently made at Barro Branco Velho, 3 meters of which, lio says, is fairly pure coal, at a depthol'only 65 meter's juelow the surface.

Seventh-one of the capital discoveries made by the greal cual testing plant of the U. S. Geological Survey at St. Louis is that impurecoals, very high in both ash and sulphur can be utilized in the manufacture of producer gas for the gas engine, (the sulphur having no deleterious effect) and when so used coals of very in lerior qualits, give a greater efficiency in the production of power than the best grades of Cardiff or Pocahontas coal when utilized through the steam engine. That even refuse and waste production of mines, when converted into producer gas, yeld large returns in power.

The test made at St. Louis of the Brasilian coal for producer gas shows that it can be successfully used for that purpose.

These conclusions would seem to render it rery probable, in view of the high price of imported coal everywhere in Brasil, that the coals of Santa Catharina and Rio Grande do Sul can be successfully marketed in competition with foreign coal if properly prepared Jy modern methods of purification. 
O arçamen to do custo da installação para britar, lavar e briquettar 300 toneladas de carvãi pol dia, feita pelas Humboldt Engineering Works de Kalk na Allemanha vão em apyendice junto a este relatorio.

\section{Schistos de Palermo}

Acima dos gres cinzentos Rio Bunito com schistos e leitos de carvă, etc., vem uma série de whistos e rochas mais molles geralmente cinzen los escuros, ou muilas vezes cinzentos amarellados.

Decompüem-se promptamente «m argillas e sedimentos lodosos de tal modo cu: as eslradas que passam por elles são de conservação difflcil. Affloram na estrada do Pio do Rasto entre os kilometros $5^{\circ}$ e $12^{\circ}$ de Mlinas, onde citam muito bem expostos, muito alterados pelo tempue com a exprisura de 90 melros, aflloram tambem na estrada de Treviso, estão expostus nesta entre Palermo oito kilometros a oeste de Minas e o affloramento do schisto preto de Iraty sobreposto, dois kilometros além, sendo por isso designados schistos de Palermo; a espessura alli é de cerca de 95 metros.

Occasionalmente argillas avermelliadas affloram nas estradas que passam por estas camadas, mas não é certo si a côr vermelha é ás vezes devida á alteração pelo tempo, ou antes seja a côr original dos depositus em questão, entretanto as observações feilas á superficie nestas rochas no Rio Grando do Sul, bem coma no Paraná e em S. Paulo, onde se veem frequentemente finas camadas de schistos cor de purpura, ou castanhos a curta distancia acima do tope das camadas Rio Bonito, tendem a mostral que aiguns dos leitos são inherentemente vermelhos, o que é tambem confirmado pelos resultados obtidos nas sundagens já mencionadas de S. Paulo, Paraná e Rio Grande do Sul em que estes estratos variegados de vermelho occorrem á profundidade de 100 a 200 metros abaixo da superficie e portanto muito afastados da zona de accão alterante, meteorica e almospherica. Estas rochas estão Jellamente expostas em cortes da estrada de ferro entre S. Gabriel, Rio Grande do Sul e 10 kilometros a éste onde, neste ultimo ponto, a bave clo schisto preto de Irraty está no leito da linha.

- Embora haja urande mudança lithologica passando-se das camadas Rio Bonito para us dos schistos de Palermo, não parece haver evidencia alguma de discordancia apezar de ser raramente visivel a linha exacta de contacto.

Os unicos fosseis observados nos schistos de Palermo são fragmentos de madeira fossil (Dadoxylon). 
The estimate of cost for such a plant, which would crush, rash, and briquette 300 tons of coal daily, as designed by the Humboldt Engineering works of Kalk, Germany, is given in the appondix to this report.

\section{The Palermo Shales}

Above the Rio Bonito gray sandstones wilh thein included coal heds shales, etc., there comes in a seriesur shales, and softer rocks, usualy of a dull gray or often buffish gray color. They decompose readily into clays, and muddy sediments, so that the roakls passing over them are difficult of maintenance. They crop along the Estrada ito rio do Rasto hetween the 5 th and 12 th kilometer's from Minas where ther are fail's well exposed in a much weathered condition, and have a thickmest of 90 meters. They also crop on the Treviso road, l, ming exposed along the same between the village of Palermo, 8 lilometers west from Minas, and the outcrop of the overlying Iraty black shale, 2 kilometers beyond, and hence have been designated the Palermo shales. The thickness there is about 95 meters.

Occasional reddish clays crop on the roads which pass over tiliese beds, but whether the red color is sometimes due to weathering, rather than to the original color of the deposits in question is not certain, although the surface olsservations on these rocks in Rio Grande do Sul, as well as in Paraná and São Paulo, where thin layers of purple, or maroon-colored shales, are frequently visible at short distance above the top of Rio Bonito beds, would tend to show that some of the beds are inherently red. This is also confirmed by the results found in the borings already recorded from s. Paulo, Paraná, and Rio Grande do Sul, in which these strata variegated with red occul at depths of 100 to 200 meters below the surface, and hence fal removed from the zone of weathering. These rocks are fairly woll exposed in the railway cut. between S. Gabriel, Rio Grande do Sul, and 10 kilometors eastward at which latter point the base of the Iraty black shate sets in along the track.

Although there is such a great change in lithology in passing from the Rio Bonito beds to those of the Palermo shales, there does not appear to be any evidence of unconformity, though the exact line of contact is seldom visible.

The only fossils observed in the Palermo shales are fragments of fossil wood (Dadoxylon). 


\section{CAPITULO VI}

\section{A serie do Passa Dois}

Acima dos schistos de Palermo vem uma série de schistos, camadas areentas e calcareas que estão Jem expostas ao longo das cabeceiras do Passa Dois, rio quo margeia parallelamente a estrada do Rio do Rasto por muitos kilometros, sendo portanto estas camadas designadas com o nome daquelle rio.

o caracter da série em conjuncto é de natureza schistosa molle, embora occorram a miudo perto do centro algumas camadas de pederneira, Jjem como algumas areentas. A espessura total da série do Passa Dois calculada por seus affloramentos na estrada do Rio do Rasto em Santa Catharina, é de 223 metros.

Estas camadas sobre a série Tubarão foram estudadas incidentemente e portanto ás pressas, de modo que as medidas dadas são approximadas.

A série como está exposta em Santa Catharina é composta de tres membros, a saber: Calcareo da Rocinha no tope separado do schisto preto de Iraty da base pelos schistos da estrada do Rio do Rasto que se interpũem e que conteem madeira fossil, restos de crustacens fosseis e concreções de pederneira.

\section{Schisto preto de Iraty}

Na base da série do Passa Dois ha um schisto preto espesso e Iargamente persistente que se estende de S. Paulo pelo Paraná e Santa Catharina até o Rio Grande do Sul. Parece ser geralmente petrolifero, de forma que tem semple o cheiro de petroleo quando quebrado de fresn e em superficie que não tenha sido alterada pelo tempo.

A esta formação foi dado o nome de Iraty, no Estado do Paraná, onde afflora em um corte da estrada de ferro a tres kilometros ao sul da estação de Iraty e contém grande numero de restos do reptil fossil que o Dr. Mc Gregor, do Museu Americano de Historia Natural, de New Y'ork, classificou Mesosaurus brasiliensis. 


\section{CHAPTER VI}

\section{The Passa Dois Series}

Above the Palermoshales, there comes a series of shales, sandy beds, and limestones which are well exposed along the upper waters of Rio Passa Dois, a stream which parallels the Estrada do Rio do Rasto for several kilometers, and hence these beds have been designated from that river.

The character of the series as a whole is of a soft and shaly nature, although someclierty beds often occur near the center as well as some sandy layers. 'The total thickness of the Passa Dois series as estimated from its crop along the Estrada do rio do Rasto of Santa Catharina is 223 metres.

These beds above the Tubarão seris were studicd only incidentally and therefore hastilly, so that the measurements given are approximate.

The series as sxhibited in Santa Catluarina is made up of three mem]jers, namelly, the Rocinha Limestone at top separated from the Iraty black shale at base by the inlervening Estrada do Rio do Rasto gray and variegated shales holding fissil wood, fossil irustacean remais, and cherty concretions.

\section{The Iraty Black Shale}

At the base af the Passa Dois series, there cumes a thick, and widely persistent black shale, extending from S. Paulo, through Paraná, and Santa Catharina, to and across Rio Grande do Sul. It appears to be generally petroliferous so that on freshly broken and unweathered surfaces it always gives out the odor of petroleum.

This formation has been designated from Iraty in the state of Paraná where it crops in a railway cutting about 3 kilometers south from the Iraty station, and contains vast numbers of the remains of a fossil reptile which Dr. Mc Gregor, of the American Museum of Natural History, New York, has named Mesosaurus brasiliensis. 
Este fossil é uma forma muito proxima do Mesosaurus tenuidens Gervais, do Karroo inferior, ou da série de Ecca da Africa do Sul.

Mais ao norte no Estado de S. Paulo Mesosaurus é substituido por Stereosternum tumidum Cope, cujos restos abundam nos schistos pretos e camadas calcareas que occorrem na zona de Iraty, daquelle Estado.

Frequentemente o petroleo do schisto de Iraty foi transformado pela oxidação em uma substancia (Albertite?) que se assemelha ao carvão, como se vê na fazenda do coronel Antonio Ribeiro dos Santos, a 13 kilometros a noroeste de Lages em Santa Catharina, onde o supposto carvão se apresenta em estreitas fendas verticaes no schisto preto.

Em Limeira, no Estado des. Paulo, este material foi transformado em coke natural pelo calor da rocha eruptiva (diabase) que correu fundida sobre aquelle, transformando o petroleo ox ydado (ou Albertite?) em coke.

As analyses abaixo, do schisto (Albertite), coke, etc., dão a composição chimica destes:

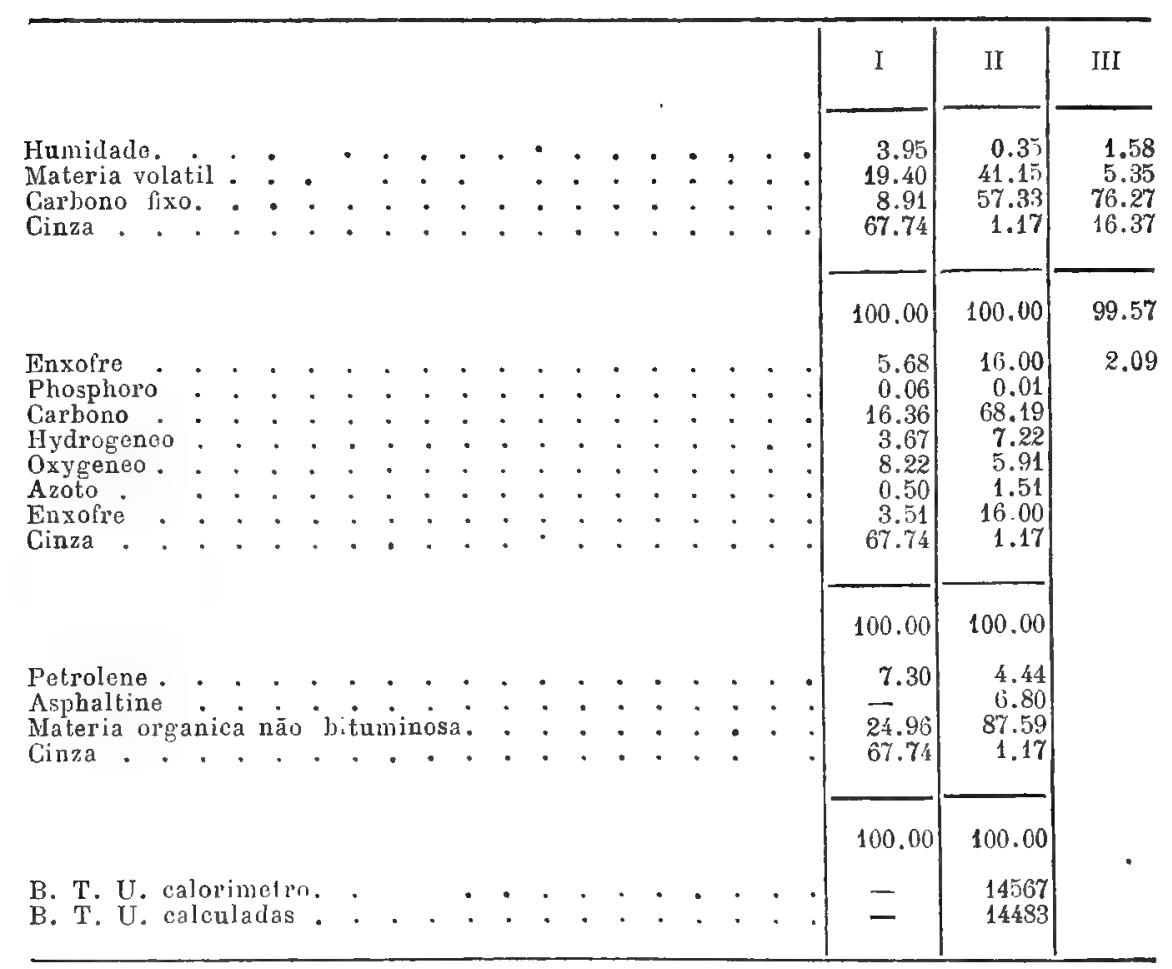

I. Schisto preto de Iraty do um poço perto de Bella Vista no Rio Grande do Sul.

II. Alhertite do schisto preto de Iraty de perto de Lages, em Santa Catharina.

III. Coke natural de horizonte do schisto preto de Iraty, perto de Limeira, S. Paulo. 
This fossil is a very near relative of Mesosaurus tenuidens, Gervais, from the Lower Karroo, or Ecca series of South Africa.

Farther north in the state of São Paulo, Mesosaurus is replaced by Stereosternum tumidum, Cope, the remains of which abound in the black shales and limy heds occurring in the Iraty zone of that state.

Frequently the petroleun in the Iraty shale has been oxidized into a substance (Albertite?) resembling coal as exhibited on the fazenda of Col. Antonio Ribeiro dos Santos, 13 bilometer's north-westward from Lages in Santa Catharina, where the supposed "coal" occur's in narrow vertical fissures in the black shale.

At Limeira in the state of São Paulo, this material has been transformed into natural coke by the heat of the eruptive rocks (diabase) which flowed over it in a molten condition, metamorphosing the oxydized petroleum or (Albertite?) into colie.

The following analyses of the shale, (Albertite ?) colie, etc., exhibit the chemical constitution of the same:

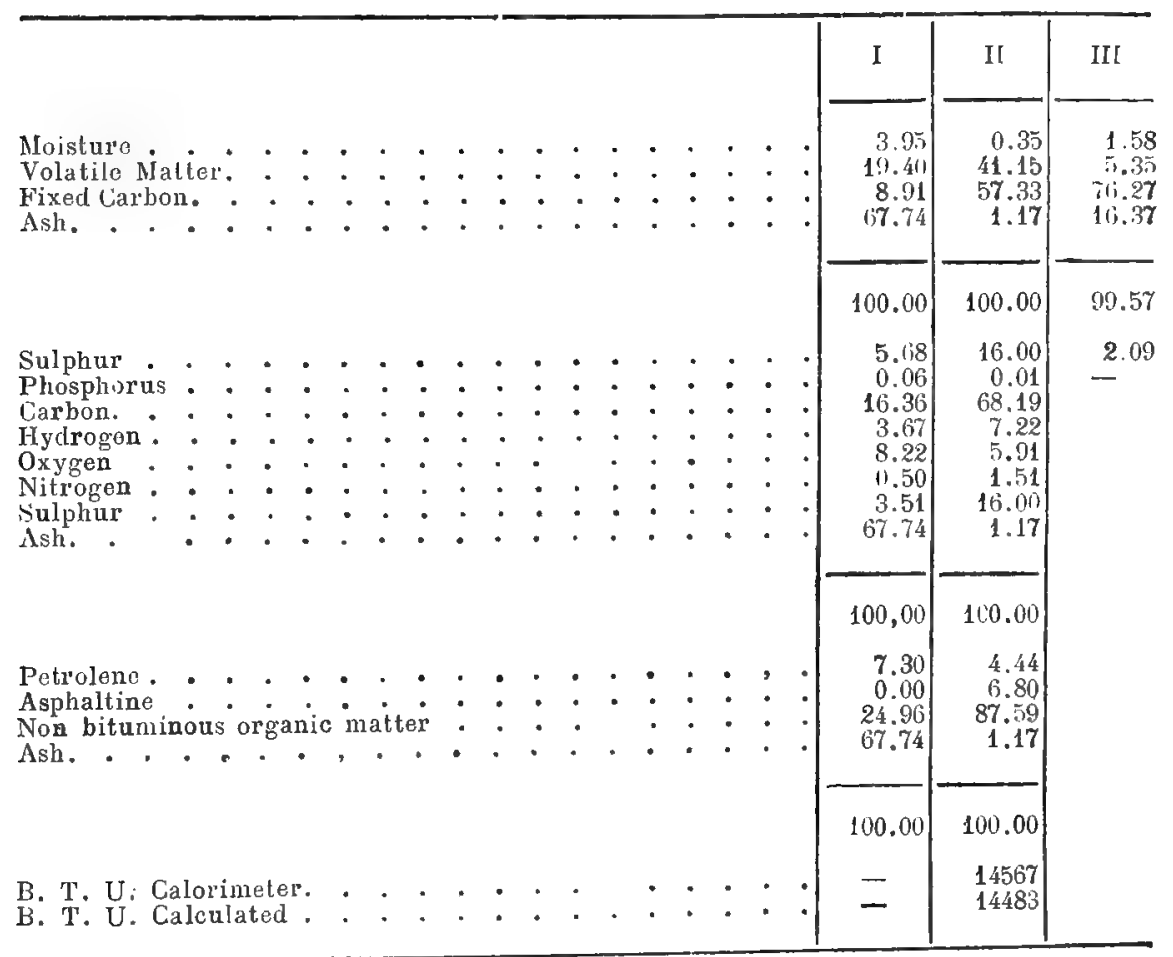

I. Iraty black shale from shaft near Bella Vista, Rio Grande do Sul.

II. (Albertite?) frou Iraty black shale near Lages, Santa Catharina.

III. Natural coke from Iraty black shale horizon, near Limeira, S. Paulo. 
A cinza don. III é pralicamenteconstituida toda por carbonatu de calciu que se dissolve no acido chlorhydrico deixando coke quasi puro, tendo-se depositado o calcareo por infiltração das camadas calcareas adjacentes.

o coke occorre em bolsas do calcareo e chistos pretos, contendo este restos de Stereosternurn tumidum e outros fosseis.

Uma amostra do petroleo ox ydado (ou Albertite) de perto de Lages foi submettida ao $\mathrm{Dr}^{*}$. Chifford Richardson, eminente director do Laboratorio de analyses de New York, autorilade e perito em bitumes, que remetteu a seguinte analyse com o parecer que a substancia é muito semelhante á Albertite.

$$
\begin{aligned}
& \text { Bitume soluvel em } \mathrm{CS}^{2} \text {. . . . . . . . . . } 5.8 \\
& \text { Materia organica insoluvel . . . . . . . . . } 77.6 \\
& \text { Materia inorganica, ou mineral. . . . . . . } 16.6 \\
& 100.00
\end{aligned}
$$

Bitume soluvel em naphta de $80^{\circ}$, traços:

0 bitume em ignição contém :

$$
\begin{aligned}
& \text { Carbono fixo. . . . . . . . . . . . . . } 49.00 \\
& \text { Hydrocarburetos volateis . . . . . . . . . . } 51.00 \\
& 100.00 \\
& \text { Bitume soluvel em tetrachloreto de carbono . . . } 0.30
\end{aligned}
$$

Este schisto muito petrolifero é uma rocha que constitue magnifica chave para os horizontes geologicos, pois que, embora varie muito em seu aspecto externo, ou alterado pelo tempo e tambem em seus caracteres petrographicos nas differentes provincias geographicas, contém sempre de algum modo compostos de petroleo e sua côr não oxydada ć sempre preta.

Depois de longa exposição ao tempo a substancia ljituminosa é geralmente eliminada e a côr preta é substituida por outra quasi tão caracteristica: a saber, uma tinta azul esverdeada ou azul celeste pallido.

Esta côr é frequentemente visivel nos cortes das estradas de rodagem e de ferro onde a oxydação descorou estes schistos.

Do norte do Paraná ao norte de Tibagy e dalli para o norte no Estado de S. Paulo estes schistos tornam-se calcareos, estando as camadas escuras entremeiadas com finas camadas de calcareo, bastante puro, em que apparecem restos de Stereosternum tumidum, dentes de reptis Labyrinthodontes, e conchas fosseis, em muitas localidades, como Limeira, Conchas, pı’oximidade de Avalé e muitas outras em S. Paulo. Estas camadas conteem calcareo, no rio Tiluagy, a 12 kilometros a noro- 
The ash in No. III is practically all carbonate of lime which dissolves in Hydroch loric acid, leaving nearly pure coke, the lime having been deposited by infiltration from the adjacent limy beds.

The coke occur's in pockets of the limestone, and dark shales, these latter containing remains of Stercosternum tumidum and other lossils.

A specimen of the oxydized petroleuin (or Albertite?) from near Lages was submitted to Dr. Chifford Richardson, the eminent Diretor of the New York Testing Laboratory, and expert authority upon bitumens. He returned the following analysis with the opinion that the substance is closely related to Albertite:

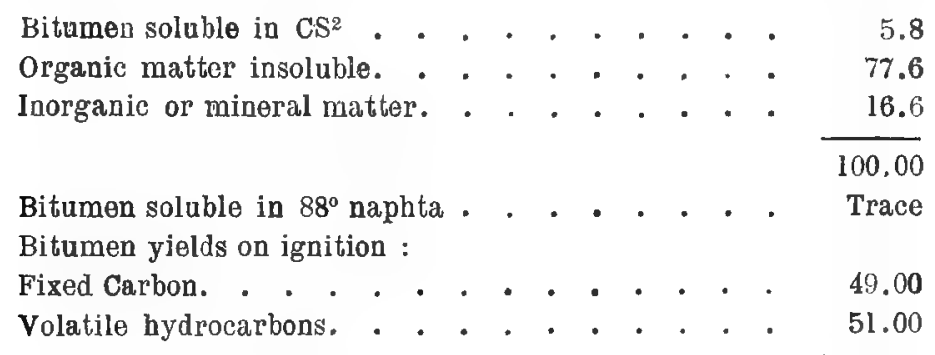

This great petroliferous shale is a fine key ruck to the geologic horizons since although it varies much in its outward or weathered phases, and also in its petrographic character in the different greographic provinces, yet it always holds petroleum compounds in some form, and its unoxidized color is generally biack.

After long exposure to the elements, the bituminous matter is usually leached out and the black color is replaced by another almost as characteristic; namely, a lavander or pale sky-bluish tint.

This color is frequently very conspicuous along the roads and in railway cuttings where long oxidation has decolorized these shales.

In northern Paraná, north from Tibagy, and from there northward through the state of $\mathrm{S}$. Paulo, these shales become limy, the dark beds being interstratified with thin layer's of fairly pure limestone, in which the remains of Stereosternum tumidum, the teeth of Labyrinthodont reptiles, as well as fossil shells, occur, at many localities, such as Limeira, Conchas, near Avaré, and many others in São Paulo. These beds contain Limestone on Rio Tibagy, 12 kilometers north55069 
este do Salto Apparado, Paraná, segundo o Dr. Cicero Campos. As camadas de calcareo da região de Therezina no mesmo Estado que o Dr. Orville A. Der'Jy considera de origem marinha, provavelmente pertencem a este mesmo holizonte.

Frequentemente occurrem massas de pederneira e madeira silificada nestas camada', como perto da fazenda do Sr. Manoel Guedes de Mello.

As vezes tambem conteem muita pyrite, cuja oxjdação dá aos schistos uma cir avermelhada e muitas vezes produz um solo semeIhante em côn ás famosas terras de café, ou "terra roxa" produzida pela oxydarão de rochas eruptivas.

Occasionalmente a peder'neira apresenta-se em finas laminas de um preto azeviche e por engano foi tomado por carvão em uma localidade a poucos kilometros ao sul de Avaré em S. Paulo, em taes casos é possivel que camadas bituminosas ten ham sido substituidas por silica como pretende o Dr. David White.

Na sondagem de Bofete em S. Paulo, esta formação foi alcançada a 145 metros e continuava ali 193 metros mais abaixo, apresentando assim uma espessura total de 48 metros naquella localidade.

Estes schistos escuros affloram na estrada de Blumenau a Lages tres a quatro kilometros a éste da cumiada de divisa da Serra Geral e 275 metros mais abaixo. Podem, tambem ser vistos com sua côr de oxydação azul pallida em pontos dos valles entre a Serra Geral e Lages.

Na estrada de Lages a Florianopolis o schisto preto de Iraty está bem exposto nos cortes entre os kilometros 124 e 129 desta cidade, estando cheio de pequenas concreções silicosas escuras no kilometro 128. A matriz é aqui bom escura e tem forte cheiro de petroleo em fractura fresca.

Na estrada do rio do Rasto a oeste de Minas em Santa Catharina o aflloramento destes schistus prelos com cheiro de petroleo é visivel a 12 1/2 kilomelrus de Minas a uma altitude 414 metros sobre o nivel do mar, ao passo que no caminho de Treviso a dous kilometros ao, sul de Palermo affloram a 370 metros, tendo assim um mergulho de 44 metros em oito kilometros, para sudoeste.

Não foram encontrados restos de Mesosaurus nestas camadas senão em Iraty e no rio Tibagy, Estado do Paraná (como foi referido pelo Dr. Campos), mas como a camada fossilifera perto de Iraty tem apenas 20 centimetros de espessura e não foram feitas ainda pesquizas syste. maticas em outras localidades, é possivel que o habitat do Mesosaurus 
vest from Salto Apparado, Paraná, according to Dr. Cicero Campos. The Limestone beds in the region of Therezina in the same state which Dr. Orville A. Derhy regards as of marine origin, proubably belong at this same horizon.

Frequently nuggets of chert and silicified rood occur in these beds as near Tatuhy on the fazenda of Sr. Manoel Guedes de Mello.

Sometimes they also contain much pyrite, the nxydation of which gives the shales a reddish tint, and often makes a soil resembling in color the famous coffee soils, or "terra roxa", derived from the oxidation of eruptive rocks.

Occasionally, the cherty material is in thin lamina, jet black, and has been mistaken for coal in one instance a few kilometers south from Avaré in São Paulo. In such cases it is possible that bituminous layers have been replaced by silica, as rlaimed by Dr. David White.

In the drilling at Bofete, São Paulo, this formation was struck at 145 meters, and extended down to 193 meters, thus giving a thickness of 48 meters at that locality.

These dark shales crop along the road between Blumenau and Lages 3 to 4 kilometers east from the crest of the divide on the Serra Geral, and 275 meters lower. They also may be seen in their pale blue oxidized condition at points along the valleys between the Serra Geral and Lages.

Along the road between Lages and Florianopolis, the Iraty black shale is well exposed in the cuttings between lilometers 12 and 129 from the latter city, being filled with small, dark flinty concretions at kilometer 128. The matrix is here quite dark and has a strong odor of petroleum when freshly broken.

On the Estrada do Rio do Rasto west from Minas, Santa Catharina, the outcrop of these black sliales with petroliferous odor, is visible at $121 / 2$ kilometers from Minas at an elevation of 4.14 meters above tide, while on the Treviso road, at 2 kilometers sonth from Palermo they crop at 370 meters, thus giving a dip of 4 ' meters in the 8 kilometers to the south-west.

No remains of Mesosaurus have been seen in these beds except at Iraty, and on Rio Tibagy, state of Paraná, (as rep.rted by Dr. Campos) but as the fossiliferous layer near Iraty is only 20 centimeters in thickness, and other localities have not been systemalically searched, it is possible that the distribution of Mesosaturus is not confined to the 
não se limite ao Eslado do Paraná. Em uma amostra de testemunho trazida deste horizonte na profunda sondagem de Xarqueadas no Rio Grande do Sul, fol observado um dente muito semelhante ao do Mesosaurus.

Este schisto se inclina para baixo do nivel das aguas devido ao mergulho geral para sudoeste, a poucos kilometros a sudoeste de Cresciuma em Santa Catharina (onde as pessoas do logar tambem tomaram-no por carvão), e não reapparece á superficie até o Rio Grande do Sul. E' possivel que o carvão que dizem existir no rio Alaranguá acima da villa deste nome seja este mesmo schisto preto.

Estes schistos affloram em grandes faixas pretas no rio S. Bento a uma altitude de 100 metros acima do rio Mãe Luzia, nove kilometros a oeste de Nova Veneza na estrada que sobe a Serra Geral .

Na profunda sondagem de Xarqueadas cujo registro foi dado em pagina anterior o tope destas camadas foi alcançado a cerca de 116 metros e a espessura é de 49 metros.

Estes schistos pretos apparecem á superficie 20 kilometros a sudoeste de Cachoeira na fazenda Graça de Deus onde conteeme videntemente muita substancia bituminosa, provavel mente (Albertite?) visto que as queimadas do capim que varrem os Campos, inflammam os schistos que ardem varios dias, ou até que as chuvas extingam o fogo. Este affloramento foi tambem considerado pela gente do logar como um deposito de carvão.

Na região de S. Sepé estes schistos affloram nas estradas que seguem as cochilas e conteem frequentemente madeira silificada.

Em um barranco a dous kilometros a sudoeste de Bella Vista a 10 kilometros a éste de S. Gabriel, estes schistos pretos de Iraty estão magnificamente expostos, bem como nos cortes das estradas de ferro. Neste logar seu aspecto bituminoso levou a pesquizas para carvão tendo sido cavado um poço de alguns metros de profundidade sem que fosse encontrada outra cousa, excepto schisto preto com forte cheiro de petroleo. Foi em amostras tiradas deste poço pelo Sr. Peter Boardman superintendente do trabalho, que as analyses que já demos foi feita.

As coal measures (formação carbonifera) ou tope das camadas Rio Bonito devem estar 100 metros abaixo do logar onde está o poço.

Parece existir um affloramento destes schistos pretos no rio Passa Dois, logo abaixo da embocadura do rio do Velho em Santa Catharina, que foi tomado por carvão.

Está a 354 metros dealtitude alli e foi parcialmente metamorphoseado por um dique de diabase que cortou suas camadas. 
stale of Palaná. In a sample of the drill core brought up from this horizon in the deep boring at Xarqueadas, Rio Grande do Sul, a tooth much resembling that of Mesosaurus was observed.

This shale passes below water level on the general south-westward dip, a few kilometers south-rwest from Cresciuma in Santa Catharina, (where it has also been mistaken for coal by the natives), and does not come up to daylight again until in Rio Grande do Sul, although it is possible that the reported coal along rio Ararangua, aloove the town of that name, is this same black shale.

These beds crop in a great black band on Rio São Bento at an elevation 100 meters above rio Mãe Luzia, 9 kilometers west from Nova Veneza, along the road which ascends the Serra Geral.

In the deep boring at Xarqueadas, the racord of which is given on a previous page, the top of these beds was struck at about 116 meters and the thickness is 49 meters

These black shales come to the surface 20 kilometers south-west from Cachoeira on the fazenda Graça de Deus where they evidently contain much bituminous matter possibly (Albertite?) since the grass fires which sweep over the campos frequently ignite the shales, and they burn for several days at a time, or until the rains extinguislt the fire. This outcrop has also been regarded by the natives as a caal deposit.

In the region of $\mathrm{S}$. Sepé, these shales crop on the roads which follow the ridges, and frequently contain silicified wood.

In the ravine 2 kilometers south-west from Bella Vista, and 10 kilometers east from S. Gabriel, these Iraty black shales are finely exposed, as well as in the cuts of the railway. Here their bituminous appearance has led to a search for coal, a shaft having heen sunk several meters in depth without finding anything except black shale with a strong odor of petroleum. It was of specimen taken from this shaft by Sr. Peter Boardman, the superintendent of the work, that the analysis already given was made.

The coal measures or top of the Rio Bonito beds would underlie the locality of the shaft by more than 100 meters.

It appears to be an outcrop of these black shales on rio Passa Dois, just below the mouth of rio do Velho, Santa Catharina, that has been mistaken for coal.

It has en elevation of 354 meters there and has been partially metamorphosed by a dike of diabase which cuts across its beds. 
o Sr. João Carvalho, muito prestimoso cavalheiro de Tubarão, refere o achado de pequenos diamantes nos seixos da confluencia do rio Passa Dois e Bonito.

E' possivel que este schisto preto de Iraty com seus depositos de petroleo tenha sido a fonte do carbono de que os diques eruptivos de diabase produziram estes diamantes no rio Passa Dois, como em muitos outros pontos do Brazil.

\section{Camadas da Estrada Nova*}

Entre o tope do schisto preto de Iraty que acabamos de descrever, e a base do grande grupo vermelho de schistos e grés, occorre uma serie de schistos cinzentos e variegados e camadas areentas que muitas vezes conteem massas de silex, restos fosseis de crustaceos, conchas e fragmentos silificados de madeira fossil. Estão muito bem expostos nos cortes da Estrada Nova (Estrada do Rio do Rasto), em Santa Catharina, entre os kilometros 13 e 18 a oeste de Minas e foram designados por esta occurrencia. A espessura dada, a saber, 150 metros é somente approximada, visto como o mergulho das camadas é bastante variavel na região týpica devido á presença de diques de diabase que cortam os estratos em todos os angulos e perturbam o gráo de inclinação. Os numeros dados não podem, comtudo, estar muito errados

Alguns leitos finos de estratos coloridos de vermelho occorrem nestas camadas, como tambem algurnas camadas calcareas e silicosas que conteem madeira fossil, assim como numerosos fragmentos do que parece serem pernas de crustaceos segundo os Srs. Girty e Stanton, da Commissão Geologica dos Estados Unidos.

A sondagem em Bofete em S. Paulo começa a cerca de 15 metros somente abaixo do tope destas camadas e os schistos pretos de Iraty foram alcançados a 145, dando assim as camadas a espessura de 160 metros naquella região.

Foi nesta localidade alguns metros acima do local da sondagem de Bofete que se achou o exemplar de Lycopodiopsis Derbyi determinado pelo Dr. David White, emquanto que nos mesmos horizontes no Rio Grande do Sul perto de S. Sepé e S. Rafael foram encontrados exemplares de Sigillaria muralis e Dadoxylon nummularium.

(*) Estrada clo rio do Rasto. 
Mr. João Carvalho, a very reliable gentleman of Tubarão, reports the finding of small diamond in the gravel at the junction of rio Passa Dois, and Rio Bonito.

It is possible that this Iraty black shale with its petroliferous deposits has been the source of the car'bon from which the eruptive dikes ol diabase have produced these diamonds on l'io Passa Dois, as well as at many other points in Brazil.

\section{The Estrada Nova Beds}

Between the top of the 1raty black shale just described, and the base of the great red group of shales and sandstones, there occurs a series of gray and variegated shales and sandy beds which often hold large nuggets of silex, fossil crustacean and shell remains, and silicified fragments of fossil wood. They are fairly well exposed along the cuts of the Estrada Nova, (Estrada do Rio do Rasto) in Santa Catharina between the 13 th and 18 th kilometers west from Minas, and have been designated from this occurrence. The thikness given namely, 150 meters, is only approximate, since the dip of the measures is quite variable in the type region owing to the presence of dikes of diabase, which cut across the ;strata at all angles and disturb the rate of inclination. The figures given, however cannot be very much in error.

Some thin beds of red colored strata occur' in these measures, as also some limy and silicious layers which hold fossil wood, as well as numerous fragments of what appear to be the limbs of crustaceans according to Messrs. Girty and Stanton of the U. S. Geological Survey .

The boring at Bofete in São Paulo begins only about 15 meters below the top of these beds, and the Iraty black shales were struck at 145 meler's thus giving the beds a thicliness of 160 meters in that region .

It was from this locality, a few meters above the location of the boring at Bofete that the specimen of Lycopodiopsis Derbyi, as identified by Dr. David White, was found, while from the same horizons in Rio Grande do Sul, near S. Sapé and S. Rafael, specimens of Sigillaria muralis and Dadoxylon nummularium were collected. 
A poucos kilometros de $\mathrm{S}$. Sepé estas camadas conteem leitos cal(areos com fragmentos de crustaceos (pernas) e tambem algumas conchas fosseir não deter'minadas que foram amavelmente offerecidas á Commissão pelo Sr. Carlos Trein de Santa Cruz.

Algumas das camadas areentas destes leitos tornam-se ás vezes bastante espessas para serem exploradas corno material de construcção, como em Araranguá cm Santa Catharina onde uma collina ao sul da villa fornece um grés molle de inferior qualidade, côr de chocolate, que parece pertencer a horizonte proximo ao tope destes leitos.

Na Estrada Nova em Santa Cathalina a éste do $8^{\circ}$ kilometro se encontram espalhadas na estrada enormes concreções de natureza silicosa com dois metros, ou mais de diametro que occorrem nestes estratos.

\section{O calcareo da Rocinha}

Bem no tope do Permiano e capeando as camadas carboniferas em Santa Catharina, ha um calcareo cinzento claro que devido a ser encontrado no rio Rocinlia affluente do rio Passa Dois em Santa Catharina, foi denominado calcareo da Rocinha.

o estrato tem um pouco mais de 3 metros de espessura, está exposto 50 a 75 metros ao longo do leito do rio e immediatamente abaixo de um paredảo de grés vermelho que parece superpor-se em discordancia ao calcareo, não se sabendo com certeza si a discordancia é meramente local, ou geral, entretanto ha toda a probabilidade de ser um caso genuino de discordancia e que o calcareo da Rocinha seja a linha divisoria entre o Carbonifero (Permiano) e o Triassico, visto que no terreno logo acima occorrem restos fosseis de reptis que são intimamente relacionados com typos Triassicos.

Nenhum fossil a não serem fragmentos de formas mínusculas, muito provavel mente de agua doce, foi observado no deposito da Rocinha.

A composição chimica do estrato é dada pelas seguintes analyses feitas sob as vistas do Prof. B. H. Hite. 
A ferv kilometers from S. Sepé, these measures hold limy beds filled with fragments of crustaceans (legs), and also some undetermined fossil shells, kindly presented to the Commission by $\mathrm{Sr}$. Carlos Trein of Santa Cruz.

Some of the sandy layers in these beds at times become thick enough to be quarried fol building stone, as at Ararangutá, Santa Catharina, where a hill south from the town furnishes a poor quality of soft chocolate gray sandstone which appears to belong near the top of these beds.

On the listrada Nova, in Santa Catlıarina, just east from the 18th kilometer, immense concretions of a silicious nature, 2 meter's or more in diameter, occul' in these strata, and are strown along the road.

\section{The Rocinha Limestone}

At the very top of the Permian, and capping out the Carboniferous beds in Santa Catharina, there occurs a light gray limestone which from its presence along Rio Rocinha, a Juranch of Rio Passa Dois, in Santa Catharina, lias been termed the Rocinha limestone.

The stratum, showing a little more than 3 meters in thickness, is exposed for 50-75 meters along the bed of the stream, and immediately below a cliff of reddish sandstone which appear's to rest unconformably upon the limestone, but whether the unconformity is merely local or general in its nature is not certainly known, although the probabilities are that it is a case of genuine unconformity and that the Rocinlia Limestone is the dividing line between the Carbonilerous (Permian) and Triassic, since in the next higher terrane occul fossil reptilian remains which are closely allied with Triassic types.

No fossils except fragments of minute forms most plobably of fresh water origin were observed in the Rocinha deposit.

The chemical constitution of the stratum is shown by the following analyses, made under the supervision of Prof. H. Hite. 
Analyse do calcareo da Rocinha

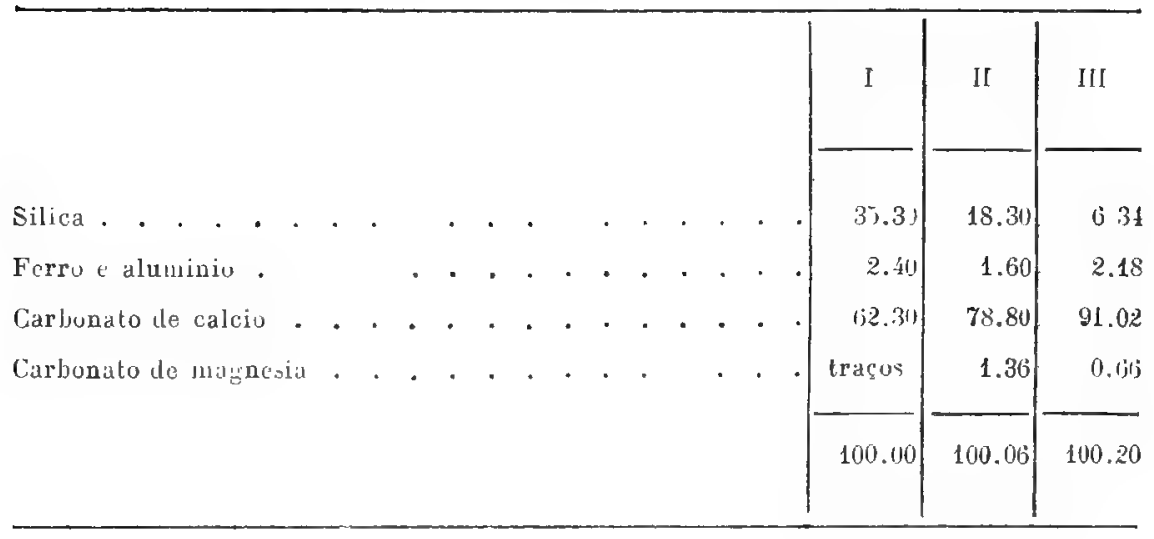

I. Autuntra de calcareo do rio Ruilula, Sanla Catharina.

II. Amontra de calcareo du rio Rocinlıa, Santa Catharina.

III. Amostra le calcaruo da Rocinha identilicalo pelo Dr. Cicero Campos, do Salto Maua, 15 loguas ao norte de Tilrary, Estado lo Parana.

Na estrada entre Florianopolis e Lages perto do kilometro 130 e a sete kilometros ao sul de Bom Retiro este calcareo tem alguns metros de espessura e se apresenla em afftoramento vertical, nas montanhas a 100 metros sobre a estrada, acima deste elevam-se os cumes escarpados da Serra Geral, cercados pelos paredões nús dos grés de S. Berito.

O Dr. Campos refere que um calcareo identico ao estrato da Rocinha apparece no leito do rio Tibagy em Salto Mauá, 15 leguas abaixo da cidade de Tibagy, onde colligiu amostras para analyse.

O horizonte deste calcareo não está exposto em nenhum dos pontos visitados no Rio Grande do Sul, de modo que nada se sabe de sua presença ou ausencia alli.

No Estado de S. Paulo é provavelmente representado pelas camadas de pederneira com madeira fossil que afflnram a 10 , ou 15 metros acima da hocca da sondagem do Bofete.

Sua presença como calcareo lJastante puro nos Estados de Santa Catharina e Paraná é facto de muita importancia commercial, pois que a cal e cimento para construcção são artigos de commercio, muito caros no interior daquelles Estados. 


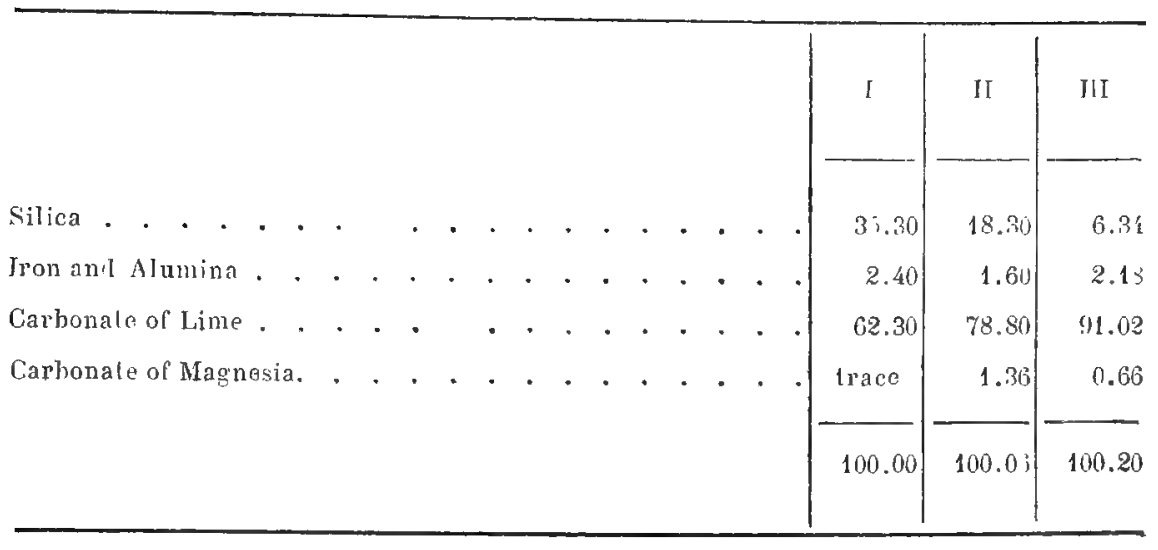

I. Sample of limestono from rio Rocinha, Sinta Calharina.

II. Sample of limestone from rio Rocinha, Santa Catharina.

III. Sample of Rocinha limestone as illentified by Dr. Lierpo Campos, fiom Sallo Mauá, 15 leagues north from Tibagy, state of Paraná.

On the road between Florianopolis and Lages near the 130th kilometer and 7 kilometers south from Bom Retiro, this limestone is several meters in thickness and makes a vertical outcrop in the mountains 100 meters or more higher than the road, above which rise the lofty summits of the Serra Geral girdled with the bold cliffs of the S. Bento sandstones.

Dr. Campos reports that a limestone identical with the Rocinha stratum occurs in the bed of Rio Tibagy at Salto Mauá, 15 leagues belnve the town of Tibagy, from which locality he collected the specimen for analysis.

The horizon of this limestone was not exposed at any point visited in the state of Rio Grande doSul, so that nothing is known of its presence or absence there.

In the state of $\mathrm{S}$. Paulo, it is probably represented by the cherty beds with fossil woud which crop 10 to 15 meters above the mouth of the boring at Bofete.

Its presence as a fairly pure limestone in the states of Santa Catharina and Parana is a matter of much economic importance, since lime and cement for structural purposes are very expensive articles of commerce in the interior of these states. 


\section{CAPITULO VII}

\section{Serie São Bento}

O systema de Santa Catharina lermina no tope com uma triplice divisão de formaçũes ([ue estão magnificamente expostas ao longo do rio S. Bento, trỉjutario do rio Mãe Luzia em Santa Catharina e dahi a denominação Serie São Bento.

As designações seguintes foram adoptadas para as tres divisões da serie principiando no tope :

Rochas eruptivas da Serra Geral .

Grés S. Bento.

Camadas vermelhas do rio do Rasto.

O contacto da porção inferior da serie, isto é das camadas vermelhas do rio do Rasto com o calcareo da Rocinna subjacente, ou tope das rochas certamente carboniferas, foi visto pelo autor em um logar somente no Brazil, no rio Rocinha perto de Minas, em Santa Catharina.

Alli um grés avermelhado e massiço se superpõe em discordancia, ao calcareo em questão, porém na limitada distancia de 50-75 metros em que a linha de contacto é visivel não foi possivel determinar, si a discordancia é simplesmente local, tal como deve ser sempre em maior ou menor escala na linha de contacto entre formações tendo tão differentes processos de origem como o calıareo e grés, ou si é o caso de uma discordancia geral e representa longo tempo de interrupção, o autor não está habilitado a determinar.

O facto entretanto de existir tão grande mudança no caracter dos sedimentos com o apparecimento de um typo de reptil tossil, que o Dr. A. S. Woodward do Museu Britannico considera intimamente relacionado com formas triassicas, levar-nos-ia, entretanto, a concluir que rião ha apparente discordancia no mergulho das rochas entre as duas series (Passa Dois e S. Bonto), tendo havido muito provavelmente um real lapso de tempo e genuina discordancia.

A idade das rochas eruptivas que cobrem as camadas clasticas e capeam o systema de Santa Catharina, não é naturalmente conhecida definitivamente, mas estão de tal forma ligadas ás outras camadas pelos 


\section{CHAPTER VII}

\section{The São Bento Series.}

The Santa Catharina system ends at top with a three-fold division of formations, which are finely exposed along Rio são Bento, a tributary of Rio Mãe Luzia in Santa Catharina, and lience the name, São Bento Series.

The following names have been adopted for the three divisions of the series beginning with the top :

Serra Geral eruplives.

São Bento sandstones.

Rio do Rasto Red Beds.

The contact of the lowest member of the series; namely, the Rio do Rasto Red Beds, with the underlying Rocinha limestone or top of the certainly Carboniferous rocks, has been seen by the writer at only one point in Brazil, and that is on rio Rocinha, near Minas, in Santa Catliarina.

There a reddish and rather massive sandstone rests unconformajsly upon the limestone in question, but in the limited distance, 50-75 meters, along which the line of contact is visible, it was not possible to determine whether the unconformity is merely local, such as must always exist to a greater or less extent at the line of contact between formations having such different methods of origin as limestone and sandstone, or whether it is a case of general unconformity and represents a long time breack, the writer is unable to state.

The fact however that there is such a great change in the character of the sediments, togrether with the appearance of a type of fossil rep. tile, which Dr. A S. Woodward, of the British Museum, regards as closely related to Triassic forms, would argue that although there is no apparent unconformity in the dip of the rocks between the two series, (Passa Dois and São Bento), ret there is most probably a real time break and genuine unconformity.

The age of the eruptive rocks which cover the clastic beds and cap out the Santa Catharina system is of course not definetely known, but they are so related to the other beds through intercalated dikes, 
diques, lençoes e laccolites, que para os fins de classificação julgamos melhor incluil-os como parte da serie S. Bento, tal como os geologos do sul da Alrica fizrram rom as camadas correspondentes a serie do Kar'mo superior, ou stormlıerg como a porção mais aita da mesma.

Esta serie de rochas S. Bento, do Brazil, pareceser exactamente equivalente á scric stormberg do Natal, Basuto Land e colonias do Orange e do Calon, no sul da Africa.

Como já foi dito esta serie de rochas cobre uma grande porção do sul do Brazil, do Estado de S. Puulo para o sul; as porções inferiores afflorando ao longo da hase e fraldas da Serra Geral, emquanto que as rochas eruptivas formam suas escarpas mais altas, especialmente no Paraná, Santa Catharina e Rio Grande do Sul. Nestes Estados a serie $\$$. Bento se estende para além dos limites occidentaes do Brazil pelo Paraguay e Argentina, parecendo terminar em S. Paulo, no'rio Grande ao norte, onde se apoia ás rochas crystallinas antigas nas vizinhanças de Rifaina, se estendendo provavelmente para oeste além do rio Paraná.

As differentes porções da serie serão descriptas agora, detalhadamente.

\section{Camadas vermelhas do rio do Rasto}

Nos schistos de Palermo, Iraty e Estrada Nova occorrem occasionalmente estratos vermelhos, côr de purpura ou castanhos, mas são sempre de pequena espessura e podem ser devidos em muitos casos a causas secundarias que agilam subsequentemente ao deposito, mas passando acima do horizonte do calcareo da Rocinha as rochas tornam-se bruscamente de uma côr vermelha escura e muitas vezes variegadas com manchas esbranquiçadas de 5 a 30 centimetros, ou mais de diametro, ąo passo que ao mesmo tempo apparecem grés espessos e conglomeratos incompletamente consolidados (excepto onde foram parcialmente vitrificados por diques, lençoes e loccolites de trap).

Estas camadas estão bem expostas nos barrancos e margens das cabeceiras do rio do Rasto ao longo da Estrada Nova onde esta sobe a Serra Geral, das Minas em Santa Catharina, tomando a designação daquelle rio. Formam a parte inferior das encostas da Serra Geral e estendemse de S. Paulo pelo Paraná, Santa Catharina até Rio Grande do Sul. 
sills and laccolites, that for purposes of classification, it was considered best to include them as a part of the São Bento Series, just as the geologists of Soutl Africa have included corresponding eruptive beds of the Upper Karroo or Stormberg series as the lighest member of the same.

This Săo Bento rock selies of Brazil appears to le the exact equivalent of the Stormberg series of Natal, Basuto Land, and of the Orange River and Cape Colonies, South Africa.

As already stated this series of rocks covers a large portion of South Brazil, from the state of São Paulo soutluward, the lower members cropping along the base and sides of the serra Geral, while the eruptives make its higher escarpments especially across Paraná, Santa Catharina, and Rio Grande do Sul. In these states the São Benlo series extends to and beyond the western boundaries of Brazil into the countries of Paraguay and Argentina, while in são Paulo they appear to end at the Rio Grande river on the north, where they rest upon the old crystallines, in the vicinity of Rifaina, and probably reach westward to and beyond Rio Paraná.

The different members of the series will now be described in detail.

\section{The Rio do Rasto Red Beds}

In the I'alermo, Iraty and Estrada Nova shales occasional red, purple, or maroon colored strata occur, but they are always of slight thickness and may be in many cases due to secondary causes operating subsequent to deposition, but in passingr above the Rocinha Limestone horizon, the roclss suddenly become dark red in color, and often variegated with whitish blotches 5 to 30 centimeters or more in diameter, while at the same time thick sandstones and conglomerates loosely consolidated (except where partially vitrified by trap dikes, sills and loccolites) make their appearance.

These beds are well exposed on the bluffs and banks of the headwaters of rio do Rasto along the line of the Estrada Nova where it ascends the Serra Geral from Minas, Santa Catharina, and hence have been designated from that stream. 
A côr vermelha escura manchada de um branco crême, ou sujo em massas globulares, ou lenticulares, parece constituir feição caracteristica destas camadas areentas e cuja explicação não é bastante clara. A theoria mais plausivel para explicar estas manchas de côr clara no meio dos sedimentos vermelhos é que o pigmento corante, ou oxydo de ferro invadio mais ou menos o deposito de areia branca, e que algumas partes da rnassa não foram alcançadas pelas aguas de infiltração que tı'anspoltaram o forro. Esta jarticularidade è especialmente accentuada nos cortes dos caminhos e das estradas de ferro, podendo ser observada em muitos pontos entre a margem do Taquary e Santa Maria no Rio Grande do Sul. Está tambem magnificamente exposta em um 'orte profundo da estrada de ferro, logo a éste de Cacequy no mesmo Estado.

Algumas destas camadas são tambem de côr verde clara e os schistos cor de tijolo ou chocolate muitas vezes alternam com as faixas verdes, como pôde ser visto a meudo ao longo da estrada de ferro entre Iraty e Porto União ao sul do Paraná.

Não foi possivel dispor de tempo para o estudo detalhado destas camadas, mas parece que conteem os troncos de arvores fosseis que são muito numerosas nas vizinhanças de Santa Maria, no Rio Grande do Sul. O Dr. Cicero Campos refere ter visto muitos destes troncos na mesma formação a 12 kilometros a noroeste de Salto Aparado no rio Tibagy, no Paraná.

\section{Reptil fossil (Scaphonyx)}

Neste horizonte de grés multicor em Santa Maria no Estado do Rio Grande do Sul, o Dr. Jango Fischer descobriu em 1902 alguns ossos fosseis que remetteu ao Dr. H. von Ihering, director do Museu Paulista, em S. Paulo e que foram descriptos para publicação na Revista do mesmo Museu pelo Dr. A. Smith Woodward, do Museu Britannico. o Dr. Woodward amavelmente forneceu á commissão copia de seu trabalho sobre o assumpto, visto que o volume contendo o original ainda não foi publicado pelo Museu de S. Paulo. 
They make the lower slopes of the Serra Geral, and extend from S. Paulo through Paraná, Santa Catharina, and Rio Grande do Sul. The deep red color, mottled with patches of dirly or creamy white on globular and lenticular masses, appear's to be a characteristic feature of these sandy beds, the explanation of which is not entirely clear. The most plausible theory to account for these light colored blotches in the midst of red sediments being that line coloring pigment or oxide of iron is an invasion of the more or less white sand deposit, and that some portions of the mass were not reached by the infiltrating vaters which carried the iron. This peculiarity is especially marked in road and railway cuttings, and may be olsserved at many points between Margem do Taquary and Santa Maria in Rio Grande do Sul. It is also finely exhibited in the deep railway cut just east from Cacequy in the same state.

Some of these beds are also light green in color, and the brick red, or chocolate shales, often alternatr with the greenish bands as may often be seen along the railway between Iral y and Porto da União in southern Paraná.

No time could be spent on the detailed study of these beds, but they appear to contain the trunks of fossil trees which are quite numerous in the vicinity of Santa Maria, Rio Grande do Sul. Dr. Cicero Campos reports seeing many of these trunks in the same formation, 12 kilomelers north-west from Salto Apparado on Rio Tibagy, Paraná.

\section{Fossil Reptile (Scaphonyx)}

In this vari-colored sandstone horizon at Santa Maria, in the state of Rio Grande do Sul, Dr. Jango Fischer in 1902 discoveled some fossil Jones which he sent to Dr. H. von Ihering, Director of the Museu Paulista at S. Pauln, and which have been described for publication in Revista do Museu Paulista, by Dr. A. Smith Woodward of the British Museum. Dr. Woodward has kindly furnished the Commission with a copy of his paper on the subject, since the volume containing the original has not yet been puljlished by the Museum in question. 
O tralıalho do Dl. Woodward é o que se segue, publicado com sua autorisação :

\section{Sobre alguns ossos fosseis de reptil do Estado do Rio Grande do Sul, por A. Smith Woodward, LL. D. F. R. S., do Museu Britannico.}

Alguns ossos fussois de l'eptil descobertos polo Dr. Jango Fisclıer em 1902 em Santa Ylaria da Bocca do Monte (Eerrito), no Rio (ipande do Sul, são de muito interesse. Elles não somente parecem determinar a idade geologica da formação em que loram encontrados, mas duixam tambem entrever a descoberta de uma fiuna terrestro mesozoica mais recente na America do Sul, que cra de ha unuito esperada. Comprehendem tres corpos de vertebra quasi completos e um fragmento de um quarto corpo de vertebra, um dedo de quatro plaalanges e uma phalinge ungual separada. Os ossos furam achados juntos e em taes circumstancias que pertencem provavelmente todos a um individuo.

Os corpos de vertebia são notaveis (I) por sua extensão antero-posterior muito curta (II) pela forma profundannent ; ovoide de suas extremidades articulares, e (III) pela constricção consideravel de sous lados. 0 exemplar melhor conservado (figs. I, l a) não foi evidentemente muito esmagado e mostra que ambas as extremidades artjculares são levemento concavas. Tambem mostra a constrieção caracteristica dos lados com a margem anterior proeminente que tem uma bossa arredondada profundamente ovoide (c) para a articulação do copitulum de uma costella bicondylar. A parte inferior da mosma margem é chanfradi de forma a $(x)$ suggerir que existiu originariamente um osso cuneiforme intervertebral. A base do arco neural $\left(n . a_{\text {. }}\right)$ ainda existe e mostra que está firmemente fundido com o corpo da vertebra $\theta$ não simplesmente articulado por sutura.

o canal neural produz um sulco raso no corpo da vertebra. Este arco extende-so quasi de extremo a extremo do corpo da vertebra, deixando love margem deste projectando na frente. Sua parte lateral projecta-se alyum tanto para baixo o termina em uma bossa arredondada profundamente ovoide ( $t$ ), para a articulação do tuberculo da costella, já mencionado. E' assim. evidente que a costella devia ter sido robusta, profunda e achatada antero-posteriormente em seu extremo superior bicondylar.

Um dus mais imperfeitos corpos de vertebra é essencialmente identico ao que acima acaba de ser descripto, mostrando semelhante articulação da costella e espaço para o osso cunsiforme. O outro specimen bom (figs. 2, 2a) é cumtudo algum tanto menor sem nenhuma indicação clara de fuceta no corpo da vertebra, quer para umin costella, quel paril um osso cunoiformo. Sels extremos articulares são lïoiramente concavos. $\Lambda$ base do arco neural parece mostrar que concorda com o de outras vertebras por sır fundido com o corpo da vertebra, emquanto quo o canal nerural forma egualmente am sulco raso.

E' obvio que o primeiro typo de vertebra (fig. l) pertenre ás cervicaes, ao passo que a segunda (igg. :2) deve ser da região dorsal. Si portanto estes specimens represuntam um mesmo individuo o pescoso deve tor sido comparativamente gl'ande e fortu, sem duvida para sustentar uma cabeça pesada. 
Dr. Woodward's paper, which is herewith published with his consent, is as follows:

On some fossil reptilian bones from the state of Rio Grandes do Sul by A. Smith Worlward, LL. D., F. R. S., of the British Museum.

$\Lambda$ few fussil reptilian bones discovered by Dr. Jango Fischer in 1902 at Santa Yaria da Bocea do Monte (Sorrito), in Río arande do Sul, are of much intorest. They not only appear to determine the geological age of the"formation from whicl thry wore obtained, but also foroshadow the discovery of an early Mesozoic South American land-fauna, which has long beon expected. They comprise three nearly complete vertebral cen lra and a fragment of a fourth centrum, with one digit of four phalanges and a separate ungual platange. The bones were found together under such circumstances that they probably all belong to one in. dividual.

The vertebral centra are remarkable (I) for th ir very short antero-posterior extent, (II) for the deoply ovoid shrpe of their articular ends, aul (III) for the con. siderable constriction of their silles. The best preserved specimen (figs. 1, la) is evidently not much crished and shows that both the articular ends are slightly concave. It also exhibits the characteristic constriction of the sides with the prominent anterior rim which bears a deeply ovoid, rounded boss (c) for the articulation of the capitulum of a double-headed rib. The lower part of the same rim is bevelled in such a way $(x)$ as to suggest that an intervertebral wedge-bone may originally havo been present. The base of the noural arch (n. a.) still remains and proves that it is firmly fused with the centrum, not merely articalated by suture.

The noural canal proluces a shallow groove in the contrum. This archextends nearly from end to end of the centrum, but leaves a slight rim of the lattor projecting in ront. Its lateral portion is producel somewhat downwards and ends in a deoply-ovoid, rounded boss ( $t$ ), for tho articulation of the tuberculum of the rib already mentioned. It is thus evident that the rib must have been stout, deep, and antero-posteriorly compressel at its double-headed upper end.

One of the more imperfect vertebral centra is essentially identical with that just described, showing a similar rib articulation and a space for a wedgebone. 'The other good specimen (figs. 2, 2a), however', is somewhat smaller, with no clear indication of a facette on the con irum either for a rib or for in twedge bone. Its articular ends are slightly concave. The base of the neural arch seems to show that it agrees with that of the other vertebra in being fused with the centrum, while the veural canal similarly forms a shallow groove.

The first type of vertabra (fig. I) obviously belongs to the cervical, while the second (fig. 2) must be referred to the dorsal region. If, therefore, these specimens represent one and the same individual, the neck must have been comparatively large and stout, doubtless for the support of a heary head. 
O dedo dé quatro phalanges (figs. 3,3 a) é interessante pola fórma da unha. A phalange ungual é comprimida easymetrica, o lado esłuerdo, ou menos profundo sendo achalado ou quasi ôco, emquinto que o outro lado é levemente convexo. O osso não tem sulco lateral algum, mas sua face inferior é consideravelmente excavada e tom uma margem fina. As duas phalanges que se seguem á ungual são curtas e largas e muito afiuadas no meio. O osso seguinte que se presta a mais de uma interpretação e mais alongado quo os que acabam de ser mencionados, mas não é tĩo longo como o ungual. Pulace estar deslocado no fossil, estando de fibcto accidentalmente virado em turno de seu eixo maior, de $45^{\circ}$, de modo que sel. lado direito imparfeito só se vê na fig. 3, e o lado esquerdo na fig. $3 a$. Si esta interpretação é correcta o osso é uma outra phalange com a fuco articular proximal em forma de sella, algum tanto mais profunda que larga.

A phalange ungual disarticulada (figs. $4,4 \mathrm{a}, 4 \mathrm{v}$ ) assemelha-se ao osso correspondente do dedo, que acaba de ser descripto, pela concavidade de sua face inferior (fig. 4 a) e pela falta de symetria bilateral, mas é relativamento maior e dilatado. Sui face articular (fig. 4 v) é obliqua e muito mais funda que larga; seu lado direito levemente convexo (fig. 4) é excessivamento grande, devido á expansão do bordo distal fino e redondo, emiquanto que seu lado esquerdo achatado (fig. 4 e) é uma área triangular comparativamente pequena.

As duas phalanges unguaes pertencem evidentemente a um e mesmo pé que deve ter tido dedos obliqua!mente curvos. Si era constituido como nos Dinosaurios Sauropodontes, este pé seri.b do lado esquerdo, a unha grande sendo do dedo I, emquanto que a serie de quatro phalanges provavelmente representa o dedo III.

E' difficil determinar as affinilades de un reptil conhecido sómente pelos restos fragmentarios como os que agora furam descriptos. E' entretanto, cvidente que os ossos são de um reptil telrestre e os caracteres das rertebras mostram que pertenceram, ou a um Anomodonte, ou a um Dinosaurio primitivo.

o facto de não mostrarem os corpos das vertebras dor'saes signal claro de uma faceta articular para a costella, parece impor-se a consideral-o um Anomodonte; ao passo que a forma e caracteres dus vertebras cervicaes são tão intimamente semelhantes aos de uma vertebra correspondente da formação Karruo da Africa do Sul, referida ao Dinosaurio Euskelesnurus por Seeley (1) que o novo reptil brazileiro é provavelmente alliado a este. A desegualdade frisunte do tamanho dos detos obliquamente curvos é tambem menos suggestiva de um Anomodonte que de um Dinosaurio e ontretanto é possivel que algum dus grandes Anumodontes tivesse uma formula digital como a dos lagartos e crocodilos, isto não era a condigão nurmal e un dedu com quatro phalanges teria mais provavelmente pertencido a um Dınosaurio, que a um membro de uma ordem mais primitiva. Refiru portantu o novo fossil brazileiro a um Dinos ıurio de pescoço curto, alliado ao Euskelesaurus e proponho denom:nar-se esce reptil Scrphonyx alludindo á excavação infur

A especie devi ser conhecida por Scaphonyx fischeri.

(1) H. G. Secley, On Euskel saurus bromnii. Ann, and Mag, Nat. Hist. (6) Vol. XIV, (189-4), pag., 399, fig. 7 . 
The digit of four phalanges (tigs. 3,3 a) is interesting on account of the shape of the claw. The ungual phalange is laterally compressed and unsymmetrical, the left or less dcep side being flattened or almost hollowed, while the other side is slightly convox. The bone is not marked by any lateral groove, but its lower face is considerably excavated and has a sharp rim. The two phalanges fullowing the ungual are short and broad, and much constricted round the middle. The next bone, which perhaps admits of more than one interpretaljon, is more elongated than those just mentioned, but not so long as the ungual. It seems to be displaced in the fossil, boing in fact accidentally turned on its long axis to an extent of $45^{\circ}$ so that its imperfect right side only is seen in fig. 3 , its left side in fig. $3 \mathrm{a}$. If this interpretation be corret, the bone is another phalange, with the saddle-shaped proximal articular face somewhat deeper than wide.

The detached ungual phalange (figs. $4,4 \mathrm{a}, 4 \mathrm{v}$ ) resembles the corresponding bone of the digit just described in the concavity of its lower face (fig. 4a) and in its lack of bilateral symmetry; but it is relatively large and expanded. Its articular face (fig. $4 \mathrm{v}$ ) is oblique and much deepor thau broad; its slightly convex right side (fig. 4) is excessively large, owing to the expansion of the thin, rounded, distal border; while its flattened left side (fig. $4 \mathrm{c}$ ) is a comparativeIy small triangular area.

The two ungual phalanges evidently belong to one and the same foot, which must have had obliquely curved digits. If constructed as in the Sauropodons Dinosaurs, this foot would be of the left side, the large claw belonging to digit $\mathrm{J}$, while the series of four phalanges probably represent digit III.

It is difficult to determine the affinities of a reptile known only by remains so Pragmentary as those now described. It is evident, however, that the bones are those of a land-reptile; and the characters of the vertebras suggest that they belong either to an Anomodont or to a primitive Dinosaur.

The fact that the dorsal vertebral centrum shows no clear mark of an articular facette for the rib, seems to prevent its reference to an Anomodont; while the shape and character of the cervical vertebra are so closely similar to those of a corresponding vertebra from the Karroo formation of South Africa ascribed to the Dinosaurian Euskelesaurus by Seeley $\left({ }^{1}\right)$ that the new Baailian reptíle is probably allied to the latter. The striking inequality in the size of the obliquely curved toes is also less suggestive of an Anomodont than of a Dinosaur; and although it is possible that some of the larger Anomodonts had a digital formula like that of lizards and crocodiles, this was not the normal condition, and a digit with four phalanges is more likely to have belonged to a Dinosaur than to a member of the more primitive Order. I therefore refer the new Brazilian fossils to a short-necked Dinosaur allied to Euskelesaurus, and I propose to name this reptile Scaphonyx in allusion to the unique inferior excavation of the ungual phalanges.

The species may be known as Scaphonyx fischeri.

(1) H. G. Seeley « On Euskelesauras brownii », Ann. \& Mag. Nat. Hist. (6) rol.' XIV, (1894), p. 339, fig. 7. 
Si esta determinação é correcta as rochas em que foram encontrados os ossos dovem ser consideradas do idade Triassica. O Scaphonyx deve ser tambem, considerado o primeiro reptil terrestre lossil descoberto na America do Sul que claramente pertence á fanna da Terra Gondroana.

\section{Explicação das flguras}

Scaphonyxffchcri sp. nov. - Triassico: Santa Maria da Bacca do Monte (Serrito) Rio Grand. do Sul.

Fif.. I Vertehra cervical, fallando grarte partodo arco n'ural vista rle frenta (A) $\theta$ vista rlo larlo 九lireito.

Fig. 2 Vertobra dorsal, fallanilo grande parle do arco nural rista de frente (A) vista do lado direito.

Fig. 3 Dedo, faces superior ( $A$ ) e inferior.

Fig. 4 Phalange ungual faces uperior (A), in ferior e (1) articular.

"r lace arlicular: c articulação para o capitulum da costella; ex excavação inferior da phalange ungual; $l$ fa $\theta$ lateral; $n$. $u$. base do arco neural; $n$. $c$. canal neural; $a$ articulaça para o tuberculo da costella.

Todos as figuras - dois terecos llo lamanho natural.

Estas conclusĩes do Dr. IVoodward concordam com a successão geologica geral do ponto de rista estratigraphico e lithologico, e parecem tambem concordar com as conclusões do Dr. Orville A. Derby que está ha tanto tempo muilo familiarisado com a geologia do Brazil.

As madeiras fosseis foram submettidas ao Dr. David White do Museu Nacional de Washington D. C., mas o Dr. White ainda não poude apresentar seu trabalho sobre estas. Em Santa Maria são muito abundantes nos cortes da estrada de ferro dous kilometros a éste da estação e de 30 a 40 metros acima do nivel das camadas reptiliferas.

A. agua que jorra destas e das rochas sotopostas é algumas vezes salobra mostrando a presença de sal, como perto de Bofele em S. Pauln, segundo o Sr. Camargo que experimentou a.

$\mathrm{E}^{\prime}$ um dos grés da base destas camadas em Bofete na fazenda do Sr. Camargo que está saturado de material asphaltico cujas amostras submettidas ao Prof. Hite para analyse, deram os seguintes resultados:

\section{Analyse do asphalto de Bofete S. Paulo}

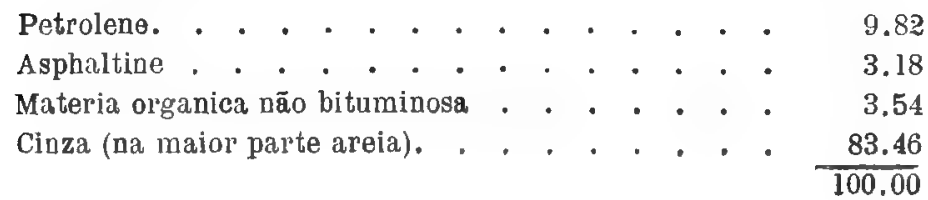


A.

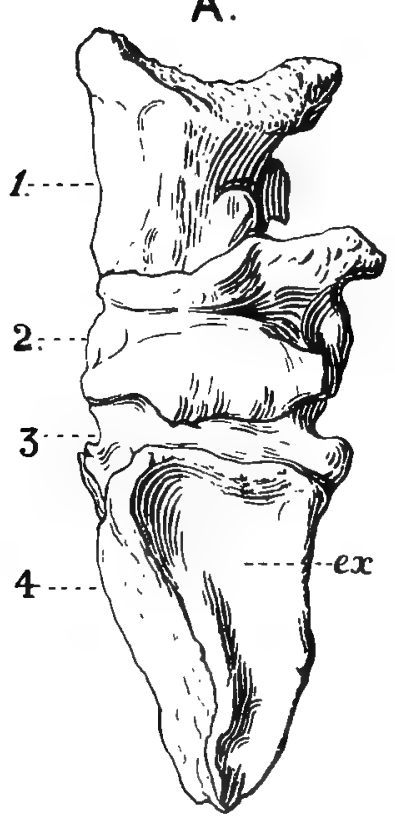

Fig. 3

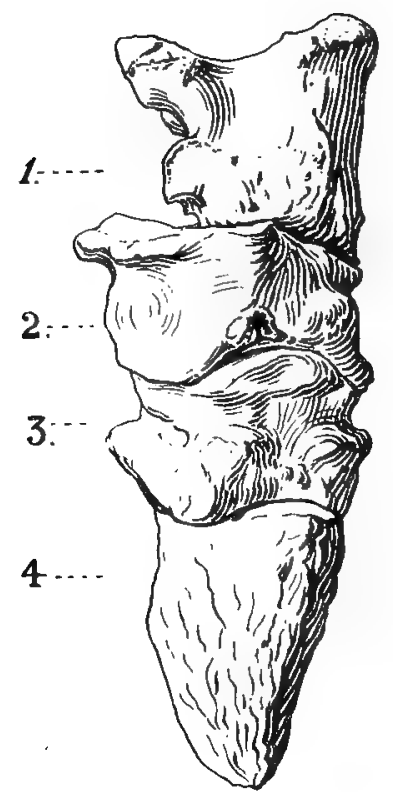

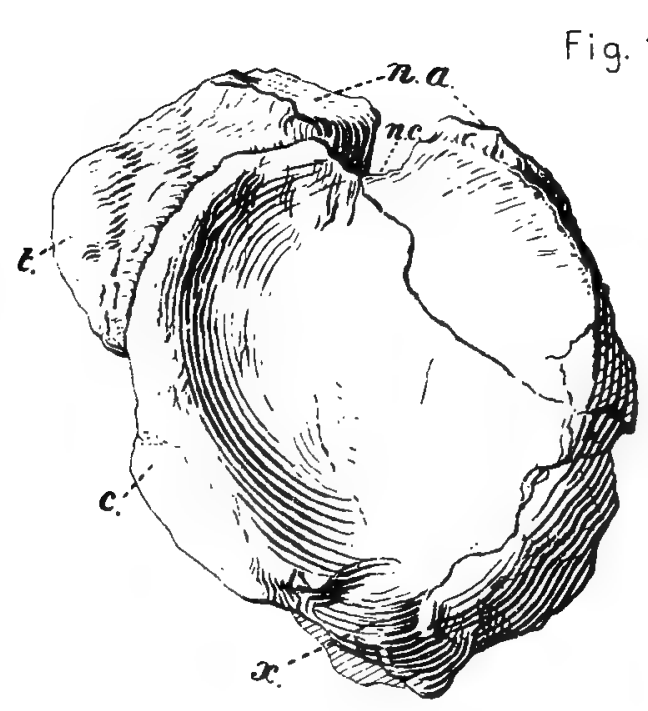
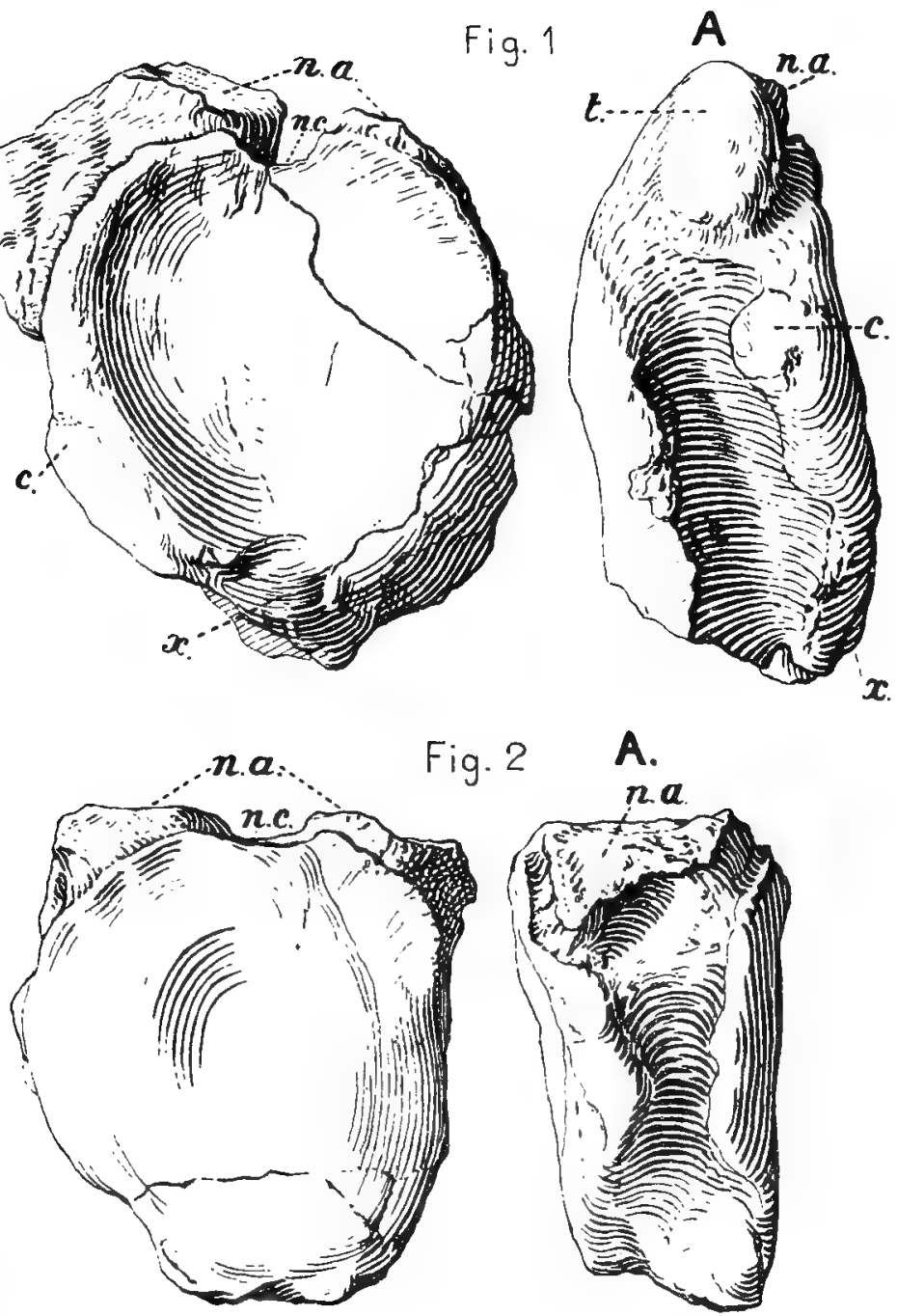

Fig. 2

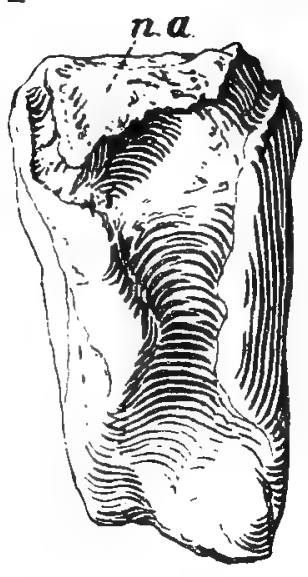

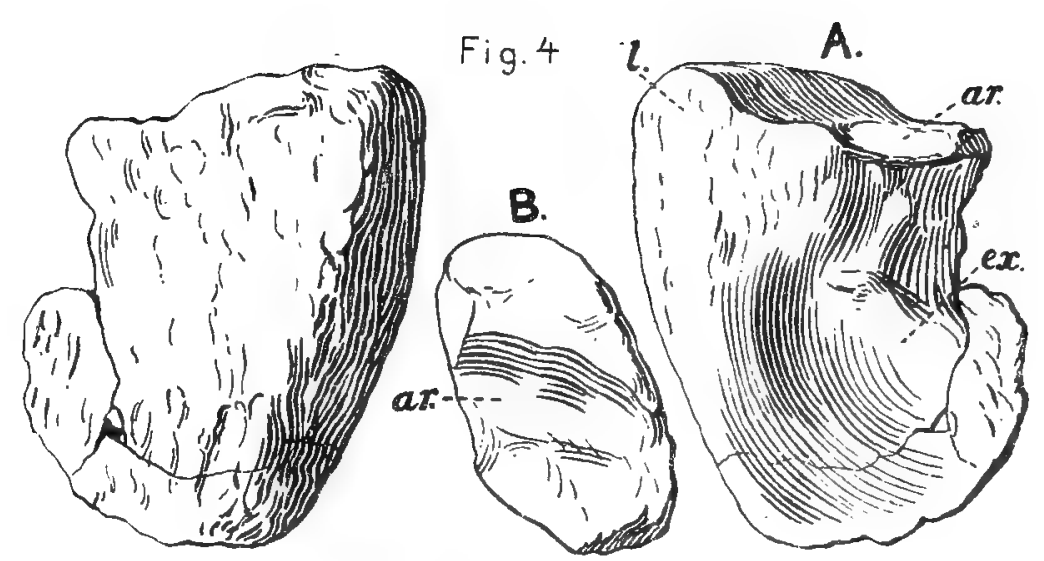



If this determination bo correct, the rocks in which the bones were found may be regarded as of Triassic age. Scaphonyx is also to be considered as the first fossil land-reptile discovered in Soutl America which clearly bolongs to the fauna of «Gondwana Land».

\section{Explanation of figures}

S'aphonyx fisheri, sp. new, -T'riassic; Sanla IIaria da Bucca du Minte (Sirrito), Riu Grande clo Sul.

Fig. 1 Cervical vertebra, lacking reater part of neural alch. Cront view and (A) right side viow.

Fig. 2. Dorsal vertebra, lacking grealer part ul neural arsh, lront view and (A) right side view.

I'ig. 3. Digit, upper and (A) lower view.

Fig. 4. Ungual phalange, upper, (1) Iowe:, and (A) articular views.

ar. articular face; $c$ articulation for capitulum of rib; ex. lower excavation of ungual phalange; 1 . lateral face; $n$. $a$. base of neural arch; $n$. $c$. neural canal $t$. articulation for tuborculum of rib.

$\Lambda$ Il the figs. two-thirus natural size.

These conclusions of Dr. Wroodward agree with the general geologic succession from a stratigraphic and lithologic standpoint, and they also appear to agree with the conclusions of Dr. Orville A. Derby who has had such a long and intimate acquaintance with Brazilian geology.

The fossil woods were submitted to Dr. David White of the National Museum, Washington, D. C., but Dr. White has not yet been able to report upon them. At Santa Maria they are quite abundant in the cuts of the railway, 2 kilometers east from the station, and 30 to 40 meters above the level of the reptiliferous beds.

The vater draining from these and underlying rocks is sometimes brackish showing the presence of salt, as near Bofete in São Paulo according to $\mathrm{Mr}$. Camargo, who has tested the water.

It is one of the basal sandstones of these beds at Bofete on the fazenda of Mr. Camargo which is saturated with asphaltic material, specimens of which submitted to Professor Hite for analysis yielded the fallowing results:

\section{Analysis of Asphalt from Bofete S. Panlo}

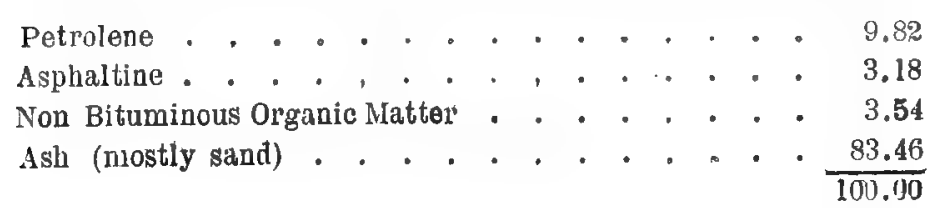




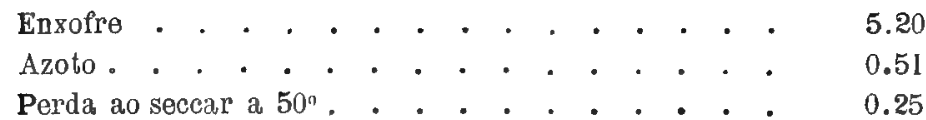

Petrolene e asphaltine são elementos do asphalto. Amostras desta areia asphaltica foram remettidas ao Dr. Clifford Richardson, Director do Laboratorio de Ensaios de New York, Long Island Cily, New York, um dos melhores peritos do mundo em asphaltos, que a respeito diz o seguinte:

\section{Laboratorio de Ensaios de New York}

Clifford Richardson

Director
Long Island City, N. Y. 6 de Julho de 1906.

Dr. I. C. White, chefe da Commissâo do Carvão Brazileiro.

West Virginia Geological Survey.

Margantown. W. Va.

Caro Senhor :

Damos abaixo os resultados de nosso exame da anıostra do material bituminoso mencionado em sua carta de 9 ultimo.

Aquella parece consistir em areia impregnada de bitume e deve ser classificada areia bituminosa de preferencia a grés.

Ensaio n. 86.326

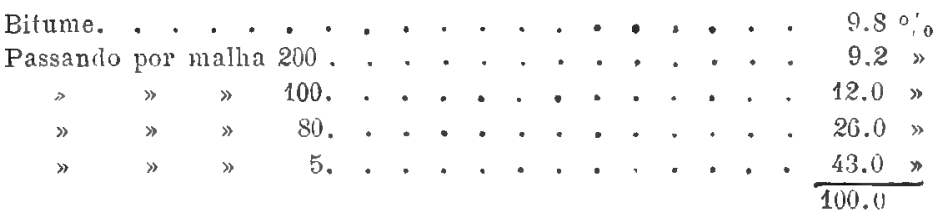

Bitume extrahido penetra $12^{\circ}$-machina Bowen.

Bitume soluvel em naphtha de $88^{\circ}$, temperatura do ar, $54 \%$.

Carbono fixo $13 \%$.

Assignado por C. N. Forrest. Laboratorio de ensajos de New York.

O seguinte resumo de uma carta pessoal ao autor dá a opinião do Dr. Richardson quanto ao valor do deposito de asphalto:

\& Quando voltei depois de uma ausencia de dois mezes em Londres e Paris a negocios, encontrei sua carta de julho $9 \mathrm{em}$ que me pergunta si o material asphaltico da areia do Brazil, que examinamos poderia ser proveitosamente extrahido e por que meios. 


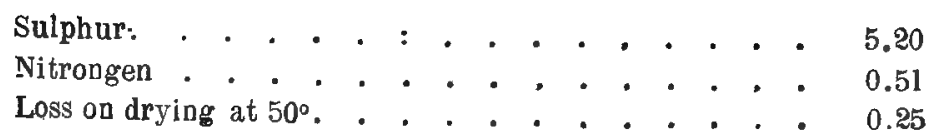

Petrolene and asphaltine are elements of Asphalt. Samples of this asphaltic sand were sent to Dr. Clifford Richardson, Director of the New York Testing Laboratory, Long Island City, New York, one of the world's best experts on the subject of asphalts, who reports upon it as follows:

\section{New York Testing Laboratory \\ Clifford Richardson, \\ Director.}

Dr. 1. C. While, Chie?, Brazilian Coal Commission,

West Virginia Geological Survey,

Morgantown, W. Va.

Dear Sir. :

We give below the results of our examination of the simple of bituminous material mentioned in your letter of the 9 th ult.

This appears to consist of sand, impregnated with bitumen, and would bs classed as a bituminous sand rather than a sandstone.

TEST N. 86326

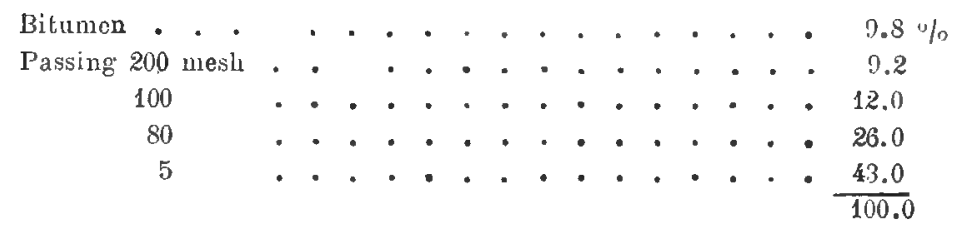

Extracted bitumen penetrates $12^{\circ}-$ Bowen machine.

Bitumen sol. in $88^{\circ}$ Naphtha, air temperature, is $54 \%$.

Fixed carbon $13 \%$,

Very truly yours,

Signed by C. N. Forrest. New York Testing Laboratory.

The following extracts from a personal letter to the writer gives Dr. Richardson's views as to the value of the deposit for asphalt :

"On my return after an absence of two months in London and Paris on business, I find your letter of July $9 \mathrm{th}$, asking as to whether the asphaltic material in the Brazilian sand which we examined could be profitably extracted, and by what moans. 
«Em resposta direi que numerosas tentativas foram feitas no territorio Indiano e na California para extrahir o bitume de tal areia. Na California foi enterrado mais de meio millaão de dollars pela Alcatraz Company, tentando fazel-o tendo como rosultado fracasso completo. Com a minha grande experiencia destas areias Le varias partes do mundo penso que andaria mais avisado dizendo aos interessados do Brazil, que a propriedade não tem valor commercial, visto que o bitume extrahido embora seja de qualidade satisfactoria, como é obtido, não poderia competir com outros bitumes encontrados livres na natureza.

«Noto que, a areia contém muito pequena porcentagem de bitume comparada com outras com as quaes foram feitas tentativas de extracç̃o na California, 9.8\% comparado com $14 \%$.

Vosso Clifford Richardson.»

Esta opinião parece ser concludente quanto á impossibilidade da extracção deste bitume para fins commerciaes.

A localidade em que este grés está saturado de material asphaltico está perto do local, onde a profunda sondagem para petroleo foi feita e cujo registro já foi dado em pagina anterior.

A espessura das camadas Rio do Rasto na Estrada Nova em Santa Catharina, é calculada em 100 metros, mas como o mergul ho é rapido e irregular póde exceder esta cifra de 50 metros, ou mais.

\section{Os grés de $\mathbf{S}$. Bento}

A serie sedimentaria termina em Santa Catharina com grés muito massiços vermelhos, cinzentos, e côr de creme, algumas vezes ligeiramente conglomeraticos. Este grupo superior é muitas vezes cozido e vitrificado pelo contacto com os grandes lençoes de diabase que se encontram tão frequentemente intercalados nas camadas massiças assim como amontoados no tope das mesmas.

As porções superiores formam enormes paredões verticaes, as vezes de 50 a 100 metros de altilude, em torno das montanhas a meio caminho das encostas da Serra Geral, sendo uma das feiçũes mais caracteristicas do panorama. As porções inferiores dão muitas vezes lages e teem sido exploradas para material de calçamento de calçadas em muitos pontos, especialmente no Estado do Rio Grande do Sul. Afflorando estas mesmas camadas nos campos perto de Lages, em Santa Catharina, deram o nome áquella cidade.

As lages são usualmente de um vermelho pallido e se desdobram em camadas uniformes muito lisas, não sendo entretanto bastante resistentes para serem muito duraveis. Teem sido empregadas para cal- 
"In reply, I would say that numerous attempts have been made in the Indian Territory and in Colifornia to extrat the bitumen from such sand. In California more than half a million dollars were sunk by the Alcatraz Company in attempting to do so, with the result that it was an entire failure. From our extended experience with these sands in various parts of the world, I think it would be wisest for you to report to your Brazilian people that the property is of no commercial value, as the extracted bitumen, while it may be of satisfoctory quality as obtained, would not meet competition with other bitumens found free in nature.

"I note that the sand contains a very small percentage of bitumen as compared to others which attempts have been made to extract in California, $9.8 \%$ as comparod to $14 \%$.

Very truly yours, Clifford Richardson."

This opinion would appear to be conclusive as to the impossibility of extracting this bitumen for commercial purposes.

The locality where this sandstone is saturated with asphaltic material is near where the deep boring was made for oil, the record of which is given on a previous page.

The thickness of the Rio do Rasto beds along the Estrada Nova (estrada do rio do Rasto) in Santa Catharina is estimated at 100 meters, but since the dip is rapid and irregular, it may exceed these figures by 50 meters or more.

\section{The Săo Bento Sandstones}

The sedimentary series ends in Santa Catharina with very massive, red gray, and cream-colored sandstones, sometimes slightly conglomeratic. This upper group is often baked and vitrified by contact with the great sills of diabase which are so frequently intercalated between the massive layers, as well as piled on top of the same.

The higher members make immense vertical cliffs often 50 to 100 meters in altitude around the mountains, halfway up the slopes of the Serra Geral, forming one of the most conspicuous features in the landscape. The lower members are often flaggy, and have been quarried for sidewalk pavement at many points especially in the state of Rio Grande do Sul, while the same beds cropping in the summits near Lages, Santa Catharina, have given name to that town.

The flags are usually of a pale red color, and split out in very smooth, and uniform layers, but are not hard enough to be very durable. They have been used for side-walks quite extensively 
çadas, em grande escala em Porto Alegre, Rio Grande, Pelotas, Bagé, Santa Maria e outras cidades do Rio Grande do Sul, tendo sido exportadas pela costa para Florianopolis, Paranagur, Santos, etc. Estas camadas parecem ser totalmentedestituidas de restos fosseis de qualquer especie, visto que nos muitos mil metros quadrados de calçamento examinados nas cidades em que estas lages foram empregadas em tão larga escala para calçadas, nem um só fossil foi observado.

As camadas massiças perto do tope foram exploradas para cantaria em varios pontos na estrada de ferro Mogyana em S. Paulo e especialmente nos altos a oeste de Rio Pardo.

Tambem são exploradas na estrada de ferro Santa Maria e Uruguay. Estes grés mais altos, tão frequentemente endurecidos e parcialmente vitrificados pelo contacto com as rochas eruptivas, formam muitas vezes píttorescas muralhas, torres e collinas perto dos cumes de picos elevados, tendo a erosão removido as camadas inferiores mais molles. Muitas destas formas topographicas especialmente no Estado de S. Paulo, se assemelham em muitos pontos aos grandes blocos falhados tão communs na parte occidental da America do Norte, e o Dr. Derby inclina-se a admittir a mesma origem ás massas em forma de blocos de S. Paulo.

Nenhuma razão concludente para tão extensas falhas observamos nestas mesmas rochas e formas topographicas no Paraná, Santa Catharina, ou Rio Grande do Sul, sendo portanto possivel que aquellas montanhas em forma de blocos sejam inteiramente devidas á erosão.

O contacto da diabase e rochas eruptivas basalticas superpostas rom o grés é visivel na Estrada Nova em Santa Catharina a 748.2 metros de altitude entre o 19 e o 20 kilometros de Minas.

Estes grés massiços formam longas linhas de paredũes na face éste da Serra Geral atravez de Santa Catharina e Rio Grande do Sul, mergulhando gradualmente para sudoeste até que ficam abaixo do nivel d'agua no rio Uruguay perto de Itaquy, na fronteira com a Argentina.

Parece ser o abaixamento gradual deste grande deposito de grés que occasionou o mergulho e desapparecimento da Serra Geral para sudoeste; de facto, parece formar a base desta cadeia de montanhas em todos os pontos por onde passa.

Onde esta cadeia de montanhas está cortada e interrompida pelo rio Iguassú na região do Porto União, no Paraná, estas rochas 
in Porto Alegre, Rio Grande, Pelotas, Bagé, Santa María, and otherof the larger towns in Rio Grande do Sul, while they have also been exported along the coast to Florianopolis, Itajalıy, Paranaguá, Santos, elc. These beds appear to be totally destitute of fussil ramains of any description, since in the many thousand square meters of pavement inspected in the cilies where the flags have been used so exlensively for side-tvalks not a single fossil has been olsserved.

The massive beds near the top have been quarried for huilding stone at several points along the Mogyana railway in São Paulo and especially in the summits west from Rio Pardo. 'Ther are also quarried along the Santa Maria \& Uruguay railway.

The higher sandstones, so frequently hardened and partially vitrified by contact with the eruptive rocks, often form picturesque walls, torrers, and butes near the summits of elevated peaks, erosion having removed the softer beds helow. Many of these tropographic forms, especially in the state of São Paulo, resemble in some respects the great faulted blocks so conspicuous in the restern portion of North America, and Dr. Orville A. Derhy is inclined to ascrilse the same origin to the block-like forms in $\mathrm{s}$. Paulo.

No conclusive evidence for such extensive faulting was observed among these same rocks and topographic forms in Paraná, Santa Catharina, or Rio Grande do Sul, and hence it is possible that these block-like mountains are due entirely to erosion.

The contact of the overlying diabase and basaltic eruptives with these sandstones is visible on the Estrada Nova in Santa Catharina at an elevation of 748.2 meters, between the 19 th and 20 th kilometer from Minas.

These massive sandstones make long lines of cliff's in the eastern face of the Serra Geral entirely across Santa Catharina, and Rio Grande do Sul, sinking gradually south-westward until they dip to water level at the U'uguay river neal Itaquy on the Argentine boundary .

It seems to be the gradual sulısidence of this great sandstone. deposit which causes the lowering and final disappearance of the Serra Geral to the south-west; in fact, they appear to form the basis of this mountain range at all points along its course.

Where this mountain range is trenched and interrupted by Rio Iguassú in the region of Portoda União, Paraná, these massive rocks 
massiças ainda continuam para nordeste formando os paredões nús da serra da Esperança e outras montan has do Estado de S. Paulo.

O pico elevado chamado Funil, om forma de grande cone, ao nivel da Serra Geral perto da estrada que vae de Lages a Blumenau em Santa Catharina, está sobre uma plataforma destes estratos duros, ao passo que a pittoresca região em redor de Lages e dalli para além de Bom Retiro na estrada para Florianopolis, é formada pelos mesmos affloramentos de paredões.

Da região de Minas em Santa Catharina, ao longo da face da Serra Geral até Santa Maria e além no Rio Grande do Sul, estes grandes paredões de grés estão quasi constantemente á rista, emquanto que os picos isolados do morro Sapucaia, perto de S. Leopoldo, Tres Irmãos, perto da margem do Taquary, morro do Butucarahy, perto de Cachoeira e morros Pellado, Carpintaria, etc., no rio Ibicuhy a oeste de Cacequy são coroados por estes grés. Os picos isolados Barabé, Itapecy e outros que se veem na passagem entre Cacecfuy e Alegrete, são simplesmente restos desta grande formação deixados pela erosão geral e conservados a uma altitude de 400 a 500 metros acima das planicies.

Nos cortes da estrada de ferro Santa Maria e Uruguay podem se observar algumas bellas exposições destes grés. As porções mais elevadas das camadas que parecem terminar a cerca de 300 metros acima do nivel de Santa Maria, são frequentemente interrompidas e grandes porções do grés em estado de semi-vitrificação estão completamente encaixadas em lençoes de diabase, ao passo que acima de 300 metros de altitude camadas eruptivas se extendem nos altos da montanha cobrindo completamente o grés. Onde as camadas são de areia quasi pura, a vitrificação das partes em proximo contacto com as rochas eruptivas é mais completa, que quando o grés contém material aluminoso.

E' muito provavel que a seric de S. Bento transgredio frequentemente os limites das rochas carboniferas subjacentes envolvendo-as para éste e para oeste, visto que em Rifaina no norte de S. Paulo 200 a 250 metros destes grés se apoiam directamente sobre os antigos gneisses e quartzitos crystallinos.

Tambem na costa do Atlantico em Torres, perto do limite entre Santa Catharina e Rio Grande do Sul, as camadas vermelhas do grupo do rio do Rasto occorrem a alguns pés acima do nivel do mar directamente abaixo de um grande lençol de diabase, muito do qual amygdaloide. As ondas cavaram as camadas areentas vermelhas em cavernas 


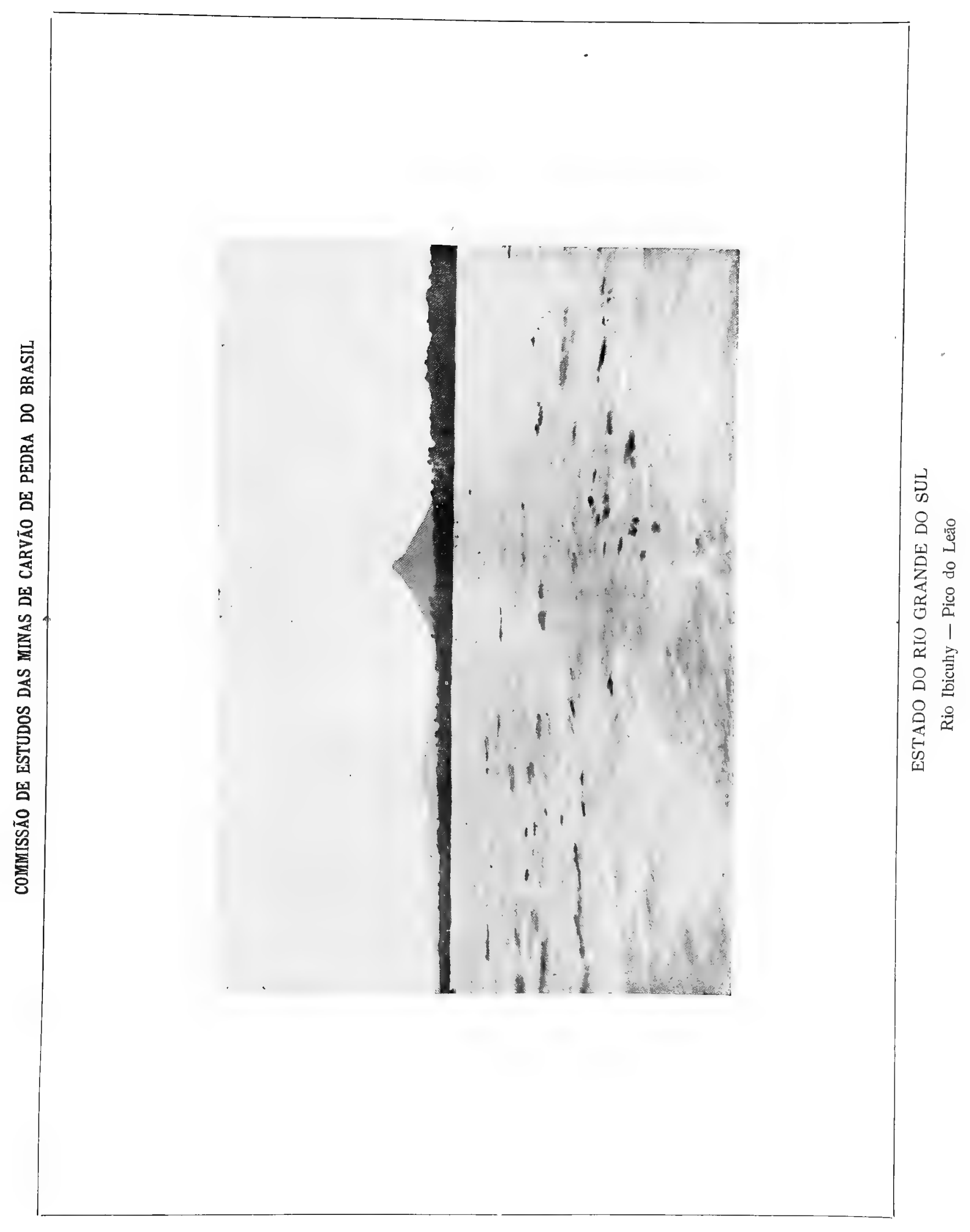





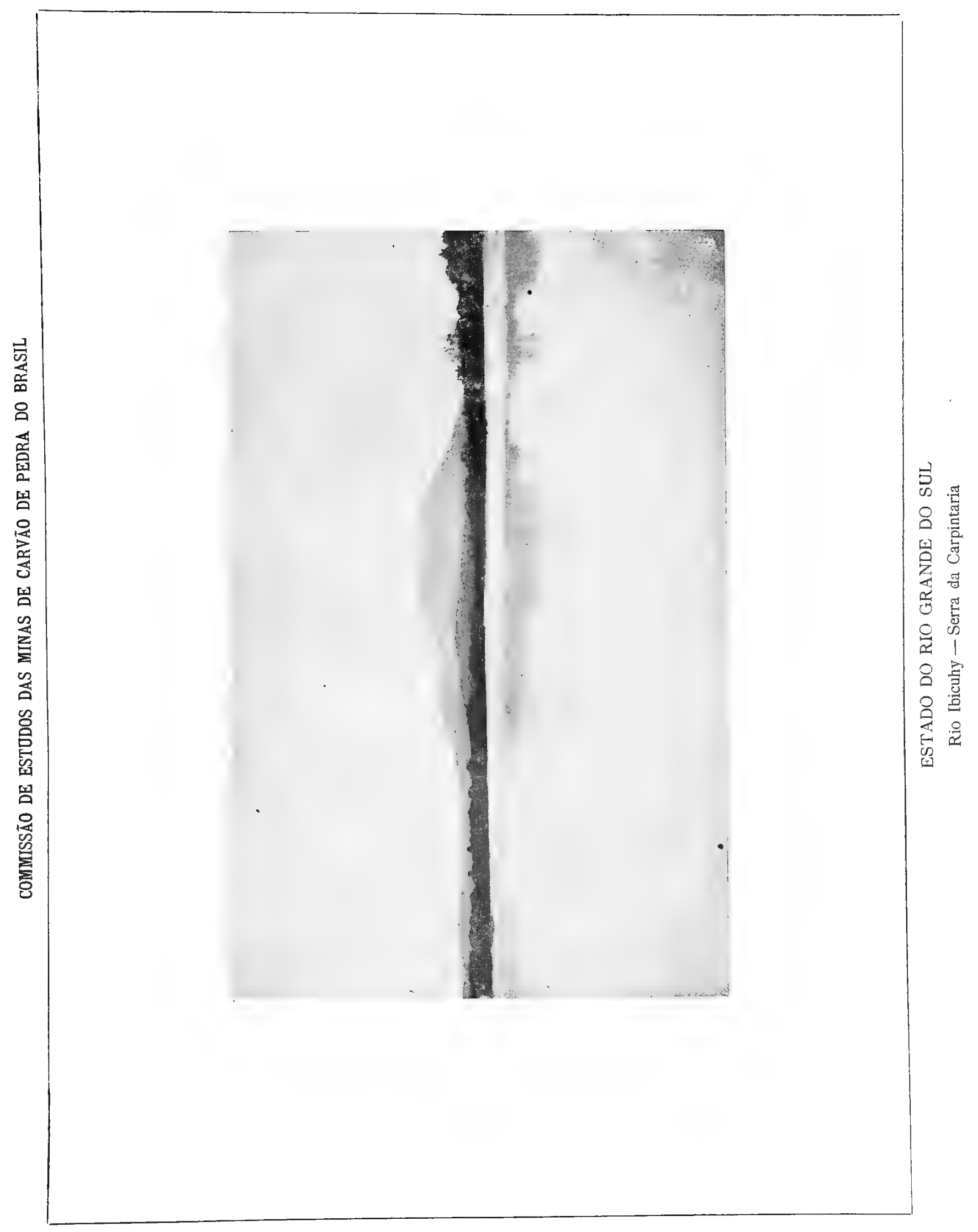



still continue on north-eastward forming the bold cliffs in Serra da Esperança and other mountains on into the state of São Paulo.

The lofty peak called Funil, which rises in a great cone from the general level of the Serra General neal the l'oad leading from Lages to Blumenan in santa Catharina, rests upon a platform of these hard strata, while the picturesque region around Lages, and from there to and beyond Bom Retiro on the road to Florianopolis, is due to the same outcropping cliffs.

From the region of Minas, in Santa Catharina, all along the front of the Serra Geral to Santa Maria and beyond in Rio Grande do sul, these great sandstone escarpments are almost constantly in sight, while the isolated pealis of Morro Sapucaia, near' S. Leopoldo, Tres Irmãos, near Margem do Taquary, Morro do Botucarahy near Cachoeira, and Morros Pellado, Carpenteria, etc., along Rio Ibicuhy, west from Cacequy are crorned by these sandstones. The isolated peaks of Barabé, Itapecy, and others, so conspicuous in the landscape between Cacequy and Alegiele, are simply remnants of this great formation left by the general erosion and preser'ved at an altitude of 400 to 500 meters above the plains.

In the'railway cuts along the Santa Maria \& Uruguay railway, some fine exposures of the sandstones may be oljserved. The higher portions of the beds which appear to end at about 300 meters above lhe level of Santa Maria, are frequently ruptured and great lenses of the sandstone in a semi vitrified condition arc completely enclosed by sheets of diabase, while above the 300 meters elevation eruptive beds extend on to the summits of the mountain completely covering up the sandstones. Where the beds are nearly pure sand, vitrification of the portions in near contact with eruptives is much more complete than when the sandstones contain aluminous material.

It is quile probable that the São Bento series lias frequently transgressed the limits of the underlying Carboniferous rocks, lapping over them eastwards as well as westwards, since at Rifaina in northern S. Paulo, 200 to 250 meters of these sandstones rest directly upon the old crystalline gneisses and quartzites.

Also on the Atlantic coast at Torres, near the line between Santa Catharina and Rio Grande do Sul, the red beds of the rio do Rasto group occur a few feet above tide level, directly beneath a great sheet of diabase much of which is amygdaloidal. The waves have excavated the red sandy beds into fantastic caverns, since they are much softer 
fantasticas, por serem mais molles que as rochas eruptivas superpostas. Si as camadas carboniferas estão abaixo do mar em Torres sol, as camadas vermelhas do rio do Rasto ou não, ou si estas transgrediram aqui para éste e estão solıre o granito, somente a sonda póde decidir.

A espessura da serie do grés de $\mathrm{S}$. Bento não é inferior a 200 metros na Estrada Nova em Santa Catharina e é possivel que attinja 300 metros no rio S. Bento, onde estão magnificamente expostas na estrada cue acompanlıa aquelle rio e conduz ao planalto da Serra Geral.

O tope da serie de grés é alcançado no rio S. Bento a 650-700 metron e 600 metros mais acima succedem-se os lençoes de diabase até ao alto da montanha a 1350 metros acima do nivel do mar.

\section{As rochas eruptivas da Serra Geral}

Succedendo ao deposito dos grés de $\mathrm{S}$. Bento que veem de ser descriptos e provavelmente, em data subsequente não afastada, seguio-se uma época de grande actividade vulcanica em grande parte da área coberta pelos mais elevados depositos sedimentarios Triassicos. Grandes derrames de lavas diabasicas e Jasalticas irromperam pelas fendas e se espalharam em vastos lençoes uns sobre os outros, na região da Serra Geral muitas vezes soterrando os grés de São Bento sob 600 metros e mais de rochas eruptivas. As vezes estes diques tomam uma direcção quasi vertical e atravessam todos os estratos superpostos, tambem os cortam diagonalmente em todos os angulos e frequentemente se insinuam horizontalmente entre as camadas, as vezes se ramificando e entolvendo grandes massas das rochas sedimentarias.

E' possivel que muitos destes derrames tenham sido de natureza laccolitica e foram expostos pela erosão posterior.

As famosas terras de café de S. Paulo com seu solo vermelho escuro ou terra roxa, são formadas pela decomposição destas rochas eruptivas que fornecem os alcalis nas proporções devidas para o creseimento vigoroso dos cafeeiros e a perfeição do fructo.

Estas rochas eruptivas estão magnificamente expostas ao longo da Estrada Nova em Santa Catharina, construida com grande despeza de Minas para serra acima pela f'alda desta, yuasi vertical para dar accesso ás pastagens do grande planalto conhecido por campos. 


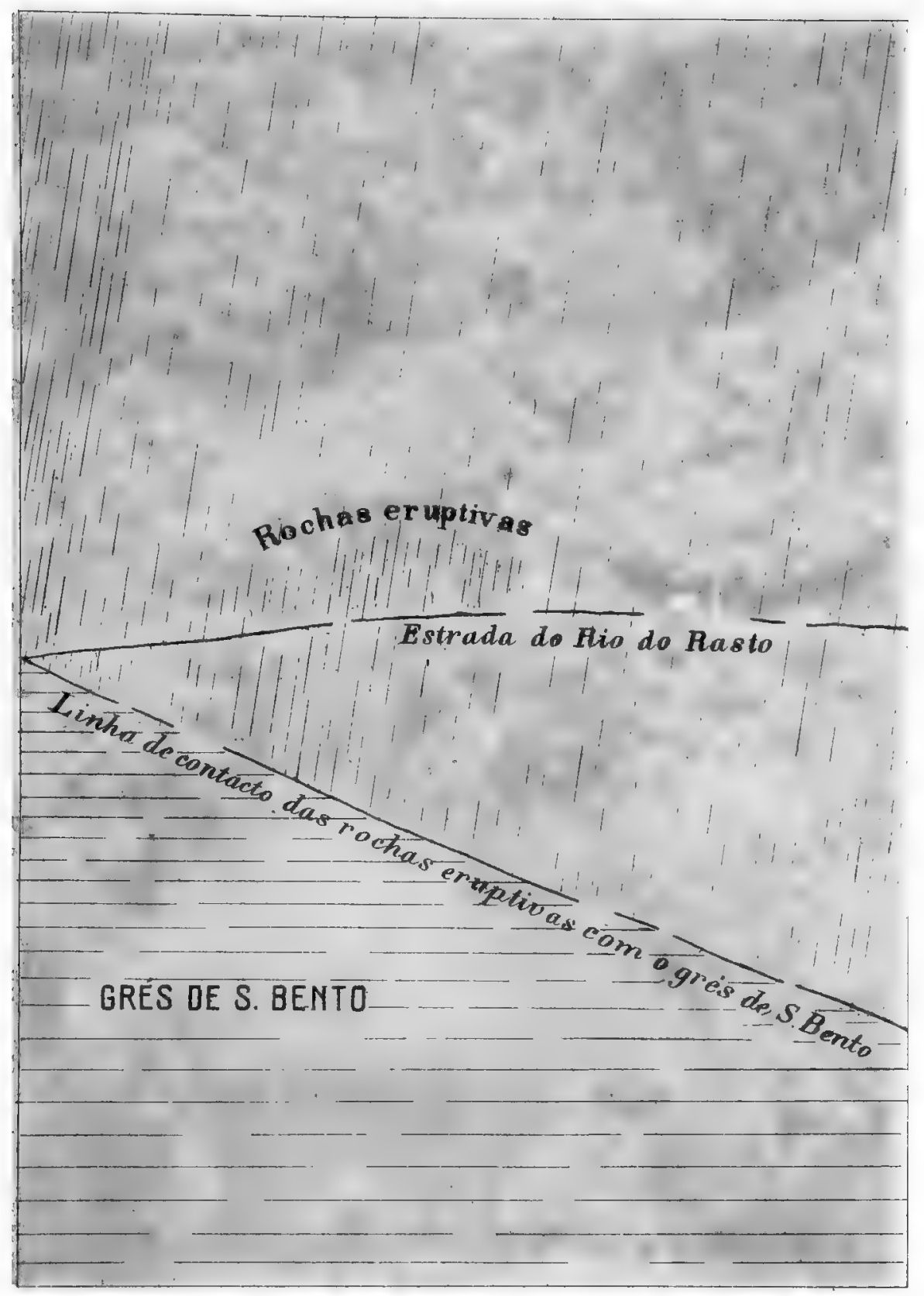





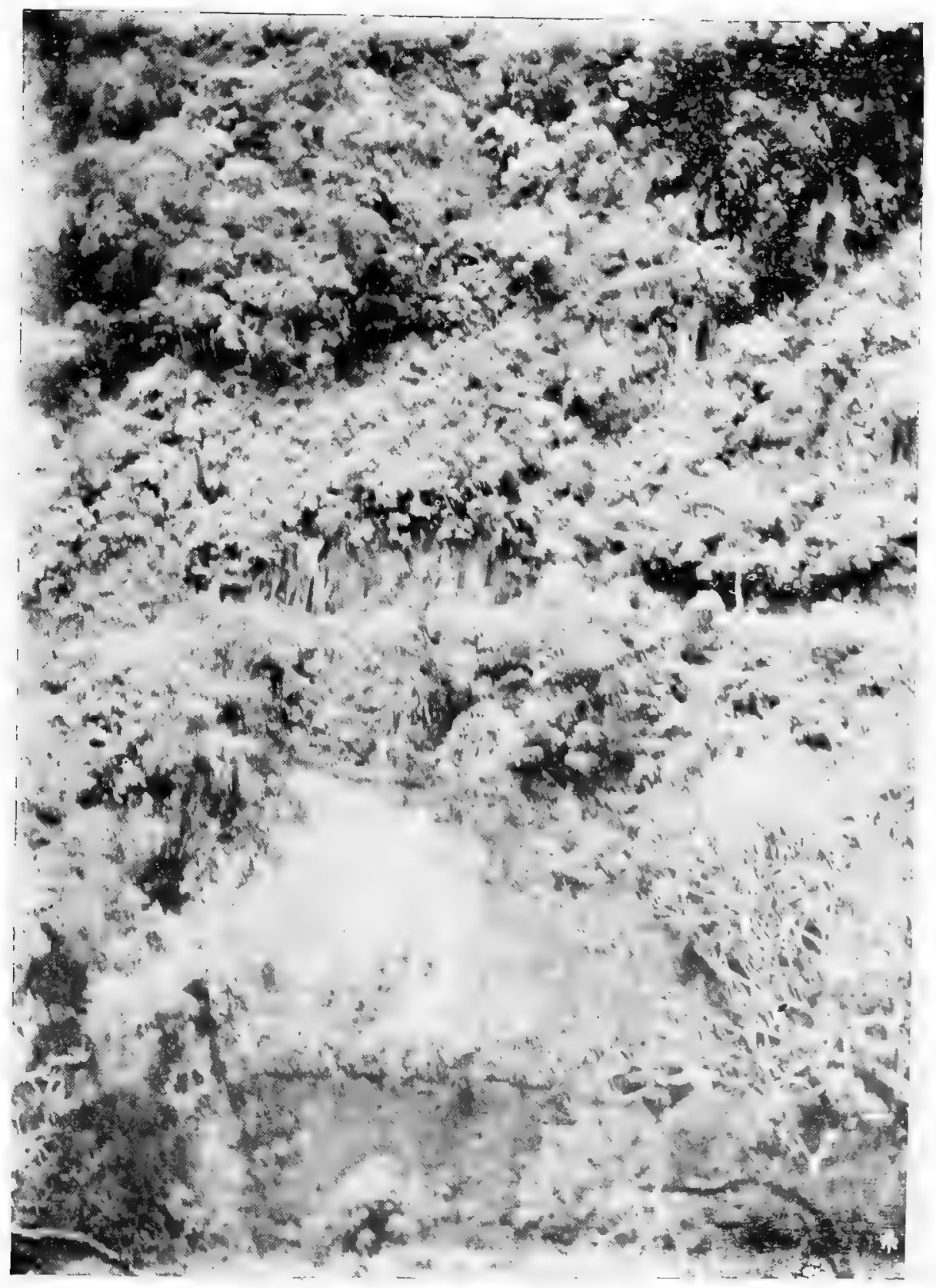

ESTADO DE SANTA CATHARINA

Serra Geral - Contacto do gres vermelho com a rocha basaltica 



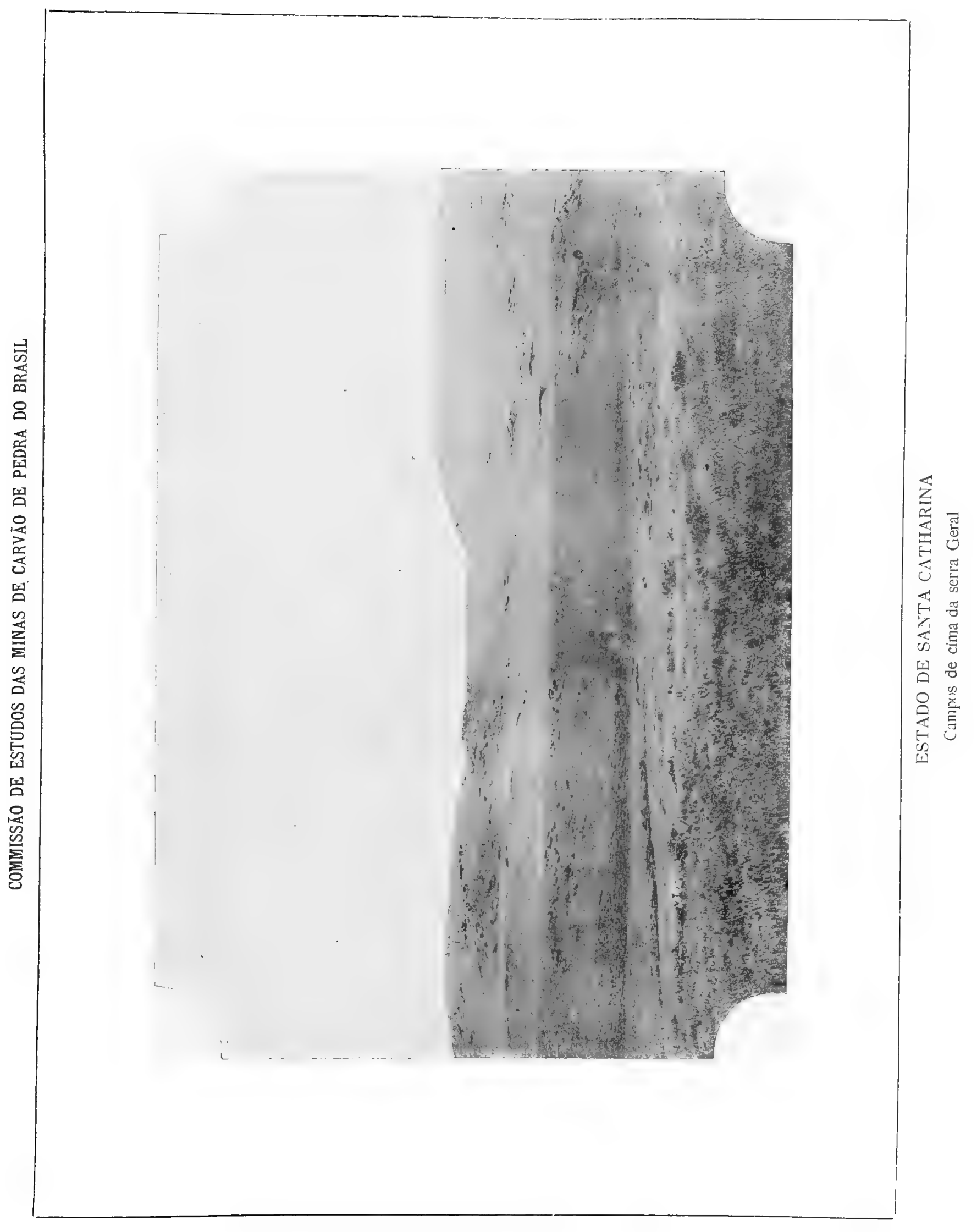





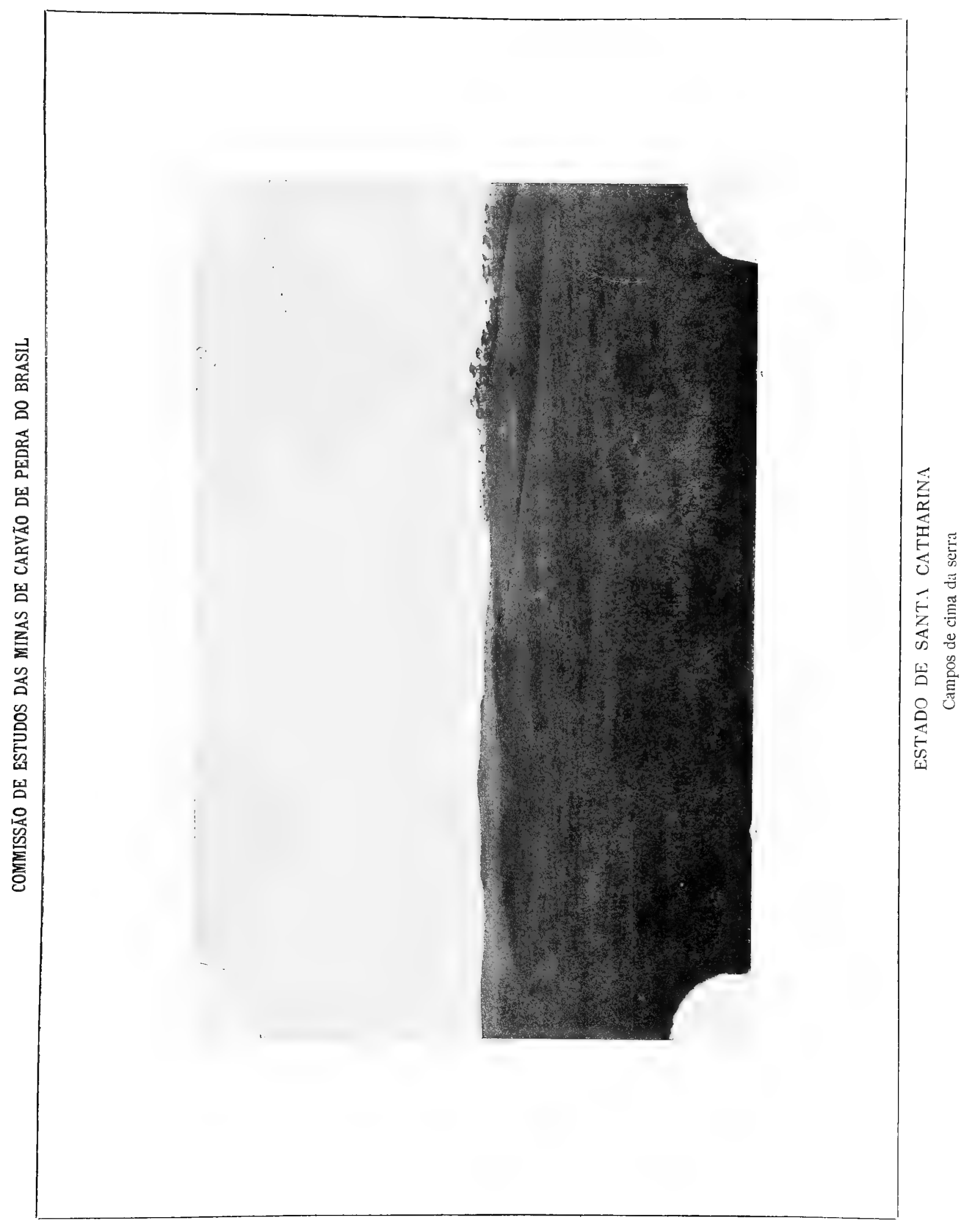



than the overlying eruptives. Whether not the Carboniferous beds underlie the sea al Torres on Jelow the Rio do Rasto red beds, or whether the latter have herce trangressed eastward and rest upon the granite, nothing but the drill can decid.

The thicliness of the São Bento sandstone series is not less than 200 meter's on the Estrada Nova in Santa Catharina, and it possibly attains to 300 meters on r'io Sãu Bento where these heds are finely exposed along the highway which follows that river and leads to the high plateau of the Serra Geral.

The top of the saml-lone series is reached in rio Säo Bento at ajout 650-700 meler's, and alovo this for 600 meler's more suceed the great sheets of diabase up to the summiti of the mounlain at 1350 melel's above the sea.

\section{The Serra Geral Eruptives}

Following the deposition of the S. Bento sandstones just descrilsed and at probajsy no distant sujjsequent date, there succeeded an epoch of great volcanic activity over a large portion of the area (overed by these highest of the Triassic sedimentary dejosits. rireat flows of dialmasic and busillic lavas welled up throngh fissures and spread out in vast sheels un' above the other along the region of the Serra Geral often submerging lhesio Bento sandstrmon with 600 metors or. more of eruptives. Sumetimes these dilies talie a nearly vertical direction, and pass through all of the overtying strata, while again they cut diagonally across the beds at all angles, and frer [uently lars horizontally letween the strata often liranching and completely enclosing large masses of the sendimentaries.

dossibly many of these flows were laccolitic in theil nature, and have been exposed by later erosion.

The famous coffee lands of Săo Paulo with their deep red or "terra roxa" soils are folmed from the decomposition of these eruptives which furnish the proper proportion of alkalies for the vigorous growth of the coffee tree, and the perfection of the coffee bean.

'These eruptives are finaly exposed along the Estrada Nova in Santa Catharina whirh has been built at sleat expense from Minas up thealmost vertical face of the Serra Geral to afford access to and from the pasture lands of the great plateau known as the Campos. 
Estas camadas eluptivas comersam a 748.2 metros acima do nivel do mar perlo de 20 lílom troi de Minas e succedem-se em lençoes, alsuns exhibindo a estructura columnal de 20 a 50 metros de espessura até 1350 a 1100 metrus no alto da Serra Geral a 25 kilometros de ninas.

E' a presenra destas rochas cruptivas e taes relevos nus que tornam a sußida da Selra Geral tão difficil em muitos pontos em Santa Catharina e Rio Gr'ande do Sul, pois que a rapida crosão dos rios cava e arrasta as rorhas Triassicas mais molles subjacentes e as camadas Permianas, tendendo assim a jrpetuar a face quasi vertical das rochas eruptivas.

Esta actividado scismica antiga rue derramou no sul do Brazil estas enormes massas de rochas eruptivas parece ter sido contempolanca dos del'ames de diabase doleritica e luasal to que penetraram as camadas Triassicas da Africa do Sul, India e onde quer que seja no hemispherio sul e deve ter sido tamlıem contemporanea das grandes erupcões que seguiram o fim do periodo Triassico no hemispherio norte.

A acrain destes digues de diabase sulyre os estratui adjacentes, do jonto de vista do metamurphisino pelo calor, nâo é muito grande. O lençol de diajoase de corca de dous metros de espessura que se intercalou nas camadas de carvão Barı Brancu e o grés superpostu no Passa Dois em Santa Catharina, apenas tornou vermelho o grés e deu apparencia anthracilica ans ros los de plantas fosseis da capa de schistos cque arompanhim o carvão.

U dicue verlical yue se encontra nas minas da cumpanhia São Jerony mo no Rio Grande do Sul affectou o cil'vĩo transformando-o parcialmente em colie, sómente na extensão de tres para quatro metros.

onde os gr's em contacto com a diajuase eram cquasi de silica pura foram parcialmente vitrificados, mas quando continham muito material aluminoso pequena alteração se póde notar.

A occurrencia destes diques não difficulta os trabalhos de exploracão das minas de carvão em Santa Catharina, ou Rio Grande do Sul, excepto onde á superficie so ví claramente sua presença, pois que de outro modo us diıues são finus e de pouca importancia.

Xão foi pursivel emplecur muito tempo no estudo destas ínteressantes rochas eruptivas, mas foram colligidas algumas amostras que furam confiadas ao Dr. G. P. Mrıill, o competente chefe da Secção de Geologia do Museu Yacional dwe Litados Unidos, Washington D. C.

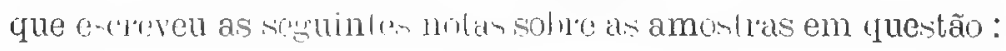


These eruptive beds begin at 738.2 metcrs above tide, near the 20 th liilometer from Minas, and succeed one another in sheets (some of which exhi])it the columnar s(ructure) of 20 to 50 meters in thickness up to 1350 to 1400 meters in the summits of the Serra Geral, 25 kilometers distant from Minas.

It is the presence of these eruptives in such bold relief that renders the ascent of the Serra Geral so difficult at most points across Santa Catharina and Rio Grande lo Sul, since the rapid erosion of the streams cuts away the softer underlying Triassic and Permian heds, and thus tends to perpetuate the almost vertical face of the eruptives.

This ancient scismic activity which poured out over South Brazil such immense masses of eruptives appear's to have been contemporaneous with the outflows of doleritic diabase and basalt which penetrate the Triassic Jeds of South Africa, India, and elscwhere in the southern hemisphere and may also have been contemporaneous with the great eruptions wirh followed the close of the Triassic poriod in the northern hemisphere.

The effect of these dikes of dialoase upon the adjacent strata in the way of metamorphism from heat is not very great. The sill of diabase nearly 2 meters in thickness which was intercalated ]etween the Barro Branco coal and an overlying sandstone on Rio Passa Dois in Santa Catharina, mercly reddened the sandstone, and gave the plant remains in the accompanying roof shales of the coal an anthracitic appearance.

The verticil dike found in the mines of the S. Jeronymo Company in Rio Grande do Sul has affected the coal ly partially coling it for only 3 to 4 meters distant.

Where sandstones in contact witl diabase were neal'ly pure silica, they were partially vitrified, but when they contained much aluminous material, very little change can be noted.

The occurrence of these dikes will not interfere seriously with coal mining operations in Santa Catharina w Rio Grande do Sul, except where the surface gives very distinct eviden e of their presence, since otherwice the dikes are thin and of small importance.

Not much time was available for the field study of these interesting eruptives, but a ferv samples of them were collected, and sul)mitted to Dr. G. P. Merril, the accomplished Head Curator of Geology in the United States National Museum, Washington, D. C., whn has kindly prepared the rollowing notes upon the samples in question. 


\section{Notas sobre rochas igneas brazileiras por Geo. P. Merril}

Todas as rochas são do ty po basalto-diabase não apresentando nenhuma differença essencial a não ser na estructura, a feição mineralogica mais interessante e sua pobresa em olivina que em muitos casos falta completamente.

N. I Rocha de grão-fino uniformemente cinzenta escura sem constituintes porphyricos de especie alguma. Ao microscopio apresenta uma densa aggregação de augito pallido e plagioclase grossa com a estructura ophitica, commum da diabrse. Como usualmonte, ha minerio de ferro espalhado. A rocha é muito fresca e raros os productos de decomposição. (Dique vertical per'to do Bonito I, Minas, Santa Cintharina.)

N. 2 Ainda mais densa que o n. l. Ao micloscopio composição mineral semeluante, mas de estructura mais basaltica e minereo de ferro em quantidade proporeionalmente grande. (Dique horizontal immediatamente superposto a camada de carvão Barro Branco, no rio Passa Dois em Santa Catharina.)

N. 3 Năo differe materialmente do n. 1. (Dique vertical perto da embocadura do rio do Rasto, Santa Catliarina.)

N. 4 Rosha parda cinzenta compacta em que nenhum dos constituintes póde ser determinado á vista desarmada. Ao microscopio, um aggregado do augito lodoso e plagioclasse ripiforme com os oxylos de ferro usuaes. Estructura basaltica. (Base da serie eruptiva na Estrada Nova, Santa Catha:ina.)

N. 5 Densa, uniformemente cinzenta escura sem elementos reconheciveis á vista desarmada. Ao microscopio essencialmente semclbante ao n. 4. (Estrada Nova, Santa Catharina.)

N. 6 Densa, cinzenta escura com uniformidade de textura e côr, interrompida occasionalmente por cavidades amygdaloides ( 1 a $10 \mathrm{~mm}$.) de que algumas são cheias e outras vasias; o material que as enche éás vezes quartzo o outras um zeolito indeterminado. Ao microscopio augito e plagioclase com abundante minereo de ferro e vidro amarellado. $\Lambda$ penas uma das áreas ovaes esbranquiçadas notadas acima se vî̀ nesta seç̧ão. Esta mostra uma cavidade amygdaloido original cheia, de chlorito e outros minoraes secundarios (Basalto). (Ém meio de derrame eruptivo, Estrada Nova, Santa Catharina.)

N. 7 Rocha castanha escur s, ocracea, muito amygdaloide muito decomposta para que possa ser satisfactoriamente estudada. O microscopio mostra pouca plagioclase em laminas estreitas encorpor ada em um vidro castanho amarellado cheio de mainereo de ferro (Basalto). (Estrada Nova, Santa Catharina.)

N. 8 Cumo o n. I na apparencia. Ao microscopio augito em granulos pequenos em abundancia em fundo crystallino, de plagioclase em laminas estreitas. Um granulo occasional de olivina (?). (Estrada Nova, Santa Catharina.)

N. 9 Quasi preta e algum tanto vitrea, apparecendo ao inicroscopio um vidro preto cheio de poeira opxea e microlitos bonitos, curvos dendriticos e incolores, g ranulos pallidos de augito, plagioclase e minereos de ferro, estes ao menos em parto titanicos (Basalto). (Estrada Nova, Santa Catharina.) 


\section{Notes on Brazilian Igneous Rocks by Geo. P. Merrill}

The rocks are all of the diabase-basalt type, presenting no essential differences except in structure. The most interesting mineralogical feature is their poverty in olivine which is in most instances completely lacking.

No. 1. Fine grainod, uniformly dark-gray rock without porphyritic constituent of any kind. Under the microscope a dense aggregate of pale augite and rather stout plagioclase, with the ophitic structure usual to diabase. There is the usual scattering of iron ore.

The rock is vely fresh and decomposition products rare. (Vertical dike near Bonito I, Minas, Santa Catharina.)

No. 2. Even more dense than No. 1. Under the microscope a similar mineral composition, but the structure more basaltic and iron ore in proportionally greater quantities. (Horizont is dike immediately overlying the Barro Branco coal bed on Rio Passa Dois, Santa Catharina).

No. 3. Does not differ materially from No. 1. (Vertical dike near mouth of rio do Rasto, Santa Catharina.)

No. 4. A compact brown-gray rock in which none of the constituents are determinable by the unaided eye. Under the micruscope, an aggregate of muddy augite and lath-shaped plagioclases, with the usual iron oxides. Structure basaltic. (Base ol eruptive series on Estrada Nova ("), Santa Catharina.)

No. 5. Dense uniformly dark-gray without constituents recounizable to the unaided eje. Under the microscope essentially similar to No. 4. (Estrada Nova, Santa Catharina.)

No. 6. Dense dark-gray, with uniformity of color and texture broken by occasional amygdaloidal cavities ( 1 to $10 \mathrm{~mm}$.), some of which are filled and other empty; filling material sometimes quartz and again an undetermined zeolite. Under the microscope augite and plagioclase with abundant iron ores and yellowish glass. This shows an original amygdaloidal cavity filled witl chlorite and other scondary minerals (Basalt). (Middle of cruptive flow, Estrala Nova Santa Catharina.)

No. 7, A dull-brown, ocherous, highly amygdaloidal rock, too much rotted for satisfactory study. The microscope shows little but lath-shaped plagioclase imbedded in a yellow-browa glass plentifully besprinkled with iron ores (Basalt). (Estrada Nova, Santa Catharina.)

No. 8. Like No. $l$ in appearance. Under the microscope an abundance o $l^{t}$ small granular augite in a ground largely crystalline, of lath-shaped plagioclase. An occasional granule of olivine (?). (Estrada Nova, Santa Catharina.)

No. 9. Nearly black and somewliat vitreous, appearing, under the micros. cope, a blick glass full of opaque dust and beautifully curved and dendritic colorless microlites, and carryang pale augite granules, plagioclase, and iron ores, the latter, in part, at least, Titanic (Basalt). (Estrada Nova, Santa Catharina.)

(*) Estrada do rio do Rasto. 
N. 10 Microscopicamente eguaI ao n. 5, tambem microscopicamente muito rico em augitos granulares. (Alto da Serra Geral na Estrada Nova, Santa Catharina.)

N. Il Egual ao n. 3. Estructura basaltica mais que ophitica. (Dique cortando o granito dois kilometros abaixo de Orleans, Santa Catharina.)

N. I2 Cinzento-escuro, quasi preto muito mais intimamente crystaliina quo qualquer das outras. Estructura francamente ophitica. Diabase normal. (Dique atravez do granito, 5 kilometros abaixo de Minas, Santa Catharina.)

As seguintes amostras representam uma outra pequena collecção confiada ao Dr. Merrill em 1906 a que não se refere seu relatorio geral sobro a natureza da collecção:

(76638) $\left(^{*}\right)$ Diolito. Pedras Altas Rio Grando do Sul. Rochas compactas esverdeadas escuras de grão demasiadamente fino para permittir a determinação de sua composição mineral á vista desarmada, mas não obstante seu aspecto dá logo idéa de sua natureza dioritica, ao microscopio mostram abundante hornblenda verde castanha, alguma mica castanha e occasionalmente spheno (?) em um fundo de plagioclase ripiforme. Tres amostras desta localidade, uma das quaes tem grupos de augito castanho e é muito mais rica om minereos de ferro que os outros.

(76639) Granito. Capão do Leão. Pedra medianamente grosseira de côr cinzenta avermelhada de textura bastante uniforme en que os elementos essenciaes são promptamente determinados a olho nú. $\Lambda$ o microscopio veem-so dois feldspathos orthoclases e uma variedade de soda calcica constituir a massa principal da rocha com o quartzo intersticial e partes de mica preta, estando esta a meudo alterada om chloritos.

(76640) Granito. Corte da estrada de ferro perto de Pedras Altas, Rio Grandt do Sul. Rocha grosseira cinzenta escura com abundantes phenocrystaes de feldspatho vermelho escuro e muita mica preta. O microscopjo revela a presença de alguma hornblenda, um pouco de epidoto secundario e grãos occasionaes de um mineral pardo escuro fracamente pleochroico com contornos caracteristicos do spheno. Os feldspathos são em parte uma variedade triclinica.

(76611) «ocha metamorphica» (Diorito laminado). Perto de Pedras Altas, Rio Grande do Sul. Rocha compacta cinzenta esverdeada escura, atravessada por pequenas veias de calcite vermelha e portanto effervescendo com acidos. Ao microscopio mostra com abundancia um material chloritico indeterminavel resultante daalteração deuma hornblenda verde fibrosa que póde ser mesmo secundaria, um pouco de quartzo e manchas de minereo de ferro e mais áreas arredondadas mais ou menos abundantes de um cinzento avermelhado escuro de substancia semelbante a gomma, apresentando com os nicoes cruzados somente a polarização de um aggregado. Depois do tratamento da lamiua pelo acido para eliminar o calcareo o outros mineraes soluveis poucas destas aireas mostram traços residuaes das strias conjugadas tão caracteristicas dos feldspathos triclinicos, a um dos quaes se referem todos. A rocha é provavelmente um diorito alterado, que a seu turno póde ter sido derivado de uma diabase.

(') Os numeros entre parenthesıs são os do registro do Museu. 
No. 10. MacroscopicaIly like No. 5, also microscopically, very lich in granular augites. (Summit of Serra Geral on Estrada Nova, Santa Catharina.)

No. 11. Like 3. Structure basaltic rather than ophitic. (Dike cutting granite two kilometers below Orleans, Santa Catharina.)

No. 12. Dar-gray, nearly black, more closely crystalline than any of the others. Structure decidedly ophitic. A normal diabase. (Dike, through granite, 5 kilometers below Minas, Santa Catharina.)

The following specimens represent another small collection sul\}mitted to Dr. Merrill in 1906 to which his general statement about the character of the collection does not apply:

(76638) (·) Diorite. Pedras Lltas, Rio Grande do Sul. Compact dark greenish rocks too fine grained to permit a determination of their mineral composition by the unaided eye, but nevertheless in appearance at once suggesting a dioritic nature. Under the microscope they show abundant green brown hornblende, some brown mica, and an occasional sphene (?) in a ground of lath-shaped plagioclase. Three samples from this locality, one of which has clusters of brown augite and is much richer in iron ores than the others.

(76639) Granite. Capão do Leão. A medium coarse stone, pinkish gray in color, of fairly uniform texture, in which the essential constituents are readily determinable by the unaided eye. Under the microscope two feldspars, orthoclase, and a soda lime variety, are soen to make up the chief mass of the rock with the usual interstitial quartz and shreds of black mica, the latter being often much altered to chlorite.

(76640) Granite. Railway cut near Pedras Altas, Rio Grande do Sul. A coarse dark gray rock with abundant phenocrysts of dull red feldspars and much black mica. The microscope reveals the presence of some hornblende, a little secondary cpidote and occasional grains of a deep brown, faintly pleochroic mineral with outlines characteristic of sphene. The feldspars are in part a triclinic variety.

(700 11) "Metamorphic Rock" (Sheared Diorite). Near Pedras Altas, Rio Grande do Sul. A compact dark greenish gray rock traversed by small veins of pinkish calcite and hence effervoscing freely with acils. Under tho microscope it shows in abundance of an indeterminable chloritic material resulting from the alteration of a green fibrous hornblende - which may itself be secondary - a little quartz and patches of iron ore. In addition, abundant more or less rounded areas of a dull pink gray gum-like snbstance showing under crossed nicols only the polarization of an aggregate. After treatment of the slide with acid to remove the lime and othor soluble minerals, a few of these areas show residual traces of the twin striae so characteristic of the triclinic feldspars, to one of which they are therefore all referred. The rock is probably an altered diorite, which in its turn, may have beon derived from a diabase.

(*) The numbers in brackets al'e those in the Museum Register'. 
(76636) Basalto. Passo Fundo, Rio Grande do Sul. Rochas cinzentas escuras e pardas escuras compactas o de grão fino. Is variedades maís claras com pequenas manchas pardas avermelhadas de oxydo do ferro. 0 microscopio mostra serem basaltos normaes. As manchas côr de ferrugem notadas formam bordis', ou halos em torno dos graulos de magnetite, indicando uma oxydaçăo ulterior do ferro ferroso em hematite.

(76642) Andesita. Passo Fundo, Rio Grando ds Sul. Rocha cinzenta parda escura, compacta, densamente provida de áreas redondas de todos os tamanhos até $5 \mathrm{~mm}$., ou mais cheias de quartzos incolores.

Ao microscopio uma base de um pardo sujo irresoluvel evidentemente um vidro parcialmente desvitrificado e decomposto, com numerosas secreçōes incolores e ripif'urmes que esta' demasiadamente alteradas para detorminação satisfactoria, mas que foram evidentenente leldspathicas. Oxydo de forro e productos chloriticos abundantes. Tres amostras, uma das quaes não tem as cavidades amygdaloides e mostra augitos esrerłeados e plagioclase muito alterada. Evidontemente andesita alterada.

(76043) Basalto. Taquarembó, Rio Grande do Sul, Rocha compacta parda escura cinzenta. Nenhum dos elementos sufficientemente desenvolvidos para serem determinados a olho nú. Ao microscopio densa aggregação de augitos $\theta$ olivinas agrupados com feldspathos em laminas ripiformes e os minereos de ferro usuaes.

(76644) Basalto. Val de Lena, Rio Grande do Sul, essencialmente o mesmo que o n. 76643.

(76645) Andesita. Dique cortando o carväo, Minas de S. Jeronymo, Rio Grunde do Sul. Rocha de um verde escuro cinzento denso com phenocrystaes minusculos abundantes. Ao microscopio tão alterada que a composição mineral orginal é sómente dsterminadı pelos contornos dos pseudomorphos. Uma base microlitica densamente esverdeada com pequenos phenocrystaes de feldspathos abundantes, raramente bastante conservados para mostrar as strias conjugadas, ou dar outras côres de polarisação que a de um aggregado. Nenhum silicats magnesiano primario nem pseudomorplos destes. A estructura em conjuncto é antes andesitica que basaltica.

(76646) Basalto, Uruguayana, Rio Grande do Sul, Rocha parda visicular muito oxydada, mas mostrando ao microscopio a estructura e composição normaes do basalto.

No Estado de S. Paulo, o Dr. Derby encontrou o que elle pensa ser uma serie muito mais recente de rochas eruptivas que se assemelham a camadas de cinzas e veem acima dos grandes lençoes de diabase, mas o autor não vio nada disto nos Estados do Paraná, Santa Catharina ou Rio Grande do Sul. 
(76636) Bassalt, Passo Fundo, Rio Grande do Sul. Dark gray to brown gray compact and fine-grained rocks, the lighter varieties thickly studded by small brown red spots of iron oxide. The microseope shows them to be normal basalts. The rust colored spots noted are seen to form borders, or halos, around the magnetite granules, indicating a further oxidation of the f'errous iron to the condition of hematite.

(76642) Andesile. Passo Fundo, Rio Grande do Sul. A dull brown gray, compact rock thickly studded with rounded areas of all sizes up to $\mathbf{5} \mathrm{mm}$. or more tilled with colorless quartzos.

Under the microscope a dirty brown irresoluble base evidently a partially devitrifled and decomposed glass, with numerous lathshaped colorless secretions which are too highly altered for satisfactory determination but which were once oridently feldspars. Iron oxide and chloritic products abundant. Three samples, one of which lacks the amygdaloidal cavities and stows greenish augites and highly altered plagioclase. Evidently an altered andesite.

(76643) Basalt. Taquarembó, Rio (rrande do Sul. A compact dark brown-gray rock with one of the constituents sufficiently developed to be determined by the unaided eje. Under the microscope a dense aggregate of clustered augites and olivines with lath-shaped feldspars and the usual iron ores.

(76644) Basalt. Val de Lena, Rio Grande do Sul. Essentially the same as No. 76643 .

(76645) Andesite. Dike cutting Coal, São Jeronymo Mines, Rio Grande do Sul. Dense dull green gray rocks with abundant minute whitish phenocrysts. Under the microscope so highly altered that the original mineral composition is determined only by the outline of the pseudomorphs. A dense greenish microlitic base carrying abundant small phenocrysts of feldspar rareIy sufficiently preserved to show twin striae or give other than the polarization colors of the same. The structure, as a whole, is andesitic rather than basaltic.

(76646) Basalt, Uruguayana, Rio Grande do 3ul. A brown vesicular rock, much oxidized but showing under the microscope the normal basaltic composition and structure.

In the state of São Paulo, Dr. Derby finds what lie thinks is a much younger series of eruptives which resemble "ash beds" and come above the great diabase sheets, but the writer did not note any such in the states of Paraná, Santa Catharina or Rio Grande do Sul. 


\section{CORRELAÇÕES}

A questão das correlaçues das Coal Measures, ou Camadas Rio Bonito do Brazil, com as de outros paizes, foi muito completamente tratada pelo $\mathrm{Dr}$. David IVhite em seu admiravel trabalho que acompanha este relatorio, a que ha pouco a juntar. O autor chegou praticamente ás mesmas concluscoes que o Dr. David White antes de confiar-lhe os fosseis para estudos criticos, excepto quanto a ju!gar possivel que as camadas Rio Bonito pódem representar o Permo-Carbonifero ou Artiuskiano da Russia que alguns geologos hesitam em collocar no Permiano genuino.

O systema de rochas de Santa Catharina, em conjuncto parece representar completamente (excepto quanto aos fosseis da serie Beaufort que ainda não foram descobertos no Brazil) o systema Karron da Africa do Sul como foi descripto pelos Drs. Corstorphine e Hatch em sua recente publicação (*) sobje a Geologia da Africa do Sul. O systema é classificado e subdividido por estes autores do modo seguinte :

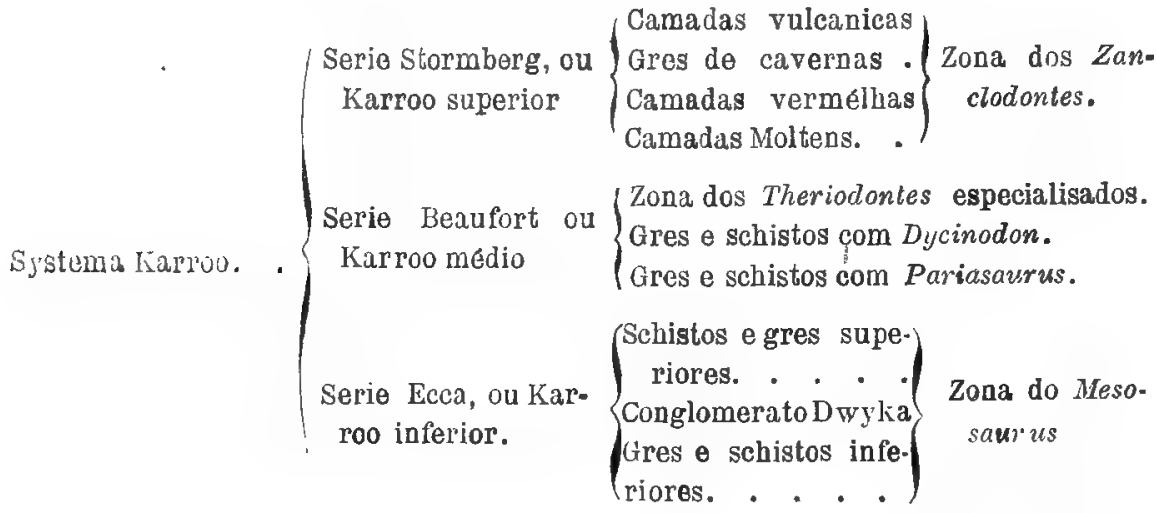

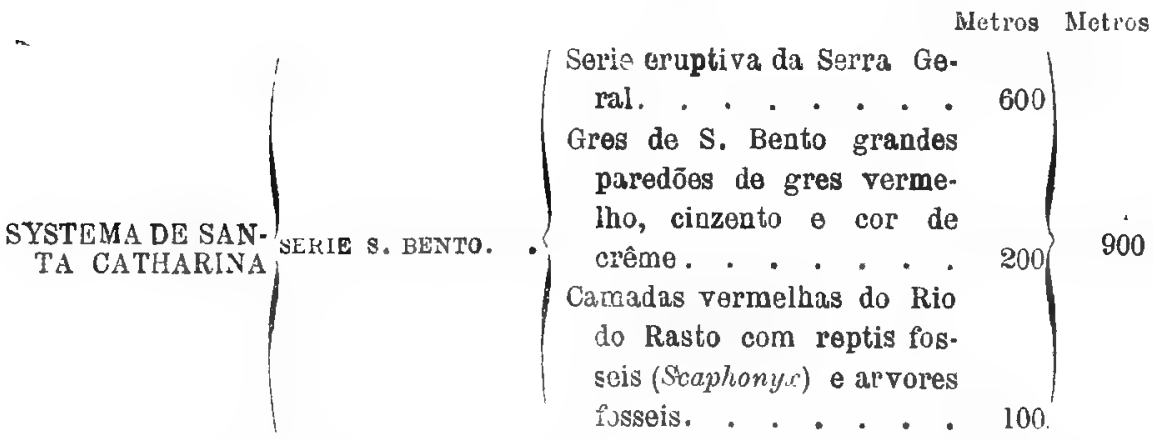

(*) The Geulugs of South Airica, por F. H. Hateh, Ph. D., I. Inst. C. E. e G. F. Curstorphine, B. SC., Ph. D., London Macmillan Company Limited, 1905. 
The sulject of the correlation of the Coal Measures, or Rio Bonito Beds of Brazil, with those of other countries, is very fully covered hy Dr. David White in his admirable paper accompanying this report, which leaves little to be added. The writer had arrived at practically the same conclusion as Dr. David Thite before submitting the fossils to his critical study, except that it was thought possible, the Rio Bonito beds might represent the Permo-Carboniferous or Artinskian of Russia which some geologists hesitate to place in the genuine permian.

The Santa Catharina system of rocks taken as a whole appears to represent completely (except that the fossils of the Beaufort series have not yet been discovered in Brazil) the Karroo system of South Africa, as described by Drs. Colstorphine and Hatch in their recent publication (*) on the geology of South Africa.

The Karroo System is classified and subdivided by these authors as follnivs :

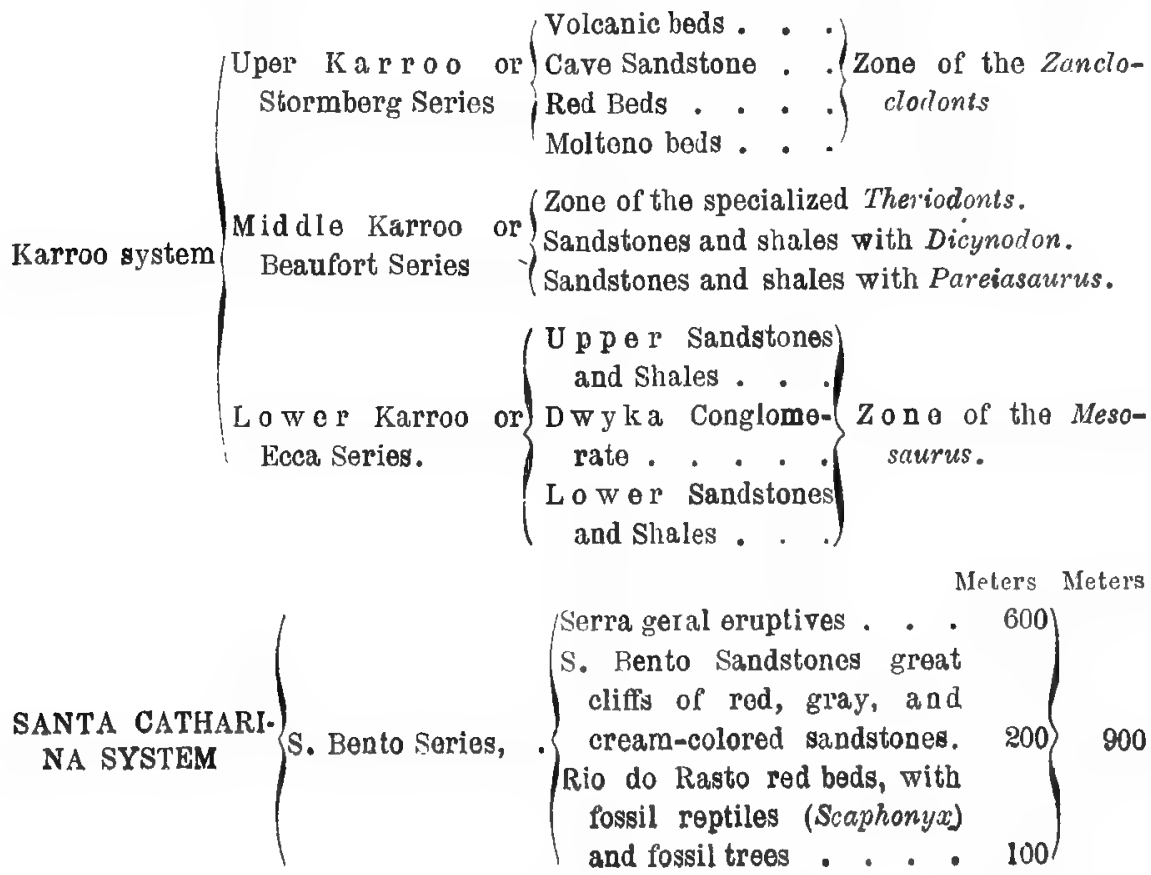

(.) The Geology of South Africa, by F. H. Hatch, PH. D., M. Inst. C. E., and C. S. Corstorphine, B. SC., PH. D., London, Macmillan " C Company, Limited, 1905. 


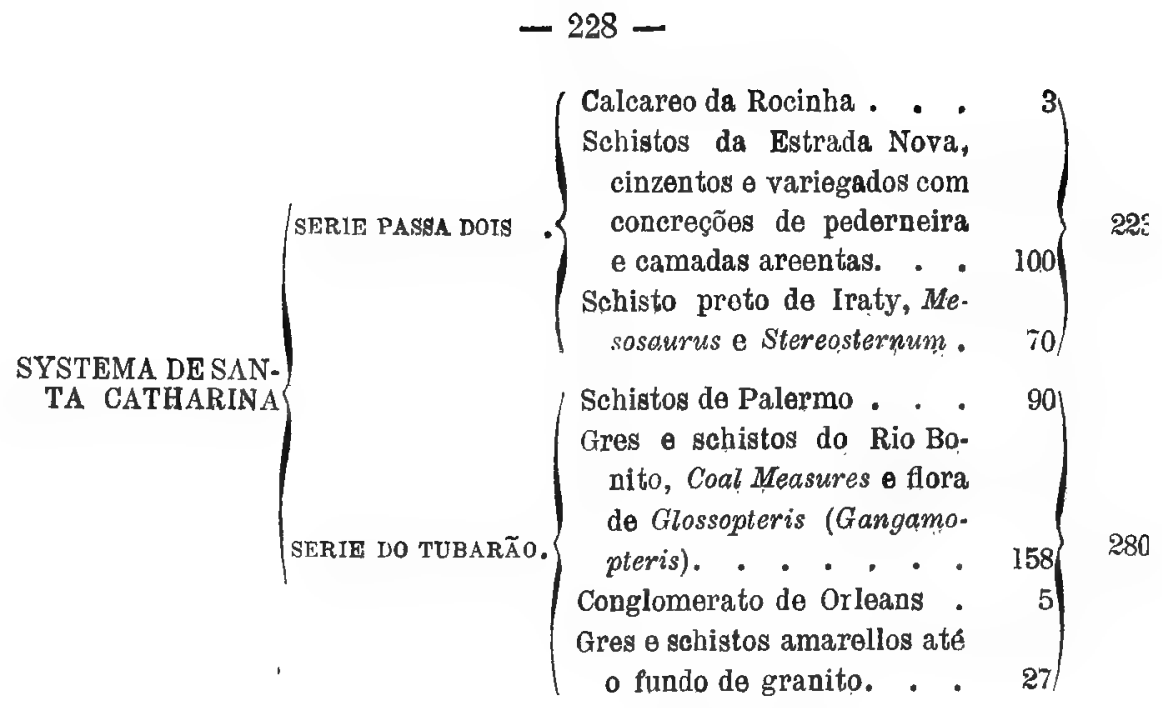

A comparação desta classificação com a dada pelo autor em pagina anterior, do systema de Santa Catharina e aqui reproduzida para mais facil confronto, evidencia estreito parallelismo tanto quanto ao caracter dos sedimentos, como quanto aos restos fosseis que estes conteem, pois que o Karroo superior e inferior são exactamente correspondentes ás series de S. Bento e Tubarão respectivamente, comprehendendo esta o Schisto Preto de Iraty com os restos de Mesosaurus e Stereosternum.

Ainda não se sabe se o Karroo médio existe no Brazil ou si suas rochas devem ser representadas pela porção superior da serie Passa Dois, ou pela inferior de S. Bento.

Ha comtudo probabilidade de não ter sido ainda descoberta no Brazil a serie Beaufort visto que a sua fauna abundante de reptis tão bizarros, escaparia difficilmente á competentencia pesquizadora do Dr. Orville A. Derby que por tan to tempo e tão cuidadosamente estudou a geologia do Estado de S. Paulo.

Esta estreita identidade, não sómente dos fosseis dos systemas de Santa Catharina e Karroo, mas tambem a semelhança geral da feição estratigraphica e lithologica que se encontram nos dois systemas, bem como no de Gondwana da India quanto ao que se refere aos membros inferior e superior, certamente vem em apoio da grande probabilidade da hypothese que admitte que os continentes meridionaes, devem ter estado unidos, durante os periodos Permiano e Triassico, por grande porção de terras, agora submersas, a que Suess denominou "Terra Gondwana ". 


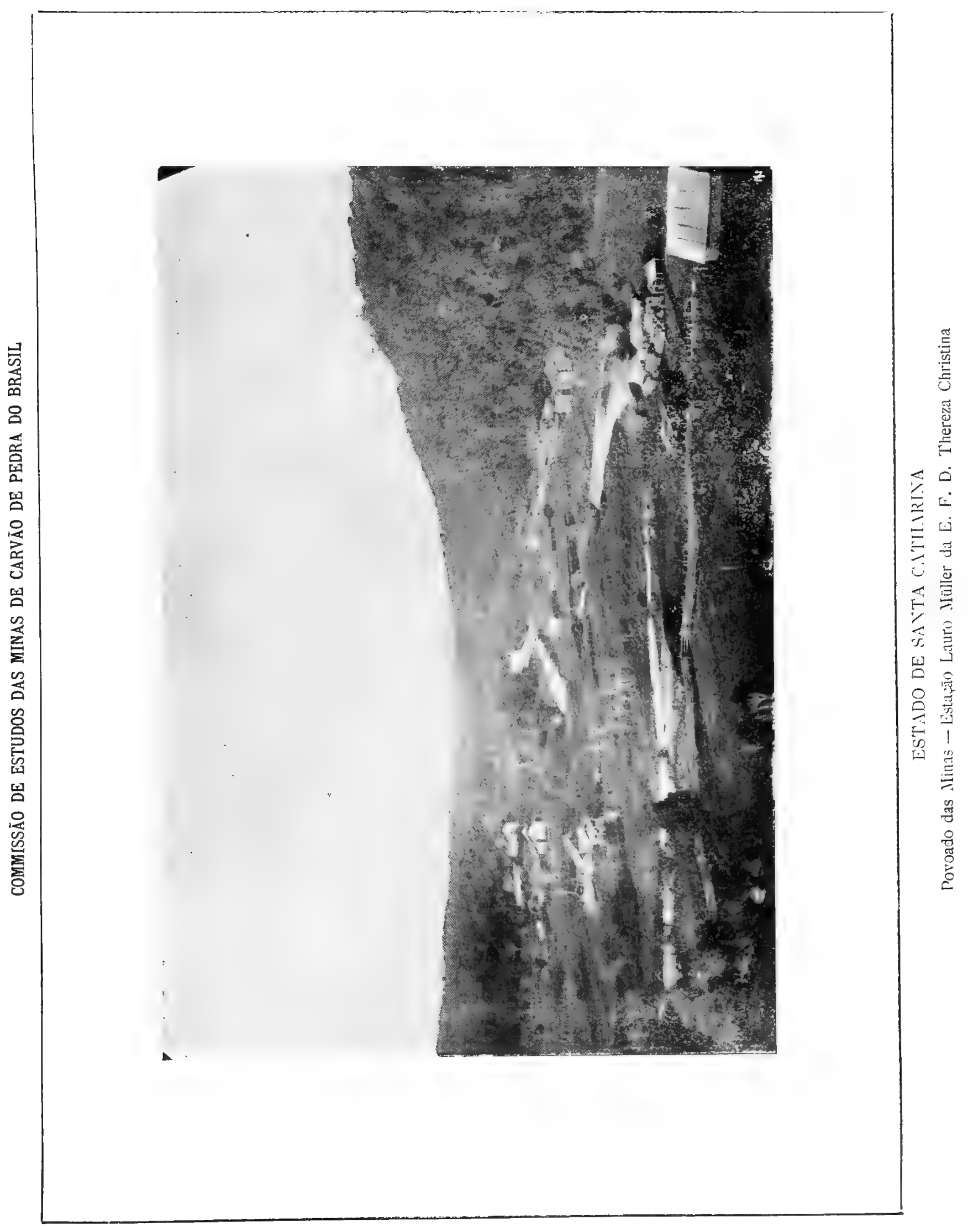





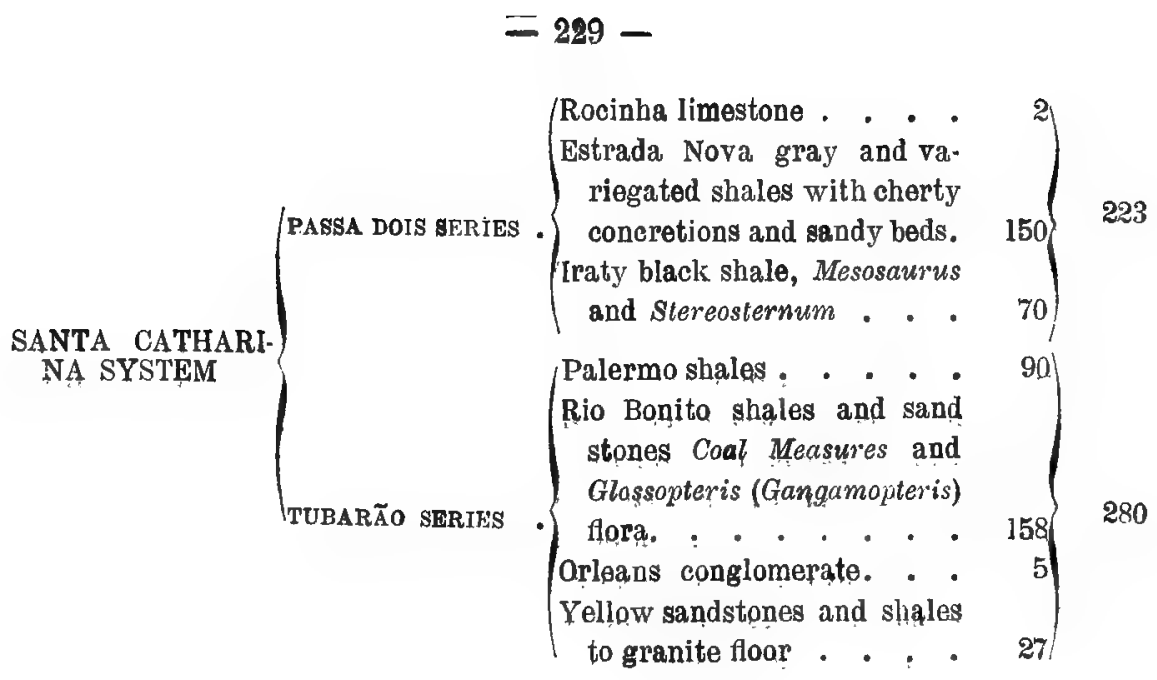

A comparison of this classification with that given by the writer on a preceding page for the Santa Catharina system and here reproduced for easy reference will disclose the close parallelism in both the character of the sediments and the included fossil remains, since both the Upper Karroo, and the Lower Karroo are the exact counterparts of the São Bento, and Tubarão series, respectively, with the latter extended upward to include the Iraty black shale with ils Mesosaurus and stereosternum remains.

Whether the Middle Karroo is absent in Brazil, or whether its rocks may be represented in the upper portion of the Passa Dois of the lower portion of the São Bento series is not yet known.

The probabilities, however, are that the Beaufort series may not yet have been discovered in Brazil, since its abundant reptilian fauna of such bizarre types could hardly have escaped the trained eyes of Dr. Orville A. Derby who has so long and carefully studied the geology of the state of São Paulo.

This close identity not only of the fossils of the Santa Catharina and Karroo systems, but also the general resemblance of the stratigraphic and lithologic features found in the two systems as well as in the Gondwana system of India so far as the Lower and Upper members are concerned, certainly lends great plausibility to the view that the southern continents must have been united in Permian and Triassic time by a great land connection now submerged which Suess has termed "Gondwana land". 


\section{Nota sobre o Erytrosuchus}

Discutindo a série de rochas de S. Bento, foi dito que nenlum fossil repre. sentando as camadas do Beaufort da Africa do Sul, tinha sido encontrado no Brazil, mas, agora o Dr. A. Smith Woodward do Museu Britannico, annuncia a identiflcação do genero Erytrosuchus em alguns ossos fosseís que the foram remettidos pelo autor $\theta$ que o Dr. Cicero Campos colligira perto de Santa Maria, no Rio Grando do Sul. Os specimens occorrem a cerca de 250 metros abaixo do tope dos gres de S. Bento nas camadas areentas manchadas de branco e vermelho, que affloram nos cortes da estrada de ferro em Santa Maria. O reptil fossil Erytrosuchus africonus com que o spocimen de Santa Maria e mais de perto alliado, sogundo o Dr. Woodward, foi figurado e descripto a 3 de maio de 1905, nos Annals of the South African Museun. vol. V, parte lII, estampa IV, pags. 187 a 196, pelo Dr. R. Broom, da porção superior das camadas Beaufort da Afrida do sul.

A occurrencia de um typo semelhante, ou estreitamente alliado nas camadas brazileiras no horizonte em questão, completa e torna perfeita a ligação de paral. lejismo entre o systema de Santa Catharina do Sul do Brazil o o systema Karroo da Africa do Sul.

Ide janeiro de 1907.

I. C. WhitR,

\section{Origem dos sedimentos Carboniferos e Triassicos}

Nem nos depositos Permianos (Carboniferos) nem nos Triassicos de Santa Catharina, ou Rio Grande do sul foi notada a existcncia de camadas marinhas, é portanto muito provavel que as rochas naquelles Estados tenham origem fluvial e lacustre. Ao norte porém, no norte do Paraná e S. Paulo as camadas de Iraty e Estrada Nova, tornam-se calcareas e conteem restos fosseis em que o Dr. Orville Derby diz (") "que ha especies de Schi:adus, Conocordium, Mytilus (ou Modiola) e Anastartella? com certo numero de generos não determinados, que parecem estranhos naquelle horizonte; não ha Brachiapodes, Aviculoides, Pectinoides Lima-Arca, ou formas semelhantes a Allorisma".

E' possivel que as grandes mudanças climatericas (glacial) e physicas que precederam ou iniciaram a época permiana no sul do Brazil; como torna evidente o conglomerato de Orleans, tenham dado origem a uma série de grandes lagos interiores e rios em forma de lagos em que os depositos Permianos e Triassicos se accumularam, em parte como sedimentos lacustres e em parte como fluviaes. 'E' certo que houve.

(*) Extrahidos de sua carta de 6 de agosto de 1906. 


\section{Note on Erythrosuchus}

In discussing the Săo Bento series of rocks, it is stated that no fossils representing the Beaufort beds of South Africa liad yet been discovered in Brazil, but now Dr. A. Smitl Woodward of the British Museum announces the identification of the genus Erythrosuchus in some fossil bones signt him by the writer which Dr. Cicero Campos had collected near Sta. Maria, in Rio Grande do Sul. The specimens occur about 250 meters below the top of the São Bento sandstones in the mottled red and white sandy beds which crop along the railroad cuttings at Sta. Maria. The fossil reptile, Erythrosuchus africanus, to which the Sta. Maria specimen is most closely allied according to Dr. Woodward, was figured and described, May 3rd 1906, in the Annals of the Sonth African Museum, Volume V, Part III, Plate IV, pp. 187-196, by Dr. R. Broom, from the upper portion of the Beaufort beds of South Africa. The occurrence of a similar or closely allied type in the Brazilian beds at the horizon in question completes and renders perfect the bond of parallelism between the Sta. Catliarina system of South Brazil and the Karroo System of South Africa.

I. ( WhitL.

Jan. 1, 1907.

\section{Origin of the Carboniferous and Triassic Sediments}

No evidence of the existence of marine beds was observed in either the Permian (Carboniferous) or Triassic deposits of Santa Catharina or Rio Grande do Sul, and hence it is quite probable that the rocks in those states may be of fluviatile and lacustrine origin. Northward, however, in northern Paraná and São Paulo, the Iraty. and Estrada Nova beds become limy and hold fossil remains of which Dr. Derby say ; ("). "There are species of Schirodus, Conocar"dizm, Mytilus (or Mod :ola) and Astartella? with a number of undetermined genera that look queer in that horizon. There are no Brachiopods, Aviculoids, Pectinoids, Lima-Arca or Allorisma-likeforms ".

It is barely possible that the great climatic (glacial) and physical changes preceding or inaugurating Permian time in South Brazil, as evidenced by the orleans conglomerate, may have given origin to a series of large inland lakes and lake-like rivers, along which the Permian and Triassic deposits accumulated partly as fluviatile and partly as lacustrine sediments. That marinc conditions existed in

(4) Etract firou lottor lated Ausist 1, 190 i. 
no interior do Paraná, na época Devoniana condições marinhas, visto que, sem duvida occorrem fosseis marinhos perto de Tibagy, Ponta Grossa, Jaguarahyva e outros pontos, mas se o mar se retirou permanentemente do Paraná e S. Paulo antes do inicio da époća Permiana não é certo devido á natureza problematica dos restos animaes encontrados no calcareo Permiano do Paraná e S. Paulo, portanto, emquanto estes não forem estudados, criticamente, a questão permanecerá sem solução pois que parece que não existem fórmas marinhas typicas. 
the interior of Parana in Devonian time is certain, since undoubted marine fossils occur near Tibagy, Ponta Grossa, Jaguariahyva and other points, but whether or not the sea had retired permanently from Paraná and São Paulo previous to the dawn of Permian time, is not certain owing to the problematic nature of the animal remains found in the Permian limestones of Paraná and São Paulo.

Hence, until these are critically studied, the question will remain unsettled, because the typically marine forms do not appear to be present. 


\section{CAPITULO VIII}

\section{Formações geologicas mais recentes}

Ha em S. Paulo, superposta ao gres de Botucatú, e mais antiga que os grandes derrames basalticos e diabasicos, uma outra serie de conglo. meratos, schistos e calcareos, em que o Dr. Derby encontrou seixos de diabase, ete., o que mostra que são mais antigos que os grandes derrames desta.

Estas camadas foram observadas em poucos pontos em S. Paulo e Minas Geraes, mas nã foi possivel estudal-as detalhadamente.

Parece que não existem em Santa Catharina e no Rio Grande do Sul, visto não terem sido encontrados depositos clasticos alli, acima das rochas eruptivas da Serra Geral.

Occorre um calcareo nestes depositos mais recentes em pontos afastados como S. Paulo dos Agudos no Estado de S. Paulo e Mangabeira e Paineiras no de Minas Geraes, que foi explorado e queimado para cal em muitas localidades e tem a mesma côr branca-crême. Daveria ser denominado calcareo de Painairas, nome da localidade perto de Uberaba, em Minas Geraes, onde é queimado para cal em escala commercial.

Contém frequentemente seixos de quartzo e outros e para a parte superior se transforma gradualmonte em um conglomerato regular.

As seguintes analyses de amostras de calcareos colligidas nas localidades referidas, foram feitas sob as vistas do professor B. H. Hite:

\section{Analyse de calcareo de Paineiras}

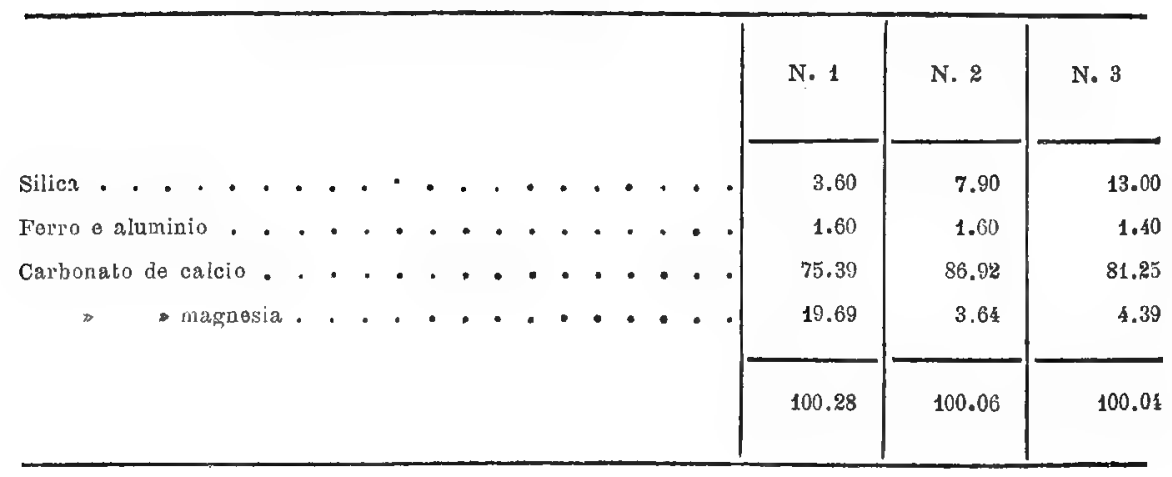




\section{The Younger Geologic Formations}

Superimposed upon the Botucatú Sandstones in São Paulo and later than the great diabasic and basaltic sheets, there comes another series of conglomerates, shales and limestones in which Dr. Derby finds pebbles of diabase, etc., showing that they are distinctly younger than the great sheets of the latter. These beds were observed at a few points in São Paulo and Min๕s Geraes, but no detailed study could be given them.

They do not appear to be present in Santa Catharina or Rio Grande do Sul, since no clastic deposits were seen there above the eruptive rocks of the Serra Geral.

A limestone occurs in these younger deposits at such widely distant points as São Paulo dos Agudos in the state of São Paulo, and Mangabeira, and Paineiras in the state of Minas Geraes. It has been mined and burned for lime at many localities, and presents the same creamy white appearance at all. It might be termed the Paineiras limestone from the locality of that name near Uberaba, Minas Geraes, where it is burned into lime on a commercial scale.

It frequently contains quartz and other pebbles and graduates upward into a regular conglomerate.

The following analyses of specimens of limestone colleeted from the localities referred to were made under the supervision of Prof. B. H. Hite:

Analyses of the Paineiras limestone

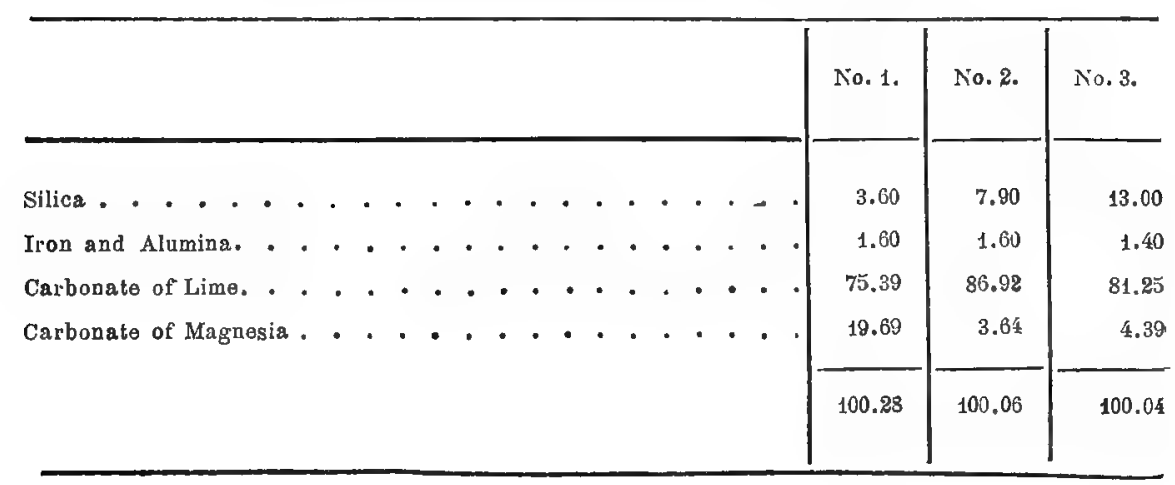


N. 1 - Painciras, Minas Gelaes.

F. 2 - Nangabeira, Minas Geraes.

N. 3 - S. Paul's dos Agudos, S. Paulo.

Estes sedimentos superiores estão muito imperPeitamente consolidados, os gres e conglomeratos sendo muito priaveis, ao passo que os sedimentos mais finos são simples argillas. Nenhum rẹsto animal foi encontrado nostes, de modo que a sua idade pode ser apenas conjecturada.

\section{Os schistos bituminosos de Taubaté}

Ao longo do Rio Parahyba, em seu curso superior, no Estado de S. Paulo, alguns kilometros abaixo do ponto em que este faz a volta admiravel de seu curso de suduoeste para nordeste, existe vasto deposito sedimentar de data comparativamente recente. Este, consiste principalmente em argilla, interestraticados com a "qual ha perto de Tabaté schistos bituminosos que foram explorados em alguma ex. tensãoe utilizados no Pabrico de gaz de iliuminação, oleo, etc. Estes schistos bituminosos conteem restos fosseís de peixes, em alguns pontos em grande numero, de um typo que o Dr. I. von Ihering, Director do Museu Paulista de S. Paulo, julga ser identico a uma especie de hagre que ainda vive em aguas brasíleiras. Os exemplares são entretonto muito mal conservados e a identidade é incerta, de modo que o Dr. Dərby julga que a idade dos depositos não está certamente conhecida; de facto estes podem ser Terciarios, ou mesmo mais antigos.

Os depositos se elevam a 50 metros, ou mais acima do nivel actual do rio, e vão a profundidade desconhecida, visto que uma sondagem feita parte de Taubaté, que dizem ter ido alem de 150 metros não alcançou o fundo destes. Estendem-se por ambas as margens do rio Parahyba por 60 kilometros, ou mais, e teem a largura de \& a 5 kilometros.

o schisto bituminoso é de uma cor cinzenta escura e se desdobra em finas laminas flexiveis. E' explorado a céo aberto em excavações dos depositos superficiaes. Ve-se em uma das velha excaçoes uma espessura de 2 metros.

As seguintes analyses, mostram a composição chimica de uma amostra de schisto, feitas sob as vistas do Prof. B. A. Hite: 
No. 1. Paineiras, Minas Geraes.

No. 2. Mangabeira, Minas Geraes.

No. 3. São Paulo dos Agudos.

These upper sediments are very imperfectly consolidated, the sandstones, and conglomerates being very friable, while the finer sediments are mere clays. No animal or plant remains were observed in them, so that their age can only je conjectured.

\section{The bituminous shale of Taubaté.}

Along Rio Parahyba in its upper course through the state of $\mathrm{S}$. Paulo, several kilometers below it makes its wonderful detour from a south-west course to a north-east one, there occurs a vast sedimentary deposit of comparatively recent date. This consist mostly of clays, interstratified with which near Taubate there occur bituminous shales which have been mined to some extent and used in the manufacture of illminating gas, oil, etc. These bituminous shales hold the remains of fossil fishes at some localities in great numbers, of a type believed by Dr. H. von Thering, director of the Museu Paulista, of S. Paulo, to be identical with a species of catfish still living in Brazilian waters. The specimens are poorly preserved, howover. and the indentity is rather uncertain, so that Dr. Derby thinks the age of the deposits is not certainly known, in fact that they may be Tertiary or even older.

The deposits extend to 50 meters or more above the present river level and go down to an unknown depth, since a boring reported to be over 150 meters in depth made near Taubaté, failed to reach their bottom. They stretch along both banks of rio Parahyba for 60 kilometers or more, and have a width of 4 to 5 kilometers.

The bituminous shale is of a dirty gray color and splits in thin elastic laminae. It is mined by stripping of the superficial deposits. A thickness of 2 metrs is visible in one of the old strippings.

The following analysis represents the chemical composition of a specimen of the shale as determined under the supervision of Prof. B, H. IIite : 


\section{IMMEDIATA}

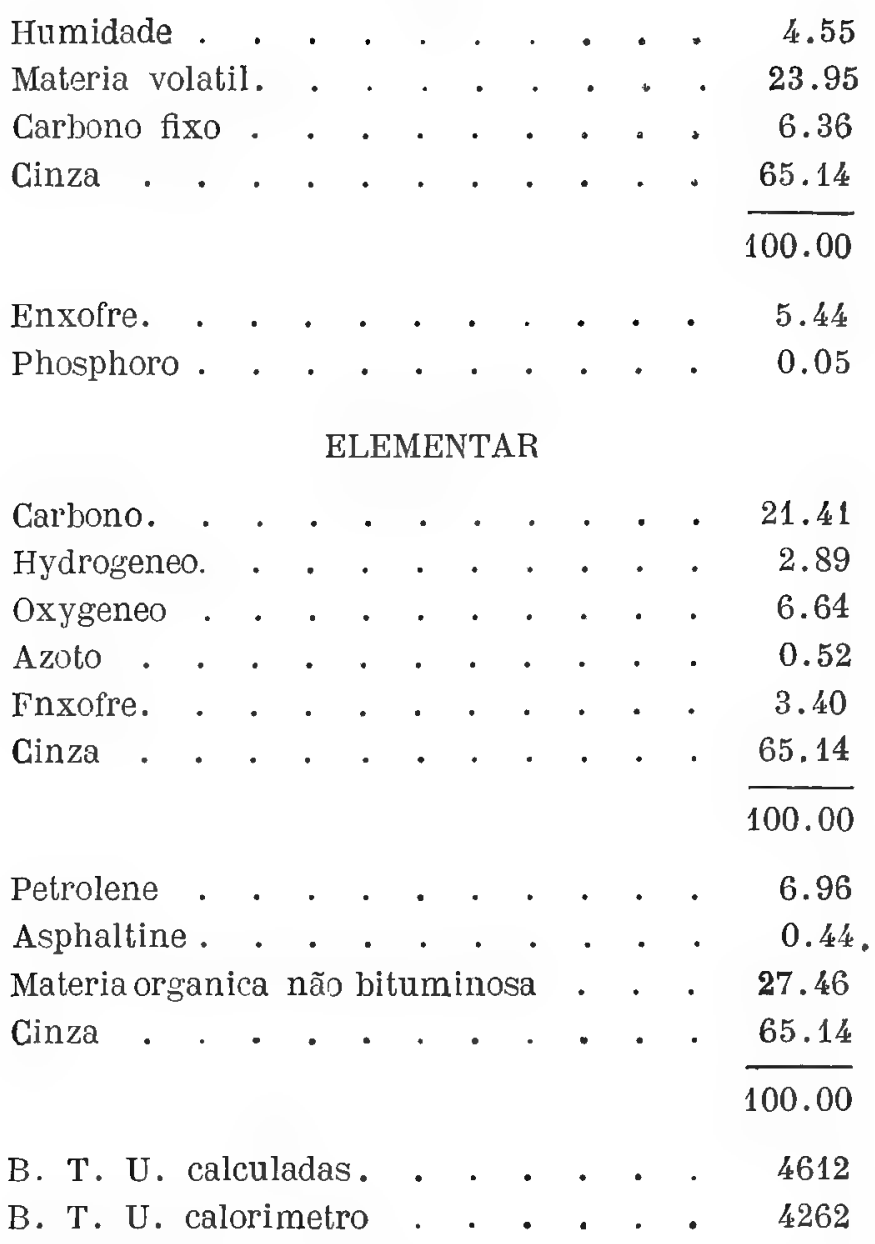

No fabrico de gaz de illuminação pareee que sa obtem melhores resultados quando se mistura o schisto com carvão de gaz de boa qualidade.

A distillação de oleo outrora em trabalho, aproveitando schistos de Taubaté não está actualmente funccionando.

Segundo a theoria do Dr. David White estes schistos devem a materia bituminosa ao crescimento de algas nas massas dagua em forma de lagos que existiram outrora no valle do Parahyba, causadas provavelmente, pela differença de altitude da parte inferior do actual valle obstruido, ou por algum derrame erruptivo de rocha ignea que obstruiu seu velho canal profundamente cavado. 


\section{PROXIMATE}

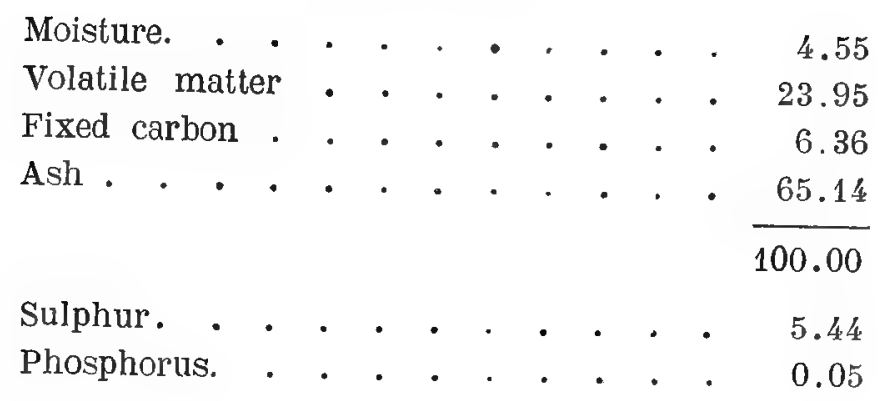

ULTIMATE

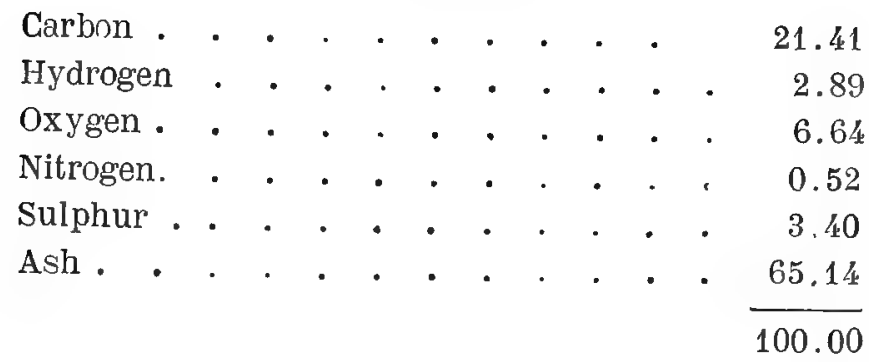

Petrolene . . . . . . . . . . 6.96

Asphaltine . . . . . . . . . . 0.44

Non-bituminous organic matter. . . 27.46

Ash . . . . . . . . . . . . 65.14

100.00

B. T. U. calculated . . . . . . . 4612

B. T. U. calorimeter . . . . . . 4262

In the manufacture of illuminating gas, better results appear to be obtained when the shale is mixed with a good grade of gas coal.

The oil works formerly engaged in the distillation of these shales at Taubté are not now in operation.

According to the theory of Dr. David White, these shales probably owe their bituminous matter to the growth of algae in the lake-like body of water which once existed along the valley of the Parahyba, caused probably, either by differential elevation in the lower end of the present filled valley, or by some eruptive flow of igneous rocks which obstructed its old and deeply eroded channel. 


\section{Depositos de Turfa, ou Boghead de Marahú}

No Estado da Bahia, e a cerca de 100 kilometros ao sul đa cidade da Bahia, estão o porto e villa Marahú.

Alli, e em muitas outras localidades naquella região, ha grandes depositos de uma especie de turfa, ou schisto bituminoso de diminuto peso especifico, conhecido por Boghead. Foi estudado e descripto pelo Dr. L, F. Gonzaga de Campos em un relatorio (*).

Outr'ora uma companhia ingleza dispendeu muitos centos de milhares de libras na construcção de uma grande fabrica em Marahú para a extracção de oleo do Boghead e preparo de velas, paraffina, etc.

A empreza não poude entretanto competir com os productos muito mais baratos obtidos do petroleo e a fabrica foi ha muito abandonada.

O material bituminoso, onde exposto á superficie tem uma cor parda clara ou cinzenta escura e fluctua facilmente na agua.

Nas sondagens abaixo da superficie alterada, a cor é mais escura $e$ contem mais carbono. Nos schistos ha plantas de fascies terciaria e o Dr. Gonzaga de Campos que fez um estudo muito cuidadoso do material e descreveut-o tăo completamente refere-o aos depositos Terciarios.

As amostras deste material foram analysadas pelo professor $B . H$, Hite que achou a seguinte composição :

\section{ANALYSE IMMEDIATA}

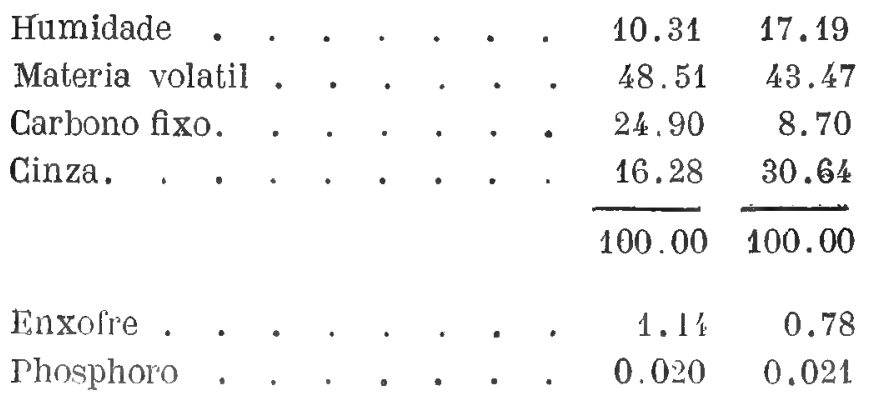

\footnotetext{
(*) Reconheciment geologico o estudo das substancias bituminosas da bacia do rio Miarahú, Eitadis da Bahia, por Gonzaga Címpos.
} 


\section{The Turf or Boghead deposits of Marahù}

In the state of Bahia and about 100 kilometers southward from the city of Bahia, ist the port and village of Marahú.

Here and at many other localities in that region occur large deposits of a kind of Turf or bituminous shale of very light specific gravity, known as Boghead, It has been studied and described by Dr. L. F. Gonzaga de Campos in a report $\left(^{*}\right)$ published in November, 1902.

An English Company once expended many hundreds of thousands of pounds in the erection of a large plant at Marahu for the manufacture of the Boghead into oil, candles, paraffine, etc.

The enterprise, however, could not compete with the much cheaper products obtained from petroleum, and the factory has long been abandoned.

The bituminous material where exposed at the surface, has a ligth brown or dark gray color, and it will readily float upon water.

In borings below the weathered surface, the color is darker, and it contains more carbon. Fossil plants of a Tertiary aspect occur in the shales, and Dr. Gonzaga de Campos, who made a very careful study of the materIal, and has so fully described the same assigns it to the Tertiary deposits.

Two specimens of this material were analyzed by Prof. B. II. Hite, who reports the chemical composition as, ollows:

\section{PROXIMATE}

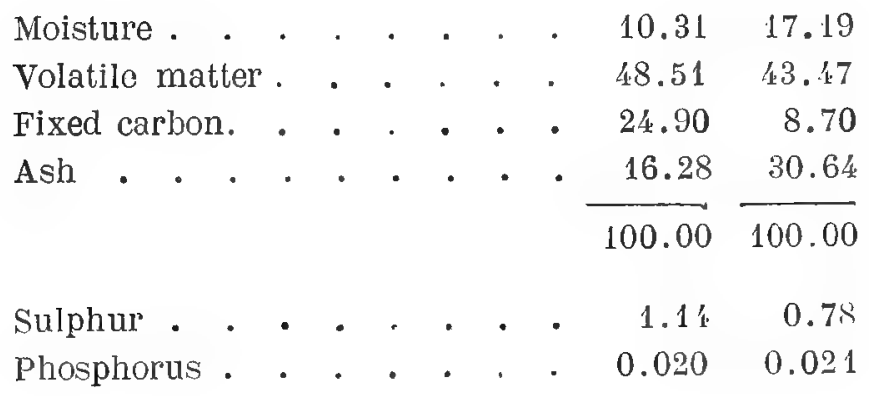

(*) Reconhocin mlo geologico e esludo das substancias bituminosas ua bacia do rio Marahu, Estado da Bahia, por Gonzaga Campos. 
ANALYSE ELEMENTAR

\begin{tabular}{|c|c|c|c|c|c|c|c|c|c|}
\hline Carbono & & & & & & & & 48.23 & 35.47 \\
\hline Hydrogeneo & & . & & 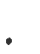 & • & . & « & 4.58 & 5.06 \\
\hline Azoto. . & . & . & - & . & . & . & & 0.44 & 0.25 \\
\hline Enxofre . & . & . & . & . & . & . & & 1.14 & 0.78 \\
\hline Oxygeneo & . & & . & . & . & . & . & 29.46 & 27.89 \\
\hline Cinz: & & & & . & . & & & 16.15 & 30.55 \\
\hline
\end{tabular}

I Amostra da sondagem em Marahú.

II Amostra do affloramento superficial em Marahú.

A analyse demonstra que a amostra da sondagem que estava sendo feita para petroleo, quando a commissão alli esteve, contem muito mais carvão que os depositos superficiaes.

Foram feitas tentativas de exportação do material para o fabrico de gaz nas cidades visinhas, mas devido a seu pouco peso especifico e o grande volume necessario para se ter uma tonelada de Boghead, estes embarques não foram bem succedidos, dizendo-se que nenhum dos dois navios despachados, jamais chegou a seu destino. Suppondo-se que do material se desprendesse gaz inflammavel de forma que os navios em questão se perderam devido a algum desastre, mas esta hypothese do gaz inflammavel não tem de facto fundamento, e se o que se diz dos navios é verdade, o facto de estes não terem chegado ao porto do destino e mais provavelmente devido a um naufragio commum por estarem os navios carregados com uma substancia volumosa mas tendo tão pouco peso.

A origem da substancia bituminosa destes schistos de Marahú é evidentemente a mesma que a dos schistos de Taubaté, a saber alguma forma de vegetação algoide $\left(^{*}\right)$.

Possibilidade da existencia de depositos de petroleo no Brasil

Ao auctor foi muitas vezes pedido, para manifestar sua opinião sobre a possibilidade de se encontrar petroleo no Brasil, em cluantidade commercial.

A questão é das que não admittem resposta adequada senão quanto ás regiǒes percorridas pelo auctor, que como já se disse comprehendem sómente uma porção daquelle grande territorio e sómente

\footnotetext{
$\left.{ }^{*}\right)$ Veja o trabalho do Dr. David White, in "Sciencia» Nova sarie, Vol. XXIII,
n. 595,25 do maio 1906, pags. $814-316-$ ou «A Source of Hydrocarbono in the Ordovician».
} 


\section{ULTIMATE}

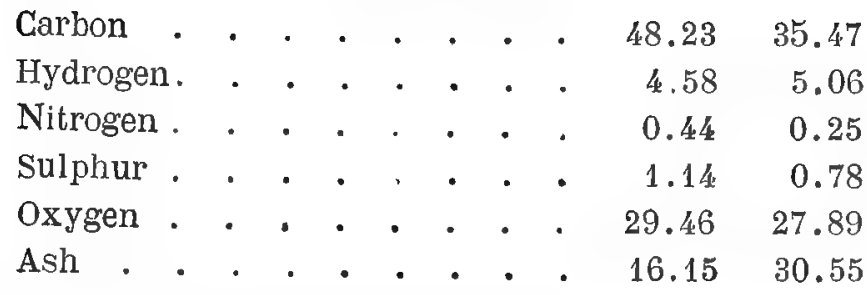

I. Sample from boring at Marahú.

II. Sample from surface outcrop at Marahú.

The analyses show that the unweathered sample from the boring, which was being sunk for petroleum at the date of the Commission's visit, contains considerably more carbon than the surface deposits.

Attempts have been made to ship the material for the manufacture of gas to neighboring cities, but on account of its small specific gravity, and the large bulk required to make a ton of the Boghead, such shipment have not been successful, one report being that neither of the two vessels sent out ever arrived at the destination. Some have supposed that the material gives of an infiamable gas and that the vessels in question may thus have met with disaster, but the inflamable gas theory has no foundation in fact, and if the "report" is true about the vessels, non-arrival at the port of destination, it is most probably due to ordinary shipwreck owing to being loaded with a bulky substance having such little weight.

The origin of the bituminous matter in these shales at Marahu was evidently the same as that in the shales at Taubaté: namely, from some form of Algoid vegetation (").

\section{The Possibility of Petroleum Deposits in Brazil}

The writer has often been asked to express an opinion as to the possibility of finding petroleum in commercial quantity in Brazil.

The question is one that does not admit of an adequate answer except for the regions visited by the writer, which as already stated, include only a portion of that great territory, and only the southern

$\left(^{*}\right)$ See paper by David White, in sciencs», New Series, Vol, XXIII, No 595 ,
May 25,1906 , pp. 8I5 - 816, on «A Source of Hydrocarbons in the Ordovician. 
o sul do Brasil; isto é os Estados do Rio Grande do Sul, Santa Catharina e Paraná, e poucas e rapidas excursões em São Paulo e Minas Geraes e a curta visita a Marahú na Bahia.

Que as camadas sedimentares do Permiano brasileiro contiveram outr'ora algum petroleo é attestado pela evidencia do schisto preto de Iraty de que se desprende o cheirs caracteristico daquella substancia desde São Paulo até Rio Grande do Sul.

o coke natural em Limeira e a Albertite perto de Lages neste mesmo schisto tambem attestam seu caracter petrolifero.

o gres saturado com residuos asphalticos em Bofete, em São Paulo conduz ao mesmo facto, isto é: que este deposito do systema de rochas de Santa Catharina conteve outr'ora petroleo, e se devemos dar credito ao que se diz, uma pequena quantidade deste foi encontrada na profunda sondagem em Bofete perto da base das camadas de Santa Catharina. Outro factor deve ser tomado em conta. As rochas deste são em toda a parte do Brasil, atravessadas por fendas, pelas quaes grandes derrames de rochas eruptivas vieram á superficie, rompendo os estratos e ás vezes cosendo-os a ponto parcialmente metamorphico. Esta actividade scismica produzio, certamente o desprendimento de todos, ou quasi todos, os productos volateis de quaesquer depositos de petroleo, deixando os que restavam como inutil residuo asphaltico tal como o que se encontra no gres em Bofete.

E' verdade que grandes areas são comparativamente livres de qualquer evidencia visivel destes antigos derrames de rochas eruptivas e é apenas possivel, que em algumas destas existam depositos de petroleo de forma aproveitavel, mas é bastante duvidoso e as probabilidades são todas contra a descoberta do petroleo em qaantidade commercial, em qualquer parte do sul do Brasil.

o resultado da profunda sondagem em Iraty que está distante de qualguer affloramento conhecido de rochas igneas, confirma esta conclusão: que é inutil esperar encontrar depositos de petroleo de quantidade consideravel em qualquer parte do sul do Brasil.

o que o norte do Brasil póde ter a este respeito, o auctor não se aventura a predizer, pois que suas viagens não se estenderam até aquella região, mas se podemos raciocinar com a presença de grandes depositos de asphalto em territorio visinho da Venezuela, etc., pois que todos os depositos de asphalto são simplesmente resicluos de antigos immensos lagos de petroleo levados á superficie, tendo sido removida pela erosão a capa original, poderiamos predizer que se algum dia se encontrarem grandes depositos de petroleo no 
portion of Brazil; namely the states of Rio Grande do Sul, Santa Catharina, Paraná, and a few rapid excursions across São Paulo, and Minas Geraes, as well as the brief visit to Marahú in Bahia.

That the sedimentary beds of the Brazilian Permian. once held some petroleum is attested by the evidence of the Iraty blacle shale which gives off the characteristic odor of this substance from São Paulo to Rio Grande do Sul.

The natural coke at Limeira and the Albertite near'Lages in this same shale also attest its petroliferous character

The sandstone saturated with alphaltic residua at Bofete in São Paulo, tells the same story; namely, that these deposits of the Santa Catharina system of rocks once held petroleum, and if reports are to be credited, a small quantity of petroleum was actually found in the deep boring at Bofete near the base of the Santa Catharina beds. But another factor must be taken into account. The rocks of this system are everywhere in Brazil traversed by fissures through which great flows of eruptives welled out to the surface ruptiring the strata and often baking them in to a partial metamorphic condition. These scismic activities would certainly release all or most of the volatile products in any petroleum deposits, and leave the remainder as an unavailable asphaltic residuum just like that found in the sandstone at Bofete.

It is true that large areas are comparatively free from any visible evidence of these old eruptive flows, and it is barely possible that in some of these, petroleum depasits might yet exist in available form, but this is quite doubtful, and the chances are all against the finding of petroleum in commercial quantity anywhere in South Rrazil.

The result of the deep drilling at Iraty, which is distant from any known outcrop of igneous rocks, confirms this conclusion, that it is useless to expect petroleum deposits of any considerable quatity anywhere in South Brazil.

What North Brazil may hold in this line, the writer cannot venture to predict, sinse his travels have not extended into that region, but if one might reason from the presence of the great deposits of asphalt in the adjoining countries of Venezuela, etc., (since all deposits of asphalt are simply residua of former immense oil pools elevated to the surface, the original cover having been removed by erosion) one might foretell that if any large deposits of petroleum are ever found in Brazil, they will be loca- 
Brasil, estarão situados no territorio drenado pelo grande rio Amazonas, no Norte do Brasil.

A referida occurrencia de petroleo em Porto Bello, enseada do Brito e outros pontos da costa de Santa Catharina, não tem fundamento, visto que as rochas são graniticas em todas estas localidades A amostra de petroleo colligida na região do sul de Marahú, no Estado da Bahia, ondo se diz existir petroleo na agua, ficou provado ser do artigo refinado e foi sem duvida tirado de alguma lata de Devoe. 
ted in the territory drained by the great Amazon river of North Brazil.

The reported occurrences of petroleum at Porto Bello, Enseada do Brito, and other points along the coast of Santa Catharina, are without foundation, since the rocks are granitc at all of these localities, while a specimen of petroleum collected from the region south of Marahú, in the state of Bahia, where petroleum is reported to exist on the water, proved to be the refined article, and was doubtless derived from one of Devoe's packages. 


\section{APPENDICE I}

O seguinte resumo de uma communicação feita pelo Dr. Gájliel Osorio de Almeida ao Club de Engenharia do Rio de Janeiro, na sessão de 29 de novembro de 1904, concernente á applicação do carvão nacional á tracção em estradas de ferro é de interesse especial, pois que dá o resultado de uma experiencia recente feita com o carvão brasileiro bruto, ou não purificado:

\section{Carvão nacional}

«Tendo sido o Club de Engenharia quem iniciou estudos sobre o carvão de pedra das jazidas existentes em Santa Catharina e no Rio Grandu do Sul, a elle compete o direito de conhecer os resultados das experiencias feitas sobre esse combustivei não sómente em nossa primeira via-ferrea, como tambem na importantissima fabrica de locomotivas dos Estados Unidos da America do Norte pertencente á Baldwin Locomotive Works Company.

Houve aqui diversas sessões em que foi estudada a questão da utilisação desse carvão em nossas industrias, tomando parte na discussão diversos socios o tendo para basa das opiniões enunciadas o parecer de dous illustrados mem. bros do Conselho Director, que tiveram o trabalho de apresentar o resultado das analyses que lhes foram entregues.

Mas, como sempre acontece em relação a productos de fim inteiramente industrial, maxime tratando-se de combustivel, as analyses de laboratorios ñ̃o representam o melhor criterio para se chegar a conclusões, que se imponham 20 espirito por sua segurança $\theta$ certeza.

A razão é clara, comeşando pelo cuidado com quo em geral, e para obe. decerem aos desejos de optimos resultados, escolhem os interessados as amostras que submettem a analyse, para terminar na consideração da dependencia que invariavelmente liga o combusfivel ao apparelho de combustão, variando o resultado conforme a melhor ou peior adaptação do segundo a natureza do primeiro.

Tive não obstante esta consideração, oceasião de mostrar a.os illustres consocios que, mesmo sob o ponto de vista dos resultados obtidos pela analyse apresentadas no pareeer que se discutia, o carvão nacional nāo era inferior ao de muitas qualidades que eram e são empregadas em outros paizes.

Năo se tratava de carvăo de primeira qualidade, mesmo porque as amos. tras, especiaimente as de Santa Catharina eram extrahidas das primeiras camadas, das que se achavam quasi á superficie do sólo. Mas nem por isso se devia desanimar e doixar de estudar a exploração das jazidas, attendendo-se ás importantissimas vantagens' que para o nosso paiz resultarian da posse desse combustivel embora mesmo de qualidade inferior ao que constmiamos e que, como todos sabom, é do melhor existente no mundo. 


\section{APPENDIX I}

The following extract taken from a communication made by Dr. Gabriel Osorio de Almeida to the Engineering Club of Rio de Janeiro at a meeting held November 29th, 1904, concerning the application

of national coal to lailway traction, is of especial interest as giving the results of actual experiment with the raw, ol' unpurified Brazilian coal :

\section{National Coal}

It having been the Engineering Club that initiated the investigation of the coal reefs existing in Santa Catharina and Rio Grande do Sul, that body is intitled to be informed of the results of the experiments made with those combustibles and carried out not only on our principal railway but also at the most important locomotive factory in the United States of North America, belonging to the Baldwin Locomotive Works Company.

Several meetings have been held here, at which the question of the utilization of this coal by our industries has been considered, various members taking part in the discussion, the opinions expressed being based upon the conclusions of the tho distinguished members of the Conselho Director who were charged to present the analyses committed to their care.

But, as is always the caso with products intended for purely industrial purposes, and especially as regards combustibles, laboratory analyses do not form the best means of arriving at conclusions which impress the mind by their safety and certainty.

The reasons are plain and begin with the care which, in obedience to the desire of obtaining the best results, is generally exersised by those interested in selecting the samples and finish with the consideratiou of the interpendence which invariably exists between the combustion apparatus, results varying in accordance with the better or worse adaptation of the latter to the nature of the former.

Notwithstanding these considerations I had oceasion to point out to my fellow members that even from the point of viow of the results obtained in the analyses presented for discussion, the native coal was not inferior to that of many qualities which were and are employed in other countries.

A coal of good quality was not, of course, in question for one thing because the samples, especially those from Santa Catharina, were taken from the first beds, found almost at the surface of the soil-but that was no reason for discouragement nor for neglecting the study and exploration of the reefs, in view of the vory important advantages that would accrue to the country from the possession of this fuel, even though it be of quality inferior to that we are now using, which, as every one knows is the best in the world. 
Convinha, por conseguiute, que se fizessem experiencias que praticamente demonstrassem ou não a possibilidade do emprego de carvão nacional como fonte de energia.

Fui o que se fez na Estrada de Ferro Central do Brasil o é o resultado das experiencias alli realizadas que tenho o prazer de trazer ao conhecimento do Club do Engenharia.

A primeira experiencia foi feita em um trem especial de passageiros, con. duzindo o Exm. Sr. Ministro da Industria, diversos cavalheiros e a administração superior da Contral, em viagrem daqui a S. Paulo. Como o Club de Engenharia vio pelas noticias publicadas pela imprensa, a viagem so fez em magnificas condiçöes, submettido o referido trem ao mesmo horario dos trens expressos.

Esta primeira experiencia demonstrou desde logo que, com o cal'vão de Santa Callharina se podil mover a locomotiva com a pressão necessaria á obtenção de grande velocidade, tal qual a que possuem os trens de passageiros da Central.

Foi ossa uma primeira victoria para aquelles que aceitaram a possibilidade da existencia desse combustivel om condiçōes de poder ser ulilizado em nossas industrias, contra os que a negavam om absoluto e baseado na comparação dos resultados obtidos pela analyse do laboratorio com o melhor carvão do mundo, qual o que constitue o typo tomado pela Central para base de suas concurrencias.

Novas experiencias, porém, foram realizadas, tanto com o carvão de Santa Catharina, como com o do Rio Grande do Sul o os resultados foram os seguintes:

\section{CARVÃO DO RIO GRANDE DO SUL}

\section{NÃO PENEIRALO}

Locomotiva n. 271, com escapamento baixo e grelhas tubulares apenas

Experiencia foita a 5 de julho de 1904:

Trens SS 3 e SS 8 (ramal de Santa Cruz) compostos de dois carros serie B, ( ${ }^{a}$ classe), 2 serie D (2a classe), 2 serie Q (bagagem), 126 unidades.

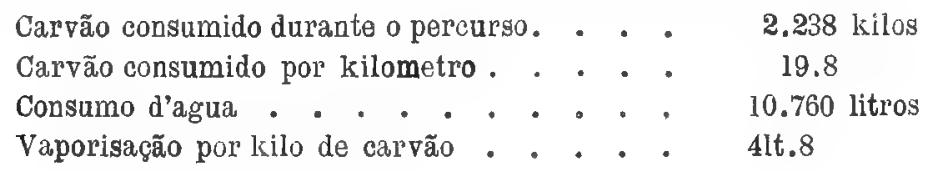

RESIDUOS

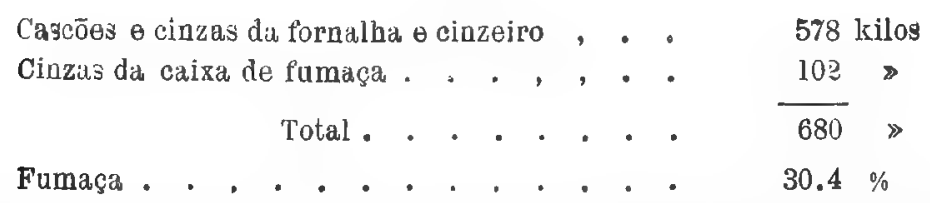

A produção da fumaça não é grande, regula a do Cardiff na côr amarella $\theta$ na quantidado.

Os treas chegavam á hora em todo o percurso. 
It was consequently desirable that practical experiments should be made to demonstrate the possibility or otherwiso of employing national coal as a source of energy.

This was done on the Central Railway of Brazil and it is the result of the trials there carried out that I now have the pleasure of bringing to the knowledge of the Engineering Club.

The first trial was made with a special passongor train carrying His Excellency the Minister of Industry, several gentlemen and the superior staff of the Central, travelling from here to São Paulo.

As the Engineering Club will have seen from statements made in the Press, the journey was spleadidly accomplished, the train in question being subject to the ordinary time table of express trains.

This first trial at once domonstrated that it was possible with the Santa Ca. tharina coal to work a locomotive such as those attached to the Central passenger lrains with the pressure necessiry for obtaining high speed.

This was a first victory for those who believe in the possibility of the existence of fuel suitable for utilization in our industries over those who absolutely deny such a thing and who base their disbelief on a comparison of the results obtained in laboratory analysos as against the best coal in the world and which constitutes the type taken by the Central as a basis for competitions.

Further experiments wore made however both with Santa Catharina coal and with that from Rio Grande do Sul, with the following results:

\section{FIRST EXPERIMENT - COAL FROM RIO GRANDE DO SUL \\ NOT SCREENED \\ Locomotive $x^{\circ}$. 271, with low escapment and lubular bars only}

Trial made on the 5th, July 1904.

Trains SS 3 and SS 8 (Santa Cruz Branch) consisting of 2 curs series B (1st class) 2 series D (2ad class) 2 series Q (luggage) l:26 units.

Coal consumed during the run.

Coal consumed per kilometer

Consumption of water ....................

Evaporation per kilo of coal.
2.238 kilos

$19.8 》$

10.760 Iitres

$41 \mathrm{t} .8$ »

RESIDUES

Clinkers and ash from the furnace and ash pan. 578 kilos

Ash from the smoke bo

Total $102 》$

680 》

Smoke . . . . . . . . . . $30.4 \%$

The production of smoke is not great and resembles that from Cardiff in its yellow color and quantity.

The trains kept the time throughout the journey. 
E' preciso, porém, notar que as grelhas da locomotiva não estavam convenientemente adaptadas ao carvão em experiencia. Dahi os seguin tes inconvenientes notados: embora a pressão se houresse mantido alta durante duas terças partes do percurso, no resto baixou, devido a escorias accumuladas na fornalha, obstruindo os intersticios da grelha.

\section{SEGUNDA EXPERIENCIA}

CARVÃO PENEIRADO

Foi realizada a 11 de julho de 1904.

Trens SS 3 e SS 8 do ramal de Santa Cruz, 2 carros serie B, 2 serie D e 2 serie $Q, 126$ unidades.

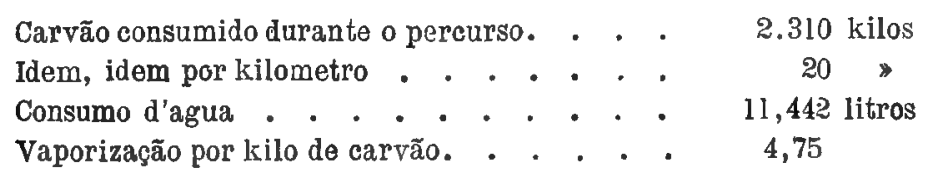

RESIDUOS

Cascões $\theta$ cinzas da fornalha e cinzeiro . . . 630 kilos

Cinzas da caira de fumaça . . . . . . 48 »

$$
\text { Total . . . . . . } \overline{678} \text {, }
$$

Fumaça amarellada $\theta$ semelhante á do Cardiff $27,3 \%$,

Os trens se mantiveram á hora.

Manifestou.se ainda o inconveniente de obstrucção das grelhas, do que resultou o abaixamento da pressão em alguns pontos do percurso total.

TERCEIRA EXPERIENCIA

CARVÃO DA MINA DE TUBARÃO EM SANTA CATHARINA

Carvão peneirado

A experiencia foi realizada a 30 de junho de 1904.

Trens SS 3 e SS 8 compostos de dous carros serie B, dous serie D e dous serie $Q, 126$ unidades.

Carvão cnnsumido durante o percurso, . . . 2.042 kilos

Carvão consumido por kilometro • . . . . 18 》

Consumo de agua . . . . . . . . . 11.885 litros

Vaporizagão por kilo de carvão. . . . 5, litros 7 ,

RESIDUOS

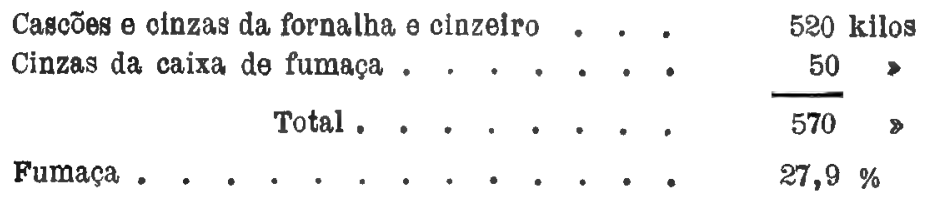


It is necessary howevel to note that the bars of the locomotive were not properly adapted for the coal under trial and gave rise to the following objections although pressure was kept high for two-thirds of the run, it fell during the remainder, owing to accumulations of dross in the furnace choking the interstices of the bars.

\section{SECOND EXPERIMENT}

TCREENED COAL

Carried out on the 11th July, 1904.

Trains SS 3 and SS 8 of the Santa Cruz Branch, 2 cars series B, ? series D and 2 series $Q, 126$ units.

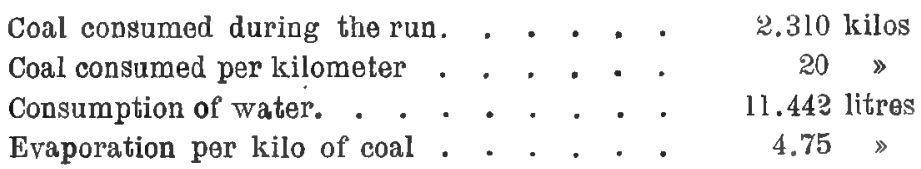

\section{RESIDUES}

Clinkers and ash from the furnace and ash pan.

630 kilos

Ash from the smoke box.

$\frac{48}{678}$

Smocke yellow and similar to that from Cardiff.

$27.3 \%$

The trains kept the time.

There was again the inconvenience of choked bars, resulting in lower pressue during some parts of the total run.

\section{THIRD EXPERIMENT}

COAL FROM THE TUBARĨO MINE IN SANTA CATHARINA

\section{Screened coal}

The trial was made on the 30th of June, 1904.

Trains SS 3 and SS 8, composed of two cars series $B$, two series $D$ and two series $Q, 126$ units.

$$
\begin{aligned}
& \text { Coal consumed during the run. . . . . . } 2.042 \text { kilos } \\
& \text { Coal cunsumed per kilometer . . . . . . } 18 \text { 》 } \\
& \text { Consumption of water . . . . . . } 11.885 \text { litres } \\
& \text { Evaporation por kilo of coal . . . . . } 5.7 \text { 》 } \\
& \text { RESIDUES } \\
& \text { Total . }
\end{aligned}
$$


Os trens se mántiveram no horario e a pressăo se conservou om regulares condiçöes.

Estas experiencias vieram domonstrar, por conseguinte, que o carvão nacional, se não e de primeira qualidado, serve entretanto para satisfazer ás necessidades de nossa industria e constitue por isso grande e util riqueza para o nosso paiz.

Nāo contente ainda com estes resultados, porém, achei conreniente satisfazer aos pedidos dos Sis. Norton, Megaw \& C., representantes nesta praça da Baldwin Locomotive Works, remettendo áquella fabrica amostras do carvão do Santa Catharina e do Rio Grande do Sul, afim de serem feitos novos ensaios, tanto mais necessarios quanto pela constituição e natureza desse carvãa foi aqui reconhecida a conveniencia de serem feitas modificações tanto nas grelhas como na caixa de fumaça das locomotivas.

Eis o parecer que a Baldwin Locomotive WVorks nos enviou:

«Com referencia ás duas amostras de carvão de Santa Catharina e Rio Grande do Sul respectivamente, temos a dizer que as analyses no nosso laboratorio dão o resultado seguinte:

\begin{tabular}{|c|c|c|c|c|c|c|}
\hline & & & & & $\begin{array}{l}\text { Carvão de Santa } \\
\text { Catbarna }\end{array}$ & $\begin{array}{c}\text { Carrão do } \\
\text { Rio Grande do Sul }\end{array}$ \\
\hline Fumidade. . & - & - & • & . & $0,30 \%$ & $4,00 \%$ \\
\hline Materias volateis. & - & . & . & . & $33,40 \%$ & $31,30 \%$ \\
\hline Carbono fixo. . & . & . & • & - & $42,59 \%$ & $38,92 \because 0$ \\
\hline Cinza . . . & . & . & . & . & $23,72 \%$ & $25,78 \%$ \\
\hline
\end{tabular}

$$
\text { Côr da cinza Cinzenlo claro Cinzento claro }
$$

Valor do aquecimento de agua por

$$
\text { cada libra em peso de carvão. 12,8 libras 11,00 libras }
$$

Observações - 0 carvão se farí em torrão nas grelhas. 0 de Santa Catharina tem maior valor de aquecimento, porém tem mais tendencia para se fazer em torrão, em tolo caso não ha differenç bastante entre as duas amostras para se tornarem necessarias duas especificacões de caldeiras apropriadas ao sen uso com exito.»

E' este o parecer da Baldwin Locomotive TVorks $\theta$, em seguida, apresenta essa compauhia as especificações de uma locomotira com as adaptaçōes necessarias ao emprego do carvão nacional, locomotivá essa que tem a força de 740 cavallos-vapor e que, com a velocidade de 25 milhas por hora, é capaz de desenvolver o esforço de tracção de 11,100 libras ou de 5.095 kilogrammas.

As modificações apresentadas so referem especialmente ás grelhas e a caixa de fumaça. Assim, diz a companhia: «As grelhas devem sar do typo «dedo» (finger), aflm de se quebrar o torrão.

Os dedos deven ser de cerca de 8" de comprimento e devem ter o maior intervallo possivel entre si, pois o carvão é do blocos grandes. A caixa de fumaça deve ser apparelbada com um bocal de escapamento baizo, isto é essencial, pois de outro modo a locomotiva não fará vapor.»

Accrescenta a Companhia Baldwin o seguinte, que para quem conhece o credito de que goza essa fabrica tem grande importancia: "Conforme as condiços acima podemos construir locomotivas para o uso com bom exito do carvão conforme as amostras enviadas.» 
The trains kept tho time, and pressure was regularly maintained.

These experiments therefore go to show that native coal, though it be not of the first quality, serves to satisfy the necessities of our industry and thereby constitutes a great and useful wealth for our country.

Not content with these results, however, I thought it desirable to accede to the request of Messrs. Norton, Megaw \& Co., lepresentatives here of the Baldwin Locomotive Works, and accordingly sent samples of the Santa Catharina and Rio Grande do Sul coal to their Works for further trials, which were the more ne. cessary because from the composition and nature of this coal it had been recognized here that alterations were desirable both to the fire bars and smoke boxes of the locomotives.

The following is the opinion which the Baldwin Locomotive Works sends us.

"With reference to the two samples of coal from Santa Catharina and Rio (irande do Sul respectively, wo have to say that analyses in our laboratory givo the following results:

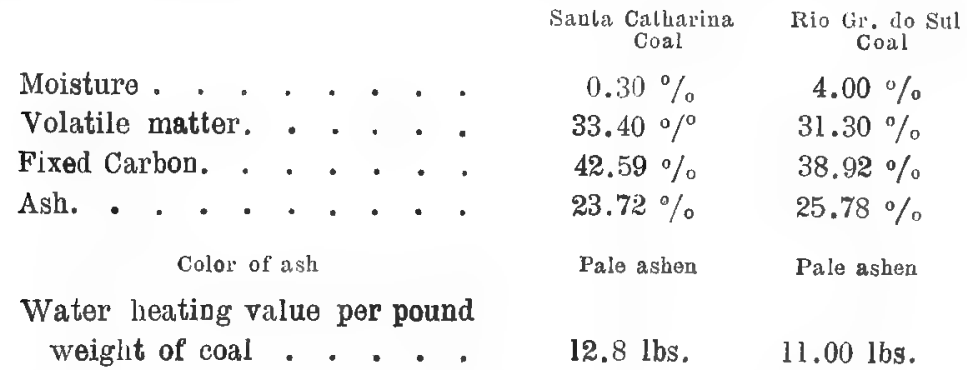

Observations. - The coal cakes on the bars. The Santa Catharina has the greater heating value but at the same time has the greater tendency to cake. In any case, however, there is not suficient difference between the samples $t a$ render two kinds of boilers necessary for using both of thom with success».

The Baldwin Locomotive Works afterwards submitted speciflcations of a locomotive adapted for the employment of native coal ; an engine of 740 horse power with a speed of 25 miles por hour and capable of developing a traction force of 11,100 Ibs. or 5,095 kilograms.

The modifications presented refer especially to the flre bars and smoke box. The Company state: The fire bars should be of the «finger» type so as to break the cake.

The «fingers» should be about 8 inches long and there should be the greatest possible space between them, as the coal is in large lumps. The smoke box should be fitted with a Iow escapement; this is essential, as othorwise the locomotive will not make steam.

The Baldwin Company added the following, which those aware of the standing of that Company regard as very important, viz: - \& In conformity with the above conditions, we are able to construct locomotives for the successful use of the coal as per sample sont. 
Temos assim uma affirmaçẫo precisa e clara de quem merece conceito, garantindo-nos a possibilidade da utilisação do nosso carvão om um serviço exigente como é o das estradas de ferro, contando-se ainda que a amostra do de Santa Catharina foi extrahido das camadas superiores, sendo de esperar que sua qualidade se torne melhor, á medida que sejam attingidas camadas mais profundas.

Năo so trata, além disso, de uma dessas affirmaçōes aereamento fuitas, que podem ser apenas o resultado do desejo do fornecimento de machinas, porque a proposta agora foita a Central o a tentativa da Companhia Baldwin, são a repetição do procedimento que tevo essa companhia para com o Japão, onde, descobertas as minas de carvão, foi este á primoira vista julgado improprio para o serviço das locomotivas, tendo sido provado o contrario mais tarde. Foram ontão, onviadas á Baldwin amostras das duas minas «Iwahi » $\theta$ «Iryana», sondo os resultados da analyso os seguintes:

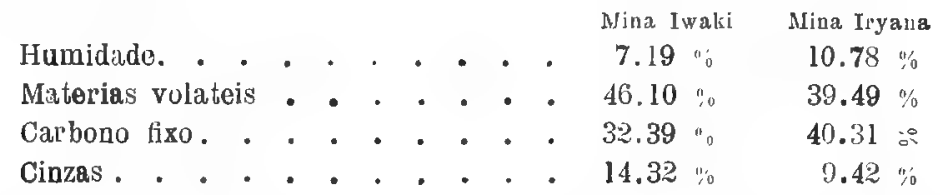

Como se vê, quer um, quel outro, apresenta, compalado com o carvão de Santa Catharina, maior quantidade de humidade e monor quantidado de carvão fixo. $\Lambda$ quantidade de humidade tornou difficil a combustäo; foi o que disse o engenheiro Sr. Baldwin ao Sr. S. M. Vauclain, em sessão de z0 de abril de 1899, do New.York Railway Club nos seguintes termos:

«This coal was very difficult to ignite on account of the moisture but after it had once loeen ignited it burned freely but rapidly.»

A Baldwin construiu locomotivas apropriadas ao emprego desse carvão, com caldeiras do typo Wootten, modificado e com grelhas calculadas, de modo a poder ser queimada quantidade de combustivel sufficiente para a produç̧ão do vapor exigido pelas dimensões dadas aos cylindros.

Foram construidas locomotivas tanto para passageiros como para cargas, destas ultimas tendo sido enviadas para o Japão $\theta$ de uma só vez quarenta $\theta$ quatro machinas, que deram excellentes resultąos.

Tratando-sa do carvão mais ou menos igual ao nosso, temos assim a agradavel certeza de podermos mais cedo ou mais tarde mover as locomotivas das nossas estradas de ferro com combustivel nacional, nāo porém com o que provém da devastação das nossas mattas, cujo desapparecimanto constitue uma calamidado para o nosso paiz, mas com o que provém das camadas subterraneas.

Pela comparação das analyses do carvão de Santa Catbarina $\theta$ do das duas amostras das minas do Japāo, acima indicadas, vê.se que a porcentagem de humidade que naquelle é apenas de 0,30, attinge a 7,19 e a 10,78 na do Jañão; que o primeiro tem menos quantidaite de materias volateis, maior proporção de cinzas, mas que em compensação tem porcentagem maior de carbono firo $-42,58 \%$, quando o carvão da mina Iwaky tem 32,29 e o da mina Iryana 40,31 $\because$

o carvāo nacional é, por conseguinte, muito semelhante ao carvão do Japão, que está sendo empregado com bons resultados no serviço das suas estradas de forro. 
We have here a precise and clear affirmation which merits respect, guaranteoing us the possibility of using our coal in an exigent service, such as a railway. Further, the Santa Catharina sample was extracted from the upper beds and it may be hoped that the quality will improve as the deeper beds are reached.

Nor is this affrmation one of those which are sometimes lightly made and which in some cases might be occasioned merely by a desire to supply machinery, because the proposal now made by the Baldwin Company to the Central is but a repetition of that Company's proccedure in Japan, where coal had been discovered that was at first considered unfit for use in locomotives, the contrary afterwards proving to be the case however. Samples were sent to Messrs. Baldwin from two mines, the "Iwaki" and "Iryana ", the results of the analyses being as follows:

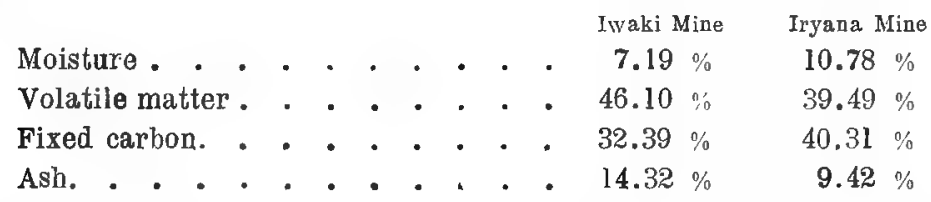

As will be noticed, either of these compared with the Santa Catharina coal shows a greater quantity of moisture and less flxed carbon. The percentage of moisture made combustion difficult, as was stated by Mr. Bald win to Mr. S. M. Vauclain at a meeting of the New York Railway Club on 20th april, 1899, his words being:

"This coal was very difficult to ignite on account of the moisture, but after it had once been ignited it burned freely but rapidly.»

The Baldwin constructed locomotives suitable for the employment of this coal, with boilers of a modified Wootten type having special bars capable of burning a sufficient quantity of fuol for the production of the steam required by the dimensions given to the cylinders.

Locomotives were built both for passengers and goods, forty-four engines of the latter type being sent to Japan in one lot, where they have given excellent results.

The coal used being about equal to ours, we have thus the agreeable certainty of being able sooner or later to work the locomotives on our railways with national fuel, and that not a fuel necessitating the destruction of our forests, which constitutes a calamity for the country, but one derived from subterranean sources.

In comparing the analyses of the Santa Catharina coal with those of the two samples from the Japanese mines above mentioned, it is seen that the percentage of moisture which in the former amounts to only 0.30 , reaches 7.19 and 10.78 in the Japanese; that the first has a smaller quantity of volatile matter with a larger proportion of ash but in compensation contains more fixed carbon, viz: $42.58 \%$, the coal from the lwaki mine having $32.29 \%$ and that from the Iryana mine $40.31 \%$.

The native coal is consequently very similar to the Japanese coal now being employed with good results in the service of their railways.» 


\section{APPENDICE II}

\section{Especificações para as installações para purificação e briquet. tagem do carvão}

As especificações detalhadas das installações combinadas para a purificaçãr e ]riquettagem de carvão, especialmente destinadas a servir para c carrão brasileiro, projectadas pela Humboldt Engineering Worlis de Kalk, Allemanha, baseadas cm experiencias praticas com uma carga de carvão de Santa Catharina e Rí; Grande do Sul, seguem se:

Kalk perto de Cologne, 25 de novembro de 1905.

Dr. I. C. White, chefe da Commissão de Estudos das Minas de Carvão de Pedra do Brazil, Rio de Janeiro.

\section{Caro Senhor}

Reportando-me á sua visita e aos ensaios feitos para T. S. em nossa fabrica, temos o prazer do remetter-lhe junto o plano, especificações e proposta descriptiva de uma installação para quebrar e lavrar por llora 30 toneladas de (arvin) e installação para lrịuettar 10 toneladas do mesmo por hora.

Fixamos este rendimento da lavagem ( 300 toneladas por dia de 10 horas), porque uma installação menor (para 100 ou 200 toneladas, por exemplo ) não seria ensivelmente mais barata, não sendo portanto razoavel.

Não é razoavel, tambem, construir a usina com disposições calculadas para ser posteriormente augmentada, visto como certos apparelhos teriim de ser feibu muito griundes proporcionalmente e ás construcçõe mesmo, deveriam ser muito grandes.

Julgamos melhor em tal caso, fazer as construcçōes e installações em duplicata, yuando se dispon ha de terreno illimitado, o que tambem serve para dividir o prejuizo em casin de desabamentr. Neste sentido é tambem facil su resolvel tudo de modo a serem attendidos os pedidos.

Quanto i montagem di usina lemos a adveltip que o salario, etc., dos profissionaes (que della se encarregarem, lem como a mão de obra não se acham incluidas na nossa proposta. Podemos mandar um mon- 


\section{APPENDIX II}

\section{Speciflcations for a coal puriflcation and briqueting plant}

The detalled specifications for a combined coal purification and briquetting plant especially designed to deal with Brazilian coal, as planned by the Irumboldt Lingineering Works of Kalk, Germany, based upon practical experiments with a carload of the coal from both Santa Catharina and Rio Grande do Sul, are as follows:

Kalk, near Cologne, 25th november, 1905.

I. C. White, Lsquire, Chief of the Brazilian Coal Commission, Rio de Janeiro.

\section{Dear Sir}

With reference to your visit here and the tests carried out for you at our Works, we have pleasure in handing you herewith plan, specificalion, tender and description of coal crushing and washing plan of 30 tons. per hour capacity and briquetting plant for same of 10 tons. per hour capacity.

We have taken this output of the washery (300 tons. per day of 10 hours) because a smaller plan (for say 100 or 200 tons) would not be appreciably cheaper and would therefore le irrational.

It were also irrational when building the plant, to immediately reckon with an extensinn of same later on, as certain apparatus would then have to lje made tos large in proportion and the building itself made very large.

We consider it better in cases such as this, where one has unlimited space at one's disposal to later on duplicate the plant, this at the same time halving the risk of breakdown. In this way it is also easy to regulate matters to suit the supply and demand.

As regards erection of the plant, we may say that the wages, etc., of the erectors and labour hands are not included in our tender. To set the plant going we would he prepared to place at your disposal one of 
tador especial para pôr a installação em andamento, percebendo 18 schillings por dia para seus serviços. Casa, alimentação e passagem de ida e volta serão pagas por V. S.

Não estabelecemos as condições dos serviços de um engenheiro, mas si desejar voltaremos a tratar deste assumpto.

Mandamos orçamento não só das machinas e motores, como tambem da estructura de ferro.

Todas as construcçũes serão feitas por V. S. e á vossa custa de accordo com os nossos projectos. Năo poderiamos emprehender este trabalho visto que a mão de obra, material e as condições locaes nos são desconhecidos.

As correias e parte das madeiras de construcção não incluimos, porque podem ser obtidas mais facilmente e mais barato no logar do que se fossem feitas aqui e tivessem de ser sobrecarregadas com altos fretes.

Esperamos que nossa proposta merecerá vossa completa approvação e que, portanto, collocareis a encommenda em nossas mãos.

Aguardando vossas ordens e sempre promptos a satisfazer qualquer pedido de informações de que careçaes

Somos caro Senhor,

Vossos Atts. Adrs.

(Assig.) Maschinenbau Humboldt.

Especificações e proposta de uma installação para quebrar, lavar e briquettar carvão para a Commissão de Estudos das Minas de Carvão de Pedra do Brasil

A) - Machinas para a installação de quebrar e lavar carvão. Capacidade 30 toneladas por hora

1. Um apparelho rotatorio para descarga de vagonetes, movido mechanicamente, consistindo em armação, roldana de aço, engrenagem ajustavel com alavanca a mão, parafuso com porcas, supportes, placa de guarda e parafusos para as fundações.

2. Uma peneira excentrica com furos de 50 millimetros de diametro e fundo tapado, consistindo em caixa de ferro com placas perfuradas, armação de suspensão, eixos com excentricos e mancaes com annel de lubrificação, polias falsas e polias fixas e parafusos para a montagem.

3. Uma calha de folha de ferro entre a peneira e o britador e uma outra entre a primeira e a segunda peneira, todas providas de parafusos para prendel-as. 
our special erectors charging 18 shillings per day for his services. Board and lodging and free passage there and back to be provided by you.

We have refrained from quotting for the services of an engineer, but if desired will revert to the matter.

Besides the machinery and the steam engines we have also quoted for the constructional ironwork.

All building work would be carried out by you in accordance with our plans and at your expense. We cannot undertake this work as the sources of labour and material, as well as local conditions are unkown to us.

The belting and woodwork are not included because these parts can be more easily and cheaply obtained on the spot than if they were made here and had to bear the heavy freight costs.

We trust that our design will meet with your complete approval and that you will be thereby induced to place the order with us.

Awaiting your further favours, and always ready to supply you with any further information you may require.

We are, dear Sir',

$$
\text { Yours faithfully, }
$$

(Signed) Maschinenbau-Anstalt Humboldt.

Specification and tender for coal crushing, washing and briquetting plant, Rio de Janeiro

(A) Machinery for crushing and washing plant, capacity 30 tons. per hour.

1. One mechanically driven rotary tippler consisting of the frame $\mathrm{C}$, steel rollels, adjusting gear with hand lever, boltss supports, guard plates and fixing bolts.

2. One excentric screen, with $50 \mathrm{~mm}$. dia. hols and plain bottom consisting of the iron Jox, with perforated plates and suspension gear, shafts with excentrics, ling lubricated bearings, frywheel, pulleys, and holding down bolts.

3. One sheet iron shoot between the screen and the jaw breaker and another one between the first and second screen, with all fastening scrers. 
4. Um britador para carvão com $500 \times 350$ millimetros de bocca completo com polias, parafusos e placas para as fundações.

5. Uma calha de ferro entre o britador e a segunda peneira, com parafusos.

6. Uma peneira, excentrica com furos de 6 millimetros de diametro como a (2), porém sem ter o fundo tapado.

7. Uma calha de chapa de ferro dupla com parafusos entre a segunda peneira e o moinho de moega.

8. Dous moinhos de moega, cada um de 1000 millimetros de diametro completos com polias e parafusos para as fundações.

9. Um obturador regulador em face do elevador de caçambas da lavagem, movido mechanicamente, completo com guias, roldanas, cadeias, eixo, mancaes, blocos de tensão, alavanca a mão e todos os parafusos para a montagem.

10. Um elevador com caçambas de 350 millimetros de largura e cerca de 27 metros de comprimento, entre os tambores, cadeia de elos de aço forjado, parafusos, eixos com tambores para as correntes, mancaes de lulurificação, apparelho de tensão, roda dentada, rodas dentadas de inversão, polias e parafusos.

11. Armação de ferro para o elevador com trilhos de guia, ferros de fricção, supportes e as folhas de ferro completas para guarnecer a armação com todos os parafusos para a montagem.

12. Uma tremonha de folha de ferro entre o elevador e o parafuso de distribuição com os parafusos para montagem.

13. Um parafuso para transporte e distribuição com 450 millimetros de diametro por corca de 9.000 millimetros de comprimento com caixa estanque, passagem, mancaes, roda dentada, polia e os parafusos para montogem.

14. Doze peneiras de percussão, systema Humboldt Vinman, com malhas de cerca de um millimetro, completas com armação de madeira e molas, mechanismo para o movimento destas, polias e parafusos para as fundações.

15. Calhas de ferro para o excesso das peneiras de percussão para os lavadores, com os parafusos para a montagem.

16. Um jogo de caixas para lavagem incluindo quatro compartimen tos com uma peneira de 4.800 millimetros de largura, consistindo em caixas W. I. com jogo de peneiras, hastes para os mergulhadores e mergulhadores excentricos ajustaveis, eixos, mancaes, aros livres, polias, tamlem descarregadores com alavancas ajustaveis e todos os parafusos para montagem. 
4. One coal breaker with $500 \times 320 \mathrm{~mm}$. jaw opening, complete with driving pulleys and foundation bolts and plates.

5. One sheet iron shoot between the jaw breaker and the second screen, with bolts.

6. One excentric screen with $6 \mathrm{~mm}$. dia. holes, same as item 2, but without plain jottnm below.

7. One double sheet iron shoot from the second screen to the bell mills, with bolts.

8. Two bell mills, each of $1000 \mathrm{~mm}$. dia., complete with driving pulleys and foundation bolts.

9. One regular shutter in front of the feed bucket elevalor of the washery, mechanically drivon, complete with guides, rollers, chain, shaft, bearings, tension-block, hand lever and all fastening screws.

10. One feed bucket elcvator, $350 \mathrm{~mm}$. wide, and about 27 meters long between chain drums, chain of forged steel links, bolts, shafts with chain drums, ring lubricated bearings, tension arrangements, spurwheel countergear and driving pulleys and bolts.

11. The iron frame wolk for the ahove elevator, with guide rails and wearing irons, supports and the complete sheet iron casing with all connecting and fixing bolts.

12. One sheet iron hopper between elevator and distributing screw, with fixing bolts.

13. One distributing screw conveyor, $450 \mathrm{~mm}$. dia. $X$ abt. $9000 \mathrm{~mm}$. long, with water tight trough, outlets, bearingৎ, spurgear, driving pulley and fastening screws.

14. Twelve percussion screens, Humbollt-Wissmann system, with about $1 \mathrm{~mm}$. meshes, complete with wooden frame and springs, driving mechanism, driving pulleys and holding down bolts.

15. The iron launders for the over size of the percussion screens, to the washers, with fastening screws.

16. One set of washing boxes, including four compartments, with a total screen width of $4800 \mathrm{~mm}$., consisting of the W I. boxes with set screens, plunger rods and plungers, adjustable excentrie's, shafts, learings, loose collars, and driving pullers, also dischargers, with adjusting levers and all fixing bolts. 
17. As calhas de ferro dos lavadores para os tanques de dragagem, com parafusos.

18. Um elevador com caçambas para drenar, com 450 millimetros de largura e cerca de 20000 millimetros de comprimento en tre os eixos dos tambores das correntes, com caçambas perfuradas, ou por outra como se especificou no n. 10.

19. A armação de ferro para este elevador como no n. 11.

20. Uma tremonha de folha de ferro entre o elevador e o transportador de raspadeiras com os parafusos.

21. Um transportador e distribuidor de raspadeiras com 400 millimetros de largura por cerca de 11 metros de comprimento com cadeia de elos de aço forjado, parafusos de aço, eixos e tambores, mancaes com annel de lubrificação, apparelhos de tensão, rodas dentadas, engrenagem de inversão, polia e tambem todos os parafusos de montagem.

22. A armação para o transportador acima com trilhos de guia e ferros de fricção supportes, revestimento de folha de ferrocom portas, guias e parafusos para a montagem.

23. Quatro mesas de raspagem com 1250 millimetros de diametro com apparelho telescopico de alimentaçãı, raspadeiras ajustaveis, rodas de engrenazem em angulo com mancaes, polias e todos os parafusos.

24. Um transportador de parafuso de 450 millimetros de diametro por cerca de 16500 millimetros de comprimento como no $\mathrm{n}$. 13 com calha de folha de ferro para o desintegrador.

25. Os tubos C. I para a parte inferior da bateria de lavagem conduzindo á calha de alimentação do elevador de carvão médio com gacheta e parafusos de flange.

26. Um elevador com caçambas para carvão médio com 450 millimetros de largo por cerca de 13 metros de comprimento como no $\mathrm{n} .10$.

27. A armação de ferro para este elevador com calha de alimentação estanque e chapas para revestimento.

28. Uma tremonha de folha de ferro e a calha de ferro de connexão com os lavadores de feldspatho, e os parafusos para montagem.

29. Quatro lavadores de feldspatho, cada um com tres compartimentos e tanques, construidos como os do n. 16 com o feldspatho necessario.

30. As calhas de ferro com os parafusos pal'a montagem, que conduzem o carvão dos lavadores de feldspatho para o tanque de dragagem. 
17. The iron launders from the washers to the dredging pit, with screws.

18. One draining bucket elevator, $450 \mathrm{~mm}$. wide $X$ about $20000 \mathrm{~mm}$. long between chain drum shafts, with perforated buckets, otherwise as especified under item 10.

19. The iron frame work for the above elevator, as item 11.

20. One sheet iron hopper between the elevator and the scraper conveyor, with bolts.

21. One distributing scraper conveyor $400 \mathrm{~mm}$. wide $X$ about 11 meters long, with chain of forged steel links, steel bolts, shafts and drums, ring-lubricated bearings, tension arrangements, spurwheel counter gear' and driving pulley, also all fixing bolts.

22. The iron frame work for the above conveyor, with guide rails and wearing irons, supports, sheet iron casing with shutters and guides and fastening screws.

23. Foul scraping tables each $1250 \mathrm{~mm}$. dia., with teleskopic feed arrangement, adjustable scrapers, beveled driving gear, with bearings and pulleys and all bolts.

24. One screw conveyor, $450 \mathrm{~mm}$. dia. $\times$ about $16,500 \mathrm{~mm}$. long, similar to that item 13, with sheet iron shoot to the disintegrator.

25. The C. I. pipes for the lower portion of the washing battery leading to the feed trough of the middle coal elevator, with packings and flange bolts.

26. One bucket elevator for middle coal, $450 \mathrm{~mm}$. wide $X$ about 13 meters long, similar to that item 10 .

27. The iron frame work for the above elevator, with the water tight feed trough and casing.

28. One sheet iron hopper and the iron connecting launder to the felspar washers with fastening bolts.

29. Four felspar washers, each with three compartments, C. I. hutches, in construction similar to those item 16, with the necessary felspar.

30. The iron launders with fixing bolts leading from the felspar washers to the dredging pit. 5569 
31. Um elevador com caçambas para dragagem com 600 millimetros de largura e cerca de 18 metros de comprimento, com caçambas perfuradas, como no n. 10.

32. A armação de ferro para este elevador.

33. Uma tremonha de folha de ferro entre o elevador e o transportador de raspadeiras com os parafusos.

34. Um elevador de poeira de carvão com 200 millimetros de largura e cerca de 12 metros de comprimento como no n. 10 .

35. A armação de ferro para este elevador .

36. Uma tremonha de folha de ferro, como no n. 33 .

37. Um transportador de raspadeiras com 400 millimetros de largura e cerca de 10 metros de comprimento, entre eixos, construido como o do n. 21.

38. A armação de ferro para este transportador.

39. Seis obturadores perfurados na parte inferior das torres de carvão fino, com guias, engrenagem, roda de cadeia, alavanca a mão e calha para a agua que gotteja.

40. As calhas de ferro do primeiro compartimento dos lavadores a feldspatho para as peneiras de pyrites com os parafusos para a montagem.

41. Duas peneiras fixas consistindo em caixas com tela de arame e todos os parafusos para a montagem.

42. Dois obturadores como os do n. 39 .

43. Os tubos C. I. da parte inferior dos lavadores de feldspatho, as calhas de alimentação do elevador com caçambas, dos residuos, com gachetas e parafusos de flange.

44. Um elevador com caçambas para residuos com 200 millimetros e cerca de 14 metros de comprimento, com caçambas perfuradas e como foi especificado acima.

45. A armação de ferro para este elevador com calha de alimentação estanque e chapas de revestimento.

46. Uma tremonha de chapa de ferro entre o elevador e o tanque de residuos com parafusos.

47. Uma calha de chapas de ferro com comporta, guias, alavancas a mão e todos os parafusos para a montagem, para conduzir os residuos para os tubos.

48. As calhas de ferro para conduzir a agua que gotteja das mezas de raspagem para o tanque de dragagem, com os parafusos para a montagem. 
31. One draining bucket elevator, $600 \mathrm{~mm}$. wide $X$ about 18 meters long, with perforated buckets, similar to that item 10.

32. The iron frame work for the above elevator.

33. One sheet iron hopper between theeIevator and the scraper conveyor with bolts.

34. One dust-coal bucket elevator, $200 \mathrm{~mm}$. wide $X$ about 12 meters long, similar to 10 .

35. The iron frame work for the above.

36. One sheet iron hopper, as item 33 .

37. One distributing scraper conveyor, $400 \mathrm{~mm}$. wide $\$ about 10 meters long between axles, in construction similar to that item 21.

38. The iron frame for the above conveyor.

39. Six perforated cut off shutters underneath the fine coal towers, with guides, racks, chain wheel and hand lever, drip mould for letting off the dropping water.

40. The iron launders from the first compartments of the felspar washers to the pyrites draining screens, with fixing bolts.

41. Two fixed draining screens, consisting of the boxes, with wire mesh screens and all fastening screws.

42. Two cut off shutters similar to those item 39.

43. The C. I. pipes for the lower portion of the felspar washers to the feed trough of the dirt bucket elevator, with packings and flange bolts.

44. One dirt bucket elevator, $200 \mathrm{~mm}$. wide $\times$ about 14 meters length, with perforated buckets, as specified before.

45. The iron frame work for the above elevator, with water tigh, feed trough and casing.

46. One sheet iron hopper between the elevator and the dirt bunker, with bolts.

47. One sheet iron chute with shutter, guides and hand lever, all fastening screws, for drawing of the dirt into tubs.

48. The iron launders for the drip water of the scraping tables, to the dredging pit, with fastening bolts. 
49. Uma bomba centrifuga para agua doce com 250 millimetros de diametro completa, com mancaes, annel de lubrificação, polias, placas e parafusos para as fundações.

50. Tubos completos para a aspiração e descarga da Jomba acima, feitos de ferro fundido incluindo todas as gachetas e parafusos de flange.

51. Os eixos e polias para transmissão para os apparelhos acima, incluindo todos os mancaes, juntas e arruellas, cunhas, chavetas, parafusos, engrenagens de desligamento e um jogo completo de chaves de porca.

Peso total approximado, das machinas $A \quad 179$ 1/2 toneladas

Preço total das machinas $A$. . . $£ 5.280$

(B) - Machinas para installação de briquettagem. Capacidade

10 toneladas por hora, de briquettes de 3 kilos cada uma

1. Uma grade C. I. de separação com 1250 X 1250 millimetros com armação de ferro em angulo e furos rectangulares de $\mathbf{4 0}$ millimetros.

2. Um elevador com caçambas com 100 millimetros de largura e cerca de 10000 de comprimento entre os tambores das cadeias, completo, com os eixos, tambores, mancaes, apparelhos de tensão, calha de alimentação, engrenagem, calha de folha de ferro para revestimento.

3. Um desintegrador $\mathrm{n}$. 2 com disco de 640 millimetros de diametro, completo, com polia e parafusos para as fundações.

4. Uma meza rotatoria de raspagem com 800 millimetros de diametro com engrenagem em angulo, apparelho de raspagem, mancaes e parafusos para a montagem.

5. Um recipiente de folha de ferro para o breu moido, embaixo do desintegrador, com engrenagem de ajustamento.

6. Um desintegrador misturador n. 4, completo com polias e parafusos para as fundações.

7. Um elevador de caçambas, para alimentação, com 250 millimetros de largura e cerca de 1500 millimetros de comprimento entre os tambores das cadeias com eixos, tambores, mancaes, apparelhos (le tensão, rodas dentadas, de inversão, e parafusos de sustentação.

8. Uma armação W. I. com trilhos de guia chapa de ferro para o revestimento inferior e calha de descarga para 'o elevador. 
49. One fresh water centrifugal pump $250 \mathrm{~mm}$. pipe diam., complete with ring lubricated bearings, pulley, bed plate and foundation bolts.

50. The complete suction and delivery piping for the abave pump, made of cast iron, including all packings, joints and flange bolts.

51. The necessary driving shafting and pulleys tol the above apparatus, including all bearings, couplings, loose collars, wedges, keys, fastening scrervs, disengaging gear and a complete set of spanners for bolts.

Approximate total weight of the machinery A 179 1/2 tons.

Total price of the machinery A . . . . $£ 5,280$.

B. Machinery for briquetting plant. Capacity, 10 tons, $3 \mathrm{~kg}$. briquettes per hour

1. One G. I. grizzly $1250 \times 1250 \mathrm{~mm}$. size, with angle iron frame and $40 \mathrm{~mm}$. square holes.

2. One bucket elevator $100 \mathrm{~mm}$. wide $X$ about $10000 \mathrm{~mm}$. long between chain drums, complete with shafts, drums, bearings, tension arrangement, feed trough, driving gear, sheet iron casing and shoot.

3. One n. 2 disintegrator, $640 \mathrm{wm}$. dia. of disc, complete with driving pulley and foundation bolts.

4. One rotary scraping table $800 \mathrm{~mm}$. dia., with heveled driving gear, scraping arrangement, bearings and fastening screrrs.

5. One sheet iron receptacle for ground pitch underneath the disintegrator, with adjusting gear.

6. One mixing disintegrator N. 4, complete with driving pulleys and foundation bolts.

7. One feed hucket elevator $250 \mathrm{~mm}$. wide $X$ about $15,000 \mathrm{~mm}$. Iong between chain drums, with shafts, drums, bearings, tension arrangement, spur wheel, counter gear and holding down bolts.

8. One W. I. frame work, with guide rails and lower sheet iron casing and outlet shoot for the above elevator. 
9. Os accesorios mechanicos para um forno com meza rotativa 6500 millimetros de diametro, com eixos, mancaes, rodas dentadas, polias todos os accessorios para os apparelhos de mecher e raspar, bem como os da fornalha e grelhas, mas sem a construcção de tijolos e sem a chaminé.

10. Dois transportadores de parafuso, com 350 millimetros de diametro eserca de 3000 millimetros de comprimento com engrenagem conica para o movimento.

11. Duas prensas para briquettar, typo n. 2, systema Couffinhal para para briquettes de $3 \mathrm{kilos}$, com capacidade de cerca de 5 a 6 toneladas por hora, completa com amassador, engrenagem de movimento e placas e parafusus para as fundações.

12. Duas calhas de chapas de ferro para as briquettes.

13. Uma correia para transportar as briquettes com 500 millimetros de largura e cerca de 12000 millimetros de comprimento entre os cylindros, com apparelho de tensão, eixos, mancaes, roldanas e os parafusos para a montagem.

14. Uma armação IV. I. para a mesma.

15. Uma calha para carregamento com balança, pesos e guia.

16. Os eixos necessarios e polias para as transmissões da installação de briquettagem com todos os mancaes, com annel lubrificador, juntas, chavetas e parafusos, mas sem correiame.

17. Os tubos necessarios hara vapor, a prensa e o forno, incluindo valvulas torneiras para agua, valvulas de vapor, juntas e gachetas.

Peso total approximado das machinas B. $\quad 801 / 2$ toneladas Preço total approximado das machinas B. $£ 2,460$

\section{C-Apparelhos motores}

1. Um motor horizontal de um cylindro, sem condensador, valvula de corrediça com as seguintes dimensões principaes (para a installação de britamento e lavagem):

Diametro do cylindro. . . . 400 millimetros.

Curso do embolo. . . . . 800 millimetros.

Rotações por minuto . . . 105

O motor é calculado para 8 athmospheras (120 libras) e para $115 \mathrm{G}$.V. com valvula de reducção de cerca de $20 \%$ do vapor, pelo que o effeito mechanico é de $85 \%$ e o consumo de vapor saturado 
9. The mechanic fittings for a warming oven $6500 \mathrm{~mm}$. table dia., consisting of the rotary table, with shafts, Jearings, spur wheel gear, driving pulley, all necessary stirring and scraping arranments, furnace fitings and grates, without brick work and chimney.

10. Two screw-conveyors $350 \mathrm{~mm}$. dia $X$ about $3000 \mathrm{~mm}$. long, with conical driving gear.

11. Two briquette presses, pattern n. 2, Couffinhal system, for making $3 \mathrm{~kg}$. briquettes with a capacity of about 5-6 tons. per hour complete with pug mill, driving gear, foundation bolts aud plates.

12. Two sheet iron shoots for the briquettes.

13. One conveying belt for the briquettes $500 \mathrm{~mm}$. wide $X$ about $12000, \mathrm{~mm}$. long between belt drums, with tension arrangement, shafts, bearings rollers and fixing bolts.

14. One W. I. frame work for the above.

15. One loading shoot with balance, weights and guides.

16. The necessary shafting and pulleys for driving the briquette, making installation, with all ring lubricated bearings, couplings, keys, fastening screws, but without the driving belts.

17. The necessary steam piping for the presses of the oven, including all valves, water shutters, steam traps, joints, and packings.

Approximate total weight of the machinel'y B . $801 / 2$ tons.

Total price of the machinery B . . . . $£ 2,460$

\section{$C-$ Driving Engines}

1. One horizontal single cylinder, non-condensing, slidevalve steam engine of the following principal dimensions (for crushing and washing plant):

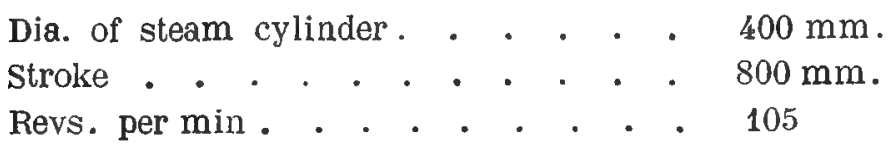

The engine is designed for $8 \mathrm{Atm}$. (120 lbs.), and for a capacity of $115 \mathrm{H}$. P. act., at about $20 \%$ cut-off, whereby the mechanic efficiency is $85 \%$ and the consumption o dry saturated- 
secco é de $11,3 \mathrm{~kg}$. por C. V. indicados por hora, depois da deducção da agua de condensação nos tubos de supprimento de vapor. E' $\mathrm{E}^{\prime}$ possivel obter um augmento de força de $164 \mathrm{CV}$. com o vapor levado a $33 \%$ e um gasto deste de $11.9 \mathrm{k}$. nas condições acima indicadas. O motor será fornecido completo incluindo valvulas de parada, valvulas de segurança, accessorios para esgotamento, lubrificação e para aparar o azeite, trilhos, almotolias, polias, volante com 3750 millimetros de diametro por 550 de face, mancaes, indicador, manometros, tubos de juncrão, regulador movido com correia, gachetas, os flanges e cylindro, todas as placas e parafusos para as fundações e um jogo completo de chaves de porca.

2. Um motor como este para mover a installação de briquettagem, porém com o cylindro de 350 millimetros de diametro, 750 millimetros de curso do embolo e 103 rotações\} por minuto. Capacidade $75 \mathrm{CV}$ com reducção do vapor a $20 \%$ pelo que o effeito mechanico é de $86 \%$ e o consumo de vapor secco saturado_de $11.6 \mathrm{~K}$. por $\mathrm{CV}$, hora indicado depois de deduzicla a agua condensada. Pode-se augmentar a força a $106 \mathrm{CV}$, com a reducção do vapor a $33 \%$ e o consumo de vapor de $12.3 \mathrm{k}$. nas condições acima indicadas. 0 motor será remettido completo com polias de transmissão, volante com 3300 millimetros de diametro e 450 millimetros de largura e o mais como acima ficou especificado.

Peso approximado destas machinas . . 25 toneladas

Preço . . . . . . . . . . . $£ 925$

\section{$D-$ Estructura de ferro}

1. A necessaria estructura de ferro para a usina de lavagem e briquettagem, consistindo em columnas com as respectivas fundações, os barrotes para os soalhos, juntas para as passagens, servindo para taboado, a plataforma para o riıador, na secção das peneiras com chapas de 10 millimetros de grossura e os passadiços da usina de briquettagem com chapas quadriculadas, o soalho do pavimento ter'reo da usina de briquettagem para ser cheio com concreto. Todas as vigas de sustentação para eixos e apparelhos. As vigas do fundo do deposito de arqueação, a armação de ferro para o deposito debaixa das peneiras de percussão, para as caixas de madeira. A armação do telhado para cobertura de folha de ferro cannelado, tambern todas as escadas 
steam 11.3 kilograms per ind. H. P. hour, after deduction of the condensing water in the steam supply piping. An increased capacity of $164 \mathrm{H}$. P. actual is attained at about $33 \%$ cutoff and a steam consumption of $11.9 \mathrm{~kg}$. under the above conditions. The engine will be supplied complete, including stop-valve, safety valves, all draining, lubricating and oil catching arrangements, also guard railing and oil moulds, belt driving fly-wheel, $3,750 \mathrm{~mm}$. dia. per $550 \mathrm{~mm}$. face, barring gear, external bearing, indicator paps, manometer (steam gauge) connecting piping, belt-driven governor, flange and plates and stuffing box packings, all foundation bolts and a complete set of screw spanners.

2. One engine like above, for driving the briquette maling installation, luut of $350 \mathrm{~mm}$. steam cycl. diam. and $700 \mathrm{~mm}$. stroke, 103 revs. per minute. Capacity $75 \mathrm{H}$. P. actual at $20 \%$ cutoff, whereby the mechanic efficiency is $85 \%$ and the consumption of dry saturated steam $11.6 \mathrm{~kg}$. per ind. H. P. hour after deduction of the condensed water. Increased capacity : $106 \mathrm{H}$. P. is attained at $33 \%$ cut-off wilh a steam consumption of $12.3 \mathrm{~kg}$. under the given conditions. The engine will bo supplied complete, with a belt-driving fly-wheel of $3300 \mathrm{~mm}$. diam. and $450 \mathrm{~mm}$. widtl, and otherwise as specified above.

Approximate total weight of ajove engines. 25 tons. Price . . . . . . . . . £ 925

\section{D-Constructional Iron Work}

1. The necessary construclional iron work for the coil washery and briquette plant consisting of the columns with their foundations, the floor girders and the joists of the runways suitable for planking, the tippler platform in the screening plant with $10 \mathrm{~mm}$. thick plates and the gangways in the briquette plant with chequered plates, the lower stage of the briquette plant for concrete filling, all supporting beams for the apparatus and sliafting, the bottom girders of the bunker for arching, the iron slieleton work for the bunliers below the percussion screens for woodon casing, the roof constructin for corrugated iron cover, also all staircases and guard railing. Approximate total weight of the iron work 225 tons (5\% allowance). 5569 
e corrimões. Peso approximado da estructura de ferro $\mathbf{2 2 5}$ toneladas $(5 \%$ de reducrão). Preço por timelada de $1000 \mathrm{k}$. $£ 10.10 .0$ pertazendo um total de cerca de 22362.10 .0 .

2. Celca de 13 ro metrui quadrados de chapas de ferro cannellado para colserturain £20.0.0 pol' 1000 kilos.

3. Cerca de 170 metros correntes de calhas a $£ 0.4,6$ por metro corrente.

4. Cerca de 135 metros correntes de tubos conductores a $£ 0.4 .6$ por metro colrente.

5. Cerca de 240 metros currentes de placas de cobertura e de cumieira a 20.2 .6 ] motr" (urente.

Prero total apploximarlo ris ns. 2 a $5 £$ 418.10.0.

\section{Resumo}

A. Nachinas para as usinas de Juitamento e lavagem cerca de $1791 / 2$ toneladas. . . $\quad \& 5.280 .00 .0$

$B$. Machinas para usina de bricuettagem $80 \quad 1,2$ toneladas . . . . . . $£ 2.460 .000$

C. Mrotores -25 toneladas. $\quad \ldots \quad £ \quad 925.00 .0$

D. Listructura de ferro 22,5 trneladas . . . . . . $\quad £ 2.362 .10 .0$ Matcrial pará colverturas. • $£ \quad$ \&18.10.0 Total cerca de. . . £ $\overline{11.41400 .0}$

Condiçòes

Todos os preços mencionados incluem o acondicionamento para a exportação e entrega a hordo, em Antuerpia.

O prasi para a entregra será dado por combinação especial.

os termos de pagamento snrão de accordo com as nossas condiries geraes para o commercio de exportação.

\section{Encarregado de montagem}

Um perito encarregadi de superintender a montagem das usinas ganha 19 rhillings por dia, emyuanto em viagem e em trabalho, e mais ar despezas de viagem, casa e comida. 
Price per ton of $1000 \mathrm{kig} . £ 10.10 .0$. Making in all about $£ 2362.10 .0$.

2. About 1340 square meters corrugated iron for the roofs at $£ 20.0 .0$ per $1000 \mathrm{~kg}$.

3. About 170 runving meters suspended gutters at $£ 0.4 .6$ per run. mt.

4. Alout 13 a running meters down pipes at $£ 0.4 .6$ per run. mt.

5. About 240 running metels covering and ridge plates $£ 0.2 .6$ per run. mt.

Approximate total price of items $2-5 £ 418.10 .0$.

\section{Summary}

A. Maclinery for crushing and washing plant; about 179 $1 / 2$ tons . . . . . $\quad £ 5.280 .0 .0$

$B$. Machinery for briquette making plant; about $801 / 2$ tons . . . . . . $£ 2.460 .0 .0$

$C$. Driving engines: about 25 tons . . . . . . $\quad \& 925.0 .0$

D. Constructional iron work; about 225 tons . . . . $\quad £ 2.362 .10 .0$

Material for the roofs; about. . \& 118.10 .0 Total; about . . . $\overline{£ 11.446 .0 .0}$

Torms

All prices given obove include export packing and delivery $f$. o. b. Antwerp.

Time of delivery by special arrangement.

Terms of payment, etc., according to our general conditions for export trade.

\section{Erector}

Our charges for one skilled erector to supervise the erection of the obove plant are $19 /$ per day for travelling and working time, and in addition all travelling expenses, board and lodging. 


\section{Garantia}

Garantimos o plano e construcção da installação por um periodo de 12 mezes, a contar do dia de inicio do trabalho, de modo que substituiremos livre de pagamento qualquer peça, ou peças que estiverem defeituosas quer quanto ao material, quer quanto a mão de obra no dito periodo, a não ser que se tenham gasto ou quebrado naturalmente. Não nos responsabilizamos por quaesquer damnos.

(Assignatura) Mascginenbau Anstalt Humboldt.

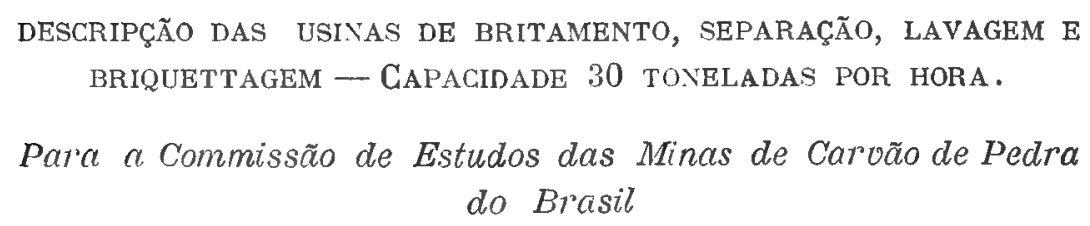

De accordo com os ensaius que fizemos, súmente cerca de $33 \%$ do carvão tratado, isto é, 10 toneladas por hora do carvão n. 1 podem ser aproveitadas, por ser o unico que se presta á briquettagem.

Com o carvão n. II um rendimento de cerca de $42 \%$ oụ 12.6 toneladas por hora podem ser obtidos.

Como a poeira aluaixo de 1 millimetro não pide ser mais enriquecida pela lavagem, dispuzemos os apparelhos de forma que poderá ser passada a secco pelas nossas peneiras patente de percussão e misturada com o carvão n. II.

Deste modo a agua de lavagem não fica suja tão rapidamente, todo o processo de lavagem è simplificado e o deposito de lodo muito pequeno.

O carvão é muito entremeiado de impurezas, sendo portanto necessario quebral-o abaixo de seis miliimetros, de modo que a laragem seja efficaz.

Suppomos que o carvão bruto é transportado em ragonete de mina directamente do poço a um altura de cerca de oito mil millimetros acima do nivel dos trilhos.

\section{Usina de britamento}

O carvão bruto é descarregado pelo virador (1) na peneira excentrica vibratoria de furos de 50 millimetros (2), os pedaços maiores de 50 millimetros passam directamente para o britador (3) para o britamento preliminar. 


\section{Guarantee}

We guarantee the design and construction of the plant quoted for a period of twelve months from the date of starting work, in so far that we undertalie to replace free of charge any part or parts proved defective in design material or workmanship during the said period, ordinary wear and tear excepted. We will not be responsible for any liquidated or other damages whatever.

\section{( Signed ) Machinenbau-Anstalt Humboldt.}

DESCRIPTIONS OF COAL CRUSHING, SCREENING, WASHING AND BRIQUETTING PLANT - CAPACITY, 30 TONS PER HOUR.

For the Brazilian Coal Commission, Rio de Janeiro

According to the tests we have made only $33 \%$ of the coal treated, i. e., 10 tons per hour of the $n$. I quality coal which is the one suitable for briquetting purposes, can be taken.

In the case of Coal $n$. II, a yield of about $42 \%$ or 12.6 tons per hour is obtained.

As the dust under $1 \mathrm{~mm}$. cannot be further enriched by was. hing, we have arranged for it to be drawn off in dry condition through our patent percussion screens, and mixed with the coal n. II.

In this way the washing water does not get dirty, so quickly and the whole process of washing is simplified and the formation of slime very small.

The coal is very ingrained and dirly, and it is therefore necessary to crush same to under $6 \mathrm{~mm}$. in order to secure efficient washing.

We assume that the raw coal is taken in mine trucks direct from the pit to a height of about $8000 \mathrm{~mm}$. above rail level.

\section{Crushing Plant}

The crude coal is dumped on to the $50 \mathrm{~mm}$. perforation eccentric swinging screen (2) by the tippler (1). The pieces over $50 \mathrm{~mm}$. pass direct into the coal jav breaker (3) for preliminary crushing. 
O carrão quebrado vae para a peneira excontrica de seis millimetros (4) na qual cahem tambem os pedaços de 50 millimetros que tinham sido peneirados (2).

os pedaços menores de seis millimetros cahem directamente no deposito (A) do elevadn com caçambas, emquanto que os pedaços maiores de seis millimetros vão para us dois moinhos (5) onde são quebrados a seis millimetros, sendo entĩo levados para o deposito (A).

\section{Usina de lavagem}

o britador (6) leva o carvão do deposito (A) para os parafusos de distribuição das doze peneiras de percussão Patent Humboldt (7) de um millimetro, atravez das quaes passa a poeira menor que um millimetro.

ns pedaços de um a seis millimetros são levados em calhas para os lavadores (8). O carvão limpo e lavado da qualidade n. I corre ern calhas para o tanque (B), do elcvador com caçambas e é elevado pelo elevador (9), para o transportador e distribuidor de raspadeira (10) e distribuido pelos quatro depositos (C).

Cada deposito tem 50 toncladas de capacidade de forma que os quatró podem armazenar 200 toneladas, sufficiente para a producção de dois dias.

Nestas torres o carvão continúa a seccar. A agua que se escoa vae directamente para o tanque (B) do elevador com caçambas.

Ha placas de raspagem (11) collocadas em baixo das aberturas de descarga das torres, de forma que uma certa quantidade de carvão é sempre levada ao transportador de parafuso (12) que o conduz ao desintegrador (13).

Os residuos do lavador (8) são descarregados em sua parte inferior e levados por meio de tulons para o elevador de residuos (14), levados para uma calha elevada e dalli para os quatro lavadores de tres peneiras (15). Nestes se obtêm tı'es productos: Carvão cqualidade n. II, schistos e pyrites.

O carvão lavado, cqualidade n. II, corre pelas callıas para o tanque (D), é elevado para o transportador de raspadeiras, de distribuição (17) pelo elevador com caçambas (16) e é distribuido pelos tres depositos (E).

A poeira menor que um millimetro das peneiras de percussão (7) é reunida no deposito (F) soh as mesmas, levada para o transportador de raspadeiras ( 17 ) pelo elevador de poeira (18) e misturada naquelle com o carvão lavado $n$. II. 
The brokien coal then goes to the $6 \mathrm{~mm}$. perforation eccentric swinging screen (4) on which the screenings under $50 \mathrm{~mm}$. from (2) also fall.

The sizes under $6 \mathrm{~mm}$. fall direct into the bucket elevator pit (A) below, while the lumps over $6 \mathrm{~mm}$. are taken to the two bell mills (5) and cruslied to under $6 \mathrm{~mm}$. when they also fall into the pit (A).

\section{Washing Plant}

The Elevator (6) lifts the coal from (A) to the distributing screws of the twelve Ilumboldt Patent Percussion Screens (7) with $1 \mathrm{~mm}$. spaces, through which the dust under $1 \mathrm{~mm}$. falls.

The sizes $1-6 \mathrm{~mm}$. are flushed away in launders to the washers (8). The clean washed coal of No. 1 quality flows through launders to the bucket elevator sump (B), is lifted by the predraining bucket elevator (9) to the distributing scraper conveyor (10), and is divided up among the four storage bunkers $(\mathrm{C})$.

Each bunker compartment holds about 50 tons, so that $200 \mathrm{~T}$. in all can be stored, sufficient for about two days output.

In these towers the coal continues to drain, the water that trickles through being taken direct to the bucket elcvator sump (B).

Scraper plates (11) are placed under the discharge openings of the towers, which enable a definite quantity of coal to be scraped off into the screw conveyors (12), leading to the disintegrator (13).

The middlings and dilt from the washer' (8) as e discharged in their lower portions, taken through pipes to the middlings elevator (14), lifted to an elevated launder, and flushed to the furr, 3 screen felspar washers (15). Three products are here obtained, viz: Coal, quality No. 2, shale, and pyrites.

The washed coal quality No. 2 flows through launders to the bucket elevator sump (D), is lifted to the distributing scraper conveyor (17) by the pre-draining bucket elevator (15), and is distributed among the three storage bunkers (E).

The dust under $1 \mathrm{~mm}$. from the percussion screens (7) is caught in the pocket (F) under same, lifted to the sclapel convejor (17) by the dust elevator (18) and mixed on the former with the washed coal No. 2 quality. 
Ha portas em baixo dos depositos (E) pelas quaes saem os productos misturados, para os vagões da estrada de ferro.

As pyrites são obtidas nos primeiros compartimentos dos lavadores (15) e vão por uma calha para as peneiras fixas de esgotamento (19) para serem depositadas nos depositos de armazenamento $(G)$ na parte inferior, antes de serem carregadas nos vagões da estrada de ferro.

o schisto eliminado no segundo e terceiro compartimentos dos lavadores (15) e levado por calhas para o elevador com caçambas (20) dos residuos em que é esgotddo antes de ser levado para o deposito de residuos $(\mathrm{H})$. O schisto é descarregado da plataforma do virador 8000 millimetros acima do nivel dos trilhos.

Dos dous tanques dos elevddores com caçambas (B) e (D) a agua clarificada corre por calhas para o tanque da bomba (P) e torna a ser elevada para os lavadores e calhas pelas bombas centrifugas (21).

\section{Usina de briquettes}

De accordo com os resultados dos ensaios de briquettagem do carvão qualidade n. 1, é necessario misturar com o carvão $5 \%$ de piche solido antes de ir para as prensas.

o espaço sob as torres $(\mathrm{C})$ póde servir de deposito de piche, o espaço entre a usina de lavagem e de britamento póde ser tambem utilizado para esse fim.

O piche é quebrado a mão sobre a pequena grade de separação, em face do elevador com caçambas (22) e elevado por este para o moinho de piche (23).

o piche cae em pequeno vaso sols o moinho e é retirado de uma placa (24) quasi na proporção com o carvão (cerca de $5 \%$ para o transportador de parafuso (12). O carvão é transportado das torres para o desintegrador (13) onde a mistura é nova e completamente mechida e quebrada.

A mistura triturada é levada pelo elevador de caçambas para o forno (26) onde o piche é amollecido. A mistura aquecida é raspada da circumferencia para os parafusos (27) e levada para os amassadores das prensas de briquettes (28).

Dos amassadores a mistura passa ás placas de onde é raspada para à fôrmas das placas das prenias.

As briquettes são submellidas a alla mrusão por dois lados, passando depois lará a colreia (29) de transporte para os vagões. 
Under the bunkers (E) shutters are placed, through which the mixed products are drawn off into railway wagons.

In the first compartments of the washers (15) the pyrites are obtained, ond goes along a launder to the fixed draining screens (19), to be collected in the storage bunkers (G) underneath, before being loaded into railway wagons.

The shale washed out in the second and thild compartments of the washers (15) is taken along launders to the dirt bucket elevator (20), in which it is drained before being lifted to the dirt bunker (H). The shale is discharged at the level of the tippler platform $8000 \mathrm{~mm}$. above rail level.

From the two buckel, elevator sumps (B) and (D) the clarified water flows over launders to the pump sump (P), and is lifted back to lhe washers and flushing launders by the centrifugal pump (21).

\section{Briquette Factory}

In accordance with the resulls of the briquetting tests on coal quality No. 1, about $5 \%$ of tar or pitch must be added to the coal before going to the presses.

The space under the towers (C) serves as a pitch cellar, while the space between the washery and the bricuelting plant can also be used for this purpose.

The pitch is broken up by hand on the small grizzly in front of the bucket elevator (22) and lifted to the pitch mill (23) by the latter.

The pitch falls into a small vessel under the mill, and is scraped off from a plate (24) underneath in quite a definite proportion to the coal (about $5 \%$ ) into the screw conveyor (12). The coal is taken in this latter from the towers to the disintegrator (13), into which the mixture is again thorouglly mixed and brolicn up.

The crushed product is lifted by the bucket elevator (25) to the warming oven (26), in which the pitch is softened. The war'm misture is scraped off at the circumference into the screws (27) and taken to the gug mills (kneaders) of the two bricuette presses (28).

From the latter the relineaded material comes on to the plates, from which it is scraped off into the moulds of the press plates.

IIigh pressure is then applied on both sides of the briquettes, which thereupon pass over shoots to the briquette loading belt (29) to the railway trucks. 
Forch

Para mover: os apparelhos de lavagem e briquettagem, ha dous motores, uma para cada installação, ambos ficam juntos em um compartimento á parte.

\section{Construçoes}

São feitas de solida obra de tijolo com estructura interna de ferro. Estas são fartamente illuminadas por grandes janellas. Todas as passagens, plataformas de trabalho e lubrificarão teem soalho de ferro e são ligadas por commodas escadas de ferro.

\section{(Assignado) Maschinenbau Anstalt Humboldt.}

\section{Condições de pagamento e entrega}

Lindereço telegraphico: Humboldt Kalk.

Codigo usado: ABG ๕ $^{\mathrm{a}}$ e $5^{\mathrm{a}}$ edições. Bedford Mc Neil and Atlantic Cable. Code Directory. Podemos empregar outros codigos desde que haja combinação prévia.

Para encommendas telegraphicas devem ser empregadas as palavras do codigo indicadas em nossas listas de preços, bem como os numeros correspondentes devem ser telegraphados.

O uso de uma palavra do codigo significa a encommenda da machina correspondente e accusamos recebimento respondendo por telegramma com a mesma palavi'a.

A execução da encommenda e sua remessa no tempo do contracto está sujeita a cası de força maior, desabamentos, collisões, etc. o tempo para entrega depende do tamanho da encommenda. 0 embarque é feito por conta o risco do freguez. Si se quizer faremos o seguro maritimo, ou outro por conta dos nossos freguezes, o methodo e o caminho para o embar'que, si não lıouver combinação especial fica á nossa disposição. No caso de encommenda no estrangeiro reservamonos o direito de fazer o seguro por conta do freguez. As listas de preços dadas em nossos catalogos são sujeitas a alterações sem aviso. Os caixões de acondicionamento estão incluidos no custo e não devem ser devolvidos. Quando for necessario revestimento de zinco para os caixões de exportação o custo excedente é incluido, mas greralmente só fornecemos fortos caixũes para o encaixotamento, para exportação.

No caso do nns serem feilas encommendas pela primeira rez, directamente do estrangeiro, exigimos uma ordem sobre um banco com a encommenda. 
 \\ Power}

For driving the apparatus in the washery and Jriquetting plant, a steam engine is pruvided for each, the two being situated together in a separale room.

\section{Buildings}

These are of solid brickwork, with internal constructional iron work. Ample provision is made for illumination through large windows. All runways, lubricating and working platforms have iron flooring, and are connected by comfortable iron stairs.

(Signed) Maschinenbau Anstalt Humboldt.

\section{Terms of payment and delivery}

Telegraphic address: Humboldt-Kalk.

Codes Used: A, B, C, 4th and 5th Ed. Bedeford Mc Neil and Atlantic Cable Code Directory. By previous arrangement other codes can also made use of.

For telegraphic orders, the code words giren in our lists should be used, and the corresponding reference numbers should also be telegraphed.

The use uf a code word means an order for a cooresponding machine, and we acknowledge the receipt of such orders by telegraphing back the same word.

The keeping of the contract time of delivery is subject to cases of "force majeure», breakdowns, strikes, etc. The time of delivery depends on the size of the order. The shipments are made at the cost of and at the risk of the customer. If desired, we effect the sea and other insurance on our customer's account. The method and route of shipment is left, failing any special arrangement, to our works In the case of orders from abroad, our works have also the right to effect the insurance in the customer's account. The list prices given in our cotalogues are subject to alteration without notice. Packing cases are invoiced at cost price, but are not returnable. When zinc linings are required for the cases for export packing, the extra cost is charged for, lout we usually provide only correspondingly strong cases for export packing.

In the case of orders received by us direct from abroad, a remittance through a Bank with the order is required, in the case of a first order. 
No caso, porém, de freguezes com quem já ienhamos feito negocic, será bastante que nos remettam parte do pagamento com a encommenda e o restante por alguma casa do continente quando receberem os conhecimentos.

No caso de encommendas de casas de commissões européas parte do pagamento deve ser feito com a encommenda $\theta$ o restante quando receberem os conhecimentos.

Não tomamos compromissos pelas dimensões é pesos dados nas tabellas de nossos catalogos, bem como pelos algarismos que se referem á força e capacidade, desenhos e illustrações.

Temos engenheiros e montadores de machinas á disposição dos freguezes, para a montagem e inicio do trabalho destas, nas condições usuaes dos negocios de exportação. 
In the case, however, of orders from customers abroad with whom we have done Jusiness for any length of time, a portion of the payment is to be made with order and the balance through a Continental house against bills of lading.

In the case of orders from European commission houses, part payment is to be made with order and the balance againts bills of lading.

The dimensions and weights given in the tables in our pamphlets, as also the figures regarding power required and capacity, and the designs in the illustrations, are not to be regarded as binding on us.

Engineers and erectors are at the disposal of customers for the erection and setting to work of the machinery, on the terms usual for export business. 

COMMISSAŌ DE ESTUDOS DAS MINAS DE CARVAÕ DE PEDRA DO BRASIL.

Proposed Coal Crushing-Washing ano Briouette Making Plant FOR THE

Brazilian Coal Commission. Rio de Janeiro.
PROJECTO DE USINAS

BRITAMENTO, LAVAGEM EBRIOUETTAGEM DE CARVÃO Commissā̃ de Estudos das Minas de Carvão de Pedra do Brasil

PELA HUMBOLDT ENGINEERING WORKS"

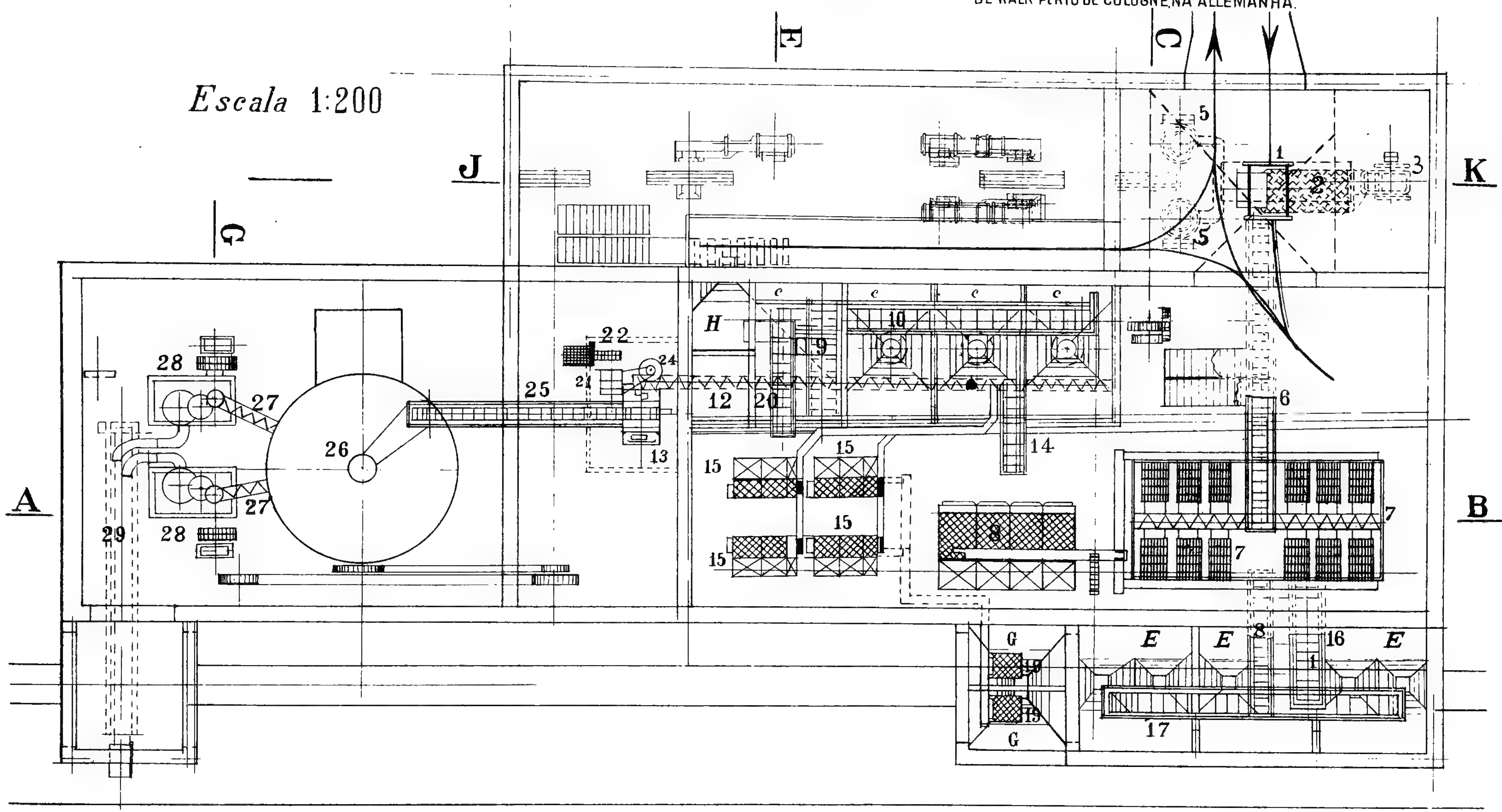

I

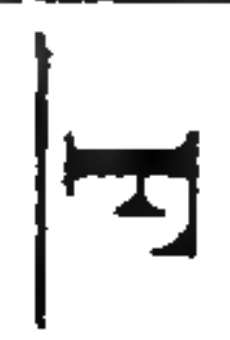

$\boxminus$ 
Proposed Conl Crushing-Washing and Briouette Making Plant

$$
\text { Brazilian Coal Commission, Rio de Janeiro. }
$$

Projecto DE Usinas

BRITAMENTO, LAVAGEM EBRIOUETTAGEM DE CARVĀO COMMISSAÕ DE ESTUDOS DAS MINAS DE CARVAOO DE PEDRA DO BRASIL PELA HUMBOLDT ENGINEERING WORKS

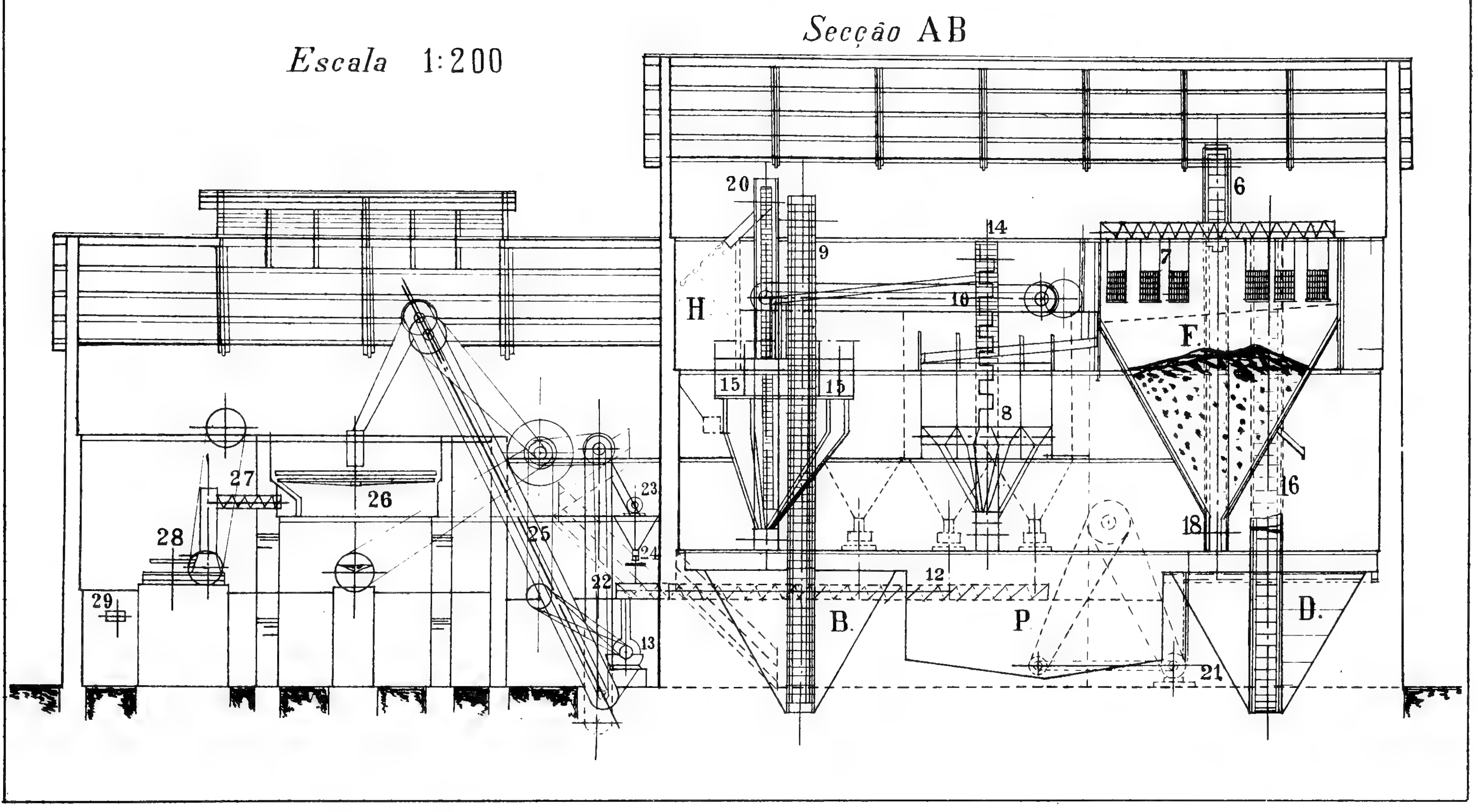


COMMISSAŌ DE ESTUDOS DAS MINAS DE CARVAŌ DE PEDRA DO BRASIL.

Proposed Coal Crushing-Washing ano Briouette Making Plant POR THE

Brazilian Coal Commission, Rio de Janeiro.

\section{ProjeCto DE Usinas}

BRITAMENTO, LAVAGEM EBRIOUETTAGEM DE CARVÃO Commissāo de Estudos das Minas de Carvá̃ de Pedra do Brasil PELA HUMBOLDT ENGINEERING WORKS

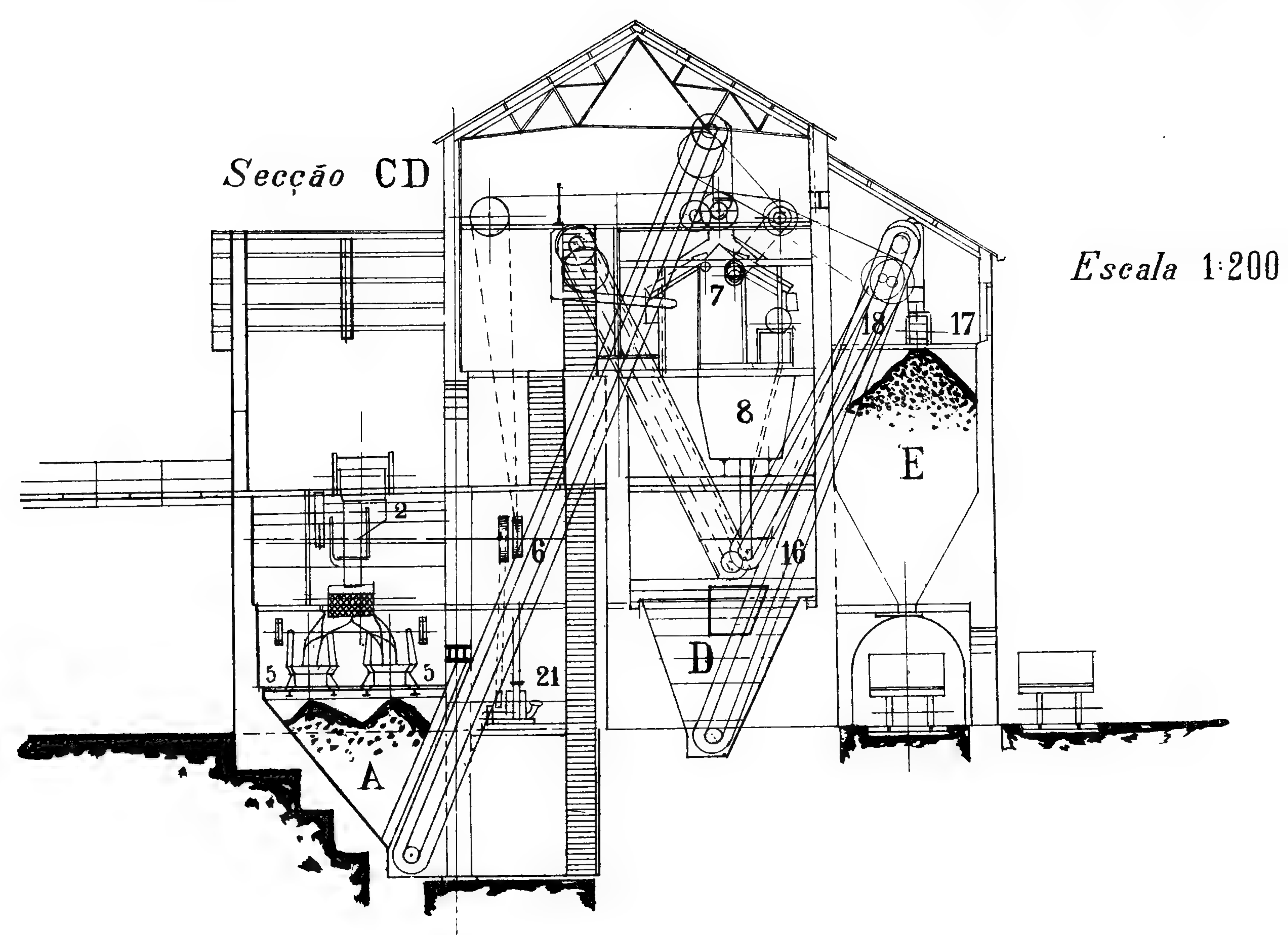


Proposed Coal Crushing-Washing ano Briouette Making Plant FOR THE Brazillan Conl Commission, Rio de Janelro.

\section{PROJECTO DE USINAS}

BRITAMENTO, LAVAGEM EBRIDUETTAGEM DE CARVÃO

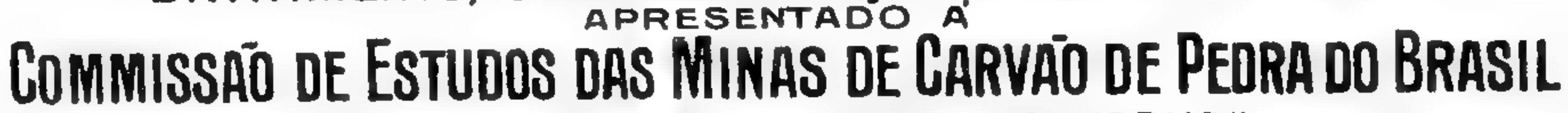
PELA HUMBOLDT ENGINEERING WORKS

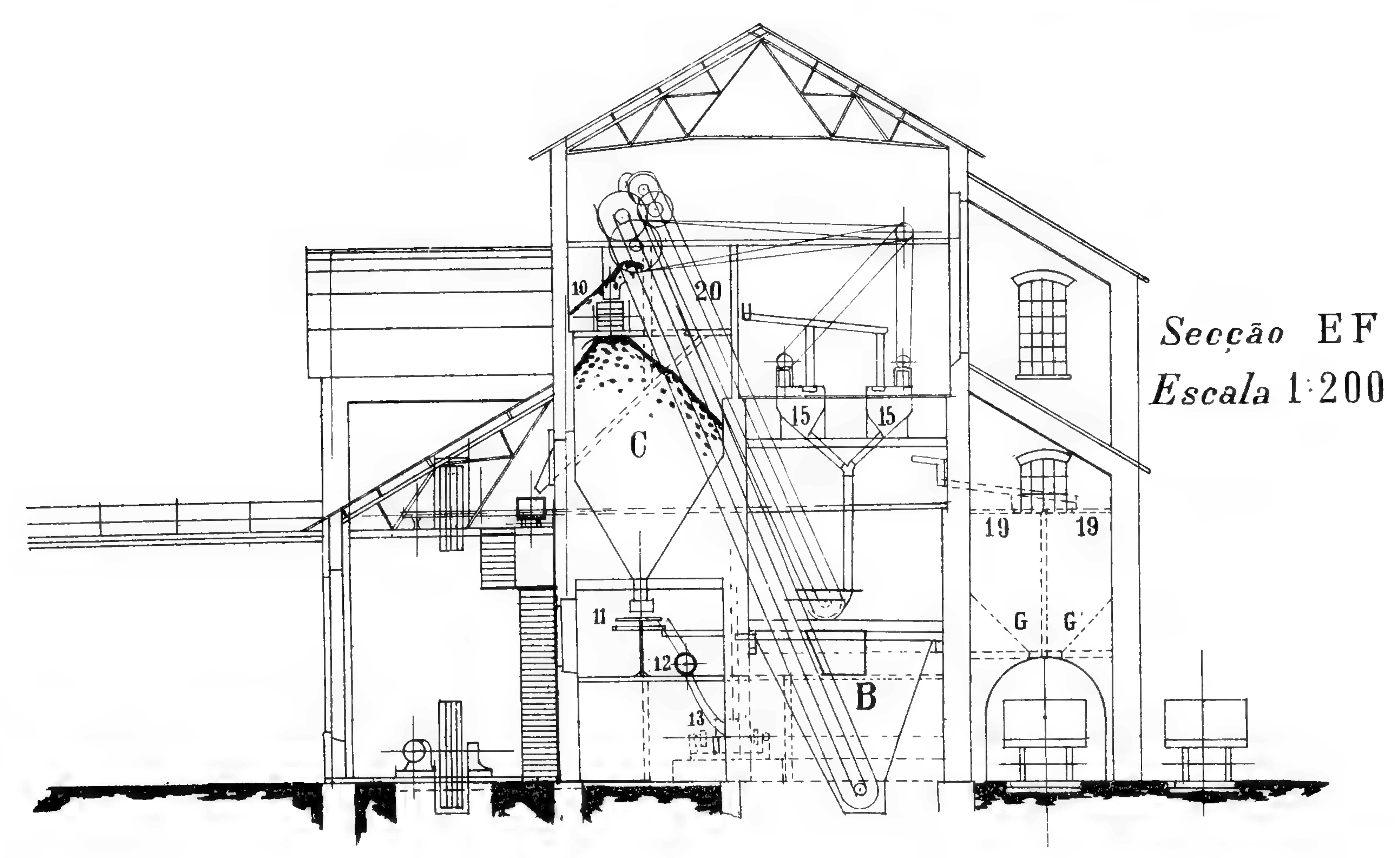


Proposed Coal Crushing-Washing ano Briouette Making Plant FOR THE Brazilian Coal Commission. Rio de Janeiro.

\section{PROJECTO DE UsINAS}

BRITAMENTO, LAVAGEM EBRIDUETTAGEM DE CARVĀO Commissā̃ de Estudos das Minas de Carvã̃ de Pedra do Brasil PELA HUMBOLDT ENGINEERING WORKS"

Secçâa GH Escala 1:200

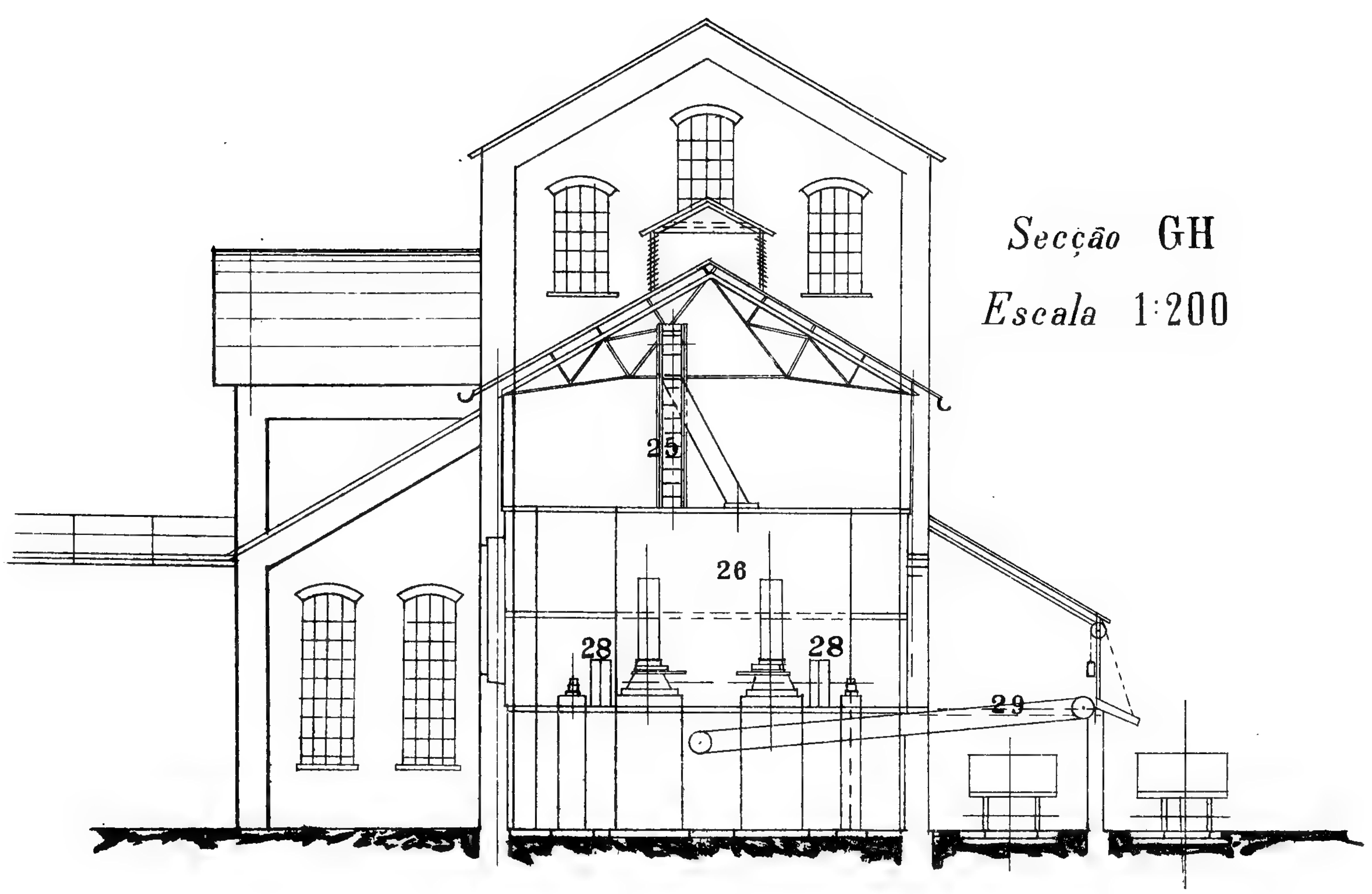


Proposed Coal Crushing-Washing ano Briouette Making Plant FOR THE

\section{Brazilian CoAl Commission. Rio de Janeiro.}

ProjeCto DE Usinas

BRITAMENTO, LAVAGEM EBRIQUETTAGEM DE CARVĀO COMMISSĀ̃ de ESTUDOS DAS MINAS dE CARVĀO DE PEDRA DO BRASIL PELA HUMBOLDT ENGINEERING WORKS"

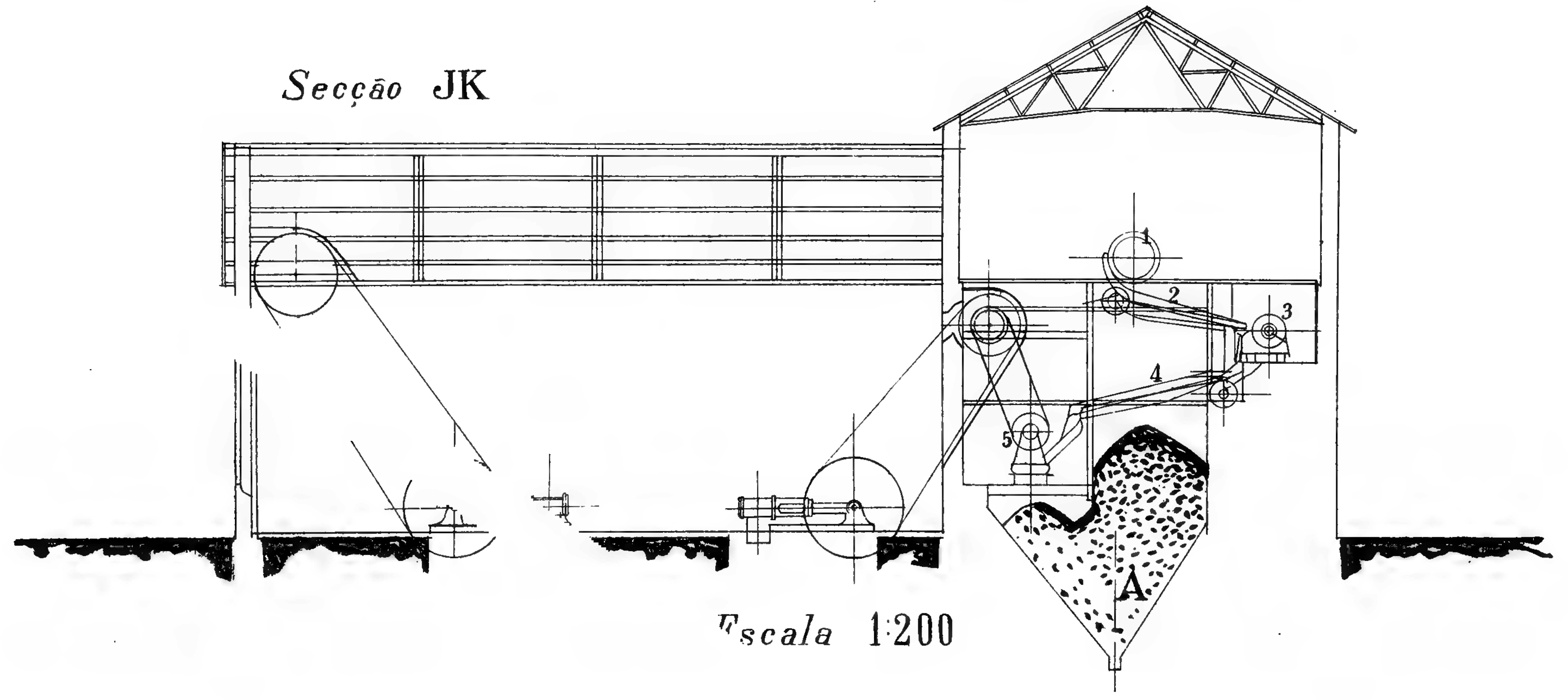





\section{APPENDIX}

\section{Bibliography}

The following list of publicatlons relating mostly to the carboniferons geology of South Brazil is taken trom the paper by Dr. J. C. Branner of Stanford University, California, published in volume XII of the Archivos do Museu Nacional do Rio de Janeiro, 1903. Dr. Branner has also kindly supplied in manuscript the titles of additional publications not given in the paper mentioned :

\section{Bibliographia}

A seguinte lista de publicações referentes em sua maior parte á geologia do carbonifero do sul do Brazil, foi tirada do trabalho do Dr. J. C. Branner, da Universidade Stanford da California, publicado no XII volume dos Archivos do Museu Nacional do Rio de Janeiro, 1903. O Dr. Branner forneceu amavelmente em manuscripto os titulos de publicaç̃es addicionaes que não estão citadas no trabalho mencionado :

Agassiz, L. - Report., on coal from Candiota. (Letter dated Rio, june 18, 1866, addressed to N. Plant. It forms parts of the report of Pakenham and Plant, p. 23 q. v.) London, 1867.

AlmeidA, Gonçalves de - Annonce qu'un gisement d'ossements fossiles vient d'etre decouvert au Brésil dans la province de Rio Grande do Sul. Comptes Rendus de l'Acad. Sci., CXIV, 378, Paris, 1892.

Almeida, Presidente Luiz A. Ferreira de, e outros - Minas de carvão de pedra do Arroio dos Ratos. Revista de Eingenharia, 28 de agosto de 1884, VI, 186, Rio de Janeiro, 1884.

Almeida, G. Osolio de - Communicação feita sobre a applicação do carvão nacional a tracção em estradas de ferro. Annuario ào Estado do Rio Grande do Sul, 1906, pp. 256-263. Porto Alegre. 1905 .

Ambauer, Henrique Schutel - A provincia do Rio Grande do Sul, descripção e viagens. Revista Trimensal do Instituto Historico, tomo LI, parte II, pags. 25-72. Rio de Janeiro, 1888.

Anon. - A mineração rilo-grandense. Catalogo da exposição estadual do Rio Grande do Sul em 1901, pp. 9-23, 4. Porto Alegre, 1901. 
Arber, E. A. Newell. - On the distribution of the Glossopteris Flora. Geol. Magazine. Aug. 1902, IX, 346-349. London, 1902.

Arber, E. A. Newell. - Catalogue of the Fossil Plants of Glossopteris Flora, British Museum. London, 1905. pp. LXXlV-255; pl. 8 , text. f. 51 .

Azanbus , Bernardo Augusto Nascentes de.-Descrīpção tợographica do mappa da provincia de Santa Catharina, organizado na Commissão do registro geral e estatistica das terrás publicas e possuidas, $8^{\circ}, 25 \mathrm{pp}$. e carta. Rio de Janeiro, 1874. Physical features of Santa Catharina.

BALIod, Car1. - Der Staat Santa Catharina in Sud-Brasilien. Inaugural Dissertation der Philosophischen Fakultät der Universität Jena, etc., $8^{\circ}$, Stuttgart, 1892, Separatabdruck aus dem Ausland, 1892, n. 27-31. (Geology and physical geography, pp. 1-25).

BECQUEREL, IIenri. - Sur les proprietés magnétiques du fer nickelé de Sainte Catherine (Brésil). Comptes Rendus de l'Acad. Sci., XCIII, 794-797. Paris, 1881.

Beçuereil, Henri and Smith, J. Lawrence. - on the magnetic properties of a specimen of nickeliferous iron from st. Catharine, Brazil, as first pointed out by J. L. Smith; with a note by J. L. Smith. Translated from the French. See Comptes Rendus Acad. Sci., XCIII, p. 794. American Journal Science, 1882, CXXII, 229่-232. New llaven, 1882.

BEM, Balthazar Francisco de.- Mineração na Provincia do Rio Grande do Sul. Annexo ao Relatorio do Ministro da Agricultura. Rio de Janeiro, 1874, 3 pp.

Brongniart, Adolphe.-- Notice sur le Psaronius brasiliensis, Bul. de la Société Botanique de France, t. XIX, pp. 3-10, 8. Paris, 1872.

Burlamaqui, F. L. C.- Noticia acerca de alguns mineraes e rochas de varias Provincias do Brazil, recebidas no Museu Nacional durante o anno de 1855 (dated sept., 1856). Revista Brasileira, II, p. 73-104. Rio de Janeiro, 1858. Geological Section of the coal fields of Southern Brazil. A foot-note says this article is a continuation of others published in the Guanabara.

Burlamaqui, F. - Noticia sobre alguns mineraes e rochas de algumas provincias do Brazil, recebidas no Museu Nacional durante os annos de 1856, 1857 e 1858. Revista Brazileira, II, 241-265. Map. of St. Gatharine coal fields, Rio de Janeiro, 1856-1858. 
Cabral, Frederico A. de Vasconcellos A. Pereira.- Memoria geologica sobre os terrenos do Curral Alto e Serro do Roque, na Provincia de S. Pedro do Sul, $8^{\circ}$, XIV, 162 pp., geologic map and colored geologic sections, Porto Alegre, 1851.

Calogeras, J. P. - (Meteorite of Santa Catharina). Jornal do Commercio, Rio de Janeiro, May 29, 1892.

Calogeras, J. P. - Ic fer nickelé de Sainte Catherine. Revue Scientifique, t. L, pp. 591-594. Paris, 1892. Abstract, N. Jahrb. $f$. Mineral., 1883, I, p. 480, (Referate.)

Calogeras, João Pandiá,-As minas do Brazil e sua legislação, 2 vols. $8^{\circ}$, Rio de Janeiro, 1905. Camara dos Deputados. Parecer apresentado á commissão especial das minas pelo relator. Vol. I, XV, 479 pages; vol. II, 627 pages. Several chapters on the geology of economic minerals. Part of one chapter translated and published under the title. "Gem mining in Brazil " in the Mining World, XXIV, 101. Chicago, Jan. 27, 1906.

Campos, Luiz F. Gonzaga de. - Note on the locality of the Santa Catharina Meteorite, Revista do Observatorio do Rio de Janeiro. Abstract : - American Journal Science, 3rd series, XXXVI (GXXXVI), 157-158. New Haven, 1888. Abstract (of abstract in American Journal Science) N. Jahrb. f. Mineral, 1889, II, pag. 281, Referate.

Campos, L. F. Gonzaga de.- Nota sobre a loca!idade do ferro nativo de Santa Catharina. Meteoritos brasileiros. Extrahida da Revista do Observatorio. Vol. III, n. 5, pp. 65-68. Rio de Janeiro, 1888, Abstract, Neues Jahrb. für Mineral, 1891, I, p. 243. Referate.

Campos, Luiz Gonzaga de.- Minas de carvão do Tubarão, Santa Catharina, 49 pags., com mappas e perfis, $4^{\circ}$, Rio de Janeiro, Imprensa Nacional, 1890. $\mathrm{E}^{\prime}$ a segunda parte do Relatorio apresentado ao Exm. Sr. general Francisco Glycerio, Ministro da Agricultura, etc., pelos engenheiros F. Hostilio de Moraes Rego, Luiz Gonzaga de Campos e João Caldeira de Alvarenga Messeder, pags. 27-76, com mappas e perfis.

Campos, Luiz Gonzaga de.- In English : The coal beds of Tubarão, Santa Catharina (Minas de carvão de Tubarão, Santa Catharina). Brazilian Mining Review, I, 102-105;168-173. Rio de Janeiro, 1903. 
Carruthers, IV. - On the plant remains from the Brazilian coal beds remarlis on the genus Flemingites. Geological Magazine, VI, 1869, 151-155, Plates V-VI, London, 1869. Separate with Plant's paper pp. 5-10, 2 plates. Abstract: $-N$. Jahrb. für Mineral. $1870,663-64$.

Cost $\Lambda$, L. A. Corrêa da. - O Carvão de peđra da Ilha Itaparica. Dated Rio, $1^{\circ}$ novembro de 1878. Revista Industrial, março de 1879 , IV, 75. New York, 1879. Analysis of coal copied from the Jornal do Commercio.

DAHNE, E. S. Eugenio.- A mineração do carvão e as concessões da companhia no Estado do Rio Grande do Sul, Brazil. Porto Alegre, 1893.

Dallne, Eugrenio. - A formação carbonifera em Tubarão, Santa Catharina. Estudo geologico feito pelo engenheiro de minas Eugenio Dahne em 1901. Publicado no jornaI A Federação, Porto Alegre, Estado do Rio Grande do Sul, 16 de fevereiro de'1904. Anno XXI, n. 39 .

DAHNE, Eugenio. - Descriptive memorial of the state of Rio Grande do Sul, Brazil. Organized by order of the President Dr. Augusto Borges de Medeiros for the International Exhibition S. Luiz, 1904. Pol'to Alegre, 1904. (Geology and minerals pp. 6-17).

DAHNE, Dr. Eugenio. - (A bacia carbonifera d'o Arroio dos Ratos.) Revista de Engenharia, n. 219, 14́ de outubro de 1889, XI, 234. Rio de Janeiro, 1889.

Damour, A. - Sur un fer mẻtallique trouvé à Santa Catharine, Brésil. (With remarks by Boussingault.) Comptes Rendus de l'Acad. Sci., LXXXIV, 478-482, Paris, 1877.

DAUBRÉE. - Observations sur le fer natif de Saint Catherine, sur la pyrrhotine et la Magnétite qui lui sont associées. Comptes Rendus de l'Acad. Sci., LXXXIV, 489-485. Paris, 1877.

DaubréE. - Constitution et structure brêchiforme du fer météorique de Sainte Catherine, Brésil (etc.). Comptes Rendus de l'Acad. Sci., LXXXV, 1255-1260. Paris, 1877.

DAUBREE. - Sur le grand nombre de joints, la plupart perpendiculaires entre eux, qui divisent lo t'l méléorique de Sainte Catherine (Brésil). Comptes Rendus de l'Acad. Sci., LXXXVI, 1433. Paris, 1878. 
Derby, O. A. - Plantąs fosseis (no Brazil). Revista de Engenharïa, 28 de dezembro de $1883, \mathrm{~V}, 348$. Extrahido do Jornal do Commercio do Rio de Janeiro. Rio de Janeiro, 1883.

Derby, O. A. - Terrenos carboniferos das provincias de S. Paulo o Paraná. Revist c de Engenharia, 28 de agosto de 1883, V, 228-229. Extrahido do Jornal do Commercio do Rio de Janeiro. Rio, 1883. Also in the Auxiliador da Industria Nacional, n. 11, novembro de 1883, pp. 258-260. Rio de Janeiro, 1883.

Derby, 0. A.- Um fossil interessante do Museu Nacional. (Psaronius brasiliensis), Jornal do Commercio, Rio de Janeiro, March 14, 1905. Also in Diario de Noticias (Bahia), march 23, 1905. (Results of Salm-Lauback in re Psaronius brasiliensis.)

Derby, A. O. - The Santa Catharina meteorite. American Journal Science CXXIX, 33-35; 496. New Haven, Jan., 1885.

Derby, O. A. - Ueber Spuren einer carbonen Eiszeit in Südamerika. Neues Jahrbuch fur Mineralogie, 1888, II, 172-176. Stuttgart, 1888.

Derby, O. A. - Is the S. Francisco do Sul (Santa Catharina) iron a meteorite? Science, XX, 254-255. Nerv York, Nov. 4, 1892.

EDDY, Henry.- On the mines, of the province of Rio Grande do Sul, Brazil. Trans. Royal Gcol. Soc. Cornwall, X, pt. V, pp. 157-160. $8^{\circ}$. Penzance, 1883.

FoetTerle, Franz. - Die geologische Uebersichtskarte des mittleren Theilles von Süd-Amerika. Mit einem Vorworte von IV. Ilaidinger Wien, 1854. (pp. 22, geol. map. of S. Amer.) The accompanying map is in Portuguese; it was constructed for von Martius, Abstract:-Neues Jahrouch für Mineral., 1855, $90-91$.

Foetterle, Fran\%. - Dịe geologie von Süd-Amerika. Petermann's Mitheilungen aus Justus Perthes' Geographischer Anstalt, 1856, pp. 187-192. Gotha, 1856.

Frank, Emanuel Paulo. - Minas de carrã de S. Jeronymo. With map of the mines, Revista de Engenharia. №. 219, 14 de outuJro de 1889, XI, 220-225. Rio de Janeiro, 1889.

Frech, Fritz. - Lethaea geognostica I. Theil. Lethaea palaeozoica. 2 Band (Die Dyas) 4 Lieferung, pp. 618-621. 4 $x^{\circ}$ Stuttgart, 1902. (The Permo-Carboniferous of Rio Grande do Sul, Santa Catharina, etc.) 
GINTY, W. G. - Report on the Candiota coal. (Letter addressed to Nathaniel Plant.) Appendix H. of "Brazil and the Brazilians" By Rev. James C. Fletcher and Rev. D. P. Kidder. 9th. ed. p. 637. London, 1879.

Ginty W. G.- Report on the Candiota coal. (Part of the paper by Mr. Pakenham, pp. 22-24, q. v.). London, 1867.

GorceIx, Henri. - Notice sur le gisement et l'exploitation de l'ol' a Lavras, province de Rio Grande du Sud. Bull. Soc. de l'Industrie Minerale, $2^{\text {me }}$ série, tome IV, 1875, 361-381. Paris, 1875.

GORCEIX. - Résultats d'une premiĉre exploration de la province de Rio Grande du Sud (Brésil). Bull. Soc. Géol. de France. $3^{\text {me }}$ série, III, 55-56. Paris, 1875.

Gorceix, H. - Noticia sobre a jazida de cobre em Lavras e Caçapava, na provincia de S. Pedro do Rio Grande do Sul. $8^{\circ}$, pp. 8. Rio de Janeiro, Typ. Nacional, 1876.

GoRcEIx, H.-Mina de Carvão de pedra em Minas Geraes. Officio dirigido ao Presidente da Provincia. Auxiliador da Industria Nacional. N. 7. Julho de 1878, XLVI, 16'-165. Rio de Janeiro, 1878.

Gorcerx, Henri.- Le Brésil en 1889 avec une carte de l'Empire en chromolithographie, des tableaux statistiques, des graphiques et des cartes. Ouvrage publié par les soins du syndicat du comitè franco-brésilien pour l'exposition universelle de Paris. Avec la collaboration de nombreux ecrivains du Brésil sous la direction de M. F. J. de Sant'Anna Nery. (Minéralogie, par Gorceix, Paris, Charles Delagrave, 1889, in- $8^{\circ}$, XIX, 699 pages. The part on coal is abstracted in The Iron and Coal Trades Review, XLII, 296, London, march 13, 1891, and in Iron and Steel Inst. 1891, I, 299, London, 1891.

GraçA, E. J. Cordeiro da. - Relatorio dos estudos mineralogicos e geologicos da Provincia de S. Pedro do Rio Grande do Sul. in- $8^{\circ}$. Rio de Janeiro, 1883.

Grateau, Ed.-Découverte de la houille au Brésil. Annales du Génie Civil. t. III (année 1864) p. 510, 8. Paris, Eugene Lacroix, editeur.

Guignet, Ed., and Almeida, I, Ozorio de.- Sur un fer méteorique très riche en nickel, trouvé dans la province de Santa Catharina, Brésil. Comptes Rendus de l'Acad. Sci, LXXXIII, 917-919. Paris, 1876. 
GuIGNET. - Sur le fer niclzelé de Sainte-Catherine au Brésil. (Lettre a M. Daubrée.) Avec olservations par Daubrée. Comptes Rendus de l'Acad. de Sci., LXXXIV, 1507-1509. Paris, 1877.

Guignet, E. - Sur divers échantillons d'argile et de houile du Brésil. Comptes Rendus de l'Acad. Scien., LXXXIV, 1326-1328. Paris, 1887.

HENSEL, Dr. Roinhold. - Beitrage zur naheren Kenntniss der brasilianischen Provinz São Pedro do Rio Grande do Sul. Zeitschrift der Gesellschaft fü.' Erdkunde zu Berlin II, 227-269; 342-376. Berlin, 1867.

Hermeyer, Captain J. - Südbrasilien. Ein Handbuch zur Belehrung für Jedermann insbesondere für Auswanderer. $8^{\circ}$, Hamburg, 1857. I Absch. Geographische Uebersichte von Südbrasilien, pp. 1-10. III. AJschnitt. von den Naturprodukten. Mineralien 19-23.

HetTNER, Alfred. - Reiseskizzen aus Súdbrasilien „ I. Ein Besuch in den deutschen und italienische Colonien bei Porto Alegre in Südbrasilien. Deutsche Rundschau für Geographie und Statistik, XIV, Heft V. Februar, 1892, 192-202 ; II, Besuch der Kohlenmine von Arroyo dos Ratos und der Colonien Estrella und Santa Cruz pp. 253-261 Wien 1892.

Hettner, Dr. Alfred.- Das südlichste Brasilien (Rio Grande do Sul). Zeitschrift der Gessellschaft für Erleunde zu Berlin. XXVI; 85-144. $8^{\circ}$. Berlin, 1891. (Geological maps and section.)

HulL, Eward. - The Brazilian coal-fields. The Quarterly Journal of Science, I, 387-390. London, 1864.

IlulL, Edivard. - The Brazilian coal-fields. (Note from the Quarterly Journal of Science. N. II, April, 1864). Appendix H. of Brazil and the Brasilians. By Rev. James C. Fletcher and Rev. D. P. Kidder, 9th. pp. 635-637. London, 1879.

Inering, Dr. H. von. - Die Lagoa dos Patos, Deutsche Gesellschaft Bremen, vol. VIII, 1885, prgs. 191 e seguintes.

IMPERIAL INSTITUTE of the United Kingdon, the colonies, and India. (Analysis of) coal from Santa Catharina... Technical Reports and Scientific Papers, edited by W. R. Dunstan, etc. London, 1903. (Analysis at page 9 is by C. S. Blake).

IsABelle, Arsène. - Excursions dans la province de Rio Grande do Sul au Brésil (1834). Extrait d'un voyage inèdit, Nouvelles 
Annales des Voyages (LXV) 257-279. Paris, 1835. Geologie, p. 262 et seq.

IsABELLE, Arsène.-Voyage á Buenos-Ayres et á Porto Alegre, par la Banda Oriental, les Missions d'Uruguay et la province de Rio Grande do Sul. (1830-1834), etc. $8^{\circ}$, Le Ilavre 1835. Review: Nouvelles Annales des Voyages, LXIX, 235-248. Paris, 1836.

Jondão, J. Najor Pacheco. - Carvão de pedra do Brazil. O Novo Mundo, Janeiro de 1877, VII, p. 19, New York, 1877 (Analyses).

KOELER, Julio.- Estudo technico industrial sobre o carvão de pedra nacional das minas do Arroio dos Ratos, Estado do Rio Grande do Sul. Rio de Janeiro. Typ. do Jornal do Commercio. 1899, in- $8^{\circ}, 63 \mathrm{pp}$.

Lange, Dr. Henri. - Contributions à la cartographie de la Province Brésilienne de Santa Catharina. Bull. Sci. Geog., Novembre, 1879, pp. 430-437. (Geographie position, Map.), 8, Paris, 1879.

LANGE, Dr. IItenri.- Die Flusegebiete des Rio Tubarão und des Rio Ararangua. Petermann's Mittheilungen aus Justus Perthes' Geographischer Anstalt, Bd. XXXIV, 10-13, 1 Karte. Gotha, 1888.

LANGE, Henry.-Eine Fahrt nach den Steinkohlengruber von S. Jeronymo. Deutsche Rundschau f. Geographie V, p. 512. 1883.

LANGe, IIenry. - Südbrasilien. Die Provinzen São Pedro do Rio Grande do Sul, Santa Catharina and Paraná mit Rücksicht auf die Deutsche Kolonisation. Leipzing, 1885. (Mineralien, 9, 45, 125$127 ; 183)$.

Lunay. - Sur le fer nickelé de Sainte-Catharine. (Extrait d'une Lettre adressée a M. Daubrée). Comptes Rendus de l'Aca. Sci., LXXXV, 84-85. Paris, 1877.

Lyon, Max.-Descliption de l'État de Rio Grande do Sul (Brésil). Comptes Rendus de la Soc. Géog., 1891, 515-525. Paris, 1891, Physical features.

MACEDo, Marcos Antonio de. - Descrịpção dos terrenos carboniferos da Comarca do Crato. Bibliotheca Guanabarense. Trabalhos da Sociedade Vellosiana, pp. 23-28. Dated Crato, 8 de janeiro de 1885. Rio de Janeiro, 1885.

MARc, Alfred. - Le Brésil; excursion à travers ses 20 provinces. Édité par M. J. C. d'Argollo Ferrão. 2 rols. in- $8^{\circ}$. Paris, 1889, (Notes on geology and mineral resources: Paraná and Santa 
Catharina, II, 377-379; 422, La houille de Tubarão, II, 438-441; Rio Grande do Sul, II, 476-477).

Mevnier, Stanislas. - Sur le mode de formation de la brèche météorique de Sainte-Catherine (Brésil). Comptes Rendus cle l'Acad. Sci., LXXXV1, 943-946. Paris, 1878.

Meunier, Stanislas.-Fer natil du Brésil. La Nature, 1877, V, 79. (The Santa Catharina mass mentioned.)

Miers, John. - (Coal in Brazil.) Report of the commitssioners appointed to inquire into the several matters relating to coal in the United Kingdom. Vol. III, pp. 261-263. $4^{\circ}$. London, Eyre and Spottiswoode, 1871. (This article is also to be credited to Nathaniel Plant.)

Mirls, James E.- Notes upon the surface greology of Rio Grande do Sul, Brazil. American Geologist, 1902, vol. XXIX.

Moraes, Eduardo José de. - Estudos definilivos da linhỉa de Cangussú, variante da Estrada de Ferro do Rio Grande a Alegrete. Memoria justificativa apresentada por Eduardo José de Moraès, chefe da Commissão. in-4̌ . Rio de Janeiro, Typographia Nacional, 1876. (Descripção geral da zona do projecto, geologia, efc., pp. 12-15.)

Mulhall, Michael G.- Rio Gránde do Sul and its German colonies. $8^{\circ}$, London, Longmans, Green and Co., 1873. Geography and Geology, 12-22. The coal fields of S. Jeronymo, 78-84.

MurRay, John. - (Experiencia do carvão de Santa Catharina). Revista de Engenharia, 28 de agosto de 1883, V, 229. Rio de Janeiro, 1883.

Netro, Ladistáo. - Noticia àcercà dos combustiveis mineraes do Brazil, precedỉda de algumas noçốes gerás sobre estes productos. Annexo ao Relatorio do Ministro da Agricultura. Rio de Janeiro, $1870,8 \mathrm{pp}$.

NetTo, Ladisláo (Presidente). - Relatorio da Companhia das Minas de Ouro e Cobre do Sul do Brazil, aṕresentado á assembléa geral extraordinaria em 15 de outubro de 1874, pp. 14, $12^{\circ}$. Rio de Janeiro, 1874.

OLIVEIRA, Francisco de Paula. - Bacias carboniferas do Brazil. Jornal do Commericio. Río de Janeiro, Beż. $15 \mathrm{th}, 1901$.

Oliveira, Paulo José de.- Relatorio sobre minas de carvão e ferro da Ilha de Itamaracá, Annexo ao Relatorio do Ministro da Agricultura, Rio de Janeiro, 186́4. $36 \mathrm{pp}$. 
Osborn, Henry F. - Recent Veriebrate Palaeontology, Science, August 3, 1906.

Parigot, Dr. Julio. - Minas de carvão de pedra de Santa Catharina, $8^{\circ}, 12 \mathrm{pp}$. Rio de Janeiro, Villeneuve \& C., 1841.

PARigot, Dr. Julio. - Memoria sobre as minas de carvão de pedra do Brazil. 4ㅇ, 30 pp., with cut. Rio de Janeiro, Villeneuve \& C., 1841 .

PARIGot, Dr. Julio. - Memoria terceira sobre as minas de carvão de pedra de Santa Catharina, $4^{\circ}, 30 \mathrm{pp}$., Rio de Janeiro, J. Villeneuve \& C., 1842 .

Pederneiras, Innocencio Velloso. - Carvão de pedra e mineraes de ferro da provincia do Rio Grande do Sul. Jornal do Commercio, 17 de abril de 1848. Rio de Janeiro, 1848. Copiado no Relatorio dos Estudos de João Cordeiro da Graça, q. v. (X-XV).

Pinheiro, José Feliciano Fernandes, Visconde de S. Leopoldo.- Annaes da Provincia de S. Pedro. Segunda edição, $8^{\circ}$, Paris. Na Typographia de Casimir, 1839. Topography and geology, Chap. I, pp. 15-41.

Pissis, A.- Mémoire sur la position géologique des terrains de la partie australe du Brésil et sur les soulevements qui, a diverses époques, ont changé le relief de cette contrèe. Comptes Rendus de l'Accd. Sci., XIV, 1044-1046. Paris, imp. nationale, 1842, in-4. 60 pp., 2 cartes et 5 pI. Same title: Mem. de l'Ins. de France. Tome X, pp. 353-413. 2 géol. maps., 3 plates of sections 1 chart.

Plant, John.- On the discovery of coal in Brazil. Trans. of the Manchester Geol. Soc, vol. IV, n. 12, 294-304. Manchester, 1864. Also The Mining and Smelting Magazine, March, 1864, vol. V, 148-151, London, 1864. Notice: The Mining Journal, Dec. 26, 1863, XXXII, p. 925. London, 1863.

Plant, Nathaniel. - The Brazilian coal fields. Geological Magazine, April, 1869, VI, 147-150. Separate pp. 1-4. Abstract: Neues Jahrb f. Mineral., 1870, 663-664.

Plant, Nathaniel. - The coal-fields of the River Jaguarão, and its tributaries the rivers Candiota and Jaguarão-Chico in the Province of Rio Grande do Sul. Appendix $H$ of Brazil and the Brazilian. By Rev. James C. Fletcher, and Rev. D. P. Kidder, 9th ed. pp. 933-935, London, 1879. 
PLANT, Nathaniel.- Report on the coal mines of River Jaguarão, in the Province of São Pedro do Rio Grande do Sul, Brazil. Reports received from Her Majesty's Secretaries of Embassy and Legation respecting coal, \&c. Presented to both Houses of Parliament, \&c., 1867, pp. 20-24. London, 1867. (This forms part of the report of $\mathrm{Mr}$. Pakenham q. v.)

Plant, Nathaniel. - (Coal in Brazil). Report of the commissioners appointed to inçuire into the several matters relating to coal in the United Kingdom. Vol. III, pp. 261-263, ' $^{\circ}$, London, Eyre and Spottiswoode, 1871. (The same article is listed under Miers; it is signed Nathaniel Plant and dated May 1868.)

Rechsteiner, Gaspar.- Carvão de pedra (do Rio Grande do Sul). Carta ao presidente da provincia sobre a qualidade e quantidade. Auxiliador da Industria Nacional, n. 11, novembro de 1882, L, pp. 255-256. Rio de Janeiro, 1882 .

REvaULT, B.-Sur une nouvelle Lycopodiaccis houillière Lycopodiopsis derbyi. Note de M. B. Renault, presentée par M. Duchartre. Comptes Rendus de l'Acad. Sci., 1890, CX, 809-81I. Paris, 1890. (Fossil Plants from Piracicaba, S. Paulo.)

RENAULT, B.- Note sur une Lycopodiacée arborescente du terrain houilier du Brisil. Bul. Soc. Hist. Nat. d'Antun, t. III, 109-124. Plate I.Y.

Revault, B.- (Nota sobre fosseis carboniferos ou permianos de Piracicaba, S. Pauln). Revista de Engenharia, n. 235, 14 de junho de 1890. XII, 13\%. Rio de Janciro, 1890.) Alsstract of the parel in Comptes Rendus, 1890, CX, 809-811.)

Saintr-IIllaire, August de.-Province de S. Pedro do Rio Grande du Sul. Nouv. Ann. de Voyages. L'II, 236-257, Puris, 1833.

Santos, Dr. José Americo dos. - Mlinas de carvão do Arroio dos halos na Provincia do Rio Grande do Sul. Revista de Engenharia, 28 de setembro de 1883, V, 259-260. Rio de Janeiro, 1883. Tests and general geology.

Santos, Dr. José Americo dos.- Minas de carvão de pedra do Arroio dos Ratos. Revista de Engenharia, 28 de agosto de 1883, T', 230. Rio de Janeiro, 1883.

ScHUltz, Woldemar. - Studien über agrarische und physikalische Verhältnisse in südbrasilien mit einem Atlas. Leipzig. E. J. Günther, 1865. $8^{\circ}, 22$ k pages. (Pages 209-22k contain a Beilage 5569 
on Mineralogy by Gustav Jenzsch). (The atlas gas, geologic sections.)

ScIultz, Wroldemar. - IIistorisch-geographisch-stalistiche Skizze der Kaiserlich-brasilianischen Provinz Rio Grande do Sul. Nach officiallen Angaben und eigener Auschauung. Zeitschritf für Allgemeine Erdkunde, N. F. IX, 194-217; 285-308, Berlin, 1860.

Scotr, D. II. - Studies in fossil Jotany. XIV, 553, $8^{\circ}$, ill. London, Adam \& Chas. Black, 1900. "'saronius brasilicnsis, pp. 271-275.

Scote, 11. Kildurn.- The mineral resources of the state of Rio Grande do Sul, Brazil. Trarsactions of the Institution of Mining Engineering, $\mathrm{XXV}, 510-528$. London and Newcastle-upon-Tyne, 1903. Parts of this article without the author's name appear in Brazilian Mining Revicto I, 206-207; 215-218. Rio de Janeiro, 1904 .

SEIVARD, A. C. - Floras of the past; their composition and distribution.

- Nuture, oct. 8, 1903, pp. 556-568, London, 1903. (Permc-Carb. flora of $\mathrm{S}$. Brazil.)

SiEmiradzki, Jos. v.- Geologisch Reisebeobachtungen in Süd-brasilien. Sitz. Ber. Akad. W'iss. Mat-nat. CI. Bd. Abt. I p. 23-39. I Taf., 1 fig., Tien, 1898.

SiEmiRADZKI, Josef. - Bogactwo kopalniane brazylijsliego stanu Palaná. Pragel emigracyjny, Lcmberg. 2, 153-15\%. (Mining properties of the state of Paraná, Brazil.)

Sineil, Francisco R.-A formação geologica de Porto Alegre (Rio Grande do Sul). Publicada no jornal A Federação, Porto Alegre, Biazil, 12 de abril (n. 86), 14 de abril (n. 87), 16 de abril (n. 89), 18 de abril (n. 91), 26 de abril (n. 97) e 29 de abril (n.99) de 1902.

Santu, Herbert H. - Geologia do Rio Rio Grande do Sul. Annuario do Estado do Rio Grande do Sul para o anno de 1901. Publicado sol, a direcrão de Graciano A. de Azambuja. 120, pp. 113-122. Porto Alegr'e, 1900. Compilation from Smith's paper on "The Nat. Brazilian Expedition " in the Anerican Naturalist. 1883, 188毛, q. v.

Solxis-Laubaci, H. Grafen zu.- Ueler die Schidksale der als Psaro. nias brasiliensis beschriebenen Fossilreste unserer Museen. (Futichnift zur Feiel des siejgigsten Geburtstages des Ilerrn Professor Di. Paul Ascherson pp. 18-26. 8, Leipzig, 1904.) 
Solms-Laubach, H. Gräen zu.- Fossil botany, Jeing an introduction to palaeophytology. Translation by Fenry E. F. Garnsey, Revised by K. B. Balfour, Oxford, Glarendon Press, 1891. (''saronius flom Brasil) pp. 170-171.

Souz, D, Diogo de.-(Carvão de pedıa na Capitania de S. Pedro.) Officio dirigido ao Conde das Galveas, 29 de marco de 1812. Revista Inst. IHist., XLI, parte 1, 365r366. Rilo de Janeiro, 1878.

Thornton, Edivard.- Report on the existence of a large coal-field in the provience of Sta. Catherine, Brazil. Quart. Jour. Geol. Soc , June, 1867, 386-387. London, 1867. Abstract: Geological Maga sine, vol. VI, p. 420. London, 1867.

Thornton, Edward. - Coal fields in the Province of Sta. Catherine. Reports received from Ijer Majesty's Secretaries of Embassy and Legation respecting coal. (In continuation of papers presented in 1867), pp. 7-8. (Parliamentary Papers) $4^{\circ}$, London, 1868.

Van LEde, Carlos.-Geologia da Provincia de Santa Catharina. Artigo extrahido da Memoria Historica, Estatisca e Commercial. . . sobre a Provincia de Santa Catharina, e vertido em vulgar pelo Dr. A. M. de Miranda Castro. Revista Trimensal do Instituto Historico, VII, 87-93; 178-195. 2nd. ed. Rí de Janeiro (2nd. edicão, 1886), 1845.

WaAgen, W.- Mittheilung eines Briefs von IJerrn A. Derly übser Spuren einer, carbonen Eiszeit in Südamarika - Neues Jahrbuch Min., G. u. P., 1888, II, 172-176.

Tragoner, L. - Paraná e Santa Calharina. Revista Industrial, Janeiro de 1878, vol. Il, pp. 9-10. New York, 1878. Notes on geolugy and physical fealures. Dated Jeffer:son, Texas, Nov. 2, 1877.)

Wappaeus, J. E. - A Geographia Plıysica do Brazil. Refundida (edição condensada.) Rio de Janeilo, Typ. Leuzinger \& Filhos, 1884. Chap. IY, aspecto physiro, montanhas e chapadões, pp. 36-13. By O. A. Derlsy, q. Ү. Chiap. Y, estructura geologica e mineraes, pp. 44-59, with map. By O. A. Derby, q. v.

Weiss. - Ueber das südliche Ende des Gebirgszuges ron Brazilien in der Provin\%. S. Pedro do Sul und der Banda Oriental oder dem Staate von Mrontevidéo; nach den Sammlungen des IIerrn Fr. Sellow, von. IIrn. Weiss. (Gelesen in der Acad. der. Wrissenschaften am 9 August, 182-, und Juni, 1825, In-f". 2 plate, pp. 217-293. Phys. Klasse, $18: 7$ (Berlin) 1828. 
THirte, David. - Flora of the Brazilian coal measures. Science. XXI, 700. May, 5, 1905.

White, I. C. - The coal measures of Brazil. Science, XXI, 699-700. May 5, 1905.

White, I. C. - Advance notice of Final Report as Chief of the Brazilian Coal Commission from July 1st 1904 to May 31st 1906, giving classification of the Carboniferous and Triassic rocks of South Brazil ; Also notice of accompanying memoir by Dr.J. H. Mc. Gregor ou Mesosaurus brasiliensis and by Mr. David White on the fossil plants (Glossopteris, Gangamopteris, flora) collected by the Coal Commission, Science, vol. XXIV. pp. Aug. 31, 1906.

Woodward, A. Smith. - On some Dinosaurian bones from South Brazil. Geological Magazine, X, 512. London, Nov. 1903. (Traces of Gondwana-land fauna from red beds of Rio Grande do Sul.) Also abstract in Rep. r3d meeting Brit. Assoc. Adv. Sci., p. 663. London, 1904 (from Rio Grande do Sul.) (Probably first traces of Gondwana-land fauna in S. America).

Xarier, Fontoura. - The mineral wealth of the Republic (of Brazil) Quoted from the International economist in the Monthly Bulletin of the International Bureau of Amer. Republics. XII, 1423-1426. Washington, 1903.

ZEILLER, R. - Sur quelques empreintes vegetales des gisements houilliers du Brésil meridional. Comptes Rendus de l'Acad. Sci. CXxI, 961-964. Paris, 1895.

ZEILLER, $R^{\cdot}$ - Note sul la flora fossile des gisements houillers de Rio Grande do Sul. Bul. Soc. Geol. de France, 3d ser., XXIII, 601-629 (3 plates), Paris, 1895.

Zeiller, R. -Sur un Lepidodendron silicifié du Brésil. Comptes Rendus de l'Acad. Sci., CXXVII, 245-247. Paris, 1898. 


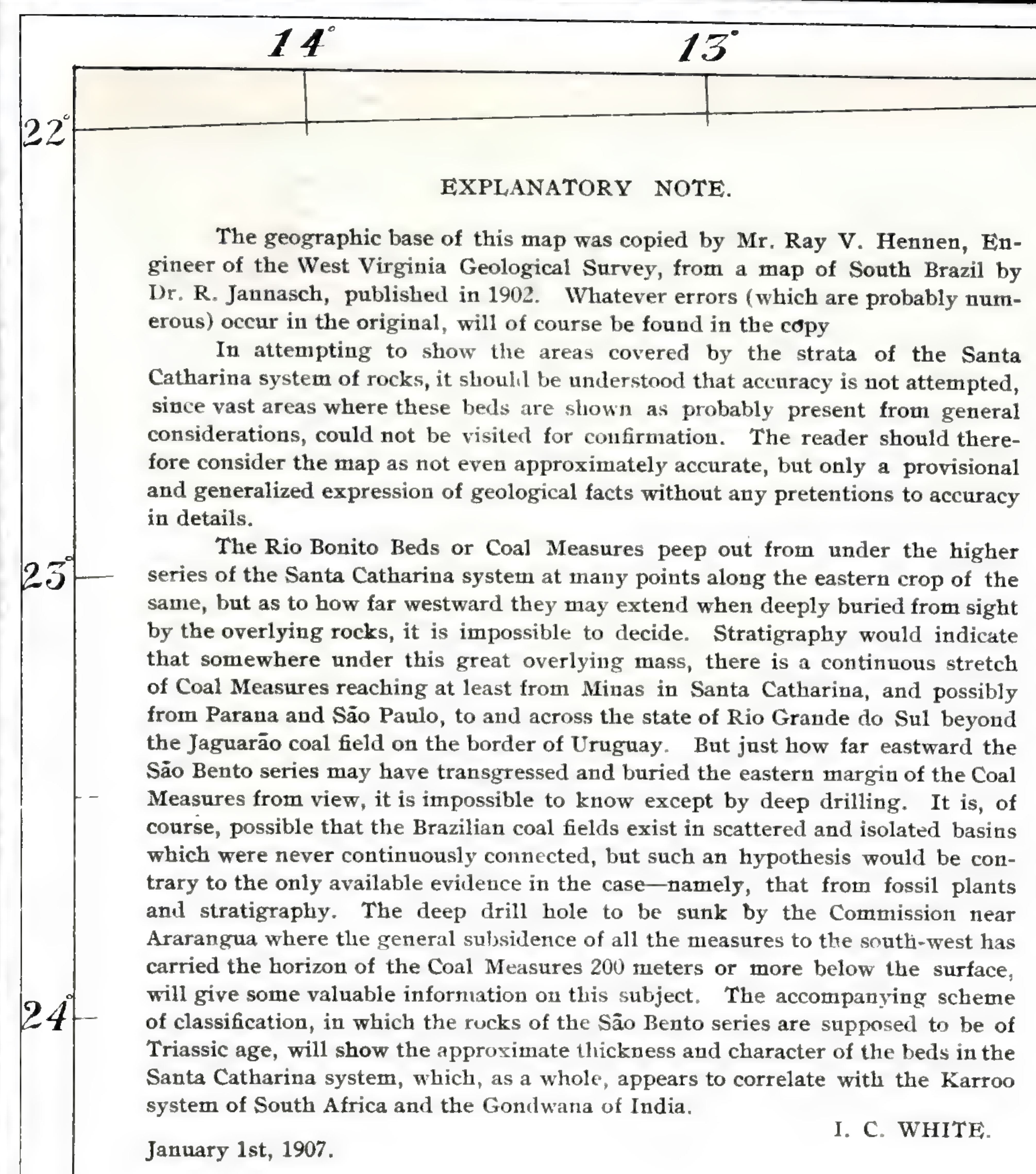

$12^{\circ}$ neer of the West Virginia Geological Survey, from a map of South Brazil by erobably num-

In attempting to show the areas covered by the strata of the Santa Cactharin is not attempted, werl

ler the higher would indicate that somewhere under this great overlying mass, there is a continuous stretch ing scheme January 1st, 1907.

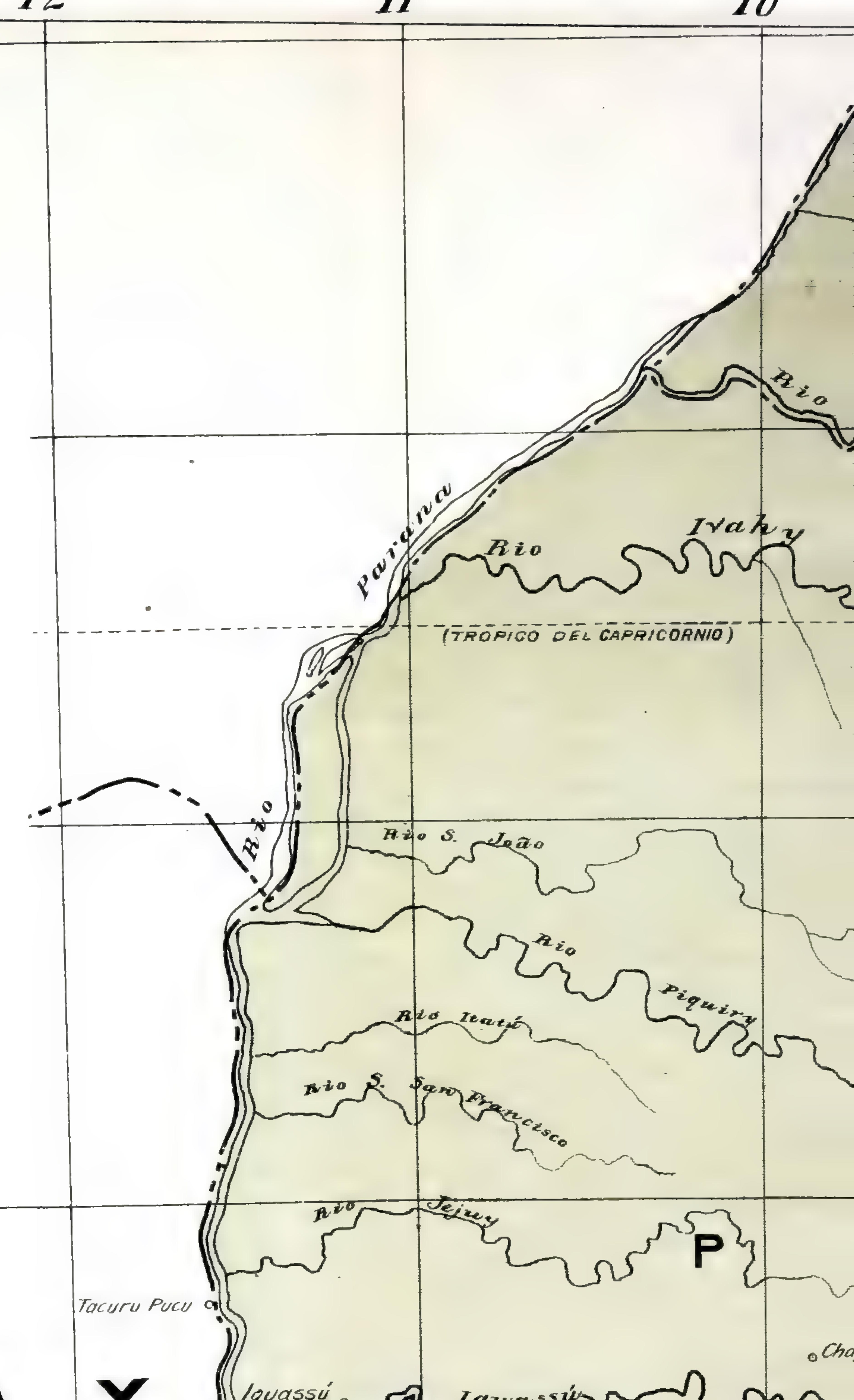

$\begin{array}{llllllll}P & A & R & A & G & \text { U } & A & Y\end{array}$
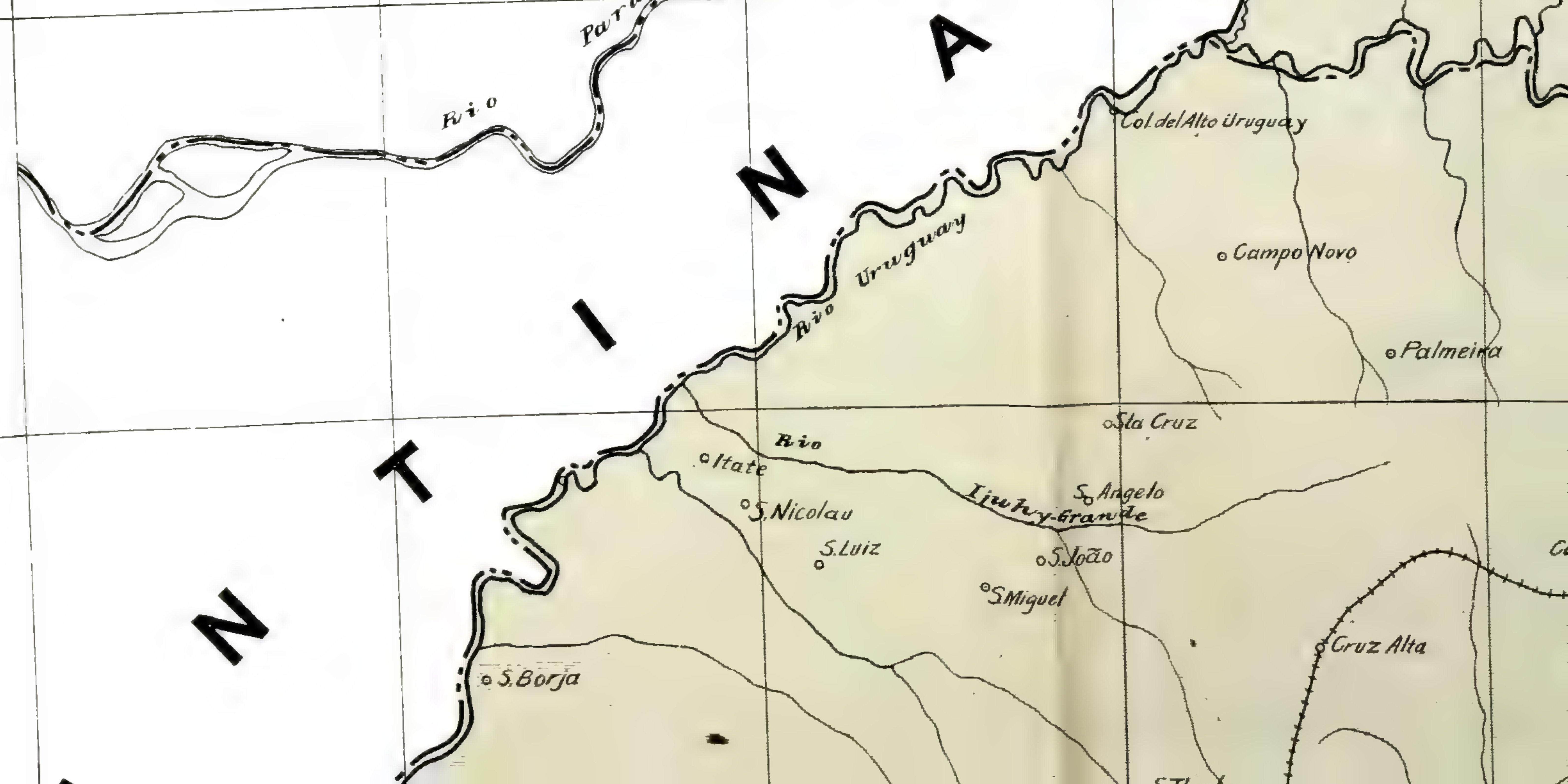


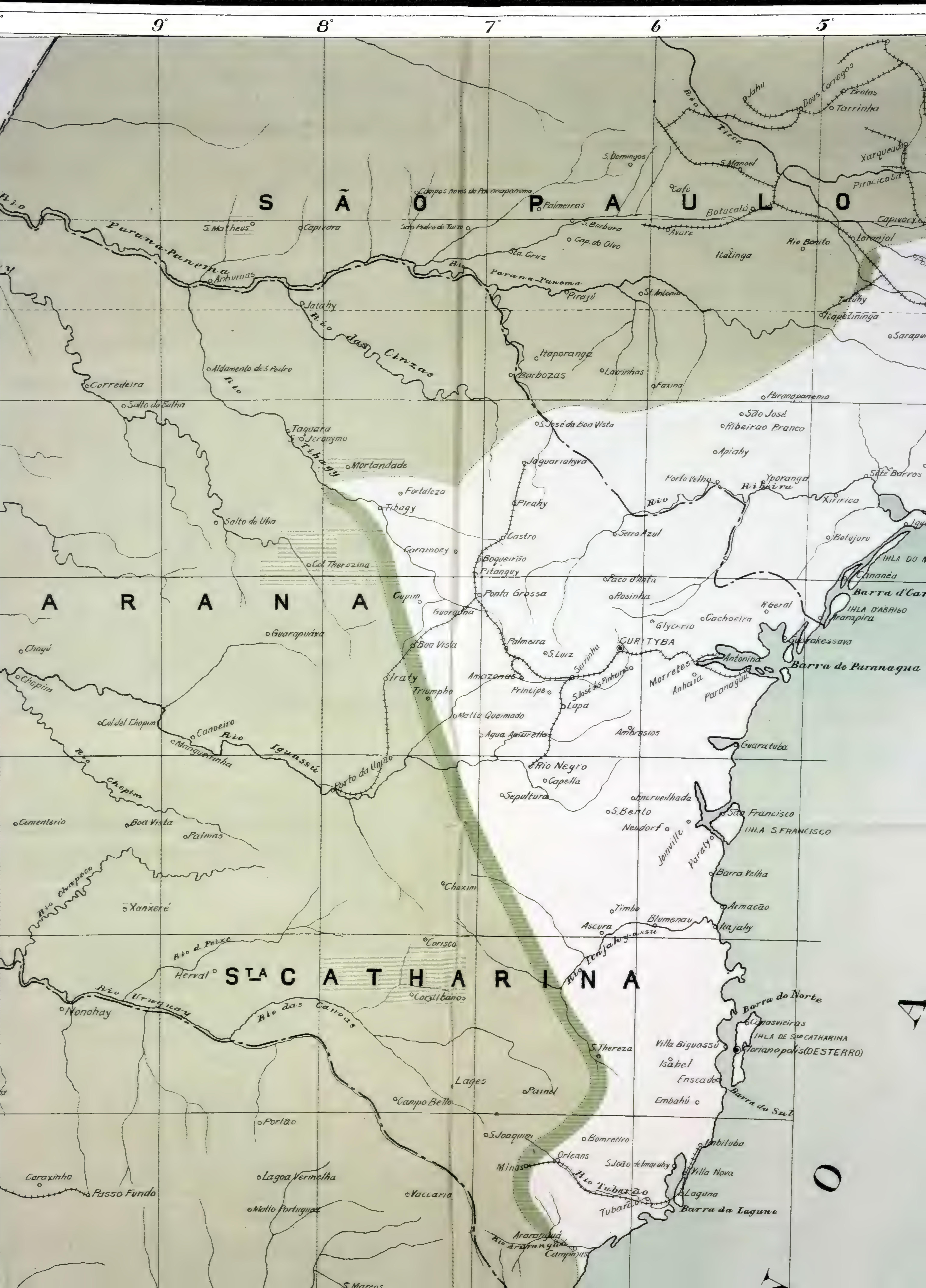



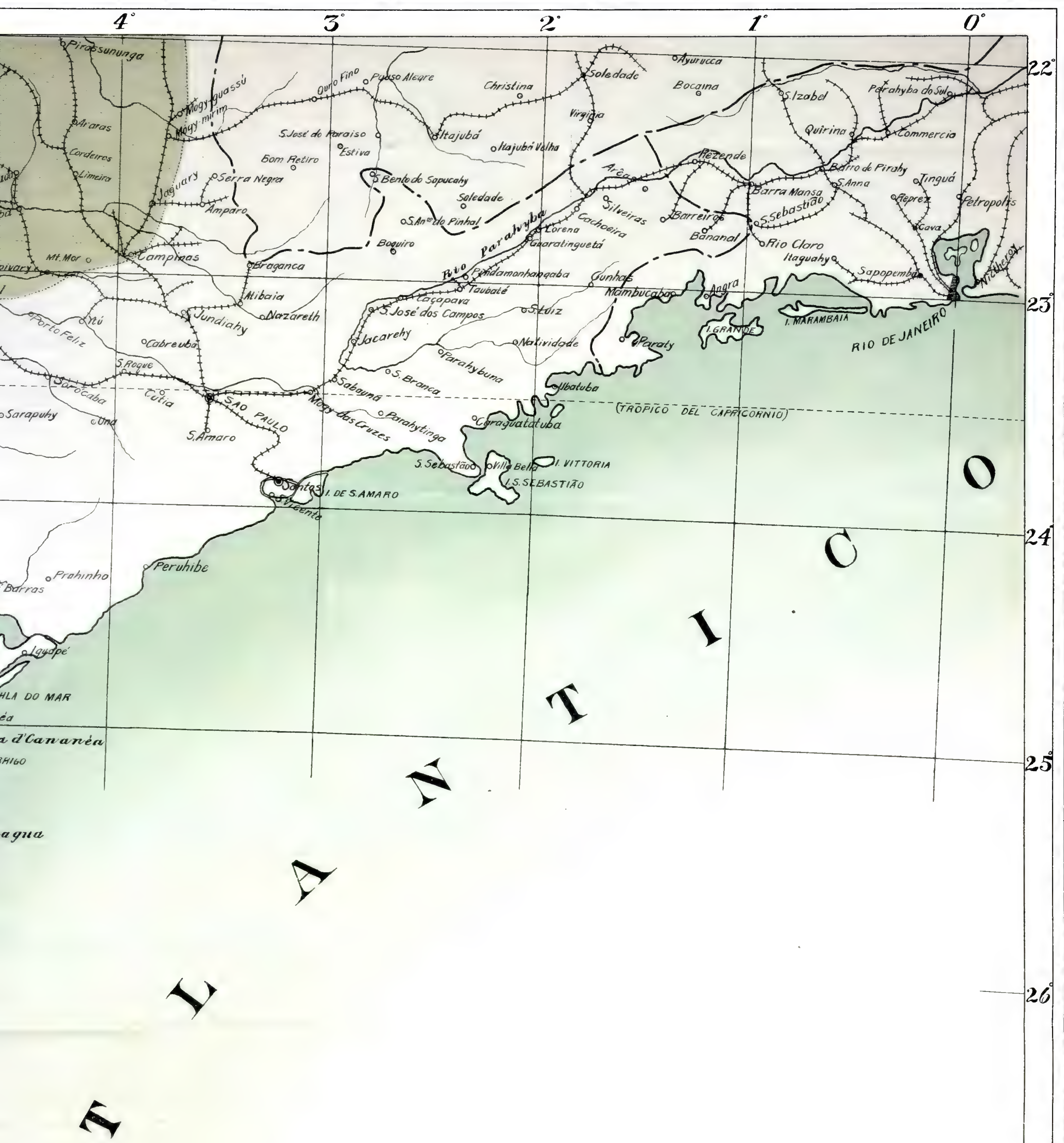

NOTA EXPLICATIVA

A base geographica deste mappa foi copiada pelo Snr. Ray V. Hennen, Engenheiro da Commissão Geologica de West Virginia, de um mappa do Sul Brasil, pelo Dr. R. Jannasch, publicado em 1902

Quaesquer erros (que sāo provavelmente numerosos) que occorram no original serão, portanto encontrados na copia.

Na tentativa feita para indicar as areas ou de se encontram as estratificacoes do systema de rochas de Sta. Catharina, deve se entender que nāo se conseguio toda exactidāo camadas estam indicadas como provavelmente presentes, em virtude, pois que vastas areas em que estas ser percortidas para verificacão. O leitor deverá, portanto, contude de consideracoes geraes, não poderam imarlamente correcto mas con mesmo como approxexpressäo generalisada e provisoria de factos geologicos em nenluuma pretensáo a exactidão em detalhes.

Os leitos, ou camadas de carvão do Rio Bonito se destacam de sob as altas series do systema de Sta. Catharina, em muitos pontos ao longo dos affloramentos éste das mesmas, mas e impossivel dizer a que listancia a oeste ellas se estendem, quanlo fóra de vista, profundamente soterras sob as roch a iores. A estratigraphia indicaria que, eni alyumas partes, sob eta gra uma serie continua de camadas de carvâo, ao menos le Minas em Sta Cathe de rochas superiores, ha Parana e São Paulo até o Estado do Rio Grande do Sul ing no limite do Uruguay.

É impossivel, pore

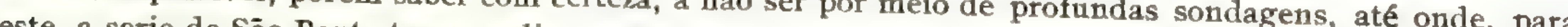
post a das camadas carboniferas. $\mathrm{F}$ entretanto

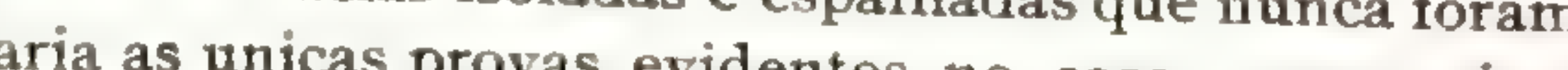
as plantas fosseis e e tratipra Ararangua onde a estratigraphia. A profunda sondagem que prove se a 200 metros, o mergulho de torlas as camadas para sudoeste, levo de classificacāo quis, abaixo da superficie, fornecerá alguns dados valiosons sobre esta questáo. O schema mostra a espessura approximada conjuncto parece relacionar - se com de Sta. Catharina, que em set 


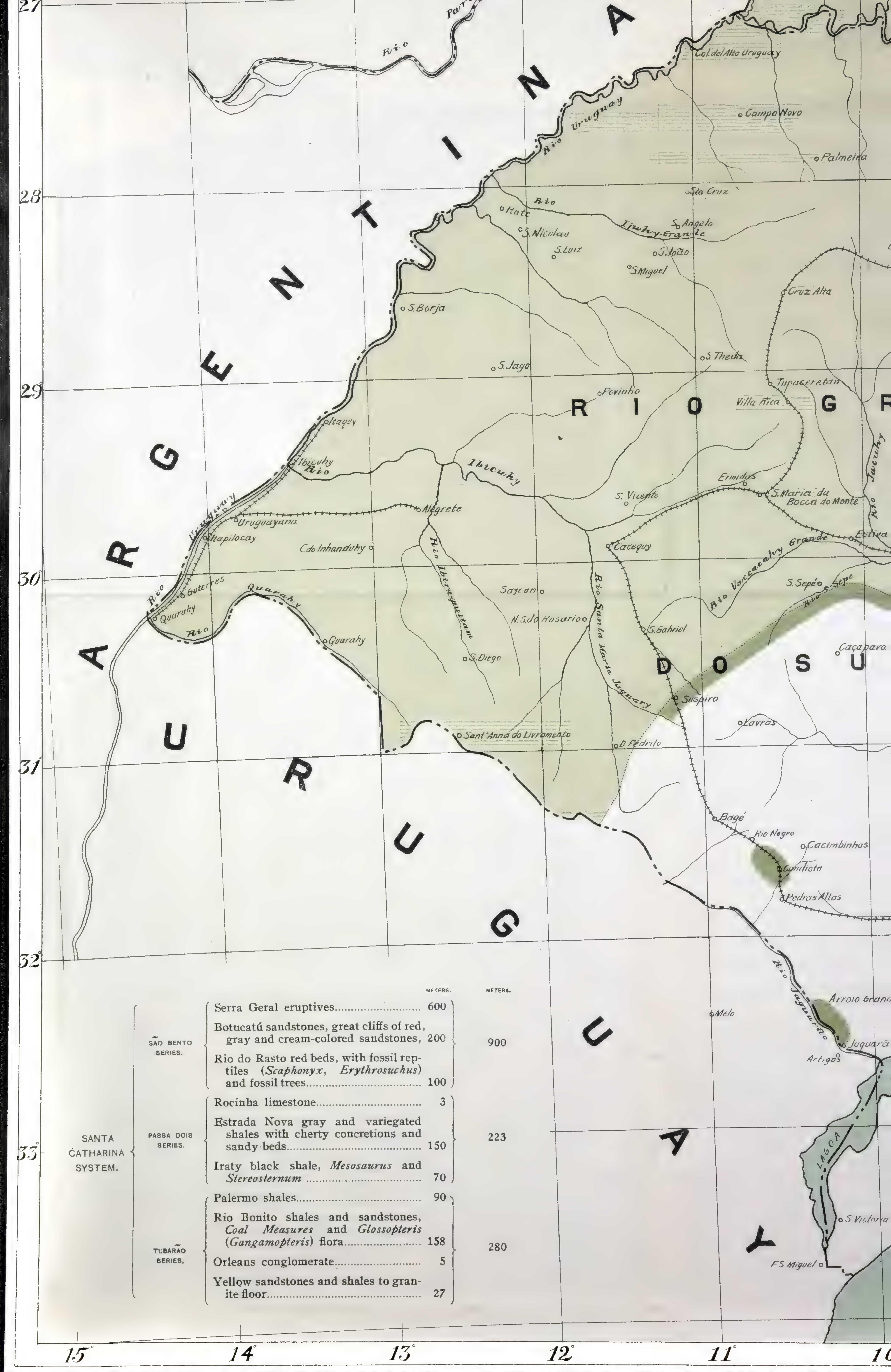


A base geographica deste mappa foi copiada pelo Snr. Ray V. Hennen, Engenheiro da Commissão Geologica de West Virginia, de um mappa do Sul Brasil, pelo Dr. R. Jannasch, publicado em 1902.

Quaesquer erros (que são provavelmente numerosos) que occorram no original serâo, portanto encontrados na copia.

Na tentativa feita para indicar as areas ou de se encontram as estratificacoes do systema de rochas de Sta. Catharina, deve se entender que não se conseguio toda exactidāo, pois que vastas areas em que estas canadas estam indicadas como provavelmente presentes, em virtude de consideracöes geraes, näo poderam se $r$ percorridas para verificacảo. O leitor deverá, portanto, considerar o mappa, nem mesto comoderam imadamente correcto, mas somente, como uma expressäo generalisada e provisoria de factos geologicos sem nenhuma pretensão a exactidäo em detalhes. Os leitos, on camadas de carväo do Ris

Catharina distancia, em muitos pontos ao longo dos affloramentos éste das mesmas, mas e impossivel dizer a que istancia a oeste ellas se estendem, quando fóra de vista, profundamente soterradas sob as rochas superiores. A estratigraphia indicaria que, em algumas partes, sob esta grande massa de rochas superiores, ha uma serie continua de camadas de carvão, ao menos de Minas em Sta. Catharina e provavelmente do Parana e São Paulo até o Estado do Rio Grande do Sul inclusivo e alem da bacia carbonifera de Jaguarão no limite do Uruguay.

É impossivel, porem saber com certeza, a nâo ser por meio de profundas sondagens, até onde, para oeste, a serie de São Bento transgredio e soterrou a margem éste das camadas carboniferas. possivel que a formacáo carbonifera do Brasil se componha de bacias isoladas e espalhadas que nunca foram continuamente ligadas; tal hypothese, porem e contraria as unicas provas evidentes no caso, camo foram as plantas fosseis e a estratigraphia. A profunda sondagem que deve ser feita pela Commissäo pejam Ararangua onde o mergulho de todas as camadas para 200 metros, ou mais, a (a) mostra a mostra a espessura approximada e o caracter das camadas do systema de Sta. Catharina, que em seu conjuncto parece relacionar-se com o systema de Karroo da Africa do Sul e o Gondwanna da India.

\title{
MAPPA GEOLOGICO
}

\section{DO}

\section{SUL DO BR ASIL}

MOSTRANDO APPROXIMADAMENTE AS AREAS OCCUPADAS PELAS ROCHAS DO SYSTEMA DE STA. CATHARINA.

POR

\section{C. W H I T E}

CHEFE DA COMMISSÃO DOS ESTUdOS DAS MINAS DE CARVÃo DE PEDRA DO BRASIL.

\author{
RAY V. HENNEN, Desenhista. \\ ESCALA, $1: 2,010,365$
}

\section{OMMISSÃO 1905-6.}

TE, Chefe da Commissão.

e Paula Oliveira, $1^{\circ}$ Engenheiro.

reira, Secretario.

pos, Engenheiro ajudante.

osé dos Santos, Engenheiro ajudante.

دlo de Oliveira, Engenhéiro mecanico.

-Carthy, Engenheiro mecanico.

Dahne, Conductor.

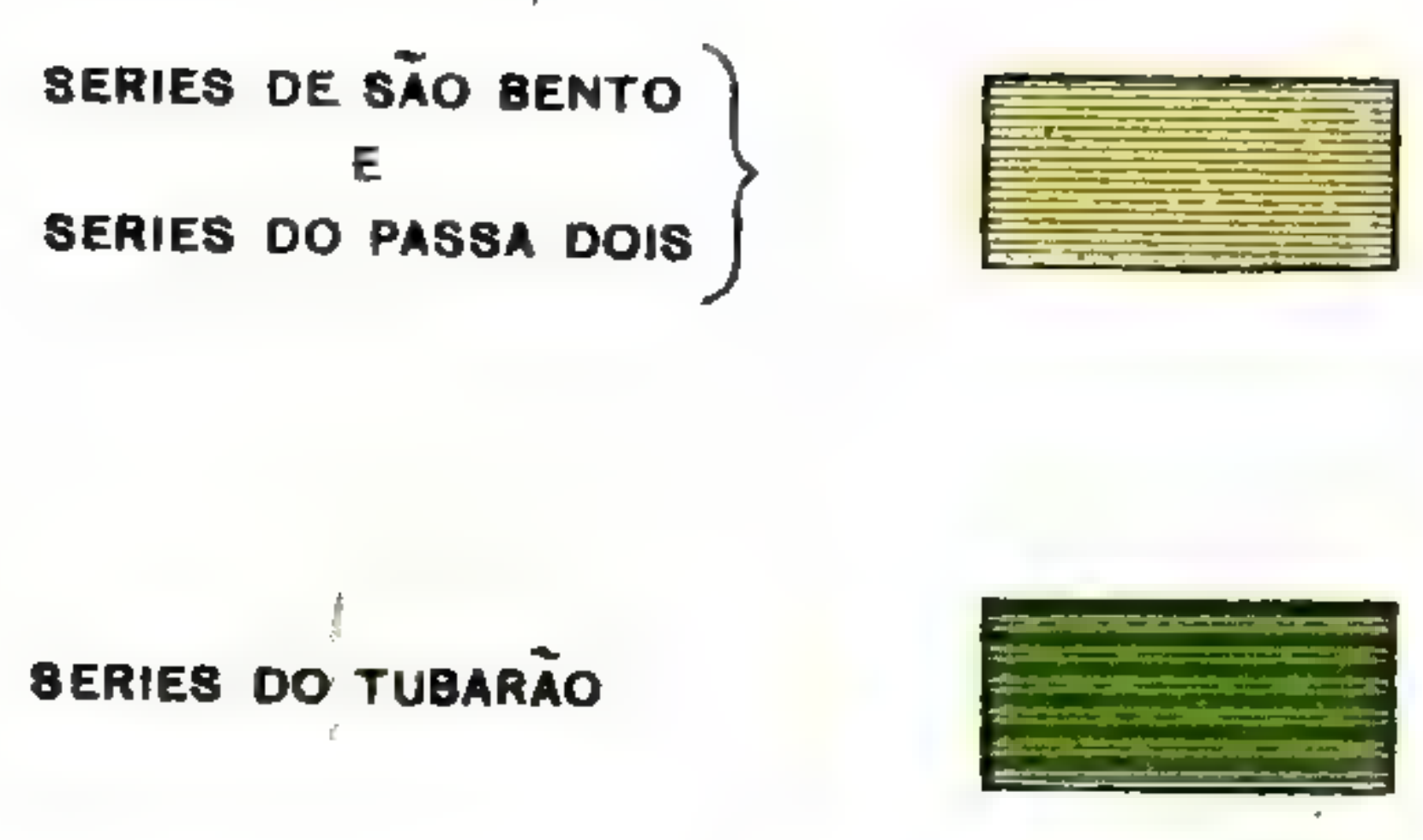



PARTE II

\title{
MESOSAURUS BRASILIENSIS nov, sp.
}

Do

\author{
Permiano do Brasil \\ POR \\ J. H. Mac Gregor \\ DA
}

COTUMBIA LNIYERSTTY, NEW YORK

PART II

On MESOSAURUS BRASILIENSIS nov. sp.

FROM TIIE

\author{
Permian of Brasil \\ $\mathrm{BY}$ \\ J. H. Mac Gregor \\ COLUMBIA UNIVERSTY, NEW YORK
}




\title{
MESOSAURUS BRASILIENSIS ņov. sp.
}

\author{
no
}

\section{Permiano do Brasil}

Os restos fosseis de reptil, que constituem o assumpto deste relatorio, se encontram em schístos bituminosos do Permiano do sul do Brasil.

A maior parte dis specimens foi colligida perto da estação de Iraty, da E. F. S. Paulo Rio Grande, Estado do Paraná, sendo alguns de uma localidade perto da estação André Rebouças. O material pertence á Commissão do Carvão Brasileiro e foi remettido ao Museu Americano de Historia Natural de New York, pelo Dr. I. C. White, chefe da Commissão. Estudei o material e preparei o seguinte relatorio:

Os restos fosseis se encontram em um schisto bituminoso qu fende-se facilmente no plano do specimen, expondo, deste modo, em alguns casos, quasi o esqueleto inteiro. Alguns ossos foram encone trados em uma argilla côr de ardosia, relativamente livre de substancia bituminosa. A collecção contem tambem um ou dois fragmentos de marga grosseira, em que se encontram alguns ossos desarticulados, pardos e muito duros. Os esqueletos achados no schisto bituminoso estão quasi completamente carbonisados e ás vezes cobertos por uma delicada pellicula de pyrite, são mais molles que o schisto, muito friaveis e expostos ao ar, cahem em pedaços. Tendo em vista esta circumstancia, achou-se que o unico meio de estudar satisfactoriamente os restos fosseis, era remover cuidadosamente os ossos carbonisados e tirar fundições dos moldes. Fizeram-se em primeiro logar, destes moldes naturaes, ou negativos, positivos de gelatina, destes, negativos de gelatina e dos moldes de gelatina. reproducções finacs com gesso. As ieproducçoos em gesso foram coloridas romparundo-se cuidadosamente os originaes com os positivos de gelatina, para differençar o osso da matriz, mostrando assim mais claramento a estructura do esqueleto, que o original. As reproducries foram photographadas pelo Sr. A. Andelson e algumas 


\section{On MESOSAURUS BRASILtENSIS nov. sp.}

FROM TUE

\section{Permian of Brasil}

The fossil reptilian remains which form the basis of the following report occul in biluminous shales from the Permian of Southern Brasil.

Most of the specimens were collected near Iraly station, S. Paulo e Rio Grande R. R., slate of Paraná, while a few are from a locality near André Rebouças station. The material is the property of the Brazilian Coal Commission, and was sent to the American Museum of Natural History, New York, by Dr. I. C. White, Chief of the Brasilian Coal Commission. I have studied the material and have prepared the following report:

The matrix containing most of the remains is a black bituminous shale, which splits rather readily in the plane of the specimen thus exposing, in some cases, almost the entire slieleton. A few bones were found in a slate-colored clay relatively free from bituminous matter, and the collection also contains one or two fragments of coarse marl in which were found a number of disarticulated bone: which are brownish in color and very hard. The slieletons found in the bituminous shale are almost completely carbonized, and occasionally covered with a delicate pellicle of pyrite. They are much softer than the matrix, very friable indeed, and crumble badly on exposure to the air. Owing to this crumbling, it was found that the only way to study the remains satisfactorily was carefully to remove the carbonized bones and to lake casts of the molds. From these natural molds or negatives, gelatine positives were fil'st made, then, from these gelatine negatives, and from the gelatine molds final positive casts were made in plaster of Paris. Aided by careful comparison with the originals and with the gelatine positives, the plaster casts were colored to differentiate bone from matrix, and thus they illustrate the skeletal structures more clearly than do the originals. The casts were photographed by Mr. A. E. Anderson, and some o 
reproduzidas em photogravura nas estampas II, III e IV. As reproducções em gesso foram feilas pelo Sr. Otto Falkenbach, do Museu Americano de Historia Natural.

Quasi á pu’imeira vista, ela claro, que o material comprehendia r'estos de especimens, apparentemente de uma só especie de um pe(queno reptil aquatico. Pela semelhança que mostrava com o Stereosternum tumidum Cope, suppuz que estes restos fosseis poderiam ser desta especie; o estudo detido revelou, porẻm, algumas differenças, sendo a mais importante o numero das vertebras presacras, tendo esta especie apenas 29 , ao passo que o Stereosternum tem $3 \dot{4}$.

Observações cuidadosas, feitas posteriormente, mostraram que esta especie differe do Stereosternum tumidum pelos seguintes caracteres:

1) o craneo ć relativamente maior, sendo mais longo que o pescoro, em vez de ser do mesmo comprimento.

2) Tem sómente 11 vertebras cervicaes em vez de 12 e sómente 18 thoraco-lombares em vez de 22 e deste modo menos cinco presacras.

3) O foramen pubico do Stereosternum é representado nesta especie por um profundo entalho como no genero da Africa do Sul, Mesosaurus (Broom, 1904). Tendo o mesmo numero de vertebras cervicaes que esta fórma e nada havendo em sua estructura em que basear uma separação generica, colloco a especie presente no genero Mesosaurus e proponho a designação especifica brasiliensis.

A fórma geral do Mesosaurus brasiliensis vê-se bem na figura n. 1 do texto e a estampa I é uma tentativa de restauração. As maxillas e dentes e especialmente os membros mostram evidentemente os habitos aquaticos do Mesosaurus, is dentes muito numerosos c aciculares são bem adaptados para apanhar pequenos peixes e uutros animaes aquaticos ageis e improprios para quebrar duras conclias de molluscos. A posição de varios esqueletos fosseis mostra que o pescoço, embora não fosse muito longo, era muito flexivel.

A comparação da posição dos membros em muitos exemplares de Mesosaurus e Stereosternum mostra que nestes Proganosaurios a articulação da espadua tinha a maior mobilidade, ao passo que o cotovello não se apresenta dobrado, ou só levemente, os membros estando estendidos directamente para fóra em angulo recto com o corpo, ou mais commumente dirigidos para atraz, ao longo do corpo. (Estampa II, fig. 2.)

A mão é pequena e tem a palma sempre virada para baixo. Julgo ser provavel que a principal funcecão dos membros anteriores 
them, reproduced in half-tone, are shown in plates II, III, and IV. The casts were made by Mr. Otto Falkenbach of the American Museum of Natural History.

It was obvious, almost at the first glance, that the material comprised the remains of specimens, apparently all of one species, of a small aruatic reptile. The resemblance to Stereosternum tumidum, Cope, was noted and it was supposed that the present remains vere assignable to that species, until careful study revealed a number of differences, the most noteworthy being in the number of presacral vertebrae, the present form having but 29, while Stcreosternum has 34 .

Further careful observation demonstrated divergence from Stereosternum tumidum in the following characters:

1). The skull is relatively larger, being longer than the neck instead of equal in length.

2). There are only 11 cervical vertebrae instead of 12, and only 18 thoraco-lumbars instead of 22 , thus five less presacrals.

3). The pubic foramen of Stereosternum is here represented by a deep notch, as in the South African genus Mesoscrurus (Broom, 1904), and since there is also agreement with that form in the number of cervicals, and no known structure on which to base generic separation, I place the present form in the genus Mesoscul'us and propose the specific name brasiliensis.

The general form of Mesoscurus brasilichsis is well whown in lext-figure 1, and Plate $I$. is an attempt at a restoration. The jaws and dentition, and especially the limbs, bear indubitable evidence of the acquatic habit of Mesosaurus, and the very numerous long needlelike teeth are well-adapted to the capture of small fishes and other active aquatic animals, though not adapted to crushing hard-shelled molluscs. The position of several of the fossilized slieletons shows that the neck, though not extremely long, was very flexible.

Comparison of the positions of the limbs in many cxamples of Mesosturus and Sterrosternum shows that in these Proganosaurians the greatest mobility was at the shoulder joint, while the eljow is usually not at all or but slightly Hexed, the limbs standing out straight at right angles to the hody or more "smmon?y directed backward along the sides. (Pl. II., fig. 2.)

In every case the small manus is placed with the palm downward. It is probable, I think, that the chief function of the fore-limbs in 5500 
era contrabalançar o corpo quando o animal nadava. Nos mem. bros pusteriores o femur projecta-se geralmente para fúra, quasi cm angulo recto com o eixn do corpo, ao passo quз o joelho está quasi compre fortemente dubrado. o pé é muito maior que a mão e os dedos augmentam de comprimento do primeiro para o quinto. o facto de serem os dedos tão direitoi e symetriçamente espaçados, em grande numero de suecimans, rapresentando ar tres especies conhecidas de Proganosaurios, torna virtualmente certo que os pés eram palmados, formando assim um orgĩo efficaz de natarãn.

Os comprimentos relativo: da calseça, pescoço e tronco, medidos em clois cxemplores, estão, maís ou menos, como 13 está para 11 e para 29. O maior cranew da crillecrão tem $110 \mathrm{~mm}$ de comprimento, sendo o comprimento provavel deste exemplal" da extremidade do focinho á Juse da cauda cerca de $1.50 \mathrm{~mm}$. e si lia nesta ceperie a mesma relarão en tre o comprimentu da canda e do tronco rue no Sterentornun,

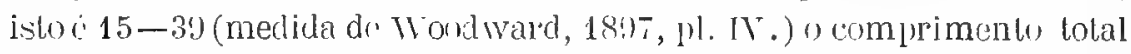
da extremilade do focinho a da cauda s'lo de cerca d: $1090 \mathrm{~mm}$. A maio" jalte porém, dus exemplares conhecidus, incluindu o maior represcntado nas cstampas, nũo excede tres quartos deste tamanho.

Quanto á posicăo systematica dos Proganosaurios, todos os caracteres do cranco, cinta escapular, etc, trazidos i luz pelas presentes investigaçũes, tendem a sustentar a inclusão desta ordem nos Diapsideos. São Diaptosaurios, cujos antepassados provieram de algum pequcno Protolosaurio terrestre, alguma forma nio muito diversa da Palacolbattcria. Considero insustentavel a opinião de Seeley e principalmente de Boulangrer, que estes animacs team affinidado com os primitivos Sauropterygios.

Uma breve diagnose do grupo deve ser como se segue:

Ordem: Prograxosaurin, Baur, 1887.

Definida originalmente pol' Baur, como compusta de replis lendis cinco elementos na sure distal do tarsu.

Familia: Mlesesurti.

(1) sub-ordem Mesosauria, como Secley definiu, 1892, flag. 63\%, não tem valor, pais que comprehendia, alem dos Prugranosaurios, uma segunda divisão Neusticosauria, um srupo de Sauropterysios primitivas.) Lstabeleço para esta familia a scguinte diagnose:

Pequenoz reptis ayuaticu, carrivurn, cum rostrum longo, com narinas externas separadas e collocadas muito 
stvimming was that of balancers. In the hind-limb the femur usually projects outward nearly at right angles to the lyody axis, but the linee is, in almost all cases, strongly flexed. The pes is very much larger than the manus, and the digits increase in length from first to fifth. The fact that the digits are so straight and so symmetrically spaced in a consideralule number of specimens, representing the three known species of Proganosaurians, renders it virtually certain that the pes was welshed, thus forming an efficient swimming organ.

The relative lengths of liead, neck and trunk in tro examples measured, are about in the proportion of 13,11 and 29. Tlie largest skull in the collection has a length of $110^{\mathrm{mm}}$, so that in this specimen the length from tip of snout to base of tail was probably alout $450^{\mathrm{mm}}$, and if the tail bore the same ratio to the length of trunk which obtains in Streosternum, i. e., 15-39, (measured flom Woodward, 1897, Pl. IV.) the total length from tip of snout to tip of tail was ajsout $1080^{\mathrm{mm}}$. Most of the specimens linown, lhowever, including the largest figured in the plates, do not cxceed thrce-fourths this size.

As to the srstematic position of the Proganosauria all the char'acters of skull, shoulder-girdle, etc., ]rought to light in the present investigation tend to support II. F. Oslorn's inclusion of this order among the Diapsida. Tliey are arfuatic Diaptosaurians, the ancestry of which probably leads back to some small torrestrial Protorosaurian, a form not greatly dissimilar to Prifieohatterir. The view held Iy Seeley and Boulenger, namely, that these animals have affinity with primitive Sauropterygians, I regard as (quite untenalsle.

A brief diagnosis of the group may toe given as follows:

Ordel' Promanosatila, Baur, 1887.

Originally defined by Baur as reptiles having five elements in the distal row of the tarsus.

l'amily. Mesnsauridæ.

Thesul).order Mesosauria, as defined by Sceley, 1892, p. is invalid, since it comprised, in addition to Proganosauria, a second division Neusticosauria, (a group of primitive Sauropterysians.) I diagnose the family as follows:

Small aquatic cornivorous reptiles with clongate ros trum, with external nares separate and placed far 
atraz, perto das orbitas. Dentição thecodonte, a maior parte dos dentes muito longos e delicados; pequenos dentes no vomer (pre-vomer). Corpos das vertebras (centra, ou cycleal) muito massicos amphicoeleos. Duas vertebras do sacrum não coalescentes. Exceptuando o atlas, todas as vertebras pre-sacras teem costellas moveis monocandylares, as da região thoraco-lombar muito massiças. Teem costellas abdominaes. Cauda muito longa. Membros adlaptados a natação. Claviculas e interclaviculas bem desenvolvidas, não teem pre-coracoide separado, o coracoide tem foramen.

Os elementos pelvicos não coossificados, pubis com foramen, ou entalho. Carpo e tarso completamente ossificados. Formula digital da mão 2, 3, 4, 4, 3 e do pé 2. 3.4. 5. 3.

Não tem escudos dorsaes :

Mesosaurus, Gervais 1867-9.

Pubis com entalho, cerca de 29 vertebras pre-sacras:

tenuidens, Gervais.

Permiano da Africa Austral.

brasiliensis, Mc Gregor, 1906.

Cabeça mais longa que o pescoç, 11 vertebras cervicaes, 18 thoraco-lombares. Permiano do Brasil.

Stereosternum, Cope, 1885.

Pubis com foramen, cabeça tão longa como o pescoço, cerca de 34 vertebras pre-sacras.

tumidum, Cope, 1885.

12 cervicaes, 22 thoraco-lombares. Pelmiano do Brasil.

\section{Descripção do Mesosaurus brasiliensis}

\section{Craneo.}

Hano material seis sraneos mais ou menos completos. o maior destes, cue está mal conservado, tem $110 \mathrm{~mm}$ de comprimento, dois outros cerca do $85 \mathrm{~mm}$. e um $78 \mathrm{~mm}$. A forma greral do craneo com seu longo focinho c dentes aciculares está ljem patente na estampa IV (figs. 6, 7 e 8). A porçăo craneana propriamente é muito curta, as urandes orbitas estão collocadas muito atraz e dirigidas dorso-lateralmente. As narinas estão muito atraz como nos Phytosaurios e Ichtyosaurios e muito largamente separadas pelos ossos nasaes. Devido ao estado de esmagamento do material, foi impossivel distinguir definiti- 


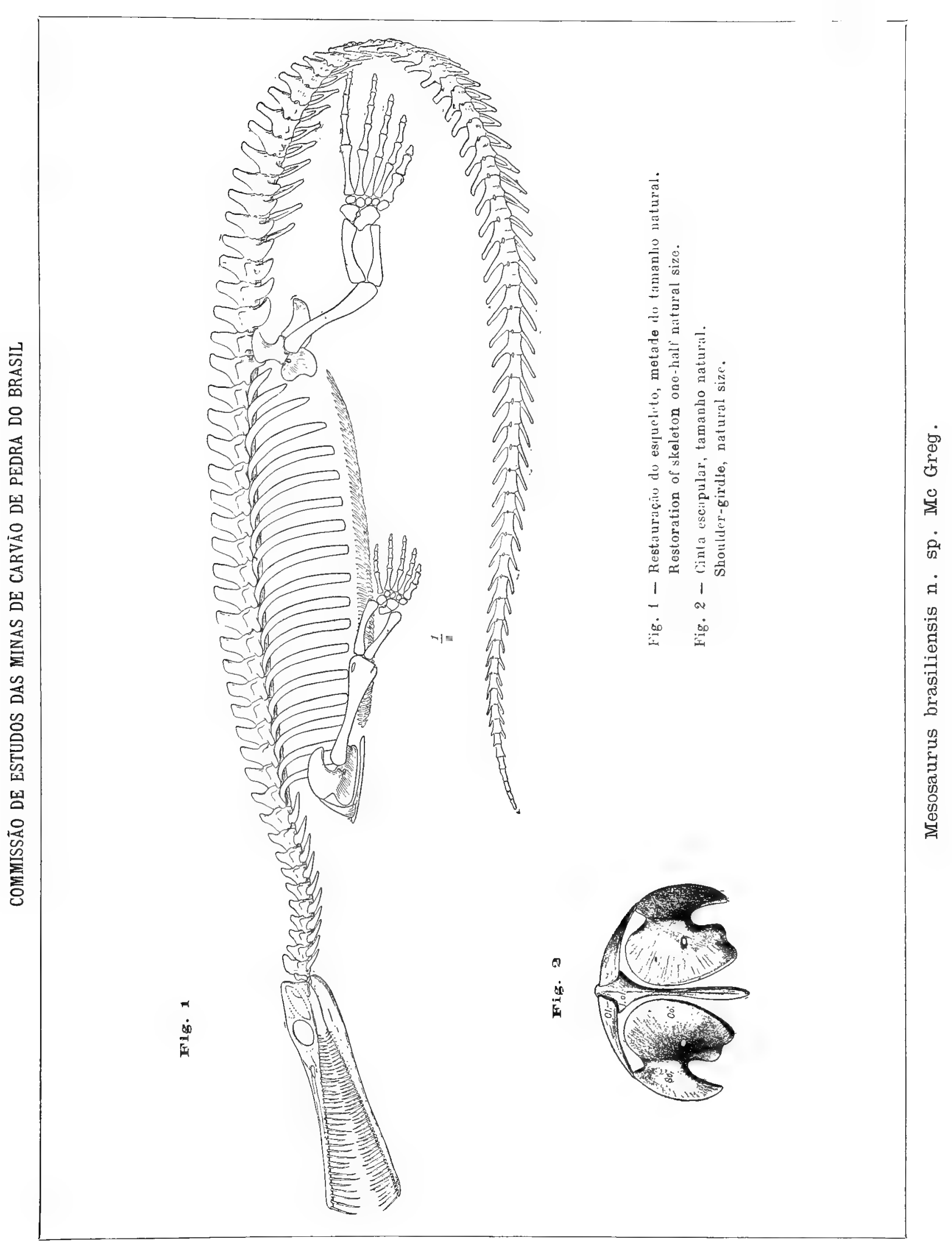



back near the orbits. Dentition thecodont, teeth mostly very long and delicate; small teeth on vomer (pre-vomer). Vertebral centra very heavy, amphicoelous. Two sacrals not coalesced. Singleheaded movable ribs on all presacrals except the atlas, those of the thoraco-lumbar region very heavy. Abdominal ribs present. Tail very long. Limbs adapted for swimming. Clavicles and inter-clavicle vell-developed, no separate pre-coracoid, coracoid with foramen.

Pelvic elements not coössified, pubis with foramen or notch. Carpus and tarsus completely ossified. Digital formula manus $2,3,4,4,3$, pes $2,3,4,5,3$. No osseous dermal scutes.

Mesosaurus, Gervais 1867-9.

Pubis with notch, presacral vertebrae about 29.

tenuidens, Gervais.

Permian of South Africa.

brasiliensis, Mc Gregor, 1906.

Head longer than neck, cervical vertebrae 11, thoracolumbars 18. Permian of Brasil.

Stereosternum, Cope, 1885.

Pubis with foramen head and neck of equal lenght, presacral vertelurae about 34 .

tumidum, Cope, 1885.

Cervicals 12, thoraco-lumbars 22. Permian of Brasil.

\section{Description of Mesosaurus brasiliensis}

\section{Skull.}

The material comprises six more or less complete skulls. Of these the largest, which is ill-preserved, measures $110^{\mathrm{mm}}$. in length; two others, about $85^{\mathrm{mm}} \cdot$; and one $78^{\mathrm{mm}}$. The general form of the skull with its long snout and needle-like teeth is well-shown in Plate IV. (Figs. 6, 7 and 8.) The cranial portion proper is very short, the large orbits placed far posteriorly and directed dorso-laterally, The nostrils are placed far back, as in Phytosauria and Ichthyosauria, and are widely separated by the nasal bones. Owing to crushing of material it has been impossible to discern definitely the structure 
vamente a estructura da região temporal, porém o estudo acurado das reproducř̃es orjiginaes em grelatina, mostra nestes specimens, evidencia da presença das arcadas, tanto supra, como infra-temporaes. O osso jugular é bifurcado como no sphenodon e nos Phytosaurios. A reproducção do tope do craneo, mostra, ou uma pequena fenestra supra-temporal, ou uma post-temporal. Foi impossivel determinar a presença de um foramen pineal. Orondỵlo occipital como se vê em dois especimens, parece ser inteiramente base-occipital, sendo redondo com uma depressão central. Infelizmente se vê muito mal o palatino, e a collocarão das narinas internas não pide ser definitivamente determinada; estando, porém, provavelmente directamente abaixo das narinas externas e largamente separadas pelos vomers. o craneo representado na estampa IV, fig. 8, mostra duas series de dentes perto da linha mediana, provavelmente nascidos na porção prenasal do vomer.

A mandibula é um pouco mais longa que o craneo, devido a um prolongamento post-articular. A symphyse é cerca de dois cquintos do comprimento total, e em um exemplar os dois ramos estão levemente afastados, mostrando que não estavam coossificados. Immediatamente antes do osso articular na superficie dorsal, ha um vacuo de cerca de $15 \mathrm{~mm}$ de comprimento.

Quanto á dentição, si a designação especifica tenuidens não tivesse sido já empregada para o seu congenere da Africa Austral deveria ser applicada á presente especie, pois que, os dentes, exceptuando os vomerianos a que me referi acima, são excessivamente longos, delicados e quasi aciculares, de secção redonda e levemente curvos. Alguns teem $14^{\mathrm{mm}}$ de comprimento com menos de $1^{\mathrm{mm}}$ de diametro. Em um craneo (Estampa IV, fig. 6 ) é possivel contar cerca de 48 alveolos em cada osso dentar, parecem ser menos numerosos na maxilla superior, cerca de 38 de cada lado, masse estendem para traz, ao menos até a or Jita e o bordo al veolar é quasi dividido em premaxillar e maxillar. Naturalmente os dentes são menores na parte posterior da serie. O facto dos dentes estarem dirigidos completamente para os lados, como sa vê na figr. 7, è devido, sem duvida, em parte ao esmagamento. Eram provavelmente cullocados cm vida, muito obliquamente, mas os dentes da maxilla superior e os da inferior, se crusavam certamente algum tanto e penso que é muito pouco provavel que o animal pudesse lechar inteiramente a bocca, um predicado que a muitos outros reptis fuzia solferer.

Os dentes elam frouxamente inseridos nos alveolns relativamente grandes e cahiam facil mente durante a decomposirin das paltes molles. 
of the temporal region, but very carein study of the original gelatine casts shows, in these specimens, evidence of the presence of both supra and infra-temporal arcades, the jugal bone being forked as in Sphenodon and in the Phytosauria. The cast of the top of the skull shows either a very small supra-temporal or a post-temporal fenestra. It was impossible to determine the presence of a pineal foramen. The occipital condyle, as shown in tro specimens, is apparently entirely basioccipital and is rounded with a central depression. Unfortunately the palate is lut poorly shorn, and the internal nares cannot be definitoly located, but they are probably almost directly Jelow the external nares and rather widely separated by the vomel's. The skull figured in Plate IV., fig. 8, shows two rows of teeth near the middle line, probably borne on the prenarial portion of the vomer.

The mandiJle is sightly longer than the sliull, owinğ to a postarlicular rxlensin. The symphysis in about wo-filth of the total lenght, and in one specimen the two sami are slightly pulled apart, showing that they were not conssified. Immediately anteriol to the articular bone on the dorsal surface is a vacuity some $15^{\text {mum }}$. long.

As to dentition, were not the specific name t'muidens preëmpted for its South African congener, it might well be applied to the present species, for the teeth, excepting the vomerine ones ahove mentioned, are exceedingly long and delicate, almost needle-like, round in section, and slightly curved. Some of them have a length of $1 \mathrm{~s}^{\mathrm{mm}}$. with a diameter of less than $1^{\mathrm{mm}}$. In one skull (Pl. IV., fig. 6) it is possible to count about 48 alveoli in each dentary bone; in the upper jaw they seem to be somewhat less numerous, alout 38 on each side, but extend hackward at least to the orbit, and the alveolar horder is about evenly divided between premaxillary and maxillary. Naturally the teeth toward the posteriol end of the series are somewat smaller. The extreme lateral direction of the teeth shown in figure 7 is doubtless due in part to clushing; they probably were not very obliquely placed in life, but upper and lower teeth must certainly have interlocked somewhat, and I regard it as unlikel that the animal was able to close its mouth entirely, a predicate from. which some other reptiles suffered.

The teeth were loosely placed in the relatively large alveoli and fell out readily during decomposition of the suft parts. I believe 
Creio que em vida do animal os dentes podiam ser movidos facilmente, circumstancia que de algum modo impedia que se quebrassem contra os da maxilla opposta, não diminuindo ao mesmo tempo suas vantagens, para a captura das presas.

Quanto á significativa adaptação da dentição, a do Mesosaurus è bem adequada para apanhar e matar rapidamente, presas de pouca consistencia taes como pequenos peixes, larvas de insectos aquaticos, etc.

Columna vertebral.

o presente material é sufficiente para elucidar toda a estructura, quanto á columna vertebral, excepto certos detalhes do atlas e o numero exacto das caudaes, sendo este ultimo, um ponto, relativamente de pouca importancia.

\section{Região cervical.}

o pescôço é comprido, embora um pouco mais curto que o craneo, excessivamente flexivel como se vê pela posição da cabeça em quatro dos exemplares estudados. (Est. III, fig. 4 e Est. IV fig. 10.) Na estampa II fig. 2 o pescoço parece excepcionalmente curto, devido ao facto de estar o craneo deslocado para atraz, cobrindo as quatro primeiras vertebras.

As cervicaes são 11, incluindo o atlas ( como no M. tenuidens, uma menos que no Stereosternum tumidum) e todas exceptoo atlas teem costellas moveis. o corpo do atlas (intercentrum) é alongado transversalmente e varios specimens mostram o que parece serem arcos atlanto-neuraes que estão separados uns dos outros e do intercentrum. 0 axis é mais curto que as vertebras seguintes e tem uma apophyse neural mais alta e mais larga. E' impossivel distinguir o odontoide e nenhuma evidencia de intercentros livres pude achar além do atlas.

Do axis para a decima primeira, ou ultima cervical estas augmentam gradualmente em todas as dimensões, mas especialmente no tamanho do processo arredondado transversal que ha, desen volvido anterolateralmente no centrum e a que se articula a costella mono-condylar. As costellas cervicaes se dirigem obliquamente para atraz e em um specimen a da decima primeira vertebra tem 1 mm $^{\mathrm{mm}}$ de comprimento. Em um caso de incompleto desenvolvimento as costellas cervicaes são truncadas na' extremidade, como no Stereosternum joven representado em figura por Osborn (1903, pp. 484 e 485), que eram sem d uvida terminadas por cartilagem. 
that during life they were rather readily movable, a condition which would, to some extent, prevent their being broken by contact with those opposite, while at the same time not diminishing their efficiency for the capture of prey.

As to adaptive significance, the dentition of Mesosaurus is well fitted for capturing and killing rapidly moving soft prey such as small fishes, aquatic insect larvae, etc.

\section{Vertebral column.}

As regards the vertebral column, the present material suffices to elucidate all structures excepting certain details of the atlas and the exact number of the caudals, the latter a point of relatively little importance.

\section{Cervical region.}

The neck is rather lung, though slightly shorter than the skull, and is exceedingly flexible, as shown by the position of the head in four of the examples studied (Pl. III. fig. 4, and Pl. IV., fig. 10). In Plate II., fig. 2, the neck appear's unduly short, owing to the fact that the skull is displaced backward, covering the first foul vertebrae.

The cervicals number 11, including the atlas (as in . II. tenuidens, one less than in Stereosternum tumidum), and all except the atlas bear movables ribs. The body of the atlas (intercentrum) is elongate transversely and soveral specimens show what seem to be atlantal neural arches which are separate from each other and from the inter. centrum. The axis is shorter than the succeding vertebrae, and has a higher and more expanded neural spine. It is impossible to make out the odontoid and I can find no cridence of any lire: intercentru hehind the atlas.

Pissing bachirard from the axis to the cleventh or last cervical, the vortebrae increase gradually in all dimensions, but especially in the size of the blunt transverse proces's which is develoned anterojaterally on the centrum, and which supports the single-headed rib. The cervical rils; extend obliquelly backward, and, in one specimen, that of the eleventh vertebrae is $1^{m m}$ in length. In an immature. example the cervical ribs are truncate at the extremity, as in the young Stereosternum flgured by Osborn (1903, pls. 484 and 485), and were doubtless tipped with cartilage. 


\section{Regiăo thoraco-lombar.}

As vertebras thoraco-lombares são em numero de 18 ,ou menos quatro que no Stereosternum tumidum, a mais admiravel disparidade em duas formas de relações tãoaffins. Esta porção da columna spinal mede, dando margem para compensar o deslocamento, em tres specimens, $133^{\mathrm{mm}}, 150^{\mathrm{mm}}$ e $163^{\mathrm{mm}}$. Todas as vertebras thoraco-lombares teem apophyses neuraes altas, desenvolvidas longitudinalmente (Est. IV, fig. 10) e os arcos neuraes rião muito entumescidos e se projectam antero-posteriormente em massiças metapophyses (Est. II, fig. 2). As lacetas zygopophysicas são quasi horizontaes. Os corpos das verteJras são pequenos mas expandem-se lateralmente formando processos transversaes massiços (Est. III, fig. 3 e 4), como em outros Mesosaurideos. No pescoço e regiãu thoracica anterior estes processos estão ligeiramente mais para diante nas verteblas, que na região lombar.

\section{Costellas.}

As costellas são muito semelhantes ás de outros membros conhecidos da familia. O unico condylo articula-se frouxamente com uma depressão pouco profunda, apenas uma faceta, no lado inferior do processo massiço transversal. De deante para traz as articulações das costellas deslocam-se da parte anterior para a mediana da vertebra correspondente. A grossura muito grande das costellas, especialmente da metade distal é muito caracteristica de todos os Mesosaurideos conhecidos e lembra as condições algum tanto similares das costellas dos mammiferos da ordem Sirenia. Das dezoito costellas thoraco-lombares desta especie, todas, com excepção das tres ultimas, parecem ser truncadas em sua extremidade distal e parece que eram terminadas por cartilagem e muito provavelmente deste modo articuladas com um esterno cartilaginoso, mas nenhuma porção de cartilagem foi fossilizada em nenhum dos exemplares. As duas ou tres ultimas costellas são mais curtas, terminadas em ponta na extremidade distal, havendo razão para se crer que suas articulações ventraes eram algum tanto mais firmes que as das mais anteriores.

\section{Sacrum.}

Ha duas vertebras sacras permanentemente separadas, como no Stereosternum. No adulto as largas costellas sacras parecem estar anchylosadas com as vertebras, ha porém alguma evidencia que el las se 


\section{Thoraco-lumbar region.}

The thoraco-lumbar vertebrae number 18, ol foul less than in Stereosternum tumidum, a most astonishing disparity in two forms so closely related. This portion of the spinal column measured-with some allorvances for displacements-in three specimens, $133 \mathrm{~mm}$., $150 \mathrm{~mm}$. , and $163 \mathrm{~mm}$. All the thoraco-lumbars bear high, longitudinally expanded neural spines (Pl. IV., fig. 10) and the neural arches are greatly swollen and produced latero-posteriorly in to heavy metapophyses (Pl. II., fig. 2). The zygopoplyysial facets are nearly horizontal. The actual centra are quite small, l,ut expanded laterally into heavy transverse processes (Pl. III., figs. 3 and f), as in other Mesosauridae. In the neck and anterior thoracic regions these processes are slightly further forward on the vertebrae than is the case in the lumbar region.

Ribs.

The ribs are rery similar to those of the other known mombers of the family. The single head articulates rather loosely with a shallow depression, scarcely a facet, on the under side of the heary transverse process. Passing backward the rib articulations recede from the anterior to the middle region of the corresponding vertebra. The very great thickness of the ribs, especially of the distal half, is very characteristic of all known Mesosauridae, and recalls the somewliat similar condition of the ribs in the mammalian order Sirenia. of the eighteen thoraco-lumbar ribs in the present species all hut the last three seem to bo truncated at their distal ends, and apparently were tipped hy cartilages, and very jrolobly thus connected with a cartilaginous sternal apparatus, but nocartilage has been fossilized in any of the specimens. The last two or three ribs are shorter, pointed distally, and there is reason to believe that their vertelural articulation was somewhat more firm than in those more anteriorly placed.

\section{Sacrum.}

There are two permanently separate sacrals, as in Stereosternum. In the adult the broad sacral ribs seem to be anchylosed with the vertebrae, but there is some evidence that they are rather readily se- 
separam facilmente na juncạão (Est. II, fig. 2 e Est. IV, fig. 10, sa 1 e sa 2). Seeley (1002, pag. 599) erroneamente dá quatro sacras ao Stereosternum, seu erro foi devido a incluir nestas as duas ultimas thoraco-lombares.

\section{Região caudal.}

O numero exacto de vertebras não póde ser determinado no presente material, mas provavelmente ha ao todo sessenta, ou mais, como no Stereosternum. As de perto do sacrum teem costellas massiças, anchylosadas com os corpos das vertebras e curvas levemente para traz, perto da extremidade. o comprimento de algumas destas de ponta a ponta é de $40 \mathrm{~mm}$. Além da setima ou oitava caudal as costellas decrescem rapidamente, faltando completamente na maior parte dn comprimento da cauda. Ao mesmo tempo as apophrses neuraes augmentam em comprimento, tornam-se mais finase obliquas. 0 primeiro par de chevrons (forquilhas) está na quinta ver lebra post-sacra. Como no Stereosternum as caudaes medianas mostram um ponto de fractura distincto e em geral a região caudal das duas especies é muito semelhante.

\section{Cinta escapular.}

Até ao presente a cinta escapular dos Mesosaurios era conhecida sómente em parte e as figuras do escapulo-coracoide publicadas por Gervais (1869), Seeley (1892) e Boom (1904) não concordam completamente. No Stercosternum joven, figurado por Osborn (1903, pag. 485), ha uma inter-clavicula alongada e a identificação duvidosa feita por úsỉorn de uma clavicula ficou provado ser correcta pelo estudo deste material que, felizmente contém praticamente informações completas, tanto sobre a porção chondrogenea, como sobre a dermogenea da cinta escapular. o esqueleto representado na estampa III mostra sua face ventral com os clementos praticamente in situ, emquanto que as figuras 10 e 4 mostram respectivamente a fare externa e interna do escapulo-coracoide. A escapula e o coracoido são completamente anchylosados no adulı. o coracoide é oval, ou antes quadrado, e levemente ental hado posteriormente. A fussa glenoide está pratiramente inteiramente no coracoide e é muito pouco profunda. Immediatamente antes da fossa glenoide, no extremo posterior da linha de uniōn da escapula e coraroide, ha uma hossa proeminente, na facc externa c a 3 a $\$ \mathrm{~mm}$. desta bossa o rnracoide i) furado por um pequeno foramen. Não ha evidencia de um preco- 
parated at the juncture (PI. II., fig. 2, and PI.,IV., fig. 10, sa ${ }^{1}$ and sa'). Seeley (1902, p. 599) erroneously reckoned four sacrals in Stereoster. num, his mistake being the inclusion of the last two thoraco-lurnbars.

\section{Caudal region.}

The exact number of caudal vertebrae cannot be determided in the present material, but there are in all probability sixty or more, as in Stereosternum. Those near the sacrum bear heavy ribs, anchylosed with the centra and curving slightly backward near the extremity. The width of some of these from tip to tip is $40 \mathrm{~mm}$. Beyond about the seventh or eighth caudal the ribs rapidly dwindle avay and they are lacking throughout the greater part of the length of the tail. At the same time the neural spines increase in length, and become slender and very oblique in position. The first pair of chevrons are borne on the fifth post-sacral. As in Stereosternum, the mid-caudals slow a distinct "breaking point», and in general the tail region of the two genera is quite similar.

\section{Shoulder girdle.}

Up to the present time the Mesosaurian shoulder-girdle has been known only in part, and the figures of the scapulo-coracoid published by Gervais (1869), Seely (1892), and Broom (1904) do not agree entirely. In the immature Stercosternum figured by Osborn (1903, p. 485) an elongate inter-clavicle was present, and Osborn's doubtful identification of a clavicle is proven to be correct by a study of the present material, which, fortunately, yields pratically complete information regarding both chondrogenous and dermogenous portions of the shouldergirdle. The skeleton figured in Plate IIl, presents a ventral viev with the elements pratically in situ, while figures 10 and 4 show respectively the outer and inner surfaces of the scapulo-coracoid. Scapula and roracoid are completely anchylosed in the adult. The coraroid is of oval form, rather scuare, and slightly notched posteriorly. The glenoid fossa is pratically entirely in the coracoid, and is very shallow. Immediately anterior to the glenoid finsa, at the posterior end of the line of scapula and roracoid, is a prominent boss on the outer surfare and some $3 \mathrm{nl}^{2}$ a $\mathrm{mm}$ from this hass the roracoid is pierced hy a small foramen. There is no evidence of a separate precoracoid, not even a 
racoide separado, nem inesmo de um entalho na margem interna do coracoide e sem duvida como se vê no joven Stereosternum o coracoide se desenvolve de um unico centro de ossificação. Pela posição relativa da clavicula e da escapula e da largura do peito, como está indicada pelas costellas thoracicas anteriores, creio que as brdas internas dos coracoides estavam quasi appostas, ou talvez liz. iramente separadas por estreitas orlas de cartilagem epicoracoideas. A superposição dos coracoides que se vê no specimen de Gervais, de Mesosaurus da Africa Austral (1867-69, Est. xLrI), creio ser derida a deslocamento post-mortem.

A porção escapular do complexo (escapulo-coracoideo) é baixa, larga e flabelliforme, sua fórma lembra a do Mesosaurus, Platecarpus e em menor gráo a do genero ichthyosauriano Mixosaurus e é provavelmente uma adaptação a habitos aquaticos. A estampa II, fig. ‘ e estampa III, fig. 4 mostram muito claramente a face interna da escapula.

A interclavicula é uma haste delgada com uma expansão na extremidade anterior com que se articulam as claviculas. No exemplar maior (Est. III, fig. 5) mede $36 \mathrm{~mm}$. de comprimento, $9 \mathrm{~mm}$. de largura na parte anterior mais larga, ao passo que na parte média mais estreita tem apenas $2 \mathrm{~mm}$. de largura. A parte anterior tem um sulco mediano estreito. A interclavicula é quasi identica á do Stereosternum segundo a figura de Osjorn (1903) e se assemelha muito a de muitos typos de Diapsideos. As claviculas teem $4 \mathrm{~mm}$. de largura nas extremidades internas que se superpoem parcialmente pela face inferior á expansão anterior da interclavicula, se approximando de cerca de $2 \mathrm{~mm}$. Na direcção do escapular a clavicula termina em ponta. No exemplar representado na est. III, fig. 3, a clavicula direita tem $16 \mathrm{~mm}$. de comprimento e mal alcança a borda da escapula. Não é impossivel que dois ou tres millimetros da extremidade externa tenham sido perdidos.

Na figura de Gervais (1867-69, pl. 'LXII) os coracoides são representados se superpondo, devido, creio, a deslocamento, mas si a figura dada por Seeley (1892, pl. XVIII) está desenhada correctamente, não podemos fugir á conclusão que os dois escapulo-coracoides foram deslocados de modo que as escapulas estão com a face ventral para a columna vertebral e as hordas internas dos coracoides estão dirigidas para fóra. As cavidades glenoides apparentes são devidas provavelmente á compressão dos coracoides sobre os liumeros. Acceito que á symetria dos dois lados na estampa de Seeley se oppõe uma tal interprelação, mas a comparação com a estampa de Gervais e com o material muito completo dos dois typos brasileiros que tenho em mãos, não deixa 
a notch on the inner coracoid margin, and undoubtedly, as shown in the young stereosternum, the coracoid developes from a single centre of ossification. From the relation of clavicles to scapulae, and width of chest, as indicated by the anterior thoracic ribs, I believe the inner borders of the coracoid were probably ncarly apposed, or possibly slightly separated by narrov epicoracoidal rims of cartilage. The overlapping of the coracoids in Gervais, specimen of the Soutll African $M e$ sosaurus (1867-69, Pl. XLII), I believe to be due to post-mortem displacement.

The scapular portion of the complex is low, broad, and fan-shaped, its form suggesting that of the Mesosaurus, Platecarpus, and, to a less degree, that of the ichthyosaurian genus Mixosaurus, is probably an adaptation to aquatic habit. Plate II., fig. 2, and Plate III., fig. 4, show very clearly the inner face of the scapula.

The interclavicle is a slender rod, expanded anteriorly for articulation with the clavicles. The largest specimen ( $\mathrm{Pl}$. III., fig. 5) measures $36 \mathrm{~mm}$. in length and $9 \mathrm{~mm}$. in witdth in the expanded portion, while the narrow median part is only $2 \mathrm{~mm}$. wide. The anterior portion shows a narrow median groove. The interclavicle is almost identical with that of Stereosterum as figured by Osborn (1903), and resembles closely that of many diapsid types. The clavicles are some $4 \mathrm{~mm}$. in width at their inner ends, where they partly overlap ventrally the anterior expansion of the interclavicle and approach each other within some $2 \mathrm{~mm}$. Toward the scapular end the clavicle tapers to a point. In the specimen shown in Plate III., fig. 3 , the right clavicle is $16 \mathrm{~mm}$. long and barely reaches the border of the scapula. It is not unlikely that one or lwo millimetres of the outer end have been lost.

In Gervais, figure (1867-69), Pl. LXII.) the coracoids are shown overlapping, due I believe to displacement, but if the figure given by Seeley (1892, Pl. XVIII.) is correctly drawn there is no escape from the conclusion that the two scapulo-coracoids have been displaced, so that the scapulae lie ventral to the vertebral column, and the inner borders of the coracoids are directed outwards. The apparent glenoid cavities are probably artefacts due to crushing of coracoids over the humeri. I admit that the symmetry of the two sides in Seeley's plate seems opposed to such an interpretation, but comparison with Gervais' plate and with the very complete material at hand of the two Brasilian types, leaves no doubt that Seely in his restoration (1902, p. 601) has re- 
duvida que Seeley em sua restauração (1902-p. 601) inverteu os elementos, descrevendo e figrurando a escapula superposta aos coracoides a chamou as partes anterior e posterior dos coracoides, respectivamente escapula e coracoide. Deve-se notar tambem que a estampa de Seeley representando as duas claviculas fundidas em uma unica barra transversal è um erro. Broom (1904, pl. IX) em uma restauração da cinta escapular do typo sul-africano, seguiu o erro de Seeley e inverteu os escapulo-coracoides. Denominou erroneamente as escapulas, precoracoides e representou-as se encontrando na linha mediana e chamou a porção anterior e posterior do coracoide respectivamente escapula e coracoide, como fez Seeley. Estas interpretaçues erroneas de Seeley e Broom são, portanto, devidas ao desiocamento post-mortem da cinta escapular no exemplar de Seeley.

Cinta pelvica.

Os elementos da cinta pelvica săo quasi identicos nesta especie e no Stercosternum, excepto quanto ao foramen do pubis que é representado nesta especie por um entalho profundo, concordando por este caracter com o Mesosaurus sul-africano, segundo a figura de Broom (1904, Est. IN fig. 4) e esta é uma das razões que me levaram a incluil-a no mesmo genero que a fórma africana. A presença do foramen pubico no Stercosternum parece estar definitivamente estabelecida e no material que tenho presente ha cinco pubes em que se vê o entalho profundo no bordo postero-lateral. Esta incisão corta o osso obliquamente, parecendo na face externa um entalho pouco profundo, emquanto que na face interna o é muito mais, com os bordos quasi unidos. (Est. III, fig. 3 e Est. IV, fig. 9 pb.)

o ilium é uma haste curta um pouco dilatada na extremidade superior, ou sacra, mais curta que as extremidades das duas costellas sacras combinadas, com as quaes deveria se articular frouxamenle.

Os tres elementos do pelvis teem uma articulação synarthica firme, não são, porem, coossificados. Os dois especimens em que se veem todos tr'es elementos em suas relações naturaes, teem,. infelizmente, sómente a face interna exposta (Est. IV, fig. 9) de malo que nũo se púde ver o acetabulum. Pelo exame de dois exemplai'es em que está exposta a face externa dos elementos ventraes, creio que o ilium concorria com a maior parte para a formação do acetabulum. O pubis e o ischium formam uma. superficie pelvica quasi 
versed theelements and has described and figure the scapulae as overlapping coracoids, and has called the anterior and posterior portions of the coracoids scapula and coracoid respectively. It may also be remarked that Seeley's representation of the two clavicles as fused into a single transverse bar is an error. Broom (1904, Pl. IX) in his restoration of the shoulder-girdle of the South African type has followed Seeley's error and reversed the scapulo-coracoids. The scapulae he miscalls precoracoids and represents them as meeting in the middle line. The anterior and posterior portions of the coracoid he names respectively scapula and coracoid, as does Seeley. These misinterpretations by Seeley and Broom are, of course, due to the post-mortem displacement of the shoulder-girdle in Seeley's specimen.

Pelvic Girdle.

The elements of the pelvic girdle are almost identical in form with those of Stereosternum, except that the pubic foramen in that genus is here represented by a deep notch. In this character it agrees with the South African Mesosaurus, as figured by Broom (1904, Pl. IX fig., 4) and this is one of my reasons for ascribing it to the same genus as the African form. The presence of the pubic foramen in Stercosternum seems to be definitely established, and in the present material there are five pubes wich show the deep notch in the postero-lateral border. This pubic incisure cuts the bone obliquely, appearing on the outer surface as a shallow notch, while on the inner surface it is much deeper, with its edges almost uniting (Pl. III., fig. 3, and Pl., IV., 9, pb).

The ilium is a short rod somewhat expanded at the upper or sacral end, but shorter 'than the combined extremities of the two sacral ribs, with which its union must have been rather loose.

The three elements of the pelvis have a firm synarthric union, but are not coossified. The two specimens in which all three elements are shown in their natural relation have, unfortunately, only the inner faces exposed (PI. IV., fig. 9), so that the acetabulum cannot be made out. From examination of two specimens in which the outer face of the ventral elements is exposed, I believe the ilium had the greatest share in the formation of the acetabulum. The pubis and ischium form a nearly solid pelvic floor, with a rather 5569 
solida, com um pequeno vacuo pubo-ischio. A pelvis é, em geral, notavelmente semelhante a da Palaeohatteria e deve ser considerada morphologicamente muito primitiva.

Membros.

Os membros são muito semelhantes aos da especie sul-africana e do Stereosternum e estão tão bem representados nas estampas que a descripção verbal deve ser breve. A comparação das figuras de Gervais, Seeley, Broom, Woodward, Cope e Osborn mostra que nos Mesosaurideos os membros anteriores e posteriores são quasi do mesmo tamanho, quanto aos mesopodiaes o carpo e tarso completamente ossificados (no adulto), mas o pé é muito maior que a mão. Uma outra feição notavel é que o braço em quasi todos os casos se estende direito para fóra, ou para atraz (cf. figuras de Gervais, Seeley e osborn e a estampa II deste trabalho), emquanto que a perna está sempre curvada no joelho (cf. figuras de Cope, Osborn, Broom, A. S. Woodward e estampas II e III deste trabalho).

Membros anteriores.

o humero em tanto quanto differe completamente do Stereosternum, parece ser relativamente mais dilatado na sua extremidade distal. São visiveis o foramen ulnocondylar (entepicondylar), bem como na face posterior, um sulco radiocondylar (ectepicondylar). A cabeça do humero é muito simples e apresenta apenas leve indicação de uma crista deltoide.

O radius e ulna são muito approximadamente do mesmo tamanho, sendo o radius levemente mais longo, suas extremidades proximaes estão estreitamente appostas e as extremidades distaes estão afastadas cerca de $5 \mathrm{~mm}$. abraçando entre elles o intermedium. A articulação do cotovello é de caracter muito simples lembrando a dos amphibios urodelos. A comparação deste material com as figuras das formas congeneres dadas por Gervais, Seeley e Osborn mostra o cotovello extendido e a palma dirigida para baixo, em quasi todos os exemplares, bem conservados, justificando a conclusão de que o cotovello era capaz súmente de muito limitada flexão e praticamente incapaz de torsão. A razão do comprimento do braço para o antebraço é exactamente de cerca de dois para um. o carpo é completamente ossificado no adulto, porém em um exemplar joven súmente os elementos proximaes e o 
small puboischiadic vacuity. The pelvis in general is strikingly similar to that of Palaeohatteria, and must be regarded as morphologically very primitive.

\section{Limbs.}

The limbs are closely similar to those of the South African form and of Stereosternum, and are so vell illustrated in the plates that verbal description may well be brief. A comparison of the figures given by Gervais, Seeley, Broom, Woodward, Cope and Osborn will show that in the Mesosauridae the fore and hind limbs are of about equal size, as far as the mesopodials, the carpus and tarsus fully ossified (in the adult), but that the pes is very much larger than the manus. Another striking feature is that the arm, in nearly every case, extends straight outward or backward (ct. figures by Gervais, Seeley and Osborn, and Plate II. in the present paper), while the hind leg is almost always flexed at the knee (cf. figures of Cope, Osborn, Broom, A. S. Woodward, and Plates II. and III. in the present papers).

\section{Fore limb.}

The humerus, in so far as it differs at all from Stereosternum, seems to be relatively wider at its distal extremity. The ulnocondylar (entepicondylar) foramen is conspicuous, and in posterior view a radiocondylar (ectepicondylar) groove is visible. The head of the humerus is very simple and there is only the merest suggestion of a deltoid crest.

The radius and ulna are of very nearly the same size, the radius very slightly the longer. Their proximal ends are closely apposed, but distally they are separated by some $5^{\mathrm{mm}}$., embracing between them the intermedium. The elbow joint is of very simple character, suggesting that of the urodele amphibia. Comparison of the present material and the figures of the related forms given by Gervais, Seeley and Osborn show the elbow extended and the palm directed downward in nearly every well preserved example, justifying the conclusion that the elbow was capable of only very limited flexure and practically no torsion. The ratio of arm and fore-arm is almost exactly two to one. The carpus is fully ossified in the adult, but in an immature specimen only the proximal elements and the second distal were ossified (In a half-grown Stereosternum figured by 
segundo distal eram ossificados. (Em um Stereosternum de meio cresa cimento figurado por Osborn o carpo é completamente privado de ossificação (Osborn, 1903, fig. 17 a). O radial é o maior elemento do carpo e está estreitamente unido ao intermedium.

Em um caso, na verdade, parecem ser coossificados mais isto póde ser artefacto. Entre o intermedium e ulnar ha uma pequena passagem para a transmissão de um vaso sanguineo, provavelmente a arteria perforans mesopodii, como foi descripto no Sphenodon por Howes. o ulnar se articula ao quinto metacarpiano. Dos quatro carpianos, o primeiro é o maior. o primeiro metacarpiano é mais curto e grosso que os ouiros quatro que são quasi do mesmo comprimento. Em nenhum dos exemplares a mão estava completa, mas pela comparação com material do Stereosternum do Museu Americano de Historia Natural, pænso que não ha duvida que a formula phalangeana da mão e: 2,3,4,4,3. A affirmativa de Osborn que o quarto dedo da mão do Stereosternum tem cinco phalanges é erronea, talvez erro typographico, visto que sua figura mostra apenas quatro (Osborn, 1903, p. 488 e fig. 17a). As phalanges terminaes são curtas e conicas e provavelmente tinham apenas vestigios de unhas e ha razão para crer que os dedos eram mais ou menos unidos por uma membrana.

Membros posteriores.

o comprimento do femur é quasi exactamente o do humero. E' cuasi recto, tendo sómente muito leve indicação da curvatura em $\mathrm{S}$ que se vê em muitos typos de reptis. A extremidade proximal é levemente arredondada, mas não ha uma cabeça bem destincta e em nenhum dos seis exemplares estudados se vê trochanter. A extremidade distal tem uma suparficie articular convexa lisa e de forma triangular. Devo me referir acqui novamente ao facto que ambos os generos de Mesosaurideos fossilisados, teem usualmente o femur collocado horisontalmente e approximadamente em angulo recto com o eixo do corpo, com a junta do joelho sensivelmente curvada, lembrando a posição da perna nos amphibios urodelos, quando nadam. Sou inclinado a crer que o movimento na anca era relativamente limitado ao movimento de natação, para diante e para atraz.

A tibia e fibula são praticamente de igual comprimento, cerca de tres quintos do do femur. Em dois exemplares de Stereosternum a razão era de cerca de quatro para sete, rie modo que, tanto quanto póde ter valor esta serie limitada de medidas, parece que no Meso- 
Osborn the carpus is entirely devoid of ossification. Osborn, 1903 , Fig. $17 \mathrm{a}$ ). The radiale is the largest element of the carpus and is in close union with the intermedium.

In one case, indeed, they seem to be coossified, but this may le artefact. Between intermedium and ulnare is a small passage for transmission of a blood-vessel, probally the arteria perforans mesopodii, as described in Sphenodon by Howes. The ulnare gives attachment to the fifth metacarpal. Of the four distal carpals, the first is the largest. The first metacarpal is shorter and thicker than the other four, which are of about the samelength. In none of the specimens was the manus complete, but by comparison with Stereosternum material in the American Museum of Natural History, I think there is no doubt that the phalangeal formula for the manus is $2,3,4,4,3$. Osborn's statement that the fourth digit of the manus of Stereosternum has five phalanges is an error, probably only a typographical error, since his figure shows hut four (Osborn, 1903, p. 488 and fig. 17 a). The terminal phalanges are short and conical and probably boreonly vestigial clavs, and there is reason to believe that the digits were more or less united fy a weh.

\section{Hind limb.}

The length of the femur is almost exactly that of the humerus. It is nearly straight with only the slightest indication of the $S$ flexure seen in many reptilian types. The proximal end is slightly rounded but there is no very distinct head and in none of the six examples studied is any trochanter discernible. The distal extremit? exhibits a convex articular surface of smooth triangular form. I may here again refer to the fact that both genera of the Mesosauridae, as fossilized, usually have the femur placed horizontally at approximately right angles to the body axis, with the knee joint markedly flexed, recalling the swimming position of the hind leg in urodele amplibians, and I am inclined to believe that motion at the hip joint was relatively limited, being chiefly the fore and aft motion of swimming.

The tibia and fibula are of practically equal length, about threefifths that of the femur. In two examples of Stereosternum the ratio was about four to seven, so that, in so far as this limited series of measurements is of value, it appears that in Mesosaurus 
scubrus brasiliensis a tibia é relativamente um pouco mais longa que - femur. A forma dos ossos da perna se vê bem na estampa III, fig. 5; a tibia pesada na parte proximal e pequena na distal, a fibula achatada, larga e curvando-se para fóra da tibia. Na parte distal estes ossos são mantidos afastados pelo grande intermedium que forma um complexo com o tibial. A tibia se articula á porção tibial deste complexo, a fibula com parte do intermedium e tambem com o fibular. o foramen para o vaso sanguineo entre o intermedium e fibular se vê claramente como no Stereosternum e os cinco tarsianos distaes (caracter diagnostico da ordem Proganosaurios de Baur, 1887, pag. 9) são tambem semelhantes aos daquelle genero. o primeiro e quarto são um pouco maiores que os restantes. No material que tenho á mão não encontrei definitivamente differença alguma no pé nos dois generos. O primeiro metatarsiano è o maior e ha augmento regular de tamanho para o quinto dedo, ou post-axial, que tem cerca do dobro do comprimento do primeiro. No Stereosternum o quinto tem quasi exactamente o dobro do comprimento do primeiro, na figura de Broom (1904, est. IX, fig. 5) do Mesosaurus do Sul da Africa tem mais do dobro. Em todas as figuras de pés de mesosaurios dadas por Cope, Seeley, osborn e Broom o quinto dedo é representado curvado levemente para fóra e separado do quarto por maior intervallo, que o que ha entre os outros dedos. A posição similar e o espaçamento regular dos dedos em tantos exemplares, indicam quasi com certeza a existencia de uma membrana natatoria, como disse Osborn (1903, p. 489). A formula phalangiana do pé é : $2,3,4,5,3$ e os elementos terminaes, como na mão, teem apenas vestigios de unhas. E' muito sensivel o grande tamanho do pé em comparação com a mão. Sem duvida aquelle servia mais efficientemente como orgão de propulsão na natação, emquanto que os membros anteriores funccionavam principalmente como balancins. Sou de opinião que estes animaes eram quasi sómente de habitos aquaticos e mal adaptados para se locomoverem em terra, embora fossem, sem duvida, de antepassados terrestres.

Costellas abdominaes, etc.

O plastron de costellas dermicas estende-se de perto da cinta escapular á pelvis, seus elementos componentes (na maior parte de 8 a 13 millimetros de comprimento) estão collocados uns junto dos outros superpondo-se e estão menos regularmente arranjados em series que em alguns reptis, as series latero-longitudinaes são prom- 
brasiliensis the tibia, relatively to the femur, is a little longer. The form of the leg bones is well shown in Plate III., fig. 5 the tibia heavy proximally, small distally; the fibula flattened, broad, and curved away from the tibia. Distally these bones are wedged wide apart by the large intermedium, which forms a complex with the tibiale. The tibia articulates with the tibiale portion of this complex, the fibula with the intermedium portion and also with fibulare. The blood-vessel foramen between intermedium and fibulare, shows clearly as in Stereosternum, and the five distal tarsals (the diagnostic character of Baur's order Proganosauria, 1887, p. 9) are also similar to those of that genus. The first and fourth are slightly larger than the rest. From the material at hand I have not been able definitely to distinguish any difference in the hind feet in the two genera. The first metatarsal is the heaviest, and there is a regular increase in length to the fifth, or post-axial digit, which is nearly twice the length of the first. In Stereosternum the fifth is almost exactly twice the length of the first, and in Broom's. figure (1904, PI. IX., fig. 5) of the South African Mesoscur'us it is more than double. In all the figures of the Mesosaurian pes given by Cope, Seeley, Osborn and Broom, the fifth digit is represented as curved slightly outward, and separated from the fourth by a greater interval than that between the other digits. The similar position and regular spacing of the digits in so many specimens almost certainly indicates a swimming web, as Osborn suggested (1903, p. 489). The phalangeal formula of the pes is $2,3,4,5,3$, and the terminal elements, as in the manus, apparently bore only vestigial claws. The great size of the pes in comparison to the manus is very striking. Undoubtedly the former served as a highly efficient propelling organ in swimming, while the forelimb probably functioned chiefly as a balancer. It is my opinion that these animals were almost wholly aquatic in habit, and ill-adapted for motion on land, though undoubtedly descended from land-living ancestors.

Abdominal ribs, etc.

The plastrom of dermal ribs extends from near the shoulder girdle to the pelvis. Its component elements (for the most part 8 to $13 \mathrm{~mm}$. long) are placed closely together and overlapping, and are less regularly arranged in series - than in some reptiles. Longitudinal lateral series are readily identified, but whether there is a single 
ptamente identificadas, mas não consegui determinar definitivamente si ha uma unica serie mediana, ou duas intero-lateraes, embora a existencia da primeira seja mais provavel. Seeley diz, referindo-se ás costellas abdominaes do $M$. tenuidens "são cinco a seis vezes mais numerosas, que as costellas costaes, e creio que são mais numerosas que no Stereosternum e, talvez, um pouco mais grossas.

Em nenhum dos specimens estudados ha a minima indicação de escudos osseos, ou qualquer especie de armadura dermica e creio que a pelle era protegida, apenas por pequenas escamas corneas epidermicas, ou então era nua como as partes da polle mais protegidas em muitos Testudineos. Alguns ossos mostram uma superficie finamente rugosa, por certo não é a superficie natural do osso, deve ser a impressão de um delicado integumento. A este respeito é interessante notar as recentes observações de Leon Vaillant (1903) que tornou a examinar os specimens originaes de Gervais. Vaillant crê que um pequeno corpo oval figurado na estampa de Gervais e considerado por elle como objecto extranho, - provavelmente uma trilobita, representa uma porção da pelle da face ventral do corpo, coberta com escamas trapezoides semelhantes ás escamas ventraes de certas serpentes. Si a interpretaçăo de Vaillaut é correcta, é certamente notavel que nenhum outro specimen mostre a mais leve indicação de escamas dermicas ou epidermicas. Um exemplar de Stereosternum que examinei mostra o contorno das partes molles muito claramente, não havendo nenhuma evidencia da presença de escudos. 
median series or two inner lateral series-though the former condition is most probable - I have not been able to determine definitely. As Seeley states regarding the abdominal ribs of $M$. tenuidens, "they are five or six times as numerous as the costal ribs", and I believe are more numerous than in Stereosternum, and perhaps somewhat heavier.

In none of the specimen studied 'is there any indication of bony scutes or any sort of dermal armature, and I believe the skin was protected only by very minute horny epidermal scales, or else was naked like the more protected parts of the skin in many of the Testudinata. A few of the bones show a finely wrinkled surface, certainly not a natural bone surface, which may be the imprint of a delicate integument. In this connection it is of interest to note the recent observations of $M$. Leon Vaillant (1903), who has reëxamined Gervais' original specimens. Vaillant believes that a small oval bódy figured in Gervais' plate and by him regarded as a foreign object, probably 'a trilobite, - represents a portion of the skin from the ventral surface of the body, covered with trapezoidal scales resembling the ventral scales of certain snakes. If Vaillant's interpretation is correct, it is certainly remarkable that no other specimen shows the slightest indication of dermal or epidermal scales. One example of Stereosternum which I examined shows the outline of the soft parts quite clearly, but yields no evidence of the presence of scutes. 


\section{Summario das mais Importantes Observações Novas}

(1) O presente material do Permiano do Brazil representa um novo typo de Proganosaurio, muito semelhante nos caracteres geraes ao Stereosternum tumidum Cope, mas differindo deste, por ter o craneo relativamente maior e um entalho no pubis, em vez de um foramen.

(2) Nestes pontos de divergencia do Stereosternum, esta forma approxima-se do genero Mesosaurus até então, sómente conhecido das camadas de Karoo na Africa do Sul ; de facto não se póde distinguil-o deste e, portanto, proponho para esta nova forma o nome Mesosaurus brasiliensis.

(3) Foram feitas as seguintes observações novas no craneo. A região craneana propriamente dita é curta, as orbitas são grandes e as narinas externas collocadas muito atraz, não longe dos olhos e separadas pelos ossos nasaes alongados. Cerca da metade da parte preorbital do craneo (rostrum) é premaxillar. Ha uma unica serie de dentes pre-nasaes em cada vomer (pre-vomer.) o condylo occipital é inteiramente base-occipital. E' praticamente certo que o craneo é do typo diapsideo, quanto ás arcadas temporaes. Os dentes são thecodontes, cerca de 48 na mandibula e poucos, cerca de 38 na maxilla superior.

(4) As vertebras cervicaes são em numero de 11 incluindo o atlas, ha 18 thoraco-lombares, fazendo 29 pre-sacras.

(5) 0 material elucida completamente a estructura da cinta escapular que foi mal interpretada anteriormente por alguns morphologistas. Ha uma escapula baixa e flabelliforme coossificada, com um grande coracoide, este perfurado por um foramen, não ha precoracoide separado, o coracoide se desenvolve de um unico centro de ossificação. Ha uma interclavicula alongada e delgada, dilatada anteriormente, por onde se articula com claviculas bem desenvolvidas.

(6) O pubis é entalhado em vez de ser perfurado por um foramen como no Stereosternum.

(7) O humero tem, um sulco radio, ou ectepicondylar além do foramen ulno-condylar (entepicondylar).

(8) De uma serie limitada de medidas, muito limitada para ser absolutamente digna de confiança, parece que a razão do comprimento ja tibia para o femur é de cerca de tres quintos, ao passo que no stere- 


\section{Summary of the most important new observations}

(1) The present material from the Permian of Brasil represents a new type of Proganosaurian, very' similar in general character to Stereosternum tumidum, Cope, but differing from it in having a relatively larger skull, and in having in the pubis a notch instead of a foramen.

(2) In these points of divergence from Stereosternum the form approximates the genus Mesosaurus, hitherto known only from the Karoo beds of Southe Africa - is in fact indistinguishable from it, and I therefore propose for the new form the name Mesosaurus brasiliensis.

(3) In the skull the following new observations have been made. The cranial region proper is short, the orbits rather large, and the external nares placed far back, not far from the eyes, and separeted by the elongate nasal bones. About one-half of the pre-orbital part of the skull (rostrum) is premaxilary. There is a single pre-narial row of teeth on each vomer (pre-vomer). The occipital condyle is entirely basi-occipital. It is practically certain that the skull is of the diapsid type as regards the temporal arcades. Teeth are thecodont, about 48 in the mandible, and fewer, about 38 , in the upper jaw.

(4) The cervical vertebrae number 11, including the atlas, and there are 18 thoraco-lumbars, making 29 pre-sacrals.

(5) The material elucidates completely the structure of the shoulder-girdle, which had previously been misinterpreted by several morphologists. There is a low fan-shaped scapula, coossified with a large coracoid, the latter pierced by, a foramen, and there is no separate precoracoid, the coracoid arising from a single ossific center. There is a slender elongate interclavicle, expanded anteriorly, where it articulates with well-developed clavicles.

(6) The pubis is notched instead of perforated by a foramen as in Stereosternum.

(7) The humerus shows a radio - or ectepicondylar groove in addition to the ulno-condylar (entepicondylar) foramen.

(8) From a limited series of meausurements, to limited to be absolutely trustworthy, it appears that the ratio of length of tibia and femur is about three-fifths, while in Stereosternum it is about 
osternum é de cerca de quatro setimos. A razão do braço para o antebraço é de cerca de um para dois em ambos os typos.

A descoberta no Permiano brazileiro de uma fórma tendo affinidades morphólogicas muito mais estreitas com o Mesosaurus das camadas 'sul africanas de Karoo, que com seu visinho geologicamente proximo, o Stereostérnum brasilleiro, ẻ de interesse consideravel apésar de năo ser surprendente, em vista das bem conhecidás relações "das formas permianas das duas regiões. Actualmente não h̉a rażão para a separação generica da nova forma do $\boldsymbol{M}$. tenzielens, visto que a ultima especie ainda não está completamente conhecida, e conhecimentos uIteriórés concernentes á esta (e.g. a formula vertebral thoraco-lómbár) podem tornar necessaria a creação de um novo genero para o $M$. brasitiensis.

ABREVIAÇÕES USADAS NAS FIGURAS

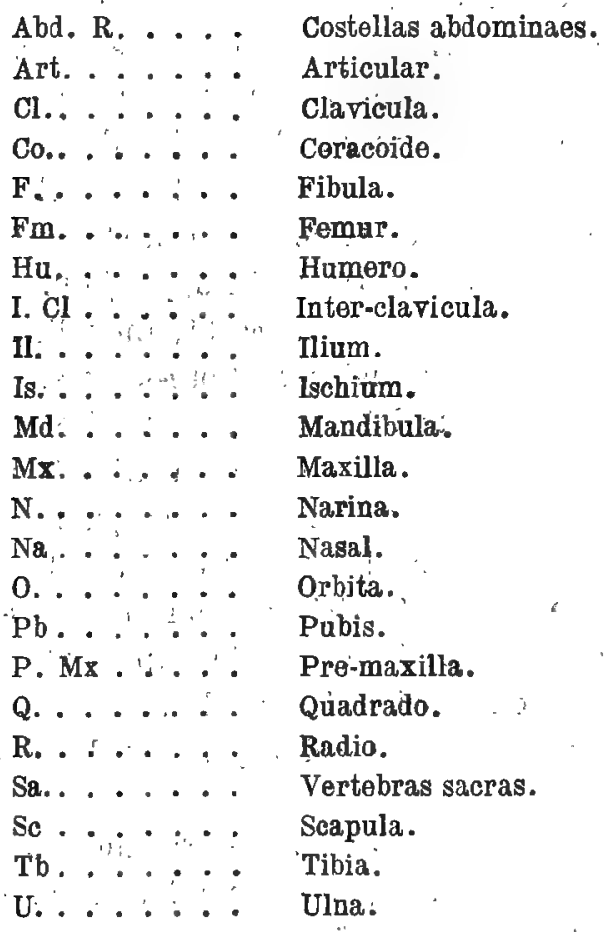


four-sevenths. The fore-arm-arm ratio is about one to two in both types.

'The discovery,', in the Brasilian Permian, of a form having closer morphological affinity to Mesosaurus of the South African Karoo beds than to its geographical near neighbor, the Brasilian Stereosternum, is of considerable interest, though not surprising in view of the well-known general correspondence in the Permian faunas of the two regions. At present there is no basis for the generic separation of the new form from $M$. tentudens, but since the latter species is not yet completely known further knowledge concerning. it (e, g., the thoraco-lumbar vertebral formula) may necessitate the erection of a new genus for $M$. brasiliensis:

ABREVIATIONS USED IN THE FIGURES

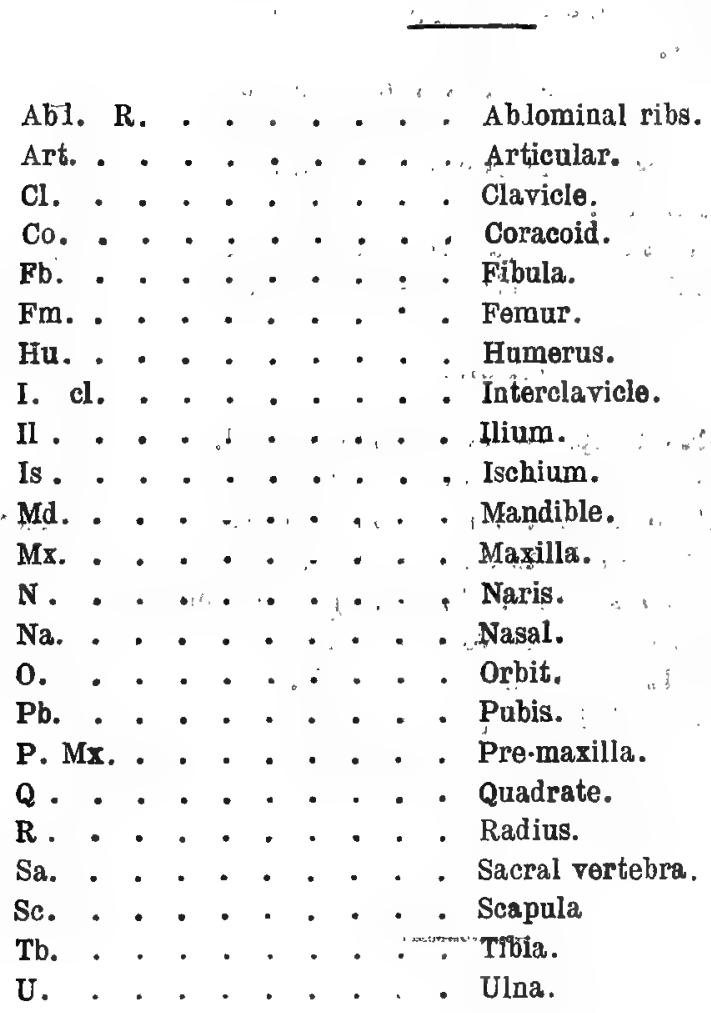




\section{EXPLICAÇÃO DAS ESTAMPAS}

Todas. as figuras representam o Mesosaurus,brasiliensis. Est. II, III e IV são photographias de fundições.

\section{ESTAMPA I}

Fig. I. Restauração, cerca de dois quintos do tamanho natural.

$$
\text { ESTAMPA II }
$$

Fig. 2. Face dorsal do esqueleto, tamanho natural.

Nesta figura o pescoço parece mais curto do que é, devido ao esmagamento do claneo sobre as quatro primeiras cervicaes.

$$
\text { ESTAMPA HI }
$$

Fig. 3. Face ventral do esqueleto, augmentado um oitavo. 0 caracoide esquerdo está levemente deslocado, o direito approximadamente in situ. Esta figura mostra o entalho do pubis.

Fig. 4. Face ventral das regióes cervical e thoracica anterior, tamanho natural.

Veem-se as extremidades posteriores das mandibulas e a face interna do complexo escapulo caracoide direito.

Fig. 5. Face ventral da perna esquerda e das caudaes anteriores, tamanho natural, tambem se vê na figura uma clavicula deslocada.

$$
\text { ESTAMPA IV }
$$

Todas as figuras nesta estampa são do tamanho natural.

Fig. 6. Craneo e vertebras cervicaes anteriores.

Fig. 7. Face dorsal do craneo. A direcçăo lateral extrema dos dentes, neste specimen, é provarelmente devida ao esmagamento.

Fig. 8. Craneo (mesmo specimen da fig. 7). Pace ventral. Esta fundição mostra o condylo occipital e os dentes vomerianos.

Fig. 9. Face interna da metade direita da pelvis.

Fig. 10. Esqueleto parcial, lado.esquerdo. 
Commissão dos Estudos das Minas

de Carvão de Pedra do Brasil.

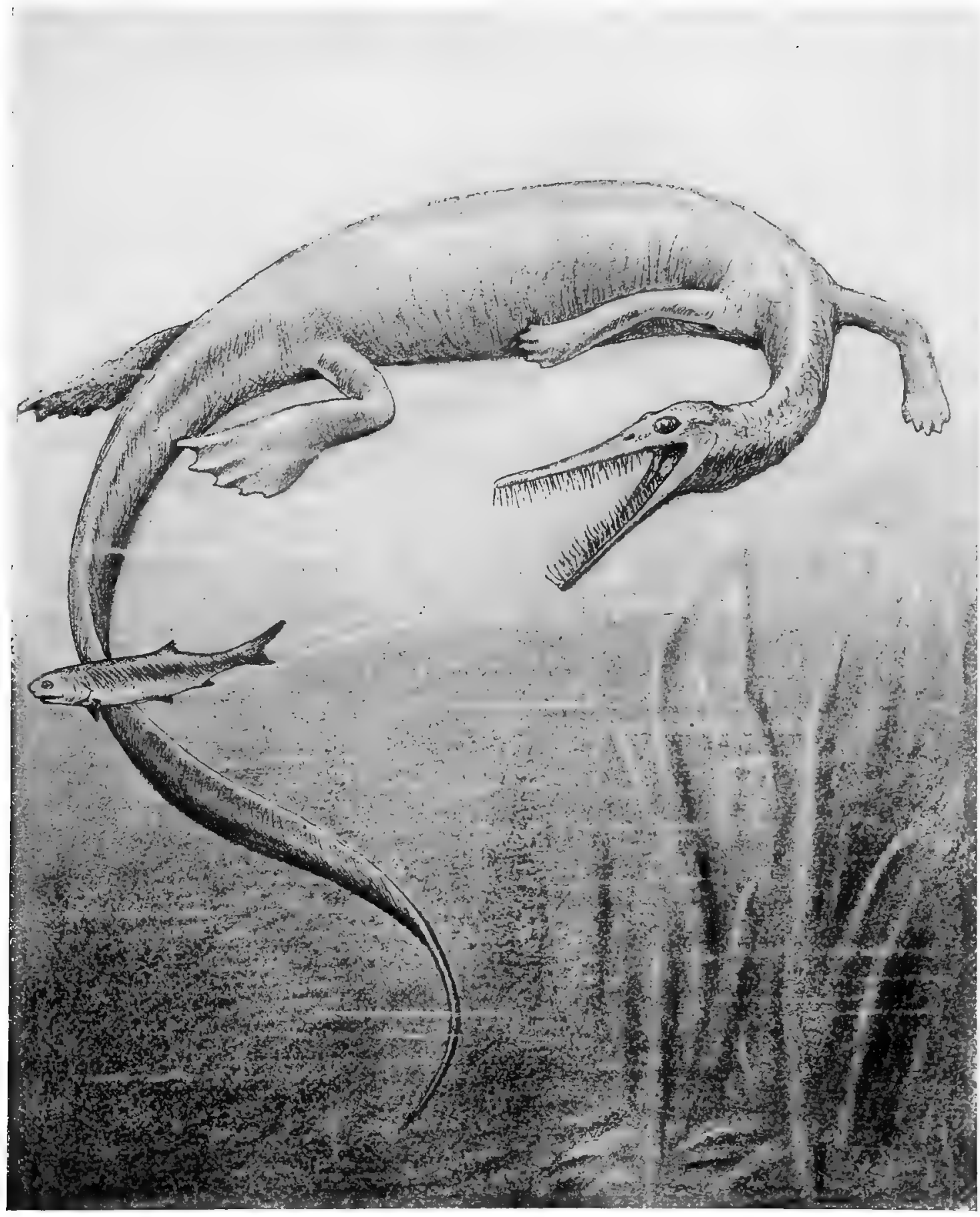

1

MESOSAURUS BRASILIENSIS.

Restoration natural size. 



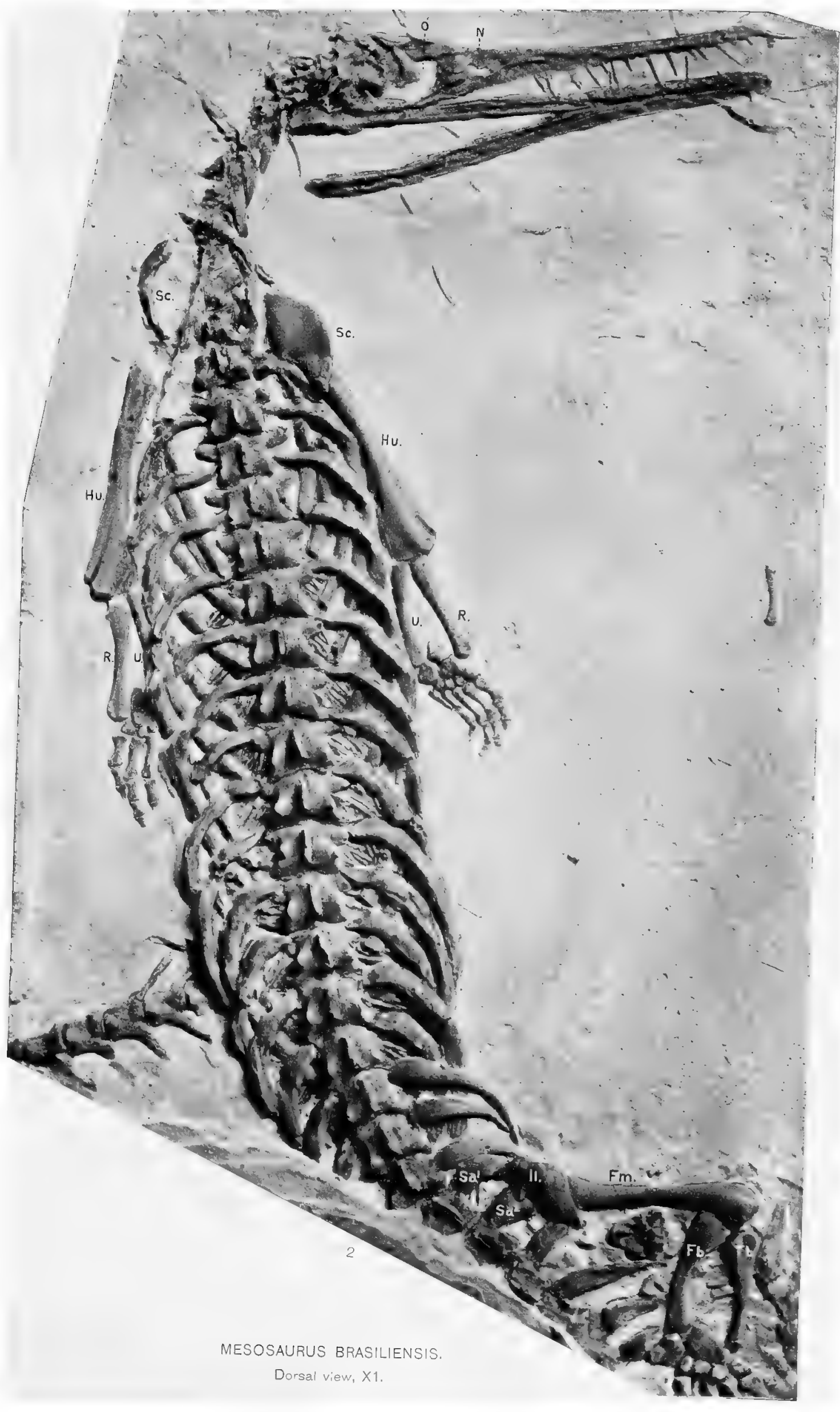




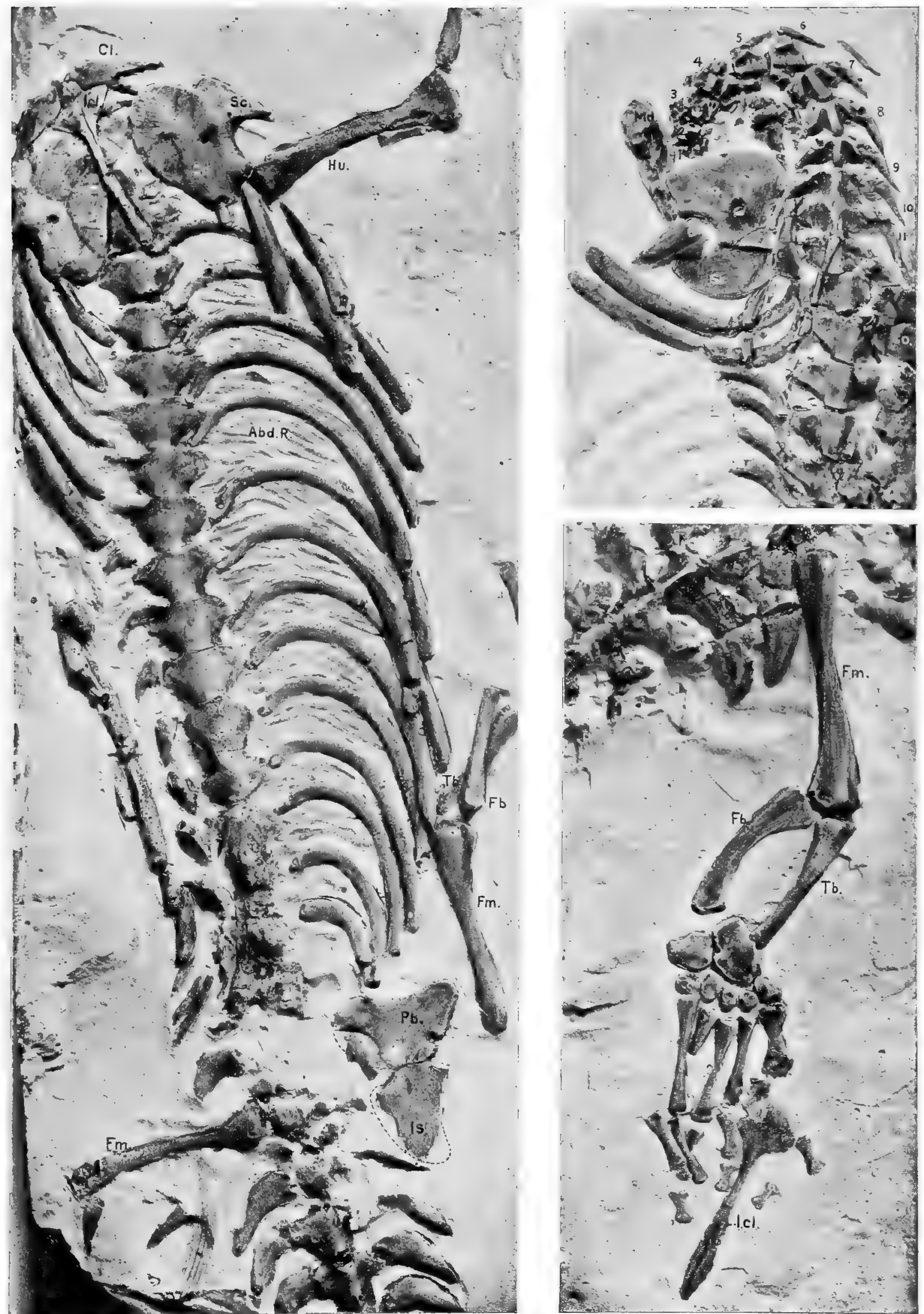

MESOSAURUS BRASILIENSIS.

Fig. 3. Ventral v'ew, $\mathrm{X}_{13}$.

Fig. 4. Cervical region, ventral view, $X 1$

Fig. 5. Left hind leg, ventral view, $X 1$. 


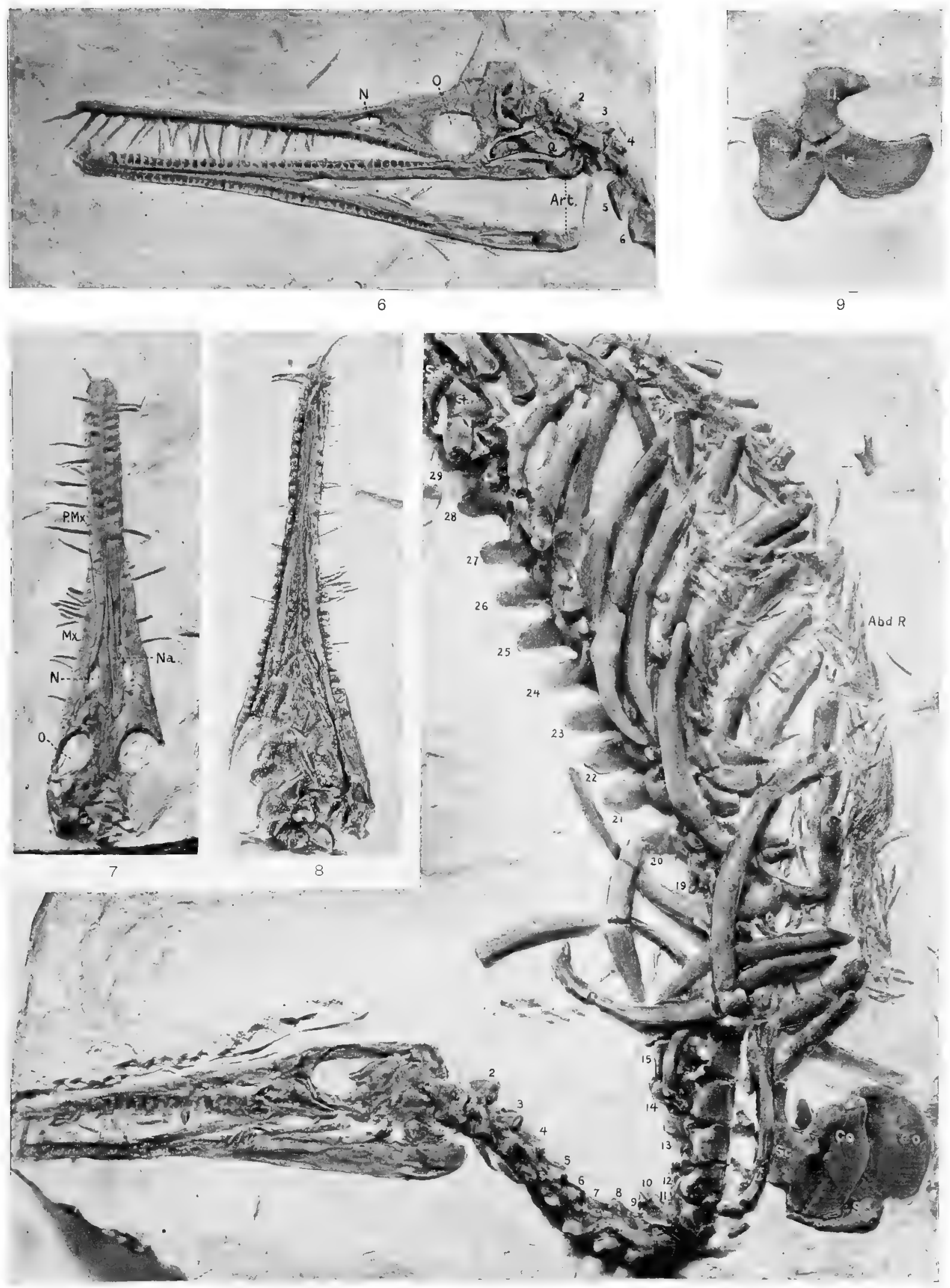

10

MESOSAURUS BRASILIENSIS.

Fig. 6. Skull, lateral view.

Fig. 7. Skull, dorsal view.

Fig. 8. Skull, ventral view.
Fig. 9. Pelvis, right s de, inner view.

Fig. 10. Partial skeleton, eft side.

All figures $\mathrm{X} 1$. 



\section{EXPLANATION OF THE PLATES}

All figures represent Mesosaurus brasiliensis. Plates II., III., and IV. are photagraphs from casts.

PLATE I

Fig. 1. Restoration, about two-fifths natural size.

PLATE II

Fig. 2. Dorsal view of skeleton, natural size.

In this figure the neck appears shorter than it is owing to the crushing of the first four cervicals.

PLATE III

Fig. 3. Ventral view of skeleton, enlarged one-eighth.

The left coracoid is slightly displaced, the right nearly in situ.

This figure shows the pubic notch.

Fig. 4. Ventral view of cervical and anterior thoracic regions, natural size. The posterior extromities of the mandibles are shown, and the inner face of the right scapulo-coracoid complex.

Fig. 5. Left hind limb and anterior caudals, ventral view, natural size. A displaced interclavicle is also shown in the figure.

\section{PLATE IV}

All figures in this plate are natural size.

Fig. 6. Skull and anterior cervical vertebrae.

Fig. 7. Skull, dorsal view. The extreme lateral direction of the teeth in this specimen is probably due to crushing.

Fig. 8. Skull (same specimen as fig. 7), ventral view. This cast slows the occipital condyle and the vomerine teeth.

Fig. 9. Right half of pelvis, inner view.

Fig. 10. Partial skeleton, left side. 


\section{BIBLIOGRAPHIA A QUE. HA REFERENCIAS \\ LITERATURE REFERRED TO}

BAdR, G. - 1887. - On the Phylogenetic arrangement of the Sauropsida. Journ. Morph. Vol. I, , 1887, p. 103.

BRoom, R. - 1904. - Observations on the structure of Mesosaurus Trans. S. Af. Philos, Soc. Vol, XV. Pt. 3, pp. 103-112, Dec. 1904. Pl. IX.

COPE, E. D. - 1885. - A contribution to the Vertebrate Paleontology of Brasil. Pal. Bull. No. 40. July 30, 1885. Proc. Amer. Philos. Soc. Vol. XXVIII, No. 121, 1885, pp. 7-15.

GeINITz. - 1900. - Sur Steresoslernum tumidum; Cope, du Musée Royal de Mineralogie de Dresde, provenant de São Paulo (Brésil). Ann. d. 1. Soc. Géol. de Belgique, Tome XXV. bis (4to) pp. 35-42. Pl. I. Liège 1900.

Gervais, P., - 1867-69. - Zoologie et Paléntologie Générales. Ser. 1, pp. 223-228. PI. XLII.

OsBoRn, H. F. - 1903. - The reptilian Sub-classes Diapsida and Synapsida and the early history of the Diaptosauria. Mem. Amer. Mus. Nat. Hist. Vol. l, part. VIII, pp. 451-507.

SEeley, H. G. - 1892 - The Mesosauria of South Africa. Quart. Journ. Geol. Soc., Vol. XLVIII, 1892, pp. 586-604; Pl. XVIII.

Vaillant, L. - 1903, - De la disposition des ecailles chez le Mesosaurus tenuidens, P. Gervais. Comptes Rendus de l'Acad. des Sciences, Tome CXXXVI. (136) p. 1286. Paris, 1903.

Woopward, A. S., - 1897. - On a new Specimen of Stereosternum. Geol. Mag. (4) Vol. IV., p. 145-147, 1897, PI. V. 


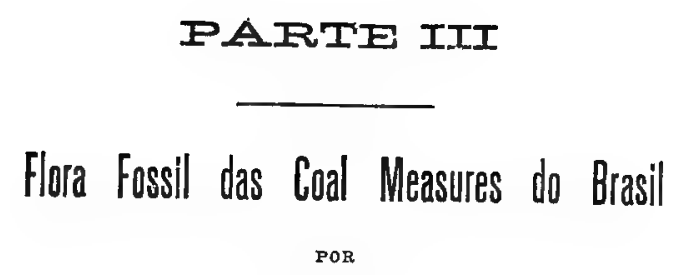

David White

\author{
PART III \\ PATI ITI \\ Fossil Flora of the Coal Measures of Brazll \\ BY \\ David White
}


Flora Fossil das Coal Measurs (*) do Brasil

REVISTA IISTORICA

o numero de plantas fosseis do Brasil até agora conhecido não é grande, entretanto estas foran sempre consideradas com muito interesse, a principio, devido a significação de sua distribuiçă, pela occurrencia de seus typos respectivos no continente sul-americano e ultimamente pelas notaveis associações floraes que as especies, embora poucas, pareciam indicar. Devido á falta de palæobotanicos no Brasil, e tambem em toda a America do Sul, tão pouco se conhece, depois de quarenta annos de exploraçũes, da flora da formação carbonilera do Brasil.

o rapido desenrolvimento actual das investigações, tanto scientificas como industriaes, na Republica, conduziram sem duvida, ao ausmento de sua riqueza palscontologica, assim como ao desenvolvimento. de seus grandes recursos economicos.

A primeira planta fossil do Brasil, que se tornou definitiramente conhecida foi o Psaronius brasiliensis.

Uma figura de um pequeno fragmento intracortical desta especie, foi publicada com o nome manuscripto de Brongniart, em 1836, por L'nger, na grande obra de Martius, sobre as palmeiras do Brasil. (1)

Esta especie foi primeiramente descripta por Brongniart, (2) tendo a sua disposição um outro exemplar mais completo, em uma sessão publica da Sociedade Botanica de França em 1872, por occasião da visita de D. Pedroá capital franceza. Este interessante trpo de tronco de feto arborescente Permo-carbonifero, que è notavel como representante de um grupo de Psaronii, especialmentè caracter isado pelas frondes que nascem em quatro linhas, ou series verticaes, foi posteriormente estudado com grande perfeição histologica por Zeiller (3). Pelas investisacĩes do conde Solms-Laubach (1) e Derby (1) parece que oflagmento

(') Formação carbonifera.

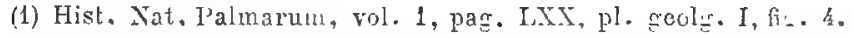

(2) Bull. Soc. Bot. France, vol. XIX par. 6.

(3) Flora fossil bassin houill et perm. Autun ot Epinac, pt. 1, 1. 0, pas. 246, pl. XXI.

(i) Festschn za P. Ascherson's siebzigsten frebul'ststare. Berlin, 1904, p. 18.

(j) Jornal do Commercio. Rio de Janeiro, 1", de mul's, de 190\%, pag. 1 (Um fossil interessante (do Museu Nacional). 


\title{
Fossil Flora of the Coal Measures of Brazil
}

\author{
IIISTORICAL REVIEW
}

The number of fossil plants hitherto known from Brazil is not great; yet these have always been regarded with much interest on account, in earlier days, of their distributional significance as standing for the occurrence of their respective types in the South American continent, and, latterly, of the remarkable floral associations which the species, though few, seemed to indicate. That after over forty years of exploitation so little should be linown of the flora of the Brazilian coal fields is explained only by the absence of resident palrobotanists, not only from Brazil, but also from all South America. The present rapid development of scientific as well as of industrial pursuits in the republic will doubtless lead to the unfolding of its palccontological wealth as well as the development of its great economic resources. I

The first plant fossil to be definitely made known from Brazi) was the $P_{\text {saronitus }}$ brasiliensis, a figure of a small intracortical fragment of which, accompanied by Brongniart's manuscript name, was published in 18:26 by Unger in Martius great work on the palms (1) of Brazil.

The species was first described from another more complete example, by Brongniart (2) at a meeting of the Botanical Society of France in 1872, on the occasion of the visit if Dom Pedro to the French capital. This very interesting Permo-Carboniferous type of tree-fern trunk, which is remarkable as the representative of a group of Psaronii especially characterized by having the fronds borne in four rows or vertical series, has since been treated with great histological perfection by Zeiller (3). From the researches of Count Solms-Laubach (4) and Derljy (5) it appears that the fragment in the Paris Ifuseum, which served as

(1) Hist. Nat. Palmarum, vol. 1, p. LXX, pl. wI. 1, fig. 4.

(2) Bull. Soc. Bot. I'r.. vol. XIX, p. 0.

(3) Fl. foss. bassing houill, et perm. Autun et Finac, pt., 1, 1890, 2. 246, pl. XXI.

(4) Festschr. z: P. Ascherson's siebzigsten freburtstage, Bcrlin, 1904, p. 18.

(5) Joinal do Comurercin, Rio de tane xo, 13 Xarch, 1905, p. 1. (Um lossil interessante do Museu Nacional). 
do Museu de Paris, que serviu de base á diagnose e discussão de Brogniart, o specimen do British Museum e de Strasbourg foram todos cortados de um segmento de um unico tronco, cuja maior parte está actualmente no Museu Nacional do Rio de Janeiro. A localidade do specimen original de Martius, que foi dado como procedente de local entre Oeiras e S. Gonçalo de Amarante, no Estado do Piauhy, foi seriamente contestada por Derby e pelo conde Solms, e se julga agora provavel que ambos os specimens provieram do Lstado de S. Paulo, ou de algum dos outros estados do Sul, o genero é caracteristico do Permo-Carbonifero.

Uma contribuição curta, porém relativamente muito interessante para a palæobotanica brasileira, foi a que publicou em 1869 W. Carruthers, descrevendo as plantas colligidas pelo engenheiro inglez Plant, nas bacias de Jaguarão e Candicta, no Rio Grande do Sul, não longe da fronteira do Uruguay.

Esta publicação (1) é precedida por uma curta descripção, pelo colleccionador (2), desta bacia carbonifera, da de S. Sepé e da de perto da villa de S. Jeronymo, que eram todas consideradas carboniferas. Carruthers publicou tres especies: Flemingites Pedroanus, Odontopteris Plantiana $e$ Voeggerathia obovata e publicou estampas de alguns megasporos muito grandes, considerados por elle como sporangias de Flemingites. Localidades certas não foram dadas. Mais de um quarto de seculo passou antes que a significação da associação das tres especies dadas então á publicidade, se tornasse clara. A Flemingites de Carruthers é actualmente referida ao genero Lepidodendron e sua Odonpteris Plantiana está verificado ser identica a uma especie Indo-sul-africana de $\dot{N e u r o-~}$ pteridium.

No anno seguinte, 1870, o professor Hartt publicou sua Geologia e Geographia Physica do Brasil (3) em que reeditou o trabalho de Plant juntamente com outras notas fornecidas por este.

Do pon to de vista palæobotanico a mais importante destas é a menção da occurrencia de Lepidodendron e Glossopteris. Na mesma publicação Hartt (4) notou a occurrencia em um logar do Estado da Bahia, de frasmentos assemelhando-se á Asterophyllites(?) scutigera Dawson. Estes deviam ser de specimens de Phyllotheca. A identificação de Glosso-

(1) Geol. Mag. vol. VI, pp. 151 e 156, pl. V, VI.

(2) Geol. Mag. vol. VI, pp. 147 e 150.

(3) Londres e Paris, 1870, pp. 521 e 527.

(4) Op. Cit., pag. 243. 
the basis of Brongniart's diagnosis and discussion, and the specimens in the British Museum and at Strasbourg were all cut from a segment of a single trunk, the main part of which is now in the Museu Nacional at Rio de Janeiro. The locality of the original Martius specimen, said to have come from between Oeiras and São Gonçalo d'A marante. in the State of Piauhy, has been seriously questioned by Derby and Count Solms, and it is now thought probable that both specimens came from São Paulo or one of the other southern states. The genus is characteristic of the Permo-Carboniferous.

A short but relatively very important contribution to Braziian palæobotany is that published in 1869 by $W$. Carruthers describing the plants collected by the English engineer, Plant, from the basin of the Jaguarão and the Candiota in Rio Grande do Sul, not far from the Uruguay border.

This paper(1) is preceded by a short description, by the collector(2), of this coal basin, the basin of the São Sepé, and that near the town of São Jeronymo, all of which were regarded as Cal'boniferous. Carruthers published three species, Flemingutes Pedrocinus Odontopteris I'lantiana and Nceggerathia obovata, and illustrated some very large megaspores regarded by him as spolangia of the Flemingites. Precise localities were not given. Over a quarter of a century elapsed before the significance of the association of the threc species then reported became apparent. Carruther's Flemingites is now: referred to the genus Lepidodendron, and his Olontopteris Plantiand is found to be identical with an Indo-South African species of Neuropteridium.

The following year, 1870, professor Hartt published his Geology and Physical Geography of Brazil (3), in which he reprinted Plant's paper together with other notes furnished by Plant. Palæobotanically the most important of the latter is that mentioning the occurrence of Lepidodendron and Glossopteris. In the same publication Hartt (4) noted the occurrence, at a point in the State of Bahia, of fragments resembling Asterophyllites (?) scutigera Dawson. These may have been specimens of Phyllotheca. The identification by Plant of Glosso-

(1) Geol. Mag., vol. VI, pp. 151 e 156, pl. V. and VI.

(2) Ceol. Man., vol. VI, pp. 147 e 150.

(3) London and Paris, 1870 , pp. 521 e 527,

(4) Op., cit., p. 243. 
ptepis feita por Plant; que nunca foi acceita pelos palæobotanicos, foi confirmada pelo material colligido pela actual Commissão do Carvão. Nenhum dos typos foi determinado especificamente.

A pressença de Glossopteris na formação carbonifera do Brasil foi novamente referida por Liais, (1) em 1872 , depois de rever a estratigraphia de Plant e de examinar suas collecções, tambem notou a occurrencia do genero Sphenopteris, bem como Calamites na mesma flora. A formação é considerada por Liais, Jurassica ou Triassica. Nenhuma descoberta de plantas fosseis, além destas, foi dada á publicidade até 1888, quando Derby escreveu a Waagen (2) communicando ter achado madeira semelhante a Dadoxylon com hastes e folhas de Lepidodendron no Estado de S. Paulo. Dois annos depois, uma haste petrificada muito interessante incluindo o cylindro vascular e cortex de jum Lepidophyte de Piracicaba, no mesmo Estado foi descripto por Renault (3), como Lycopodiopsis Derbyi. O auctor diz, baseado na auctoridade de Derby que enviou-lhe a collecção, que o specimen foi encontrado junto com Psaronius e madeiras Corclaitaleas em camadas não muito afastadas do horizonte dos restos fosseis de vertebrados, descriptos por Cope como Stereosternum tumidum.

A bacia caruonifera do Arroio dos Ratos, no Rio Grande do Sul, foi descripta por Hettner(4) em 1891 e por Dahne(5) em 1887 e 1893, tendo o primeiro colligido plantas fosseis na mina do Arroio dos Ratos, que foram mandadas por elle para o Museu de Berlim e as consideravam Triassicas. Hettner que affirmou que o professor Kolien reconhecera elementos da "Flora de Glossopteris» na sua collecção, foi o primeiro a chamar seriamente a attenção (6) para este facto muito importante, cuja confirmacão despertou o mais vivo interesse e espectativa da parte, tanto dos palæontologistas, como dos geologos. Assim é que em 1895, vemos (7) o distincto palæobotanico francez, professor R. Zeiller, exa-

(1) Clinats, geologie, faune e geọr. botanique du Bresil, Paris 1872, pp. 201 e 203.

(2) Waagen, n. Jahrh. F. Nin. 1888, vol. II, p. 172. Rec. Geol. Surv. India, vol. XXII, pt: $21889, \mathrm{pg} .69$.

(3) Comptes Rendus, vol. CX, p. 809. Bull. Soc. hist. nat. Aut. rol. III, 1892, p. $109, \mathrm{pl}$. VIII. 125.

(4) Zeitsch. d. Fresell. Erdkunde zu Berlin, vol. XXvI, pp. 84, 144, v. pp. 91 e

(5) Rolatorio das exploraceues geologicas e medição das latas mineraes feitas por ordem da Companhia de carvāo de pedra do Irroio dos Ratos, Rio de Janeiro 1897tambem - I mineração do carvão e as concessōes da Companhia Estrara de Ferro e Minas de S. Jeronymo no Estado do Rio Grande do Sul. Porto Jlegre, 1893.

(6) Steiman-lmer. Nat. vol. XXV, 1891, pag. 857.

(7) Comptes Rendues. Vol. CXXXI, 1895, pag. 951. Bull. Soc. Geol. France (3) vol. XXIII, 1896, p. 601 . 
pteris, which has never been accepted by palæobotanists, is confirmed by the material collected by the present Coal Comission. Neither of the types was specifically determined.

The presence of Glassopteris in the Brazilian coal fieldes was again reported, in 1872, by Liais, (1) after reviewing Plant's stratigraphy and examining his collections. He also noted the occurrence of the genus Sphenopteris as well as Calamites in the same flora. The beds are regarded by Liais as Jurassic or Triassic. No further discoveries of fossil plants were made known until 1887, when Derby wrote to Waagen (2) of finding Dadoxylon-like wood with stems and leaves of Lepidodendron in the State of São Paulo. Two years later a very interesting petrified stem, including both vascular cylinder and cortex, was deseribed by Renault (3) as Lycopodiopsis Derbyi. The specimen is said, on the authoriby of Derby, who forwarded the collection to Renault, to have been associated with Psaronius and Cordaitalean woods in beds, which are not far from the horizon of the vertebrate remains described by Cope as Stereosturnum tumidum.

The coal basin of the Arroio dos Ratos in Rio Grande de Sul was described by Hettner (4) in 1891 and by Dahne (5) in 1887 and 1893, the former having collected, at the Arroio dos Ratos mine, fossil plants some of which were sent by him to the Berlin Museum.

He regarded them as Triassic in age. Hettner, who stated that professor Koken had recognized "Glossopteris flora" elements in his collection, was the first seriously to call attention (6) to this most important fact, the confirmation of which has since aroused the lieenest interest and expectancy on the part of both palæontologists and geologists. Accordingly, in 1895, we find (7) the distinguished French

(1) Climats, geologie faune et geogr. botanique du Brazil, Paris, 18i2, pp. 201-203.

(2). Waagen, N. Jahrb. f. Min., 1888, Vol. II, p. 172; Rec. Gcol. Surr. India, Vol. XXII pt. 2,1889, p. 69.

(3) Comptes Rendus, Vol. CX, p. 809 ; Bull. Soc. hist. nat. Autun, Vol, III, 1892, p. 109 , pl. VIII. 91 and 125 .

(4) Zeitschr, d. Gesell. f. Erdkunde za Berlin, Vol. XXVI, pp. \$4-144. Sec pp.

(5) Relatorio das exploracoues geologricas e medição das datas nineraes feitas por ordom da Companhia das minas de carrāo do pedra do Arroio dos Ratos, Rio de Janeiro, 1887; also A mineração de carvão o as concessóes da Companhia estrada de ferro e minas de São Jeronymo no Estado do Rio Grande Sul, Porto Alegre, 1893.

(6) Steinmann, Amer. Nat., Vol. XXV, 1891, p. 857.

(7) Comptes Rendus, Vol. CXXXI, 189., p. 961; Bull, Soc. geol. Br., Vol. XXIII, 1896, p. 601. 
minar a collecção da Condessa d'Eu, em Paris e a de Hettner do Museu de Berlim. Nesta reconheceu Gangamopteris cyclopteroides var. attenuata um representante typico da fiora de Glossopteris. Em consequencia do estudo destas collecções, ambas procedentes da mina do Arroio dos Ratos, Zeiller relata a presença no carvão no Estado do Rio Grande do Sul de:

1. ' Lepidophloios laricinus, um representante da flora Permocarbonifera do Norte;

2. Fragmentos corticaes de grandes troncos de um verdadeiro Lepidodendron a que elle refere especificamente Flemingites Pedroanus de Carruthers;

3. ${ }^{\circ}$ Fragmentos indecisos, cautelosamente e muito em duvida refericlos a Stigmaria, outro typo do Norte;

$4 .^{\circ}$ Gangamopteris cyclopteroides, var attenuata;

$5 .^{\circ}$ Uma madeira fossil notavel, de um gymnospermeo, com grande medulla triradiada e pequenos poros redondos, do valle do Jaguarão, descriptos por elle como Dadoxylon Pedroi.

o Lycopodiopsis Derbyi de Renault referido acima, é considerado por Zeiller (1) como sendo provavelmente o eixo petrificado e cortex gasto de Lepidodendron Pedroanum. Dá, figura de um typo de megasporo que elle julga que pertencia a Sigillaria, duas formas de microsporos lepidophyticos, um typo de sporo provavelmente lepidophytico e uma forma gymospermica de grão de pollen.

Elle refere o carvão do Estado ao Stephaniano supericr, ou Permiano da serie do Norte e ao Karharbari da serie Gondwana.

A contribuição muito importante de Zeiller é especialmente interessante por ter sido o primeiro a notar a intercurrencia na formação carbonifera do sul do Brasil de elementos do Permo-carbonifero da provincia Septentrional com representantes do Gondwana inferior, ou flora Austro-Parmo-carbonifera.

Comtudo a maior parte das provas desta ultima, deve ser notado, foram fornecidas pela formação carbonifera da Argentina, a que em seguida nos referimos resumidamente.

Não se póde, logicamente, discutir a descoberta de plantas PermoCarboniferas no Brasil e as importantes conclusũes a tirar da peculiar associação floral que alli se vê, sem nos referirmos aos depositos con-

(i) Comptes Rendus, vol. CXXVII, 18:8, p. 245 . 
polæobotanist, professor R. Zeiller, examining the collection of the Countess d'Eu in Paris and the Hettner collection from the,Berlin Museum. In the latter he recognized Gangamopteris cyclopteroides var. attenuata, a typical lepresentative of the Glossopteris flora. As the result of the study of these collections, both of which came from the Arroio dos Ratos mine, Zeiller leports the presence, accompanying the coals in the State of Rio Grande do Sul of ;

(1) Lepidophloios laricinus, a l'epresentative of the nol thern PermoCarboniferous flora;

(Ii) cortical fragments of large trunks of a true Lepidodendion to which he specifically refers Carruthers, Flemingites Pedroanus;

(III) obscure fragments, cautiously and with much doubt referred to Stigmaria, another northern type,

(IV) Gangamopterts cyclopteroides var. attenuata;

and (V) a remarkable fossil gymnospermic wood with large triradiate pith and small round pores, from the valley of the Jaguarão, described by him as Dadoxylon Pedroi.

Renault's Lycopodiopsis Derbyi, noted above, Zeiller (1) regards as probably the petrified axis and abraded cortex of Lepidodendron Pedroanum. He also illustrated a type of megaspore which he thinks should belong to Sigillaria, two for'ms of lepidophytic microspores, one spore type possibly lepidophytic, and a gymnospermic form of pollen grain.

The coals of the state he refers to the Upper Stephanian or the Permian of the Northern Series, and to the Karharbari of the Gondwana series. Zeiller's ver'y important contribution is especially interesting, since is the first to point out the intermingling, in tho coal fields ol" Southern Brazil, of elements of the l'el'mo-Ca'Junilerous of the Nol'.. thern Province with lepresentalives of the Lower Gondwana or Southern Permo-Carbonilerous flora,

However, the greater part of the evidence for the latter was, it must be observed, furnished by the coal fields of Argentina, which will next be briefly considered.

A discussion of the discovery of Permo-Carboniferous plants in Brazil and of the important conclusions drawn from the peculiar florat associations there present, cannot logicalliy be carried forward without

(1) Comptes Rondus, Vol. Cxxitil, 1848, p. 蛙. 
temporaneos da Argentina que forneceram os dados mais essenciaes para mostrar a presença da flora de Glassopteris do Gondwana inferior no hemispherio occidental.

Em 1894, o professor Kurtz da Universidade de Córdoba, publicou um trabalho (1) "Sobre a existencia del Condwana inferior en la Republica Argentina” em que elle relata a presença de Neuropteridium validum, Gangamopteris cyclopteroides, Equisetites Morenianus (2), Sphenozamites multinervis (3), Noggerathiopsis Hislopi, variedades subrhomboidalis e euryphylloides e Walchia sp.

As camadas em que estas apparecem em Bajo de Velis, provincia de S. Luiz na Argentina, são consideradas por aquelle auctor, provavelmente como Karharbari e do periodo Permiano. Zeiller em seu artigo sobre a flora carbonifera do Rio Grande do Sul, já citado (4), toma em conta aquelle trabalho, referindo a Euryphyllum a Noggerathiopsis Hislopi var. euryphylloides de Kurtz seu Sphenozamites sendo considerado como pertencendo a Noggerathiopsis.

No mesmo anno, 1895, Bodenbender (5) publicou a descripcão da formação carbonifera da Argentina, em que elle cita a occurrencia de plantas fosseis em varios pontos. Este auctor diz que o professor Kurtz identificou entre estas não somente muitas das que foram ennumeradas no trabalho acima citado como tambem Glassopteris sp. Esta, diz elle, é a primeira descoberta deste genero na America do Sul. O trabalhu de Bodenbender foi seguido em 1896, pela publicação feita por Zeiller (6) de parte de uma carta de Kurtz em que este communica ter, feito grande collecção em Bajo de Velis, incluindo Noggerathiopsis Hislopi, Gangamopteris cyclopteroides, Rhipidopsis ginkgoides, Rhipidopsis densinervis e Equisetites Morenianus e diz mais, que Bodenbender achara nos montes Llanos na parte sul da provincia La Rioja abundantes specimens de Glossopteris, com Neuropteridium validum, Sphenopteris sp. Equisetites, varias formas de Phyllotheca, Cyclopitys (?) dichotoma Noggerathiopsis, Walchia etc., e que em Trapiche perto de Guandacol na parte norle de La Rioja, Neuropteridium validum foi encontrado asssociado a Lepidophyte provavelmente pertencendo a Lepidophloios laricinus. Kurtz conclue que

(1) Revista del Museu de La Plata, vol. V1, pt. 1, 1891, pp. 125, 139 pl. II-IV.

( 2 e 3) Lova especie.

(4) Bull. Soc. Geol, France (3) XX'III, 1896, pg. 605.

(5) Revista del Museu de La Plata. vol. VIl, pt. 1, pp. 131 . 148.

(6) Bull. Soc. Geol. France, (3) XXIV, 1896, p. 466. 
reference to the contemporaneous deposits in Argentina which afforded the data most essential in showing the presence of the Glossopteris (Lower Gondwana) flora in the western hemisphere.

In 1894 professor Kurtz, of the University of Cordoba, published (1) a paper, "Sobre la Existencia del Gondwana Inferior en la Republica Argentina," in which he records the presence of Neuropteridium validum, Gangamopteris cyclopteroides Equisetites Morenianus (2) Sphenozamites multinerois (3) Nceggerathiopsis Hislopi varieties subrhomboidalis and euryphylloides, and Walchia sp.*

The beds in which they occur at Bajo de Velis, providce of San Luis in Argentina, are considered by him as probably Karharbari and Permian in age. This paper is talien into account by Zeiller in his ar'ticle on the coal flora of Rio Grande do Sul, already cited, (4) where Kurtz's Noeggeratgiopsis Hislopi var. euryphylloides is referred to Euryphyllum, his Sphenowamites being regarded as belonging to Noeggerathiopsis.

In the same year, 1896, Bodenbender (5) published a description af the coal formations of Argentina in which he notes occurrance of fossil plants at several points. He states that among the latter prolessor Kurtz had preliminarily identified not only most of those enumerated in the paper just cited, but also Glossopteris sp. This, he says, is the first discovery of the latter genus in South America. Bodenbender'spaper was followed, in 1896, by the publication by Zeiller(6) of a part of a letter from Kurtz in which the latter announces the accumulation of a considerable collectian irom Bajo de Velis, including Noeggerathiopsis Hislopi, Gangamopteris cyclopteroides Rhipidopsis ginkgoides, Rhipidopsis densinervis, and Equisetites Morenianus. Headds that Bodenbender had found, in the Llanos mountains of the southern part of the province La Rioja, abundant specimens of Glossopteris with Neuropteridium validum, Sphenopteris sp., Equisetites, several forms of Phyllotheca, Cyclopitys dichotoma, Noeggerathiopsis, Walchia, etc.; and that, at Trapiche, near Guandacol, in the northern part of La Rioja, Neuropteridium validum had been found associated with a Lepidophyte probably belongig to Lepidophloios

(1) Revista Museu d: la Plata, Vol. VT, pt. 1, 1894, pp. 125-139, pl. II IV

(2 e 3) New species.

(4) Bull. Soc. geol. Fr., (3) XXIII, 1896, p. 605.

(5) Revista del Museo de la PIata, Vol. VII, pt. 1, pp. 131-148.

(6) Bull. Soc. geal. Fr., (3) XXIV, 1896, p. 466. 
na ultima regiăo temos uma mistura de typos do norte e do sul tal como no Rio Glande do Sul, no Brasil, e que em ambos os districtos as camadas são provavelmente Permianas.

A discussão desta communicação, de Zeiller', em connexão com um commentario mais desenvolvido da flora Altai de Schamalhausen, parece ser quasi contemporanea de um outro trabalho de Boden bender (1), a discussão da estratigraphia das camadas de plantas de Sierra de S. Luir, Sierra de Los Llanos, e Sier'in de La Rioja, onde foram encontrados: Neuropteridium validum, Glossopter is communis, Glossopteris retifer Gangamapteris cyclopteroides, Phyllotheca sp. Equisetites Morenianus, Lepidodendron Pedroanum, Lepidodendron, Sternbergii Noeggerathiopsis Hislopi, Euryphyllum Whitianum (?) Rhipidopsis ginkgoides, Rhipidopsis densinervis e Cyclopitys dichotoma. Depois de discutir os equivalentes estratigraphicos desta serie de camadas que elle refere a Karharbari, Bodenbender diz que uma parte ao menos da serie que apresenta plantas, deve ser pre-Permiana.

As relações estratigraphicas das camadas que conteem plantas, tanto quanto foram determinadas na Argentina, foram discutidas muito mais completamente em um artigo intitulado "Devono y Gondwana en la Republica Ảrgentina " publicado (2) em 1897 por Bodenbender, que verificou a formação Permo-Carbonifera em longa distancia nas montanhas da base da Cordilheira. Parece que nesta região, como no Sul do Brasil, as camadas palæeozoicas, de plantas e de carvão, teem immediatamente sobrepostas as camadas vermelhas que se suppóe serem Triassicas. Os dados geologicos sobre a flora do antigo Gondwana. foram augmentados de uma maneira importante por Bodenbender em uma outra publicação descrevendo as formaçóes da "precordillera 》 da provincia de San Juan e Mendoza e das serras centraes da republica, publicado em 1902 (3).

As especies de plantas tan lo deste como dos anteriores trabalhos de Bodenbender foram determinadas de accordo com a autoridade do Prof. Kurtz. Os fosseis da visinhança da mina de Cruz de Caña, na região de Carpintaria são, segundo Kurtz: Sphenopteris (Asplenites) Maesseni*, Sphenopteris Salamandra*, Sphenopteris sanjuanina*, Rhacopteris Szajnochai*, Glossopteris Browniana, Gangamopteris cyclopteroides,

(1) Beobachlungen uber Devonen Gondwana-Selichten in d.r Argenlinischen Rupublik Zeitschr d. Deulsch. geol. Cxessell., vol. XLVIII, 1806, pp. 743-772.

(2) Boll. Acad. Nac. Ciencias, Cordoba, vol. XV, pp. $201-252$.

(3) Bol. Acad. Nac. Ciencias Cordoba, vol. Xvil, pas. 203-261. 
Taricinus Titrtz concludes that in the latter region we have a mingling of northern and southern types similar to that in Río Grande do Sul in Brazil, and that in both districts the beds are probably Permian.

Zieiller's discussion of this communication in connection with a more extended commentary on Schamalhausen's Altai flora, seems to be nearly contemporaneous with another paper by Bodenbender (1) containing a stratigraphical discussion of the plant beds of the Sierra de S. Luis, sierra de los Llanos, and Sierra de la Rioja, from vihich aré recoided: Neuropteridium validum, Glossopteris communis, Glossopteris retifera,Gangamopteris cyclopteroides, Phyllotheca sp., Equisetites Morenianius, Lepidodendron Pedroanum, Lepidodendron Sternbergii, Noeggerathiopsis Hislopi, Euryjhyllum Whittianum?, Rhipidopsis ginkgoides, Rhipidopsis densinerois, and Cyclopitys dichotoma. After discussing the stratigraphical equivalents in these ranges of the beds, which he correlates with the Karharbari, Bodenbender further argues that a part, at least, of the plantbearing series may be pre-Permian.

The stratigraphical relations of the plant-bearing terranes, so far as ascertained in Argentina, are discussed much more fully in an article entitled "Devono y Gondwana en la RepuJlica Argentina ", published (2) in 1897 by Bodenbender, who traced the Permo-Carboniferous for a long distance along the cordillieran foothills. It appcars that in this region, as well as in southern Brazil the Palaeozoic plant beds and coals are immediately overlain by red beds of supposed Triassic age. The geological data relating to the older Gondwana flora are augmented in an important way by Bondender in another paper describing the formations in the "precordillera" of the provinces of San Juan and Mendoza and in the central sierras of the republic, (3) published in 1902.

In this, as in Bondenhender's former papers, the plants were named on the autority of professor Kurtz. The fossils from the vicinity of the Cruz de Cana mine, in the Carpinteria region, include, according to Kurtz: Sphenopteris (Asplenite) Maesseni," Sphenopteris Salamandra," Sphenopteris sanjuanina," Rhacopteris Ssajnochai," Glossopteris Browniana, Gangamopteris cyclopteroides, Cordaites (?),

(1) Beobachtungen uber Dovon-u. Gonlwana-Schichten in der Argentinischen Repahlik, Zeitsch1. h. Deutsch, geol. Gesell., Tol. XLVIII, 1896, pp. 743-778.

(2) Bol. Acad. Nac. Cieneias, Cordoba, Vol. Xr, pp. 201-25\%.

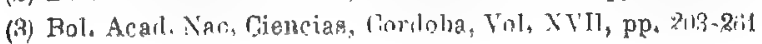


Cordaites (?) e Ginko Meisteri" ; ao passo que a collecção do mesmo horizonte de La Rinconada, um pouco mais ao norte, continha: Sphenopteris Bodenbenderi* Sphenopteris Fonsecae* Cardiopteris polymorpha, Neuropteridium validum, Adiantites antiquus e Lepido. dendron sp. As especies marcadas com um asterisco ainda não foram descriptas, pelo que sei, e é de esperar que o sejam em breve completamente e publicadas, si as designações já não foram tornadas validas por descripções e illustrações.

A presença de um Rhacopteris junto com Cardiopteris polymorpha, um typo distinctamente do carbonifero inferior, na flora do norte e de Adiantites antiquus em uma flora caracterisada por um certo numero de elementos typicos do Gondwana inferior, é cousa notavel e merece ser tratada detalhadamente do ponto de vista palæbotanico. Si as especies foram correctamente determinadas e foram realmente contemporaneas, sua associação é do maior interesse, pois que tende a determinar directa e concludentemente uma data anterior para o advento da flora de Gondwana na America do Sul. São necessarios mais esclarecimentos sobre a occurrencia, tambem em um ponto da região de Carpintaria de Glossopteris ampla e associação apparente com Bergiophyton insigne, Lepidodendron cf. australi e Archaeolamites, scobriculatus segundo a lista de specimens colligidos pelo Sr. Fonseca.

Kurtz identificou entre fosseis da villa de Famatina, Sphenopteris Bodenbenderi* e Phyllotheca deliquescens, ao passo que achou nas collecções de perto de La Pena na Sierra Central: Neuropteridium validum var. argentinae, Pachypteris riojana*, Glossopteris retifera, Glossopteris indica, Aphlebia sp. Phyllotheca lepidophylla*, Annularia argentina*, Noggerathiopsis Hislopi var cuneifolia, e Cyclopitys dichotoma. O numero de especies do carbonifero do Norte na America do Sul foi augmentado com a descoberta de Lepidodendron sellaginoides e Lepidendron veltheimianum em Saladillo e Lepidodendron aculeatum, em Amano. A occurrencia destes typos do Norte addicionaes na provincia Gondwana é por si mesma cheia de interesse; mas é importante que as relaçóes estratigraphicas destas camadas de Lepidodendron com as de Glossopteris e Gangamopteris sejam determinadas e que lambem as extraordinarias associações indicadas nas listas de Cruz de Caña e de La Riconada se tornem completamente validas. No valioso catalogo do professor Arber" (1) "Flora de Glosso-

(1) Cat. Foss. Pl. of the Glossopteris Flora in the Dept. Geol Brit. Mus. London, 1905. p. IXXI. 
and Ginkgo Meisteri; ${ }^{*}$ while the collection from the same horizon at La Rinconada, a little farther north, yielded: Sphenopteris Bodenbenderi," Sphenopteris Fonsecae, ${ }^{*}$ Cardiopteris polymarpha, Neuropteridium validum, Adiantites antiquus and Lepidodendron sp. The species marked by an asterisk have not yet, so far as I am aware, been described, and it is hoped that they may soon be fully published, if, indeed, the names are not already validated by description or illustration.

The presence of a Rhacopteris, together with Cardiopteris polymorpha, a distinctly Lower Carboniferous type in the northern flora, and of Adiantites antiquus in a flora characterized by a number of typical lower Gondwana elements is a remarkable thing, and merits a detailed palrobotanical presentation. If the species are correctly determined and really contemporaneous, the association is of the greatest interest since it tends to furnish directly and conclusively an early date for the advent of the Gondwana flora in South America. More light should be thrown on the occurence, also at a point in the Carpinteria region, of Glossopteris ampla in apparent association with Bergiophyton insigne, ${ }^{*}$ Lepidodendron cf. australe and Archaeocalamites scrobiculatus, as listed from the specimens collected by Sr. Fonseca.

Kurtz identified Sphenopteris Bodenbenderi* and Phyllotheca deliquescens in the fossils from the village of Famatina, while, in the collections from near La Pena in the Central Sierra, he finds: Neuropteridium validum var. Argentinae,, Pachypteris riojana, , Glossopteris retifera, Glossopteris indica, Aphlebia sp., Phyllotheca deliquescens, Phyllotheca leptophylla, ${ }^{*}$ Annularia argentina*, Noeggerathiopsis Hislopi var . cuneifolia, and Cyclopitys dichotoma. The number of Northern Carboniferous species in South America is furthel increased hy the discovery of Lepidoclendron selaginoides and Lepidodendron veltheimianum at Saladillo, and Lepidodendron aculeatum at Amano. The occurrence of these additional Northern types in the Gondwana province is in itself full of interest; but it is important bolh that the stratigraphical relations of these Lepidodendron beds to the Glossopteris and Gangamopteris beds should be determined, and also that the extraordinary associations indicated in the lists from the Cruz de Cana and La Rinconada should be fully validated. In Professor Arber's valuable catalogue(1) of the "Glossopteris Flora "

(1) Cat. Foss. Pl, of the Flossupieris Flora in the Dept, Geol. Brit. Mus. Sondon. 1905, p. 1xxi. 
pteris „, o Lepidodenton Sternbergii de Bodenbender é considerado synonymo de Lepidodendron lycopodioides e Euryphyllum Whittianum e referidn ao genero Nceggerathiopsis, como Nceggerathiopsis Whittianc. Creio que a synopse acima dá idéa da Flora do Gondwana inferior da Republica Argentina, como é conhecida actualmente.

Voltando á flora do Brasil encontramos as especies brasileiras discutidas abreviadamente, com sua distribuição summariada, na monographia de Arber a que nos referimos acima. As especies ennumeradas formam uma lista completa das plantas Permo-cartooniferas do Brasil conhecidas antes da exploração feita pelo Dr. I. C. White, sob os auspicios da Commissão do Carvão, a saber:

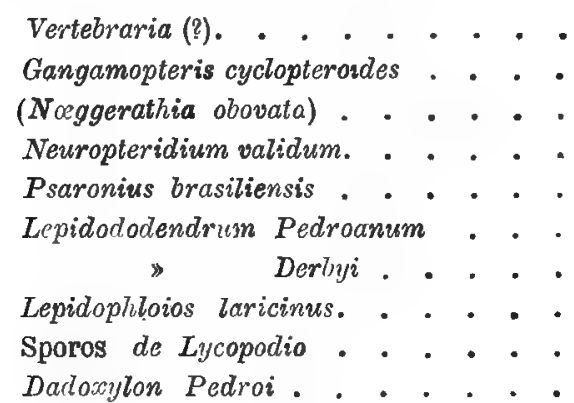

Rio Grande do Sul

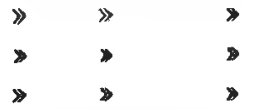

Piauhy?

Rio Grande do Sul

$\begin{array}{lll}\gg & \gg & \gg \\ \gg & \gg & \\ \gg & \gg\end{array}$

Devem ser men‘ionados tambem varios typos não incluidos por Arber, porém do ha muito citados como do Brasil, como se viu nesta revista historica, a saber:

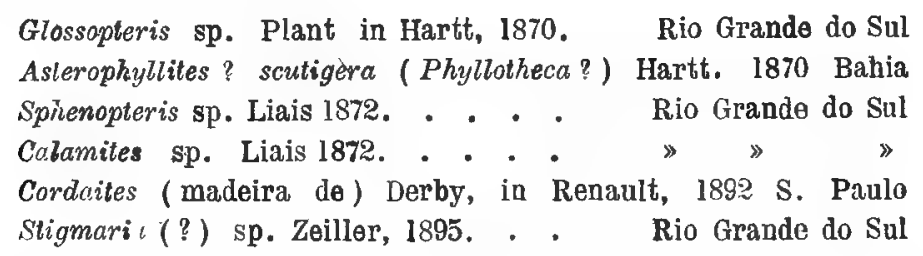

Todos estes fosseis com excepção de Psaronius brasiliensis, o Asterophyllites e as madeiras fosseis parecem proceder do Rio Grande do Sul.

Tanto quanto posso saber a monographia do Professor Arber é o ultimo trakalho sobre a flora carbonifera do Brasil. Omitte entretanto um breve resumo publicado anteriormento á memoria, que trata do material colligido pela Commissão do Carvão.

Em março de 1905 contribui com uma informação para a Sociedade Geologica de Washington, exposição preliminar dos resultados dos 
the Lepidodendron Sternbergii of Bodenbender's paper is placed under Lepidodendron lycopodioides, and the Euryphyllum Whittianum is referred to the genus Noeggerathiopsis, as Noeggerathiopsis Whittiana. The above synopsis embraces I believe, the lorver Godwana flora, so far yet known, of the Argentine Republic.

Returnigig to the flora of Brazil, we find the Brazilian especies briefiy discussed, with a summarized distribution, in Arber's monograph to which reference has just been made. The species enumerated by him embrace a complete list of the Permo-Carboniferous plants known from Brazil prior to the exploration carried on by Dr. I. C. White under the auspices of the Coal Commission, viz:

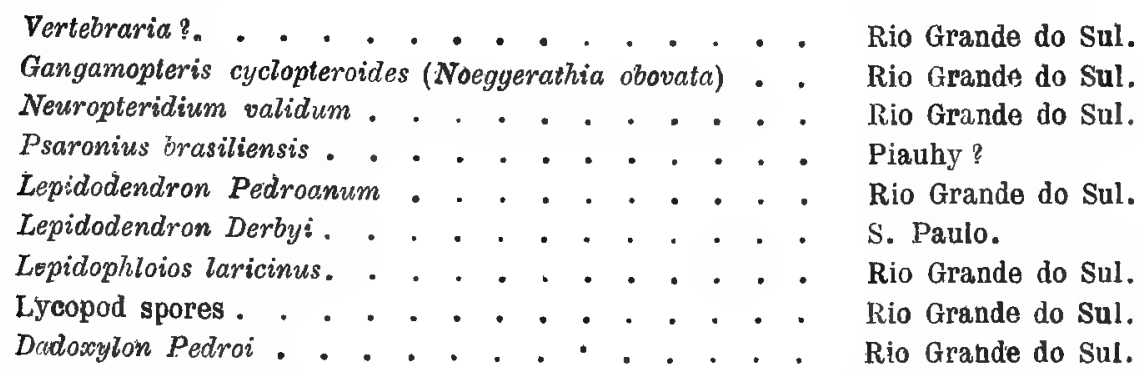

Mention slould also be made of several types not included by Alber, but more or less indefinitely reported from Brazil, as shown in the above historical review, viz:

Glossopteris sp., Plant, in Hartt, 1870. . . . . . Rio Grande do Sul. Asterophyllites (?) scutigera (Phylotheca), Hartt, 1870. . Bahia. Sphenopteris sp., Liais, 1872. . . . . . . . Rio Grande do Sul. Calamites sp., Liais, 1872. . . . . . . . . Rio Grande do Sul. Corduites wood, Derby in Renault, 1892. . . . . . S. Panlo. Stigmaria (?) sp., Zeillor, 1895. . . . . . . Rio Graude do Sul.

All of the above fossils, with the exception of Psaronius brasiliensis, the Asterophyllites, and the fossil woods, appear to have come from Rio Grande do Sul.

Professor Arber's monographis, so far as I am aware, is the last publication touching the Brazilian coal flora. I linve, however, omitted a brief abstract which antedates his momoir and which deals with the material collected by the Coal Commission.

In March, 1905, 1 informally contributed to the Geological Society of Washington a preliminary statement of the results of the study 
estudos de uma parte do novo material, acompan hada pela discussão da distribuição da florá do Gondwana inferior e illustrada com um mappa manuscripto. 0 resumo dos trabalhos apresentados na sessão (1) consigna a occurrencia de Glossopteris indica, Gangamopteris obovata, Gangamopteris cyclopteroides, Phyllotheca australis e Noggerathiopsis Hislopi em camadas cerca de 55 metros acima das crystallinas antigas, perto de Lauro Müller (Minas) no Estado de Santa Catharina e Glossopteris indica, Noeggerathiopsis Hisljpi, Ottokaria sp. e Cardiocarpon sp. do carvão de Irapuá no Estado do Rio Grande do Sul. Chamo a attenção para o facto que segundo as observaçóes estratigraphicas do Dr. I. C. White geologo e chefe da commissão, as camadas com Lepidophytos estão estratigraphicamente um pouco mais alto que as que conteem as plantas ennumeradas acima. Este material é mais completamente discutido nas paginas seguintes.

Procedencia e relações estratigraphicas das collecções estudadas neste trabalho

O material de plantas fosseis estudado neste trabalho, consiste quasi inteiramente em collecções feitas sob a inspecção pessoal do Dr. I. C. White, chefe da Commissão de Estudos das Minas de Carvão de Pedra do Brasil em 1904 e 1905 e pelo engenheiro Esdras do Prado Seixas em 1904. A maior parte dos fosseis são das camadas carboniferas do Estado de Santa Catharina de cuja flora carbonifera não tinlıamos ainda praticamente, nenhuma informação. Esta flora é mais interessante visto provir de um logar do estado ao norte do Rio Grande do Sul e portanto um pouco mais perto da flora typica do Norte.

Graças á muita habilidade e grande familiaridade do Dr. White com a estratigraphia das formações carboniferas, foram determinadas as relações estructuraes das bacias e as posições estratigraphicas dos horizontes que conteem plantas, mas em alguns casos, camadas individuaes foram correlacionadas, entre as bacias. Esta é a parte mais importante, sinão a mais difficil tambem, visto que as camadas carboniferas destes Estados estão em contacto immediato discordante com a superficie eroida do ante-granito antigo, ou de outras rochas crystallinas primitivas. Na enumeração das diversas localidades da região das Minas do Estado de Santa Catharina, em que foram encontradas plantas,

(1) Spienca, H.g. „ 
of a part of the new material, acompanied by a discussion of the distribution of the lower Gondwana flora, illustrated by a manuscript map. The abstract of the proceedings of the meeting (1) records the occurrence of Glossopteris indica, Gangamopteris obovata, Gangamopteris cyclopteroides, Phyllotheca cf. australis and Noeggerathiopsis Hislopi in beds about 55 meters above the old crystallines near (Minas) Lauro Muller in the State of Santa Catharina; Glossopteris indica, Noeggerathiopsis Hisloppi, Ottolearia sp., and Cardiocarpon sp. from Irapuá coal in the State of Rio Grande do Sul. Attention is called to the fact that, in accordance with the stratigraphical observation of Dr. I. C. White, geologist and Chief of the Commission, the beds with Lepidophytes are stratigraphical a little higher thant those with the plants last enumerated. This material is more fully discussed in the following pages.

Sources and stratigraphic relations of the collections treated in this report

The fossil plant materials treated in this report consist almost entirely of collections made under the personal supervision of Dr. I. C. White the Chief of the Brazilian Coal Commission in the seasons of 1904 and of 1905, and by Engineer Esdras do Prado Seixas in 1905. The greater part of the fossil come from the coal fields of State of Santa Catharina, of whose coal flora we hitherto have had practically no information. This flora is the more interesting since its source is in the state to the north of Rio Grande do Sul, and so a little nearer the typical Northern flora.

Thanks to the distinguished ability and great familiarity with Coal Measures stratigraphy on the part of Dr. White, not only have the structural relations of the basins and the stratigraphical positions of the plant-bearing horizons been made out, but in some instances, at least, individual beds have been correlated between the basins. This is the more important, if more difficult also, since the Coal Measures of these states rest in immediate unconformable contact on the eroded surface of the old granite and other ancient crystallines. Accordingly, in enumerating the several plant localities in the region of Minas in the State of Santa Catharina, relerence will, in many

(1) Science n.s., Vol. XXJ, May 5, 1905, p.i70n, 
om muitos casos serd́ feita referencia não só á distancia solure a base da serie, mas tambem a do schisto preto de Iraty que está no districto das Minas approximadamente a 280 metros sobre a base da serie e que o Dr. White poude felizmentè determinar tanto no Estado do Rio Grande do Sul, como no do Paraná e S. Paulo.

- A posição das camadas de plantas, nesses estados será dada quando possivel, corn referencia ao schisto preto de Iraty. Devo á bondade do Dr. White estas informaçđ̃es muito importantes sobre a estratigraphia. Em seu relatorio especial serăo encontrados complelos detalnes estratigraphicos sobre as diversas localidades.

\section{Fistado de Santa Catharinea}

1. Logo acima do tope do conglomerato de Orleans, perto das Minas, cerca de 35 metros acima do granito, ou 255 metros abaixo do schisto preto do Iraty. Plantas em schisto micaceo duro, cor de camurça pardacenta. Fragmento de vegetaes pequenos e indeterminaveis e pedaços de follhas de Noggerathiojsis. Lote 3596 .

2. Uma milha abaixo das Minas; cerca de 35 metros sobre o granito e $\mathbf{2 5 5}$ metros abaixo do schisto preto de Iraty. Schisto micaceo pardacento duro. Lote 3590 .

3. Nordeste das Minas, 55 metros acima do granito, ou 256 metros abaixo do sch isto preto de Iraty. Schisto levemente micaceo, creme; com abundantes impressũes de plantas, com muito pequeno residuo. granular carbonaceo. Abundantes restos de Calamarias, Gangamopteris, Samaropsis, Voltzia, etc. Lote n. 3586, colligido pelo engenheiro Esdras dn Prado Seixas e lote $\mathrm{n} .3921$, colligido pelo $\mathrm{Dr}$. White.

4. Schisto do carvão Bonito, perto das Minas, 120 metros acima do granito e cerca de 160 metros abaixo do horizonte do schisto prelo de Iraty. Schisto pardo escuro com grande massa de grandes mesgaporos do typo descripto por Carruthers o Zeiller. Lote 3595.

5. Estrada Nova (Estrada do Rio do Rasto) perto das Minas, cerca de 40 metros abaixo do Barro Branco, cerca de 125 metros acima do granito, ou 145 metros abaixo do schisto preto de Iraty. A matriz consiste em : $1^{\circ}$ schisto arenoso azulado escuro com risiduos granulados carhonaceos; de plantas; 2o argilla refractaria com silex, branca e azulada, de grão fino, com residuos pretos carbonaceos minusculamente articulados; $3^{\circ}$ schisto arenoso pardacento, com fragmentos de Noggerathiopsis, Glossopteris, etc., em impressão com nūīito cârvãก. Lote $392:$. 
cases, be made not only to their distance above the base of the series, but also to their distance from the Iraty black shale, which lies approximately 280 meters above the base of the series in the Minas district, and which Dr. White has been able fortunately to identify in the State of Rio Grande do Sul, as well as in Paraná and São Paulo.

The position of the plant beds in these states will be given, when possible, with relerence to the Iraty black shale. For this very imputant stratigraphic intormation I am indebted to the kinduess of Dr. White, in whosc epecial report will be found full slratigraphic details relatings to the individual localities.

\section{state Santa Catharind}

1. Just above the top of the Orleans conglomerate near Minas; about 35 meters above the sranite, or 25.j meters below the Iraty black shale. Plant; in stiff buff-brown micaceous shale. Small and mostly indeterminable vegetable fragments and portions of the leaves of Noeggerathiopsis. Lot. 3596.

2. One mile below Minas; aljout 35 melers above the granite, and 255 meters below the Iraty Jlack shale. Stiff' brownish micaceous shale. Lot. 3590 .

3. Northeast of Minas; 55 meters above the granile, or 225 meters below the Iraty black shale. Gream colored slightly micaceous shale, with abundant brownish plant impressions with very little granular carbonacaous residue. Abundant Calamarian remains, Gangamopteris, Samaropsis, Voltwia, etc. Lot. 3586 collected by Engineer Esdras do Prado Seixas, and lot. 3921 collected by Doctor Thite.

4. Shale in the Bonito coal near Minas; 120 meters above the granite, and about 160 meters below the Iraty black shale horizon. Dark brownish shale crowded with large megaspores of the lype described by Carputhers and Zeiller. Lot 3595.

5. Estrada Nova, near" Minas; about 40 meters below the Barro Branco coal ; about 135 meters above the granite, or 145 meters below the Iraty black shale. The matrices conșist of 1) a dark bluish sandy shale with, granulated carbonaceous plant residues; 2) white and bluish flinty fire-clay, fine grained, with black carbonaceous residues minutely jointed; 3) brownish sand shale, with obscure Iragments of Neoggerathiopsis, Glossopteris, etc., in impression and largely destitute of carbon. Lot 3923. 
6. Carvão Barıo Branco, Estrada Nova, perto das Minas, cerca de 175 metros acima do granito, ou 105 metros abaixo do schisto preto do Iraty. Argilla com silex, dura de grão fino cheia de raizes do typo referido, por tentativa, á Vertebraria, em residuo preto carbonaceo. Lotes 3922 e 3589.

7. Cerca de 10 metros sobre o rio Tubarão, perto das Minas, schisto molle, saibroso, micaceo, com fragmentos de plantas de mistura com sementes e Hastimima. Lote 3588.

8. Estrada de Treviso, perto das. Minas, primeiro conglomerato acima de Orleans. Schisto grosseiro, arenaceo, micaceo, amarello pardo, com fragmentos de Gangamopteris e semenles. Lote 3587, colligido pelo engenheiro Esdras do Prado Seixas.

\section{Estado do Rio Grande do Sul}

9. Capa do carvão do Irapuá a oeste da casa do Dr . Ramiro Barcellos, perto do Irapuá. O horizonte do carvão Irapuá está a 135 metros abaixo do schisto preto de Iraty, na sondagem das Xarqueadas, e a cerca da mesma distancia acima do granito, ou como foi identificado na região das Minas Santa Catharina, cerca de 165 metros acima do granito. Arliose branca molle com restos pardos carbonaceos de Glossopteris e Mceggerathiopsis, ou schisto pardo azulado micaceo com restos de plantas, muito fragmentarios e macerados. Lote 3591 .

10. Capa do carvão de S. Jeronymo, perto de Candiota, carvão de S. Jeronymo, referido pelo Dr. White ao carvão do Barro Branco de Santa Catharina, está a cerca de 20 metros acima do carvão de Irapuá mencionado no n. 9. Raizes carbonisadas em argilla refractaria com silex, azul clara e schisto foliaceo pardo-preto recamado de folhas de Noeggerathiopsis. Lote 3924.

11. Capa de carvão perto de $\mathrm{S}$. Jeronymo, cerca de 20 metros acima do carvão de Irapuá, ou cerca de 20 metros abaixo do schisto preto de Iraty. Carvão impuro com camadas saibrosas claras, as partes escuras cheias de fragmentos lenhosos e de folhas em carvão de madeira. Lepidodendron, Lepidophloios e folhas Lepidophyticas (Flemingite). Lote 3593.

12. Carvão S. Jeronymo, 15 kilometros a sudoeste do Irapuá localidade em terras da sesmaria do tenente Ricardo. Carvão impuro com camadas claras saibrosas, as partes escuras consistindo largamente em carvão de madeira de Lejpidodendron, Sigillaria, etc. Lote 3594 . 
6. Barro Branco coal, Estrada Nova, near Minas; about 175 meters above the granite, or 105 meters below the Iraty black shale. A hard fine-grained flinty clay filled with roots of the type tentatively referred to Vertebraria, in black carbonaceous residue. Lots 3922 and 3589.

7. About 10 meters above Rio Tubarão, near Minas; soft brown gritty micaceous shale with mostly commingled plant fragments, seeds, and Hastimima. Lot 3588 .

8. Treviso Road, near Minas; just above orleans conglome. rate brown, micaceous, stiff sandy shale, with Gamgamopteris fragments and seeds. Lot 3587 ; collected by Engineer Esdras do Prado Seixas.

\section{State of Rio Grande do Sul}

9. Roof of the Irapua coal, west of house of Doctor Barcellos near rio Irapuá. The horizon of the Irapuá coal is 135 meters below the Iraty black shale in the boring at Xarqueadas and about the same distance above the granite there, or, as identified in the Minas, Santa Catharina, region, about 165 meters above the granite. Soft white arkose, with brown carbonaceous remains of Glossopteris and Noeggerathiopsis; or bluish-brown micaceous shale with very fragmen. tary macerated plant remains. Lot 3591.

10. Roof of São Jeronymo coal near Candiota. The São Jeronymo coal, correlated by Doctor White with the Barro Branco coal of Santa Catharina, lies about 20 meters above the Irapuá coal mentioned under n. 9. Carbonized roots in light bluish, flinty fire-clay, and matted leaves of Noeggeratiophsis in brownish-black foliate shale. Lot 3924 .

11. Roof of the coal near São Jeronymo; about 20 meters above the lrapuá coal, or about 120 meters below the Iraty black shale. Impure coal with bright jetty layers, the dull portions filled with woody and leaf fragments in charcoal. Lepidodrendon, Lepidophloios, and Lepidophytic (Flemingites) leaves. Lot 3593.

12. São Jeronymo coal, 15 kilometers southweast from the Irapuá locality on land of Sesmaria do tenente Ricardo. Impure coal with bright jetty layers, the dull portions consisting largely of natural charcoal from Lepidodendron, Sigillaria, etc. Lot 3594. 
13. S. Raphael perto de S. Sepê. I Lote 3926.

14. Capa de schisto preto 6 metros acima do granito, 4 (poste kilometrico 492) kilometros a éste de suspiro, sahisto pardo-creme, micaceo com camadas duras, amarellas, todas com Gangamopteris em abundancia. Lote 3592 .

15. Santa Maria, 220-250 metros abaixo do tope do grés de São Bento. Madeira fussil. Lote 3917.

16. Perto das Minas de S. Jeronymo 110 melros acima do carvão de S. Jelonymo. Madeira fossil. Lote 3917.

17. Butiá, 30-60 metros acima do carvão de S. Jeronymo. Madeira fossil. Lote 3916 .

18. Perto de S. Sepé, apparentemente nas camadas vermelhas, 100 a 200 metros acima do carvão de S. Jeronymo: Madeira fossil. Lote 3916.

19. Na estrada, entre a casa do Sr. Brun e S. Raphael. Madeira fossil em schisto vermelho, 100 a 200 metros acima da camada de carvão. Lote 3918.

20. Specimens da superficie em rocha apparentemente decomposta 1 1/2 kilometros a éste da estação de Santa Maria (poste kilometrico 160-161) Madeira fossil. Lote 3915.

\section{Distribuição local das especies}

De ha muito está reconhecido que a flora das camadas carboniferas do Brasil é composta de uma mistura de especies do antigo Gondwana e do Permiano do Norte.

A presença de elementos do Gondivana no Braśil, foi dada a conhecer por Hettner, e Zeiller contribuio com valiosa discussão demonstrando a combinação dos typos do norte e sul e as consequentes deducções relattras aos limites das duas grandes provincias floraes do periodo Permo-carbonífero. Nas paginas seguintes se verá que temos no sul do Brasil flora do Gondwana inferior, typica, abrangendo os principaes typos caracteristicos daquella flora na India, Australia e Africa do Sul, com uma pequena parte derivada mais ou menos directamente da flora do Permo-carbonifero do Norte, principalmente composta de Lepidophytos.

Tambem se verá que as formas do Gondwana existiam nos sedimentos inferiores, emquanto que as formas do Norte apparecendo um pouco mais tarde, parecem tornar-se mais aburtantes e variadas nas camadas superiores. 
13. São Raphael near São Sepé. Lot 3926.

14. Roof of the black shale 6 meters above the granite, 4 ( 492 Kilometer Post) kilometers east of Suspiro. Brownislt cream-colored and micaceous shale with hard yellowish layer's, all with abundant Gangamopteris. Lot 3592.

15. Santa Maria; 220-250 meters below the top ol' the S. Bento sandstone. Fossil wood. Lot 3917.

16. Near' São Jeronymo mines 110 meters alıove São Jeron!̣mo coal. Fossil wood. Lot 3920 .

17. Butiá; 30-60 meters alıve São Jeronjmo coal. Fossil wood. Lot 3916 .

18. Near São Sapé; apparently in red heds 100-200 meters above S. Jeronymo coal. Fossil wood. Lot 3919.

19. Road between Mr. Brun's and S. Raphael. Fossil wood in red shale, 100-200 metel's above coal beds. Lot 3918.

20. Surface specimens in apparently decomposed rock $11 / 2$ kilometers east of Santa Maria station (160-161 Kilometer Post). Fossil wood. Lot 3915.

\section{Local distribution of the species}

That the flora of the Brazilian coal measures is composed of mingled older Gondwana and Northern Permian species has long been recognized.

The presence of Gondwana elements in Brazil was noticed by Hettner, and Zeiller has contributed a very valuable discussion of the intermingling of Northern and Southern types and of the consequent deductions as to the boundaries of the two great corresponding floral provinces in Permo-Carboniferous time. In the following pages it will be shown that we have in southern Brazil a typical lower Gondwana flora, embracing the principal types characteristic of that flora in India" Australia and South Africa, to which is added a smaller part, chiefly composed of Lepidophytes, derived more or less directly from the Northern Permo-Carboniferous flora.

- Also it will be seen that the Gondwana forms were present in the lowest sediments of the series, while the Northern elements, appearing a little later, seem to become more abundant and varied in the higher beds. 
O total da flora tanto quanto até hoje se tem descobertó, está comprehendido na seguinte

Lista das plantas fosseis das regiơes carboniferas do Brasil

Reinschia australis Bert \& Ren. var. Jrasiliensis n. var.

Rosellinites Gangamonteris n. sp.

Hysterites brasiliensis n. sp.

Equisetites calaminitinoides n. $\mathrm{sp}$.

Schizoneura? sp.

Phyllotheca Griesbachi Zeill.

Phyllotheca?.sp.

Lycopodiopsis Derbyi Ren.

Lepidodendron Pedroanum (Carr.) Zeill.

Lepidophloios laricinus Sternb.

Sigillaria Brardii Brongn.

Sigillaria australis n. $\mathrm{sp}$.

Sigillaria murallis (?) n. sp.

Sigillaria sp.

Sphenopteris hastata Mc. Coy?

Sphenopteris sp.

Psaronius brasiliensis. Brong (não representado nas collecções.)

Neuropteridium Plantianum (Carr.) D. W. (Não represèntado nạs collècções.

Glossopteris Browiniana Brongn.

Glossopteris indica (Brongn) Schimp.

Glossopteris ampla Dana.

Glossopteris occidentalis n. sp.

Glossopteris sp.

Vertebrabia sp.

'Gángamopteris obovata (Carr.) D. W.

Ottoliaria ovalis n. sp.

Arberia minasica n. g. n. sp.

Derbyella aurita n. g. n. sp.

Nongrerathiopisis IIislopi (Bunb.) Feist.

Cardiocarpon Seixasi n. sp.

Cardiocarpon Moreiranum n. sp.

Cardiocarpum Oliveiranum n. sp.

Cardiocarpon Barcellusum n. sp. 
The total flora, so far as yet discovered is included in the following.

\section{List of the Fossil Plants from the Coal-fields of Brazil}

Reinschia australis Bert. \& Ien. var. Jrasiliensis n. var.

Roselinites gamgamopleridis n. sp.

Hysterites brasiliensis n. sp.

Equisetites calamitinoides n. sp.

Schizoneura? sp.

Phyllotheca Griesbaclii Zeill.

Phyllothecir Nuellerianan. sp.

Phyllotheca (?) sp.

Lycopodiopsis Der])yi Kien.

Lepidodendron Pedroanum (Cal'x.) Zeill.

Lepidophloins laricinus stern]).

Sigillaria Brardii Brongn.

Sigillaria australis n. sp.

Sigillaria sp.

Sigillaria (?) muralis n. sp.

Sphenopteris hastata Mc. Coy?

Sphonopteris sp.

Psaronius brasiliensis Brongn. (Not represented in the collections).

Neuropteridium Plantianum (Carr.) D. W. (Not represented in the collections.)

Glossopteris Browniana Brong'n.

Glossopteris indica (Brongn.) Schimp.

Glossopteris ampla Dana.

Glossopteris occidentalis n. sp.

Glossopteris in).

Vertebraria sp.

Gangamopteris obovata (Carr.) D. W.

Ottoliaria ovalis n. sp.

Arberia minasica n. s., n. sp.

Derbyella aurita n. g., n. sp.

Noeggerathiopsis Hislcpi (BunJ.) Feist.

Cardiocarpon Seixasi n. sl).

Cardiocalpon Moreiranum n. sp.

Cardiocarpon Oliveiranum n. sp.

Cardivcarpon Bar'c 110 sum n, sp. 
Voltzia? sp.

Dadoxylon Pedroi Zeill.

Dadoxylon nummularium n. sp.

Dadoxylon meridionale n. sp.

Carpolithus sp.

Hastimima Whitei n. g. n. sp.

Comquanto o numero das formas não seja avultado, sendo ao todo quarenta, comtudo vê.se immediatamente que abrange especies dos quatro grupos caracteristicos dominantes da flora do velho Gondwana como: Phyllotheca, Glossopteris, Gangamopteris, e Noggerathiopsis encontrando-se todas em identicas especies orientaes. Na flora acima mencionada as regiões do velho Gondwana do Hemispherio Oriental são generica ou especificamente representadas por Reinschia australis (1) var. brasiliensis, Phyllotheca Griesbacini, Phyllotheca Muelleriana, Phyllotheca sp., Sphenopteris hastata? Neuropteridium Plantianum, Glossopteris Browniana, Glossopteris indica, Glossopteris ampla, Glossopteris occidentalis, Gossopterts sp., Vertebraria sp., Gangamopteris obovata, Arberia minasica, Ottokaria ovalis, e Noeggerathiopsis Hislopi. (2).

Os typos descriptos dos generos Rosellinites equesitites, Derbyela e Hastimima embora novos, devem ser considerados como pertencentes á flora do sul e devem provavelmente ser encontrados em outras zonas inferiores do Gondwana.

A fiora do Norte é, especificamente representada por duas especies: Lepidophloios laricinus e Sigillaria Brardii e indirectamente por quatro especies apenas: Lepidodendron Pedroanum, Sigillaria australis, Sigillaria? muralis e Psaronius brasiliensis.

Talvez seja reconhecido mais tarde que Lycopodiopsis Derbyi, o Psaronius já mencionado (3), os týpos referentes a Dadoxylon e as especies de Cardiocarpon são na realidade antes caracteristicas da flora do sul que de uma zona de transição de especies misturadas.

$\mathrm{E}$ ' de facto provavel que as madeiras fosseis, algumas das sementes e o Lycopodiopsis sejam typos do Sul.

(1) Veja a nota da paú. 406

(2) Como prova ulterior da identidacle do velho Gondwana na $\Lambda$ merica do Sul, deve se mencionar a idlentificą̧üo lriba polo proliessor liurtz (om Bodenbender, Bol. Acad. Nac. Ciuncias, Curdoba, vol. XVII, 190\%, par. 203) de camadas das mesmas series na Argonlina de Glossoyteris retifera, Euryphyllum I"hitianum Rhipdopsis guinkgoides, Rhipidopsis densinenvis, e Phyllotheca deliquescins.

(3) A seçāo totrasticlıa de Psaronius representada por Psaronius brasiliensis, ainda não foi jeconhecida na flura do Nierte. 
Voltzia? sp.

Dadoxylon Pedroi Zeill.

Dadoxylon nummularium n. sp.

Dadoxylon meridionale n. sp.

Carpolithus? sp.

Hastimima Whitei n. g., n. sp.

Although the number of forms, forty in all, is not large, it will at once be noted that it embraces representatives of the four dominant and characteristic groups of the older Gondwana flora, - viz: Phyllotheca, Glossopteris, Gangamopteris, and Noegyerathiopsis-all of which are present in identical oriental species. In the flora enumerated above the older Gondwana regions of the Eastern IJemisphere are generically or spccifically represented by Reinschia australis (1) var brasiliensis, Phyllotheca Griesbachi, Phyllotheca Muelleriana, Phyllotheca sp., Sphenopteris hastata? Neuropteridium Plantianum, Glossopteris Browniana, Glossopteris indica, Glossopteris ampla, Glossopteris occidentalis, Glossopteris sp., Vertebraria sp., Gangamopteris obovata, Arberia minasica, Ottokaria ovalis, and Noeggerathiopsis Hislopi(2).

The types described under the genera Rosellinites, Derbyella, and Hastimima also while new, are to be regarded as belonging to the Southern flora, and will probably be found in other lower Gondwana areas.

The Northern fiora is specifically represented by but two species, Lepipophlois laricinus, and Sigillaria Brardii; and, indirectaly, by Lut four species, Lepidodendron Pedroanum, Sigillaria australis, Sigillaria (?) muralis, and Psaronius brasiliensis.

It will perhaps be found later that Lycopodiopsis Derbyi, the Psaronius (3) just mentioned, the types referred to Dadoxylon and the specirs of Cardiocarpon, arc in reality characteristic of the Southern flora, rather than of a transitional zone of intermingled specics.

It is, in fact, probable that the fossil woods, some of the seeds, and the Lycopodiopsis are Southern types.

(1) S if note on p. - $10 \pi$.

(2) Is further pront of the identity of the oller Gondwan flora in South America mention may be made of the identilication ly Professor Kurt\% (in Bodenbender, Bol. Acarl Vac Ciencias, Curroba rol KVIJ, 1902, p. 203), from beds af the same series in

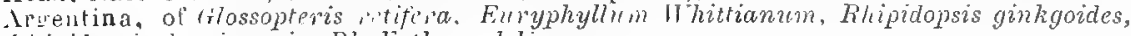
lihipitopsis dinsine'tis, Phyliothed deliquescens.

(3) The totrastichous section ol Psaronius, represented by Paronius brasilienris has not jot been recornized in the Tortbern flora. 
Excluindo as madeiras e sementes, verificamos que cerca da metade dos typos são distinctamente do Sul, emquanto que, apenas seis, ou cerca de 15 por cento das especies, teem, embora indirectamente, direito a um grupamento na flora do Norte (1).

E' completamente descabido tentar differençar as floras Norte e Sul, desde que na natureza, devem existir áreas compostas de lloras parcialmente entremeiadas, transicionaes entre a flora interglacial da Australia, a permiana da Europa Occidental e da parte Oriental da America do Norte.

Se examinarmos a occurrencia e serie nas secções do Brasil, encontramos a flora de Gangamopter is immediatamente em seguida do conglomerato e gres da base (2).

Perto de Suspiro, no Rio Grande do Sul, encontra-se Gangamopteris obovata na parte superior de um schisto preto intercalaảo no gres, a uma distancia de scis metros apenas do manito. Assim parece que tanto no Brasil como na India e Africa do Sul este genero é provavelmente o primeiro a apparecer, com as melhores condiçũes climatericas.

Passando á seguinte camada superior de plantas de importancia, a nordeste de Minas, Santa Catharina, em um horizonte apenas 55. metros, acima do granito, temos: Rosellinites gangamopterides, Histerites brasiliensis, Phyllotheca Griesbachi, Phyllatheca muelleriana, Phyllotheca sp. Glossopteris Browniana, Vertebraria?, Gangamopteris obovata, Arberia minasica, Derbyella anrita, Noeggerathiopsis Hislopi, Cardiocarpon (Samaropsis) Seixasi, Cardiocrrpun Moreiranum, Voltria? e Hastimima Whitei.

Esta flora deve ser considerada simplesmente como flora do Sul, ou Gondrana sem misturas de typos do Norte. A ausencia de Lepidophytos ou outros elementos pertencentes á flora Permo-Carbonifera do Norte, explica-se, ou pela hypothese do clima ou por outras condições do meio que não se tinha tornado ainda apropriado á volta

(1) Ontros typos do Norte rolacionados pelo pro'issor líultz de colloceũes da Ar-

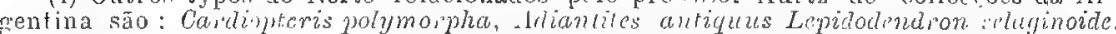

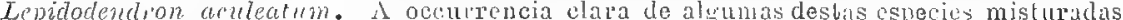

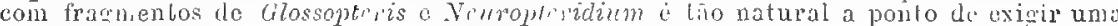

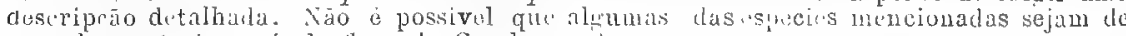
'alladas anteriol'als ás fla llora do Gondwana?

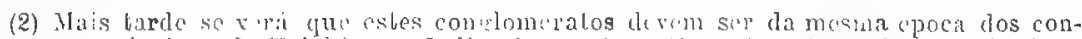

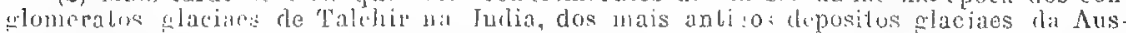

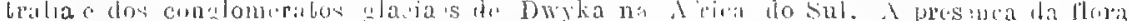

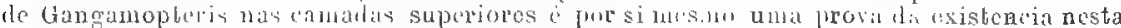
parte do mundo da l'lora gue immediabamule ciracherisa us dupositos post-glaciaes

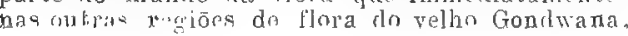


Excluding the woods and seeds, we find that over one hall of the types are fairly distinctly Southern while not more than six, or about $15 \%$ of the species, lay distinct claims to even an indirect membership in the Northern flora (1).

It is manifestly unwise, however, to attempat sharply to differentiate the Southern from the Northern floras, since in nuture there inevitably must have been land areas clothed with intermediate and partially intermingled floras, transitional between the interglacia flora of Australia and the Permian flara of western Europe and eastern North America.

If we examine the stratigraphical occurrence or range of the species in the Brazilian sections we find the Gangamopteris flora immediately following the fbasal conglomerates or sandstones (2).

Gangamopteris obovata is found in the roof of black shale interbedded in the sandstone at a distance of but 6 meter's ajove the granite, near suspiro, Rio Grande da Sul. Thus it appears that in Brazil, as in India and Sooth Africa, this genus is probably the first to appear with the amelioration of the climatic conditions.

Passing to the next higher plant bed of importance, we find, nor theast of Minas, Santa Catharina, at an horizon but 55 meters above the granite, Rosellinites gangamopteridis, Hysterites brasiliensis, Phyllotheca Briesbachi, Phyllotheca Muelleriana, Ihyllatheca sp., Glossopteris Braconiana, Vertebraria?, Gangamopteris obavata, Arberia minasica, Derbyella aurita, Noeggerathiopsis Hislopi, Cardiocarpon (Numaropsis) Seixasi, Cardiocarpon Moreiranum, Voltzia? sp., and Hastimima Whitei.

This flora is to ba regarded as a purely Southern or Gondwana flora, without contamination by northern types. The absence of Lepidophytes or other elements belonging to the northern Permo-Carboniferous flora may lo explained either on the hypothesis that the climatic or other environmental condilions had not yet become hospi-

(1) Other Northern types listerl by Professor Kurtz in colleclions from .Irgeptina are ('ardinulenis polymorpha, Adiantites antiquzs, Lepidodenùron selaginoides and Lepidod'ndron arulcatum. The ostensible occurrence of these species mingled with forms of Glossopteris, Neuropteridium is so striking as to call for a detailed description. Is it not possible that some of the specimens listed are from beds antedaling the Gondwana flora?

(2) It will later in shown that theso conglomerafes may be ol the same age as the

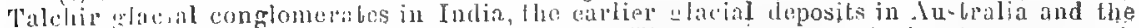

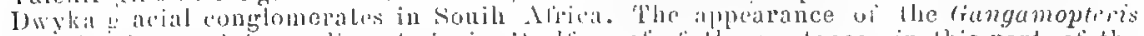

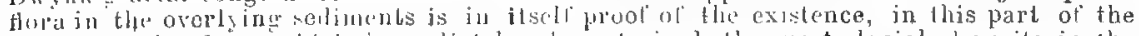
carth of the thuta which immediately charachorized the post-glacial reposits in the other regions of the oldir Gonelwanas. 
da flora do Norte contemporanea, ou pela supposição de que plantas do Norte ainda não tinham tído tempo de reconquistar o solo perdido por ellas mesmas, ou seus antepassados, no tempo do resfriamento da região. Não se póde admittir sériamente a razão da falta de continuidade das terras por onde a flora do norte pudesse emigrar das regiões que occupava.

A evidencia da presença de L_epidophytos na série, encontra-se pela primeira vez na collecção do carvão do Bonito onde se encontram megasporos provavelmente de Sigillaria a 120 metros acima do granito, em camadas formando parte do carvão. O mesmo typo de sporos junto cum fragmentos de cascas e folhas de Sigillaria se encontram em uma camada a 135 metros acima do granito e 40 metros abaixo do carvão Barro Branco, perto de Minas onde encontramos: Equisetites calamitinoides, Schi oneura (?) sp. Sigillaria australis, Sphenopteris hastata (?), Glossopteris indica, Glossopteris ampla, Glossopteris occidentalis, Nceggerathiopsis Hislopi, Cardiocarpon Oliveiranum e Carpolithus sp.

De accordo com as relações estratigraphicas do $\mathrm{Dr}^{2}$. White, o carvão Irapuá encontra-se a poucos metros abaixo do Carvão Barro Branco, em Santa Catharina, sendo este ultimo equivalente ao de S. Jeronymo, perto de Candiota, no Rio Grande do Sul. Destes carvũes yue estão entre o granito e o schisto preto de Iraty, organizaram-se pequenas collecçũes contendo : Lepidophloios laricinus (?), Glossopteris Browniana, Glossopieris indica, Glossopteris sp. Vertebraria sp. Gangamopteris obovata, Ottokaria ovalis, Noggerathiopsis Hislopi, Cardiocarpon Moreiranum e Cardiocarpon Barcellosum. Os elementos typicos da flora de Gangamopteris ou Gondvana inferior estão alli presentes.

$E^{\prime}$ pena cue as collecções feitas, nos horizontes superiores acima citados, não sejam maiores e explicitas nelles dados paloeolıotanicos tão interessantes quanto importantes.

Num horizonte ainda mais elevado, ou pouco mais ou menos 20 metros acima do carvão Irapuá, no Rio Grande do Sul, encontram-se camadas de carvão, ou carvão impuro, cheias de impressões ou restos carbonizados de Lepidodendron Pedroanum, Lepidophloios laricinus e Sigillaria Brardii.

Este material assemelha-se á porção denominada "bone" em alguns de nossos carvões do Norte e está cheio de tyjpos identicos ou semelhantes, embora a matriz não seja tão compacta e petrificada.

As collecções organizadas pela Commissão do Carvão conteem apenas um simples fragmento de tronco de Lycopodiopsis Derbyi e 
table for the return of the contemporaneous northern flora or by the supposition that northern plants had not yet had time to recover the ground lost by themselves or their ancestors at the time of the refrigeration of the region. That there was lack of land connection along which to migrate from some quarter occupied by the northern flora is not to be seriously considered.

Evidence of the presence of Lepidophytes in the series is first found in the collection from the Bonito coal, where, at 120 meters above the granite, megaspores, probably Sigillarian, are met in layers forming a part of the coal. The same type of spore, together with fragments of cortex and leaves of Sigillaric, are met in a bed 135 meters above the granite and 40 meters below the Barro Branco coal near Minas, where we find Equisetites calamitinoides, Schironeur $a$ ? sp., Sigillaria australis, Sphenopteris hastata?, Glossopteris indica, Glossopteris ampla, Glossopteris occidentatis, Noeggerathiopsis Hislopi, Cardiocarpon Oliveiranum and Carpolithus? sp.

According to Doctor White's stratigraphical correlations the Irapuá coal is but a few meters beneath the Barro Branco coal in Santa Catharina, and the Iatter coal is equivalent to the São Jeronymo coar near Candiota, Rio Grande do Sul. From these coals, about midway between the granite, and the Iraty black sliale, small collections were made containing Lepidophloios laricinus? Glossopteris Browniana, Glossopteris indica, Glossopteris sp., Vertebraria? sp., Gangamopteris obovata, Ottokaria ovalis. Noeggeratgiopsis Hislopi, Cardiocarpon Moreiranum, and Cardiocarpon Barcellosum. The trpical elements of the Gangamopteris or lower Gondwana flora are here present.

It is unfortunate that the collections made at the above named and higher horizons are not larger and more comprehensive; for it is certain that interesting as vell as important palæobotanical data are to be found therein.

At an horizon a little higher still, or about 20 meters above the Irapuá coal in Rio Grande do Sul, coaly layers or a dirty coal is found filled with the impressions or carbonized remains of Lepidodendron Pedroanum, Lepidophloios laricinus and Sigillaria Brardii.

This material resembles the "bone" partings in some of our northern coals, and is filled with identical or similar types though the matrix is not so compact or lithified.

The collections made by the Coal Commission contain but a single stem fragment, Lycopodiopsis Derbyi, and pieces of fossil 
pedaços de madeiras fosseis de um horizonte superiu ao que foi descripto por ultimo. Entre estes encontro o typo gymnospermeo descripto ultimamentecomo Dadoxylon mericlionale de camadas de 30 a 60 metros acima do carvão Barro Branco, em Butiá, no Rio Grande do Sul, o tronco de Lycopodiopsis Derbyi, de cerca de 155 metros acima do schisto preto do Iraty, ou a cerca de 285 metros acima do carvão Barro Branco, em Bofete, em Săo Paulo, Dad̆oxylon numularium das camadas vermelhas, 100 a 200 metros acima do carvão S. Jeronymo na região de S. Raphael e um fragmento muito interessante da arvore Lepidophyte, Sigillaria (?) murallis de perto da mesmo horizonte nas proximidades de S. Sepé, no mesmo Estado.

A presenca do grande typo Lepidophitico de madeira fossị em um horizonte entre 100 a 200 metros acíma do carvĩu de Barro Branco, ou digamos, 75 metros acima do horizonte do schisto preto do Iraty e a occurrencia de Lycopodiopsis Derbyi na mesma scile, convence-nos, de uma maneira muito positiva, da idade palæozoica das camadas alé um nivel de muitos metros acima do schisto pretu do Iraty.

o schisto preto de Iraty, que por si mesmo é notavel, não sómente por conter ossos de Mesosaurus e Stereosternum, mas tambem pelas suas propriedades especiaes, como rocha que contem petroleo, parece ser palæeeozoíco, pela presença ủe Lepidophitos fosseis.

A posição estratigraphica das madeiras fosseis, incluindo $L y c o-$ podiopsis Derbyi e Dadoxillon Pedroi examinados por Zeiller e Renault e, ao que dizem, associados a outros tỵpos de madeiras do coniferas a Psaronius e a Stereosternum em S. Paulo, não foi dada com a descripção da especie, mas de-sua associaçăo com restos de vertebrađos, púde-se deduzir quasi com certeza que procedem do horizonte do schisto preto de Iraty e da mesma sílie de camadas si)brepostas que fornecam as madeiras fosseis e o specimen Lycopodiopsis Derbyi colleccionado pela Commissão do Carvão. Parece-nos haver pouca duvida quanto á certeza desta referencia estratigraphica das madeiras colleccionadas e enviadas por Derby a Renault e a Zeiller, e a referencia torna-se ainda mais interessante desde que accusa a presença de Psaronius cm algum horizonte nas camadas acima do carvão Barro Branco.

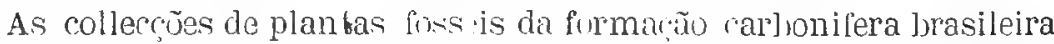
ainda sũo insufficientes o demais limitadas quanlo á distribuição estratigraphira c geographira para formar una base para conclusio definitiva quanto á ordem e sequencia dos rarios lypos. 
woods from an horizon higher than that last described. Among these I find the gymnospermous type later to be described as $D a-$ doxylon meridionale from beds $ّ 0-60$ meters above the Barro Branco coal at Butiá, Rio Grande do Sul ; the stem of Lycopodiopsis Derbyi, from about 155 meters above the Iraty black shale, or about 285 meters above the Barro Branco coal horizon at Botefe in São Paulo; Dadoxylon nummularium from the red beds 100-200 meters above the S. Jeronymo coal in the S. Raphael region, Rio Grande do sul; and a very interesting fragment of a tree Lepidophyte, Sigillaria (?) muralis, from near the same horizon, vicinity of S. Sepé, in the same state.

The presence of the large Lepidophytic type of fossil rood at an horizon between 100-200 meters above the Barro Branco coal, or say 75 meters above the Iraty Jlack shale, and the occurrence of Lycopodiopsis Derbyi in the same series argues very strongly for the Palaeozoic age of the beds up to a level of many meters above the Iraty black shale.

The Iraty black shale itself which is notable not only for the occurrence of the Mesoscurus and Stereosternum bones therein, Jut also for its special properties as an oil-bearing rock, appears; on the evidence of the fossil Lepidophytes in the higher beds, to be Palaeozoic.

The stratigraphical position of the fossil woods, including the Lycopodiopsis Derbyt and Dadoxylon Pelroi examined H Renault and Zeiller and said to je associated with other coniferous types of wood, Psatronius, and with Stereosternum ins. Paulo wat not stated in connection with the description of the species; but from their association with the vertebrate remains it is to be inferrel almost with certainty that ther como from the horizon of the Iraty hlack shale, and tho same serier of overlying beds that has furnished the fossil woods and the specimen of Lycopodiopsis Derbyi collected by the Coal Commission. There would seem to be little room for doubt as to the rorrectness of this stratigraphical reference of the woods collecled and sent by Derljy to Renault and to Zeiller; and the refercnce is the more interesting since it involves the occurrence of Psarorius at some hnrizon in the seriesa love the Barro Branco coal.

The r)llections of fossil plant from the Brazilian coal fields are

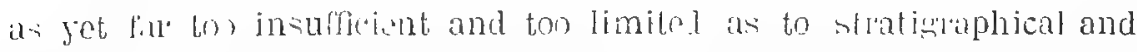
gentraphical distribution to form a havis for definite molusions as to the range and -ecuence of the varions types. 
Mesmo julgando com os escassos dados, a disposição pareceria que, seguindo um movimento continental e um periodo concomitante de mudança rigorosa climaterica, a região possuio uma flora de Gangamopteris pura e typica, que á medida que o clima melhorou, ou 'que appareceram difficuldades de migração, foi gradualmente invadida pelos representantes do Lepidophytos do Norte, misturados, talvez, com fórmas indigenas da zona de transição.

Como demonstramos nas séries car]Joniferas, o numero das especies do Norte, ou suas derivadas provaveis, parece augmentar até que no carvão Barro Branco, onde verificamos que a maior parte da materia carbonifera parece ter sido fornecida por Lepidodendron e Sigillaria.

A presença de Psaronius nas proximídades, ou acima do schisto preto de Iraty na série, crêa e, substancialmente, alimenta a esperança de que frondes de Pecopteris, ou mais provavelmente do grupo Cladophlebis, serão encontradas mais tarde nesta parte da série, mostrando que, com a restauração das condiçũes uniformes do clima, os mais resistentes precursores do grupo Lepidophitico foram seguidos pelos representantes dos grupos de fetos do Norte, ou cosmopolitas.

\section{Distribuição estrangeira das especies}

o principal criterio para a correlação e determinação da edade dos carvões brasileiros, é o fornecido pelos dados da distribuição das especies de plantas fosseis. Lista evidencia, como veremos, é em geral notavelmente clara e directa.

Entre as nossas especies, que se encontram em outros continentes, ou que teem estreitas relações com as especies estrangeiras, notarn-se as seguintes :

1 - Reinschir rustralis do schisto de kerozene, New South Wales.

2 - Rosellinites gangamonteridis tendo relações estreitas apparentemente com um especie do Raniganj da India.

3 - Hystrites brasiliensis, relacionada directamente com uma especie do Rothliegende da Thuringia.

4 - Phyllothec a Griesbachi do grupo Barakar na India, relacionada com Phyllotheca Australis da serie de New Castle, New South 
Yet, judging from the meagre data in hand it would appear that, following a continental movement and a concomitant period of severe climatic change, the region was possessed by a typical and pure Gangamopteris flora, which, as the climate, ameliorated or the difficulties of migration were overcome, was gradually invaded by representatives of the Northern Lepidophytes, mingled, perhaps, with forms indigenous to the transitional zone.

As we ascend in the coal bearing series the number of northern species or their probable derivatives appears to increase until, in the Barro Branco coal, we find that the greater part of the carbonaceous matter seems to have been contributed by Lepidodendron and Sigillaria.

The presence of Psaronius near or above the Iraty black shale in the series creates and substantially fosters the expectation that fronds of the [Pecopteris, or, more probably, of the Cladophlebis groups will later be found in this part of the series, showing that, with the restoration of uniform climatic conditions, the hardier forerunners in the Lepidophytic group were followed by representatives of the northern or cosmopolitan groups of ferns.

\section{Foreign distribution of the species}

The principal criteria for the cerrelation and age determination of the Brazilian coals are those afforded by the records of the distribution of the fossil plant species. This evidence, as we shall see, is in general remarkably clear and direct.

Among our species which occur in other continents, or which have very closely related foreign species, are the following:

1. Reinschia australis (*), from the kerosene shale, New South Wales.

2. Rosellinites Gangamopteridis, apparently closely related to a form in the Raniganj of India.

3. Hysterites brasiliensis, closely related to a form from the Rothliegend of Thuringia .

4. Phyllotheca Griesbachi, from the Barakar group in India, and related to Phyllotheca australis from the Newrastle series, New South

( $\left.{ }^{\star}\right)$ See note on pag. 407 . 
Wales e Phyllothecr equisetitoides do Permiano e do Tungusca inferior, da Siberia.

5 - Phyllothera Muclleriana, directamente relacionada com Phyilotheca indica de Raniganj da India.

6 - Hastes di Phyllothech apparentemente identicas ás formas do Raniganj da India, aus schistos de Lcea do Transvaal e do grupo New Castle, New South Wales.

7 - Lycopodiopsis Deroyi provavelmente identica ás formas dos schistos do Transvaal e do Permiano da Siberia.

8 - Lepidophloios laririnus commum no Carbonifero superior da Europa e America do Norte e na região carbonifera da Argentina.

9- Sigillaria Brardii dos schislos de Ecca no Transwaal e largamento espalhada no carbonifero superior e l'ermiano da Europa e da America.

10 - Sigillenia rustralis relacionada com Sigillaria oculina do gres variegado da Europa.

11 - Lepidodendron Pedrocinum relacionado com Lepidodendron ob̄ovatum e Lepidodendron dichotomum do Carbonifero superior do Norte e com Lepidodendron oculisfelis las proximidades da base do Permiano da China.

12 - Sohenopteris hastata do grupo Nerv Castle, New South Wales e proveniente tambem da Tasmania.

13 - Neuropteridium plantianum (oclidum) do Talchir e Karharbari da India, dos schistos de Ecca de Cape Colony, das camadas carboniferas da Argentina e directamente relacionado com Neuropteris tasmanica de Hobart na Tasmania.

14 - Glossopteris Brownicunr da serie de New Castle New South Wales, da formação carbonifera do Mersey River, Tasmania e Barakar e Raniganj da India, das camadas de Beaufort em Cape Colony e das de Ecca do Transvaal, Natal, Colonia Orange River e da Africa Occidental portugueza, da Argentina e do Rhetic do Tonquin.

15 - Glossopteris indica, do Talchir, Karharbari, Barakar e Raniganj na India, da serie de New Castle, New South WaTes, das regiões carboniferas de Mersey Tasmania, da serıe de Bowen River em Qeensland, das camadas de Beaufort em Cape Colony, dos schistos de Ecca no Transtǎal, Africa oriental portugueza, das camadas carboniferas da Argentina, do Fermiano superior da Russia, e do Trias do Panchet e Jabalpur grupos da India, e do Rhetic do Tonquim. 16 - Glossopteris "minll da selie de New Castle, New South Wales, da serie de Bowen Riven, Queensland de Mersey River na 
Wales, and Phyllotheca equisetitoides from the Permian of the lower Tungusca, in Siberia.

万. Phyllotheca . Iuelleriana, closely related to Phyllothena indica, from the Raniganj in Tulia.

6. Phillothece, stems, apparently identical with forms from the Raniganj of India, the Ecca shales of the Transvaal, and the Newcastle group, New South Wales.

7. Lycopodiopsis Derbyi, po-sibly identical with forms from the Ecca shales.in the Transraal, and the Permian of Siberia.

8. Lepidophloios laricinus, common in the Upper Carboniferous of Europe and North America, and in the coal measures of Argentina.

9. Sigillaria Brardii, from the Lcca shales in the Transvaal, and widespread in the Upper Caxboniferous and Permian of Europe and America.

10. Sigillaria custralis, related to Sigillaria oculina from the Bunter sandstone of Europe.

11: Lepidodrendron I'edroanum, related to Lepidodendron obovatum and Lepidodendron dichotomum from the Northern Upper Carboniferous and to Lepidodendron oculisfelis, from near the base of the Permian in China.

12. Sphenopteris hastata?, from the Newcastle group, New South Wales, and reported also from 'Tasmania.

13. Neuropteridium Plantianum (=validum) flom the Talchir and Karharbari in India, the Ecca shales of Cape Colony, the coal mesures of Argentina, and closely related to Ncuropteris tasmanica from Hobart, Tasmania.

14. Glossopteris Brouniana, lrom the Nerrcastle series, New South Wales, Mersey River coalfield, Tasmania, the Barakar and Raniganj of India, the Beaufort beds in Cape Colony, the Ecca beds of the Transvaal, Natal, Orange River colony, and Portuguese East Africa, from Argentina, and from the Rhetic of Tonquin.

15. Glossopteris indica, from the Talchir, Karharbari, Barakar, and Raniganj in India, the Newcastle series, New South Wales, the Mersey coalfield, Tasmania, the Bowen River series in Queensland, the Beaufort beds in Cape Colonj, the Licca shales in the Transvarl, and Portuguese East Arrica, the coal measures of Argentina, the upper Permian of Russia, and in the Trias of the Panchet and Jabalpur groups of India, and the Rhetic of Tonquin.

16. Gilossopteris ampla, from the Newcastle series, New South Wales, the Bowen River series, Queensland, the Mersey River in 
Tasmania, do Talchir e Raniganj na India e das camadas carboniferas da Argentina.

17 -Glossopteris occidentalis relacionada com Glossopteris stricta do Raniganj da India e do Permiano superior da Russia.

18 - Gangamopteris obovata (cyclopteroides var. attenuata var. major) do Talchir Karharbari e Raniganj na India, do grupo New Castle, New South Wales, da região carbonifera de Mersey, Tasmania, de Beaufort em Cape Colony, dos schistos de Ecca no Transvaal, das camadas carboniferas da Argentina e do Permiano superior da Russia.

19 - Noggerathiopsis Hislopi do Talchir, Karharbari e Barakar da India da serie de New Castle em New South IVales, da serie de Mersey River da Tasmania, das camadas de Ecca da Africa do Sul, das camadas carboniferas da Argentina e do Rhetic do Tonquim.

20 - Arberic minrsica relacionada directamente com Arberia indica do Talchir Karharbari da India.

21 - Ottokaria ovalis relacionada com Ottokaria bengalensis da Karharbarı da India.

22 - Cardiocarpon Seixasi relacionada com especies do Karharbari da India.

23 - Hastinima Whithei relacionada provavelmente com Dictyopteridium sporiferum do Talchir e Raniganj, grupos da India.

\section{Correlações}

O exame da distribuição das especies no Systema Gondivana da India, mostra a mais intima relação da nossa flora com as do Talchir Karharbari e grupos Damuda. Quer por sua composição restricta, quer por seus elementos dominantes, a flora da formação carbonifera brasileira, mostra ser mais propriamente aliada ás series do Talchir e Karharbari. A occurencia de uma porção relativamente grande destas especies, tambem nas series Damuda e especialmente no grupo Barakar, é provavelmente devido, a muito maior riqueza da flora Damuda, comparada com a mais restricta de Karharbari, e a relativamente pobre do grupo Talchir. Por conseguinte, podemos dahi concluir, que o equivalente do grupo carbonifero brasileiro encontra-se na serie Talchir Karharbari, da India. E' evidente que collecções maiores que tenho em mãos confirmam as conclusões a que Zeiller chegou anteriormente, a respeito da idade do carvão do Rio Grande do Sul. 
Tasmania, the Talchir, and Raniganj, in India, and the coal measures of Argentina.

17. Glossopteris occidentalis, related to Glossopteris stricta from the Raniganj of India and the upper Permian of Russia.

18. Gangamopteris obovata, (= cyclopteroides var. attenuata and var. major ), from the Talchir, Karharbari, Barakar and Raniganj in India, the Newcastle group, New South Wales, the Mersey coalfield, Tasmania, the Beaufort in Cape Colony, the Ecca shales in the Transvaal, the coal measures of Argentina, and the upper Permian of Russia.

19. Noeggerathiopsis Hislopi from the Talchir, Karhabari and Barakar of India, the Newcastle series in New South Wales, the Mersey River series of Tasmania, the Ecca beds of South Africa, the coal measures of Argentina, and the Rhetic of Tonquin.

20. Arberia minasica, very closely related to Arberia indica, from the TaIchir-Karharbari of India.

21. Ottokaria ovalis, related to Ottokaria bengalensis from the Karharbari of India.

22. Cardiocarpon Seizasi, related to forms in the Karharbari of India, and

23. Hastimima Whitei, possibly related to Dictyopteridium sporiferum from the Talchir and Raniganj groups of India.

\section{Correlations.}

The examination of the distribution of the species in the Gondwana system of India shows a most intimate relation of our flora with that of the Talchir-Karharbari and Damuda groups. In its restricted composition and in its dominant elements the flora of the Brazilian coal group appears to be most closely allied to that of the Talchir-Karharbari series. That a relatively large portion of these species occurs in the Damuda series also, and particularly in the Barakar group, is probably due to the far richer flora of the Damuda as compared with the more restricted Karharbari and the relatively meager flora of the Talchir group. We may therefore conclude that in India the equivalent of the Brazilian coalmbearing group is to be found in the Talchir-Karharbari series. The evidence of the larger collections in hand is thus found to corroborate the conclusions earlier reached by Zeiller as to the age of the coals in Rio Grande do Sul. 
A porção superior da serie brasileira, incluindo o schisto preto de Iraty, e os 150 metros, ou mais das camadas vermelhas e cinzentas etc., com Lycopodiopsis Derbyi, Sigillaria murallis, Dadoxyllon (?) e provavelmente Psaronius, deve ser considerada como correspondendo, em idade pelo menos, á uma parte de serie Damuda da India. Espero confiante, que subsequentes estudos destas camadas, hoje pouco conhecidas palæobotanicamente, confirmarão perfeitamente esta tentativa de correlação.

E' claro que a nossa flora tem estreita identidade na Australia e Africa do Sul, com as series New South Wales, series Bowen River de Queensland e Mersey da Tasmania, e com a serie de schistos de Ecca e Beaufort do Transvaal, Cape Colony, Natal, Orange River Colony e Africa Oriental allemã. Camadas da mesma idade foram descobertas na Argentina por Bodenbender e Kurtz, nas precordilheiras e serras Pampeanas, das provincias de San Juan, La Rioja, San Luiz e Mendoza.

As relações systematicas geraes destas formações estam indicadas de um modo geral no quadro junto, compilado de varias fontes.

$\mathrm{E}^{\prime}$ dada a tabella das formações mesozoicas anles para mostrar a continuidade que a comtemporaneidade das camadas no mesmo nivel. Sobre discussões a respeito da serie veja: Frech, Lethaea Geognostica, vol. II Pt. 4, 1902, pp. 579-623 Feistmantel, Mem. Geol Surv.,N ew South Wales n. 3, 1890, p. 66; Arber, The Glossopteris Flora, 1905, p. XXXVII. 
The higher portion of the Brazilian series, including the Iraty black shale and the overlying 150 meters or more of red and grey beds, etc., with Lycopodiopsis Derbyi, Sigillaria (?) muralis, Dadoxylon (?), and Psaronius, is to be regarded as corresponding in age to a portion, at least, of the Damuda series in India. I confidently expect that subsequent studies of these beds, which are at present little known palreobotanically, will fully confirm this somewhat tentative correlation.

In Australia and South Africa it is clear that our flora finds its close identities in the Newcastle series of New South Wales, the Bowen River series in Qaeensland, the Mersey series of Tasmania, and in the Ecca shales and Beaufort series in the Transvaal, Cape Colony, Natal, Orange River Colony, and German East Africa. Beds of the same age in Argentina are recognized by Bodenbender and Kurtz in the precorm dilleras and in the Pampean sierras in the provinces of San Juan, La Rioja, San Luis and Mendoza.

The general systematic positions of these formations is indicated in a very broad way in the accompanying table compiled. from various sources.

The tabulation of the Mesozoic formations is given to show the sequence, rather than to indicate the contemporaneity of the beds placed at the same level. For discussions of the equivalences of the series see Frech: Lethaea Geognostica, vol. II pt. 4, 1902, pp. 579-623; Feistmantel, Mem. Geol. Surv. New South Wales, n. 3, 1890, p. 66 ; and Arber, The Glossopteris Flora, 1905 p. XXXVII. 


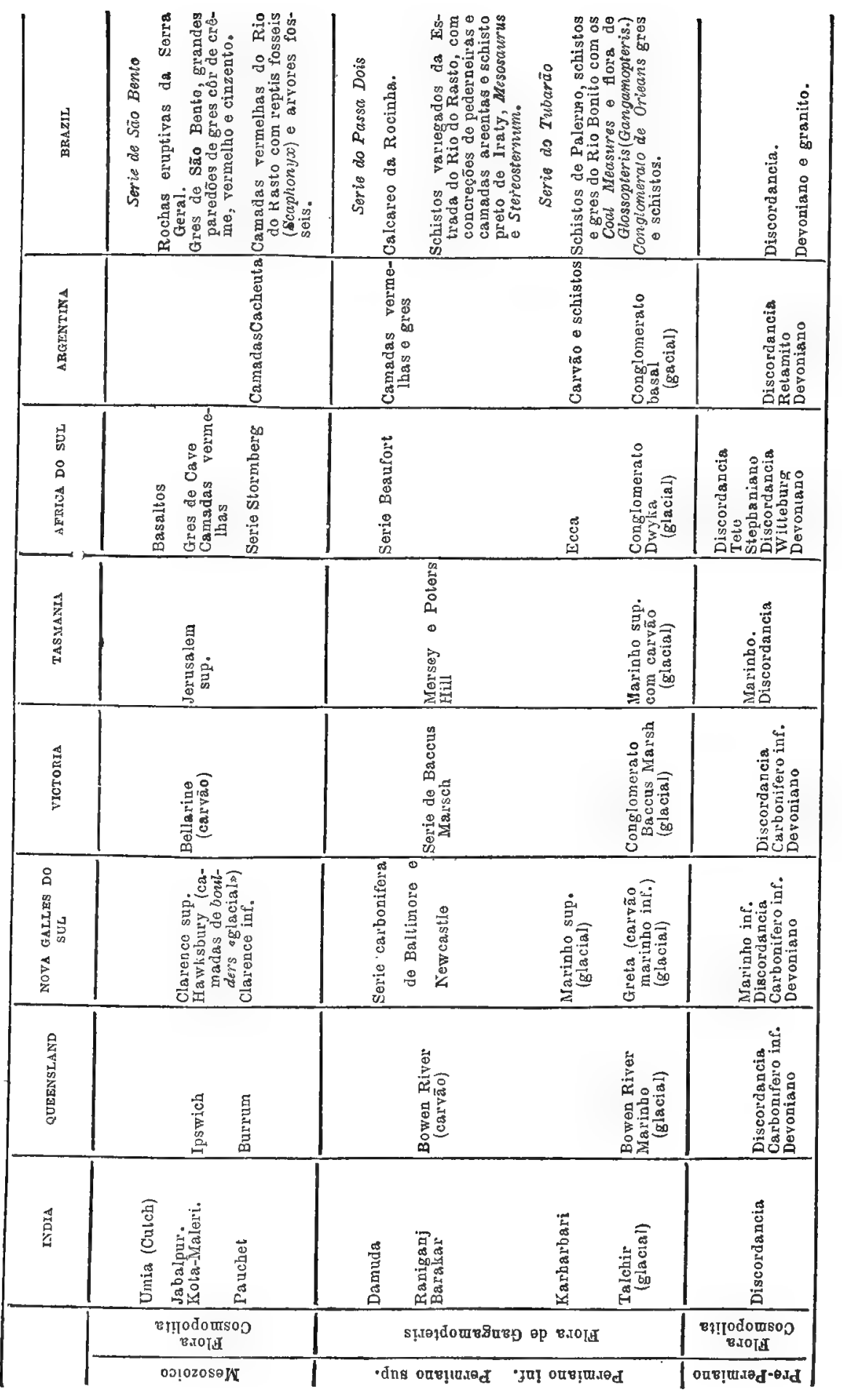




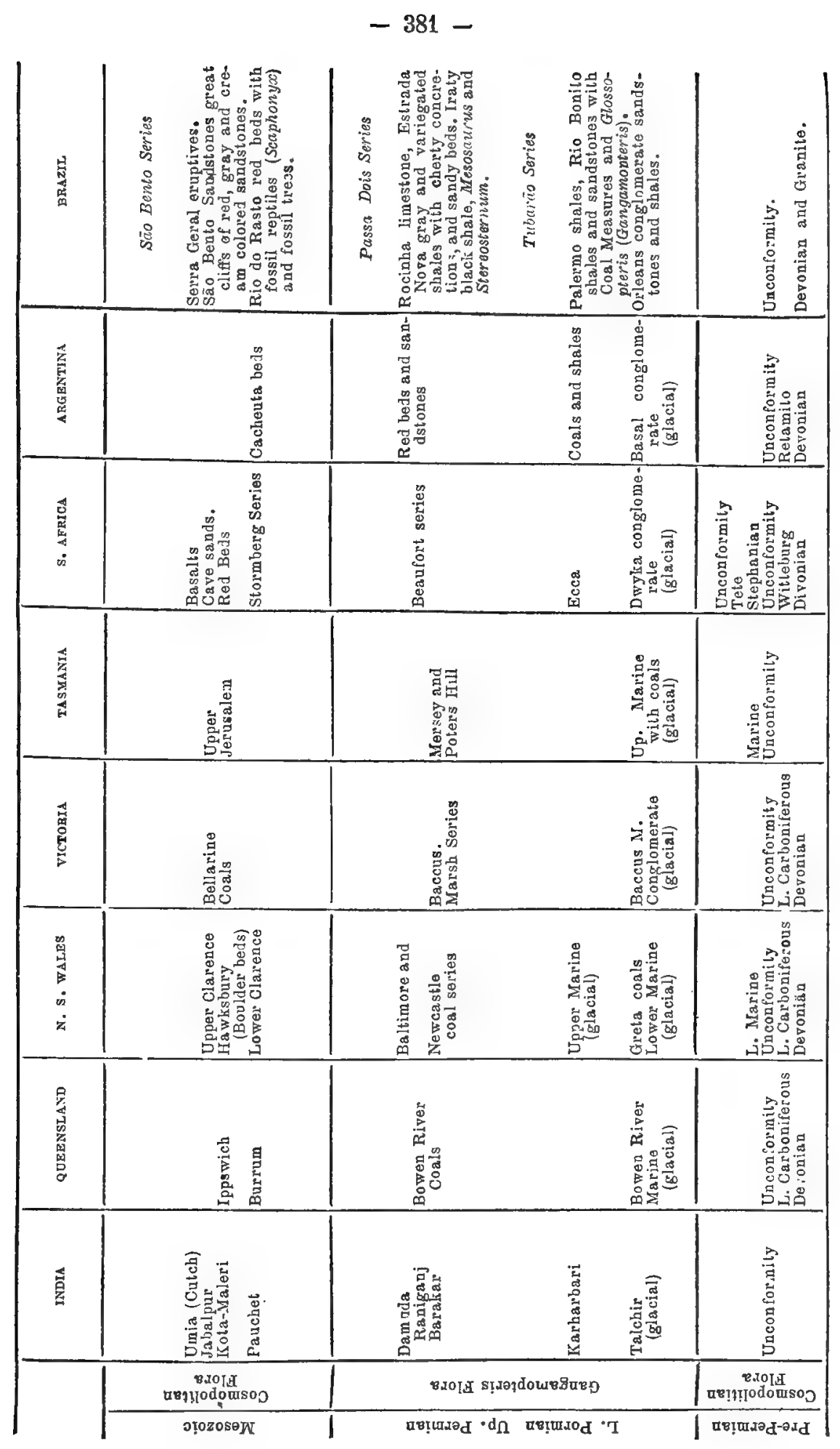




\section{Idade da flora}

o que ha de mais notavel na flora de Gangamopteris (1), ou antigo Gondwana, é relativo a seu isolamento geographico e sua uniformidade de composição. Ambas estas notaveis feições são indubitavelmente devidas mais ou menos directamente ás condições da origem da flora, a principal, e sobretudo a mais importante das quaes foi a severidade do clima anterior, ou muito provavelmente contemporaneo, de seu desenvolvimento.

A flora de Gangamopteris, é actualmente conhecida por ter florecido em um estado de relativa pureza, nas regiões carboniferas da India, em Queensland, New South Wales e Victoria na Australia, na Tasmania, Este da Africa Portugueza e.Allemã, Sudoeste da Africa Portugueza, Rhodesia, Zulluland, Transvaal, Orange River Colonyi na Africa do Sul, e na America do Sul no Brasil e na Argentida. (2) A sua presença nota-se tambem em Kashmir, Afganistan e Persia na Asia do Sul e em Bornéo e na Australia Occidental, embora o material palæbotanico destas regiões seja ainda muito pobre.

A grande uniformidade na composição desta flora e o gráo extraordinario de identidade, de suas especies, nestas distantes regiões, demonstram a necessidade da existencia de ligação das terras, pelas quaes os diversos typos de plantas terrestres pudessem distribuir-se por si mesmo com tal facilidade que habilitasse a flora a conservar praticamente a sua composição em massa. A evidencia apresentada pela flora é confirmada pelo testemunho dos vertebrados, tambem caracteristicos da mesma serie.

Com effeito a probabilidade de uma ligação anterior das terras, no hemispherio sul entre as regiões continentaes de flora Gondwana foi

(1) Gangamopteris í aqui empregado em vez de Glossopteris introduzido por Neumayr para designar a parte mais antiga ou Palreozoica da flora de Gondwana, pelas seguintes razōes : 0 genero Glossopteris não í só das formaçōes Permo-carboniferas, tambem se encontra no Rhetic do Tonquim. Na bibliographia palrobotanica antiga o termo Glossopteris era genericamente applicado ao genero que agora se chama Lipidophyllum e mais tarde, depois de sua applicação presente, foi conlundido com o genero Lagenopteris das formações Triassicas e Jurassicas. As floras Mesozoicas com Glossopteris, apresentam uma composicão cosmopolita ou de typos cosmopolistas misturados com sobreviventes de Gondwana o são differentes da antiga fiora de Gangamopteris: 0 genero Gangamopteris está quasi sempre, e por todo a parte, presenta no flora palseozoica Gondwana e é caracteristico da serie. E' uma planta grancle que se reconhece facilmento e que praticamente não se póde confundir com outro genero. Além de tudo não se sabe cue tenha transgredido no intervallo do Pormiano ao Mesozoico do modo que é directa e difinitivamente applicavel á parte mais antiga, ou Palæozoica, da flora Gondwana em toda a sua provincia.

(2) Acaba de ser annunciado o reconhecimonto de Phyllotheca.e proravelmente Schisoncura tambem, entre fosseis das ilhas Falkland, veja: Nithorst, Bull. Geol. Inst. Upsala , . . VII-1906 pag. 72. 
Age of the Flora.

The most striking features of the Gangamopteris, or older Gondwana, flora (1) are its relative geographical isolation and its uniformity in composition. Both of these remarkable features are no doubt due more or less directly to the conditions of the origin of the flora, the chief and by far the most important of which was the severity of the climate antecedent to or very probably concurrent with its development.

The Gangamopteris flora is now known to have flourished in a state of relative purity in the coalfields of India, in Queensland, Nerv South Wales, and Victoria in Australia, in Tasmania, in German and Portuguese East Africa, Portuguese South-East Africa, Rhodesia, Zululand, the Transvaal, the Orange River Colony, Natal and Cape Colony in South Africa, and in Argentina and Brazil in South America (2). Its presence is also indicated in Kashmir, Afghanistan and Persia in Southern Asia, and in Borneo and Western Australia, though the palæobotanical material from these regions is still very meager.

The great uniformity in the composition of this flora and the extraordinary degree of identity in its species in these distant regions has long since been recognized as necessitating the existence of land connections along which these varied types of terrestrial plants could distribute themselves with such facility as to enable the flora to preserve its composition practically en masse. The evidence afforded by the flora is corroborated by the distributional testimony of the vertebrates, also characteristic of the same series.

Indeed the probability of a former land connection in the Southern hemisphere between thess continental regions of the Gondwana fiora

(1) "Gangamopteris" is here employed instead of the name "Glossopteris", introduced hy Neumayr, to designate the older or Palaeozoic portion of the Gondwana floras, for the following reasons: The genus Glossopteris is not confined to the Permo-Carboniferous formations, but is found to pass up into the Rhetic of Tonquin. In the early palæobotanical literature the name Glossopteris was generically applied to the genus now called Lepidophyllum. and, later, after its present application, it was confused with the genus Sagenopteris of the Triassic and Jurassic formations. The Mesozoic floras with Glossopteris present either a cosmopolitan composition or mingled cosmopolitan types and Gondwana survivors, and are distinct from the older with Gangamopteris. The genus Gangamopteris is nearly always and everywhere present in the Palaeozoic Goodwana flora, and is characteristic of the series. It is a large, asily recognized plant and is practically free from confusion with other genera.

Above all, it is not known to transgress the palaeobotanical break between the Permian and the Mesozoic ; so that it is directly and definitively applicable to the older or Palaeozoic portion of the Gondwana flora îhroughout its province.

(2) Announcement is just made of the recognition of Phyllotheca, and possibly Schizoneura also. among fossils from the Falkland Islands. See Nathorst, Bull. Geol. Inst., Upsala, vol. VIL. 1906, p. '72. 
estabelecida independentemente pelos palæontologistas que se dedicam ao estudo dos vertebrados fosseis. Para explicar a migração animal e vegetal Suess (1) propoz a hypothese de um continente a que se deu o nome de "Terra Gondwana", constituido por parte da Asia Meridional, Australia e Africa do Sul. Este continente está agora augmentado para abranger uma grande parte da America do Sul. E' provavel que as terras que existem actualmente na regiăo Antarctica, contenham restos deste antigo continente de que tenha sido outr'ora o centro. Embora todas as regiões de genuina flora de Gangamopteris, não fossem parte de um unico continente, eram entretanto grandes areas de terra, bastante proximas de modo a permittirem permuta de seres vivos com a maxima facilidade.

O grande systema Gondwana da India é de agua doce, incluido em diversas bacias; a serie do Karroo inferior abranje uma successão de sedimentos epicontinentaes com a extensão de muitas milhas quadradas e os conglomeratos da base da formação carbonifera, brasileira se apoiam nos granitos antigos de uma superficie da terra eroida. o nome "Terra Gondwana» é muito apropriado, pois que, deste modo muitas especies mesozoicas do Gondwana puderam estender seus dominios da India a Tonquim á Australia, Africa do Sul e Argentina, onde o professor Kurtz reconheceu muitas plantas do Rajmahal e o professor Ameghino descobrio relações correspondentes entre as faúnas mesozoicas de vertebrados.

A prova palæontologica da existencia de uma vasta "Terra Gondwana " é sustentada mais adiante pela extensão da glaciação que nella houve. Na India, Australia, Tasmania e Africa do Sul, a flora de Gangamopteris parece ter feito o seu apparecimento $\mathrm{em}$ um periodo de grande glaciação. A serie "Greta » (2) em New-South Wales é encontrada com uma serie carbonifera, que dizem estar entre camadas de boulders glaciaes, mas em outras regiões citadas, é precedida por depositos de boulders ; em cuja formação as geleiras, ou gelos fluctuantes, desempenharam papel inequivoco. (3)

(1) Antlitz d. Erd., vol. I, 1885, p. 768.

(2) Veja o quadro da pag. 380.

(3) As provas da glaciacão Palreozoíca foram reunidas por Frech. Lethaea Palæzoica, vol. II Lief 4, $1902 \mathrm{pp}$. 572 - 627 e Geikie, Textbook of Geology, vol. II, 1903. pp. 1058 et seq. Na peninsula Indiana o conglomerato de Talchir de grande extensão contém boulder's de cerca de cinco metros de diametro e pesando umas 15 toneladas, depositados em schistos e gres de orräo fino. Alguns dos boulders transportados são lisos, facetados e striados einquanto que o calcareo subjacente é localmente liso, polido, arranhado e sulcado. Para dados sobre a accão do gelo do Gondwana na Indıa, veja: Noetling, N. Jahrb. für Min. 1896, BI. II, p. U1; Waagen, Jahrb. d. k. k. geol. Reichsanst. vol. 
has quite indepentently been established by the students of vertebrate palrontology. To meet the migrational necessities of faunas and floras a continent, to which Suess (1) gave the name "Gondwana-land", was proposed, to include portions of southern Asia, Australia and South Africa. This continent is now extended to include a large portion of South America. It is probable that the land masses now existing in the Antarctic include remnats of this ancient continent, of which they may once have been the nucleus. Whether or not all the regions of the true Gangamopteris flora were parts of a single continent, it is certain they were land areas of large size sufficiently close to permit interchanges of life with the greatest freedom.

The great Gondwana system of India is a fresh water system included in several basins; the Lower Karroo series embraces a series of epicontinental sediments many thousands of square miles in area ; and the basal conglomerates of the Brazilian coal measures lie on the old granites of an eroded land surface. The name "Gondwana-land" is most appropriate; for by this route many of the Mesozoic Gondwana species also were able to extend their domain from India and Tonquin to Australia, South Africa, and Argentina, where Professor Kurtz has recognized many of the Rajmahal plants and where Professor Amigheno has discovered corresponding relations between the Mesozoic vertebrate faunas.

Te palæontolegical proof of the existence of a great Gondwanaland is supported, further, by the great magnitude of the glaciation which it sustained. In India, Australia, Tasmania, and South Africa, the Gangamopteris flora seems to have made its appearance at about the time of a period of great glaciation. In the Greta series (2) in New South Wales, it is found accompanying a group of coals which are said to lie between glacial boulder beds; but in the other regions cited it is preceded by boulder deposits in the formation of which glaciers or floating ice have played an unmistakable part. (3)

(1) Antlitz d, Erd., vol. 1, 1885, p. 768.

(2) See the table, p. 381 .

(3) The proofs of palaeozoic glacition are summired by Frech, Lethaea Palaeozoica, Bd. II, Lief. 4, 1902, pp. 572-627; and Guikic, Texthook ol Greology, vol. II, 1903, pp. 1058 et seq. In the Indian peninsula the Talchir conglom crate, of gr at exteut, includes boulders nearly 5 meters in diameter and weighing as much as 15 tons, dropped in fine grained sandstones and shal 's. Some of the transported boulders are smooth, facetted and striated, while the underlying limestone is locally smoothed, polished, scratched and grooved. For data relatino to Gondwana ice work in India see: Noctling, N. Jahrb. f. Min., 1896 Bd. II. p. 61; Waagen, Jahrb. d. k.-k. geol. Reichsanst., vol. XXXVII, 1887, p. 143; 
Está portanto reconhecido agora que a flora de Gangamopteris deve provavelmente a sua origem á existencia durante algum tempo de um clima glacial na "Terra Gondwana " que exterminou, repelliu, constituio-se em obstaculo á flora cosmopolita, durante um consideravel periodo em que parte della foi incapaz de resistir a seu rigor, adaptando-se ou transformando-se.

Entretanto os typos mais antigos do Gondwana, productos dos elementos mais resistentes na flora do Norte, desenvolveram-se e espalharam-se por ambos os hemispherios, hem que não se supponha terem elles nascido sob condiçũes glaciaes contemporaneas, é fóra de duvida que appareceram emquanto a região tinha ainda baixa temperatura, inteiramente inhospita para os typos contemporaneos do Norte ou cosmopolitas.

Ainda não se chegou a accordo quanto ás causas da glaciação Palæozoica da "Terra Gondwana". Entre as principaes hypotheses apresentadas para explicar o apparecimento e a area do clima frio, ha o do deslocamento do eixo da Terra de modo a levar um dos polos, para a parte meridional do Oceano Indico. Outras são: da grande altitude da superficie terrestre; da reducção do gaz acido carbonico $\left(\mathrm{CO}^{2}\right)$ da atmosphera; durante longos periodos de continua decomposição das rochas seguindo o levantamento e pela influencia da formação do carvão, dando em resultado a perda do calor, pela irradiação, e o estabelecimento das zonas climatericas; o gráo de salinidade e con-

XXXVII, 1887, p. 143; Oldham, Man. Geol. India, 2a ed., 1893, chap. VI, and VII ; Blanford, Quart. Journ. Geol. Soc. vol. XLII, 1886, p. 249 ; Blanford, Rec. Gcol. Surv. India, vol. XX. 1887, pg. 49 ; Oldbam, Geol. Mag. (3) vol. III, 1887, p. 32.

E' sabido que as camadas de boulder's glaciaes, da Australia se estenden por uma aren entre $1370^{\circ}, 30^{\circ}$ de long. F. e $151^{\circ}, 34^{\prime}$ E. e de $40^{\circ} \mathrm{S}$. Na Tasmania até as regióes carboniferas de Bowen River, $20^{\circ}, 30^{\prime} \mathrm{S}$. em Queensland. Os typos são todos de grão flno, contendo boulders, arredondados, facetados e striados ; rochas moutounées, etc. Diz-se que alguns milhares de milhas quadrarlas em Victoria são cobertos por conglomeratos glaciaes que com as camadas intercaladas, attingem uma espessura de mais de mil metros. Observamse nove ou dez camadas distinctas de boulders com expessos depositos entremeados na sèrie Baccus Marsh desta Colonia. A capa do relo parece que se moveu en alrumas regiúes em uma direcção geral de sul para norte. Veja T. W. E. David. Quart Journ. Geol. Soc. vol. LII, 1886, p. 289. Penck. Zeitschr. Gosell. Erdkunde, vol. XXXV, 1900, n. 4, p. 239 ; David and Howchin, Trans Roy. S. Australia, vol. XX, 1897, par. 61, and Rep. 7 th. Meeting Austr. Assoc. Adv. Sci.. 1893, p. 114; Ollicer and Homa, Proc. Roy. Soc. Victoria n. s., vol. X. 189\%, part. 1, pg. 60, pt.2181) ; R. M. Johnston, Geology Tasmania, 1888. Na Airica do Sul o conglomerato de Dwyka attinge uma espessura de mais de 350 metros, incluindo camadas de boulders de 20 metros com seixos facetados, etc, Fvidencia de corte; glaciaes, bossas, etc., se veem em muitos pontos em uma area incluindo grande parte de muitas das colonias. Veja Geikie, Text-book Geol. vol. II, 1903, pag. 105̆7: Mohlengraf, Bull. Soc. Geog. Fr. (4), vol. I, 1901, pp. 18, 67 e Trans. geol. Soc. S. Atri v. IV. 1898, pg. 103; Trans Phil. Nioc. S. Atr. vol. XI. 1900, p. 113\% Rogers, Trans. S. Afr. Phil. Soc., vol XI, 1902; Anderson, 2d Report Geol. Survey Natal and Zululand, 1904, pgs. 13, 50; Girard-La Geographie, III, 1901, p. 423 and Bull Soc. Belg. paleont., Hydrol, vol. XVI, 1902, pag. 92; Davis, Bull. Geol. Soc. Amer., 1906 (ainda não publicado) e Dubois, Archives Tyler, (2) vol. VII, p. 4, 1901, and vol. VIII, pt, 1, 1902; The Geology of South Alrica by F. H. Hotch and H.S, Corstorphine, 1905. 
It is therefore now recognized that Gangamopteris flora probably owed its origin to the existence, for a time, in Gondwna-land of a glacial climate which either exterminated or drove back and held in check for a considerable period the cosmopolitan flora, or so much of it as was not able, by mutation or adaptation, to withestand its rigor.

Meanwhile the older Gondwana types, offshoots of the hardier elements in the Northern flora developed and distributed themselves in both hemispheres. Though it is not supposed that they came into being under actual glacial conditions, there is hardly room for doubt that they appeared while the region was still cold and quite inhospitable to the contemporaneous northern, or cosmopolitan, types.

The causes of the Palaezoic glaciation of Gondwana land are not yet agreed upon. Among the earlier hypotheses offered in explanation of the occurrence and area of the cold climate was a shifting of the earth's axis so as to bring one of the poles in the region of the southern part of the Indian Ocean. Others are the great altitude of the surface of the land mass; a reduction of the carbonic acid gas $\left(\mathrm{C} \mathrm{O}^{2}\right)$ in the atmosphere through long periods of rock decomposition following uplifts the agencies of coal formation, the result being a loss of heat by radition and the establishment of climatic zones and the degree of salitiny and consequent car-

Oldham, Man. Geol. India, 2d Ed., 1893, chaps. vi, and vii; Blanford, Quart. Journ. Geol. Soc, vol zlii, 1886, p. 249; Blanford, Rec Gool Surv. India, vol. XX, 188\%, p. 49; Oldham, Geol. Mag., (3) vol. III, 1887, p. 32 .

In Australia the glacial boulder beds are known to have been distributed over an area between longitude $137^{\circ}, 30^{\circ} \mathrm{E}$. and $151434^{\circ} \mathrm{E}$., and from $40^{\circ} \mathrm{S}$. in Tasmania to the Bowen River coallield, $20^{*} 30^{\prime} \mathrm{S}$. in Queensland. The criteria include boulders, rounded. facetted, and striated, in fine-grained silts; roches moutonnées, etc. Several thousands of square miles in Victoria are said to be covered with olacial conglomerates, which, with their included beds, atliain a thickness ol over 1000 meters. Nine or ten distinct boulder leds with thick intervening,deposits are observed in the Baccus Marsh series of this colony. The ice cap appears in some ragions to have noved in a general direction from south to north. See T. W. E. David, Quart. Journ. Geol. Soc. lii, 1896, p, 28y; Penck, Zeilschr. Ciesell. Erdkunde, vol. XXXV, 1900, no. 4, p. 239; David and Howchin, Trans. Roy. Soc. S. Australia, vol, XX, 1897. p, 61, and Rept. 7 th Meeting Austr. Assoc. Adv, Sci., 1898, pg. 114; Officer and Hogg, Proc. Roy. Soc. Victoria, n. s., vol. X, 1897, pt. 1, p. 60, pt. 2, p. $180 ;$ R. M. Johnsten, Geol. Tasmania, 1888.

In South Africa the Dwyka conglomerate reaches a lhickness of over 350 moters, inclurling houlder beds 20 melers in thickness, with facetted pebbles, etc. Evidence of glacial cutling, bossses, etc., is seen at many points over an area including large portions of several of the colonies. See Geikie, Texl-book Geol. vol. II, 1903, p. 1057; Mohlengral, Bull. Soc. geol. Fr., (4) vol. I. 1901, pp. 13. 67, and Traus. geol. Soc. S. Afr., vol. IV, $18 j 8$, p. 103, aud Trans. Phil. Soc, Afr., vol. XI, 1900, p. 113; Rogers, Trans S. Afr. Phild. Soc, , vol. XI, 1902; Anderson, 2d Ropt; Geol Surv. Nalal aud Zululand, 1904, pp. 13,50; Girard, La Geographie, vol, III, 1901, p. 423, and Bull. Soc, belg. geol. paleont, Hydrol,, vol. XVI, 1902, p. 92; Davis, Bul. Geol. Soc. Amer., 1906 (not issued) and Dubois Archives 'Tyler, (2) vol. vii, pt. 4, 1901, and vol. viii, pt.1. 1902; The Geology of South. Alicica by P. H. Hotch add N. S. Corstorphine, 1905. 
sequente carbonisação das correntes oceanicas e os effeitos das grandes variações na direcção (1) destas correntes.

Uma discussão destas hypotheses, para explicar a glaciação Gondwana, ultrapassaria os limites deste Relatorio e não é possivel mencionar-se mais do que alguns dos mais importantes factos, sem nos referirmos especialmente a nenhum delles. A extensão da flora de Gangamopteris na America do Sul, e as deducções muito certas do clima, indicadas por esta, são bastante para nos dispensar de admittir qualquer grande deslocamento do eixo terrestre, se com effeito a variação da extensão norte da acção glacial, não pudesse de todo ser explicada pela configuração continental e pelas mudanças das correntes oceanicas.

Ha muito que dizer em apoio da refrigeração climaterica zonal como resultado do empobrecimento da athmosphera em acido carbonico. As condições da sedimentação das camadas vermelhas, muitas vezes seguida de grande precipitação de gesso e outros saes, no fim do carbonifero, e particularmente no Permiano e Trias mais antigo, constituem um poderoso argumento, em defesa desta theoria, que é em minha opinião, ha muito tempo, a melhor explicação geologica até hoje apresentada para a extinção da grande flora carbonifera cosmopolita e a mudança esmagadora na vida das plantas terrestres, que marcam a passagem relativamente curta do Stephaniano superior e começo do Trias. Se nestas condições tivermos em mente, que as superficies continentaes do hemispherio Septentrional que eram baixas e approximavam-se cada vez mais do nivel das terras baixas quasi ao nivel do mar, durante o periodo Permo-Carbonifero, de modo que as zonas climatericas seriam menos accentuadamente indicadas na região do norte, não é difficil ver-se até que ponto nas mais elevadas massas terrestres da terra Gondwana, não somente a temperatura media deveria ser baixa, como tambem as dfferenças de estação seriam de muito mais forte contraste. Maior elevação da terta com reducção do acido carbonico teria naturalmente exaggerado as differenças entre o clima das areas continentaes baixas das altas do Sul, como tambem teria exaggerado fortemente as differenças das estações.

Estamos habituados por muito boas razóes, a considerar a flora Permo-Carbonifera cosmopolita do Norte, como tendo se desenvolvido

(1) Chamberlin, Science, n. s., vol. XXIIl. 1900, p. 930. A extensa publicacão das proposiços muito resumirlamente delineadas no relatorio do professor Chamberlin ainda não appareceu. E', por conseguinte, impossivel dar actualmente á sua theoria a devida consideraçāo. 
bonation of the oceanic currents, and the effects of great changes in the direction (1) of these currents.

A discussion of these hypotheses to account for the Gondwana glaciation would go beyond the limits of this report, and it is not possible here to more than mention a few of the most important facts specially relating to any of them. The extension of the Gangamopteris flora into South America, and the very certain deductions as to climate indicated thereby go far to relieve us from the necessity of assuming any great shifting of the earth's axis, if indeed the variation in the northward extension of the glacial action may not wholly be explained by continental configuration and changes in ocean currents.

There is much to be said in support of zonal climatic refrigeration as the result of the atmosphere in carbonic acid. The conditions of deposition of the red beds, often accompanied by great precipitation of gypsum and other salts, at the close of the Carboniferous, and particularly in the Permian, and earliest Trias, constitute a strong argument in support of this theory, which is, in my opinion by far the best geological explanation yet offered for the extinction of the great cosmopolitan Carboniferous flora and the overwhelming changes in terrestrial plant life that mark the relatively short passage from the upper Stephanian to the beginning of the Trias. If, in this connection, we bear in mind that the continental surfaces in the Northern Hemisphere were low and approaching nearer and nearer to base level during Permo-Carboniferous time, so that climatic zones would be less strongly marked in the northern regions, it is not difficult to see how, on the higher land masses of Gondwana-land, not only would the mean temperature be lower, but the scasonal differences would be in far stronger contrast. Increased elevation of the land would, naturally, under conditions of carbonic acid reduction, not only exaggerate the differences between the climate of the low northern and of the high southern continental areas, but it would also greatly exaggerate the seasonal differences.

We are acustomed, for very good reasons, to regard the cosmopolitan Northern Permo-Carboniferous flora as having developed

(1) Chamberlin, Science, n. s, vol XXIIT, 1906, p. 930. The full publication of the propositions very briefly outlined in Professor Chamberlin's abstract has not yet appeared. It is therefore impossible to give his theory due consideration at this time. 
e proseguido sua existencia, sob eguaes condições climatericas de um aspecto subtropical, ou tropical.

'Tendo em vista as floras do Carbonifero superior e antigo Pel'miano, é sem duvida verdade que o clima foi egual e provavelmente subtropical perto do nivel do mar, mas a conservação da egualdade em um estado apenas ligeiramente alterado nestas regives no principio do Permiano, deve ter sido somente pela approximação cada vez maior das massas de terra que lhes serviam de habitat (base level) de terras baixas pouco acima do nivel do mar, com o augmento concomilante das áreas oceanicas adjacentés, contrabalançando assim em grande parte as mudanças climatericas que estavam já em progresso com tão impressivos resultados biologicos e geologicos nas altas massas de terras do continente meredional. Sabemos que este continente era alto pelos caracteres dos productos de erosão, expostos ainda agora mesmo, em enorme quantidade e pela grande extensão e espessura de grandes systemas de depositos de agua doce de sua superficie.

A vasta extensão, topographicamente muito irregular, de superficie de rochas cobertas pelos lençoes de gelo, offerece uma prova addicional á hypothese da elevação das terras. Que houve, entretanto augmento na variação do clima, nas areas da flora do Norte é indicado pelos muitos signaes frequentes de anneis annuaes, nas madeiras fosseis gymnospermeas do Permo-Carbonifero mais antigo, ao passo que nas da formação Carbonifera media e inferior os anneis annuaes são muito raros (1).

A circumstancia de algum modo contrarịa á sufficiencia da explicação dada acima, e a presença de depositos marinhos de restos glaciaes na região de New South Wales; incluindo materiaes transportados pelos gelos fluctuantes. 0 facto de geleiras attingirem o mar nestas, ou mesmo em inferiores latitudes, parece invocar o auxilio concomitante das correntes oceanicas mudadas. Sem duvida as correntes na região das elevadas massas de terra do Sul eram muito diversas, das dos mares do Sul existentes. Pode se ter analogias do modo como se comportam as correntes nas costas Antarticas actuaes. o abaixamento de uma superficic congelada abaixo do nivel do mar,

(1) Mesmo nas maleiras do Purmjano mais antigo os anneis annuzes nas áreas do Norte quando existem são commumente obscuros, ou muito estreitos. E' pissivel que as madeiras com estes anneis tenham vindo rio abairo do interior e partes altas dos continentes, os signaes occasionaes de anneis, nos principaes typos tambem podem ser attribuidos simplesmente aos periodos de repouso ou de produccão. 
and continued its existence under equable climatic conditions of a sub-tropical or tropical aspect.

That the climate altending our Upper Carboniferous and; earlier Permian floras was equable and probably subtropical near sea level is undoubtedly true; but the maintenance of the equability in a state but slightly impaired in those regions towards the beginning of the Permian may have been accomplished only by the ever nearer approach of their land mass habitats to a base level, with concomitant extension of the adjoining oceanic areas, thus for the most part counterbalancing the climatic changes which were already in progress, with such impressive geological and biological results, on the higher land mass of the Southern Continent. That this continent was high is shown by the character of the erosion products, even now exposed in tremendous amounts, and by the enormous extent and thickness of the great systems of 'fresh-water deposits on its surface.

The vast extent of the topographically very irregular rock floors over-ridden by the ice sheets additional support to a belief in the alevantion of the land. That there was nevertheless an increase in seasonal variation in the areas of the northern flora is, however, indicated by the more frequent signs of annual rings in the later Permo-Carboniferous fossil gymnospermic wood, whereas in those of the middle and lower coal measures unquestionable annual ring are extremely rare (1).

A circumstance in some degree adverse to the sufficiency of the explanation given above is the occurrence, in the region of New South Wales, of marine deposits of glacial debris including materials transported by drifting ice. The ability of glaciers to reach the sea in these or even lower latitudes seems to involie the concurrent aid of changed oceanic currents. Without doubt the currents in the region of the greal southern land mass were very different from those in the existing southern seas. Analogies may be drawn from the behavior of the currents along the Antarctic coasts of to-day. The subsidence of a glaciated surface beneath sea level would

(1) Even in the woods of the earlier Pepuian of the Northerth areas annual rings, it present, are usually obscure or very narrow. It is possible that the woods with these rings may have cone down the rivers frum the interior and higher portions of the continents. On the other hand in the earlier types occasional signs of annulation may have been due unerely to d'esting or reproductive periods. 
concordaria perfeitamente com a melhoria do clima que parece ter se seguido ao periodo de mais extensa acção glacial. Parece-nos de todo provavel que a glaciação da terra Gondwana foi devida a varias causas concurrentes, sendo principaes a reducção do acido carbonico da athmosphera e a elevação da superficie continental.

Relativamente á epoca da primeira glaciação Gondwana ha diversas opiniões, embora todas concordem que se deu em periodo Palæozoico, ou Permo Carbonifero. A principaI evidencia relativa a esta questão, é a fornecida pela Palæontologia, o testemunho da geologia physica sendo modificado e interpretado em termos de historia palæontologica. O testemunho dos invertebrados marinhos para a edade das camadas de boulders tem valor apenas em alguns pontos, visto que em muitas regiões as series que conteem floras de Gangamopteris, são epicontinentaes.

As camadas marinhas associadas aos depositos glaciaes em New South Wales, forneceram fosseis considerados por Frech (1) eguaes em edade ao Permiano, e ás series glaciaes geralmente suppostas em discordancia com o Carbonifero inferior, ou rochas mais antigas, sendo collocadas por elles na base do Permiano. As faunas de Phyllotheca, Glossopteris, e Noggerathiopsis encontradas na serie Greta, em grupo diminuto de "Coal Measures" inferiores, apparentemente collocado entre camadas de boulder's neste districto, são consideradas como os mais antigos representantes da antiga flora Gondwana que até hoje se tem encontrado.

As floras da terra Gondwana apresentam provas da idade interna em suas relações genericas e a identidade das especies invasoras, ou transicionaes.

Isto é explicado pela presença de Annullaria na serie «Greta» que acaba de ser mencionada; Sphenophillium, de Damuda da India, e do Karroo inferior do Natal; Psygnophyllium Lepidodendron mencionado do Transvaal ; Annullaria Rachopteris, Pachypteris, Lepidadendron e Walchia, citada por Bodenbender da Argentina, e os Lepidophytos do Brasil. E' provavel que as especies locaes de alguns destes generos, tal como Annularia em particular, sejam forte producto de descententes dos reprsentantes cosmopolitas, preglaciaes do mesmo genero, como não ha duvida no caso de Phyllotheca que apresenta-se tanto no Westphaliano como no Permiano do Norte.

(1) Lethaea Geognostica, Lethaea Palaeozoica - vol. II, Lief 4.1902, p. 590. 
conform well with the amelioration of the climate which seems to have followed the period of most extended ice action. On the whole it appears probable that the glaciation of Gondwana-land was due to several concurrent causes, chief of which were atmospheric reduction in carbonic acid and elevation of the continental surface.

Concerning the date of the early Gondwana glaciation there is some difference of opinion though all are agreed that it falls within Palaeozoic or Permo-Carboniferous time. The principal evidence relating to this question is that furnished by palæontology, the testimony of physical geology being itself modified and interpreted in terms of palæontological history. The evidence of marine invertebrates as to the age of the boulder beds is available at but few points, since in most regions the series containing the Gangamopteris flora are epicontinental.

The marine beds associated with the glacial deposits in New South Wales have furnished fossils regarded by Frech (1) as Permian in age; and the grlacial series, lying generally unconformably on Lower Carboniferous or older rocks, is placed by them at the base of the Permian. The forms of Phyllotheca, Glossopteris and Noeggerathiopsis found in the Greta series, a thin group of "Lower Coal Measures " apparently lying between boulder beds in this district, are believed to be the oldest representatives of the older Gondwana flora that have yet been discovered.

The floras of Gondwana-land themselves present internal age evidence, in their generic relations and the identity of the invading or transitional species.

This is illustrated by the presence of Annularia in the Greta series just mentioned; Sphenophyllum in the Damuda of India and the Lower Karoo of Natal ; Psygmophyllum and the reported Lepidodendron in the Transvaal ; Annularia, Rachopteris, Pachypteris, Lepidodendron, and Walchia, reported by Bodenbender from Argentina; and the Lepidophytes in Brazil. It is probable that the local species of some of these genera, such in particular as Annularia, are hardy offshoot descendants of the pre-glacial cosmopolitan representatives of the same genera, as no doubt is the case in Phyllotheca, which is present in the Westphalian as well as the Permian of the North.

(1) Lethaea Geognostica, Lethaea Palaeozoica, rol, II, Lief. 4, 1902, p. 590. 
Outras especies locaes deste genero cosmopolita juntas com identicas especies, do Torte como Volt wia heterophylla, do Karharbari e Raniganj da India, Sigillaria Brardii do Transvaal e Brasil, Lcpidophloios laricinus da Argentina (1) e Brasil são provavelmente forles invasores da flora do Norte ou indigenas, da zona de transição entre as regiões mais frias, e as terras baixas das regiões septentrionaes. A presença dos elementos de Psygmophyllum, Walchia e Voltzia dá ás series uma idade Permiana.

A principal evidencia extra Gondwana, da idade da flora de Gangamopteris referc-se á descoljerta por Amalitzky (2) de Gangamopteris major (Gangamopteris obovata) Glossopteris indica, Glossopteris angustifolia, Glossopteris strictca e Tértebraria, misturadas com Callipteris conferta, Lepidodendion e invertebradros superiores de Zeiclistein do Norte da Russia, a occurrencia dos typos antigos de Phyllotheca do Gondwana no Permiano de Altai e Siberia e o achado por Noetlling (3) de um Gangamopteris do Permiano da serie Salt Range em Kashmir. Os representantes da flora de Gangamopteris da Siberia e Norte da Russia são de presumir emigrantes nos dominios da flora do Norte.

A mistura das especies do Norte e Sul, na Siberia, Norte da Russia, Africa do Sul, Argentina e Brasil está conclusivamente em evidencia contra o isolamento completo da flora de Ganganopteris por um obstaculo geographico.

Houve talvez meios de emigração no tempo Permiano em diversos pontos entre a terra Gondwana e a provincia da. flora do Norte, ou houve logar em alguma parte da terra Gondwana para uma flora de transição typica cosmopolita, fúra das areas glaciaes e dos dominios ainda mais comprehensiveis da pura flora de Gangamopteris.

Que a primeira glaciação e deposição das camadas de boulders não antecederam longo tempo o principio do Permiano é incon testavelmente demonstrado pela presença em Tête na Zambezia, Africa Sudoeste Portugueza, de uma flora (4) pura e typica de idade Stephaniana media, ou inferior em uma região dentro da area de distribuição conhecida,

(1) Candioptrois polymonpha, Adcantites antiquas, Lepidodendron selaginoides, Lepi. todendron aculeatum e Iepidodendron l'cltheimianam citados por Bodenbender (Bol. Acad. Naci. Cordoba, vol. XVII, 1902, p. 212, 252, 253,) estâo ahi omittidos visto que não tenho cerleza qunlo à maneira de occurrencia com respeito as especies de Gondivana.

(2) Comptes Renclus vol CXXXl1, 1901 p. 591.

(3) Gen. Rept. Geol. Surv. India 1902, 1903 p. 22.

(4) Veja Zeillor Anmales des Mines. (8) mom. vol. IV 1883 p. 594. 
Others of the local species of these cosmopolitan genera, logether With the identical northern species, viz Voltaia heterophylla in the Karharbari and Raniganj of India, Sigillaria Brardii in the Transvaal, and Brazil, and Lcpidophloios laricinus in Argentina (1) and Brazil are probably eilher hav'dy invaders from the Northern flora or indigenous to the transitional zone between the colder regions and the baselevelled regions. The presence of the Psygmophyllum, Walchic, and Voltwia elements points to a Permian age for the series.

The principal extra-Gondwana evidence as to the age of the Gangamopteris flora relates to the discovery by Amalitzky (2) of Gangamopteris major (= Gangamopteris obovata), Glossopteris indica, Glossopteris augustifolia, Glossopteris stricta and Vertebraria, mingled with Callipteris conferta, Lepidodendron, aud upper Zechstein. invertebrata, in northern Russia; the occurrence of older Gondwana types of Phyllotheca in the Permian of the Altai and Siheria, and the collection by Noetling (3) of a Gangamopteris from the Permian of the Salt Range series in Kashmir. The Siberian and north Russian representatives of the Gangamopteris flora are presumably migrants in the domain of the Northern flora.

The mingling of Northern and Soulher'n species in Siberia, Norther'n Russia, South Africa, Argentina and Brazil, is conclusively in evidence against a complete isolation of the Gangamopter is flora by a geographical Jarrier.

Eilher there were means of migration in Permian time at several points hetween Gondwana-land and the province of the northern Hora, or there were left room somewhere on Gondwana-land for a transitional or possibly the typical cosmopolitan domain of the pure Gangamopteris flora.

That the early glaciation and boulder-ljed deposition could not long have antedated the beginnig of the Permian is irrefragably shown I:- ])y the presence, at Tete on the Zambesi in Portuguse Southeast Africa, of a pure and typical flora (1) of middle or lower Stephanian age, in a region well within the known distribution, at a later period, of the Gangamo-

(1) Cardiopteris polymorpha, Adiantiles antiquns, Lepidendron selaginoides. Lepirodendron aculcatum and Lepidodendron Trelcheimianum, quoted by Bodenhander (Bol. Acad. Nacional Ciencias, Cordoba, vol. XVII. 1902, pp. 212, 2.2, 253 ) aro here omitted, since I am not certain as to the modo of occurrence with reference to tho Gondwana specics.

(2) Comptes Rendus, vol. CXXXII, 1901, p. 591.

(3) Gen. Rept. Geol. Surv. India, 1902-1903, (1903), p. 22.

(4) Sée Zeiller, Annales des Mines, (8) mem., vol. IV, 1883, p. 594. 
em um periodo posterior de flora de Gangamopteris e pela persistencia ao menos muito approximada do Permiano, da flora cosmopolita na provincia de Shansi na China (1).

E' certo que a glaciação Gondwana, em data anterior, deixaria vestigios distinctos na flora do norte. De outro modo o caracter e a uniformidade na distribuição desta se oppõem a que se admitta uma epoca glacial entre a base do carbonifero superior e o fim da formação carbonifera superior (coal measures) que marca o desapparecimento de muitos typos da formação carbonifera (coal measures). Desde aquelle tempo as mudanças da flora foram relativamente rapidas de modo que chegando ao Zechstein, a grande flora propriamente carbonifera tinha desapparecido. Por minha parte estou fortemente disposto a consideral a glaciação e a data proxima da origem da flora Gangamepteris não anterior aos movimentos orogenicos e mudanças da flora que precederam o Permiano. Em minha opinião é muito provavel que uma grande parte do Gondwana Palæozoico é mais antiga que a Rothliegende e que mesmo se achem plantas de idade Zechstein (2) ainda em outras regioues do Norte e veremos que contêm representantes addicionaes da flora de Gondwana.

o conglomerato de Hawlisbury, que alguns geologos suppõem ter resultado de uma segrunda invasão do gelo, parce malcar o principio do Trias na região Australiana e com elle o desapparecimento de Gangctmopteris e da composição caracteristica da flora Gondwana mais antiga.

A existencia de depositos glaciaes Palaeozoicos na America do Sul não está ainda provada (3). Todavia deve-se notar que o Dr. Dorby em 1888 communicou a Waagen (4) os resultados de observações feitas em camadas de bculders no Paraná e S. Paulo, que elle estava inclinacio a considerar como indicio da acção do gelo fiuctuante.

Independentemente da evidencia lithologica, pro ou contra a acção glacical, somos forçados pelo testemunho dos elementos palæobotanicos, a concluir que as camadas de boulders da base da serie das ca-

(1) Von Reichstofen-China Vol. $1 V 1883$ p. 209, tambem Abbado pal. Italica vol. Vl $1900, \mathrm{p} .125$.

(2) A flora do Permiano superior ou Zechstein la Provincia do Norte é pobre e conhecida en poucas regiōes.

(3) O aulor David While nāo estása ao par das provas encontradas, pela Commiss ão do Carvão da existencia de condiçies glaciaes no sul de Brasil no comeco do periodo Permiano. Por esta razão as suas conclusōes são mais notaveis assim como confirma. tivas da existencia de condiçues glaciaes no Brasil durante a época do conglomerato de Orleans. 1. C., W.

(4) Rec, Geo'r. Surv. India vol. XXIT, pt. 21889, pag, 69. 
pteris flora; and II:- by the persistence, very nearly at least, to the Permian, of the cosmopolitan flora in the province of Shansi in China (1).

It is certain that Gondwana glaciation at an earlier date would have left its distinct imprint on the Northern flora. On the other hand the cosmopolitan character and uniformity in distribution of the latter forbid the admission of a glacial epoch between the base of the upper Carboniferous and the close of the upper Coal Measures, which marks the disappearance of many of the Coal Measures types. From that time on the floral changes are relatively rapid, so that by the time ve reach the Zechstein the great Carboniferous flora has essentially disappeared. For my orvn part, I am strongly disposed to ragard the glaciation and approximate date of origin of the Gangamopteris flora as not earlier than the orogenic movements and floral changes which ushered in the Permian. It is, in my judgment, highly probable that a large part of the Palaeo\%oic Gondwanas are later than the Rothliegende and that, should we find plants of Zechstein age (a) in still other regions of the Northern hemisphere, they would ba found to include additional representatives of the Gangamopteris flora.

The Hawksbury conglomerate - supposed by some geologists to have resulted from a second ice in vasion - appears to mark the beginning of the Trias in the Australian region, and, with it, tha disappearance of Gangamopteris and the characteristic composition of the older Gondwana flora.

The cuestion of the existence of Palaeozoic glacial deposits in South America ramains unproved (3). It may be noted, however, that Dr. Derby, in 1888, communicated to Wraggen (4) the results of observations on boulder beds in Paraná and São Paulo which he was inclined to regard as indicating the agency of drifting ice.

Regardless of the lithological evidence for or against glacial action, we are led by the palæobotanical testimony to conclude that the boulder beds at the base of the coal-bearing series, and resting on

(1) Von Richthofen, China, vol. IV, 1883, p. 209; also Abbado, Pal. Italica, vol. VI, 1900 , p. 125.

(2) The flora of the upper Permian, or Zechstein, of tho Northern Province is meager and known in but few regions.

(3) The author (David White) was not aware of the evidence found by the coal Commissinn, for the existence, of Glacial conditions in South Brazil at the beguining of Permian time. and hence his conclusions are all the more remarkable, as well as confirmatory of Glacial conditions existing in Brazil during the epoch of the Orleans Conglomerate, I. C. W.

(4) Rec. Geol. Surv. India, vol, XXII, pt. 2, 1889, p. 69. 
madas carboniferas no antigo solo eroido, que repousam sobre as rochas crystallinas no Brasil, são da mesma edade que o conglomerato glacial de Talchir na India, e que os velhos depositos glaciaes de Queensland, New South Wales e Tasmania na região Australiana e os depositos glaciaes de Dwyka (Ecca) nos Estados da Africa do Sul.

A presença logo acima dos conglomeratos da base, no Brasil, de uma flora egual em composição e muito identica em especies, ás das camadas que se succederam aos depositos de "boulders» glaciaes, na India, Australia e Africa do Sul, obrigam ao conhecimento da existencia no tempo deste deposito, de semelhantes ou identicas condições climatericas em ambas as partes éste e sul da America.

Não se segue cue a flora daquella época vegetou e desenvolveu-se em clima glacial, mas é claro que era adaptada á um clima como o que se seguiu á retirada dos ge'os. As camadas Greta contendo precursores da flora de Gangamopteris parecem representar essencialmente uma formação interglacial com cerca de 72 metros de espessura, contendo diversas camadas de carvão. Que o clima foi rjgoroso vê-se logo pela polreza da flora, desde seu primeiro apparecimento, e que foi por longo tempo inhospito para os typos do norte vê.se pela ausencia destes.

O enriquecimento gradual da flora de Gangamopteris durante a época do Karharbari e Damuda deve ser attribuido a terem melhorado as condições climatericas. O mesmo facto permittiu anteriormente a introducção das formas mais resistentes encontrados entre os Lepidophytos (1) da flora do Norte, ou da zona de transição, ou mesoclimatica.

A composição variavel da flura vae até demonstrar a existencia de um clima ainda mais suave durante a época Damuda, como prova tambem o enriquecimento da flora pelo augmento de mais variados typos do Norte.

Isto é notado no Brasil pelo ausmento dos Lepidophytos e o advento nas mais elevadas partes das secçũes, de Psaronius com diversos typos coniferos. Semelhantemente na India o Damuda é cara-

(1) A evidencia do poder de vencer as difficuldades climatericas e migratorias que os Lepirlodendron e Sigilaria mostram ter apresentado em sua invasão da flora do volho Gondwana, está en completo accordo con sua extraordinaria distribuiçäo muitas vezes como especies identicas sobre a superlicie da terra, durante o periodo Dovoniano antigo $\theta$ Carbonifero. Näo é possivol que alguns destes Lepidophytos incluindo representantes do grupo Sigillaria Brardii, que em tempo algum tenham sido impellidos para fora, dos limites da flora de Gangamopteris com que podiam se misturar quando ofrio diminuisse. 
the ancient floor of eroded crystallines in Brazil, are of the same age as the Talchir glacial conglomerates in India, the older glacial deposits of Queensland, New South Wales and Tasmania in the Australian region, and the Dwyka (Ecca) ice deposits in the states of suthern Africa.

The presence just over the basal conglomerates in Brazil of a flora, purely agreeing in compsition and largely identical in species, with that in the beds succeeding the glacial boulder deposits in India, Australia and South Africa, compels the recognition of the existence, at the time of this deposition, of similar if not identical climatic conditions both in this part of Sout America and in the East.

It does not follow that the flora actually developed and flourished in a glacial climate; but it is clear that it was adapted to a climate such as followed the retreat of the ice. The Greta beds, carryng forerunners of the Gangamopteris flora, appear essentially to represent an interglacial formation about 72 meters in thickness and containing several coals. That the climate was severe is shown by the magerness of the flora on its first appearance; and that it was for a long time inhospitable to the Northern types is shown by the absence of the latter.

The gradual enrichment of the Gangamopteris flora during Karharbari and Damuda time may be attributed to amelioration of climatic conditions. The same amelioration at an early date permitted the introduction of some of the hardier forms found among the Lepidophytes (1) of the Northern flora, or from the transitional or mesoclimatic zone.

The changing composition of the flora goes to show a still milder climate during Damuda time, as is proven also by the enrichment of the flora and by the accession of more varied northern types.

This is marked in Brazil by the increase of the Lepidophytes, and the advent, in the higher portions of the sections, of, Psaronius with various coniferous types. Similarly, in India the Damuda is

(1) The evidance of the pown of ovorcoming climatic and migrational difliculties which the Lepidodendreae and Sigillariece appear to have exercised in thoir invasion to the oldor Goudwana flora is in complete aryment with their oxtraordinary distribution, often as identical spocies, oy tho earth's land surfaces during later D vonian and in Carboniferous time. It is not improbable that some of thes Lapidophytes, including representativ's of the Sigilla'ia Brandit group. were at no time driven beyond the? outskirts of the Gangamoptris flora, with which th'y wers able to mingle on the abatemont of the cold. 
cterisado pelo accrescimo das formas de Pecopterideos (1), Taeniopteris, Cycadaceos e Ginkgoales.

Outras provas de melhoria do clima durante a época do Gondwana primitivo são dadas pelas madeiras fosseis. As descriptas por Shirley (2) e Arber (3) da parte inferior da serie New South Wales, são todas caracterisadas pelos anneis annuaes bem indicados e largos. Posso tambem accrescentar aqui, que o Dr. Derby, obteve em S. Paulo de horizontes na apparencia inferiores áquelles em que foram encontradas as madeiras examinadas por mim, typos gymnospermeos fosseis, em que los anneis estão claramente em evidencia, embora não sejam largos. Entretanto nas madeiras colligidas no intervallo de 100 metros acima do schisto preto de Iraty, ha pouca evidencia, ou nenhuma, de anneis annuaes, como se vê nas estampas XIII e XIV deste relatorio. o clima modificado parecendo predominar na região do schisto preto de Iraty, parece ter sido muito apropriado á introducção de algumas das formas de Psaronius, e como já disse, é possivel que os estudos palaeobotanicos desta parte da serie conduzam á descoberta de outros emigrantes da flora cosmopolita.

Pode ser de interesse, mencionar de passagem, as madeiras fosseis das camadas consideradas como Triassicas de perto da estação de Santa Maria no Rio Grande do Sul, que parecem ter anneis muito mal definidos e muito estreitos.

Parece provavel, pela recapitulação dos dados acima, que as formações carboniferas (coal measures) dos Estados de Santa Catharina e Rio Grande do Sul, são de edade Permiana, ou que, ao menos, uma parte das camadias de boulders das regiōes carboniferas do Brasil sejam provavelmente contemporaneas da actividade glacial e deposito de materiaes de moraines em outras regiões de uma grande area continental do Sul, ou areas próximas umas das outras e denominadas terra Gondwana; que as camadas, logo acima, contendo pura flora de Gangamopteris ou Gondwana antiga, foram depositadas, durante um periodo de declinio da glaciação e que com a melhoria das condições climatericas outros typos, incluindo identicas especies ás da flora cos-

(1) As primeiras formas descriptas como Cladopthlebis e Pecopteris do Gondwana Palaeozoico são muito relacionadas com as formas do Permiano da parte oriental dos Estados Unidos, descriptas pelo prolessor Fontaine e Dr. White como Callepteridium.

(2) Bull. Geol. Survey, Queensland, n. 7, 1898, pag, 14.

(3) T'ho Glossopteris Flora 1905, pag. 191. 
characterized by the accession of forms of Pecopterids, (1) Taeniopteris, Cycads and Ginkgoales.

Further proof of climatic amelioration during early Gondwana time is offered by the fossil woods. Those described by Shirley (2) and Arber (3) from the lower portion of the series in New South Wales are all characterized by well marked and thick annual rings. Also I am at liberty to add here that Dr. Derby has obtained, in São Paulo, apparently from horizons lower than those from which the woods examined by myself were derived, fossil gymnospermic types in which the rings are clearly in evidence though not broad. On the other hand, in the woods collected in the interval extending 100 meters above the Iraty black shale there is little or no evidence of annual rings, as may be noted by reference to Plates xiii and xiv of this report. The modified clmate shown to prevail in the region of the Iraty black shale should have been well suited to the introduction of some of the associates of Psaronius; and, as I have already remarked, it is probable that the palæobotanical study of this part of the series will lead to the discovery of other migrants from the cosmopulitan flora.

In passing it may be of interest to mention that the fossil woö from beds regarded as Triassic near Santa Maria station in Rio Grande do Sul, appears to exhibit very narrow, and rather poorly deflned annual rings.

From the above review of the data it scems probable that the coal measures in the states of Santa Crtharina and Rio Grande do sul are of Permian age; that a portion at least of the basal boulder beds of the Brazilian coalfields are approximately contemporaneous with glacial activity and the deposition of morainic material in certain other regions of a great southern continental area, or approximate areas, called "Gondwana-leand"; that tha beds next above, containing a pure Gangamopteris, or older Gondwana flora, were laid down during a period of waning cold climate following the period of glaciation; and that with ameloration of climatic conditions other types, including identical species in the Northern cosmopolitan flora, were

(1) The earlic forms described as Cladophlebis and Prenpteris from the Palaeozoioc Gondwanas are v'ry intimately connected with the 'orms trom the Permian of the Eascren United Slates describad by Prolessor Fontane and Doctor Whita as Cullipteridillm.

(‡) Bull. Geol. Surv. Queensland, no. 7, 1\$98, p. 14.

(3) The Glossopteris flora, $1905, \mathrm{p}, 191$. 
mopolita do Norte, voltaram para esta região. As provas algum tanto fragmentarias, de valor actual, parecem indicar que os primeiros typos do norte que puderam ganhar terreno foram especies de Sigillariae e Lepidodendrece, e que ainda mais tarde e provavelmente durante um periodo em que houve condições climatericas mais favoraveis, as camadas de cerca de 100 metros se depositaram superpostas ao schisto preto de Iraty, e outros typos do norte, incluindo fetos, puderam vegetar nesta rigião.

\section{Descripção das especies}

O material descripto nas paginas seguintes é na sua maior parte muito fragmentario e as vezes muito mal conservado. Na maior parte dos specimens a rocha é arenosa e algum tanto micacea, os fosseis apparecendo usualmente em forma de manchas pardacentas revestidas por um residuo de maceração carbonosa granular e fendilhada. Detalhes mais minuciosos raras vezes são claros em taes exemplares, e frequentemente os contornos são mais distinctos á simples vista que observados com lente. Todavia, como acontece em casos semelhantes e como foi notado pelo Professor Zeiller em suas estampas de Lepidodendron Pedroanum e Lepidophloios laricinus, as delineações obtidas photographicamente são mais completas do que a imagem percebida pela retina. Por esta razão, bem como para evitar qualquer vicio de interpretação individual, ao delinear o material algum tanto macerado, utilizei-me de photographias toda a vez que foi possivel, completando-as quando se tornava neceessario e praticavel com pequenos desenhos de detalhes. Nenhuma destas photographias foi retocada.

A bibliographia referente á flora do Gond wana mais antigo é, geralmente, de relativa solidariedade, embora um tanto volumosa. Ha em appendice das obras recentes de Servard (1) e Arbor (2) listas bibliographicas e revistas da historia dos estudos palaeobotanicos das floras do Gondwana (Glossopteris) dos varios continentes, teem sido publicadas por numerosos autores, incluindo Feistmantel, R. Etriage, Jr. Zeiller e Arber. A monographia de maior valor, deste ulimo trouxe um grande auxilio, especialmente quanto á distribuição das especies.

(1) Ann. South African Mus., vol. IV p.t. 1, 190'.

(2) Flora de Glosscpteris. Catalogo de Plantas losseis da flora de Glossopt ris no Dep. Geol. Brit. Mus, 1905, p. 227. 
able to return to this region. The somewhat fragmentary criteria at present available seem to indicate that the first of the Northern types able to gain a foothold were members of the Sigillariene and Lepidodendreae, and that, still later and probably under more favorable climatic conditions during the continuance of which the beds near and for 100 meters above the Iraty black shale were laid down, others of the Northern types including ferns also, were able to inhabit this region.

\section{Description of the species}

The material described in the following pages is, for the most part, very fragmentary and often very badly preserved. In the greater number of specimens the matrix is gritty and somewhat micaceous, while the fossils usually appear as Jjownish stains coated with a contracted granular carbonaceous maceration residue. The more minute details are seldom very clear in such examples, and frequently the outlines are more distinct to the unaided eye than when seen under the lens. Yet, as often happens in similar cases and as has been noted by Professor Zeiller in his illustrations of Lepidodendron Pedroanum and Lepidophloios laricinus, the delineation obtained photographically is more complete than the image perceived through the retina of the eye. For this reason, as well as for the sake of avoiding the equation of individual interpretation in delineating somewhat macerated material, I have utilized photographs wherever possible, supplementing them when necessary and praticable by small detail drawings. None of the photographs has been retauched.

The literature relating to the older Gondwana flora is in general of comparative solidarity though somewhat voluminous. Bibliographic lists are appended to recent works by Servard (1) and Arber, (2) while reviews of the history of paleobotanical work on the Gondwana Glossopteris floras of the several continents have been contributed by numerous author's including Feistmantel, R. Ethridge Jr., Zeiller, and Arber. In the latter's most valuable monograph I have found great assistance, especially regarding the distribution of the species.

(1) Annals S. African Mus, vol. IV, pt. 1, 1903.

(2) The Glossopteris Flora; Catalorue of the Fossil Plants of the Glossopteris Flor's in the Dept. Gool., Brit. Mns., I90.5, p. 227. 
A synonymia das especies do antigo Gondwana que é complicada apenas em poucos casos, é repetida em algumas publicações por Feistmantel e mais completamente estudada, como resultado da revisão critica, ou exame dos typos, por Zeiller, Seward e Arber, e mais particularmente por este ultimo palæobotanico, que reuniu a bibliographia de toda a flora em um trabalho, que está tão ao alcance de quem queira estudal-a, que, agora, não haveria justificativa, para a repetição da synonymia.

Restringirei, portanto, em muitos casos, minhas citações ás publicações originaes typicas e áquellas em que ha figuras das especies, juntamente com as citações de algumas obras addicionaes em que ha muitas referencias, sinão todas, ás especies.

Foi minha intenção, a principio, tratar unicamente das especies representadas nas collecções que tenho em mão. Achei entretanto, mais tarde, que o numero das especies brasileiras restantes, ou excepcionaes era tão diminuto que julguei melhor incluil-as tambem. Os dados relativos ao deposito dos typos destas especies foram tirados do catalogo do Professor Arber. Em beneficio dos estudiosos brasileiros que não possam dispor da bibliographia estrangreira da flora do antigo Gondwana ou flora de Gangamopteris, dei, em muitos casos, peruenas, e digamos genericas, descripç̃̃es das especies.

Os pequenos accrescimos dos typos conhecidos da"flora carbonifera brasileira, aqui indicados, são apenas primicia da riqueza palæobotanica que se descobrirá nesta grande e cuasi inexplorada região da terra. Esperamos que as lacunas aqui apontadas e os problemas palæobotanicos delineados, chamarão a attenção dos investigadores brasileiros para a necessidade de pesquizas palæobotanicas systematicas e completas, nas formarões Permo-carboniferas, e outras, da Republica . 
The synonymy of the older Gondwana species, which is complicated in but few instances, is repeated in many of the papers by Feistmantel and more fully elaborated as the result of critical revisions or examinations of types by Zeiller, Seward, and Arber, and more particularly by the last named palæobotanist, who has collocated the literature of the entire flora in a work that is so accessible to students as hardly to justify synonymic repetition at so early a date.

I have therefore in many cases confined my citations to the original or type publications and to publications in which the species are illustrated, together with the citation of some additional works in which copious, if not all, references for the species are given.

At the outset it was my intention to confine the systematic treatment to the species represented in the collections in my hands. Later, however, the number of exceptional or remaining Brazilian species was found to be so small that it was thought best to include these as well. The data as to the repository of the types of the latter are taken from Professor Arber's catalogue. For the benefit of Brazilian students who may not have access to the foreign literature on the lower Godwana or Gangamopteris fiora, I have in most cases given short generic characterizations as well as the descriptions of the species.

The small addition to the known types of the Brazilian coal fiora here recorded offers but an earnest of the palaeobotanical wealth that is to be gained from this great and as yet almost unexplored region of the earth. It is hoped that the deficiencies here exposed and the palaeobotanical problems outlined will draw the attention of Brazilian students to the need of systematic and thorough palaeobotanical research in the Permo-Carboniferous as well as other for mations of the Republic. 


\section{ALGAE}

\section{HYDRODICTY ACEAE ?}

\section{Reinschia ( $\left.{ }^{1}\right)$}

Bertrand e Renault, Bull. Soc. Hist. nal. Autun, vol. Y $1892, \mathrm{p} .172$.

Reinschia australis Bert. e Ren., brasiliensis n. var. Pl. XI, figs. 11 e 12.

1892 - Reinschia australis, Bertrand e Renault, Bull. Suc. hist. nat. Autun, vol. V, pag. 172 ; Bertrand e Renault, Bull. Soc. geol. Belg., vol. VII, 1893, mem. p. 64, pl. V, figs. 23 -4.1 ; Bertrand e Renault, Bull. Soc. hist, nat. d'Autun, vol. VI, 1893, pag. 321, pl. IV-TII. Bertrand, Bull. Soc. hist. nat. d'Autum, vol. 1X, 1896, p. 193; Renault, Fl fossil bassin houill. et perm. d'Autun et d'Epinac, pt. 2, 1896, p. 540; Bertrand. Ann. Soc. geol. nord., vol. XXIX, 1900, p. 33, Renault - Sur quelcques microorg. cond. fossi, 1900, pag. 157, pl. XX.

Algas globulares fluctuantes com thallos concavos verticalmente mais ou menos achatados, com o diametro médio horizontal de 200 microns eás vezes excedendo 500 microns mais ou menos redondos, sublobados, ou cerebriformes em seç̧ăo horizontal, consistindo em uma unica camada de cellulas de paredes espessas com camadas gelatinosas (gelosicas) superpostas; cellulas polyedricas, as verticaes medindo 20 a 30 microns de altura e 1015 microns de diametro, prismaticas quando novas c pyriformes, tendo a extremidade menor para o exterior, quando maduras, as paredes lateraes muito espessas e as paredes distaes muito mais delgadas.

(1) Emquanto se estava inprimindo eslas paginas, e portanto muilo tarde pari

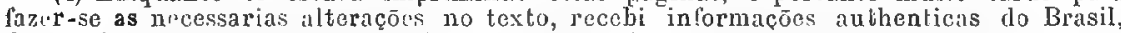
de que ha annos foram encontrados liagmentos de carvão boghead, semelhante ao quo aqui $\dot{e}$ discutido, em varios pontos, em parte consideravel da costa do Brasil, e em circumstancias que levaram os geologos brasileiros, que os cxaminaram, a attribuil-os a navios de passagem.

Um grande pedaco encontrado perto de Santos figurou na exposição de Chicago, en 1893, e acompanhando a nota que me loi remettida havia um fragmento encontrado na costa de Santa Catharina. Esta amostra ć tão semelhante em seus caracteres physicos ás que aqui sāo descriptas, que praticamente nāo podem dcixar duvida alọuma sobro o material, quanto á sua origem. De outro modo, a identidade acima notada de sua composição microscopica com a do schisto de kerozene de Nova Galles do Sul, torna absolutamente certo que a interpretacão dos reologos brasileiros acima reterida, $\dot{e}$ correcta. Como é sabido, o material australiano toi cxporlado para a Europa em frando escala e provavelmente os navios que o lransportavam passaram pela costa do Brasil, onde um ou mais destes naufragaran.

I' vista da larpa distribuiça do malorial na costa do Brasil e do interessa que tem despertado de tempos a tempos, näo é talvez para lastimar que por um equivoco $t \rightarrow$ ha sido incluidu no estudo clos restos vegetaes tosseis do Brasil. 


\section{ALGAE}

\section{HYDRODICTYACEAE ?}

\section{Reinschia $\left({ }^{1}\right)$}

Bertrand and Renault, Bull. Soc. hist. nat. Autun, vol. V, 1892, pag. 172.

Reinschia australis Bert. \& Ren., brasiliensis n. var.

Pl. XI, Figs. 1112.

1892. Reinschia australis Bertrand \& Renault, Bull. Soc. hist. nat., Autun, vol. V, p. 172: Bertrand \& Renault, Bull, Soc. gèol. Belg., vol. VII, 1893, mem. p. 64, pl. V, fig. 23-41; Bertrand \& Renault, Bull. Soc. hist. nat. Autun, vol. VI, 1893, p. 321, pl. IV-VII ; Bertrand, Bull. Soc. hist. nat. Autun, vol. IX, 1896, p. ${ }_{1}^{193}$; Renault, Fl. foss. bassin houill. et perm. d'Autun et d'Epinac, pt. 2, 1896, p. 540 ; Bertrand, Ann. Soc. géol. Nord., vol. XXIX, 1900, p. 33 ; Renault, Sur quelques microorg. comb. foss., 1900, p. 157, pl. XX.

Globular floating algae, with hollow, vertically more or less flattened thalli, averaging about 200 microns in horizontal, diameter sometimes exceeding 500 microns more or less round, sublobate, crenulate or cerebriform in horiwontal section; consisting of a single layer of thick-walled cells backed by a gelatinous (gelosic) layer; cells polyhedral, the vertical ones measuring 20-30 microns in height and 10-15 microns in diameter, primastic when young, and pyriform, the smaller end outward, when mature, the lateral walls very thick, the distal walls much thinner.

(1) As these pages were being printed and to late to make the necessary alterations in the text $I$ have received authentic information from Brazil to the effect that for a number of years past, fragments of boghead coal, similar to the one here discussed, have been found at various points along a very considerable section ot the Brazilian coast and under circumstances that have led the Brazilion geologists who have examined them to attribute them to passing vessel. A larpe block found near Santos figured in the Clicago Exposition of 1893 , and accompanying the note sent was a lragment found on the coast of Santa Catharina. The latter specimen is so like, in its plysical characters, the ones here described as to leave practically no room for doubt regarding the identity of the material as to source. On the other hand the identity above noted of its microscopic composition with that of the kerozene shale of New South Wales makes it almost absolutely certain that the above mentioned interpresation of the Brazilian Geologists is the correct one. As is well known the Autralian material has been extensively shipped to Furope and probaluly for the most part the vessels conveying it have passed along the Brazilian coast where one or more of them may have suffered shipwreck.

In vicw of the wide distribution of this material on the coast of Brazil and of the interest that it has from time to time awakened it is perhaps not to be regretted that, under a misapprehesion, it as been incluled in the study of Brazilian vegetable remains. 
Entre os specimens geologicos, presenteados an Museu Nacional dos Estados Unidos pelos commissarios encarregados da exposição do Governo Brasileiro em S Luiz, em 1904, fui encontrada uma grande amostra de carvão boghead com a etiqueta de "Puhuy", Bahia?, Brasil.

A posição geographica desta localidade é desconhecida por mim e não pude confirmar com o auxilio de cartas as relações de uma cidade chamada "Puhuy» com o Estado da Bahia.

Comtudo dou os dados geographicos como foram transcriptos por um representante do Museu Nacional.

Quer haja ou não erro, ou confusãu, na transcripção da etiqueta da localidade brasileira, é certo que o specimen veio da exposição do Brasil em S. Luiz, e o exame microscopico dos specimens mostrou-se tão interessante, que me aventurei a incluir uma curta descripção delle neste trabalho.

o boghead Jurasileiro ë massiço, conchoidal e preto, com muito pouco brilho setinoso em qualquer superficie. Quando finamente pulverisado ou examinado em extremidades muito delgadas, parece um tanto pardo. A rocha é muito densa, recusando-se á clivar em superficie plana, em qualquer direcção. O seu aspecto, bem como a sua composição microscopica, são tão semelhantes ao schisto boghead de kerozene de New South Wales, que se não fora a origem do specimen e o registro da etiqueta original, difficilmente me arriscaria a descrevel-o como pertencendo a palæontologia brasileira.

Quando a rocha é cortada em secções delgadas e verticaes ás camadas, vê-se que é composta de uma substancia basica ou geléa (phylozyma) fundamental, muito parda, escura, cheia de corpos brilhantes, muito translucidos, de contornos algum tanto irregulares, porém, mais ou menos distinctamente lenticulares.

Estes corpos comprehendem os residuos gelatinosos (gelosicos) e fossilisados, thallos de algas, do genero descripto por Bertrand e Renault como Reinschia.

Como se vê na secção vertical photographada, Pl. XI, fig. 11, estes thallos fosseis variam muito de tamanho, medindo, alguns delles, cerca de 500 microns de diametro maximo horizontal, tendo muitas vezes o tamanho dos exemplares novos. Observaremos que estes restos amarellos de algas constitutm a maior parte da rocha, sendo mais de $80 \%$ do total da massa. Na secção horizontal, que se vê na fig. 12, as paredes das cellulas em alguns thallos apparcem como uma franja um tanto grosseira de columnas salientes. 
Among the geological specimens presented to the United States National Museum by the Commissioners in charge of the exhibit of the Brazilian Government at Saint Louis in the United States, in 1904, there was found a large specimen of boghead coal, labeled as coming from "Puhuy, Bahia?, Brazil ».

The geographical position of this locality is unknown to me, and I have not been able cartographically to corroborate the relations of a town named Puhuy with the State of Bahia.

However, I give the geographical data as transcribed by a representative of the National Museum.

Whether or not there is error or confusion as to the transcription from the Brazilian locality label; it is certain that the epecimen comes from the Brazilian Exhibit at Saint Louis; and the microscopical examination of this specimen has proved so interesting that I venture to include a brief description of it in this report.

The Brazilian boghead is massive, conchoidal, and black, with very little satiny lustre on any surface. When finely pulverized or viewed in extremely thin edges it appears somewhat brownish. The rock is very dense, refusing to cleave on a plane surface in any direction. Its aspect as well as its microscopical compositiun is so similar to that of the kerozene shale boghead from. New South Wales that, were it not for the source of the specimen and the record of the original label, I should hardly venture to describe it as pertaining to Brazilian palaeontology.

When cut in thin sections vertical to the bedding, the rock is found to consist of a very dark brown, amorphous ground mass or fundamental jelly (phytozyme), filled with brilliantly translucent, yellow bodies of somewhat irregular outline, but more or less distinctly lenticular.

These bodies comprise the fossilized, gelatinous (gelosic) residue of algal thally of the genus described by Renault and Bertrand as Reinschia.

As shown in the photographed vertical section, Pl. XI. fig. 11, these fossil thalli vary greatly in size, some of them, nearly 500 microns in greatest horizontal diameter, being many times the size of the young individuals. It will be observed that these yellow algal remains comprise the greater part of the rock, constituting over $80 \%$ of the total rock matter. In the horizontal section shown in fig. 12 the cell walls in many of the thally appear as a rather coarse fringe of projecting pillars. 
São estas as paredes lateraes das cellulas, as distaes ou externas, foram em alguns casos destruidas em consequencia da accăo bacteriana.

Uma densa massa fundamental triturada, de gelatina, sustenta as cellulas e reveste a camada interna, que se vê distinctamente em alguns thallos, em ambas as secções. (1)

Bertrand e Renault referiram que o numero de cellulas nos thallos novos é tão consideravel como nos crescidos, o augmento de tamanho do thallo é acompanhado por variações das cellụlas individuaes. Estas são primeiramente prismaticas ; apenas seu conteúdo protoplasmatico toma gradualmente um desenvolvimento pyriforme, tendo a parte mais larga para dentro. Esta dilatação das extremidades interiores das cellulas forma uma unica camada no thallo, produz a circumvolução, ou invaginação para dentro da cavidade do mesmo, tornando as circumvoluções mais ou menos cerebriformes como se yê um tanto indistinctamente em ambas as figuras .

os restos gelatinosos que representam o genero Reinschia, que Renault considerava mais directamente relacionado com as Hydrodictyaceas e Volvocaceas. Devem ter fluctuado em indescriptivel abundancia, perto ou á superficie da agua, indo ao fundo em porções consideraveis, A conservação de uma quantidade tão grande destes thallos é devida provavelménte á existencią de algumą propriedade antiseptica, provavelmente de producção bacteriana no fundo da área tranquilla em que nasceram e cahiram.

Como em muitos carvões de algas e schistos petroliferas, os organismos parecem ter exercido uma influencia electiva sobre varios hydrocarburetos, incluindo certas combinações de alto valor eluminativo, e, pertanto, foram enriquecidos além de seu teor original em hydro: carburetọs. Muito pouco material de vegetaes estranhos, como sparos a outros fragmentos de plantas, apparece nas secções.

Para termo de comparação mostro na fig. 13 uma porção do schisto de kerozene (boghead) de Blue Mountąin, em New South Wales, cortado em direcção quasi vertical ás camadas. Sua șemelhança com a secção correspondente do boghead brasileiro será logo notada. Distingo este como variedade brasiliensis, por causa da abundancia proporcionalmente grande de thallos, como se vê nas figuras :

(1) A secçāo horizontal que se vê na fig. 12 foi, infelizmente, cortada de uma rocha en que os thallos estão ligeiramente mais desorganisados que na camada representada pelo corte vertical. 
These are the lateral walls of the cells, the distal or external walls having in most cases been destroyed as a result of bacterial action.

A dense 'ground mass of gelatine supports the cells and sur'ounds the internal cavity which is distinctly seen in many of the thalli, in both sections (1)

Bertrand and Renault have reported that the number of cells in the young thallus is as great as that in the large one, the increase in size of the thallus being accompanied by changes in the individual cells. The latter are at first prismatic, but the protoplasmic contents sradually assume a pyriform development, the broader end being inward. This enlargement of the inner ends of the cells, which form a single layer in the cavity of the thallus, producing more or less brain-like convolutions, as is somewhat indistinctly shown in both figures.

The gelatinous remains, which represent the genus Reinschia, are regarded by Renault as most closely related to the Hydrodictyacece and the Volvocacea. They must have floated in indescribable abundance at or near the surface of the water, in which they fell in showers to the bottom. The preservation of so great an amount of these thalli is probably due to the presence of some antiseptic property, possibly of bacterial production, at the bottom of the quiescent area in which they generated and fell.

As in many of the other algal coals and oil shales, the organisms appear to have exercized an elective influence on various hydro-carbons, including certain combinations of high illuminative value, and accordingly to have been enriched beyond their original hydro-carbon contents. Very little foreign vegetal)le mätier such as spores and other debris of higher plants appears in the sections.

For the sake of comparison, I have shown in fig. 13 a portion of the kerozene shale (boghead) from Blue Mountain. in New South Wales, cut in a direction nearly vertical to the bedding. Its similarity to the corresponding section of the Brazilian boghead will at once be observed. I have distinguished the latter as the variety brasiliensis on account of the proportionately grèater abundance of the large thalli, as shown in the illustrations.

(1) The horizontal section shown in fig. 12 is unfortunately cut from a portion of the rock in which the thalli are slightly mors disorganized than in the layer topresented by the vertical section. 
o genero Reinschia, foi primeiramente conhecido como Reinschia australis, Bertrand e Renault de New South Wales, e Reinschia capensis (1) de Ermels, do Transwal na Africa do Sul.

O facto de encontrar-se no Brasil especies identicas ás australianas, é uma questão de muito interesse palaentologico, visto que não só mostra uma distribuição commum na terra Gondwana de uma outra classe de plantas, como tambem apresenta mais uma evidencia da uniformidade de condições e liberdade de emigração no periodo Gondwana primitivo. Se Reinschia é considerada como um dos generos caracteristicos da flora de Gondwana inferior, parece que temos pelo menos, um representante desta flora, occorrendo no Brasil em latitude não muitos gráos distante do Equador.

A occurrencia desta especie em boghead, dado como procedente do Estado da Bahia, è por si mesmo sufficiente para garantir a presumpção que as camadas contendo o boghead são Permo-carboniferas, conclusão que encontı'a algum apoio na indicação da presença de $P$ saronius, no visinho Estado do Piauhy.

O boghead brasileiro provavelmente será mais completamente estudado pelo autor em discussão subsequente, de alguns schistos pretoliferos americanos.

LOCALIDADE : "Puhuy, Bahia?, Brasil». Especimen presenteado ao Museu Nacional dos Estados Unidos pela commissão brasileira da Exposicão Luisiania em S. Luiz. U. S. A. em 1904. Lot. B. R. $33 \mathrm{~A}$.

\section{FUNGI}

\section{PIRENOMYCETEAE}

\section{Rosellenites}

Potonié, fl, Rothl. Thurigen, 1893 p. 27

Rosellinites gangamopterides n. sp. pl, V, fig. 1, 1a, $1 \mathrm{~b}$,

Perithecias entre as veias e parallelas a estas, largamente ovaes, 5-9mis quasi sempre; $75^{\mathrm{mm}}$ de comprimento, em media $5 \mathrm{~mm}$ de largura; arrendondadas nas extremidades, proximas mas não contiguas, cercadas por uma bainha muito estreita, redondo convexa proximo

(1) Renault. Sur Quelques Microorganismes des Combustibles Fossiles, 1900, pl. XX, figs. $1-12$. 
The genus Reinschia has previously been known by Reinschic australis Bertrand and Renault from New South Wales and Reinschia capensis (1) from Ermels in the Transvaal in South Africa.

That the identical Australian species should also be found in Brazil is a matter of much palaeontological interest, since it not only shows a common distribution in Gondwana-land of another class of plants, but it includes further evidence for uniformity of conditions and freedom of migration in early Gondwana time. If Reinschia be regarded:as one of the characteristic genera of the lower Gondwana flora, we seem then to have at least one representative of this flora occurring in Brazil in latitude not many degrees from the equator.

The occurrence of this species in boghead said to have come from the State of Bahia is in itself sufficient to warrant the presumption that the strata containing the boghead are Permo-Carboniferous, a conclusion that finds some support in the record of the occurrence of Psaronius in the contiguous State of Piauhy.

The Brazilian boghead will probably be Inore fully illustrated by the writer in connection with a subsequent discussion of a number of American oil shales.

Locality: "Puhuy, Bahia ?, Brazil». Specimen presented to the United States National Museum by the Brazilian Commission to the Luisiana Purchase Exposition, at St. Louis, U. S. A., in 1904. Lot. B. R. $33 \mathrm{~A}$.

FUNGI

\section{PYRENOMYCETEAE}

Rosellinites

Potonié, fl. Rothl Thuringen, 1893, p. 27.

Rosellinites gangamopteridis n. sp. pl. V, figs. 1, 1 a, 1 b,

Perithecia between the veins and parallel to them, broadly oval .5-. $9 \mathrm{~mm}$ mostly $.75 \mathrm{~mm}$ in length, and averaging about $.5 \mathrm{~mm}$ in, width, rounded at the ends, close but not contiguous, surrounded, by a very narrow furrow round-convex near the periphery, plano-

(1) Renault, Sur Quelques Microorganismes des Combustibles Fossiles, 1900, pl. XX figs. $1-12$, 
da peripheria, planoconvexà no tope e algumas vezes mostrando o ostiolum proximo do centro.

As feições mais proeminentes destas perithecias são: a regularidade approximada em tamanho, a superficie planoconvexa coriacea e a bordẩ distincta e estreita que ás circunda. Como se vê nas photogràphias Pl. V, Figs 1, e 1 a, a perithecia occupa toda a largura da lamina entreas veias. O respiradouro ou ostiolum se vê em algumas perithecias, como está na figura augmentada, Fig. lb. é claramente visivel em muitos individuos unidos. A especie aqui descripta encontra-se 'em algumas folhas de Gangamopteris obovata. E' de interesse notar, que a especie typo do genero, Rosellinites Beyschlagii, foi descripta por Potonié do cortex de Aspidiopsis coniferoides, um suppjsto typo gymnospermeo da Thuringia Rothligende.

As perithecias desta são mais variaveis em tamanho, geralmente o dobro maiores e menos redondas nas extremidades. Suppondo que os pequenos corpos em forma de bracteas dos grupos de Raniganj de que Feistmántel (1) dá figura como, sendo talvez escama de Noeggeräathiopsis, são cómparaveis á Rosellinites.

A relação deste genero com Rosellinites actual é complêta e convincentemente discutidà (2) por Pótonié.

Lacalidade: Nordeste de Minas, Santa Cátharina, 55 metrós acima do granito, ou 225 metros abaixo do schisto Prétóde Iraty. Lot. 3586.

\section{Hysterites}

Unger, Chloris Protogaea, 1841, p. 1.

\section{Hysterites Brasiliensis}

$$
\text { N. sp. Pl. V, fig. } 2
$$

Perithecias afastadas, longitudinaes, estreitas e âs vezes muito alongadas, com 2, 5 e $6 \mathrm{~mm}$ de comprimento e $1 \mathrm{~mm}$ de largura, longitudinalmente decrescentes, com uma borda algum tanto convexa, säliente ; èm folha de Nóggerathiopsis Hislopi.

Na falta de dados sobre à éstructura micróscopica, as perithecias quie sè veém em tămanho natural na Pl. V, fig. 2, são caracterisadas principalimentè por sua fórma muito alongàda, assim como grande

(1) Fl. Gond. Syst. Vol. ill pt, 2 pl. Xtvil fig. 23

(2) Fl. Rothl. Thuringia, Ab. I. Pr. Geol. Landesanst N. F. Hft: 9, H. 2, 1893, p. 28. 
convex on the top, and somentimes exhibiting the ostiolum neatr the center.

The more prorninent features of these perithecia are their approximate regularity in size, the planoconvex, leathery surface, and the distinct narrow surrounding crease. As shown in the photographs, Pl. V, Figs. 1 and 1a, the perithecium occupies the full width of the lamina between the veins. The vent or ostiolum is seen in some of the perithecia, as showon in the elarged illustration, Fig. Ib. It is clearly visible in many of the collapsed individuals. The species here described is found on a number of the leaves of Gangamopteris obovata. It is interesting to note that the type species of the genus, Rosellinites Beyschlagii, was described by Potonie from the cortex of Aspidiopsis coniferoides, a supposed gymnospermous type, from the Thuringian Rothliegende.

The perithecia in the latter are much more variable in size, generally twice as large, and less rounded at the ends. I suspect that the small bodies on the bract-like leaf from the Raniganj group illustrated by Feistmantel (1) as perhaps the scale of Noeggerathio. psis is comparable to Rosseilinites.

The relation of this genus to the living Rosellinia is fully and convencingly dicussed (2) by Potonié.

Locality: Northeast of Minas, Santa Catharina; 55 meters above the granite, or 225 meters below the Iraty black shale. Lot: 3586 .

\section{Hysterites}

Unger, Chloris Protogaea, 1841, p. I

\section{Hysterites Brasiliensis}

$$
\text { N. sp. pl. V, fig. } 2
$$

Perithecia distant, longitudinal, narrow and often much elongated, 2,5-6 mm. in length, and $1 \mathrm{~mm}$. in width, longitudinally. dehiscent, with rather broad, raised convex rim; on the leaf of Noeggerathiopsis Hispoli.

In the absence of data respecting the microscopical structure the perithecia, shown in natural size in $\mathrm{Pl} . \mathrm{V}$, fig. 2, are characterized chiefiy by their greatly elongated form as well as generally large

(1) Fl. Gondwana Sysl.. yol. 111, pt. 2, pl, XLVII A, fig. 23.

(2) Fl. Rothl. Turingen; Abh. K. Pr. Geol. Landesanst. N. F., Hft. 9, H. 2, 1893, p. 28. 
tamanho. Em confronto com Hysterites cordaites Grand'Eury(1), especie que mais de perto se relaciona com Hysterites brasiliensis differe especialmente por suas perithecias muito mais alongadas, muitas vezes mais longas que largas (2). Potonié descreveu algumas especies do Permiano da Thuringia, como Hysterites cordaites que pareciam ser muito semelhantes á nossa, differindo apenas muito pouco, em tamanho, das da America do Sul, e de modo que a principio parecia não ser muito acertado consideral-as distinctas, mas o exame da descripção original e da figura de Grand'Eury juntamente com o estudo de especimens da formação carbonifera (3) da America do Norte convenceu-me da uniformidade de tamanho e outras leições das perithecias da especie de Grand'Eury, estas teem quasi todas de comprimento menos que metade que as da Hysterites brasiliensis, embora sejam quasi da mosma largura(4). Muitas, na especie brasileira, são mais que tres vezes tão longas, que as daquella.

Por estas razões não posso considerar o nosso cogumello como especificamente identico á Hysterites cordaites.

A evidencia de relações dos fosseis palæozoicos com o genero actual Hysterium Tode, creio eu, deduz-se satisfactoriamente da discussão completa de Potonié. A semelhança indicada por elle, do typo carbonifero com Hysterium nervisequum, que vive actualmente nas follhas de Abies alba, é sem duvida, tão notavel quanto instructiva.

O hospedador do typo de Grand'Eury é Cordaites principalis da formação carbonifera da bacia do Loire em França.

o especie de Potonié, vive tambem em uma folha de Cordaites considerada por elle como provavelmente da mesma especie do Rothliegende da Thuringia. A presença de uma especie palæozoica directamente relacionada com Noeggerathiopsis, está em completo accordo com a relação mais estreita entre os generos Cordaites e Noggerathiopsis. Não sómente as especies palæozoicas de Hysterites se encontram em hospedadores Gymnospermeos, porém, tambem as outras unicas especies encontradas em rochas mais antigas que o Cretaceo.

(1) Fl. carb. dep. de la Loire 1877, p. 10, pl. 1, fig. 7.

(2) Fl. Roth, Thuringien, 1893, p. 25, pl. 1, fig. 5.

(3) Veja Monog. U. S. Geol. Surv, , vol. XXXVII, 1899, p. 13, pl. III.

(4) Tanto as figuras dadas por Grand'Eury, como por Potonie, são copiadas por Meschinelli : Fungorum Fossilium Omnium Hucusque Cognitorum, Iconographia; Vicetiae, 1898, pl. XV, fig. 9 e 7 . 
size, in comparison with Hysterites Cordaitis Grand'Eury(1) its nearest related species, Hysterites brasiliensis differs especially by its very much elongated perithecia which are several times as long as broad. Pontonié has, it is true, described (2) as Hysterites Cordaites some specimens from the Thuringian Permiam which would seem to be very close to ours, differing but little except in size from those from South America, and which would at first make it seem unwise to lreat the latter as distincl. But the examination of Grand Eury's original description and figure, together with the study of specimens from the North American Coal Measures (3) convinces me of the uniformity of size and other features in the perithecia of Grand Eury's species.

The latter are nearly all less than one-half as long as in Hysterites brcusiliensis, though nearly as wide (4). Many of those in the Brazilian species are over three times as long.

For these reasons I am unable to regard our fungus as specifically identical with Hysterites Cordaites.

The evidence for the relationship of the Palaeozoic fossils to the recent genus Hysterium Tode is, I believe, very satisfactorily shown in the full discussion given by Potonie. The similarity, as pointed out by him, of the Carbonilerous type to the living Hysterium nervisequum on the leaf of Abies alba is certainly very striking as well as instructive.

The hoste of Grand Eury's type is Cordaites principalis from the Coal Measures of the basin of the Loire in France.

Potoniê's specimen also is on a Cordaites leaf, regarded by him as probably the same species, from the Thuringen Rothliegende. The occurrence of a Palaeozoic species, so closely related, on the Noeggerathiopsis is in complete accord with the very close relationship between the genera Cordaites and Noggerathiopsis. Not only are the Palaeozoic specios of Hysterites on gymnospermous hosts, but the only other species recorded from rocks older than the Cretaceous, the Hysterites Friesii Nath., from the Rhetic of Sweden,

(1) Fl, carb, dep, d3 la Loire, 1877, p. 10, pl, I, fig. 7.

(2) Fl. Roth. Thuringien, 1893, p. 25, pl. I, fig. 5.

(3) See Monogrr. U. S. Geol. Surv., vōl. XXXVII, 1899, p. 13, pl. III.

(4) The illustrations given both by Grand'Eury and by Potonié are copied by Mes. chinelli: Fungorum Fossilium Omnium Hucusque Cognitorum. Iconographia: Vicetis, 1898, pl. XV, tigs. 9 aud 7 . 
A Hysterites liriesii Nath. do Rhetic da Suecia, occorre tambem na folha de um outro gymnospermeo, o Cycadaceo Padazamites distans.

Localidade - Nordeste de Minas, Santa Catharina, 55 metros acima du granilo ou 225, ahaixo do Schisto preto do Iraty. Lot 3921.

\section{PTERIDOPHITA}

\section{FQUISETALES}

\section{Equisetites}

Sternherg, Versuch Fl. Vorwelt, vol. $2^{\circ}, 1833, \mathrm{p}, \mathbf{4 3}$

Equisetites calamitinoides, n. sp.

pl. v, fig. 7,7 a.

Bainlua muito curta, dentes erectos, quasi contiguos, tendo de comprimento quasi a largura da haste, delgada, as bordas quasi parallelas tornando-se muito gradualmente ponteagudas para o apice,estreita e aguda, nervura mediana muita grossa, quasi egual a largura do centro da base, onde é convexa nos bordos lateraes, de convexidade achatada no dorso, e finamente estruda longitudinalmente, tornando-se rapidamente ponteaguda logo acima do ponto de bifurcação, até cerca da metade de sua largura basal, tornando-se para cima convexodeprimida, com leve diminuição de largura na direç̧ão do apice que se estreita bruscamenle, lamina estreita sotoposta aos sulcos estreitos entre as nervuras medianas da base da folha, de ambos os lados quasi egual em largura a neroura mediana até o meio, na direcção da extremidade superior, estreita-se gradualmente para o apice agudo no terço distal.

A especie acima descripta, é baseada inteiramente em caracteres da bainha e das folhas, visto que pouco conhecemos acerca dos caracteres da haste. No fragmento que se vê na Estampa T, Fig. 7, o cixo parece ser representado apenas pelo cortex que está lascado e obliquamente superposto. Leves indicios de nervura estão. topographicamente indicados no specimen que mostra indistinctamente um outro nó, $13 \mathrm{~mm}$ abaixo que o que tem a bainha conservada. O aspecto do cortex destacado lembra a Calcmitina Weis. A bainha é relativamenle curta, tendo pouco mais de $2,5 \mathrm{~mm}$ de allura. A forma de uma das folhas, mostrando felizmente o apice, se vê na Fig. 7 a, a direita do specimen. 
also occurs on the leaf of another gymnosperm, the cycad, Podozamites distans.

Locality: Norheast of Minas, Santa Catharina. 55 meters above the granite, or 225 meters below the Iraty black sliale. Lot 3921.

\title{
PTELIDOPHYTA
}

\section{EQUISETALES}

\author{
Equisetites \\ Slernbera, Velsuch Fl. vol. 20, 1833, p. 43 \\ Equisetites calamitinoides n. sp. \\ pl. v, figs. 7,7 a.
}

Sheath very short, appressed; teeth erect, nearly contiguous, in length nearly equalling the: width of the stcm, slender, linear, the borders nearly parallel, tapering very gradually near the apex, narrowly acute; midrtb very thick, nearly equalling the breadth of the tooth at the base, where it is canvex at the lateral borders, flatly convex dorsally and minutely striated longitudinaly, tapering rather rapidly just above the point of fission to about one half' its basal width, and passing upward, flatly convex, with slight diminution in width, to the abruptly narrowed apex; lamina narrow, subtending the narrow sulci between the midrib at the base of the leaf, on either side nearly equal to the midrib in width half way up, and, in the distal third; narrowing gradually to the slender apex.

The spicies defined above is based entirely on the characters of sheath and leaves little being known of the features of the stem. In the fragment shown in Plate V, Figure 7; the axis seems to be represented by the cortex only which is split and obliquely overlapped. Slight traces of ribs are topographically indicated in the specimen, which shows indistinct evidence of another node $13 \mathrm{~mm}$ below that bearing the preserved sheath. The aspect of the detached cortex suggests that of Calamitina Weiss. The sheath is relatively short, being little over $2.5 \mathrm{~mm}$ in height. The form of one of the leaves fortunately showing the apex, on the right of the specimen, is shown in Fig. $7 \mathrm{a}$. 
Ordinariamente as folhas parecem ter sido erectas e quasi contiguas na maior parte de seu comprimento.

O fragmento representado aqui; das proximidades de Minas, é evidentemente equisetaceo, e que não seja só pela antiguidade deveria com propriedade, ser referido a Equisetum. No hemispherio occidental as hastes equisetaceas não são desconhecidas, mesmo em um horizonte inferior ao do carbonifero superior, exemplos de troncos com bainhas muito bem desenvolvidas, e dentes longos e delgados, se encontram na formação Lookout (Pottsville inferior) da edade Millstone Grit(1) na extremidade Sul da bacia Appalachiana.

Localidade: Estrada Nova (Estrada do Rio do Rasto) proximo de Mìnas, Santa Catharina; cerca de 40 metros abaixo do carvão Barro Branco, ou 135 metros acima do granito, e 145 metros abaixo do horizonte do schisto preto de Iraty. Lot. 3923.

\section{Phyllotheca}

\section{Brongniart, Prodrome, 1828, p. 151}

Applica-se o nome de Phyllotheca a um typo ramoso equisetaceo caracterisado, em particular, por ter suas folhas lineares lanceoladas, unidas em alguma distancia pela base, formando curta bainha que geralmente se alarga em fórma de funil, em vez de ser erecta ou em contacto com a haste.

o dente, ou a porção livre da folha, tem apenas uma nervura, sendo usualmente largo e recurvo, embora a ponta seja muitas vezes algum tanto curvada para dentro. Os sporangios nascem em sporangiophoros peltados, dispostos verticalmente entre as espiraes das bracteas nas porções terminaes do eixo principal ou lateral.

O genero é tido como se estendendo da parte inferior (Westphaliano) do Carbonifero superior ao Jurassico, embora haja logar para algumà duvida, quanto á identidade generica completa das especies do carbonifero com as do oolitico.

Os typos palæozoicos teem maiores hastes de aspecto de Calamaria cujas reproducções de medulla não se podem distinguir das de algumas Calamites, que teem apenas uma alteração parcial das nervuras dos nós.

(1) Veja-se Lesquereax, Coal Flora vol. III, 1884, p. 729, pl. XC, flg. 5. 
Ordinarely the leaves seem to have been erect and very nearly contiguous for the greater part of their length.

The fragment here shown, from near Minas, is evidently equisetaceous, and but for its antiquity might with propriety be refered to Equisetum. In the western hemisphere equisetaceous stems are not unknown, even at a low horizon in the Upper Carboniferous, exemples of stems with very well developed sheaths and long slender teeth being found in the Lookout (Lower Pottsville) formation, of Millstone Grit age, in the southern end of the Appalachian trough, (1)

Locality: Estrada Nova, near Minas, Santa Catherina. About 40 meters below the Barro Branco coal, or 135 meters above the granite, and 145 meters below the horizon of the Iraty black shale. Lot 3923.

\section{Phyllotheca}

Brongiart, Prodrome, 1828, p. 151

The name Phyllotheca is applied to a ramose Equisetaceous type characterized in particulary by having its linear-lanceolate leaves coherent for some distance at the base in a short sheath, which is generally spread out or funnel-shaped, instead of erect or appressed.

The tooth or free portion of the leaf has but a single nerve and is usually long and recurved, though the tip is often somewhat incurved. The sporangia are borne on peltate sporangiophores verticillatelly arranged between whorls of bracts on terminal portions of the main or lateral axes.

The genus is recorded as ranging from the lower part (Westphalian) of the Upper Carboniferous $t$ ) the Jurassic, though there is room for some doubt as to the complete generic identity of the species from the Carboniferous with those from the Oolite.

The Palaedozoic types have rather large stems of Calamarian aspect, the pith casts of which are indistinguishable from those of some of the Calamites that have but a partial alternation of the ribs at the joints.

(1) See Lesquereux, Coal Flora, vol. III, 1884, p. 799, pl. XC, fig. 5. 
Veem-se exemplos na pl. V, figs. 3 e 5. Os ramos de Phyllotheca são semelhantes aos das Annularias Calamarianas, ás de Phyllotheca Rallii Zeiller (1), do Westhphaliano da Asia Menor, sendo muito parecidos com os de Calamites ramosus (Annularia ramosa). (2)

o estrobilo fertil de Phyllotheca Rallii, como Zeiller mostrou, está do mesmo modo em estreita concordancia com o typo Calamostachys, isto é, o cone de Annularia. A fructificação, de uma ao menos das fórmas Jurassicas, tem alguns verticillos de esporophyllos entre dois verticillos de folhas. As especies mais antigas são, indubitavelmente, muito mais proximas de Annularia.

Ainda que as plantas Jurassicas estejam identificadas sob o nome de Phyllotheca, o genero é essencialmento um typo Permo-carbonifero, de vasta distribuição, sendo conhecido da Siberia, França, Asia Menor e Estados Unidos da flora do norte, da India, Australia, Africa do Sul e America do Sul da provincia de Gungamopteris, ou antigo Gondwana. $E^{\prime}$ de todo possivel que o fossil da plantação sisterio em Rio Pardo, na Bahia, comparado como tentativa com Asteraphyllites (?) scutigera Dawson por Hartt (3) seja uma especie de Phyllotheca.

\section{Phyllotheca Griesbachi Zeiller}

Pl. V. Figs. 9 e 10

1902 - Phyllotheca Griesbachi Zeiller, Pal. India, n. s. vol. II, n. I p. 30, pl. VII, fig. 1 ; Arber, The Glossopteris Flora 1905, p. 25.

1905 - Phyllotileca cf. australis Brong. D. White, Science n. s. vol. XXI, p. 700 .

Haste finamente costifera, entrenós com $1 \mathrm{~cm}-1,5 \mathrm{~cm}$ de comprimento, 25-30 folhas em cada verticillo com $20 \mathrm{~mm} 25 \mathrm{~mm}$ de comprimento, unidas na extensão de cerca de $1 \mathrm{~cm}$, formando uma bainha, segmentos livres, lin inres agudos estreitamente sulcados na parte ventral, se dilatando horizontalmente para fora, ou mesmo um tanto recurvos e curvando-se novamente para cima, junto dos apices, bainha obliqua na base, e abrindo-se rapidamente em uma posição quasi horizontal.

(1) Mam. Soc. Geol. Fr. Palaent. n. 1, p. 65, pl. I, fig. 2-12.

(2) Uma especie não descripta muito prosima, por seus caracteres, da Phyllotheod Rallit Zeill., occorre na parte inferior da série Kanawha (Westphalian) do Sul de West-Virginia nos Estados Unidos.

(3) Geo. e Phys. Grogr. do Brasil, 1870, p. 243. 
Examples are shown in pl. V, Figs. 3 and 5. The branches of Phyllotheca are like those of the Calamarian Annullarioe, those of Phyllotheca Rallii Zeiller (1), from the Westphalian of Asia Minor, being, very similar to those of Calamites ramosus (Annularia ramosa) (2).

The fertile strobilus of Phyllotheca Rallii, as Zeiller has pointed out, is similarly in close agreement with the Calamostachys type, f. e. the Annularian cone. The fructification of one, at least, of the Jurassic forms has several sporophyll verticils between two whorls of leaves. The older species are undoubtedly very much closer to Annularia.

Although Jurassic plants are identified under the name Phyllotheca, the genus is essentially a Permo-Carboniferous type of wide distribution, it being known in Siberia, France, Asia Minor, and the United States, in the Northern flora, and from India, Australia, South Africa, and South America, in the Gangamopteris or lower Gondwana province. It is quite possible that the fossil from the Sisterio plantation on the Rio Pardo, Bahia, tentatively compared by Hartt (3) with Asterophyllites (?) scutigera Dawson, may be a specimen of Phyllotheca.

\section{Phyllotheca Griesbachi Zeiller}

Pl. V, Figs. 9 and 10

1902. Phyllotheca Griesbachi Zeiller, Pal. Indica, n. s., vol. H, n. 1, p. 30, pl. vii, fig. 1; Arber, The Glossopteris Flora, 1905, p. 25.

1905. Phyllotheca cf. australis Brongn., D. White, Science, n. s., vol. xxi, p. 700.

Stem finely costate; internodes $1^{\mathrm{om}}-1.5^{\mathrm{cm}}$ long; leaves $25-30$ to the verticil, $20^{\mathrm{mm}}-25^{\mathrm{mm}} \cdot$ long, uniled for a distance of about $1^{\mathrm{cm}}$ to form a sheath; free segments linear, acute, narrowly sulcate ventrally, spreading outwards horozontally or even reflexed somewhat, and turning upward again near the apices; sheath oblique at the base and rapidly opening to " nearly horisontal position.

(1) Mém. Sac. Géol. Fr., Palaeont., 11. 1, p. 65, pl. I, fig. 2-12.

(2) An undescribed species very olose in its characters to Phyllotheca Rallii Zeill., occurs in the lower part of the Kanawha Series (Westphalian) of southern West Virginia in the United States.

(3) Geol. and Phys. Geagr. of Brazil, 1870, pag. 243. 
Diversos specimens da rocha que tenho á mão conteem verticillos separados, de folhas de uma grande Phyllotheca, de que dois exemplares fragmentarios estam figurados na pl. V. Figs. 9 e 10 . Todos estão mais ou menos macerados, o que provavelmente dá as folhas o aspecto molle que não lhes é proprịo. A primeira inspeção do material estava disposto a consideral-o como pertencendo á Phyllotheca australis Brong, devido á estreita semelhança com os exemplares dados por Feistmantel nas figs. 2 e 3, pl. XIV de sua memoria (1) sobre a flora Palaeozoica e Mesozoica da Australia Oriental e Tastamania. O exame, descripções e illustrações anteriores, dos especimens da serie New Castle, do Museu Nacional dos Estados Unidos, convenceu-me de que, á nossa planta, falta a bainha erecta e folhas rigidas, caracteristicas das especies Australianas, de Dana (2), Jack, Ethridge (3) e outros. Ao contrario a bainha se expandindo rapidamente para fora, as folhas curvadas para traz, que são pouco molles e viradas para cima junto aos apices, e a nervura mediana estreita deprimida na face inferior da folha, parecem mostrar completa identidade especifica, com as especies do grupo Barakar da bacia South Rewah da India, descriptas por Zeiller. Os especimens figurados, de Phyllotheca equisetitoides do Permiano da velha Tungusca na Siberia, descriptos por Schmaulhausen (4) mostram estreita semelhança com a nossa planta, embora as folhas sejam proporcionalmente mais estreitas.

Os apices se veem muito raramente nos especimens brasileiros dẹido á má conservação. Em regra, as folhas são proporcionalmente um pouco mais largas que as do specimen typo de Zeiller.

Attingem occasionalmente uma consideravel largura, como se vê no pequeno fragmento fig. 9. No specimen photographado, fig. 10, notar-se-á que as folhas de mais de um verticillo estão sobrepostas, indicando o pouco comprimento dos entrenós. E' possivel que o fino fragmento de baste dado como de Schizeneura sp. ? na fig. 6 da mesma estampa represente a haste desta especie sendo as suas saliencias longitudinaes quasi eguaes em largura ás que se veem indistinctamente no ramo esquerdo da fig. de Zeiller.

Localidade: Nordéste de Minas, Santa Catharina, em camadas de 55 metros acima do granito, ou 225 metros abaixo do schisto preto de Iraty, nas collecções feitas pelo Dr. Seixas. Lots. 358633921.

(1) Mem. Geol. Surv. N. S. W, Palaeont. n, 3, 1890, p. 79.

(2) Wilckes Expl. Exped. 1849, vol. X, Atlas, pl. XIII fig. 6.

(3) Geol a Pal, Queosland 1892, Atlas, pl. XVII fig, 13.

(4) Jura-Flora d. unt. Tungusca, 1879, pl. 71, pl. XII, fig, 1-4. 
Several of the rock specimens before me contain detached vel'ticils of the leaves of a large Phyllotheca, two fragmentary examples of which are illustrated in PI. v, Figs. 9 and 10. All are more or' less macerated so as to give a probably. unduly lax aspect to the leaves. On first inspection of the material I was disposed to regard it as belonging lo phyllotheca australis Brongn., on account of the close similarity to the oxemples shown by Feistmantel in figures 2 and 3, plate xiv, of his memoir (1) on the Palaeozoic and Mesozoic flora of Eastern Australia and Tasmania. The examination of the earlier descriptions and illustrations, as well as of specimens from the Nevcastle Series in the Unlted States National Museum, convinces me that our plant lacks the erect sheath and rigid leaves characteristic of the Australian species, as shown by Dana, (2) Jack \& Ethridge, (3) and others. On the contrary, the rapidly flaring sheath, the backivard curved lenves, which are somewhat lax and upturned near the apices, and the narrow midrib, ventrally depressed in the leaf, seem to show a complete specific identity with the species described by Zeiller from the Barakar group in the South Rewah basin of India. The illustrated specimens of phyllotheca equisetitoides described by Schmalhausen (4) from the Permian of the-lowel' 'T'ungusca in Siberia, bear a close resemblance to our plant, though the leaves are proportionately narrower.

The apices are very rarely seen in the Brazilian spccimens, on account of the poor preservation. As a rule the leaves are proportionately a little broader than those in Zeiller's type specimen.

Occasionally they attain a considerable width, as is seen in the small fragment, Fig. 9. In the specimen photographed in Fig. 10 it will be noticed that the leaves of more than one verticil are superposed, indicating the shortness of the internodes. It is possible that the slender stem fragment shown as aschizoneura? sp. in Fig. 6 of the same Plate, represents the stom of this species, its costation Jeing nearly equal in width to that indistinctly seen in the branch on the left in Zeiller's figure.

Locality: Norrheast of Minas, Santa Catharina, in beds 55 meters above the granite or 225 meters below the Iraty black shale. In collections by Doctor White and Doctor Seixas. Lots 3586 and 3921 .

(1) Mem. Geol. Surv. N. S. W., Palaeout., no. 3, 1890, p. 19.

(2) Wilkes Expl. Exped., 1849, vol. x, Atlas, pl. xiIr, fig. 6.

(3) Geol, and Pal: Queensland, 1892, Atias, pl.: xiri, fig. 13.

(4). Jura.Flora d. unt. Tungusca, 1879, p. 71, pl. xul, figes, 1-4. 5560 


\section{Phyllotheca Muelleriana}

Pl. V, Fig. 8

Folhas delicadas um pouco molles, lineares, unidas na base em cerca de $5 \mathrm{~mm}$. a $7 \mathrm{~mm}$., formando uma bainha erecta, arqueadas abruptamente para for'a na extremidade da bainha para tomar uma posição muita aberia, ou quasi horiwontal em curta distancia, virando-se depois paracima ficando quasi verticaes em grande parte de seu complimento, os apices ligeiramente obtusos as veres um tanto claramente curvados para dentro, bainha estreita e erecta cm dous ter'ços ou mais de' seu comprimento, abrindo-se depois rapidamente para fora no ponto de bifurcação, nerour'a mediana distincta, com "er'ca de um quarto da largur'a da lamina, na parte média da folha.

Este typo equisetaceo muito interessante, é representado apenas por um unico exemplar que como se vê na pl. V Fig. 8, contem partes de nove verticillos destacados. A orientação destes na rocl_a, indica provavelmente procedencia commum de uma unica planta. Todo o material está ligeiramente macerado, e não se veem traços definidos da haste commum.

Os caracteres essenciaes da especie são : a dilatação abrupta do tope da bainha, a forte arqueação das folhas para fóra em alguma distancia, para alem da bainha, formando um calice, tendo tres ou quatro vezes a largura da porção erecta da bainha, tomando depois posição erecta. A curvatura das partes terminaes, que se observa em muitas folhas, parece muito uniforme e bem accentuada para ser attribuida a emmurchecimento, ou a um mero accidente na conservação. Em algnns casos a extremidade das folhas está enrolada como a prefoliação circinal de um feto.

A apparencia dos verticillos é á primeira vista suggestiva de uma enorme Calymmatotheca, ou de uma Beinertia.

As especies do Gondwana que se encontram mais proximamente relacionadas à Phyllotheca Muelleriana são Phyllotheca Griesbachie Phyllotheca indicá. Pela sua attitude geral, assim como pela curvatura das folhas para lora e depois para cima, a nossa planta, assemelha-se um pouco á Phyllotheca Griesbachi, embora a forma do calice colresponda do desta somente em menor gráo.

Em outro caso a forma erecta da bainha, e as folhas abrindo-se para fora lembram-nos logo os verticillos menores da Phyllotheca indica e Phyllotheca australis. Apenas a dilatação da parte superior da bainha 


\section{Phyllotheca Muelleriana n. sp.}

Pl V, Fig. 8.

Leaves delicate, a little lax, linear, united for about $5 \mathrm{~mm}$. to $7 \mathrm{~mm}$. at the base, to form an erect sheath, and abruptly arched outward at the top of the sheath to assume avery open or nearly horizontal position for a short distance, then turning upward to nearly vertical for the greater part of their length, the rather obtuse apices being often somewhat sharply inward hooked; sheath narrow and erect for about two thirds or more of its length, then very rapidly opening outward to the point of fission; medium nerve distinct, about one fourth the width of the lamina through the middle portion of the leaf.

This very interesting equiselal type is represented by but a single specimen which, as shown in Pl. V, Fig. 8, contains portions of nine detached verticils. The orientation of these on the rock indicates a probable common derivation from a single individual plant. All the material is slightly macerated, and no definite trace of the parent stem is seen.

The essential characters of the species are the abrupt dilation of the sheath at the top, the strong outward arching of the leaves for some distance beyond the sheath to form a cup about three or four times the width of the erect portion of the sheath; and the subsequent assumption of an erect position. The incurving of the apical portions observed in most of the leaves seems far too uniform and well marked to be ascribed to wilting or the mere accident of perservation. In some instances the top of the leaf is inrolled like the circinnate vernation of a fern.

The aspect of the verlicils is at first glance suggestive of an enormous Calymmatotheca, or of a Beinertia.

The Gondwana species that appear most nearly related to Phyllotheca Muelleriana are Pinyllotheca Griesbachi and Pyllotheca indica. By the general attitude, aswell as by the outward and subsequent upward curve of the leaves our plant somewhat resembles Phyllotheca Griesbachi, though the shape of the cup corresponds only in a minor degree.

On the other hand the erect form of the smaller verticils of Phyllotheca indica and Phyllotheca australis; but the dilation of the upper portion of the sheath seems to differ from that of Phyllotheca 
parece differir da Phyllotheca indica. Quando se comparar estd especie deve ser feita referencia as figuras originaes publicadas por Bumbury (1), ou ás que dá Feistmantel (2). As folhas de Phyllotheca custralis devem ser verticaes ou reflexas como mostam $\mathrm{Mc} \operatorname{Coy}(3)$; Dana(4) e Arber(5). Nenhuma destas especies apresenta o calice grandemente alargado em forma de verticillo, ou as partes apicaes das folhas curvadas para dentro, que se vê no tyjpo brasileiro. Os vertícillos com a dilatação da bainha para cima reproduzida em figura por Etheridge (6) como Phyllotheca sp.! parecem mais semelhantes aos da planta que tenho em mão, embora a parte livre da folha seja um tanto estreita.

E' de muita conveniencia que os especimens addicionaes e melhor conservados destas interessantes plantas, sejám colleccionadas de forma a fornecerem dados relativos á sua forma, haste e estructura.

Esta especie é assim denominada em honra ao Dr. Lauro Muller, Ministro da Industria, sob cuja autoridada os tra]ualhos da Commissão do Carvão proseguiram.

Localidade: Nordeste de Minas, Santa Catharina. Cerca de 55 metros acima do granito. Colleccionada pelo Dr. Seixas, Lot. n. 3586 .

$$
\begin{gathered}
\text { Phyllotheca (?) sp. } \\
\text { Pl. V, Figs 3, 4, } 5
\end{gathered}
$$

Os schistos areentos e cor de creme a cerca de 55 metros acima do granito a nordéste de Minas, no Estado de Santa Catharina, conteem um grande numero de grandes fragmentos de hastes de Equisitaceas, consistindo principalmente em esqueletos vasculares ou reproducçáes em turfa de cor parda escura, ou residuos mais ou menos carbonaceos granulares, os tecidos intermediarios mais tenros, e as epidermes sendo algumas vezes vistas por causa da cor pallida, contrastando apenas pouco com a cor da matriz. Quasi todas estão quasi completamente achatadas. O maior destes fragamentos, não excede $3.5^{\mathrm{cm}}$ de largura, medindo o maior entrenó $73 \mathrm{~mm}$. formando parte de uma haste de $22 \mathrm{~mm}$. de largura, sendo de 10 o numero de nervuras salientes no lado a vista.

(1) Quart Journ. Geol. Soc. vol, XVII, 1861, p 335, pl. x, fig. 7.

(2) Foss. fl. Gondwana System, vol. III, p. 2. pl. XIIA, ligi. 3-9.

(3) Geol. mag. vol. XX 1847, pl. XI. fig. 2 (Phyllotect ramosa Mc. Coy) e figs. 4-5

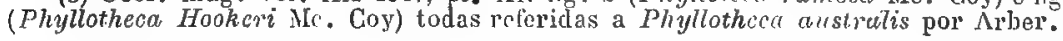

(4) Geol. Wilkers explor, Exped, vol, X 1819, pl, XIll fig. 6. p. XIV fig. 1.

(5) Flora Glossopteris, 1905, p. II. fig. 7-8 p. 17.

(6) Rec. Geol. Surv. N. S. W., vol. iv, 1896, pl, xviii, Ggs. 4, 5. 
indica. In comparing the latter species reference may be made to the original figures published by Bunbury (1) or those given by Feistmantel (2). The leaves of Phyllotheca australis may be vertical or reflexed as shown by Mc Coy, (3) Dana, (4) and Arber, (5) None of these species exhibits the greatly broadned cup form of verticil or the incurved apical portions of the leaves seen in the Brazilian type. The verticils with upward dilation of sheath illustrated bv Etheridge Jr., (6) as "Phyllotheca sp?" seem to approach more closely to the plant in hand, though the free portion of the leaf is nearly straight.

It is desirable that additional and better preserved specimens of this interesting plant be collected in order to supply other data relating to its habit, stem, and structure.

The species is named in honor of Dr. Lauro Muller, Minister of Industry, under whose lauthority the work of the Coal Commission has been prosecuted.

Locality: North East of Minas, Santa Catharina. About 55 meters above the granite. Colleted by Doctor Seixas. Lot 3586 ,

\section{Phyllotheca (?) sp.}

$$
\text { Pl. V, Figs. 3, 4, } 5
$$

The cream colored sandy shales lying about 55 meters above the granite to the North-East of Minas, in the state of Santa Catharina, contain numerous large Equisetaceous stem fragments consisting chiefly of vascular skeletons or pith casts in dark brown color and with more or less carbonaceous granular residue, the intervening softer tissues and cuticles being sometimes shown by a pale brownish tint contrasting but little with the color of the matrix. All are almost completely flattened. The broadest of these fragments does not exceed $3.5 \mathrm{~cm}$. in width, and the longest internode, measuring $73 \mathrm{~mm}$, forms part of stem $22 \mathrm{~mm}$ in width, the number of ribs being ten on the side in view.

(1) Quart. Jour. Gool. Soc., vol. xvii, 1861, pl. x, fig. 7

(2) Foss. Fl.. Gondwana System, vol. iii, pt. 2, pl. xi iA, figs. 3-9.

(3) Gool. Mag., Vol. XX 1847, pl. xi, fig. 2, (Phyllotheca ramosa McGoy), and figs 4, 5 (Phyllotheca Hookeri HeCoy), fall referred by $\Lambda \mathbf{r b e r}$ to Phyllotheca australis.

(4) Geol. Wilkes Explor. Exped., vol. x, 1849, pl. xiii, fig. 6; pl. xir, fig. 1.

(5) The Glossopteris Flora. 1905. pl. ii, figs. 7, 8, p. 17.

(6) Rec, Geol. Surv. N. S. W., ol, iv, 1896, pl. xviii, figs. 4, 5. 
Como se vê na photographia pl. V.Fig.5, o aspecto da haste deste typo é distinctamente calamariano. No specimen representado na figura apparece um nó na extremidade do fragmento e um outro $6^{\mathrm{cm}}$ mais abaixo. A maior parte das nervuras salientes são continuas em seu alinhamento nos nós, embora algumas, se verifique claramente serem neste assim como em outros exemplos irregulares e muitas vezes distinctamente alternas no mesmo nó. O nó é por si mesmo muito compacto, os fios alternando passam abruptamente pelo nó, até o feixe proximo. os traços de nervuras algumas vezes apparecem como pontos diminutos, perto da linha transversal do nó.

Ha muito pouca evidencia tanto de constricção accentuada do nó, como de dilatação dos internós.

Os fragmentos de haste como os que se veem nas figs. 5 e 3 , não apresentam caracteres pelos quaes possamos distinguil-os das hastes de Calamites do rorte, em identico estado de conservação, e as tentativas de referencias á Phyllotheca feitas neste relatorio, se baseiam unicamente na falta de verdadeira folhagem do typo de Asterophyllites, ou Annullaria das camadas desta idade, no continente SulAmericano, e em sua associação nas rochas com os verticillos de Phyllotheca. Muito pouco auxilio se encontra na consulta das estampas das hastes de outras regiũes da provincia Gondwana.

Destas, comtudo, deve-se fazer menção especial dos specimens illustrados, por Zeiller (1) como pertencentes provavelmente a Schizaneura gondwanensis do grupo Raniganj, da bacia South Rewah, por Seward (2) como Phyllotheca sp. do Transwaal e por Feistemantel como Pinyllotheca australis (3) das camadas New Castle, New South Wales, e como Schizoneura Gondwana do Damuda Indiano(4). Outros fragmentos comparaveis têm sido illustrados por varios autores como "hastes Equisitaceas" ou troncos de Phyllotheca, ou Schizonura.

A figura 4 de Zeiller, a estampa de Seward, e o desenho de Feistmantel representando o fragmento da Australia, parece que não apresentam ponto algum de differença de algumas hastes brasileiras sendo exacta a sua semelhança.

Estes concordam tambem com os fragmentos ha pouco publicados por Nathor'st, das ilhas Falkland (5). Devemos concluir que as identi-

(1) Pal. Indica n. s, vol. II. n, 1, 1902. p. Vl, fì, 3, 4 .

(2) Quart. Journ. Geol. Soc. vol. LHl, 189\%, p. XXIV fig. 1.

(3) Mem. Geol. Surv, N.S.T . Palaent, , n, 3, p, XlV, fig. 5.

(4) Fl. Gondwana System, vol. 111. p. 2, pl, Vll A. fig. 1a.

(5) Bull. Geol. Inst. Upsala. rol. VII, 1906, p. 73. 
As shown in the photograph, pl. V, Fig. 5, the aspect of the stem of this type is distinctly Calamarian. In the illustrated specimen a node occurs at the top of the fragment and another $6 \mathrm{~cm}$. lower. Most of the ribs are continuous in their alignment at the nodes, though some are clearly shown in this as well as other examples to be irregular and often distinctly alternate at the same node. The nod itself is very compact, the alternating strands passing abruptly across to the proximate bundles. The nerve traces sometimes appear as minute points close to the transverse line of the node.

There is very little evidence of marked constriction of the node, nor of inflation of the internodes.

The stem fragments, like that shown in Figures 5 and 3 presenl no characters by which to distinguish lhem from stems of the Northern Calamites in a similar state of preservation, and their tentative reference in this report to Phyllotheca is based merely on the absence of true Asterophyllitean or Annularias foliage from the beds of this age in the South American continent; and on their association in the rock with the verticils of Phyllotheca. Very little aid is to be drawn from the consultation of the illustrations of stems from other regions of the Gondwana province.

of the latter, particular mention should however, be made of the specimens illustrated by Zeiller (1) as probably belonging to Schizoneura gondwanensis from the Raniganj group, South Rewah basin, by Seward (2) as Phyllotheca austratis (3) from the Newcastle beds, New South Wales and as Schisoneura gondwanensis from the Indian Damuda. (4) Other comparable fragments have been illustrated by various authors as either "Equisetaceous stems» or trunks of Phyllotheca or Schizoneura.

Zeiller's figure 4, Sewar'd's illustration, and Feistmantel's draving of the Australian fiagmenl appear to offer' no point of differance from some of the Brazilian stems, the agreement being exact.

The latter agrees also with the fragments just published by Nathorst, from the Falkland Islands (5). We must conclude either

(1) Pal. Indica, n. s., vol. II, no. 1,1902, pl. vi figs. 3, 4.

(2) Quart. Jour. Geol. Soc., vol. liii, 1897, pl. XXIV fig. 1.

(3) Mem. Geol. Surv. N. S. W., Palaeont., no. 3, pl. XIV, fig. 5.

(4) Fl. Gondwana Syst., vol. III, pt. 2, pl. viiA, fig. la.

(5) Bull. Geol. Inst. Upsola, vol. VII, 1906, p. 73. 
fícações das liastes por estes auctores sejam em parte erroneas, ou que como observa Seward, (1), seja impossivel definir-se os caracteres distinctivos de Phyllotheca e Schizoneura na falta de folhas.

o material brazileiro é, comtudo, especialmente inteessante, visto que dois dos specimens apresentam bases de haste ou de ramos. O que se vê na figura 3 , apresenta um fragmento da base da haste com cerca de $10 \mathrm{~cm}$. de comprimento. A base, que não está bem a vista na photographia, é conica, com bordas fortemente convexas e uma ponta obtusa. O entrenú distincto, mais baixo, mede apenas $3,5 \mathrm{~cm}$. de comprimento, tendo as nervuras salientes $2,25 \mathrm{~cm}$. de largura. Observam-se nove intervallos que se alongam successivamente. De um dos nós, a meio caminho para a parte superior do fragmento, um grande ramo ergue-se á direita com a base alargandose rapidamente de um ponto de inserção um tanto estreito, de fórma calamariana typica. As nervuras salientes deste ramo, cuja largura total não se vê, é de pouco mais de $2 \mathrm{~mm}$.

A fórma conica da base das hastes, ou ramos vê-se melhor em um fragmento menor na fig. 4. Alli como em muitos fragmenlos de grandes hastes, temos uma fórma de matriz, comparavel directamente aos tuberculos das nervuras, ás formas calamarianas do Norte, como por exemplo á commum Calamite Suckowi.

A relação estreita da Phyllolheca, com o material das collecções de typo calamarianos, é mais notada pela estructura de seu estrobilo que se achou ser semelhante ao de Calamostachys.

$\mathrm{E}^{3}$ possivel que o fino fragmento de haste pl. V. fig. 6. determinado em duvida, como de Schizoneura possa realmente pertencer ao mesmo genero que as grandes hastes que vimos de descrever.

Localidade: Nordeste de Minas, Santa Catharina, Camadas 55 metros acima do granito, ou 225 metros abaixo do schisto preto de Iraty. Lots. 3586 e 3921.

\section{Shizoneura}

Schimper e Mougeot. Monog. pl. foss. gres bigarre Vosges 1844

$$
\text { p. } 48 \text {. }
$$

O genero Schizoneura contem formas equisetaccas ramosas, especialmente caracterisadas pela completa união das folhas em una bainha

(1) Loc, cit. D. 355. 
that the identifications of the stems by these authors were in part erroneous, or that, as Sevvard (1) remarks, it is impossible to define the distinctive characters of Phyllotheca and Schironeura in the absence of leaves.

The Brazilian material is especially interesting, however, since two of the specimens offer stem or Jranch Jases. That shown in Fig. 3 exhibits a basal stem fragment about $10 \mathrm{~cm}$ in length. The base, which is not well shown in the photograph, is conical, with strongly convex borders and a blunt point. The lorvest distinct internode is but $3.5 \mathrm{~mm}$ in length, the rilss being $2.25 \mathrm{~mm}$ in vidth. Nine successively elongating intervals are to be ouserved. From one of the nodes, midway up the fragment, a large branch arises on the right, with base broadening out rapidly flom a lather narrow point of connection in typical Calamarian form. The ribs on this branch, the full width of whichl is not seen are a little more than $2 \mathrm{~mm}$ broad.

The conical form of the base of the stems or branclies is better shown from a smaller fragment in Fig. 4. Here, as well as in many of the fragments of large stems, we have a form of cast, directly comparable, even to the nerve tubercles, with the Northern Calamarian forms, such, for example, as the common Calcmites Sucleowii.

The close relationship of Phyllothece to the typical Calamarian stock is further shown by the structure of its strobilus which has been found to be similar to that of Calamostachys.

It is possible that the slender stem fragment, Pl. V, Fig. 6, placed with doubt under Schizoneura may really belong to the same genus as do the large stems just described.

Localities: Northeast of Minas, Santa Catharina. Beds 55 meters above the granite, or 225 meters below the Iraty black shale, Lots 3586 and 3921.

\section{Schizoneura}

Schimper and Mougeot, Monogl. pl. foss. gres bigarré Vosges, 1844, p. 48 .

The genus Schizoneuracontains ramose Equisetaceous forms specially characterized by the complets union of the leaf, and the

(1) Loc. cit., p. 3:5, 
sem dentes liv'es, no primeiro periodo da folha e a fissuração da mesma em um periodo posterior, sendo usualmente a divisão em dous membros, ou grupus lineares-ovaes plurinerves, embora as vezes as divisões maiores se devidam em parte pelo menos, em folhas individuaes uninerves e aber'tas. Nas divisões multinerves, as nervuras convergem ao passar para o apice.

A haste de Schizoneura é semelhante a de Asterophyllites, embor'a se diga que as nervuras não alternam usualmente nos nós. $E^{\prime}$ duvidoso se aquella pode se distinguir, em muitos casos, dos ramos de Phyllotheca.. Os detalhes essenciaes da espiga fertil, cue é terminal, ainda não estão con hecidos.

Tanto quanto é sabido, o genero Schizoneur'a estava confinado á epoca Permo Carbonifera á provincia floral Gondwana inferior, mas no Trias o genero torna-se casmopolita.

\section{Shianeura? sp. \\ Pl. V, fig 6.}

o fino fragmento de haste que se vê na photographia pl. V. fig. 6 é collocado neste genero como lentativa e com muito duvida, somente por causa de sua grande semelhança com hastes parecidas de outras regiões da flora do Sul encontradas (1), ou reunidas com as folhas deste genero, ou em tal associação e com tal concordancia de caracteres de modo a garantir sua referencia ao mesmo typo generico. o nosso epecimen apresenta cinco nós, em intervallos de cerca de $1,5 \mathrm{~cm}$, sendo mais curtos os entre nús superiores. Ila dez nervuras na largura, no nó mais baixo. As nervuras são relativamente largas, um tanto chatas ${ }_{1}$ em alguns casos, altermadas nos nós, embora em muitos sejam continuas em posição. O aspecto da haste achatada não dilatada nos nós, nos dá uma ideia de cylindro levemente engrossado. Impressões lineares orladas de cada lado, por linhas finas marcam a passagem dos canaes. As cicatrizes redondas das folhas são mais estreitas que as nervuras e inconspicuas.

o fragmento que tenho em mão não offerece caracteres pelos quaes possamos differencial-o de Annularia ou Asterophyllites. Mesmo a continuidade predominante das nervuras salientes nos nós, tem muito pouca importancia. Os tuberculos das folhas das hastes Norte-America-

(1) Veja-se Feistmantel Fl. Gondw. Syst. v, 1. III 2, pl, IY A-pl. VIII A. 
fission of this sheath at later stage, the division being usually in two opposite linear-oval plurinervate members or groups though sometimes the larger divisions become, in part at least, split into individual linear, uninervate, spreading leaves. In the multinervate divisions the nerves converge in passing to the apex.

The stem of Schizoneurd is similar to that of Asteroplyyllites, though the ribs are said usually not alternate at the nodes. It is doubtful if it can in many cases be distinguished from the branch of Phyllotheca. The essential details of the fertile spike which is terminal, have not yet been made known.

So far as known, Schizoneur $\alpha$ was, in Permo-Carboniferous time, confined to the lower Gondwana floral provinee; Jut in the Trias the genus Jecame cosmopnlitan.

\section{Schironeura? sp. \\ Pl. T, Fig, 6.}

The slender stem fragment shown in the Photograph, Pl. Y, Fig. 6, is tentatively and with much doubt placed in this genus only on account of its close agreement with similar stems from other regions of the Southern flora (1) found either in union with the leaves nr the genus or in such association and with such agreement of characters as to warrant their reference to the same generic type. ()ur specimen presents five nodes at intervals of about $1.5 \mathrm{~cm}$, the upper internodes heing shorter. It is ten ribs in width at the lowest node. The ribs are relatively broad, rather flat, and in some instances alternate at the nodes though in most cases they are continuous in position. The aspect of the flattened stem, which is not cnlarged at the nodes, suggests a slightly thickened cylinder. Lineate moulds hordered on each side by fine lines mark the passage of the canals. The rounded leaf scars are narrower than the ribs and inconspicuous.

The fragment in hand offers no characters by which to differentiate it from Ammularia or Asterophyllites. Even the prevailing continuity of the costation at the nodes is of little weight. The leaf tubercles of the North American stems, descriled by Lesquereux as

(1) Sco Feistmantel, Fl, Gondwana Syst.,, 1 . III pt. 2, pl. iv A-pl. viii A. 
nas descriptas por Lesquereux como Annullaria (Polystachya) tuberculata ( Sternb) Lx (1) são tão grandes e proeminentes, como as dos specimens brasileiros.

Localidade : Nova Estrada perto deMinas, Santa Catharina, cerca de 135 metros acima do granito, ou 145 metros abaixo do schisto preto de Iraty. Lot. $392 ?$.

\section{LYCOPODIALES}

\section{Lycopodiopsis}

Renault, Comptes Rendus, vol. CX, 1890, p. 809

Lycopodiopsis Derbyi Ren.

pl. n. Figs. 11-1la.

1890 - Lycopodiopsis Derbyi Renault, Comptes Rendus Tol. CX, p. 809, Renault Bull. Soc. Hist. nat. Antun vol. III - 1890 p. 809 .

1898 - Lepidodendron Derbyi (Ren.) Zeiller, Comptes Rendus, vol. CXXXII, p. 245 ; Arber, The Glossopteris Flora $1905, \mathrm{p} .159$.

Cortex espesso com mamelöes foliaceos proximos, redondos ovaes, ou redondos, collocados, quasi achatados, sobre a superficie do cortex, ou lecemente deprimidos, muitas veraes agglomerados de modo a produnir formas polygonaes, quasi chatos, lisos e ligeiramente annelados nobordo, cicatri:es das follhas pequenas no meio, ou pouco acima do ccntro do mameläo da folha, redondas, comprehendendo um annel. espesso, saliente com cerca de um terço sobre o diametro do mamelão, incluindo um unico vestigio de nervura punctiforme, superficie do cortex marcada por impressões um tanto distantes, longitudinaes, rinombo-fusiformes obliquas correspondendo à passagem das nervuras para as cicatrias das folhas, haste de estructura centripeta, parerendo-se com a de Lepiclodendron, folhas e fructos desconhecidos.

O aspecto do unico fragmento representando esta especie na collecção, é tão distinctamente egual ao de uma Stigmaria com cicatrizes muitojuntas, que porleria promptamente ser referida áquelle genero,

(1) Lezquereux. Coal Flora val. III, 1881, p.723 pl. LXXXIX fig. 1, 2. 
Annulerice (Polystachia) tuberculata (Sternb.) Lx., (1) are fully as large and prominent as in the Brazilian specimen.

I.ocality : Nova Estrada near Minas, Santa Catharina. About 135 meters above the granite, or 145 meters below the Iraty black shale, Lot. 3929 .

\section{LYCOPODIALES}

\section{Lycopodiopsis}

Renault, Comptes Rendus, rol. rx, 1890, p. 809

Lycopodiopsıs Derbyi Ren.

pl. V, Figs. 11, $11 a$.

1890. Lycopodiopsis Derby, Rənault, Comptes Rendus, vol. $\mathrm{cx}$, p. 809 ; Renault, Bull. Soc. hist. nat. Autun, vol. III, 1890, p. 809.

1898. Lepidodendron Derbyi (Ren.) Zeiller, Comptes Rendus, vol. cxxvii, p. 245; Arber, The Glossopteris Flora, 1905 , p. 159.

Cortex thick, with close, round oval to round leaf cushions placed nearly flat on the surface of the cortex or slightly depressed, often crovded so as to give rise to polygonal forms nearly flat, smooth and usually annulate at the border leaf, scars small, at or a little above the middle of the leaf cushion, round comprising a thick raised ring, about one third the diameter of the cushion, enclosing a single punctiform nerve trace; internal surface of cortex marked by rather distant longitudinal rhombi-fusiform oblique impressions corresponding to the passage of the nerves to the leaf scars; stem structure centripetal, closely resembling that of "Lepidodendron"; leaves and fruit unknown.

The aspect of the single fragment representing this species in the collection is so distinctly like that of a Stigmaria with very close scars that it might readily he referred to that genus but for the charac-

(1) Lesquereux, Coal Flora, vol. IIT, 1384, p. 723, pl. LXXXIX, fig. 1, 2. 
apenas pelos caracteres do cortex interno e que se veem nos fragmentos enviados pelo Dr. Derby ao fallecido professor B. Renault.

o largo disco redondo, ou redondo oval descripto pelo professor Renault como mamelão da folha, é annulado no bordo, formando uma zona achatada em torno da cicatriz da folha que com seu pequeno circulo de paredes espessas contornando o minusculo vestigio de nervura é notavelmente semelhante ao vestigio da nervura e á bainha da cicatriz de Stigmarix. Em um dos nossos specimens descriptos pelo professor Renault a cicatriz da folha não é tão redonda como a que se vê na fig. 11, estampa V das nossas collecções, ao passo que os mamelões das folhas são quasi contiguos. Em um outro exemplo descripto pelo mesmo auctor as cicatrizes das folhas ș̃o ligeiramente exagonaes como resultado de compressão.

O specimen cm mão é de um ramo menor e mais novo que os que estão figurados no trabalho de Renault. A haste ć um pouco mais que meio achatada, tendo a impressão cerca de $1 \mathrm{~cm}$. de espessura. Veem-se bem as cicatrizes em diversos pontos da photographia. E' caracteristico do typo o grande angulo de quasi 90 gráos que fazem as duas espiraes da phyllotaxe, Por estas feições Lycopodiopsis Derbyi concorda com certas formas lepidophiticas do Devoniano medio da America do Norte.

A estructura interna da haste de Lycopodiopsis é descripta algum tanto detalhadamente pelo professor Renault, que interpretou o cylindro lenhoso como discontinuo e apenas pouco differente do de Lycopodium, porém, o professor Zeiller, que examinou o material addicional da mesma região, enviado pelo Dr. Derby, refere que o cylindro vascular é continuo e estreitamente semelhante ao do Lepidodrendon Harcourtii. 0 exame das feições superficiaes de seus specimens em que o cortex exteriol não parece ter sido bem conservado, convenceu o professor Zeiller de que as especies pertencem a Lepidadendron a emergencia do vestigio de nervura, sendo como a de Lepidodendron selaginoides. As differenças nos caracteres dos mamelões das folhas entre Lycopodiopsis e Lepidodendron são explicadas por Zeiller como sendo devidas á decorticação parcial no typo brasileiro.

Não posso concordar com esta opinião.

Os caracteres dos chamados mamelões das folhas, são tão claros, a superfirie tão plana, o contacto com a superficie circumdante da haste tão bem marcado pelo bordo annelado; de facto toda a combinação de caracteres é tão differente da de qualquer Lepidodendron 
ters of the inner cortex and stem revealed in the fragments sent by Doctor Derby to the late Professor B. Renault.

The broad, round, or oval-round disc described by Renault as the leaf cushion or bolster is annulate at the border, and forms a flat zone about the leaf scar which, with its small thickwalled ring surrounding the minute nerve trace, is strikingly similar to the nerve trace and sheath in the Stigmarian scar. In one of the specimens described by Renault the leaf scars are not so round as in that shown in Fig. 11, Plate V, in our collections, while the leaf cushions are nearly contigous. In another example described by the same author the leaf scars are slightly hexagonal as the result of pressure.

The specimen in hand is from a smallel' and younger branch than those figured in Renault's paper. The stem is a little more than half-flattened, the cast being about $1 \mathrm{~cm}$. in thickness. The scars are well shown at several points in the photograph. The wide angle, nearly 90 degrees, between the two directions of the spirals of the phyllotaxy, is characteristic of the lype. In this feature Lycopodiopsis Derbyi agrees with certain Lepidophytic forms from the Middle Devinian of North America.

The internal structure or the stem of Lycopodiopsis is described at some length by Renault, who interpreted the woody cylinder as discontinuous and but little different from that of Lycopodium; but Professor Zeiller, who has examined additional material sent by Doctor Derby from the same region, reports that the vascular cylinder is continuous and closely similar to that of Lepidodendron Harcourtii. The examination of the superficial features of his specimens, in which the outer cortex does not seem to have been well preserved, convinced Professor Zeiller that the species belonged to Lepidodendron, the emergence of the nerve trace heing like that in Lepidodendron selaginoides. The differences in the characters of the leaf cushions between Lycopodiopsis and Lepidodendron are explained by zeiller as being due to partial decortication in the Brazilian type.

In this opinion I can not agree.

The characters of the so called leaf cushion are so clear, the surface so smoth, the contact with the surrounding surface of the stem so well marked by the annulate border; in fact, the whole combination of characters is so different from that of any par- 
decorticado que sempre me despertou a attenção de fórma que sou obrigado a considerar os generos de Renault como validos.

Não parece tambem impossivel que o material parcialmente decorticado enviado ao professor Zeiller possa ter contido specimens mal conservados de Lepidodendron Pedroanum, já conhecido do sul do Brazil, ou algumas outras formas do genero ainda não reconhecidas por seus caracteres superficiaes. Ha, comtudo, logar para duvidar-se si a superficie descripta como mamelão da folha corresponde exactamente ao "mamelão" da folha de Lepiclodendron ou Sigillaria.

Lsta queștău púde ser decidida unicamente pela verificação do caractel e modo de inselção das proprias folhas de Lycopadiopsis de que Lycopodiopsis Derbyi é o typo generico e creio que é uma das plantas caracteristicas da flora Gondwana mais antiga. Alguns fragmentos que são em parte tão semelhantes ás nossas especies, de fórma a melecerem a mais estreita e cuidadosa comparação, foram descriptos e illustrados por sewar'd de Vereeniging (1), no Transwaal, como Bothrodendion Leslii. Pelo exame das illustrações de Seward, estou disposto a acreditar que seus specimens que elle refere á Bothrodendron, sómente com duvida, podem ser provavelmente referidos ao genero brasileiro. O professor Arber (2) chama insistentemente a altenção tambem para a semelhança entre os specimens do Transvaal e alguns fragmentos da India referidos em duvida a Rhipidopsis por Feistmantel (3).

Deveria se clıamar a attenção para o lar'go fragmento axial da região do Petchora da Siberia, collocado por Schmalhausen (4) em Rhipdopsis ginkgoides, mas que talvez seja congenere do typo brusileiro. Os specimens originaes de Lycopodiopsis Derbyi, deu o Dr. Derby (5) como procedentes de Piracicaba, no Estado de S. Paulo, onde estavam associados com madeiras fosseis silicificadas, de coniferas, Cordaites, fragmentos de Psaronius e com restos do reptil Stereosternum tumidum. Uma camada de carvão terroso diz-se que existe proximo do horizonte destes fosseis. Destas notas dadas pelo professor Renault, deduzo que o horizonte dos specimens enviados pelo Dr. Derby está

(1) Ann. S, Afr. Mus, vol. IV p. 1. 190:3, p. 87, pl. XI, figs. 1, 4, 5, 6. Veja-se tambem Arber. Flora Glossopteris, p. 167, fig. 36 .

(2) Op. cit. p. 168.

(3) Fl. Gond. Syst. vol. III, pt. 2, p. 124, pl. XLVII A, figs. 5-7.

(4) Beitr. z. Jura. Flora de Ptschora-Landes 1879, pl. VIII, fig. 12.

(5) Veja Renault, Bull, Soc. hist. nat. Autun, vol. 1II, 1890, p. 109, nota. 
tially decorticated Lepidodendron that has ever come 10 my attention, that I am obliged to regard Renault's genus as valid.

It seems not impossible, also, that the partially dacorticated material sent to Professor Zeiller may have included poorly preserved specimens of Lepidodendron Pedrocnum, already known from southern Brazil, or some other form of the genus not yet recognized by its surface criteria. There is, however, room for doubt as to whether the surface described as the "leaf cushion" corresponds exactly to the leaf cushion of the Lepidodendron or siffllaria.

This question can le answered only by ascertaining the character and mode of attachment ol the leaver themselves. Lycopodiopsis, of which Lycopodiopsis Derbyi is the generic type, is, I believe, one of the characteristic plants of the older Gondwana flora. Some fragment's which are in part so similar to our species as to deserve the closest and most careful comparison have been described and illustrated by Serard (1) from Vereeniging, in the Transvaal, as Bothrodendon Les7ii. From the examination of Seward's illustrations 1 am disposed to believe that his specimens, whinh he refers Bothrodendron only with doubt, are probably referable to the Brazilian genus. Professor Arber (2) very pertinently calls attention also to a similarity between the Transvaal specimens and some fragment's from India doulutfully referred liy Feistmantel (3) to Rhipidopsis.

Attention should also be called to the broad axial fragment from the Petchora region of Siheria, placed ly Schmalhausen (4) in Rhipidopsis ginkgoides, but which is perhaps congeneric with the Brazilian type. The original specimens of Lycopodiopsis Derby were reported by Doctor Derby (5) to have come from Piracicaba in the state of Sũo Paulo, where they were associated with silicified fossil roods of conilers, Cordaitrs, fragments of Psaronius, and with remains of the reptile, Stereosternum tumidum. A bed of earthr coal is said to lie near the horizon of these fossils. From these notes given by Renault I infer that the horizon of the specimens sent ]y Derlyy is pro-

\footnotetext{
(1) Ann. S. Alr. Mus., vol, iv, pl. 1, 1903, p. 87, pl, xi, fig. 1, 4, 5, 6. See also Arlber. The Glossopteris Flora, p. 167, $\mathrm{ig}$. 36.

(2) Op. cit., p. 168.

(3) Flora Gondwana Syst, v. III pt. 2. p. 121, pl. xlviiA, figs. 5-7.

(4) Beitr. z. Jura-Fl. d. Petschora-Landes, 187!, pl. riii, fig. 12.

(5) See Renault, Bull. Soc, hist. nat. Iut un, vol. iii, 1890. p. 109, note. 5560 
provavelmente proximo do do specimen que se vê na fig. 11, ou não muito longe do schisto preto de Iraty.

Localidade: Bofete. S. Paulo, horizonte cerca de 155 metros acima do schisto preto de Iraty.

\section{Lepidodendron}

Sternberg. Fl. d. Vorwelt. vol. I, fasc. 1; 1820, p. 25

n genero Lepidodendron abrange um grupo de Lepydophitas arborescentes, cujos typos mais affins da flora actual encontram-se nas Lycopodiaceas. As arvores, que algumas vezes attingiram grande tamanho, são dichotomas em divisões iguaes ou desiguaes. Os pequenos ramos sendo fortes e rigidos em algumas especies e graciosamente esbeltos e pendentes em outras. A maior parte da espessura do tronco é composta pelo cortex muito espesso, que é um tanto complicado na sua structura. o eixo interno consiste em um cylindro de lenho primario, ou centripeto com ou sem medulla párenchymatosa. Em muitas especies desenvolveu-se do lado externo do lenho primario em algumas phases do crescimento da arvore, um cylindro de lenho secundario exogeneo, consistindo em vasos espiraes ou reticulados, a que se succedem tracheides scalariformes, algum tanto irregularmente separadas pelos raios medulares. A casca dividida em cortex interno e externo, comprehendendo uma periderme que marca outra linha de desenvolvimento oxogeneo.

Em muitos restos comprimidos e carbonisados de Lepidodendron os cortices, especialmente o cortex externo, constitue a principal materia residual e é esta que usualmente fórma a bainha fina e carbonacea que envolve as impressões, em gres, de troncos erectos.

As feições essenciaes pelas quaes o genero e as especies de Lepidodendron são reconhecidas, são as fórmas rhomboides dos mamelões que revestem o cortex externo, e que sustentam as folhas ou as cicatrizes destas. Estes mamelẽes são rhomboides e mais ou menos alongados, no sentido longitudinal, de modo a se tornarem algumas vezes fusiformes. São quasi sempre proeminentes, ás vezes projectando-se ligeiramente para cima, e, ou são marcados por uma cinta longitudinal interrompida pelas cicatrizes das folhas, ou são um tanto furtemente convexos e frequentemente transversalmente enrugados. A cicatriz da folha está proxima do meio, ou na metade superior das dos mamelões é transversalmente rhomboide com angulos lateraes 
bably near that of the specimen shown in Fig. 11, or not far from the Iraty black shale.

Locality: Bofote, São Paulo. Horizon about 155 metel's above the Iraty black shale.

\section{Lepidondendron}

Sternberg, Fl. d. Vorwelt, vol. I, fasc. 1, 1820, p. 25.

The genns Lepidodendron includes a group of arborescent Lepido. phytes whose nearest relatives in the flora of today are found in the Lycopodiaceo. The trees, which sometimes attained great size, are dichotomous in equal or unequal divisions, the branchlets being stout and rigid in some species and gracefully slender and drooping in others. The greater part of the thickness of the trunck is comprised of the very thick cortex which is somewhat complicated in structure. The inner axis consists of a cylinder of primary or centripetal wood, with or without a parenchymatous pith. In most of the species there is developed, external to tho primary wood, at some stage in the growth of the tree, a cylinder of secondary, exogenous wood consisting of spiral and reticulate vessels succeeded by scalariform tracheides, somewhat irregularly parted by medulla'y rays. The bark is divided into an inner and an outer cortex, embracing a periderm which marlis another line of exogenous development.

In most flattened and carbonized remains of Lepidodend'on the cortices, especially the outer cortex, constitute the chief residual matter, and it is this which usually forms the thin carbonaceous sheath enveloping the sandstone casts of uprigth trunks.

The essential features by which the genus and species of Lcpidodendron are recognized are those of the rhomboidal leaf cushions which support the leaves or leaf scar's. These leaf cushion are rhomboidal and more or less elogated in the longitudinal sense so as sometimes to become fusiform. They are usually prominent, sometimes projecting slightly upward, and are either marked by a longitudinal crest which is interrupted by the leaf scar, or they are somewhat strongly convex and frequently transversely wrinkled. The leaf scar is placed near the middle, or in the upper half of the leaf cushions and is tranversely rhomboidal, with acute lateral angles. It is marked, at or above the level of its greatest hurizontal diameter, by three, usually 
agudos. E' mar'cada acima ou abaixo do nivel do seu maior diametro horizontal, por tres cicatriculas, quasi sempre pontudas, das quaes a do centro representa a secção transversal da nervura mediana da folha, as duas cicatriculas lateraes (parichnos) correspondem á passagem, das partes lacunosas e parenchymatosas, que se originam no cortex interno, e se communicam pelos parichnos com as zonas stomatiferas da folha. Em ambos os lados do angulo inferior da cicatriz da folha, e constiguos a este, ha em muitas especies do genero duas pequenas impressĩes ovaes chamadas algumas vezes appendices.

Segundo Patonié, estas impressões são pontos em que os tecidos transpiratorios lacunosos se põem em contacto com a epiderme que provavelmente, não é mais que uma membrana apparentemente dilacerada em muitos casos. Logo acima da cicatriz da folha o mamelão é entalhado por uma pequena cova que se verificou conter uma ligula homologa da de Selaginella que vive actualmente.

As folhas de Lepidodendron são as vezes longas, delgadas, e como as das gramineas, rigidas, e outias vezes curtas, pequenas e curvadas romo as de varios genros coniferos que vivem actualmente. São marcadas pela impressão do traço da nervura, ou nervura mediana, que é carenada na superficie dorsal e á pequena distancia de ambos os lados da nervura mediana, por um sulco estreito longitudinal que contem os stomates.

A fructificação do Lepidodendren consiste em cones mais ou menos alongados ou strobilos conhecidos como Lepidostrobus. Os sporos, tanto os microsporos como os megasporos, se encontram em. sporangias de paredes finas, cada uma dellas ligada longitudinalmente a base estreita de uma das bracteas ou escamas em espiral, ou embricadas. Sem os caracteres externos dos mamelões e cicatrizes das folhas em muitos casos é impossivel determinar as especies de Lepidodendron.

Quando falta a epiderme e cicatrizes das folhas, mas os tecidos subjacentes, ou esponjosos dos mamelões existem o fossil é ás vezes conhecido por Bergeria ou, si resta pouca cousa do tecido esponjoso, por Aspedaria. Quando falta o cortex em grande extensão o estado de conservação é muitas vezes o que foi descripto como Knorria. Os Lepidodendron eram cosmopolitas em sua distribuição e se estendem na flora do norte do Devoniano inferior ao Permiano inferior. Na flora Permo-Carbonifero do Sul, são definitivamente reprssentados somente na Argentina e Brazil, embora tenha sido referido, sujeito a discussão, a existencia do genero na serie Karoo na Africa do Sul. 
punctate, cicatricules, of which the middle represents the cross section of the median nerve of the leaf the two lateral cicatricules (parichnos) corresponding to the passage of the lacunose parenchymatous tracts, which originate in the inner cortex and communicate by way of the parichnos with the stomatiferous zones of the leaf. On either side of the lowel angle of the leaf scar and contiguous to the latter there are, in most species of the genus, two small oval imprints, sometimes called appendages.

These, according to Potonie, are points at which the lacunose transpiratory tissue comes in contact with the epidermis which is here, perhaps, hardly more than a mem])rane apparently ruptured in most instances. Just above the leaf cushion is indented by a small pit which is found to cotain a ligule homologous with that of the living Selaginella.

The leaves of Lepidodendron are sometimes long, slender, and grass-like, thougt rigid; at other short, small, and curved like those of various living coniferous genera. They are marked by the impression of the nerve trace, or midrib, which is carinate on the dorsal surface; and, at a little distance on either side of the midrib, bi a narrow longitudinal dorsal furrow which contains the stomata.

The fructification of Lepidodendron consists of more or less elongated cones or strobili known as Lepidostrobus. The spores, both microspores and megaspores, are contained in thinwalled sporangia, each of which is longitudinally attached alonis the narrowed base of one of the spirally arranged and imbricated bracts or scales. Without the external characters of the leaf cushion and leaf scars it is impossible, in most cases, to determine the species of Lepidodendron.

Where the epidermis and leaf scar are wanting, but the subjacent or spongy tissue of the bolster remains, the fossil is sometimes known as Bergeria, or if but little of the spongy tissue is left, Aspidaria. When the cortex is largely removed the condition of preservation often is that described as Knorria. The Lepidodendra were cosmopolitan in their distribution and range in the Northern flors, from the lower Devonian into the lower Permian. In the southern Permo-Carboniferous flora it is definitely represented only from Argentina and Brazil, though there liave been records, subject to question, of the genus from the Karoo series, in South Africa. 


\section{Lepidodendron Pedroanum (Carr.) Zeiller}

1869 - Flemingites Pedroanus, Carruthers Geol. Mag. Vol. VI, p. $15 \mathrm{~L}$ pl. V; Hartt Geol, and Phys. Geogl . Brazil 1870, p. 521 ; Zeiller Comptes Rendus vol. CXXI 1895, p. 962 Zeiller Bull. Soc. Geol. lir. (3) vol. XXIII 1896, p. 607, 1). VIII figs. 1-4; Zeiler Comptes Rendus vol. CXXVII, p. 246;D. White Science Vol. XXI 1905, p. 700 ; Arher The Glossopteris Flora 1905, p. 156, pl. I, fig. 2.

1896 ? - Lepidodendron Sternber'yii Brongn., Bodenbender, Zeitschr, d. Deutsch, geol. Gessel. Vol. XLVIII opp. p. 770.

Mameloes las folhas proeminentes, projectando-se levemente para cima, rhomboides, (is veres largamente rhomboides), juntos, muitas vezes arredondados nos angulos lateraes, não carenados sob a cicatriz da follha, cicatriz de follua collocada em um ponto a tres quartos do comprimento do mamelão, relativamente grande nas hastes e ramos mais maduros, muito largamente rhomboides, lateralmente ayudos, os angulos superiores einferiores bem redondos, cicatriculas punctiformes, o parichnos um pouco distante.

Este, é o primeiro ty po lepidophy tico provindo do Brazil, está repreesentado nas collecções por diversas impressões, em fragmentos chatos de carvão em muito baixo relevo, e consistem na maior parte em moldes ligeiramente encrustados com camadas de carvão natural de madeira, pulverulento, ou "mãe do carvão". Um dos specimens apresenta uma phase Knorria exactamente semelhante a illustrada photographicamente pelo prof. Zeiller, na estampa 8, fig. $l_{k}$, de seu valioso trabalho "Note sur la flore fossile des gisements huilliers de Rio Grande do Sul, Brésil meredional impresso no $23^{\circ}$ volume do "Bulletin de la Societé de Geologie de France" (1).

$\mathrm{Ha}$ nas collecç̄̃es organisadas pelo $\mathrm{Dr}^{2}$. Thite duas placas cobertas com pequenas folhas estreitas exactamente como as que se reem nas figuras 5 e 6 da estampa acima citada. Não obstante a posição dos sulcos stomatiferos tão perto do bordo, caracter que obrigou o prof. Zeiller a consideral-as como folhas de Sigillaria, estou disposto a referil-as a folhas de Lepidodendron Pedronnum. Verificou-se que as cicatriculas lateraes as parichinoianas da cicatriz da folha,

(1) Paris 189j, pp. 6)1-629, VIIL-X. 
Kepidodendron Pedroanum (Carr.) Zeiller

1869 - Flemingites Pedroanus Carruthers, Geol. Mag.. vol. vi, p. 151, pl. v: Hartt, Geol. and Phys. Geogr., Brazil, 1870, p. 524; Zeiller, Comptes Rendus, vol. cxxi, 1895, p. 962 ; Zeiller, Bull. Soc. Géol. Fr., (3) vol. xxiii, 1896, p. 607, pl. viii, figs. 1-4; Zeiller, Comptes Rendus, vol. cxxvii, p. 246; D. White, Science, vol. Xxi, 1905, p. 700 ; Arber, The Glossopteris Flora, 1905, p. 156, pl. fig. 2 .

1896 ? - Lepidadendron Sternbergii Brong., Bodenbender. Zeitschr. d. Deutsch. geol. Gesell., vol. xlviii, opp. p. 770.

Leaf cushions or bolsters prominent, and projecting slightly upward, rhombic, sometimes broadly rhombic, close often "ounded at the lateral angles, not carinate below the leaf scar ; leaf scar placed at a point about three fourths of the lenght of the bolster, relatively large on the more mature stems and branches, very broadly rhomboidal, laterally acute, the upper and lower angles well rounded; cicatricules punctiform, the parichno a little distant.

This, the first Lepidophytic type to be reported from Brazil, is represented in the collections by several impressions on flat fragments of coal. They are in very low relief and consist for the most part of slightly encrusted moulds in layers of smutty "mother of coal» or natural charcoal. One of the specimens presents a Knorria stage exactly similar to that photograpbically illustrated by Professol Zeiller in plate 8, figure 4, of his valuable paper, «Note sur la flore fossile des gisements houillers de Rio Grande do Sul (Brésil méridional), printed in the $23 \mathrm{rd}$ volume of the Bulletin de la Société géologique de France."(1)

Two slabs in the collection made by Doctor White are covered with narrow small leaves exactly like those shown in Figures 5 and 6 on the plate above cited. Notwithstanding the position of the stomatiferous grooves so near to the border, a character which inclined Professor Zeiller to regard them as possibly leaves of Sigillaria. I am disposed to consider them the leaves of Lepidodendron pedroanum. The lateral or parichnoian cicatricules of the leaf scar,

(1) Paris, 1896. pp. 'ol-'29, pl. viii-x. 
como se vô em um dos nossos specimens, verificou-se (1) são pequenas e distantes concordando essencialmente crm a posição das zonas stomatiferas.

A associação dos fragmentos favorece esta correlação. Comtudo não está ainda bem definitivaments provado que as folhas tão bem figuradas pelo sabio palaeobotanico francez, sejam de Lepidodendron. As suspeitas de Zeiller baseadas nestas follhas, que Sigullaria existia na formacão carbonifera hrasileira, eram de algum modo prophelicas, pois que o genero está representado nas nossas collecções, como se verá posteriormente.

Os maiores fragmentos de tronco de Lepidodendron Pedrocinum são caracterizados pelos mamelões das folhas, relativamente largos, e a largura desusada das cicatrizes das folhas. Esta feição tomada juntamento com a posição elevada e proeminente, caracteristica da cicatriz das folhas, nos mamelões destas e o encurtamento anterior das impressões achatadas, dão frequentemente aos specimens 0 aspecto de um Lepidophloios. Esta semelhança se vê na figura 3 de Zeiller, estampa VIII.

o Lepidodendron Pedroanum é mais propriamente relacionado com Lepidodendron obvatum, Sternb, da flora do Norte. Deve ser tambem comparado com Lepidodendron dichtomum Sterb. Alguns aspectos, da impressão cortical, lembram o Lepidodendron oculis. felis de Abbado(2) das camadas que não devem estar distantes da base de Permiano da provincia de Shansi na China. As grandes hastes das especies do Sul, estão tão bem illustradas por Zeiller, de modo a não precisarem novas illustrações.

As formas dos pequenos troncos ou ramos, estão bem representadas por Carruthers e Arber, nos trabalhos ja citados. Devido a estreita semelhanca entre alguns ramos figurados por diversos autores como Lepidodendron Sternbergii, e as partes correspondentes de Lepidodendron Pedroanum parece-me provavel que as hastes que figuram nas listas e que não foram descriptas, ou illustradas por Bodenbender, (3) sob a designação anterior pertencem realmente, como foi suggerido por Arber, a especie do Brasil, descripta por Carruthers. os megasporos illustrados por Carruthers (4) como pertencentes a

(1) Infelizmente com o trabalho para remover o residuo de carvão de madeira, das impressóes dos mamolōes deste espocimen, para reproduzil-o em estampa, quasi toda a impressão foi accidentalmente apagada.

(2) Palaent. Italica, vol. V. 1900, p. 141, pl. XVIII, fig. 7.

(3) Zeit.chr, d, Goo, Gescll, vol. XLXIII, 1896, p. 770; estampa.

(4) Op. cit. p. V, fig. 1-5. 
as shown in one of our specimens, were found (1) to be small and distant, essentially in agreement with the position of the stomatiferous tracts.

The association of the fragments favors this correlation. However, it is not yet definitely proven that the leaves, sowell figured by the learned French palæobotanist, were borne by Lepidodendron. Zeiller's suspicion, based on these leaves, that Sigillaria was present in the brazilian coal measures was in a way, prophetic, since the genus is present in our collections, as will later be shown.

The larger trunk fragments of Lepidotendron Pedroanum are cliaracterized by the relatively broad leaf cushions, and the unusual width of the leaf scars. This feature, taken together with the characteristically high and prominent position of the leaf scars on the leaf cushions and the vertical foreshortening of the latter in many of the fiattened impressions, frequently give the specimens the aspect of a Lepidophloios. This similarity is well shown in Zeiller's figure 3 on plate viii.

Lepidodendron Pedroanum is probably most nearly related to Lepidodendron obovatum Sternb. of the northern flora. It is also to be compared with Lepidodendron dichotomum Sternb. Some aspects of the cortical impression call to mind the Lepidodendron oculis felis of Abbado (2) from beds which should not be far from the base of the Permian in the province of Shansi, China The large stems of the Southern species are so well illustrated by Zeiller as to require no further illustration.

The features of the smaller stems or branches are well shown by Carruthers and Arber, in the papers already cited. On account of the close resemblance between some of the branches figured liy' various authors as Lepidodendron Sternbergii and the corresponding parts of Lepidodendron Pedroanum it appears to me probable that the stems listed, but not described nor illustrated, by Bodenbender (3) under the former name really belong, as has been indirectly suggested by Arber, to the species described by Carruthers from Brazil. The megaspores illustrated by Carruthers, (i) as referable to this

\footnotetext{
(1) Unfortunately in the efort to clear away the encrusting charcoal residue from the bolster impressions of this specimen, in order to illustrate it, nearly the whole mould was accidently effaced.

(2) Palaeont. Italica, vol. $\nabla, 1900, \mathrm{p} .141, \mathrm{pl} x \mathrm{xiii}$, fig. 7.

(3) Zeitschr, d. Deutsch, greol. Gesell., vul, xlviii, 189j, p. 7io (table).

(4) Op. cit., pl. v. fig. 1-5.
} 
esta especie são consideradı por Zeiller como Sigrillarianos. Os typos destas especies existentes no Museu Brilannico são de Serro Partido, Candiota, Rio Grande do Sul. Topotypos collecionados por Plant, potulados por Carruthers, e adquiridos pelo Sr. D. C. Lacoe em troca de specimens, estão agora na collecção Lacoe de plantas fosseis, no Museu dos Estados Unidos. Os specimens descriptos por Zeiller são do Arroio do: Ratos, no mesmo estado, e das mesmas minas que os collecionados pela Commissão do Carvão.

Localidades : Tope do carvão do Arroio dos Ratos, perto de São Jeronymo Rio Grande do Sul, cerca rle 20 metros acima do carvão Irapuá, ou 120 metros abaixo do schisto preto de Iraty. Lot. 3593.

\section{Lepidophloios}

Sternberg, Versuch FI. Torwelt, vol. I, Tent., 1826 p. XIII.

o gennro L'pidophlois encerra Lepidophytas arborescentes, ou especies affins Paleozoicas das Lycopodiales, actualmente existentes, com troncos e ramos que se dichotomizam successivamente, semelhante a Lepidodendron pela forma geral de seu crescimento, mas, defferindo em particular pelos caracteres do mamelão e cicatriz das folhas. Os mamelōes das folhas são transversalmente rhomboides, tendo o diametro horizontal maior que o vertical. São contiguos e muito salientes, e nas hastes velhas são usualmente desenvolvidos para baixo de modo que a cavidade ligular na face ventral um pouco acima da cicatriz da folha, é bem exposta e distincta.

As cicatrizes das folhas são muito alongadas horizontalmente tendo angulos agudos lateraes, ao passo que os bordos supurior e inferiol' são arredondados. A flexão do mamelão das folhas para baixo quasi sempre desloca as cicatrizes das folhas para os angulos inferiores do mamelão destas que nos spccimens desen rolvidos, achatados, podem ser em parte, encobertas pelas bases embricadas das folhas, embora nas hastes mais novas estejam proximas ou no topete do mamelão. A cicatri\% da folla contem cicatriculas punctiformes e um pouco distantes, a mediana ou vestigio da nervura sendo um pouco maiol que as nutras (pariclinos).

Os cones de Lepidophloios estão reunidos sob o nome generico Lepidostrobus. Nasceram em espiral nos ramos das formas conhecidas como Halonia. Lepidophloios é representado no Brazil por uma unica especie, o Lepidophoios laricinus de Sternherg, a mais commum e 
species are considered by Zeiller as proballly Sigillarian. The types of this species, in the British Museum, are from Serro Partido, Candiota, Rio Gronde do Sul. Topotypes, collected by Plant, labeled by Carruthers, and acquired by Mr. R. D. Lacoe through exchange of specimens are now in the Lacoe Collection of fossil plants in the United States National Museum. The specimens described by Zeiller are from Arroio dos Ratos, in the same state, and from the same mines as those collected by the Coal Commission.

Locality: Roof of the coal at Arroio dos Ratos near São Jeronymo, Rio Grande do Sul. About 20 meters above the Irapuá coal, or about 120 meter's below the Iraty ljack shale. Lot. 3593.

\section{Lepidophloios}

Sternberg, Versuch Fl. Vorwelt., vol. 1, Tent., 1826, p. xiil.

The genus Lepidophloios includes arborescent Lepidophytes, or Palaeozoic relatives of the living Lycopodiales, with successively dichotomizing stems and Jranches resembling Lepidodendron in general form of growth, but differing in particular by the characters of the leaf cushions and leaf scar. The leaf cushions are transversely rhomboidal, the horizontal being greater than the "vertical diameter. They are contiguous and very prominent; and in the older stems, they are usually grown downward so that the ligular pit, on the ventral surface a little above the leaf scar, is well exposed and distinct.

The leaf scars are much elongated horizontally, and have acute lateral angles, while the upper and lower borders are rounded. The downward flexion of the leaf cushions usually brings the leaf scars at the lower edges of the cushion or, in the flattened adult specimens, they may be partly covered by the imbricated leaf Jasas, though, in the younger stems, they are at or near the lop of the leaf cushion. The leaf scar contains three punctiform and rather distant cicatricules, the median, or nerve trace, being a little larger than the others (parichnos).

The cones of Lepidop/loios are included under the generic name Lepidostrobus. They were spirally borne on branches of the form known as Halonia. Lepidophloios is represented in Brazil by a single species, the Lepidophloios laricinus of sternberg, the most common 
mais largamente espalhada especie do genero da flora Permo Carbonifera do Norte. Nas regiões do Norte esta especie se encontra do Westphaliano inferior á porção da base do Permiano.

\section{Lepidophloios laricinus, Sternb.}

1820. Lepidodendron laricinus Sternberg, Versuch. Fl. Vorwelt, vol. I. p. 23, pl. XI, figs. 2-4; Geinitz, Darstell, Ilain. - L'Jersdorf, 11. 1854, p. 47, pl, XI, figs. 4, 5 e 7.

1826. Lepidofloyos laricinus Sternberg, op. cit., Tent., p. XIII.

1862. Lepidophloios laricinum Stb., GoldenJerg, Fl. Saraep, foss., Lief. 3 p. 30, pl. XVI, figs. $2-6$.

1870. Lepidophlois laricinus Stb., Schimper, Traité, vol. II, p. 51, pl. LIX, fig. 4; pl. LXIV, figs. 4, 6, 8; Weiss, Fl. jüngst. Steink, 1871, p. 154, pl. XV, figs. 6, 7, 9; Zeiller, veg. foss. terr. houill., 1880, p. 113, pl. CLXXli, figs. 5, 6; Zeiller, Fl. foss. bassin. houil., Valenciennes, 1886, p. 471, pl. LXXII, figs. 1, 2 ; Kidston, Trans. R. Soc. Edin]s., vol. XXXVII, ? . 3, 1893, p. 555, pl. I, fig. 4 ; pl. II, fig. 8 ; Zeiller, Bull. Soc. geol. Fr., (3) vol. XXIII, 1896, p. 612, pl. IX, fig. 1, 3 ; Kidston Pro. Yorks. Gel. \& Poly. Soc., vol. XIV, 1902, p. 348, pl. LVI, fig. 2 ; Zalessky, Mem. Com. Geol., n. s. vol. XIII, 1904, p. 30, pl. V, fig. 9, pl. Vl, figs. 8,10 ; pl. VII, figs. 1, 2 ; pl. VIII, figs. 7, 9; D. White, Science, n. S., vol. XXI, 1905, p. 700 ; Arber, The Glossopteris Flora, 1905 , p. 163.

Mamelöes das folhas alongados, imbricados, escassamente carenados, dirigidos para baixo, porção exposta dos mameloes das folhas rhomboide, ou alongada transversalmente, angulos lateraes $e$ superiores agudos, angulo inferior geralmente redondo. Cicatriz das folhas collocada no alto dos mamelões drrigidos para baixo, ou ligeiramente abaixo do cume, rhomboides ou transversalmente rhomboide-alongados, angulos latercles muito agudos e salientes, angulos superior e inferior ligeiramente arredondados; dentro da cicatriz da folha ha tres cicatriculas collocadas ao centro, ou ligeiramente acima, ou abaixo do centro, as duas lateraes punctiformes, a central punctiforme, ou subtriangular. Quando o cicatriz da folha estú ccllocada ligeiramente abaixo do apice do mamelão inclinado, duas linhas correm de scus angulos lateraes, encontrando a margem 
and widespread species of the genus in the Northern Permo-Carboniferous flora. In the Northern regions the species ranges from the lower Westphalian to the basal portion of the Permian.

\section{Lepidophloios laricinus Sternb.}

1820. Lepidodendron laricinum Sternberg, Versuch, Fl. Vorwelt, vol. 1, p. 23, pl. xi, figs. 22-4; Geinitz, Darstell. Hain. - Ebersdorf. 1i., 1854, p. 47, pl. xi, figs. 4, $5,7$.

1826. Lepidofloyos laricinus. Sternberg, op. cit., Tent., p. xiii.

1862. Lepidophloios laricinum. StJ , Goldenberg, Fl. Saraep. foss., Lief. 3, p. 30, pl. xvi, figs. 2-6.

1870. Lepidophloios laricinus. Stb., Schimper, Traité, vol. II, p. 51 . pl. lix, fig. 4; pl. lxiv, figs. 4, 6, 8; Weiss, Fl. jüngst. Steink., 871, p. 154, pl. xv, figs. 6, 7, 9; Zeiller, Veg. foss. terr. houill., 1880, p. 113, pl. clxxii, fies. 5, 6 ; Zeiller, Fl foss. bassin houill. Valenciennes, 1886, p. 471, pl. lxxii, figs. 1, 2; Kidston, Trans. R. Soc. Edinb., voi . xxxvii, pt. 3, 1893, p. 555, pl. i, fig. 4; pl. ii, fig. 8 ; Zeil er; Bull. Soc. géol. Fr., (3) vol. xxiii, 1896, p. 612, pl.ix, fig. 1-3; Kidston, Proc. Yorks. Geol. \& Poly. Soc., vol. xiv, 1902, p. 348, pl. 1vi, fig. 2; Zalessky, Mem. Com. Géol., n.s., vol. xiii, 1904, p. 30, pl. v, fig. 9, pl. vi, figs. 8, 10, pl. vii, fig. 1, 2, pl. viii, figs. 7, 9, D. White, Science, n. s., vol. xxi, 1905, p. 700, Arber. The Glossopteris Flora, 1905, p. 163.

Leaf-cushions elorgated, imbricate, scarcely keeled, directed downwards; exposed portion of cushions rhomboidal or elongated transversely; lateral and upper angles acute, lower angles generally rounded. Leaf-scar placed at the summit of the downward directed leaf-cushion, or only slightly below the summit, rhomboidal, or transversely rhomboidal-elongate, lateral angles very sharp and prominent, upper and lower angles slightly rounded; within the leaf-scar are three cicatricules placed centrally, or slightly above or below the centre, the two lateral punctiform, the central punctiform, or sub-triangular. When the leaf-scar is placed slightly below the apex of the deflexed cushion, two lines run from its lateral angles, which meet the margin of the cushion a short distance beloro the leaf scar. The leafcushion 
do mameläo a pequena distancia nubaixo da cicatriz. Onameläo tem quasi sempre abaixo da cicatriz um pequeno tuberculo con una depressão circular, ou subtriangular. O fructificação nasce nos ramos de forma Halonial.

A descripção da especie dada acima, foi lirada da valiosa memoria de Kidston, soljre o genero. (1)

A especie descripta e illustrada por Zeiller, do Arroio dos Ratos no Rio Grande do Sul, está representada na presente colleção, apenas por poucos fragmentos mal conservados, como impressũes formadas em uma camada de carvão de madeiı,a, nalural a cheias com detrictos carbonosos. Lislas fornecem comludo, Jastantes elementos para se estabelecer' sua concordancia com as formas de specimens mais claros e melhor figurados pelo professol Zeillel. A especie ainda não é conhecida de outra região de flora do antigo Gondwana.

Localidade: Tope do Carvão perto de São Jeronymo no Rio Grande do Sul, a cerca de 20 metros acima do carvão de Irapuá, ou 120 metros abaixo do Schisto preto de Iraty. Lot. 3593. Tambem em material duvidoso do tope do cal'vão São Jeronjmo, 15 kilometros a sudoeste de Irapuá em terras da sesmaria do tenente licicardo. Lot. 3̋594.

\section{Sigillaria}

Brongniart, Mus. hist. nat. Paris, vol. VIII, 1822, p. 209.

Os caracteres pelos quaes se destingue o genero Sigillaria de Lepidodendron, são os que apresenta o cortex exterior e se referem principalmenteá forma e disposição das cicatrizes e mamelõas. O gener'o comprehende dous grandes grupos as Er,-Sigillar'ias e as Sub-Sigillarias, e embora os typos de transição tornem impraticavel a distincção formal destes grupos, podem em muitos casos ser distinctamente separados.

As Eu-Sigillarias se dividem em duas seceñes: Rh.ytidolepis que Lem costellas (2) longitudinaes reclas, lar'gas, cada uma com uma ordem de cicatrizes, em geral ovaes exagonaes, mais ou menos distantes, collocadas ao longo de uma zona central achatada; e Favularia, em que as costellas menos rigidas, são separadas por sulcos estreitos mais ou menos em zig-zag, emquanto que uma linha ou vinco transversal atra-

(1) Trans, R. Soc. Edinb. vol, XXXril, pt. 3, 1893, pag. 555.

(2) Costellarib, côte; saliencia, elevaç̧o semi-cylindrica ao longo da haste, do pamo ou do tronce (N.d. T). 
frequently beri's, immediately benerth the leaf-scar, a small tubercle with circular or subtricangular depression. Fructification borne on Halonial branches.

The description given above for the species is taken from Kidston's valuable memoir on the genus.

This species, which has been described and illustrated by Zeiller from Arroio dos Ratos, in Rio Grande do Sul, is represented in the present collection by but a few fragments poorly preserved as moulds formed in a larer of natural charcoal and filled with coaly dirt. Ilowever, enough can be made out from them to establish their agreement with the forms figured ly Professor Zeiller from specimens much clearer and better preserved. The species is not yet known from any other region of the older Gondwana flora.

Localities: Roof of the coal near São Jeronymo, Rio grande do Sul. About 20 meters alıove the Irapuá coal, or 120 meters below the Iraty black shale. Lot 3593. Also, in doubtful material, from roof of the São Jeronymo coal 15 kilometers southwest from Irapuá on land of the sesmaria do tenentc Ricardo. Lot 359 亿.

\section{Sigilliaria}

Brongniart, Mus. his. nat., Paris, vol. viii, 182?, p. 209.

The essential criteria which distinguish the genus Sigillaria from Lepidodendron are those furnished by the outer cortex. They relate chiefly to the forms and arrangement of the leaf scars and the leaf cushions. The genus comprises two large groups, the Eu-Sigillariae and the Sub-Sigillariae, and though transitional types render impraticable the formal distinction of these groups they are in most cases very readily separated.

The Eu-Sigillariae includ two sections: Rhytidolepis, which has straight, broad, prominent longitudinal ribs, each bearing a row of more or less distant, and in general ovate-hexagonal leaf scars placed along a flattened central zone; and Favularia, in which the less rigid rilus are separated by sharp, more or less distinctly zigzag furrows, while a transverse line ol crease crosses the narrow point of the rib

(1) Trans. R. Soc. Eilinb, vol. XXXVII, pt. 3, 1893, p 555. 
vessa a parte estreita da costella, justamente um pouco acima de cada cicatriz que é muitas vezes mais distinctamente exagonal ou oval-exagonal. As costellas apresentam muitas vezes diversos typos de ornamentos locaes, taes como: rugosidade, chagrenado, relevos, zonas, etc., que fazem parte da caracterisação especifica. Frequentemente as cicatrizes nesta secção estão collocadas em mamelões desenvolvidos fóra dacostella, mais ou menos distinctos e imperfeitamente hexagonaes. Nos grandes troncos de algumas das especies da secção Rhytidolopis, as costellas algumas vezes attingem á largura de mais de tres centimetros. As hastes deste typo estam entre as mais facilmente reconheciveis das fơrmas Palaeozoicas affins dos Licapodios.

As Sub-Sigillarias têm dous typos que muitas vezes não se distinguem um do outro: Clathraria em que os mamelōes hexagoneas estão juntos, collocados em espiral e Leiodermaria em que as cicatrizes estam collocadas mais ou rnenos distantes no cortex essencialmente chato. Em algumas especies, tanto as fórmas Clathrarias como as Leiodermarias se veem na mesma haste. Nas fórmas com o cortex chato, tendo o mamelão inconspicuo, ou de modo algum desenvolvido a superficie é muitas vezes enrugada, ou ornamentada com desenhos particulares que servem como um caracter diagnostico. As cicatrizes das Sub-Sigillarias são hexagonaes, com maior diametro transversal entre os dous angulos agudos lateraes.

A especie do Brasil pertence as Sub-Sigillarias. E' rara a evidencia de ramificação em Sigillaria, embora as arvores sejam muitas vezes de grande tamanho sendo encontrados specimes, medindo tanto comoseis pés de diametro, ou quasi 100 pés de comprimento. Em todos os typos de Sigillaria as cicatrizes estam dispostas em espiral. Logo acima de cada uma das cicatrizes ha uma ligeira depressão, ou uma cavidade punctiforme marcando a posição da cavidade ligular. Onde quer que os mamelõos individuaes estejam em evidencia, mostram mais ou menos distinctamente uma fórma hexagonal, e tem a cicatriz que é ligeiramente obliqua ao plano do tronco, collocada mais proximo do lado superior dó mamelão. Quando qualquer dos angulos da cicatriz torna-se redondo, o primeiro arredondamente apparece nos dous angulos do lado superior. A fórma mais distinctamente hexagonal da cicatriz vê-se nas Sub-Sigillarias.

A cicatriz contém tres pequenas cicatriculas, no meio ou acima desta como no Lepidodendron. A central ou vestigio de nervura é usualmente punctiforme, ou tem a forma de um V largo; as duas lateraes (Parichnos) são geralmente alongadas, mais ou menos dis- 
just a little above each leaf scar which is often more distinctly hexagonal, or more broadly ovate-hexagonal. The ribs often exhibit various types of topographical ornamentation, such as rugosity, shagreening, fretting, banding, etc., which take part in their specific characterizaction. Frequently the leaf scars in this section are situated on more or less distinct and imperfectly hexagonal leaf cushions growing out of the ribs. In the large trunks of some of the species in the Rhytidolepis section the ribs sometimes attain a width of over three centimeters. The stems of this type are among the most easily recognized of the Palaeozoic relatives of tha Lycopods.

In the Sub-Sigilliariae there are two types which are often indistinguishable from each other: Clathraria, in which the hexagonal leaf-cushions are close and spirally arranged; and Leiordermarta, in which the leaf scars are more or less distantly arranged on the essentially flat cortex. In some species both Clathrarian and Leiodermarian forms are seen on the same stem. In the forms with flat cortex, having an inconspicus if any development of a leaf cushion, the surface is often lightly corrugated or otherwise ornamented in some particular design which serves as a diagnostic character. The leaf-scars of the Sub-Sigilliariac are hexagonal, with the greater diameter transversely between the two usually acute lateral angles.

The species from Brasil belong to the Sub-Sigilliarine. Evidence of branching is rare in Sigillaria, though the trees were often of very large size, specimens being found to measure as much as six feet in diameter, or nearly 100 feet in length. In all the types of Sigillaria the leaf scars are spirally disposed. Just above each of the scars there is a slight depression or punctiform pit marking the position of the ligu lar cavity. Wherever individual leaf cushions are to some degree in evidence they show more or less distinctly a hexagonal form, and have the leaf scar, which is usually slightly oblique to the plane of the trunk, located nearer the upper side of the cushion. When any of the angles of the leaf-scar become rounded, the rounding first appears in the two angles on the upper side. The more distinctly hexagonal form of scar is seen in the Sub-Sigillariae.

The leaf scar contains three small cicatricules at or above the middle, as in Lepidodendron. The central one, or nerve trace, is usually punctiform or broadly $\mathrm{T}$ shaped; the two lateral (Parichncs) are generally elongated more or Iess distinctly in the longi5560 
tinctamente na direcção longitudinal e muitas vezes têm a fórma de crescente tendendo a abranger o vestigio da nervura. Nas hastes decorticadas principalmente, especialmente as de Rhytidolepis, as impressões das duas cicatriculas lateraes são a miudo muito grandes e claras. As folhas de Sigillaria são rigidas como as das gramineas, e longas, algumas vezes de um metro ou mais de comprimento. Sua estructura é muito semelhante ás das folhas de Lipidodendron.

Os cones de Sigillaria (Sigillariostrobus) assemelham-se a Lepidostrobus, e nascem em longos pedunculos inseridos lateralmente. São heterosporos. A raiz das arvores deste genero, está comprehendida sob o nome de Stigmaria.

A superficie de uma pequena raiz da qual cahiram as finas radiculas, é muito estreitamente comparavel a do fragmento da de Lycopodiopsis Derbyi Ren. que se vê na est. V, fig. 11. De facto eu collocaria este especimen no grupo Stigimariano, apenes pelos detalhes anatomicos evidenciados por Zeiller e Renault. A constituição interna da madeira das Sigillarias não offerece caracteres constantes pelos quaes se possa distinguil-as de Lepidodendron e é possiveI que o fragmenlo descripto adeante como Sigillaria? murallis pertença realmente ao outro genero.

A secęão Rhytidolepsis das Sigillarias é conhecida em rochas tão antigas como o Devoniano superior, mas o genero em sua totalidade é especialmente caracteristico do Carbonifero superior, onde é mais abundante na formação carbonifera (Coal measures) superior e inferior Sigillaria é rara no Permiano. Foi descripta uma especie do Trias cuja identidade generica está um pouco sujeita á duvida. ú typo do Brasil que descrevi como sigillaria australis, approximase desta por alguns dos seus caracteres.

\section{Sigillaria Brardii Brong.}

Pl. V, Fig. 12

1822. Clathraria Brardii Brongn. Mem. mus. hist. nat., vol. VIII, pp. $209222, \mathrm{pl}$. I, fig. 5.

1826. Faoularia Brardii (Brongn.) Sternberg, Versuch FI. Vorwelt., Vol. 1, Tent., p. XIV.

1828. Sigillaria Brardii Brongniart, Prodrome, p. 65 ; Brogniart, Hist. Vege. foss., 1836, p. 430, pl. CLVIII, fig. 4; Germar, Verst. Steinck Wettin u. Löbe jun, 1845, p. 29, pl. XI, 
tudinal direction, and very often they are crescentric, tending to embrace the nerve trace. In the partially decorticated stems, especially those of Rhytidolepis, the casts of the tw. lateral cicatricules are often very large and conspicuous The Sigillarton leaves are rigid, grasslike and long, sometimes a meter or more in length. Their structure is much the same as in the leaves of Lepidodendron.

The cones of Sigillarta (Sigilliariostrobus) resemble Lepisdostrobus, and are borne on long, laterally attached, peduncles. They are. heterosporous. The root of the trees of this genus included under the name Stigmaria.

The surface of a small root, from which the slender rootlets have fallen is very closely comparable to that of the fragment of Lycopodiopsis Derbyi Ren., shown on Pl. V, Fig. II. In fact I should have placed this specimen in the Stigmarian group but for the anatomical details brought out by Renault and Zeiller. The internal constitution of the Sigilliarian wod offers no constant criteria by which to distinguish it from that of Lepidodendron, and it is possible that the fragment described on a latter page as Sigillaria? muralus really belongs to the other genus.

The Rhytidolepis section of Sigillaria, is known from rocks as old as the Upper Devonian; but the genus, as a whole, is especially characteristic of the Upper Carboniferous, where it is mo:t abundant in the lower and middle Coal Measures. Sigillaria is rare in the Permian. A spocies, whose generic identity is slightly open to question, has been described from the Trias. The type from Brasil which I shall describe as Sigillaria australis approaches the latter in some of its characters.

Sigillaria Brardii Brongn.

Pl. V, Fig. 12 .

1822. Clathraria Brardii Brongniart, Mem. mus. hist. nat., vol. viii, pp. 209, 222, pl. i, fig 5.

1826. Favularia Brardii (Brongn.) Sternberg, Versuch Fl. Vorwelt., vol. 1, Tent., xiv.

1828. Sigillria Brardii Brongniart, Prodrome, p. 65 ; Brongniart, Hist. Veg. foss.,-1835, p. 430 , pl. clviii fig, 4 ; Germar, Verst. Steink. Wettin u. Löbe jun, 1845, p. 29, pl. xi, figs. 1,2; 
figs. 1-2 ; Goldenberg, Fl . foss. Saraep. pt. 2 1857, p. 25, pl. VII, ng. 7, 8; Schimper, Traité, vol. II 1870, p. 102 pl. LXVII, fig. 10; Weiss, Fl. Jüngst. Steinck. u Rothl. Saarrh. Geb 1871, p. 161, pl. XVI fig. 1, pl. XVII, flg. 7, 9 ; Zeiller, Veg. foss, terr. houill., 1879, p. 135, pl. CLXXIV; fig. 1; Feistmantel, Arch. natul'w. Iand. Böhmen, vol IV, 1881, no 6,9 th Abth., p. 88, pl. v, fig. 1.2; Weiss Zeitschr. d. Deutsch. geol. Gesell, vol. XL, 1888, p. 569, fig. 4; Zeiller, Bull. Soc. Geol. Fr. (3) vol. XVII, 1889. pag. 603, pl. XIV; Renault Fl. foss. bassin houill. Commentry, pt. 2, 1890, pl. LXIII, fig. 1; Grand'Eury, Geol. et. pal.. Jjassin houill. . Gard, 1890. p. 250, pl. XI, fig. I; Potonié, Fl. Rothl. Thuringen 1893, p. 190, pl. XXVII, fig 2; Seward, Quart. Jour. Geol Soc., vol. LIII, 1897, p. 326, pl. XX, fig. 3, pl. XXIII, fig. 2; Kidston, Proc. Yorksh. Geol. \& Poly. Soc. vol. XIV, 1902, pt. 3, pl. LVIII, fig. 2, pl. LIX, fig. 1; Arber, The Glossopteris Flora 1905, p. 170, pl. VIII, fig. 1. 1893. Sigillaria mutans Weiss \& Sterz., forma Brardii (Brong) Weiss \& Sterzel, Sigill. d. Pr. Steinck, pt. II. p. 131.

Mamelöcs clathrarianos, contiguos, proeminentes, roemonte inclinados para cina, hexagono-rhomboides, ligeiramente redondos em cima e carenados embaixo dos angulos lateraes da cicatrï, esta de tamanho moderado, estendendo-se quasi atê o tope do mamelão, não tão larjga como este ultimo e muito mais baixa: hexagonal muito largamente arrendondada com uma cavidade na base, redonda ruse fortemente concava em baixo dos angulos lateraes, concava em pequena distancia no bordo superior proximo dos angulos, depois quasi recta em distancia considernvel, antes de arquear-se fortemente para cima, sobre e dentro da cavidade mediana redonda e profunda, vestigio da folha pequeno un pouco acima do centro da cicatris; cicatriculas lateraes um pouco mais altas do que o vestiglo da folhu, un tanto distantes, pequenas e verticalmente ovaes.

Os caracteres pelos quaes se distinguem os specimens acima descriptos, da Sigillaria Brardir normal são: a) obliquidade dos mamelōes que nos specimens cumprimidos muitas vezes curvam-se para baixo da parte superior das cicatrizes, dando frequentemente aos speeimens o aspecto de um exemplo de achatamento como em um pequeno Lepidophlotos; b) as cavidades medianas muito fundas e redondas; c ) a posição das cicatriculas lateraes um tanto distantes e mais altas que o vestigio da norvura que é central. 
Goldenberg, Fl. ross. Saraep., pt. 2 1857, p. 25, pi . vii, fig. 7,8; Schimper, Traité vol. II, 1870, p. 102 pl. Ixvii, figr. 10 ; Weiss, Fl. jüngst. Steink. u. Rothl. Saarrh. Gej., 1871, p. 161, pl. xvi, fig. 1, pl. xvii, figs. 7,9; Zeiller, Vég. foss. terr. houill., 1879, p. 135, pl. clxxiv, fig. 1; Feistmantel, Arch. naturv. Land. Böhmen, vol. iv, 1881, no. 6, 9th Abth., p. 88, pl. v, fig. 1,2; Weiss, Zeitschr. d. Deutsch. geol. Gesell., vol. xl, 1888, p. 569, fig. 4; Zeiller, Bull Soc. geol. Fr., (3) vol. xvii, 1889, p. 603 , pl. Xiv. Renault, Fl. foss. bassin houill. Commentr?, pt. 2, 1890, pl. lxiii, fig. 1 ; Grand Eury, Géol. et pal. bassin houill. Gard, 1890. p. 250, pl. xi, fig. 1 ; Potonié, Fl. Rothl. Thuringen, 1893, p. 190, pl. xxvii, fig. 2 ; Servard, Quart. Jour. Geol. Soc., vol. LIII, 1897, p. 326, pl. xx, fig. 3, pl. xxiii, fig. 2 ; Kidston, Proc. Yorksh. Geol. \& Poly. Soc., vol. xiv, 1902, pt. 3, pl. lviii, fig. 2, pl. lix, fig. 1; Arber, The Glossopteris Flora, 1905, p. 170, pl. viii, fig.

1893. Sigillaria mutans Weiss \& Sterz. forma Brardii (Brongn.) Weiss \& Sterzel, Sigill. d. Pr. Steink., pt. ii. p. 131.

Leaf cushions Clathrarian, contiguous, prominent, slightly upward inclined, hexagonally rhomboidal, slightly round above and below, carinate from the lateral angles of the leaf scar; ieaf scar of moderate siwe, extending nearly to the top of the cushion, less than the latter in woidth, and much less in altitude, hexagonal, very braadly rounded below or shallowly sinused in a rounded, strongly concave beneath the slender acute lateral angles, concave for a very short distance in the upper border next to the anyles, then nearly straight for a considerable distance before arching strongly upward and over into the deep and rounded medial sinus; leaf trace small, a little above the center of the leaf scar; lateral cicatricules a little higher than the leaf trace, rather distant, small, and vertically oval.

The features which distinguish the specimens above described from the normal Sigillaria Brardii are; (a) the obliquity of the cushions which in the compressed specimens often fold under the upper part of the leaf scars, and which frequently gives the specimens the aspect of a flattened example of a small Lepidophloios; (b) the very deep, rounded, median sinuses; and (c) the position of the lateral cicatricules, rather distant and higher than the nerve trace which is central. 
Como indica a photographia, est. V. fig. 12, a haste brasileira é typicamente clathrariana e como tal se refere ao grupo Brardii. A forma das cicatrizes dos specimens do Transvaal, se approxima da dos specimens do Brasil, sendo aquelles considerados como da mesma especie por Seward (1). Comtudo alguns dos mamelões dos specimens do Transwaal teem o contorno semelhante ao do nosso ; o vestigio da folha é mais alto, na cicatriz, e as cicatrizes lateraes são mais altas e mais curtas, ou quasi redondas. No presente estado de apuro excessivo na classificação de especies no grupo Brardii de Sigillaria é frequentemente difficil determinar satisfactoriamente com precisão, as especies de specimens em um estado medio de conservação; e é muitas vezes mais difficil quando o material é escasso e mal conservado.

Conseguintemente um numero de eminentes palæolsotanicos europeus incluindo o professor Arber (2) reagindo contra tão trabalhda subdivisão de especies, e de formas subordinadas systematicamente differenciadas, estam dispostos a collocar um grande numero das antigas especies incluindo Sigillaria Menardi, descripta por Brongniart e outras, sob a unica denominação de Sigillaria Brardii. Por minha parte duvido que o material descripto, do Transwaal ou do Brasil, possa ser considerado com propriedade como desta ultima especie.

O typo brasileiro é na apparencia mais estreitamentte relacionado com Sigillaria Menardi Brongn. Comtudo dependendo ainda da descoberta de espacimens que mostrem caracteres mais exactos, considero-o como Sigillaria Brardii, como esta especie é actualmente interpretada por muitos palaeobotanicos. E' de esperar que material addicional e melhor conservado seja encontrado no Brasil, afim de fixar mais precisamente as suas condições especificas. Não resta duvida, comtudo, quanto á unidade do typo Sul Americano e do grupo Sigillariano do Norte, tendo como typo Sigillaria Brardii.

Localidades ; Tope do carvão proximo a São Jeronymo, Rio Grande do Sul, cerca de 20 metros acima do carvão Irapuá, on 120 metros abaixo do schisto preto de Iraty. Lote. 3593 .

(1) Quart. Journ. Geol. Soc. vol. LIII, 1897. p. 327, fig. 2

(2) The Glossopteris Flora, 1905, p. 170 
As indicated by the photograph, Pl. V, Fig. 12 the Brasilian stem is typically Clathrarian and as such is referable to the Brardii group. Specimens from the Transwaal with leaf scars in form approaching those from Brasil are referred by Seward (1) to the same species. Although some of the cushions of the Transwaal specimens are in outline similar to ours, the leaf trace is higher in the scar, and the lateral cicatricules are much higher, and short or nearly round. In the present state of over-refinement in the classification of species in the Brardii group of Sigillaria it is frequently difficult satisfactorily to determine with precision the species of specimens in an average state of preservation; and it is often most difficult when the material is scanty or poorly preserved.

Consequently a number of leading European palaeobotanists, including Professor Arber, (2) in reaction from so elaboratea subdivision in species, and systematically differentiated subordinated forms, are disposed to place a large number of the older species, including Sigillaria Menardi, described by Brongniart and others, under the one name Sigillaria Brardii. For my own part I doubt whether the material described from either the Transwaal or Brasil may properly be included in the latter species.

The Brasilian type is apparently more closely related to Sigillaria Menardi Brongn. However, pending the discovery of specicmens exhibiting its more exact characters I place it within the comprehensive Sigillaria Brardii, as that species is now broadly interpreted by many palaeobotanists. It is hoped that additional and better preserved material may be found in Brasil in order to more precisely fix its specific status. No doubt remains however, as to the unity of the South Anerican type with the Northern Sigillarian group, trpified in Sigillaria Brardii.

Locality : Roof of the coal near São Jeronymo, Rio Grande do Sul. About 20 metres above the Irapuá coal, or 120 metres below the Iraty black shale. Lot 3593 .

(1) Quart, Jour. Geol. Soc., vol, liii, 1897, p. 327, fig. 2.

(2) See The Glossopteris Flora, 1905, p. 170. 


\section{Sigillaria australis n. sp.}

$$
\text { Pl. VI. fig. 11-11 a-11 d }
$$

Cortex com relevos baixos, essencialmente Leiodermario, extremamente chagrenados em direçāo geralmente vertical entre as cicatrizes algum tanto distantes, mamelão muito mal de finido, grande

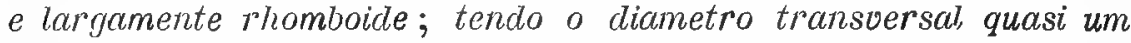
terço maior que o vertical, arredondado ao longo do bordo inferior, achatando-se perto dos angulos lateraes, mais ou menos agudos, algumas vezes acuminados, ligeiramente emarginados no centrodo bordo superior, carenados lateralmente e distantes um do outro na mesma espiral um pouco menos que o diametro obliquo do mamelão; cicatrizes perto, ou na margem superior do mamelão muito largamente ihomboide, ou elliptico-rhomboide, quasi em forma de crescente em baixo, agudo ou um tanto largamente pontudo lateralmente, flancos superiores rectos perto dos angulos arqueados $e$ denteados pouco profundamente ao centro, diametro vertical um pouco menor que a metade do horizontal, vestigio da neroura perto ou pouco acima do centro da cicatriz; cicatriculas lateraes proximas do vestigio da neroura, grandes, oblongas e un tanto alongadas verticalmente parecendo muito grandes e ovaes em forma de crescente, estendendo-se pela maior parte da altura da cicatriz nas phases subepidermicas.

O specimen photographado na estampa VI fig. 11 é o unico representante desta especie na collecrsão. E' quasi completamente achatado e ligeiramente macerado por baixo da epiderme, de modo que é muitas vezes difficil, distinguir os mamelões, e a cuticula parece ter sido ligeiramente deslocada em certos pontos.

Embora falte clareza ás fórmas dos mamelões e da cavidade ligular o fussil apres inta certas feições tão frisantes quanto interessantes, que tornam possivel distinguil-o especificamente com facilidade. 0 aspecto do mamelão varia muito em differentes partes do fragmento.

Como está comprimido na parte inferior esquerda do specimen, assemelha-se em seu contorno á uma enorme cicatriz de Sigillaria. lim alguns casos o mamelão achatado e obscuro suggere pela sua collocarão a ideia do avental de Asolanus.

A forma das cicatrizes se vê na photographia á direita e nos detalhes figs. $11 b, c \in d$. Onde estão melhor conservadas são pontudas nos angulos lateraes, embora em muitos casos sejam muitas vezes 


\section{Sigillaria australis n. $s p$.}

Pl. vi, Fig. 11, lld lld

Cortex in low topography, essentially Leiodermarian, extremely finely shagreened in a generally vertical direction between the somewhat distant leaf scars; leaf cushion very poorly defined, large, broadly rhomboidal, the transverse diameter nearly one third greater than the vertical, round along the lower border, flattening near the more or less acute, sometimes acuminated lateral angles, slighty emarginate at the middle of the upper border, laterally carinate, and distant from one another in the same spiral a little iess $t_{\text {han }}$ the oblique diameter of the cushion, leaf scar at or near the upper side of cushion very broadly rhomboilal or ellipticorhomboidal, nearly crescentic below, acute or somewhat broadly pointed laterally, the upper flanles straight near the angles, arched, and shallowly indented at the middle, the vertical diameter being a little less than one half the horizontal; nerve truce near or a little above the center of the scar; lateral cicatricules close to the nerve trace, large, oblong, and somewhat elongated vertically appearing very large, and oval, crescentic, extending across the greater part of the height of the scar in the subepidermal phases.

The specimen photographed in pl. vi., Fig. 11 , is the sole representative of the species in the collection. It is nearly completely flattened and slightly macerated beneath the epidermis so that the cushions are often difficult of definition, while the cuticle appears to have been slightly dislocated in places.

Though lacking distinctness as to bolster forms and ligular pit the fossil presente certain striling as well as interesting features which render it easily distinguished specificaly. The aspect of the cushion varies much in different parts of the fragment.

As compressed in the lower left of the specimen it resembles in outline an enormously large Sigillarian leaf scar. In a few instances the flattened and obscure bolster topographically suggeste the apron of Asolanus.

The form of the leaf scars is seen on the right in the photograph and in the details, Figs. $11 b, c$ and $d$. Where best preserved they are pointed at the lateral angles though in other instances they are 
obtusas. O vestigio da nervura é pequeno e não muito distante do centro da cicatriz, embora parecendo muitas vezes, verticalmente alongado especialmente nas phases subepidermicas. As variações do aspecto das cicatriculas lateraes, são ainda maiores e mais notaveis; mesmo nas menol'es phases de conservação subepidermica, Fig. $11 \mathrm{~b}$, são relativamente grandes. Em outros casos ennunciados tambem superficialmente, são muito maiores e verticalmente alongadas, emquanto que ainda em outros casos em que a pelle subcarbonosa muito fina foi removida, apparecem como se vê na fig. $11 \mathrm{~d}$.

A distribuição e fórma de cicatrizes na Siyllaria australis são suggestivas de Sigillaria biangula Wreis(1) e Sigillaria aculina Blanckenhorn (2) do grés variegado de Commern. O chagrineamento vertical do cortex, a fórma da cicatriz e o desenvolvimento das cicalrizes lateraes indicam uma relação mais estreita com a ultima especie em particular, que deve ter provindo do mesmo stock que o da planta em mãos. A arvore brazileira não apparece estreitamente relacionada com nenhuma especie de Sigillaria da flora Permo Carbonifera do Norte. E' possiveI que a madeira Lepidophytica fossil que será descripla mais adeante como Sigillaric (?) muralis, represente o xylem secundario ou endogeneo da especie ora descripta.

Localidade: Estrada Yova, proximo de Minas, Santa Catharina, 135 metros mais ou menos acima do granito e 40 metros abaixo do carvão Barro Branco. Lot. 3923.

\section{Sigillaria (?) muralis n. sp.}

Pl. XIl. figs. 1-4

o xylem secundario, molle e esponjoso, composto de tracheides scalariformes com paredes finas divididas por grande numero de raios de cellulas grandes; tracheides collocadas distinctamente em raios muito longos, sinllosos, as veres meandriformes, agudas, reticuladas, em contacto com as cellulas medullares, na secção transver'sal; tracheides muito desiguaes em lotogura, viriando muito em diametro e proporções relativas; comtudo medindo 65 microns, ou mais de diametro tangencial, e 75 microns, ou mais de diametro

(1) Wo's.s. Sir.ill. Pr. Steink. n. Rothlie?, pt. 2, 1893, p. 75, pl. vl.

(2) Palaento raphica vol. Xxxll, 1886, p. 134, pl XX, lig. 9. Veja-so tambem Potonio

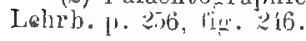


often obtuse. The nerve trace is smail and not far above the center of the scar, though often seeming elongated vertically, especially in the subepidermal stages. The changes in the aspect of the lateral cicatricules are still greater and more remarkable. Even in the smallest phase of subepidermal preservation, Figure $11 \mathrm{~b}$ they are relatively large. In other cases, also expressed superficially, they are much larger and vertically elongated; while in still other instances, where the very thin carbonaceous skin is removed, they appear as shown in liig. $11 d$.

The distribution and form of the leaf scars in Sigillaria australis are surgestive of Sigillaria biangula Veiss, (1) and Sigillaria oculina Blanckenhorn, (2), from the Bunter sandstone of Commern. The vertical chagreening of the cortex, the form of the leaf scar and the enlargement of the lateral cicatricules point toward a closer relationship in particular to the latter species which may have been derived from the same stocls as that of the plant in hand. The Brasilian tree does not appear closeiy related to any species of Sigillaria in the Northern Permo Carboniferous flora. It is possible that the fossil Lepidophytic wood which will be described on a latter page as Sigillaria (?) muralis represents the endogenous or secondary xylem of the species just described.

Locality: Estrada Nova near Minas, Santa Catharina. About 135 meters above the granite and 40 meters below the Barro Branco cunl. Lot 3923 .

\section{Sigillaria (?) muralis n. sp. \\ Pl. XII, ligs. 1-4.}

Secondary xylem soft and sponyy, composed of thin-torlled :calariform tracheides prirted by great numbers of very largecelled rays; trarheides distinctly radirl in orrangenent, cor"! lon!, sinuate', sometimes meanderiny, acute, reticulatr in contart roith the medullary cells; in transoerse section tracheides very unequal in width, varying much in diannerir and relative proportions though averaging 6.5 microns or more in tangentirl diameter and is microns or more in ratial dirmeter, those in contact rith the rays bcing more or less

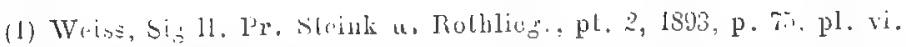

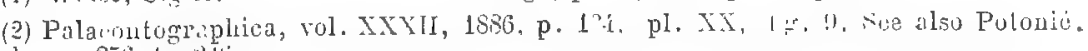

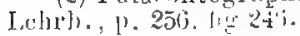


radial, as que estão em contactó com os raios sendo mais ou menos distinctamente rectangulares com angulos ligeiramente redondos, ao passo que as outras são frequentemente muito polygonaes; raios medullares grandes e profusos, variando de 1 a 35 cellulas na altura de 1-4 cellulas na largura, geralmente fusiformes, as vezes attenuados e sinuosos, raramente mais que duas tracheides distantes uns dos outros, cellulas dos taios variando muito en tamanho, na secção transversal, tendo as ve „es de altura, 120 microns e em media 80 microns ou mais, usualmente mais estreitas que altas, relativamente oblonyas, e estreitas transversalmente nos raios estreitos, e poiygonaes nos raios mais largos; distinctamente rectangulares e muriformes na seção radial, diametro radial, excedendo consideravelmente o tangencial, frequentemente maior que uma ver e meía áquelle.

A especie acima descripta está representada na collecção por um unico fragmento de $7,5 \mathrm{cms}$ de diametro longitudinal $6 \mathrm{cms}$. de radial e $75 \mathrm{cms}$ de diametro tangencial. O especimen está um pouco alterado e foi ligeiramente arredondado de um lado, provavelmente antes da deposição. O fragmento é evidentemente da um typo arborescente de grandes proporções, visto que a convergencia dos raios nos lados oppostos do bloco difficilmente se percebe. Nada se sabe quanto á madeira primaria ou cortex. A textura molle do xylem deu em resultado varias zonas de deformação que parecem comtudo ser totalmente independentes de qualquer differenca em estructura.

A tentativa de referencia desta madeira a Sigillaria, baseia-se meramente no grande desenvolvimento evidente do xylem secundario no typo. Deve representar o xylem de uma das especies descriptas nas paginas precedentes Todavia devemos lembrar que os generos Sigillarta e Lepidodendron, nem sempre se distinguem pelos caracteres de sua organização interna, mesmo quando a madeira primaria está bem conservada, sendo os unicos caracteres decisivos, os que offerece a superficie das hastes. A feição do corpo da madeira exogenea não offerece meios de separação generica.

A Siyillaria (?) muralis, é especialmente caracterizada pela profusão de raios muriformes, pelo grande tamanho das cellulas medullares, a regularidade das cunhas do xylem, e o grande tamanho occasional das iracheides que são distinctamente r'eticuladas em contacto com as cellulas dos raios

No specimen acima descripto não observei nenhum feixe que pareça atravessar os raios medullares em direcção ás folhas e se estes 
distinctly rectangular with slightly rounded angles, while the others are frequently polygonal; medullary rays very large and profuse, varying from 1 to 35 cells in haight and from 1 to 4 cells in width, generally fusiform, sometimes attcnuate and sinuate, rarely more than two tracheides distant from one another, ray cells varying, much in sine in transverse section, sometimes reaching a height of 120 microns and averaging 80 microns or more, usually narrwer than high, relatively oblong and narrow transversely in the narrow rays ant polyyonal in the broader rays, distinctly rectangular and murilorm in radial section, the radial diameter considerably exceeding the tangential, frequently by over one and one-half times the latter.

The species described above is represented in the collection by a single fragment $7.5 \mathrm{~cm}$ in longitudinal diam $3 t e r, 6 \mathrm{~cm}$ in radial and $7,5 \mathrm{~cm}$ in tangential diameter. The specimen is weathered a little and has been slightly rounded on one side, probably prior to deposition. The fragment is evidently from an arborescent type of large proportions, since the convergence of the rays on the opposite sides of the block is hardly perceptible. Nothing is known as to primary wood or curtex . The soft texture of the xylem has resulted in several zones of deformation, which appear, however, to be totally independent of any difference in structure.

The tentative reference of this wood to Sigillaria is based merely on the evidently great development of the secondary xylem in the type. It may represent the xylem of one of the species described on the preceding pages. We must remember, however, that the genera Sigillaria and Lepidodendron cannot always be distinguished by the characters of their internal organization even when the primary wood is well preserved, the only decisive criteria being those offered by the surface of the stems. The features of the body of the exogenous wood offer no means for a generic separation.

Sigillaria? muralis is specially characterized by the profusion of the muriform rays, tha graat size of the medullary cells, the regularity of the xylem wedgas, and the occasionally very large siza of the tracheides which are distinctly reticulate in contact with the ray cells.

In the specimen described above I have not observed any bundles that seem to traverse the medullary rays in route to the leaves, and, 
existem, ou os confundi com as margens das tracheides que estão por Jjaixo do plano da secção, devido ao seu pequeno tamanho, ou nãn lui capaz de differençal-os de algumas das tracheides mais frisantemente meandrifolmes. Occasionalmente estas sobrepujam ás illustradas por IVilliamson na sinuosidade anomala de seus cursos.

l' pussivel que os vestigios das folhas estivessem tão distantes por causa do grande crescimento da arvore de forma que não succedeu que as secções interceptassem nenhuma dellas em sua passagem, condicção esta que deve occorrer em um typo Leiodermario ou Rhytidolepis muito velho. Os pequenos raios que se veem nas secções são presumivelmente accessorios, sendo os mais alongados naturalmente primarios. As cunhas do xylem são bem regulares, e não ha evidencia de anastomose tal como apparece na madeira exogenea de Stigmaria.

A evidencia da acção bacteriana se vê bem distinctamente na desintegração das par'edes reticuladas, como está illustrado na fig. 3 . Com maiol augmento na figura 4 o specimen parece ter aspecto muito distincto, de colonias naturaes de «bacterioides».

Lucalidades: Proximo de S. Sepé, Rio Grande do Sul, evidentemente em camadas vermelhas alteradas, 100 a 200 metros acima do carvão São Jeronymo. Lot. 3919. O typo é B R 22.

\section{Sigillaria sp.}

Pl. VI. figs. $10-10^{\mathrm{a}}$

Grandes megasporos semelhantes os illustrados por Carruthers em 1869, e referidos por elle (1) a Flemingites (Lepidodendron) Pecroanus, occorrem em grande abundancia 110 tope do carvão Bonito proximo de Minas, onde constituem a maior parte da rocha, que furma sedimentos, em certas camadas do schisto carjonoso. o aspecto do schisto se vê em ploolographia na estampa VI, fig. 10, rendose mais distincla a forma dos asporos augmentados na fig. 10 a. Variam de $1.2 .5 \mathrm{~mm}$ a $1.7 .5 \mathrm{~mm}$ en diametro, quando são completamente chatos. E' possivel ver a abertura triradiada em alguns specimens. Assim como dos merasporos descriptos por Zeiller (2), do Rio

(1) Geol, MIrit, rul. VI, p. 153, pl, V,figs. 2-5.

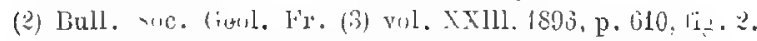


if such are present, either I have mistaken then for the edges of tracheides lying below the section plane on account of their small size, or I have not been able to differentiate them from some of the more markedly meandering tracheides. Occasionally the latter surpass those illustrated by Williamson in the anomalous sinuosity of their courses.

It is possible that the leaf traces were so distant, on account of the large growth of the tree, that the sections have not happened to intercept any of them in their passage, a condition that might occur in a very old Leiodermarian or a Rhylidolepis type. The small rays shown in the section are presumably accessory, the very much elongated ones being prohably primary. The xylem wedges are fairly regular, and there is no evidence of anastomosis such as appears in the exogenous wood of Stigmaria.

Evidence of bacterial action is very distinctly shown lucally in the disintegration of the reticulate walls, as illustrated in fig. 3 . Under a higher magnification, fig. 4, the specimen has the very distinct aspect of having natural colonies of "bacterioids" .

Locality: Near São Sepé, Rio Grande do sul. Apparently in red beds (weathered) 100-200 meters above the S. Jeronymo coal. Lot 3919. The type is BR 22.

Sigillaria sp.

Pl, vi, fig. 10, 10 a.

Large megaspores similar to those illustrated by Carruthers in 1869 and referred by him (1) to Flemingites (Lepidodenron) Pedroanus occur in great abundance in the roof of the Bonito coal near Minas, where they constitute the greater part of the rock-forming sediments in certain layers of the coaly shale. The aspect of the shale is photographically shown in Pl. VI, fig. 10, the features of the spores being more distinctly seen in the enlargement, fig. $10 \mathrm{a}$. They vary from $1.25 \mathrm{~mm}$ to $1.75 \mathrm{~mm}$ in diameter when completely flattened. The triradiate vent is discernable in many of the specimens. As with the inegaspores discribed from Rio Grande do Sul by Zeiller $(2)$ there is nothing re-

(1) Gool, Mag., rol. vi, pg. 153, pl, v. flgs. 2-5.

(2) Bull. Soc. geol. Fr. (3) vol. XXIII, 1893, p. 610, fig. 2. 
Grande do Sul nada resta sinão o exosporo, que é liso e sem lustro. Nenhum dos examinados por mim attinge o diametro maximo de $2.25 \mathrm{~mm}$, notado por elle nos specimens do Arroio dos Ratos.

Devido ao grande tamanho dos megasporos, foram estes considerados por Zeiller como Sigillarianos em vez de pertencerem a Lepidodendron sendo muito estreita a semelhança com os megasporos de Sigillariostrobus Tieghemi. Esta asserção de Zeiller quanto á origem da especie foi com effeito prophetica. A presença do genero Sigillaria no Brazil, está agora completamente demonstrada. Megasporos approximando-se em tamanho dos specimens figurados podem, creio eu, pertencer tambem ao genero Lepidophloios outro typo presente na flora carbonifera barsileira, mas os esporos aqui illustrados podem muito bem ter provindo dos cones de Sigillaria australis que se encontra no mesmo ponto.

A uma das especies de Sigillaria descriptas acima se refere provavelmente o fragmento de folha que se vê na est. V fig. 3. Esta representa a porção da base de uma folha, de cerca de $3 \mathrm{~mm}$ de largua, que da base á extremidade partida tem $8.5 \mathrm{~cm}$; vê-se outra fractura ligeiramente sobreposta na parte inferior. A folha torna-se um pouco aguda para a extremidade no fragmento, a nervura mediana é delgada e os sulcos stomatiferos são collocados largamento distantes. Ha pouca duvida que o specimen pertença a Sigiliaria, ou Lepidophloios e visto que occorre no mesmo schisto com Sigillaria australis e em associação muito intima com alguns dos megasporos acima notados, não hesito em referil-os ao mesmo genero.

Localidade: Os sporos estão em um schisto no carvão Bonito perto de Minas, Santa Catharina, 120 metros acima do granito ecerca de 160 metros abaixo do horizonte do schisto preto de Iraty Lot. 3595. Tambem da Estrada Nova perto de Minas $13 \mathrm{~J}$ metros mais ou menos acima do granito. Lot. 3923. A folha é desta ultima localidade.

\section{IILICALES}

Sob esta denominação estão grupados apenas os typos que, ou não apresentam caracteres Pteridospermicos Cyycadofilices, ou não pa. recem tão estreitamente relacionados com outros typos Pteridosper * micos, de modo a fazer parcer que realmente pertencem a mesma classe. Por consequencia Glossopteris e Gangamopteris juntamente com Neuropteriditum estão excluidos dos verdadeiros fetos neste relatorio. As rasões serão mais completamente discutidas, quando for 
maining but the exospore, which is smooth, and without lustre. Yone of those examined by me attain the maximum diameter, $2.25 \mathrm{~mm}$, noted by him in the Arroio dos Ratos spscimenr.

On account of the large size of the megaspores they have been regarded by Zeiller as projuably Sigillarian, instead of belonging to Lepidodendron, the resemblance to the megaspores of Sigllariostrolus 'rieghemi heing very close. 'This expression on zeiller's part as to tho ol'igin of the species was in effect prophetic. The presence of the genus Sigillaria in Brazil is now fully demonstrated. Megaspores approaching in size the specimens figured may, I believe, also ljelong to the genus Lepidophloios, another type present in the Brasilian coal flora; but the spores here illustrated may well have been derived from the cones of Sigillaria culstralis, which is found at the same point.

To one of the species of Sigillaria described above is probably to be referred the leaf fragment shown in $\mathrm{Pl}$. $\mathrm{Y}$, fig. 3. This represents the basal portion of a leaf nearly $3 \mathrm{~mm}$ in width. From the base to the broken end is $8.5 \mathrm{~cm}$, another fracture, with slight overlap, being secn in the lower part. The leaf tapers but little in the fraginent the midrib is slender, and the stomatiferous furrorvs are wide set. There is little doubt that the specimen belongs to Sigillaria or Lepidophloios, and since it occurs in the same shale with Sigillaria australis.s and in most intimate association with some of the megaspores noted above I do not hesitate to refer it to the same genus.

Locality: The spores are in a shale in the Bonito coal near Minas, Santa Catharina. 120 meters above the granite, and about 160 meters below the Iraty black shale horizon. Lot 3595. Also from Estrada Nova near Minas. About 135 meters above the granite. Lot. 3923. The leaf is from the latter locality.

\section{FILICALES}

Iereunder are included only the types which either do not themselves present Pteridospermic Cycadofilic characters or do not secm so closely related to other Pteridospermic types as to make it appear probable that they really belong to the same class. Accordingly Glossopteris and Gangamopteris, together with Neuropteridium. are in this report excluded from the true ferns. The reasons will be more fully discussed in connection will the discussion of each genus. 
feita a discussão de cada genero. Os typos que se podem referir aos fetos parecem ser raros, tanto em especies como em numero, quasi em toda a parte de flora Gondwana inferior do hemispherio oriental, sendo tambem muito raros, tanto quanto se sabe na flora carbonifera do Sul do Brasil, havendo apenas dois pequenos fragmentos, ambos do genero Sphenopteris nas collecções que tenho a vista.

A occurrencia de Psaronius nos estados do Piauhy e S. Paulo, um pouco ao norte, e a evidente approximação do Brasil da flora Permiana do Norte, como se ve pelo numero dos generos de Lepidophytas do Norte, nos leva a prever a descobarta de uma flora mais numerosa de fetos, incluindo membros de Pecopteris ou Cladophebis e outros generos mais communs na provincia floral do sorte.

\section{SPHENOPTERIDEAE}

\section{Sphenopteris}

Sternberg, Versuch, Fl. Vorwelt, vol. I, Tent. 1826, p. XV

\section{Sphenopteris hastata Mc Coy?}

Pl. 6. VI. fiig. 1

1847. Sphenoteris hastata Mc. Coy. Ann. Mag. N. H. vol. XX p. 149, Est. X, flgs. 1 e 1 a.

O fragmento que se ve na estampa XI, fig. 1 éo unico representante nas nossas collecções do grupo estreitamente relacionado que contem as especies acima mencionadas. Infelizmente a matriz de arkose molle contem traços de nervuras tão obscuros, que a identificação deve ficar duvidosa,dependendo da descoberta de mais material, A planta que tenho em mão differe de Sphonopteris Hughesi (Feistm), Zeiller (1) por suas pinnas largamente triangulares, curtas e subordenadas ; e o rachis estreitamente alado, embora as subdvisões sejam em alguns casos semelhantes em fórma e lobação.

o professor Arber (2) referiu recentemente Sphenopteris hastata juntamente com Sphenopteris plumosa, Sphenopteris germana e Sphenopteris flexuosa de Mc. Coy, á Sphenopteris lobifolia Morr. A união das tres primeiras especies mencionadas, todas provenientes da mesma localidade Mulubrina, New South Wales, pareceria bem

(1) Veja-se Feistmart Fl. Gondwana System Vol. III, pl. 2, pl. XXIIIA flg. 1, 2.

(2) Flora de Glossopteris, 1905, p. 135. 
Types referable to the ferns appear to be rare, both in species and number, nearly everywhere in the lower Condwana flora of the Lastern hemisphere, and they are also very rare, so far as known, in the coal flora of Southern Brazil, there being but two small fragments, Joth referable to the genus Sphenopteris in the collections before me.

The cccurrence of Psaronius in the states of Piauhy and São Paulo a little to the north, and the evident nearness of Brazil to the Northern Permian flora, as shown by the number of Northern Lepidophytic genera, lead us to look forward to the discovery of a larger filicate flora including members of Pecopteris or Cladophebis and other genera more common in the Northern floral province.

\section{SPHENOPTERIDEAE}

\section{Sphenopteris}

Sternberg, Versuch Fl. Vorwelt, vol. I, Tent., 1826, p. XV

Sphenopteris hastata Mc Coy?

Pl. VI. Fig. 1.

1847. Sphenopteris hastata Mc Coy, Ann. Mag. N. H., vol. XX, p. 149, pl. x, flg. 1, 1 a.

The fragment shown in Plate VI, Fig. 1, is the sole representative, in the collection, of the closely related group which includes the species named above. Unfortunately the soft arkose matrix yelds such obscure traces of the nervation that the identification must remain uncertain pending the discovery of more material. 'The plant in hand differs from Sphenopteris Hughesi (Feistm.) Zeiller (1) by its more broadly triangular, short, subordinate pinnae, and the narrowly alate rachis, though the subdivisions are in some cases similar in form and lobation.

Professor Arber (2) has racently reforred Sphenopteris hastata togetlier with McCoy's Sphenopteris plumosa, Sphenopteris germana and Sphenopteris flexuosa to Sphenopteris lobifolia Morr. The union of the three species first mentionel, all of which come from the same locality, Mulubima, New S'ath Wales, would saem to be well foun-

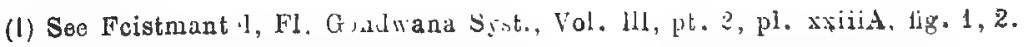

(2) The Glossopteris flora, 1905, p 135. 
fundada, pois que as differenças entre el las não são mais que as que so encontram em differentes pontos nas frondes de uma mesma planta.

Nenhuma illustração addicional de Sphenopteris hastata foi dada por outros autores (1) que citam a diagnoze ol'iginal. Pela posição e fórma das pinnas e até certo ponto pela lobação a planta do Brazil é comparavel as especies australianas estreitamente relacionadas e descriptas poi Brongniart (2), como Pecopteris alata, da serie New Castle em New South Wales ao passo que existe semelhança mais estreita entre esta e a pequena fórma da espacie de Brongniart descripta por Morris (3) como variedade exilis.

Localidade: listrada Nova, proximo de Minas, Santa Catharina 40 metros approximadamente abaixo do carvão Barro Branco, ou cerca de 145 etros abaixo do Schisto pieto de Iraty: lote 3923.

\section{Sphenopteris sp.$$
\text { P. VI lig. } 2
$$

O specimen minusculo e mal conservado que se ve na estampa v1 fig. 2, é o unico representante na collecção de um outro Spluenopterideo. Pelns seus lobuly; paquenos obliquos, truncados, arredondados, um tanto expessos, ligeiramente imbricados, da-nos a idéa de varias cspecies de Permo Carbonifero do norte com espacialidade de Callipteris Curretiensis Zeiller (4) e Ca'lipteris diabolica Zeiller, do Permiano da Jacia de Brives em l'lan("a e Sphenopteris Ohmanniana do Permiano da Thuringia (5) dado por Potoniè. o fragmento que tenho em mão, embora differente de alguns outros, descriptos da flora do Gondwana inferior, è muito intelessante, visto indicar a presença de uma forma que ć provavelmente relacionada com algumas especies da tiora PermoCar'jonifera do norte, si não fir identica.

Localidade: listrada de Treviso perto de Minas, Santa Catharina, horizonte logo acima do conglomerato de orleans, lot. 3587.

(1) Bipinnarlas, pinnas longas autas lanceoladas com marem largamente alada, pinnulas cllipticas obscuramente ondulato-dentadas, tendo tuis ramos alcancando cuda lobulo da martem, Ann, ina

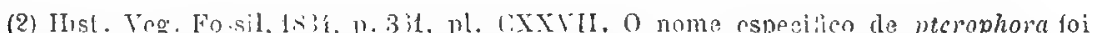

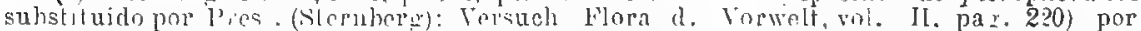

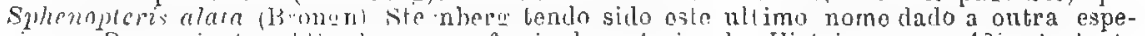
cie po. Bro.sgniarl pu'slitadu em um fis siculo anterion du «lisloire" pag. 180. A planta australiana deveria por conse unte sardenominada Sphenopteris pterophora Presl.

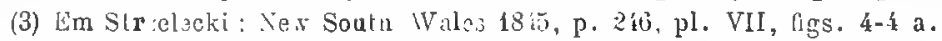

(4) F1. foss has in houill ot perm. d. Brives 18,2. pr. 36, 37, pl. VII, fig. 3-5.

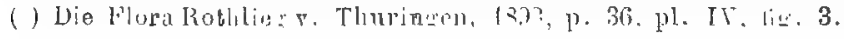


ded; for the differences between them are prohably not moro than are to be found at different points in the fronds of a single plant.

No additional illustration of Sphenopteris hastata have Jeen given by other suthors, who quote tho original dingnosis. (1) By the position and form of the pinnae anu to some extent by the lobation the plant from Brazil is comparable to the closely related Australian species described by Brongniart (2) as l'ecopteris alati from the Xew Castle series in Nev South Wales, while a still closer similarity exisls between it and the small form of Brongniart's species idescribed by Morris (3) as the variety exilis.

Locality : Estrada Nova, near Minas, Santa Catharjna. About 40 meters below the barro Branco coal, or approximately 145 meters below the Iraty black shale. Lot 3923 .

\section{Spluenopteris sp.}

Pl. V'. Fig. 2

The minute and poorly preserved specimen shown in Pl. VI. Fig. 2, is the sole representative of another Sphennpterid in the collection. By its small, oblique, round-truncate, rather thick lobes, which are slightly imbricated, it suggests several species of the Northern Permo-Carboniferous, especially Callipteris Curreticnsis Zeiller (4), and Callipteris diabolica Zeiller from the Permian of the Jasin of Brives in France, and the Sylcenopteris Ohmannicunc shown l,y Potonie from the Permian of Thuringla (5). The fragment in hand, while unlike any other described in the lower Gondwana flora, is extremely interesting as indicating the presence of a form that is probably related to, if not identical with, some species of the Northern Permo-Carboniferous flora.

Locality : Treviso road neal Minas, sinta Catharina; horizont just above that of the Orleans conglomerate. Lot 3587.

(1) Bipinuate, pinnac long, acutcly lanceolate will a bondly alate margin, pinnules clliptical, obscruely nndulate-dentate, having thre olssolete lobis on cach side. ners's bipinnate, two branchos reaching each lobe of the margin. Ann. mag. X. II., rol. xx, $1847 .$, p. 149.

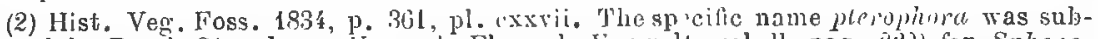

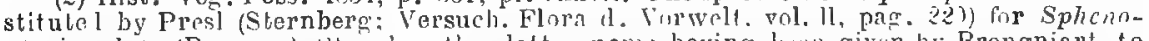
pteris alata (Brongm, Sternb., th. latt n num having her given by Brongniart to another speciss publinh in an carlicr fascicle $(p$. 180) of th. "Histnirs". The Iustralian plant should therefore be designated Sphcmoptcris prerophora Presl.

(3) In Strzelecki : New South Walcs, 184j, p. 24i, pl rii, figs.4, 4 a.

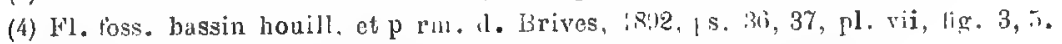

(5) Die Flora d. Rotlilixg. .. 'Phuringen, 1:93, p. 30, pl. iv, lig. 3. 


\section{Psaronius}

Cotta, Dic. Dendrolithen, 1832, p. 27

Sob esta denominação estão reunidos troncos petrificados de fetos arborescentes, tendo um cylindro central lenlıoso envolvido por uma zona cortical de parenchyma, usualmente espessa, atravessada por numerosas raizes descendentes adventicias.

o cylindro lenhoso contém um numero variado de stelas em forma de cintas achatadas, algumas vezes sinuosas, ou curvadas em secção, ordenadas em circulos concentricos e anastomosando-se em uma massa fundamental de tecido parenchymatoso conjunctivo. Ha em algumas especies faixas sclerenchymatosas anastomosadas intercaladas proximo da peripheria que éalgumas vezes marcada por uma bainha sclerenchymatosa. A stela individual é concentrica em estructura consistindo em um cordão central de trachèas scalariformes cercadas de phloem.

Os cordões das folhas em forma de bandas convexas no dorso, sahem das anastomoses das stelas externas. Cada raiz adventicia intercortical tem uma stela polyarca central, distinctamente stelada em secção, um cortex parenchymatoso interno e um cortex sclersnchymatoso externo.

As frondes de Psaronilus estão incluidas em Pecopteris, e abrangem especies com typos de fructificação de Asterotheca e Scolecopteris. Săo mais propriamente relacionados com as Marattiaceae actuaes, em bora representando uma tril)u totalmente extincta. Na flora do norte o genero occorre no Stephaniano e Permiano, tanto da Europa como da America do Norte.

Psaronius brasiliensis Brong.

1850. Psaronius brasiliensts Brongniart. mss. Unger in Martius. Hist nat. palmarum, vol. I, p LXXX, pl. geol. fig. 4; Brongniart Bull. Soc. Bot. Fr. (5) vol. XIX 1872, p. 3, Bennett e Murray, Handb. Grypt. Bot. 1889, p. 123, fig. 95; Leiller Fl. foss. basin, houill, Autun et Epinac, pt. 1, 1890, p. 246, p. XXI, fig. 1, Zeiller, Bull. Soc. Geol. Fr. (3), vol. XXIII, 1896, p. 605, Scott Fossil Botany, 1900 p. 271, fig. 96 ; Solms Laubach, Festchr, 


\section{Psaronius}

Cotta, Die Dendrolithen, 1832, p. 27.

Under this name are included petrified trunks of tree ferns having a central wood cylinder surrounded by an usually thick cortical zone of parenchyma traversed by numerous descending adventitious roots.

The woody cylinder contains a variable number of steles in the form of flat bands, often sinuate or hooked in section, arranged in concentric circles and anastomosing in a ground mass of parenchymatous conjunctive tissue. Anastomosing sclerenchymatous bands are, in some species, intercalated near the periphery, which is sometimes marked by a sclerenchymatous sheath. The individual stele is concentric in structure, consisting of a central strand of scalariform tracheides surrounded by phloem.

The leaf strands, in the form of dorsally convex bands, spring from the anastomoses of the outer steles. Each intra cortical adventitious root has a central polyare stele distinctly stellate in section, an inner parenchymatous cortex, and an outer sclerenchymatous cortex.

The fronds of Psaronius are included in Pecopteris and embrace species with the Asterotheca and Scolecopteris types of fructifications. They are most nearly related to the living Marattiacece though representing a totally extinct tribe. In the Northern flora the genus occurs in the Stephanian and Permian of both Europe and North America.

\section{Psaronius brasiliensis Brong.}

1850. Psaronius brasiliensis Brongniart, mss., Unger in Martius, Hist. nat. palmarum, vol. 1, p. LXXX, pl. géol. 1, fig. 4; Brongniart, Bull. Soc. bot. Fr., (5) vol. XIX, 1872, p. 3 ; Bennett and Murray, Handb. Grypt. Bot., 1889 , p. 123, fig. 95 ; Zeiller, Fl. foss. bassin houill. Antun et Epinac, pt. 1, 1890, p. 246, pl. XXI, flg. 1 ; Zeiller, Bull. Soc. géol Fr., (3) vol. XXIII, 1896, p. 605 : Scott, Fossil Botany, 1900, p. 271, fig. 96 ; Solms-Laubach, 
1. Ascherson's, Siebz Geburtstag 1904, p. 18 ; Derby Jorn. do Commercio Rio de Janeiro Março 13, 1906, p. 1 ; Arber The Glossopteris Flora, 190j, p. 148, pl. VIl.

Cylindto lenhoso, corcado por uma bainha sclerenchymatosa continua, stelas periphericas em numero de quatro, separadas da região contral em parte de seu comprimento, por cintas sclerenchymatosas, fortemente enroladas nas extremidades as quaes curvam-se para trä, quasi para o centro. Atrais de cada uma das quatro stelas criteriores ha uma sirin radial de 2 ou 3 stelas fortemente arqucadas, algumas das quaes ainda se dividem de novo, ou em outros casos unem-se formando um annel completo. Alternando-se entre estas stelas e as vezes unidas a ellas; ha outras cintas que são mais ou menos arqueadas, sendo as exteriores mais largas que as que se acham perto do centro do tronco, folhas en quatro alinhamentos verticaes, provavelmente em pares oppostos oul sub-oppostos; ciro das raizes adventicias formado de 6 a $\&$ feisis confluentes; tecido conjunctivo do annel radicular, continuo ron o do tronco, corter interior não lacunoso, mas parece apresentar canaes de gomma em numero variado dispostos mais ou menos sm riprulo.

o Psaronitus hrasiïensis não está representado nas collecções organisadas pela Commissão. O material, do Museu de Ilistoria Natural de Paris, descripto por Brongniart, foi completamente estudado yelo professor 'Zeiller de cuja diagnose a descripção acima foi extrahida. Os specimens de Londres foram novamente descriptos e illustrados por Arber (2). O specimen figurado por Unger diz-se que foi colleccionado por Martius entre Oeiras a São Gonçalo de Amarante no Estado do Piauhy.

As investigações feitas pelo conde Solms-Laubach mostram que os spccimens que contem porção do cylindro interior, actualmente em Paris, Londres e Strasburgo são todos tirados de um grande segmento de um lirnco (que se acha actualmente no Museu do Rio de Janeiro. A origem deste tronco parece estar em duvida, mas julga-se provavel que elle tenha vindo de São Paulo, ou do Rio Grande do Sul, no Sul do Brazil o rue na verdade na opinião do Dr. Derby, deve

(1) Fl. foss. hasin houill e perm. Autun o Epinac pt. 1, 1890, p. 246.

(2) The Glossopt'ris Flora 1905, p. 148, pl. VII: 
Festschr. P. Ascherson's Siebz. Geburtstag, 1904, p. 18 ;

Derby, Jor. do Commercio, Rin de Janeiro, Março 13, 1906,

p. 1 ; Arber, The Glossopteris Flora, 1905, p. 148, pl. VII.

Woody cylinder surrounded by a continuous sclerenchymatous sheath; peripheral steles 4 in number, separated from the central region for a part of their extent by sclerenchymatous bands, and strongly intolied at the extremities which sometimes loop backvard nearly to the middle. Behind each of the four. outer steles is a radial series of 2 or 3 strongly arched steles, some of which sometimes divide again, or in other instan'es unite to form a complete ring. Alternating between these steles, and sometimes joined to them, are other bands which are more or less arched, the outer ones being broader than those nearer the center of the trunk; leaves in four vortical rows, probably in opposite or subopposite pairs; axis of the adventitious root formed of $6-.8$ broadly confluent bundles; conjunctive tissue of the radicular ring continuous with that of the trunte; inner cortex not lacunose, but appearing to carry gum canals in a varyning number more or less regularly arranged in a circle.

Psaronius brasiliensis is not represented in the collections made by the Commission. The material describad by Brogniart in the Museum d'Hisioire Naturelle at Paris has been very fully treated by Professor Zeiller (1) from whose diagnosis the above description is extracted. The London specimens have been re-described and illustrated by Arber. (2) The specimen figured by Unger is said to have been collected by Martius between Oeiras and San Gonralo d'Amarante, in the state of Piauhy.

The investigations made by Count Solms-Laubach shor that the specimens containing portions of the inner cylinder, now in Paris, London and Strasburg were all derived from the large segment of a trunk now in the Museum at Rio de Janeiro. The source of this trunk appears to be in doubt, but it is thought probable that it came from São Paulo or Rio Grande do Sul in Southern Brazil, as indeed, in the opinion of Doctor Derby, may also the original

(1) Fl. foss. bassin houill. et perm. Autun et Epinac., pt. 1, 1890, 1. 246.

(2) The Glossopteris Flora, 1905, p. 148, pl. VII. 
ter-se dado com o specimen original levado por Martius para Paris. Isto é importante por justificar a expectativa de Pecopteris ser encontrada na mesma região.

lím Lodo o caso Psaronius se encontra em São Paulo associado com Lycopodiopsis Derbyi madeira de Cordcites e coniferas e ossus de Stereosternum, como foi referido pelo professor Renault (1) e por Zeiller baseados na auctoridade do Dr. Derby. Julga-se que o genero se encontra tambem no Lstado do Paraná.

Por conseguinte não parece improvavel, que Pecopteroides representante: da flora Permo Carbonifero do norte possam se encontrar tão ao sul como as bacias carboniferas dos Estados de Santa Catharina e Rio Grande do Sul. Comtudo deve-se guardar em mente que as madeiras fosseis e os restos de vertebrados com que Psaronius parece estar ossociado, parecem pertencer a camadas proximas, talvez do horizonte do schisto preto de Iraty. Devemos por isto esperar que as frondes de Peconteris pertencendo provavelmente ao grupo Cladophleboide de fórmas Permianas serão encontradas em camadas mais elevadas que a maior parte dos carvões e conseguintemente de data mais posterior a das plantas do antigo Gondwana, que occorrem em abundancia nas camadas inferiores da formação carbonifera de Santa Catharina e Rio Grande do Sul. Mais ao norte, talvez tanto ao Sul como os Estados de Piauhy e Bahia, os typos do norte podem ter prosperado contemporaneamente com Gangamopteris e Glossopteris do sul do Brazil.

Localidade: Entre Oeiras e São Gonçalo, Estado do Piauhy (?):

o typo figurado por Unger acha-se no Museu de Historia Natural de Paris.

\section{PTERIDOSPERMEOS}

Pelas razões que serão mais completamente explicadas nas discucsões do genero individualmente, transferi para as Pteridospermens os generos Neuropteridium, Glossopteris e Gangamopteris, incluides anteriormente nos fetos. As estreitas affinidades entre as frondes estereis dos dois ultimos generos citados e as dos Cyclopteroides (iucluindo Neuropteroides) e Taeniopteroides Cycadofiliceos e os caracteres cycadaceos dos orgãos sporangiferos, que se encontram reunidos

(1) Sinll. Soc. Hisl, wat. Autun vol. III, 1890, p. 109. 
specimen brought to Paris by Martius. This is important, as it justifies the expectation that Pecopteris also was present in the same region.

In any event Psaronius was present in São Paulo where it is associaled with Lycopodiopsis Derbyi, wood of Cordattes and conifers, and bones of Stereosternum, as reported by Renault (1) and by Zeiller on the authority of Doctur Derby. Tlie genus is lelived to be present in Parana also.

It therefore seems not improjiable that Pecopteroid representatives "I the Northern Permo-Carboniferous flora may be found as far south as the coal basins of the states of Santa Catharina and Rio Grande do Sul. It must, lowever be borne in mind that the lossil woods and vertebrate remains, with which the Psaronius is said to be associated, appear to belong to beds perhaps near the horizon of the Iraty black shale. We may expect, that therefore, Pecopteris fronds possibly bolonging to the Cladophleboid group of Permian forms, will be found in beds higher than most of the coals, and consequently of later date than the older Gondwana plants which occur so abundantly in the lower coal measures of Santa Catharina and Rio Grande do Sul. Farther north perhaps as far south as the states of Piauhy and Bahia, the northern types may possibly have thriven contemporanenusly with the Gangamopteris and Glossopteris of southern Brazil.

Locality : Between Oeiras and San Gonçalo state of Piauhy (?) The type figured by Unger is said to be in the Museum d'Histoire Naturelle at Paris.

\section{PTERIDOSPERAS}

For reasons which will be explained more fully in the discussions of the individual genera l lave transferred to the Pteridosperms the genera Neuropteridium, Glossopteris and Gangumoptris, previously included with the ferns. The close affinities letween the sterile frond $=$ of the two sonera last named and those of the cyclopteroid (including 1 he Yeurupteroid) and T'aeniopteroid Cycadfilices, and the Crcadalean characters of the sporangiferous organs found

(1) Bull. Soc. hist. nat., Lutun, vol. III, 1890, p. $10 \%$. 
ou associados intimamente com as folhas destes generos, exigem parece-me, que sejam collocados nos Cycadofilices.

Ao mesmo grupo referi tambem os generos Ottokaria e Derbyella, e suspeito que este ultimo pertence á Gangamopteris. Não é de todo improvavel que uma, ou mais das especies de sementes reunidas, tenham nascido de alguma planta tendo folhas de Gangamopteris, ou Glossopteris.

\section{NEUROPTERIDE $\not \mathrm{E}$}

\section{Neuropteridium}

Feistmantel Fl. Gondwana Syst. vol. III, 1880, p. 84

A designação Neuropteridium foi a principio proposta por Schimper (1) para designar uma secção de Neuropteris com frondes simplesmente pinnadas em que os pinnulas variam de uma fórma quasi redonda e inteira á um ty po oblongo, l'edondo lobado sempre largamente ligado e decorrente do rachis.

Os lobulos são juntos curvando-se gradualmente para fóra das bases fortemente decorrentes.

A nervação deriva-se um tanto flabelliforme de um feixe muito obliquo, divergindo gradualmente e logo desapparece dichotomisando-se em nervillas que se curvam graciosamente passando para ơ bordo. A especie typo é do gres variegado dos Vosgues; porém, o representante do genero mais interessante e espalhado é Neuropteridium validum (Neuropteridium Plantianum da flora de Gangamopteris).

A posição systematica do generoé duvidosa, ao passo que a correlação de Zeiller (2) das frondes estereis do Bunter, Neuropteridium, com as frondes ferteis tambem Triassicas, descriptas por Schimper e Mongeot (3) como Crematopteris é agnra geralmente admittida; os detalhes dos sporangios que parecem cobrir a superficie da folha, são muito insufficientes para fornecerem uma base satisfactoria para a referencia definittva do typo aos Heelices ou Cycadofilices. A especie do Gondwana ainda não revelou traço algum de fructificação, embora se

\footnotetext{
(1) Traité Pal. Veg. vol, I, 1869, p. 447.

(2) Eléments de paleobotanique 1900, p. 10 ).

(3) Monogr. pl. foss. grés, bigarre des Vosgues, 1814, p. 73.
} 
either in union or in intimate association with the leaves of these genera demand, it seems to me, that they be placed with the Cycadofilices.

To the same group I refer also the genera Ottokaria and Derbyella, the latter of which I suspect belongs to Gangamopteris. It is not improbable that one or more of the specimens of associated seeds was borne by some plant having the leaves of Gangamopteris or Glossopteris .

\section{NEUROPTERIDE $\bar{E}$}

\section{Neuropteridium}

Feismantel, Fl. Gondwana Syst., vol. III, 1880, p. 84

The name Neuropteridium was first put forward by Schimper (1) to designate a section of Neuropteris with simply pinnate fronds on which the pinnules, varying from a nearly round and entire form to an oblong, round-lobate type, are al ways broadly attached and decurrent on the rachis.

The lobes are close, curving gradually outward from the strongly decurrent base.

Ths enervation is derived. somewhat flabellately from a gradually diverging, very oblique bundle which soon vanishes in dichotomizing nervilles that curve gently in passing to the border. The type species is from the Bunter sandstone of the Vosges; but the most interesting and widespread representative of the genus is the Neuropteridium validum (Neuropteridium Plantianum) of the Gangamopteris flora.

The systematic position of the genus is uncertain ; for while Zeiller's correlation (2) of the sterile fronds of the Bunter Neuropteridium with the fertile fronds, also Triassic, described by Schimper and Mongeot (3) as Crematopteris is now generally admitted, the details of the sporangia which appear to crowd the surface of the leaf are too meager to afford a satisfactory basis for the definite reference of the type to either the Filices or the Cycadofilices. The Gond wana species has not yet revealed any trace of fructification though it is said to be very

(1) Traité Pal. Vég., vol. 1, 1869, p. 447.

(2) E'léments de Paleobotanique, 1900, p. 109.

(3) Monog. pl. foss. grès bigarré des Vosges, 1844: p. 73. 
diga serem muito abundantes nas camadas Karharbari da India e não muito rar'os na Africa do Sul, Brazil e Argentina. Estas circumstancias, tomadas junto com uma affinidade presumida, baseada nos caracteres vegetativos, com o Neuropterideo da flora Permo Carbonifera do Norte, levou Seward (1) a questionar si a flora do Gondwana não é de facto Cycadofilicea A suggestão de Servard da affinidade da nossa planta com Car'dirnter'is do Carboniforo inferjor do norte, é, a meu vêr, bem fundamentada, como é tamluem a comparação suggerida com Atrchoeopteris Datosoni de stur. A planta do Gondwana é igualmente comparavel. cleio eu, com as frondes do carbonifero inferior da parte oriental dos Estados Lnidos descripta por Meek (2) como Cyclopteris virginiana.

A folha desta especie que nunca foi convenientemente illustrada, apresenta alguns pontos de frisante semelhança com Neuropteridium Plantianun.

Ambos os typos, parece-me, devem ser considerados como sendo plovavelmente Gycadofiliceos.

A questão sobre a congenereidade de Crematopteris Triassica do Gondwana inferior com Neuropteridium, parece merecer attenção acurada.

Neuropteridium Plantianum (Carr.) D. W.

1869. Odontopteris Plantiana, Carruthers, Geol. Mag. vol. VI, p. 155, pl. VI, fig. 2, 3 ; Hartt, Geol. a. Phys. Geol. Brasil 1870, p. 524.

1876. Neuropteris volida Feistmantel, Rec. Geol. Surv. India, vol. IX, pt. :3, p. 75 ; Feistmántel F'l. Gondwana Syst. vol. III, 1879, p. 10 ; pl. II-T1, Oldham Geol. India 1893, p. 158. 1880. Neuropteridium validum, Feistmantel FI. Gondwana, Syst. vol. III, pt. 2, p. 84 ; Feistmantel. op cit. suppl., 1881 p. 53; Kurtz, Pevista Mus. La Plata, vol. VI, 1894, p. 127, pl. 1, figs. 1, 2; Zeiller, Comptes Rendus, vol. CxxI, 1895, p. 963 ; Zeiller, Bull. Soc. géol. Fr. (3) vol. XXIII, 1896, p. 616 ; lodenbender, Revista Mus. La Plata, vol. VII. 1895, p. 148, Bodebender, Zeitsch, d. Deutsch. Geol. Gesell, vol. XLVIII,

(1) Aun. S. Afr. MLus., vol. IV, pt. I, 1903, p. 83.

(2) Bull. Phil. Soc. Mialing Lon, rol. II, 1876. Appendix pl. XVIU, p. I, fig̣. 3. 
abundant in the Karharbari beds of India and not very rare in South Africa or Brasil and Argentina. These circumstances, taken in connection with a presumptive relationship, based on vegetative characters, with the Neuropterids of the Northern Permo-Carboniferous flora, led Seward (1) to question whether the Gondwana plant is not really Cycadofilicate. Seward's suggestion of a relationship of our plant with Cordiopteris, from the Northern Lower Carboniferous, is, in $m y$ judgment, well founded, as also is the suggested comparison with Stur's Archaeopteris Dawsoni. The Gondwana plant is equally comparable, I believe, with the frond from the Lower Carboniferous of the Easlern United States described by Meek (2) as Cyclopteris virgi niana.

The leaf of the latter species, which has never been adequately illustrated, presents some points of striking similarity to Neuropteridium Plantianum.

Both types, it seems to me, are to be regarded as probably Cycadofilicate.

The question ot the congenerity of the Triassic crematopteris and the lower Gordwana Neuropleridium is one appearing to deserve careful consideration.

\section{Neuropteridium Plantianum (Carr.) D. Y.}

1969. Odontopteris Plantiana Carruthers. Geol. Mag., vol. vi, p. 155, pl. vi, fig. 2, 3 ; Hartt, geol. a. Phys, Geogl' Brasil, 1870, p. 524 .

1876. Neuropteris valida Feismantel, Rec. Geol. Surr. India, vol. ix, pt. 3, p. 75 ; Feistmantel, Fl. Gondwana Sțst., vol. iii, 1879 p. 10, pl. ii-vi ; Oldham, Geol. India, 1893, p. 158.

1880. Neuropteridium validum Feistmantel, Fl. Gondwana Syst., vol. iui, pt. 2, p. 8' ; Feistmantel, op. cit., Suppl., 1881, p. 53 ; Kurtz, Revista Mus. La Plata, vol. vi, 1894, p. 127, pl. I, figs. 1, 2; Zeiller', Comptes Rendus, vol. cxxi, 1895, p. 963; Zeiller, Bull. Soc. Géol. Fr., (3) rol. xxiii, 1896, p. 616; Bodenbender, Revista Mus. La Plata, vol. vii, 1895, p. 148 ; Bodenbender, Zeitsch. d. Deutsch Geol. Gesell., vol. xlviii, 1896, p. 772; Seward,

(1) Amn. S. Afr. Mus., vol, iv, pt. 1, 1903, p. 83.

(2) Bull. Phil. Soc. Washington, vol. II, 1876, Appendix, p. xviii, pl. l, lig. 3. 
1896, p. 772 ; Seward Ann. S. Afr. Mus. vol. IV, pt. 1, 1903, p. 85, p]. X, fig. 1. Arber The Glossopteris Flora 1905, p. 116, fig. 28 , pl. VI ; fig. I.

1905. Neuropteridium Plantianum (Carr.) D. White, Science,

n. s. vol. XXI, p. 700.

Fronde longa e iinear, pinnada, rachis forte, com pinnulas que na parte inferior da fronde são inteiras, de forma mais ou menos senicircular, se transformando gradualmente em segmentos mais longos c lobados. As pinnulas mais longas pelo rachis acima que attingem um comprimento de $0^{\mathrm{m}}, 6$ ou menos, não são ligadas por toda a base, como os segmentos mais fortes e largos na parte basal da fronde, porem o lobo basal da extremidade superior do segmento é desligado do rachis. Apice das pinnulas obtusamente arredondado, nervuras divergentes, curvando-se na direção da extremidade das pinnulas com ramificação dichotoma repetida e convergindo nos segmentos mais longos, formando uma nercura mediana bem distincta, na parte inferior da lamina.

A descripção acima foi extrahida do intesessante estudo do professor Seward, da especie, publicado no primeiro volume (p. 85) dos Annaes do Museu Sul-Africano. Este typo muito importante e caracteristico da flora de Gangamopteris não se acha representado na collecção que tenho em mão, embora tenha sido primeiro descoberto e descripto no Brazil. O professor Kurtz (1) descreveu e illustrou a mesma planta que actualmente é referida de diversas localidades da Argentina. A especie occorre na Africa do Sul, assim como na India e America do Sul.Johnston (2) diz existir na Tasmania uma fórma estreitamente relacionada com Neuropteridium Plantianum..

A identidade de Odontopteris Piantiana de Carruthers com Neuropteris valida de Feistmantel foi primeiro suggerida por Zeiller, (3) depois confirmada por Seward (4) e Arber (5), tendo cada um delles examinado o typo original de Carruthers.

Não ha por conseguinte duvida quanto a prioridade ou applịcação do primitivo nome proposto por Carruther, que deve prevalecer, não

(1) Revista IIus. La Plata, v. VI, 1894, p. 127, pl. 1.

(2) Paper and Proc. R. Soc. Tasmania 1886 (1887) p. 171. Teuropteris Tasmaniensis,

(3) Bull. Soc. Geol. Frr. (3) vol. XXIII, 1896, p. 610.

(4) Ann. S. Africa Mus. vol. IV, pt. 1, 1903, p, 86.

(5) The Glossopteris Flora 1905, p. 119. 
Ann. S. Afr. Mus., vol. iv, pt, 1, 1903, p. 85, pl. x, fig. 1; Arber, The Glossopteris Elora, 1905, p. 116, fig. 28, pl. vi, fig. 1.

1905. Neuropteridium Planticnum (Carr.) D. White, Science, n. s., vol. xxi, p. 700 .

Frond long and linear, pinnate, rachis strong, bearing pinnules which in the lower part of the frond are chtire and more or less semi-circular in form, and gradually pass into longer and lobed. segments as tee ascend the rachis. The longer pinnules, tohich may reach a length of $6 \mathrm{~cm}$. or more, are not attached by the whole of the base, like the stouter and broader segments in the basal portion of the frond, but the basal lobe of the upper edge of the segment is froe rom the rachis. Apex of pinnules bluntly rounded. Veins spreading, curving towards the rdgr of the pinnules with repeated dichotomous branching, and converging in the lonyer segments to form a fairly distinct mirlrib in the lower part of the lamina.

The above description is quoted from Professor Seward's very interesting treatment of the species published in the first volume (p. 85) of the Annals of the South African Museum. This very important and characleristic type of the Gangamopteris flora does not happen to be present in the collection before me though it was first discovered and described from Brasil. Professor Kurtz (1) has described and illustrated the same plant, which is now reported from several localities in Argentina. The species occurs in South Africa as well as in India and South America. A form said to be nearly related to Netropteridium Plantianthn is reported by Johnston (2) from Tasmania.

The identity of Carruthers' Odontptris Plantiana with Feistmantel's Neuropteris valicla, first suggested by Zeiller, (3) has since been confirmed by both servard (4) and Arber (5) each of whom has examined the original Carruthers types. There is therefore no question as to the priority or application of the name earlier proposed by Car 4 ruthers, which should prevail, notwithstanding the unfamiliarty with

(1) Rovista Mus. La Plala, vol. vi, 1804, p. 12r, pl.i.

(2) Papers and Proc. R. Soc, Tasmania, 1885 (1887), p. 171. Neuropteris Tasmaniensis.

(3) Bull. Soc. Géol. Fr., (3) vol, xxiii, 1890, p. 616.

(t) Anı. S. $\Lambda$ fr. Mus., vol. iv, pt. 1, 1903, p. 86 .

(i) The Glossopteris Flora, 1905, p. 119. 
ojsstante não se estar familiarisado com elle o que se dará temporariamente. E' muito proprio que o nome do engenheiro inglez que bastante irabalhou para o desenvolvimento commercial das regiões carbuniferas do sul do Brazil, seja deste modo honrado.

Localidade : Specimen sem localidade certa, Rio Grande do Sul. O typo colleccionado por Plant e descripto por Carruthers está actualmente na secção de Geologia do Museu Britannico de Historia Natural.

\section{DICTYOPTERIDE $A$}

\section{Glossopteris}

Brongniart, Prod. his. vég. foss., 1828. p. 54.

A designação Glossopter's é applicada a um grupo de frondes foliformes, usualmente espatuladas ou lanceoladas, mas variando da fórma redonda-oval á linear, acuminada a emarginada no apice e estreitamente cuneiforme a cordiforme na base, que quasi sempre é peciolada. A folha tem uma nervura mediana distincta, que em muitas especies é persistente, perfeitamente no apice, ou multo proximo deste. As nervuras muito numerosas, secundarias ou lateraes, arqueadas, partem mais ou menos obliquamente, e bifurcando-se uma ou mais vezes na sua passagem para o bordo, se anastomoseam formando areolas variando em fórma, tamanho e distribuiçáo, conforme a especie.

As folhas cresceram pravavelmente isoladas em pares, ou em feixes, de um grande rhizoma que ou é alado com juncçōes transversaes occasionaes, entreas cristas, de um modo comparavel e Struthiopteris, como foi descripto por Zeiller, (1) ou comoalguns outros autores são inclinados a crer é provido de uma haste alada. Este rhizoma foi descripto como Vertebraria pelo professor Royle em 1833, e embora tenha sido conclusivamente provado pertencer ás frondes de Glossopteris, o nome é ainda mantido pala razão que não é especificamente tão differenciado como são as folhas, e seus representantes teem sido ainda encon trados juntos com duas unicas especies de Glossopteris, apenas Glossopteris Browniana e Glossopteris indica.

Os rhizomas são tambem providos de pequenas escamas ou escamas frondosas abjvadas, cordiformes, arredondadas, ou de outras fórmas variadas, com norvillas bifurcadas e anastomosadas, porém, sem ner-

(1) Bull. Soc géol. Fr. (3) vol, XXIV p. 351 . 
the name which may temporarily result. It is highly appropriate that the name of the British engineer who for so long labored for the commercial development of the coalfields of Southern Brazil should thus be honored.

Locality : Specimens without exact locality; Rio Grande do Sul. The types collected by Plant and described by Carruthers are now in the Department of Geology, British Museum of Natural History.

\section{DICTYOPTERIDE $\approx E$}

\section{Glossopteris}

Brongniart, Prod. his. vég. foss. 1828, pag. 54.

The name Glossopteris is applied to a group of leaf-like fronds, usually spatulate or lanceolate, but varying from round-oval to linear in form, acuminate to emarginate at the apex, and narrowly cuneate to cordate at the base which nearly always is petiolate. The leaf has a strong distinct median nerve which is in most species persistent quite or very nearly to the apex. The very numerous, arched, secondary or lateral nerves originate more or less obliquely, and while forking one or more times in passing to the loorder they anastomose to form areoles varying in form, size, and distribution, according to the species.

The leaves probably grew singly, in pairs, or in bunches, from a large rhizome which is oither alate, with occasional cross-junctions between the crests, in a manner comparable to that of Struthiopteris as described by Zeiller, or, as some other authors are inclined to believe, it is provided with an alate axis. This thizome was described as Vertebraria by Royle in 1833, and though it has been conclusively shown to belong to the fronds of Glossopteris, the name is still maintained for the reasons that it is not specifically so highly differentiated as are the leaves, and its representatives have as yet been found in union with but two species of Glossopteris, viz: Glossspteris Browniana and Glossopteris indica.

The rhizomes arealso provided with small scales or scale-fronds obovate, cuneate, round and petiolate, or in other varying forms, with forking and anastomosing nervilles, but destituted of a midrib.

(1) Bull. Soc. géol, Fr., (3) vol XXIV, p. 331 
vura-mediana. Diversas foiçc̃es accidentaes, devidas á maceração ou conservação das frondes tèm sido descriptas por diversos palæbotanicos como sori ou sporangios de Glossopteris, mas todas carecem de confirmação.

Todavia o professor J. A. Newell Arber descrever com alguns detalhes os orgãos sporangiformes encontrados por elle em um excellente estado de conservação, embora carbonisados, nas escamas frondosas de Glossopteris Broconiana. Estes são orgãos sacciformes, de fórna algum tanto elliptica de 1,2 a $1,5 \mathrm{~mm}$ de comprimento e 6 a $8 \mathrm{~mm}$ de largura, afinando-se asymetricamente para as extremidades, sendo uma destas arqueada, dando-lhe fórma semi-retorta.

o sporangio é provido de uma camada cellular exterior de cellulas caracteristicas, alongadas, rhombicas. e de uma camada interior mais alongada e menos conspicua. Estas abrem-se por uma abertura longitudinal. Embora, ainda não se tenham descolerto oporos na materia carbonacea, ha difficilmente duvida que os orgáos sejam sporangios eo professor Arber mostra-se francamente disposto a consideral-os como microsporangios comparaveis aos de um Cycadea a que se assemelham em tamanho, fórma e modo de dehiscencia. Estou fortemente inclinado a acreditar que as escamas foliformes muito espessas que se veem na Est. VII, figs. $5-6$, representam orgãos semelhantes de fructificação.

Como resultado de um exame exhaustivo e comparação dos typos, descripções e figuras relativas à Glossopteris, o professor Arber publicou em sua monographia "The Glossopteris Flora" (1) uma chave synoptica cuidadosamente preparada, das especies deste genero. Devido á concisão e excellencia desta chave cital-a-ei aqui, tendo a certeza que será de grande auxilio pratico aos Jrasileiros que se dedicam ao estudo da flora Permo-carbonifera sul-americana. (2)

Synopse das especies de Glossopteris.

I - Typo de Glossopteris Browniana - Malhas de lar'gura média, ou estreitamente alongadas, nervura mediana persistente.

(1) Catalurue uf he Fossil Plants of tho Glossopterns Flura in the Departement of Gevlugy $y^{\prime}, \mathrm{Br}$ itibh Musum London, 19:

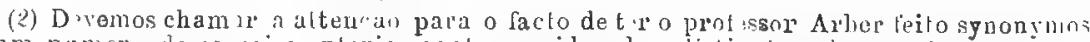
d. um numero de.est ocis anteriormente considerad s clistinctas, ie maneira que o nuHer total destas que elle reconheca como ralidas é um pouco menor que o cas especies admitlidas por feistmantel e outros auctores. Na mon geraphia do professor Arber ha una synomy'mia completa. 
Various features accidental to the maceration or perservation of the ironds have been described by different jaleututanists as sori, or sporangia of Glossopteris, but all have lacked confirmation,

llowever, Professor E. A. Newell Arber has descril.sd witl some detail the sporangium-like organs found by him in a beautiful state of preservation, though carbonized, on the sc.le-fronds of Glossopteris Brotoniana. These are sac-like organs, somewhat elliptical in form, 1.2-1 $5 \mathrm{~mm}$ in length and $6-8 \mathrm{~mm}$ in widh, tapering asymmetrically at the ends, one end boing bent to give a semi-retort form.

The sporangia are provided with an outer cell layer of characteristic elongated rhombic cells and an inner layer more elongated and less conspicuous. They open by a longitudinal vent. Although no spores have yet been made out in the carbonaceous matter, there is hardly room for doubt, that the organs are sporangia, and Professol Arber seems slightly disposed to regard them as microsporangia comparable to those of a cycad, which they resemble in size, shape, ande mode of dehiscence. I am strongly inclined to believe that the greatly thickened scale leaves shown in $\mathrm{Pl}$. vii. Figs. 5 and 6, represent similar organs of fructification.

As the result of an exhaustive examination and comparison of the types, descriptions, and figures, relating to Glossopteris, Professor Arber has published, in his monograph, "The Glossopteris Flora", (1) a carefully prepared synoptical key to the species of this genus. On account of the succinctness and excellence of this key I will here quot it, feeling sure it will be of great pratical aid to Brazilian students of the South American Permo-Carboniferous flora (2).

\section{Synopsis of species of Glossopteris}

I. Type of Glossopter'ss Broconiana. Meshes of medium Jjreadth, or narly elongate, midrib persistent.

\footnotetext{
(1) Catalogue of the Fossis Plants of the Glussupteris Fluria in the Tepartment of Geu. $\log y$, British N̂I useum; London, 1905, p, 47.

(?) Attention shonld be callad to te fact that Prof 's l' Arher makes synonyms of a number of species previously treated as distinct, so that the totul number of species. recognized by him as valid is somewhal h's, than those admitted by feistmantel and otler authurs. Frall nyonjmy is given in Prolessor Mrluer's monograph.
} 
(1) Folhas espatuladas, sub-ovaes, ou lineares, obtusas, malhas de largura média.

1. G. Browniana, Brong.

(2) Folhas lanceoladas, ou lineares, agudas, ou acuminadas.

(a) Malhas muito estreitas, alongadas, sem ser regra, assignaladamente mais largas nos bordos da nervura mediana que no resto da lamina.

Fronde larga, longa, lanceolada, ou oval-lanceolada .

2. G. indica, Schimper.

Fronde de comprimento médio, estreita e linear'.

3. G. augustifolia, Brong.

(b) Malhas muito estreitas, alongadas, excepto de cada lado da nervura mediana onde são comparativamente largas e polygonaes.

4. G. stricta, Bunb.

(3) Folhas largas, largamente obovaes, obtusas ou emarginadas, nervura mediana espessa, nervuras juntas e sub-parallelas e malhas estreitas, excepto proximo da nervura mediana.

5. G. ampla, Dana.

II - Typo de Glossopteris retifera - malhas muito largas, nervura mediana persistente.

Fronde de comprimento médio, lanceolada ou oval lanceolada. Malhas não muito mais longas que largas.

6. G. retifer $a,\}_{3}^{\prime}$ Feist.

Fronde bem larga, espatulada, ou oval lanceolada, malhas alongadas polygonaes, mais compridas que largas.

7. G. conspicua, Feist.

Fronde linear, malhas largas, oblongo-polygonaes.

8. G. formosa, Feist.

III - Typo de Glossopteris tortuosa, nervuras lateraes sinuosas ou tortuosas.

Fronde bem estreita, malhas largas em cada lado da nervura mediana, largamente polygonaes, as seguintes mais estreitas, alongadas polygonaés, ou trapesoides.

9. G. tortuasa, Zeiller.

Fronde bem larga, malhas largas irregulares, quasi do mesmo tamanho em toda a lamina e muito alongadas. 
(1) Leaves spatulate, sub.oval, or linear; obtuse; meshes of medium breadth.

1. G. Browniana, Brong.

(2) Leaves lanceolate, or linear, acute, or acuminate.

(a) Meshes very narrow, elongate, not as a rule markedly broader on the borders of the midrib than in the rest of the lamina.

Frond large, elongate-lanceolate or oval-lanceolate.

2. G. indica, Schimper.

Frond of medium size, narrow, linear.

3. G. angustifolia, Brong.

(b) Meshes very narrow, elongate, except on either side of the midrib, where they are comparatively broad and polygonal.

Frond large, lanceolate.

4. G. stricta, Bunb.

(3) Leaves large, broadly obovate, obtuse, or emarginate, midrib thick, nerves very close and subparallel, and meshes narrow, except near the midrib.

5. G. ampla, Dana.

II. Type of Glossopteris retifera. Meshes very broad, midrib persistent.

Frond of medium size, lanceolate or oval-lanceolate. Meshes not much longer than broad.

6. G. retifera, Feist.

Frond fairly large, spatulate or oval-lanceolate. Meshes elongate-polygonal, much longer than broad.

7. G. conspucua. Feist.

Frond linear. Meshes broad, oblong-polygonal.

8. G. formosa. Feist.

III. Type of Glossopteris tortuosa. Lateral nerves sinuate, or tortuous.

Frond fairly narrow. Meshes on either side of the midrib large, broadly polygonal, the succeeding meshes narrower, elongate-polygonal or trapezoidal.

9. G. tortuosa, Zeiller.

Frond fairly broad. Meshes broad, irregular, of nearly equal size throughout the lamina and very elongate. 
10. G. divergens, Feist.

IV - Typo de Glossopteris decipiens. A nervura mediana não é persistente na parte superior da fronde em distancia consideravel do apice.

Fronde estreitamen te espatulada truncada na base. Malhas estreitas, oblongas.

11. G. decipiens, Feist.

Fronde oblonga.oval, peciolada. Malhas largas oblongas.

12. G. longicaulis, Feist.

V - Typo de Glossopteris orbicularis. Frondes orbiculares, subemarginadas, malhas largas oblongo-polygonaes.

13: G. orbicularis, Feist.

Ao grupo de especies com folhas alongadas representado por Glossopteris stricta na synopse acima, pelo professi $r$ Arber deve-se juntar Glossopteris occidentalis caracterisada ainda mais por suas folhas muito alongadas, com a lase cordiforme, apice aģudo e nervação treniopteroido arqueada e de largas malhas junto ao rachis, mas parallelas muito juntas raramente anastomosando-se, ao passar quasi em angulo recto para a margem.

Glossonteris é um dos typos(1) mais facilmente reconheciveis e caracteristicos do antign Gondwana, ou flora Permo-Carbonifera do Sul, a que Neumayr deu o nome de "Flora de Glossopteris". A' excepção de Victoria na Australia o genero se encontra em todas as regiües ( $(2)$ em que a flora Gond wana está em evidencia, na Asia, Australia, Africa do Sul e America do Sul.

E' tam] sem citado por Amalitzky do Permiano superior do Norte da Russia. Como jí foi notado, os orgãos sporiferos, definitivamente cnrrelarionados com as folhas de Glossopteris estão talvez relacionados mais estreitamente com typos de inflorescencia de cycadeas.

Entre os milhares de specimens de differentes regiõos trasidos con-

(') O genero fanganouter is, como jả foi dito, é tão caracteristico, senāo o mais, da flori typica está quasi st mpre presente, e visto eatar con'inado a flora Permo-Carboni-

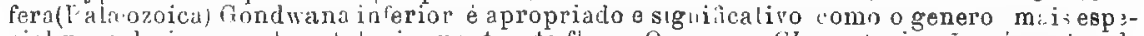
cial para d 'siguar palu'ontologi úmente esta flora. O genero Glossopteris não sómente ulcanca, de mistura com lypes mais recentes a altura d, Rhetico, como tem alem disso a

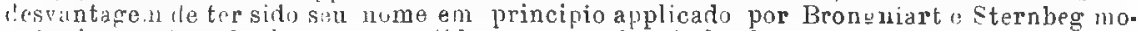
noty picamer te e absolutamente valido ars sestos fosseis de pl.ntas actualmente cinheirda:pol" 1.epiclophyllum.

(2) Pernia, Afrhanistan. India, Bornen, Nova Gales do Sul, Victorix, Queneland, Australia, Occidental, Tismania. Nora Zelandia, Culonia do Cabo, Natal, Zululaud, Transvaal, Rhorlesia,Su loeste $\Lambda$ 'licano Portug'uez, Este Africano Altemāo, Argentina, Chile e Brusil. 
10. G. divergens, Feist.

IV. Type of Glossopteris decipiens. Midrib impersistent in the upper portion of the frond at a considerable distance from the apex.

Frond narrowly spatulate, truncated at the base. Meshes narrow, oblong.

11. G. decipiens, Feist.

Frond oblong-oval, petiolate. Meshes broad, oblong.

12. G. longicaulis, Feist.

V. Type of Glossopteris orbicularis. Fronds orbicucalar, subemarginate. Meshes broad, oblong-polygonal.

13. G. orbicularis, Feist.

To the group of species with elongated leaves, represented by Glossopteris stricta in the above synopsis, is to be added the Glossopteris occidentalis characterized, in addition, by its greatly elongated leaf with cordate base, acute apex, and Taeniopteroid nervation, arched and wide meshes close to the rachis, but parallel, extremely close, and very rarely anastomosing while passing, nearly at a right angle, to the margin.

Glossopteris is the most easily recognized and one of the most characteristic types (1) of the older Gondwana or Southern PermoCarboniferous flora, to which Neumayr accordingly gave the name "Glossopteris flora". with the exception of Victoria in Auslralia the genus is found in all regions (2) where the Gondwana flora is in evidence, in Asia, Australia, South Africa, and South America.

It is also reported by Amalitzky from the Upper Permian of northern Russia. As already noted the spore-bearing organs definitely correlated with the. leaves of Glossopteris are perhaps nearest related to the cycad type of inflorescence.

Among the many thousands of specimens from different regions

(1) As has already been stated, the genus Gangamopteris is equally if not more charracteristic of tropieal flora and is nearly always present; and since it is confined to the lower, or Permo-Carbonilerus Palaeozoic, Gondwana flora, it is far more appropiate and signilicant as the speeial geuus by whieh paleontonica'ly to d signate this flora. Not unly docs the genus Glossopteris range, mingling "ith youn er t pes, as hit h as the Rh tic, but it has the furth $\mathrm{r}^{*}$ disadvantage of having had its name originaliy applied by Brongniart and Sternberg, monotypicaily and with absuluce val.dıty, to the fcss $\perp$ plant remains, now known as Lepidophyllum.

(2) Persia, Afghanistan, India, Borneo, New South Wales, Victoria, Queensland, West Australia, T'smania, New Zealand, Capo Colony, Natal, Zululand, Transwaal, Rhodesia, Portuguese S. E. Africa, Grrman E. Africa, Argentina, Chili and Brazil. 
junctamente para exame, incluindo specimens tão bem conscrvados de modo a permitlir a delineação das cellulas epidermicas e stomates; ainda nenhum lypo de frutificarăo desto feto foi descoberto. Esta evidencia, de natureza cycadofilicea do genero, e de facto puramente negativa.

Baseados nos caracteres das frondes estereis, o genero tem sido geralmente classificado com os Tceniopieridece ou Dictyopteridece que se compõem principalmente de typos collocados agora nos pteridospermeos (Cycadofiliceos). Em publicação anterior (1) eu suggeri a relação generica de Glossopteris com o grupo Megalopterideo em que col loquei Taeniopteris, Neuropteris e Leisleya (2). O genero mencionado por ultimo da base do carbonifero superiol, póde muito bem ser antepassado de Glossopteris de que differe somente pela falta de anastomoses nas nervuras.

O Pragmento abaixo descripto como Glossopteris $s p$ e illustrado na pag. VII, figs. 5 e 6 . representa orgãos sporangileros quasi certamente de Glossopteris comparaveis a inflorencencia das Cycadeas. Pelas razũes já mencionadas colloco tanto Glussopteris como seu proximo aparentado apparen temente Gangamopteris nos Pteridospermeos não obstante o caracter de feto do rhizoma, Vertebraria. Ao mesmo yrupo, estou convencido que devem ser referidos os orgãos sporangi feros descriptos como Ottakaria e Derbyella:

\section{Glossopteris Browniana Brongn}

Pl. VI figs, 3. 4. 6.

1828 - Glossopteris Brotoniana - Brongniart, Prodrome p. 54 (nomen nudum) Goeppert, Syst. fil. foss. 1836, p. 346, pl. XXI, fig. 9-10, Morris in Strzelecki, New South Wales, 1845 p. 247, pl. VI, figs. 1-1a Dana, Wilkes, Expl. Exped, vol. X, 1849, p. 716, pl. XII, figs. 13 a, 13 b, 13 c, Tate, Quart. Journ. Geol. Soc; vol. XXIII, 1867, p. 140, pl. VI, figs. 5-7 : Feistmantel, Palaeontogr., Suppl. III, 1878, p. 78, pl. VIII. figs. 3-4, pl. X, flgs. 1, 3, 4, 5, 7, pl. XI, fig. 1; Feistmantel, Fl. Gondwana, Syst. vol. III, pt. 2, 1880, p. 102, pl. XXVIA, fig. 2, pl. XXVIIA, fig. 2, pl. XXIXA, figs, 1, 2, 3, 6, 8, pl.

(1) Bu'l. Geol. S. c. Anter. vol. IV, 1893, p. 123.

(2) Veja-so Lesquereux: Ceal Flora, vol. I, p. 143, pl. XXV, fis. 1 e 3. 
broughl together for examination, including specimens so well preserved as to admit the delineation of the epidermal cells and stomata, no recognized fern type of fructification has yet jeen discovered. This evidence for a cycadofilicate nature in the genus is, of course, purely negative.

On the basis of the characters of the sterile fronds the genus has generally been classified with the Taeniopterideae or the Dictyopterideae, which are composed chiefly of types now placed in the Pteridosperms (Cycadofilices). In an earlier paper. (1) I have suggested the genetic relationship of Glossopteris to the Negalopterid group in which I placed Tacniopteris, Neuropteris and Lesleya. (2) The genus las named, from the base of the Upper Carboniferous, may well have been ancestral to Glossopteris, from which it differs only by the absence of anastomosis in the nervation.

The fragment described below as "Glossopteris sp.," and illustrated in Pl. vii, Figs. $5 \& 6$. almost certainly represents sporangiferous organs of Glossopteris comparajle to the cycad inflorescence. For the reasons just referred to I place both Glossopteris and its apparently near relative Gangamopteris in the Pteridosperms, notwithstanding the fern-like character of the rhizome Vertebraria. To the same groupe is to be referred, as I am convinced, the sporangiferous organs described as Ottokaria, and Derbyella.

\section{Glossopteris Biovoniana Brongn.}

$$
\text { PI. vi, Figs. 3, 4, } 6
$$

1828. Glossopteris Brotoniana Brongniart, Prodrome, p. 54 (nomen nudum); Goeppert, Syst. fil toss. 1836, p. 346, pl. xxi, fig. 9, 10 ; Morris in Strzelecki, New South Wales, 1845 , 247, pl, vi, figs. 1, 1a; Dana, Trilkes Lxpl. Exped., vol. $x$, 1849, p. 716, pl. xxii. figs. 13a, 13b, 13c ; Tate, Quart, Jour. Genl. Soc., vol, xxiii, 1867, p. 140, pl. vi, figs. 5, 7; Feistmantel, Palaeontogr'., Suppl. III, 1878, p. 78, pl. viii, figs, 3, 4, pl. x, figs. 1, 3, 4, 5, 7, pl. xi. fig. 1, Feistmantel, Fl. Gondwana Syst., vol. iii, pt. 2, 1880, p. 102, pl. xxviA, fig. 2, pl. xxviiA, fig. 2, pl, xxixA, figs. 1, 2, 3, 6, 8. pl. xls, fig. 5 ; Feistmantel. 
XLA, fig. 5, Feistmantel. Fl. Gondwana Syst. vol. IV, pt. 1, 1882 , p. 34, pl. XII, fig. 4, pl. XX, fig. 3 ; Feistmantel, FI. Gond. Syst. vol. IV, pt. 2, 1886, p. 28, pl. 1 A, fig. 2 ; Johnston Geol. Tasmania, 1888, p. 111, pl. IX, fig. 1, Feist mantel. Abh Bohm Gesell Wiss, Prag (7), vol, III 1889, p. 36, pl. IV, fig. 6 ; Feistmantel, Mem. Geol Surv. N. S. W ; Palaeont, $\mathrm{n}^{0} 3$, 1890, p. 121, pl. XIII, flg. 1, pl. XVI, fig. 3-4, pl. XVII, figs. 1, 3, 4, 5, pl. XX, fig. 2, Jack \& Etheridge, Jr, Geol, e Pal. Queensland 1892, p. 193, pl. XVI, fig. 8, pl. VVII, figs. 9-10, pl. XVIII, fig. 14, Zeiller, Bull. Soc. Ceol. Fr, (3) vol. XXIV, 1896, p. 362, figs. 8-10 ; pl. XVI, figs. 1-14, Seward. Quart. Jour. Geol, Soc. vol. LIII, 1897, p. 218, pl. XXI, fig. 1, pl. XXIII, fig. 1 ; Seward, 2d Rept. Geol. Surv., Natal, 1904, p. 98, pl. IV, figs. 1, 5, 6, Arber, The Glossopteris. Flora, 1905, p. 48, fig. 16, pl. II, figs. $1-5$, pl. III, figs. 1-2.

1830 - Glossopteris, Browniana - var. $\alpha$. australasica Brongniart-Hist, vég. foss. p. 223, pl. LXII, fig. 1, Bunbury, Quart. Journ. Geol. Soc, vol. XVII, 1861, p. 329, pl. VIII, fig, 5.

1847-Glossopteris lincaria-Mc. Coy Ann. \& Mag. N. H. vol. XX, p. 151, pl. iX, fig. 5, Feistmantel, Palaeontogr. Suppl. III, 1878, p. 91, pl. VIII, figs. 1-2, pl. XI, figs. 3-4, pl. XIl, fig. 4.

1849-Glossopteris elongata, Dana, Wilkes, Explo. Exped. vol. X, p. 718 , pl. XlI, fig. 4 .

Geralmente as folhas não são muito grandes, espatuladas, espatulado-oblongas, oblongas, ou lineares espatuladas, obtusas ou redondas no apice e estreitanlo-se para baixo para a base peciolada, neroura mediana forte, persistente até, ou quasi até o apice anastomosando-se em malhas polygonaes juntas, im tanto abertas alongadas, tendo as areolas dos bordos não muito differentes, das que se acham junto á neroura mediana.

Nenhum dos specimens, nas collecções anteriores ás minhas, mostra as formas largamente espatuladas, que parecem ser tão communs nas camadas de New Castte, embora correspondam bem em fórma e nervação a algumas das fórmas estreitas de New South Wales, bem como á exemplos de varias regiões, referidos por differentes auctores á mesma especie. No specimen que se vê na est. VI, fig. 6, temos um fragmento de folha, das proximidades de Minas, admiravelmente 
Fl. Gond. Syst., vol. iv, pt, 1, 1882, p. 34, pl. xii, fig. 4, pl. xx, fig. 3 ; Feistmantel, Fl• Gond. Syst., vol. iv, pt. 2, 1886, p. 28, pl. 1A, fig. 2 ; Johnston, Geol Tasmania, 1888, p. 1ll, pl. ix, fig. 1; Feistmantel, Abh. Böhm. Gesell. Wiss., Prag. (7) vol. IIl, 1889, p. 36, pl. iv. fig. 6 ; Feistmantel, Mem. Geol . Surv. N. S. W., Palaeont., no. 3,1890, p. 121, pl. xiii, fig. 1 pl. xvi, fig. 3, 4, pl. xvii, figs. 1, 3, 4, 5, pl. xx. fig. 2; Jack \& Etheridge Jr., Geol. \& Pal. Queensland, 1892, p. 193, pl. xvi, fig. 8, pl. xvii, figs. 9, 10, pl. xviii, fig. 14; Zeiller, Bull. Soc. Geol. Fr., (3) vol, xxiv, 1896, p. 362, figs. $8-10$, pl. xvi, figs. 1-14; Seward, Quart. Jour. Geol. Soc., vol. liii, 1897, p. 218, pl. xxi, fig. 1, pl. xxiii, fig. 1; Seward, 2d Rept. Geol. Surv, Natal, 1904, p. 98, pl. iv, figs. 1, 5, 6 ; Arber, The Glossopteris Flora, 1905, p. 48, fig. 16, pl. ii, figs. 1-5, pl. iii, fig. 1, 2.

1830. Glossopteris Browniana var. a australasica Brongniart, Ilist. vég. foss. p. 223, pl lxii, fig. 1 ; Bunbury, Quart. Jour. Geol. Soc., vol. xvii, 1861, p. 329, pl. viii, fig. 5.

1847. Glossopterts linearis Mc Coy, Ann. \& Mag. N. H., vol. $\mathrm{xx}$, p. 151, pl. ix, fig. 5 ; Feistmantel, Palaeontogr., Suppl. III, 1878, p. 91, pl. viii, figs. 1, 2, pl. xi, figs. 3-4, pl. xii, fig. 占.

1849. Glossopteris elongata Dana, Wilkes Explor Exped, vol., $\mathrm{x}$, p. 718 , pl. xiii, fig. 4 .

Leaves usually not very large, spatulate, spatulate-oblong, oblong, or linear-spatulate, obtuse, or rounded at the apex, and narrowed downward to the petiolate base; midrub strong, persistent to or nearly to the apex; neroulles oblique, arched, not very close, anastomosing in a polygonal, rather open, elongated mesh, the areoles at the border being not greatly different from those near the midrib.

None of the specimens in the collections before me exhibit the very broadly spatulate forms which appear to be so common in the Newcastle beds, though they correspond well both in shape and in nervation to some of the narrow forms from New South Wales, as well as to examples from various regions referred by different authors to the same species. In the specimen shown by Pl. vi, Fig, 6, we have 2 fragment of a leaf, from near Minas, that is strikingly similar in both 
semelhante em fórma e nervuras aos illustrados por Zeiller (1) e Séward. (2) da Alrica do Sul. As proporções e aspectos deste specimen lem]ram muito, al:rumas das grandes fórmas linguladas de Neuropteris Scheuchacri do Stephaniano superior da parte oriental dos Estados Lnidos. (1) specimens illustrados nas figs. 3 o 4 mostram uma malha mais curta c mais destincta. Estes são comparaveis em particular a alguns dos figurados por Feistmantel (3) do grupo Raniganj da India(1) e Australia e por Arber (5) da série New Castle. Tambem concordam em caracteres com alguns dos specimens trazidos por Dana da Trilkes Exploring Expedition.

Glossopteris Browoniand distingue-se de outras especies do genero, do Brasil, pelas suas folhas espatuladas, ou alongadas ovaes, que são obtusas e pela distribuição quasi uniforme das malhas estreitas, alongadas angulares e por toda a nervação arqueada e não muito junta.

Embora Glossopteris Brotoniana seja da Argentina, é interessante notar sua presença, a mais commum e caracteristica especie da flora de Glossopteris, tão ao norte quanto Minas em Santa Catharina onde, como em La Rioja, Argentina, encontra-se na zona dos typos misturados do norte e de Gondwana.

Localidades: Nordeste de Minas, Santa Catharina, cerca de 55, m sobre o granito, ou 225 metros abaixo do schisto preto de Iraty. Lot. 3586, colleccionado pelo engenheiro Seixas e lot. 3921 colleccionado pelo Dr. I. C. White. Tambem do tope do carvão Barro Branco. Estrada do Rio do Rasto, proximo das Minas, Santa Catharina, a cerca de 155 metros acima do granito Lot. 3922. Tope do carvão Irapuá a oeste da casa do Dr. Ramiro Barcellos, proximo ao Rio Irapuá, Rio Grande do Sul, a cerca de 140 metros abaixo do schisto preto de Iraly, 3591.

\section{Glossopteris indica (Brongn.) Schimp}

PI VI figs. 5. 7. 8.

1830.-Glossonteris Brouniana-val. P inclick Brongniart, Ilist. ver. foss. p. 223 , pl. Lxil, fig. 2 ; Bunbury, Quart. Journ. Geol. Soc. vol. XVII, 1861, p. 326, pl. VIll, fig. 1-4,

\footnotetext{
(1) Bull, Soc. Gool. Fr, (3). vol. XXIV, pl. XVI, fig. 4.

(i) Guart. lour. Geol. Soc. vol. LIII, p. XXY, fig. 1.

(3) Pl. Cionllwana syst. vol. IIT, pt 2 , pl XXIVA.

(i) Mrm. treol. Surv. N. S. W. Palaeont. n. 3, pl. XVII, fig. 4, 5, 7.

(.) The Glowpteri- Flora pl Ir, ligs. 2, 3.
} 
nervation and form to those illustrated by Zeiller (1) and Seward (2) from South Africa. The proportions and aspect of this specimen strongly suggest some of the very large lingulate forms of Neuropteris Scheuchareri in the upper Stephanian of the Lastern United States. The specimens illustrated in Figures 3 and 4 exhibit a shorter and more distinct mesh. These are comparable in particular to some of those figured by Feistmantel from the Raniganj group in India (3) and from Australia (4) and by Arber (5) from the Newcastle series. They also conform in characters to some of the specimens brought back by Dana from the Willies Exploring Expedition.

Glossopteris Browniana is distinguished from otler species of the genus in Brazil by its spatulate or elongated-oval leaves, which are obtuse, and by the nearly even distribution of the rather narrowly elongated angular meshes throughout the arched and not very close nervation.

Although Giossopteris Browniana is reported from Argentina, it is interesting to observe the presence of this most common and characteristic species of the Glossopteris flora as far north as Minas in Santa Catharina, where, as in La Rioja, Argentina, it lies in the zone of mingled Northern and Gondwana types.

Localities: Northeast of Minas, Santa Catharina. Abont 5., meters above the granite, or 225 meters below the Iraty black shale. Lot 3586 ; collected loy Engineer Seixas, and lot 3921, collected by Dr. I. C. White. Also from roof of the Barro Branco icoal, Nova Estrada near Minas, Santa Catharina. About 155 meters above the granite. Lote 3922. Roof of the Irapuá coal, west of the house of Doctor Ramilo Balcellos, near Rio Irapuá, Rio Grande do Sul. Abrut 140 meters below the Iraty black shale. Lot 3591 .

\section{Glossopteris indica (Brongn.) Schimp \\ Pl. vi, Figs. 5, 7, 8}

1830. Grossopteris Brotoncand rar, $\beta$ inclie, Brongniart, Ilist. vég. foss., p. 223 , pl. lxii, fig. 2 ; Bunbur'y, Quart. Jour. Geol. Soc., vol., xvii, 1861, 1). 326, pl. viii, fig. 1-4;

\footnotetext{
(1) Bull. Soc. géol. Fr., (3) vol. xxiv, pl. xvi, f.s. 4 .

(2) (uart. Jour. Geol. Soc., vol. liii, pl. xxi, fic.. 1.

(3) Fl. Gondwana Syst., vol. III, pt. 2, pl. xxivג.

(4) Iem. Geol. N. S. W., Palaeont., no. 3, pl. xvis, lig. 4, 5, i

(5) The Glossopteris Flora, pl. ii, fig. 2, 3.
} 
Seward, Ann. S. Afr. Mus. vol. IV, pt. I, 1903, p. 77, pl. X, fig. 3-4, pl. XIII, fig. 1. Seward, Quart. Journ. Geol. Soc. vol. LIII, 1897, pl. XXI, figs. 2-3 ; Seward, 2nd, Rept. Geol. Surv. Natal, 1904, p. 99, pl. IV, fig. 2.

1869-Glossopteris indica. (Brongn) Schimper Traité, vol. 1. p. 645, Feistmantel, Fl. Gondwana, System. vol. III, pt. 2, 1880, p. 101, pl. XXIVA. pl, XXVA, fig. 1-3, pl. XXVIA fig. 3, pl. XXVIIA, fig. 3, 5, pl. XXXVA, fig. 4, pl. XXXVIIIA, fig. 4, Feistmantel, Op. cit. vol, IV, pt 2, 1886, p. 27, pl. XIIA, fig. 2, $6, b$ pl. XIVA. fig. 7, Zeiller Bull. [Soc. Geol. Fr. (3) vol. XXIV, 1896, p. 366, p. 367, fig. 11, 12, pl. XVII, fig• 1-3; Potoniẻ, Deutsch, Ost. Africa, vol. VII, p. 496, fig. 22, Zeiller, Pal. indica, n. s. vol. II, 1902, p. 8, pl l, figs, 1-5, pl. II, figs. 1-4, pl. III, figs. 1-3, Zeiller, Fl. foss. Charb Tonkin, 1902, p. 84, pl. XVI, figs. 2-5, pl. LVI, fig. I; D. White Science, N. S. vol. XXI, 1905 p. 700 : Arber The Glossopteris Flora 1905, p. 64, figs. $17-18$ a.

1876 - Glossopteris communis-Feistmantel. Journ, As. Soc. Bengal. vol. XLV. pt 2, p. 375, pl. XXI, f. 5, Feistmantel, Fl. Gondwana Syst. vol. III, pt 1 1879, p, 16, pl. XVIl. figs, 1-2, pl. XXXI. figs. 4-5, pt 2, 1881. p. 98, pl. XXIVA, XXVA figs. 1-4, pl. XXVIIA, fig. 1, pl. XXIXA, figs. 4-5-9, pl. XXXIIA, fig. 2, pl. XXXVA, fig. 1-3, pl. XXXVIA, figs. 1-2, pl. XXXVIIA, figs. 3-4, pl. XXXVIIIA, figs. 1-2, pl. XLA, fig. 4 ; Feistmantel. Op. Cit. vol. IV, pt 1, 1882, p. 32, pl, XII, fig. 1, pl. XXII, figs. 13, 14, pt 2, 1886, p. 26, pl. IIA, figs. 1-2, pl. XIA, figs, 6-8, pl. XIIA, fig. 1 ; Feistmantel Mem. Geol. Surv. N. S. W. Palaeont. no. 3. 1890, p, 123, pl. XVII, figs. 2,6, Oldham, Rec. Geol. Surv. India, vol. XXX, pt 1. 1897, p. 45, pl. III ; Shirley, Bull, Geol. Surv, Queensland, no. 18, 1902, p. 13.

A maior parte dos specimens representando o genero Glossopteris na nossa collecção pôdem referir-se a esta especie bem conhecida e largamente destribuida. Nenhum dos fragmentos é muito grande, comtudo a semelhança de fórma e nervação com as illustrações e descripções publicadas sobo nome acima, é tão completa e satisfactoria que não deixa duvida alguma quanto á sua identidade especifica. Nas figuras 5 e 7. Est. $\mathrm{VI}_{\text {c }}$ se veem fragmentos da parte inferior da folha que são directamente comparaveis com os do Gondwana da India, 
Seward, Ann. S. Afr. Mus., vol. iv, pt. 1, 1903, p. 77, pl x, fig. 3, 4, pl. xiii, fig. 1 ; Seward. Quart. Jour, Geol, Soc. vol. líii .1897, pl. xxi, fig. 2, 3 ; Seward, 2nd Rept. Geol. Surv. Natal., 1904, p. 99, pl. iv, fig. '2.

1869. Glossopteris indica (Brongn.) Schimper, Traité, vol i, p, 645 ; Fẻistmantel, Fl, Gondwana Syst., vol. iii, pt 2, 1880 p. 101, pl. xxivA; pl. XxvA, fig. 1-3, pl. xxviA, fig. $3, \mathrm{pl}$ xxviiA, fig. 3, 5, pl. xxxvA, fig. 4, pl. xxxviiiA, fig. 4 ; Feistmantel, Op. cit., vol. iv, pt. 2, 1886, p. 27, pl. xiiA, fig, 2 , $6 b$, pl. xivA, fig. 7 ; Zeiller, Bull. Soc. géol. Fr. (3) vol. xxiv, 1896, pp, 366, 367, figs. 11, 12, pl. xvii, figs. 1-3; Potonié, Deutsch Ost-A frika, vol. vii, p. 496, fig: 22; Zeiller, Pal, Indica, n. S., vol. ii, 1902 , p. 8 , pl. 1, figs. $1-5$, pl. ii, figs. 1, 4 pl. III, figs. 1-3, Zeiller, Fl. foss, Charb. Tonkin, 1902, p. 84, pl. xvi, figs. 2-5, pl. Ivi, fig. 1; D. White, Science, n. s., vol. xxi, 1905, p. 700 ; Arber, The Glossopteris Flora, 1905, p. 64, figs. $17,18 \mathrm{a}$.

1876. Glossopteris communis Feistmantel, Jour. As. Soc. Bengal, vol. xlv, pt. 2, p. 375, pl. xxi, f. 5 ; Feistmantel, Fl. Gondwana Syst,, vol. iii, pt. 1, 1879, p. 16, pl. xvii, figs. 1, 2, pl. xxxi, figs. 4, 5 pt. 2, 1881, p. 98, pl. xxivA, [pl. xxviA, figs, 1, 4, pl. xxvilA, fig. 1, pl. xxixA, figs. 4, 5, 9; pl. xxxiiA, fig. 2, pl. xxxvA, fig. 1-3, pl. xxxviA, figs. 1, 2, pi. xxxviiA, figs. 3, 4, pl. xxxviiiA, figs. 1, 2, pl. xlA, fig. 4 ; Feistmantel, Op., cit., vol. iv, pt. l, 1882, p. 32. pl. xii, fig. 1, pl. xxii, figs. 13, 14, pt. 2, 1886, p. 26, pl. iiA, figs. 1, 2, pl. xiA, flgs- 6, 8, pl. xiiA, fig. 1; Feist-mantel, Mem. Geol. Surv. N. S. W., Palaeont., no. 3, 1890, p. 123, pl. xvii, figs. 2, 6 : Oldham, Rec. Geol. Surv. India, vol. xxx, pt. 1, 1897, p. 45, pl. iii ; Shirley, Bull. Geol. Surv. Queensland, no. 18, 1902, p. 13 .

The greater part of the specimens representing the genus Glossopteris in our collection are referable to this well known and widely distributed species. None of the fragments is very large, yet the agreement both in form and in nervation with the illustrations and descriptions published under the above name is so complete and satisfactory as to leave no doubt concerning the specific identity. In Figs. 5 and $7, \mathrm{Pl}$. VI, are shown fragments from the lower part of the leaf that are directly comparable with those from the Indian Gondwana, 
publicados por Feistmantel (1) e Zeiller (2) sob esta denominação. Outros fragmentos do Brasil mostram que a lamina estreita-se gradualmente para baixo e ligeiramente asymetrica para um peclolo grosso como nas folhas do Oriente.

o apice da folha de Glossopteris indica estreita-se mais ou menos distinctamente em uma extremidade pontuda, figura 8, est. VI, mostra uma fórma muito estreita de folha. Todavia este fragmento não é tão estreito como os do grupo Raniganj illustrado por Feistmantel (3). Considero-o desta especie sómente em duvida devido á sua estreiteza não commum, relativa simplicidade e rectidão da nervação muito obliqua a pequena distancia da nervura mediana.

A nervação em nosso material é geralmente fina, junta e parallela com areolação estreita e alongada, que é ligeiramente maior proximo da nervura mediana. Segue se que o nosso specimen corresponde ao descripto por Feistmantel como Glossopteris communis. Zeiller (5) mostrou comtudo completamente, ser esta ultima especie inseparaveI de Glossopteris indica.

Pelo aspecto da nervação nossas especies são exactamente comparaveis ás da India, illustradas por Feistmantel (6) na South Rewah Flora e Zeiller (7) e em particular no material da Africa do Sul, publicado por Seward (8), como Glossopteris Browniana var. indica.

Glossopteris indica differe de Glossopteris occidentalis que será descripta ulteriormente, por sua base estreita e peciolada, por suas folhas mais curtas, falta de parallelismo nos bordos lateraes, e pela nervação obliqua e arqueada que é mais egualmente anastomosada.

Glossopteris ampla é separada de Glossopteris indica pelo maior tamanho d'aquella, por seu apice redondo obtuso ou emarginado, e a direç̧ão quasi parallela de suas nervuras, cujas anastomoses são muito mais fortemente accentuadas na região da nervura mediana.

Localidades : Estrada do rio do Rasto, proximo de Minas, Santa Catharina, cerca de 40.m, abaixo do carvão Barro Branco, 135 metros acima do granito, ou 145 metros abaixo do schisto preto de Iraty,

(1) Fl. Gondwana Syst. vol. 3, pt. 2, pl. XXVA, figs. 1-3 reja-se tambem Glostopteris communis, Loc. cit pl. XXXVA.

(2) Palaeontologia indica N. S. vol. II, $\mathrm{n}^{0} 1$, pI I, figs 1-2.

(3) FI, Gondwana Syst. vol. III, pt. 2, pls, XXIVa XXIXa, fig. 4.

(4) Fl. Gondwana 3yst vol. Il, pt. 2, pl. XXVla figs. 1-4.

(5) Bull. Soc, Geol F anca (3), vol, XXIV, p. 360

(6) Fl Gondwana $S_{\text {ist }}$ vul. IV, pt. 2, pl. IIA, fig. 1-2.

(7) Palaeontologia Indica N. S. vol. 2, no 1, pl. 1, fig. 4, pl. II, fig. 1.

(8) Quart. Journ. Gool. Soe. vol. LIII, pl XXl, figs. 2, 3. 
published by Feistmantel (1) and by Zeiller (2) under this name. Other fragments from Brazil show the lamina to narrow gradually downward, slightly asymetrically, to a thick petiole in agreement with the leaves from the Orient.

The apex of the leaf of Glossopteris indica narrorvs to a more or less distinctly pointed tip. Figure 8 , Plate vi, illustrates a very narrow form of leaf. Although this fragment is not much narrow than those from the Raniganj group illustrated by Feistmantel (3) I only with doubt include it in this species, on account of its unusual narrowness and the relative simplicity and straightness of the very oblique nervation at a little distance from the midrib.

The nervation in our material is generally fine, close, and parallel, with narrow elnngated areolation which is but slightly larger near the midrib. It follows that our specimens correspond to those described by Feistmantel (4) as Glossopteris communis. The latter species has, however, fully been shown by Zeiller (5) to be inseparable from Gilossopteris indica.

In the aspect of the nervation our specimens are exactly comparable to those from India, illustrated in the South Rewah Flora by Feistmantel (6) and Zeiller (7), and, in particular, in the material from South Africa, published by Seward (8) as Glossopteris Browniana var. indica.

Glossopteris indica differs from Glossopteris occidentalis, to be described later, by its narrowed petiolate base ${ }_{1}$ by its shorter leaves and its lack of parallelism in the lateral borders, and by the oblique and arching nervation which is more equally anastomosed.

Glossopteris ampla is separated from Glossopterts indica by the greater size of the former, its round, obtuse, or emarginate apex, and the nearly parallel direction of its nerves, whose anastomoses are much more strongly marked in the region of the midrib.

Localities: Estrada Nova near Minas, Santa Catharina. About 40 meters below the Barro Branco coal, 135 meters above the granite, or 145 meters below the Iraty black shale. Lot. 3923. Roof of the

(1) Fl. Gondwana Syst.. vol. 3, pt. 2, pl. xxva, figs. 1, 3, Sce also Glossopteris communis, Loc. cit.. pl, xxxva.

(2) Palaeontologia Indica, n. s. vol. II, no. 1, pl. i, figs. 1. 2.

(3) Fl. Gondwana syst., vol. iii, pt. 2, pls, xxiva, and xxisa fig. 4.

(4) Fl. Gundwana Syst., vol. i.i, pt. 2, pl. xxvia, figs. 1, 4.

(5) Bull. Soc. gèol. France, (3) vol. 'X́xiv', p. 36).

(6) Fl Gondwana Syst vol iv, pt. 2, pl. Il A, figs. 1, 2.

(7) Palaeontologia Indica, n. s. vol. 2, no. 1, pl. i, fig. 4, pl. ii, fig. 1.

(8) Quart. Journ, Geol. Soc., rol. liii, pl. xxi, figs. $2,3$. 
Lot. 3923. Tope do carvão Irapuá na parte occidentál da casa do Dr. Ramiro Barcellos, proximo do rio Irapuá, Rio Grande do Sul. Cerca de 135 metros acima do granito, ou o mesmo intervallo approximadamente abaixo do schisto preto de Iraty, Lot. 3591.

\section{Glossopteris cunpla Dana \\ P]. VI, fig. 9.}

1849. Glossopteris ampla Dana, Wilkes Explor. Exped. vol. X, p. 717, pl. XIlI, fig. 1 a, 1 b; Feistmantel, Palaeontogr. Suppl. III, 1878, p. 91, pl. XI, fig. 2, pl. XII, fig 7, Johnston, Geol. Tasmania 1888, p. 111, pl. VIII, fig. 3, pl." IX, fig. 3; Feistmantel, Mem. Geol. Surv. N. S. W. Palaeont n. 3, 1890, p. 122, pl. XIX, fig. 1-2 ; Feistmantel, Spis. poct, ju'sil. c. Král, ceskú, spol, Nank. (2) vol. III, 1890, p. 16, pl. 1, fig. 4, Jack \& Etheridge, Geol. Pal . Queensland, 1892, p .195, pl.XV, fig. 7, Arber, The Glossopteris. Flora 1905, p. 78, fig. 20.

Folhas muito grandes pecioladas, tornando-se lar'gamente ovaes a oblongo ovaes, estrcitas mais ou menos e agudas na base, obtusamente pontudas ou. ligeiramente emar'gunadas no apice. Nervura mediana muito larga, tornando-se rapidamente aguda para a apice da folha; nervuras lateraes obliquas, arqueando-se rapidamente e anastomosando-se, formando malha um tanto regular e alongada, tornando-se contigua e parallela a uma outra mais estreita e alongada passando obliquamente para o bordo onde se contam de 35 a 40 por centimetro.

O material da Estrada Nova, perto das Minas, contem dois fragmentos de grandes folhas que representam claramente a especie da série New Castle em New South Wales descripta por Dana (1) em 1849. Comparando-se o specimen brasileiro com o typo original de Dana, n. 1359, da collecção de plantas fosseis do Museu Nacional dos Estados Unidos, o exemplar brasileiro apenas differe pelas malhas ligeiramente mais juntas e mais regularmente parallelas, assim como anastomosando-se com menor frequencia na zona peripherica da folha. Deve-se ao mesmo tempo notar cque o contraste que existe entre as areolas proximas da nervura mediana e as que se acham proxiınas do bordo não

(1) Wilkes Exploring Expedition, vol. X, pl. XfI, figs. $1 \mathrm{a}-1 \mathrm{~b}$. 
Irapua coal west of the house of Doctor Ramiro Barcellos, near Rio Irapuá, Rio Grande do Sul. About 135 meters above the granite or the same interval approximately below the Iraty blacli shale. Lot 3591 .

\section{Glossopteris ampla Dana \\ Pl. vi, Fig. 9.}

1849. Glossopteris ampla Dana, Wilkes Explor. Exped., vol. x, p. 717, pl. xiii, fig. la, lb; Feistmantel, Palaeontogr., Suppl, 1878, p. 91, pl. xi, fig. 2, pl. xii, fig. 7 ; Johnston, Geol. Tasmania, 1888, p. 111, pl. viii, fig. 3, pl. IX, fig. 3; Feistmantel, Mem. Geol. Surv. N. S. W., Palaeont., no. 3, 1890, p. 122, pl. xix, fig. 1, 2 ; Feistmantel, Spis. poct. jubil. c. Král. ceskú. spol. Nank, (2) vol. III, 1890, p. 16, Pl. 1, fig. 4; Jack \& Etheridge, Geol. Pal. Queensland, 1892, p. 195, pl. xv, fig. 7 ; Arber, The Clossopteris Flora, 1905, p. 78, fig. 20.

Leaves very large, petiolate, broadly ovate to oblong-ovate, narrowed more or less acutely at the base, obtusely pointed or slightly emarginate at the apex; midrib very broad, tapering rapidly to the apex of the leaf; lateral nerves oblique, arching rapidly while anastomosing in a somewhat irregular elongated mesh, becoming close and parallel with a more elongated and narrower mesh while passing obliquely to the border where they number 35-40 to the centimeter.

The material from Estrada Nova near Minas contains two fragments of larg leaves that clearly represeut the species described by Dana, (1) in 1849, from the Newcastle series in New South Wales. As compared with Dana's original types, no. 1359 of the fossil plant collection in the United States National Museum, the Brazilian specimens differ only by a slightly closer and more regularly parallel as well as less frequently anastomosing mesh in the peripheral zone of the leaf. It should at the same time be noted that the contrast between the areoles near the midrib and those near the border is not as shown in the original illustration, there being no distinction or zona-

(1) Wilkes Exploring Expedition, vol, x, pl, xıii, figs. la, lb. 
é como se vê na illustração original, não havendo distincção ou zonação (1) na malha. A areolaçăo em uma malha alongada é continua até o bordo.

Como está illustrado em nossa fig. 9, estampa VI, a anastomose é é tão alongada e a nervação é tão junta e parallela nos specimens Sul Americanos que lembra á primeira vista Taeniopteris ou Macrotaeniopteris. Estes fragmentos assemelham-se frisantemente a Glossopteris musaefolia de Bunbury (2) do grupo Kamthi de Nagpur na India. Esta especie que apenas se conhece de uma unica localidade foi recentemente combinada por Arber (3) com Glossopteris ampla após o exame do typo de Bumbury. A fórma brasileira é quasi egualmente illustrada pelo material figurado por Jacobi e Etheridge (4) e por Feistmantel (5) das camadas Bowen River de Queensland da série New Castle em New South Wales. O professor Zeiller (6) illustrou como Glossopteris indica um specimen da série Damuda semelhante em fórma e aspecto superficial.

Localidade : Estrada Nova, proximo á Minas em Santa Catharina. Cerca de 135 metros acima do granito ou 145 metros abaixo do horizonte do schisto preto de Iraty. Lot. 3923. O typo da especie está sob o numero 1359 na collecção de plantas palaeozoicas do Museu Nacional dos Estados Unidos.

\section{Glossopteris occidentalis n. sp \\ P. VII, figs, 1-4-4 a.}

Folha muito grande, um tanto espessa taeniada, largamente cordiforme na base sessil, bordos lateraes parallelos, convergindo rapidamente proximo co tope, formando um apice acuminado ou agudo; neroura mediana muito larga, persistente para o apice, nerouras lateraes emergindo em angulo agudo, arqueando-se logo fortemente, anastomosando-se um tanto irregularmente em malhas relativamente grandes polygonaes, porém, mais ou menos alongadas, proximo

(1) As areolas a meio caminho das margens foram desenhadas muito largas e angulares nas illustrações de Dana.

(2) Quart. Jaurn. Geol. Soc. vol. XVI, 1861. p. 329, pl. VIII, fig. 6.

(3) The Glossopter's Flora, p, 78.

(4) Geol. de Queenslander 189\%, pl. XVI, fíg. 7.

(5) Mem. Gsol. Surv. N. S. W. Palaeont. n. 3, 1890, p. 122, pl. XIX, figs, 1, 2.

(6) Pal. indica n. s. vol. II, n. 1, pl. Ill, fig. 1. 
tion (1) in the mesh. The areolation in an elongated mesh is continued to the border.

As illustrated in our Fig. 9, Pl. vi, the anastomosing is so elongated and the nervation so close and parallel in the South American specimens as at first glance to suggest Taeniopteris or Macrotaeniopteris. These fragments strikingly resemble the Glossopteris musaefolia of Bunbury (2) from the Kamthi group at Nagpur in India. This species which has been known from but the single locality, has recently been combined with Glossopteris ampla by Arber (3) after an examination of Bunbury's types. The Brazilian form is almost equally illustrated by the material figured by Jack and Etheridge (4) from the Bowen Rlver beds in Queensland, and by Feistmantel (5) from the Newcastle sereis in New South Wales. Professor Zeiller (6) has illustrated a specimen similar in form and superficial aspect, from the Damuda series, as Glossopteris indica.

Locality : Estrada Nova near Minas, Santa Catharina. About 135 meters above the granite, or 145 meters below the horizon of the Iraty black shale. Lot 3923. The types of the species, from New South Wales, are under no. 1359 in the Palaeozoic plant collection in the United States National Museum.

\section{Glossopteris occidentalis n. sp.}

Pl. vii, Figs. 1-4, 4a.

Leaf very larg, rather thick, taeniate, broadly cordate at the sessile base, the lateral, borders parallel, rapidly converging near the top to form an acuminate or acute opex; midrib very broad, persistent to the apex; lateral nerves emerging at an acute angle and at once arching strongly while anastomosing somewhat irregularly in relatively larg polygonal but more or less elongated meshes near the midrib, then quickly assuming a direction nearly at right angles to the

(1) The areolation midway to the margin are drawn much too broad and angular in Dana's illustrations.

(2) Quart. Jour. Geol. Soc., vol. xvi' 1861, p. 329, pl, viii, fig. 6.

(3) The Glossopteris Flora, p. 78.

(4) Geol. of Queensland, 1892, pl, xvi, fig. 7.

(5) Mem. Geol. Surv. N. S. W., Paleont., no. 3, 1890, p. 122, pl. xix, figs. 1, 2.

(6) Pal. Indica, n. s. vol. II, no. 1, pl. iii, fig. 1. 
da nervura mediana, tomando em seguida rapidamente uma direcção quasi em angulo recto com a neroura mediana e passando usualmente parallelas e proximas, em linha recta, com anastomoses obliquas e raras, para o bordo onde se contam de. 48 a 55 por centimetro.

As feições caracteristicas das folhas desta especie, são : $1^{\text {a }}$ a base largamente sessil e cordiforme; $2^{a}$ alongamento da fol ha em fórma taeniopteroide; $3^{\mathrm{a}} \mathrm{o}$ apice $\mathrm{m}$ tanto bruscamen te acuminado $4^{\circ} \mathrm{o}$ aspecto taeniopteroide da nervação muito junta que passa para o bordo quasi em angulo recto na maior parte dos fragmentos.

$\mathrm{Na}$ est. VII, fig. 2, vê-se um fragmento incluindo o base de uma folha. A apparencia geral do specimen lembra a base de Gangamopteris cyclopteroide var. auriculata, ou Glossopteris decipiens (1) a unica especie do genero até hoje conhecida, 'que possúe a base da folha um tanto cordiforme e provavelmente sessil (2).

Em Glossopteris occidentalis a nervura mediana tem cerca de $12^{\mathrm{min}}$. de largura na base, espessa e densamente lineada e as nervuras lateraes curvam-se bruscamente para fóra, anostomosando-se ao mesmo tempo formando malhas algum tanto alongadas polygonces proximo da nervura mediana, em seguida dirige-se em linha recta em direcção quasi em angulo recto com a nervura mediana, finalmente parallela e com mallhas alongadase estreitas para o bordo. A nervação na base é em todos os respeitos essenciaes precisamente semelhante á que se encontra proximo do apice. Comtudo, como acontece muitas vezes, nas folhas deste genero o areolação é um pouco mais distante.

Em resumo, a nervação é caracteristicamente glossopteroide proximo da nervul'a mediana e superficialmente no resto do trajecto para o bordo estreitamente taeniopteroide, onde no specimen figurado, as nervuras são em numero de 55 por centimetro.

A fig. 4 mostra um fragmento um tanto mais alto da fronde. Neste exemplar, um detalhe de cuja nervação se vê na fig. - 4 a a nervura mediana ainda conserva uma largura de quasi $7^{\text {uाm }}$, e as nervuras lateraes depois de chegarem a uma distancia de $3^{\mathrm{mm}}$ da nervura mediana são um pouco ligeiramente obliquas para a nervura mediana e bordo. A fig: 3 mostra a parte do centro da folha. Neste specimen a nervura mediana de mais de $9^{\mathrm{mm}}$ de largura perto da extremidade inferior, estreitr-se menos

(1) Fei-tmantel Fl. Gondwana System. vol. III, pt. I, p. 17, pl. XXIII, figs. 3-5, pl. XXIV, fig. 6. Veja-so tambem Arber The Glossopteris Flora, p. 90; fig. 24.

(2) A ultima especie citada approxima-se pela fórma da parte central superior da folha de Glossopteris Browniana; a nervação muito obliqua é a de Glossopteris indica e a base do limbo não se sabe se é sessil. 
midrib, and passing usually straight, parallel, and close, with rare and oblique ar.astomoses to the border where they number 48-55 to the centimeter.

The characteristic features of the leaves of this species ale (1) the broadly sessile, cordate base, (2) the elongation of the leaf in Taeniopteroid form, (3) the somewhat abruptly acuminate apex, and (4) the Taeniopteroid aspect of the very close nervation which passes, in most of the fragments, nearly at right angles to the border.

A fragment including the base of a leaf is shown in Pl. VII, Fig. 2. The general appearance of the specimen suggests the base of Gangamopteris cyclonteroides var. auriculata, or Glossopteris decipiens (1) the only species of the genus hitherto known to possess a somewhat cordate and probably sessile leaf base. (2)

The midrib in Glossopteris occidentalis is about $12^{m 1 u}$. in width at the base, thick and densely lineate; and the lateral nerves bend sharply outward, while at the same time anastomosing a some elongated polygonal mesh near the midrib, then pass straight in a direction nearly at a right angle to the midrib, finely parallel, and with rery greatly elongated narrow meshes, toward the border. The nervation at the base is in all essential respects precisely similar to that near the apex, though, as often happens in the leaves of this genus, the areolation is a little more distant.

In short the nervation is characteristically Glossopteroid near the midrib, and, superficially, closely Taeniopteroid the rest of the border, whele, in the specimen figured the nervas count 55 to the centimeter.

A fragment somervhat higher in the frond is shown in Fig. 4. In this example, a detail of whose nervation is shown in Fig. 4 a, the midrib still preserves a width of nearly $7^{\mathrm{mm}}$, and the lateral nerves

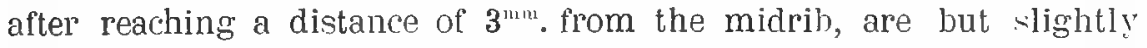
oblirgue to midrib and border. A pnrtion from the middle of the leaf is shown in Fig. 3. In this specimen the midrib, nver $g_{12}$. in width near the lower end, narrows to less than $5^{\mathrm{mm}}$. on reaching the upper

(1) Feistmantel, Fl. Gondwana Syst.. vol. III, pt. 1, p. 17, pl, xriii, figs, 3-5, pl, xxir, fir. 6. Sie also. Alher, The Glossopteris Flora, p. C0, Pig. 21.

(2) The species last named approaches Glossopteris Brouniann in the form of the middle and upper portious of the leaf: the very oblique nervation is ol that Glosspteris iudira; and the base of the blade is not known to be sessile. 
de $5^{\mathrm{mm}}$, attingindo a linha superior de fractura. A nervação que na parte inferior é typica, torna-se mais obliqua e arqueada do que em qualquer dos fragmentos da collecção. Esta obliquidade relativamente grande é sem duvida devida em parte á dilaceração e torção da parte superior da folha, onde a lamina apresenta evidencia de contracção junto á nervura mediana gasta.

A extremidade da folha que se vê na fig. 1, illustra tanto a fórma do apice que é usualmente aqui ponteagudo como a nervação que em aspecto é finamente taeniopteroide e como acima e quasi em angulo recto para o bordo.

Entre outras especies do genero a planta brasileira parece encontrar fórmas de semelhantes relações mais estreitas em Glossopteris stricta de Bunluury de Nagpur na India e Glossopteris taeniopteris de Feistmantel das Coal measures superiores de New South Wales. E' comparavel ao specimen de Bunbury (1) pelo alongamento da folha, origem e aspecto da nervação e pela diversidade relativamente grande da nervação. Tambem o exemplo dado por Feistmantel na fig. 1, Est. XXXVIIA da segunda parte, terceiro volume, da Flora Gondwana (2) é frisantemente semelhante á nossa folha pela nervura mediana e nervação. Glossopteris taeniopteroides (3) de Feistmantel é taeniopteroide, porém, com nervação e mal has de egual comprimento. O spécimen de Nigapur illustrado por Arber (4), como Glossopteris stricta, tem a sua nervaçõo muito mais obliqua do que a de nenhum specimen da nossa série e é menos taeniopteroide.

Nossa especie pela sua forma taeniada e larga faixa vascular, lembra algum tanto Gangamopteris Kashmirensis de Seward (5) e estou ligeirameate inclinado a considerar a ultima especie citada mais relacionada com Glossopteris que com Gangamopteris como se vê pelo peciolo, pela continuidade da faixa vascular, central, a fórma e nervação do folha. Glossopteris occidentalis citada mais adiante distinque-se de todas as especies acima citadas principalmente por sua base sessil largamente cordiforme, assim como atti certo ponto por seu apice obtusamente acuminado.

Glossopteris (2) Kashmirensis Seward e Glossopteris occidentalis juntamente com Glossopteris decipiens talvez sejam até certo ponto

(1) Quart. Journ. Geol. Soc. vol. XVII, 186l, p. 331 , pl. IX, fig. 5.

(2) Vuja-se tamber vol. [II, pt. 1, pl. XXI, fig. 11.

(3) Memo. Geol. Surv. N. S. W. Palaeont. n. 3, pl. XVIII, fig. 1.

(4) The Glossopter s Flora, p. 76, pl. IV, fig. 1.

(5) Pal. Indıca N.S. vol. II, n. 2, 1905, pl. VIII. Veja-se ligs. 1 禾. 
line of fracture. The nervation, which is typical in the lower part, becomes moreoblique and arched than in any other fragment in the collection. This relatively great obliquity is undoubtedly due in part to tear and strain in the upper part of the leaf, where the lamina bears evidence of contraction near the abraded midrib.

The top of a leaf shown in Fig. 1, illustrates both the form of the apex, which is here unusually sharp pointed, and the nervation which, as before, is finely Taeniopteroid in aspect, and nearly at right angle to the border.

Among other species of the genus the Brazilian plant seems to find its closest relations in Bunbury's Glossopteris stricta from Nagpur, India, and Feistmantel's Glossopteris taeniopteroides from the upper coal measures of New South Wales. It is comparable to Bunbury's specimen (1) in the elongation of the leaf, the origin and attitude of the nervation, and the relatively great density of the nervation. Also the example shown by Feistmantel in Fig. 1, plate xxxviia, of the second part, third volume, of the Gondwana Flora (2) is strikingly similar in midrib and nervation to our leaf. Feistmantel's Glyssopteris taeniopteroides (3) is Taeniopteroid, but coarsely nerved with meshes of equal length. The specimen frim near Nacrpur, illustrated by Arber (4) as Glossopteris stricta has its nervation far more oblique than that of any specimen of our series, and is less Taeniopteroid.

In the taeniate form and the broad vascular band our species reminds one somewhat of the Gangamopteris Kashmirensis of Seward (5) and $1 \mathrm{am}$ slightly inclined to regard the last named species as more nearly related to Glossopteris than to Gangamopteris, as shown by the petiole, the continuity of the central vascular band, the form of the leaf and the nervation. Glossopteris occidentalis, further, is readily distinguished from all the above named species by its broadly cordate sessile base, as well as, to a certain extent, by its bluntly acuminate apex.

Gangamopteris (?) Kashmirensis Seward and Glossopteris occidentalis, together, perhaps, with Glossopteris decipiens, are to some extent

(1) Quart. Jour. Geol. Soc., vol. svii, 1861, p. 331, pl. ix, fig. 5.

(2) See also vol. IIl, pt. 1, pl. xxi f g. 11.

(3) Mem. Grol. Sur. N. S. W., Palaeont., no. 3, pl. xviii, fig. 1.

(4) The Glossopteris Flora, p. 76, pl. iv, fig. 1.

(5) Pal. Indica, n. s.,vol, no. 2, 1905, pI. VIII, (see figs. 1-4). 
intermediarias entre Glossopteris e Gangamopteris e tendem a mostrar uma relação generica entre estas, as duas mais crracteristicas do genero do antigo Gond wana.

Localiclade: Estrada Yora proximo de Minas, Santa Cathurina. Cerca de $135^{\mathrm{m}}$ acima do granito on 145 metros abaixo do schisto preto de Iraty. Lot. 3923 .

\section{Glossopteris sp.}

Pl. VII, figs. 5, 5 $5^{a}, 6$

Associado com fragmenlos de Glossopteris Browniana do tope do carvão Irapuá, no Estado do Rio Grande do Sul, encontro um unico fragmento representando uma fronde escamosa pedicellada pertencendo provavelmente a Glossoptepis. A fronde é fortemente concava convexa e contém em sua superficie quantidade consideraval de materia carbonacea granular. A impressão da superficie convexa da folha que se vê na Est. Vli, fig. 6, apresenta uma topographia relativamente lisa, embora ljem redonda, atravessada por densas nervuras um tanto juntas ou fasciculos de nervuras i rradiando sinuosamente, e anastomosando-se occasionalmente em malhas geralmente alongadas agudo-angulares, e irregulares.

Proximo dos hordos ha occasionalmente depressões irregulares. o bordo mesmo era evidentemente espesso, mas deste lado da impressão não é de modo algum claro. As nervuras que convergem na base e passam para o pedunculo estreito tem na parle inferior da folha alguma semelhança com os fasciculos de Ottokaria.

A impressão da superficie dorsal (?) do orgão que se vê na fig. 5, é um tanto profundamente concava e sobre a maior parte interior é marcada por grandes cavidades polygonaes um tanto fortemente marcadas. Estas, canforme se vê ne ampliação photographica, est. VII, fin. 5, são de fórma irregular, muito isodiametricas ligeiramente concavas no fundo e são separadas por paredes limitadas, fortemente definidas, um tanto espessas. A porção de materia carbonacea adherente é consideravel, porim, sua estructura é obscurecida pelo aspecto granulado da superficie da matriz, arkose um tanto grosseira.

o bordo do fossil é lizeiramente enrolado para traz, especialmente perto do pedunculo estreito, onde parece ser estreitamente redondo lobado, de modo suggestivo do bordo de Ottokaria. 
intermediate between Glossopteris and Gangamopteris and tend to show a genetic relationship between these, the two most characteristic of the older Gond wana genera.

Locality : Estrada Nova near Minas, Santa Catharina. About 135 meters above the granite, or 145 meters below the Iraty black shale. Lot 3923 .

\section{Glossopteris sp.}

$$
\text { Pl. vii, figs. 5, 5a e } 6
$$

Associeated with the fragments of Glossopteris Browniana from the roof of the Irapuá coal in the state of Rio Grande do Sul I find a single specimen representing a pedicellate scale-frond probably belonging to Glossopteris. The frond is strongly concave convex and bears a considerable quantity of granular carbonaceous matter on its surface. That it was very thick and fleshy is further shown by the difference in character between the convex and the concave surfaces. The impression of the convex surface of the leaf, shown in Pl. VII, fig, 6. presents a relatively smooth though well rounded topography, traversed by rather close dense nerves, or nerve fascicles, radiating sinuately and occasionally anastomosing in generally elongated, acute-angled, irregular meshes.

Near the borders there are occasional irregular depressions. The border itself was evidently thick, but on this side of the mold it is not at all clear. The nerves, which converge at the base and pass down the narrow pedicel, bear, in the lower part of the leaf, some resemblance to the fascicles in Ottokaria.

The impression of the dorsal (?) surface of the organ, shown in fig. 5, is rather deeply concave and, over the greater portion of its interior, is marked by larg, rather strongly impressed, polygonal pits. These, as shown in the photographic enlargement, Pl. VII, fig. 5a, and are separated by sharply defined, rather thick, boundary walls. The amount of adherent carbonaceous matter is considerable, but its structure is obscured by the granulated condition of the surface of the rather coarse, arkose matrix. The border of the fossil is slightly backward rolled, espeeially on approaching the narrow pedicel where it appears to be obscurely and narrowly round-lobate, in a way suggastive of the border of Ottokaria. 
Pela composição evidentemente muitc espessa do fossil e o aspecto peculiar das cavidades que se veem no interior da impressão da superficie dorsal (?) estou fortemente disposto a consideral-a corno representando um orgão de fructificação. As paredes espessas que separam estas depressões que consistem em apparencia sómente na matriz dearkose, estão em relevo entre entre as impressões que considero provelmente sporangios. Estas paredes divisorias não mostram traços de nervação, sendo compostas do molde de arkose, e são muito espessas para serem consideradas representando nervuras anastomosando-se. De facto, a impressão da superficie concava dos orgãos, não mostra vestigios a não ser que estejam nos bordos, de alguma cousa que a meu ver possa ser considerado como nervação.

A impressão da superficie convexa, fig 6, mostra, ao contrario, uma nervação relativamente distincta com malha muito estreita e alongada; de todo differente da areolação que se vê na fig. 5, que representa a superficie concava, bem como a nervação e a fórma geral do fossil em conjuncto levam-me a consideral-o como representando provavelmente uma fronde escamosa fertil e pedunculada de Glossopteris (1). A fórma da sua superficie concava, suggere a comparação com as fórmas cycadaceas de inflorescencia. O specimen deve-se comparar com Dolerophyllum pollinifero dado por Saporta (2) e outros com Discostachys cebennensis (3) e Plinthiotheca de Heraclea na Asia Menor (4) dercripta por Zeiller.

Localidade: Tope do carvão Irapuá a oéste da residencia do Dr. Ramiro Barcellos, proximo ao rio Irapuá, Rio Grande do Sul; 135 metros mais ou menos abaixo do schisto preto de Iraty. Lot. 3591.

\section{Vertebraria}

Royle, III, Bot. \& Nat. Hist. Hymalayan Mts., vol. I, 1839 , p. XXIX.

\section{Vertebraria? sp.}

As argillas duras e de côr clara do horizonte do carvão Barro Branco, conteem grande quantidade de pequenas raizes, ramificando-se

(1) Vejam-se as frondes cscamosas da cerio Damuda, illustradas por Zeiller, Pal. Indica. N. S., vol. I, 1902, pl. III, figs. 4, 11. Tambem Bull, Soc. Geol. Fr. (3), vol. XXIV,
p. 365 , pl. XVl, ligs. 6 e 14.

(2) Evol de Rigne legetal, vol. I, 1885, p. 76, fig, 37, p. 75, fig. 35.

(3) Géol. et Paleont Bassin houill, Gard, 1890, p. 306, pl. VIII, fig. 2.

(4) Mem. Sóc. Geol. Fr.; n. 21, 1899, p. 54, pl. IV, Higs. 18, 18a. 
From the evidently very thick composition of the fossil and the peculiar aspect of the large pits shown in the interior of the impression of the dorsal (?) surface, I am strongly disposed to regard it as representing an organ of fructification. The thick walls separating these depressions apparently consist only of the arkose matrix standing in relief between the impressions of what I regard as probably sporangia These partition walls show no trace of nervation, being compased of the arkose mold, and they are far too thick to be regarded as representing anastomosing nerves. In fact, the impression of the concave surface of the organs shows no trace, unless it be at the borders, of anything which, in my judgment, may be regarded as nervation.

The impression of the convex surface, fig. 6 , shows, on the contrary, a relatively distinct nervation with a very narrow, elongated mesh, absolutely different from the concave surfac. The characters of the concave surface, the nervation and the general form of the fossil as a whole lead me to regard it as probably representing a fertile pedicellate scale-frond (1) of Glossopteris. The features of its concave surface strongly sugggest. comparison with the cycadaceous forms of inflorescence. The specimen is to be compared with the polliniferous Dolerophyllum shown by Saporta (2) and others, with Grand'Eury's Discostachys cebennensis, (3) and the Plinthiotheca described by Zeiller (4) from Heraclea in Asia Minor.

Locality: Roof of the Irapuá, coal, wast of the residence of doctor Ramiro Barcellos, near rio Irapuá, Rio Grande do Sul. About 135 meters below the Iraty black shale. Lot 3591 .

\section{Vertebraria}

Royle, III. Bot. \& Nat. Ilist. Ilimalayan Mits., vol. I, 1839, p. XXIX.

\section{Vertebraria? $s p$.}

The hard light colored clajs from the horizon of the Barro Branco coal contain great quantities of small roots somewhat irre-

\footnotetext{
(1) See scale fronds from the Damuda series illustrated by Zeiller, Pal. Indica, n. s., vol. II, 1902, pl. III, figs. 4 e 11. Also Bull. Soc. Géol. Fr. (3), vol. XXIV, p. 365, pl. XVI, ligs. 6 e 14 .

(2) Ėrol, d. Règne Végétal, vol. I, 1835, p. 76, fig. 37, p. 75, 6g. 35.

(3) Géol. et paléont bassin houill. Gald, 1890, p. 305, pl. VIII, fig. 2.

(4) Mém. Soc. Géol. Fr., n. 21, 1899, p. 54, pl.1V, fig. 18 \& $18^{8}$.
} 
um ianto irregularmente em um angulo muito aberto. Parecem concordar tanto com ns pequenos fragmentos de raiz que Feistmantel (1) e Zeiller (2) descreveram como Vertebraria indica que provisoriamente refiro-os ao mesmo genero. Ainda não foram descobertos fragmentos, mostrando distinctamente a segmentação rectangular tão caracteristica das impressões achatadas destes rhizomas.

Por conseguinte, am vista das difficuldades attinentes á interpretação das pequenas raizes quando apenas conservadas como impressões, deve restar alguma duvida, quanto a referencia generica dos fragmentos em questão. Como foi dito em minhas notas sobre Glossopteris, o genero Vertebraria è baseado em rhizomas de que Zeiller (3) e Oldham (4) provaram evidentemente terem nascido as folhas conhecidas como Glossopteris.

Localidades: carvão Barro Branco. Estrada Nova perto de Minas, Santa Catharina, cerca de 175 metros acima do granito ou 105 metros abaixo do schisto preto de Iraty. Lot. 3589. Tamber a nordeste de Minas Santa Catharina, 55 metros acima do granito ou 225 metros abaixo do schisto preto de Iraty . Lote 3921 . Carvão S. Jeronymo, perto de Candiota, Rio Grande do Sul, cerca de 20 metros acima do carvão Irapuá. Lot. 3924 .

\section{Gangamopteris}

Mc Coy Trans. R. Soc. Victoria, vol. V, 1861, p. 107.

o genero Gangamopteris differe de Glossopteris, principaImente pela falta de uma nervura mediana e peciolo distinctos. Suas folhas, algumas vezes de grande tamanho, variam da fórma orbicular-oval á estreita e linear, São usualmente longas oboraes em sua forma geral e mais ou menos estreitas para a base, ás vezes cordiformes ás vezes um tanto estreitas e cuneiformes.

As partes basal e central são atravessadas por nervuras juntas, erectas e parallelas, anastomosando-se occasionalmente, e as exteriores successivas curvam-se gradualmente para fóra, bifurcando-se varias vezes, ao passo que se anastomosam em angulos agudos.

(1) Fl. Gonlwana, Syst., vol. IV. p. 22, pl. VA, fị. 1.

(2) Bul. Soc. Geol. Fr. (3) rol. XXI', p. 351, pl. XV, figs. 2 e 8.

(3) Lac. cit., p. 377.

(i) Rece (riol. Surv, In lia, vol. XX: 1897, p. 45. 
gularly branching at very open angle. They seem to agree so far with the small root fragments described by Feistmantel (1) and Zeiller (2) as Vertebraria indica that I provisionally refer them to the same genus. No fragments distinctly showing the rectangular segmentation so characteristic of the flattened impressions of these rhizomes have yet been found.

In view, therefore, of the difficulties attending the interpretation of small roots when preserved as impressions only, some doujt must remain as to the generic reference of the fragments in hand. As stated in my remarks on Glossopteris, the genus Vertebraria is founded on rhizomes which have been independently proven by Zeiller (3) and Oldham (4) to have borne the leaves known as Glossopteris.

Lacalities: Barro Branco coal, Nora Estrada near Minas, Santa Catharina. AJjout 175 meters above the granite, or 105 meters below the the Iraty black shale. Lot 3589. Also Northeast of Minas, Santa Catharina, 55 meters above the granite or 225 meters below the Iraty black shale. Lot 3921. S. Jeronymo coal near Candiota, Rio Grande do Sul. About 20 meters above the Irapurá coal. Lot 392 作.

\section{Gangamopteris}

Mc Coy. Trns. R. Soc. Tictoria. vol. V, 1861, p. 107.

The genus Gangamopteris differs from Glossopteris chiefly by the absence of a distinct midrib and petiole. Its leaves, sometimes of very great size, vary from orbicular-oval to narrow and linear. They are usually long-obovate in general form, and more or less narrowed towards the sometimes cordate, sometimes rather narrow cuneate base.

The basal and central portions are traversed by close, erect, and parallel veins, occasionally anastomosing, the successive outer ones gradually bending outward and forking several times while anastomosing at acute angles. The mesh is generally shorter and narr-

(1) Fl. Gondwana syt, rol. IV, p. 22, pl. YA, fig. 1 .

(2) Bull. Soc. Gíol. Fr., (3) rol. XXlY, p. 351, pl. XT, figs. 2 e 8.

(3) Lac, cit., p. $37 \%$.

(4) Rec. Géol. Surv., India, rol. Xxx, 1837, p. 45. 
A malha é geralmente mais curta e estreita mais proximo do bordo da folha. As follhas normaes são ás vezes acompanhad xs de pequenas folhas escamosas, uma das quaes se vê na fig. 7, est. VIII. Nada se conhece da frutificação do genero, e a inclusão de Gangamopteris nos fetos, é devido á suas effinidades apparentemente estreitas com Glossoptriris que tem sido considerada como feto.

Devido á grande abundancia de specimens de folhas e seu magnifico estado de conservação é certo que, si são fetos, são dimorphicos, não tendo sido reconhecidas as frondes ferteis.

Como será mais completamente estabelecido em pagina ulterior, as inflorescencias que teem sido observadas, associadas nas mesmas camadas tanto da India como do Brazil e que determinei como Arberia, é possivel que pertençam antes a Gangamopteris que a Noeggerathiopsis.

Si se provar ser esta hypothese verdadeira não haverá duvida alguma, por mais tempo, quanto á relação entre os Pteridospermeos, ou Gymnospermeos e Gangamopteris.

Devido a seus caracteres filicrides, sua relação genetica presumivel com o grupo Cyclopteroide (Neuropteroide) e o argumento de sua associação com os typos ferteis descritos como Arberia e Derbyella e devido ao sério argumento negativo da falta de frondes terteis reconhecidas pertencentes a este genero, tenho pouca hesitação em collncar o genero nos Pteridospermeos em associação com Glossopteris, Ottokaria e os dous generos inflorescentes que veem de ser citados.

Outra circumstancia cque favorece a natureza cycadofilicea de Gangamopteris e Glossopteris é a occurrencia de um tão grande numero de especies distinctas de Cardiocarpos nas mesmas camadas, se rem que um unico representante das Cordaitales, Noeggerathiopsis Hislopi pareça existir na flora. Gangamopteris póde muito bem ter sido derivada de typo Cyclopterideo proximo de Cardiopteris do Carbonifero inferior do Norte.

O genaro é representado apenas por poucas especies, o unico typo principal e largamente distribuido, sendo Gangamopteris Cyclopteroides que é considerada por Seward e Arber especificamente inseparavel de Gangamopteris abovata da formação carbonifera brasileira. 
ower nearer the border of the leaf. The normal leaves are sometimes accompanied by ismall scale-leaves, one of which is illustrated in fig. 7 , on Plate vin. Nothing has Jeen known of the fructification of the genus and the inclusion of Gangamopteris in the ferns has largely been due to its apparently close affinities with Glossopteris which has been regarded as a fern.

From the very great abundance of specimens of the leaves, and their fine state of preservation it is hardly less than certain that, if. ferns, they are dimorphic, the fertile fronds Jeing not yet recognized.

As will be more fully stated on a later page, the inflorescences that have been observed associated in the same beds both in India and in Brazil and which I have designated as Arberia, possibly belong to Gangamopteris rather than to Noeggerathiopsis.

If this hypothesis proves true, there will no longer be any doubt as to the relationship of Gangamopteris to either pteridosperms or the gymonosperms.

On account of its filicoid characters, its presumable genetic relation to the Cyclopteroid (Neurnpteroid) group, and the weight of its association with the fertile types described as Arberia and Derbyella, and on account of the serious negative argument of the absence of fertile fronds, recognized belonging to this genus I have little hesitation at placing the genus in the pteridosperms, in association with Glossopteris, Ottokaria, and the two inflorescent genera just mentioned.

Another circumstance favoring the Cycadofilicate nature of Gangamopteris and Glossopteris is the occurrence of so large number of distinct species of Cardiocarpa in the same beds, though but one representative of the Cordaitales, Noeggerathiopsis Hislopi, appears to be present in the flora. Gangamopteris may well have been derived from a Cyclopterid type close to Cardiopteris, of the Northern Lower Carboniferous.

The genus is represented by but few species, the principal and only widespread type being Gangamopteris cyclopteroides which is regarded by Seward and Arber as specifically inseparable from Gangamopteris obovata of the Brazilian coal measures. 
Gangamopteris obovata (Car.) D. IT.

P. VIIl. figs. $1-7$

1869 - Noeggerathia abovata Carruthers, Geol. Mag. vol. VI. p. 155, pl. VI, fig. 1 ; Hartt. Geol. Phỳs. Geogra. Brasil, 1870, p. 525.

1875 - Gangamopteris spatulata McCoy. Prod. Pal. Vict. Dec. II, p. 12, pl. XlII, figs. 1-1a.

1876 - Gangarnopteris cyclopteroides - Feistmantel, Rec, Geol. Surv. India, vol. IX, pt. 3 p. 73 ; Feistmantel, Fl. Gondw. Sist. vol. IIl. 1879, p. 12 (in part) Kurtz Rev. Mus. La Plata, vol. VI, 1894, p. 129, pl. II, flgs 1-3, Seward, Ann, S. Alr. Mus. vol. IV, p. 79, Arber The Glossopteris Flora, 1905, p. 105 e 106.

1879 - Gangamopteris ryclopteroides var. attenuata Feistmantel, Fl. Gond. Syst. vol. III, pt. I, p. 14. pl. Xl, fig. I, pl. XII, fig. 1, pl. XIII, fig. 3, pl. XIV, figs. 1, 2; pl. XVI, fig. 5, pl. XXVIl, fig. I; Feistmantel op. cit., vol. IV, 1882, p. 38, pl. XVI, fig 4 b, pt. 2, p. 32, pl. VIII a, fig. I, pl IX a, flg. 4 a, pl. XIII a, figs. 4-6, pl. XN a, fig. 6; Feistmantel, Abh, bolim, Gessel Wiss, ( 7 ), III, 1839, p. 37, pl. IV, fig. 2; Zeiller, Bull, Soc. geol. Fran. ( 3 ) vol. XIII, 1896, p. 615, pl. X, figs. $1-3$.

1879 - Gangamopteris major - Feistmantel Fl. Gond. Sist. vol. III, pt, I p. 15. pl XIV, fig. 3 pl. XVI figs. 1, 2 e 3, 2 a; Feistmantel, Op. cit. vol. IV, 1882, pt. I p. 38, pl. XV, figs. 13 c 1k, pl. XX, fig. 2, pt. 2, 1886, p. 33, pl. Va, fig. 9, pl. XI a, fig. 9 .

1905 - Gangamopteris abovata (Car.) D. White Science, n. vol, Xxl, p. 700 .

1905 - Gangamopteris cyclopteroides var. major (leist) Arber, The Glossopteris Flora p. 113, fig. $27: 3$.

Folhas alongadas abovaes espatuladas, ou ovaes espatuladas a obovaes linguladas, contrahidas, usualmente com os bordos inferiores concavos, em uma base estreita algumas ceres muito estreitamente cuneiforme e um tanto delgado; o apice da folha as vezes arren londado o' otal arredondato, lamina espessa, ais vezes convexe na parte inferior entre nerouras muito juntas parallelas dichmiomas certicalmente; raramente ranastomosernolo-se yminariu- 
Gangamopteris obovata (Car.) D. W.

Pl. viii. Figs. 1-7.

1869 - Noeggerathia obovata Carruthers, Geol. Mag. vol. vi, p. 155, pl. vi, fig. 1 ; Hartt, Geol. Phys. Geogr. Brazil, 1870, p. 525.

1875 - Gangamopteris spatulata, Mc Cus, Prod. Pal. Vict., Dec. II, p. 12, pl. xiii, fig. 1, 1a.

1876 - Gangamopteris cyclopteroides Feistmantel, Rec. Geol. Surv. India, vol. ix, pt. 3, p. 73; Feistmantel, F1. Gondwana Syst., vol. iii, 1879, p. 1' (in part); Kurtz, Rev. Mus. La Plata, vol. vi, 1894, p. 129, pl. ii, fig. 1-3; Seward, Ann. S. Afr. Mus., vol. iv, p. 79 ; Arber, The Glossopteris Flora, 1905, p 105, 106.

1879 - Gangamopteris cyclopteroides var attenuata Feistmantel, Fl. Gondwana Syst., vol. iii, pt. 1, p. 14, pl, xi, fig. 1, pl. xii, fig. 1, pl. xiii, fig. 3. pl xiv, flg. fig. 1,2, pl. xvi, fig. 5, pl. xxvii, fig. 1; Feistmantel, Op. cit., vol. iv, 1882, p. 38 , pl. XVI, fig. 4] pt. 2 pg. $32 \mathrm{pl}$ viiia, fig. 1 pl. ixa, fig. 4a pl. xiiia, fig. 4, 6, pl. xiva, fig. 6; Feistmantel, Abh. böhm. Gesell. Wiss (7, vol iii, 1889, p. 37, pl. iv, fig 2 ; Zeiller Bull. Soc. Géol Fr., (3) vol. xxiii 1896 p. 615, pl x, fig. 1-3.

1879 - Gangamopteris major Feistmantel, Fl. Gondwana vol. iii, pt. 1, p. 15, pl. xiv, fig. 3, pl. XVI fig. 1, 2, 2a; Feistmantel, Op. cit., vol. iv, 1882, pt. 1, p. 38, pl. xv, flg. 13, 14. pl. xx, fig. 2, pt. 2, 1886, p. 33, pl. va, fig. 9, pl. xia, fig 9 .

1905 - Gangamopteris obovata (Carr.) D. White, Science, n. s., vol. xxi, p. 700 .

1905 - Gangamopteris cycloperoides val. major ( Feist.) Ar'ber, The Glossopteris F'lora, p, 11:, fin. 273.

Leaves elongated obovate-spatulat', or oval-spatulate to obovatelingulate, contracted, usually, with concave lower borders, in a narrow, sometimes very narrowly cuneate, often rather slender base, the apex of the leaf being rounded or onate-round, lamina thick, often convex ventrally between the nerves; nervation rather coar'se, from many close parallel and vertical dichotomous and rarely anastomosing primary veins in the brsal portion, the out'r' teins arching very 
mente na parte basal, as nervuras exteriores, arqucando-se muito suavemente para o bordo, na parte inferior da folha, e mais fortemente nas partes mais altas, bifurcando-se e anastamoseando-se mus frequentcmente, com especialidade proximo ao bordo, onde as nervillas são muito proximas, com uma malha muito mais curta; a curvatura da nervação lateral, varia muito na parte inferior da folha, de accordo com a largura da sua base, as nervillas arqueam-se mais fortemente nas furmas de follhas mais largas, frondes escamosas cuneiformes abovadas, estreitas e algum tanto concavoconvexas.

As folhas desta especie associadas em abundancia com uma pequena especie de Samaropsis, são os fosseis mais communs nas collecções da camada de plantas a nordeste de Minas, onde se encontram fragmentos em cada superficie de clivagem dos schistos cor de creme. Muitos dos specimens estão ligeiramente macerados, e a dilaceração da lamina como se vê nas figuras é muito frequente.

$\mathrm{Na}$ est. VIII, figs. 2-4-5 e 6 se veem exemplos typicos dos fragmentos das collecçũes. Todos são caracterisados pela base estreita, cuneiforme, e de bordo levemente concavo. Os exemplos que se veem nas figs. 2 e 3 corre-pondem exactamente ao spcimen original de Candiota, Rio Grande do Sul, figurado por Carruthers (1) como Noeggerathia abovata, se bem que em muitos specimens o bordo superior não seja sinuoso como na figura publicada por Carruthers. Uma pequena folha provavelmente, nova, e lembrando Euriphyllum pela for'ma se vê na fiğ 6 e na fig. 7, está photogiraphicamente illustrada uma folha escamiforme referente sem duvida á Gangamopteris obovata.

A parte espical da folha que se vê na flg. I que é correspondente a da flg. 5 , parece illustrar a phase mais larga dos apices deste typo e está em estreita concordancia com muitas do material illustrado como Gangamopteris cyclopteroides Feistmantel. Ger'almente as folhas brasileiras abrangem as fórmas illustradas, por Kurtz e Zeiller e uma mais estreita e mais distinctamecte esputulada que as que se reem na fig. 3 .

A nervação na especie brasileira é parallela e quasi sempre erecta na parte basal estreita e só depois que a folha principia a alargar-se é uue as nervuras começam a arquear-se de forma apreciavel. As anastomoses não parecem ser tão frequentes como em muitas especies orientaes e a malha é muitas vezes tão longa e as nervuras quasi tão

(1) Geol. Mag. vol. VI, 1869, p. 155, pl, VI, fig. I. 
gently to the border in the lower part of the leaf, and more strongly in the higher portions, while forking and anastomosing more frequently, especially near the border, where the nervilles are very close, with a much shorter mesh; curvature of the lateral nervation varying greatly in the lower part of the leaf in accordance with the width of the base of the leaf, the nervilles arching more strongly in the broader leaf forms; scale fronds cuneately obovate, narrow, and somewhat concavo-convex.

The leaves of this species abundantly associated with a small species of Samaropsis are the most common fossils in the collections from the plant bed northeast of Minas, where fragments may be found on every cleavage surface ${ }_{L}$ of the cream colored shales. Most of the specimens are slightly macerated, and tearing of the lamina, as shown in the figures, is very frequent.

Typical examples of the fragments in the collection are shown in Plate viii. Figs. 2, 4, and 6. All are characterized by the narrow, cuneate, slightly concave-bordered base. The examples seen in figs. 2 and 3 , exactly correspond to the original specimens from Candiota, Rio Grande do Sul, figured by Carruthers (1) as Noeggerathia obovata, though in most specimens the upper border is not sinuate as in the figure published by Carruthers. A small leaf, probably young; and suggestive of Euriphylum in form is seen in fig. 6, and a scale leaf, undoubtedly referable to Gangamopteris obovata is photographedly illustrated in Fig. 7.

The spical portion of the leaf shown in Fin. 1, which corresponds to that in Fig. 5, seems to illustrate the broader phase of the apices of this type and is in close agreement with much of the material illustrated as Gangmopteris cyclopteroides Feistmantel. In general, the Brazilian leaves range from the forms illustrated by Kurtz and Zeiller, to a phase even narrower and more distinctly spatulate than that shown in Fig. 3.

The nervation in the Brazilian species is parallel and nearly always erect in the narrow basal portion; and it is only aftel the leaf begins to widen out that the veins commence to arch appreriably. Anastomosis appears not to be so frequent as in most of the oriental specimens and the mesh is often so long and the nerves so nearly

(1) Geol. Mag., vol, V1, 1839, p. 155, pl Vl fig. 1. 
parallelas que exigem ser examinadas de perto para perceber-se as connexões muito obliquas, excepto proximo dos bordos da folha.

o professor Seward (1) depois de um exame critico do typo original de Carruthers, actualmente no Museu Britannico, convenceu-se de que a planta brasileire i identica a Gangamopteris cyclopteroides de Feistmantel especie commum e que se encontra quasi por toda a parte (ainda não conhecida de New S. W'ales) de flora do Gondrrana inferior. Com esta combinação especifica das fórmas Indianas e Sul Americanas, sob o mesmo nome, Arber (2) concordou, depois de novo exame do trpo de Carruthers que Zeiller previamente referira a Euryphillum como provavelmente identico a Euryphillum Whittianum (3). Não póde haver duvida quanto á concordancia e identidade especifica de um numero de fórmas da India descriptas, com as folhas da formaçãn carbonifera brasileira, por conseguinte parece não haver motivo algum para dar-se dois nomes especificos á estas plantas. Nisto estou de accôrdo com o eminente palaeobotanico inglez, embora discordando quanto ao nome á que se deve dar a preferencia.

Todavia dere-se observar que comquanto a variedade attenuata de Gnngamopteris cyrlopteroides e a variedade major pareça que se podem distinguir das variedades de folhas brasileiras, nenhuma das muito largas, com base larga, ou bordos inferiores arredondados, e nervação arçueada como as originalmente illustradas por Feistmantel (4) e que elle mais tarde (5) figura como mostrando todos os caracteres das folhas originaes dos schistos de Talchir, veio ás minhas mãos, procedente do Brasil.

Nas collecções não parece haver fórmas correspondentes ás variedades subauriculata, aureolata e cordifolia, embora a sua occurrencia na America do Sul possa ser revelada por pesquizas posteriores, no campo.

Em outro caso os specimens do Arroio dos Ratos figurados por 7eillel (6) como Gangamopteris cyclopteroides var. attentuata săo mais largos para a base que qualquer dos specimens da nossa collecrão. Exemplos com bases cuneiformes ainda mais estreita figurados

\footnotetext{
(1) Inu. S. Afr. IIus. vol. IV, 1903, p. 83.

(2) The Glossopteris flora, $190 \overline{0}$ pp. 106, 111.

(3) Bull. Sor. gitol, Fr. (3) vol. XXIIT. 1896, p. 617.

(4) FI. (rundwana Sysh, vol ILI, pt. $11879 \mathrm{p} .12 \mathrm{pl}$. VII, VIII, IX, etc.

(.) Op. cit. vol. III, Expl, pl, XXXI, fig. 2 .

(6) Bull. Sive. (ri,l. France, 3) vol XXlll. 1896, pl. X, figs. 1-2,
} 
parallel as to require close scrutiny to perceive the very oblique connecting bundles, except near the borders of the leaf.

Professor Seward (1) after a critical examination of Carruthers' original type, now in the British Musum, is convinced that the Brazilian plant is identical with Feistmantel's Gangamopteris cyclopteroides, the common and almost omnipresent (not yet known from New South Wales) species of the Lower Gondwana flora. In this specific combination of the the indian and South American forms under the same name, Arber concurs, (2) again after an examination of Carruthers, type, which Zeiller had previously referred to Euriphillum as probably identical with Euriphyllum whittunum (3). There can be no question as to the arreement and specific identity of a number of the forms described from India with the leaves from the Brazilian coal measures, and consequently there seems to be no room for two specific names for these plants. In this I agree with the eminent British paleobotanist, though disagreeing as to which name should be given preference.

However, it should be observed that while the rariety attenuata of Gangamopteris cyclopteroides and the variet! major seem to be indistinguishable from the variations in the Brazilian leaves, none of the very large Jroad leaves, with broad bases or rounded lower borders and arching nervation like those originally illustrated by Feistmantel (1) and which lie later (.) figurs as showing all the characters of the original leaves from the Talchir shales, have come to my hand from Brazil.

Forms corresponding to the varieties subauticulata, areolal $\alpha$, and cordifolia do not seem to lie present in the collections, though their occurrence in South America may be revealed by further search in the field.

On the ther hand the specimens from Arroio dos Ratos, figured by Zeiller (6) as Gangamopteris cyclonteroides var. attenuata ale broader toward the base than any of the spreimens in our collections. Examples with still norrower cuneate bases, figured by Feistmantel

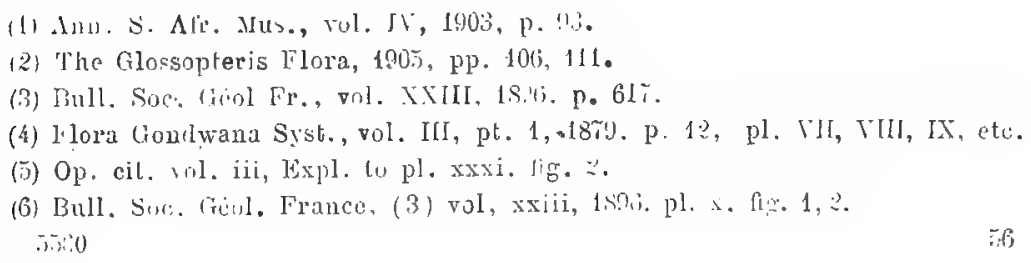


por Feistmantel sob o mesmo nome de variedade, correspondem perfeitameute a alguns dos nossos specimens brasiTeiros e não ha logar para duvida alguma, sobre a sua identidade especifica; mas como está indicado pelas figuras, a maior parte do nosso material, approxima-se mais estreitamente da fórma que Feistmantel descreveu cumo Gangamópteris major (1) de que Zeiller fez uma variedade de Gangamopteris cycloptoroides. A nomenclatura da nossa especie é um pouco complicada e exige algumas palavras de explicação. Se Gangamopteris abovata, é especificamente indistinguiveI de Gangamopteris cyclopteroides, como segundo Sewarl e Arber parece ser o caso, deve aquelle nome, tendo prioridade prevalecer em sua applicação á especie A variedade attenuata si realmente é distinguivel como variedade da typica Gangamopteris abovata, deve-se juntar como uma variedade a esta. E' duvi łoso si a variedade major pode separar-se, mesmo como variedade, da folha typica brasileira. De outro modo a typica ou original Gangamopteris cyclopteroides que eu não fui capaz de reconhecer nos nossos specimens, póde se verificar ser uma fórma sub-especifica da ordem.

A polymorphia das folhas de Gangamopteris, é tão grande que não é impossivel que o typo Indiano muito grande e typico seja encontrado eventualmente no Brasil, ainda que eu esteja disposto pelo menos actualmente, a consideral-o como não menos distincto como variedade da fórma que se vê na est. Vlll.

As alterações exigidas pelas regras de nomenclatura não affectam o importante e interessante facto da occurrencia de formas identicas destac especies na Asia, Australia, America do Sul e Brasil.

Localidades: Nnrdeste de Minas, Santa Catharina $\mathbf{5 5}$ metros mais ou menos acima do granito ou $225 \mathrm{~mm}$. abaixo do schisto preto de Iraty. Lol. 3.586 e 3921.

Estrada Nova perto de Minas. Tope do carvão Barro Branco cerca de 175 metros acima do granito, ou 105 metros abaixo do schisto preto de Lot. 3589.

Tope do schisto preto, 6 metros acima do granito 4 kilometros (492 poste kilometrico) a éste de Suspiro Rio Grande do Sul, Lot. 3592 . (1) Veja-se particularmmente Feistmantel, Fl. Gondwana System. vol. 11l, p. 14,
pl. XIV, tig. 3 e pl. XVl, Ige. 1, 2. 
under the same varietal name, correspond fairly well with some of our Brazilian specimens, and there is no room for doubt as to their specific identity. But as is indicated by the figures, the greater part of our material approaches more closely to the form described by Feistmantel as Gangamopteris major (1) which Arber makes a variety of Gangamopteris cyclopteroides. The nomenclature of our species is a little complicated and requires a few words of explanation. If Gangamopteris obovata is specifically indistinguishable from Gangamopteris cyclopteroicles, as according to Saward and Arbar seems to be the case, the former name, having priority, must prevail in its application to the species. The variety attenucta, if really distinguishable varietally from the typical Gangumopteris obovata is to be appended as a variety under the latter. It is doubtful whether the variety major can be separated even varietally from the typical Brazilian leaf. On the other hand, the typical or original Gangamopteris cyclopteroides, which I have not been able to u'ecognize in our specimens, may possibly be found to be a form varietal, sub-specific, or formal in rank.

So great is the polymophy in the leaves of Gangamopteris that it is hardly improbable that the very larga typical Indian type will eventually be found in BraziI; ret I am disposed, for the present at least, to regard it as not less than varietally distinct from that shown in Plate VIII.

The changes required by the rules of nornenclature do not affect the important and interesting fact of the occurrence of identical forms of this species in Asia, Australia, South America and Brazil.

Localities: Northeast of Minas, Santa Catharina, about 55 meters above the granite, or 225 meter's below the Iraty black shale. Lot. 3586 . and 3921 .

Estrada Nova, near Minas roof of the Barro Branco coal about 175 meters above the granite, or 105 meters beIow the Iraty black shale. Lot. 3589.

Roof of the black shale, 6 meters above the granite, 4 kilometers ( 492 kilometer Post) east of Suspiro, Rio Grande do Sul Lot. 3592 .

(1) See, in particular, Feistmantel, Fl. Gondwana Syst,, vol. iii, p. 14, pl. xiv fig. 3 and pl. XVl fig. 1,2, 


\section{Ottokaria}

Zeiller, Pal. Indica, n. s. vol. II, 1902, n. I, nota a pag. 34

Othokaria soalis ne.sp.

Pl. YII, fig. 7 e 7 a.

Foliolo peciolado, oval, tendo o limbo de 2 a 5 centimetros de romprimento e a centimetros de largura, muito espesso, e orlado de dentes curtos, rectos, abtusamente reclondos " radiados, com cerca de 1 a 1,5 mullimetriss de comprimento "quası tão largos; neroação irradiando do apice do piciolo densamente estriado em fasciculos um tanto sinuosos, largos e curvados para fora dirhotomisando-se, cujas ultimas divisôes fibrosas penetram nos dentes arredondados.

O specimen acima descripto é evidente e genericamente identico ao rossil das camadas Karharbari, publicado por Zeiller.

Differe da especie typo Ottokaria bengalensis (") pela forma oval do limbo e pelos dentes muito mais curtos, pequenos e redondos. A nervação do typo indiano, Zeiller descreveu, como formada de filamentos delgados reunidos em fasciculos que irradiam da extremidade do peciolo, ao mesmo tempo dichotomisando-se.

O specimen brasileiro, confórme está indicado na fig. 7, est. VII, tem a nervação similar á do typo asiatico. Porém, com um exame rigoroso vê-se que as faixas vasculares dichotomas e um tanto flexuosas, approximam-se até á contiguidade em alguns logares, e até mesmo parecem soffrer uma troca de fibras de que se vão formando, serundo me parece, obscuras anastomoses. O exame feito com lente da ampliação photographica da folha dada pelo professor Zeiler na figr. $9 \mathrm{~A}$, da sua memoria, parece-me mostrar um aspecto suggestivo de malhas alongadas indistinctas comparaveis ás do typo da America do Sul. Além disso, nossos specimens săo marcados por depressõ zs rasas exactamente semelhantes ás indicadas obscuramente na ampliação photographica. Estas depressões do specimen brasileiro correspondem ás posições dos pequenos corpos ovaes sporangioides, est. VII, fig. 7 a, que se vểm no reverso do fossil. Outro ponto de concordancia é a

(1) Feistmantelia bengutensis, como estad descripta na pag. is, vol. II, n. s. dat Pa. Iaeontologia Indica, mas mudado para Ottokaria em uma nota correctiva supplementa. trndo sido aquella desirnaçäo gonerica já empreçada em outros generos de plantas fass is do Mesozuico Norte Americano, pelo protessol" Lester, F. Ward. 


\section{Ottokaria}

Zeiller, Pal. Indica, n. s., vol. II, 1902, no. 1, note to p. 34.

Ottoiraria ovalis $n . s p$.

Pl. vii, fig. $7,7 \mathrm{~A}$

Leaflet pedicellate, oval, the blade being 2.5 centimeter's in length and 2 centimeters in width, very thick, and bordered by short, close obtusely rounded, radiate teeth, about 1-1.5 milimeter in length nearly as broad; nervation radiating from the apex of the densely striate petiole in broad, somewhat sinuate, outward curved dichotomising fascicles, the ultinate fibrous divisions of which enter the rounded teeth.

The specimen described above is evidently generically identical with the fossil published by Zeiller from the Karharbari beds.

It differs from the type species, Ottokeria hengrlensis (1) by the oval form of the blade, and the very much shorter, smaller, and more rounded teeth. The nervation of the Indian type is described ly Zeillel. as formed by slender filaments reunited in fascicles which radiate from the summit of the petiole, at the same timo dichotomising.

As indicated in figure 7 , Plate vii, the Brazilian specimen has a nervation similar to that of the Asiatic type. But on a close examination it is seen that the dichotomous and somewhat flexuose vascular bands approach to contiguity in placcs and even seem to experience an interchange of fibres amounting, as it seems to me, to obscure anastomosis. The examination, with the lens, of the photographic enlargement of the leaf shown by professor Zeiller in figure $9 \mathrm{~A}$ of his memoir seems to show an aspect suggestive of indistinct elongated meshes comparable to those in the type from South America. Furthermore our specimens are marked by shallow depressions exactly similar to those obscurely indicated in his photographic enlargement. These depressions correspond in the Brazilian specimen to the positions of the small oval sporangioid bodies, $\mathrm{Pl}$. vii, figure 7 a, seen on the counterpart of the fossil. Another point of agreement lies in

(1) Feistmantelia bengalensis as described ond p. 34, rol. II, 11. s., of the Palaeontologia Indica, but changed to Ottokaria in a supplementary correclive note, the lormer nuneric name having been already employed by professor Lester F. Ward lor another genu; of fonsil plants from the North American Mesozoic. 
obliquidade do plano do limbo, em relação a direcção do peciolo como se vê claramente na photographia de Zeiller e que equivale á Jase em parte quebrada do limbo, levemente superposto no nosso specimen.

O specimen sul-americano representa evidentemente o limbo de uma consistencia carnosa espessa. Este se ve tanto pelo residuo carbonaceo em um lado fossil (obverso) e pela absoluta falta de traços de nervação nesta superficie. De outro modo o residuo carbonaceo granular que incrusta esta superficie do fossil, é largamente occupado, começando a alguma distancia do bordo e extendendo-se para dentro na direcção do peciolo, pelas impressões de pequenos corpos ovacs de consideravel espessura relativa, de 1 millimetro a 1,25 millimetro de comprimento e um pouco mais de 5 millimetros de largura, collocados parallelamente na direcção da nervação correspondente ás malhas que se veem na parte contraria, tendo as extremidades distaes um pouco mais largas. Vê-se muito indislinctamente uma ponta pequena redonda ou levemente oval um pouco acima do centro, em algumas das impressões.

E' difficil dizer o que sejam os corpos acima descriptos a não ser pela hypothese de que sejam sporangios e que a lamina carnuda espessa, evidentemente pertença á um orgăo sporanirifero. Em proporção estes corpos são comparaveis aos sporangios, descriptos por Arber das folhas escamiformes de Glossonteris ainda que sejam differentes pelo seu contorno mais regular e por sua posição radiada.

Da evidencia citada acima, parece que o genero Ottokaria baseia-se em certas laminas carnudas, mais ou menos redondas, que são provavelmente sporangiferas. Quanto a identidade generica das especies indiana e brazileira não póde haver duvida, embora no unico specimen ainda encontrado, daquelle sporangio póde não estar sufficientemente desenvolvido para poder ser observado. Os pequenos corpos da lamina parecem ser comparaveis aos microsporangios das Cycadeas e o genero deve, creio eu, ser antes assoriado aos Pteridospermeos ou Cycadeas que a Whittleseya, como primeiro se propoz. São tambem provavelmente comparaveis á Plinthiotheca de Zeiller e Androstachys de Grand'Eury.

Os pontos communs a Otlokaria ovalis e aos specimens illustrados na est. VII, figs. 5 e 6 como Glossopteris sp. induzem fortemente a se admittir estreito parentesco sc não congenerico entre os dois fosseis. Ottokaria póde bem representar um orgão sporangifero de Glossopteris ou Gangamopteris, sendo ambos muito provavelmente Pteridospermeas. 
the obliquity of the plane of the blade to the direction of the petiole, as shown very clearly in Zeiller's photograph, and which ac. counts for the partly broken base of the slightly overlapping blade in our specimen.

The South American specimen evidently represents a blade of a thick fleshy consistence. This is shown both by the coaly residue on the one side (obverse) of the fossil and by the almost entire absence of traces of nervation on this surface. On the other hand this granular carbonaceous residue which encrusts this surface of the fossil is largely occupied, beginning at some distance within the border and extending well in toward the petiole, by the impressions of small oval bodies of considerable relative thickness, 1 milimeter 1.25 milimeter in length and a little over 5 milimeters in width, lying parallel to the direction of the nervation, and corresponding to the meshes shown in the counterpart, the distal ends being a little vvider. A small round or slightly oval point is very indistinctly seen a little above the middle on a number of the impressions.

It is difficult to account for the bodies described above except by the hypothesis that they are sporangia, and that the evidently thick fleshy lamina belongs to a sporangiferous organ In proportions these bodies are comparable to the sporangia described by Arber on the scale leaves of Glossopteris, though they differ by their more regular contour and radiate position.

From the evidence cited above it appears that the genus Ottokaria is based on certain long-pedicellate, more or less round, fleshy laminae, which are probably sporangifernus. Of the generic identity of the Indian and Brazilian species there can be no doubt, though in the only specimen yet found of the former sporangia may not be sufficiently developed to be observed. The small dudies on the lamina seem to be comparable to the microsporangia of cycads, and the genus is, I believe, to be associated with the pteridosperms or cycads, rather than with Whittleseya, as first proposed. They are also probably comparable to Plinthiotheca, Zeiller, and Grand'Eury's Androstachys.

The points in common between Ottokaric ovalis and the specimens illustrated on $\mathrm{Pl}$. vii. figures 5 and 6 , as Glossopteris sp., strongly argue for a close if not congeneric relationship between the two fossils. Ottokaria may well represent a sporangiferous organ of Glossopteris or Gangamopteris, both of which are probably Pteridospermic. 
Localjdade: Tope do Carvăo Irapuá na parte occidental da casa do Dr. Ramiro Barcellos, na visinhança do Rio Irapuá, Rio Grande do Sul cerca de 135 metros abaixo do schisto preto de Iraty. Lot. 3591.

Arberia $n$. gen.

Tanto no Lstado de Santa Catharina como no Gondwana inferior da India, occorrem folhas escamiformes pequenas, ovoides, largamente pedunculadas, divergentes, ou redondas, profundamente incisas, coriaceas, ou estriadas de nervuras espessas, cujos lobulos distantes, recurvados e truncados, parecem dever as suas terminações abruptas ou mesmo levemente car'comidas ao destacamento de alguma especie de corpos que se presumem da natureza dos reproductivos. Bunbury descreveu (1) como "Felicites (Glossopteris?)》 um specimen de Kampti na India, e Feistimantel illustrou (2) um exemplar maior e melhor conservado da divisão Talchir-Karharbari como uma inflorescencia pertencente a Noegger athiopsis Hislopi. Não foi dada á publicidade mais nenhuma prova quanto á natureza destes fosseis, e a questão acerca das suas relações genericas, continùa em espectativa, mesmo o typo permanece sem nome.

A descoberta de specimen evidentemente do mesmo typo generico no Brasil é interessante, não só devido á vasta distribuição que esta indica, mas tambem ao facto dos exemplos Sul-Americanos confirmarem essencialmente a na،ureza reproductiva do fossil, se bem que na minha opinião elles não confirmem de um modo completo a opinião de Feistmantel, quanto á seu parentesco com Noeggerathiopsis. Nossos specimens representam uma forma menor e. muito mais curta oval, de pendunculo mais curto, profunda e mais estreitamente incisa que o specimen das rochas Indianas.

Os lobulos abluptamente truncados apresentam toda evidencia de destacamento de orgãos reproductivos, provavelmente sementes, emquanto a evidentia circumstancial da associação, justaposição e orientar,ão, indicam uma connecção 'om um pequeno e não descripto Carcliocarpon (Sanaropsis) Scixasi. o nosso material não apresenta confirmação absoluta da união da semente e follıa, embola a prova indistincta de connexão vascular seja quasi convincente. As razões que nos levam a ronsideral-os como pertencente ao mesmo organismo serão mencionadas na discussão das especies hrasileiras.

(1) Guarl, Journ. Geol, Soc. vol. XVII, 1861, pl, X, f.g. 亿.

(i) Fl. Contwana sist. vol. III, p. 59, pl. XXVlli, fig. 5. 
Locality: Roof of the Irapuá coal, west of Doctor Ramiro Barcellos' house, vicinity of Rio Irapuá, Rio Grande do Sul. Horizon about 135 meters below the Iraty black shale. Lot. 3591 .

\section{Arberia $\mathrm{n}$ gen}

Both in the state of Santa Catharina and in the lower Gondwanas of India there occur small, broadly pedicellate, spreading, ovate, oval, or rounded, deeply incised, coriaceous or striate and thicknerved scale leaves whose distant recurvate and truncate lobes appear to orve their abrupt or even slightly ragged terminations to the detachment of some sort of bodies, presumably reproductive in nature. Bunbury described (1) a specimen from Kampti in India, as "Filicites (Glossopteris?)" and Feistmantel illustrated (2) a large and better preserved example from the Talchir-Karharbari division as an "inflorescence " probably belonging to Noeggerathiopsis Hislopi. No further evidence as to the nature of these fossils was brought to light, and the question as to their generic relations has been in abeyance, even the type itself remaining without name.

The discovery of specimens obviously of the same generic type in Brazil is interesting not only on account of the wide distribution indicated thereby, but also for the reason that the South American examples essentially confirm the reproductive nature of the fossil, though I believe they do not fully confirm Feistmantel's opinion as to their relationship to Noeggerathiopsis. Our specimens represent a smaller and much shorter, oval form, more briefly pedicellate and deeply, as well as much more narrowly, dissected than the specimens from the Indian rocks.

The abruptly truncate lobes bear every evidence of separation from reproductive bodies, probably seeds, while the circumstancial evidence of association, juxtaposition and orientation point toward a connection with a small, undescribed winged Cardiocarpon (Samaropsis) Seixasi. Absolute confirmation of the union of seed and leaf is lacking in our material, though the indistinct evidence of vascular connection is almost convincing. The reasons for regarding them as belonging to the same organism will be stated in the discussion of the Brazilian species.

(1) Quart. Journ. Geol. Soc., vol, XVII 1861, pl. X, fig. 4.

(2) Fl. Gondwana Syst. vol. III, p. 59, pl. XXVIII, fig. 5. 
Os specimens que tenho em mão são da camada de Gangamopteris, a Nordeste de Minas, em Santa Catharina. Occorrem em todos os casos, na mais intima ossociação com Samaropsis sendo ambos os fosseis circumáados por grande numero de Gangamopteris obovata.

A inflorescencia Arberia da India diz-se associada com Noegerathiopsis Hislopi. Cardiocarpon é considerado como um genero exclusivamente cordaiteano, e a união actual destas sementes, com as folhas escamiformes fendidas induziriam a crer no parentesco com Noeggerathiopsis, genero tão intimamente ligado a Cordaites que sua separação generica tem sido discutida por alguns palaeobotanicos. A evidencia da associação por outro lado, indica Gangamopteris.

Em todo caso o typo de inflorescencia do Gondwana differe tanto de Antholithus de Cordaites que sendo definitivamente referida a Noeggerathiopsis não dá logar a duvida algurna quanto á uma grande distinç̧ão generica entre as folhas do Cordaites do norte e Noeggerathiopsis do Godwana. Incidentemente á mesma correlação as differenças especificas muito distinctas entre os typos indianos e brasileiros de Arberia deveriam envolver a ideia da differença especifica correspondente, alternativa esta que, mais tarde seria exigida pelas differenças especificas das especies de Cardiocarpon associadas.

Parece existir uma differença de variedade se não especifica entre algumas das formas de Gangamopteris indiana o brasileira, porém não é assim com Noeggerathiopsis. Todavia devemos lembrar que o numero de especies de Cardiocarpon na flora do norte é muitas vezes o das especies até agora classificadas das folhas de Cordaites. Dependendo da descobarta de prova addicional, a affinidade do typo de inflorescencia, de que vimos tratando, deve ficar indeterminada. Por consequencia sua referencia aos gymospermos ou pteridospermos ficará incerta, sendo a meu ver pteridosmermico o genero Gangamopteris. Entretanto para designação systematica deste typo muito interessante e bem definido proponho a nome generico de Arberia, escolhido em reconhecimento ao Professor Arber palas suas contribuições muito importantes para o nosso conhecimento dos fructos pteridospermicos, assim como por seu valioso trabalho monographico sobre a flora de Glossopteris. o typo do genero é a especie brasileira Arberia minasica. o typo indiano conforme Feistmantel (1) figurou e descreveu deve especificamente denominar-se Arberia indica.

(1) Flora Gond, Syst. rol. III, p. 59, pl. XXVIIt, fig. 5. 
The spacimens in hand are from the Gangamopteris, bed, northeast of Minas, Santa Catharina. They occur in every instance in the most intimate association with the Samaropsis, both fossils being surrounded by great numbers of Gangamopteris obovata.

In India the inflorescence (Arberia) is said to be associated with Noeggerathiopsis Hislopi. Cardiocarpon is regarded as exclusively a Cordaitean genus, and the actual union of these seeds with the dissected scale leaves would argue for a relation to Noeggerathiopsis, a genus so closely connected with Cordaites itself, that its generic separation has been questioned by some paleobotanist. The evidence of association, on the other hand, points strongly toward Gangamopteris.

In any event the Gondwana type of inflorescence differs so widely from the Antholithus of Cordaites that, if definitely correlated with Noeggerathiopsis, it would leave no room for doubt as to a wide generic distinction between the leaves of the northern Cordaites and Gondwana Noeggerathiopsis. Incidental to the same correlation the very distinct specific differences between the Indian and Brazilian types of Arberia would involve a corresponding specific difference in the leaves, an alternative that, further, would he urged by the specific differences in the associated Cardiocarpa.

There appears to be a varietal if not specific difference between some of the Indian and the Brazilian forms of Gangamopteris; but not so with Noeggerathiopsis. However, it must be remembered that in the Northern flora the number of species of Cardiocarpon is many times that of the species as yet distinguished in the leaves of Cordaites. Pending the discovery of additional evidence the relationship of the type of inflorescence under consideration must remain undetermined. Consequently its reference to the Gymnosperms or the Pteridosperms will rest in doubt, the genus Gangamopetris being, in my judgment, Pteridospermic. Neanwhile for the systematic designation of this very interesting and well marked type, I propose the generic name Arberia, a name chosen in recognition of Professor Arber's very important contributions to our knowledge of the Pteridospermic fruits, as well as for his valuable monographic work on the Glossopteris flora The type of the genus is the Brazillian species, Arberia minasica. The Indian type as figured and described by Feistmantel (1) may be specifically mamed Arberia indica.

.) Fl. Godwara Sjot., vol. III, p. 59, pl. XIVIll, lig. 5. 
drocira mirasica n. sp.

Pl. VIII, figs. $8,9,10$

Frondes escamosas ferteis, pequenas, de contorno redondo a oval, de pedunculo estreito e curto mais ou menos concavo-convera profundamente fendido em muito numerosas divisōes obliquas. lineares divergentes, muitas vezes recurvas ao longo de um eixo e rapidamente diffusas, que perto do apice podem se bifurcar de novo em subdivisoes curtas, estreitas, divaricalas, $e$, tanto quanto foi observado, abruptamente truncadas, lamina espessa, chata e grosseiramente estriada, rugosa, nas partes ditaes, nervação derivada de varias nercuras primarias, oerticaes, parallelas, que bifurcam.se para prover de uma nervur'a secundaria cada divisão da foina, bifurcando-se a neroura divisoria para fornecer um ramo a cada subdivisão, espraiando-se ao mesmo tempo em um largo fasciculo, ao approximar-se dos apices truncados em que os fasciculos terminam abruptamente. A fructificação é provavelmente uma semente que nasce no apice de cada subdivisão, ou lobulo.

Ve-se bem o aspecto das inflorescencias descriptas aqui pelos fragmentos photographados na estampa VIII, figs. 8, 9 e 10 que requerem peçuena descripção. A primeira vista lembram uma Aphlebia pequena, fendida, profundamente rugosa ou coriacea recurva ou truncada, lobada. A base é estreita e o fossil inteiro tem a apparencia de ter sido um tanto expesso em textura,

As nervuras são distantes e fortes sob a epiderme estriadarugosa, que torna-se especialmente fibrosa nos lobulos achatados. Estes, particularmente os que se acham proximos da Jase, curvam-so mais ou menos distinctamente para a parte ventral que é concava.

Com estas escamas que não são l'aras nas camadas de Gangamopteris, a nordeste das Minas, ha um grande numero de uma especie de Śmaropsis Seixasi, ás vezes em posicão e orientaç̃o taes que levantam a queståo sobre si não foram em tempo unidas, visto se acharem actualmente. A questão da união organica, $\dot{0}$ uma das mais difficeis dedicidir, devido á maceração parcial de muito deste material e ao frequente descoramento da rocha, produzido pelo ferro, junto aos restos vegetaes. Mas em dois exemplos dos quaes um se vê na fig. 8 , parece ainda liaver uma connexão vascular entre o lobulo truncado e a base da pequena noz verde. Em apoio da hypothese de provir $S a m \alpha$ ropsis de Arburiu mincsica devemos chamar attenção para a correspon- 
Arberia minasica n. sp.

Pl. VIII Figs. 8, 9. 10.

Fertile scale-fronds, small, round to oval in contuztr, briefily and rather narrowly pedicellate, more or less concave-convex, ver!y deeply dessected along a narrow, rapidly difuse axis in numerous oblique, linear, divergent, often recurved divisions which, near the ap's, inaty, fork again into short, narow, devaricate, and, so far as olistr'ved abruptly truncate subdivions; lamina thich, flat, and coarsely striaterugose in the distal portions; nervation derived from siceral vertical parellel, coarse primary nerves which fork to provide a secondary nerve for each division of the leaf, the divisional nerve bifurcating to supply a branch for each subdivision, and at the same time spreading in a broard fascicle on approaching the truncate apices in which the fascicles abruptly abut; fructification probably a seed borne at the apex fof caci subvision or lobe.

The aspect of the inflorescences here described is so well shown by the fragments photographed in Pl. VIII, figs, $8,9,10$, as to require little further description. At first glance they suggest a small, deeply dissected, rugose or coriaceous, recurvate and truncate lobed Aphlebia. The base is narrow, and the entire fossil has the appearance of having been rather thick in texture.

The nerves are distant and strong beneath the striate-rugose epidermis, which becomes especially tibrous in aspect in the flattened lobe. The latter, particulary those near the base, curve more or less distinctly toward the ventral side which is concave.

With these scales, which are not rare in the Gangamopteris bed northeast of Minas, are large numbers of a species of Samaropsis Seixasi, sometimes in such position and orientation as to raise the question as to whether they liave not once been, if they are not now, in actual union. The question of organic union is one difficult of decision on account of the partial maceration of most of this material and the frequent discoloration of the rock by iron in proximity to the vegetable remains. But in two examples, one of which is shown in fig. 8, there seems still to be vascular connection between the truncate lobe and the base of the immature nutlet. In support of the hypothesis of derivation of the Samaropsis from $A r^{2}$ - 
dencia coincidente das extremidades truncadas dos lobulos, que as vezes reteem diminutos fragmentos de dilaceração nos angulos, para a largura das bases das sementes e a sua linha de separação, e para a semelhança de textura entre o lobulo e a região chalazal do fructo, (1). E' muito desejada a descoberta de material que possa resolver concludemente está questão. Como já foi dito em minhas notas sobre o genero Arberia, estou mais inclinado a consideral-o antes como a inflorescencia de Gangamopteris que de Noeggerathiopsis, embora Cardiocarpon (Samaropis) Sdixasi pelas suas estreitas relações directas com as especies de Cardiocarpon do Norte denote forte parentesco Cordaiteano e por conseguinte com Noeggerathiopsis.

Arberia minasica distingue-se de Arberia indica (2) e outros especies da serie Talchir-Karharbari pelo seu pequeno tamanho, forma mais oval, e especialmente pela sua incisão dichotoma profunda, lobulos finos que terminam um pouco em ponta.

Localidade: Nordeste de Minas, Santa Catharina. Horizonte cerca de 55 metros acima do granito, ou 225 metros abaixo do schisto preto de Iraty. Lots. 3586 e 3921.

Derbyelba n. g.

Sob o nome acima descreverei um typo de folha escamosa fertil, consistindo em uma lamina carnosa pequena, oval ou oblonga, ligeiramente estreita na base em um largo ligamento e orlada por escamas estreitas radiarias e juntas. A nervação é dichotoma em certo numero de nervuras parallelas penetrando na base da folha.

Uma unica nervilla passa para a base de cada um dos pequenos lobulos marginaes; estes são mais ou menos distinctos convexos na parte dorsal concavos na ventral, usualmente um pouco torcidos e na maior parte dos casos voltados levemente para cima, para o apice da escama, na base desta, está situado um grande esporangio (?) que na especie typo Derbyella aurita, é quasi egual em diametro á largura do lobulo. Um curto ramo pequeno da nervura do lobulo passa da parte distal (ventral) deste para o esporangio (?). Os caracteres do tyo assemelham-se tanto aos de algumas follas ferteis de Cycadas actuaes. que parecem requerer uma transferencia para as Cycadofiliceos.

(1) Veja-se estampa X, figs, 6 e 7.

(2) Veja-se Feistmantel, Fl. Gonduana, Syst. Vol. III Pl. XXVIII. Fig. 5. 
beria minasica attention may be called to the coincident correspondence of the truncate ends of the lobes, which often retain minute laceration fragments at the corners, to the width of the seed bases, and the line of separation of the latter; and the textural similarity betwen the lobe end and the chalazal region of the fruit (1). The discovery of material that will conclusively determine this question is much to be desired. As already stated in my remarks concerning the genus Arberia I am more inclined to regard it as the inflorescence of Gangam spteris than of Noeggerathiopsis though the Cardiocarpon (Samaropsis) Seixasi by their close relations to the Northern Cardiocarpa argue very strongly for a Cordaitean relationship, and consequently, with Noeggerathiopsis.

Arberia minasica is distinguished from Arberia indica (2) the only other species of the genus, from the Talchir-Karharhari series by its small size, more oval form and especially by its very deep dichotomous dissection in slender lobes that taper but little.

Locality: Northeast of Minas, Santa Catharina. Horizon about 55 meters above the granite or 225 meters belcw the Iraty black shale. Lots 3586 and 3921 .

\section{Derbyella n. g.}

Under the above name I shall describe a type of fertile scaleleaf consisting of a small, oval or oblong fleshy lamina, slightly constricted at the base to a broad attachment and bordered by narrow, radiating, close, oblong scales. The nervation is dichotomous from a number of parallel primary nerves entering at the base of the leaf.

A single nerville passes to the base af each of the small marginal lobes; the latter are more or less distinct, dorsaly convex, ventrally concave, usually somewhat twisted, and in most cases turned slightly upward toward the apex of the scale. At the base of the scale is situated a large sporangium (\%) which in the typ especies, Derbyella. aurita, nearly equals in diameter the width of the lobe. A short branchlet of the lobe nerve passes from the distal (ventral) side of the latter to the sporangium (?). The characters of the type so strongly resemble those of some of the fertile leaves among the living cycads that they seem to demand assignment to the Cycadofilices.

(1) Soo Plate, X. Figs. 6 and 7.

(2) See Feismantel. Fl. Gondwana Syat., vol. III, pl. XXVIII, Gg. 5. 
Pela reunião de especimens na camada de folhas de Gangamopteris a nordeste de Minas, estou disposto a acreditar. que Derby clla deve ser em ultima analyse uma folha escamosa deste genero. A nervação no interior do especimen é muito obscura para se poder perceber distinctamente, porém, creio que se anastomosa em malhas relativamente grandes longas e angulares. Si vier a ser verificado que a nervação possue estes caracteres, sua identidade com Gangamopteris parecerá mais provavel.

Tenho satisfação em classificar este genero em honra do distincto geologo de S. Paulo, que tanto tem feito para o conhecimento da Palaeontologia e geologia da Republica do Brasil. O typo do genero è Derbyella aurita.

Derbyella aurita n. $s p$.

Pl. IX, figs. 1, 1a, 2, 2a, 3 .

Orgãos folices asymetricos, pequenos oblongos ou ovaes-oblongos, 1.25 a $2 \mathrm{~cm}$. de comprimerto, e $8-10 \mathrm{~mm}$ de largura, redondos no "pice, contrahidos abruptamente na base, lamina um tanto espessa, quasi lisa na área central, e cortados nos bordos em lobulos muito pequenos, estreitos ou oblongos, abstusamente redondos, ridicdos 2.5-3.5 mm. de comprimento, 1-1.5 $\mathrm{mm}$. de lar gura; na base de cada um delles está situado um grande sparangio redondo, quasi egualando em diametro a largura do lobulo; lobulos levemente augmentados perto da base, usualmente ligciramente torcidos e na face ventral de concavidade rasa alcin do sporangium (?) voltado mais ou menos para cima; a superficie convera (dorsal) voltada para traz e mais ou menos para baixo; nervaç̃̃o pouco visivel, um tanto distante, flabellada da base, dichotoma, passando un unico nervo por cima até perto da base de cada lobulo, onde bifurca-se agudamente; a divisão curta distal (ventral) arqueando-se ligeiramente para cima passando para o sporangio (?), a divisão inferior atravessando completamente o lobulo; impressão do sporingio (?) um tanto profunda, redonda, cerca de $9 \mathrm{~mm}$. de diametro, ligeiramente convexa no centro, com uma pequena cicatriz mammilada

A planta acima descripta é representada apenas por dois specimens que, com uma impressão se veem na estampa IX, figs. 1,2 , e 3 . A forma da folha se vê na figura 2. A impressão do sporangio(?) que está situado na base de cada lobulo, vê-se nas figs. 1a e 2a, emquanto 
On account of the associotion of the specimens in the bed filled wilh the leaves of Gangamopteris, to the northeast of Minas, I am disposed to believe Derbyella may ultimately prove to be the fertile scale leaf of the latter genus. The nervation in the interior of the specimens is too obscure for distinct perception, but I am inclined to believe that it anastomoses in a relatively large, elongated, angular mesh. Should the nervation prove to possess these characters its identity with Gangamopteris will appear the more probable.

1 take pleasure in naming this genus in honor of the distinguished geologist of São Paulo who has done so much to build-up our knowledge of the palaeontology as well as of the geology of the Republic of Brazil. The type of the genus is Derbyella aurita.

\section{Derbylla aurita n. $s p$.}

Pl. IX, Figs. 1, 1a, 2, 2a, 3 .

Small, oblong, or oval-oblong, asymetrical foliar or gans, $1.25-2 \mathrm{~cm}$. in length, 8-10mm, in width, round at the apex, contracted abruplly at the base; lamina rather thick, nearly sinooth over the central area, and cut at the border in very small, narroto, oval or oblong obtusely rounded, radiate lobes, $2.5-3.5 \mathrm{~mm}$. in length, 1-1.5mm. in vidth, on the base of each of which is deeply seated a large round sporangium (2) in diameter nearly equalling the vidth of the lobe; lobes slughtly enlarged about the base, usually slightly twisted and ventrally shallowly concave beyond the sporangitm (?) and more or less turned upward, the convex (dorsal) surface baing directed backward nervation not well seen, rather distant. flabellate from the base, dichotomous, a single nerve passing upward to near the base of each lobe, where it forles acutely, the short distal (ventral), division arching slightly upward in passing to the sporangium (?) the lower division completely traver sing the lobe'; impression of the sporangia (?) rather deep, round, or nearily so, about $9 \mathrm{~mm}$. in diametr", an'l slightly convere at the "enter with a v.r"y small, obsure, mammillate scar

The plant described above is represented by Jut two specimens which, with one counterpart, are illustrated on Pl. IX, Figs. 1, 2, and 3. The form of the leaf is shown in Fig. 2. The impression of the sporangium (?), which is situated at the Joase of each lobe, is shown in 
que a configuração do lobulo se vê indistinctamente nas figs. 1 e $1 a$. Nesta figura, bem como na fig. 2a, a nervação é indistinctamente visivel, passando um unico feixe para a base de cada lobulo. o curto ramosinho nasce em angulo agudo logo abaixo do sporangio (?) e arqueando-se ligeiramente para cima, curva-se para tora para este. A nervação do specimen não se vê sufficientemente distincta de forma a tornar certo se as nervillas são anastomosadas ou não, porém estamos muito dispostos a interpretal-as como se anostomosando em uma malha um tanto longa e angular.

O typo acima descripto é a meu ver homologo da folha fertil de Cycada. Seu parentesco com as Cycadas é suggerido pela posição dos sporangios (?) na superficie ventral das escamas que em muitos casos são torcidas e voltadas para cima de modo que a superficie dorsal convexa volta-se para traz e para baixo. O aspecto do orgão e a posição dos pequenos corpos reproductivos na base dos lobulos lembram a disposição dos ovulos das folhas escamosas ferteis de algumas das Cycadas actuaes. Os sporangios, si o são, estão um tanto indistinctos nos specimens que se veem na fig. 3, embora se apresentem evidentemente nos lobulos distaes que são um tanto fortemente voltados para cima. Devido á larga inserção e espessa textura, eu interpreto a folha com uma folha escamiforme e semelhante na disposição á dos corpos reproductivos da base dos lobulos marginaes e podem ser considerados creio, mais directamente relacionados com os Cycadofelices, ou Cycadas.

A associação dos specimens com Gangamopteris obovata lembra muito a correlação destes orgãos ferteis com as folhas desta especie, correlação que parece encontrar apoio no aspecto reticulado da ner vação.

Localidade: Nordéste de Minas, 55 metron acima do granito, ou 225 metros abaixo do schisto Preto de Iraty. Lots. 3586 e 2921.

\section{G Y MNOSPERMOS \\ CORDAITEAS}

\section{Noeggerathiopsis}

Feistmantel Fl. Gond. Syst. Vol. III, 1879, p. 23

As folhas deste genero se distinguem promptamente das do genero Gangamopteris, pela falta de anastomoses na nervação parellela. \$ão 
Figs. 1a and $2 a$, while the configuration of the lobe is indistinctly seen in Figs. 1 and 1a. In this flgure, as well as in Fig. 2a, the nervation is indistinctly observable, a single strand passing torvards the base of each lobe. The short branchlet springs from this at an acute angle just below the sporangium (?) and, arching slightly upward, curves outward toward the latter. The nervation in the specimens is not shown sufficiently distinctly to make it certain whether the nervilles anastomose or not, but I am strongly disposed to interpret them as anastomosing in a rather long, angular mesh.

The type described above is, in my judgment, homologous with the fertile leaf of the cycad. Its relationship to the cycads is strongly suggested by the position of the sporangia (?) on the ventral surface of the scales which, in most instances, are twisted and upturned so that the convex dorsal surfaces look backward and downward. The aspect of the organ and the position of the small reproductive bodies at the bases of the lobes remind one of the arrangement of the ovules on the fertile scale-leaves of some of the living cycads. The sporangia, if such they be, are somewhat indistinct in the specimens shown in Fig. 3, although they are evidently present on the more distal lobes which are rather strongly upward turned. On account of the broad attachment and thick texture, I interpret the leaf as a scale leaf ; and on account of the similarity in the disposition of the reproductive bodies at the bases of the marginal lobes, they may be regarded, I believe, as most closely related to the Cycadofilices or Cycads.

The intimate association of the specimens with Gangamopteris obovata strongly suggests the correlation of these fertile organs with the leaves of this species, a correlation that appears to find support in the reticulate aspect of the nervation.

Locality: northeast of Minas. Horizon 55 meters above the granite or 225 meters below the Iraty black shale. Lots. 3586, and 3921 .

\section{G I MNOSPER MS \\ CORDAITALES}

\section{Noeggerathiopsis}

Feistmantel, Fl. Gondwana Syst., vol. III, 1879, p. 23.

The leaves of this genus are readily distinguished from those of the genus Gangamopteris by the absence of anastomosis in the parallel 
espessas, espatuladas, lanceoladas a lineares lanceoladas, redondas no apice cuneiformes em baixo, com numerosas nervuras primarias erectas, que bifurcam-se repetidamente em angulo muilo agudo, curvando-se ao passar, geralmente um tanto distante, para o bordo. A fructificaçāo não é conhecida, porém suppõe-se que seja representada pelas sementes do genero Cardiocarpon (Samaropsis), que occorrem nas mesmas camadas. E' possivel que se verifique que as folhas inflorescontes descriptas neste relatorio como Arberia pertençam a Noeggerathiopsis questão que foi mais completamente discutida em minha nota sobre o genero Gangamopteris, descripto anteriormente.

As folhas de Noeggerathiopsis são muito semelhantes ás de Cordaites, o princ pal caracter distinctivo entre os generos como são commumente definidos, sendo a ausencia de nervuras falsas ou feixes hypodermicos entre as verdadeiras nervuras.

Muitos specimens de Noeggerathiopsis Hislopi na collecção mostram feixes distinctos delgados hypodermicos quando no bom ponto de maceração, ainda que as falsas nervuras estejam tão profundas que não appareçam nos exemplares melhor conservados.

Noeggerathiopsis é um dos generos caracteristicos das foras Gondwana, e como as suas associadas Gangamopteris e Glossopteris está representada em quasi todas as regiões destas floras. Seu ligar na flora Permo-carbonifera do Sul, é quasi o mesmo que o de Gangamopteris comecando com o advento do flora do Gondwana inferior e estendendo-se até o fim do Permiano (Damuda), ou, se o que affirma - Professor Zeiller é correcto se encontra no Tunquim tão tardiamente quanto o Rhetic.

Noeggerathiopsis Hislopi (Bunb) Feist.

Pl. IX. fig. 4, 7, 6a

1861 - Noeggerathia? (Cyclopteris?) Hislopi, Bunbury. Quart. Journ. Geol. Soc. vol. XVlI, P. 334 pl. X, fig. 5.

1879 - Noeggerathiopsis Hislopi (Bunb.) Feistmantel Fl. Gondwana Syst, vol. IlI, pt. 1, p. 23, pl. XIX. fig. 1-6 pl. XX fig. 1 pt 2, 1881, pl. 118, pl. XLVA, fig. 1-11, pl. XlviA, figs. 3-4, Suppl. p. 58, pl. XXVIII, figs. 1-4. 6-7, pl. XXIX, fig. 1-4, pl. XXX, fig. 5-9 vol. IV, 1882, p. 41, pl. IX, fig. 1-3; pl. XIII, fig. 2-4, pl. XIV, fig. 1-3, 6-9, pl. XV, fig. 佔, pl. XYII. fig. 4, pl. XVIII, fig. 1 pl. XX, fig. 10, pl. XXI, fig. 6-8-10, 
nervation. They are thick, spatulate, broadly lanceolate to linearlanceolate, rounded at the apex, cuneate below, with numerous erect primary nerves that fork repeatedly at a very acute angle, and curve but little in passing, generally rather distant, to the border. The fructification is not known, but it is supposed to be represented by the seeds of the genus Cardiocarpon (Samaropsis) occurring in the same beds. It is possible that the inflorescent leaves described in this report as Arberia may be found to belong to Noeggerathiopsis, a question more fully discussed in my remarks on the former genus and on Gangamopteris.

The leaves of Noeggerathiopsis are very similar to those of Cordaites, the chief distinction between the genera, as commonly defined, being the absence of false nerves or hypodermal strands between the true nerves.

But many of the specimens of Noeggerathicpsis Hislopi in the collection show distinct slender hypodermal strands when in the right stage of maceratoin, though the false nerves are so deeply buried as not to appear in the better preserved examples.

Noeggerathiopsis is one of the characteristic genera of the Gondwana floras, and like its associates, Gangamopteris and Glossopteris, is represented in nearly all regions of those floras. Its range in the Southern Permo-Garboniferous flora is nearly the same as that of Gangamopteris, beginning with the advent of the Lower Gondwana flora and extending to the close of the Permian (Damuda); or, if the record by Professor Zeiller is correct, it is present in Tonquin as late. as the Rhetic.

Noeggerathiopsis Hislopt (Bunb) Feist.

$$
\text { Pl. IX, fig. 4-7,6a. }
$$

1861. Noeggerathea? (Cyclopteris?) Ilislopi Bunbury, Quart. Journ. Geol. Soc., vol. xvii, p. 33 ', pl. x. fig. 5.

1879. Noeggerathiopsis His!opi (Bunb.) Feistmantel, Fl. Gondwana Sysí., vol. III, pl. 1, p. 23, pl. xix, fig. 1-6, pl. xx, fig. 1, pt. 2, 1881, p 118, pl. xlvA, figs. 1-11, pl. xlviA, figs. 3, 4, Suppl., p. 58, pl. xxviii figs. 1,+4, 6-7: pl. xxix, fig. 1-4, pl. $\mathrm{xxx}$, fig. 5-9 vol. IV, 1882, p. 41, pl. ix, fig. 1-3, pl. xiii, fig. 2-4, pl.xiv, fig. 1-3, 6,9, pl. xv fig. 4 b, pl. xvii, fig. 4, pl. xviii, fig. 1, pl.xx, fig. 10, pl. 
pt. 2, 1886, p. 40, pl. XIIA, fig. 5A, pl. XIIIA, fig. 5; Feistmantel Aljh. K. bohm. Ges. Wiss; (7) vol. III, 1889 p. 38, pl. IV fig. 1 ; Oldham. Man. Geol. India pp. 162, 158 ; Zeiller Bull. Soc. geol. Fr. (3) vol. XXIV, 1896, p. 372, fig. 16-17, pl. XVIII, fig. 6-9; Seward, Ann. S. Afr. Mus., vol. IV, 1903, p. 96, pl. X, fig. 5, pl. XIII, fig. 2-4; D. White, Science, n. s.. vol. XXI, 1905, p. 700 ; Arber, The Glossopteris Flora, 1905, p. 179, fig. 37, pl. VI, fig. 2-3, pl. VIII, fig. 2.

Folhas em geral grandes, simples, cuneiformes, espatuladas, li. neares espatuladas ou abovadascuneiformes, redondas obtusamente ou estreitamente redondas no apice, cuneiformes, muitas vezes com bordos concavos em balxo para a base geralmente estreita; lamina espessa as vezes convexa na face ventral entre as nerouras; nerouras distinctas e um pouco forles, numerosas, erectas, parallelas e um pouco distantes na base, bufurcando-se repetidamente em um angulo muito agudo, co curvam-se ligeiramente para for $a$. As nervuras verdadeiras passam muito distinctamente, em geral a cerca de 5 mill. 11 mill. de distancia do bordo a que vão ter muito obliquamente excepto no apice redondo da folha; feixes hypodermicos delgados, rectos bem regulares e parallelos; usualmente em numero de 2 a 4 entre cada par de nerouras, $e$ quasi sempre immersos idteiramente e invisiveis, na lamina espessa.

O specimen que representa esta especie na collecção brasileira, concorda tanto na variedade de fórma como em nervação com as folhas tão abundantemente illustradas nos relatorios publicados sobre a flora Gond wana (1). Os maiores specimens são verdadeiramente Cordaiteanos em aspecto e proporçũes. Este se vể no original da estampa IX, fig. 5, que é comparavel aos da série Talchir Karharbari, que se veem nas estampas XXVIII e XXIX, do terceiro volume da flora Gondwana. O apice largamente redondo que se vê na nossa fig. 4 tem o seu reverso tambem nas mesmas estampas da grande obra de Feistmantel. A falta de symetria que se nota neste typo, é caracteristica do grupo Cordaiteano. Na collecção encon tram-se outros exemplos da mesma localidade exhibindo as fórmas menores com apices mais estreitos como os illustrados por Feistmantel nas estampas XIX da obra que venho de citar, ou que se

(1) Veja-so particularmente Feistemantel Fl, Gond. Syst. Vol. III, 1879 pI. XIX, pl. XX, pl. XXVIII, pl. XXIX, vol. IV, 1880, pl. IX, fig. 1-3, pl. X'III, figs, 2-4, pl. XXl, figs. 6-8-10, pt. 2, pl. XIIIa, fig. 5 . 
xxi, fig. $6,8,10$, pt 2, 1886, p. 40, pl. xxiiA, fig. 5a, pl. xiilA, fig. 5 ; Feistmantel, Abh. K. bohm. Ges Wiss., (7) vol. III, 1889, p. 38, pl. iv, fig. 1 ; Oldham, Man. Geol. India, pp. 162, 158; Zeiller, Bull. Soc. Géol. Fr.., (3) vol. xxiv, 1896, p. 372, fig 16, 17, pl. xviii, fig. 6.9; Seward, Ann. S. Afr. Mus., vol. IV, 1903, p. 96, pl. x, fig 5, pl. xiii, fig. 2-4; D. White, Science, n. s, vol. xxi, 1905, p. 700; Arber, The Glossopteris Flora, 1905, p. 179, fig. 37, pl. vi, fig. 2, 3, pl. viii, fig3 2 .

Leaves generally large, simple, cuneate-spatulate, linear-spatulate spatulate or obovate.cuneate in form, round, obtusely rounded or narrowly rounded at the apex, cuneate, often with concave borders below, to the generally narrow base; lamina thick, often convex ventrally between the nerves; nerves distinct and rather strong, numerous, erect, parallel, and a little distant at the base, forking repeatedly at a very acute angle while curving slightly outward, the true veins passing, very distinct and generally about $5 \mathrm{~mm}-11 \mathrm{~mm}$ distant, to the border which they meet very obliquely except in the rounded apex of the leaf; hypodermal strands slender, straight, fairly regular and parallel, usually 2 or 4 in number between each pair of nerves, and usually entirelly immer'sed and invisible in the thick lamina.

The specimens representing this species in the Braziiian collections agree both in the variation in form and in the nervation with the leaves so abundantly illustrated in the reports (1) on the Gondwana flora. The larger specimens are truly Cordaitean in their aspect and proportions. This is illustrated in the original of Pl. IX, Fig. 5, which is comparable to those from the Talchir-Karharbari series shown in plates xxviii and xxix of the third volume of the Gondwana Flora. The broadly rounded apex seen in our Fig. 4, has its counterpart also in the same plates of Feistmantel's great work. The lack of symmetry seen in this type is characteristic of the Cordaitean group. Other examples in the collection, frum the same locality, exhibit the smaller forms with narrow apices such as those illustrated by Feistmantel in plate xix of the report just cited, or that shown in fig. 1, plate xviii, of the South Rewah me-

(1) Seo, in particular, Feistmantel, Fl. Gondwana Syst., vol. III, 1879, pl. xix, pl. xx, pl. xxviil, pl. xxix, rol. IV, 1880, pl. ix, figs. 1-3, pl. xiii, figs. 2-4, pl. xxi, figs, 608,10 , pt. 2 , pl, xiiiA, fig. 5 . 
veem na fig. 1, estampa XVIII da memoria de South Rewah (1). Um fragmento do tope do carvão Irapuá, Rio Grande do Sul, é cuneiforme, alargando se para cima, partindo de um ligamento muito estreito. Tanto em fórma comn em dimensões, concorda bem com os de Johannesburg, no Transvaal, pułlicadós por Zeiller (2).

Alguns caracteres interessantes das folhas de Noeggerathiopsis Hislopi são evidenciados por varias condições de conservação. Em muitas impressũes do $s$ histo de grão fino côr de creme, de que foram pela maior parte removidos os residuos carbonaceos, deixando pouco mais que uma leve mancha parda na impressão, a superficie é marcada por myriades de diminutas impressões como curtos cabellos ou lanugem, cujas bases estão marcadas por particulas de materia carbonosa. A deducção de terem sido as fol has da especie villosas, foi evidenciada pelos caracteres da epiderme que foram detalhadamente figurados por Zeiller (3). Esta é especialmente comparavel em seus detalhes ás cuticulas Cycadeanas. Alguns dos nossos specimens brasileiros apresentam tambem zonas de residuos extremamente granulares e diminutos entre as nervuras, concordando na apparencia em caracteres exactamente com o specimen (4), que Zeiller explicou ser devido a pontuaçães correspondentes aos estomates da superficie dorsal da folha.

Tomei cuidado em indicar a concordancia entre as folhas sul-americanas e as da India e de outras regiões de flora Gondvana, pela razão que as falsas nervuras entre as verdadeiras de Noeggerathiopsis Hislopi são perceptiveis em muitos dos specimens que tenho em mão são fracamente indicados até mesmo em partes da grande folha que se vê na fig. 5. Em muitos casos apparecem irregularmente e apenas em pequenas areas de pequena extensão como os feixes intermediarios ás nervuras em alguns dos Neuropteroides Cyclopteroides, ou em Dolerophyllum. Alguns dos schistos pardos carbonaceos associados ao carvão Barro Branco proximo de Candiota no Rio Grande do Sul, consistem em grande parte em folhas de Noeggerathiopsis Hislopi acamadas. Na fig. 6 se vê um fragmento deste schisto em que se nota distinctamente a verdadeira nervação.

Com o auxilio de lente se veem algumas, usualmente tres e quatro, falsas nervuras ou intermediarias que atravessam a lamina entre as

(1) Fl. Gondwana s'yst. vol. IV, 1882, pt. 1.

(2) Bull. Soc. geol. I'r. (3) vol. XXIV, 1831, p. 372, pl- XVIIl, fig. 7.

(i) Loc. cil. p. 37? figs. 1ib-17.

(i) Loc, cir. pl, Xvirl, ligg, 8 
moir (1). A fragment from the roof of the Irapuá cual, in Rio Grande do Sul, is cuneate, widening upward from a very narrow attachment. In both form and dimensions il agree well with lhat pullished by Zeiller (2) from Johannesbur's in the Transvaal.

Some interesting character's of the leaves of Noeggerathiopsis Hislopi are brought out hy the various condilions of preservation. On many of the impressions in the fine-grained clum colored shales from which the carbonaceous lesidue has lol the most part been removed, leaving little else than a slight stain of brown in the mold, the surface is malked by myriads of minute impressions, as of short hairs or down, the bases of which are marked by particles ol' anly mattel'. 'The inference that the leaves of the species were villous is not borne out by the fea ture of the epider'mis which have been portrayed in detail by Zeiller. (3). The latter is especially comparable in its details to the Gycadean cuticles. Some of our Brazilian specimens also exhibit zones of extremely minutely granular residue between the nerves, in charicteres apparcntly agreeing exactly with the specimen (4) explained by zeiller as clue to punctations corresponding to stomata on the dorsal surface of the leaf.

I have take care to point out the agreement between the South American leaves and those from India and other regions of the Gondwana flora for the reason that false nerves between the true nerves of Vocggerathiopsis Hislopi are perceptible in many of the specimens before me. They are very faintly indicated even in portions of the large leaf shown in Fig. 5. In many cases they appear irregularly and only in small areas for short distances like the strands intermediate to the nerves in some of the Neuropteroid Gyclopterids or in Dolerophillum. Certain of the brownish, earbonaceous shales associated with the Barro Branco coal near Candiota, Rio Grande do Sul, consist largely of the matted leaves of the Noeggerathiopsis Hislopi. A fragment of this laminated shale is shown in Fig. 6, in which the true nervation is distinctly seen.

Under the lens, however, a number, usually three or four, of intermediate or false nerves, as is photograplically illustrated, in the four

(1) Fl. Gondwana Sjst., vol. IV, 1832, pt. 1.

(2) Bull. Soc. Geol. Fr., (3) vol. xxiv, 18!6, p. 372, pl. xriii, fïg. $\tau$.

(3) Loc. cit., p. 372, figs. $16,17$.

(4) Loc. cit., pl, xviii, frg. 8 . 5560 
nervuras principaes, conforme está photographicamente illustrado na porção da mesma rocha, auğmentada (juatro vezes na estampa IX, fig. 6a. As falsas nervuras são regulares, parallelas, e podem ser seguidas individualmente por consideraveis distancias. Estas nervuras são provavelmente profundamente hypodermicas e são visiveis devido ao estado de macerurãa das folhas.

o reconhecimento da presença de falsas nervuras entre as verdadeiras em Noeggerathiopsis Hislopi elimina uma das principaes distincções entre Cordaites e Noeggerathiopsis e tende a estabelecer a probabilidade de que ambas sejam genericamente identicas. A semelhança das fórmas de Cardiocarpon dos schistos brasileiros com os referidas a Cordaites do Permo-Carlıonifero do Norte reforça o argumento de sua união. Porém de outro modo as folhas escamosas com inflorescancia descriptas como Arberia de que suppon ho ter nascído Car diocarpon (Samaropsis) Seixasi, partencem reslmente a Noeggethiopsis como Feistm ntel era propenso a crer, não ha possibiiidade das folhas do norte e sul sarom congeneres, a firberic larga incisa e flabellada com seus lobulos dichctomos é conspicuamente distincta de Antholithus espigada e bracteada. Se os specimens que veem de ser descriptos não são identicos a Toeggerathiopsis Hislopi, como eu os considerei, devemos concluir que o genero Corclaites, invadiu esta região antes que o carvão Barro Branco se depositasse.

Devemos lembrar que especies de Cardiocalpon (Samaropsis) estào associadas com Noeggerathopsis nas camadas Karharbari da India (1).

Um caracter tambem commum aos Cycadofilices e Cycadas é o da presença de granulos, muito pequenos, subesphericos ou espessamente discoides, profundamente collacados na lamina entre as nervuras. Observei istn em um unico specimen de Noeggerathiopsis Hislopi que 11ĩn se vê bem lu tịg. 7. Tas fulhas de Nilssonia polymorpha (2),

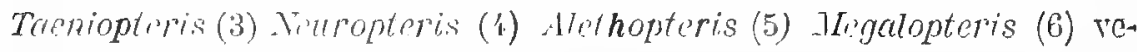
om-sc algumas vezes granukie semelhantes talrez de natureza glandular, ou lalvez meros 'crlpos scleroticos. Os cquatro generos citados lor ultimo sũo Pteridospermos.

(1) Veja Fe'stniantol, Fl. Gondwana Syst., vol. III, p. 59, pl. XXVIIl fin. 5.

(2) Voja-se Nathorst. Bella : till Sverigus Foss. Fl. pt. 1, 18\%6, pl. 1. VIII. Ags. 12-13.

(3) Scllards, Kansas, Univ. Quart. Vol. X, 1. 1, 1901 p. 5, pl. 1, fig. 6.

(i) Neuropteris n, sp. Lecipuraux; Lacoe Coll. U. S. Nac. Museum.

(i) Rept. Goul. Surv. Olio, vul. II, palaoont. 1873, p, 421, pl. L, fig. 3.

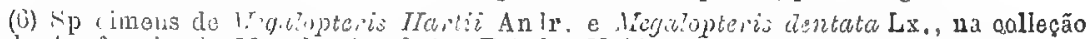
de plant's fusseis do Mis. Nácioual dos Estatos Uni lis. 
times enlarged portion of the same rock, Pl. IX, Fig. 6a. The false nerves, are regular parallel, and may be individually traced for considerable distances. These nerves are probably deeply hypodermal and their disclosure is due to the state of maceration in the leaves.

The recognition of the presence of fals? nervas Jjetween the true nerves in Noeggerathiopsis Hislopi removes one of the principal distinctions regarded as separating Cordaites from Noeggerathiopsis, and tends to establish a prohability that both are generically identical. The similarily of the Cardiocarpon forms in the Brazilian shales to those related to Cordrites in the Northarn Permo-Carboniferous reinforces the argument for their union. But, on the otliop Jand, if the inflorescencebaring scale leaverdescribel as _lrberic which I suepert of having borne the Cardiocurpon (Samaropsis) Srixasi, leally lon Inng to Noeggerathiopsis, as lecistmantel was inclined to bolieve, thme is no possibility that the Nowthern and Southern leaves are congeneric, the broad flabellate dissected Arberia, with its dichotomizing lojes, being conspicuously distinct from the spicate, bracteate Antholithus. If the specimens just described are not identical with Noeggerathiopsis Hislopi, as I have regarded them, we must conclude that the genus Cordcites has itself invaded this region before the Barı Branco coal was laid down.

It must be remembered that species of Cardiocarpon (Samaropsis) are associated with Noeggerathiopsis in the Karharbari Jeds of India (1).

Another feature also common to the Cycadoflices and Cjcads consists of the presence of very small subspherical or thickly discoid smooth granules deep in the lamina between the nerves. I have observed this in but a single specimen of Noeggerathiopsis Hislopi, not well shown in Fig. 7. Similar granules, perhaps glandular in their nature, or possibly merely sclerotic bodies, are sometimes seen in the leaves of Nilssonia polymorpha, (2) Taeniopteris (3) Neuropteris, (4) Alethopteris, (5) and Megalopteris. (6) The four genera last named are Pteridospermic.

(1) Sec Feistmaclu, Fl, Gondwana Sycl., vol. III, p. 79 , pl. xxriii, fig. 5.

(2) See Nathorst: Bitlat till Sveriges Foss. Fl., pt. 1, 18,i, pl. viii, lins. 12, 13.

(3) Sellarils, Kansas Univ. Quart, volx, no. 1, 1931, p. 5, pl. 1, fig. $($. .

(4) Tezroptcris n. sp., Lesquersux; Lacoe Collection, U. S. National Museum.

(5) Rept. Geol. Surv. Ohio, rol II, palaeont., 1873, p. 42L, pl, L. fig, 3.

(b) Specimens of Megalopteris IIartii AnIr., Megalopteris denlata Lx., in the fossil plant collections of tho U. S. National Museum. 
Ism sur villosa memolia monographicea (1) "a Flora de Glossopler'is" o prof. Al'bel depois de um cuidadoso estudo revisorio, deu uma synonymia das especies do genero Noeggerathiopsis, em que elle relere Noeggerathiopsis espatulata e medu a Noeggerathiopsis Hislopi. Depois de ter examinado o typo de Noeggerathia espatuInta (2) de Dana estou inclinada a crer que Feistmantel (3) tem razão em reconhecer a distincção destas especies a que elle juntou Noeggerathia media de Dana ('́). Distingue-se pelo apice da folha triangular e sub-agudn.

Localidades: Rara no material da camada de plantas 55 metros acima do granito, ou 225 metros abaixo do schisto preto de Iraty, nordeste de Minas, Santa Catharina, Lots. 3586, 3921. Tambem na Estrada Nuva (listrada do Rio do Rasto) proximo de Minas, cerca de 135 metros acima du granili e $\mathbf{1 4 5}$ metros al aixo do schisto preto de Iraty. Lot. 3923. Tambem do Car’vão Barpo Branco. Estrada Nova perto de Minas, 175 metros acima do granito. Lot. 3589. Abundante no schisto lamanido carjononoso da l'egião do carvão de S. Jeronymo perto de Candiota, Rio Grande do Sul. Horizonte a cerca de 20 metros aeima do Carvão Irapuá, Lot. 3924 .

\section{Cardiocarpon}

Brnugniart, Prodome, 1828, p.87

Este genero tem sementes chatas, bilateraes, lenticulares em sessão transversal, geralmente cordiformes, reniformes, ovaes ou de contorno quasi redondo, mais ou menos distinctamente cordiformes na base. Os fosseis usualmente mostram duas cascas na semente, um sclerotesto resistente, que envolge o nucello, ou sua impressão, e um outro carnoso externo, ou episperma que é muitas vezes muito mais expesso na extremidade superior da semente, lateralmente dilatado em forma alada e inciso, ou levemente emarginado no apex. Quando o sarcotesto se desenvolve em aza muito delgada e extensa, muitas vezes de dimensões relativamente grandes è frequentemente denominado Scmaropsis. Este é reconhecido como um genero distincto, por alguns auctores, quando a aza é membranacea.

(1) Cat. Foss. Pl. da Flora do Glossopteris do Dep. Geol. Brit. Mus Lond. 1905, p. 176.

(2) Em Wilk's. Expol Exped. vol. X, 1849. p. i1, pl. XII, fig. 5. o typo tem o numero 1357 cla colleéção de plantas fisseis ro Museu Nacional dos Estados Unidns.

(3) Mem. Geol, Surv. N.S. W. Palaeont. n. 3, p. 1.4 X, pl. XXI, fig. 3-5.

(i) Op. cit. p. $71.7 . \mathrm{pl}$. XII, fig. 10 . 
In his valuable. monographic memoir (1) on "the Glossopteris Flora Professor Arber has, after a careful revisory study, given a full synonomy of the species of the genus Noeggerathiopsis, in which he refers Dana's Noeggerathia spatulata and media to Noeggerathiopsis Hislopi. After examining the type of Dana's Noeggerathia spatulata (2) I am disposed to believe that Feistmantel (3) is justified in recognizing the distinction of the latter species, to which he adds Dana's Neoggerathia media (4). It is distinguished by the triangular, subacute apex of the leaf.

Localities: Rare in the material from the plant bed 55 meters above the granite, or 225 meters below the Iraty black shale, northeast of Minas, Santa Cathrina. Lots 3586 and 3921. Also Estrada Nova near Minas,; about 135 meters above the granite, and 145 meters below the Iraty black shale. Lote 3923. Also from the Barro Branco coal, Estrada Nava, near Minas; about 175 meters above the granite. Lot 3589. Abundant in the laminated coaly shale from the $\mathrm{S}$. Jeronymo coal near Candiota, Rio Grande do Sul. Horizon about 20 meters above the Irapuá coal. Lot 3924 .

\section{Cardiocarpon}

\section{Brongniart, Prodome, 1828, p. 87}

This genus contains flattened, bilateral seeds, lenticular in crossection and generally cordate, reniform, oval or nearly round in contour and more or less distinctly cordate at the base. The fossils usually exhibit two seed coats, a resistent sclerotest, which surrounds the nucellus or its cast, and an outer fleshy sarcotest or episperm, which is often thickened greatly toward the upper end of the seed, laterally dilated in the alate forms, and incised or narrowly emarginate at the apex. When the sarcotest becomes developed as an extensive ver'y thin wing, often of relatively large dimensions, it is frequently designated as Samaropsis. The latter, when the wing is membranaceous is recognized as a distinct genus by some authors.

(1) Cat. Foss. Pl. of the Glossopteris Flora in the Dept. Geol. Brit. Mus., London, 1905, p. 176.

(2) In Wilkes Explor. Expel., vol. x, 1849, p. 715, pl xii, fig. 5. The type is no. 1357 of the fossil plant collection in the U. S. National Museum.

(3) Mem. Geol. Sur. N. W., Palaeont., no. 3 p. 154, pl. xxi, figs. 3-5.

(4) Op. cit., p. 715, pl. xii, fig, 10. 
Os Cardiocarpos em geral são considerados como pertencentes ás Cordaiteas e entre ellas certas formas ovaes, ou orbiculares com bordas sarcotestaes estreitas qua foram definitivamente incluidas nas Cordaites são conhecidas como Cardiocarpon. Suppõe-se que o typo Samaropsis é proprio do grupo Dory Cordautes. As varias formas de Cardiocarpon, ou Samaropsis que teem sido encontradas na flora do Gondwana inferior são consideradas por muitos paleobotanicos como pertencendo provavelmente a Noeggerathiopsis. Iim minhas observacũes s)bre o genero Arberia suggeri que Cardioctrpon ( $S a$ maropsis) Scieasi, abaixo descripta deve so referir a Gangamopteris rue considero como Pteridospermo.

Julgo muito provavel que nem todas as sementes descriptas sob n nome genericn acima, pertençam ás Cordaiteas, mas que algumas, emfim, proveem de typos Cycarlofiliceos.

\section{Cardiocarpon (Stmapropis) Seixasi n. sp.}

$$
\text { Est. Y figs. } 5 \text { e } 8
$$

Nucello baixo, ronvexo, fina e irregularmente rugosostriado, ovular ou oval, ou raramente elliptico, méde $8-10 \mathrm{~mm}$. de comprimento e $5 \mathrm{~mm}$. de largura, distincimmente apiculado, as vezes acuminado e estreitando-se levemente em forma de cunha na base para a linha truncada de ad/herencia, que é egual a cerca de um terço do diametro tranverso maximo, perto do meio do nucello; sc'erotesto fino com 25 a $26 \mathrm{~mm}$ de largura ao longo da borda, nos specimens achatados, mas estreito na parte superior, mais largo na base, as vezes muita claramente definido; sarcotesto provavelmente de pouca espessura dilatado lateralmentc em todo o comprimento do nucello de modo a formar uma a.sa finn, muito finamente lineada cuja forma varia algum tanto, $2- \pm m m$ de largura em cada lado, usualmente mas estreita um pouco abaixo do meio, donde desce ao longo do nucleo $e$ as vezes em pequena distancia abaixo até a linha de separação, é yeralmente mais larga jara o apice onde se prolonga para cada lado em labo muito largrmente angular que se curva levemente para dentro, na direcção do sinus africal que s? abre muito largamente em angulo.

As sementes acima descriptas se encontram espalhadas prafusamente na camada "fte contem plantas a nordeste de Minas, onde estão tão intimamente associadas ás folhas de Gangamopteris abovata 
The Cardiocarpa in general are regarded as helonging to the Cordaitales; and certain, oval or orbicular forms among them with narrow sarcotestal borders that have been definitely correlated with Cordaites are known as Cardiocarpon. The samaropsis type is supposed to be especially proper to the Dory-Cordaites groups. The various forms of Cardioca.pon or Samaropsis that have been found in the lower Gondwana flora are considered Jy most paleobotanists as probably belonging to Noeggerathiopsis In my remarks on the genus Arberia I have suggested that Cardiocarpon (Samaropsis) Seixasi, described below, may be referalle to Gangamopteris which I regard as Pteridospermic.

It is, in my judgment, highly probulsle that not all of the seeds described under the above generic name belong to the Cordaitales; but that some, at least, of them nisy lave been born by Cycadofilicate types.

Gangamopteris (Samaropsis) Seixasi n sp.

Pl. x, igs. 5 e 8

Nucellus low, conver, finely and irregularly rugose-striate, ovate to oval, or rarely elliptical, averaging $8-10 \mathrm{~mm}$ in length, and $5 \mathrm{~mm}$ $i_{n}$ width, distinctly apiculate, sometimes acuminate, and slightly cuneately narrowed basally to lhe broad truncate line of detachment which equals about, one third the maximum transoerse diameter, near the middle, of the nucellus itself; sclerotest thin, $25.6 \mathrm{~mm}$ in width along the border in the fattened specimens, narrovest in the "pper part, widest at the base, often very clearly defined; sarcotest probably of little thicleness, dilated laterally throughout the entir' lenght of the nucellus to form a thin, very fincly lineate wing that is somewhat variable in form, 2.4 mm in vidth on either side, usually narrowest a little below the middle. whence it descends along the nucieus and often for a little distance below it to the line of separation, and gencrally broadest toward the apex where it is prolonged on either side in a very broadly angular lobe which hoolss slightly inward toward the very wide-angled open apical sinus.

The seeds described above are scattered in great profusion in the plant bed northeast of Minas, where they are associated so inti ${ }^{-}$ mately with the leaves of Gangamopteris ooobata that they appear 
que apparecem em quasi todos os pedaços de rocha com aquellas (1). Ambas as especies são as mais abundantes na collecçäo. Grande numero das sementes como as que se veem na estampa $\mathrm{X}$ figura 8, é desprovido de sarcotesto. De facto esta condição é tão cornmum que justifica a conclusão que a pellicula externa era separada do sclerotesto por um tecido sarcotestal tão molle e de facil remoção, que permittia a facil saida do conteudo duro, em um estado pouco adiantado de maceração. o exemplo da figura 8 mostra o sclerotesto na parte superior da semente, embora a parte inferior tenha soffrido deformação lateral. Outras sementes se veem nas figuras 3 a 4 desta estampa.

Specimens de sementes mostrando a aza estam representados nas figs. 5, 5 e 7. Na fig. 7 á esquerda se veem os lóbos pteryformes no apex da semente, ao passo que á direita se veem : a parte inferior de uma outra semente mostrando o chalaz largo e o ligeiro prolongamento basal da aza sarcotestal de cada lado, a aza está em apparencia levemente enrugada, ou dilacerada. A laceração é um caracter do modo de separação da semente que é frequentemente observado e é melhor representado na figura 6 . No original da fig. 5 esta desce ao longo dochalazcuneiforme que parece tornar-se diffuso passando ao ponto da fractura. O aspecto ordinario do lóbo apical pteryforme se vê tambem, nas figs 6 e 7 da estampa VIII. No exemplo reproduzido na fig. 7 da estampa X os lóbos são usualmente obtusos e divergentes. A delgada substancia e a grande dilatação, especialmente na base, destas sementes são conformes com a definição de Samaropsis.

Sementes do grupo Samaropsis foram encontradas em varias regiões de flora de Gangamopteris, entre estas as formas mais affins de Samaropsis Seixasi são as que estam representadas em figuras sem designaȩão especifiea por Feistmantel (2), du Karharbari da India e por Johnston (3) como Câtópöithés Tasmanücus do Permo Carbonifelồ da Tasmania, ambos estes são muito maiores, sendo a semente da India cordiforme e não divaricadamente emarginada, a da 'Tasmania, tambem é rnaiol", com azá mais estreita e de egual largura em todo o comprimento da semente. o Cardiocarpon sp. do Karharbari de que Feistmantel (4) dá a figura apresenta uma differença muito accentuada nas proporções da aza e sua adaptação ao nucello.

(1) Vide Estampa VIII, fig. 2, 5, 6, 7 .

(2) Fl. Gondwana Sist., vol. III, 1881, pag. 59 pl XXVIII, fig. 8.

(3) Geolog. Tasmania, 1888, pl. VIII; fig: 7 (năo dlescripta).

(4) Op, cit. pl. XXIV, fig. 5 . 
on neinly all the rock fragments with the lattor (1). The two species. are by far the most abundant in the collection. A large number of the seeds, like that seen in Pl. $\mathrm{x}$, fig. 8, are deprived of sarcotest. In fact this condition is so common as to afford ground for the conclusion that the outer skin was separated from the sclerotest by a sarcotestal tissue so soft and easily removed as readily to permit the escape of the hard contents at an early stage of maceration. The example, fig. 8 , shows the sclerotest in the upper part of the seed, though the lower part has suffered lateral deformation. Additional seeds are in figs. 3 and $k$ of this Plate.

Specimens of the seeds showing the wing are illustrated in figs. 5, 6 and 7 . In fig. 7 the apex of a seed with the wing lobes is seen on the left, while on the right is shown the lowver part of another seed exhibiting the broad chalaza and the slight basal prolongation of the sarcotestal wing on either side. The wing is here slightly uneven or torn in appearance. The torn or lacerated character of the basal separation of the seed is frecruently oluserved and is better illustrated in fig. 6. In the original of fig. 5 , it descends along the cuneate chalaza which seems to become diffused in passing down to the point of fracture. The ordinary aspect of the apical wing lobes is shown also in figs. 6 and 7, on $\mathrm{Pl}$. viii. In the example drawn in fig. $7, \mathrm{PI} . \mathrm{x}$, the lobes are unusually obtuse and divergent. The thin substance and the wide dilation, especially at the base, of these seeds conform to the definition of Samaropsis.

Seeds of the Samaropsis group are reported from various l'egions of Gangamopteris flora. Among these the forms nearest Samaropsis Seixasi are those illustrated, without specific name, by Feistmantel (2) from the Karharbari of India, and by Johnston, (3) as Carpolithes Tasmanicus from the Permo Carboniferous of Tasmania.

Both of the latter are much larger, the Indian seed being cordate and not divaricately emarginate, the Tasmanian also larger, with narrower wing of equal width the whole length of the seed. The Cardiocarpon (?) $s p$. figure by Feistmantel (4) from the Karharlbari presents a very marked difference in the proportions of the wing and in its adaptation to the nucellus.

(1) Seo pl VIII, figs. 2, 5, 6, 7.

(2) Fl. Gondwana Syst., vol. iii, 1881, p. 59 pl. XXvil, fig. 8.

(3) Geol. Tasmania, 1888, pl. VII, fig. 7 (not descrilue 1).

(4) Op. cit. pl. XXIV, fig. 5 . 
As sementes das Minas teem um numero de especies muito affins na flora do Permo-car]onifero do Norte, embora nenhuma destas se approxime tan to pela sua feição combinada do nucello e aza, que torna difficil a distincção especifica.

A forma do nucello se approxima muito da semente publicada por Schmalhausen (1), como um fructo de um Ginkgo da Siberia.

Como notei em minhas observacũes sobre Arberia lıa alguma eridencia, insufficiente ainda, indicando a união de Cardiocarpon Seixasi com os lóbos truncados de Arberia minasica, folluas ferteis provavelmente pertencendo a Gangamopteris obocatc. Corntudo, tendo em vista a asssociaçĩo geral de formas de Samaropsis com memJros das Cordaiteas da flora do Norte e rom Noeggerathiopsis da do Sul, incluo a especie nas Cordaiteas. E', todavia, certo que nem todos os differentes typos de sementes da collecção que serão naturaimente referidas ás Cordaiteas, poderiam ter sido produzidas por uma unica especie de Voeggerathiopsis. A semelhança da semente com Arberia, „provaria, creio, a relacão de Cardiocarpon Seixas com as Cycadofiliceas.

Esta especie foi denominada em Inonra do colleccionador, engenheiro Dr. Esdras do Prado Seixas, a cujo interesse e cooperação nos trabalhos da Commissão devemos grande parte do rico e interessante material de plantas fosseis, colligidas na localidade a nordeste das Minas.

Localidade: Nordeste das Minas, Santa Catharina, Horizonte a cerca de 55 metros acima do granito, ou 225 metros abaixo do schisto preto

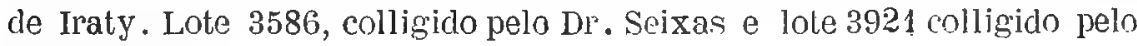
Dr. White.

Cardiocarpon Moreirartme n. sp.

$$
\text { Est. X, fig. } 10
$$

Sementes muito pequenas, quasi redondas, com un clualaz largo, nucello oval-arredondado, 5 mm., ou menos de altura e 3.5 cle diametrotransverso, levemente apiculadas, densamente striadas; sclerotesto bem definido, estreito na base e cerca de 0.75 na maior largura perto do apice, sarcotesto muito delgado na base e tornonclo-se mais largo para cima atí a largura de 1.j no apice, que é levemente emarginado para uma curta linha miropylar.

(1) Beitr, zur Konntn, Jura-F」, Kusnek am Altai, 1879, p. 3.5, pl. IT, fig. 7 . 
The seeds from Minas have a numbar of close relatives in the Nolthern Permo-Carboniferous flora, though none of the latter approach so closely the combined features of nucellus and wing, as to make difficult the specific distinction.

The form of the nucellus closely approaches that of the seed published by Schmahhausen (1) as a Ginkgo-fruit, from Siberia.

As noted in my remarlis on Arberia there is some evidence, insufficient as yet, indicating a union of Cardiocarpon Seixctsi with the truncate lobes of Arouria minasica, fertile leaves possibly belonging to Gangamopteris obovata. However, in view of the general asso. ciation of the Samaropsis forms in members of the Cordaiteae in the Northern flora, and with Noeggerathiopsis in the Southern, I place the species with the Cordaital.? Yet it is certains that not all of the different types of seeds that would naturally be referred to the Cordai-

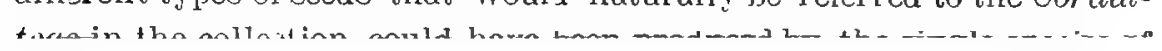

Pag. 582

Em vez de Moreirarum leia Moreiranum.

White.

Cardiocarpon Moreirantm n. sp.

Pl. x, Fig. 10

Seeds very small, nearly round, with a rather broad chala.: : nucellus ovaterpound, $5 \mathrm{~mm}$ or less in altitude and $3,5 \mathrm{~mm}$ in transverse dianeter, slightly spiculate, densely striate; sclerotest well marked, narrow at base and nearly $76 \mathrm{~mm}$ at widest near the apex ; sar"cotest very thin al the base, and broadening upward to a width of $1.5 \mathrm{~mm}$ at the apex which is slightly emarginate to short micropylar line.

(1) Doitr. zu. Kennta. Jura, Fl. IKaesnk an Altai 1879, p. 35, pl. iv, fig. 7. 
As sementes das Mina teem um numexo de especies muito affins na flora do Permo-carbonifero do Norte, embora nenhuma destas se approxime tanto pela sua feição combinada do nucello e aza, que torna difficil a distincção especifica.

A forma do nucello se approxima muito da semente publicada por Schmalhausen (1), como um fructo de um Ginkgo da Siljeria.

Como notei em minhas observacũes sobre Arberia ha alguma evidencia, insufficiente ainda, indicando a uniãis de Cardiocarpon Seixasi com os lóbos truncados de Arberica minasica, follas ferteis provavelmente pertencendo a Gangamopteris obovata. Comtudo, tendo em vista a asssociação geral de formas de Samaropsis com memJros das Cordaiteas da flora do Norte c com Noeggerathiopsis da do Sul, incluo a especie nas Cordaiteas. L', todavia, certo que nem todos os differentes typos de sementes da collécção que serão natu-

Dr. White.

Cardiocarpon Moreirarum n. sp.

$$
\text { Est. } \mathrm{I}, \mathrm{fig} \cdot 10
$$

Sementes muito pequenas, quasi redonclas, com um chalaz largo, nucello oval-arredondaxo, $5 \mathrm{~mm}$., ou menos de altura $e .5 .5$ de dianetro transverso, levemente apiculadas, densamente striadas; sclerotesto bem definido, estrcito na base e cerca de 0.75 na maior largura perto do apice, sarcotesto muito delgado na base e tornando-se mais largo para cima até a largura de 1.5 no apice, que é levemente emarginado para uma curta linha miropylar.

(1) Beitr. zur Kennta. Jura-Fı. Kusnek am Altai, 1879, p. 35, pl. IY, fig. 7. 
The seeds from Minas have a numbar of close relatives in the Nolthern Permo-Carboniferous flora, though none of the latter approach so closely the combined features of nucellus and wing, as to make difficult the specific distinction.

The form of the nucellus closely approaches that of the seed published by Schmalhausen (1) as a Ginkgo-fruit, from Sijeria.

As noted in my remarlis on Arberic there is some evidence, insufficient as yet, indicating a union of Cardiocarpon Seixasi with the truncate lobes of Aripria minasica, fertile leaves possibly belonging to Gangamopteris obovata. However, in view of tlie general asso. ciation of the Samaropsis forms in members of the Cordaiteae in the Northern flora, and with Foeggerathiopsis in the Southern, I place the species with the Cordaital?s. Iet it is certains that not all of the different types of seeds that would naturally be referred to the Cordaiteae in the collection could have been produced by the single apecies of Noeggerathiopsis. The correlation of the seed with Arberice would, I believe, go far to prove a Cycadofilic relationship for the Cardiocarpon Seixasi.

The species describel ajove is named in honor of the collector, lingineer, Dr. Lisdras do Plado Seixas, to wliose interest and cooperation in the work of the Commission we owe a large part of the richly interesting fussil plant material collected from the locality northeast of Minas.

Locality : Northeast of Minas, Santa Catharina. IIorizon about 55 meters above the granite or 2.2.5 meters below the Iraty black shale. Lot. 3586, collected by Dr. Seixas; and lot 3921, collected by Dr. White.

Cardiocalpon Moreiranz!m n. sp.

$$
\text { Pl. x, Fig. } 10
$$

Seeds very small, nearly round, with a rather broad chala.: ; nuccllus ovate-round, $5 \mathrm{~mm}$ or less in altitude and $3,5 \mathrm{~mm}$ in transverse diameter, slightly spiculale, densely striate; sclerotest vell marked, narrow at base and nearly $76 \mathrm{~mm}$ at widest near the apex; sarcotest very thin al the base, and broadening upuard to a width of $1.5 \mathrm{~mm}$ at the apex which is slightly emarginate to short micropylar line.

(1) Deitr. zu. Kenntr. Jura, Fl. Iruesnk an Altai 1870, p, 35, pl, iv, fig. 7. 
o specimen que se vềna fig. 10, est. X é o maiol de uma serie da collecção. Seus caracteres são tão bem accentuados e constantes cque nâo hesito em consideral-o maduro, apezar de seu pequeno tamanho. Alguma rariação na forma e impressão do sarcotesto em differentes exemplares é devida á maceração e deslocamento.

Esta especie differe de Cardiocarpon Oliveirarum pelo seu nucello mais oval e levemente apiculado, o testo interno mais forte e a margem relativamente mais larga, que é apenas levemente incisa no apice. o nucello não é tão grande como a metade do daquella especie.

Cardiocarpon Moreirarum como a especie seguinte parece per $\rightarrow$ tencer ao grupo do Norte de typos redondo-ovaes e concorda completamente com estes.

o exemplar descripto acima é denominado em reconhecimento ás eminentes contribuições á sciencia de parte de Carlos Moreira, Zoologo do Museu Nacional do Brazil e pelo seu grande interesse em desenvolver a paleontologia do Brazil, bem como por sua habilidade c fidelidade no trabalho, como sccretario da Commissão do Carvão, tanto no campo como assistente do Dr. White, como no gabinete como traductor de seus relatorios.

Localidades: Carvão Barro Branco, Estrada Nova, (estrada do rio do Rasto), perto das Minas, Santa Catharina. Cerca de 175 metros acima do granito, ou 105 metros abaixo do schisto preto de Iraty. Lote 3922 (typo). Tambem da camada de plantas 55 metros acima do granito a nordeste das Minas. Lote 3921.

\section{Cardiocarpon Oliveiranum n. $s p$.}

$$
\text { Est. X. fig. } 9 \text {. }
$$

Semente pequent sub-orbicular, muito levemente condiforme na bass", ligeiramente entalhada no "pine e um pouco rugoso-estriada; sclerotesto muito fino; margem muito estreita, alcançando uma langura maxima de cerca de $75 \mathrm{~mm}$. no tope e um pouco estreitamente fendido em lobos muito curtos e angular'es.

Os caracteres essenciaes desta especie são a forma quasi redonda e a borda extraordinariamente estreita, que é como o nucello entalhada no apice. Nada conheço da flora do Gondwana inferior com que possa ser está estreitamento comparavel. Por outro lado seus caractéres são is de algumas de nossas especies redondas do norte, de 
The specimen shown in fig. 10. Plate $\mathrm{x}$, is the largest of a series in the collection. Its characters are so well marked and constant that I do not hesitate to regard it as mature, notwithstanding its small size. Some variation in the form of the impression of the sarcotest in different examples is due to maceration and displacement.

The species differs from Cardiocarpon Oliveiranum by its more ovate, slightly apiculate nucellus, the strong inner test and the relatively much broader margin which is but slightly incised at the apex. The nucellus is not one half as large as that of the latter species.

Cardiocarpon Moreiranum, like the following species, appears to belong to the Northern group of round-oval types, and is in complete agreement therewith .

The specimen described above is named in recognition of the eminent contributions to science on the part of Carlos Moreira, Zoologist of the National Museum of Brazil, and his deep interest in building up the palaeontology of Brazil, as well as his skillful and faithful work as secretary to the Coal Commission, both in the fietd as an assistant to Dr. White, and in the office as translator of his reports.

Localities: Barro Branco coal, Estrada Nova near Minas; Santa Catharina. About 175 meters above the granite, or 105 meters below the Iraty black shale. Lot 3922 (type).

Also from the plant bed 55 meters above the granite, northeast of Minas. Lot 3921.

Cardiocarpon Oliveiranum n. sp.

$$
\text { Pl. x, Fig. } 9 \text {. }
$$

Seed small sub-orbicular, very faintly cordate at the base, slightly notched at the apex, and rather strongly rugose-striate; sclerotest very thin ; border very narrow, reaching a maximum width of nearly. $75 \mathrm{~mm}$ at the top and rather narrowly cleft in very short angular lobes.

The essential characters of this species are the nearly round form, and the unusually narrow border, which, like the nucellus is notched at the apex. I know of nothing in the lower Gondwana flora with which it is closely comparable. On the other hand, its features are those of some of our Northern round species of Cardiocarpon, among 
Cardiocarpon, entre estas se assemelha especialmente a Cardlocarpon orbiculare Newberry (1) da porção inferior (Westphaliano) do Carbonifero superior do Ohio. Esta especie constitue um outro helo unindo a flora do Brasil á do Permo-carbonifero do Norte, sendo a connexão neste caso a mais interessante por ser Gymnosperma, ou Pteridosperma.

Cardiocapon O iverincinum foi denominado em honra do distincto geologo veterano do Brasil Dr. F. de Paula Oliveil'a.

Localidades: Estrada Nova, perto das Minas, Santa Catharina. Cerca de 40 nictros a]ıaixo do carvão Barro Branco, ou cerca de 135 melros acima do glanito. Lote 3923 (typo). Tambem de um horizonte cerca de 10 merros acima do rio Tubarão, perto das Minas. Lote 3588 .

\section{Cardiocarpon Barcellosum n. ss.}

Est. X. fig. 11

Nucello cordiforme, cerca de $5 \mathrm{~mm}$. de comprimento e um pouco mais de larrura; sclerotesto estreito, denso; sarcotesto largo, medindo $3 \mathrm{~mm}$ de largura na parte mais estreitu opposla ao meio do nucello, alargando-se até $5 \mathrm{~mm}$ ao passar em torno do apice onde é levernente emarginado no extremo do distincto canal micropylar e prolongando-se para baixo, por baixo do nucello em uma distuncia de 3,5mm de modo a dar ci semente inteira um contorno quasi oval, ou levemente maior sendo seu comprimento approximadamente metade que a maior largura.

o specimen da figura é o unico desta especie que existe nas collecções. O nucello quasi exactamente cordiforme é lavemente convexo e uma linha de carvão indica a densidade do envolucro sclerotico. o envolucro externo era eridentemente algum tanto denso, pois que, embora ligeiramente deformado no decurso da fossilisação, ainda ha muito carvão adherente á impressão. A larga extensão da aza ou sarcotesto e a egual espessura apparente deste no todo, dá direito á especie a um logar na seç̧ão Samaropsis, do genero.

Poucas especies da flora Gondwana, descriptas, são comparaveis as da fig. 11, estampa $\mathrm{X}$, entre estas a sementa incompleta do Kar-

(1) Ropt, Goolog. Surv, Ohio, v. 1 Paleont., 1873, p. 374, pl, XLILI, fig. 10. Vide tamben Lesquereux, Cual Flora, vol. II, 1880, p. 569, pl. LXXX ${ }^{\prime}, 1 \mathrm{~g}, 40$. 
which it is particularl! close to Cardiocarpon orbiculare Newherry (1) from the lower portion (Westphalian) of the upper Carboniferous of Ohio. The species constitutes another link binding the flora of Brazil to that of the Northern Permo-Carboniferous, the connection in this instance being the more interesting it is Gymnospermic or Pteridsspermir .

Cardiocarpon Oliveirantm is named in honor of the distinguished veteran geologist of Brazil, Dr. F. de Paula Oliveira.

Localities: Estrada Nova, near Minas, Santa Catharina. About 40 meters below the Barro Branco coal, or about 135 meters above the granite, Lot 3923 (type). Also from a horizon about 10 meters above Rio Tubarão, near Minas. Lot 3588 .

\section{Cardiocarpon Barcellostum n. sp.}

$$
\text { Pl. X, Fig, } 11 \text {. }
$$

Nucellus cordate, about $5 \mathrm{~mm}$ in length and a little more in breadth; sclerotest narroto, dense ; sarcotest broad, measuring $3 \mathrm{~mm}$ in width at the narrovest point, opposite the middle of the nucellus, and broadening to $5 \mathrm{~mm}$ in passing around the aper tohere it is but slightly emarginate at the end of the distinct micropylar canal, and prolonged downward below the nucellus for $a$ distance of about $3.5 \mathrm{~mm}$ so as to give the entire sceil a nearly oval or slightly obovate oval contour, the length being nearly omr half greaterthn the greatest breadth.

The specimen figured is the only one of its kind in the collec tions. The almost exactly cordate nucellus is slightly convex, and a line of carbon indicates the density of the sclerotic envelope. The outer envelope was evidently somewhat dense, for although slightly deformed in the course of fossilization considerable carbon still adheres to the impression. The broad extension of the wing or sarcotest and the apparently equal thickness of the latter throughout, entitle the species to a place in the Samaropsis section of the genus.

Few specimens described from the Gondwana flora are comparable to that figured in $\mathrm{P} . \mathrm{X} \mathrm{Fig}$. 11. Among these the incomplete

(1) Rept. Geol. Surr. Ohio, rul. 1. Palacon', 1873, p. 37i. pl. XLIII, fig., 10. See a'so Les.juereux, Coal Flora, vol. II, 1880, 1. 569, pl. LXXXY. lig. 4n. 
har.Juri, descripla e representada em figura por lieistmantel (1) como Samaropis e a do Transwaal representada em figura e descripta por Seward (2) como Catrdiocarpon sp. merecem menção. Os nucleos são da mesma fórma que os de Cardiocarpon descriptos por Zeiller (3) do genero de Barakar, embora a impressão do sarcotesto seja muito differente.

Cardiocarpon Barcellosum é mais estreitamente alliado a algumas especies allongadas e de larga aza do Permo-carbonifero do Norte. Está particularmente muito proximo do Cardiocarpon annullatum de Newberry (4) do Pottsville superiol (Westphaliano) do Ohio e do Cardiocarpon pachytestum (5) das camadas da mesma edade da formação anthracitica do Norte da Pensylvania. As estreitas relações entre estas sementes do Norte e do Sul indicam certamente uma relação affim similar, entre os typos que as produzem, estejam actualmente aquellas em que genero estiverem.

Cardiocarpon Barcellosum foi assim designada em honra do Dr. Ramiro Barcellos distincto senador pelo Rio Grande do Sul que tanto tem feito, para tornar conhecido o carvão e outros recursos mineraes do Sul do Brazil.

Localidades: Capa do Carvão Irapuá a oeste da casa do Dr. Barcellos perto do Rio Irapuá, Rio Grande do Sul. Cerca de 135 metros abaixo do schisto preto de Iraty. Lote 3591.

\section{CONIFERAS}

\section{Voltzia}

Brongniart, Prodrome, 1828, p. 108

Voltzia? sp.

Estampa VIIl, figs. 11, 10, 13, 13a, $13 \mathrm{~b}$.

As collecções da camada de plantas a nordeste das Minas conteem pequenos fragmentos de ramos frondosos que embora iusufficientes mesmo para uma identificação generica definitiva, teem muito

(1) Fl. Gondwana Syst., vol. Ill, 1881, p. 59, estamp. XXV, fig. 8.

(2) Quart. Journ. Geol. Soc., vol. LIII, 1897, p. 324, 332, fig. 1 d.

(3) Pal. Indica, n. s., vol. II, 1902, p. 38, pl, VII, fig. II.

(4) Rep. Geolog. Surv. Ohio, vol. I Palaenot., 1873, pag. 374, pl. XLIIl, fig. 8, 8 a. Lesquereux, Coal Flora, vol. IJ, 1880, p. 564, pl. LXXXV, figs. 36 e 37 .

(5) Coal Flora, vol. I, pag. 565, vol. III, p. 809, pl. CIX, figs. 13 e 15. 
seed from the Karharbari, described and illustrated by Feistmantel (1) as Samaropsis, and that from the Transvaal illustrated and described by Seward (2) as Cardiocarpus $s p$, deserve mention. In form the nuclei are similar to those of the Cardiorarpon described by Zeiller (3) from the Barakar group, though the impression of the sarcotest is very different.

Cardiocarpon baricellosum is most closely allied to some of the broadly alate and olongated spacies in the Northern Permo-Carboniferous. It stands particularly close to the Cardiocarpon annulatum of Newljerry (4) from the upper Pottsville (Vestphalian) of Ohio, and Cardiocaryon prichytristum of Losqueroux (5) from heds of the samo age in the Yorthern Anthrarite ficld of Pennsylvania. The close relalionship between the Corthern and Southern sceds rertainly indicates a similarly clow relation betwon types that lore them, in whatever genera the latter may now l'est.

Cardiocarpon J3arcellosum is named in honor of Dr. Ramiro Balcellos, the distinguished Senator from the State of Rio Grande do Sul who has done so much to make known the coal and other mineral resources of South Brazil.

Locality :- roof of the Irapuá coal, west of the house of Doctor Barcellos, near Rio Irapuá, Rio Grande do Sul. About 135 meters helow the Iraty hlack shale. Lot 3591.

\title{
CONIFERALES
}

\author{
Voltria \\ Brongnialt, Prodrome, 1829, p. 108 \\ Voltzia? sp \\ PI. VIII, figs. 11, 12, 13, 13a, $13 \mathrm{~b}$.
}

The collections from the plant bed northeast of Minas contain several small fragments of leafy twigs which, though insufficient for even a definite generic identification are full of interest as indicating

(1) Fl. Gondwana Syst., vol. III, 1831, p. 59, pl. XXV, fig. 9.

(2) Quart. Journ. Geol. Soc., vol. LIII, 1897, p. 324, 332, fig. $1 \mathrm{~d}$.

(3) Pal. Indica, n. s., vol. II, 1902, p. 38, pl. VIl, fig. 11.

(4) Rep. Geol. Surv. Ohio v. I, Palaeont. 1873, p. 374, pl, XLIII, figs. 8, 8 a . Lesqueroux, Coal Flora, v. II, 1880, p. 561, pl. LXXXV, figs. 36, 37.

(5) Coal Flora, vul. I p. 565, vol. III, p. 809, pl. CIX, figs. 13, 15. 5560 
interesse porque indicam a presença nas camadas carboniferas do Brasil de typos de coniferas, que além disto se referem aos do PermoTrias. Tres dos melhor conservados destes fragmentos estam representados nas figs. 11, 12 e 13 na estampa VIII. As folhas, como se vê na fig. 13 são lanceoladas, um pouco mais largas acima da base decurrente, depois afinando para cima até o apice agudo. São concavo convexas, arredondadas na face dorsal, mas não carenadas, as vezes algum tanto curvas para dertro, ou mesmo algum tanto uncinadas. A nervura mediana é clara e persistente, om um fragmento, muito obscuro para ser reproduzido em figura, algumas das folhas são mais abertas e são levemente recurvas, lembrando Toltzia heterophylla.

o fragmento com folhas mais largas e mais curtas que se ve na estampa VIII fig. 11, está na mesma rocha que a que acabamos de mencionar e é o orjiginal da fig. 12. Visto que suas folhas superiores são alongadas e visto que occorre associada com ramos de longas folhas ć permittido cansideral-o presumivelmente pertencendo ao mesmo typo, em que as folhas são talvez dimorphicas.

Entre outras coniferas de regiões de flora de Gondwana, descriptas, nossos fragmentos de folhas mais longas, são comparaveis aos specimens delgados de Karharbari, descriptos e representados em figura por Feistmantel (1), como Voltzia heterophylla Brong., ou ao material publicado pelo mesmo auctor (2) como Palissya indica da serie do Gondwana superior .

Não obstante as estreitas relações de nossos fragmentos com o de Valtáia da India, ou com a mesma especie como schimper $\theta$ Mougeot (3) descreveram, do Bunter dos Vosges, hesitei, a vista da ausencia de formas maiores desta especie, em referil-a a este typo.

Tambem se pode comparar com Palissya Braunii Endl. como foi descripta por varios auctores e com Walchia linearifolia do Permiano (4) da Saxonia e Bohemia.

0 facto de não se ramificarem distichiamente se oppõe a referil-a a Walchia, embora o aspecto do fossil seja muito semelhante ao de alguns specimens de Göppert.

Os caracteres que apresentam us fragmentos que tenho em mão, tornam provavel que descobertas posteriores mostrarão que per-

(1) FI. Gondwiana Syst., vol. Ill, p. 30 est. XXIV, fig. 4, pt. 2 p. 122, pl. XLVIlA, figs. 20, 22, 24 .

(2) Op. cit., vol. 1 pt. 2 p. 27, pl. XV, fig. 15.

(3) Monogr. pl. foss. grés bigarrè d. Vosges, p. 25, pl. VIII, pl, IX pl. X.

(4) Foss. Fl, d, Perm. Form., p. 242, pl. II figs. 7, 11. 
the presence in the Brazilian coal measures of coniferous types related to those of the Pelmo-Trias elsewhere. Three of the best preserved of these fragments are shorvn in figs. 11, 12 and 13, on Pl. VIII. The leaves, as shown in fig. 13, are lanceolate, broadest a little above the decurrent base, then tapering upward to a narrow acute apex. They are concaro-convex, rounded dorsally but not carinate, and often somewhat incurved or even somervhol uncinate. The midrib is clear and persistent. In one fragment, too obscure for iltustration, some of the leaves are much more open and slightly recurved, suggesting Voltwla heterophylla.

The fragment with broader and shorter leaves shown in Pl. VIII, fig. 11, lies on the same stone with that last montioned and the original of fig. 12. Since its uppermost leaves are elongaling, and since it occurs associated with the twigs with longer leaves, it is permissible to regard it as presumably belonging to the same type, in which the leaves are perhaps dimorphic.

Among other conifers described from the regions of the Gondwana flora, our fragments with the longer leaves are comparable to the most slender Karharbari specimens, described and illustrated by Feistmantel (1) as Voltzia heterophylla Brongn., or the material publised by the same author (2) as Palissya indica from the upper Gondwana series.

Notwithstanding the close relationship of our fragments to those of the Indian Voltzia, or with the same especies as described by Schimper and Mougeot (3) from the Bunter of the Vosges, I hesitate, in the absence of the larger forms of the species, to refer it to this type.

Comparison may also be made with the Palissya Braunii Endl. as described by various authors, and with Goeppert's Walchia linearifolia from the Permian (4) of Saxony and Bohemia.

The fact that the Brazilian twigs do not appear to branch distichously stands against a reference to Walchia, though the aspect of the fossil is very close to that of some of Göppert's specimens.

The characters offered by the fragments in hand make it probable that further discoveries will show them to belong to either the Arau-

(1) Fl, Gondrana Sys', vol. III. p. 30, p1, XXIV, fig. 4, pt, 2, p, 122 pl,XLVII ligs. $20,22,21$.

(2) Op. cit., vol. I. pt. 2, p. 27, pl. XV. fig. 15.

(3) Monogr. pl. foss. grés bigarré d. Vosges, p. 25, pl. viii, pl. ix, pl.x.

(4) Foss. Fl, d. Perm. Form, pag. 242, pl. If figs. 7, 11. 
tencem, ou á divisão Araucariana, ou a Taxodiniana das Pinaceas, ou muito mais provavelmente ao grupo Voltziano. Deveriam ser feitas pesquisas especiaes em procura de cones de que não ha fragmento algum na collecção.

Localidade: Nordeste das Minas, Santa Catharina. Camada de plantas a 55 metros acima do granito e 225 metros abaixo do schisto preto de Iraty. Lote 3921.

\section{Dadoxylon}

Endlicher, Synopsis Coniferarum, 1847, p. 298

o nome generico Dadoxylon é actualmente applicado em geral ans represeutantes palaeozoicos de um typó de madeira deconifera de anatomia estreitamente comparavel a das especies que ainda vivem de Arancaria ou Dammara.

o xylem é formado centrifugamente as trachcides arranjadas radialmente, sendo pontuadas $\mathrm{cm}$ suas paredes radiaes com orificios geralmente pluriseriados de margens contiguas que extam as vezes um pouco distantes, mas muitas vezes agglomerados, sendo neste caso hexagonaes. Os poros são geralmente oblicjuamente ovaes ou ellipticos.

o genero está actualmente, ampla e comprehensivelmente constituido, de modo a incluir muitos dos typos palaeozoicos, de madeira de coniferas que não teem tecido lenhoso primario, ou centripeto e que não teem relação com Cordaites pela presença de uma medulla dividida em grandes camaras transversaes. As madeiras post-palaeozoicas correspondendo a Ddoxylon são collocadas em Araucarioxylon por Kraus.

Incontram-se madeiras fosseis que se referem a Dadoxylon em rochas tão antigas como o Devoniano medio. Nos typos mais velhos as pontuações estam algumas vezes ein quatro alinhamentos e mesmo em grupos (Dadoxylon Newberryi).

E' muito raro encontrarem-se em evidencia, anneis, de crescimento annual em todos, menos nos ultimos typos Car]joniferos e Permianos e estes casio, ás rezes excepcionans podem, emfim ser devidos a parada do crescimento, ou repouso, antes rue a mudanças climaticas accentuadas. 
carian or the Taxodinian divisions of the Pinaceae, the evidence favoring the Voltzian group. Especial search should be made for cones, no fragments of which are present.

Locality : Northeast of Minas, Santa Catharina. Plant bed 55 meters above the granite of 225 meters below the Iraty black shale. I,ot. 3921:

\section{Dadoxylon}

Enddlicher, Synopsis Conifrarum, 1817, p. 298.

The generic name Dadoxylon is now generally applied to the $\mathrm{Pa}-$ laeozoic representatives of a coniferous type of wood cxlibiting an anatomy closely comparable to that of the living Araucaric or Dammara.

The xylem is formed centrifugally, the radjally arranged tracheides being punctuate on their radial walls with generally pluriseriate and contiguous bordered pits, which are sometimes a little distant but often crowded, in which case they are hexagonal. The pores are generally obliquely oval or elliptical.

The genus is now broadly and comprehensively construed so as to include most of the Palaeozoic coniferous types of wood which have no primary or centripetal wood and which are not corlelated with Cordaites by the presence of a very large transversely chambered pith. The post-Palaeozoic woods correspnnding to Dadoxylon are placed in Araucarioxylon Kraus.

Fossil woods referred to Dadoxylon are found in rocks as old as the middle Devonian. In the oldin types the punctations are sometimes in as many as four rows, and even in groups (Dadoxylon Netoberryi).

Evidence of rings of annual growth is very rare in all but the later Car]oniferous and Permian types, and in these somervhat exreptional cases it may, in many instances at least, be due in reproductive or resting stages, wher than the marked climatic (hanges. 


\section{Dadoxylon pedroi Zeill.}

1895. Dadoxylon Pedror Zeiller, Comptes Rendus, vol. CXXI p. 964; Bull Soc. Geol. Fr., (3) vol. XXIII, 1896, p. 619, figs. 8-19, pl. IX, fig. 4; Arber, The Glossopteris Flora, 1905, p. 199.

Medulla muito grande sem camaras, cylindrica, tri-radiada em quilhas, ou rugas genesicas, continuas estreitas arredondadas equidistantes, ao longo de cuja superficie as cunhas de madcira estam em angulos rectos e de que é provavel que nascessem os ramos e folhas. A medulla é cinda caracterizada pela presença de grupos de 2-15 cellulas secretoras, espalhadas em seu interior em contacto com as quaes as cellulas parenchymatosas são estreitas e alongadas em uma pseudo bainha. As cellulas da medulla são tambem alongadas proximo do casos espiraes no apice das cunhas do xylem. O crescimento do xylem é exclusivamente centrifugo em cunha de largura muito variavel, principiando com vasos espiraes e passando rapidamente por tracheides anmulares, ou scalariformes as perfuradas que compóm exclusivamente o xylem a curta distancia do apice da cunha. Estas tracheides são longas, finas, algum tanto irregularmente dispostas e são marcadas em suas paredes radiaes por uma, ou alguma vezes duas linhas de punctuaçôs. areoladas que estão raramente distantes umas das outras, mas que são geralmente fechadas e parcialmente polygonaes onde estam em contacto, especialmente quando em duas linhas. O poro central é pequeno $e$ exactamente redondo em vez do oval ou elliptico e é as vezes excentrico. Os raios medullares são largos a principio, mas tornam-se rapidamente mais estreitos, até a largura de uma unica cellula, em. bora aqui, ou alli uma cellula se divida verticalmente por fissiparidade. Os raios são muitas vezes de grande altura as vezes alcançando a altura dc 50 cellulas, ou mais, emquanto que outras vezes tem apenas uma cellula de altura. As cellulas individuaes são 5-6 vezes mais longas que largas, geralmente sotopostas a tres ou cinco tracheides e são quasi tão largas como altas. São ponctuadas por pequenos paros obliquos cllipticos, espalhados, em contacto com as tracheides.

A diagnose acima foi tirada da admiravel descripção dada pelo Professor Zeiller dos caracteres anatomicos desta madeira, de um specimen da colleçãn da condessa d'Eu, do valle do Jaguarão no Rio Grande 
Dadoxylon Pedrui Zeill.

1895. Dadoxylon Pedroi Zeiller, Comptes Rendus, vol. cxxi, p. 964; Bull. Socc. géol. Fl'., (3) vol. xxiii. 1896, p. 619, figs. 8-19, pl. ix, fig. 4: Arber, The Glossopteris Flora, 1905, p. 199 .

pith very large, without chambers, cylindrical, tri-radiate in continous narrow, rounded, equidistant keels or generative ridges, along the surface of which the wedges of wood stand at right angles, and from which it is probable that branches and leaves had their origin. The pith is further characterized by the presence, scattered in its interior, of groups of 2-15 secretory cells, in contact with which the parenchymatous cells are narrowed and elongated in a pseudo-sheath. The pith cells also elongate approaching the spiral vessels at the apices of the xylem wedges. The xylem growth is exclusivelly centrifugal, in wedges of greatly varying toidth, beginning with spiral vessels and rapidly massing through annular or scalariform to the pitted tracheides which cxclusively compose the xylem after passing a very short distance from the apex of the wedge. These tracheides are long, slender, somewhat irregularly disposed, and are marked on their radial walls by one or sometimes two rows of areolate punctations, which are rarely distant from one another, but which are generally close and partially polygonal where in contact, espccially when in two rows. The central pore is small and exactly round instead of oval or elliptical, and is sometimes eccentric. The medullary rays are very wide at first, but they rapidly narrow to a thickness of but a single cell, though here and there a cell divides vertically by fission. The rays are often of great altitude, sometimes reaching a heighi of 50 cells or more, while at other times they are but a single cell in height. The individual calls are 5-6 times as long as voide, generally subtending three to five trachcides, and they are about as broad as high, they are punctated with scattered small oblique elliptical pores in contact with the tracheides.

The above description is drawn from the admirable account given by Professor Zeiller of the anotomical characters of this wood, from a specimen in the collection of the Countess d'Eu from the valley of 
do Sul. Tenhum dos specimens da nossa collecção que examinei apresenta distinctamente os caracteres que especialmente distinguem c typo, embora pareça que este esteja representado por material mal conservado que deve provir das zonas externas do tecido lenhoso secundario.

Os caracteres notaveis da especie são $1^{\circ}$ : a fơlma tricarenada da medulla muito grande e sem camaras, tendo grupos de cellulas secretoras, $2^{\circ}$ a disposiçăo ás vuzes afastada dos orificios areolados das tracheides, que não sãn disposlas em linhas radiaes regulares na cunha de xylem; $3^{0}$ a fólma exactamente redonda do poro que é muitas vezes excentrico na arenla, 1 $^{\circ}$ a origem das fol has e provavelmente dos ramos lambam nis cristas dar tros carenai longiludinaes muito salicnles.

Ainda não foram determinadas as relaconss de Druduxylon Pedroi de Zeiller e sua connexão possivel, ou provavel com algum dos typos foliaes da flora permiana do Brasil, já descriptos. O grande tamanho da medulla, a presença nella de vasissecretores, o fórma polygonal das cellulas medullares na porção basal dos alinhamentos e a fórma algum tants irregular das tracheides nos alinhamentos radiaes levemente indefinidos na cunha do xylem, concordam com o typo Crcadofiliceo, ou Cycadaceo. A ausencia, porém, de tecido lenhoso centripeto primario e o desenvolvimento estrictamente centrifugo das cunhas de tecido lenhoso parecem excluil-o daquelle grupo.

A sequencia centrifuga de tracheides espiraes, sclariformes e areoladas é confurme com o typo Cordaiteo, embora como Zeiller faz notar a ausencia de camaras o destingam da madeira de Cordates.

Zeiller é propenso, não obstante, a considerar a especie pertencente ao grupo Cordaiteo, provavelmente a Noeggerathiopsis ou Euryphyllum em vez de Cordaites.

Sobre esta questão deve-se notar que o Prefessor Arber é inclinado a considerar seu Dadoxylon australe (1) ou algum dos outros typos mais distinctamente Arancanianos, da Nova Gulles do Sul, provavelmente como madeira de Noeggerathiopsis. Embora a opinião de Zeiller pareça provavel, parece-me não ser impossivel que Dadoxylon Pedrot deva representar hastes, ou ramos de Gangamopteris, ou de algum outro typo anatomicamente desconhecido, cujos caracteres foliaes ou orgãos de inflorescencia conduzir-nos-iam a referil-o aos Cycadofiliceos.

(1) The Glossopteris Flora, p. 191, pa:s, 40 e 43. 
the Jaguara's in hio Grande do sul. None of the specimens so far examined in onr collertion distinctly jresent the peculiar character's that specially distinguish the type, though it appears to be represented by poorly preserved material, that may have come from the outer' zones of the secondary wood.

The l'emarkable features of the species are $\left(1^{\circ}\right)$ the thit:arinate form of the very large, chamberless pith which contains shoups of secretorycells; $\left(2^{\circ}\right)$ the sumelimes distant arrangement of the areolate pits of' the tracheides, which are not in regular radiate rows in the xylem wedge; $\left(3^{\circ}\right)$ the exactly round form of the pore, which is often somewhat eccentric in the areole; and $\left(1^{\circ}\right)$ the origin of the leavos and probabl! of the branclies also; frum the crests of the three ver! lureminent longitudinal lieels.

The relationship of Zeiller's Ladoxylon Pedroi and its possible or probable connection with some one of the foliar types already descrijed in the Permian flor'a of Brazil l'emains undetermined. The large size of the pith, the presence of secretory vessels in the pith, the polygonal forms of the medullary cells in the basal portions of the rass and the somerhat irregular form of the tracheides in the slightly indefinite radjal rows in the xylem wedge, agree with a cycadofilicate or cycadaceous reference of the type. Bul the absence of a centripetal primary rood, and the strictly contrifugal development of the rood wedges seems to exclude it fiom that group.

The "centrifugal sequence ol spiral, scalariform and areolate tracheides conforms to the Cordaitean type, though, as Zeiller points out, the absence of chamber's distinguishes it from the wood of Cordaites.

Zeiller is inclined nevertheless to regard the species as belonging to the Cordaitean group, though plobalyly to Noeggerathiopsis or Ellryphyllum instead of Cordaites.

In this connection it may the noted that Professor Arlyer is disposed to regard his. Dadorylon australe (1) or some of the other more distinctly Araucarinian types from Nerr South Niales. as probably the wood of Noeggerathiopsis. Though Zeiller's views appear probalule il seems to me not at all impossible that Dadoxylon Pedroi may represent the stems or Jranches of Gangamopteris or some other type, anatomically unknown, whose foliar characters or inflorescent organs would lead to its reference to the Cycadofilices.

(1) The Glusiopteris Flora pate. 191 tin. $40-43$. 5560 
Sou de opiniăo que é mutto seriamente duvidosa a inclusão da especie de Zeiller no genero Dadoxylon. A grande medulla proeminentemente tricarenada, a funç̧ão generica das carenas, a irregularidade na fórma das tracheides, a disposição normalmente, uniseriada e algumas vezes afastada das areolas e especialmente a figura exactamente redunda dos pequenos poros parecem excluir a especie do genero Dadoxylon de Endlicher, ao passo que justificam reconhecel-a como um typo generico distincto.

A presença de uma medulla carenada em Dadoxylon Pedroi lemJra o Dadoxylon Spenceri de Scott (1) da formação carbonifera de Halifax, embora no exemplar inglez a medulla tenha cinco carenas, contendo tambem camadas lenhosas mesarchicas plimarias (contripetas.)

Quanto ao que se refere á decomposição destas madeiras é muito interessante observar que Zeiller acha as ceillulas das camadas medullares infestadas por pequenos corpusculos bacterioides com 7 a $8 \mu$ de diametro que elle considera muito intimamente alliados ao Micrococus hymenophagus var a de Renault. (2).

Localidade: - Valle do Jaguarão, Rio Grande do Sul. O Typo está na colleção da Ecole superieure des Mines, Paris.

\section{Dadoxylon nummularium $n$ sf}

Est. XIII, figs. 1 -4

Tracheides em alinhamentos radiaes bom regulares, e'stremamente longos, estreitos, sinuosos, agudos, relativamente grandes, embora variando muito em diametro na mesma secção, geralmente squarrosas, enbora muitas ve'ses algum tanto redondas nos angulos com um diametro tangencial cm média de 34 u, usualmente maior que - diametro radical, especialmente nas cellulas maiores; camadas medullares muito numerosas, juntas, usualmente apenas uma, ou duas tracheides distantes, $1-30$ cellulas média 6 ou 7 de altura, as mais das vezes uniseriadas, embora frequentemente biseriadas da aitura de duas, ou tres cellulas; cellulas radiaes distinctamente squarrosas quando uniseriadas de forma un tanto irregular onde são biseriadas geralmente mais altas que largas tendo 30 m mais ou menos

(1) Tran.j. R. Soc. Elinb, rol. XL. pt. 2 1902, p. 357, pl: II, fig. 12-13; pl, VI,

(2) Bull. Soc hist. nat. Autun, vol. VIJ, 1895. P. 45s Fl. fos3. bassin honill et. form. d'Autun et Epinac, pt. 2, 1896 pas. 465 lig. 105. 
The reference of Zeiller's species to the genus Dadoxylon is, in my judgment, very seriously to be questioned. 'The prominently tricarinate form of the large pith, the generative function of the keels, the irregularity in form of the tracheides, the usually uniseriate and sometimes distant arrangement of the areoles and especially the exactly round figure of the small pores seem to me to exclude the species from Endlicher's Didoxylon while arguing for recognition as a distinct generic type.

The presence of a carinate pith in Dadoy ylon Pedroi reminds one of Scott's Dadoxylon Spenceri, (1) from the Halifax coalfield, though in the British specimen the pith is 5-keeled, while at the same time it contains mesarch primary (centripetal) wood strands.

Concerning the decomposition of these woods it is very interesting to observe that Zeiller finds the cells of the medullary rays infested with small hacterioid corpuscles, $7 \mu .8 \mu$ in diameter, which he regards as most closely allied to the Micrococus hymenophagus var. a of Renault (2).

Locality : Valley of the Jaguarão, Rio Grande do Sul. The type is in the collection of the Ecole supérieure des Mines, Paris.

Dadoxylon nummularium n. sp.

Pl. xiii, Figs. 1-4

Iracheides in fairly regular radial rows, extremely long, narrow, sinuate, acute, relatively large though varying greatly in diameter in the same section, generally squarrose, though often somewhat rounded at the angles, with a tangential diameter averaging $34 \mu$, usually greater than the radial diameter, especially in the larger cells; medullary rays very numerous, close, usually not, more than one or two tracheides distant, 1-30 cells, averaging 6 or 7 in height, mostly uniscriate, though frequently biseriate for the height of two or three cells; ray cells distinctly squarrose where uniseriate, somewhat irregular in form where biseriate, generally higher than broad, averaging $30 \mu$ in height, usually rectangular in radial section, and ordinarily

(1) Trans. R. Soc. Edinb. vol. XL. pt. 2, 1902, p. 357 pl. II, fig. 12, 13; pl. VI, figs. $24,25$.

(2) Bu'l. Soc. hist, nat. Autun, vol, vii, 1895, p. 458, Fl, foss, bassin houill, et perm. d'Autun et Ejinac, pt. 2, 1896 p. 465. fig. 145. 
de altura usualmente rectangulares nim seccäo radical e ordinaria mente satupostas a 6 tracheides; cellulas medullares estreitrmente cllipticas quando o raio tem apenas a altura de uma cellula, arestas redondas, au quasi redondas com 10 is de diametro, unuseriadas, ou raramente biseriadas en curta distancia, usualmente um pouco distantes âs veres contiguas, com póros centraes muito pequenos, redondos, ou quresi redondos.

A especie affui descripta é representada por um fragmento pequeno pardo amarellado e prismatico, que por sua josição approximadamente parallela das cunlias mostra ter sido de parte afastada do centro da arvore. A medulla e o cortex não são conhecidos. Nenhum dado possuimos, portanto referente aos caracteres da madeira primaria sem oque a determinação generica deve ficar incerta, apezar da feirão geralmente auracariana do xylem secundario. Neste como cm muitos dos outros fragmentos da collecção o tecido está aqui e alli mais ou menos decomposto pela acção de bacterias anaerobias. Ob)serram-se bacterioides nas areas de decomposição parcial.

Comtudo ha partes de madeira muito luem conservadas mesmo para definil-as por uma côr pardo escura das membranas cellulares que são flanqueadas pelo espessamen to das paredes de um amarello de ouro. Não se veem traços distinctos de anneis annuaes, nem ha evidencia de canaes de resina.

Na disposição em geral ligeiramente distante das areolas e forma dos pequenos póros Dadoxylon nummularium assemelha-se a Dadoxylon Pedroi Zeiller embora diffira pela disposição mais regular das tracheides e pelos caracteres dos raios medullares, é provavel que a descoberta do xylem primario e da medulla em nossa arvore trará á luz differenças muito mais importantes que as de que carece uma separaŗão generica dos dois typos. A madeira que tenho em mão concorda quanto á abundancia e forma dos raios medullares com Dadoxylon australo descripto por Arber (1) da serie Newcastle da Nova Galles áo Sul.

Todas as madeiras australianas descriptas, das camadas do antigo Gondwana teem anneis annuaes muito distinctos ao passo que a que foi publicada pelo Professor Arber tem areolas multiseriadas sobre tracheides muito curtas. De Dadonylon merydionale o typo que acaba de ser descripto se distingue por suas tracheides mais angulares e maiores,

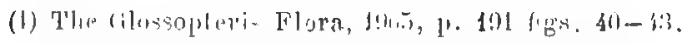


sublending about 6 tracheicles; medullary cells narrowly clliptical when the ray is but one cell in height, areoles round or rearly so, $10 \mu$ in diameter, uniseriate, or" "ar'ely bisoriate for" a short distance, usually a little distant, somettmes contiguous, with very small, round or nearly round, central pores.

The species here descrihed is represented by a small ycllowishJrowll prismatic fragment which is shown lyy the approximately parallel position of the wedges to have been a long distance from the center of the tree. The pith and cortex are unknown. Tre have, therefore, no data regarding the characters of the primary vood, without which the g'eneric identification must remain uncertain, notwithstanding the generally Araucarinian features of the secondary xylem. In this, as in most of the other fragments in the collection, the tissue is here and there more or less decomposed through the agency of anaerojic Jacteria. Bacterioids aro to be observed in the areas of partial decomposition.

Portions of the wood are, however, very well preserved, even to the definition, by a dark brown color, of the cell meminanes which are flanked by the golden-yellow wall-thickening. No distinct trace of annual rings is to be seen, nor is there evidence of resin ducts.

In the generally slightly distant arrangement of the areoles and the form of the small pores Dadorylon nummularium resembles Dadorylon Pedroi Zeill, , though differing by the more regular disposition of the tracheides as well as by the characters of the medullary rays. It is probable that the discovery of the primary rood and pith in our tree will bring to light far more important differences that may necessitate a generic separation of the two types. The wood in hand agrees as to the abundance and form of the medullary rays with Dadoxylon australe described by Arber (1) from the Nerrastle series in Nerr South Wales.

All the Australien woods described from the older Gondwana becis have very distinct annual rings, while that published by Professor Arber has multiseriate areoles on very short trancheides. From Dadorylon mericlionale the type just described is distinguished by its larger and more angular tracheides, the noticeably greater number of tho

(1) 'Tho Glusentoris I'lou'a, 19015, p. 191, fig's. 4(1)-13. 
- maior numero notavel de raios medullares que são mais commumente parcialmente biseriados e cujas cellulas são menos redondas e pelas areolas redondas usualmenle um pouco distantes muito ràramente biseriadas, com póros pequenos redondos.

Localidade - Estrada entre a casa do Sr. Brun e S. Raphael, Rio Grande do Sul. Madeira fossil em schistos vermelhos $100-200 \mathrm{me}$ tros acima das camadas de carvão. Lote 3918. O typo é BR 23.

$$
\begin{aligned}
& \text { Dadoxylon meridionale n. sp. } \\
& \text { Pl. XIV, Figs. } 1-4
\end{aligned}
$$

Laminas de xylem secundario bem regulares e de largura moderada; tracheides longas, agudas, regulares, levemente onduladas, pequenas transversalment:, de paredes um tanto espessas, poligonaes e variaveis cm serção transversal, sendo o duametro radial geral. mente cqual, ou um pouro maior que o diametro tangencial que tem cerca de 26 : ; raios medullares, numerosos, juntos, 1 - 6 tracheides distantes namesma linha transversal, estreitas 1-30 cellulas, ou mais de altura, usualmente uniseriadas, raramente biseriadas na altura de 1 - 5 rellulas, raios cellulares mais ou menos distinctamente sub-redondos, ou ovaes cm sernio tangencial e um pouco mais altos que largos tendo cerca de 25 i. de altura e em seção radial, angulares goralmente sotopnstas a 4 oll is tralleides e ligeiramente estreitas para os eretremos; aroolas estrictamente uniseriadas, relativamente grandes, distinctamente mais largas que altas, tendo cerca de $13 \mu$ de diametro transversal, usualmente contiguas às vezes um pouco agglomeradas longitudinalinente alravessadas por poros obliquos ovaes.

As secçũes representadas em parte na estampa XIV foram cortadas de um fragmento pardo de $0^{\mathrm{m}}, 06$ de comprimento, $0^{\mathrm{m}} 08$ de diametro radial e $0^{\mathrm{m}}, 05$ de diametro langencial.

Como indica o parallelismo dos raios os exemplares provieram de uma arvore provavelmente de $0^{\mathrm{m}}, 5$ de cliametro. A secção tangencial, fig. 3 é da face peripherica do fragmento. Jaltam, o cortex e a parte central do cylindro do xylem, incluindo a medulla. A referencia portanto do typo ao genero Dadorylon é snjeita a durida.

Não obstante a desintegração parcial do tecido em algumas partes das placas a conservarão em uutras é muito perfeita as membranas das cellulas estam bem distinctas. As bacterias que parecem estar repre- 
medullary rays which are more utten partially biseriate and whose cells are less rounded, and by the round, usually a little distant, areoles, very rarely biseriate, with small round pores.

Locality: Road between Mr. Brun's and S. Rafael, Rio Grande do Sul. Fossil wood in red shales 100-200 meters above coal beds. Lot. 3918 . The type is BR 23.

Dadoxylon meridionale $n$. sp.

Pl. xiv. Figs. 1-1.

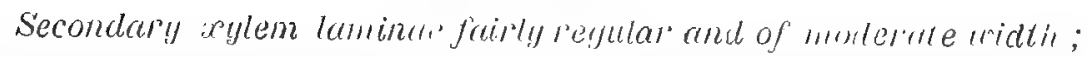
tracheides long, acute, regular, but slightly undulate, transoersely small, rather thich-ualled polygonal and variable in cross-section, the radial cliameter being generally equal to or "little greater than the tangential diameter, which averages about $26 \mu$; medullary rays, numerous, close, $1-6$ tracheides distant on the saine transoerse line, narrow, 1-30 or more cells in height, usually uniseriate, rarely biseriate for the height of $1-5$ cells; roy cells more or less distinctly subround or oval in tangential sertion and " litlle higher than toide, averaging about $25 \mathrm{~m}$ in lieight. and in radial section, angular, generally subtending 4 or 5 tracheides, and stightly nar rowed towards the ends; areoles shictly uniseriatc, rolutivel!y large, distinctly broader than high, averaging about 13 in in trinswerse diameter, usually contiguous, sometines a littes crouded longitudinally, and traversed by oblique oval pores.

The sections represented in part in Plate xiv, were cut from a brownish fragment $6 \mathrm{~cm}$. long, $8 \mathrm{~cm}$. in radial, and $5 \mathrm{~cm}$. in tangential diameter.

As indicated by the parallelism of the rays the specimens must have been derived from a tree probably as much as $50 \mathrm{~cm}$. in diameter. The tangential section, Fig. 3 , is from the peripheral side of the fragment. Both the cortex and the inner part of the xylem cylinder, including the pith, are wanting. The reference of the genus Dadoxylon is therefore subject to doubt.

Notwithstanding the partial disintegration of the tissue in portions of the slides the preservation is in othel parts very imperfect, the cell membranes being yuite distinct. The bacteria, which seem to 
sentadas por aluundanles "Juaclerioides» parece que atacaram as memJranas dás cellulas em muitos casos em que o espessamento destas é apenas um pouco colroido. Como se verá na secção transversal, fig. 1 não lia vestigios de anneis annuaes. Isto é o mais interessante e importante, pois que o liorisonte do specimen está tão perto do do carvão e as follhas fosseis a estes associadas, de modo a tornar muito provavel que as condições do clima não foram muito mudadas durante o periodo que medeiou entre o deposito do carvão e o solerramento da arvore fossil.

No material em que foram feitas as seç̧ões não pude descolı1'ir cellula alguma de resina, ou vaso que pareça secretor. Nem se vê no fragmento evidencia alguma de ramificação do tronco. A variação do diametro transversal das cellulas dos raios como se vé em uma secção tangencial fig. 3 é devida em grande parte ao Pacto que uma parte dellas é cortada perto dos extremos estreitados.

Dadoxylon meridionale se distingue das especies orientaes associadas á flora de Gangamopteris pela ausencia de anneis annuaes e pela disposição das areolas em um só alinhamento, este caracter bem como a differença nos raios medullares com suas cellulas dos raios mais arredondados, promptamente differenciam a especie de Dadoxylon nummularium em que além disto ns póros são redondos.

Localidade :- Butiá, Rio Grande do Sul. Horizonte $30-60$ metros acima do carvăo de S. Jeronymo. Lote, 3916. o typo é B R 20.

\section{Madeiras de Gymnospermos não determinadas}

Em additamento aos specimens acima, examinei outras madeiras que, ou estão muito mal conservadas para uma determinação satisfactoria, ou são identicas a especies já estudadas. Os exemplares de que se prepararam cortes proveem de sete localidades differentes.

Em todos os casos o exame das placas é difficil por causa das silicificações amorphas sem contraste de cor como as que produzem as inflltrações de oxidos de ferro ou manganez, soluções humicas, ou bituminosas, etc. $\mathrm{E}^{\prime}$ provavel que ao menos em alguns destes exemplos houve substituição da substancia que si tivesse ficado teria colorido as paredes ou conteudo das cellulas.

Os resultados da actividade bacteriana estão esplendidamente illustrados em muitas das madeiras e algumas placas mostram magniflcos bacterioides. Frequentemente spherolithos se desenvölveram no tecido parcialmente desorganisado. 
lue represented by abundant uncterioicles, appear to have allacked the cell membranes in many cases where the cell tlikckening is but little corroded. As will Je observed in the transverse section, Fig. 1, there is nutlace of annual ring's. This is the more interesting as well as important since the horizon of the specimen fulls so near that of the cols and their aswiociated fossil leares as to rendor it highly probable that the rlimalic rondilions were not greally rhanged during

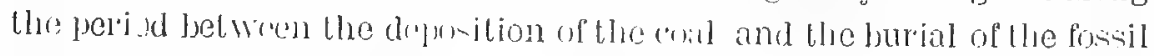
tree.

In the muterial sectionol I have nol been able to distrer any resin cells or vessels that appear to Jje secretory. Neither is there any evidence of branching of thestem to be scen on the fragment. The variation in transverse diameter of the ray cells, as shown in a tangential section, ligg. 3, is largely dus to the fact that a portion of them are cut near the rarrroweil ends.

Dadosyion merilonals: is dislinguished from the oriental species

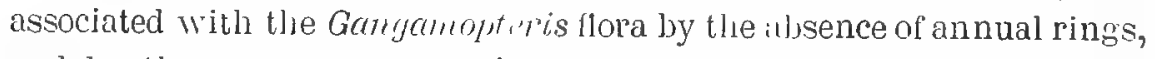
and by the ariangement of the areoles in a single row. The latter character, as well as the difference in the medullary rays with their more nearly round ray cells, readily differentiate the species from Dado sylon nummulurium, in which, moleover, the pores ale round.

Locality: : Butiá, Rio rirande du Sul. Horizon 30-60 meter's alyove the S. Jeronymo coral. Lot:3916. The t? pe is I?R 20.

\section{Undetermined Gymnospermous Woods}

In addition to the specimens described above I have examined several other. woods which are either too poorly preserved for satisfactory determination, or they are identical with other species already treated. The specimens sectioned come from seven different localities.

In every case threxamination of the slides is clifficult on arcount. of the amorphous silicification withoul contrast of color such as is afforded by infiltrations of oxides of irun $\mathrm{Ol}^{\circ}$ manganese, humic, or bituminous solutions, etc. It is probable that in some, al least, of these examples there was replacement of the cell walls or contents.

The results of bacterial activity are splendidly illustrated in many of the woods, and a few of the slides afford fine exhibitions of bacterioids. Frequently spheroliths are developed in the portially dicriganized lissue. 
Um fiagmento apanhado nos detrictos a cerca de 1 1/2 kilometro (poste kilometrico 160-161) a éste da estação de Santa Maria, no Rio Grande do Sul, (lote 3915) parece pelo exame macroscopica que tem anneis annuaes um tanto distinctos bem indicados, distantes de 2-4 $\mathrm{mm}$.

Nas secções a apparencia de anneis parece sel devido pela maior parte a manchas concentricas; e anneis annuaes si " são, são muito mal desenvolvidos, estreitos e inconspicuos.

A madcira é de um ginnospermo e provavelmente proximu de Dudoxylon meridionale D. IV. Um outro fragmento da mesma localidade consiste na maior parte em quartzo branco com spherolites. Tem raios medullares com a largura de uma cellula apenas e muito altos, concordando pela fúrma e cellulas dos raios com Dadoxylon Pedroi Zeill. A madeira ostá infectada pol' lacterioides cque em certos lngares sẽo levemente pardacentos em matri\% branca.

L'm fragmento encontrado a 100 melros acima do carvão S. Jeronymo perto de S. Jeronymo, tem raios medullares muito numerosos que parcem ter apenas a largura do uma cellula e raramente mais de 12 cellulas de altura. A parede das trachoides tem apenas um alinhamento de arcolas em que os poros parecem ser redondos.

o estado de conservação nas placas examinadas não permitte a determinação das especies, sem a"preparação de córtes addicionaes; mas a madeira è apparentemente affim da de Dadoxylon Pedroi e Daloxylon nummularizum.

Uma porção de um pecueno tronco ou l'amo do horizonte do schisto preto de Iraty de perto do Tatully, S. Paulo i interessante pelo facto que emquanto a estructura interna está quasi totalmente mascarada por chalcedonia amorpha a zona peripherica apresenta, em um grupo, ma§nifica illustração de espessamento das paredes das tracheides que apparecem em corte transversal como anneis isolados, tendo sido remoridas as membranas cellulares pela acrão bacteriana.

A presença de madeiras fosseis de coniferas e cordaiteas no Rio Grande do Sul e em S. Paulo onde se encontram associadas a Psaronius, foi notada tanto por Zeiller (1) como Renault (2) juntamente com a descripção de Lycopodiopsis Derbyi e Dadornjlon Pedroi .

(1) Bull, Suc. geolug. F., (3) 1896, vol. XXIl I, p. 619.

(D) Bull. Soc, his. nat, Autun, rol, 111, 18?n, pag. Ju, 
A fragmont gathered from the detritus about $11 / 2$ kilometers (160-161 kilo. post) east of Santa Maria Station, in Rio Grande do Sul, (lot 3915), appears macroscopically to have well marked and rather distant annual rin rss, 2-4 $\mathrm{mm}$ distant.

In the sections the ring-asicet seems for the most part to be due to concentric staining; and annual rings, if such they lic, are very poorly developed, narrow, and inconspicuous.

The wood is gymnospermic and projobly close to Dadoyylon me. ridionale D. IV. Another fragment, from the same locality, consists mostly of white qual'tz, with spherolites. It has medullary, rays but one rell in width and very high, agresing as to form and ray cells with Dado.rylum l'edron Zeill. The wood is infested with Jacterioids, which in places apo slightly Jrownish in the whilo matrix

A fragment from 110 meter's above the S. Jeronymo coal near Sũr Jeronymu, has rery numerous medullary rays which appear to be but one cell wide, and seldom over 12 cells high. The tracheid wall has but one row of areoles, in which the pores seem to je round.

The preservation in the slides examined cloes not permit of an identification of the species, without the preparation of additional sections, but the wood is apparently allied in that of Dadoxylon $P_{e}{ }^{\prime} r^{\circ} \circ i$ and Dadoxylon nummularium.

A portion of a small stem or branch from the horizon of the Iraty black shale near Tatuhy, S. Paulo, is interesting for the fact that, while the internal structure is almost totally masked by amorphous chalcedony, the peripheral zone presents, in one group, a fine illustration of tracheidal wall-thickening which appears in transverse section as isolated rings, the cell membranos having been removed as the result of bacterial worli.

The presence of conifarous and Crrlaitalean fossil woods in Rio Grande do Sul, and in São Paulo where ther are associated with Psaronius, has been noted $1 \%$ both Renault $(1)$ and Zeiller $(2)$ in connectian with the description of Lycopodiopsis Derbyi and Dadoxylon Pedroi.

(1) Bull. Soc, hist, nat. $\Lambda \mathrm{n}$ lun, Tol. I[i, p. 10!)

(2) Rull, Soc. peol. Fin, (3), vol, XXIII, p. 619. 


\section{Carpolithus (")}

Carpolithus sp.

Est. $X$ figs. 12,12 a

A collecção da Estrada Nova (estrada do rio do Rasto) perto de Minas contém uma unica semente ovoide-oval com $6 \mathrm{~mm}$ de comprimento e $4 \mathrm{~mm}$ de largura, redonda no apice e ligeiramente cordiforme na direcção de uma chalaza larga, o nucellus ć orlado por um envolucro extremamente estreito e sclerotico apparecendo como uma linha nitida.

Nenhum vestigio de aza, ou sarcotesto, ou espessamento notavel se apresenta. A superficie exposta da semente como se vê na ampliarão, fig. 12 éatravessada longitudinalmente por cerca de 13 costellas pequenas, finas e laixas um tanto distantes que quasi desapparecem antes de alcançar o apice. O specimen figurado apresenta alguma semelhanca com os das camadas Karharbari illustrados por Feistmantel, (1) em descripção, como Samaropsis .

Localidade:-Estrada Nuva perto de Minas (Lauro Muller), Santa Catharina cerca de 135 metros acima do granito, ou 1 份 metros abaixo do sihistro preto de Iraty . Lote 3923.

\section{INCERT $A$ S SEDIS}

Hastimima $\mathrm{n}, \mathrm{g}$.

Hastimimat Whetei n. sp.

Ist. X figs. 1-1; Est. XI figs. 1-10

A collecção da camada de plantas a nordeste de Minas, Santa Catharina, contem alguns fragmentos de uma lamina apparentemente sem nervação, mais ou menos densamente provida de pequenos tuberculos ovaes ou obl ngos um tanto baixos que os colleccionadores consideram como um typo de fruclificacão de feto. A lamina mesmo parece ser

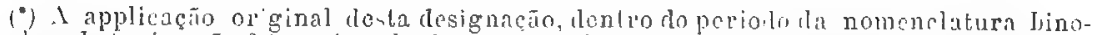

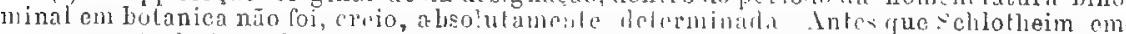

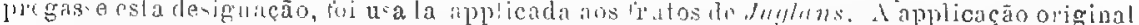

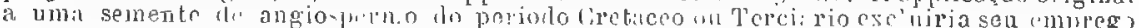

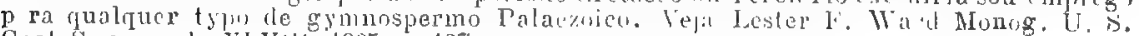
Gcol.Surs., vol. XI.VIII, 1905, p. 137.

(1) Fl. Gondwana Syst., vol. IV, 1885, p. 50, .1. XXI, fig. 2. 


\section{Carpolithus (*)}

\section{Carpolithus? sp.}

Pl. X, Figs. 12, 12 a.

The collertion from Estradi Nova (estrada do rio do Pasto) near Minas contains a single ovate-oval seed $6 \mathrm{~mm}$. in length and $4 \mathrm{~mm}$. in width; rounded at the apex, and slightly cordate to broad chalaza, the nucellus is hordered $h$ an extremely narrow sclerotic envelope appearing as a sharp line. To trace of wing or sarcotest of noticeable thickness is present. The exposed surface of the seed, as shown in the enlargement, Fig. 12, is longitudinally traversed by about 13 slender, rather distant, little low ribs that nearly vanish before reaching the apex. The specimen figured bears some resemblance to those from the Karharbari beds illustrated without description ly Feistmantel (1) as Scrmaropsis.

Locality : Estrala Nova near Minas, Santa Catharina. About 135 Ir eters above the granite, or 14: meters below the Iraty black shale. Lot 3923 .

\section{INCERT $Æ$ SEDIS}

Hastimima $n$, g . Hastimina Whitei $n$. sp.

Pl. x, Figs. 1-1; P1. xi, Figs. 1-10.

The collection from the plant bed northeast of Minas, Santa Catharina, contains a number of fragrnents of an apparently enervate lamina more or less thickly scattered with small oval or oblong rather low tubercles regarded by the collectors as a type of fern fructification. The lamina itself appears to bs supported Jy a thick

(") The original application of this nane willin the period of binominal nomenclafure in hotany has not, I believe, boen olno utoly ascertaine.l. Prior to schlotheim's employment of the s me it had licu in un for the pruits of Jugicns. The original application to on Angiospermic seed of Crelaceons or Tertiary age would debar its cm. ployment for any type of Palaeozoic gymnosperm. Sue Lester F. Ward, ILonog. U. S. icol. surv, vol, xlviii, $1905, \mathrm{p} .137$.

(1) Fl. Condwana Syst., vol. IV $188 i$, p, 5), pl, xxi, fig. 2. 
mantida por uma orla espessa e alnum tanto rigida, cujos restos fossilisados apresentam uma estructura porosa, ou vesiculo-granular sem vestigios distinctos de feixes vasculares.

Onde a lamina que é um tanto espessa, é peripherica ou livre é serreada espaçada passando a denteada arredondada grosseira no bordo, os dentes mesmo apresentam ás vezes uma estructura vesicular ou superficie escamosa granular comparavel a da orla rigida, embora em pequena escala. A hrpothcse do serem esporangios é a mais natural visto como tubar'ulos maiores da lamina são marcados perto do ex tremo menor e mais proeminentes por cavidades umbilicoides ou cicatrizes que lembram os poros de certos esporangios de letos.

Examinando os specimens estava prutco convencido que os tuberculos deveriam ser correctamente interpretados como fructificação. Ao contrario as formas cjue se veem nos fragmentos, seu grande lamanho os caracteres da orla, o aspecto coriaceo da lamina a variação $\mathrm{cm}$ tamanho e distribuição dos tuberculos e a ausencia opparente de toda nervacŭo levou-me a duvidar da natureza vegetal do organismo, não nbstante a apparencia esporangioide dos tuherculos e a symetria bilateral apaesentada por um dos fragmentos.

Os fosseis pareciam-me antes suggerir a idéa de partes da extremidade e integumento de algum animal, mais provavelmente saurio, ou batrachio.

Visto isto sulımetti specimens ou photographias do fossil a alguns dos mais eminentes especialistas em Palaeontologial dos vertebrados, mas nenhum quiz reconhecer o fossil pertencente a sua especialidade. A consulta a varios esperialistas em carcinologia, ichthyologia e palaeon. tolngia dos invertebrados deu o mesmo resultado. Aventuro-me portanto a descrevel o fossil embora duvidando grandemente da propriedade de incluil-o entrc as plantas fosseis.

o caracter muito particular que os fragmentos da orla apresentam, o bordo, a lamina cos tubarculos são tão claros e distinctos de modo a servirem completamento para o l'econhecimento pela diagnose tanto especifica como generica destes singulares restos fosseis.

Visto como nenhum dos fragmentos presentes está bastante completo para indicar mesmo syntheticamente a forma do organismo em conjuncto, ou suas proporções principaes posso apenas apresentar a outros palaeontologistas, com tantos detalhes quanto for possivel os dados de que disponho, deixando á pratica de outrem o a futuras descohertas a determinação das relações exactas das partes aqui representadas 
and somewhal rigid framewurk, the remains of which, in the fossilized condition, exhibit a porous or vesicular granulate structure without any distinct trace of rascular bundles.

Wherever the lamina, which was rather thick, is peripheral or free it is distantly serrate to coarsely round-dentate at the border, the teeth themselves often showing a vesicular structure or' scaly granular surface comparable to that of the rigid frame though on a small scile. The conception of sporangia is the more natural since the larcrer tubercles on the lamina are marked near the smallw and more prominent end ly small umbilicoid pits or scar's suggestive of the pores of certain fern sporangia.

On examining the specimens I was havdy convinced that the tubercles were to be correctly interpreted as fructifications. On the contrary the forms shown in the fragmente, their large size, the characters of the framework, the leathery aspect of the lamina, the variation in size and distribution of the tubercles and the apparent ajsence of all nervation led me to cuestion the vegetable nature of the organism, notwithstanding the sporangioid appearance of the tubercles and the bilateral symmetry shown by one of the fragments

The fossils seemed to me rathor lu suggest portions of the extromilies and integument of some animal, more probably saurian or ]ృtraclian.

Accordingly I submitted specimens or photographs of the fossil to a number of eminent American specialists in vertebrate paleontolog?, none of whom have been willing to regard the fossils as pertaing to their specialty. Consultation of various experts in carcinology, ichthyology, and invertebrate palaeontology, has led to no better result. I therefore venture to describe the fossil, though greatly doubting the plopriety of including it among los.il plants.

The rery peculiar characters shown $]$ the fragments of frame work, the border, the lamina and the tubercles are so clear and distinctive as amply to serve for the diagnostic recognition, both generically and specifically, of these singular fossil remains.

Since none of the fragments present are sufficiently complete to indicate, even synthetically, the shape of the organism as a whole, or its main proportions, I :an on]y place before other palaeontologists, with so much detail as may be practicable, the data in hand, leaving to the experience of others and to future discoveries the determination of the exact relations of the parts here reprosuted and the nature of the 
e a natureza do oryanismo, os specimens illustrando a differentes formas e detalhus variaveis serür portanto descriptos um tanto completamente.

O especimen que sic vé representado na photographia de tamanho natural na estampa $x$. fig. 3 lentis'a por sua forma uma nervura mediana espessa de um oryão folial. li' o unico specimen que apres'nta tanto symetria jyilateral como o yue pode talve' ser interpretado como uer'ura mediana. O revelso ou impressão deste specimrn sc vê na fig, $\{$. (s tujerculs dus zonas intcrmediarias, da lamina neste exemplo são um tanto distantes o de tamanho mediano. Estes, assim c mo a nervura mediana são levemente mais escuros devido a mancha de ferro mais densa da superficie yue solrre o tuberculo ė geralmente um pouco mais lisa que nos espaçus intermediarios da lamina.

Não ha praticamente residuo algum carbonaceo adherente a este ou aos outros specimens do organismo excepto um ligeiro residuo granular em algumas das impressões dos tuberculos que se reem na fig. 4́ e alguns pouco; outros fragmentos. A extremidade proximal ariedondada do tuberculo é muito proeminente e as vezes indistincta, mas a extremidade distal levanta-se algum tan to e é nitidamente definida como está illustrado em ampliação de um outro exemplo, na estampa XI. fig. 3.

A minuscula cicatriz, umbilicoide punctiforme, fig. 5 estampa XI, está collocada no apice distal do tuberculo neste expecimen e muitas vezes é apenas deprimido tendo antes leve relovo. (1)

A Inargem i espaçadamente incisa fol'lnando dentes quasi verticacs curtos e estreitos, cujos apices 'urvam-se para traz em forma de minusculos pontos concavos.

A nervura mediana é larga na base, persistente para o apice extremo e achatada, o bordo sendo indistincto em alguns pontos. Esta evidentemente espessa e immersa na espessa substancia da lamina como mostra a reproducção desta, chata em relevo transversal lenticular e especialmente onde esta está quebrada e removida, como se vê em pontos do reverso, estampa $X$, fig. 4 (2).

A lamina que apresenta tuberculos normaes se vi que se estende continuamente sobe estes. A. superficie da nervura mediana apresenta densa agglomeração de minusculas escamas, ou tuberculos escamosos um tanto irregulares, todos mais proeminentes distalmente e talvez

\footnotetext{
(1) Sinto ter '[uo explicar yun a luz $\dot{e}$, por orro, da direila em algumas photographias Rererindo-se ao texto se verá si o especimen i cin rolevo ou impressão, invertando-se a
estampa se corrigirí o orro photographico.

(2) O vardadriro aspato da implessa se tera invertendo a figura.
} 
organism. Accordingly the specimens illustrating the differente forms and varying details will be described somewhat fully.

The specimen photographically shown in natural size in $\mathrm{Pl} . \mathrm{x}$, Fig. 3, suggests by its form, and thick midrib a foliar organ. It is the only specimen exhibiting either lilateral symmetry, or the presence of what may possibly he interpreted as a median nerve. The counterpart $\mathrm{Ol}^{\circ}$ impression of this specimen is shown in Fig. \&. The tubercles on the intermediate zones of the lamina in this example are rather distant and of medium size. They, like the midrib, are slightly darker on arcount of the denser brown iron stain on the surface, which, on the tubercle, is generally a littlo smonther than on the intervening lamina.

There is prartically" no carbonaceous l'esidue adhering to this or the nther specimens of the nrganism, except a slight granular residne in some of the tubricular impressions shown in Fig. ', and a few other fragments. The rounded proximal end of the tubercle is very little prominent and often indjstinct, but the distal ond rises somewhat and is sharply defined, as illustrated, enlarged from another example, in Pl. xi, Fig. 3 .

The minute, punctiform, umbilicoid scar, Fig. 5, Pl. xi, is placed at the distal apex of the tubercle in this specimen and it often is scarcely depressed, being rather in slight relief (1).

The margim is distantly cut in nearly vertical short narrow teeth the apices of which turn backivard as minute concave points.

The midrib is broad, at the Jase, persistent to the extreme apex, and flattened, the $]$ nrder being indistinct in portions. It is evidently thick and immersed in the thick sulustance of the lamina as is shown hy the flattened cast in lenticular cross section, and especially where the cast is broken away, as illustrated in portions of the counterpart, Pl. x, Fig. 4. (2).

The lamina, bearing normal tuhercles, is seen to extend continuously baneath it. The surfine of the midrib is densely crowded with minute and scmewhat irregular low scales or sculy tubercles, all more prominent distally, and possibly a very little jmbricated.

(1I I r net to hare to pxplain that tha light is, Iy err r. from the right in some (f the pho!nmriphs. Reluence to the trat will show whether the specimen is in reliof or depressed; ant invession of the plate will then correct the phatographical error.

(2) The t: ue aspect of the imeresion will bo luesent if the figure is inverted. 5560 
muito ponco imbriados. Seus caractercs são essencialmente os da cosLella marginal que se vê na estampa X fig. 1 embora menores, os tujerculos da nervura mediana fig. 3 são tão curtos e pequenos que lhes dá uma apparencia granulosa. A presença de tuberculos de tamanho e arranjo normal na lamina sobrepostos ao eixo achatado, que se veem na base da figura indica a continuidade do integumento esporangiado atravez (la nervura mediana, de um modo difficilmente crmrativel rom uma ner'ura mediana filicoide(1).

O specimen, fig. : i levemente concarn com luberculos em relevo, ao passo que o reverso ligciramente convexo, fig. h. mostra os tuberculos como si fossem impressũes denteadas na matri\%. Lstou disposto a considerar este como impressão da superficie ventral do orgão ou membrı. Da symetria hilateral deste specimen devemos concluir (que é provavelmente um fragmento mediano.

o orignal da fig. 2 estampa X com seu reverso, fig. 1 í talrez o mais interessante specimen da collecrão. Representa a porção distal de um membro claramente asymetrico em um lado do qual ha uma orla marginal espessa graciosamente curva, spiniforme. Nin reverso, fig. 1 os grandes tuberculns e costella $(2)$; aprosentam como forte impressão, sendo aquelles cỉaros e distinctos, ao passo que esta quasi meio redonda na impressão é marcada por pequenos tulserculos escamosos agglomerados, comparaveis aos da nervura mediana do original da fig. 3 .

Os tuberculos da fig. 2 vê-se que são menores perto da costella lateral e na porção longe do bordo são tambem juntos.

o bordo da lamina á direita, é marcado por uma zona estreita de escamas curtas agglomeradas e um tanto imbricadas, ou tuberculos que se projectam ligeiramente e produzem um perfil denticulado como se vê ampliado photographicamente na fig. 9, estampa XI. Tuberculos escamosos embora muito menores apparecem perto da nervura mediana os que estão mais proximo desta estão agglomerados e dispostos irregularmente. Afastada da nervura mediana e antes de alcançar os grandes tuberculos a superficie é granulosa como a que se vè augmentada quatro vezes na parte inferior da estampa XI fig 3.

o positivo ou lado em relevo deste specimen que se vê na fig. 1 differe do outro principalmento pelo aspecto da costella lateral de es-

(1) Compule as porẹues infciiores clas figuras 30 t, estampa $\mathrm{X}$.

(2) Fallando de partes da orla on escueleto das partes representadas, os terno: «cos. tellin e "nerviara m. di ina" săo em! regados antes pror conreni"ncia quo como estricta o delinitivamentis appleinvoi: 
Ils character's al'e essentially those ol thé border rib slıown in $11 . x$. Fig. 1, though smaller, the tubercles on the midrill, Fig. 3, heing so short and small as to impart a granulose appearance. The presence of tubercles in normal size and arrangement on the lamina overlying the flattened axis, seen at the base of this figure, indicates a continuity of the sporangiate integument, across the midril, in a way hardly compatible with a fitlcoid median nesve. (1).

The specimen, Fig. 3, is slighth concave with tubercles in relief, while the slightly convex counterpart, Fis. 4, shows the tubrrcles as indented impressions in the matrix. I am disposed to regard the latter as the impression of the ventral surface of the organ or member. From the bilateral symmetry of this specimen we may conclude that it is probably a medial fragment.

The original of Fig. 2, Pl. $\mathrm{x}$, with its reverse, I'ig. 1, is perhaps the most interesting specimen in the collection. It represents the distal portion of a conspicuousiy asymmetrleal mem]jer', at one side of which lies a thick, gently curved, spine-like marginal rib. In the counterpart, Fig. 1, the large tubercles and rib (2) are seen in strong impression, the former boing clear and distinct, while the latter, nearly half round in the impression, is marked Jy small crowded scale-tubercles comparable to those on the midrib of the original of I is 3.

The tubercles in lig. 2, ate seen to be smaller near the lateral rib, and in the portion farther from the border they are also close.

The border of the lamina, on the right, is marked by a narrow zone of short, crowded and somewhat imbricated scales or slightly projecting tubercles which give a denticulate profile, as is seen, photographically enlarged, in Fig. 9, Plate xi. Similar though much smaller scalelike tubercles appear near the midrib, those nearest the latter being crowded and irregularly arranged. Farther out from the midril, and before reacling the large Iubercler, the surface is manuloce

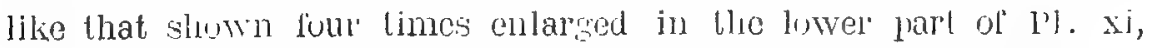
Fig. 3 .

The positive, or reliel, side of the specimen shown in Fir. 1 differ's from the other chiefiy in exhibiting a rather coarse, scaly, vesicular.

(1) Compare the lower parts of ligures 3 and 4 , Plate $x$.

(2) In speaking of the purtions of the frams or skeleton of th purts represented, the terns rijs and midrid are used for convenicnce ralber than as strictly and clutino tely applicable. 
tructura um tanto gr'usseira, escamosa e vesicular. As impressies escamosas augmentadas na fig. 1 a, são produzidas por tuherculos aggiomerados e variando em tamanho, mas providos ao menos em parte, de cicatrizes punctiformes umbilicoides como os dos grandes tuberculos da lamina.

Neste specimen, fig. 1 porçũes do fossil descamadas na rerião perto da nervura mediana, mustrain embaixo de uma leve camada da matriz, a impressão da superficie opposta ou cuticula do membro. Nesta superficie opjosta cque se rê como uma impressão abaixo do meio da fig. 1 a, os tuberculos são muito diminutos e não muito distantes. Uma krr,ão da superticic de grandes tuberculos se vê na parte superior do mesmo augmento photographico. Como no outro fragmento fig. 3 o lado com tuberculos em relero c leremente concavo. Parece que nada mais ha que enchimento da matriz de argilla entre a superficie do fossil, convexa ou de tuberculos finose a concura ou de tuberculos grosseiros. Portanto devemos concluir que a abertura representa, ou um delgado orgão ou appndice em que as laminas superior e inferior, ou cuticulas (integumentos?) não estavam muito afastados, ou um corpo carnoso de que os tecidos molles apodreceram.

o pequen', fragmento que se vî quatro vezes augmentado na es. tampa XI, fig. 3 representa a impressão de uma porção da lamina, em que passando para um lado os grandes tuberculos desapparecem ao passo que, ao mesmo tempo a lamina torna-se distinctamente granulosa escamosa, ou finamente escamosa tuberculada como a que se vê em partes do mijecimen já escripto.

Os grandes luberculos deste exemplu musblam distinclamente a diminuta vicatriz umbilicoide nos apices proeminentes.

o exemplo de que se rế uma parte de tamanho natural na estampa XI, fig. 1 contem um fragmento irregular da cuticula do typo que se vê no lado convexo ou priterior do ruiginal da lig. I estampa X como acima foi desclijun. Pur conveniencia quando me referir a esto integumentó ou cuticula que apresenta os tuborculos um tanto contimuos e muito pequenus, designal-a-ci por cuticula "conrexas e a cuticula com os tuberculos grandes da outra superficie do orgão ou membro, cuticula «concava». Qual destas é dorsal ou rentral ainda não está determinado.

Os caracteres da cuticula convexa se veem augmentados quatro vezes, de um outro especimen na estampa xI fig. 4, os tubarculos contrastam notavelmente em tamanho como se púde ver pela comparação da fig. 4́ com a fĭg. 3 ambas augmentadas egualmente. No 
like structure of the lateral rib. The scale impressions, enlarged in Fig. 1a, are produced by tubercles crowded and varying in size, but provided, in part at least, with punctiform umbilicoid scars like those on the large laminar tubercles.

In this specimen, Fig. 1, portions of the fossil are-caled off in the region near the midrib, revealing beneath a thin laver of matrixfilling, the impression of the opposite suriace or cuticle of the member. On this opposite surface, seen as an implession, lower middle of Fig. 1a, the tubercles are vel'y minute and not very distant. A portion of the large-tubercular surface is scen in the upper part of the same photographic enlargement. As in tho other flasment, I'ig. 3, the side with tubercles in reliel is slishty concave. Thel's appears to tic nothing but clay matrix-filling between the convex or finely tubercular and concave or coarsely tubercular surfaces of the fossil. Hence we may infer that the opening lepresents eiter a thin organ or appendage in which the upper and lower lamince or cuticles (integuments?) were not far appart, or a fleshy hody in which the soft tissue decayed.

The small fragment shown four times enlarged, in Plate $x i$, Fig. 3, presents the impresion of a portion of the lamina on which, in passing to one side, the large tuberclos disappear while at the same time the lamina hecomes distinctly sranulose-scaly ol finely-tuberculate like that seen in portions of the specimens already desclibed.

The large tubercles in this example distinctly show the minute umbilicoid scar at the prominent apices.

The example, a part of which is shown, natural size, in Pl. xi, Fig. 1; contains an irregular fragment of the cuticle of the type seen on the coluvex or back sids of the original of Fig. 1, Plate $\mathrm{x}$, as described above. For convenience I vill speak of this integument or cuticle, which Jears the rery" small and rather close tubercles, as the "convex" cuticle, the cuticle with the large tubercles, on the other surface of the organ or member, being called the "concave" cuticle. Which of these is dorsal or ventral is undetermined.

The features of the convex cuticle are shown, enlarged four times, from another specimen, in Pl. xi, Fjg. 4. The tubercles contrast remarkably in size as may be olserved by comparing Fig. \& with Fig. 3, both equally enlarged. In the original of Fig. 1, they are 
original da fig. 1 são quasi mais chatos e muitas vezes propolciunalmente mai largos e as cicatrizes punctiformes estão frequentemente perto do centro da elevação em vez de estar perto do apice proemincnte, como em muitos dos tuberculos tanto grandes como pequenos.

A porção de cuticula incluida na fig. 4 que vem de sel descripta c apenas uma parte de um fragmento, um tanto indefinidamente oblongo que alcanca o ljordy da lamina somenle em um extremo. Quando proximos do bordo os tuberculos augmentam rapidamente de tamanho e numero de modo a dar uma apparencia escamosa.

A esta zona estreita de tuberculos escamiformes que corresponde cxactamente á que fica proximo do bordo livre no original da estampa X, fig. 1., succede um alinhamento de grandes escamas tuberculadas, ou dentes marginaes, estampa XI, fig. 10 de cerca de $2 \mathrm{~mm}$ de comprimento, um pouco mais de largura redondo-obtusos no apice e separados por depressões arredondadas. Estas escamas são exactamente semelliantes ás que se veem no pequeno fiagmento á direita da fig. 3 , estampa $\mathrm{X}$.

Um outro fragmento com escamas marginaes pouco menores e mais estreitamente redondas se vê augmentado quatro vezes na es-1 tampa XI fig. 7. A superficie cuticular granulosa estendendo-se mesmo até as bases das escamas ć identica á que se vê em par'te da fig. 3 que é tambem augmentada. Onde esta cuticula está removida de parte de dous dentes, á direita, se vê a impressão finamente tuberculosa do lado opposto do fossil.

Esta feição que se vê ainda melhor na fiğ. 8, tambem augmentada, parece indicar que os tuberculos menores se estendem ao lóbo, ou dente tuberculoso daquelle lado da lamina. O fragmento que se vê augmentado quatro vezes, na fig 6 , apresenta usualmente grandes dentes escamiformes marginaes de que dous parecem estar em processo de fissura no apice. Póde ser de interesse notar que estes dentes estam no bordo de uma area de cuticula "convexa" granular ou de pecuenos tuberculos, a uma parte da qual a cuticula "concara» ou de grandes tuberculos se superpoem.

Um enchimento de matriz de quasi $1,5 \mathrm{~mm}$ de espessura separa as duas cuticulas. Que ambas as cuticulas pertencem ao mesmo individuo é indicado pelo parallelismo e orientação dos grandes tuberculos e as escamas.

Um dos mais interessantes especimens da serie é o que se vê em tamanho natural na estampa XI fig. 2 e em parte ampliado photographicamente na fig. 2 a. 
more nearly flat, and often froportionally Jroader, and the punctiform scar's are frequently near the middle of the elevation instead of near the prominent apex as in most of the tubercles both large and small.

The portion of cuticle included in Fig. 3, just described, is but a part of a rather lax oblong fragment that reaches the border of the lamina at one end only. When near the border the tubercles rapidly increase in size and number so as to wive a scaly appearance.

'This narrow zone of scale-like tubercles, which corresponds exactl? to that next to the free border in the original of Pl x, Fig. 1, is immediately succeeded by a row of large tuhcrculate scales or marginal teeth, Pl. xi, Fig. 10, about $2 \mathrm{~mm}$ in lenght, a little more in with, round obtuse at the apex and separated by rounded sinuses. These scales are exactly like those shown on the small fragment to the right in Fig. 3, Pl. x

Another fragment with slightly smaller and more narrowly rounded marginal scales is seen four times cnlarged in Pl, xi, Fig. 7. The granulose cuticular surface extending even to the bases of the scales is identical with that shown in a portion of Fig. 3, which is equally enlarged. Where this cuticle is remored from portions of two of the teeth on the right, the finely tubercular impression of the opposite side of the fossil is seen.

This feature, still better shown in Fig. 8, equally enlarged, seems to indicate an extension of the smaller tubercles out on the lobe or tooth-tubercle on that side of the lamina. The fragment scen four times enlarged in Fig. 6, exhibits unusually large marginal tooth scales two of which appear to be in the process of fission at the apex. It may be of interest to note that these teeth are at the border of an area of granular and small-tuberculate or « convex" cuticle, a pontion of which is overlain hy a fragment of the "convex" or largeberculate cuticle.

A flling of matrix (cast) nearly $1.5 \mathrm{~mm}$ in thickness separates the two cuticles. That both cuticles Jelong to the same individual is indicated by the parallel position and the oricntation of the large tubercles and the scales.

One of the most interesting specimens in the series is that shown in natural size, Pl, xi, Fig. 2, and in part photographically enlarged in $\mathrm{Fi}_{\mathrm{m}} 2 \mathrm{a}$. 
Temos uma parte de um membro dividido em quatro lobulos ou espinhos. O maior e mais longo destes, á esquerda, tem tuberculos estreitos e alongados variando de tamanho e agglomerados de modo a formar malha. Esta estructura incluindo as cicatrizes uml,ilicoides perto da extremidade distal dos tuberculos é precisamente a que se vê na costella marginal do original da fig. 1, na estampa X e ampliado na fig. 1 a, é a impressãn do dorso ou face (concava) de grandes tuberculos, do fossil. Nos tres lobulos mais curtos a superficie, proxima (convexa) se rê fortemente convexa em cada lobulo.

Neste lado temos como se vô em leproducçã photographica ampliada quatro vezes na fig. 2 a, tuberculos agglomerados, largos, irregulares, variando de tamanho e muitas vezes interpostos.

As cicatrizes umbilicadas cĩo grandes e claras perto das extremidades distaes dos tubarculos. A interferencia dos tuberculos e sua freçuente deformaçiin lembram iima ligeira imbricação. Esta ideia é sustentada pelo perfil do grande espinho á esqu rda, em que os pontos distaes prozminentes projectam -se ligeiramente para fóra e para cima, exactamente com a fórma que se vê na sorreacão muito pequena do bordo do original da fig. 1 , estempa $x$.

Deve-se fazer menção do facto que os tres lobulos conatos da direita da fig. 2, estampa XI se veem cruno a superficie superior do enchimento o material do enchimento tendo rerca de $2 \mathrm{~mm}$. de espessura no ponto mais alto dasuperficie convexa. Sobre esta superficie convexa os tuberculos agglomerados de cue fallei acima, não estam em relevo, mas são marcados por linhas de contorno estreitas do salientes, as cicatrizes umbilicoides estam tambem no mesmo relevo.

o lado dorsal do fossil que se vê na parte inferior do especimen, onde o enchimento foi yuebrado e removido, mostra a impressão da cuticula opposta (concava) com o typo grande de tuberculos um tanto distantes; e a cuticula no lado opposto do fossil apresenta o typo grande de tuberculos cm relevo. Liste lado inferior, ou quasi chato no especimen que tenho em mão, corresponde exactamenteá superficie concava com grandes tuberculos dos olgins nu membros que se reem nas figs. 1 e 3 da estampa $x$, ao passo que a superficie superior, ou convexa que se rô nos lobulos curtos corresponde á conrexa, a superficie com tuberculos pequenos que se vicm farlo na fig. 1 a, da cstampa $x$ e figs. 1 e f́ da estampa x1.

Os curacteres dus especimen descriptos acima concordam tăn completamente, as feicriez muito variadas que apresentam fragmentos em uniüo nrganica, que é impossivel duvidar que todos pertençam ao 
We have here a portion of a member divided into four unequal lobes or spines. The larger and longer of these, on the left, has narrow elongated tubercles varying in size and crowded so as to form a mesh. This structure, including the umbilicoid scars near the distal ends of the tubercles, is precisely that seen in the marginal rib of the original of Fig. L, on Plate $\mathrm{x}$, and shown enlarged in Fig. 1a. It is the impression of the back or large-tuberculatc (concave) side of the fossil. In the three shorter lobes the near (convex) surface is seen, strongly convex in each lobe.

On this side, we have, as photographically shown four times enlarged in Fig. 2 a, broad irregular crowded tujsercles varying in size and often interfering.

The umbilicate scars are large and clear, near the distal ends of the tubercles. The interference of the tubercles and their frequent deformation suggest a slight imbrication. This suggestion is supported by the profile of the large spine on the left in which the distal prominent points project slightly outward and upward, in exactly the form seen in the very small serration at the border of the original of Fig. 1, Platex.

Mention must be made of the fact that the three connate lobes on the right in Fig. 2, Pl. xi, are seen as the upper surfaces of casts, the cast material being nearly $2 \mathrm{~mm}$ thick at the highest points of the convex surface. On this convex surface the crowded tubercles, noted above, are not in relief; but they are marked by narrow raised boundary lines, the umbilicoid scars also being in the same relief.

The back side of the fossil, shown in the lower part of the specimen, where the cast has been broken away, exhibits the impression of the opposite (concave) cuticle with the large type of rather distant tubercles; i. e, the cuticle on the opposite side of the fossil bore the large type of tubercle in relief. This under or nearly flat side in the specimen in hand corresponds exactly to the concave surface with large tubercles in the organs or members shown in Figs. 3 and 1, on Plate $x$, while the upper or convex surface, seen in the short lobes corresponds to the convex, small-tuberculate, surface seen in part on Fig. $1 \mathrm{a}$, of Plate $\mathrm{x}$, and Figs. 1, and 4. of Plate xi.

The characters in the specimens described above are in such complete agreement, the highly varied features being presented by fragments in organic union, that it is impossible to doubt that all pertain 
mesmo typo de organismo. E' provavel tambem que sejam todos de uma unica especie. Quanto á natureza deste organismo, posso apenas dizer de novo que estou muito inclinado a consideral-o como não sendo vegetal. Nenhum typo de planta conheço que apresente nma combinação analoga de caracteres tão anomalos de forma e textura.

E' possivel que o genero Hastimima se refira a supposta planta fossil da serie do Gondwana inferior que Feistmantel (1) figurou sem descripção como Dictyopteridium sporiferum. Os fosseis indianos conteem formas estreitas oblongas, ou lanceoladas, quasi chatas apparentemente symetricas, arqueadas no bordo e que se expandem em proeminencias ovaes, ou ellipticas, approximadas estas teem menos que $1 \mathrm{~mm}$ de comprimento, todas quasi de egual tamanho em disposição arcoradial e são providas de cavidades punctiformes umbilicadas. O professor Zeiller que descreveu (2) o fossil não sómente duvida da presença da nervação em fórma de rede desenhada por Feistmantel, como tambem acha impossivel interpretar os tuberculos como sendo esporangios. estando ao contrario disposto a considerar os especimens indianos comn raizes, ou rhizomas carnosos providos de orgãos appendiculares caducos mais ou menos comparaveis aos de Stigmaria os vestigios umbilicoides punctiformes correspondendo segundo seu modo de pensar, ao vestigio de nervura da cicatriz de Stigmaria. A semelhança entre Dictyopteridium o o typo do Brazil está sómente na ausencia de nervação e na presença de tuberculos ellipticas providos de minusculos vestigios umbilicoides. De outro modo a variação em tamanho e arranjo dos tuberculos, a asymetria accentuada a presença de uma orla esquelitica espessa, os caractéres especialisados dos bordos, a presença de integumentos superior e inferior differindo pelos caractéres e o desenvolvimento de grandes appendices alados, ou digitados, ou orgãos no typo brasileiro não permittem que se considere este como congenere do typo indiano, comtudo suspeito que os dois são affins.

Si Hastimima é vegetal parece que os tuberculos deveriam ser considerados como esporangios, ou esporangiferos, como mamelões dando origem a algum appendice, ou glandula. Não encontro vestigios de esporangios, ou outros appendices que pareçam ter estado ligados aos tuberculos, ao passo que a variação destes em tamanho e sua modificação ao approximarem-se dos bordos impedem de explical-os como glandulas.

(1) Fl. Gondwana siyst. vol. IlI pt. 2, 1881 pp. 7, 14 e 34: pl. XXIIIA, figs. 4-6, 14 ; vol. IV pt. 2, 1886, p. 34, pl. VA, fir. 3 .

(2) Pal. Indiod, 4. s. vol. It, 1902, 1. 24, pl. IV, HE. B. 
to the same type of organism. It is probable also that they concern but a single species. As to the nature of this organism I can only say again that I am strongly inclined to regard it as not vegetable. I know of no plant type presenting an analogous combination of such anomalous features in form and texture.

It is possible that the genus Hastimima is related to the supposed fossil plant from the lower Gondwana series, figured without description by Feistmanjel (1) as Dictyoptertdium sporiferum. The Indian fossils include narrow oblong or lanceolate forms, nearly flat apparently symmetrical, arched at the border and closely spread with oval or elliptical prominences. The latter are less than $1 \mathrm{~mm}$ in length, alI nearly equal in size, in arched-radial arrangement, and are provided with punctiform umbilicate pits. Professor Zeiller who has described (2) the fossil not only questions the presence of the netted nervation drawn by Feistmantel, but also finds it impossible to interpret the tubercles as sporangia. He is, on the contrary, disposed to regard the Indian specimens as roots or fleshy rhizomes provided with caducous appendicular organs more or less comparable to those of Stigmaria, the punctiform umbilicate trace corresponding in his judgment to the nervetrace in the Stigmarian scar. The similarity between Dictyopteridium and the type from Brazil lies only in the absence of nervation and the presence of salient elliptical tubercles provided with minute umbilicoid traces. On the other hand the variation in size and arrangement of the tubercles, the marked asymmetry, the presence of a thickened skeletal framework, the specialized characters of the borders the presence of both a lower and an upper integument differing in character and the development of large alate or digitate appendages or organs in the Brazilian type do not permit the latter to be regarded as congeneric with the Indian type. However, the two are, I suspect, related.

If Hastimiua is vegetable it would seem that the tubercles should be interpreted as sporangia or sporangiferous, as cushions giving rise to some appendages, or as glands. I find no traces of sporangia, or other appendages that would appear to have been attached to the tubercles, while the variation in size of the latter and their modification on approaching the border preclude explaining them as glands.

\footnotetext{
(1) Fl. Gondwana Syst., vol. III, pt. 2, 1881, pp. 7, 14, 34; pl. xxiiiA, figs, 4-6, 14 : vol. iv, pt. 2,1886, p. 34, pl. v $\Lambda$ fig. 3 .

() Pal. Indica, n. s., vol, II, 19n2, p. 24, pl. iv, fig. 8.
} 
Nenhuma nervação, nenhum traço de feixes nas costellas, nenhuma folha adherente ha, para fornecer a prova de sua origem vegetal. Esta evidencia negativa combina-se com as anomalias de fórma e estructura dos fragmentos para me animarem a pensar que o typo deve ser animal e se assim é, presumivelmente vertebrado, ou crustaceo. Deve-se ainda dizer que nem a ramada de plantas de que proveem os fosseis, nem nenhuma outra proxima do mesmo horizonte, contem, tanto quanto sei, fragmento algurn de osso, escama, ou dente. A explicação destes fosseis problematicos é uma interessante tarefa que espera os que se dedicam ao estudo da palaeontologia do Brasil e os colleccionadores.

A especie acima descripta denominei em honra do chefe da Commissão de Estudos do Carvão Brasileiro, Dr. I. C. White, que em additamento a seus longos e muito valiosos serviços nos estudos estratigraphicos do problema que se refere ao carvão, petroleo e gaz, tomou parte importante no augmento de nossos conhecimentos da Flora Permiana da America do Norte.

Localidade: Nordeste de Minas - Santa Catharina. Cerca de 55 metros acima do granito, ou 225 metros abaixo do schisto preto de Iraty. Lot. 3586. 
No nervation, no traces of bundles in the ribs, no adhering leaves are here to furnish evidence of their vegetable origin. This negative evidence combines with the anomalies in form and structure of the fragments to influence, me in thinking the type may be animal, and if so, presumably either vertebrate or crustacean. Yet it must be said that neither the plant bed from which the fossils come nor any other near horizon has, so far as I am aware, yielded a fragment of bone, scale, or tooth. The explanation of these problematic fossils is an interesting task awaiting the hands of Brazilian palaeontological students and collectors.

The species descrihed above is named in honor of the chief of the Coal Commission, Dr. I. C. White, who, in addition to his long and most valuable services in the stratigraphical study of the problems relating to coal, oil, and gas, has himself taken am important part in increasing our knowvledge of the North American Permian flora.

Locality: Northeast of Minas, Santa Catharina About 55 meters above the granite, or 225 meters below the Iraty black shale. Lot 3586 . 


\title{
EXPLICAÇÃO DAS ESTAMPAS
}

\author{
ESTAMPA V
}

Fig. 1 - Rosellinites gangamopterides n. sp. Fragmento de folla de Gangamopteris obovata infestado pelo fungus.

1 a - Porção da colonia ampliada quatro vezes para mostrar as perithecias. Perithecia com ostiolo em « $X 》$.

$1 \mathrm{~b}$ - Perithecias isoladas de um outro specimen ampliadas quatro diametros.

Fig. 2-Hyterites brasitiensis n. sp. Porção do folha do Noeggerathiopsis Hislopi em que ha espalhadas perithecias alongadas com bordos distinctos. Tamanho natural.

Figs. 3 e 5-Phyllotheca sp.

3 - Porção basaI da haste de que um ramo com base conica calamitoide, nasce na parte superior do lado direito. A haste affim tambem é contrahida em base conica que a photographia não mostra, embora os interaós de extremos curtos estejam indicados.

4 - Base conica de uma outra haste (molde). O aspecto do fossil é exactamente o de muitas fórmas Equisetaccas do Permo Carboniforo e Triassico.

5 - Esqueleto vascular de uma haste com segmentos mais longos; um no no tope $\theta$ um outro $2 / 3$ para baixo em que algumas das costellas alternam.

Fig. 6 - Schisoneura sp.

Fragmento de haste flna incluindo varios nós.

Fig. 7 - Equisetites calamitinoides n. sp.

Porȩão do cortex, parcialmente lascado, com a bainha adherente no tope. Um outro nó está obscuramente indicado a meia distancia paralbaixo do superior.

7 a - Dente augmentado para mostrar a forte nervura mediana e a lamina estreita partida quasi na base.

Fig. 8-Phylloteca Muelleriona n. sp.

Fragmento de rocha com verticilos destacados egualmente orientados e provavelmente de uma unica planta.

Figs. 9 e 10 - Phyllotheca Griesbachi, Zeill.

Fig. 11 - Lycopodiopsis Derbyi, Ren.

Fragmento de pequena naste parcialmente achatada.

11 a - Mamelão e vestigio de folha aquelle assemelhando-se a Sigmaria.

Fig. 12 - Sigillaria Brordii, Brong.

l'́ a - Cicatriz da folha, augmontada dous diametros.

Fig. 13 - Sigillario sp.

Porção da folha provavelmente pertencendo a sigillaria.

13 a - Fragmonto augmentado para mostrar a nervura modiana e sulcos stomatiferos. 


\section{PLATE V}

Fig. 1. Rosellinites gangamopterides n. sp. Fragment of leaf of Gangamopteris obovata infested with the fungus.

1 a. Portion of colony enlal'ged four times to show the perithecia. Perithecium with ostiolum at $\ll x »$.

1 b. Isolated perithecia, from another specimen. Enlarged four diameters.

Fig. 2. Hysterites brasiliensis n. sp. Portion of loaf of Noeggerathiopsis $\#$ islopi, on which are scattered the elongated peritheeia with distinct borders. Natural size.

Figs. 3-5. Phyllotheca sp.

3. Basal portion of stem from which a branch, with conical Calamitoid base, originates on the upper right. The parent stem also is contracted to a conical base, not well shown in the photograph, though the shortened internodes are indicated.

4. Conical base of another stem (cast). The aspect ol the fossil is exactly that of many of the Equisetalean forms of the Pormo-Carboniforous and Triassic.

5. Vascular skeleton of a stem with longer segments; a node at the top, and another, two-thirds of the way down, at which some of the ribs alternate.

Fig. 6. Schizoneura? sp.

Fragment of slender branch including several nodes.

Fig. 7. Equisetites calamitinoides $\mathrm{n}$. sp.

Portion of cortex, partially split, with adhering sheath at top. Another node is obscurely indicated half way below the upper one.

7 a. Tooth onlarged to show the strong midrib and the narrow lamina parted nearly to the base.

Fig. 8. Phyllotheca Muelleriana n. sp.

Kock fragment with detached verticils similarly oriented and probably from a single plant.

Figs. 9, 10. Phyllotheca Griesbachi Zeill.

Fig. 11. Lycopodiopsis Derbyi Ren.

Fragment" of small stem partially flattened.

11 a. Cushion and leaf trace, the former resembling Stigmaria.

Fig. 12. Sigillaria Brardii Brongn.

12 a. Leaf scar , enlarged two diameters.

Fig. 13. Sigillaria sp.

Portion of leaf, probably belonging to Sigillaria.

13 a. Fragment enlarged to show midrib and stomatiferous grooves. 
ESTAMPA VI

Fig. 1- Sphenopteris hastata, Mc. Coy?

Fig. 2- sphenopleris sp.

Figs. 3, 4 e 6 -Glossopteris Browniana, Brong.

3 e 4 - Fragmentos apicaes em gres.

6 - Fragmento de folha com nervação neuropteroide.

Figs. 5. 7 e $8-$ (?) Glossopteris indica (Brong). Schimp.

5 e 7 - Fragmentos de bases curvadas, de folhas.

8 - Forma muito estreita com nervuras obliquas, é possivel que representem outra especie.

Fis. 9 - Glossopteris ampla, Dana.

Fig. 10 - Sigillaria sp.

Rocha parda carbonosa composta de camadas de megasporos acamados, provavelmente de Sigillaria.

10 a - Porção da mesma rocha augmentada quatro diametros para mostrar os megasporos individuaes que estão representados pelos exosporos unidos. A abertura tri-radiada se vê em alguns dos esporos.

Fig. 11 - Sigillaria australis n. sp.

Fragmento de cortex em que se veem as cicatrizes foliaes, embora os mamelões foliaes estejam muito obscuramente definidos.

11 a - Cicatriz folial augmentada, com parte de seu mamelão folial. Da direita do specimen.

11 b - Ampliação semelhante de uma cicatriz com cicatriculas mais proeminentes.

11 c e Il d-Cicatrizes em que se vê o augmento sub-cutaneo do parichnos, marcado.

ESTAMPA VII

Figs. 1 \& 4 -Glossopteris occidentalis $\mathrm{n}$. sp.

1 - Apice da folha. A nervação fina parallela so vê que está quasi em angulo recto com o bordo.

2 - Base sessil e cordiforme mostrando a nervura mediana muito larga e chata e a nervação como na fig. 1 .

3 - Fragmento do meio da folha mostrando a nervura mediana muito larga $e$ a nervação em malhas grosseiras perto da nervura mediana fina parallela se anastomosando depois de virarem-se para fóra passando para o bordo.

A obliquidade das nervuras devido á contracção ao longo da nervura mediana gasta, è o que se vê muito no especimen.

4. Fragmento com nervação typica.

4 a. Porção da mesma augmentada quatro diametros para mostrar as nervuras que formam malhas alongadas perto da nervura mediana larga e parallelas muito juntas e raramente se anastomosando perto do bordo.

Figs. 5-6. Glossopteris sp.

Folha escamiforme peciolada concavo-convexa carbonosa e espessa. 
T1ATL YI

Fig. 1. Sphenopteris hastula Mc Coy?

Fìg. 2. Sphenopteris sp.

Figs, 3, 4, 1. Glossopleris brouniona Blongu.

3, 4. Apical fragments in sandstone.

(i. Fragment of leaf with Neuropteroid nervation.

Figs. 5, 7, 8 (?). Glossopteris indica (Brongn.) Schimp.

5, 7. Fragments frou cuneate bases of leaves.

$\therefore$ Very narrow form with oblique nerves, possibly representing another species.

Fig. 9. Cilossoxloris mmll Dana.

Hig. 10. Sigillaria sp.

Brown, coaly rock composed of layer's of matted megaspores, probably of Sigilluria.

10 a. Portion of the same rock enlarged fuur diameters to show the individual megaspores, which are represented by the collapsed exospores. The triradiate vent is seen in some of the sporos.

$\mathrm{Fig}$. 11. Sigilleria oustralis n. sp.

Fragment of cortex on which the leaf scars are seen. though the Ieaf-cushions are very obscurely defined.

11 a. Leaf scàr enlarged, witlı part of its indistinct loaf cuslion. From the lelt of the specimen.

Il b. Similar enlarsement of a sear with more prominent cicittricules.

$11 \mathrm{c}, 11 \mathrm{~d}$. Siars in which the marked subcutancous enlargement of the parichnoi is shown.

PLATE VIT

Flos. 1-4. Glossopteris occidentulis $\mathrm{n} . \mathrm{sp}$.

1. Apex of the leaf. The fine parallel uervation is seen to be nearly at a right angle to the border.

2. Sessile and cordate base, showing vory wide llat midrib, and nervation as in Figure 1.

3. Frarment of middle of leaf, showing very broad midrib, and the nervation coarsely meshed near the midrib, fine, parallel and very distantly anastomosing after turning outward to pass to the border.

The obliquity of the nerves, due to contraction along tho abraded midril), is the greatest seen in the specimen.

4. Fragment with typical nervation.

4 a. Portion of the same enlarged to lour diameters to show the nerves elongately moshed near the broad midrib, and parallel, very close, and rarely anastomosing near the border.

Figs. 5, 6. Glossopteris sp.

Petiolate, concaro-convex, thick couly scale leaf. 
5. Superficie concava com grandes malhas polygonaes cheias de residuo car. bonaceo, provavelmente dos esporangios ou receptaculos de pillen.

5 a. Parte da mesma augmentida pbotugr. phica mente quatro liametros para mostrar as impressões das massus polygunaes e as rugas estreitas irregulat'es, não vasculares, que ai separam.

6. Superficie cunvexa de uma untra folha, mostiando a nervação em um typo de malha de Glossopteris, un tinto estreitamente alongada.

Fig. 7. Ottokaria ovalis $\mathrm{n}$. $\mathrm{sp}$.

Superficie do fossil mostrando a nervação fisciculada, flexuosa e provavelmente anastomosando-se ao bifurcar-se as ultimas divisões se extendendo pelos dentes redondos.

i $a$. Corpos ovaes-ovoides em dísposic;ão radiaria, provavelnente microesporangius, que se vêem no resiluo carbonacco do reverso do exemplo que se vi na fig. 7. Estes corpos que se vêem augmentados quatro diametros, parecem, pela sua distribuição, corresponder á ni:lha que se rè no reverso do especimen.

ESTAMPA VIII

Figs, 1-7. Gangamopteris obovala (Carr) D. W.

Specimen mostrando as fórmas dos apices das folhas e a fórma estreita da base que se vê em alguns dos fossois. Espalhadas nas resmas rochas ha numerosas sementes de Cardiocuipon (Samaropsis) Seixasi, a maior parte sem aza, embora esta se veja na parte superior á direita da fig. 2, na parte superior á esquerda da fig. 6 e á esquerdil da fig. 7 .

7. Folba eicamiforme.

Figs. 8-10. Arberic minasica n. :5, n. sp.

Estes typos pedicellados, divididos, recurvados, provavelmente representain folhas escamiformes influrescentes incisas os lobulos al,ruptamente truncadus, algumas vezes ligeiramente lizeradios e cstriados sĩo os pedicellos de que se julga que as sementes cahiram, estando em todos os casos mais intimamente associados a pequenas sementes indistinguiveis das fórmas novas de Cardiocarpon seisasi.

Figs, 11-13. Voltsic (?) sp.

11. Rebento com folhas curtas em baixo e fulhas mais largas no apice.

13. Fragmento com follhas longas, finas.

13 a. Folha, mostrando a fórma, do mesmo specimen.

136. Folha de perfil.

ESTAMPA IX

Figs. 1-3. Derbyella antrila n. g., n. sp.

1. Folba escamiforme quasi completa.

l a. A mesma augmentada quatro diametros, mostrando os lobulos marginaes e os esporangios (?) na base de cada lobulo.

2. Reverso do exemplo que se vè na fig. 1.

2 a. A mesma augmentada quitro diametros. A posição torcida e virada para cima dos lobulos margidues esti indicada í esquerda nesta figura e na parte inferior á direita na figura $1 a$. 
5. Concare surface with large polygonal mesh filled with carbonaceous residue, probably from sporangin or poll-n cases.

5 a. Part of the saıne p.utographic ally eularyod to four diameters to show the impressiuns of the pulygonul masses, separated by irregular narrow, non-vascular rillges.

0. Convex surface, frum another leap, slowing the nervation in a rather narrowly elongated Glossopteris type of mesh.

Fig. 7. Oltokaria ovalis n. sp.

Surface of fossil showing the fascicul ite nervation, flexuose, and probably anastomosing while forkin, the ultimate divisiuns entering the rounded teeth.

7 a. Oval-ovate, radially arpanged bodies, probably micro-sporangia, seen in the coaly residuc of the counterpart of the example shown in Firure 7. These bodies, shown enlarged to four diameters, appear in distribution to correspond to the mesh seen in the obverse of the specimen.

PLATS: VIIL

Figs. 1-7. Gangamopteris obovala (Carr.) D. W.

Specimen showing the forms of the apices of the leaves, and the narrowed form of base seen in some of the fossils. Scattered abuut on the same rocks are numerous seeds, Cardiocarpon (Samaropsis) Seixasi, mostly without the wing, though the latter is shown in the upper right in Fisure? the upper left in Figur' 7 .

Figs. 8-10. Arberia minasica D. g., D. sp.

These pedicellate, recurvately divided types probubly represente dissected inflorescence-scale leaves, the abruptly truncated sometimes slightly lacerated, striated lobes being the pedicils from which seeds are believed to have fallen. They are in all crses most intimately associated with small seeds indistinfruishable from the young forms of Cardiocurpon Seixasi.

Figs. 11-13. Vollzia (?) sp.

11. Twig with short leaves below, and longer leaves at the apex.

13. Fragment, with long slender leaves.

13 a. Leal, showing form, from the same specimen.

13 b. Leaf in profile.

PLATE IX

Figs. 1-3. Derbyella aurila n.

1. Nearly complete scale-leaf.

la. The same, enlarged to four dianeters, shoring the mar inal lobes and the sporangium (?) on the base of each lowe.

2. Connterpart of tha example shown in Fig. 1.

2a. The same, enlarged to four diameters. The twisted and upturnod position of the maruival lobes is irdicated on the left in this figure, and on the lower right in Fig. la. 
3. Exemplo menor e provavelmente mais novo.

Figs. 4-7. Noggerathiopsis Hislopi (Bunb.) Feist.

5. Felha muito grande, de proporções cordaiteas.

6. Schistos com folhas escamosas, ligeiramente maceradas.

6 a. Porção do mesmo fragmento, augmentado quatro diametros, para mostrar os feizes hypodermicos, ou falsas nervuras que apparecem nos specimens parcialmente macerados.

7. Porção de um specimen macerado, augmentado quatro diametros, para mostrar os corpos pequenos ovaes ou suhesphericos do mesophyllo.

\section{ESTAMPA $\mathrm{X}$}

Figs. 1-4. Hastimima Whiti. n. g., n. sp.

1. Grande fragmento com costella marginal ospessa no bordo superior ; bordo fino denticulado escamoso á direita; grandes tuberculos dispostos radialmonte om superficie llgeiramente concava,

Fjg. I $a$. Porção da costella marginal, augmentada quatro diametros, com impressão da superficie posterior ou convexa do fossil, que se vê na parto inferior.

2. Reverso do especimen que se vê na fig. I.

3. Fragmento biluteralmente symetrico com nervura mediana larga o espessa e bordo muito obliquamente serreado.

4. Reverso do mesmo, mostrando os grandes tuberculos da superficie concara exposta, onde a nervura mediana está destacada da rocha perto do extremo do fragmento.

Figs. 5-8. Cardiocarpon (Simaropsis) Seixasi n. sp.

6. Specimen em que a aza está ligeiramente lacerada na basc. O aspecto normol da aza se vê melhor nas figs. 5 e 7. Veja tambem estampa VIII, figs. 2, 5 o 6.

Fig. 8-Especimen de que o involucro externo e azas se perderam. Veja tambem á direita da figura 3.

Fig. 9-Cardiocarpon Oliveiranum n. sp.

Fig. 10 - Cardiocarpon Moreiranum n. sp.

Fig. 11 - Cardiocarpon Barcellosum n. sp.

Fig. 12 - Carpolithus ? s. p.

Fig. l丷a - 0 mesmo augmentado para mostrar as costellas indecisas.

\section{ESTAMPA XI}

Figs. 1 - Hastimima Whitei n. g. n. sp.

1 - Fragmento de cuticula da superficie convexa (dorsal?).

2 - Lobulos conatos basaes, ou divisöes digitiforiues parcialmente achatadas. Os tuberculos escamiformes no lobulo graude são como os da costella marginal, estampa 10, figura la. $\Lambda$ impressão do lado posterior do fossil que $s \theta$ $\nabla \hat{\theta}$ na parte inferior, mostra os tuberculos grandes e mais distinctos. Veja tambem figura $2, a$. 
2 a - Porção da mesma, incluindo o terceiro lobulo augmentando quatro diamotros. O tuberculo escamiforme é mareado em sua porção distal por uma pequena cicatriz umbllicolde.

3 - Fragmento augmentado quatro diametros, mostrando a phase escamosa da cuticula em baixo, com grandes tuberculos en cima.

4 - Cuticula da superficic «convexa» augm $n$ tada quatro diametros.

5 - Grandes tuberculos com vestigios puactiformes umbilicoides perto dos apices distaes, augmentados quatro diametios.

6 - Phase escamosa da cuticula proximo do dente escamiforme marginal, arredondado de quo dous estão divididos por fissura, augmentada quatro diametros.

7 - Borda com dentes escamiformes succedendo á cuticula do caracter que se vê na flgura 4, augmentada quatro diametros.

8 - Bordas com escamas dentiformes zonadas; augmentadas quatro diametros.

0 - Porção da maruem augmentada quatro diametros da direita do especimon, estampa X, figura 1 , mostrando a area escamosa adjacente e grandes tubsrculos mais para dentro.

10 - Borda de um outro fragmento, augmentada quatro diametros.

Figs, 11 12-Reinschic australis brasiliensis n. var.

11 - Córte vertical do boghen'l augmentado sessenta e cinco diametros. para mostrar as algius fosseis gelosicas cuja cor amarella de ouro marcam as partes claras da photographia.

o especimen mostra a predominancia de grandes colonias.

$1:$ - Córte horizontal, mesmo aumento, da mesma rocha, mostrando as fórmas dos thallos ocos e traços das paredes espesaas lateraes das eellulas.

Fig. 13 - Reinschia australis. Iiert of lien.

Córte vertical do boghead (schisto de kerosene) de Blue Mountains, New South Wales, junto para comparação. O mesmo augmento da figura 11.

ESTAMPA XII

Fig. 1 - 4- Sigillaria (?) mewralis n. sp.

1 - Seção transversal. As trachueides arredondadas, quadradas ou ovaes, em cunhas separadas pelos raios medullares com cellulas apenas levemente rectangulares alongadas. Lugmento: 50 diametros.

2 - Secção tangencial di mesma mostrando raios abundantes o tracheides sinuosas e escalariformes, uma tracheide meandriforme á direita. A rigmento 50 diametros.

3 - Secção radial da mesnà, as tracheides scalariformes, roticuladas em contacto com as cellulas dos raios relativamente curtas. A destruição parcial das paredes das cellulas pola acção bacteriana está em evidencia em logares perto ou em contacto com os raios. Ausmento 50 diametros.

4 - Porção da meśna seção anghmentada nil diametros para mostraz as zonas de destruição das pireeles las cellulas, estando o tecido em parte destruido infestado de «bacterioides» 
2a. Portion of the same, including the thiro lobe, onlargad to four diameters. The scale-like tubercle is marlied in its distal portion by a small umbilicoid scar.

3. Fragment, enlarged to fuur diameters, showing the scaly phase of cuticle below, with large tubercles above.

4. Cuticle from «convex» surface, enlarred to fuur diameters.

5. Large tubercles with umbilicoid punctiform traces neas the distal apices; enlarged to four diameters.

6. Scaly phase of cuticle next to rounded marginal scalo teeth, two of which are dividing by fission; enlarged to four diameters.

7. Bordel with scale-tecth succeding cuticle of the character shown in Fis. 4 ; enlarged to four diametors.

8. Border with zonate tooth-seales; enlarged to four diameters.

9. Portion of border, enlaryed to four diameters, from the right of the specimen, Plate x, Fig. 1, showing scaly adjacent area, and large tubercles farther in.

10. Border ol anothor segment, enlarged to four diameters.

Figs. 11, 12. Reinschia, australis brasiliensis $\mathrm{n}$. var.

11. Vertical section of borhead, enlarged sixty-five diameters, to show the fossil gelosic algae, the golden yellow color of which makes the light portions in the photograph.

The specimen shows the prevalence of laruce colonies.

12. Horizontal section in the same onlargement, from the same rock showing the forms of the hollow thalli, and traces of the thick lateral cell, wells.

Fig. 13. Reinschia australis Bert, \& Ren.

Vertical section of boghead (kerosene shalo) from Blue Mountain, New Souti, Wales, included for comparison. The magnification as in Fig. 11.

PIATE XII

Figs. 1-4. Sigillaria (?) muralis n. sp.

1. Transverse setion. The rounded, squarrose ol oval trachoides in wedges separated by the «medullary » rays, with but slightly clongated rectangular colls. Eularged fifty diameters.

2. Tangontial section of the same showing abundant rays, and simuate, scalariform tracheides; a meandering tracheid on the right. Enlargod fifty diameters.

3. Radial section of the same, the scalariform tracheides reticulate in contact with the relatively shors ray cells. The partial destruction of the cell walls through bacterial action is in evidence in places near to or in contact with the rays. Enlarged fifty diameters.

4. Portion of the same section enlarged to one thousand diameters to show the zone of destruction of the cell walls, the purtially destroyed tissue being infested with «bacterioids 


\section{ESTAMPA XIII}

Figs. $1-3-$ Dadoxylon nummularium n. sp.

I - Secção transvorsal, augmentada 50 diametros.

2 - Secção tangencial, augmentada 50 diametros mostrando os raios modullares muito abundantes.

3 - Porção da mesma secção augmentada noventa diametros para mostrar as areolas com pequonos póros redondos nas paredes radiaes das tracheides. A occurrencia de areolas em mais de um alinhamento 6 muito rara. 4 - Secção radial, augmentada 50 diamotros.

\section{ESTAMPA XIV}

Figs. 1 - 4 - Dadoxylon meridionale. n. sp.

Fig. I - Secção transversal, augmentada 50 diametros.

Fìg. 2 - Secção radial da mesma, augmentada 50 diametros.

Fig. 3 - Secção tangencial da mesma, augmentada 50 diametros.

Fig. 4 - Porção da secção illustrata na fig. 2, augmontada 90 diametros, para mostrar as areolas uniseriadas nas paredes das tracheides. 
PLATE XIII

Figs. 1-3. Dadoxylon nummularium n. sp.

1. Transverse section, enlarged fifty diameters.

2. Tangential section, enlarged fifty diameters, showing the very abundant medidlary rays.

3. Portion of the same section, enlarged ninety diameters, to show the areoles with small round pores on the radial walls of the tracheides. The occurrence of the areoles in more than one row is very rare.

4. Radial section, enlarged fifty diameters.

PLATE XIV

Figs. 1-4. Dadoxylon meriodionale n. sp.

Fig. 1. T'ransverse section, enlarged fifty diameters.

Fig. 2. Radial section of the same, enlarged tifty diameters.

Fig. 3. Targential section of the same, enlarged fifty diameters.

Fig. 4. Portion of section illustrated in Fig. 2. enlarged ninety diameters, to show the large uniseriate areoles on the radial walls of the tracheides. 



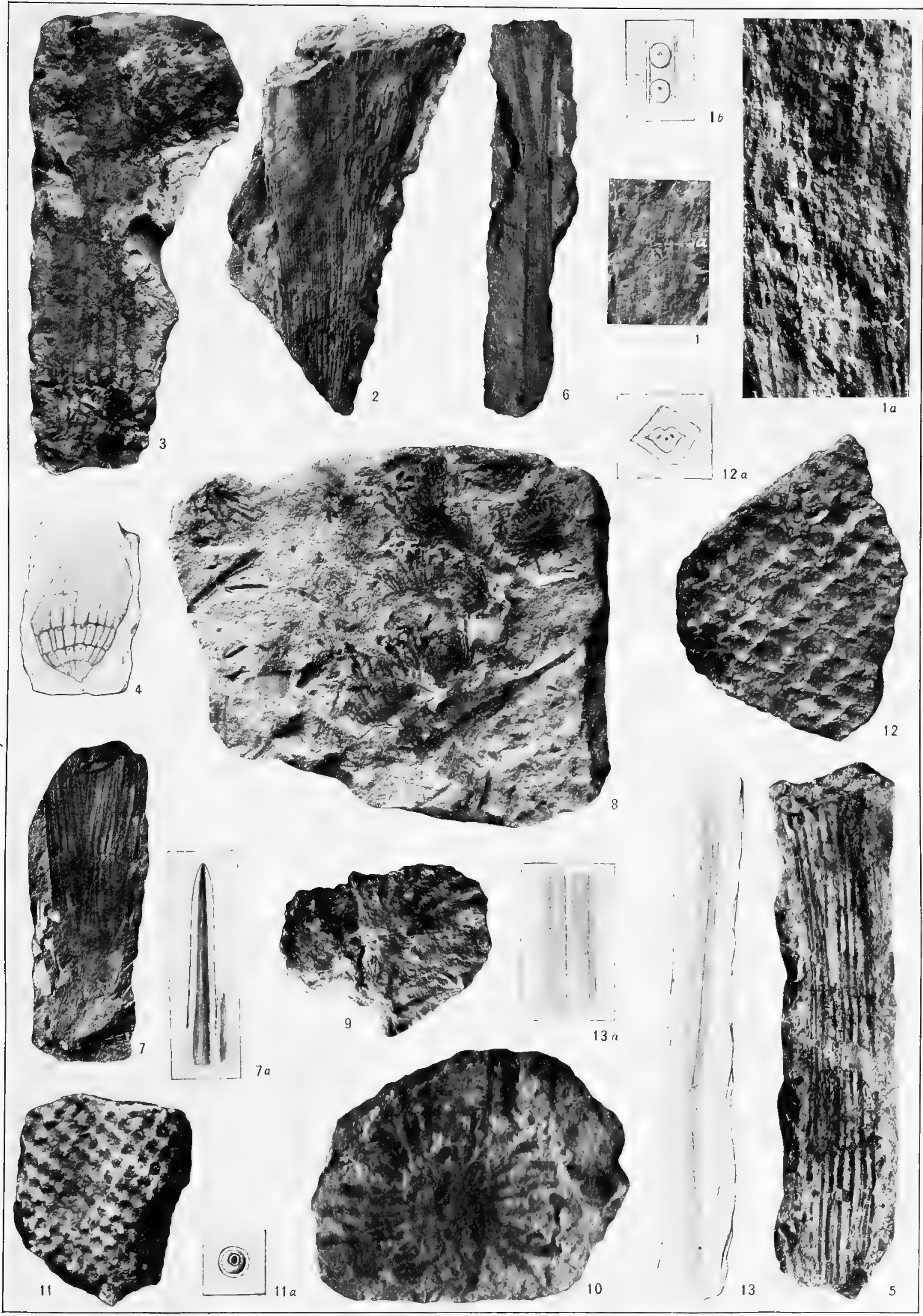

ROSELLINITES GANGAMOPTERIDIS, 1. HYSTERITES BRASILIENSIS, 2. PHYLLOTHECA SP., $3 \mathbf{- 5 .}$ SCHIZONEURA (?) SP., 6. EQUISETITES CALAMITINOIDES, 7.

PHYLLOTHECA MUELLERIANA, 8. PHYLLOTHECA GRIESBACHI, 9, 10.

LYCOPODIOPSIS DERBYI, 11 . SIGILLARIA BRARDI, $12 . \quad$ SIGILLARIA SP., 13. 



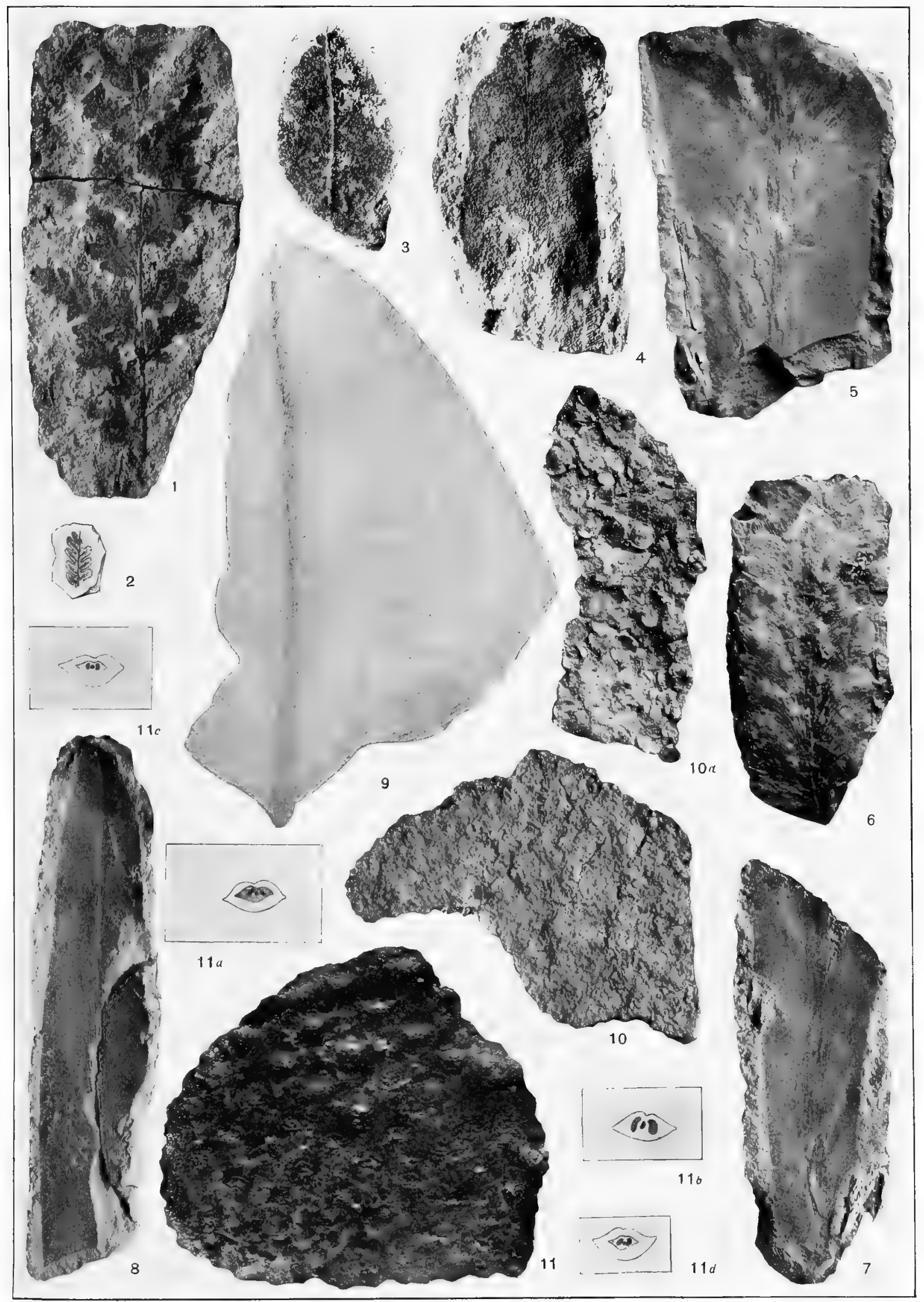

SPHENOPTERIS HASTATA (?) 1. SPHENOPTERIS SP., 2. GLOSSOPTERIS BROWNIANA, 3, 4, 6. GLOSSOPTERIS INDICA, 5, 7, 8. GLOSSOPTERIS AMPLA, 9. SIGILLARIA AUSTRALIS, 11. SIGILLARIA SP., 10. 



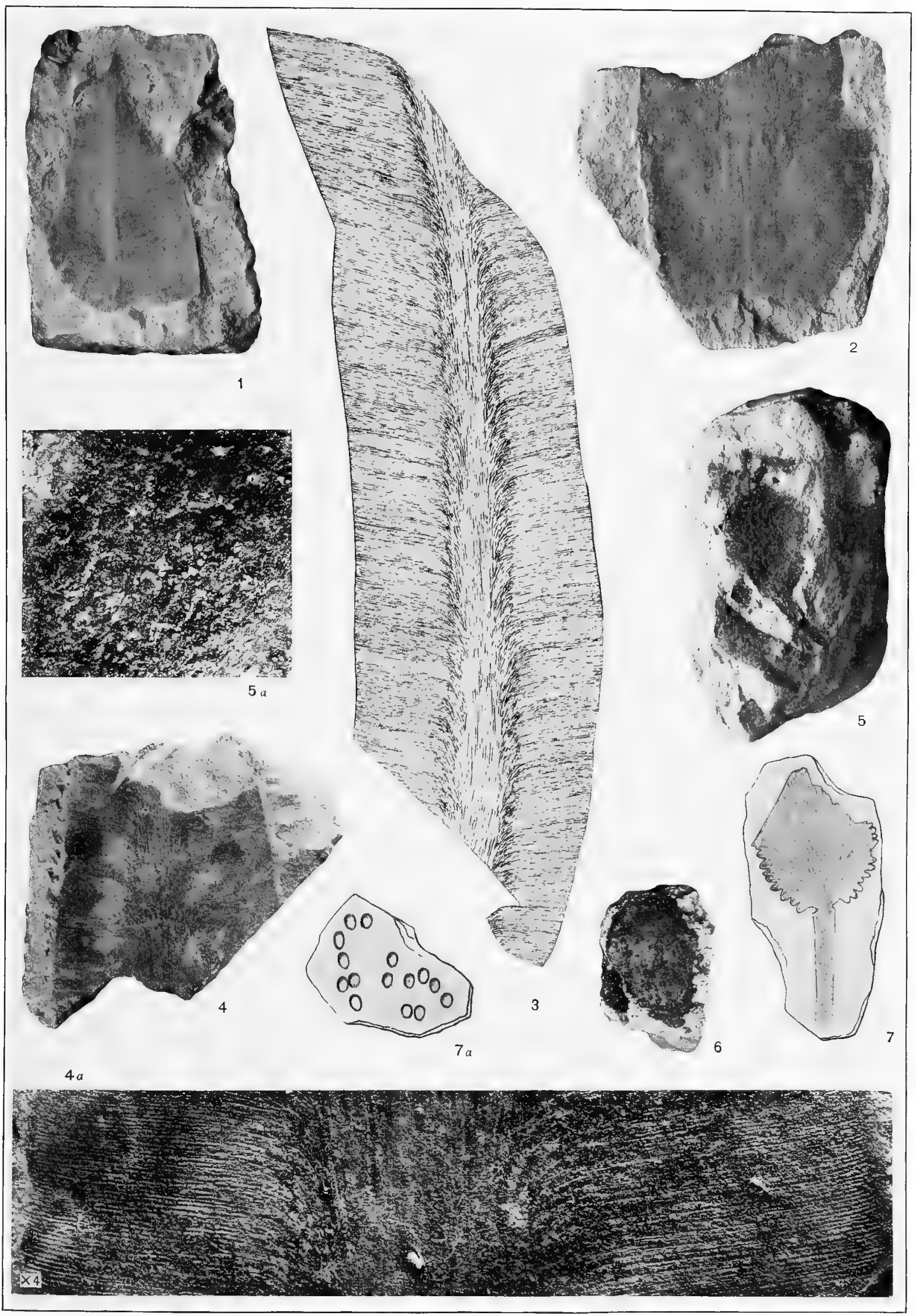

GLOSSOPTERIS OCCIDENTALIS, 1-4. GLOSSOPTERIS SP., 5, 6. OTTOKARIA OVALIS, 7. 



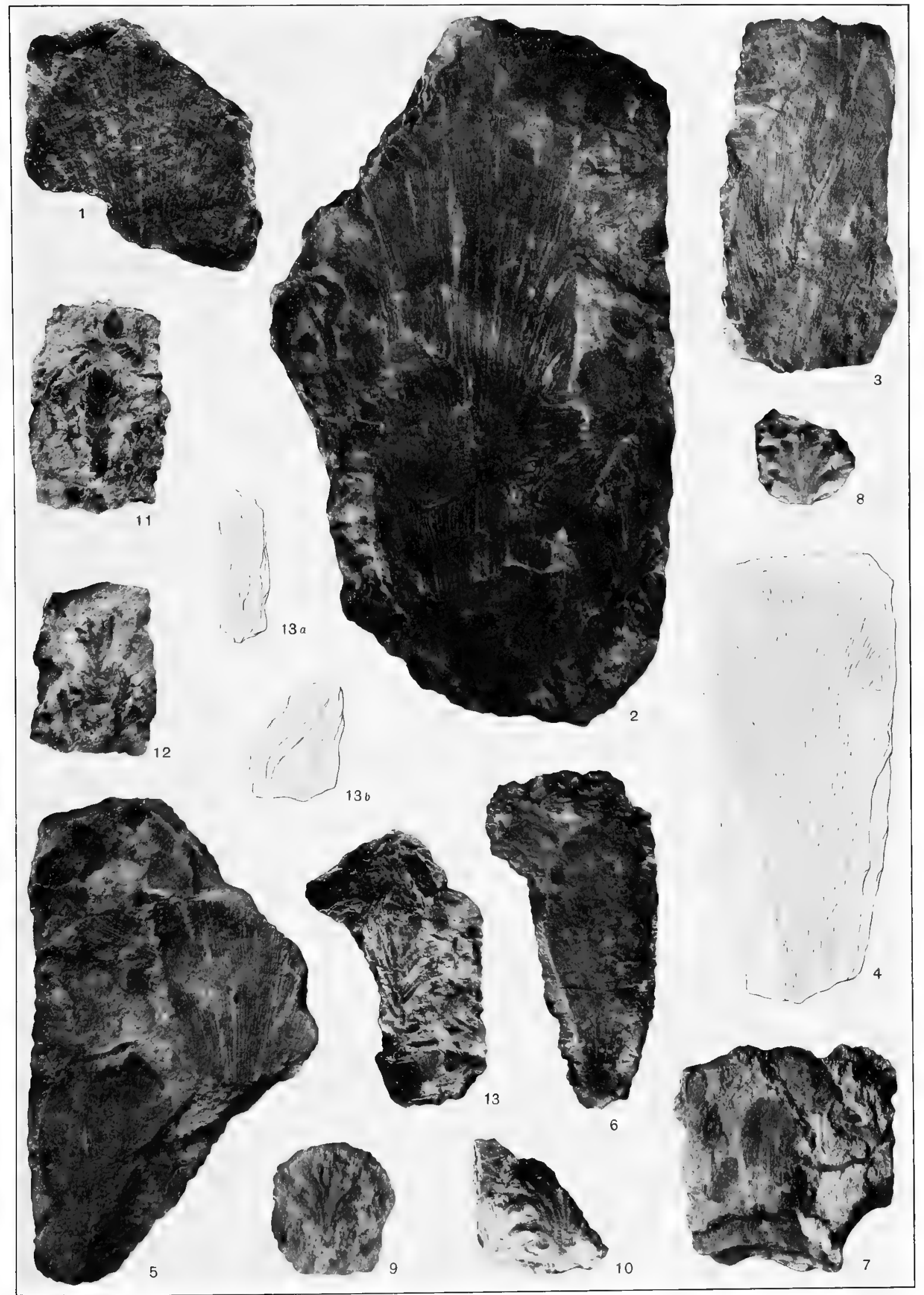

GANGAMOPTERIS OBOVATA, 1-7. ARBERIA MINASICA, 8-10. VOLTZIA (?) SP., 11-13. 



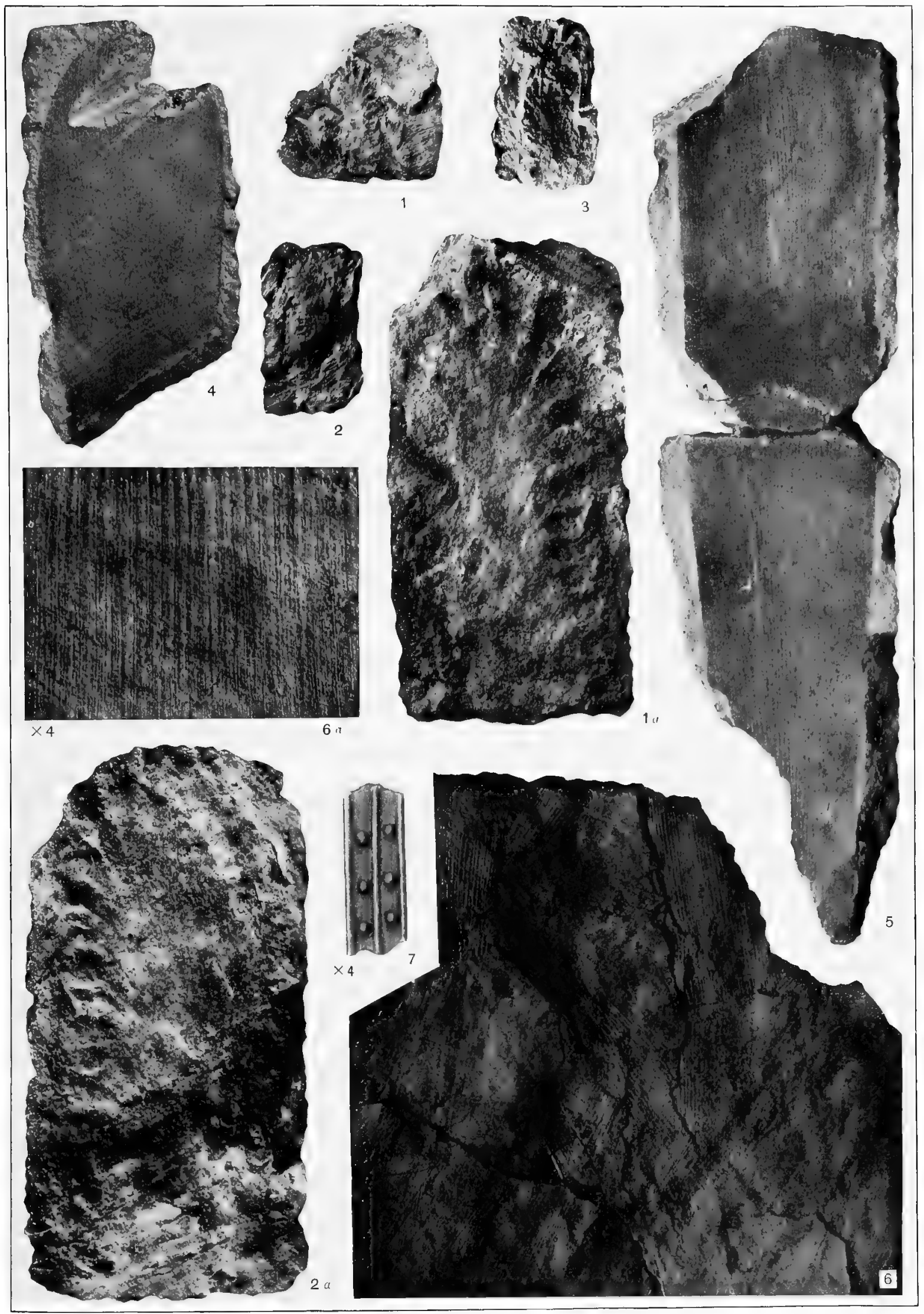

DERBYELLA AURITA, 1-3. NOEGGERATHIOPSIS HISLOPI, 4-7. 



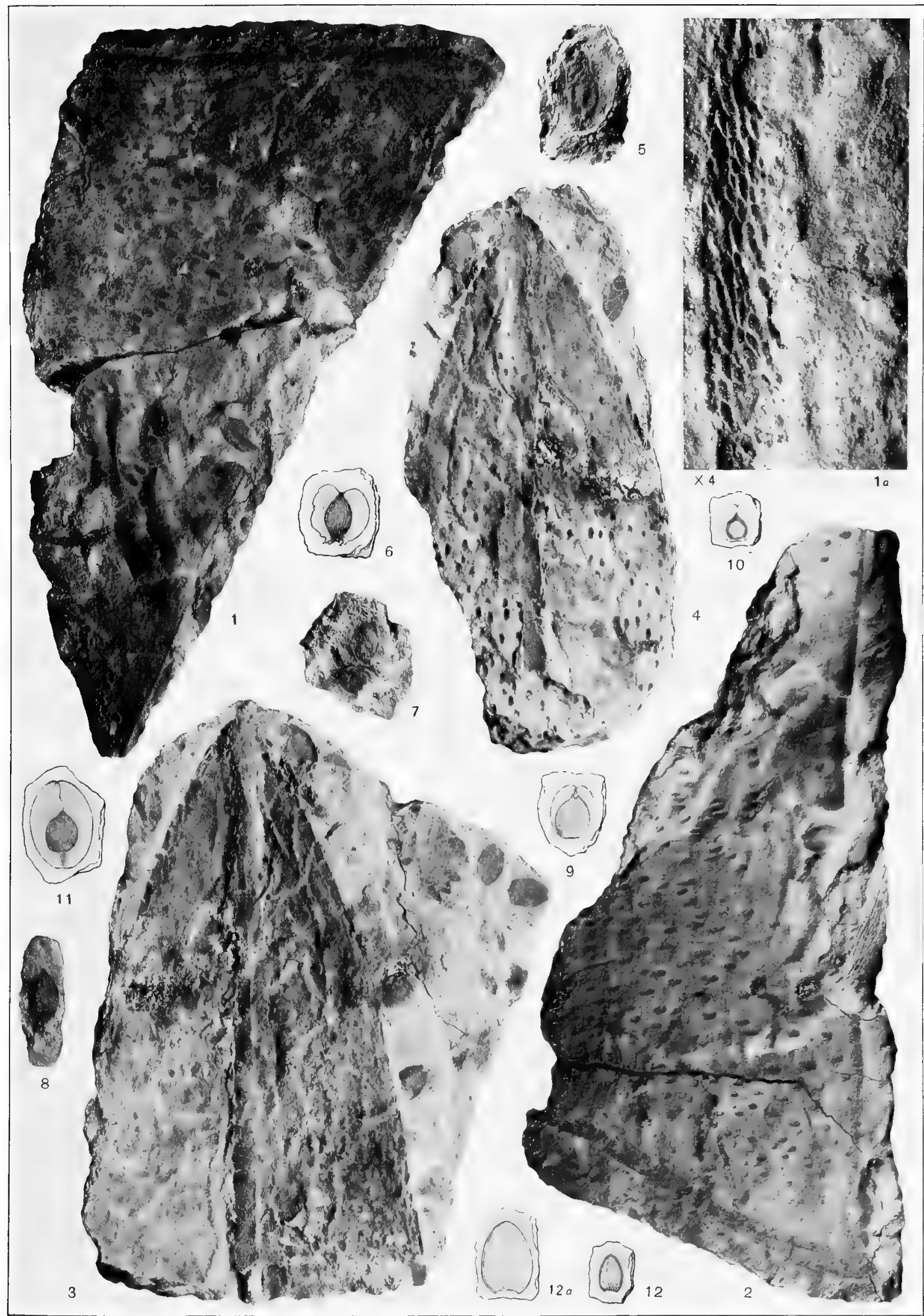

HASTIMIMA WHITEI, 1-4. CARDIOCARPON SEIXASI, 5-8. CARDIOCARPON OLIVEIRANUM, 9. CARDIOCARPON MOREIRANUM, 10. CARDIOCARPON BARCELLOSUM, 11. 



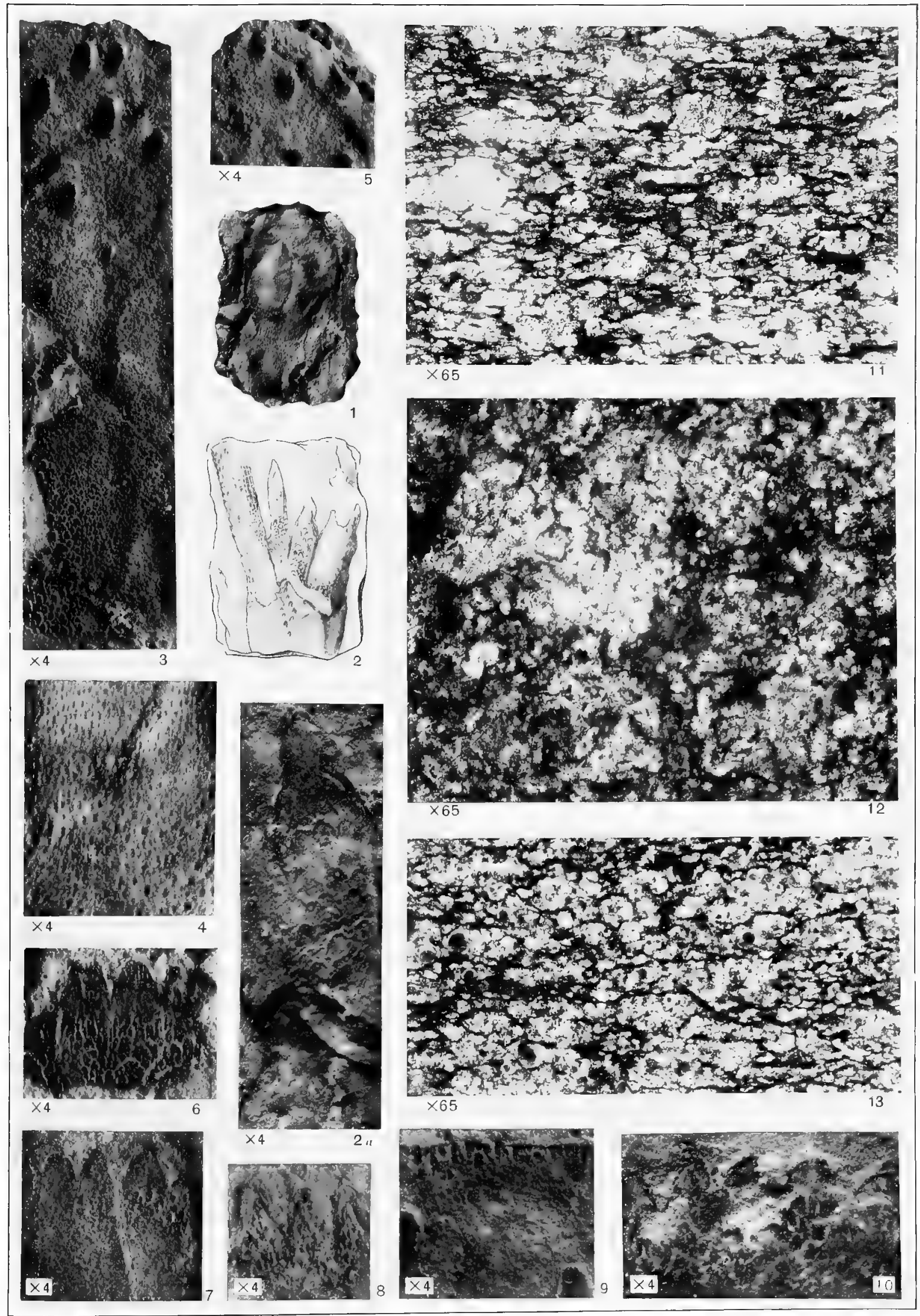

HASTIMIMA WHITEI, 1-10. REINSCHIA AUSTRALIS BRASILIENSIS, 11, 12. REINSCHIA AUSTRALIS, 13. 


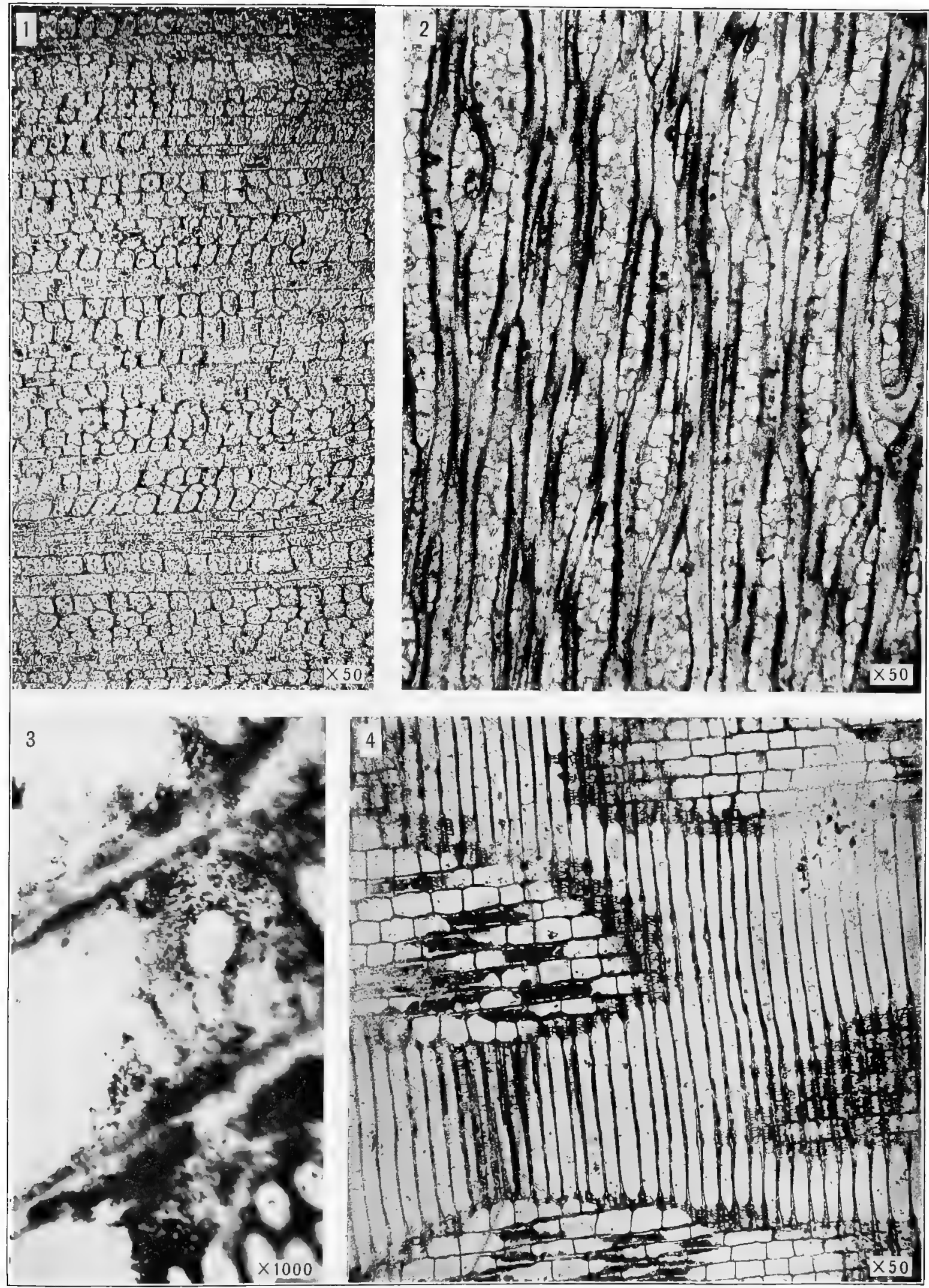

SIGILLARIA (?) MURALIS. 



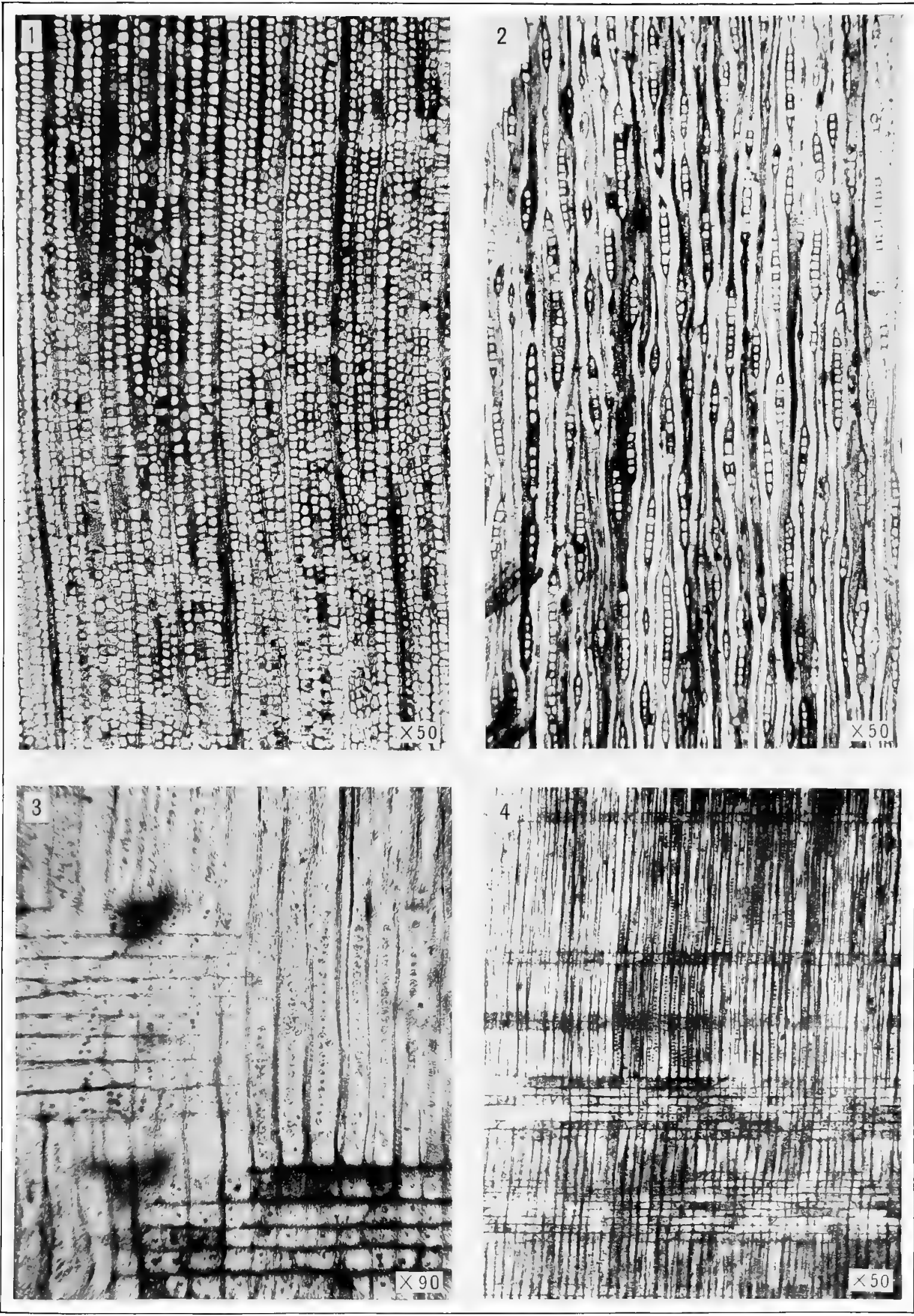





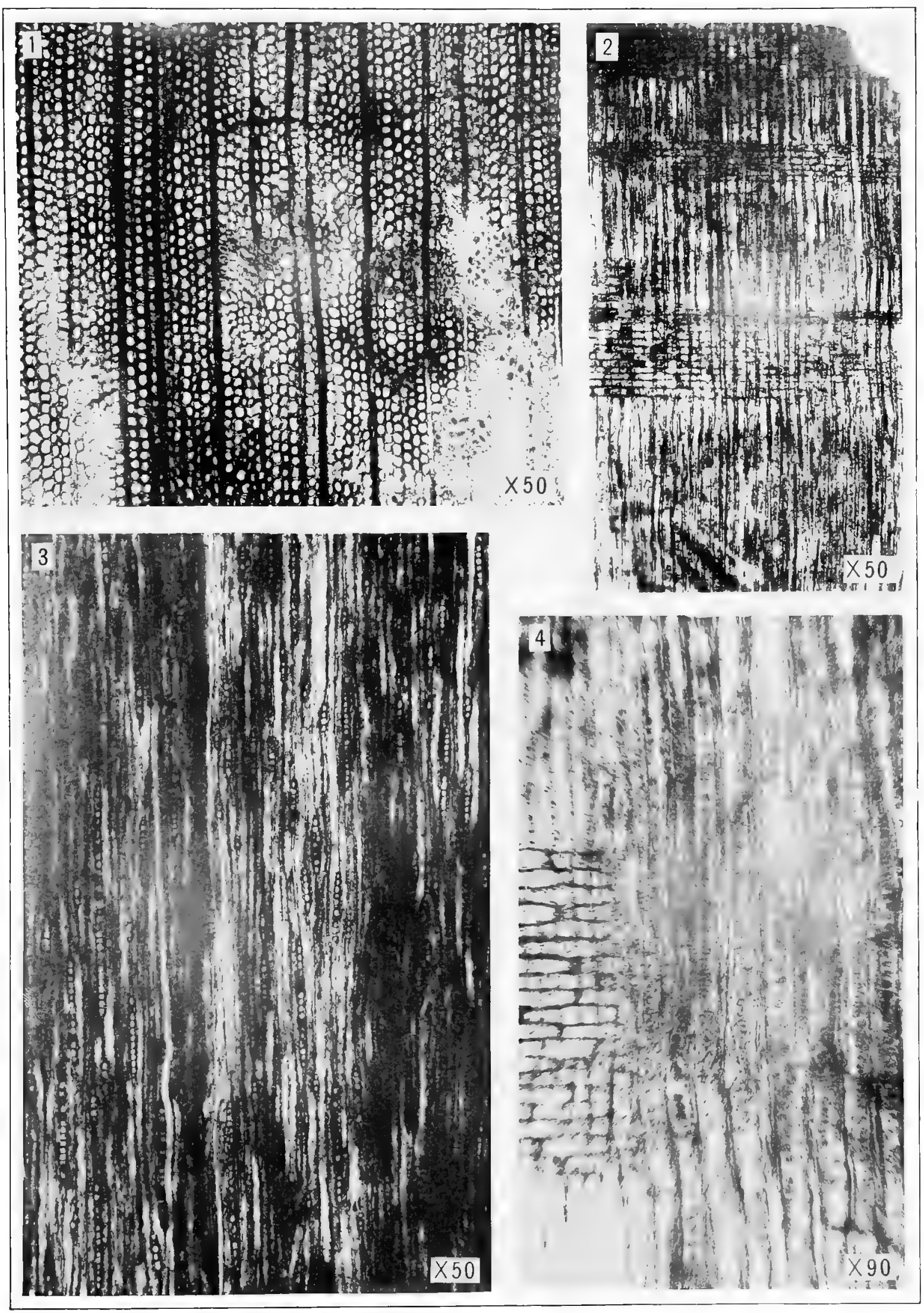








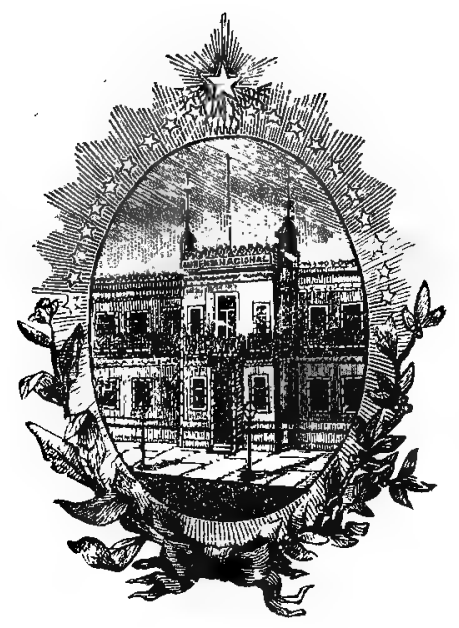





